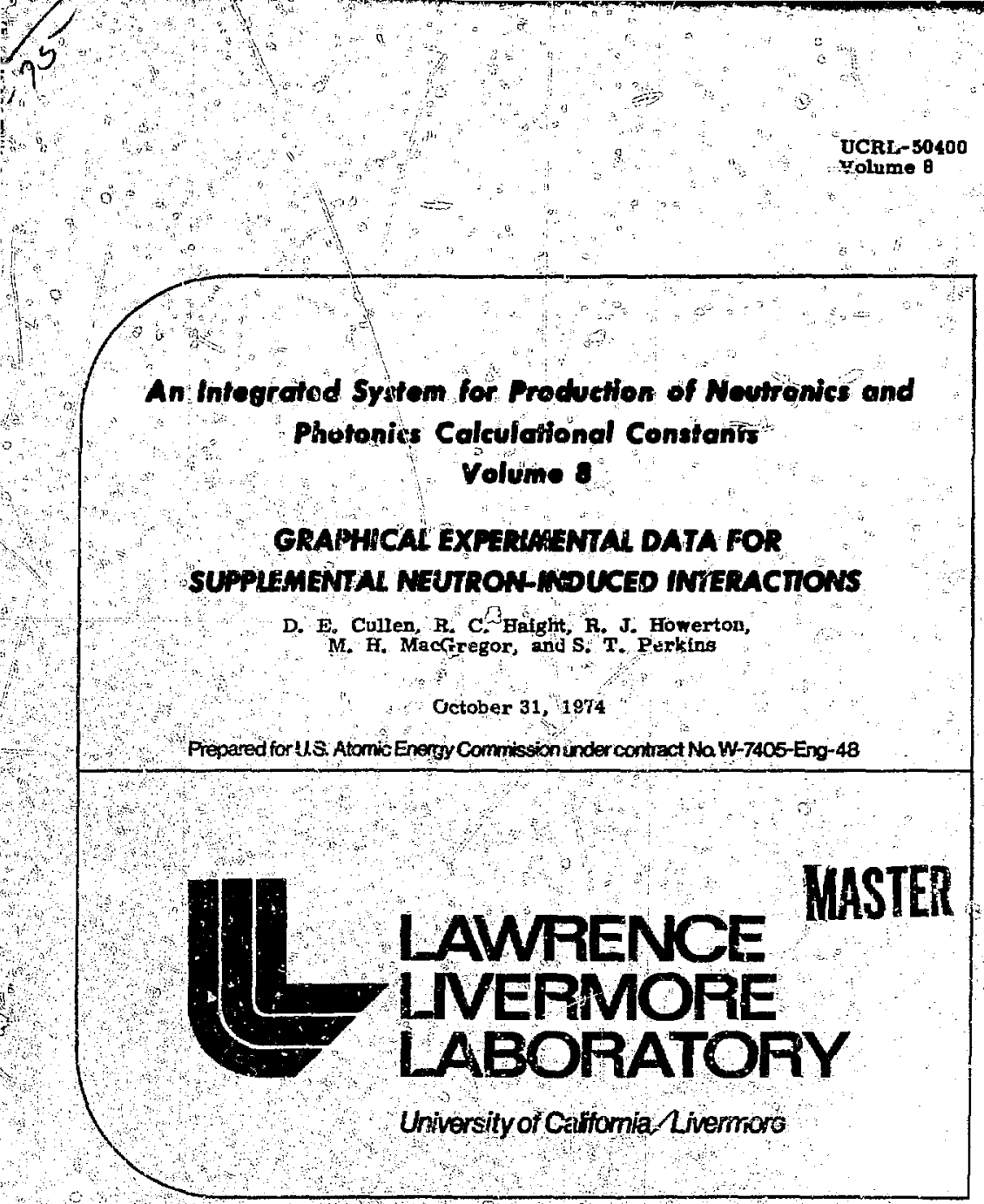

UCRL-50400

Holume $\theta$ 


\section{迎 \\ LAWRENCE UNERMORE LABORATOFY}

Universityot Caftomia Lhermore, Calfomia g45Sn

(C) $[,-50400$ vilume

\section{GRAPHICAL EXPERIMENTAL DATA FOR SUPPLEMENTAL NEUTRON-INDUCED INTERACTIONS}

1. H. Cullen, R, C. Traigh, R. I. Iindoptor.

ll. H. Macerregur, and S. T. Pertins

Mis. date: Ordsber 31, 1974

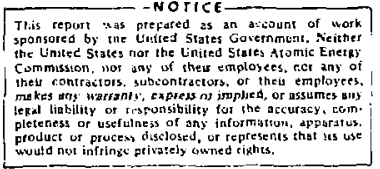




\section{Foreword}

The UCRL-50400 series describes an integlated and computer-oriented system for the production ano application of neutronics and photorizs calculational consterus.

Thu systern must supply reliable upto-rate data, select specific types of data on regusist, provide output in a variety of forms - iltimately in the form of input to other sonipurer codes, and furction rapidly and fficisntly. The system has now been developed to a point whera these goals are being realized.

The UCR $\mathrm{C}-50400$ series, An Integrated System fr Production of Neutronics and Photonirs Calculational Constants, com* prises the fol wering valumes:

- Vol. 1. ECSIL, A System for Storage, Retrievil and Display of ExDerimental Neutron Uata, March 1374 .

- Vol. 2, A Bibliograpliy of the $\mathrm{Ex}$ perimental Daia of Neutron-Induced Interactions, March 1974.

- Vol. 3, An tndex of the Experimenrai Data of Neutron-Induced Iriteractions, March 1974.

- Vol. 4, Evaluated Nuclear CrossSection Library, April 1971.

- Vol. 5, CLYDE: A Nuclear DataProcessing Computer Program for
Producing Calculational Constants. May 2971.

- Vol. 6, Photon Cross Sections 1 keV to $100 \mathrm{MeV}$, October 1968.

- Vol. ?, Graphical Experimental Data for Major Neutron-Induced Interactions, April 1974.

- Vol. 8, Graphical Experimental Data for Supplemental NeutronInduced Interactions, to be published.

- Vo1. 9, Thresholds of Nuclear Reactions Induced by Neutrons, Photons, Deuterons, Tritons, and Alpha Particles, September 1970.

- Vol. 10, Tabulated Experimental Data for Neutron-Induced Lnterac: tions, May 1974.

- Vol, 11, Experimental Data, Indexes and Techniques of Obtaining a Selected Set of Neutron Resonance Paramcters, May 1972.

- Vol. 12, An Atlas of Resolved Neutron Resonance Parameters, July 1572.

- Vol. 13, An Atlas of Jnresolved Neutron Resonance Parameters, Septentier 1972.

- Vol. 19, TARTNP: A Coupled Neutron-Photon Monte Carlo Transport Code, June 197\%. 


\title{
GRAPHICAL EXPERIMENTAL DATA FOR SUPPLEMENTAL NEUTRON-INDUCED INTERACTIONS
}

\begin{abstract}
Volumes 7 and spresent graphs of all cross seclions chitained in tha lexperiment crose hection Information libcary (liCsit) as of mareh 1, 1974. Volume 7 consists primarily or interactions wiere a single data set contains enough points to show cross section behavior. folume is colssists of interactions where more than ont: data set is necsied to show

crosss section behavior. Thus, the total. elastic, capture, and fission cross sections falong with the parameters $i$. or, and $n$ ) are found in s'ol. 7. All other reastions ar" in t'ol. 8. For the sake of clarity, the data are plotted withour associated escur bars. The plots are arranged in ascending order of atumic number $(X)$ and at omic weight $(A)$.
\end{abstract}

\section{Introduction}

In 1958 , a computerized system for the storagi anil retpicvel of experimental neutron-intera:tion data was installed at

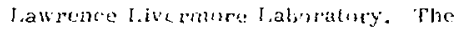
system has developed gradually and it is still being improved.

lhe present sustim ${ }^{1}$ is marte up of two separate liles: $A$ nueneric data file and a biblisgraphic information file. The two liles aro linked through the use of a four digit number which ts uniquely assigned to each reference.

In $3: 5,3$ and 1960 , tabujations of intefralud ant differentinl neutron ceress sec tions bolow 15 wel wore published.
Since that tine the number of ent riv's in the system has increased by more than an wder of magnitude. Consicquenty.

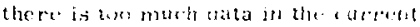
library (almost un million data poiris) to publish tabulations of this information; the rosulting volt. at s walld be grobitsilively expensive and butks. Hewerele by presinting the data in graphs ${ }^{2}$ and in microfiche. 3 we ran signilicantly reduc. the cxponst and the bulk. Mlureoser. the reduction in bulk moans that indexest and bibliographias san be axdderd to holp in the manuplation of thre clata.

\section{Graphicai Data}

'The prestent festh, librar contains 145 153 prints, of which 823 jog puints are eresis sertions. or these points

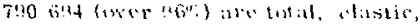

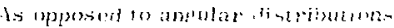
and turegy distributiant, 


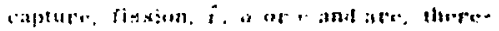

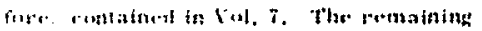
i2 41. points ale antaltest in Vol. B. A-

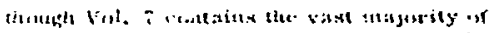

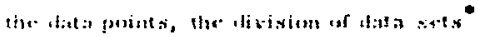

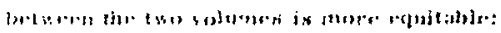

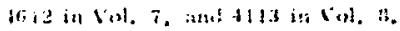

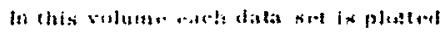

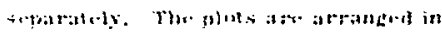

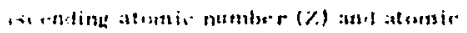

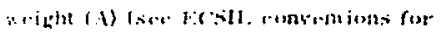

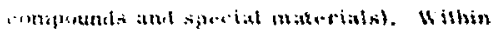

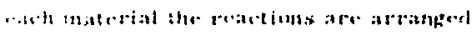

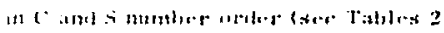

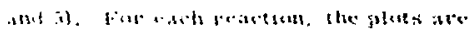

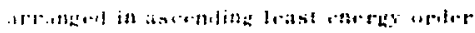

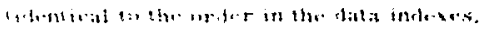

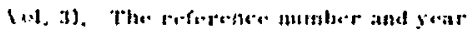

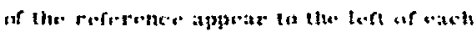

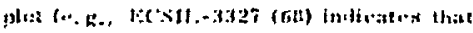

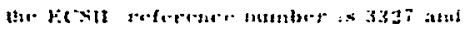

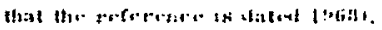

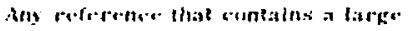

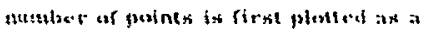

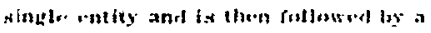

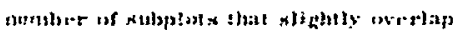

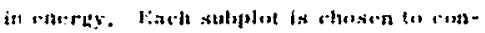

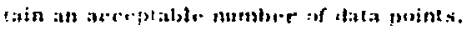

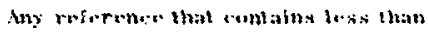

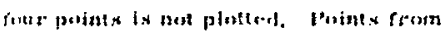

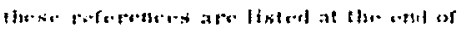

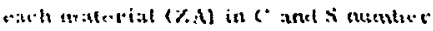

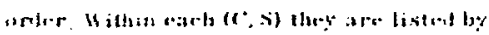

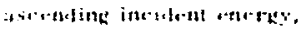

\section{Relationship to Other Volumes}

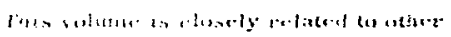

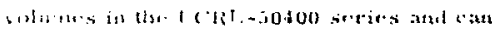

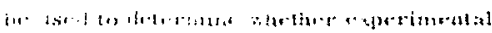

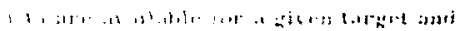

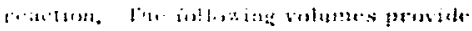

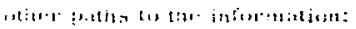

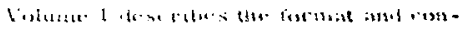

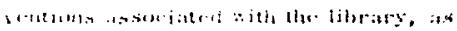

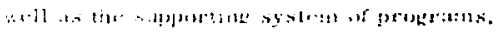

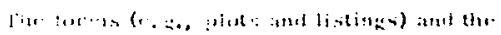

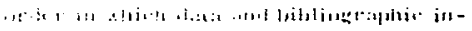

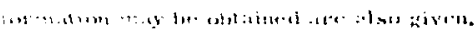

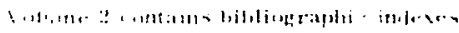

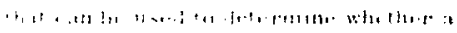

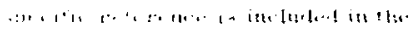

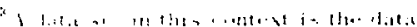

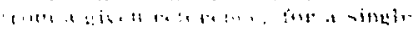

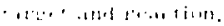

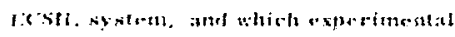

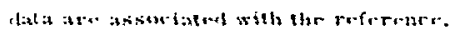

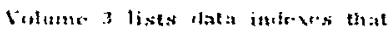

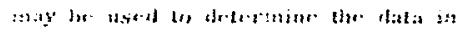

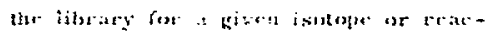
tiins.

bumer is a eraphical prescutation

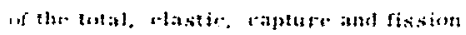

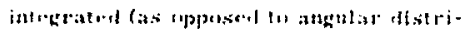

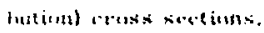

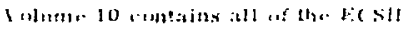

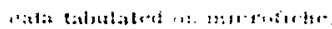

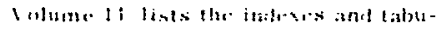

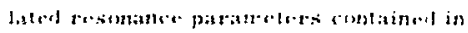
r.s.5il.

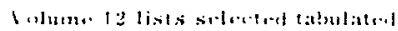

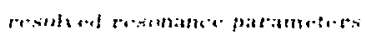

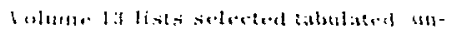

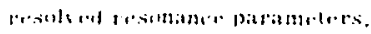




\section{Acknowledgments}

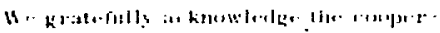

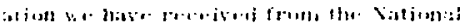

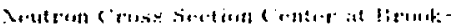

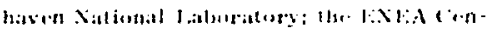

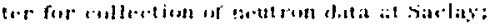

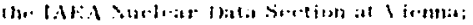

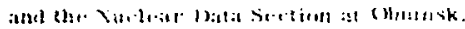

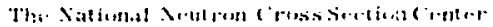

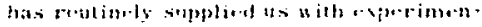

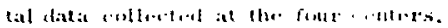

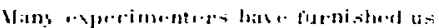

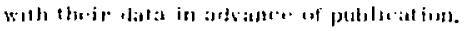

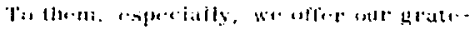
fal thanks. Finally. Wre sould like lu

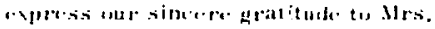

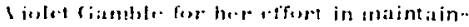
ing the hildiasterabic fild and to Bas.

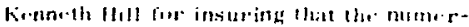
ots atmputer runs were satistaturity -antuplatint.

\section{References}

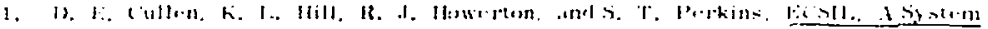

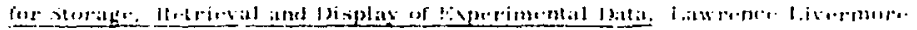

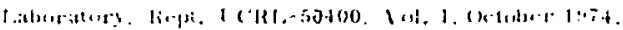

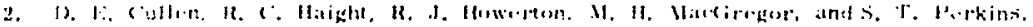

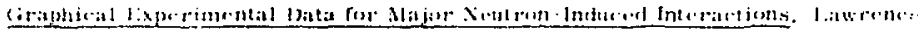
1.50.

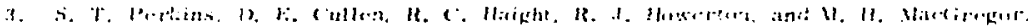

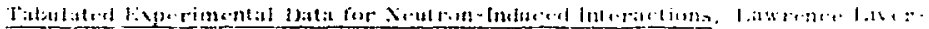

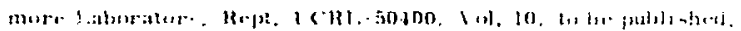

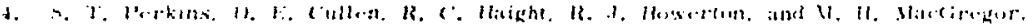

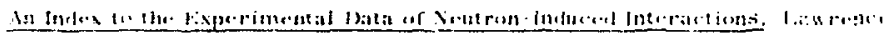

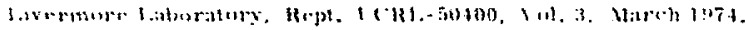

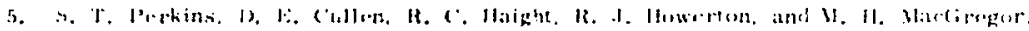

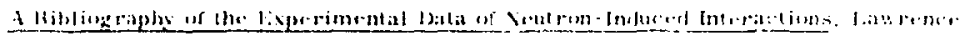

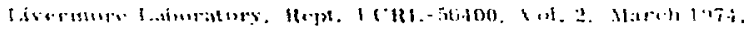




\section{ECSIL Conventions}

The ECSiL Data System describes experimental neutron-induced cross sections and relateo information by indicating:

- Target - The ZA number is used to describe the target. There are several special conventions. For example, $A$ is set equal to zero for elemental mixtures. For compounds, the $Z$ of the element that appears first in the molecular formula is used, and $A$ is defined as 300 plus the molecular weight (e.g., $\mathrm{H}_{2} \mathrm{O}$ is assigned $Z=1$ and $\mathrm{A}=318$ ). For unstable targets, the longest-lived Isumer is assigued the Z.A of the target: short lived isomers are assigned the $Z$ of the target, and $A$ is defined as 600 plus the $A$ of the target $i \cdot g .,{ }^{242} \mathrm{~B} A m$ is assigned $Z=95$ and $A=84 \%)$. Sie

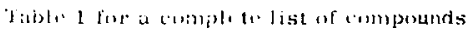
atto specelal isotrupes.

- Interactirn - A numerical equivaient is used to deEiffnate the interaction: totial, clastic, rapture, etc. In ECSIL. this numerical tequivalent is reReried to as the basic $C$ number. I'able 2 gives a complete list of all basic $C$ numbers.

Ilsit; Is
- Interaction Property - A numerical equivalent designates tha interaction properties that are measured, such as cross section, angular distribution, or energy distribution. In ECSiL this numerical equivalent is referred to as the $C$ increment number. The total $C$ number used to describe the interaction and its property is the sum of the $\mathrm{C}$ number increment and the basic $C$ number [e.g., 11 indicates the total $\left(N, N^{\prime}\right)$ cross section, whereas 311 indicates the $\left(N, N^{\prime}\right)$ secondary neutron energy spectruml. Table 3 gives a complete list of all $\mathrm{C}$ number increments. Table 4 lists miscellaneous quantities that are not included in the basic $C, C$ increment scheme. - Interaction Modifier - A numerical equivalent is used to further qualify or describe the interaction. This quantity indicates conditions such as target temperature, the cross section for excitation of one or more levels of the residual nucieus, and the cross section for production of one or more photons. In ECSIL this numerical equivalent is referred to as the $S$ number. Table 5 gives a complete list of all $S$ number's. 
Table 1. Compourıds and special isotopes (assigned ZA's).

\begin{tabular}{|c|c|c|c|}
\hline $\begin{array}{c}\text { Assigned } \\
\text { ZA }\end{array}$ & Material & $\begin{array}{c}\text { Assigned } \\
\text { ZA }\end{array}$ & Material \\
\hline 1302 & $\mathrm{H}_{2}$ (gas) & 14360 & $\mathrm{SiO}_{2}$ \\
\hline 1318 & $\mathrm{H}_{2} \mathrm{O}$ & 16364 & $\mathrm{SO}_{2}$ \\
\hline 1320 & $\mathrm{I}_{2} \mathrm{O}$ & 22349 & $\mathrm{TiH}_{0.6}$ \\
\hline 5370 & $\mathrm{~B}_{2} \mathrm{O}_{3}$ & 22350 & $\mathrm{TiH} 1.9$ \\
\hline 6328 & $\mathrm{C}_{2} \mathrm{H}_{4}$ & 26460 & $\mathrm{Fe}_{2} \mathrm{O}_{3}$ \\
\hline 6331 & $\mathrm{CH}_{3} \mathrm{OH}$ & 27660 & ${ }^{60} \mathrm{~m}_{\mathrm{Co}}$ \\
\hline 6376 & $\mathrm{C}_{5} \mathrm{H}_{6}$ & 40391 & $\mathrm{ZrH}_{0.63}$ \\
\hline 6384 & $\mathrm{C}_{6} \mathrm{H}_{12}$ & 40352 & $\mathrm{ZrH}_{0.98}$ \\
\hline 6.386 & $C_{8}{ }^{H}{ }_{14}$ & 70393 & $\mathrm{ZrH} \mathrm{H}_{1.5}$ \\
\hline fi:3:2 & $\mathrm{C}_{3} \mathrm{H}_{33} \mathrm{O}_{3}$ & 40,394 & $\mathrm{ZrH} 1,08$ \\
\hline 6404 & ${ }^{\circ}{ }_{s} \mathrm{H}_{y}$ & $40+23$ & $\mathrm{xrO}_{2}$ \\
\hline 6652 & $\mathrm{C}_{25} \mathrm{H}_{52}$ & $\$ 0636$ & $\mathrm{Nd}_{2} \mathrm{O}_{3}$ \\
\hline 73213 & $N$, (gas) & $817+8$ & $1+8 g \mathrm{gm}$ \\
\hline $7 \div 53$ & $\mathrm{NII}_{4} \mathrm{Cl}$ & 8200? & RAIXO-Rb \\
\hline 73918 & $\mathrm{NH}_{4}$ I?r & 92570 & $1(1)$ \\
\hline $74: 5$ & $\mathrm{NII}_{-1} \mathrm{l}$ & $4,3: 42$ & 2. $\mathrm{Am}$ \\
\hline $13: 332$ & $1), 2($ gas $)$ & W:5iti & $3 \cdot 12 \mathrm{~m}$ \\
\hline 12340 & $M_{1} y_{3}()$ & 406.54 & elstitis \\
\hline 13.102 & Al. ${ }^{6 !} \cdot 3$ & & \\
\hline
\end{tabular}


Table 2. Basic reaction designator (basic $\mathrm{C}$ ).

\begin{tabular}{|c|c|c|c|}
\hline $150.1 \times$ & Cross section tyoe & $\underset{C}{B a s i c}$ & Cross section type \\
\hline 1 & l'otal & 26 & $(\mathrm{~N}, \mathrm{P})$ \\
\hline$\stackrel{1}{\prime}$ & Vlastic & 27 & $(\mathrm{~N}, \mathrm{XP})$ \\
\hline ; & Nonelastic & 28 & $(\mathrm{~N}, \mathrm{D})$ \\
\hline+ & $\begin{array}{l}\text { Nerutron enussion (clastic } \\
\text { - nontlastir) }\end{array}$ & $\begin{array}{l}29 \\
30\end{array}$ & $\begin{array}{l}(N, S U) \\
(N, T)\end{array}$ \\
\hline . & $\begin{array}{l}\text { riral scattering (inelastic } \\
\text { rlustic) }\end{array}$ & $\begin{array}{l}30 \\
31\end{array}$ & $(\mathrm{~N}, \mathrm{XT})$ \\
\hline '. & Xulurun nomelasle emission & 32 & $\left(N^{3}{ }^{3} \mathrm{He}\right)$ \\
\hline ; & Rethesal & 3.3 & (N, $\left.\mathrm{X}^{\circ} \mathrm{He}\right)$ \\
\hline$\therefore$ & - & 34 & $\langle\mathbb{N}, \alpha\rangle$ \\
\hline . & - & 35 & $\left(\mathrm{~N}, \mathrm{X}_{\alpha}\right)$ \\
\hline$! 11$ & - & 36 & Activaticn \\
\hline 11 & (N,X') & 37 & $(N, 2 \alpha)$ \\
\hline $1:$ & $(x, 2 x$ & 38 & - \\
\hline$\because$ & $(x, x)$ & 39 & - \\
\hline : & $\therefore, X \mid 1$ & 40 & 一 \\
\hline & $\therefore, x^{\prime} ! 11$ & +1 & Bound atom \\
\hline$\cdot$ & $(x, 1)$ & 42 & Freo atom \\
\hline$\therefore$ & $\therefore, \therefore, 11,1$ & +3 & roherent scattering \\
\hline$\therefore$ & $\therefore, \cdots, x$ & $H$ & Incoherent srattering \\
\hline 1. & 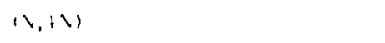 & +5 & - \\
\hline$\therefore$ & - & +6 & $\begin{array}{l}\bar{v} \text { pronep neutrons per fission } \\
\text { (average })\end{array}$ \\
\hline $\begin{array}{l}? ! \\
\vdots !\end{array}$ & 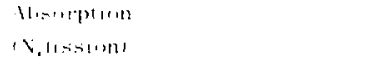 & +7 & $\begin{array}{l}\overline{i^{\prime}} \text { de delayed neutrons per fission } \\
\text { daveragel }\end{array}$ \\
\hline$\therefore:$ & 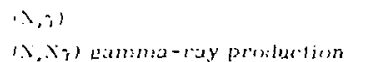 & $\because 4$ & $\begin{array}{l}\text { ni, neutrons produes per non- } \\
\text { elaslic }\end{array}$ \\
\hline$\therefore$ & 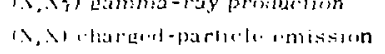 & 40 & $x$, capture-to-fission ratio \\
\hline
\end{tabular}


Table 3. Reaction designator increments (C increment).

\begin{tabular}{|c|c|c|}
\hline increment & $\begin{array}{l}\text { Rezction property } \\
\text { (units) }\end{array}$ & Definition \\
\hline 0 & $\begin{array}{l}\text { Integrated cross sections } \\
\text { (barns), or related parameters }\end{array}$ & $\sigma$ \\
\hline 50 & $\begin{array}{l}\text { Spectrum-averaged cross sec- } \\
\text { tion (barns) }\end{array}$ & $\bar{\sigma}$ \\
\hline $100^{\mathbf{a}}$ & $\begin{array}{l}\text { Angilar distributions (harns/ } \\
\text { steradian) }\end{array}$ & $\sigma(E, \theta)$ \\
\hline 200 & $\begin{array}{l}\text { Fnergy distributions (barns/ } \\
\text { MeV) }\end{array}$ & $\sigma\left\langle E, E^{\prime}\right\rangle$ \\
\hline 250 & $\begin{array}{l}\text { Angular distributions integrated } \\
\text { between fixed angular limits } \\
\text { (barns) }\end{array}$ & $\sigma: \mathrm{E}, \theta_{\min }, \theta_{\text {max }}{ }^{j} \mathrm{lab}$ \\
\hline 300 & $\begin{array}{l}\text { (Diferential energy distributions } \\
\text { (barns/sterndian Mel') }\end{array}$ & $\sigma\left(t:,:^{\prime}, o\right)$ lad \\
\hline 350 & 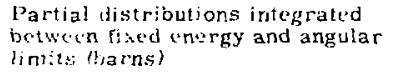 & 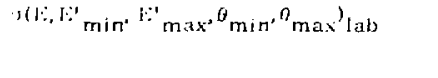 \\
\hline 400 & $\begin{array}{l}\text { Ene'gy distr bulions integrated } \\
\text { between fixed entergy limits } \\
\text { (bathis) }\end{array}$ & $g\left(1 ;, F_{\min }^{\prime}, F_{\max }^{1}\right)$ \\
\hline $450^{\mathrm{a}}$ & 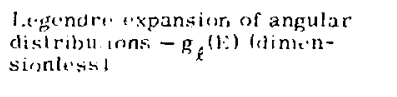 & $\left.g(t, \theta)=\sigma(1) \sum_{\ell=0}^{\infty} \frac{2 \ell+1}{4 \pi} g_{\ell}(1 ;) 1\right)_{2}(\cos \theta)$ \\
\hline 500 & Resonane integt'ills fbarnsil & R.I. $\left.=\int_{\mathrm{E}}^{\mathrm{min}} \mathrm{\operatorname {max }} \sigma \mathrm{l}\right) \frac{\mathrm{d} H}{\mathrm{~F}}$ \\
\hline $\sin 0^{a}$ & 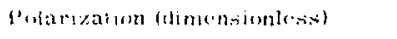 & $P^{\prime}(1,0)$ \\
\hline 600 & 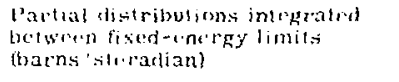 & 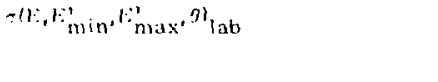 \\
\hline 6.50 & 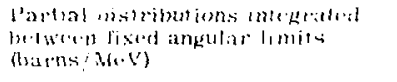 & 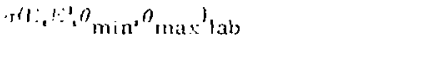 \\
\hline 300 & 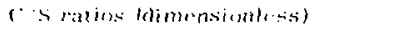 & \\
\hline$\therefore 0$ & 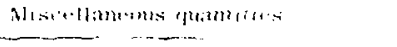 & Sien: t:abls: i \\
\hline
\end{tabular}


Table 4. Reaction designator for miscellaneous quantitics.

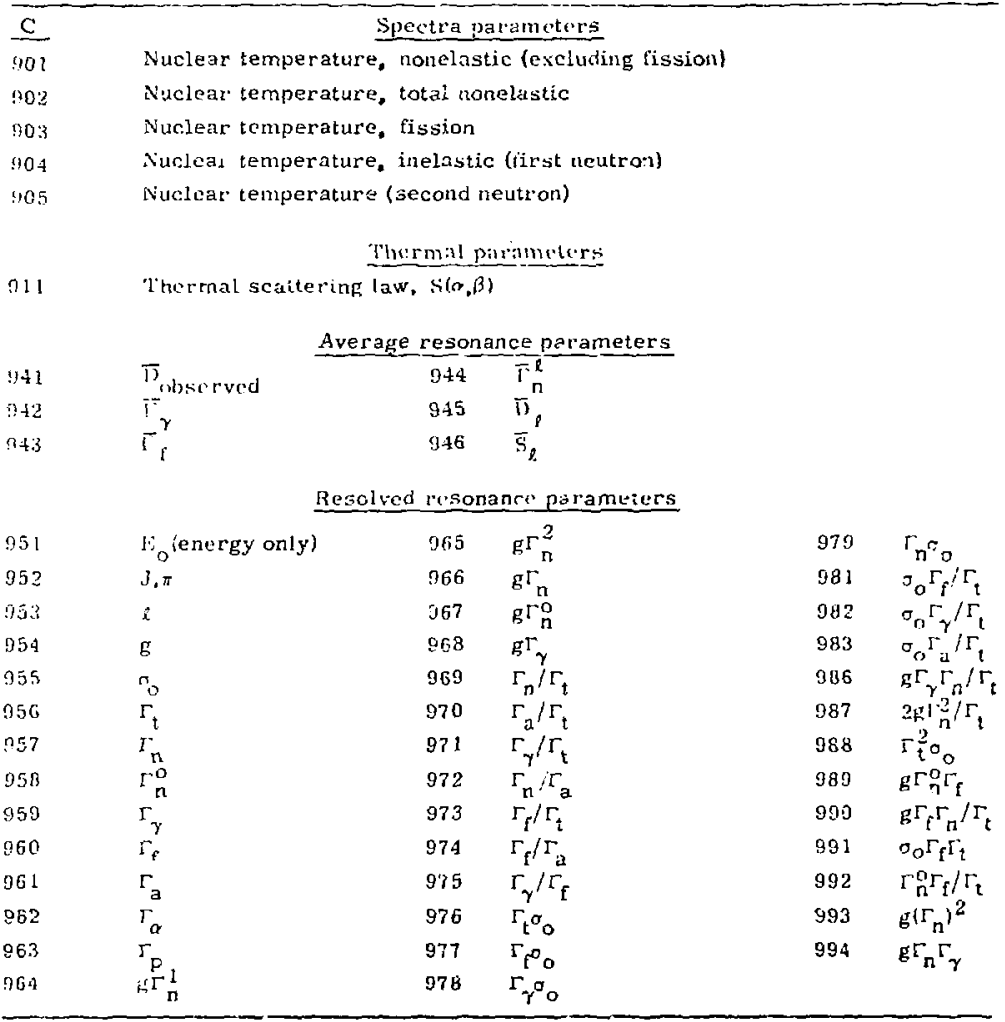


Tidble 5. Reaction designator modifier ${ }^{a}$ (S number).

\begin{tabular}{|c|c|}
\hline S & Modification (units) \\
\hline 1 & Level excitation (MeV) \\
\hline 2 & Isomer production (seconds) \\
\hline 3 & Isomer production (minutes) \\
\hline 4 & Isomer praduction (hours) \\
\hline 5 & Isomer production (days) \\
\hline c & Isomer production (years) \\
\hline 7 & Photon production (MeV) \\
\hline$R$ & Inresolved level excitation (MeV) \\
\hline 4 & Waterial temperature (Kelvin) \\
\hline 10 & $\begin{array}{l}\text { linresolved photor paroduction } \\
\left(\mathrm{H}_{\mathrm{C}} \mathrm{V}\right)\end{array}$ \\
\hline 11 & Spin slate (dimensionlt:ss) \\
\hline 12 & $\begin{array}{l}\text { [sotope bound in material } \\
\text { (dimensionless) }\end{array}$ \\
\hline 1.3 & (Oriented orystal (Miller number) \\
\hline $1+3$ & fieriron production Whet' \\
\hline 20 & $\begin{array}{l}\text { Transmission measuremen' } \\
\text { (harns.a(c i) }\end{array}$ \\
\hline
\end{tabular}

$\mathrm{NGS} / \mathrm{ru} / \mathrm{hm}$

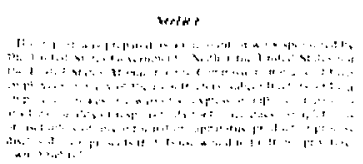

Printed in the faltod States of Anterica Available from

National. Technical [nformation Service

U.S. Departmeni of Commerce 5285 Port troyal Road

Springfield, Virginia 22151

(is/ru/ Th

Prire: Printed copy s ; Microficlie

$\$ 1.45$

$\frac{\text { Pages }}{1-50}$
$51-150$
$151-325$
$326-500$
$501-1000$

NTIS

Selling Price

$\$ 4.00$

$\$ 5.45$

$\$ 7.60$

$\$ 10.50$

\$1.3.60

-xi- 


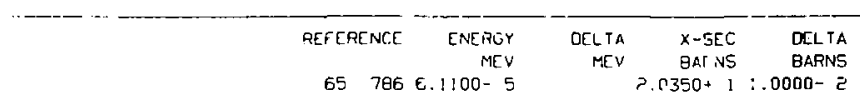

\begin{tabular}{|c|c|c|c|c|c|c|c|c|c|c|}
\hline \multicolumn{3}{|c|}{$03 / 21 / 74$} & \multicolumn{5}{|c|}{ ABSORPT ION } & \multicolumn{3}{|r|}{$1-H-1$} \\
\hline YLF [RENCE & ENERGY & $O L_{L}^{T}$ & $x-5 E C$ & UE: $T$ & & RETF.PENCE & ENERGY & DELTA & $x-5 E C$ & DEL TA \\
\hline & MEV V & MEV & BARISS & EARN & & & MEV & MEV & BAFNS & BARINS \\
\hline 592995 & $.5359-3$ & & $3.2800-1$ & 1 6. $0000-$ & 3 & 59 こ担! & $2.5300-\theta$ & & $3.3700-1$ & $5.0000-3$ \\
\hline $5 \mathrm{e}$ 2؟95 & $2.5300 \quad 3$ & & $3.3600 \cdots$ & $=5.000$. & 3 & 58 2782 & $\therefore .5300-8$ & & $3.2700-1$ & $4.0000-3$ \\
\hline 552940 & $2.5360-9$ & & 3. $2900-1$ & I U & $\therefore$ & 54 e7g3 & 己.5300- E & & $3 ? 300-1$ & $3.0000-3$ \\
\hline 56 293! & $2.530 C-B$ & & $3.3500-1$ & 14.0030 & 3 & $54 \quad 2730$ & $2.5300-8$ & & $3.2300-1$ & $8.0000-3$ \\
\hline $56 \quad 2930$ & $2.5300-B$ & & 3. 3700- 1 & 1: $: 500 \%$ & $c^{\prime}$ & $53=785$ & ट. $5300-8$ & & 3. $2100-1$ & $5.0000-3$ \\
\hline 532786 & $2.5300-B$ & & $3.2900-1$ & 14.0920. & 3 & 53 ᄅ784 & ट.5300- 8 & & $3.3200-1$ & $7.0000-3$ \\
\hline 422787 & ㄹ.5360- 붕 & & $3.30[3-1$ & 2. 20.50 & $\bar{c}$ & $E 5: 565$ & ट.5s00- 9 & & 3. $2600 \cdots 1$ & $3.0000-3$ \\
\hline $59 \geq 792$ & $2.5300-8$ & & 3. $3000-1$ & B.0000- & 3 & 6ij eg: & $2.5300-8$ & & $3.3500-1$ & $5.0000-3$ \\
\hline
\end{tabular}

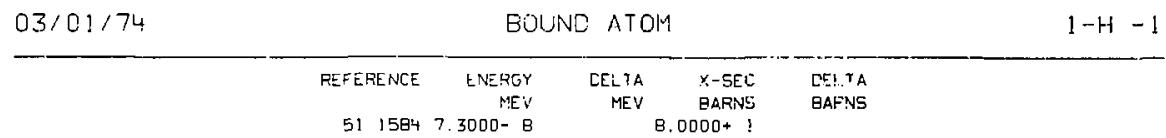

$03 / 01 / 74$

FREE ATOM

$1 \cdot-H-1$

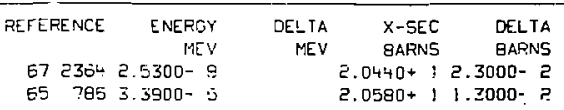

03/01:74 COHERENT SCATTERING

\begin{tabular}{|c|c|c|c|c|c|c|c|c|c|}
\hline RETERENICE & $\begin{array}{r}\text { ENERG } \\
\text { MEV }\end{array}$ & $\begin{array}{r}\text { DELTA } \\
\text { MEV }\end{array}$ & $\begin{array}{l}x-5 E C \\
\text { BARNS }\end{array}$ & $\begin{array}{l}\text { CEL OA } \\
\text { BARNS }\end{array}$ & REF ERENCE & $\begin{array}{r}\text { ENERGY } \\
\text { MEV }\end{array}$ & $\begin{array}{r}\text { CELTA } \\
\text { MEV }\end{array}$ & $\begin{array}{l}X-\bar{X} \text {-5C } \\
\text { GARNS }\end{array}$ & $\begin{array}{l}\text { DEL IA } \\
\text { BARNS }\end{array}$ \\
\hline 552926 & $.5300-8$ & & $2.3400+0$ & $1.5000-1$ & 62 2798 & $5300-8$ & & $1.7600+0$ & $2.0000-2$ \\
\hline 512790 & $.5300-8$ & & $1.8000+0$ & z.0000- & 472799 & $5300-\theta$ & & $1.9600+0$ & $1.2000-1$ \\
\hline 532789 & $.5300-8$ & & $1.8100+0$ & $15.0000-2$ & $51 \quad 1584$ & $3900-8$ & & e. $0000+0$ & $1.6000-$ \\
\hline
\end{tabular}


LRUSS SEし I IUIV

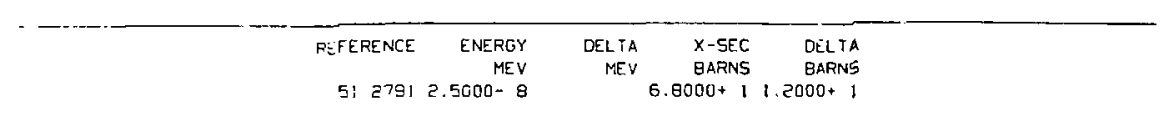

5) $27912.5000-8 \quad 6.8000+11.2000+1$

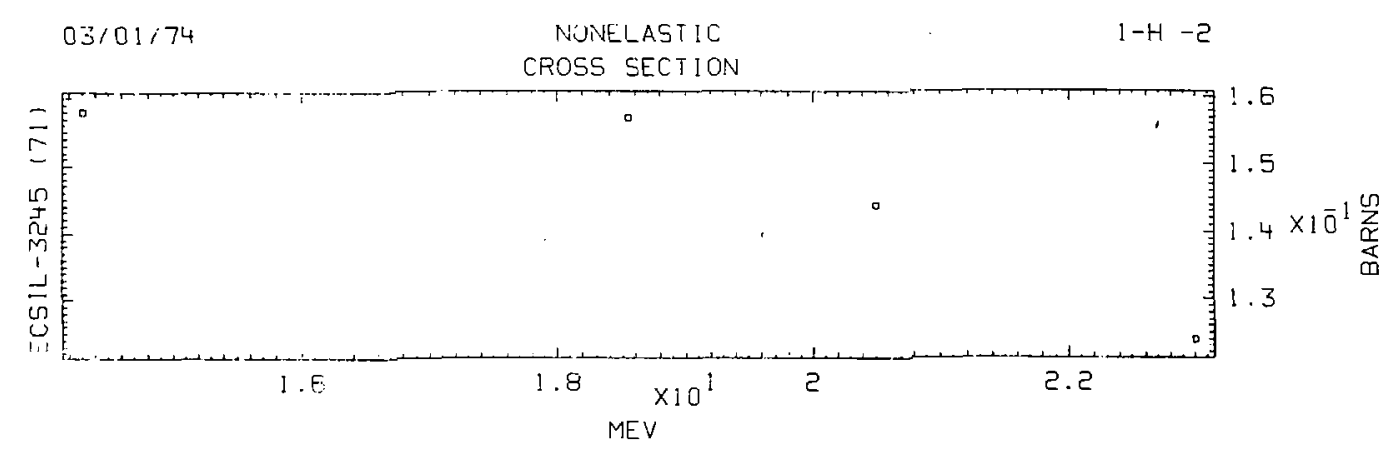



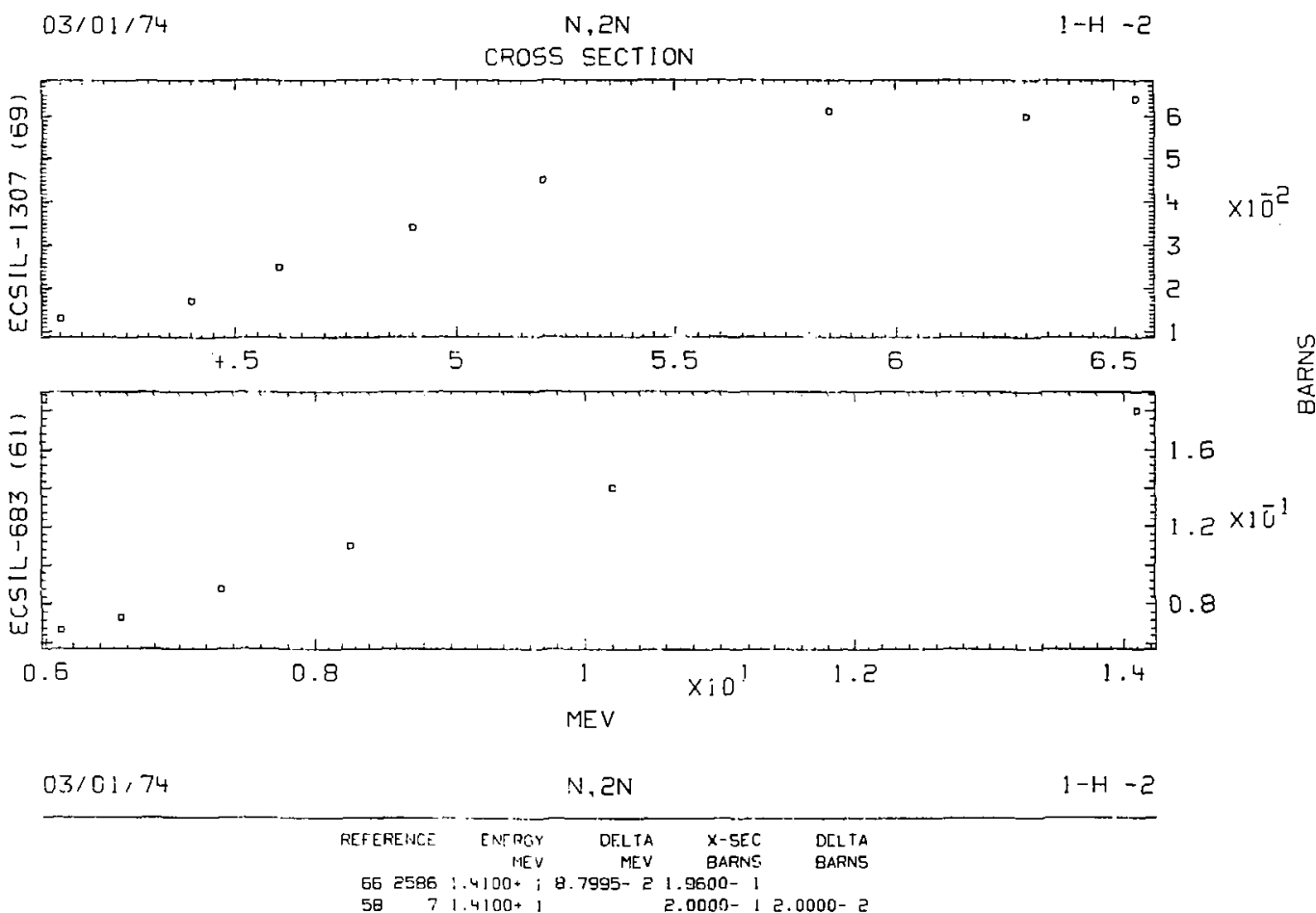


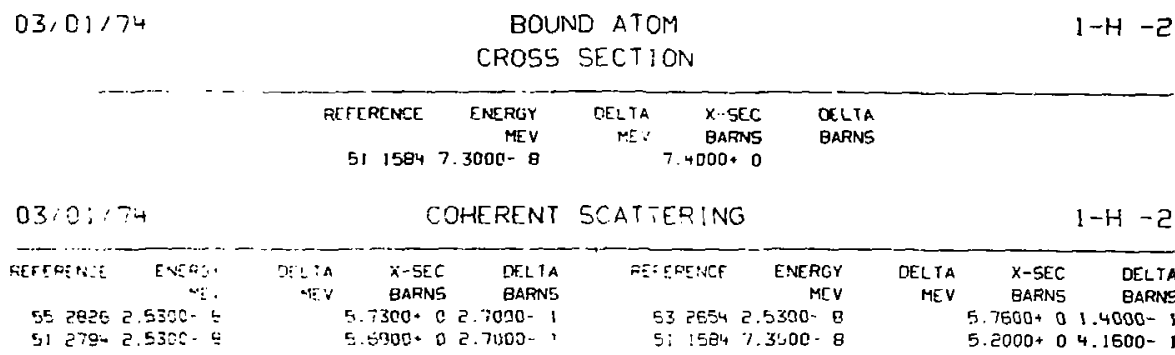

03:01,74

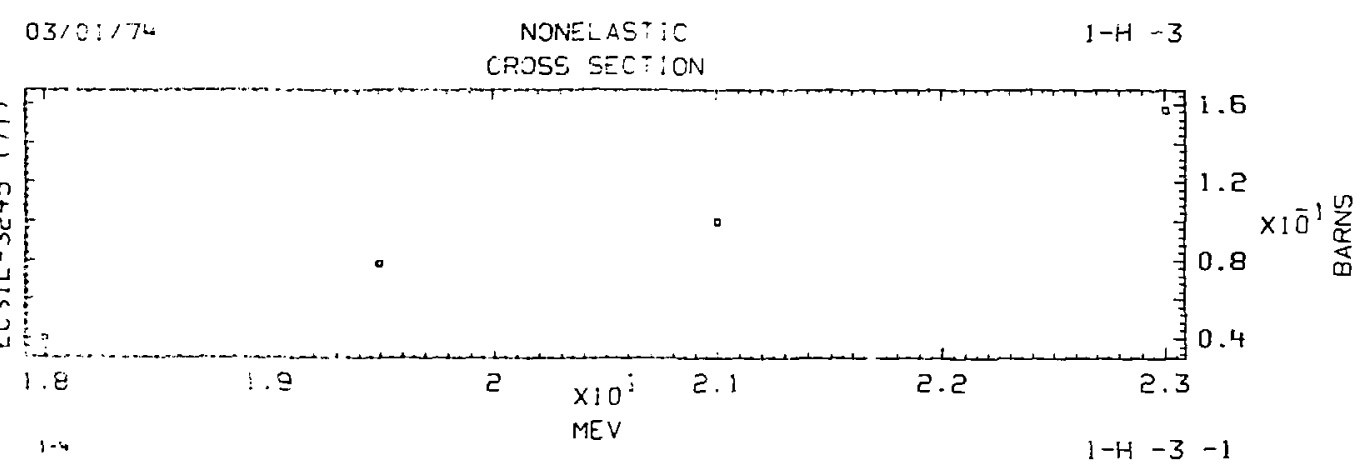


$03 / 01 / 74$

FREE ATOM

H2O

CROSS SECTION

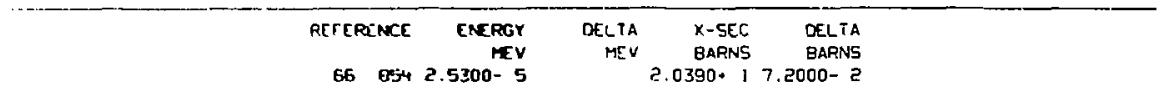

$03 / 01 / 74$

TOTAL SCATTERING

D20

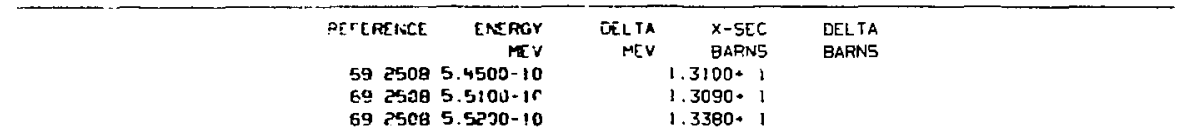

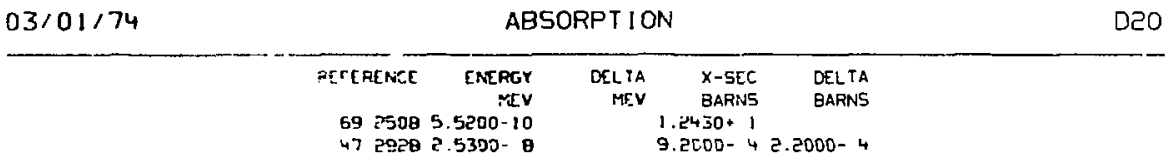

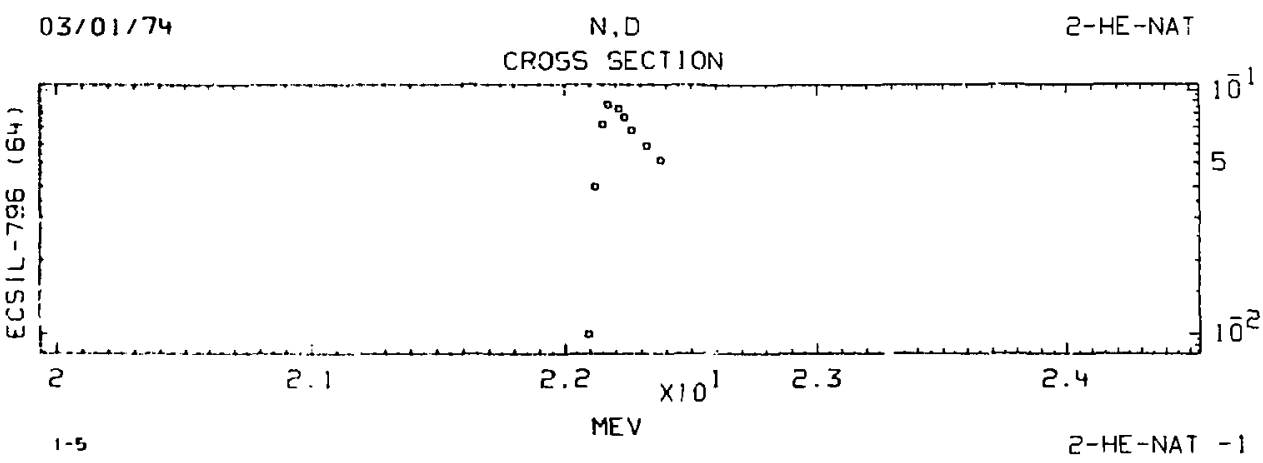




$\begin{array}{rrrrr}\text { REFERENCE } & \text { ENERCY } & \text { DELTA } & \text { X-SEC } & \text { OELTA } \\ \text { HEV } & \text { MEY } & \text { BARNS } & \text { BARNS } \\ 692998 & 2.5300-8 & 7.7300-19.0000-3 \\ 6.3 & 797 & 2.5300-8 & 7.2000-1 & 3.0000-2\end{array}$
$03 / 01 / 74$
$N, P$
P-HE -3
C.POSS SECTION
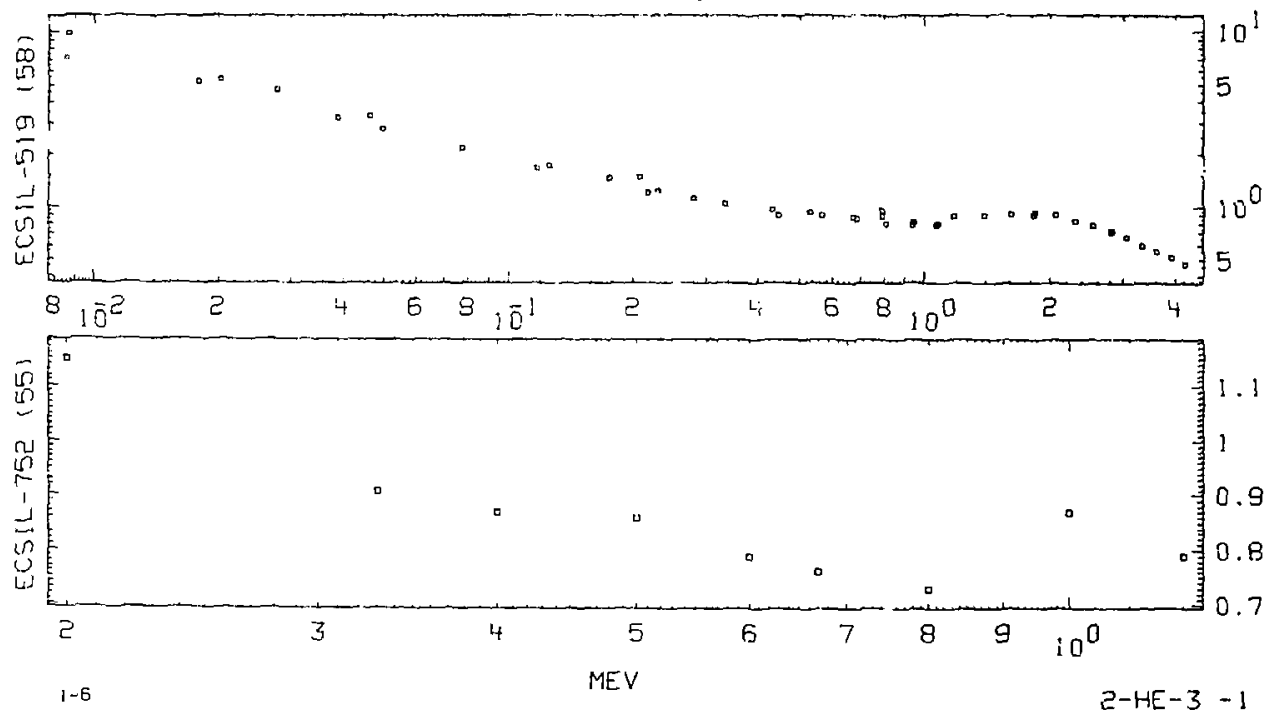

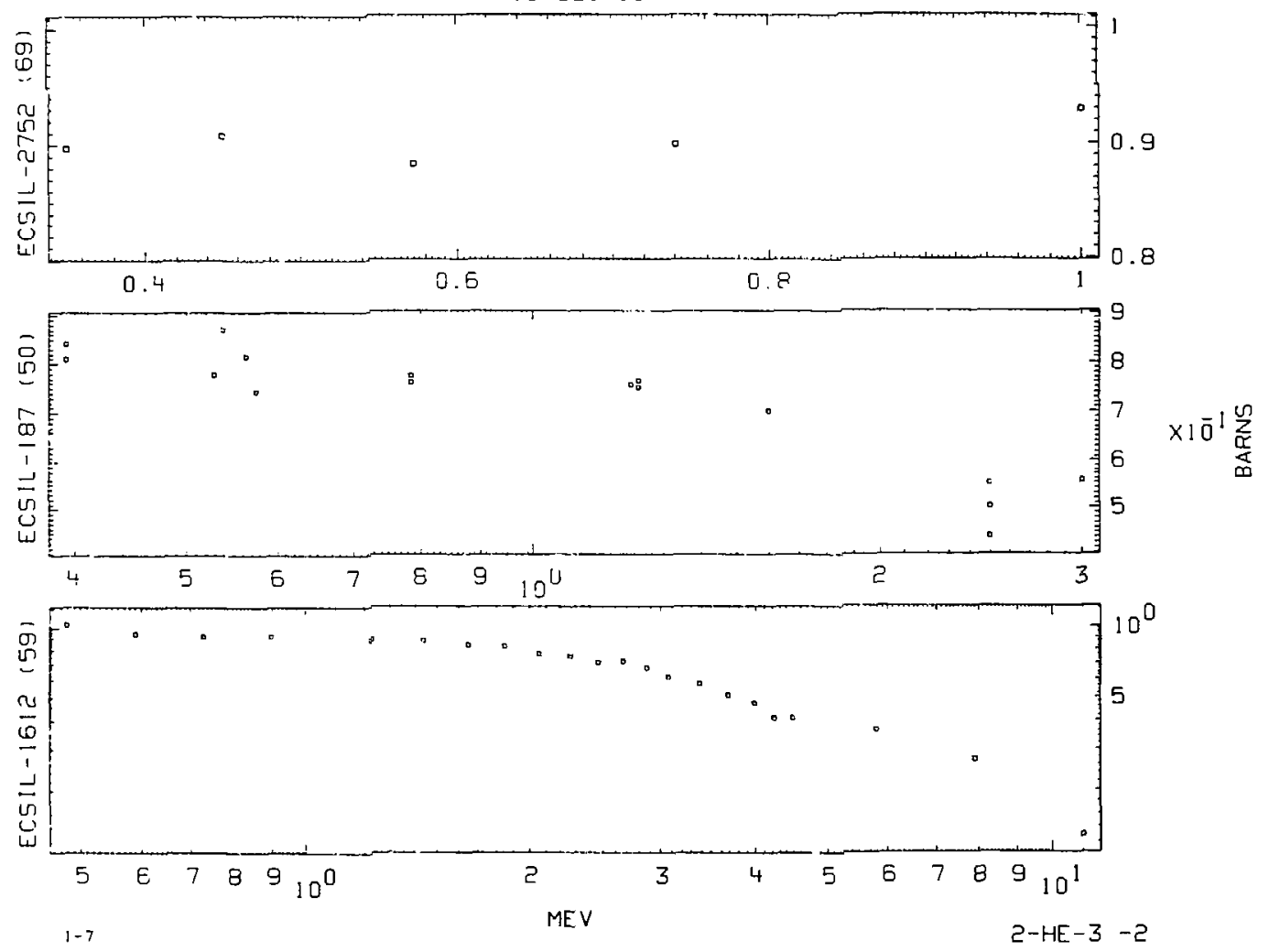

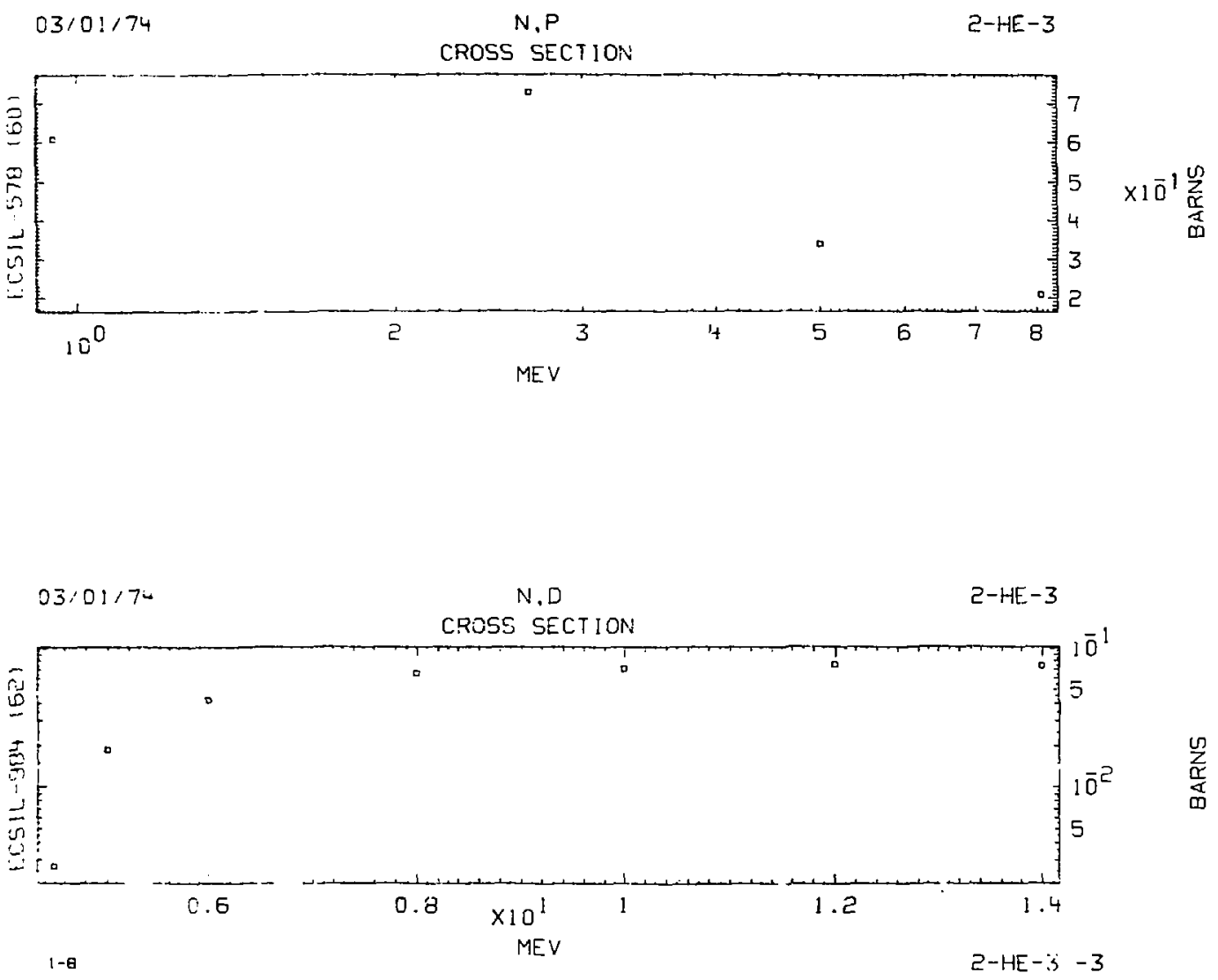


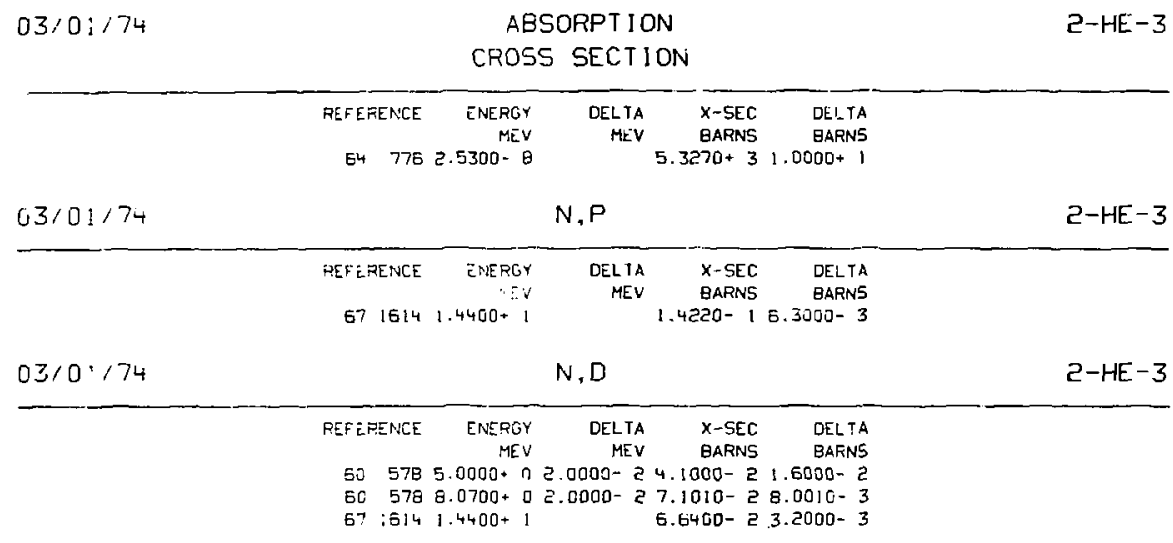

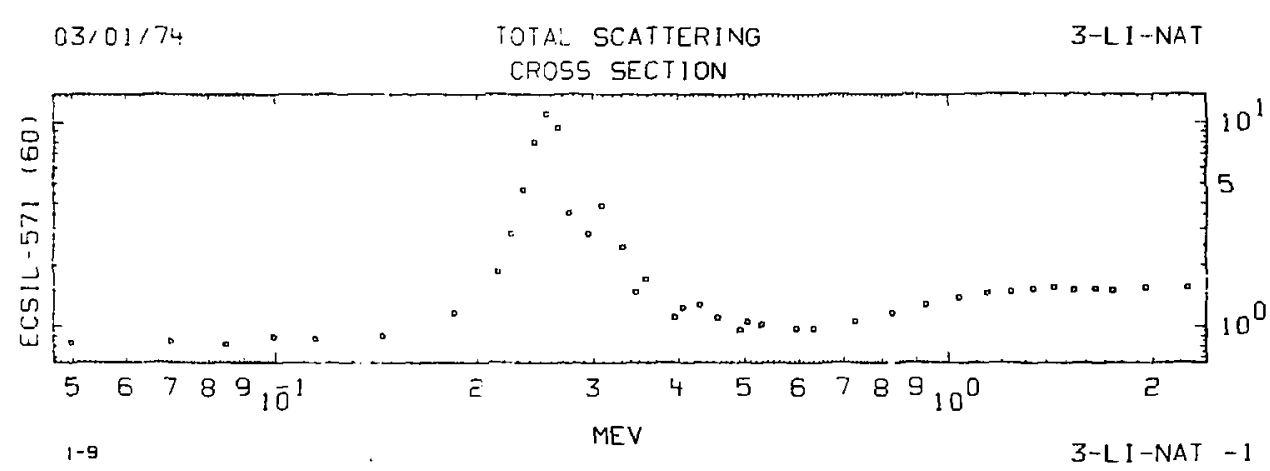




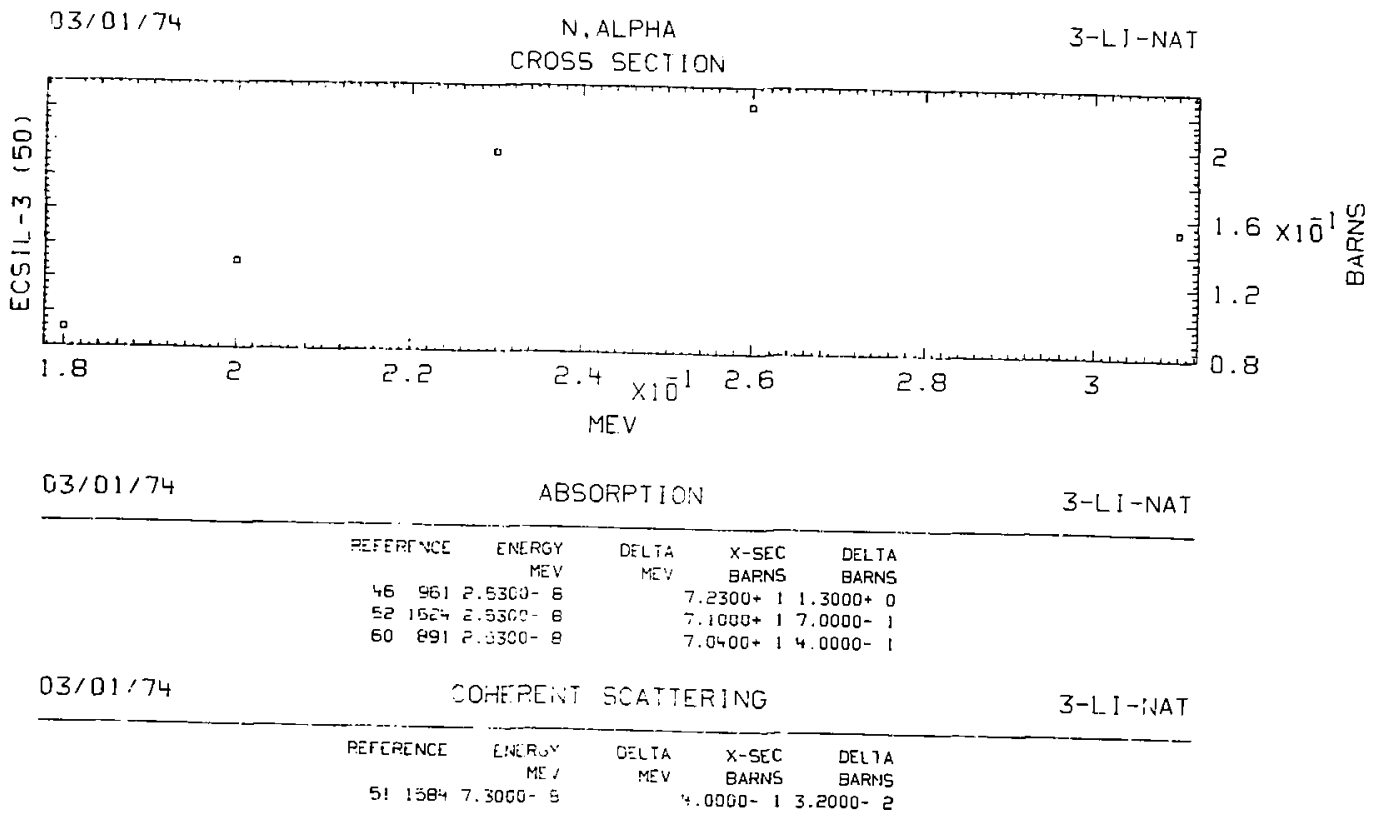


$03 / 01 / 74$

TOTAL SCATTERING

$3-L I-6$

CROSS SECTION

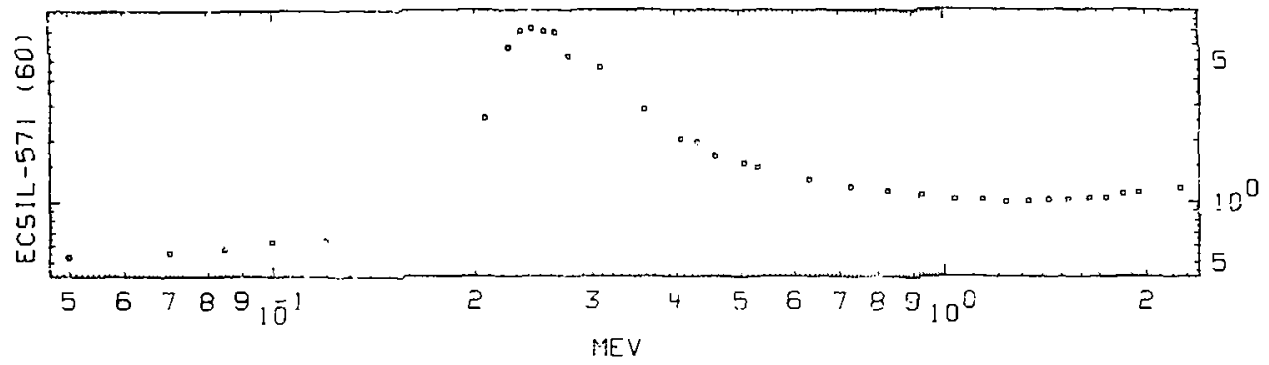

$03 / 01,74$

$N, N^{\circ}$

$3-L I-6$

CFISS SECTIO'

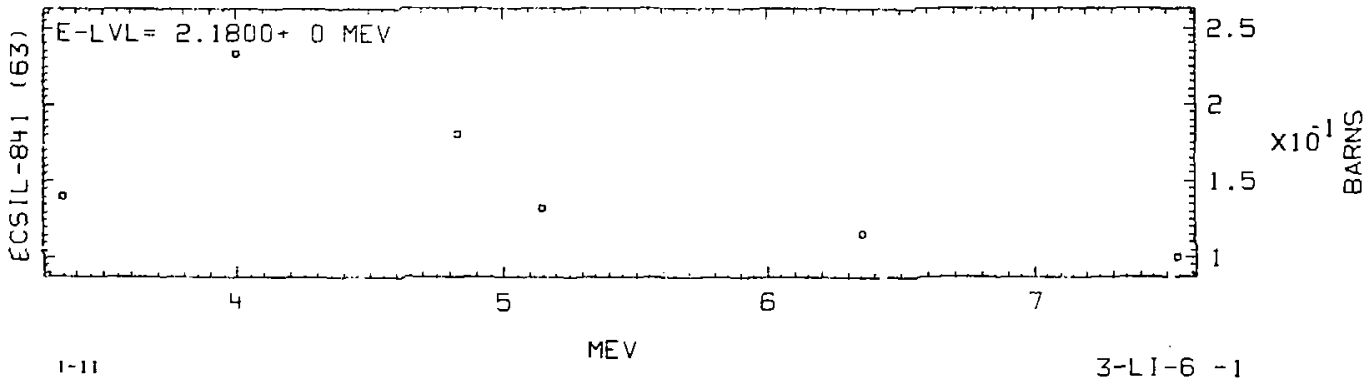




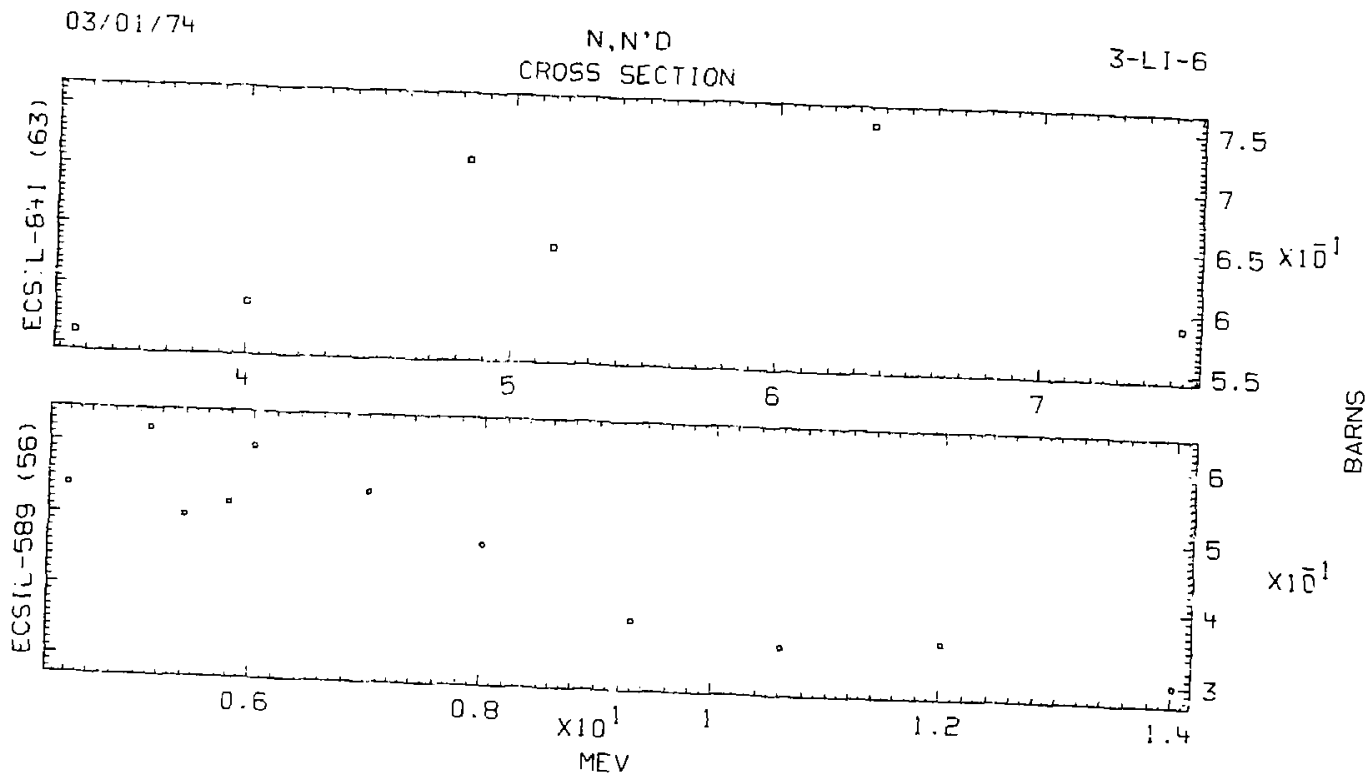

$1-12$ 


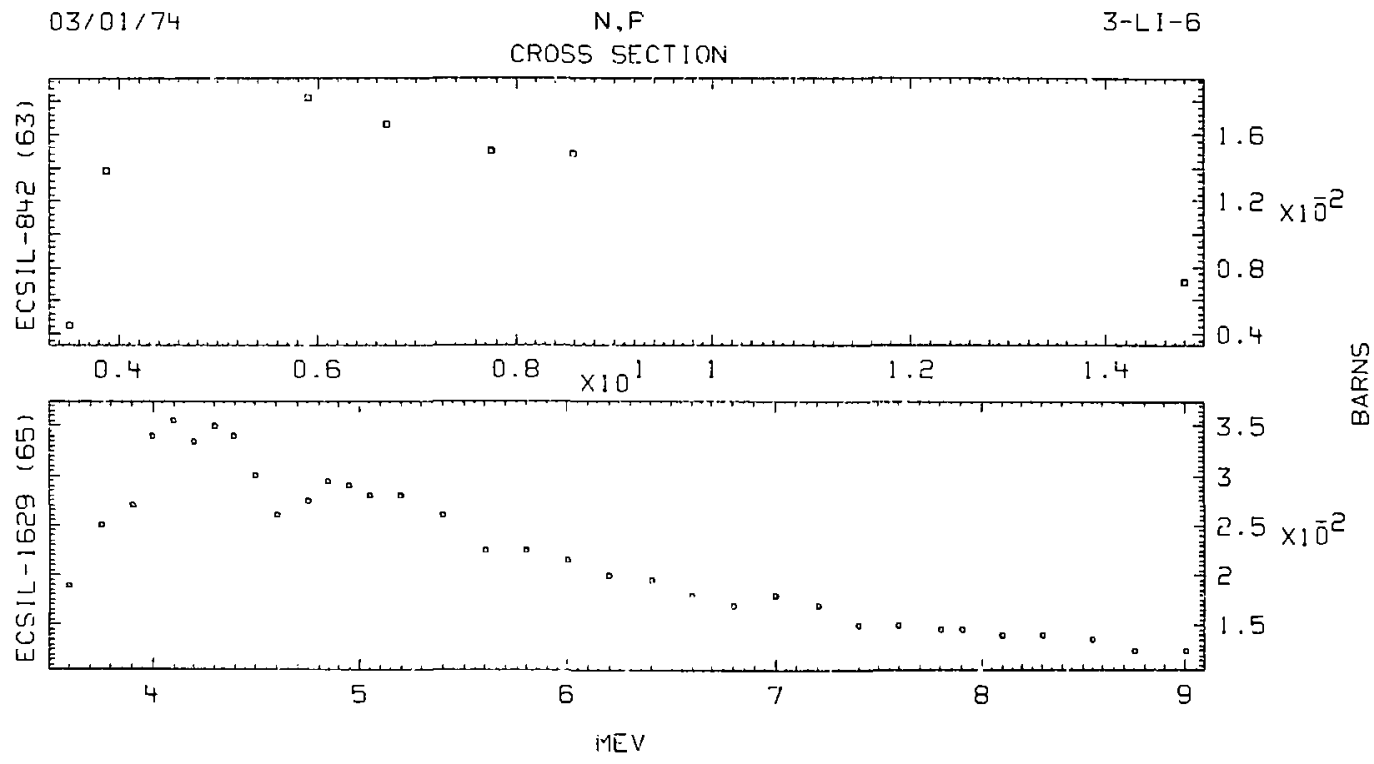

$1-13$

3-L I-6 - 3 


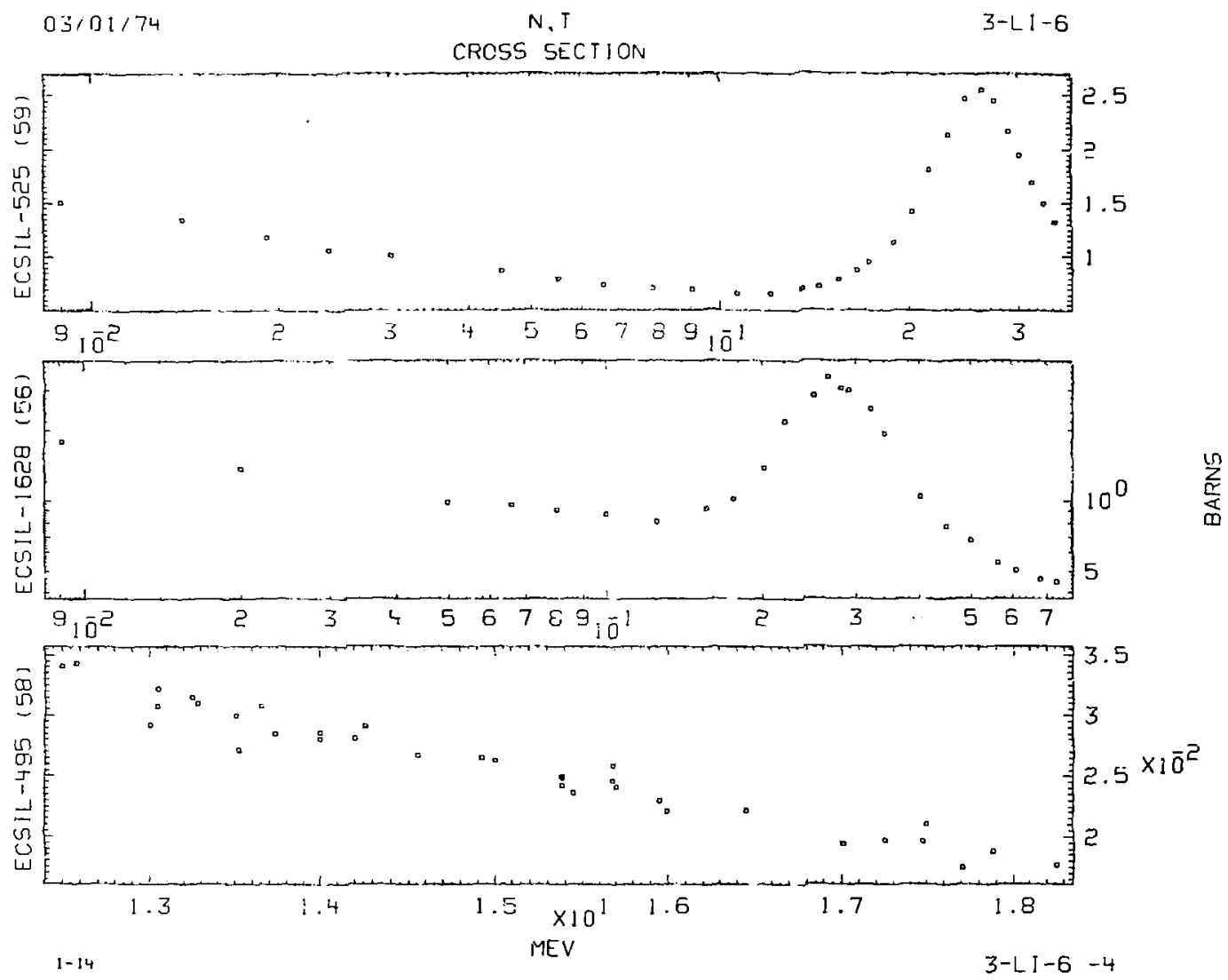



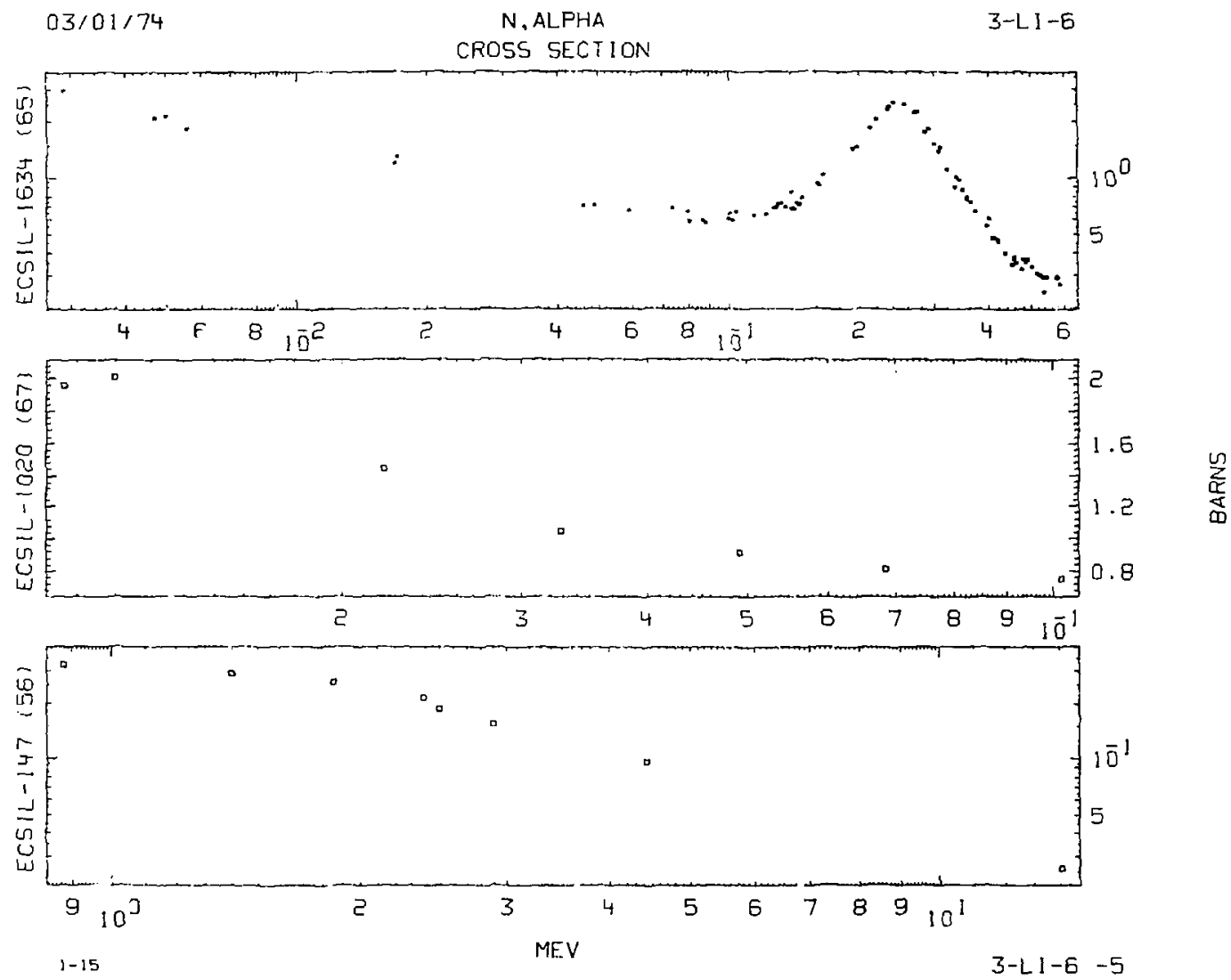

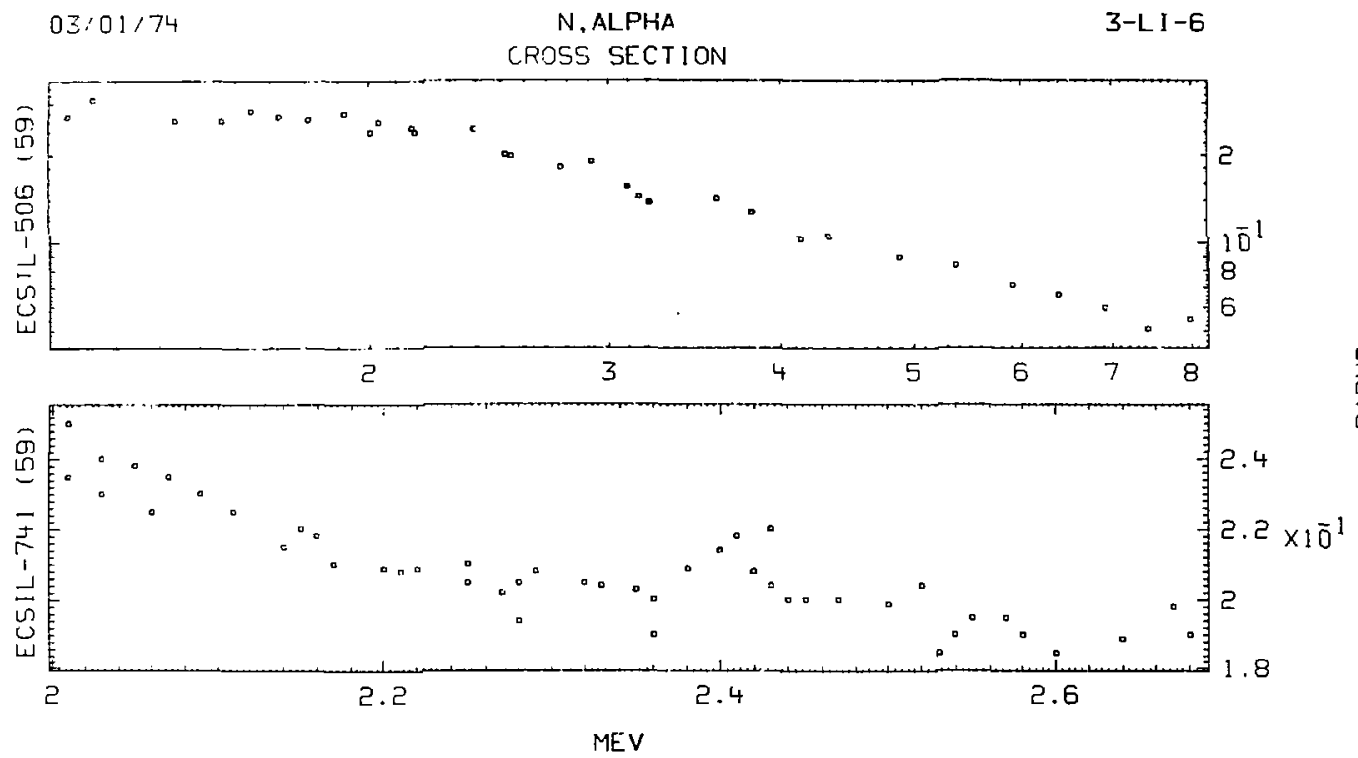

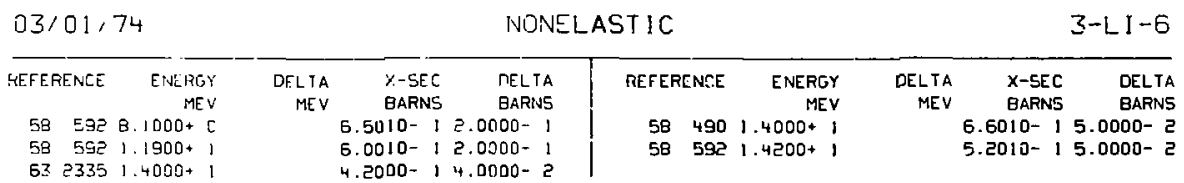


CROSS SECTION

$\begin{array}{rrrrr}\text { REFERENCE } & \text { ENERGY } & \text { DEL TA } & \text { X-5EC } & \text { DELTA } \\ & \text { MEV } & \text { MEV } & \text { BARNS } & \text { BARN5 } \\ 632335 & 1.4000+1 & & 1.4700+0 & 1.6000-1\end{array}$

$54153314100+11.0000-11.4400+0110000-$

$0 z / 01 / 74$

IN, $N^{\prime}$

$3-L J-6$

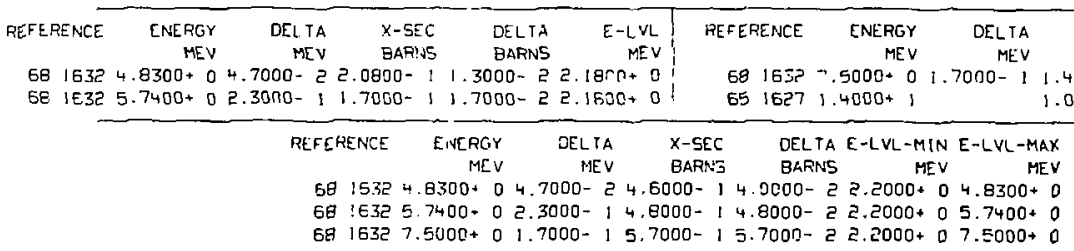

$03 / 01 ; 74$

$N, 2 N$

3-L I - G

\begin{tabular}{|c|c|c|c|c|c|c|c|c|c|c|}
\hline \multirow[t]{2}{*}{ PEFERENCE } & EJNERGY & DELTA & $x-5 E C$ & DEL.TA & \multicolumn{2}{|c|}{ AEF EPENCE } & ENERGY & DELIA & $X$-SEC & DELTA \\
\hline & MEV & MEV & BAFNS & BAFNS & & & MEV & MEV & BARNS & BARNS \\
\hline $60 \quad 593$ & $1.0200+1$ & & $3.3000-2$ & $1.5000-?$ & 58 & 594 & $1.4100+1$ & & $7.0010-2$ & $6.0010-3$ \\
\hline $\begin{array}{ll}63 & 2355 \\
61 & 2375\end{array}$ & $\begin{array}{l}1.4000+1 \\
1.4000+1\end{array}$ & & $\begin{array}{l}8.7000-2 \\
1.4000-1\end{array}$ & $\begin{array}{l}3.2000-2 \\
6.0000-2\end{array}$ & 61 & 487 & $1.4100+1$ & & $5.0000-5$ & $1.0000-2$ \\
\hline
\end{tabular}
$03 / 01 / 74$
N.N'D
$3-L I-6$

\begin{tabular}{|c|c|c|c|c|c|c|c|c|c|}
\hline REFERENCE & $\begin{array}{r}\text { ENERGY } \\
\text { MEV }\end{array}$ & $\begin{array}{r}\text { DELTA } \\
\text { MEV }\end{array}$ & $\begin{array}{l}X-5 E C \\
\text { BAFNS }\end{array}$ & $\begin{array}{l}\text { UELIAA } \\
\text { GARNS }\end{array}$ & RE $F$ ERENCE & $\begin{array}{r}\text { ENERGY } \\
\text { MEV }\end{array}$ & $\begin{array}{r}\text { DEL TA } \\
\text { MEV }\end{array}$ & $\begin{array}{l}X \text {-SEC } \\
\text { BARNS }\end{array}$ & $\begin{array}{l}\text { DELTA } \\
\text { BARNS }\end{array}$ \\
\hline $\begin{array}{ll}68 & 1632 \\
68 & 1532\end{array}$ & $\begin{array}{l}8300+c \\
7400+0\end{array}$ & $\begin{array}{l}4.7000-2 \\
\text { ᄅ. 3000- } 1\end{array}$ & $\begin{array}{l}5.7000-: \\
5.5000-\end{array}$ & $\begin{array}{l}4.2000-\bar{E} \\
5.1000-\overline{2}\end{array}$ & $\begin{array}{r}601632 \\
61487\end{array}$ & $\begin{array}{l}7.5000+0 \\
1.4100+1\end{array}$ & $100+0$ & $\begin{array}{l}7.2000-1 \\
7.0000-2\end{array}$ & $\begin{array}{l}5.9000-2 \\
1.2000-2\end{array}$ \\
\hline
\end{tabular}




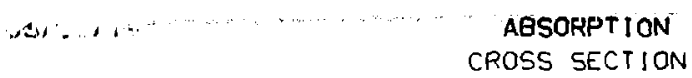

$3-L I-6$

CROSS SECTION

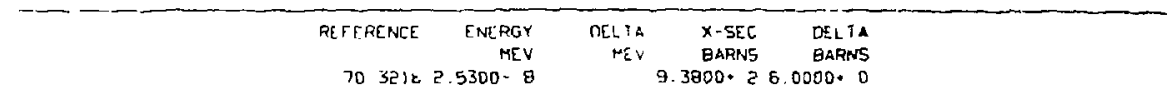

70 32) $2.5300-8$

$9.3800 \cdot 26.0000 \cdot 0$

$03 / 01 / 74$

N.P

$3-L I-6$

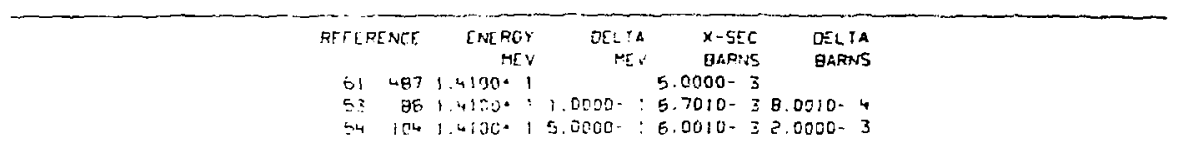

$03 / 01 / 74$

N.T

$3-L .1-6$

\begin{tabular}{|c|c|c|c|c|c|c|c|c|c|c|}
\hline EFERENCE & $\begin{array}{r}\text { ENERGY } \\
\text { AEV V }\end{array}$ & $\begin{array}{r}\text { OSI TA } \\
\text { MEV }\end{array}$ & $\begin{array}{l}\text { X-crs } \\
\text { GARNS }\end{array}$ & $\begin{array}{l}\text { OELIL } \\
\text { BARNS }\end{array}$ & ， & netgienes & $\begin{array}{c}\text { ratsy } \\
\text { of: }\end{array}$ & $\begin{array}{c}\text { Ort: } \\
\text { :t: }\end{array}$ & $\begin{array}{l}x-\sec \\
\text { exisis }\end{array}$ & $\begin{array}{l}\text { OCLiA } \\
\text { Daners }\end{array}$ \\
\hline $66 \quad 1631$ & $2.5000-2$ & E. $\operatorname{cec}{ }^{\circ} 3$ & $\therefore .0020+0$ & $7.0050-2$ & & 595 & 2.00020 & & $1.9000-1$ & $1.5000-2$ \\
\hline $66 \quad 1631$ & E.7000- $\bar{c}$ & i. $300-\bar{z}$ & 9.:1000-! & E. $0000-c$ & & $5^{+} \mathrm{z}^{2} 99$ ! & 2. $9002=$ & & $1.6500-1$ & 2.1000- Z \\
\hline $65 \mathrm{~J} 63 \mathrm{I}$ & 1.0000- : & $1.3 .00-2$ & $6.9000-1$ & $2.5000^{-3}$ & & $5: 483$ & $1, \div C=$ & & $2.7000-2$ & $6.0500-3$ \\
\hline 591526 & $2.7000-1$ & & $3.7000 \cdot 0$ & $4.0000-1$ & & $52 \leq E C$ & 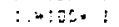 & & $2.5000-2$ & $2.0000-3$ \\
\hline $51+109$ & 1.500000 & 6. $\cos 0-1$ & $3.2002 . !$ & $5,0000-2$ & . & 52163 & : .u2zn- ! & & $2.6000-2$ & $3.6000-3$ \\
\hline $54 \quad 103$ & $2.0000+0$ & & $2.4000-1$ & $4.0000-2$ & & 5269 ! & $\therefore-050$ & c.0002 ! & $3.6005-2$ & $3.0000-3$ \\
\hline 521637 & 2.4900. & & $1.8000-1$ & $2.6320-2$ & & & & & & \\
\hline
\end{tabular}

03:01174 N.ALPHIA 3-L1-6

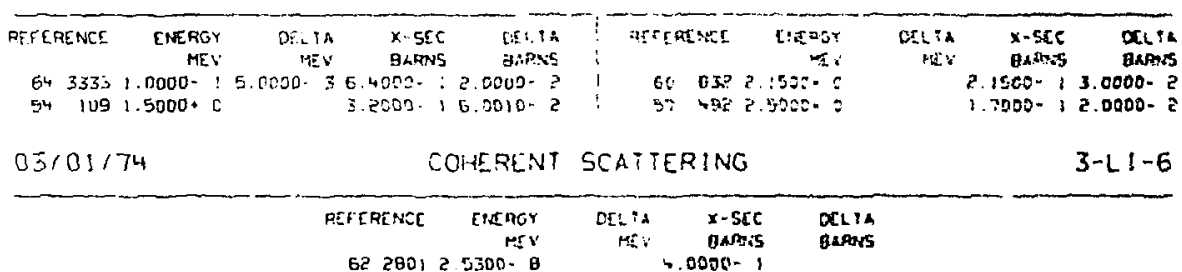



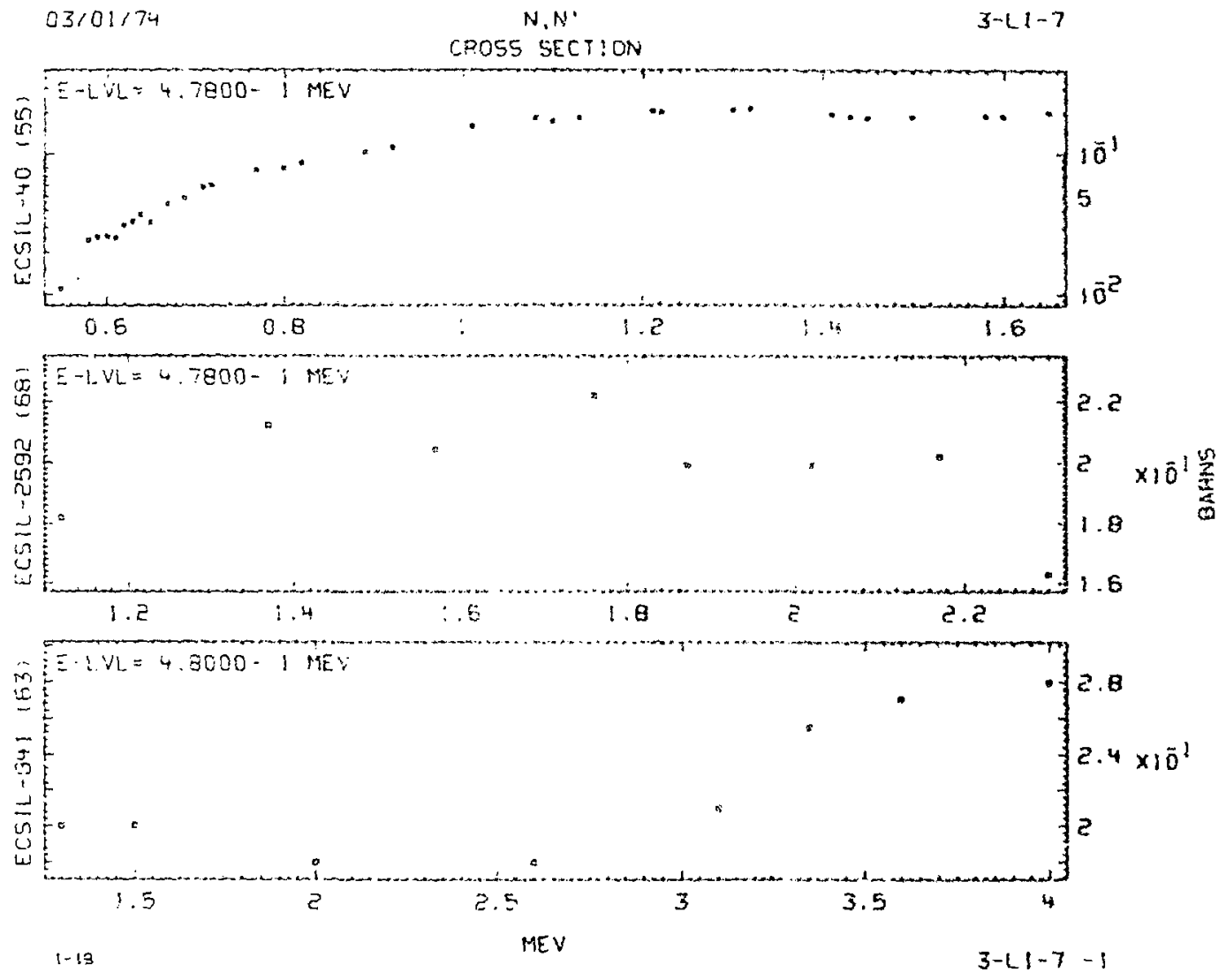

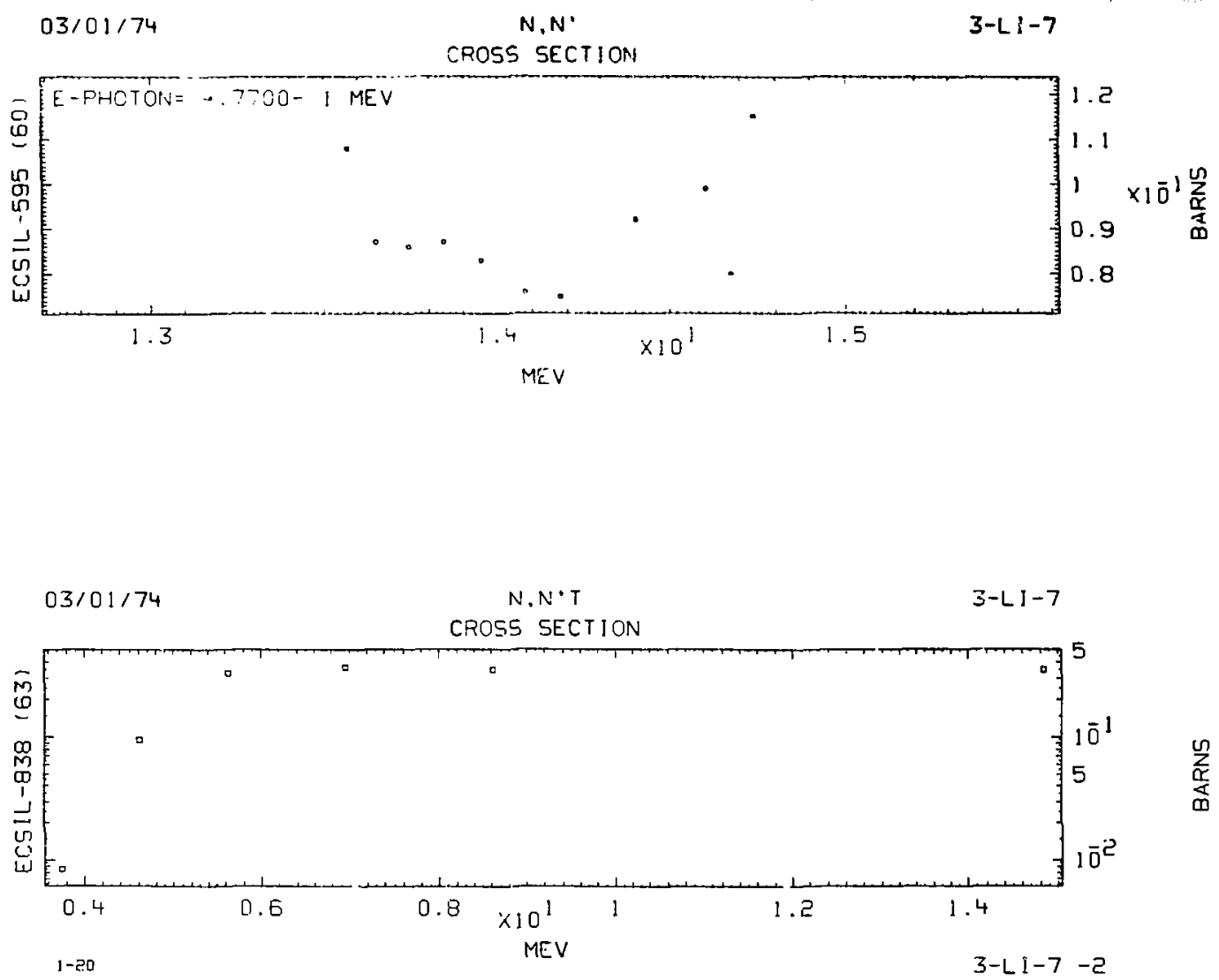


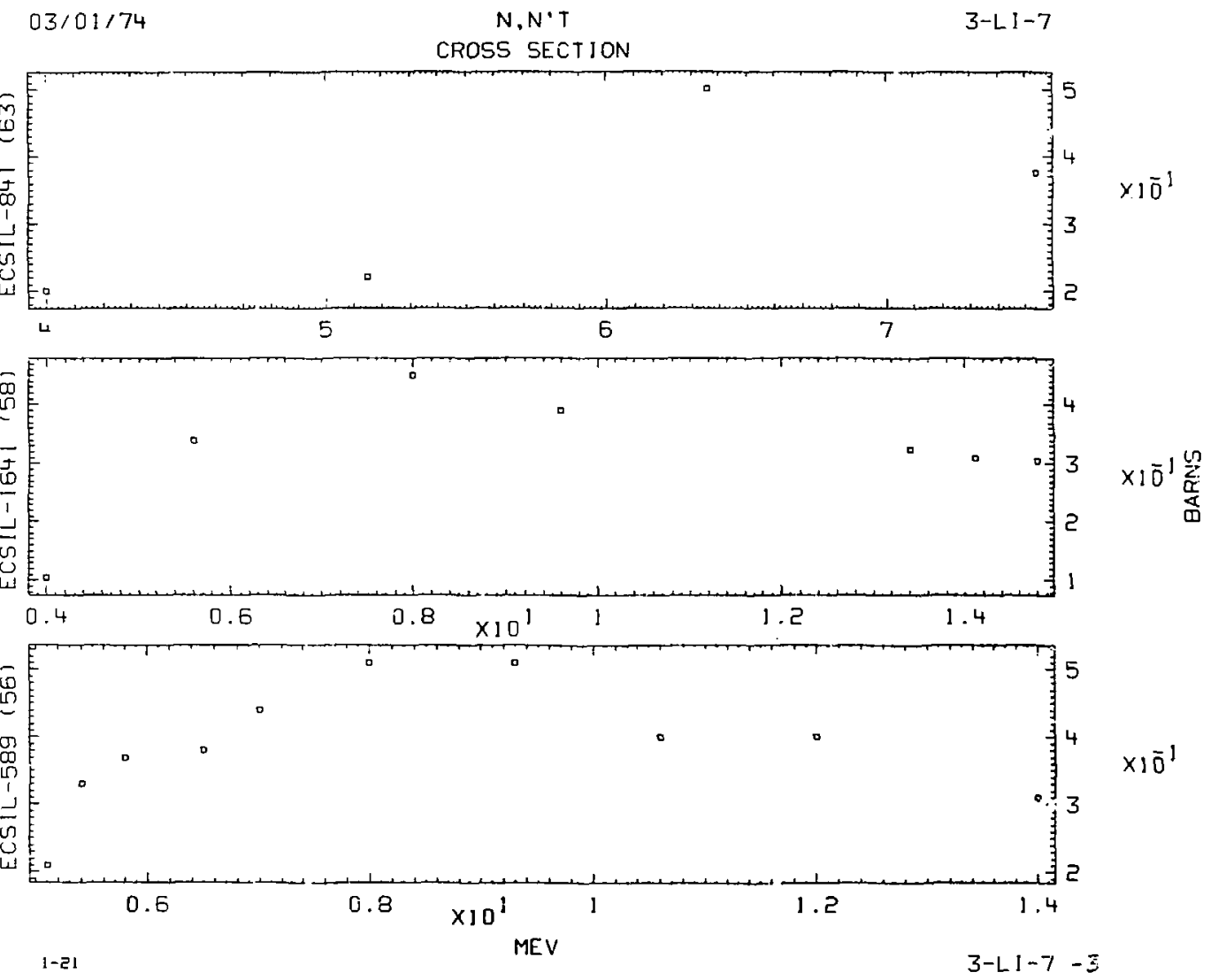


CROSS SECTION

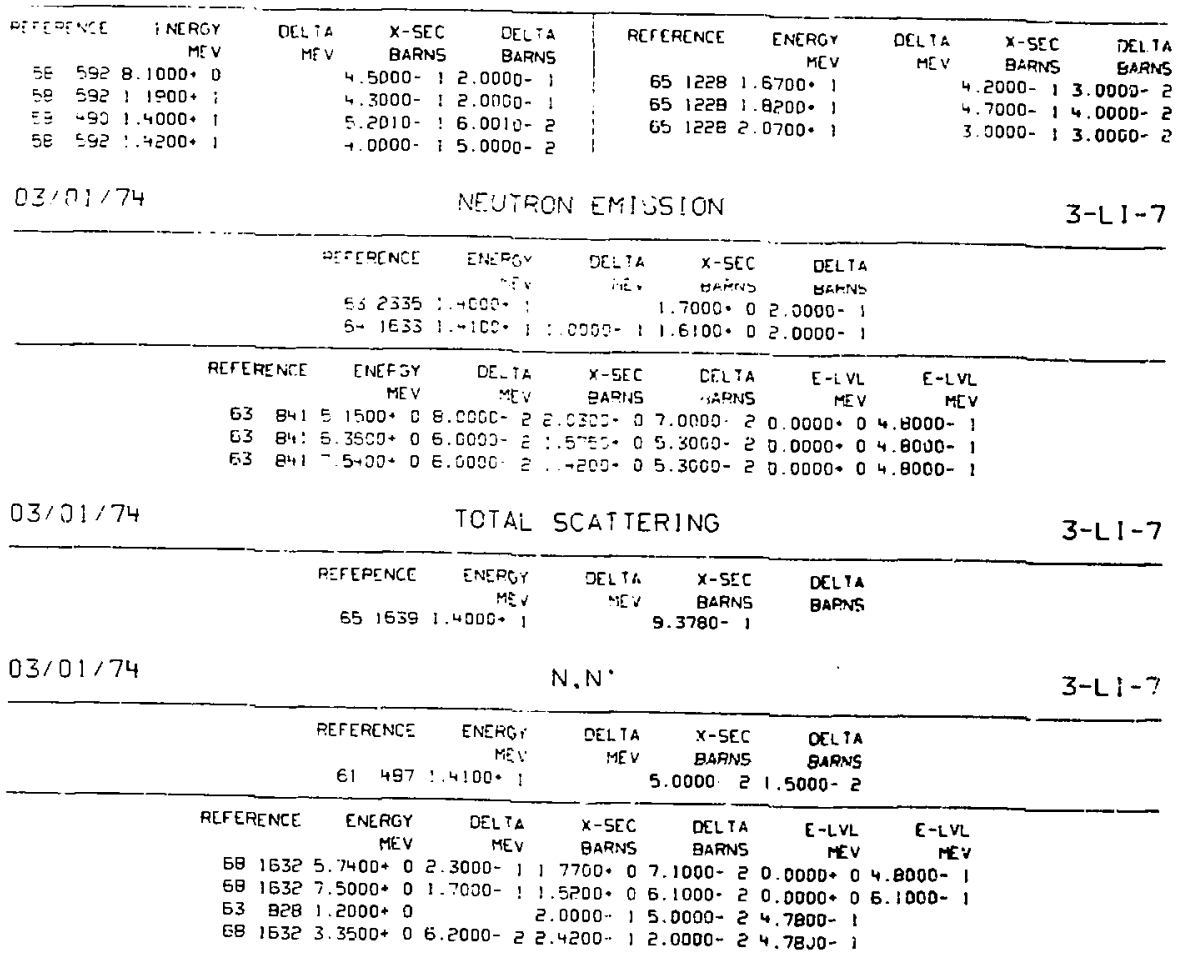


CROSS SECTION

\begin{tabular}{|c|c|c|c|c|c|c|c|c|}
\hline & $\begin{array}{rr}\text { REFERENCE } \\
\\
69 & 1632 \\
56 & 1640 \\
65 & 1639 \\
5 E & 1632 \\
53 & 84 ! \\
5 E & 1632 \\
53 & 841\end{array}$ & $\begin{array}{r}\text { ENERGY } \\
\text { MEV } \\
4.8300+0 \\
1.4000+1 \\
1.4000+1 \\
5.7400+0 \\
6.3600 \cdot 0 \\
7.5000+0 \\
7.5400+0\end{array}$ & $\begin{array}{r}\text { DELTA } \\
\text { MEV } \\
4.7000-1 \\
2.3000-1 \\
6.0000-2 \\
1.7000-1 \\
6.0000-2\end{array}$ & $\begin{array}{r}\text { X-5EC } \\
\text { BARNS } \\
1.7800-1 \\
1.3500-1 \\
1.2600-1 \\
1.1400-1 \\
1.2000-1 \\
1.2200-1 \\
1.3600-1\end{array}$ & $\begin{array}{r}\text { OELTA } \\
\text { BARNS } \\
2.7000-2 \\
2.0000-2 \\
1.7000-2 \\
6.5000-2 \\
1.2000-2 \\
2.5000-2\end{array}$ & $\begin{array}{r}\varepsilon-L V L \\
M V V \\
4.7800-1 \\
4.4300 \cdot 0 \\
4.6000 \cdot 0 \\
4.6300 * 0 \\
4.6300 \cdot 0 \\
1.6300+0 \\
4.6300+0\end{array}$ & $\begin{array}{r}E-L V L \\
M E V\end{array}$ & \\
\hline & 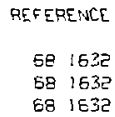 & $\begin{array}{r}\text { ENERGY } \\
\text { MEV } \\
4.8300+0 \\
5.7400+c \\
7.5 C O 0+0\end{array}$ & $\begin{array}{r}\text { Ot! If } \\
\text { ACs } \\
4.7000-2 \\
2.3000-1 \\
1.7800\end{array}$ & $\begin{array}{r}\text { X-5EC } \\
\text { BAPINS } \\
1.0000-1 \\
2.2000-1 \\
3.1000-1\end{array}$ & $\begin{array}{r}\text { CELTA } \\
\text { BARNS } \\
3.2000-2 \\
3.4000-2 \\
3.7000-2\end{array}$ & $\begin{array}{r}E-L V I-M I N \\
M E V \\
4.6500 * 0 \\
4.6500 .0 \\
4.6500 .0\end{array}$ & $\begin{array}{r}E-L V L-\operatorname{MAX} \\
\text { MEV } \\
4.8300 * 0 \\
5.7400 * 0 \\
7.5000+0\end{array}$ & \\
\hline \multirow[t]{2}{*}{$03 / 01: 74$} & & & & $N, 2 N$ & & & & $3-41-7$ \\
\hline & & 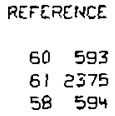 & $\begin{array}{r}\text { ENEPGY } \\
\text { MEV } \\
1.0200+1 \\
1.4900+1 \\
1.4100+1\end{array}$ & $\begin{array}{r}\text { OELTA } \\
\text { MEV }\end{array}$ & $\begin{array}{r}\text { X-SEC } \\
\text { BARNS } \\
2.7000-2 \\
1.3000-i \\
5.6010-2\end{array}$ & $\begin{array}{r}\text { OELTA } \\
\text { BARNS } \\
1.5000-3 \\
3.0000-2 \\
5.0000-3\end{array}$ & & \\
\hline
\end{tabular}

$03 / 01 / 74$

N.N.T

$3-L I-7$

\begin{tabular}{|c|c|c|c|c|c|c|c|c|c|}
\hline REFERENCE & $\begin{array}{r}\text { ENERGY } \\
\text { MEV }\end{array}$ & $\begin{array}{r}\text { DELIA } \\
\text { HEV }\end{array}$ & $\begin{array}{l}X-5 E C \\
\text { BARNS }\end{array}$ & $\begin{array}{l}\text { OELTA } \\
\text { BALYNS }\end{array}$ & RER EPENCE & $\begin{array}{r}\text { ENERGY } \\
\text { MEV }\end{array}$ & $\begin{array}{r}\text { HEV } \\
\text { KETA }\end{array}$ & $\begin{array}{l}x-\operatorname{SEC} \\
\text { BARNS }\end{array}$ & $\begin{array}{l}\text { DCLIA } \\
\text { BABNS }\end{array}$ \\
\hline 681632 & $4.8300+0$ & $4.7000-2$ & $1.0000-1$ & $3.2000-E$ & 61238 ' & $1.4000 \cdot 1$ & & $3 \cdot 3500-1$ & $1.2000-2$ \\
\hline $68163 i$ & $5.7400 * 0$ & $\ddot{c} \cdot 3000-1$ & $3.3000-$ & 3. Bnnt- 2 & 6) 48 ? & $1.4100 \cdot 1$ & & $5.0000-2$ & $1.2000-2$ \\
\hline
\end{tabular}

$68,16327.5000+0$ a $1.3000-13.3000-: 3.901400-$

$05 / 01 / 74 \quad$ N.D $3-L 1-7$

\begin{tabular}{|c|c|c|c|c|c|c|c|c|c|}
\hline REF $\subseteq R E N C$ & $\begin{array}{r}\text { ENEROY } \\
\text { MEV }\end{array}$ & $\begin{array}{r}\text { OELTA } \\
M[V\end{array}$ & $\begin{array}{l}X-5 C C \\
\text { BARNS }\end{array}$ & $\begin{array}{l}\text { OELTA } \\
\text { BARNS }\end{array}$ & REFERENCE & $\begin{array}{r}\text { ENERGY } \\
\text { MEY }\end{array}$ & $\begin{array}{r}\text { DELTA } \\
\operatorname{MEV}\end{array}$ & $\begin{array}{l}X-5 E C \\
\text { BARNS }\end{array}$ & $\begin{array}{l}\text { DELTA } \\
\text { BARNS }\end{array}$ \\
\hline E 1 & $.4100+:$ & & $000-3$ & & 53 & $4100+1$ & $\because 0000-1$ & $9.8010-3$ & $000-$ \\
\hline $814 E$ & $1.4100+1$ & & $5.0000-3$ & $00-3$ & $53 \quad 842$ & $.4800+1$ & $2.5000-1$ & $1.4000-z$ & $1.5000-$ \\
\hline
\end{tabular}


CROSS SECTION

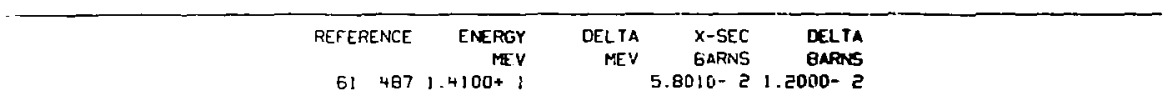

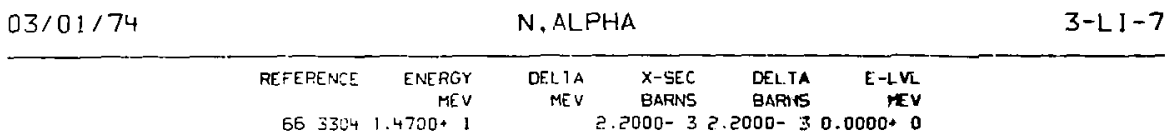

$\frac{\text { BOUND ATOM }}{\text { AEFERENCE }}$
$\begin{array}{rrrr}51 & 1584 & 7.3000-8 & \text { MEV }\end{array}$

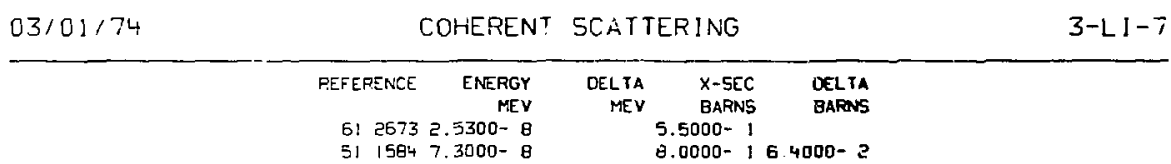



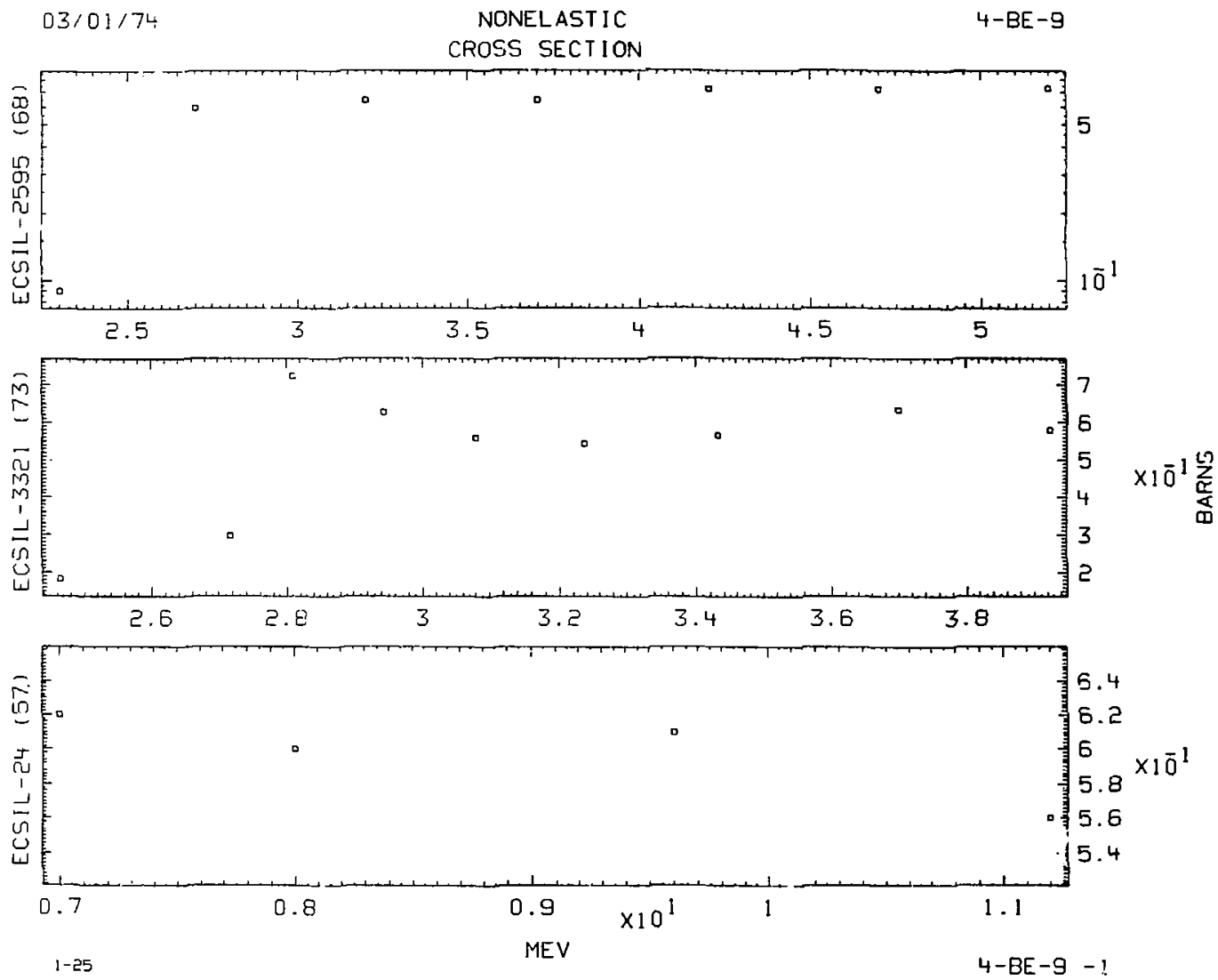

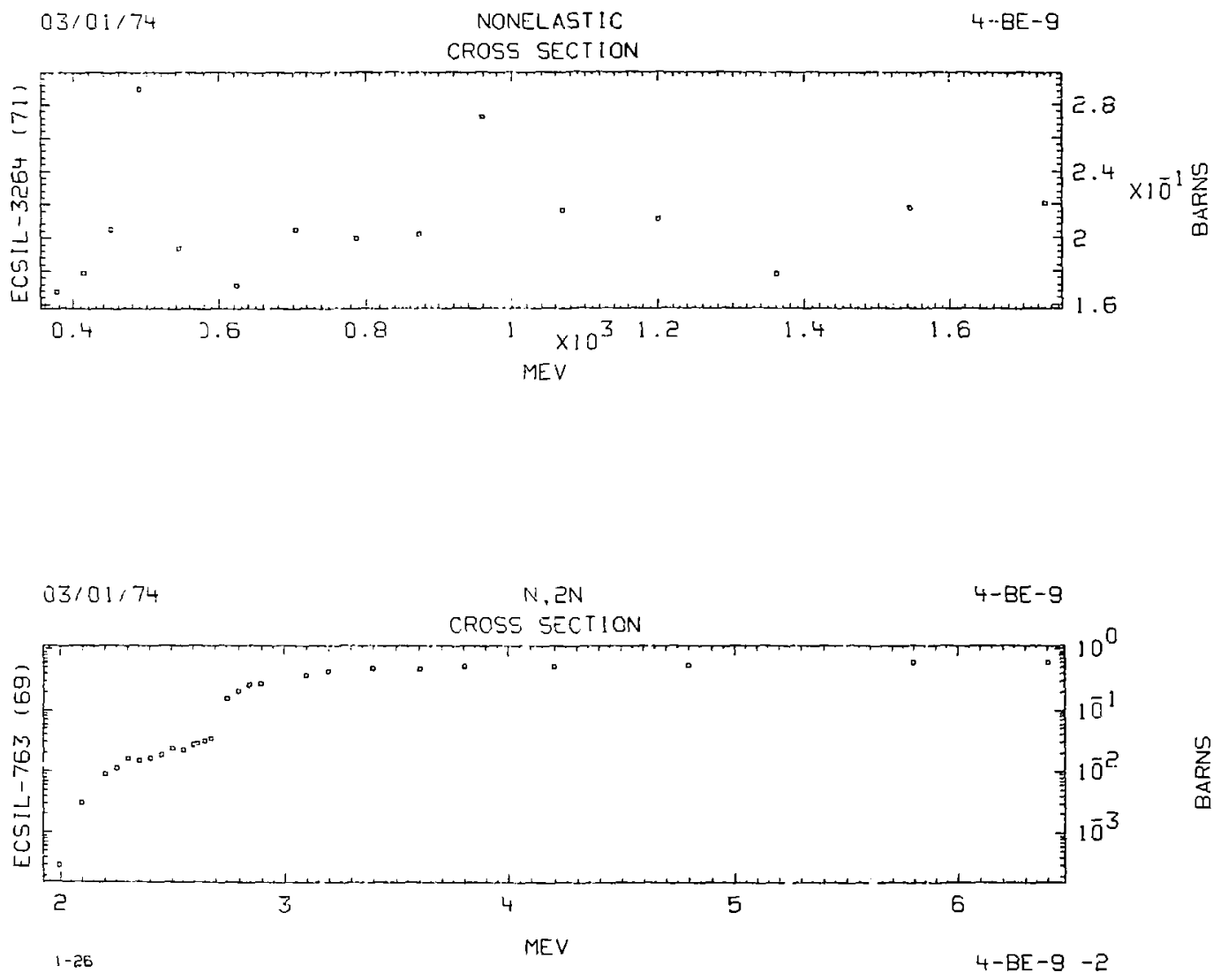

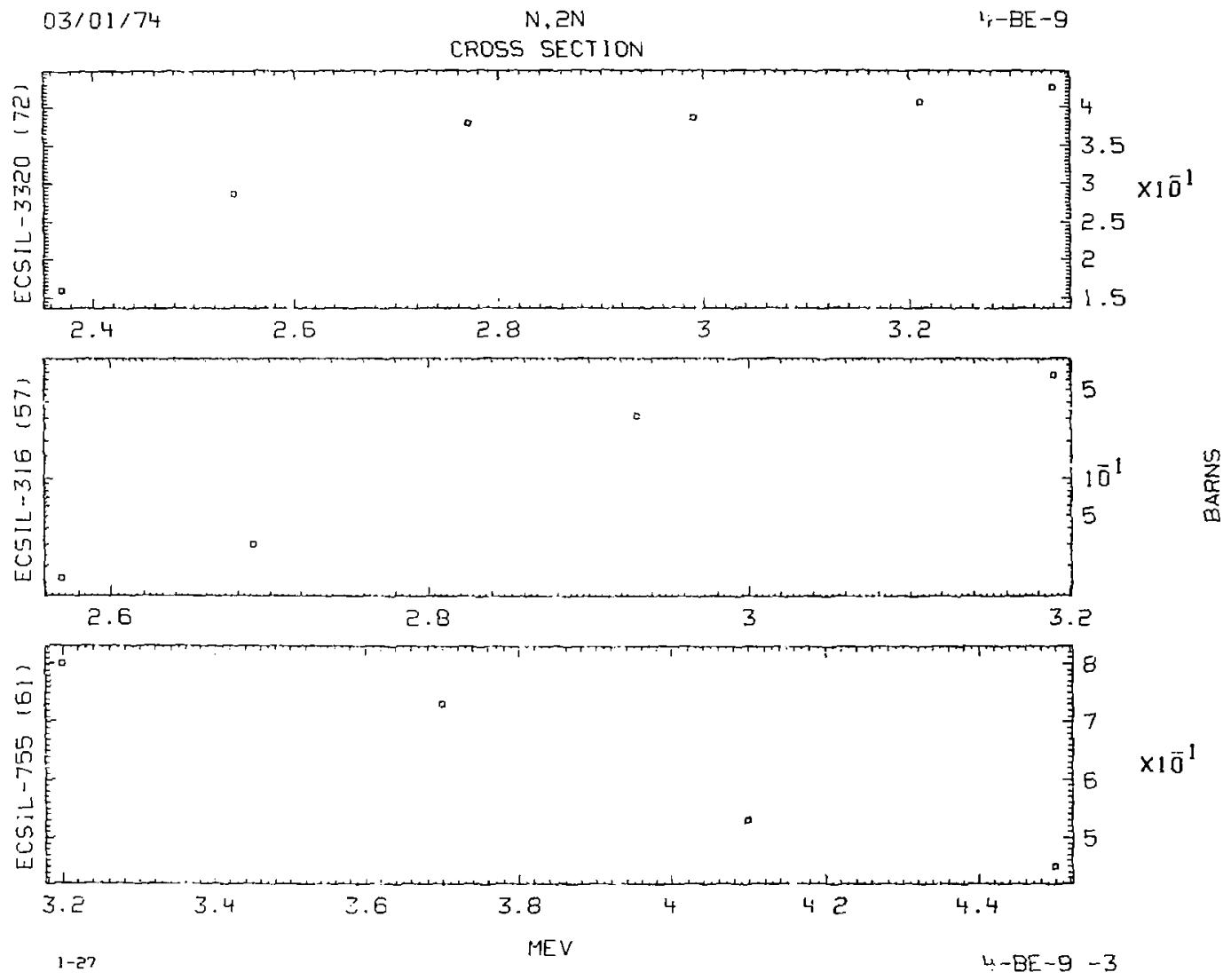


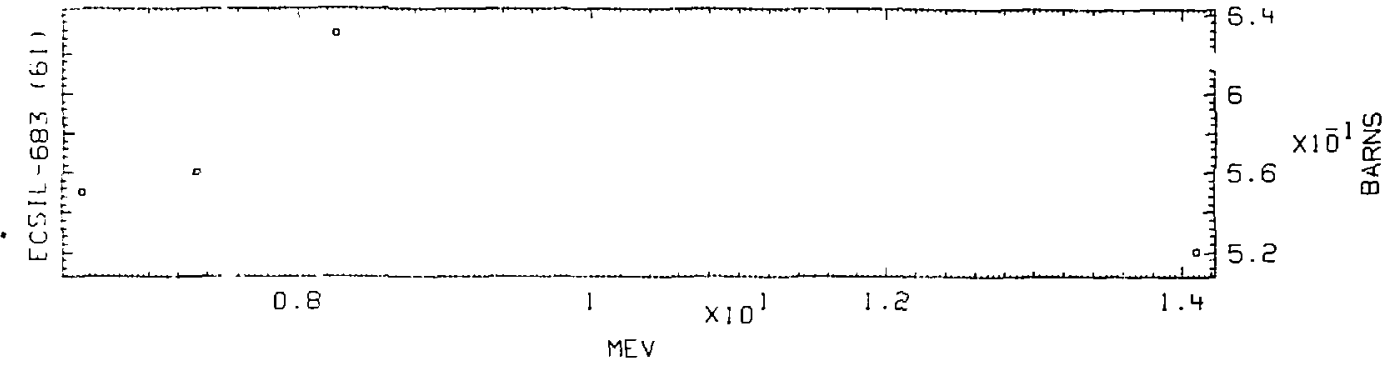

$03 / 01 / 74$

N.D

$4-B E-9$

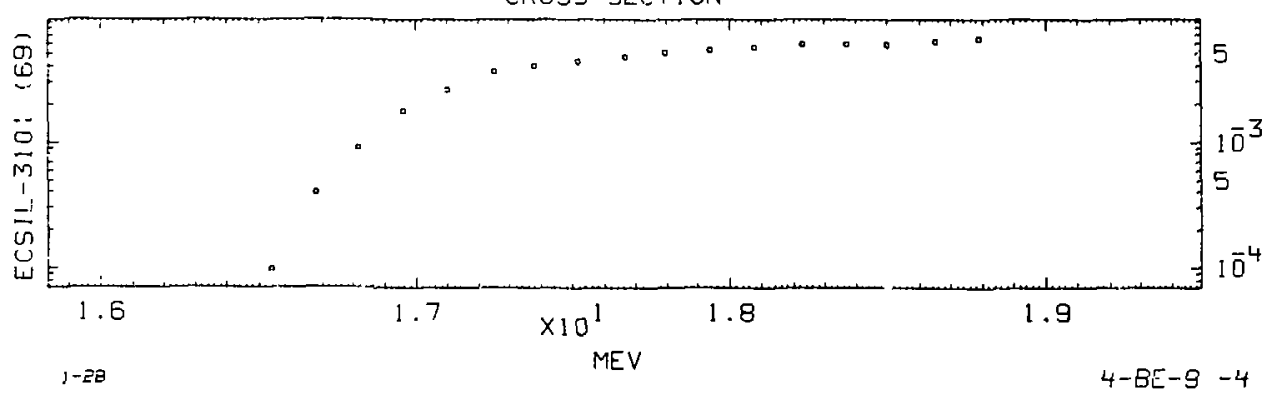



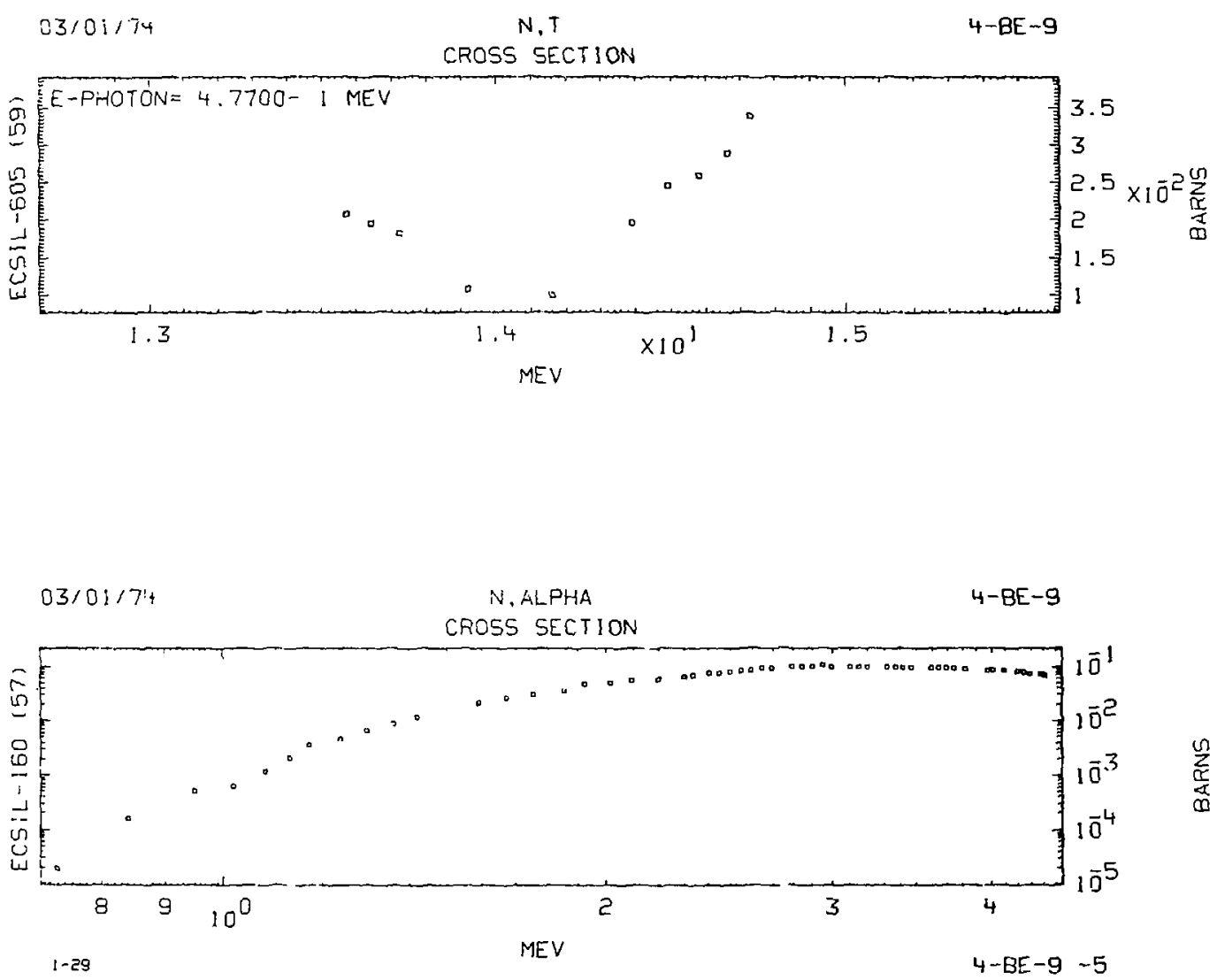
CROSS SECTION
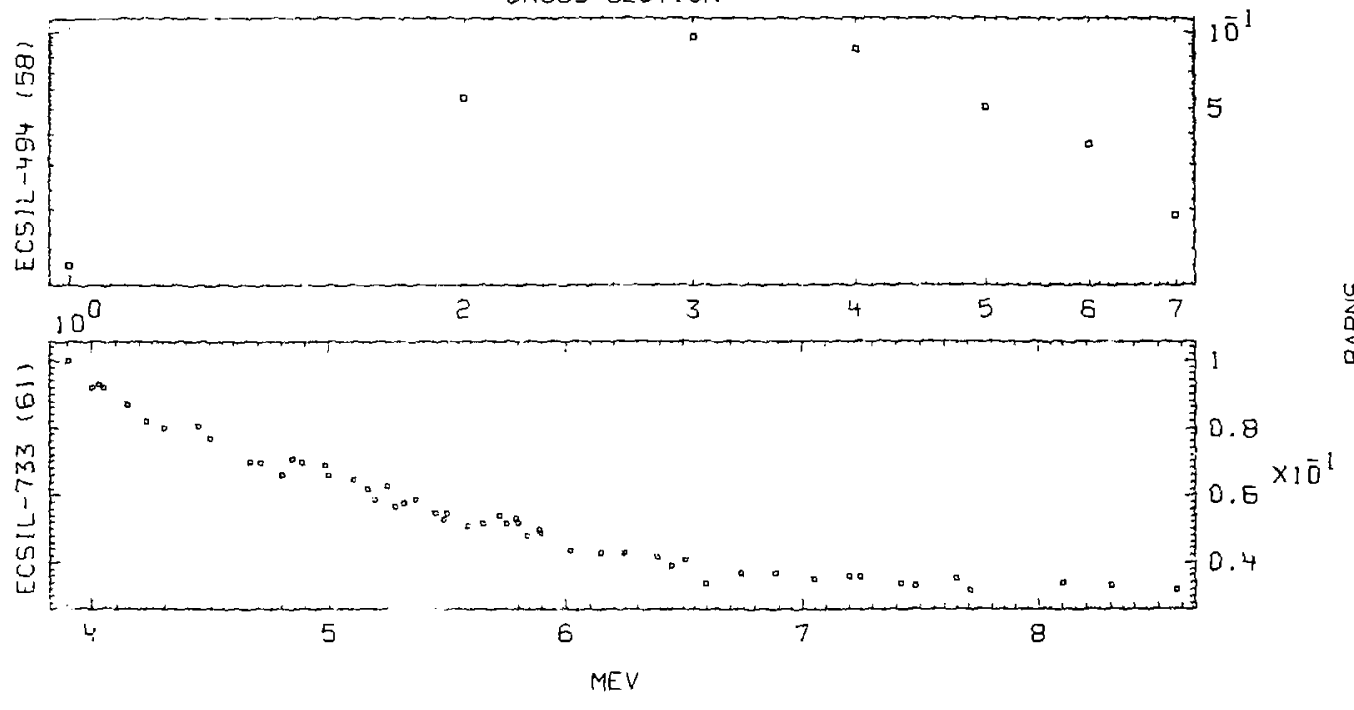

$03 / 01,74$

NONELASTIC

$4-B E-9$

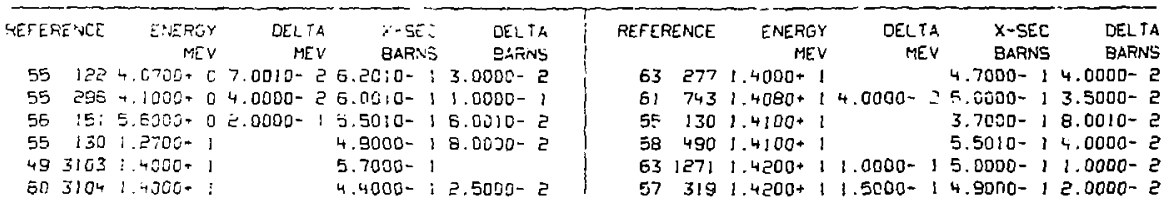


CROSS SECTION

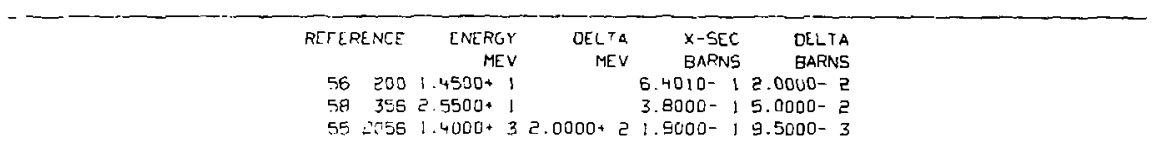

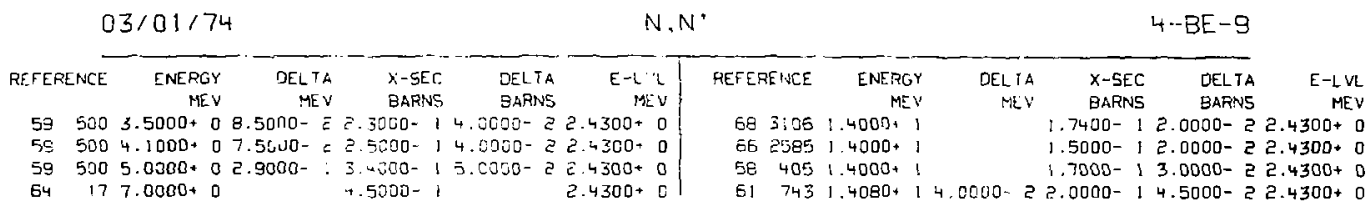

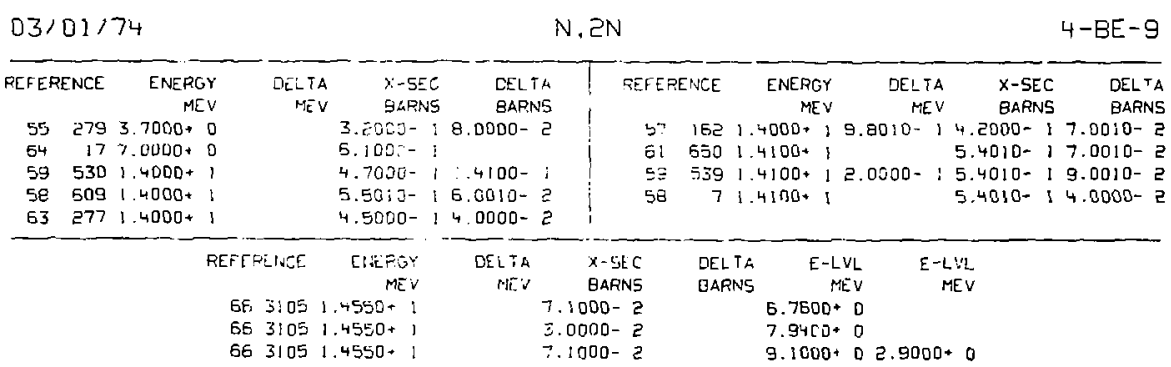

$03 / 01: 74$

ABSORPT ION

4 - BE-9

$\begin{array}{rrrrr}\text { PEFCRENCE } & \begin{array}{r}\text { ENERGY } \\ \text { MEV }\end{array} & \text { DELTA } & x-5 E C & \text { DELTA } \\ & \text { MEV } & \text { BARN5 } & \text { BARN5 } \\ 472935 & 2.5300-8 & & 1.0200-25.0000-4 \\ 522805 & 2.5300-8 & & 1.0000-2 & 1.0000-3\end{array}$




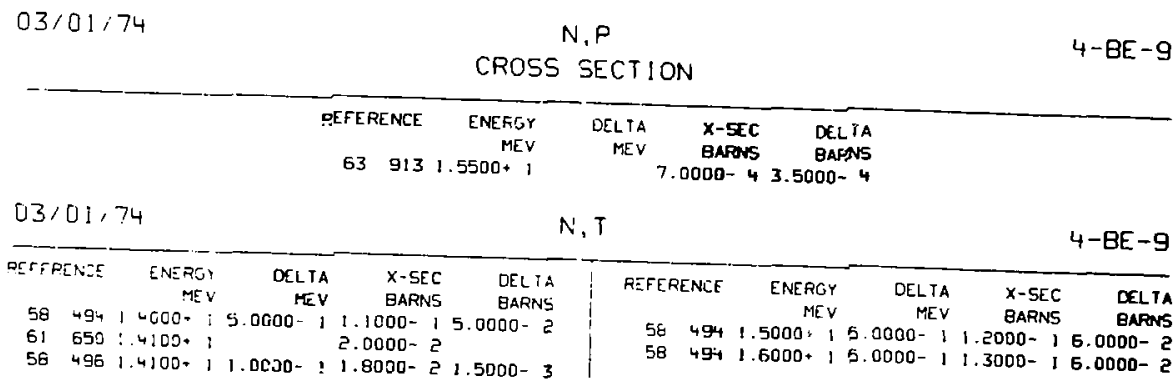

$$
03 / 01 / 74
$$

$$
\text { N, ALPHA }
$$$$
4-B E-9
$$

WEFERNCE

ENERGY

MEV DELTA X-SEC

X-Sec

DELTA

BARNS

$53861.4100 * 11.0000-11.0000-2$ 1.0000-3

5! $6501.4100+1$ 1.1000- $24.0000-3$

\begin{tabular}{|c|c|c|c|c|c|}
\hline $03 / 01 / 74$ & \multicolumn{4}{|c|}{ BOUND ATOM } & $4-B E-9$ \\
\hline & $\begin{array}{r}\text { REFERENCE } \\
51 \quad 1584\end{array}$ & $\begin{array}{r}\text { ENERG: } \\
\text { MEV } \\
7.3000-8\end{array}$ & $\begin{array}{rr}\text { DELTA } & \text { X-SEC } \\
\text { MEV } & \text { BARAS } \\
7.5000+0\end{array}$ & $\begin{array}{l}\text { DELTI } \\
\text { BAARS }\end{array}$ & \\
\hline $03 / 01 / 74$ & & - OHERENT & SCATTERING & & $4-B E-9$ \\
\hline & $\begin{array}{r}\text { RCFERENCE } \\
51 \quad 1584\end{array}$ & $\begin{array}{r}\text { ENERGY } \\
\text { MEV } \\
7.3000-9\end{array}$ & $\begin{array}{rr}\text { DELTA } & \text { X-SEC } \\
\text { MEV } & \text { BAFNS } \\
7.7000+0\end{array}$ & $\begin{array}{l}\text { DELTA } \\
\text { BARNS } \\
600-1\end{array}$ & \\
\hline
\end{tabular}

$\begin{array}{rrrrrr}\text { PEFEFENCE } & \text { ENERGY } & \text { DELTA } & \text { X-SEC } & \text { OELTA } & \text { E-LVL } \\ & \text { MEV } & \text { MEV } & \text { BARNE } & \text { DARNS } & \text { TEV } \\ 672367 & 1.4400+1 & & 1.1700-2 & 1.8000-3 & 0.0000+0\end{array}$


INCOHERENT SCATTER. CROSS SECTION

ENERGY DELTA

$\begin{array}{rrrrr}\text { REFERENCE } & \text { ENERGY } & \text { DELTA } & \text { X-SEC } & \text { DELIA } \\ \text { MEV } & \text { MEV } & \text { BARNS } & \text { BARNS } \\ 632563 & 2.5300-8 & & 4.0000-3 & 1.0000-3\end{array}$

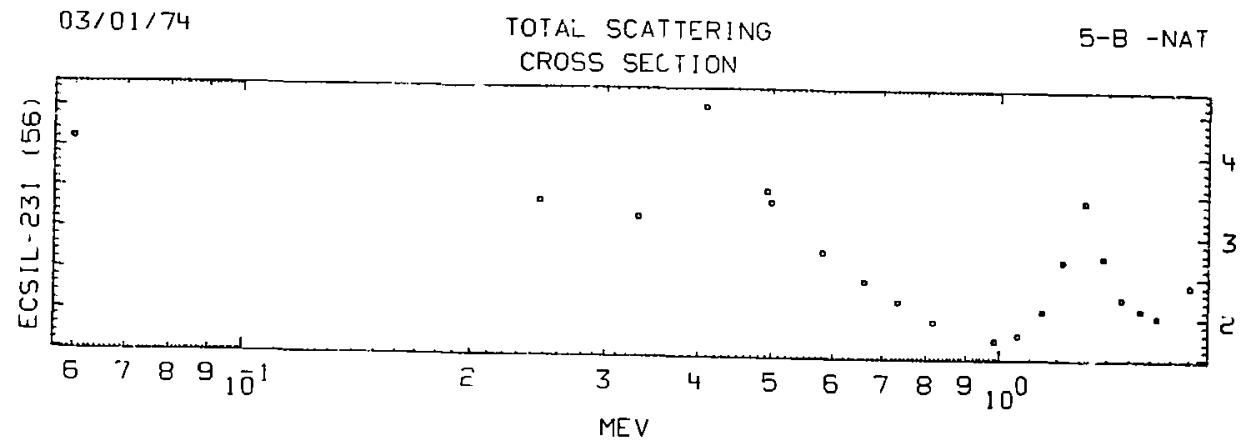




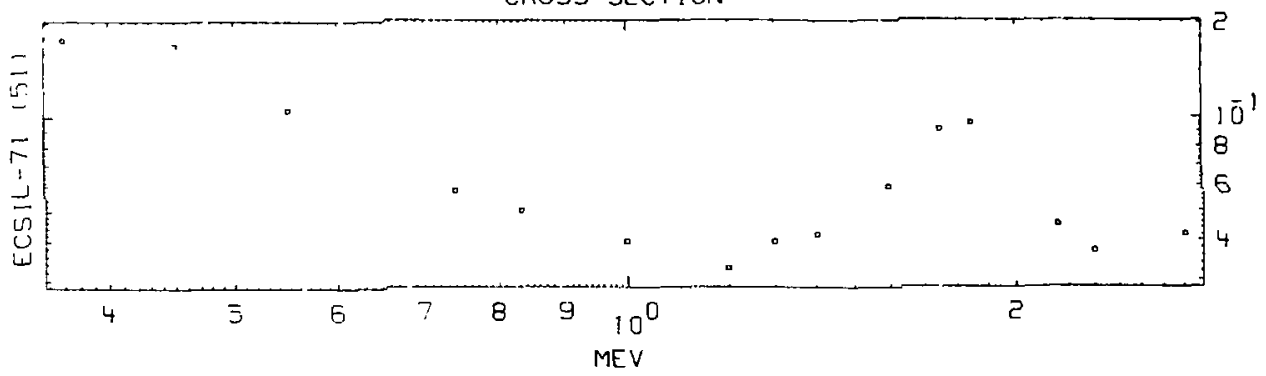

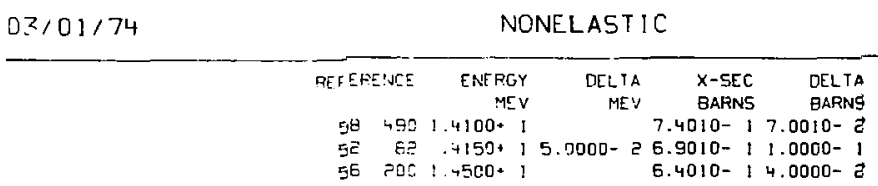

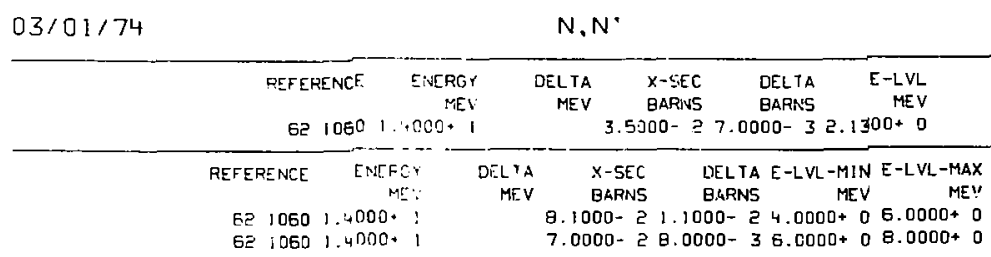




\begin{tabular}{|c|c|c|c|c|c|c|c|c|c|}
\hline REFEPENCE & $\begin{array}{r}\text { ENERGY } \\
\text { PIEY }\end{array}$ & $\begin{array}{r}\text { DELTA } \\
\text { MEV }\end{array}$ & $\begin{array}{l}x-S E C \\
\text { BARNS }\end{array}$ & $\begin{array}{l}\text { DELTA } \\
\text { BARNS }\end{array}$ & REFERENCE & $\begin{array}{r}\text { ENERGY } \\
\text { MEY }\end{array}$ & $\begin{array}{r}\text { DELTA } \\
\text { MEV }\end{array}$ & $\begin{array}{l}x \text {-SEC } \\
\text { BARNS }\end{array}$ & $\begin{array}{l}\text { DELTA } \\
\text { EARNS }\end{array}$ \\
\hline $65 \quad 1053$ & $2.5000-8$ & & $7.6010+2$ & $1.5000+0$ & $60 \quad 1995$ & $2.5300-8$ & & $7.5600+2$ & $8.0000+0$ \\
\hline E) 2933 & $2.5300-8$ & & $7.5900+2$ & $1.1000+1$ & $64 \quad 776$ & e. $5300-8$ & & $7.5910 \div 2$ & $2.0000+0$ \\
\hline 5) 2805 & $2.5300-8$ & & $7.6100 * 2$ & $3.0000+0$ & 63463 & c. $5300=8$ & & $7.6080+2$ & $1.9000+0$ \\
\hline 532786 & $2.5300-0$ & & $7.5500+2$ & $3.0030+0$ & $60 \quad 805$ & $2.5300-8$ & & $7.6400+2$ & $3.0000+u$ \\
\hline 582807 & 2. $5300-8$ & & $7.6000 * 2$ & $4.0000+0$ & 53809 & $2.5300-8$ & & $7.4900+2$ & $4.0000+0$ \\
\hline G) 2805 & $2.5300-6$ & & $7,6400+2$ & $3.0030+3$ & $57 \quad 432$ & e.5500- 8 & & $7.7100+2$ & $5.0000+0$ \\
\hline E) 2805 & $2.5300-8$ & & $7.6200+2$ & $3.0000+0$ & 50891 & $2.5300-\theta$ & & $7.5400+2$ & $4.0000+0$ \\
\hline
\end{tabular}

\begin{tabular}{|c|c|c|c|c|c|}
\hline & / & & & & $N, X$ \\
\hline AEFERENCE & $\begin{array}{r}\text { ENERGY } \\
\text { GEY }\end{array}$ & $\begin{array}{l}\text { DELTA } \\
\text { MEV }\end{array}$ & & $\begin{array}{l}\text { DLLLTA } \\
\text { BARNS }\end{array}$ & $\begin{array}{l}\text { A E-FHOTON } \\
5 \text { MEY }\end{array}$ \\
\hline ติ8 2997 & $1.4000+1$ & 8.0000-! & ! . Irigo-! & $4.6500-2$ & $53.1000+6$ \\
\hline EE 2997 & $1.4000+1$ & 8.00ut- i & $3.3000-2$ & $1.5400-2$ & ट ट.9500+0 \\
\hline $68299 ?$ & $1.4000+1$ & B.0000- i & $1.6000-z$ & $0.0000-3$ & $33.3850+0$ \\
\hline 58 2997 & $1.4000+1$ & B. $0000-i$ & 1. $5000-2$ & $8.0000-3$ & $33.7000+0$ \\
\hline $58 \quad 2997$ & $1.4000+1$ & $8.0000-i$ & i.3000- & $0.0000-3$ & $3+.0000+0$ \\
\hline
\end{tabular}

$03 / 01 / 74$
COHERENT SCATTERING

REFERENCE ENERGY

$$
5-B-N A T
$$

$6829971.4000+18.0000-I 1.2600-14.0000-24.4500+0$ $6829971.4000+19.0000-12.8000-21.0000-25.0500+0$ 58 2097 1.4000+ $18.0000-12.5000-21.5000-27.0000+0$ 68 2997 1.4000- $19.0000-15.0000-33.0000-38.5000+0$ $6829971.1 .000+18.0000-15.0000-33.0000-35.2000+0$

REFERENCE

$6426542.5300-8$ $3.6600+05.0000-2$ 

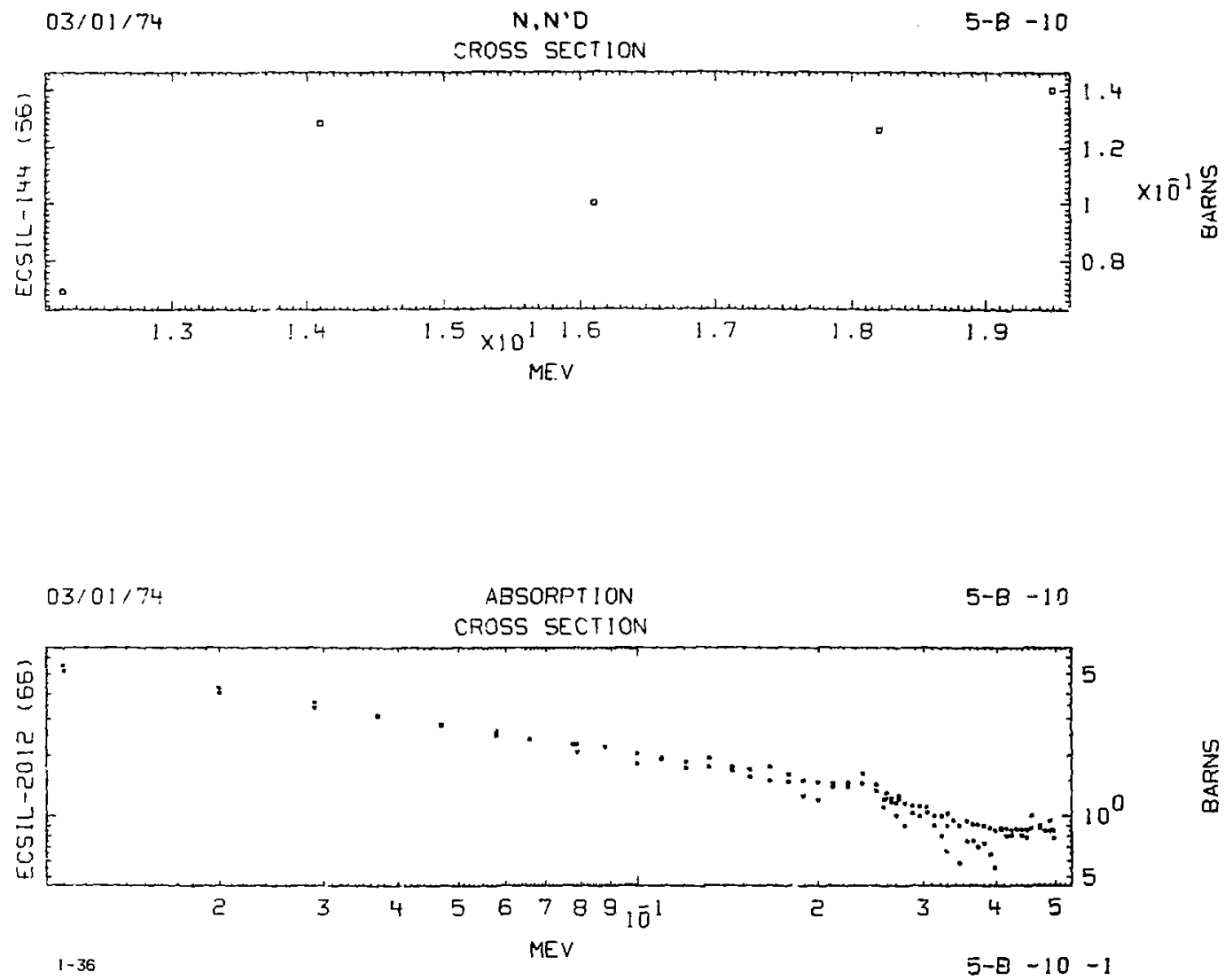


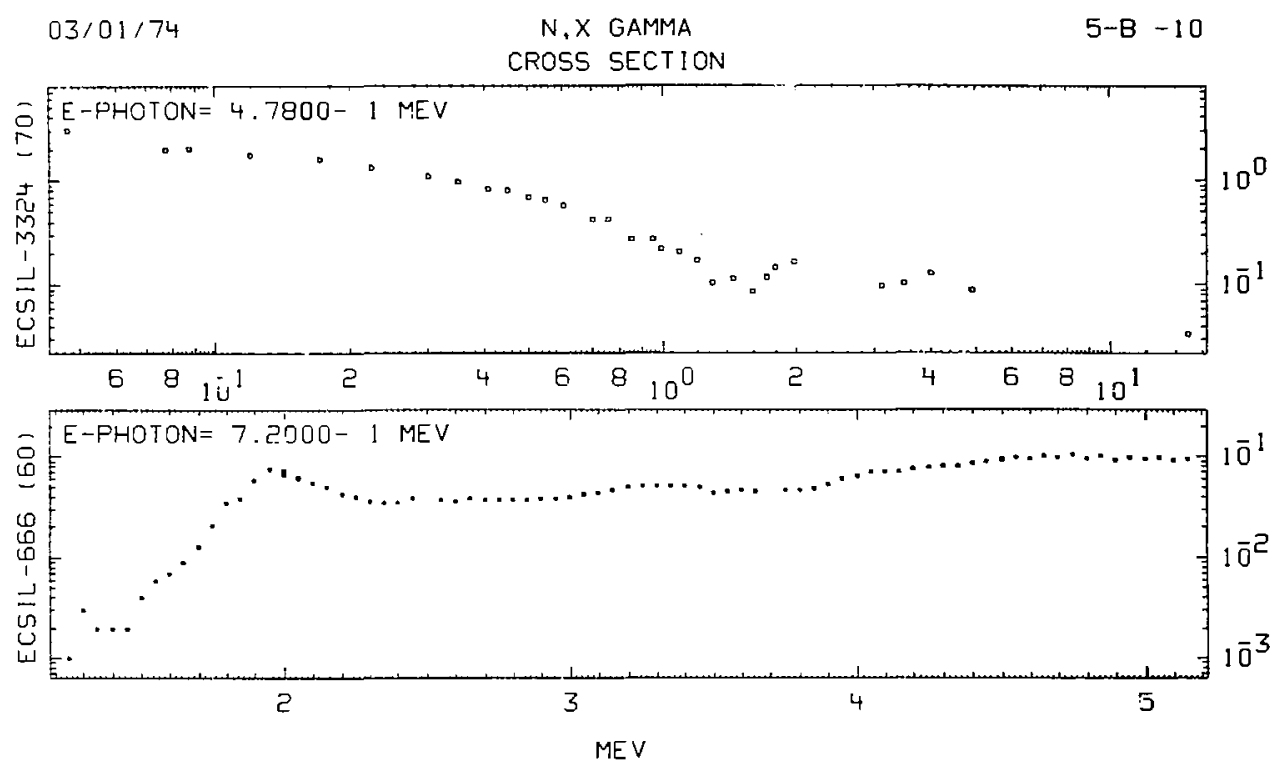

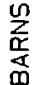



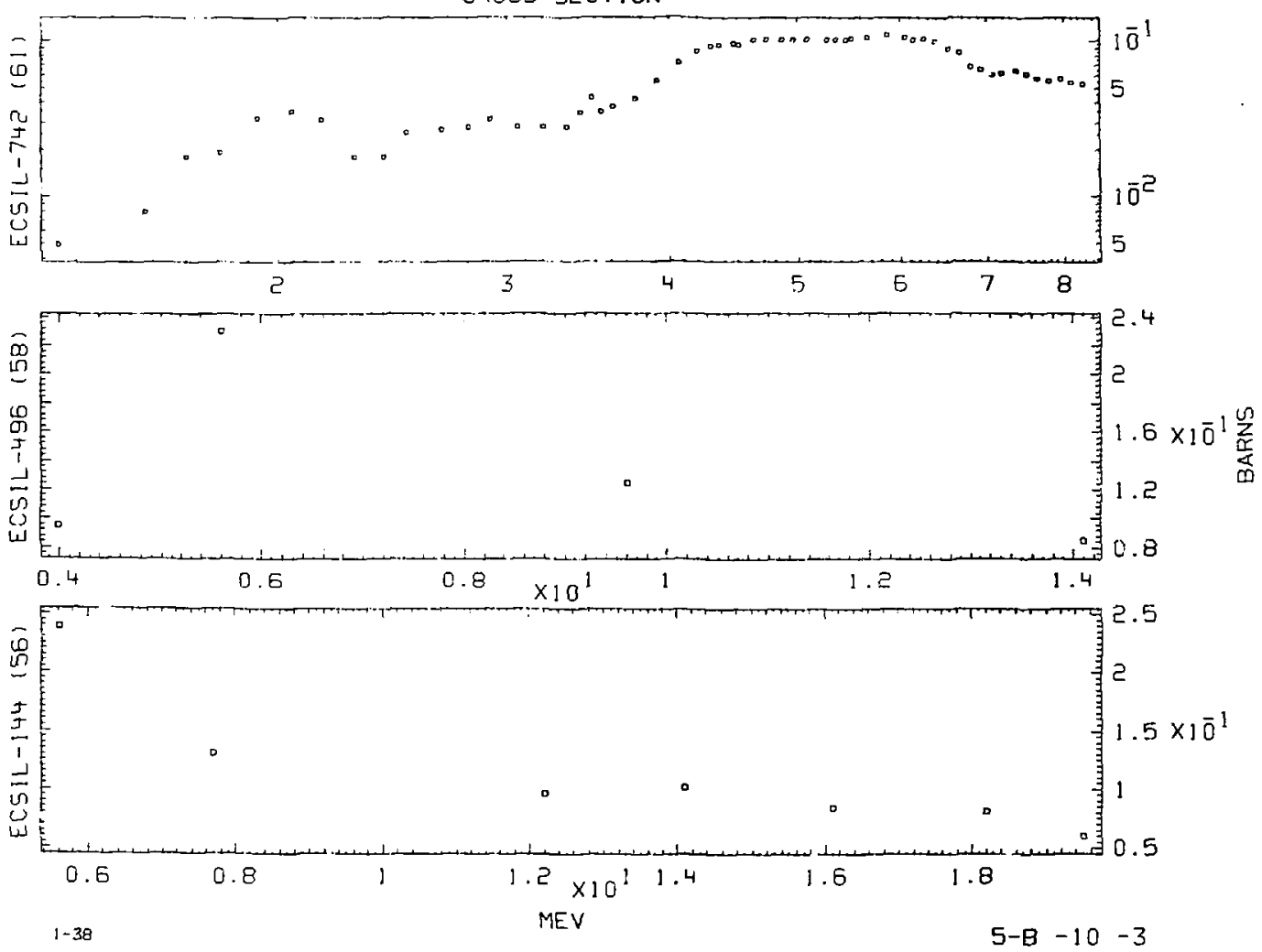
SNy

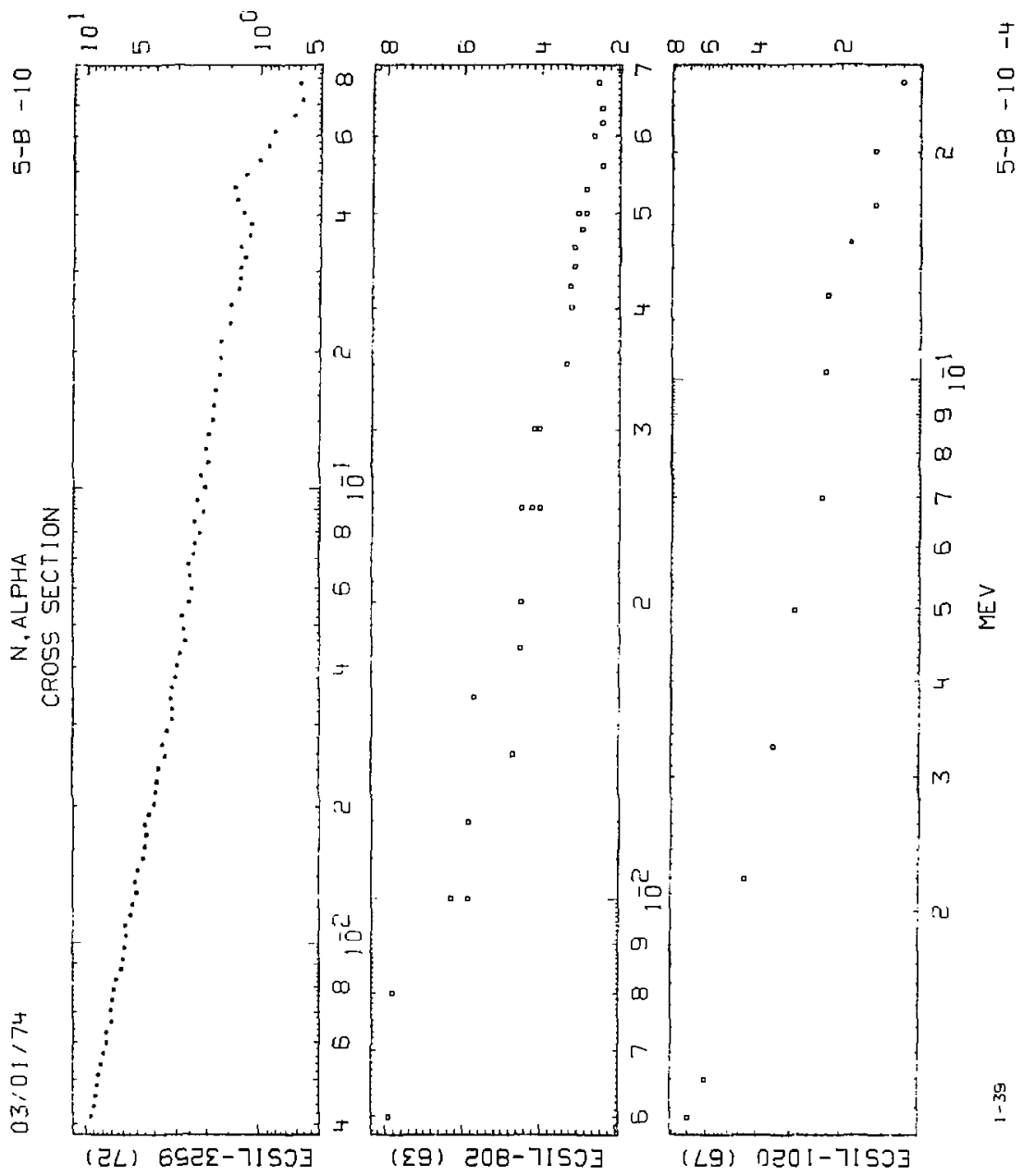



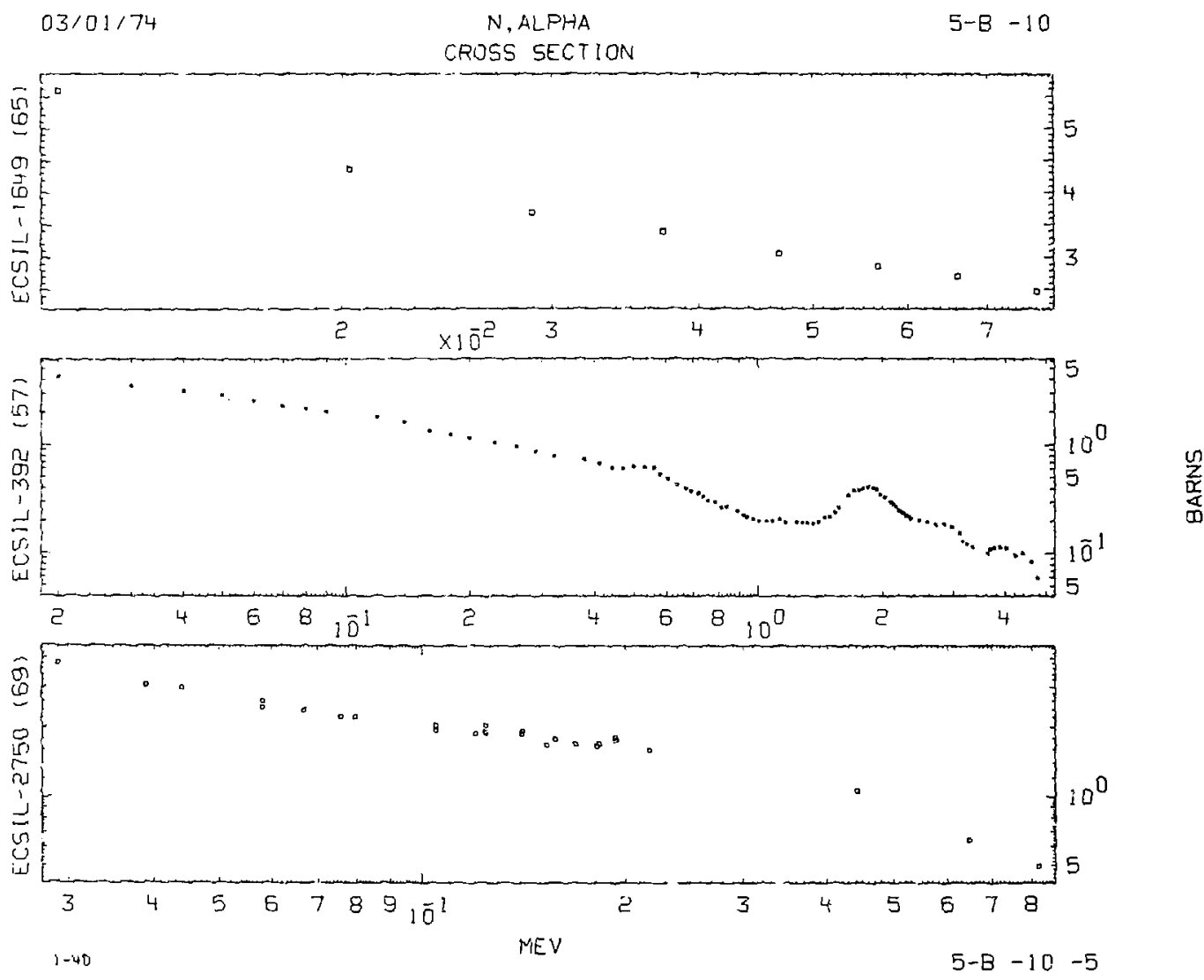

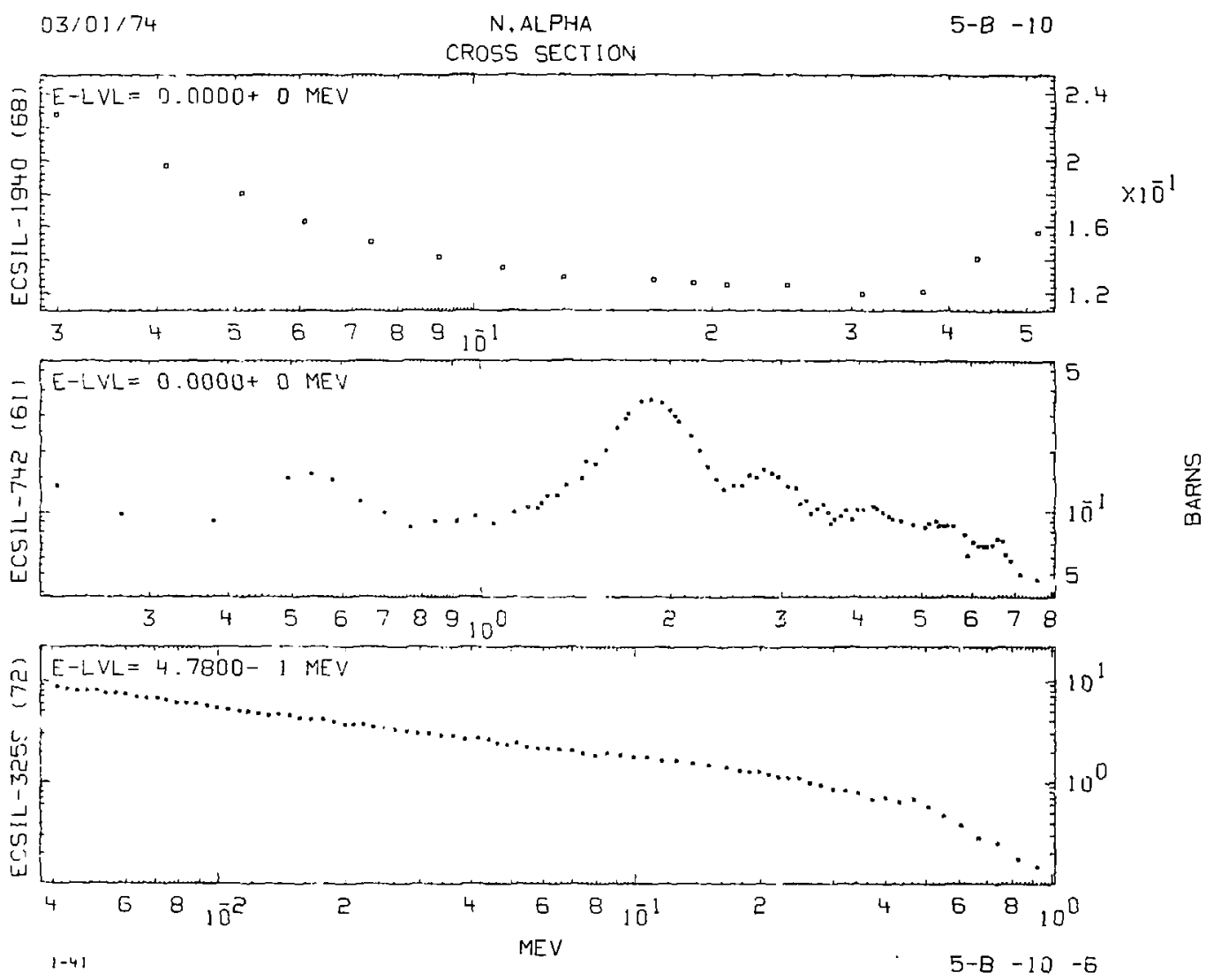


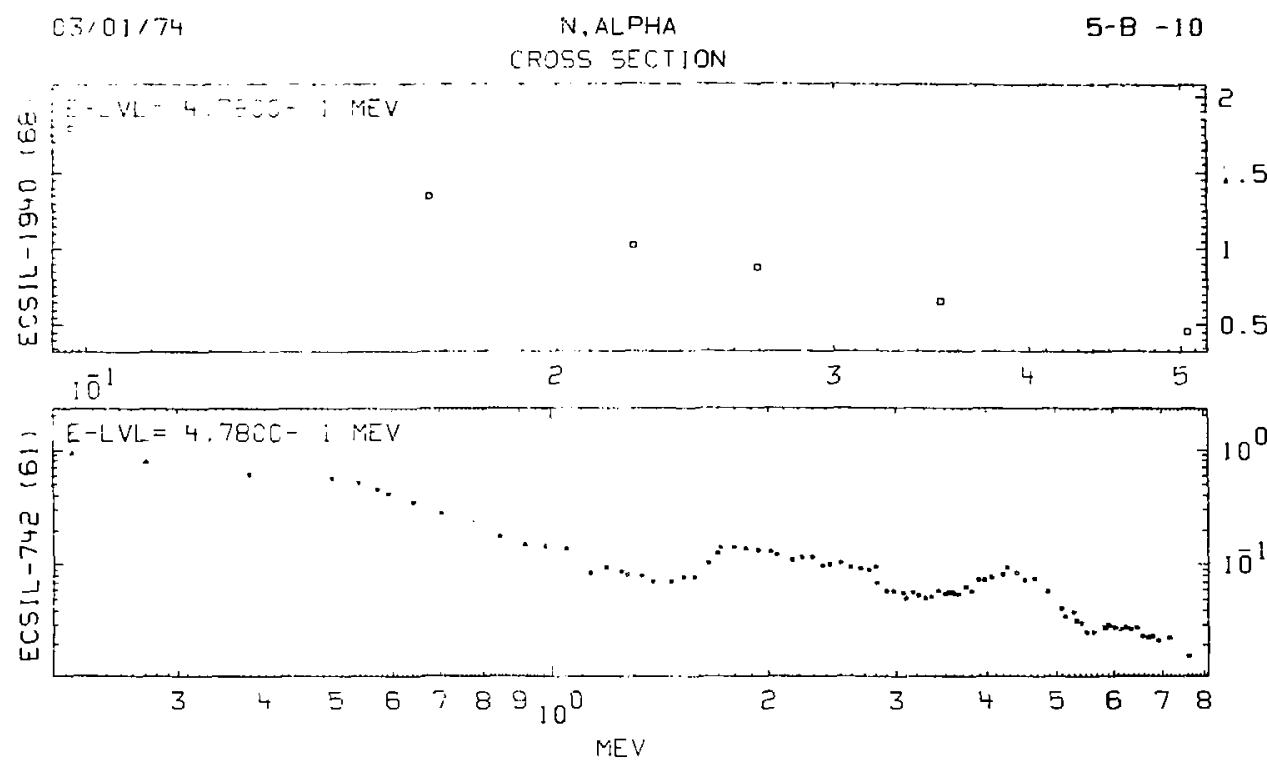

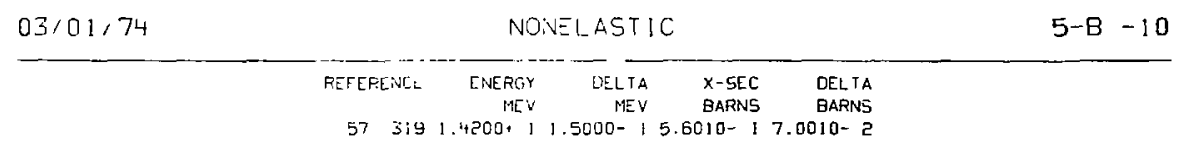




$\begin{array}{rrrrr}\text { REFERENCE } & \text { ENERGY } & \text { DELTA } & \text { X-SEC } & \text { DELTA } \\ \text { MEV } & \text { MEV } & \text { BARNS r BARNS } \\ & 5929997.0200+0 & & 1.2570+0 & 0.7006-2 \\ 692999 & 7.5500+0 & 1.2000-11.1750+0 & 1.3000-2\end{array}$

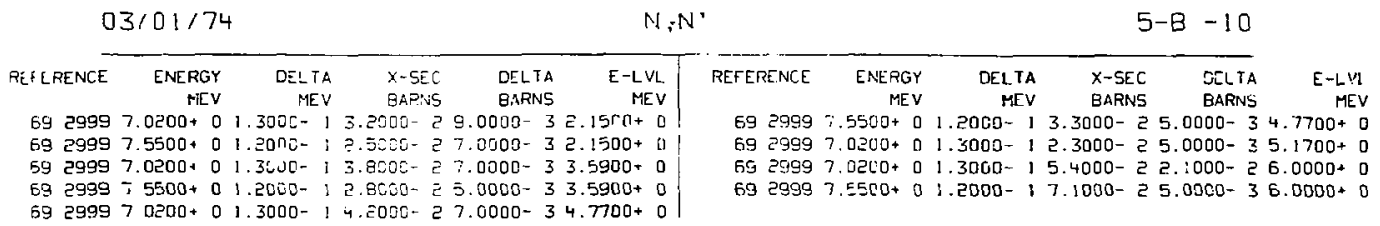

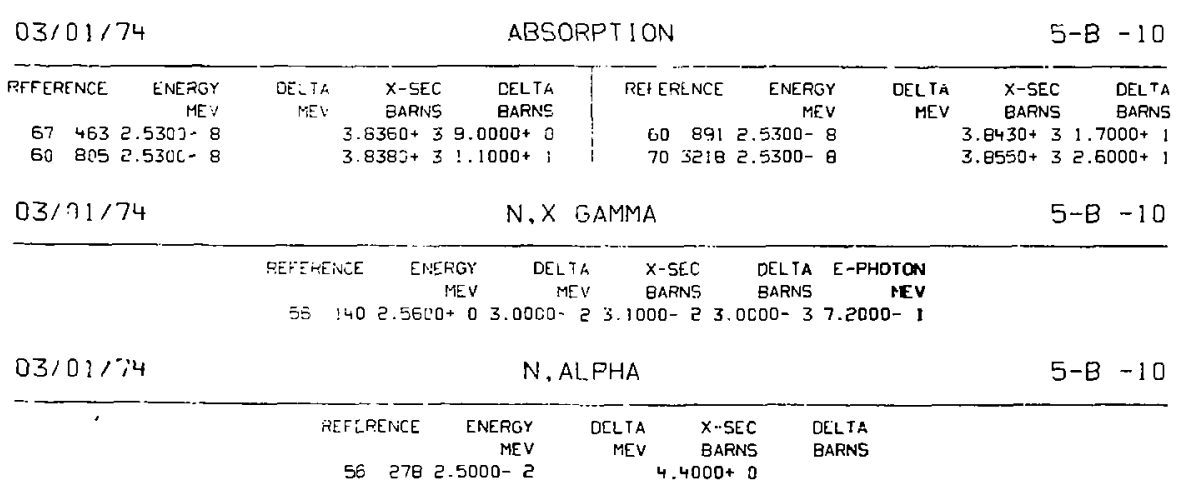




\section{CROSS SECTION}

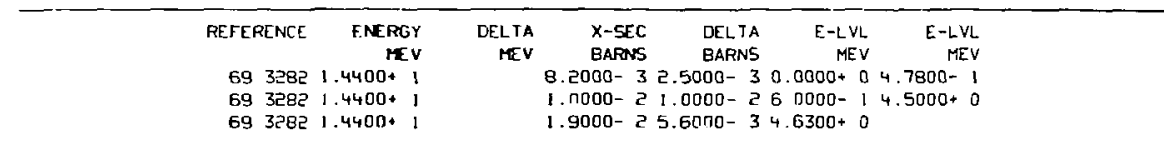

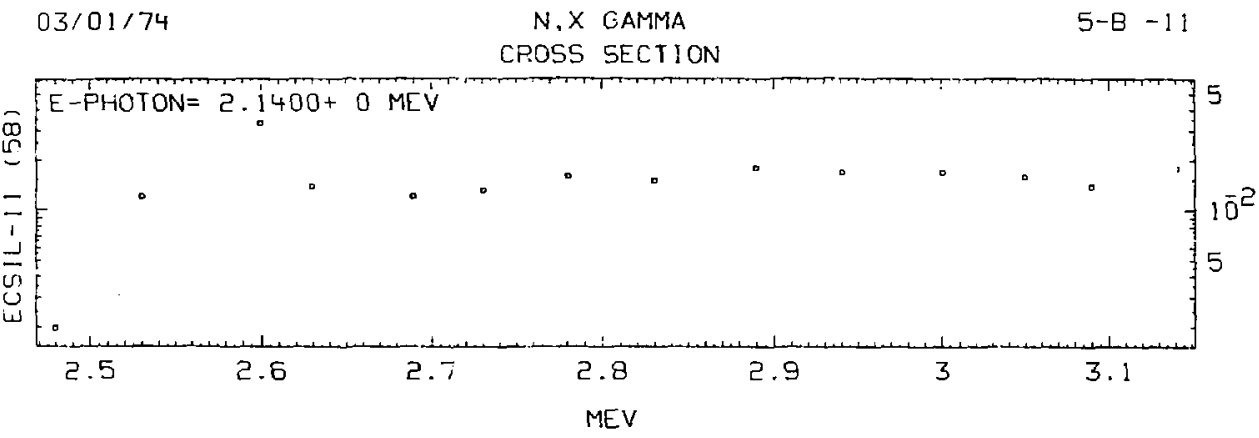




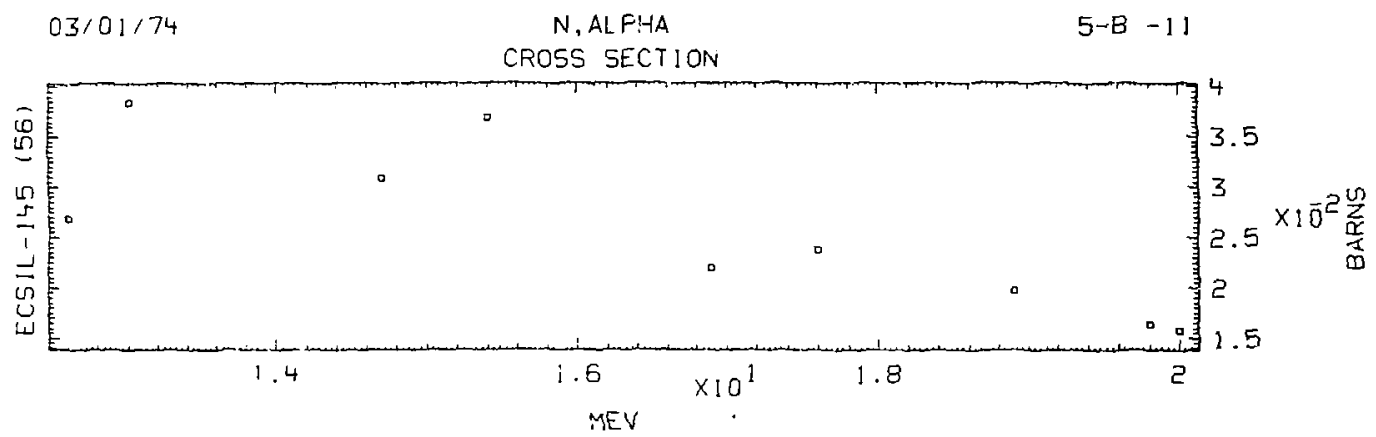

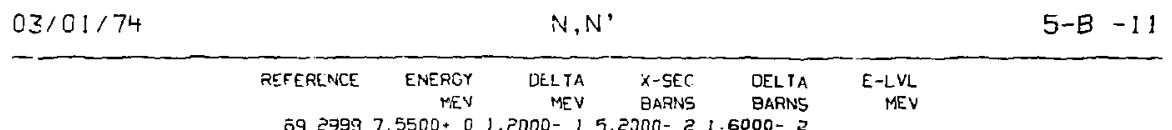

$6929997.6500+01.2000-11.6600-12.5000-24.4605+0$

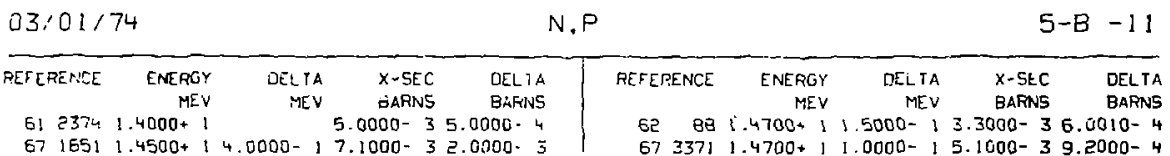

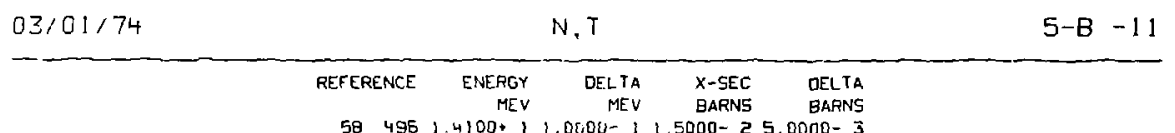

$58496, .4100+, 1.0000-1,1.5000-25.0000-3$ 


\section{CROSS SECTION}

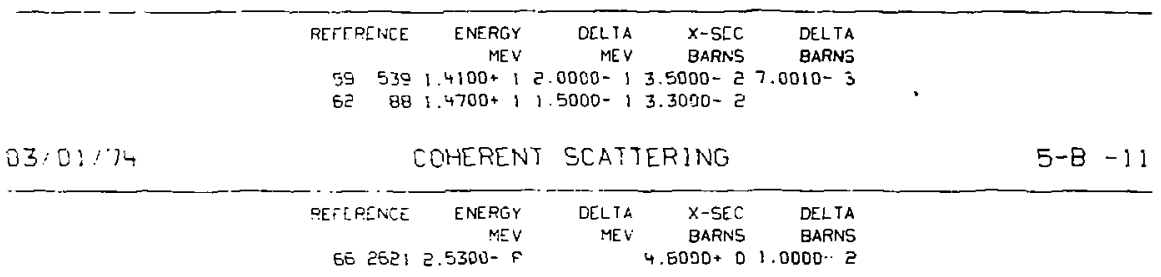

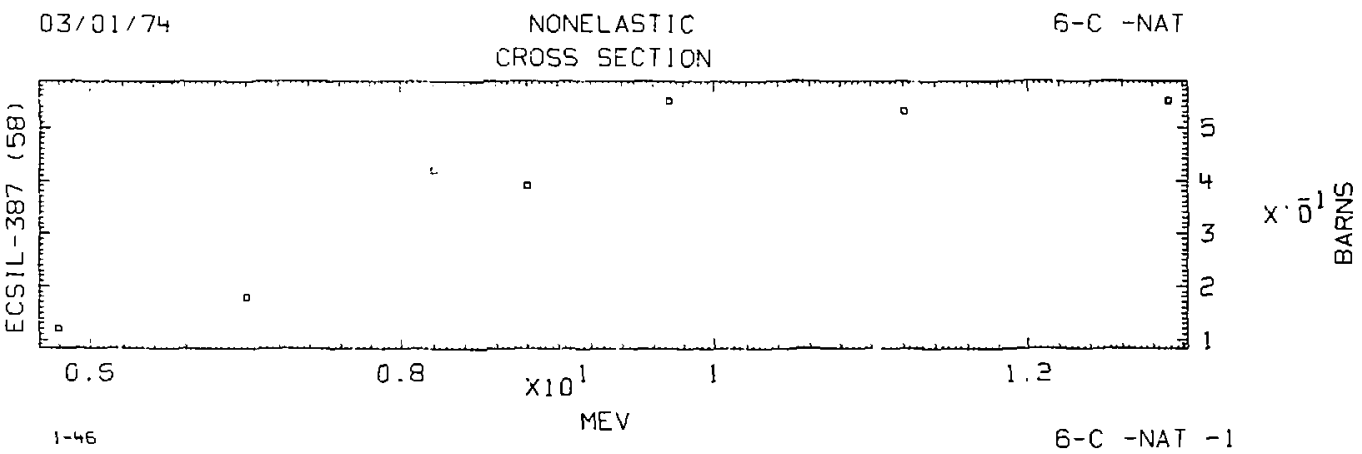




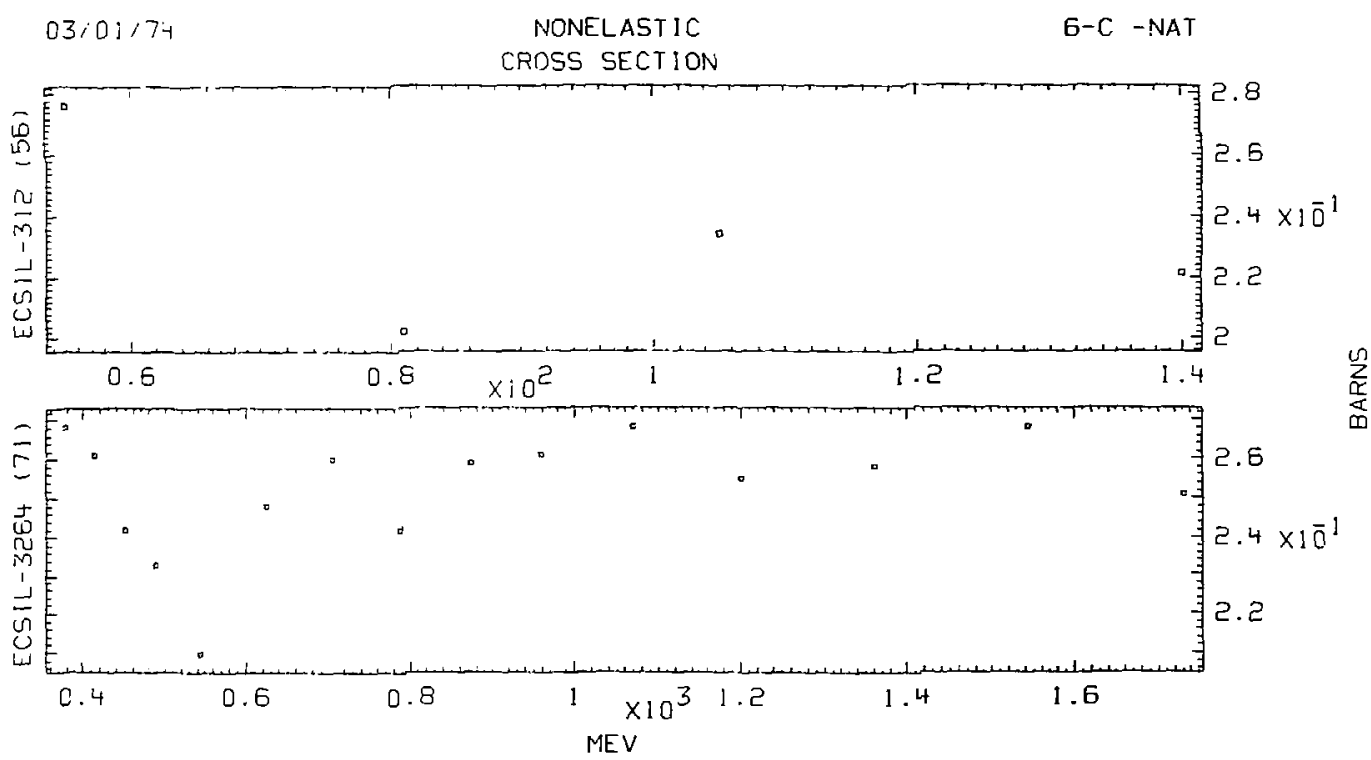

$1-47$ 

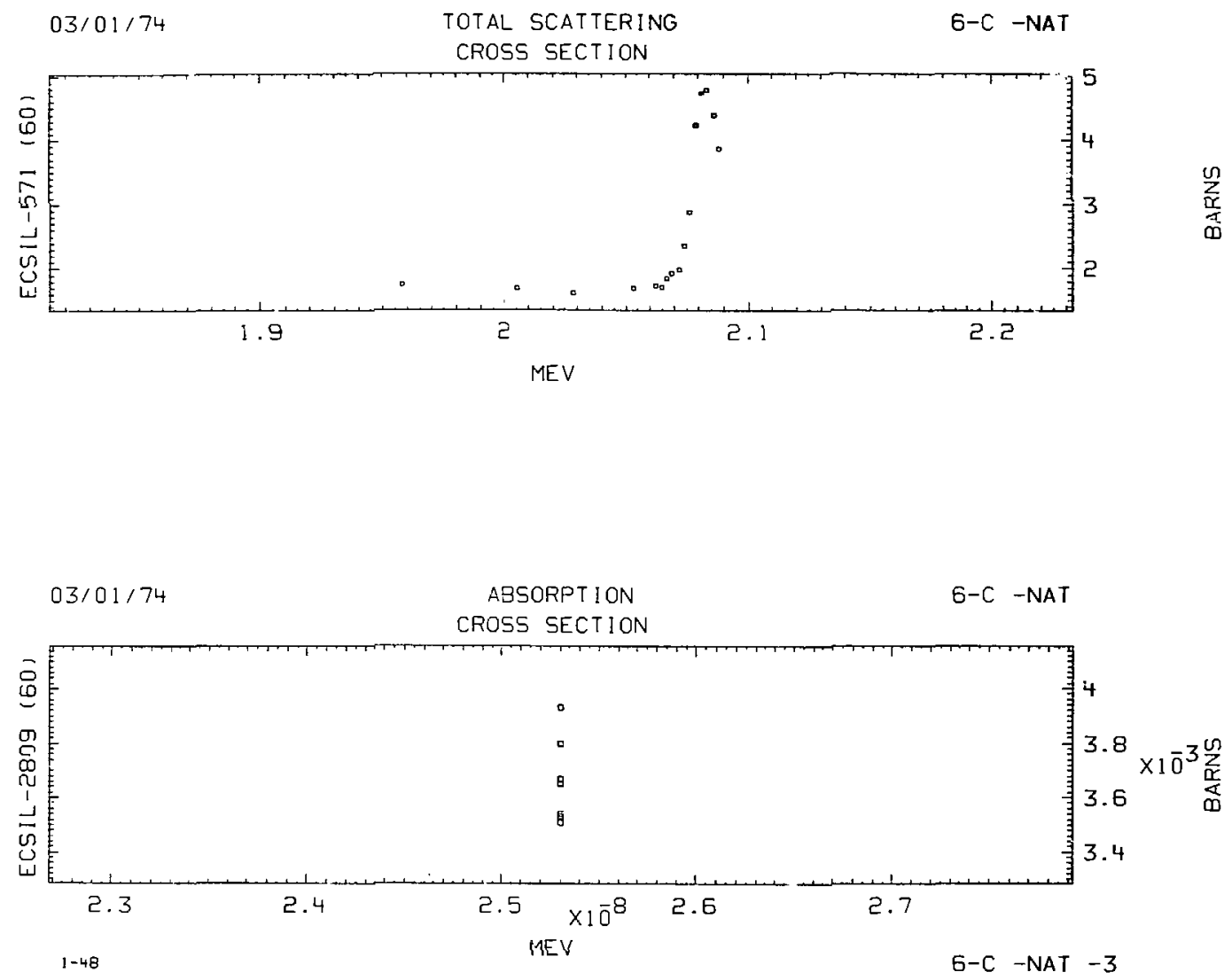


\begin{tabular}{|c|c|c|c|c|c|c|c|c|c|c|c|}
\hline \multicolumn{2}{|c|}{ REFERENCE } & $\begin{array}{r}\text { ENEFGY } \\
\text { MEY }\end{array}$ & $\begin{array}{r}\text { DELTA } \\
\text { MEV }\end{array}$ & $\begin{array}{l}X-5 E C \\
\text { BARNS }\end{array}$ & $\begin{array}{l}\text { OE:TAA } \\
\text { BARNS }\end{array}$ & REFER & RENCE & $\begin{array}{r}\text { ENERGY } \\
\text { MEV }\end{array}$ & $\begin{array}{r}\text { DELTA } \\
\text { MEV }\end{array}$ & $\begin{array}{l}X \text {-SEC } \\
\text { BARNS }\end{array}$ & $\begin{array}{l}\text { DELTA } \\
\text { BARNS }\end{array}$ \\
\hline 56 & 151 & z.5000*0 & 4.00000- & $5.0000-2$ & $25.0000-2$ & 57 & 24 & $1.4200+1$ & $17.0010-2$ & $5.5010-1$ & $3.0000-2$ \\
\hline 55 & 125 & $4.0700+0$ & 0 & $4.0000-2$ & $4.0000-\vec{c}$ & 57 & 319 & $1.4200+1$ & $11.5000-1$ & $5.6010-1$ & $2.0000^{-}$ \\
\hline 55 & 290 & $4.1000-0$ & $04.0000-2$ & B. B.010- & 2 $1.0000-1$ & 56 & 200 & $1.4500+1$ & 1 & $7.3010-1$ & e. $0000^{-}$ \\
\hline 56 & 151 & $7.0000+0$ & $02.0000-1$ & $1.7000-1$ & $13.0000-2$ & 57 & 1656 & $1.4800+1$ & $11.0000-1$ & $5.5000-1$ & 2.0000- 2 \\
\hline 55 & 130 & $1.2700+1$ & 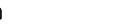 & $5.6010-1$ & $11.0000-1$ & 65 & 1228 & $1.5200+1$ & 1 & $6.2000-1$ & e.0000- \\
\hline 58 & “90 & $1.4000+1$ & i & $6.3000-1$ & $16.0000-2$ & 68 & 2746 & $1.5300+1$ & 1 & $5.5400-1$ & $3.0000-2$ \\
\hline 55 & 790 & $1.4000+1$ & 1 & $6.3010-1$ & $15.0000-2$ & 65 & 1228 & $1.9800+1$ & 1 & $6.5000-1$ & e.0000- 2 \\
\hline 64 & 845 & $1.4: 00+1$ & $9.0010-1$ & $7.3010-1$ & $17.0010-2$ & 58 & 356 & $2.1000+1$ & 1 & $4.9000-1$ & $4.0000-2$ \\
\hline 55 & 117 & $1.4100+1$ & 1 & $6.0110-1$ & $16.0010-3$ & 58 & 356 & $2.5500+1$ & 1 & $4.4000-1$ & $14.0000-E$ \\
\hline 55 & 130 & $1.4100+1$ & 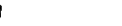 & $5.1010-1$ & $18.0010-2$ & 58 & 350 & 2.9200+ 1 & 1 & $4.5000-1$ & $14.0000-2$ \\
\hline 52 & 82 & $1.4150+1$ & $15.0000-2$ & $27.6310-1$ & $14.0000-2$ & 5 & 2056 & $1.4000+3$ & $3=.000$ & $2.0000-1$ & $11.0000-$ \\
\hline
\end{tabular}

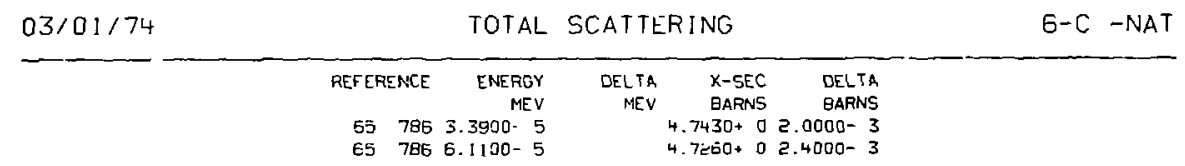

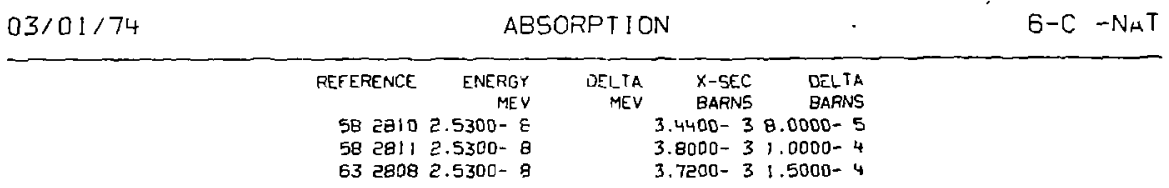

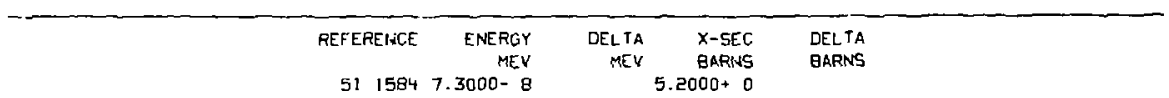




$\begin{array}{cc}03101,74 & \text { COHERENT SCATTERING } \\ \text { CROSS SECTION } & \text { G-C -NAT }\end{array}$

REFERENCE

ENERGY

MEV

DELTA

$X$-SECC DELTA

5) $15847.3000-8$ MEV BARNS BARNS

$2000+C 4.1600-1$

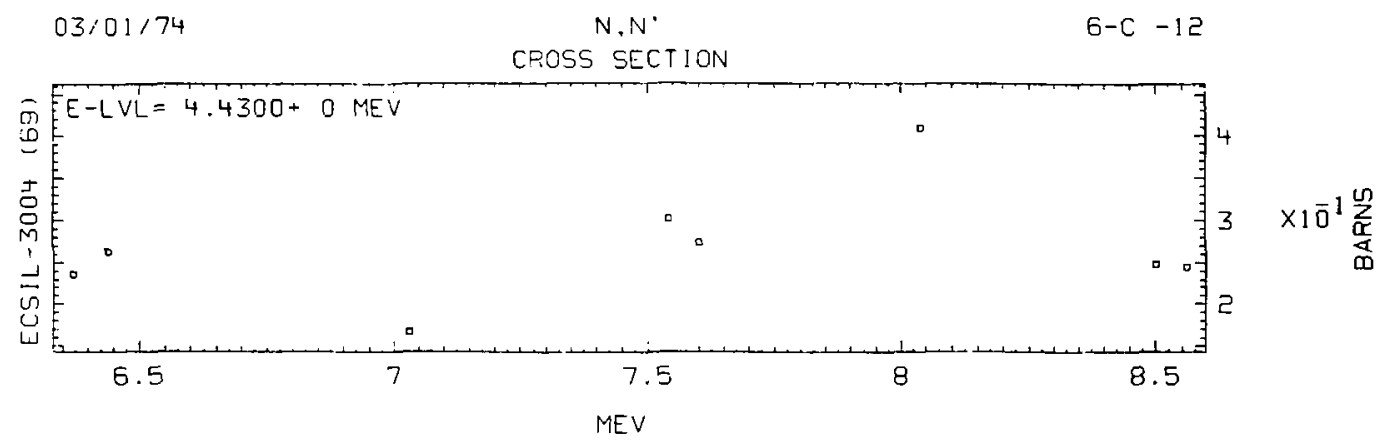



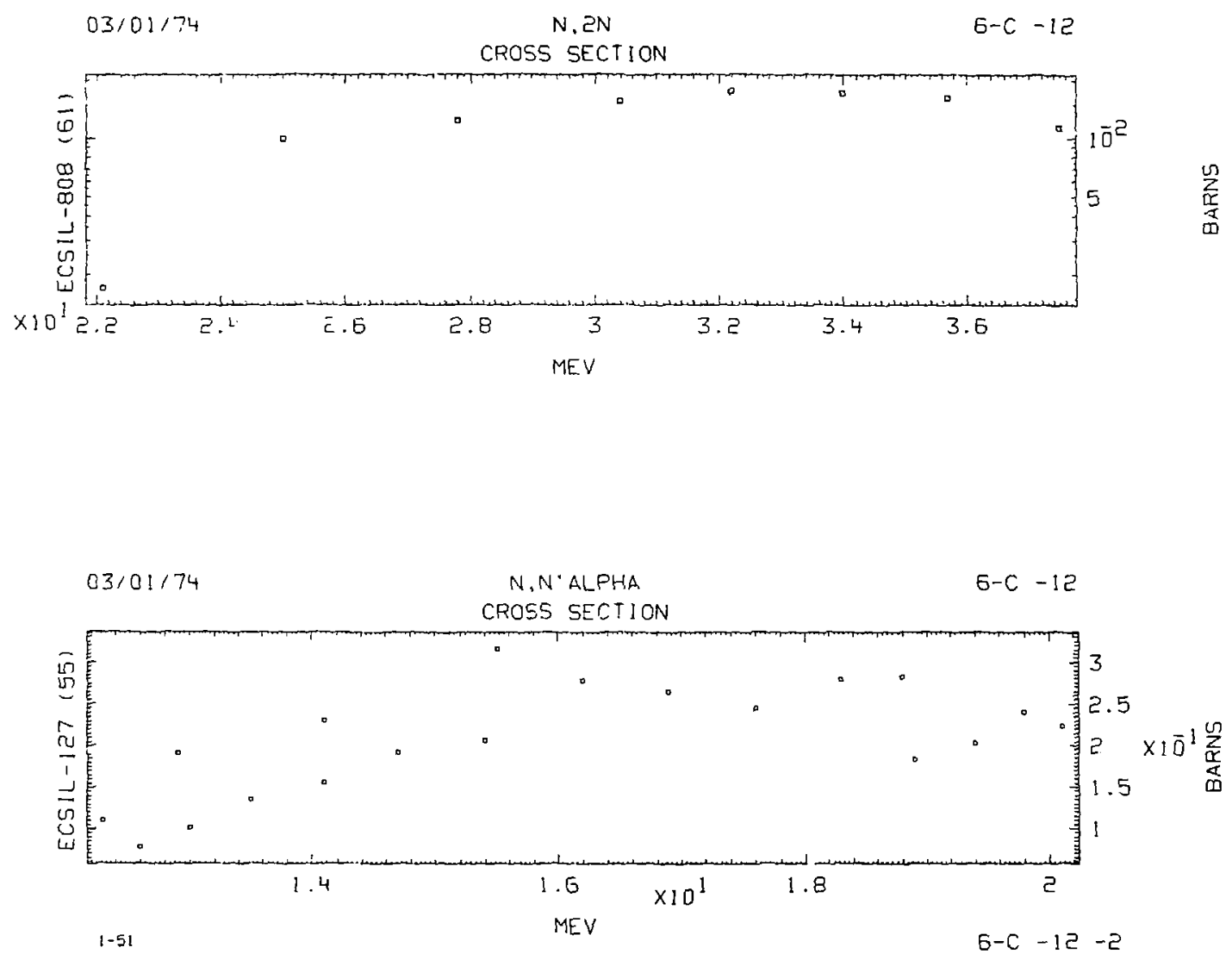

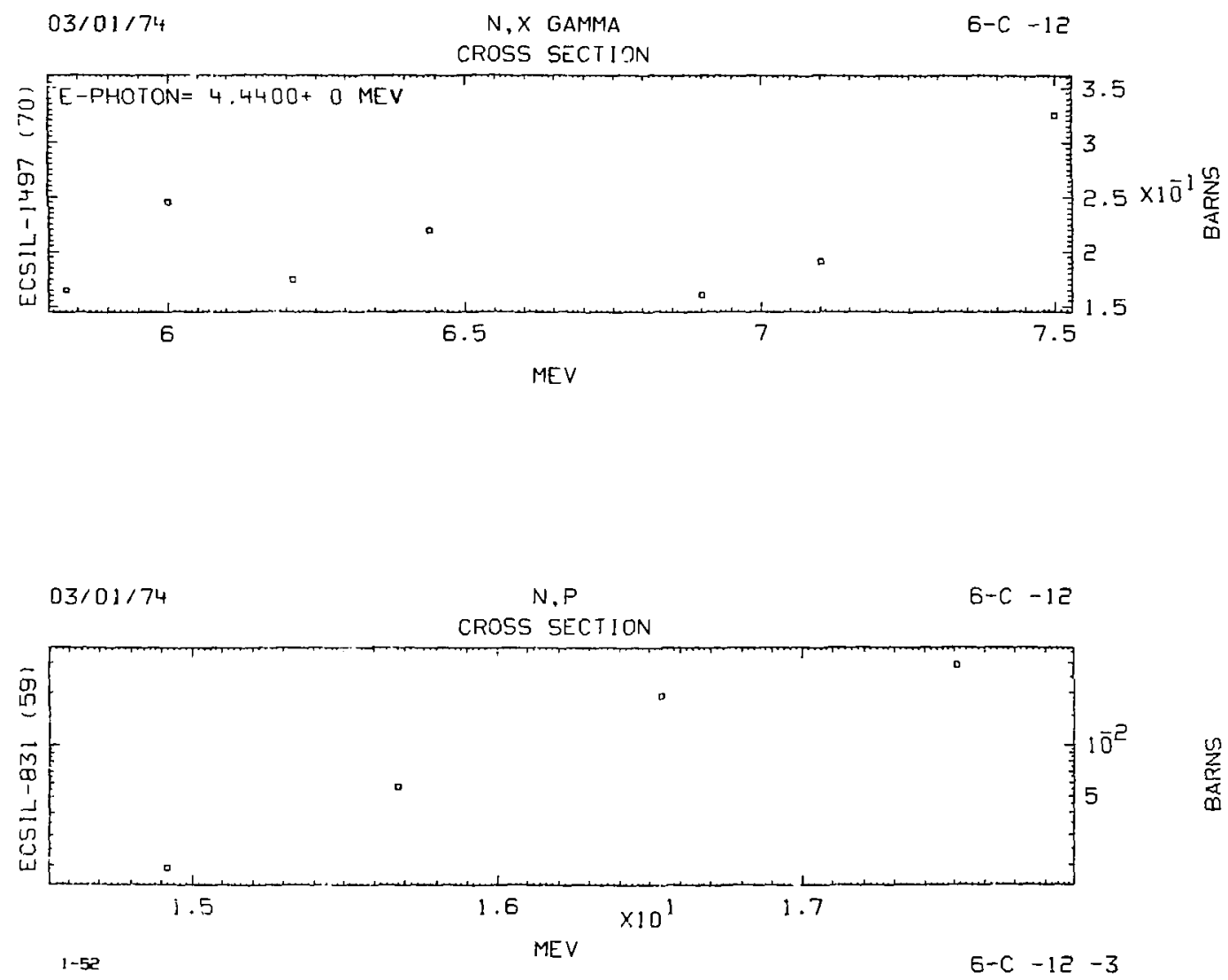


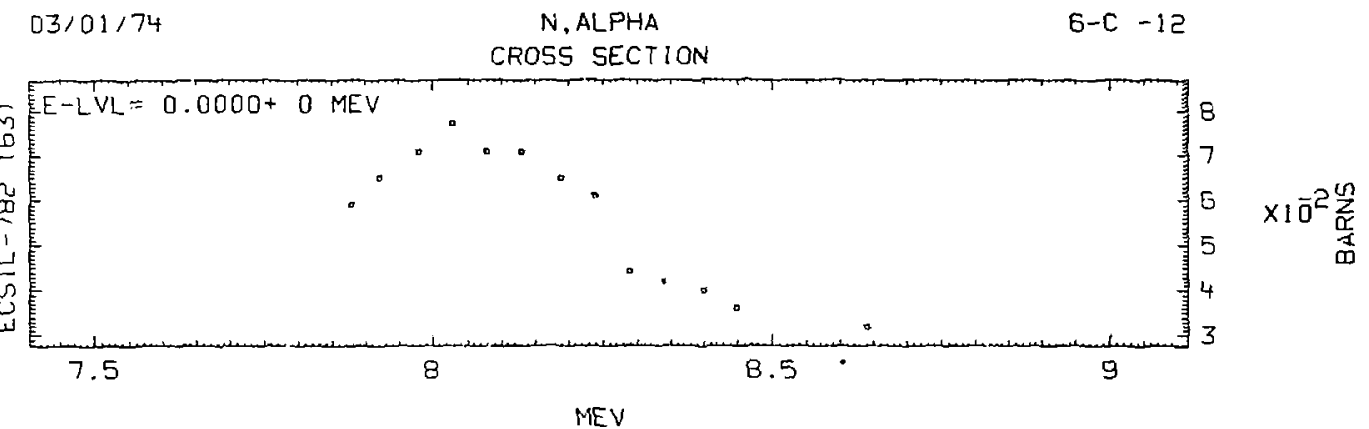

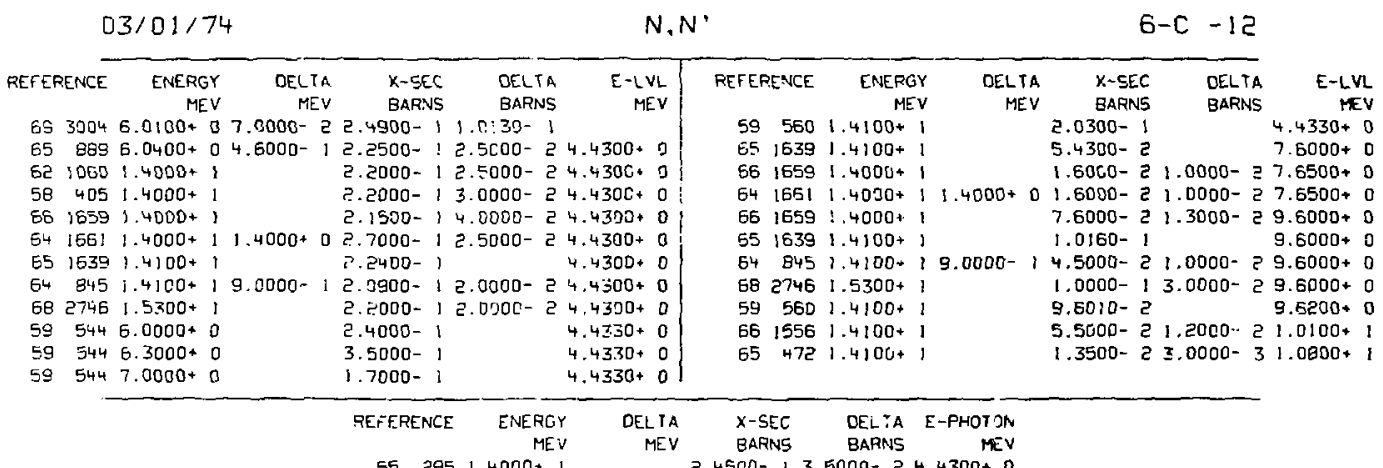


CROSS SECTION

\begin{tabular}{|c|c|c|c|c|c|c|c|c|c|}
\hline EF CRENCE & LNERGY & DELTA & $X-\operatorname{SEC}$ & DELTA & REFERENCE & ENERGY & DELTA & $x-S E C$ & A \\
\hline & MEV & $\mathrm{MEV}$ & BARNS & BARTIS & & MEV & MEV & BARNS & BARNS \\
\hline 58 & $1.4100+1$ & & $6.0010-3$ & $6.0010-3$ & 52 & $4000+1$ & $0000+0$ & $5.0000-3$ & $0000-3$ \\
\hline 52 & $32.3000+1$ & $2.00[7+0$ & $4.7500-3$ & $1.0000-3$ & $5 \vec{e}$ & $7000+1$ & $2.0000+0$ & $1.0000-2$ & $1.0000-3$ \\
\hline
\end{tabular}

$03 / 01 / 74$

$N, N \cdot P$

$6-C-12$

RETLRENCS

$\begin{array}{cccc}\text { ENERGY DELTA } & X \text { SEC } & \text { DELTA } & \text { E-LVL } \\ \text { MEV } & \text { MEV } & \text { BARNS } & \text { BARNS } \\ \text { MEV }\end{array}$

$611664+.4000+22.0000+13.2000-38.0000-44.66000+0$

$61: 6641.4000+\bar{z} 2.0000+17.0000-43.5000-45.0400+0$

61 lEV $1.4000+22.0000+1$ i.4000- $37.0000-4 \equiv .8000+0$

$03 / 01,74 \quad N, X$ GAMMA $\quad 5-C-12$

\begin{tabular}{rrrrrr} 
RETCFENCE & ENNERGY & DELTA & $X$-SEC & DELTA \\
MEV & MEV & BARNS & BARNS \\
53 & 294 & $1.4200+1$ & & $1.9000-$ & $5.0000-2$ \\
\hline
\end{tabular}

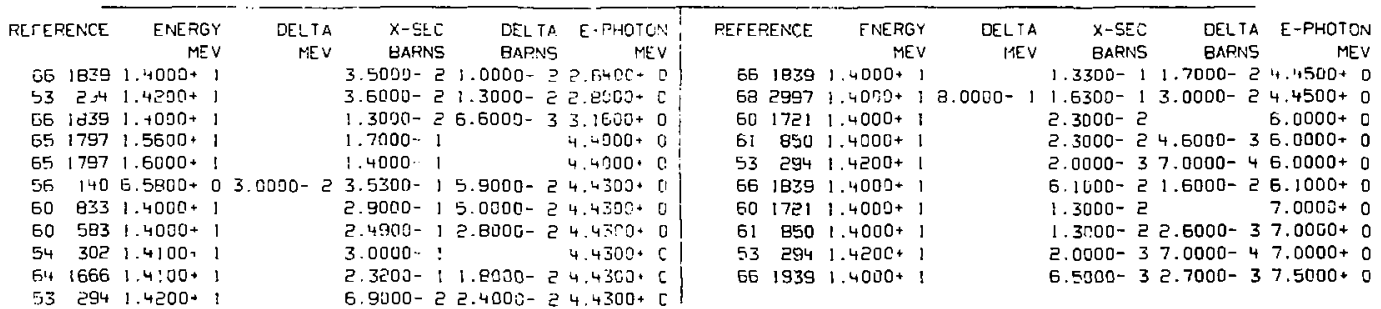




\begin{tabular}{|c|c|c|c|c|c|c|c|c|c|c|c|}
\hline 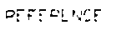 & $\begin{array}{r}\text { FNIDEY } \\
\text { PEEY }\end{array}$ & $\begin{array}{l}\text { DELTA } \\
\text { MEV }\end{array}$ & $\begin{array}{l}x+5 E C \\
8 A R+55\end{array}$ & $\begin{array}{l}\text { DLLTA } \\
\text { BARNS }\end{array}$ & $\begin{array}{r}E-I V L \\
\text { MEV }\end{array}$ & REFERENCE & $\begin{array}{c}\text { ENERGY } \\
\text { ME! }\end{array}$ & $\begin{array}{r}\text { CELIA } \\
\text { MEV }\end{array}$ & $\begin{array}{l}X-5 E C \\
\text { BARNS }\end{array}$ & $\begin{array}{l}\text { OEL TA } \\
\text { BARNS }\end{array}$ & $E-L V L$ \\
\hline & $4500 \cdot 0$ & & $5.9010-2$ & $1.3000-2$ & $0.0000+0$ & 663022 & 1. $6000+$ & & $+.7000 \cdot 2$ & $1.6000-2$ & $0.0000+$ \\
\hline $7: \quad 300$ & $4620 \cdot 1$ & & $7.5000-2$ & $4.0000-2$ & $0.0000+0$ & 663022 & $1.7000+1$ & & $3.4000-z$ & $1.8000-2$ & $0.0000+$ \\
\hline
\end{tabular}

$03 / 01 / 74$

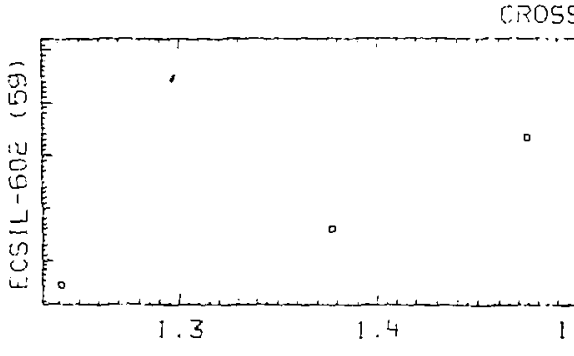

N. ZN
SECTION

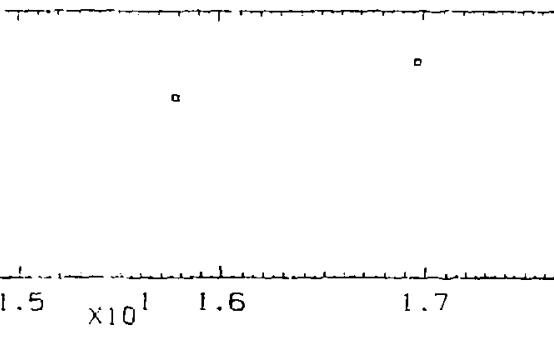

MEV
7-N -NAT

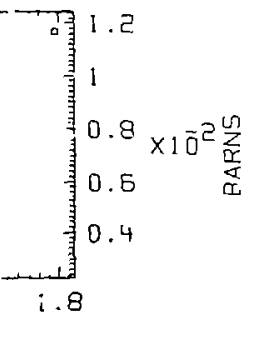



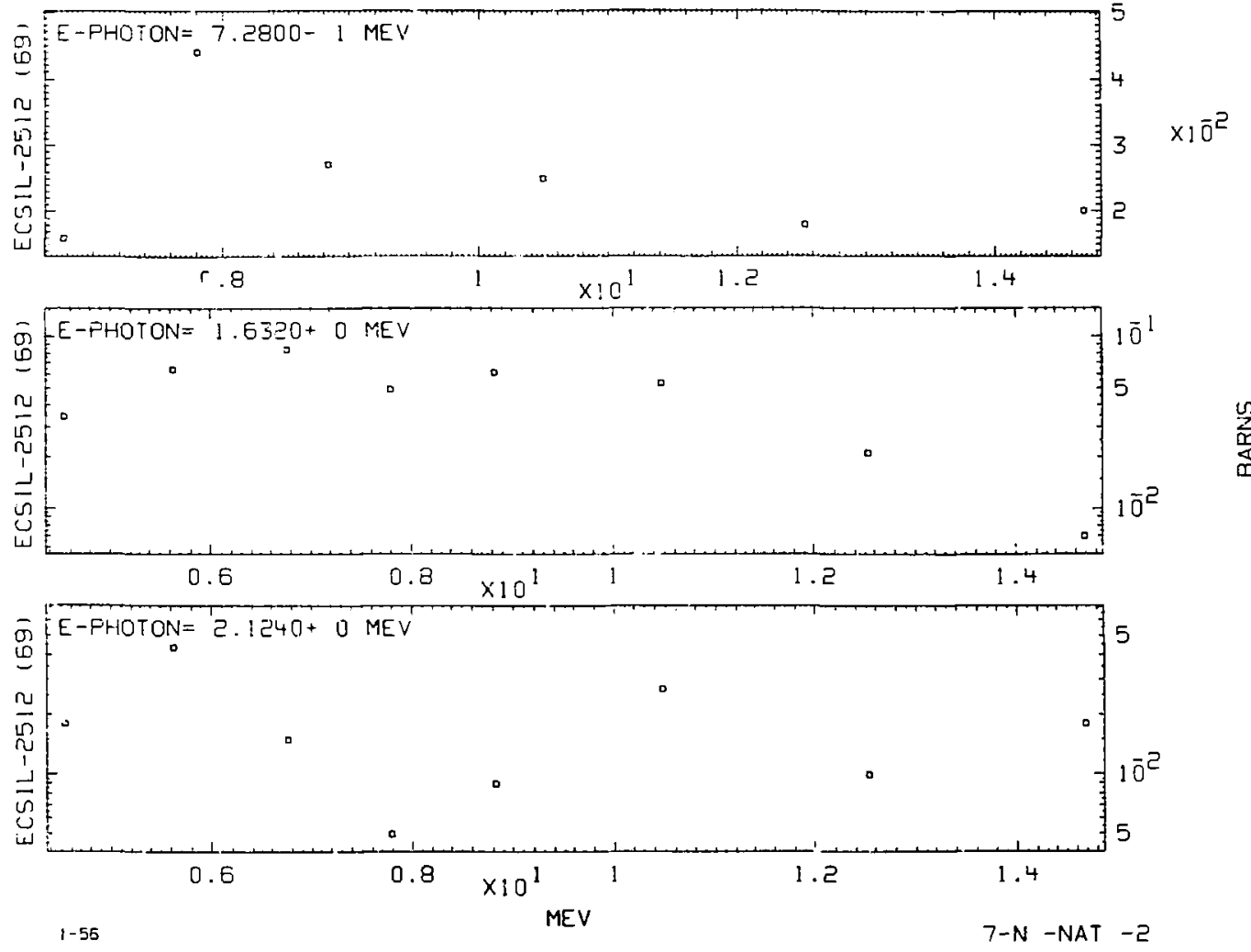


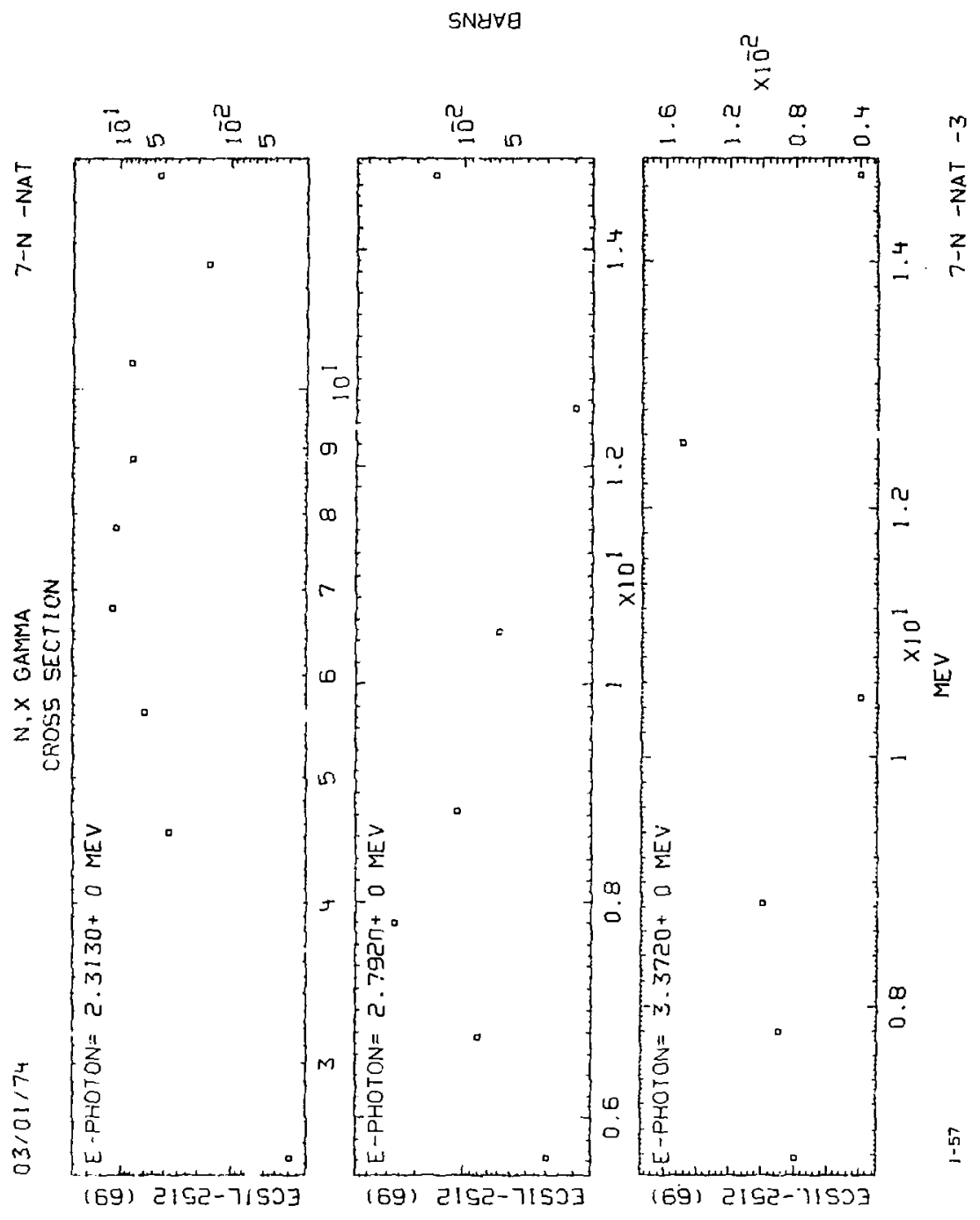



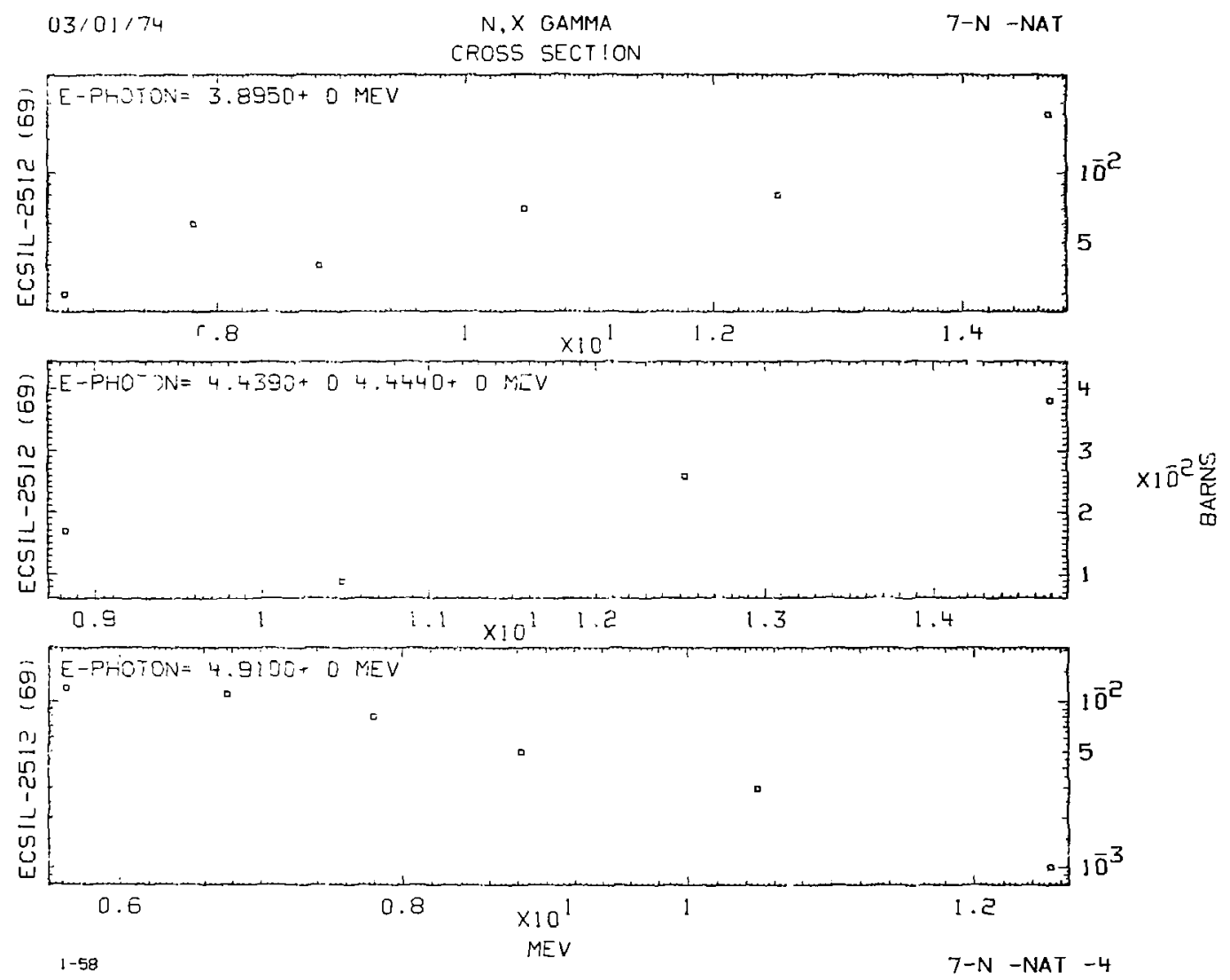


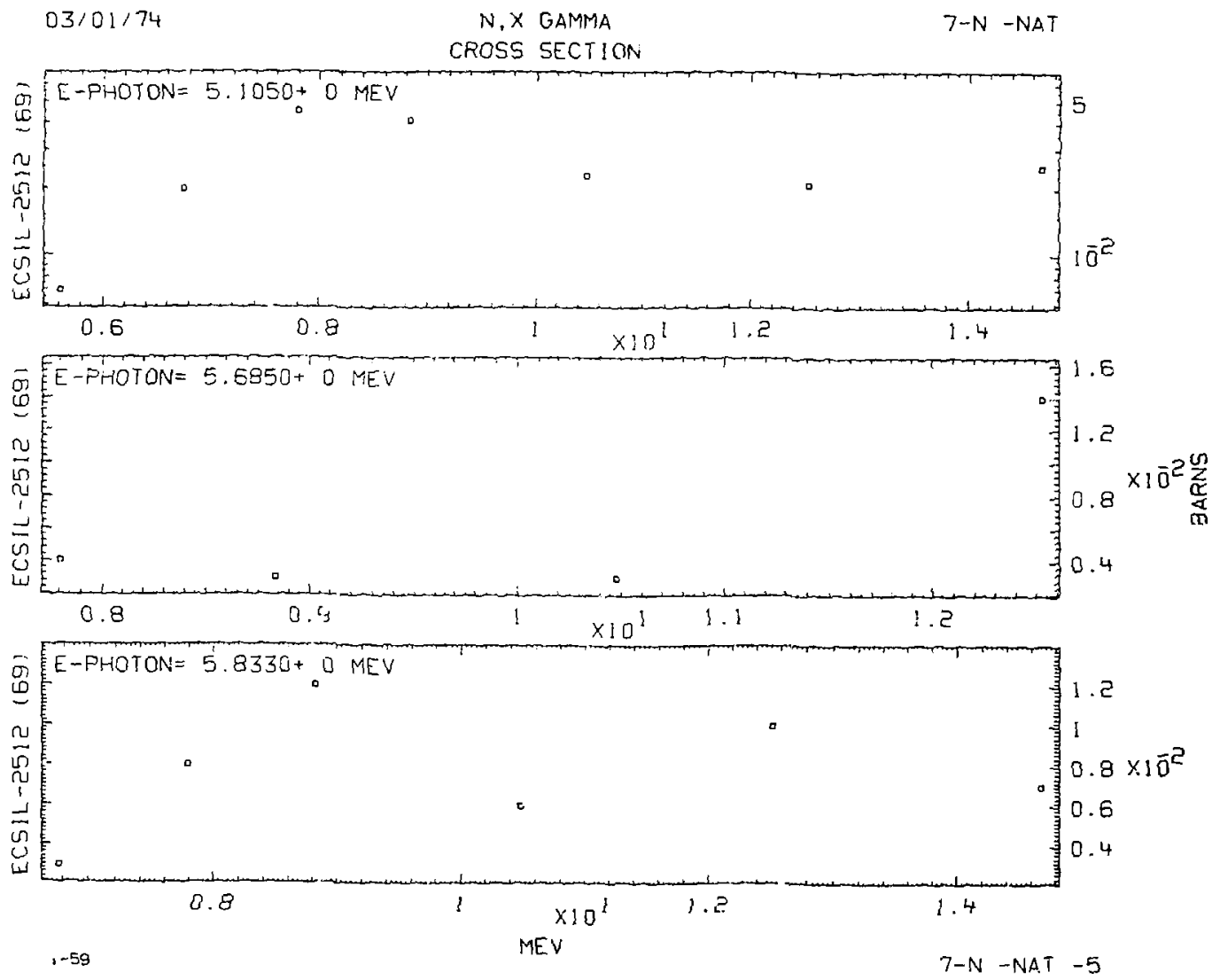



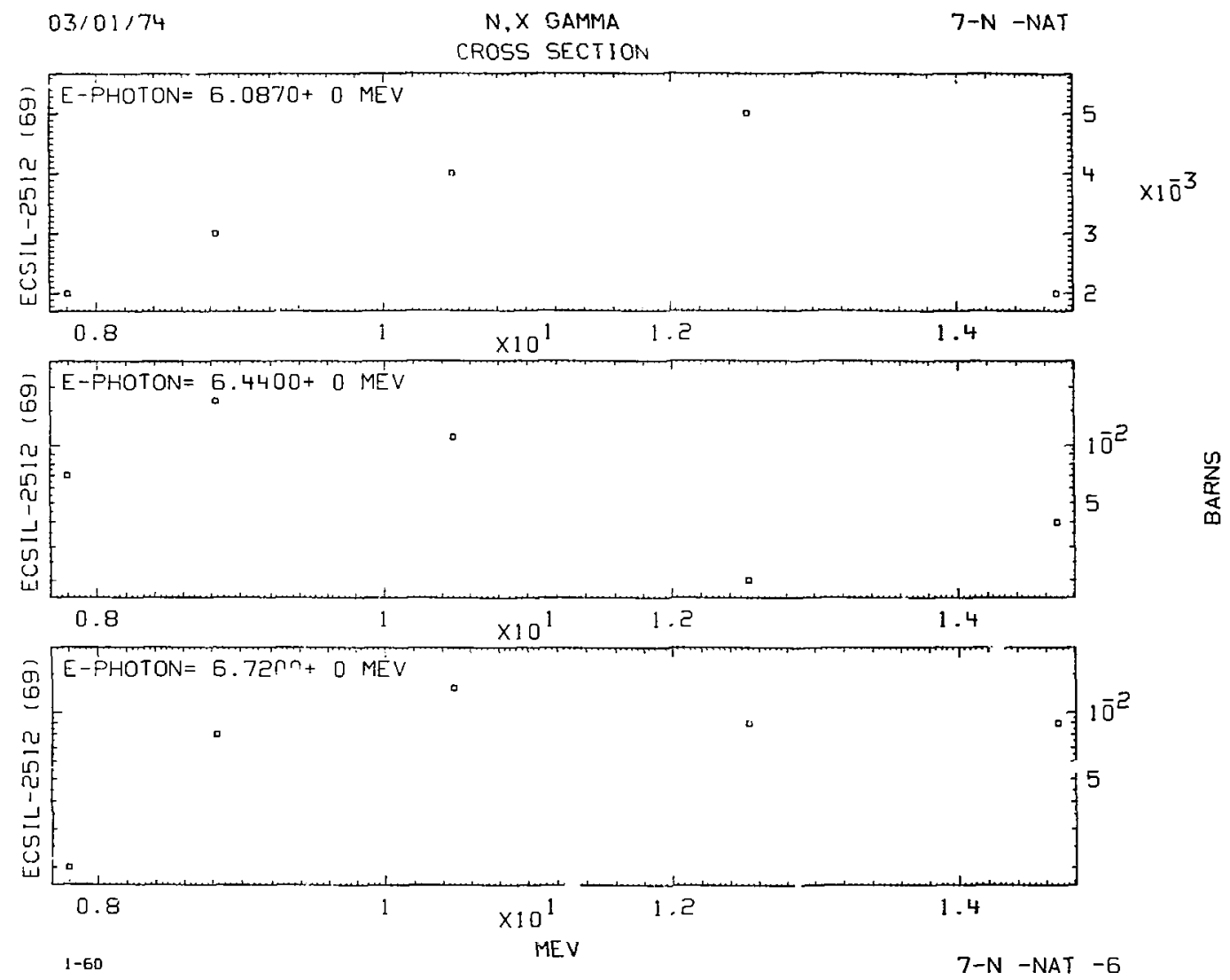

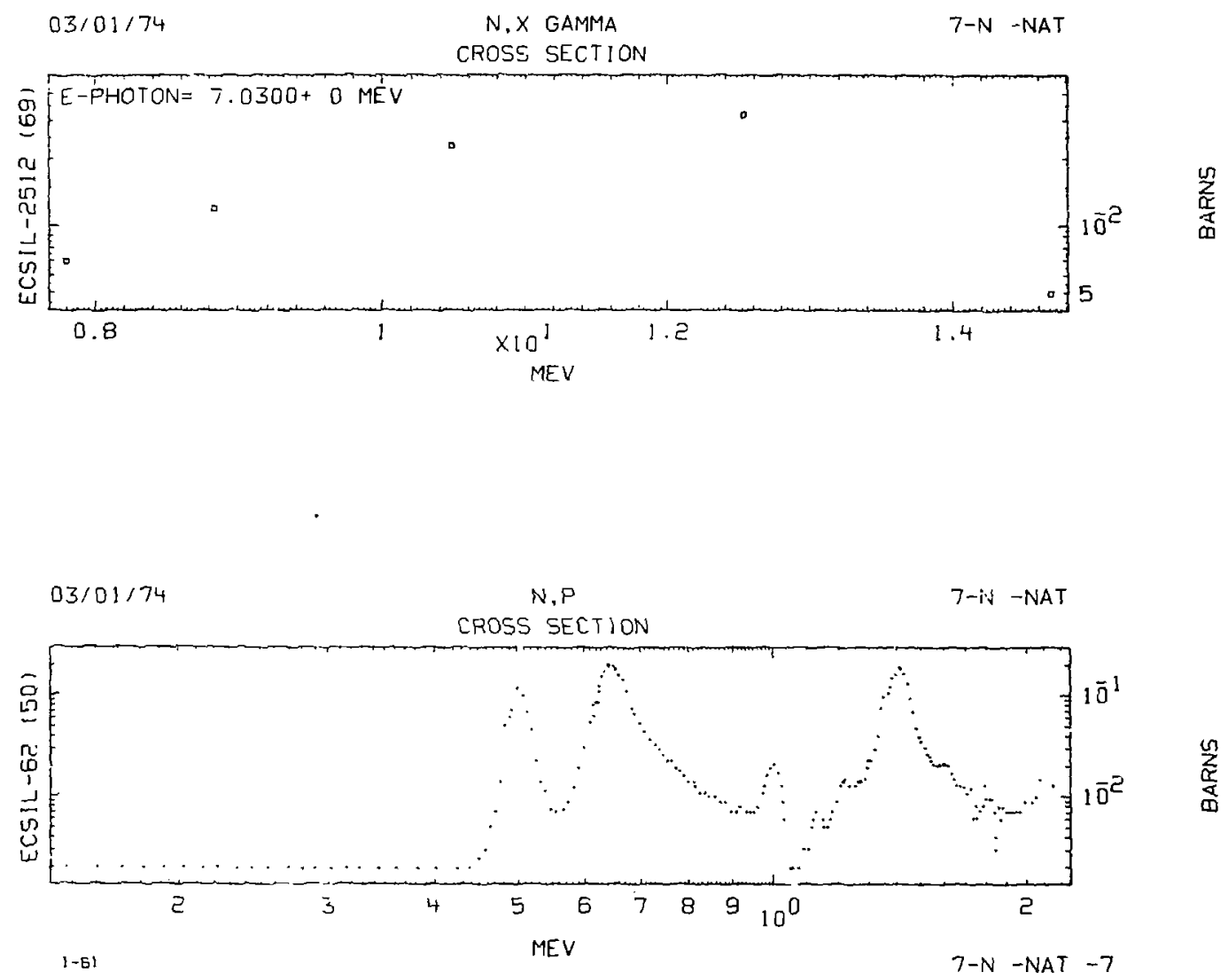


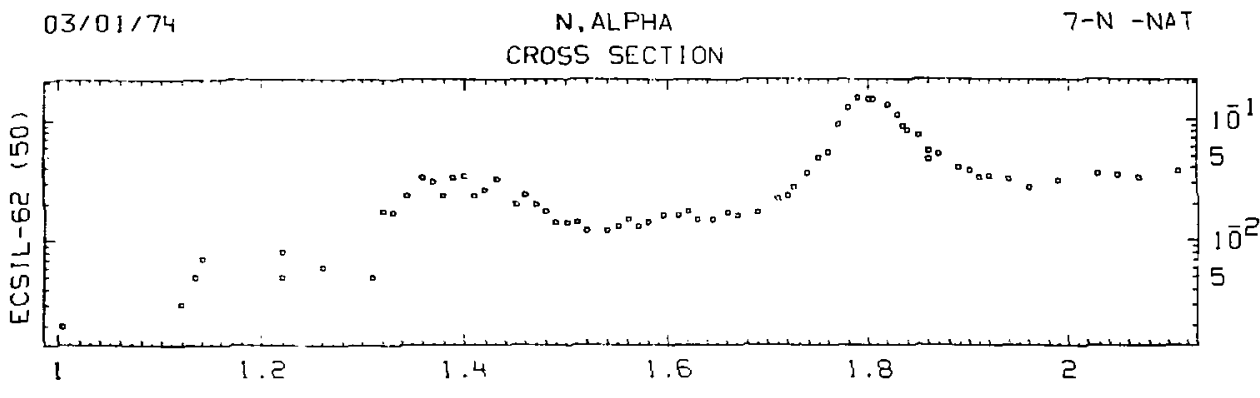

MEV

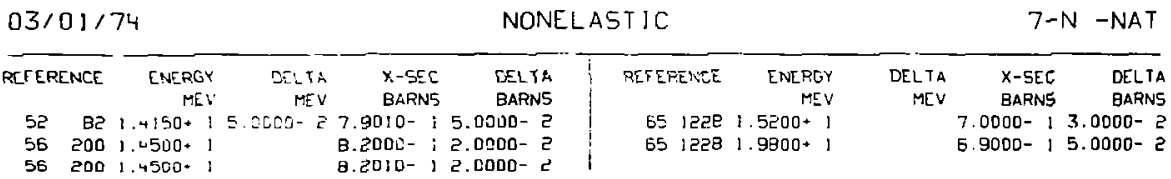

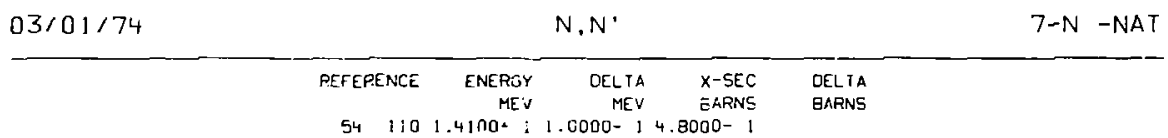

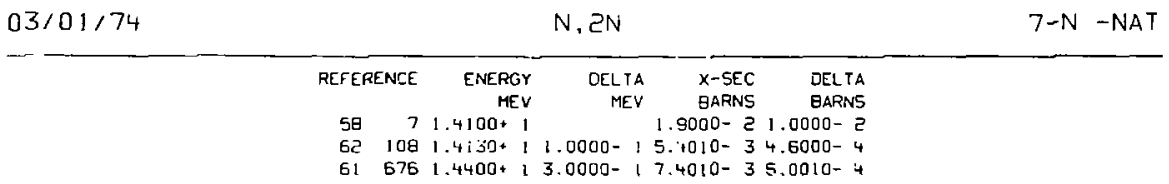




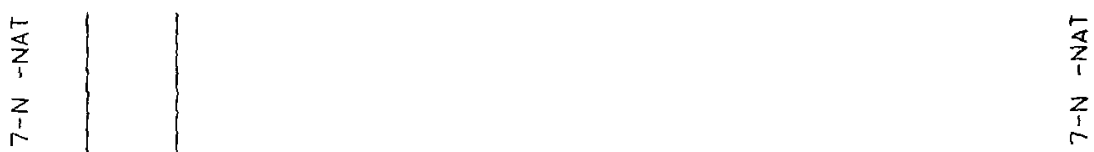

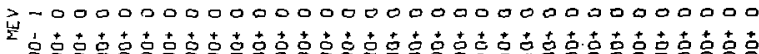

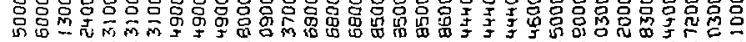

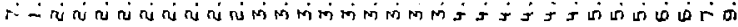

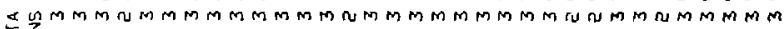

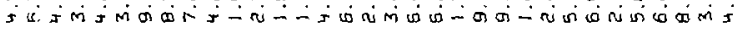
U U U N N

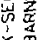

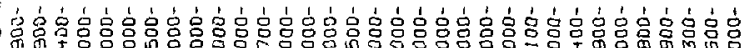

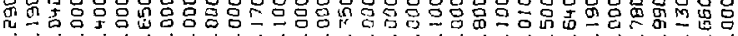
Qimar-

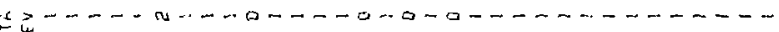

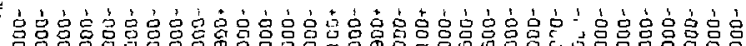

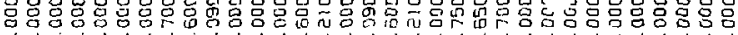

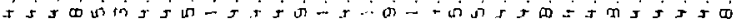

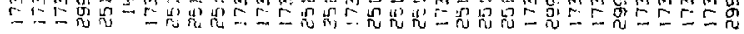

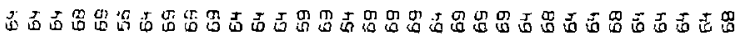


CROSS SECTION

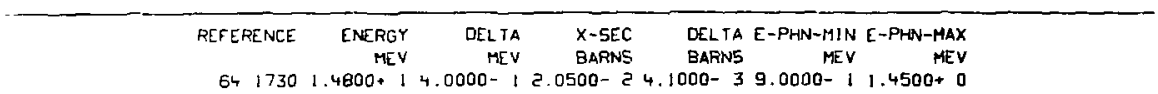

$6417301.4800+14.0000-12.0500-24.1000-39.0000-11.4500+0$

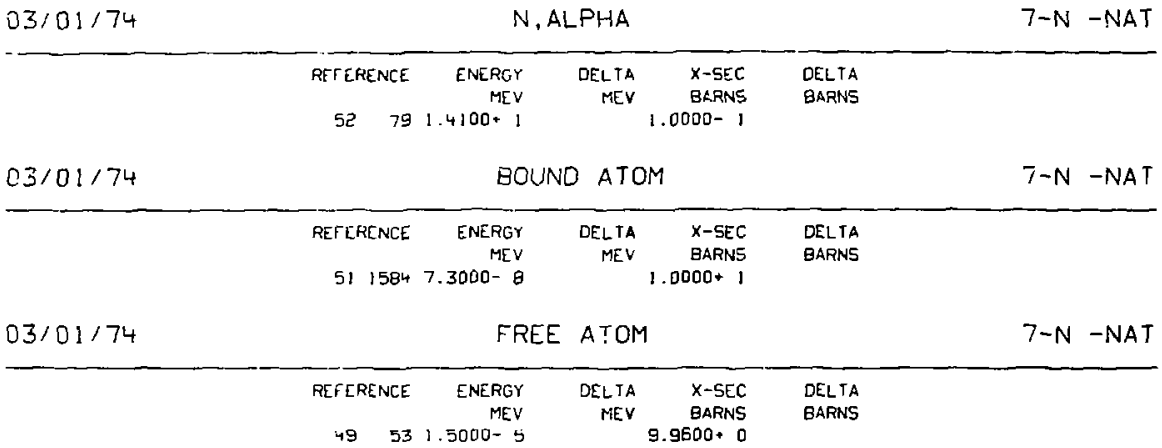

\begin{tabular}{|c|c|c|c|c|c|c|c|c|c|}
\hline \multicolumn{2}{|c|}{$03 / 01 / 74$} & \multirow[b]{2}{*}{$\begin{array}{l}\text { DÉLTA } \\
\text { MEV }\end{array}$} & \multicolumn{2}{|c|}{ COHERENT } & SCATTERING & \multirow[b]{2}{*}{ ENERGY } & \multicolumn{2}{|c|}{$7-N$} & -N -NAT \\
\hline REFER & $\begin{array}{l}\text { ENERGY } \\
\text { MEV }\end{array}$ & & $\begin{array}{l}x-S E C \\
\text { BARNS }\end{array}$ & $\begin{array}{l}\text { DELTA } \\
\text { BARNS }\end{array}$ & REFE & & $\begin{array}{l}\text { ELITA. } \\
\text { MEY }\end{array}$ & & $\begin{array}{l}\text { DELTA } \\
\text { BARNS }\end{array}$ \\
\hline 512 & $.5300-8$ & & $1000+1$ & $1.5000 * c$ & 5128 & $.5300-8$ & & $9.10,00+0$ & \\
\hline $\begin{array}{l}512811 \\
522816\end{array}$ & $\begin{array}{l}5300-8 \\
.5300-8\end{array}$ & & $\begin{array}{l}.7000+0 \\
1100+1\end{array}$ & $\begin{array}{l}1.1000+0 \\
3.0000-1\end{array}$ & $\begin{array}{lll}64 & 2654 & ? \\
51 & 1584 & 7\end{array}$ & $\begin{array}{l}5300-8 \\
.3000-8\end{array}$ & & $\begin{array}{l}1.0600+1 \\
9.1000+0\end{array}$ & $\begin{array}{l}3.0000- \\
7.2800-\end{array}$ \\
\hline
\end{tabular}



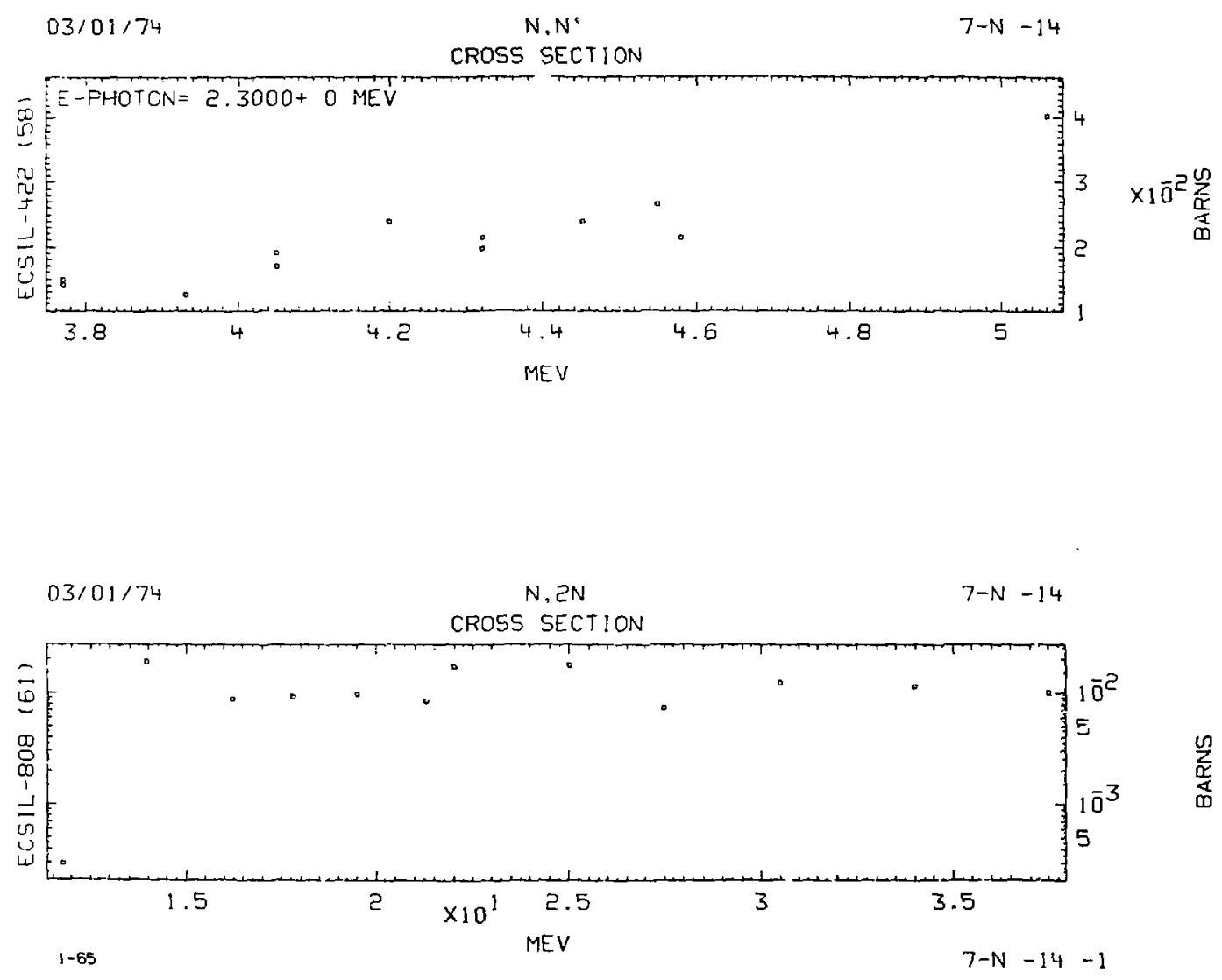


\section{CROSS SECTION}

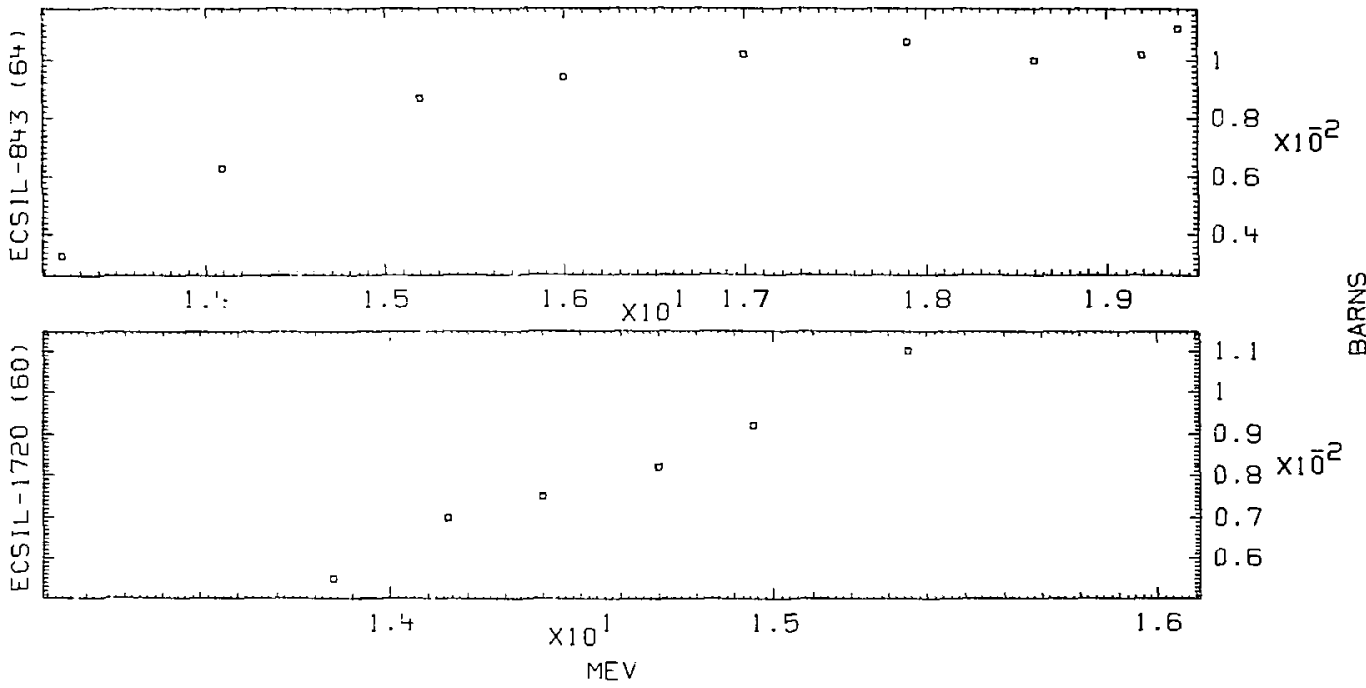

$\underset{\substack{\alpha \\ \alpha}}{\frac{w}{\alpha}}$ 


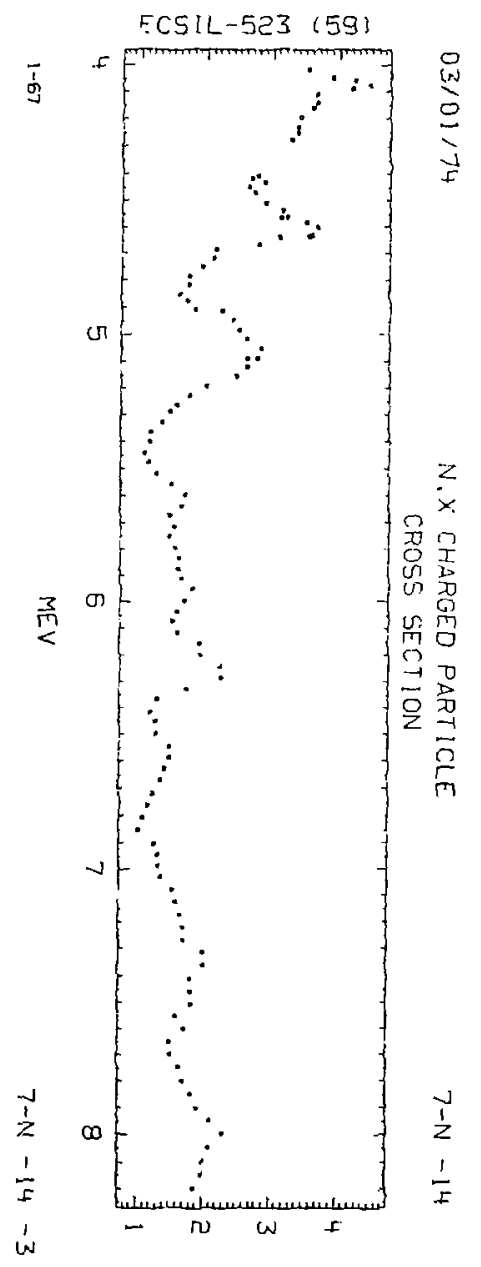

$\frac{x}{0 !}$

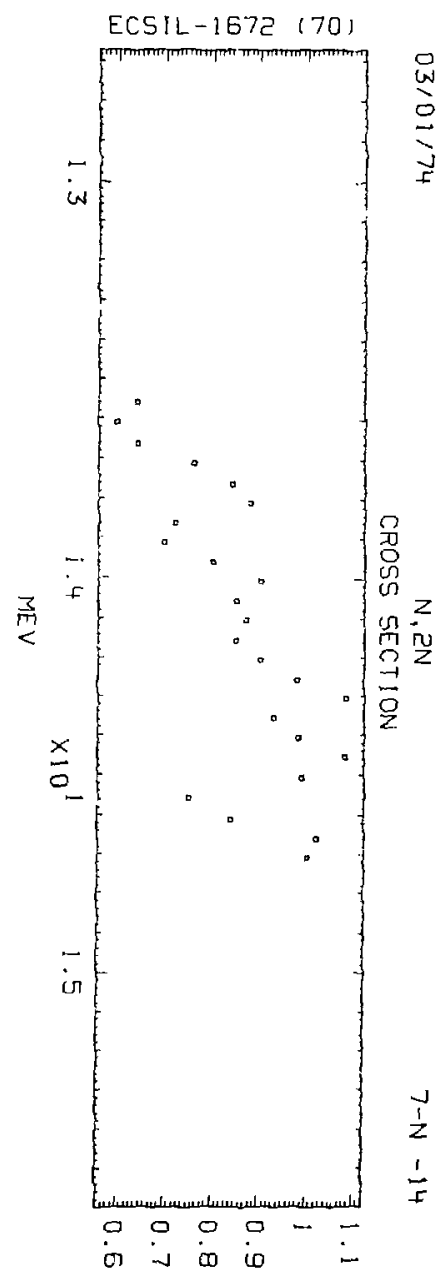

RELAT IVE 

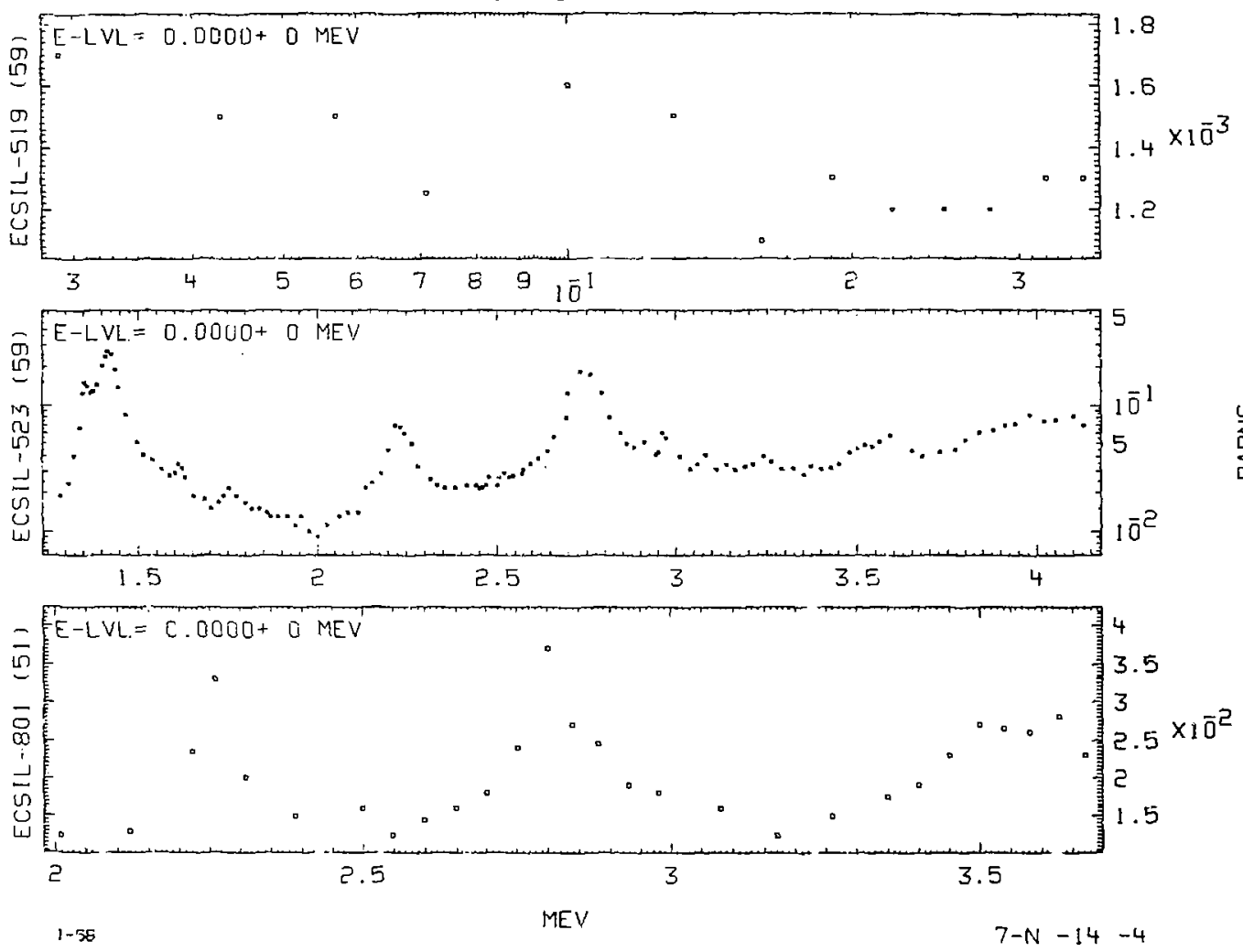

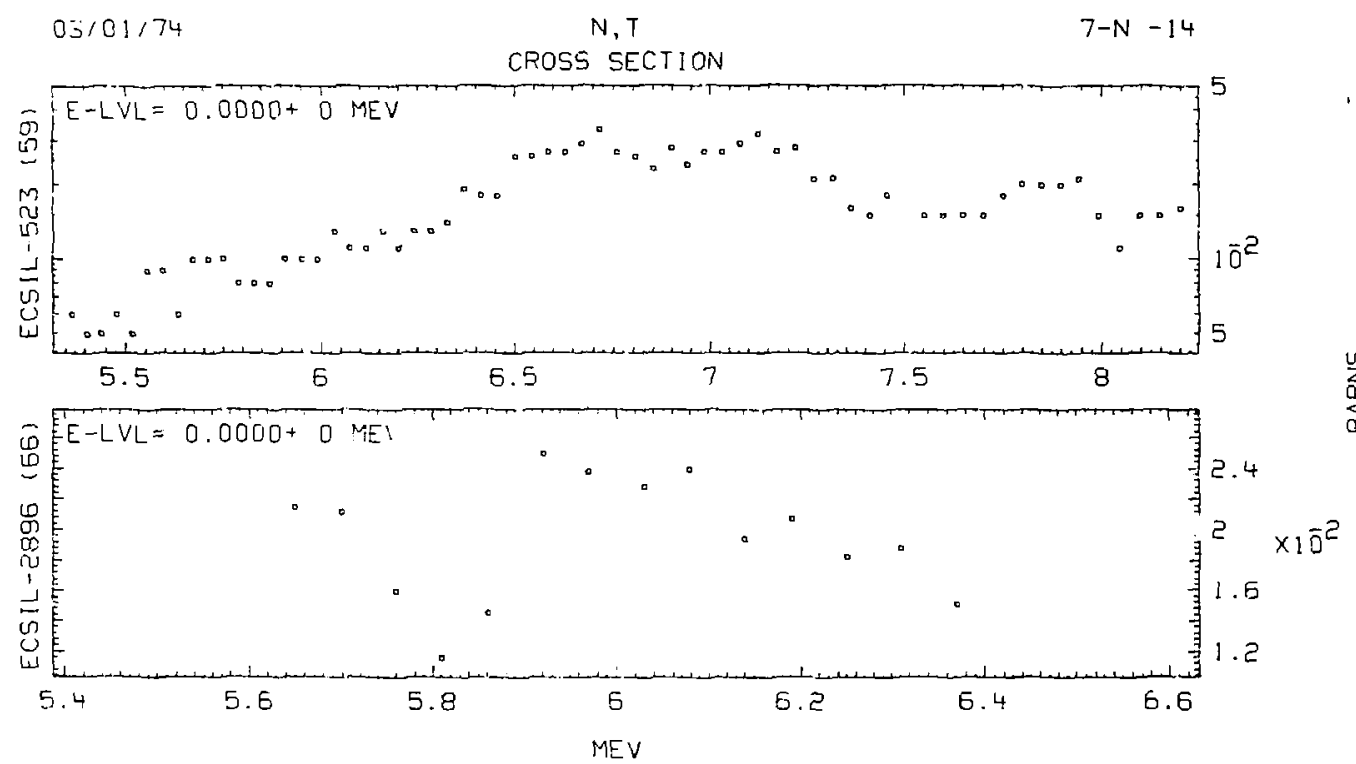


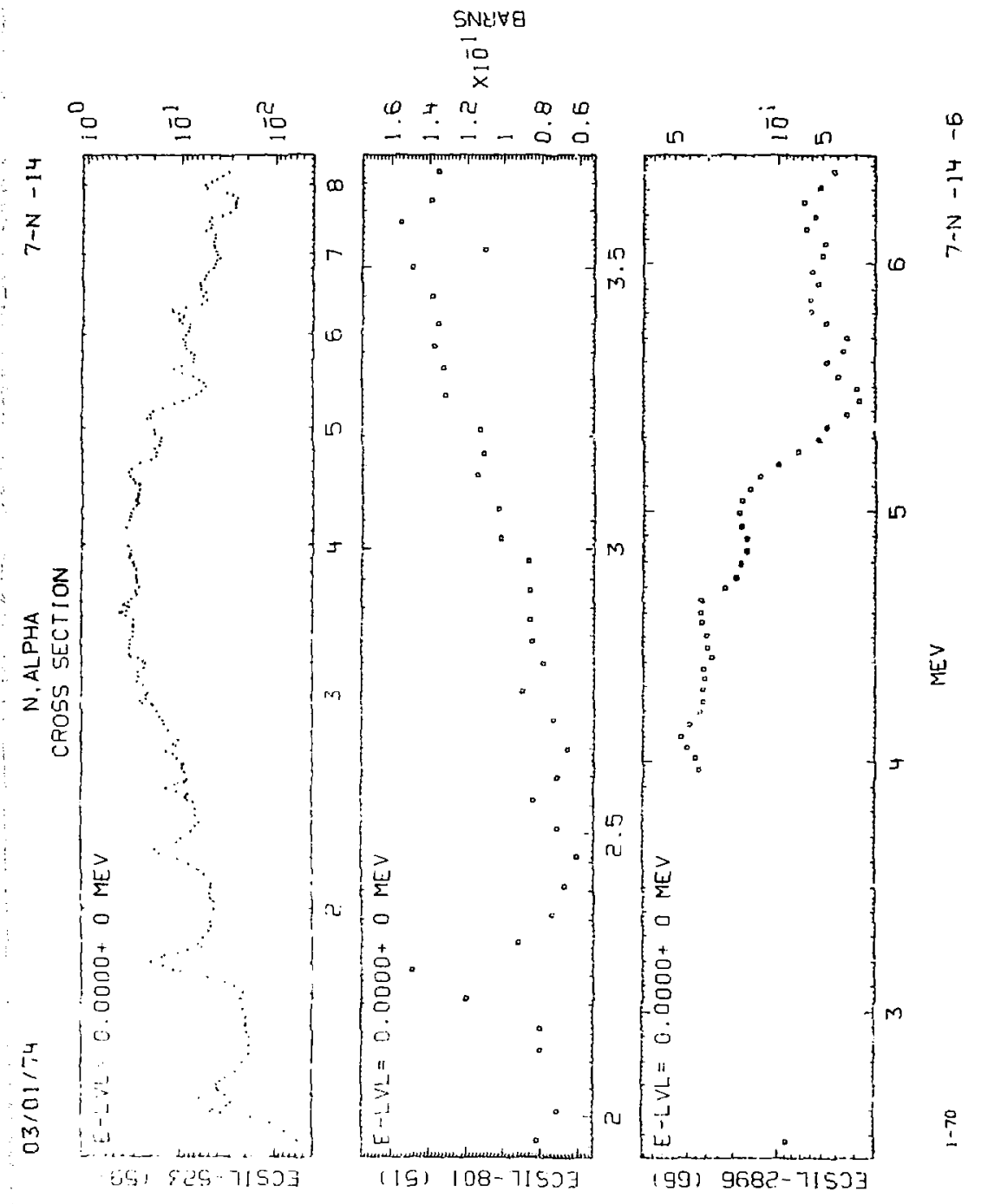




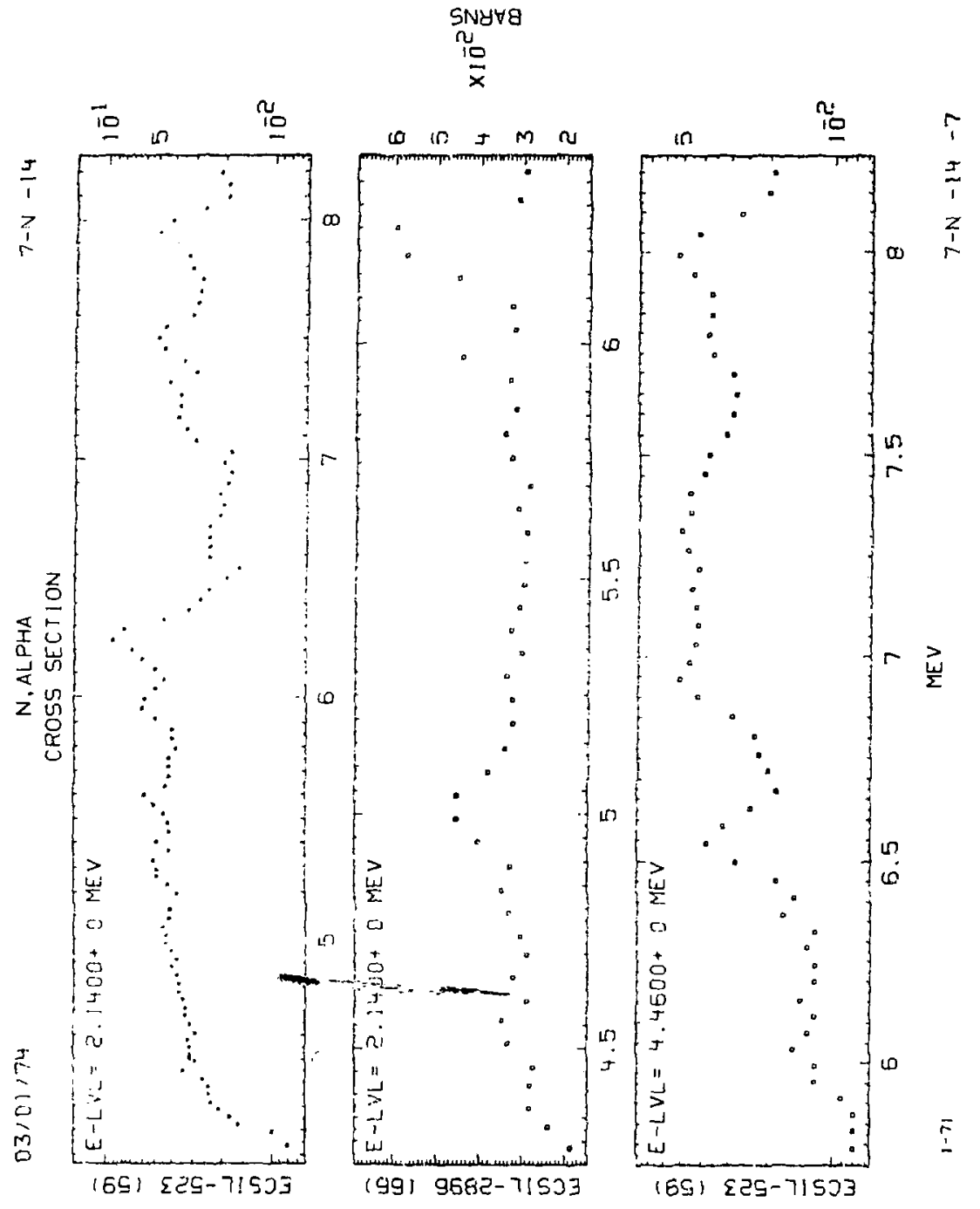



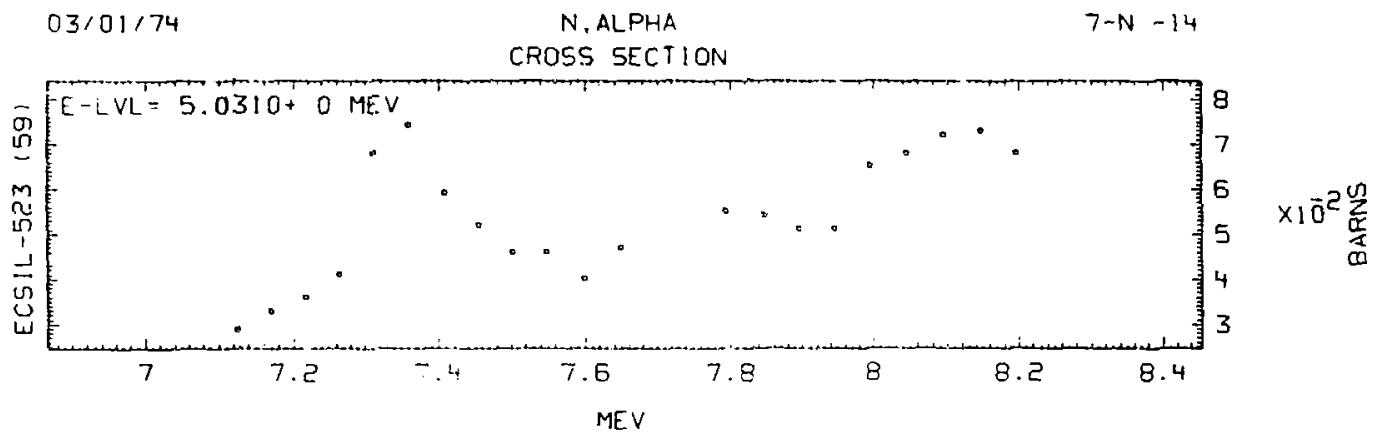

03/01/74

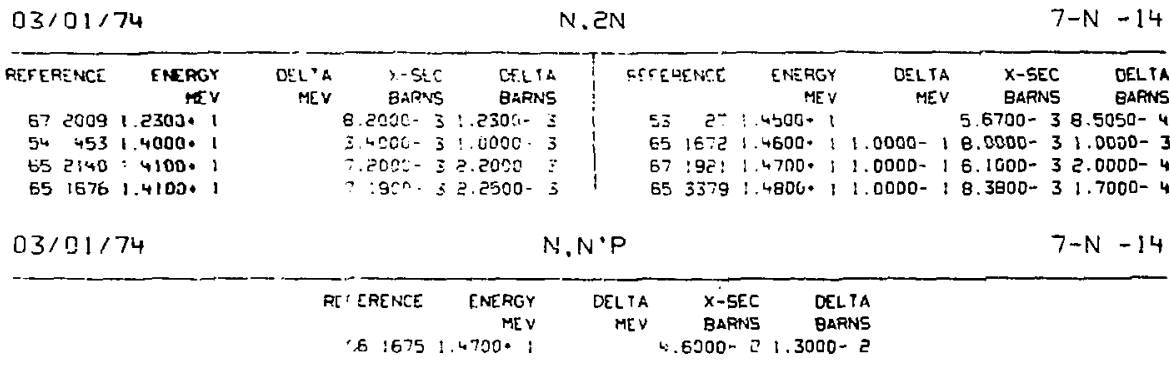




\section{CROSS SECTION}

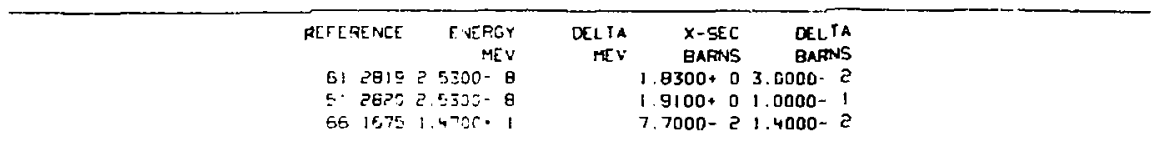

03/2!:74

$67.5+3$ i.5.00-: $5.5000-1$ 8.0000- $45.0000-1,9.6300 \cdot 0$

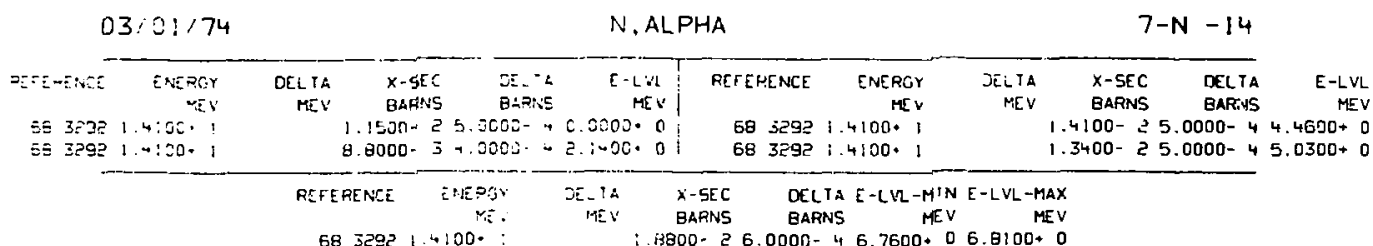

$683292+100$ : : $\quad:$ B $3800-26.0000-46.7600+06.9100+0$

$03 / 5 ; 774$

N. 2 ALPHA

$7-N-14$

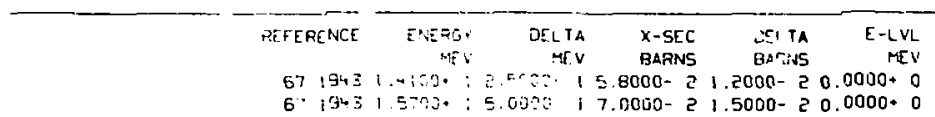

$03: 01: 74$

N.P

$7-N-15$

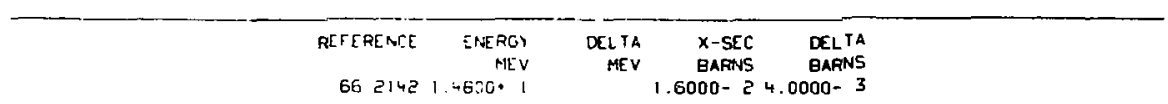



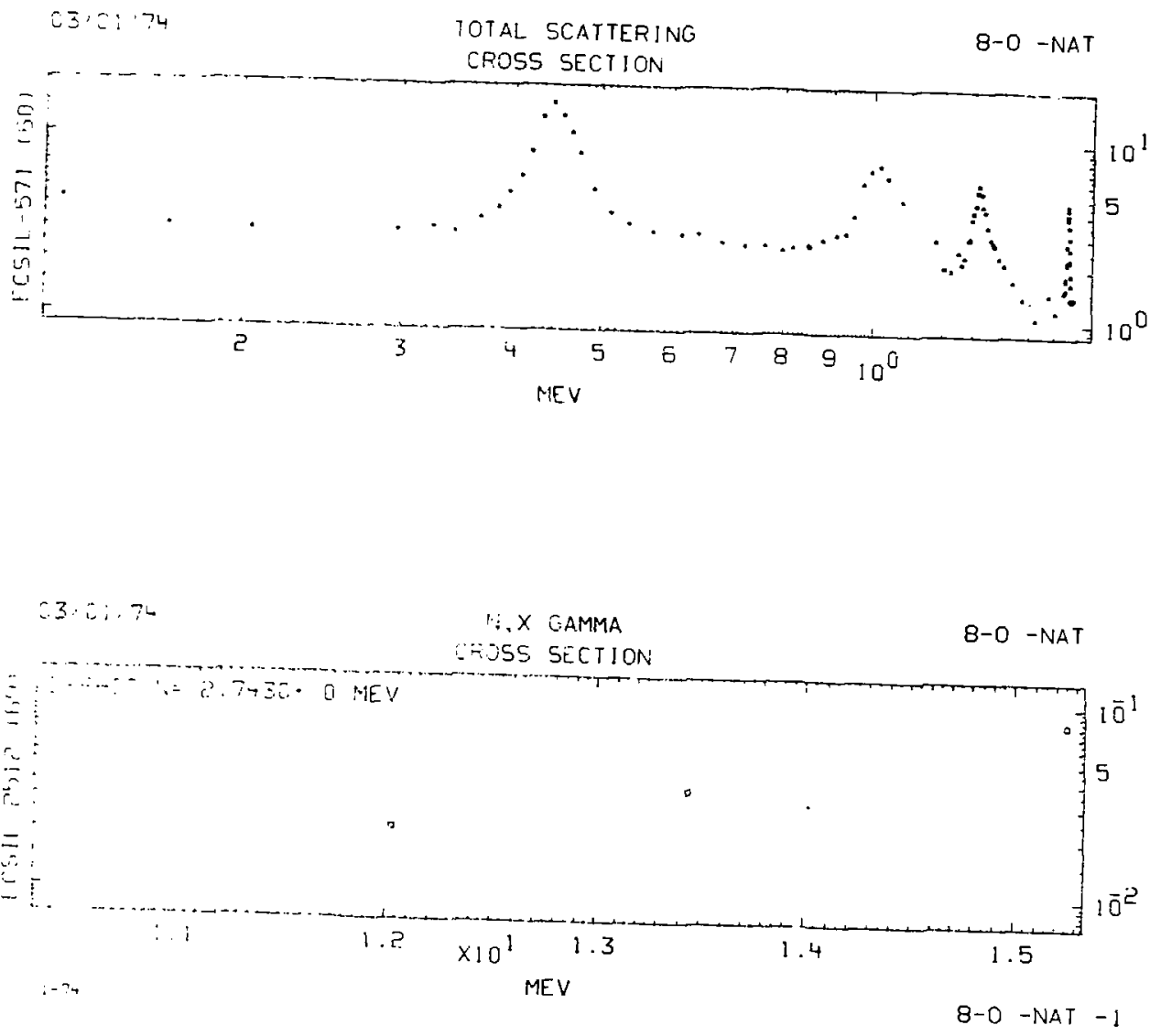


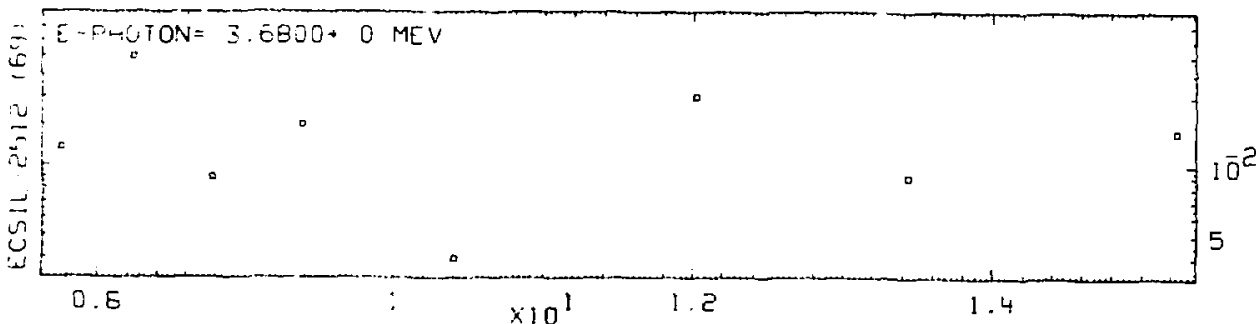

$=$
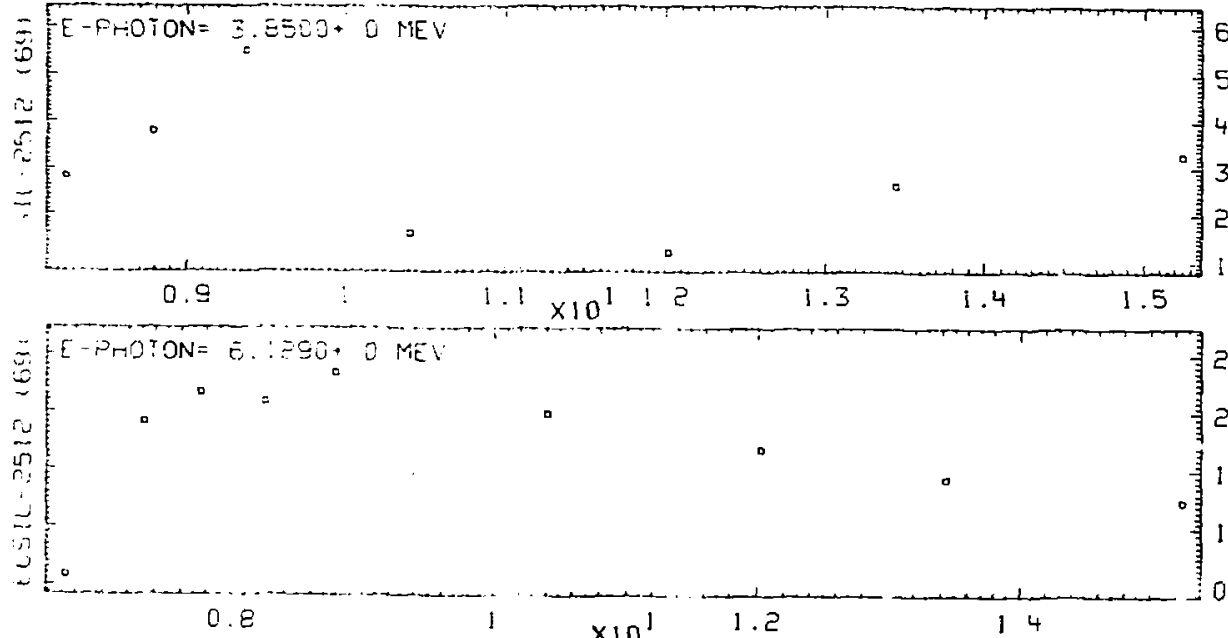

1. 75
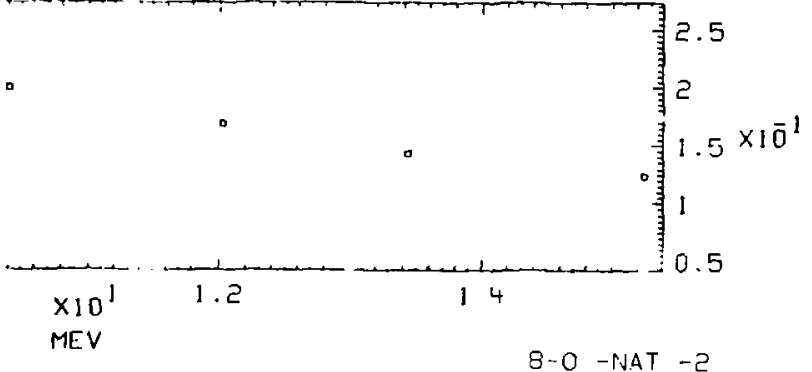


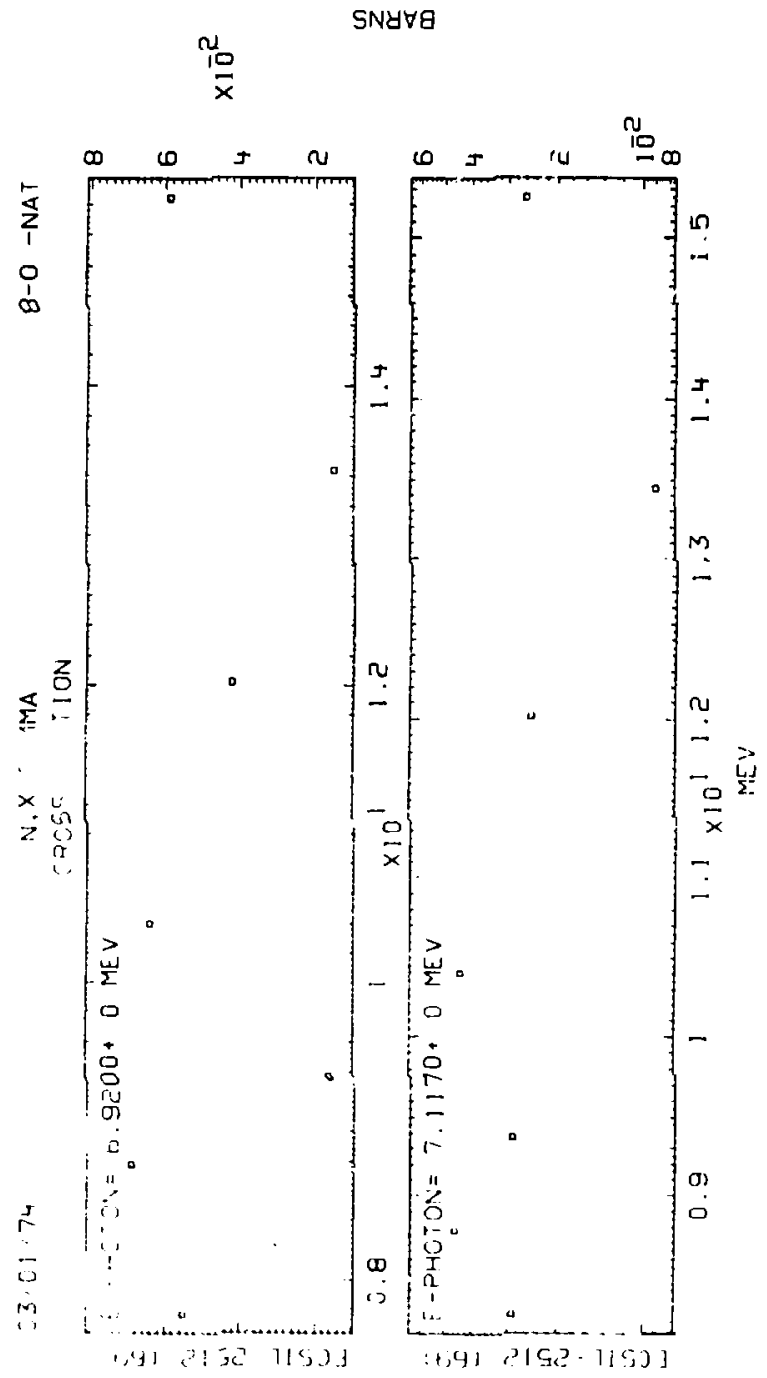

$m$
$\vdots$
1
1
1 

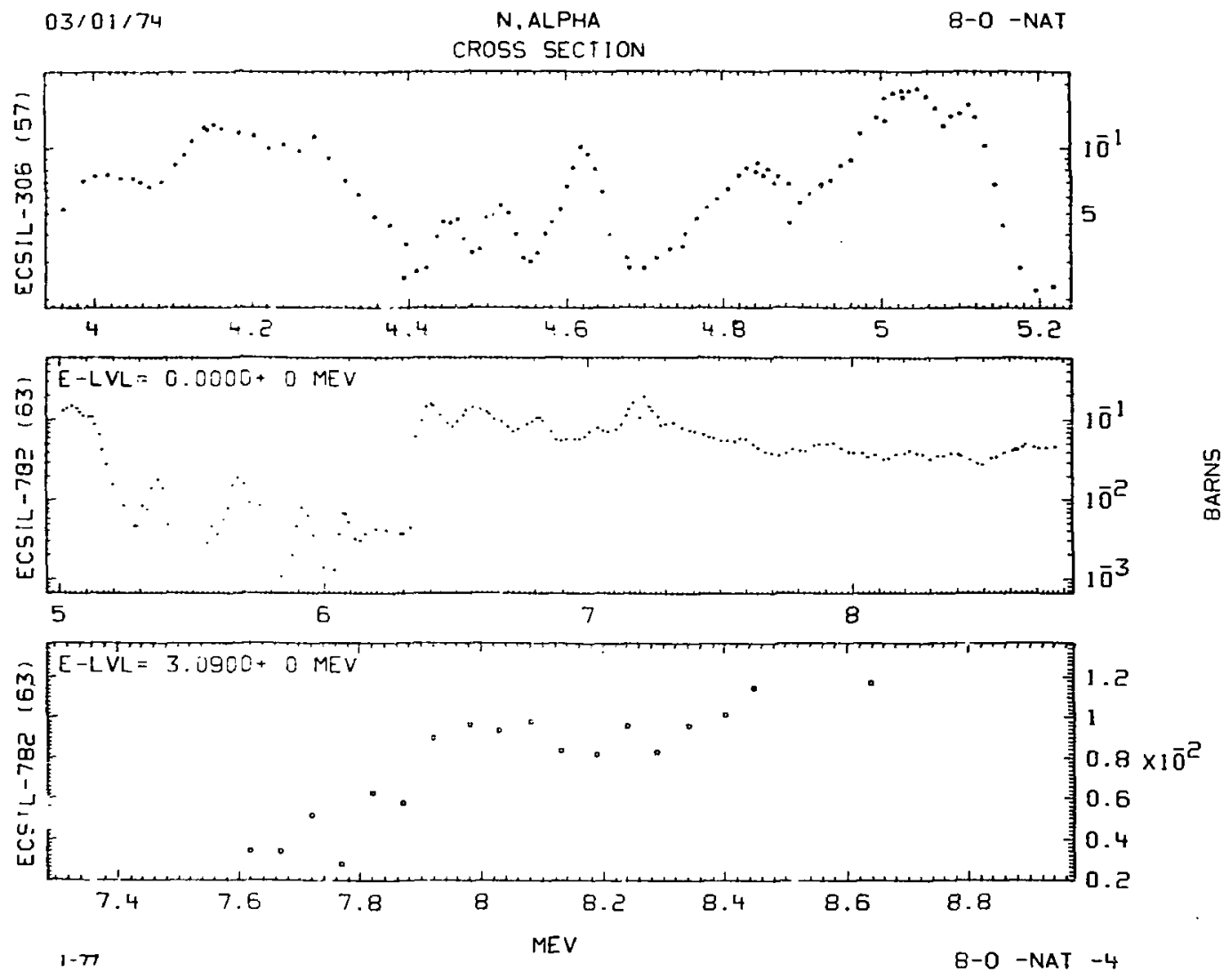


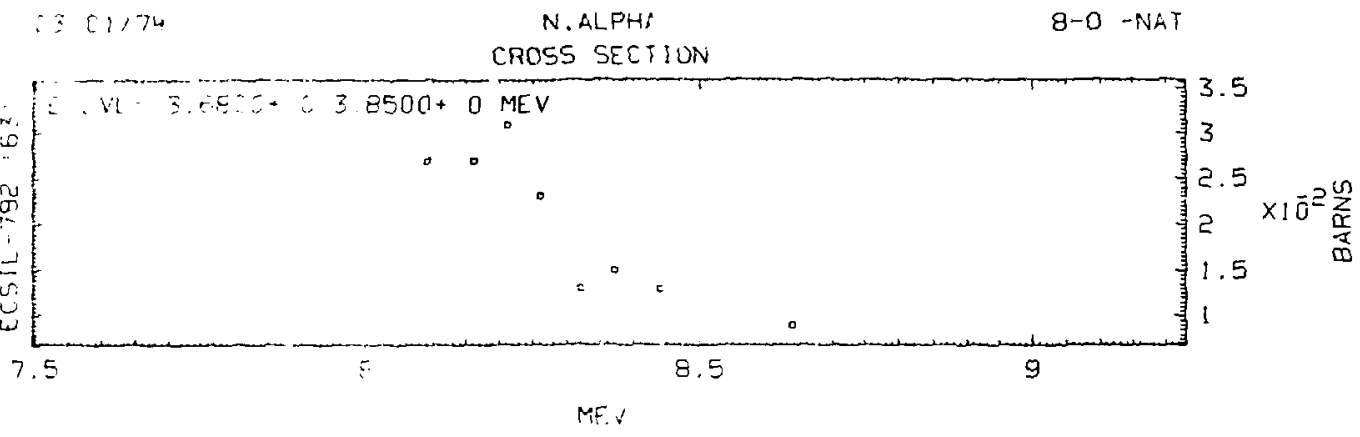

Q3:01,74

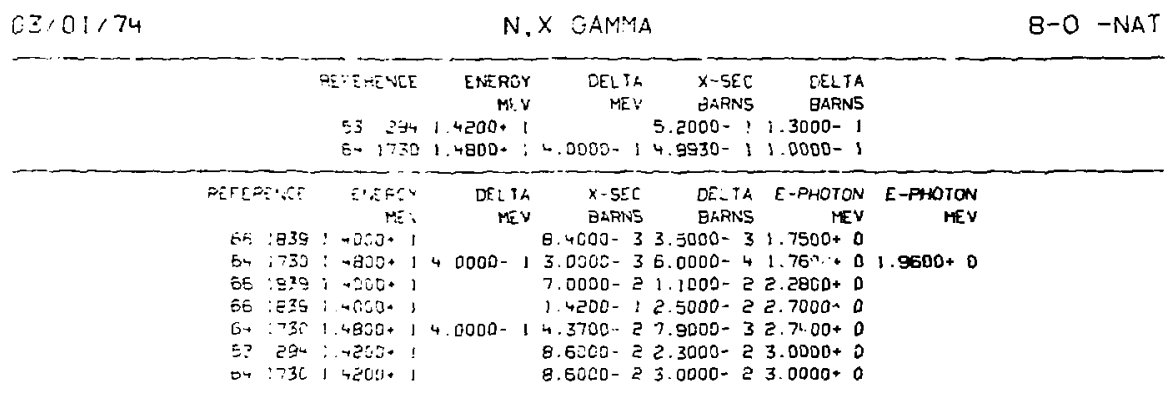




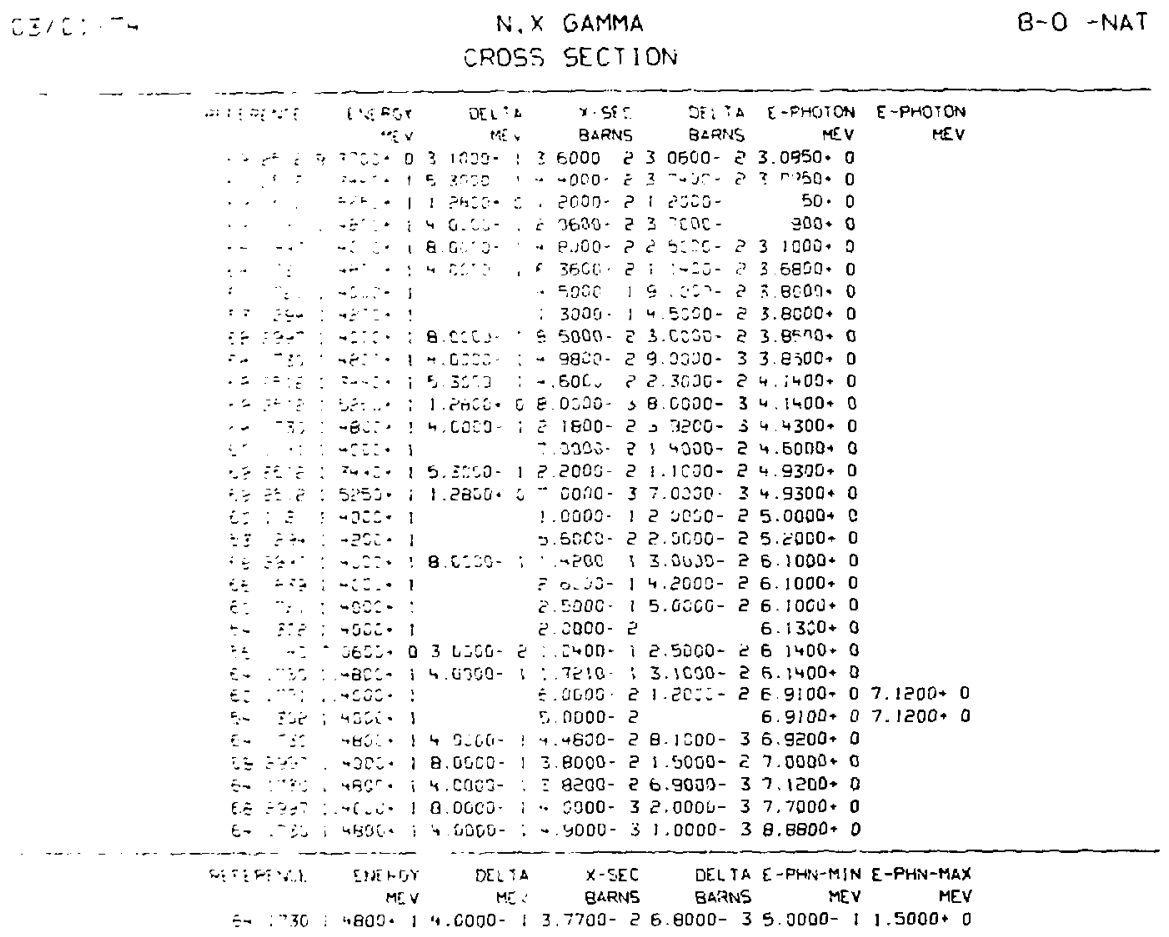




$0310.174 \quad$ CROSS SECTION

628014700 : : $5000-13.8200-25.0000-3$

03,01774

$51158473000-8 \quad 42000+[$

0 15:01/74

$4953: 5000-5 \quad 3.7300$ *

\begin{tabular}{|c|c|c|c|c|c|c|}
\hline $03 / 01 / 74$ & & DHEREN & SCATT & $I N G$ & & 8-0 -NAT \\
\hline & $\begin{array}{l}\text { FEFERENCE } \\
64 \text { E๑54 } \\
62: 275 \\
51 \quad 1584\end{array}$ & $\begin{array}{r}\text { ENERGY } \\
\text { MEV } \\
.5300-8 \\
.2000-8 \\
.3500-8\end{array}$ & $\begin{array}{r}\text { DELTA } \\
\text { MEV }\end{array}$ & $\begin{array}{l}X-\text { SEC } \\
\text { BARNS } \\
300+D \\
300+0 \\
000+0\end{array}$ & $\begin{array}{r}\text { DELLTA } \\
\text { BARRSS } \\
.0000-2 \\
3600-1\end{array}$ & \\
\hline
\end{tabular}



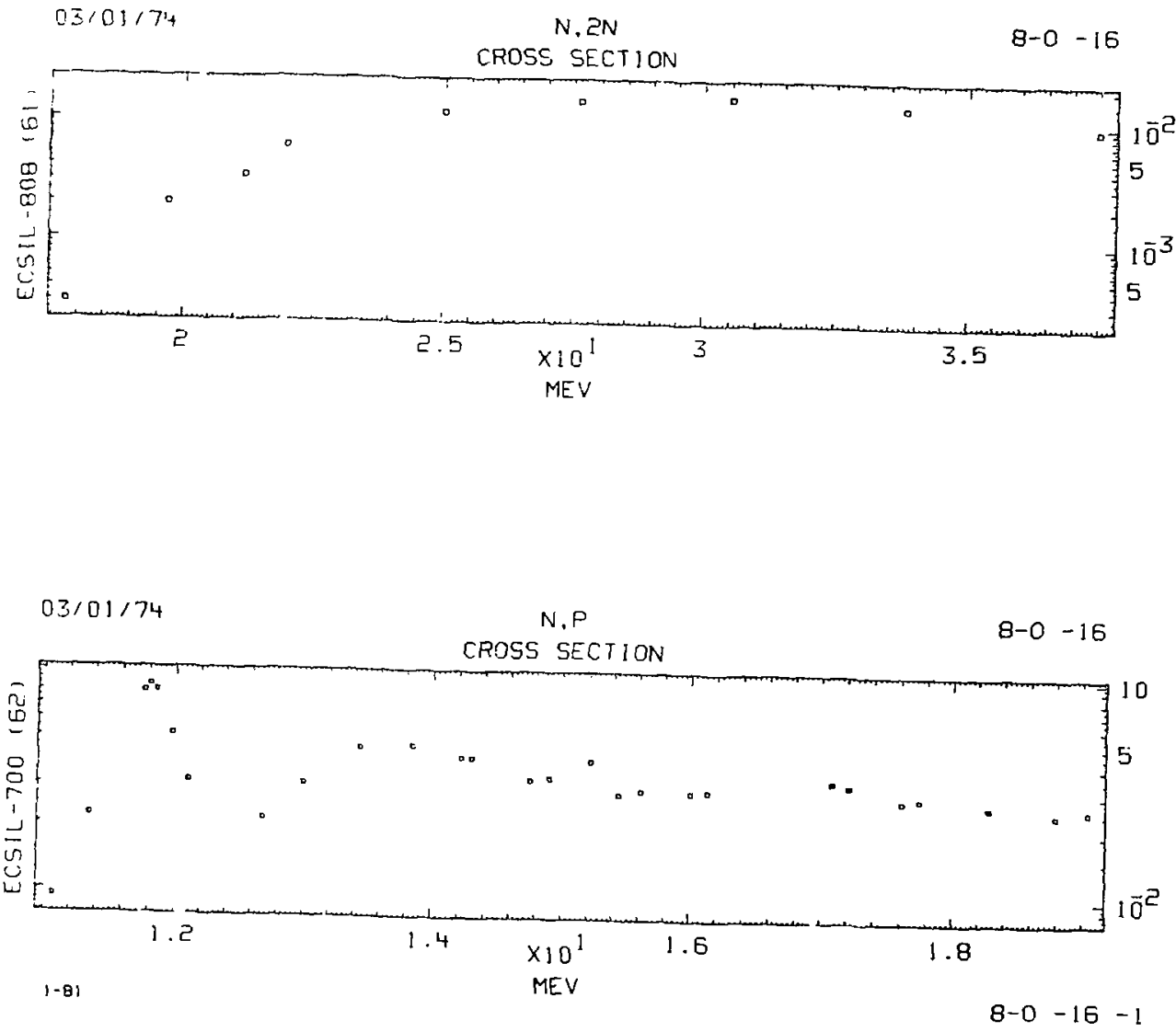


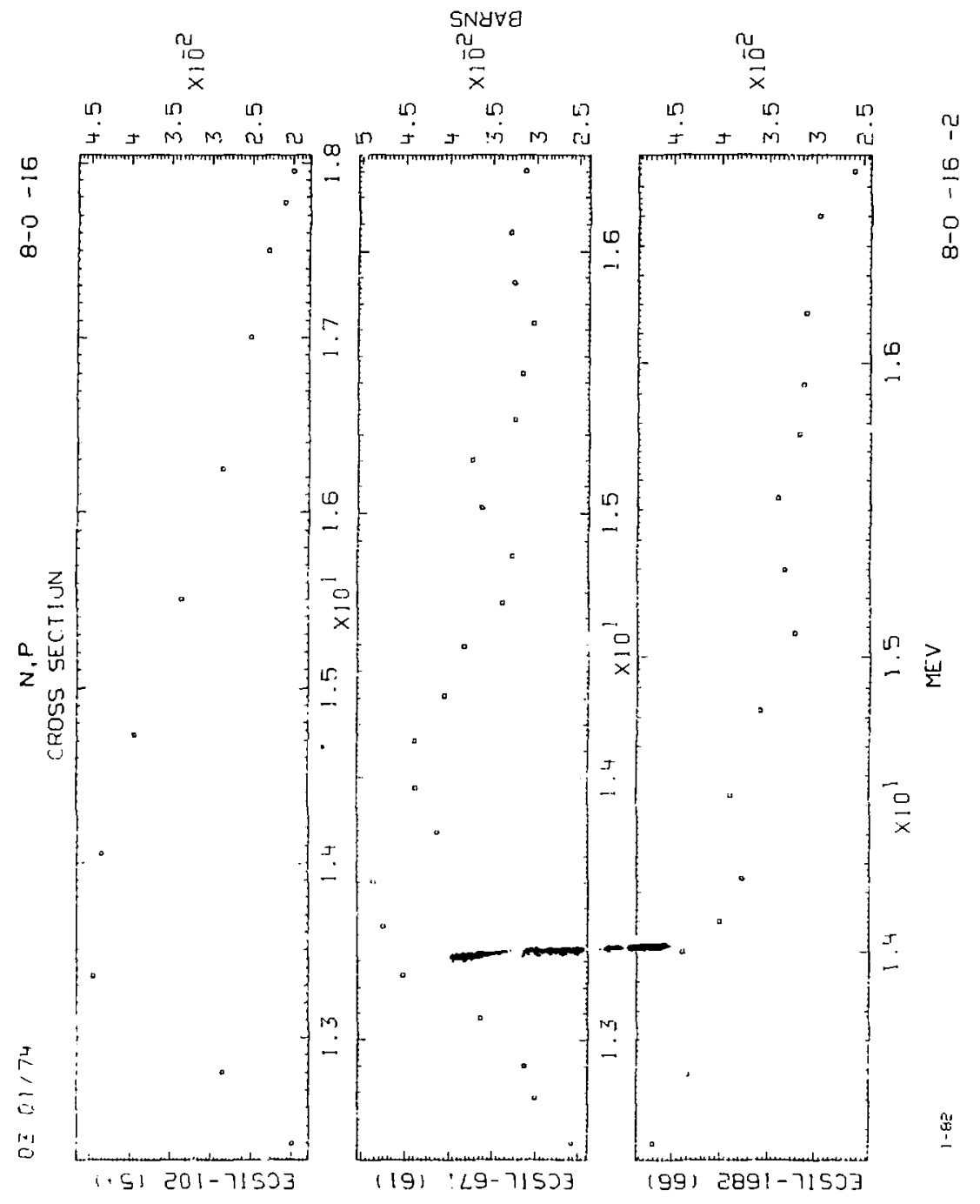




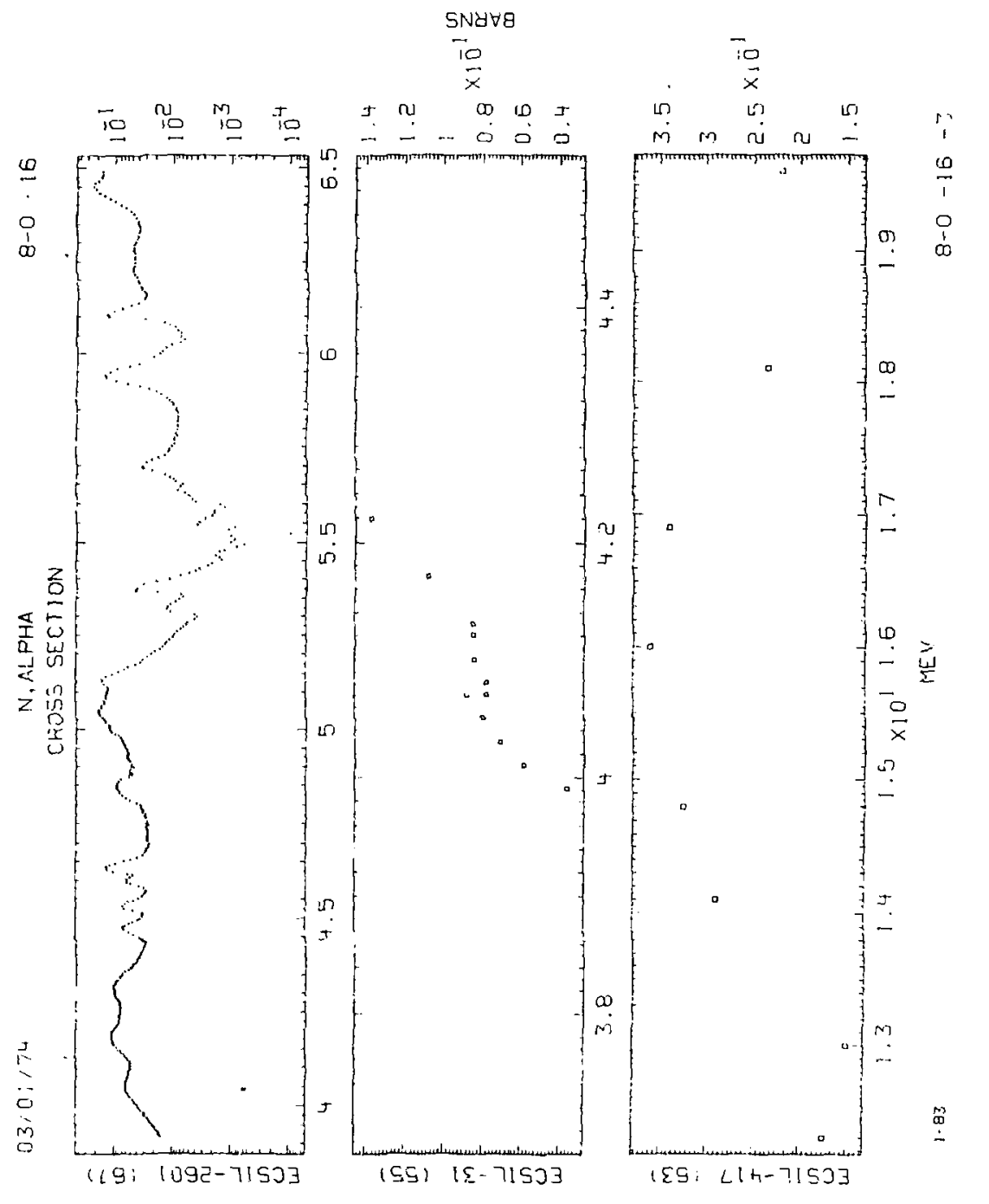


CROSS SECTION

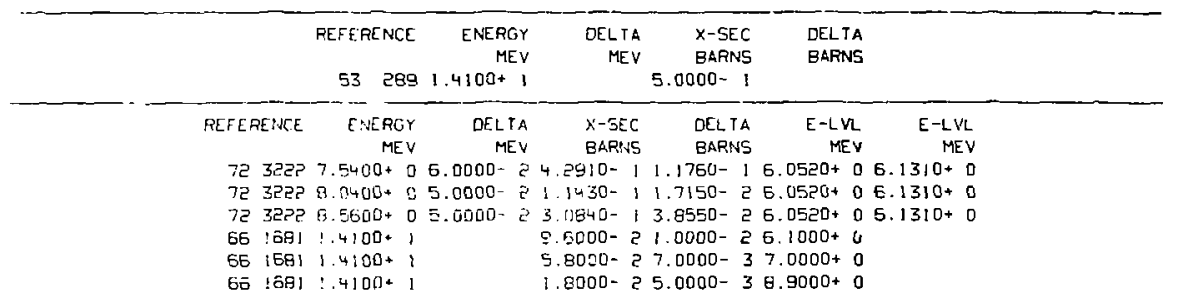

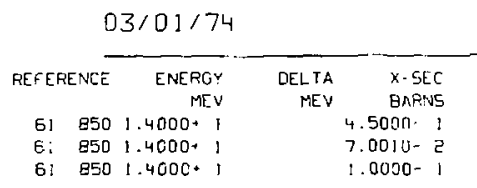

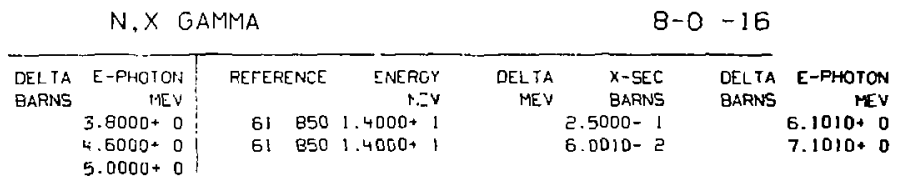

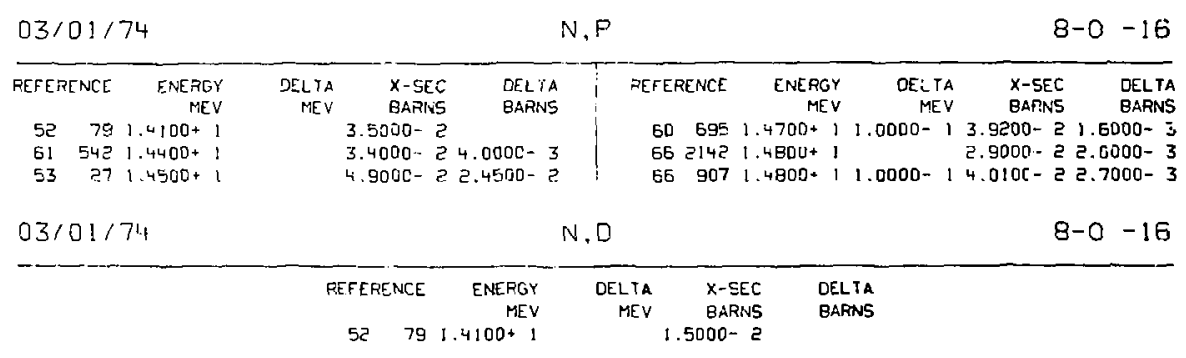




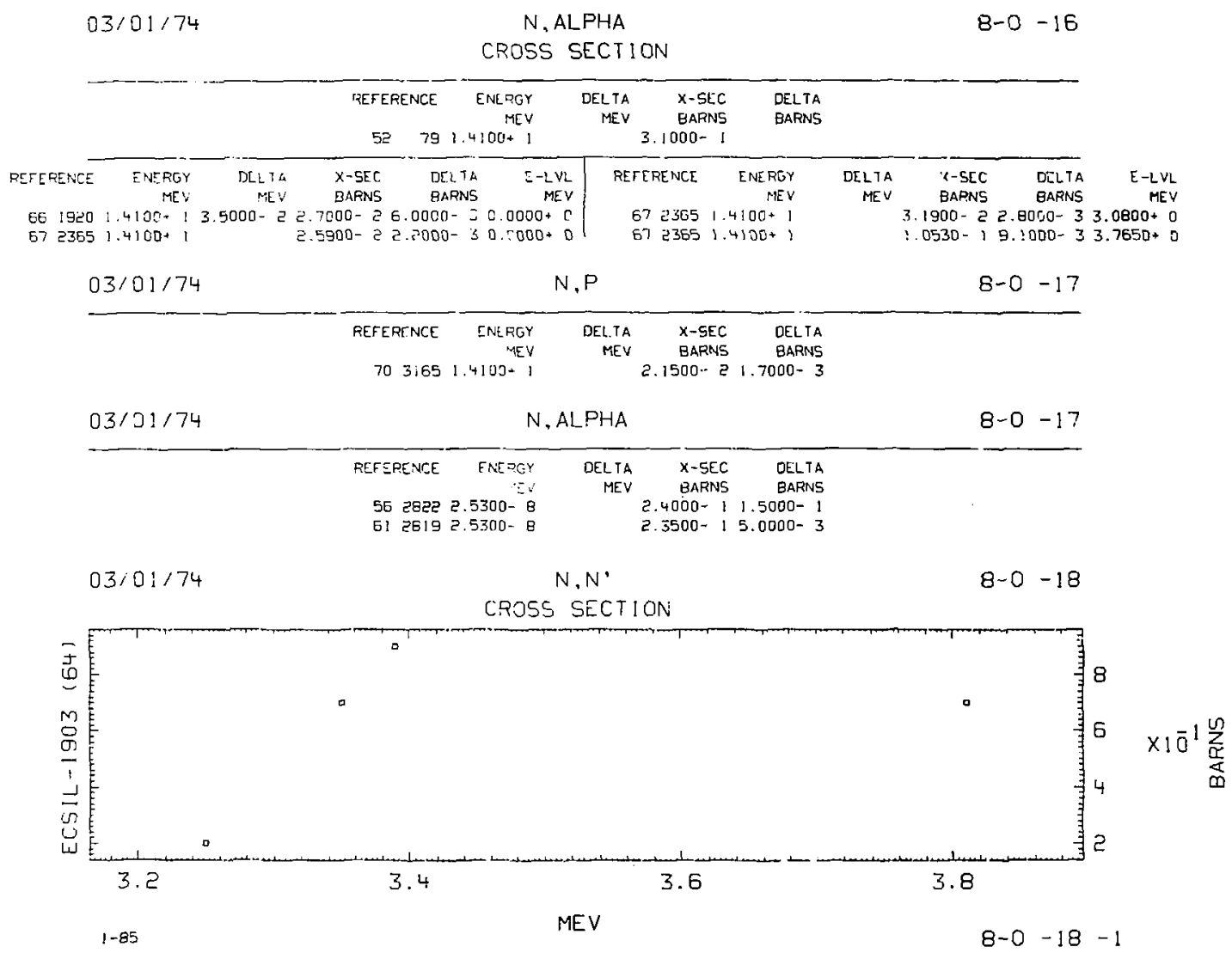




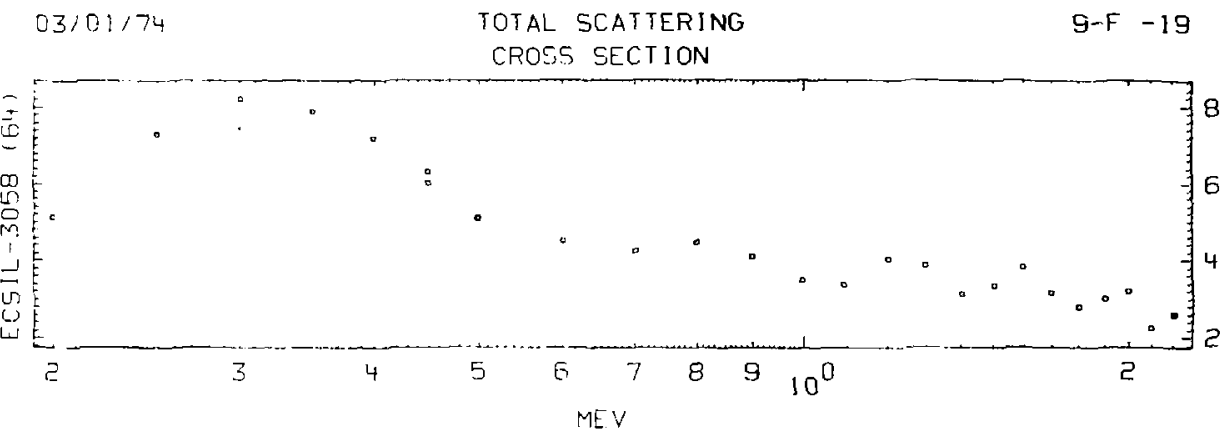

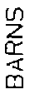

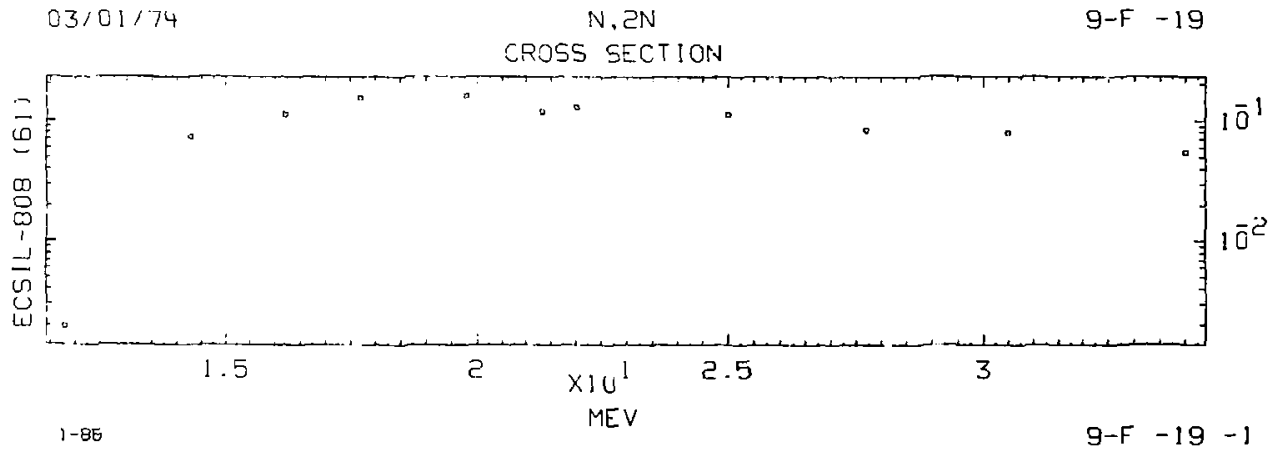

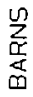




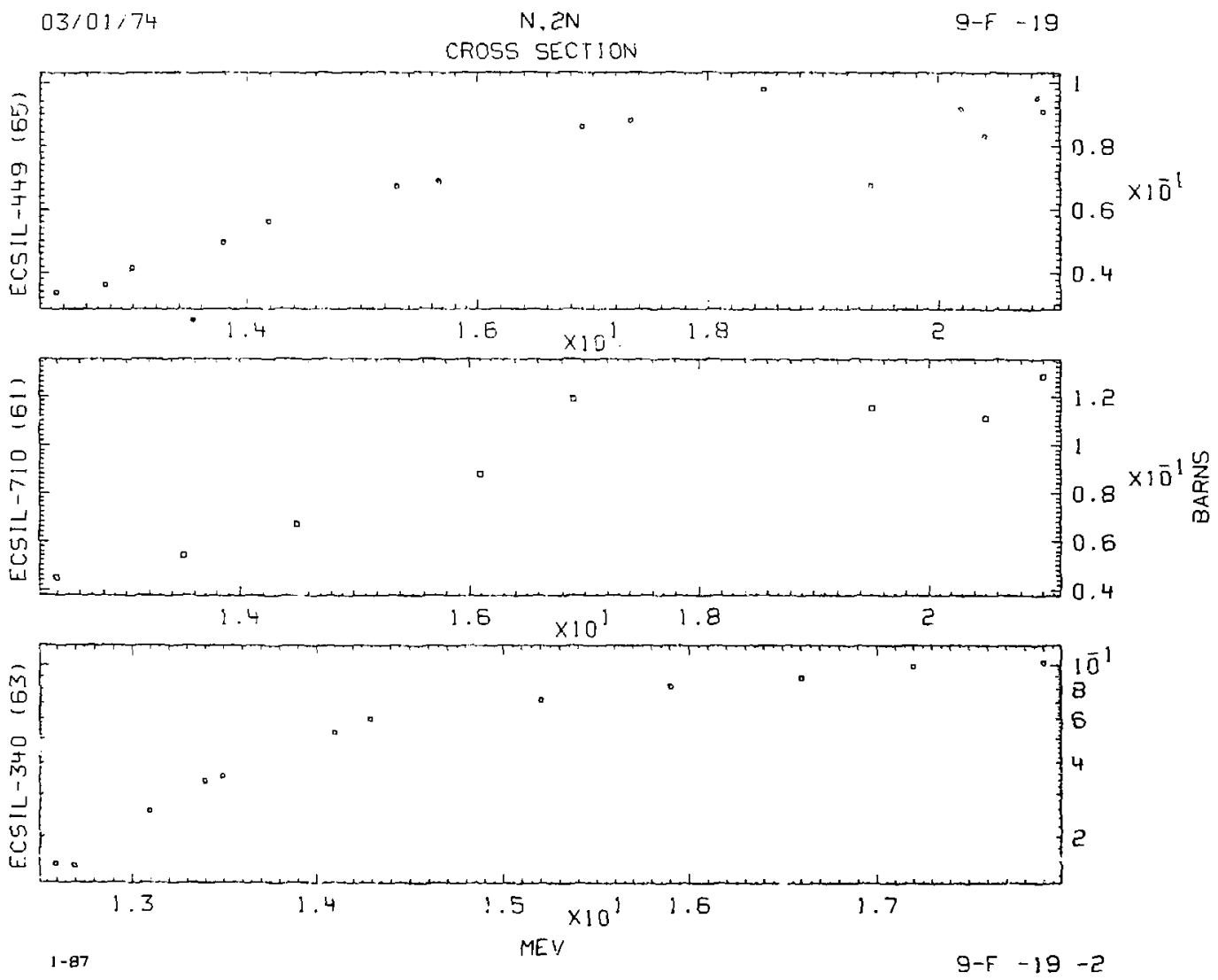


SNkivO

$\frac{10}{x}$

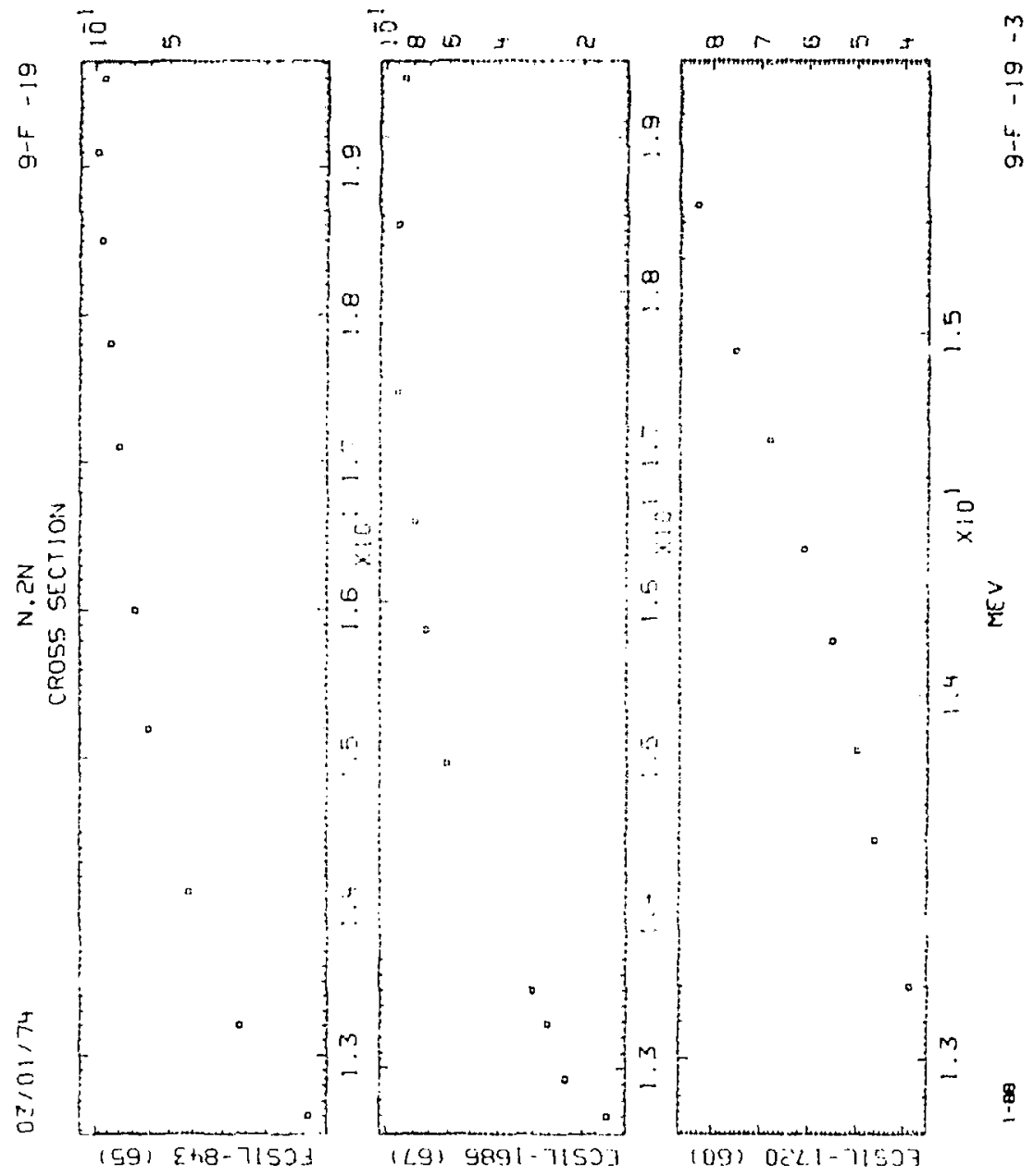




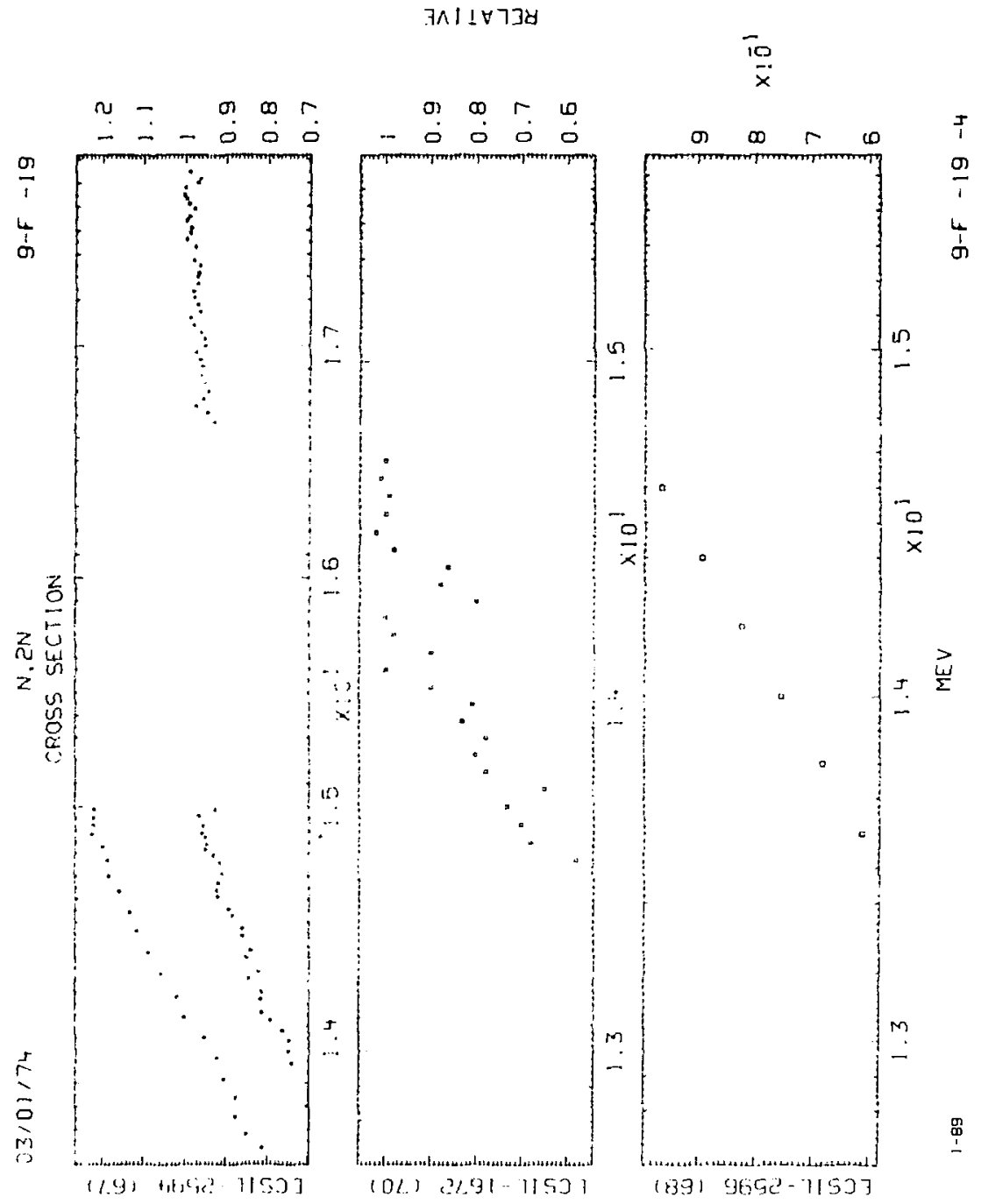



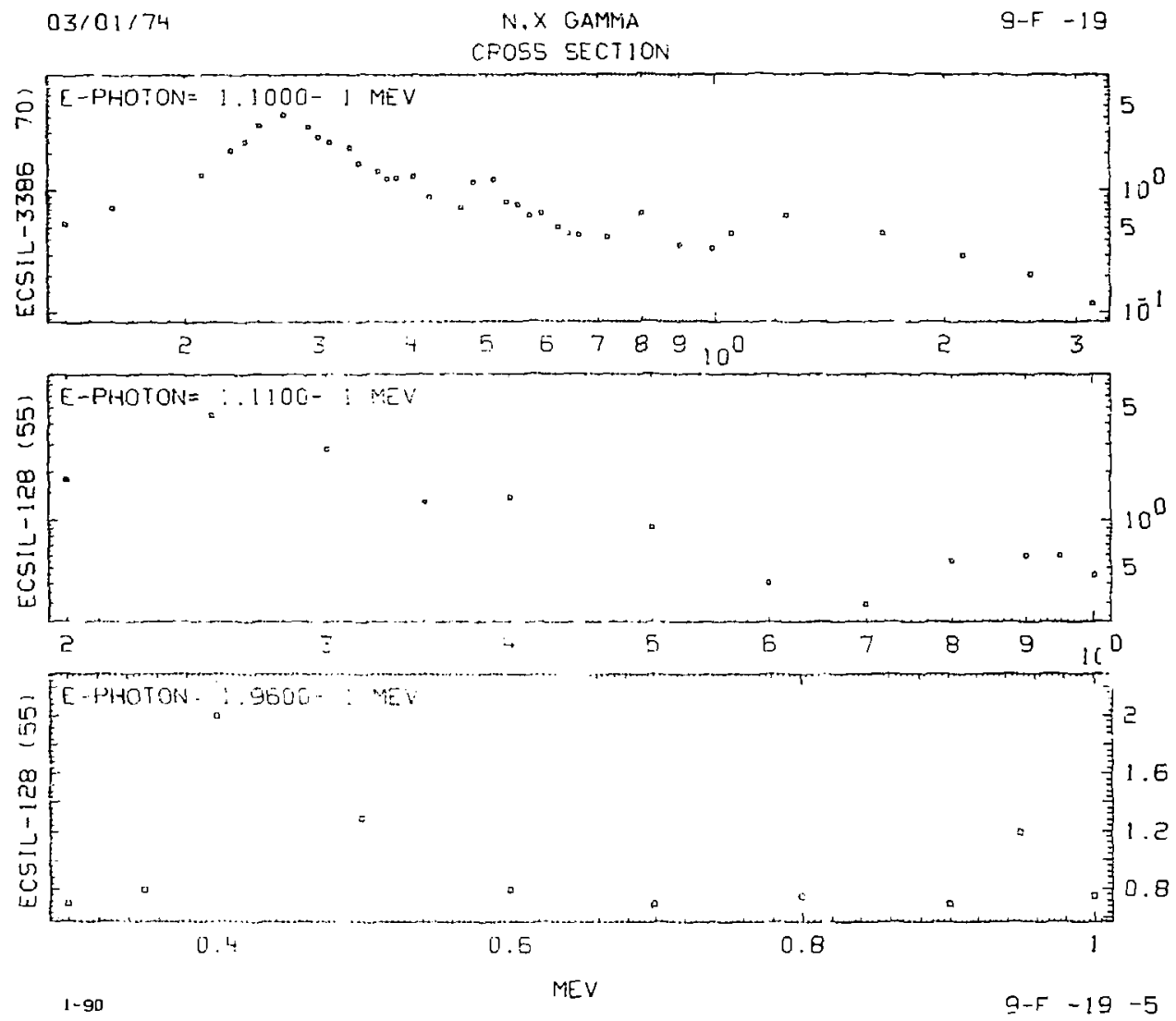


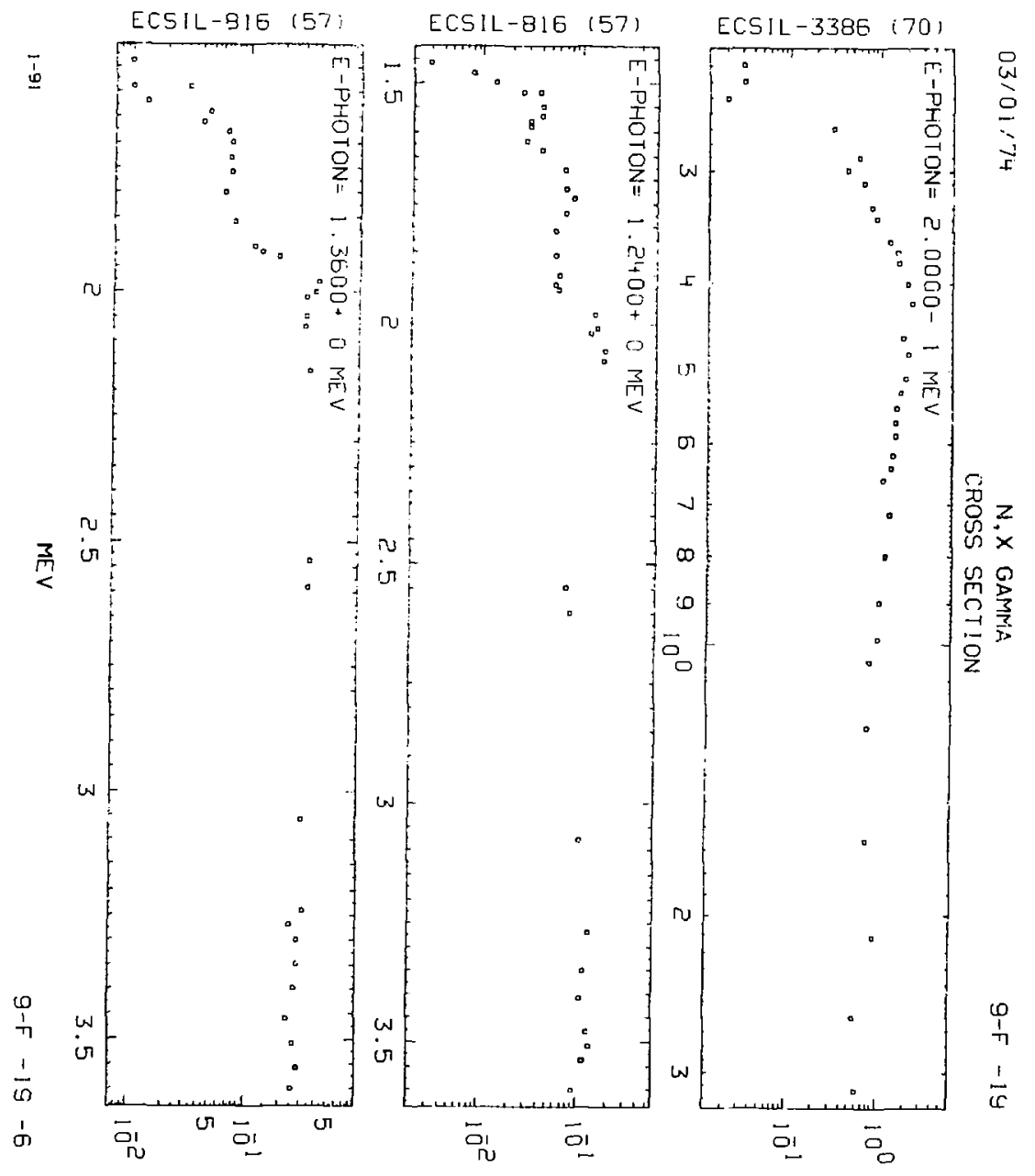

BARNS 

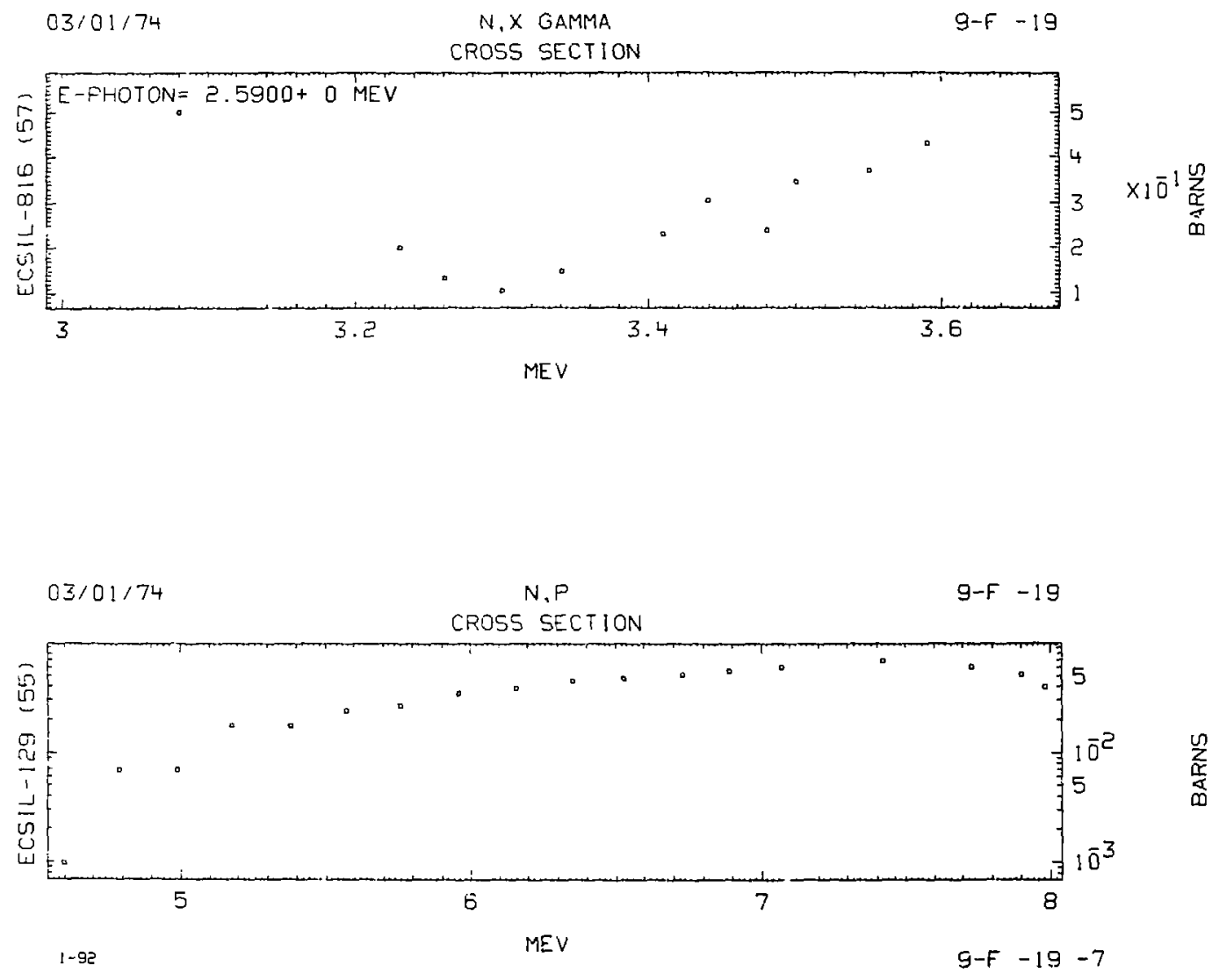

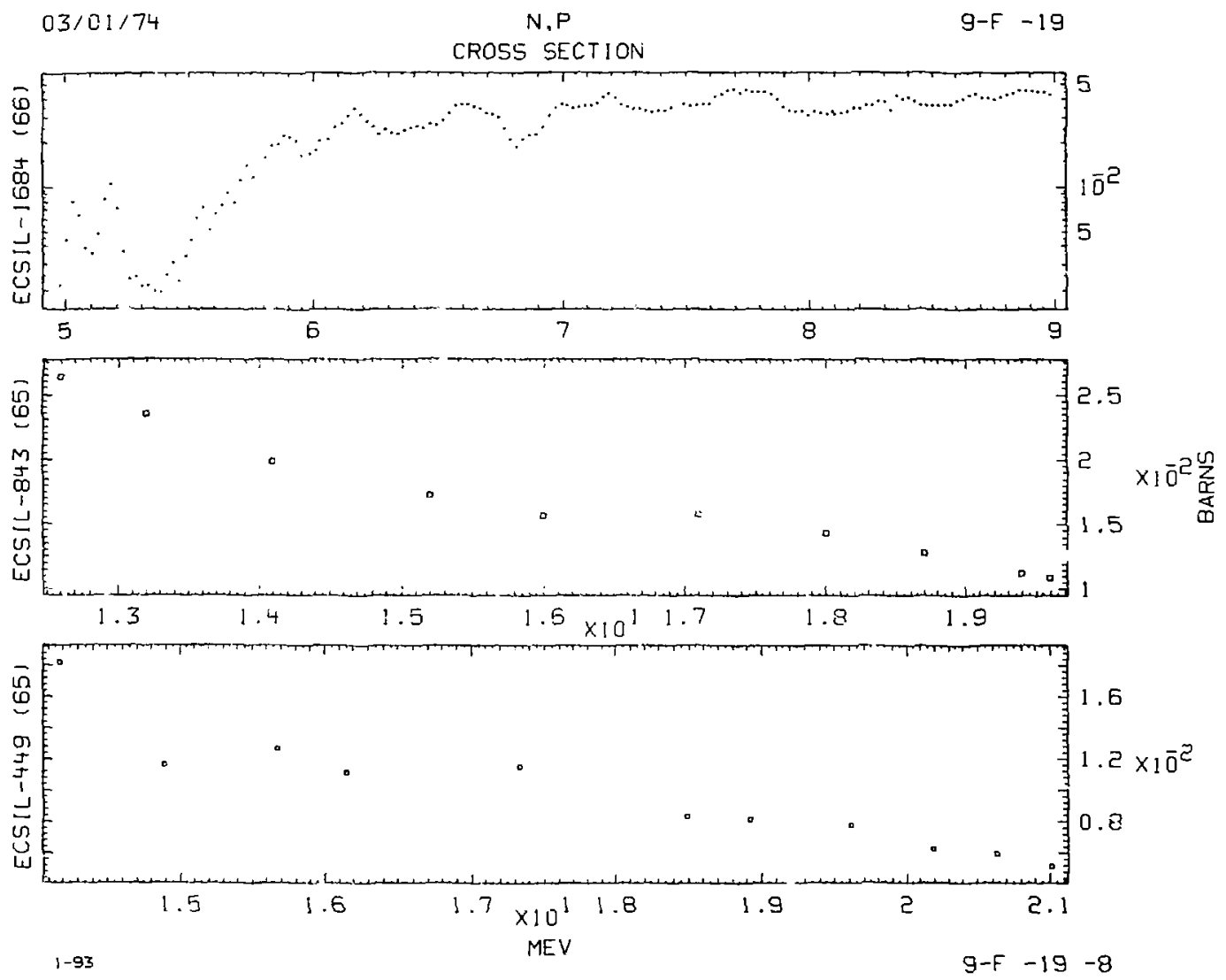
SNY $\forall B$

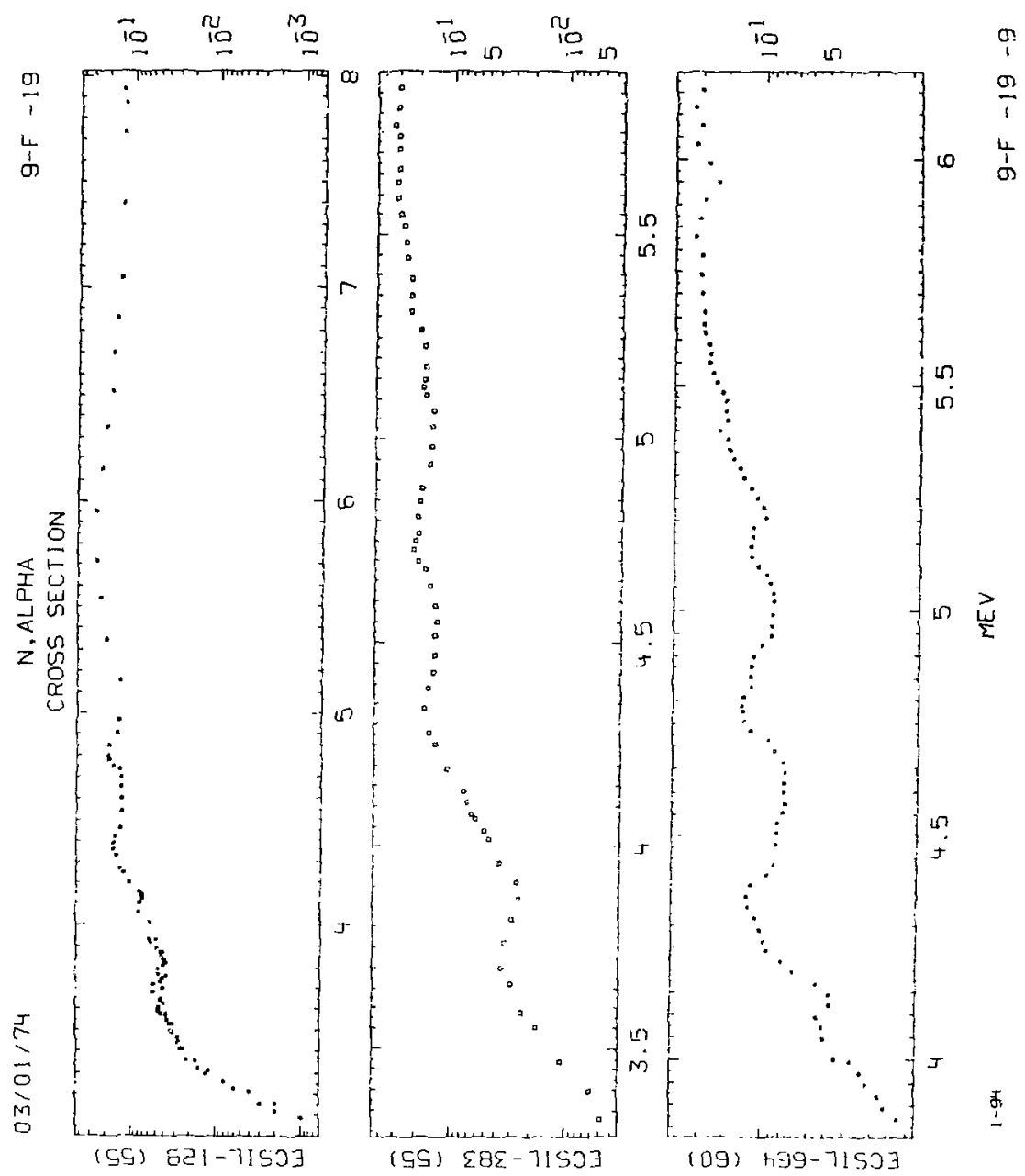




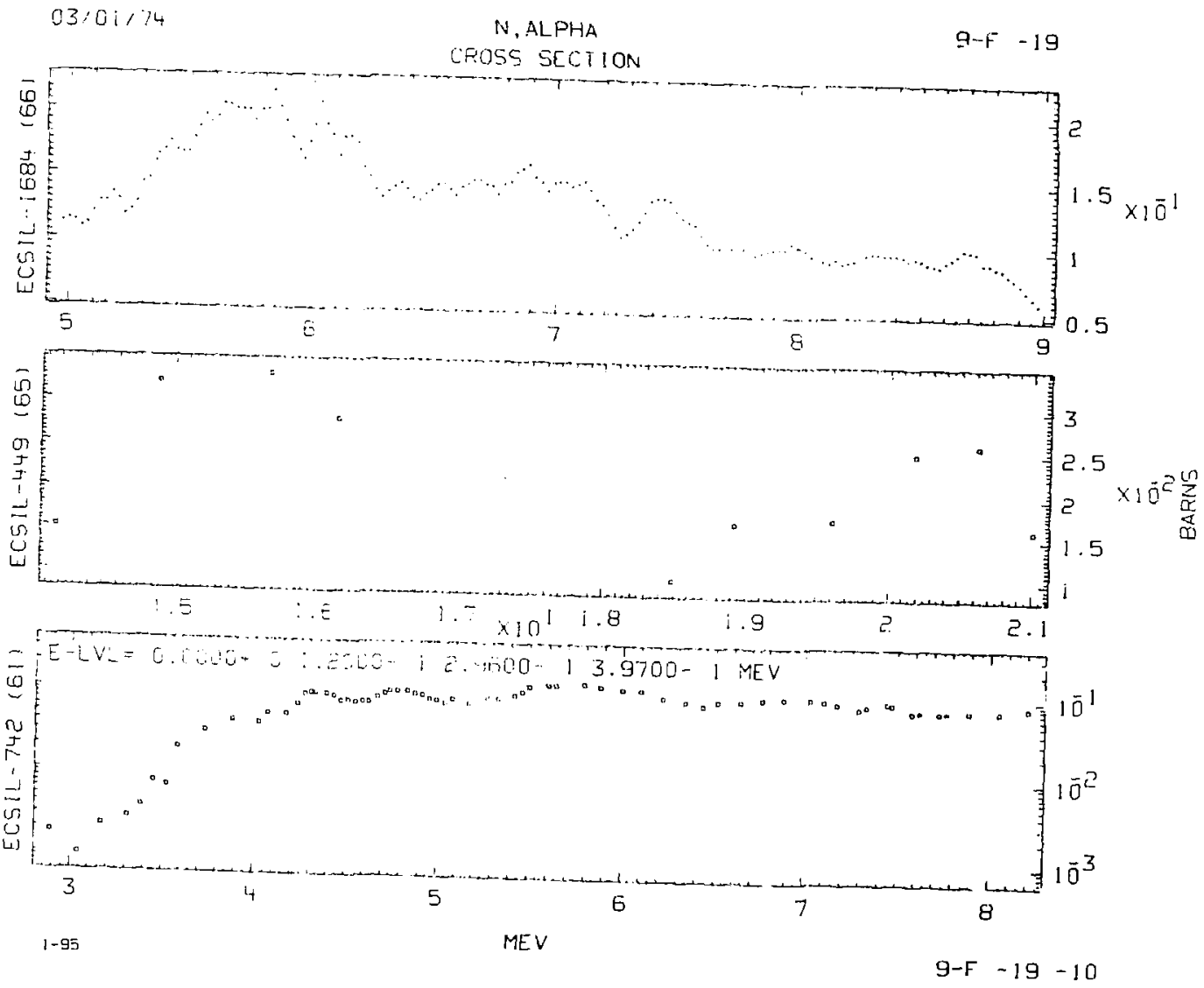




$\begin{array}{ccccc}\text { SEFERTNCE ENERGY } & \text { DFL A } & x-E-C & \text { DELTA } \\ \text { MEV } & \text { MEV } & \text { BARNS } & \text { BAFNS }\end{array}$

$573191.4200+11.5000-18.3010-15.0000-2$

$03 / 2: 174$

$$
N, N^{*}
$$$$
9-F-19
$$

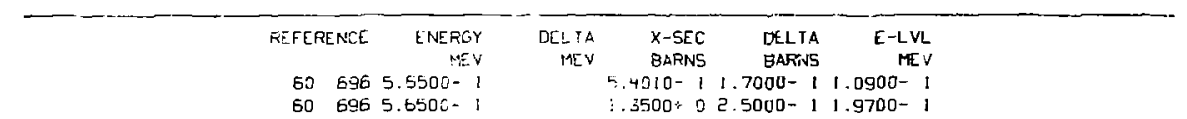

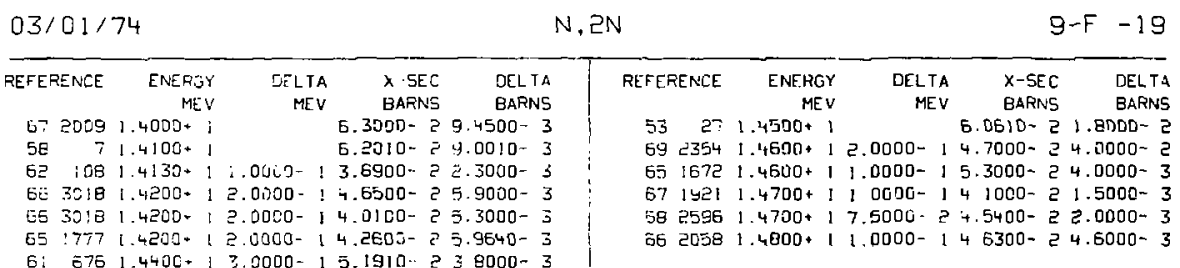
$03 / 01 / 74$
$N, X$ GAMMA
$9-F-19$

\begin{tabular}{|c|c|c|c|c|c|c|}
\hline \multicolumn{2}{|c|}{ REFERENCE } & $\begin{array}{l}\text { E:JERGY } \\
\text { MEV }\end{array}$ & $\begin{array}{r}D E \text { E i i } \\
\text { MEV }\end{array}$ & $\begin{array}{l}X-5 E C \\
\text { BARNS }\end{array}$ & $\begin{array}{l}\text { DELTAA } \\
\text { BAP'IS }\end{array}$ & $\begin{array}{l}\text { E-PHOTONS } \\
\text { MEV }\end{array}$ \\
\hline 56 & 1402 & $2.5600+0$ & $3.0000-2$ & $1.9300-1$ & 3.8000? & $1.1100-1$ \\
\hline 56 & 1402 & $2.5600 \cdot 0$ & $3.0050-\bar{c}$ & $5.3700-1$ & 7. $20=0-2$ & 1.9700 \\
\hline 55 & 140 & $2.5600+0$ & 3.0000-2 & $5.0000-2$ & $1.2000-?$ & $1.23+0+0$ \\
\hline 56 & 140 & $5600+0$ & $3.0000-2$ & $3.0700-i$ & $3.200 a^{4}-?$ & $1.3580+0$ \\
\hline 52 & 284 & $2.3000 * \mathrm{u}$ & & $5.2800-1$ & !.EOOO 1 & $1.3500+6$ \\
\hline 56 & $140 \geq$ & $2.5650-0$ & $3.0050-2$ & $5.7000-2$ & 1. $6000-2$ & $1.4600+c$ \\
\hline 56 & 1417 & $45 c 0+0$ & $3.0000-2$ & E. $1300-2$ & $1.4000-2$ & $1.5500+5$ \\
\hline
\end{tabular}

\begin{tabular}{|c|c|c|c|c|c|}
\hline F.FE & ERGY & & & & $\begin{array}{l}\text {-PHOTON } \\
\text { MEV }\end{array}$ \\
\hline & & 8 & 4 & & $0+0$ \\
\hline & & & & & \\
\hline 997 & 1.4 & $3-1$ & $0-2$ & & \\
\hline 632997 & $1.4000+1$ & $18.0000-1$ & 2.2000- & 1.0 & $0+0$ \\
\hline 682997 & $1.4000+i$ & $8.0000-1$ & $2.5000-2$ & $1.0000-2$ & $00+0$ \\
\hline 69 ¿597 & $1.4000+1$ & 1 B. $0000-1$ & $4.0000-3$ & $3.0000-3$ & $37.7000+0$ \\
\hline
\end{tabular}


CROSS SECTION

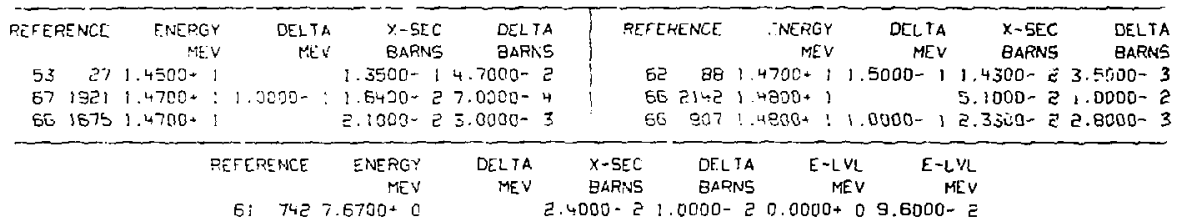

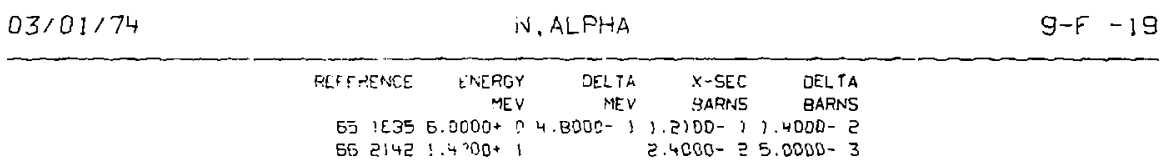

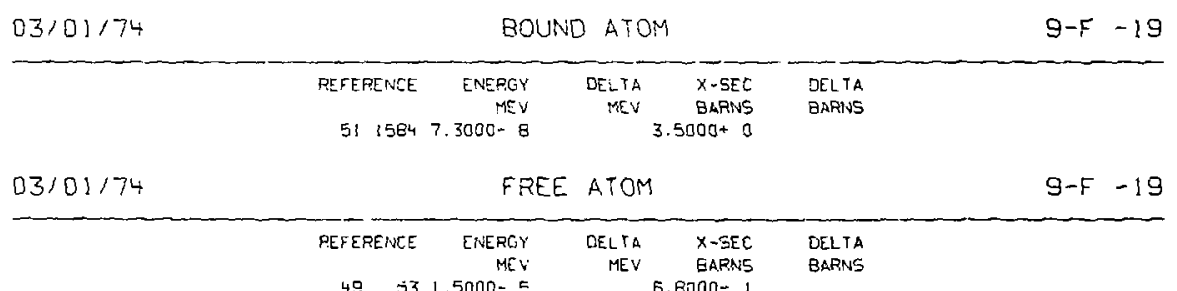

$49531.5000-5 \quad 5.8000-1$

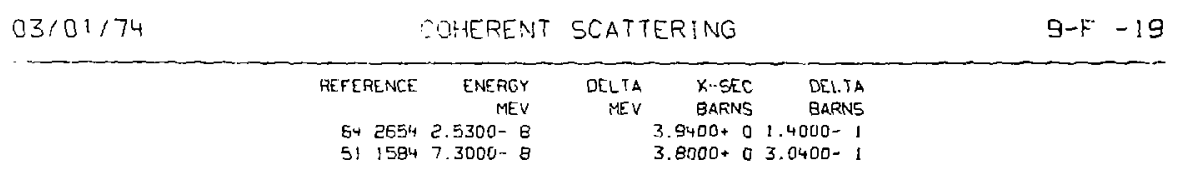




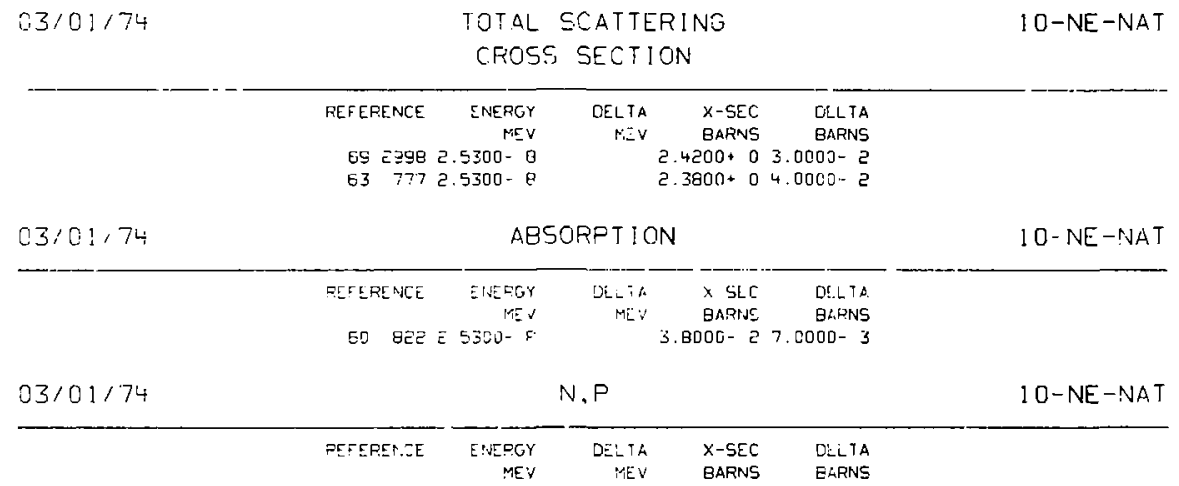

$6616991.4100+11.0000-11.4200-12.8055-2$

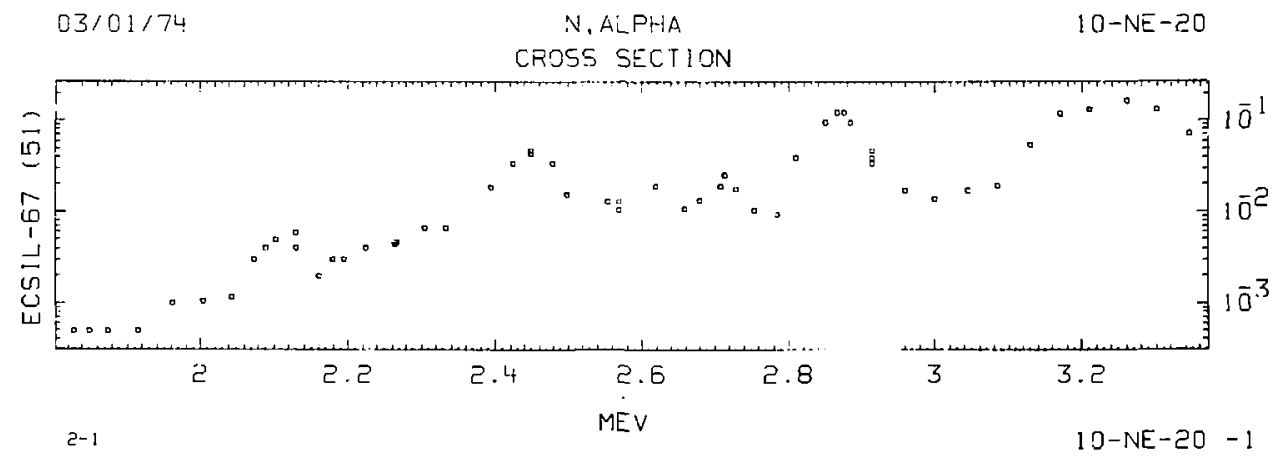



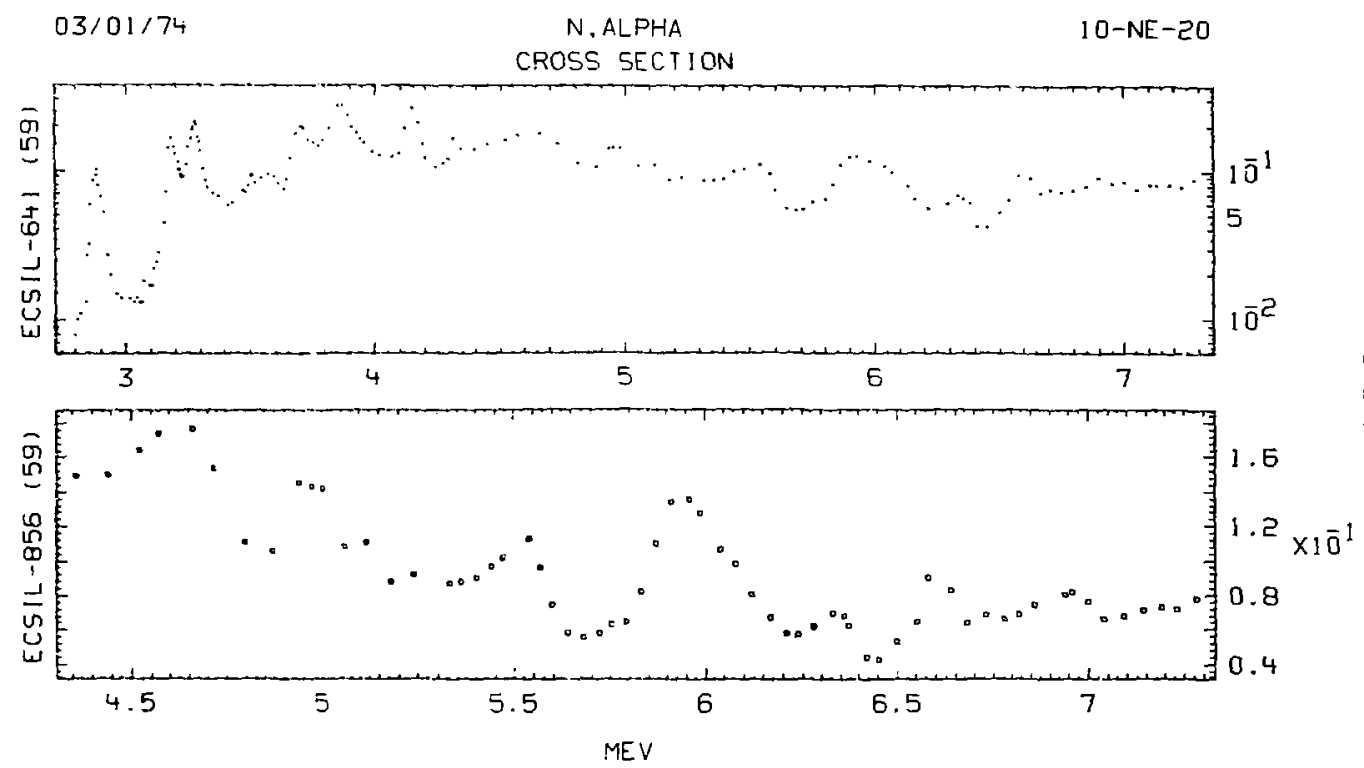

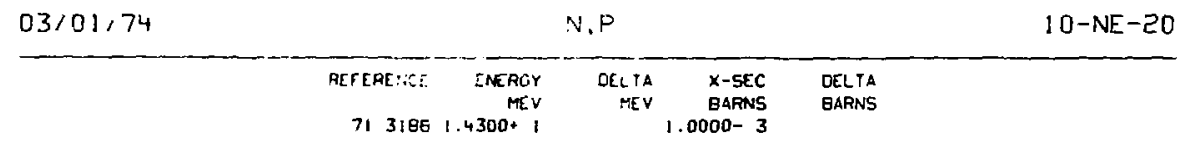




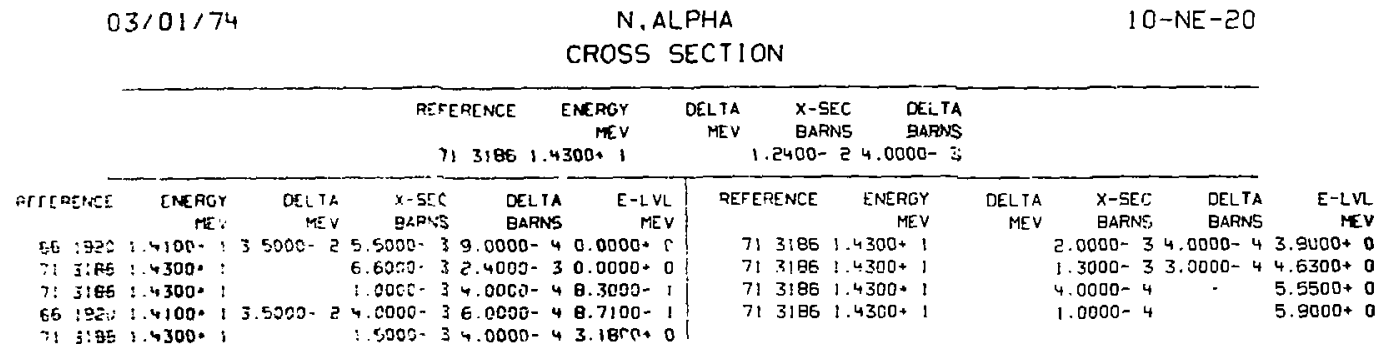

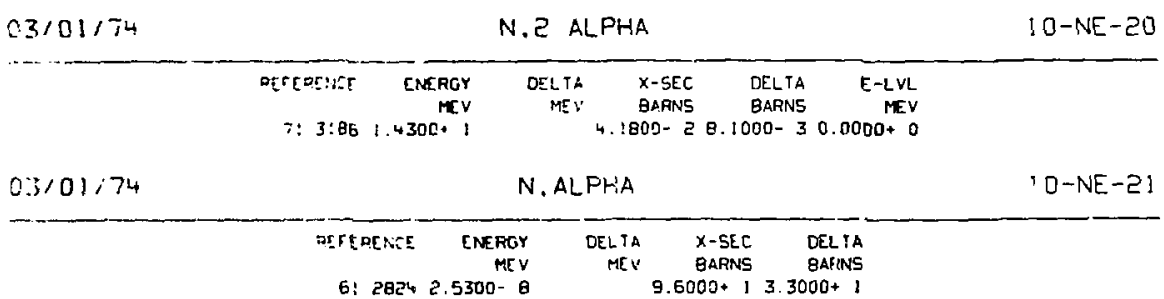



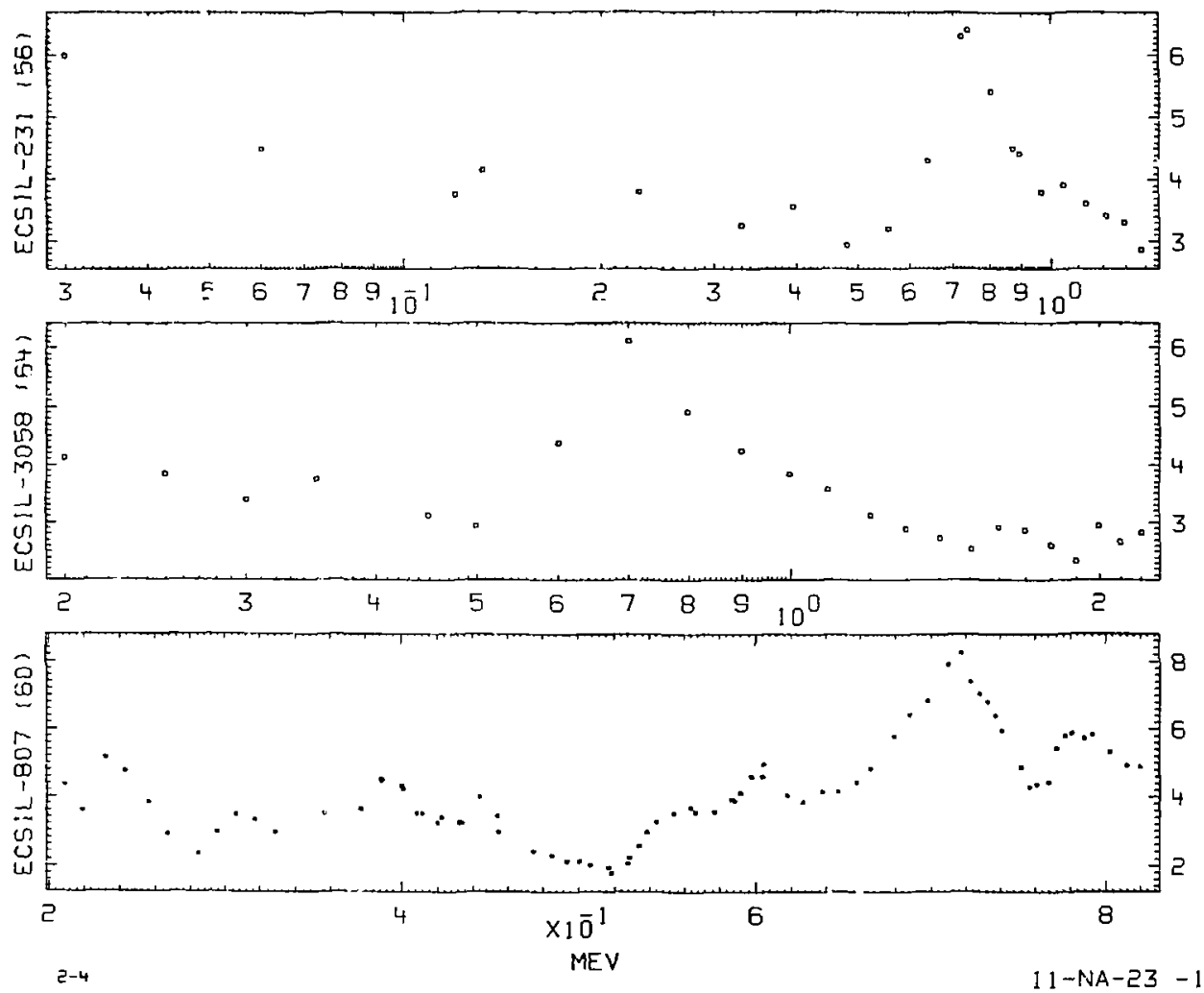


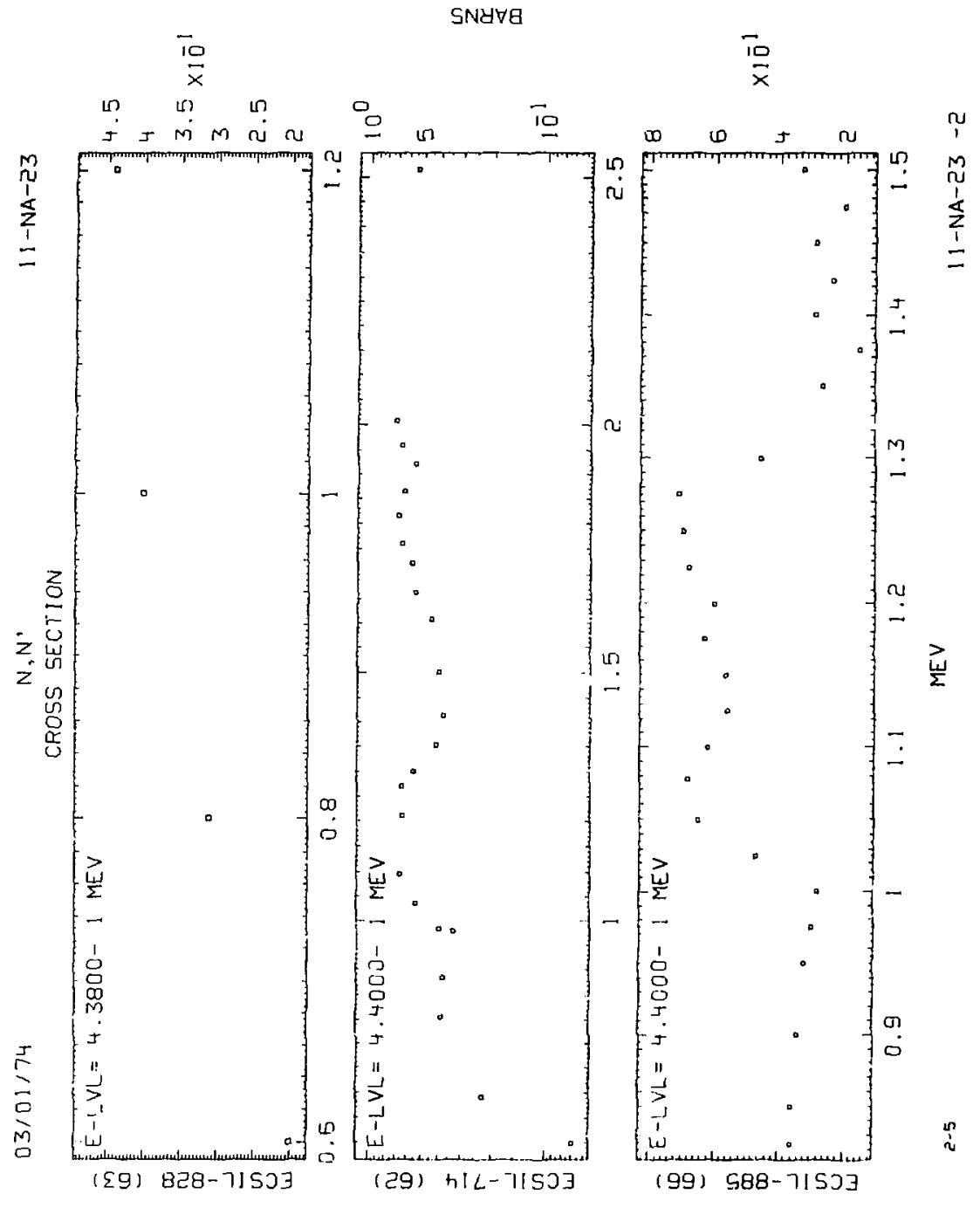


$03 / 0 ! / 74$

\section{CROSS SECTION}
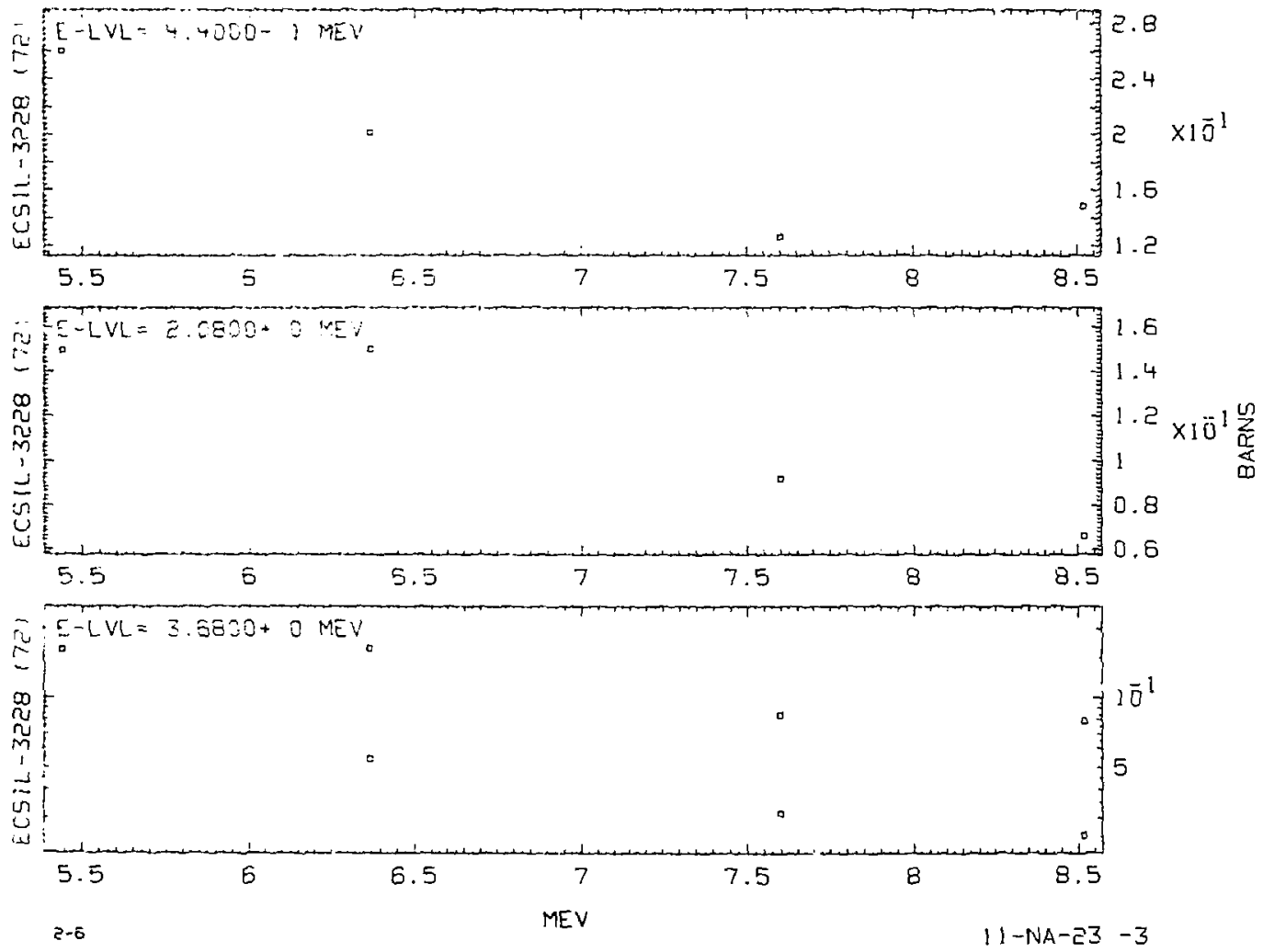


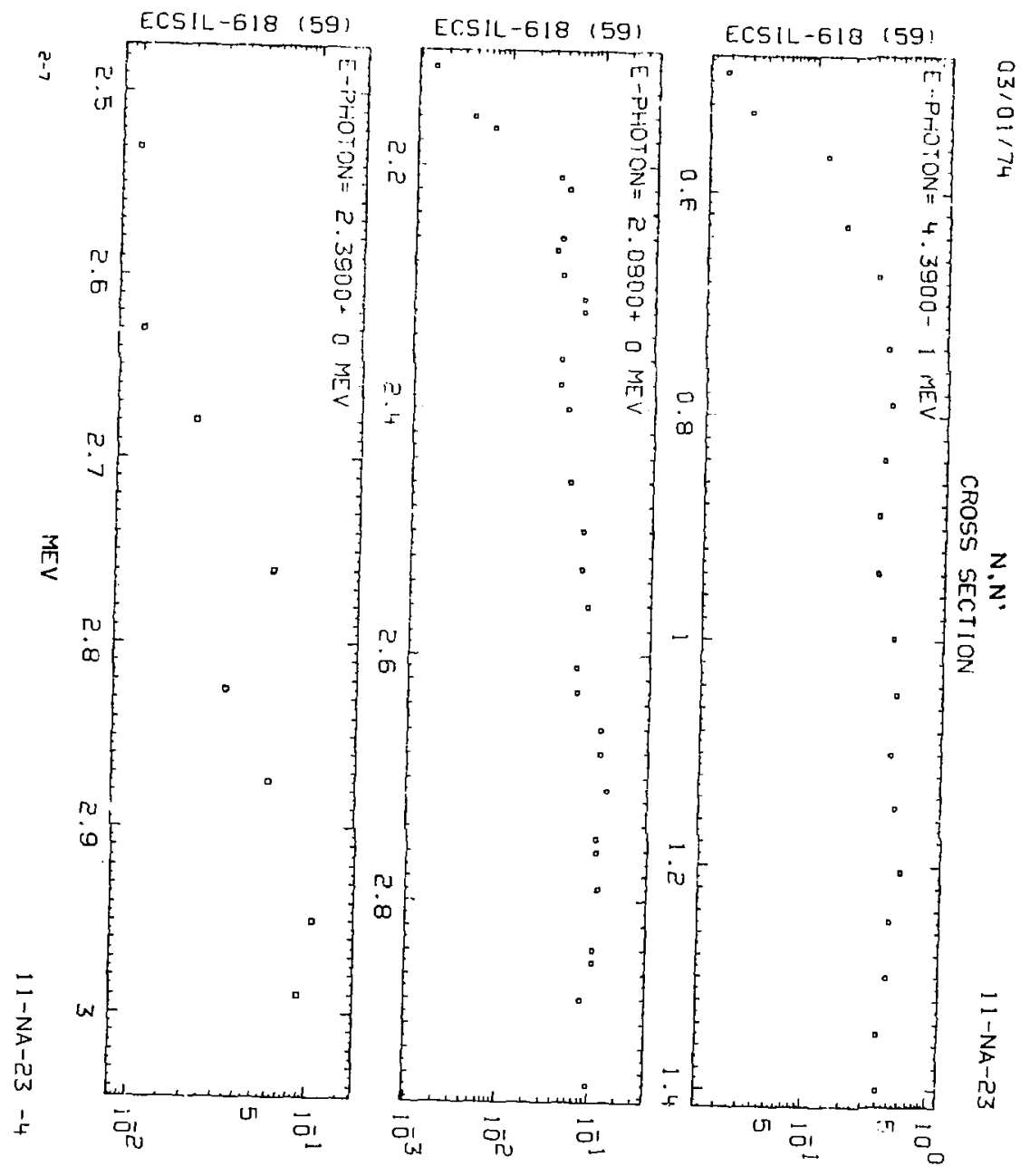

BARNS 


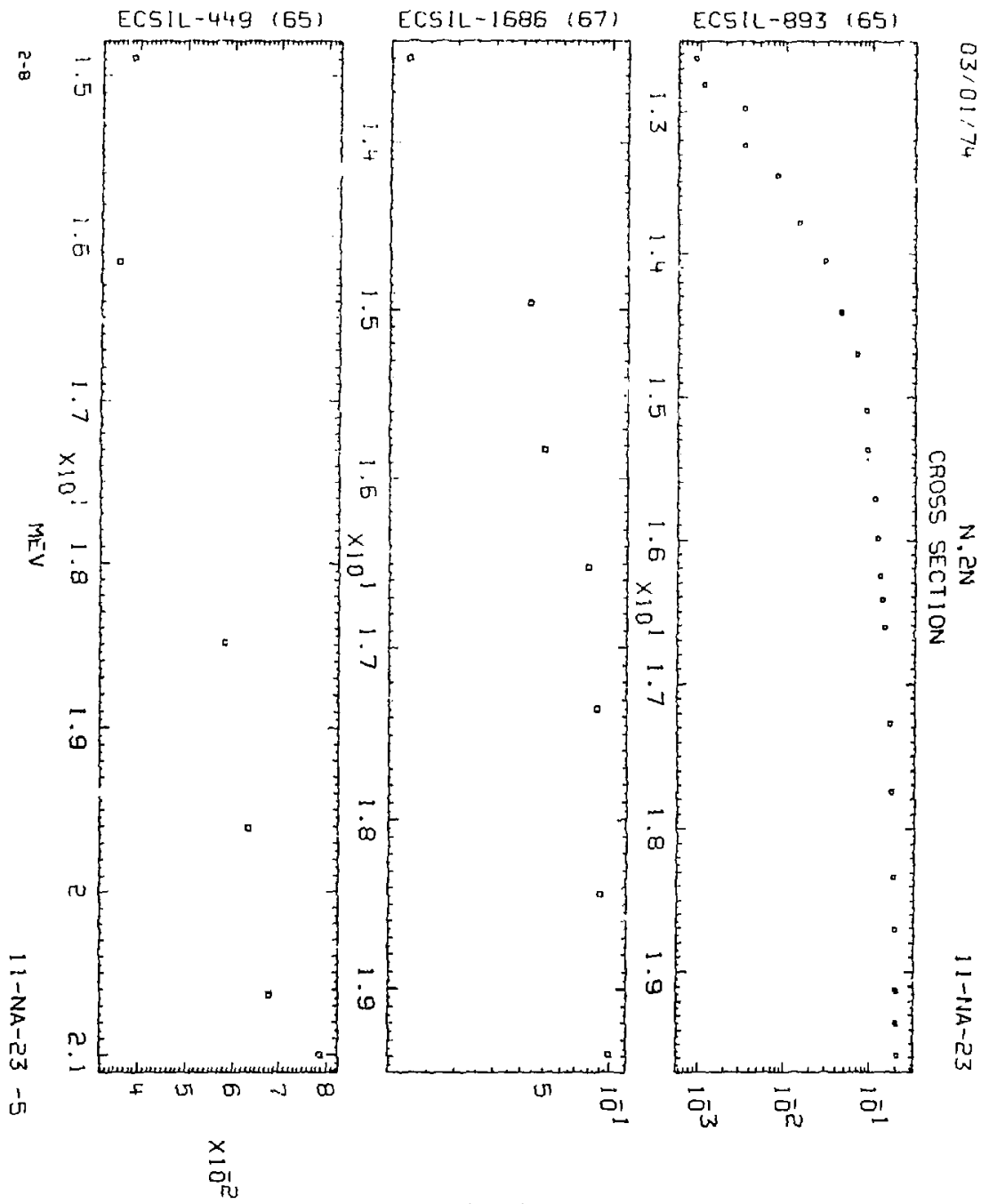

BARNS 

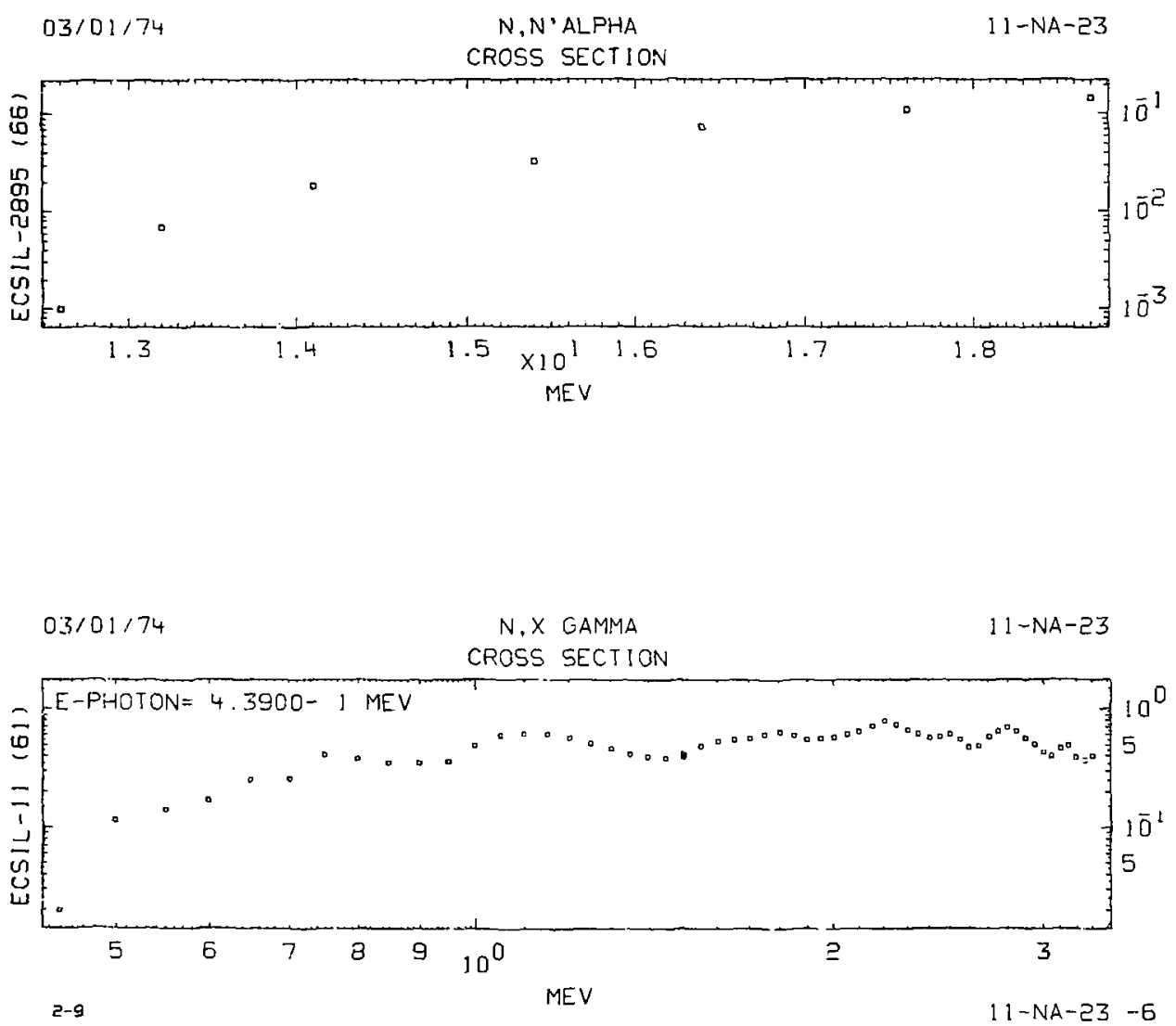

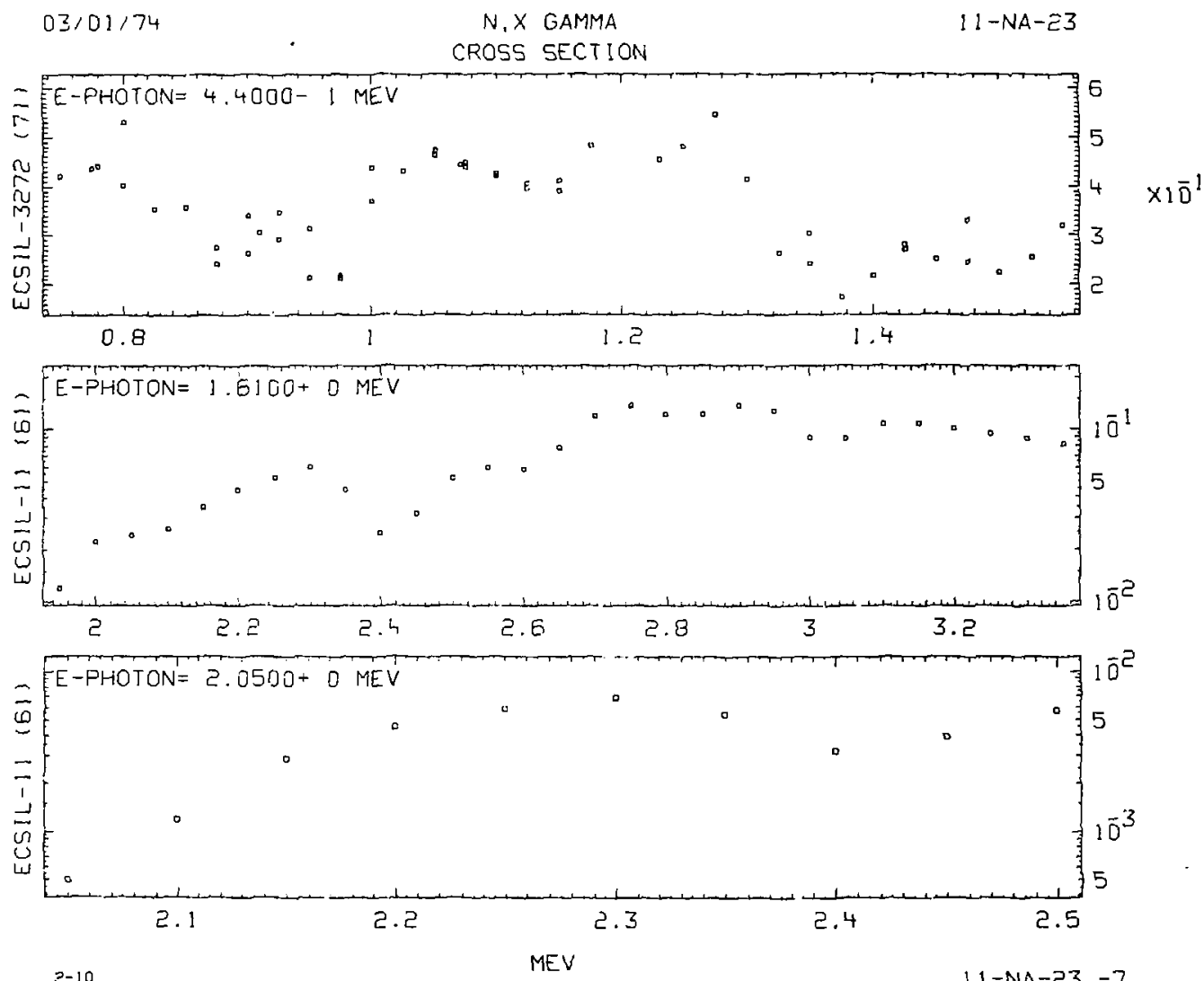

$11-N A-23-7$ 


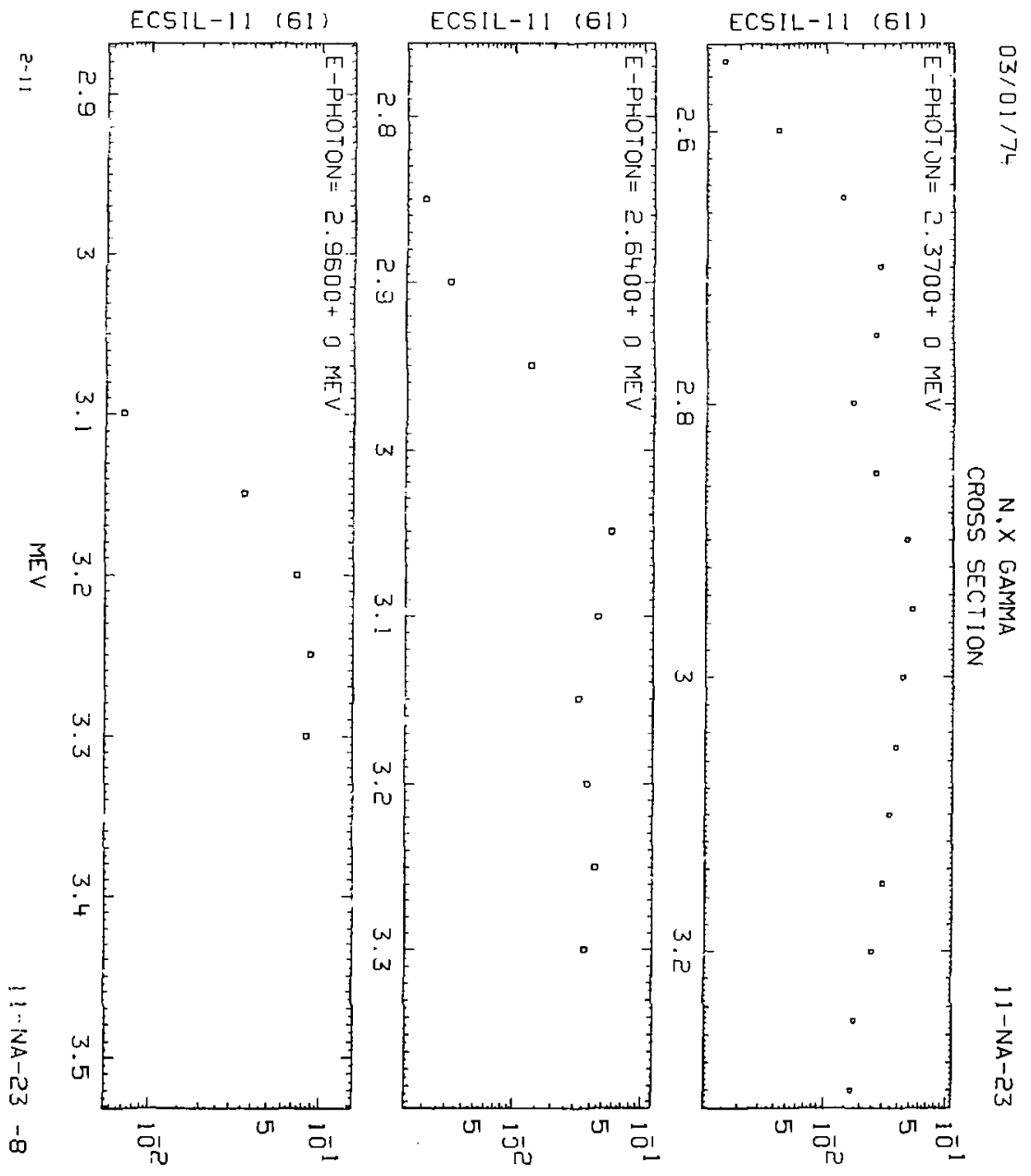

BARNS 

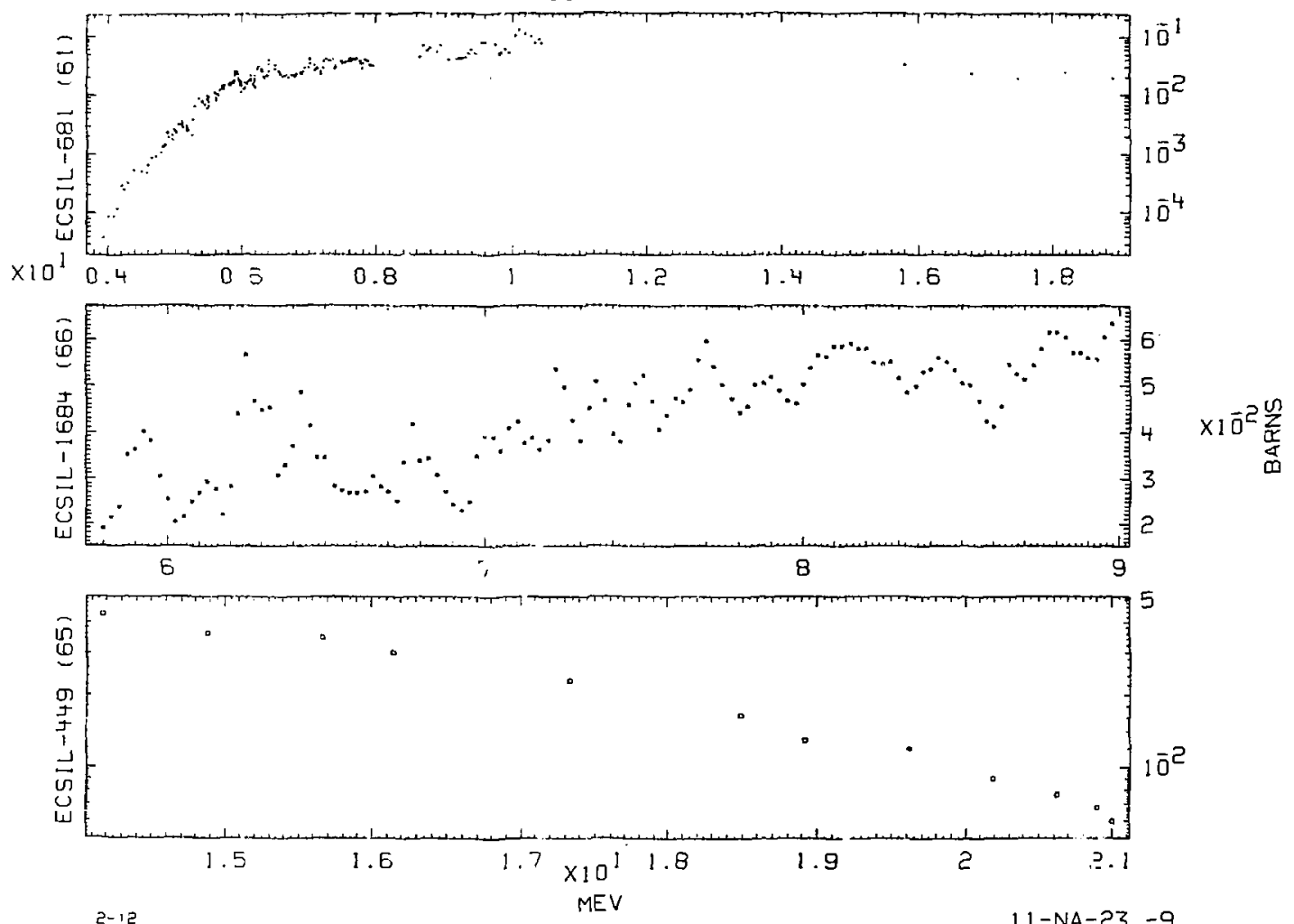

$2-15$

$11-N A-23-9$ 


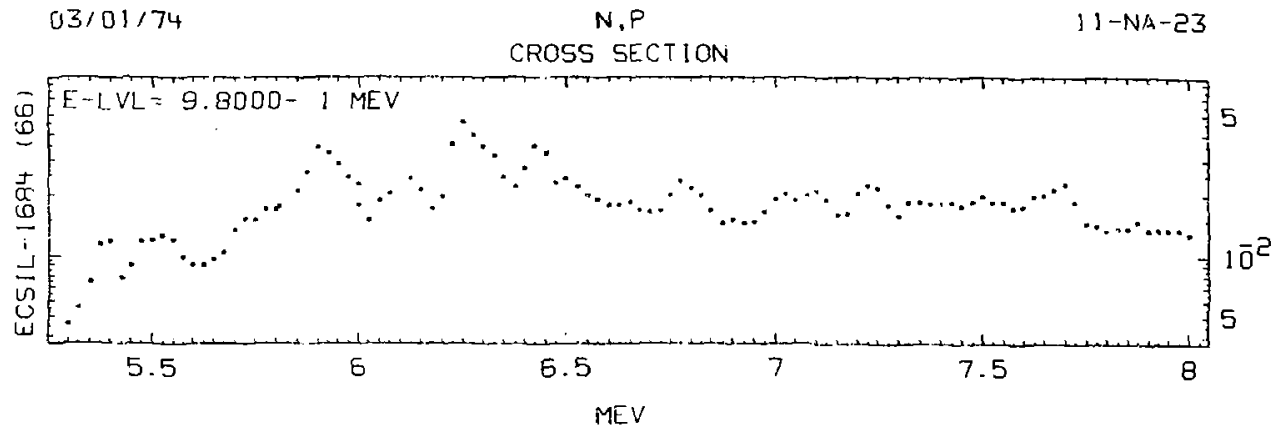

$03 / 01 / 74$

iV ALPYAS

$11-N A-23$ CROSS SECTION

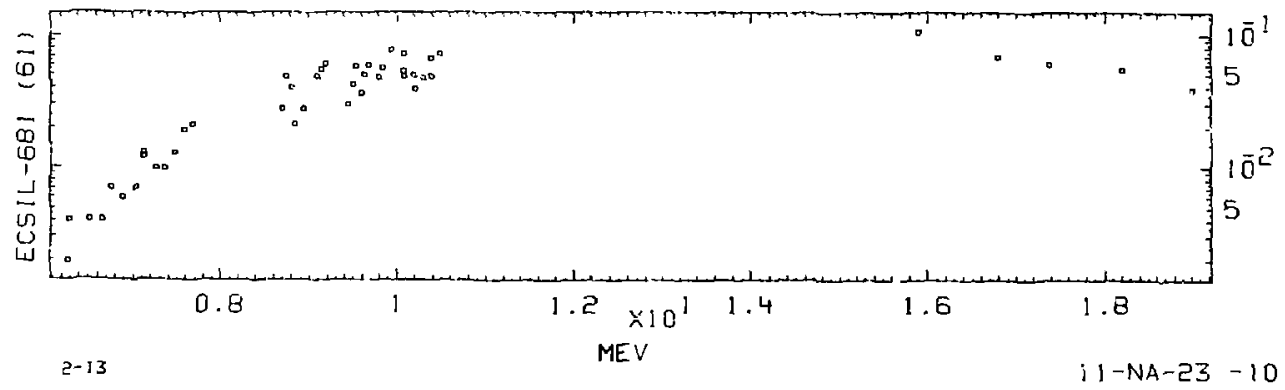

$\underset{\substack{n \\ \frac{\alpha}{\alpha}}}{\frac{w}{x}}$ 


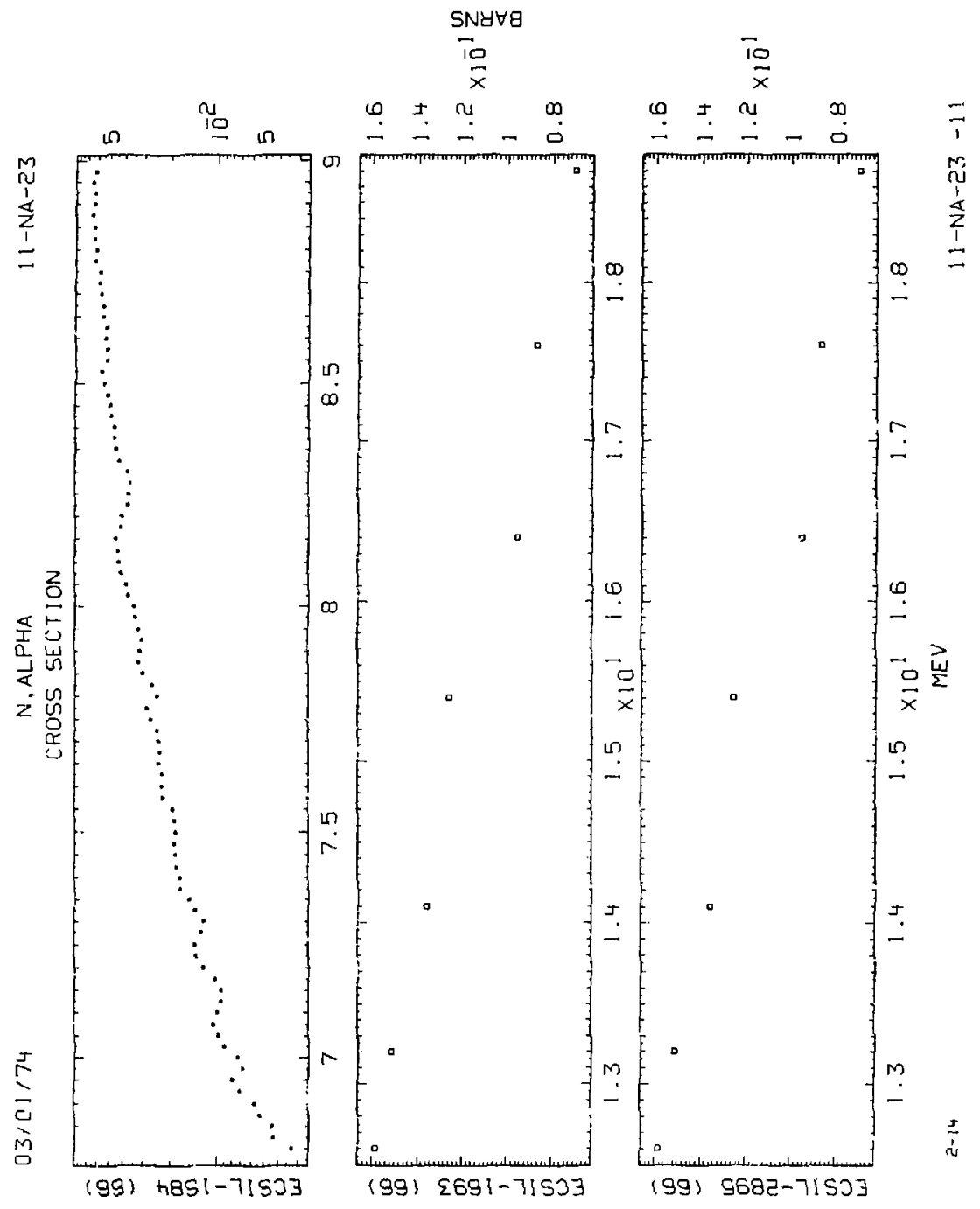



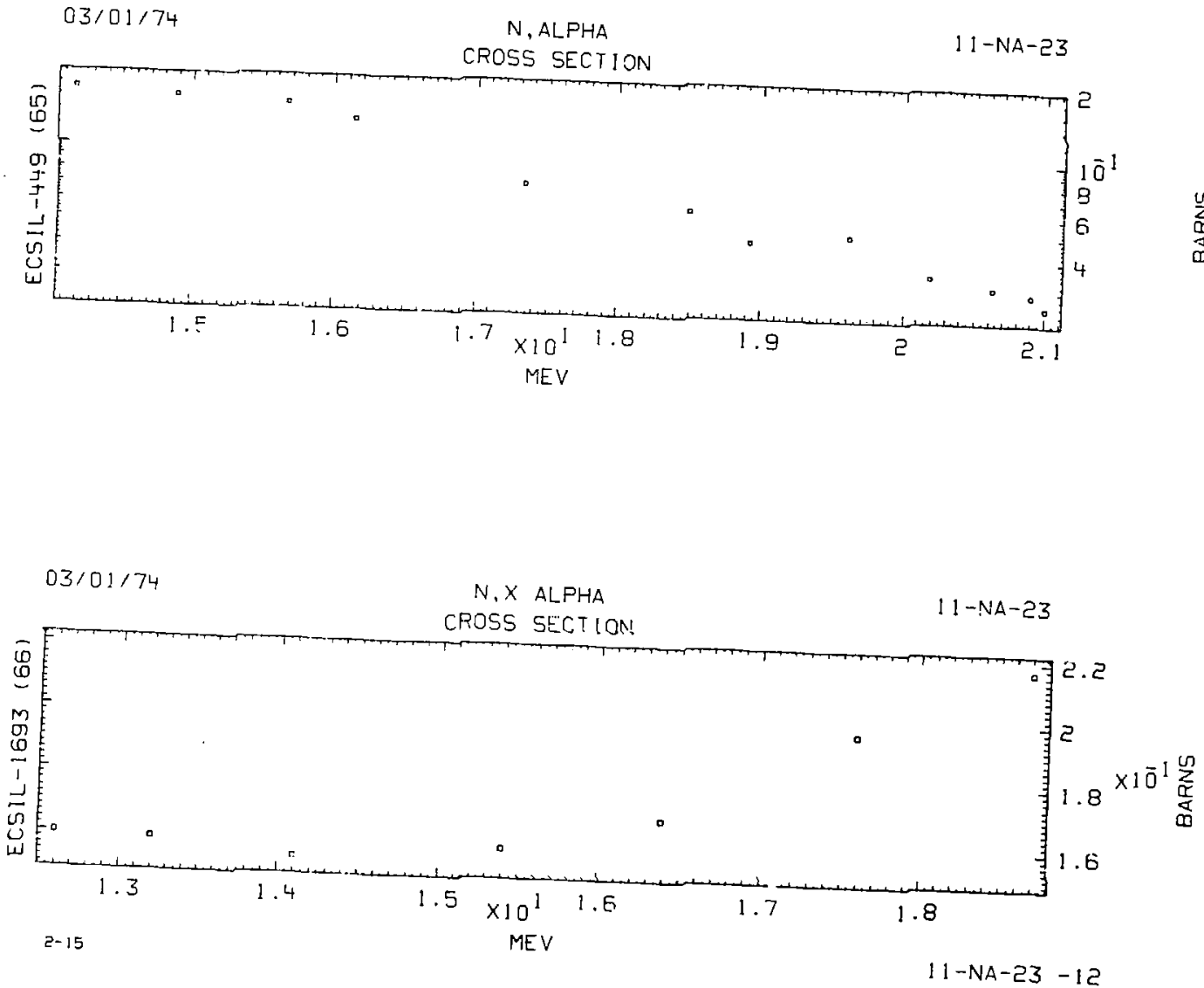


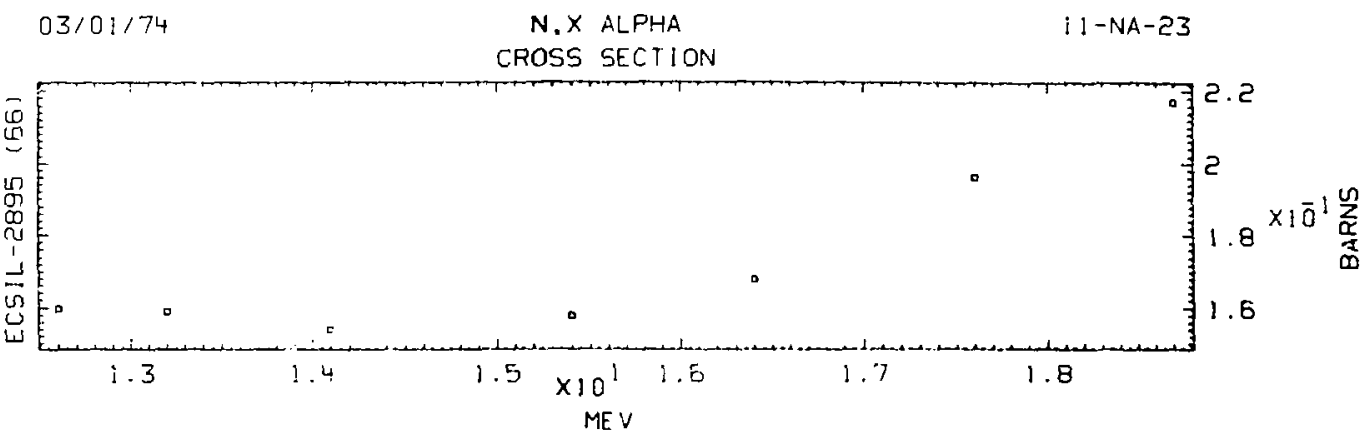

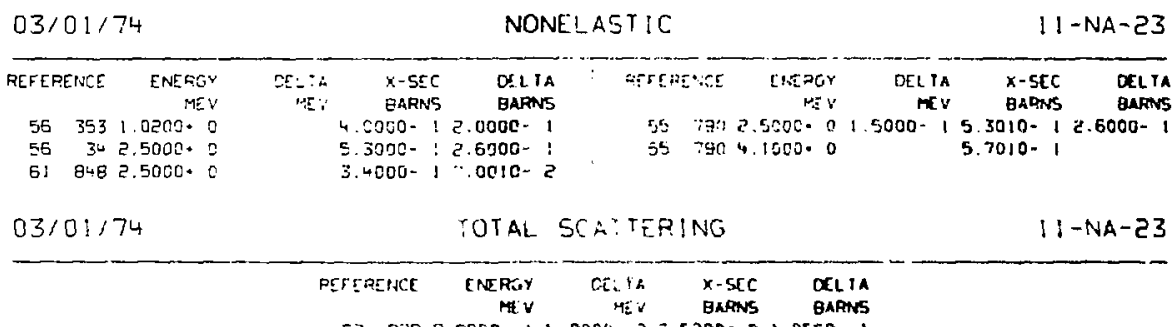

53 6:9 9.8000-: : 20009 ? 3.52000 - 0 1.0560- 1

03/01/74 $\because Y U T R O N$ NOIEL.EMISS. 11 NA-23

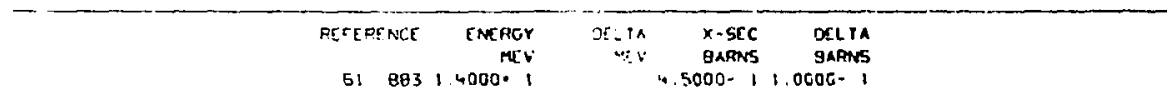

$2-16$

1) $-N A-23-13$ 


\section{CROSS SECTION}

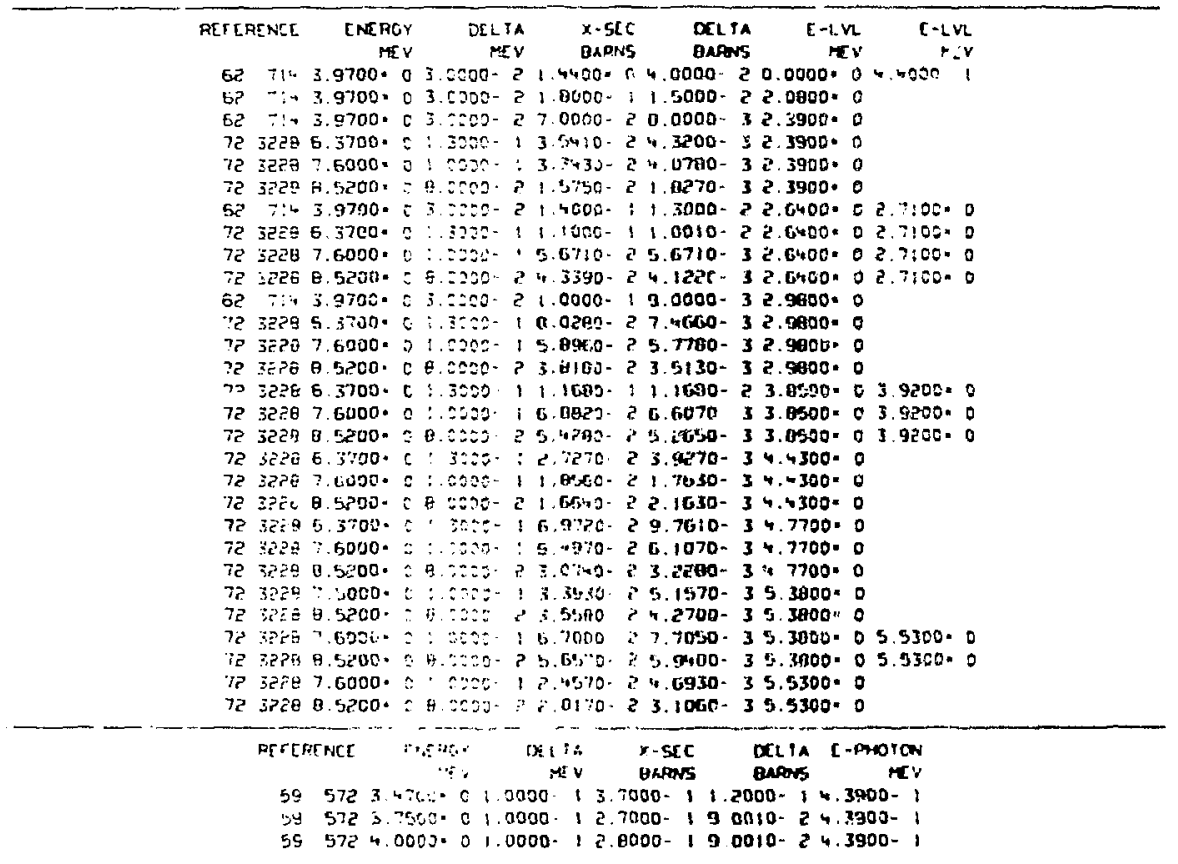


CROSS SECTION

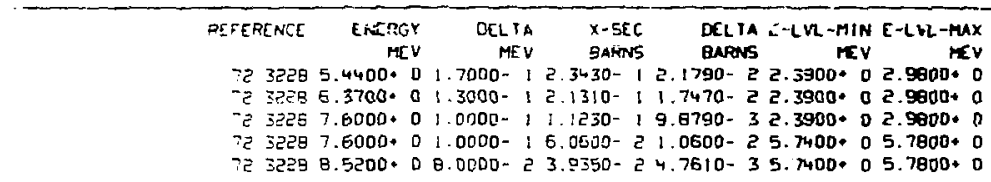

$03 / 01 / 74$

N. 2N

$11-N A-23$

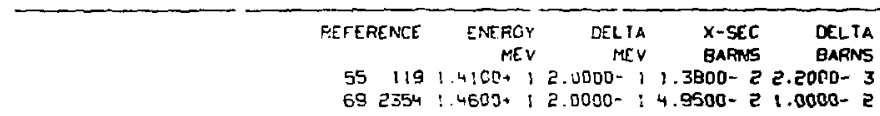

$03 / 01 / 74$

ABSORPT ION

$11-N A-23$

$\begin{array}{rrrrr}\text { AEFERENCE } & \text { ENERGY } & \text { DELTA } & \text { X-SEC } & \text { DELIA } \\ & \text { MEV } & \text { MEV } & \text { BAFNS } & \text { BARNS } \\ 591162 & 2.5300-8 & 5.3600-1 & 8.0000-3 \\ 60 & 691 & 2.5300-8 & 9.7000-1 & 6.0000-2\end{array}$

$03 / 01 / 74$

$N, X$ GAMIAA

1) -NA-23

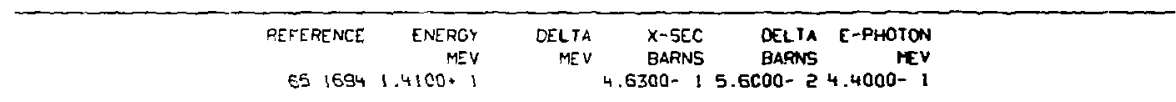

$03 / 01 / 74$

$N, P$

$11-N A-23$

\begin{tabular}{|c|c|c|c|c|c|c|c|c|c|c|c|c|}
\hline \multicolumn{2}{|c|}{ REFERENCE } & $\begin{array}{r}\text { ENERGY } \\
\text { MEV }\end{array}$ & $\begin{array}{l}\text { JELTA } \\
\text { MEV }\end{array}$ & $\begin{array}{l}x-\text { SEC } \\
\text { GARNS }\end{array}$ & $\begin{array}{l}\text { OFLL TA } \\
\text { GARNS }\end{array}$ & REFEF & RENCE & $\begin{array}{r}\text { ENERC } \\
M E\end{array}$ & & $\begin{array}{r}\text { DELTA } \\
\text { MEV }\end{array}$ & $\begin{array}{l}X \text {-SEC } \\
\text { BARNS }\end{array}$ & $\begin{array}{l}\text { DCLTA } \\
\text { BAROS }\end{array}$ \\
\hline$E C$ & 585 & $1.4000+1$ & & $9.0000-3$ & $4.0000-3$ & 87 & 3371 & $1.4700+$ & & $1.0000=1$ & $4.4000-2$ & $000-3$ \\
\hline 61 & $36 !$ & $1.4000+1$ & & $5.7010-2$ & 2. . $000-2$ & 66 & 2142 & $1.4800+$ & 1 & & $4.5000-2$ & $0000-3$ \\
\hline 53 & 27 & $1.4500 * 1$ & & $3.3900-2$ & $1.5000-2$ & 66 & 907 & 1.4800 & I & $1.0000-1$ & $\left.4.180^{\prime}\right)-2$ & $3.8000-3$ \\
\hline 67 & 1921 & $1.4700+1$ & 11.0000 .1 & $4.1000-2$ & $1.2000-3$ & 65 & 1697 & $1.4800+$ & 1 & & $4.5000-2$ & 5. $0000-3$ \\
\hline 66 & i 675 & $1.4700+1$ & & $3.9000-2$ & $4.0000-3$ & 61 & 660 & 1. $4800+$ & 1 & & อ.9000- & $3.0000-$ \\
\hline
\end{tabular}




\section{CROSS SECTION}

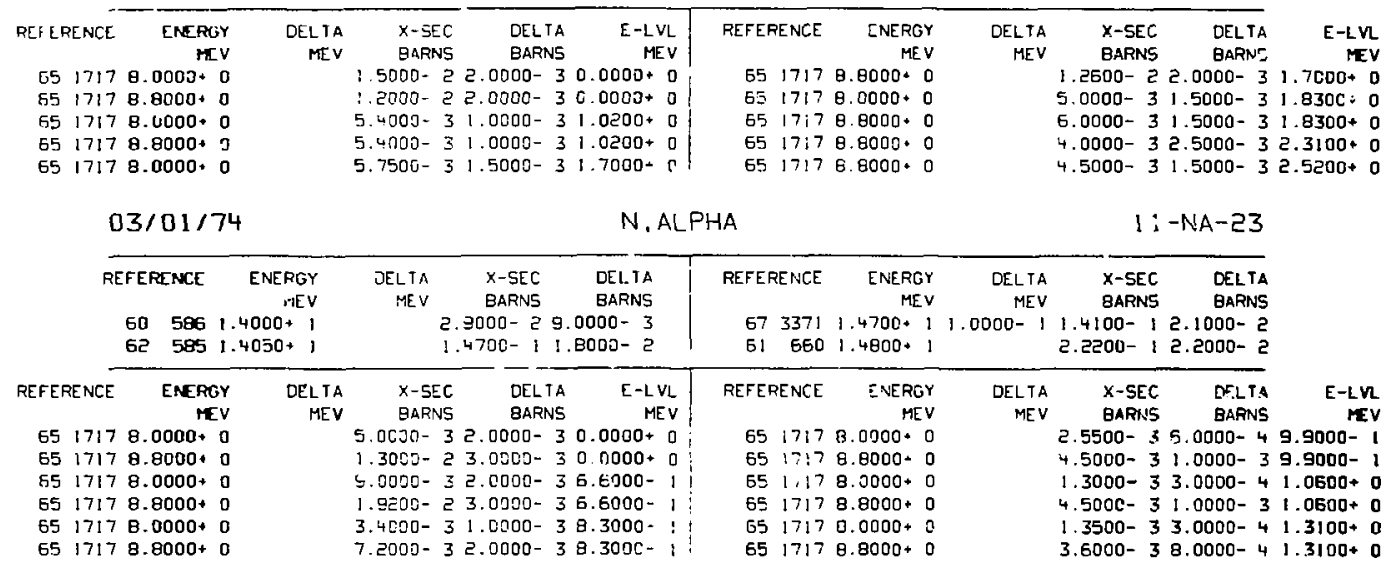

$03 / 01 / 74$

BOUND ATOM

$11-N A-23$

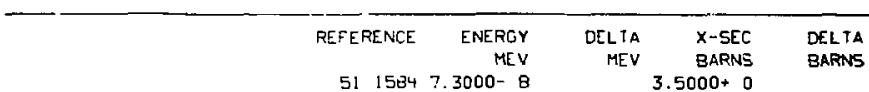

$03 / 01 / 74$

SOHERENT SCATTERING

$1:-N A-23$

$\begin{array}{rrrrr}\text { REFERENC. } & \text { ENERGY } & \text { OELTA } & \text { X-5EC } & \text { OELTA } \\ \text { MEV } & \text { MEV } & \text { BARN5 } & \text { BARNS } \\ 511584 & 7.3000-8 & & 1.5000+0 & 1.2000-1\end{array}$



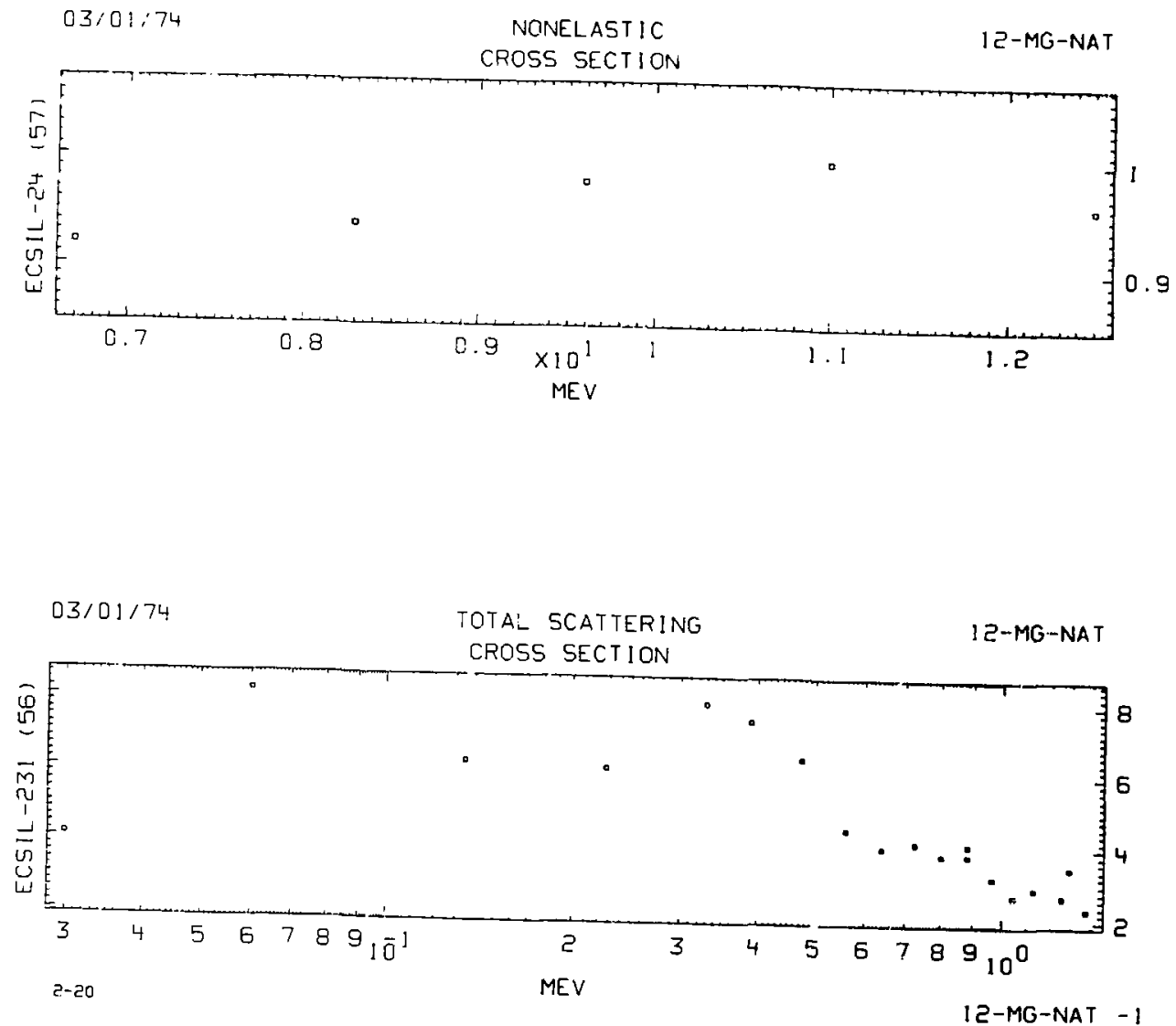

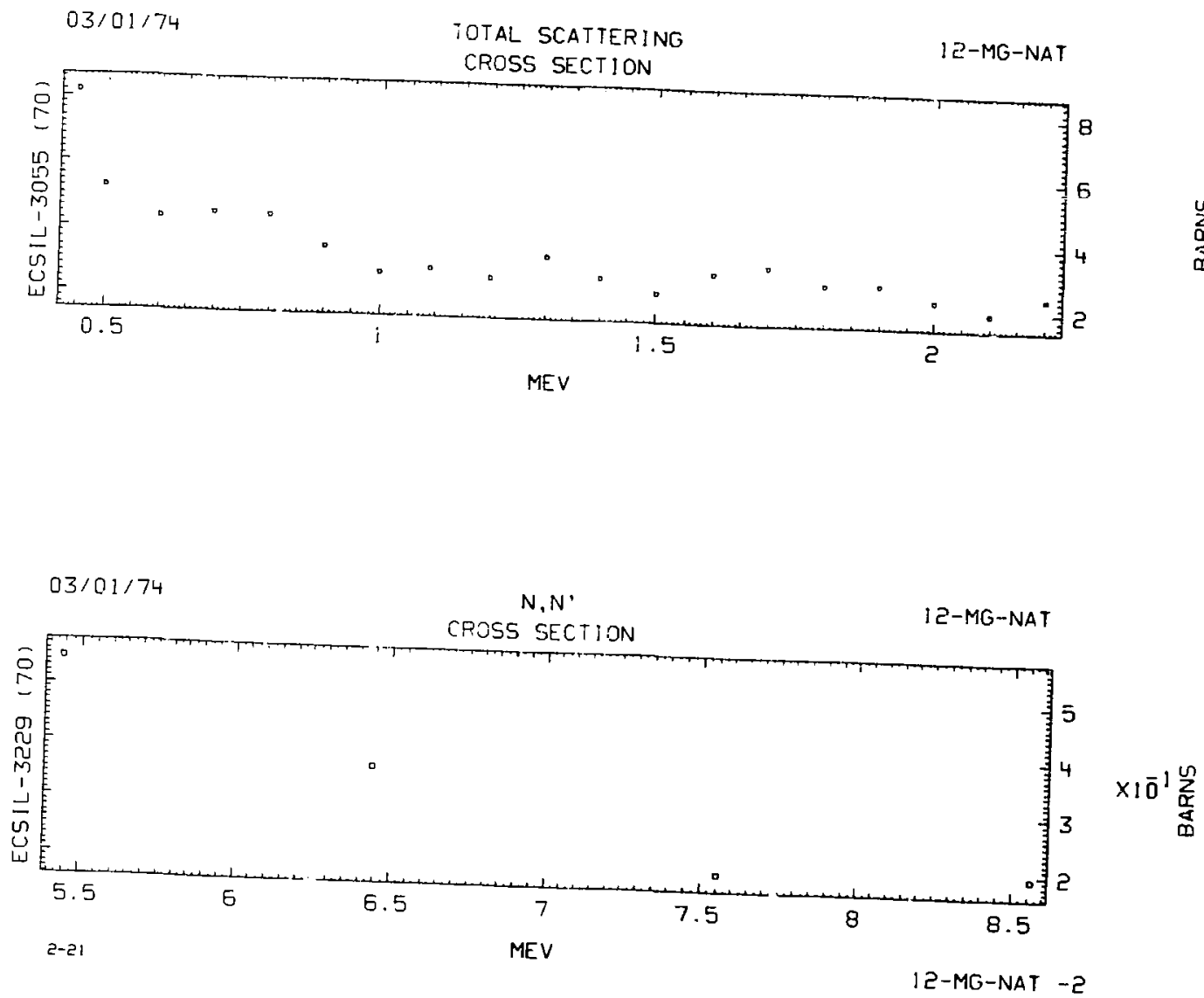

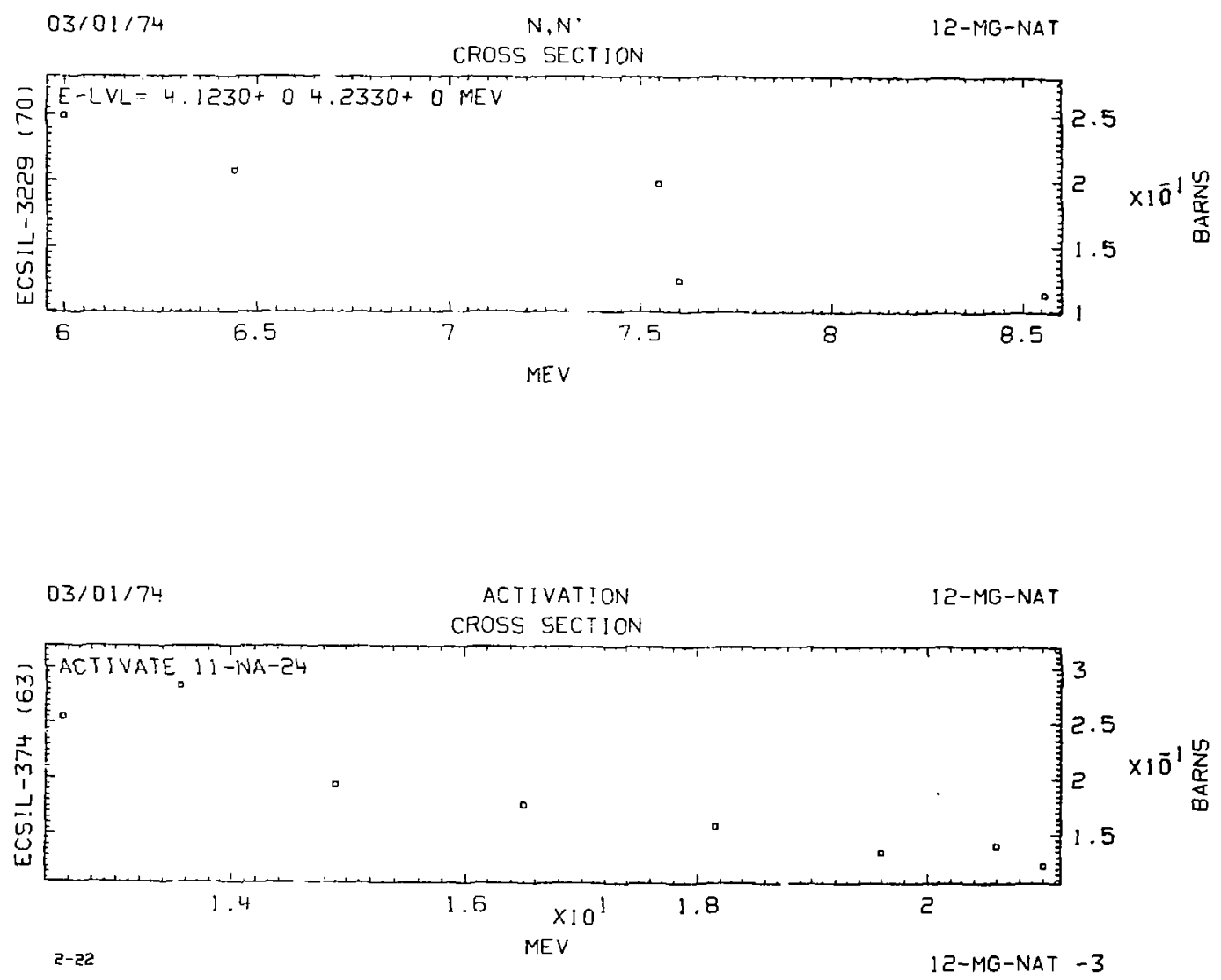
CROSS SECTION

\begin{tabular}{|c|c|c|c|c|c|c|c|c|c|c|c|}
\hline \multicolumn{2}{|c|}{ REFERENCE } & $\begin{array}{c}\text { ENERGY } \\
\text { MEV }\end{array}$ & $\begin{array}{r}\text { OELTA } \\
\text { MEV }\end{array}$ & $\begin{array}{l}X-S E C \\
\text { BARNS }\end{array}$ & $\begin{array}{l}\text { DELTA } \\
\text { EARNS }\end{array}$ & \multicolumn{2}{|c|}{ REFERENCE } & $\begin{array}{c}\text { ENEROY } \\
\text { ME }\end{array}$ & $\begin{array}{l}\text { DELTA } \\
\text { MEV }\end{array}$ & $\begin{array}{l}X \text {-SED } \\
\text { GAFNS }\end{array}$ & $\begin{array}{l}\text { DELTA } \\
\text { BARAS }\end{array}$ \\
\hline 56 & 34 & $5000+0$ & 0 & $7.7010-1$ & $12.5000-1$ & 57 & 319 & $200+1$ & $11.5000-1$ & $9.9010-1$ & $0000-2$ \\
\hline 55 & 790 & $0+0$ & $01.5000-1$ & $7.7010-1$ & $12.5000-1$ & 5 & 500 & $0+1$ & 1 & $0-1$ & $0^{-}$ \\
\hline 55 & 790 & $10 * 0$ & 0 & 7.8010 & $12.0000-1$ & 58 & 356 & z. $1000+1$ & 1 & $0-1$ & $100-2$ \\
\hline 55 & 790 & $\therefore 4000+1$ & 1 & $1.0800+$ & $09.0010-2$ & 58 & 355 & $2.5500+1$ & 1 & $0-1$ & $100-$ \\
\hline 57 & 193 & $1.4100+1$ & 1 & $3.6010-1$ & $18.0010-2$ & 58 & 356 & 2.9200+ & & $7.6010-1$ & $15.0000-2$ \\
\hline
\end{tabular}

$03 / 01 / 74$

TOTAL SCATTERING

12-MG-NAT

$\begin{array}{rrrr}\text { REFERENCE ENERGY DELTA } & \text { X-SEC } & \text { DELTA } \\ \text { MEV MEV } & \text { MARNS } & \text { BARNS }\end{array}$

$46.1972 .5000+01.5000-1 ; .6000+02.0000-1$

$03 / 01 / 74 \quad$ N.N' 12-MG-NAT

RLFERENCE ENERGY DELTA M-SEC DELTA E-LVL E-LVL

$7032398.5600-08.0000-24.2520-28.9530-34.1230+0$

703259 9. $5600-0$ 8.0000- 5 5. $1240-21.2550-24.2330+0$

$7032257.5500-04.2000-25.3150-27.0690-35.2280+0$

$7032297.6000+0$ i.j000- i $5.54 \hat{c}^{\prime} 0-29.8780-35.2280+0$

$7032299.5600+08.0000-27.4590-26.7880-35.2290+0$

$7030257.5500+0.4 .0000-25.8470-21.9760-25.0000+0$

$7032297.6000 \cdot 01.0000-14.3050-27.0140-36.0000+0$

70 $32598.5600+08.0000-25.6920-25.8060-36.0000+0$

703 3อ2 $3.5600+08.0000-24.5520-27.4200-36.0400+05.4360+0$

$70322 \leq 85600+06.0000-23.6600-25.3070-36.4360+0$

\begin{tabular}{|c|c|c|c|c|c|c|c|c|c|c|c|c|c|}
\hline \multicolumn{2}{|c|}{ REFERENCE } & ENEFIGY & DELTA & $x-S E C$ & DE-TA & E-PHCTON & \multicolumn{2}{|c|}{ PEFERENCE } & [NERGY & DELTA & $x-\sec$ & DELTA & E-PHOTON \\
\hline & & MEV & MEV & GARNS & ZAPNS & MEV & & & MEV & MEV & BARNS & BARNS & MEV \\
\hline E) & 350 & $1.4000+1$ & & $2.8000-1$ & $8.4000-2$ & $4.2000+0$ & 61 & 650 & $1.4000+1$ & & $3.0000-2$ & $9.0000-3$ & $36.1000 \cdot 0$ \\
\hline 61 & 850 & $14000+1$ & & $7.0000-2$ & 2. $1420-2$ & $4.8000+0$ & 6: & 850 & $1.4000+1$ & & $3.0000-2$ & $9.0000-3$ & $6.5000+0$ \\
\hline 61 & 650 & $1.4000+1$ & & $1.0000-1$ & $3.0000-2$ & $5.3000+0$ & & & & & & & \\
\hline
\end{tabular}




\section{CROSS EECTION}

\begin{tabular}{|c|c|c|c|c|c|c|c|c|c|c|}
\hline \multirow[t]{2}{*}{ REFERENCR. } & ENERGY & DEL IA & $x-5[c$ & OELTA & \multicolumn{2}{|c|}{ REFERENCE } & ENERGY & DELTA & $x-S E C$ & DELTA \\
\hline & MEV V & MEV & BARNS & GARNG & & & MEV & MEV & BARNS & EARAS \\
\hline 5) 2569 & $2.5300 \cdot 8$ & & $6.5000-2$ & $5.0000-3$ & 58 & 364 & $2.5000-z$ & $24.0000-3$ & $1.9000-2$ & $3.0000-3$ \\
\hline G5 1491 & 2.5300 .3 & & $6.4200-2$ & $1.5000-2$ & 58 & 364 & 2. $2000-1$ & 1 2.0000- & $1.3000=2$ & $1.0000-2$ \\
\hline$S B \mid 16 x$ & $2.5300-\varepsilon$ & & $7.3000-2$ & $2.1000-3$ & 58 & 364 & $2.3000-1$ & $14.0000-2$ & $1.0000-2$ & $4.0000-3$ \\
\hline
\end{tabular}

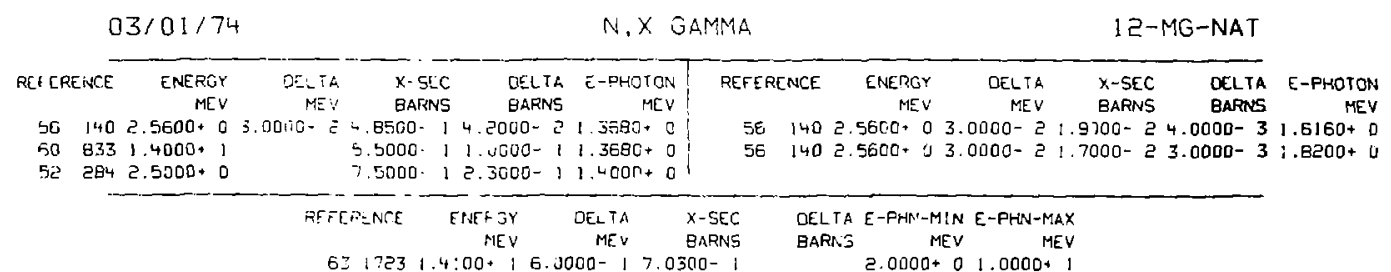

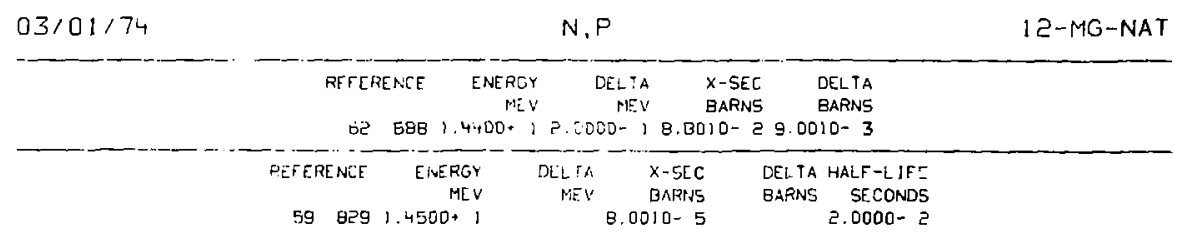

$03 / 01 / 74$

SOUND ATOM

IZ-MG-NAT

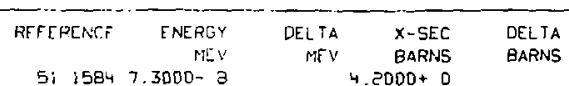




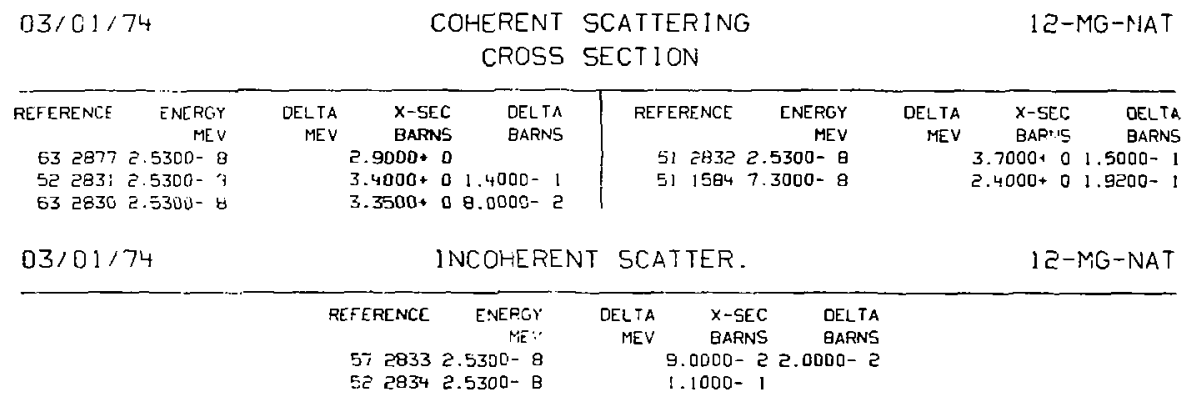
$02 / 01 / 74$
N. N.
$12-M G-24$ CROSS SECTION

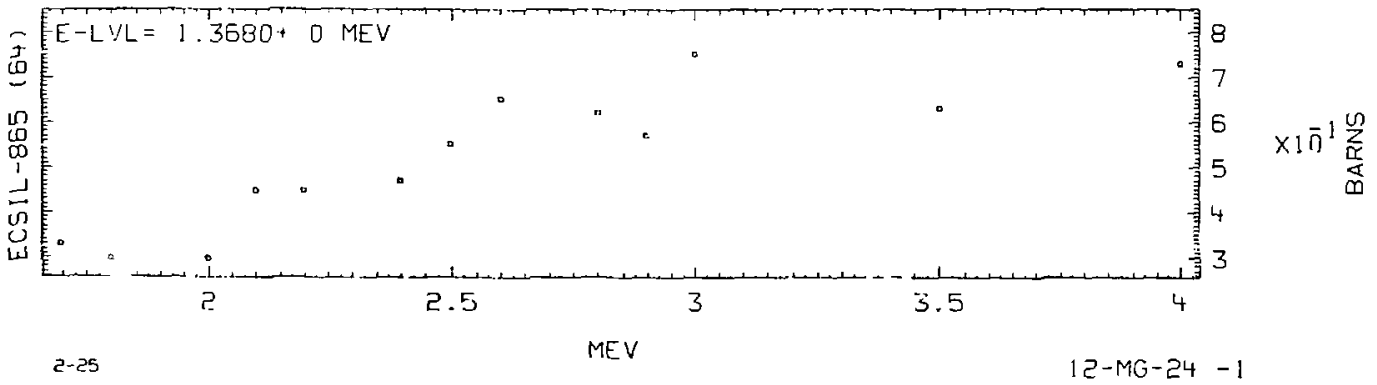



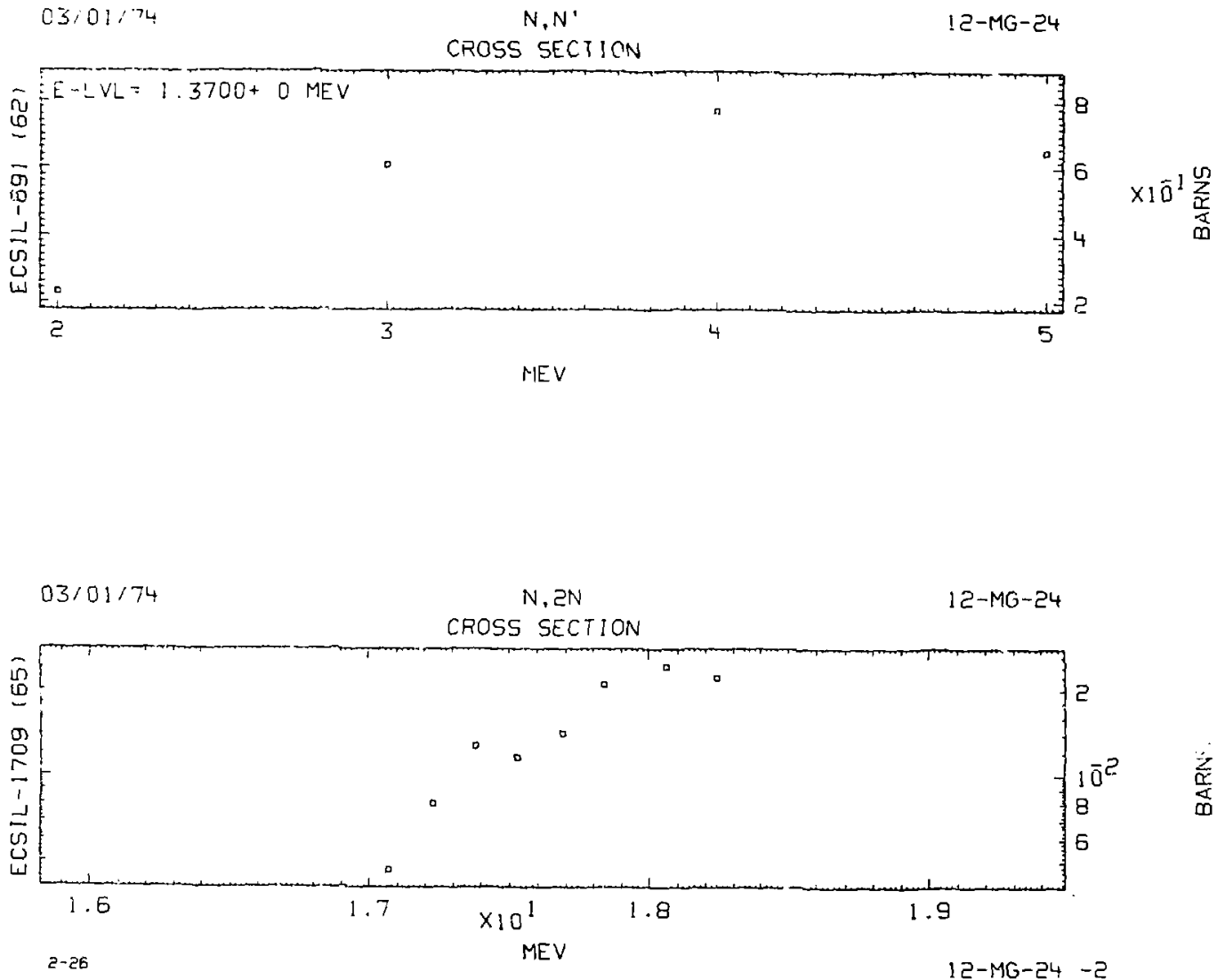


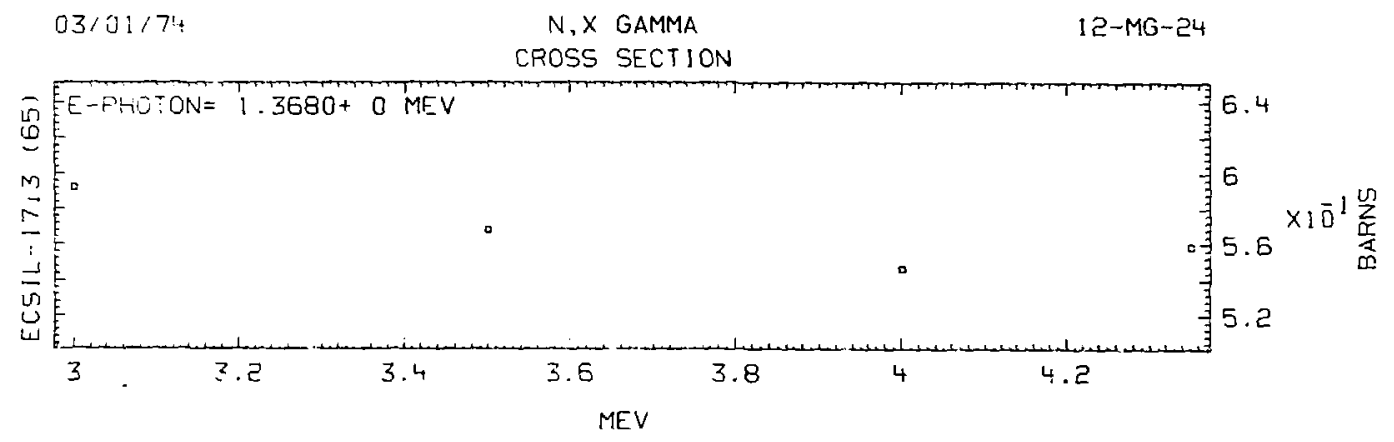

$03 / 01 / 74$

N.P

$12-M G-24$

CROSE SECTION

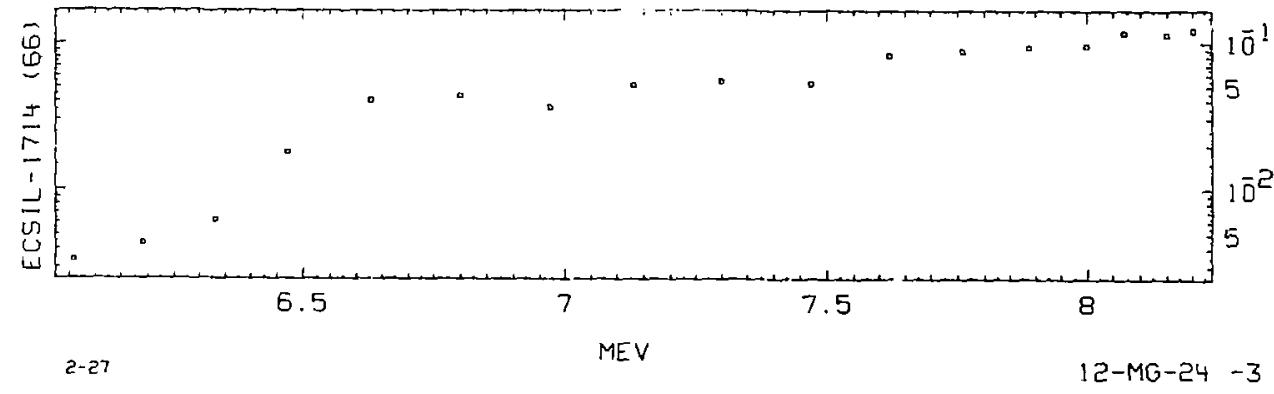




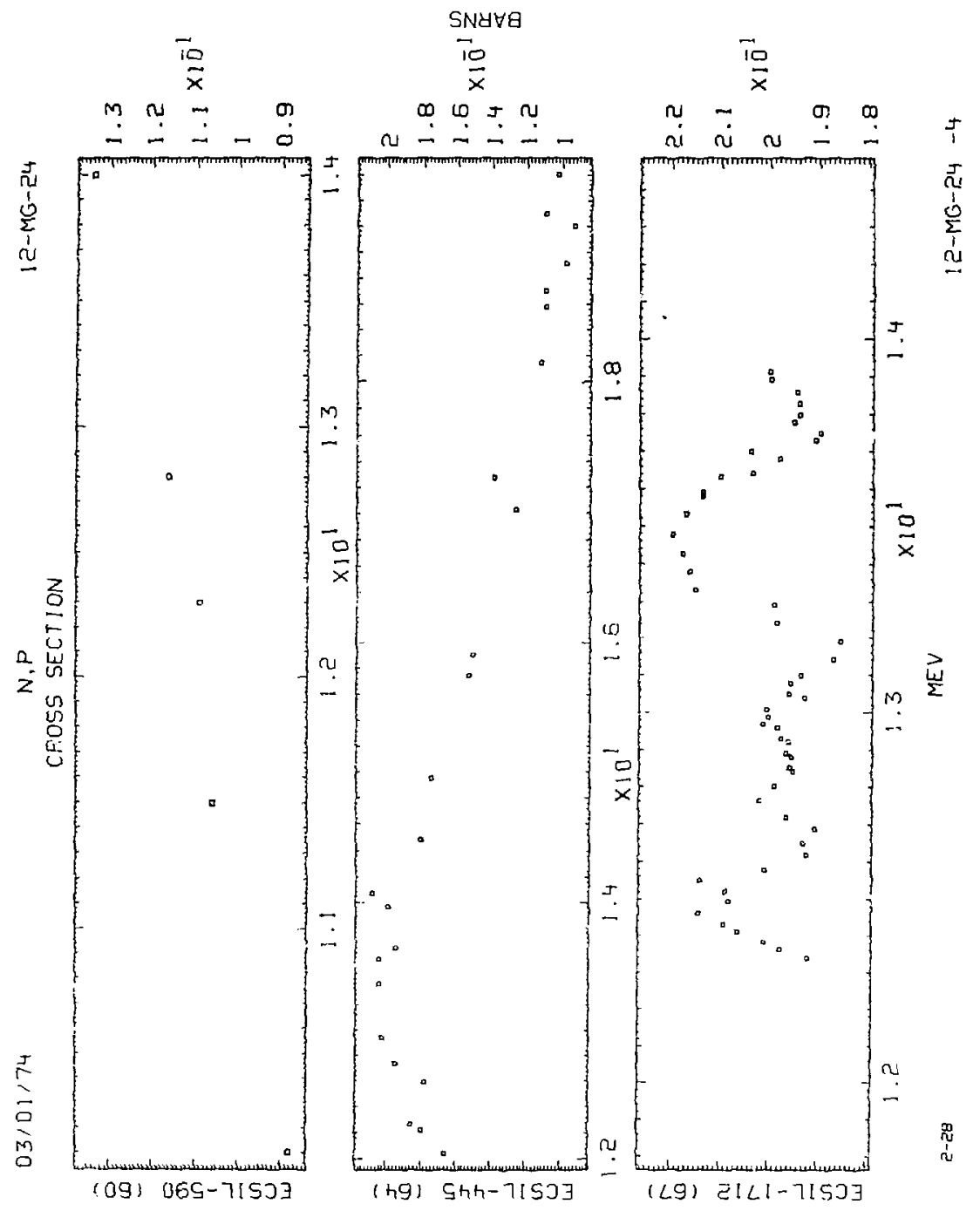




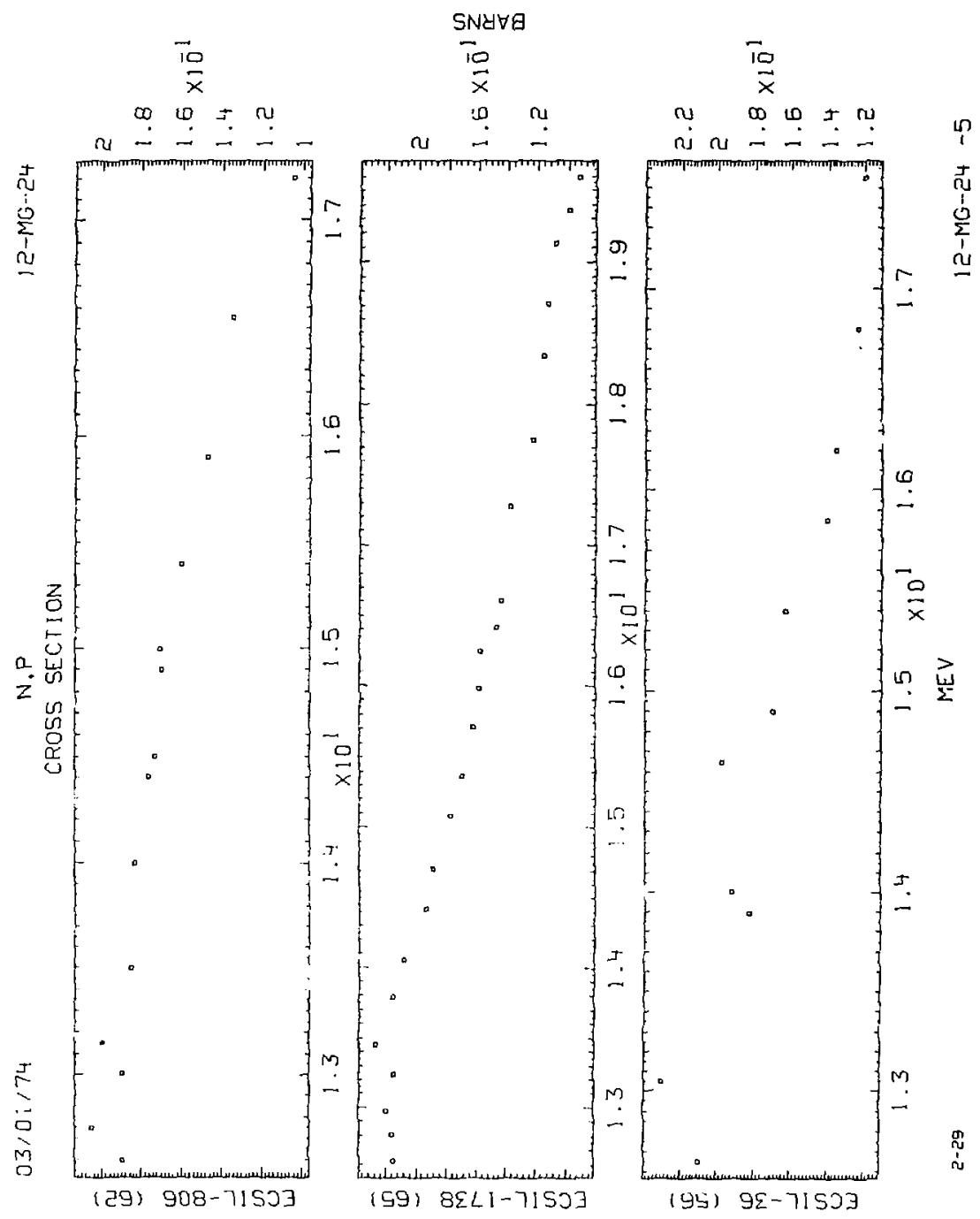




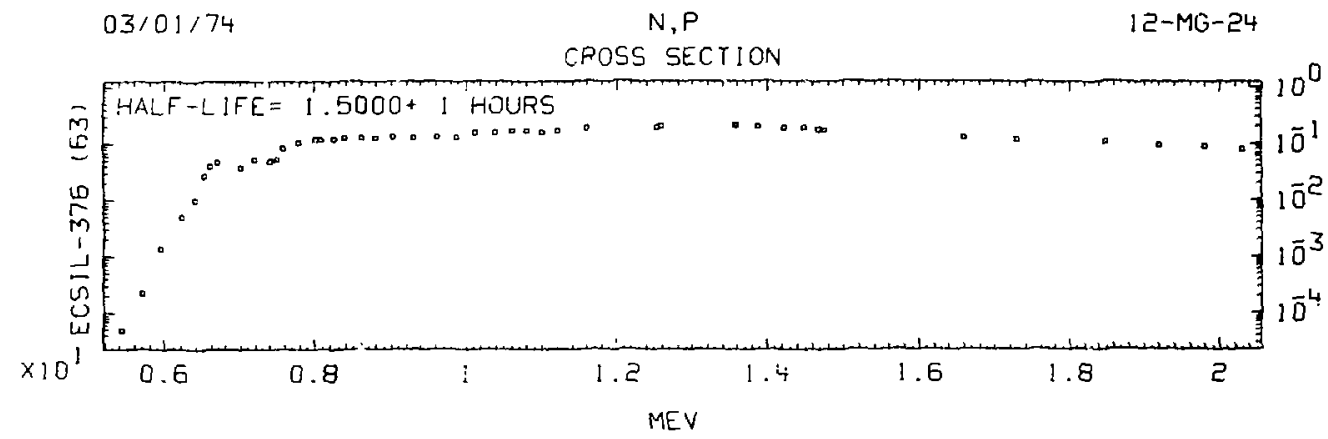

$\frac{\substack{2 \\ \frac{2}{2} \\ 0}}{0}$

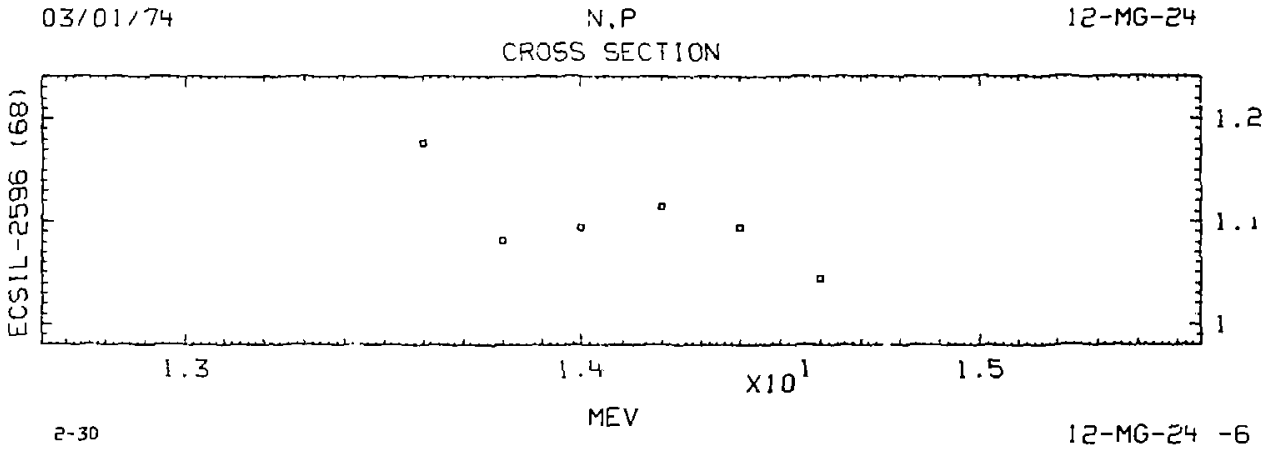

$\underset{5}{2}$ 


\section{CROSS SECTION}

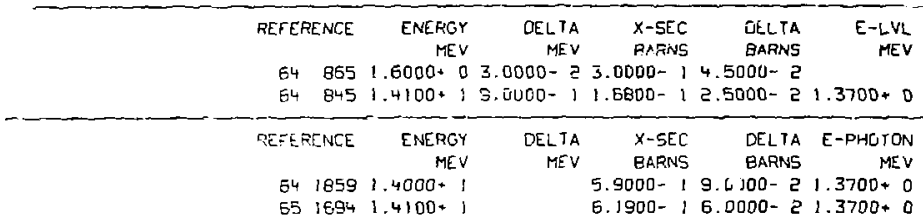

$03 / 01 / 74$

$N, X$ GAMiIA

$12-M G-24$

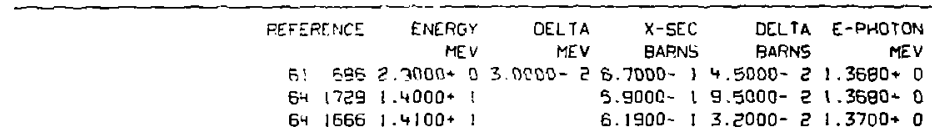

$03 / 01 / 74$

N.P

$12-M G-24$

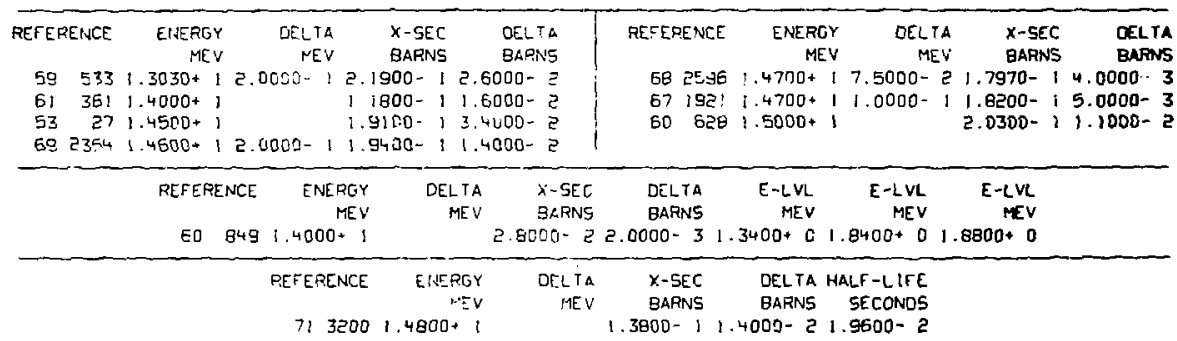



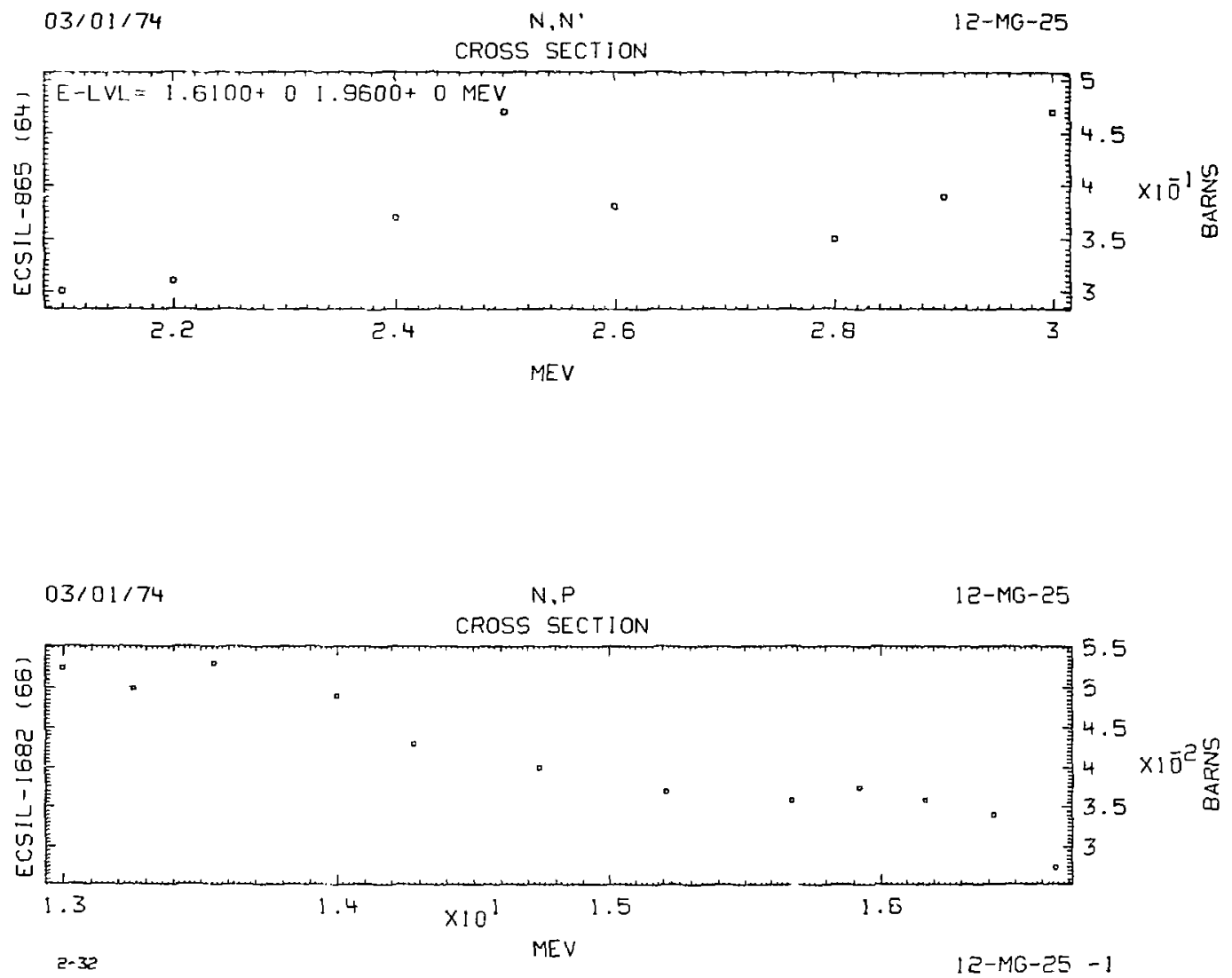


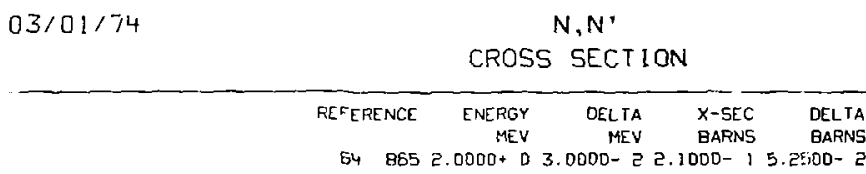

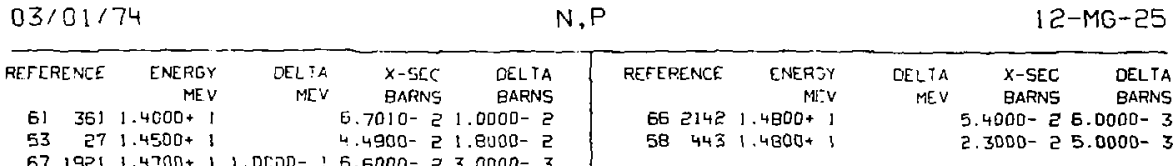

$7071.4700+1,0000-10.6000-33.0000-3$

$03 / 01 / 74 \quad$ N.N $\quad 12-M G-26$ CROSS SECTION

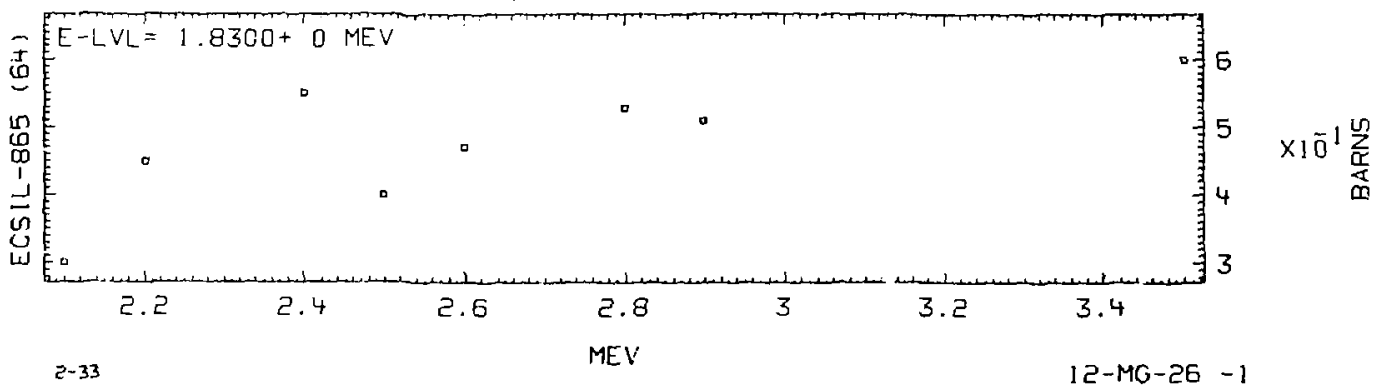


SNYYG

ก

$\frac{10}{x}$
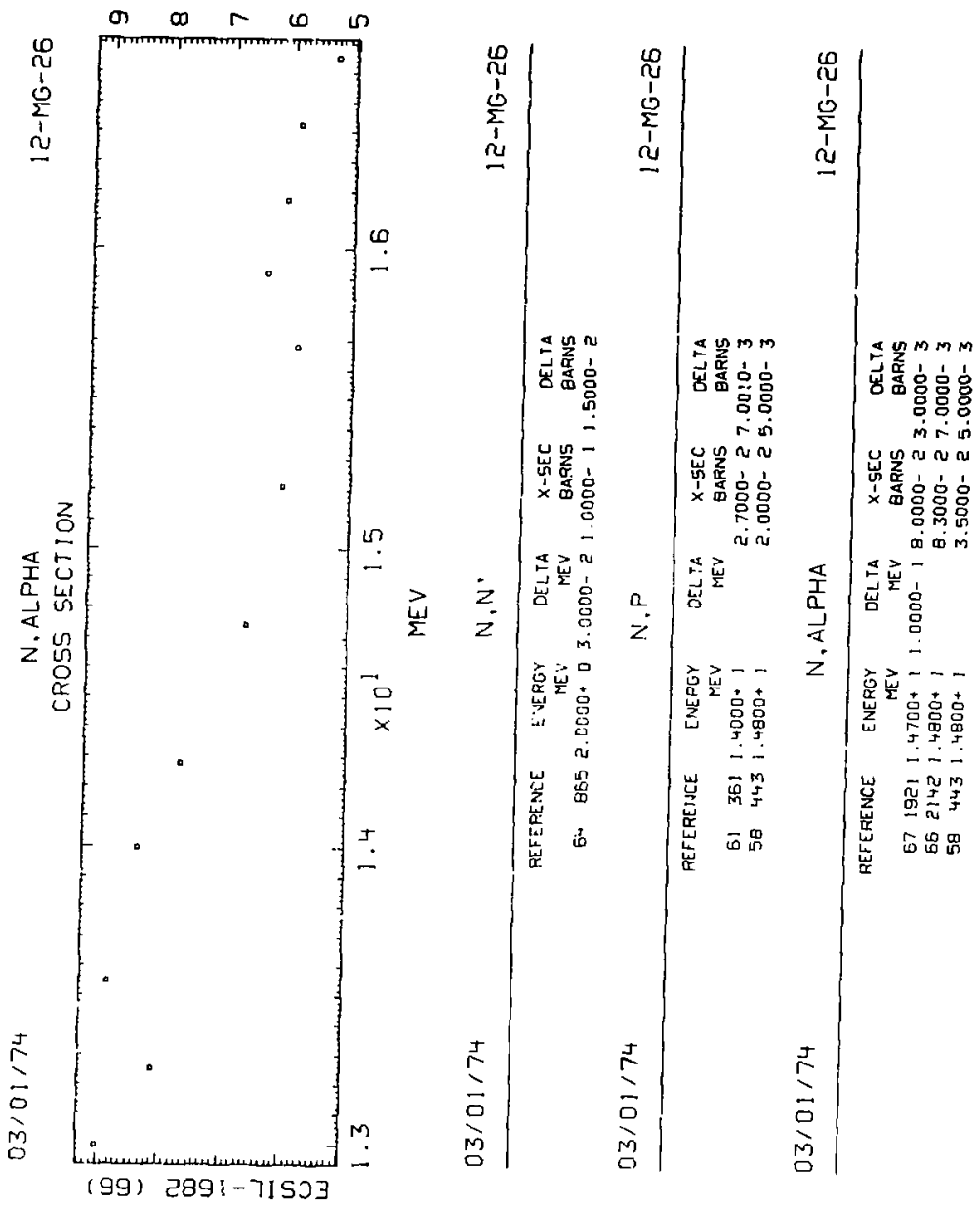

Y

品

1

กิ 

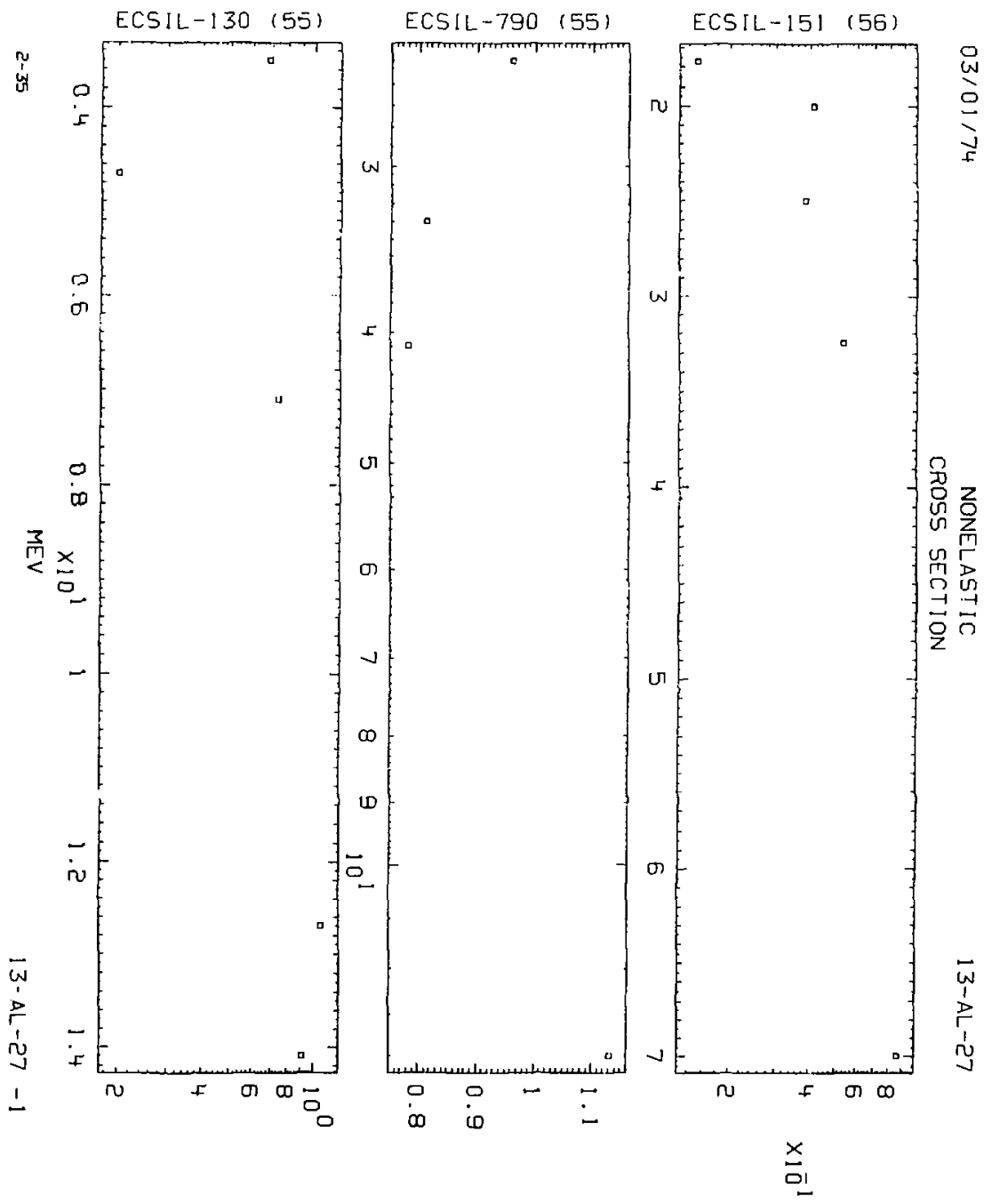

BARNS 

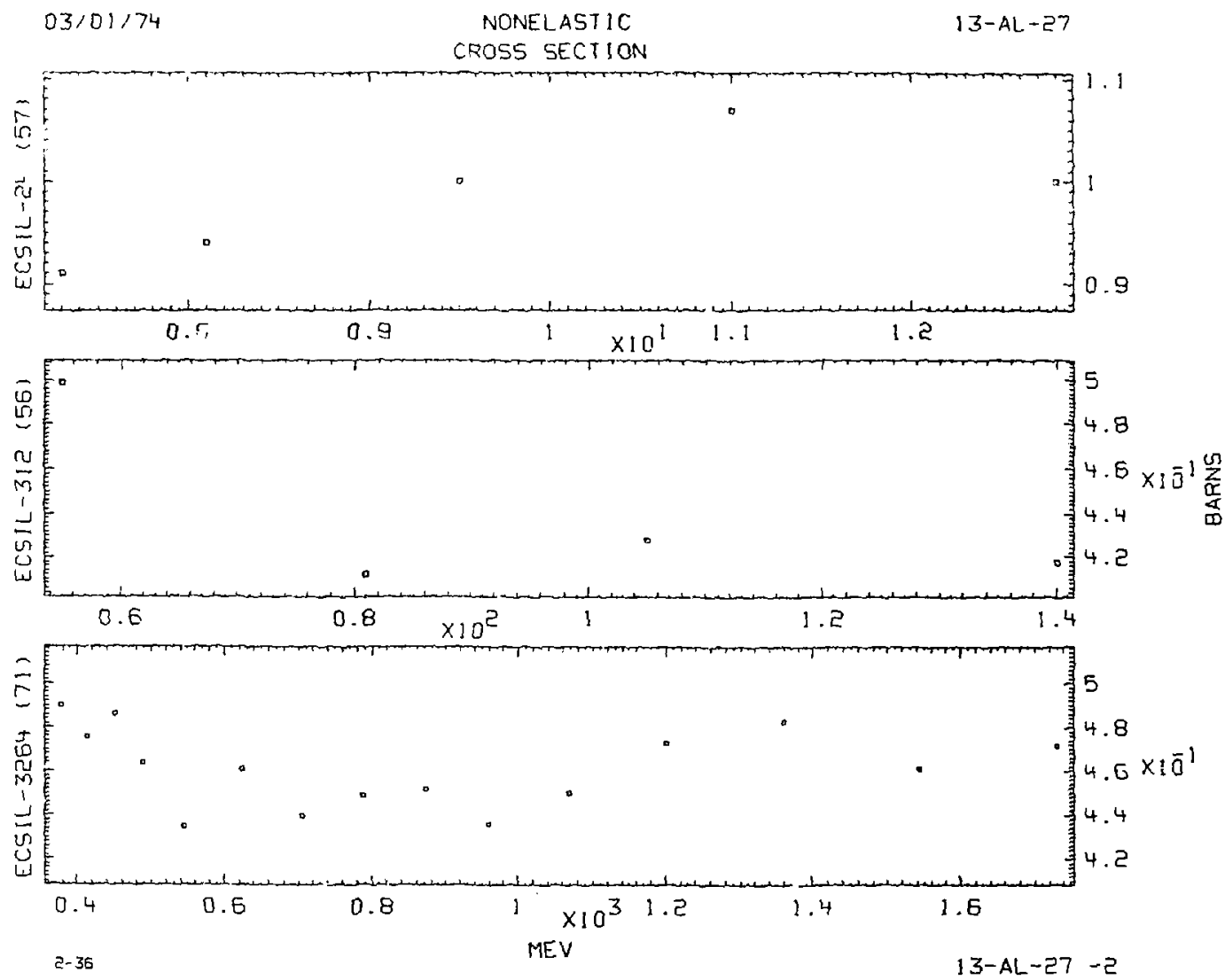


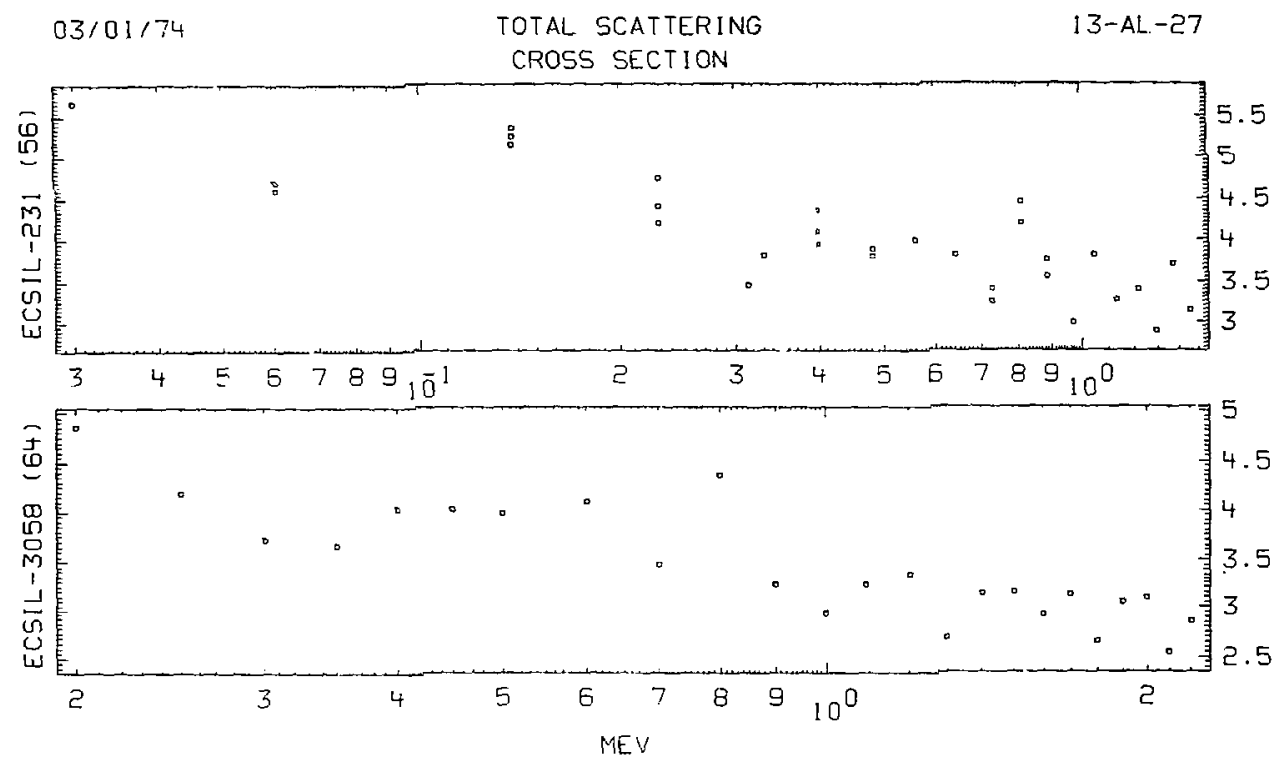




\section{CROSS SECTION}
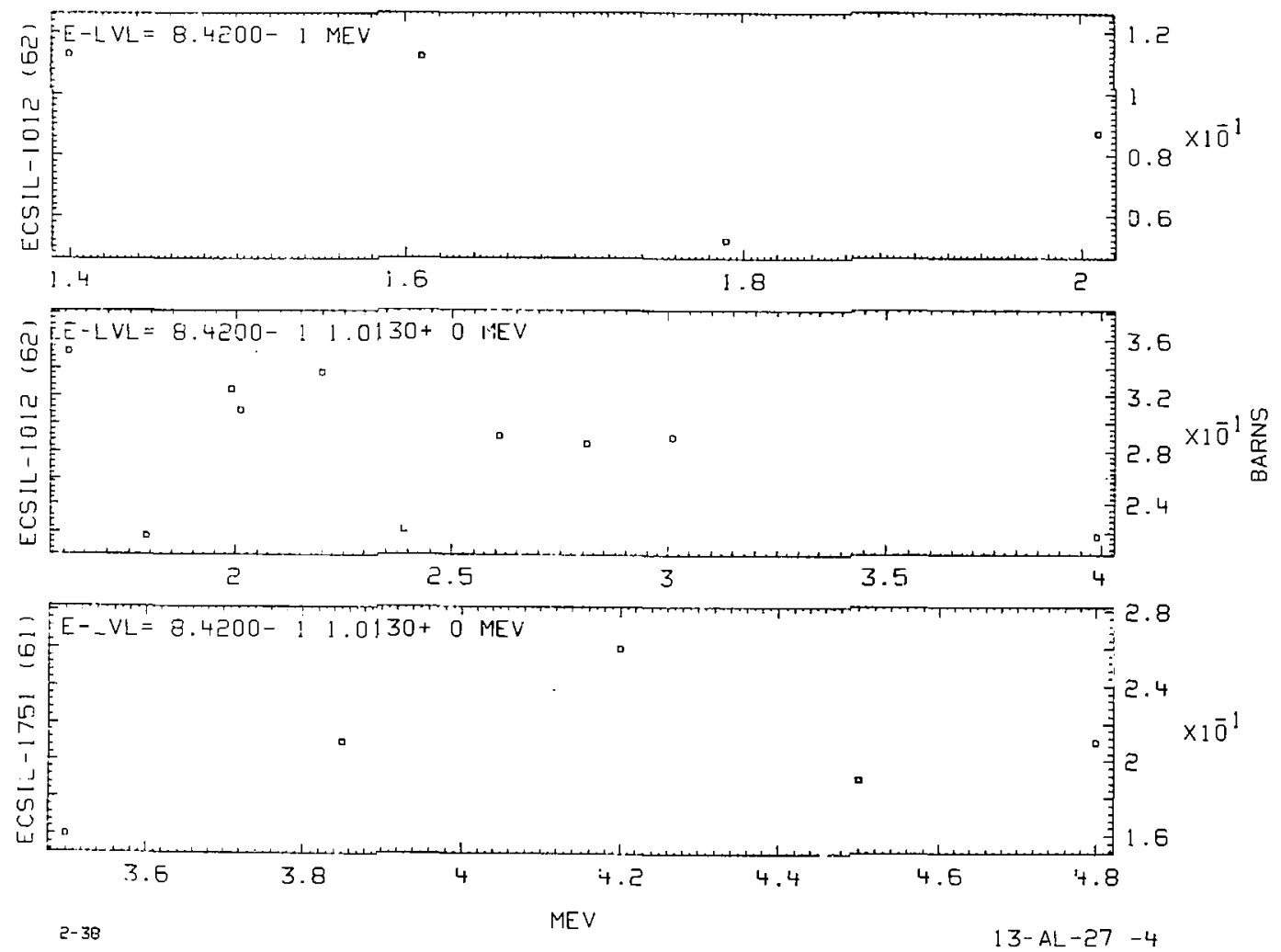

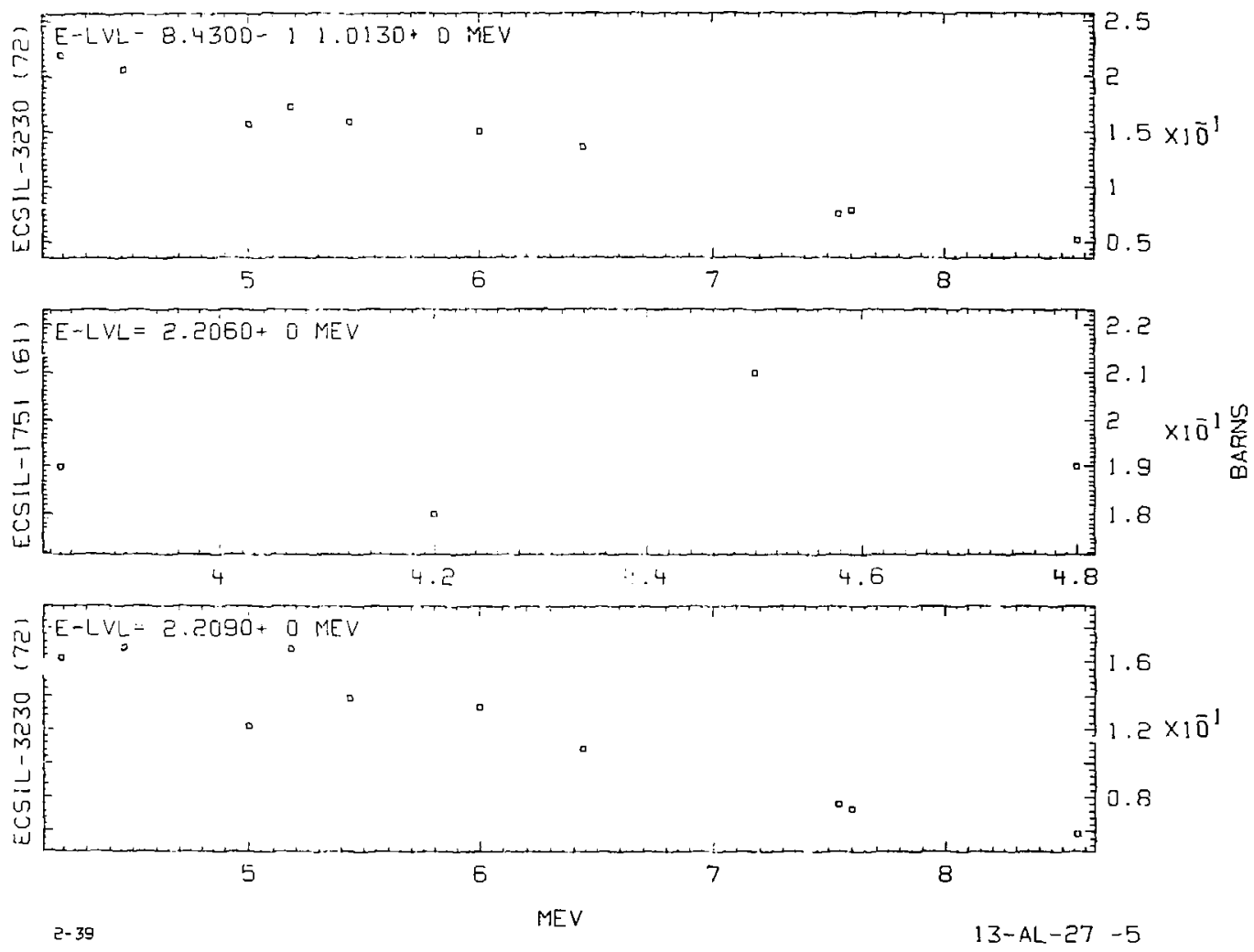

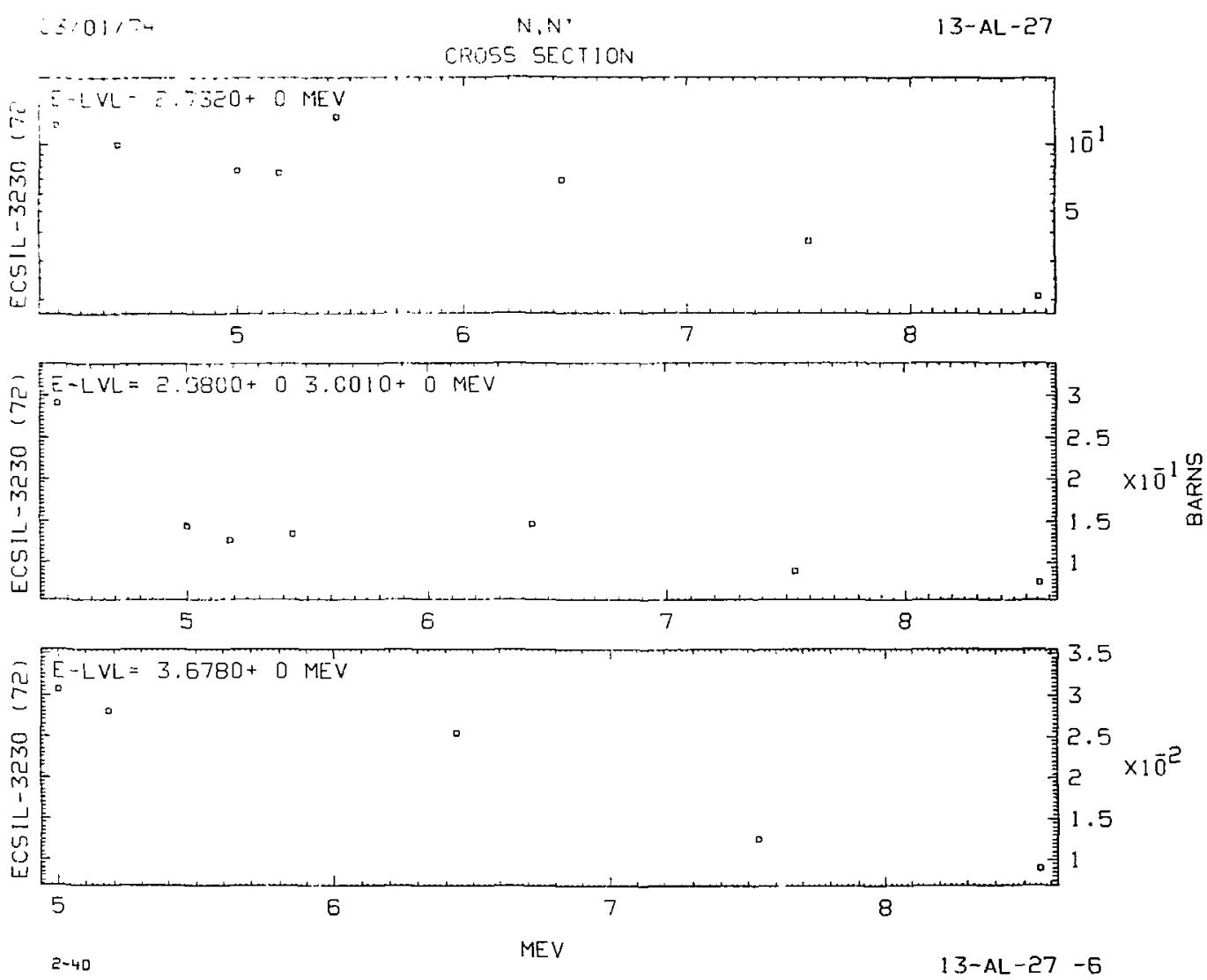

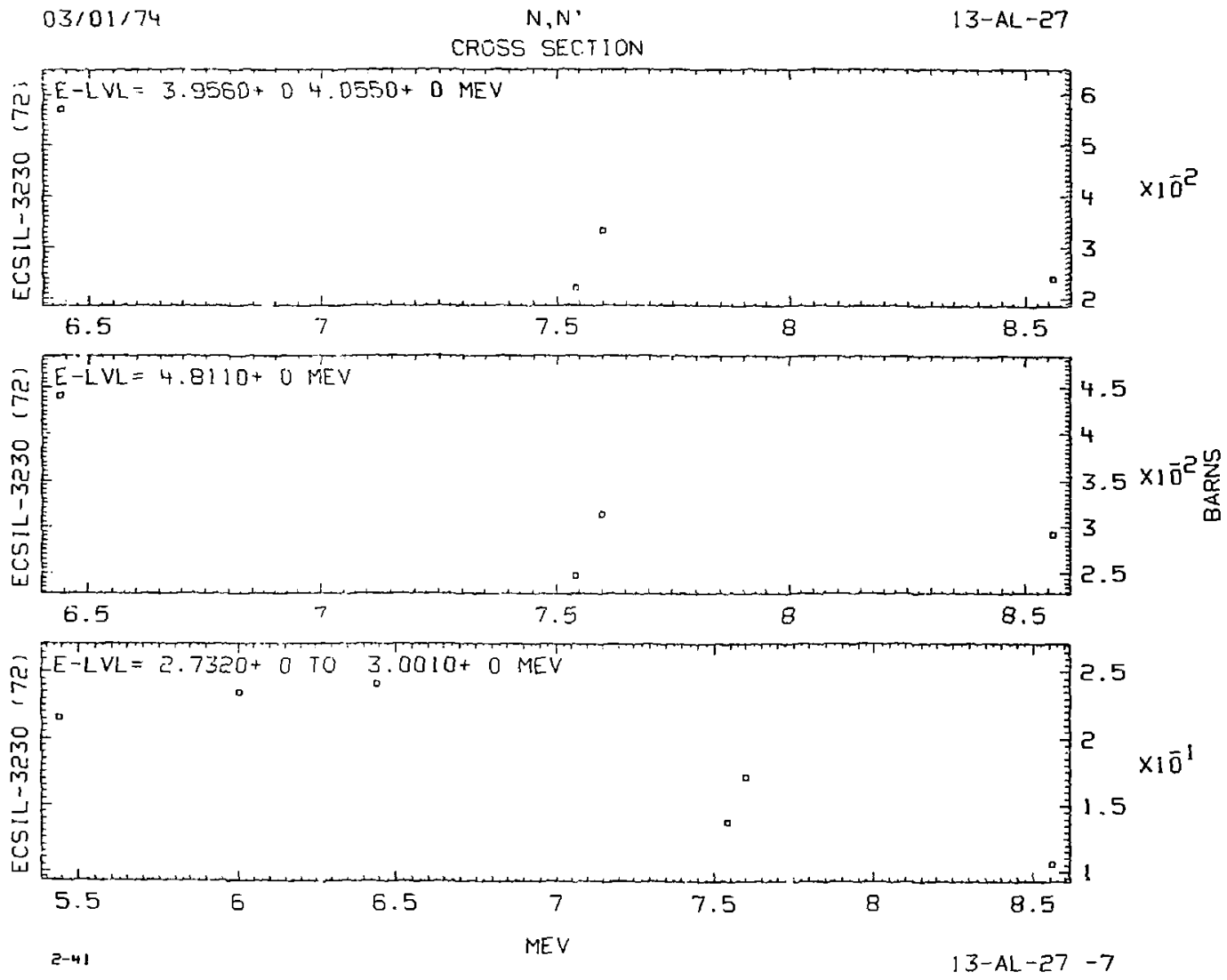

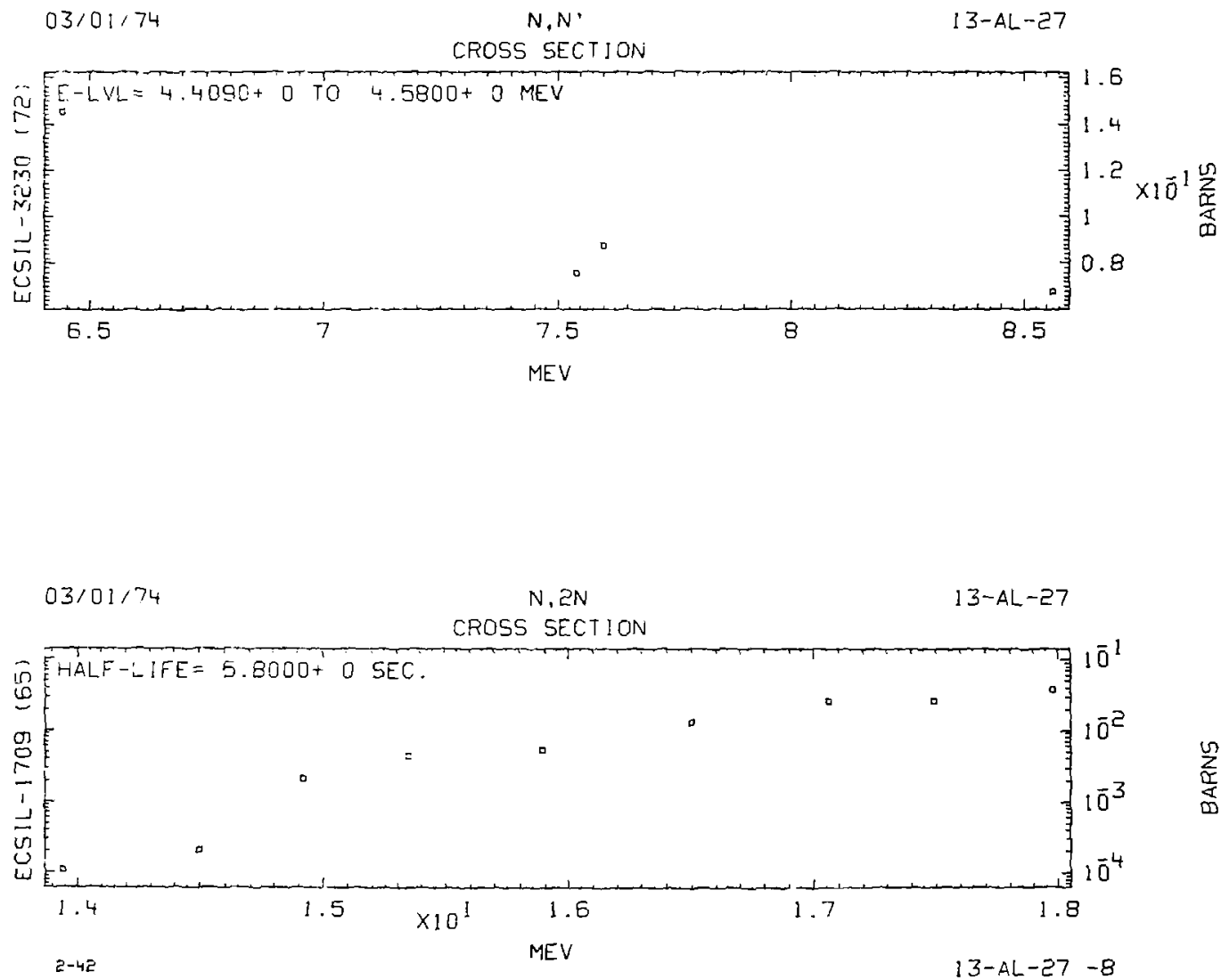

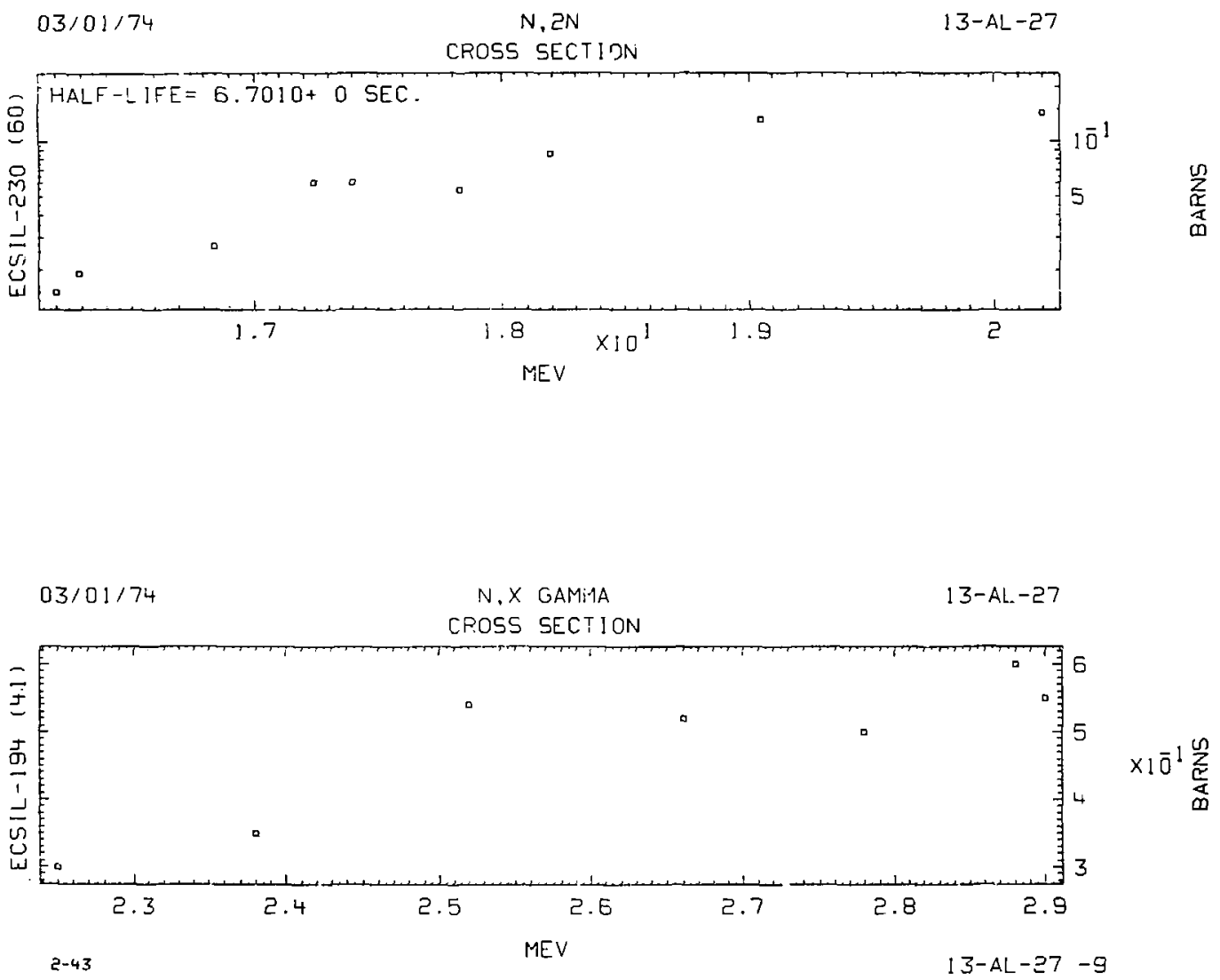

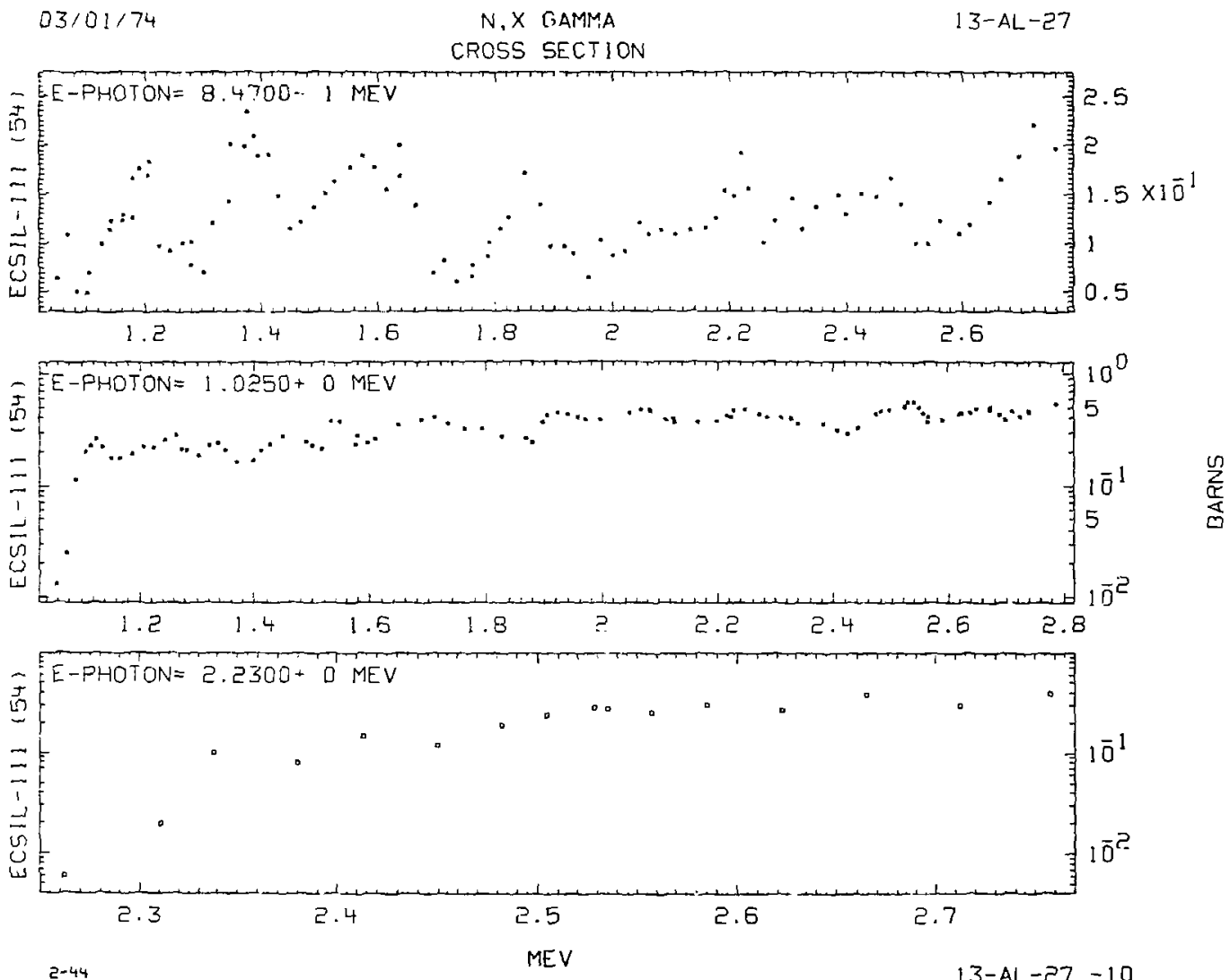

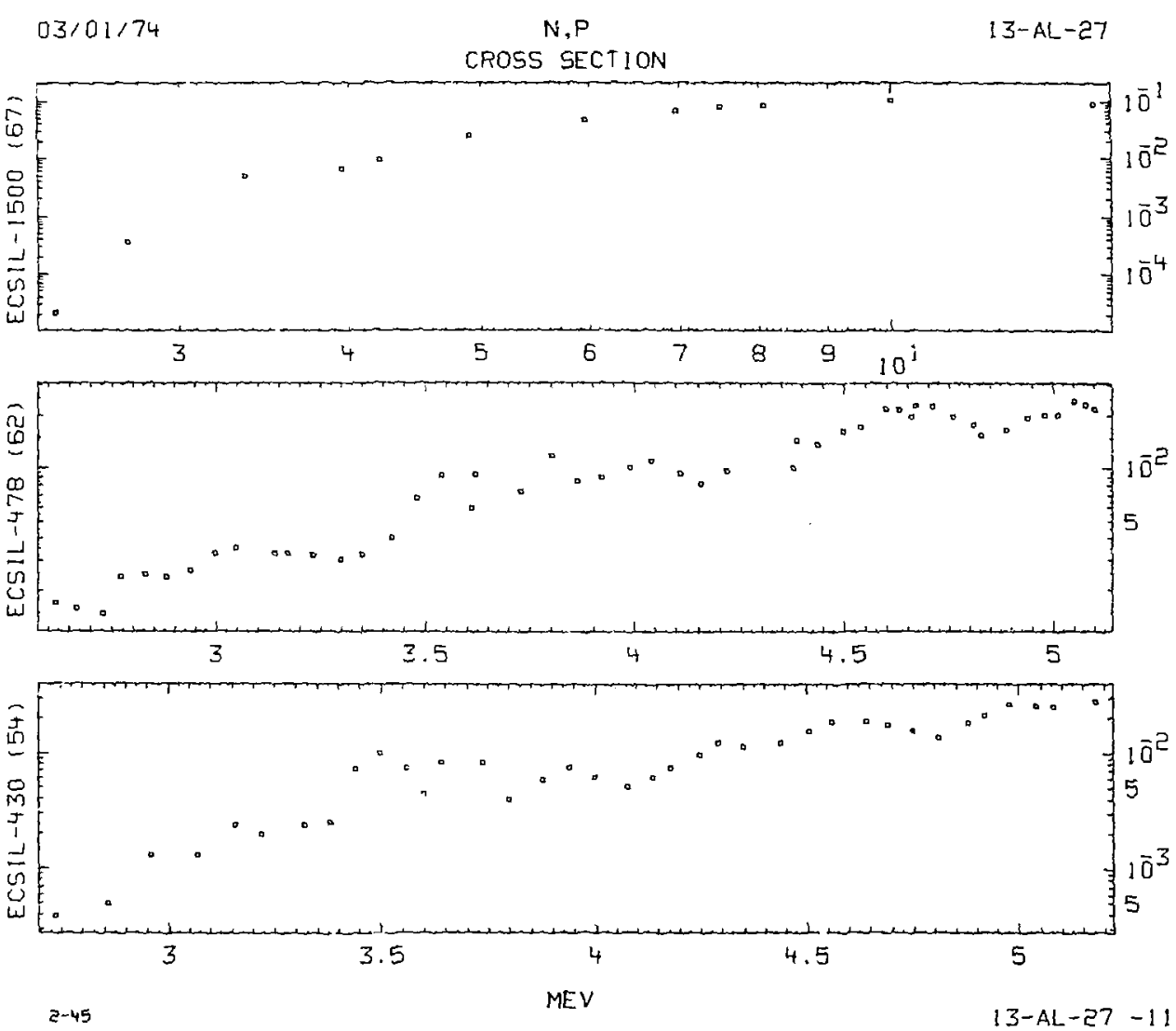

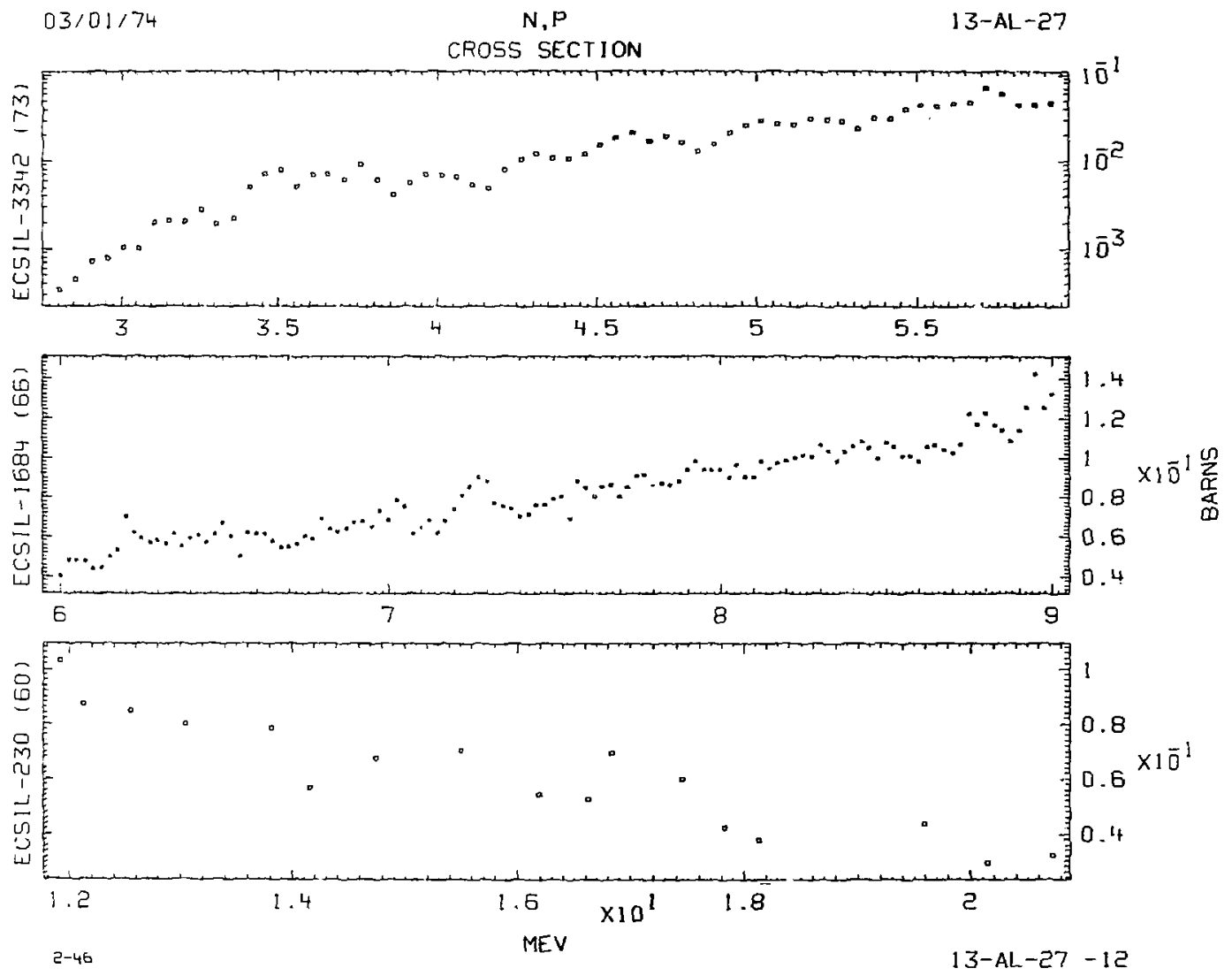


\section{CROSS SECTION}
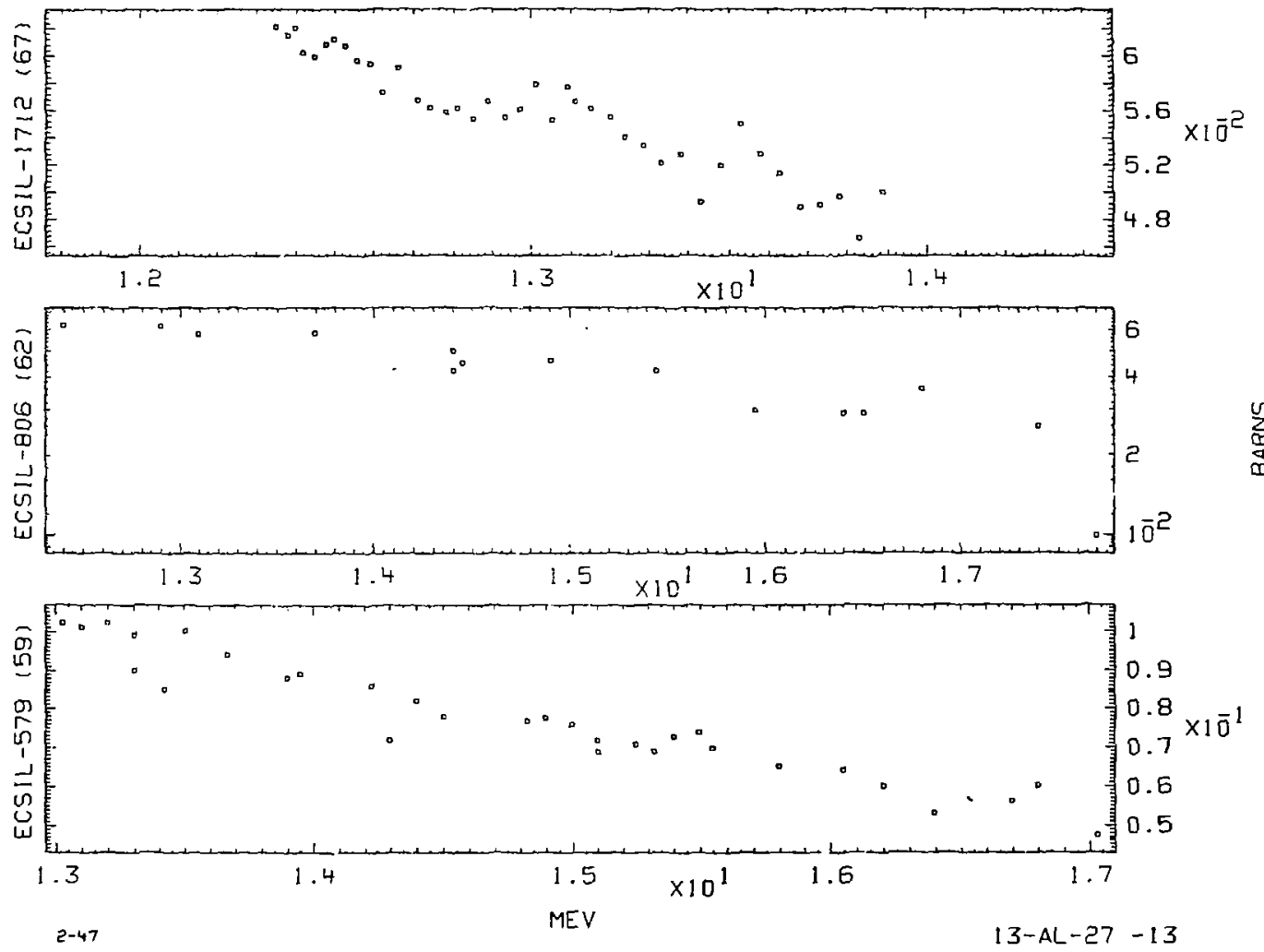


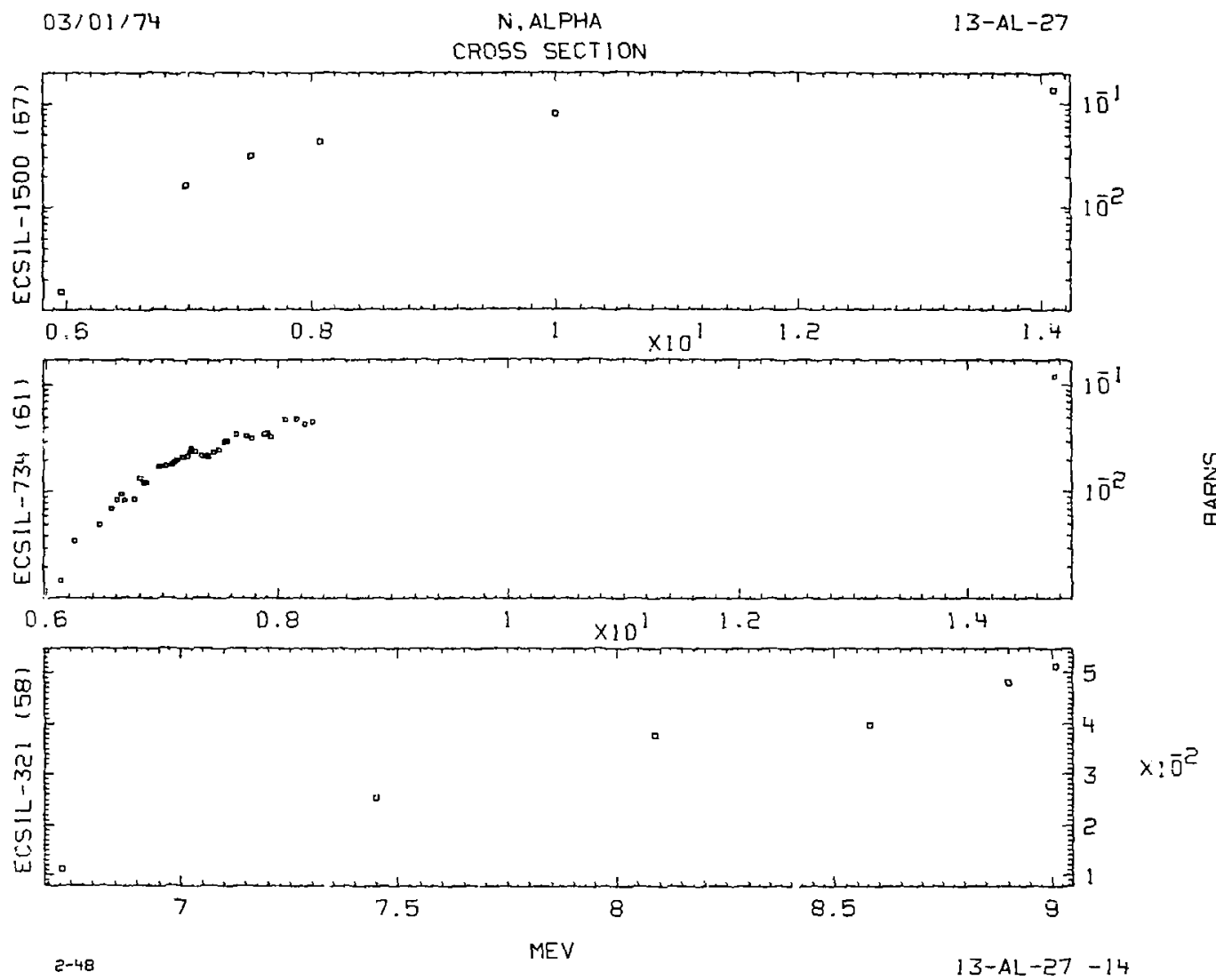



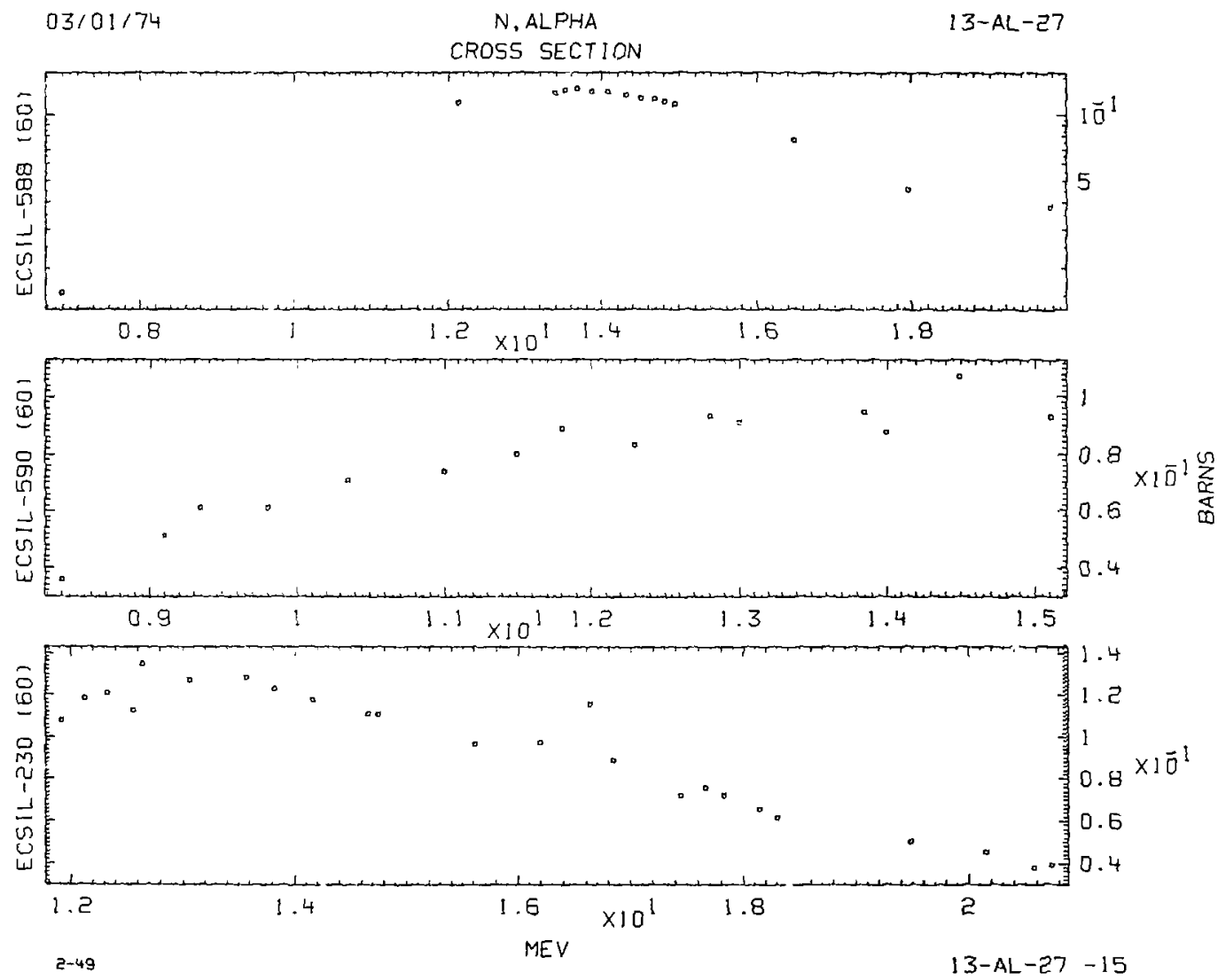


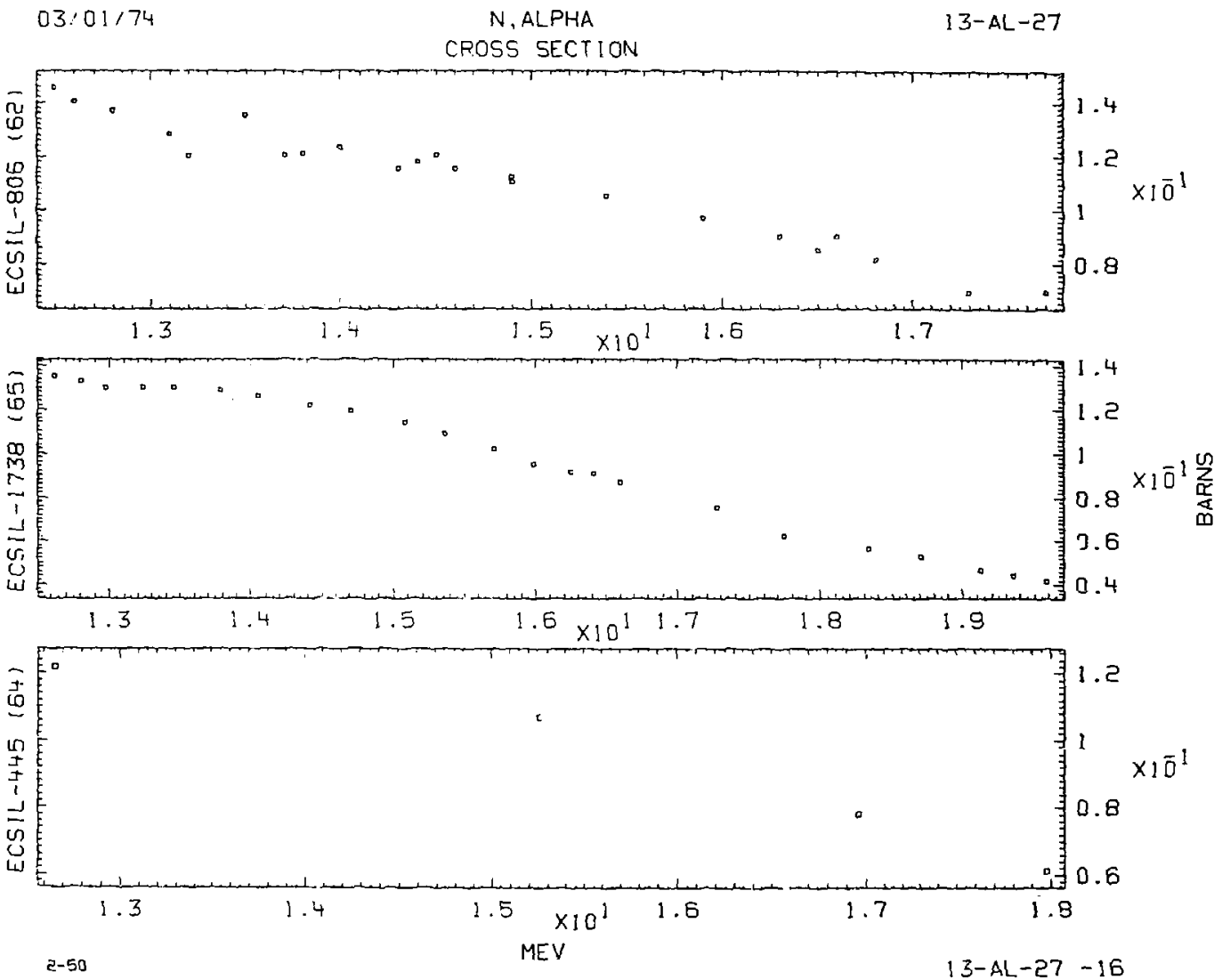




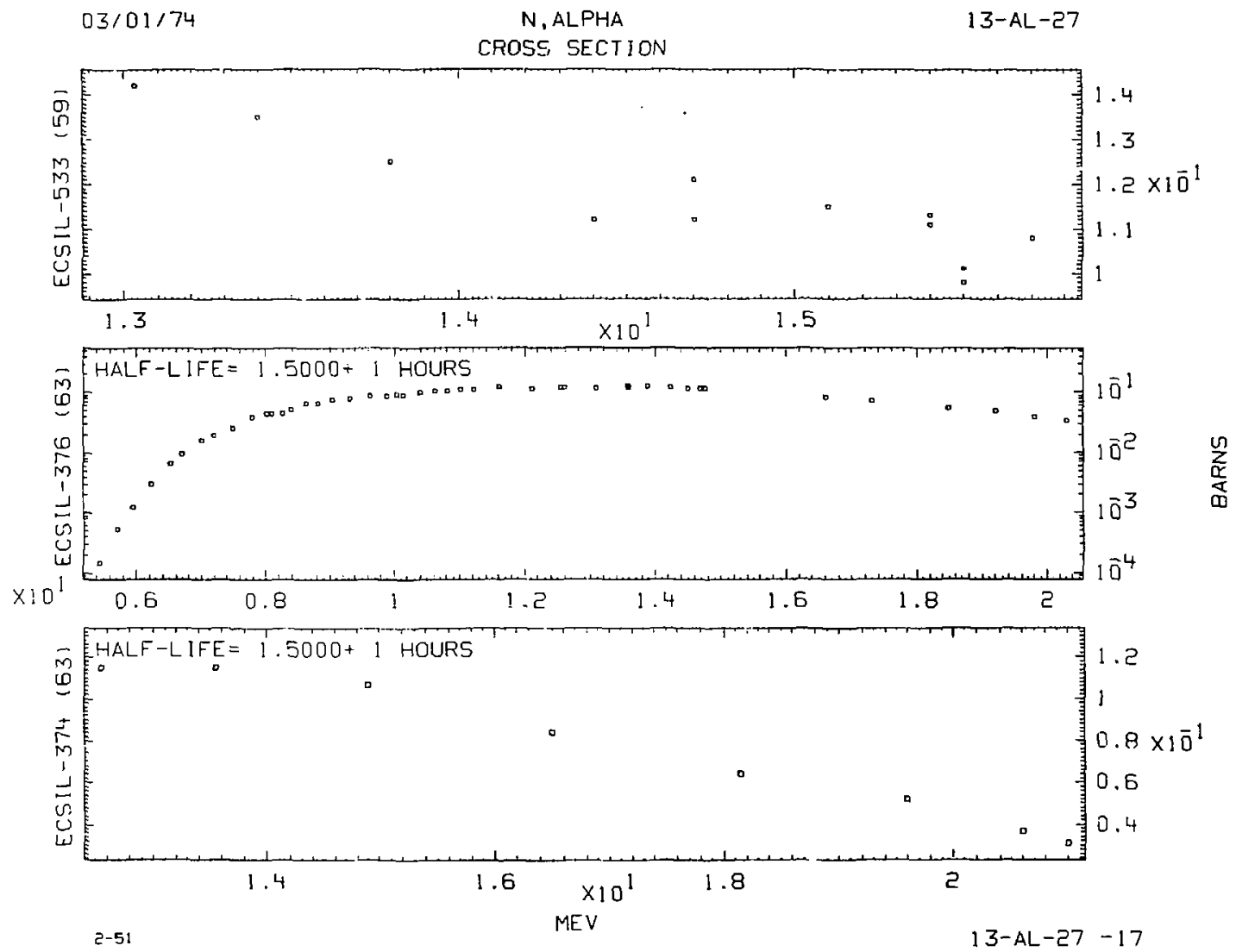



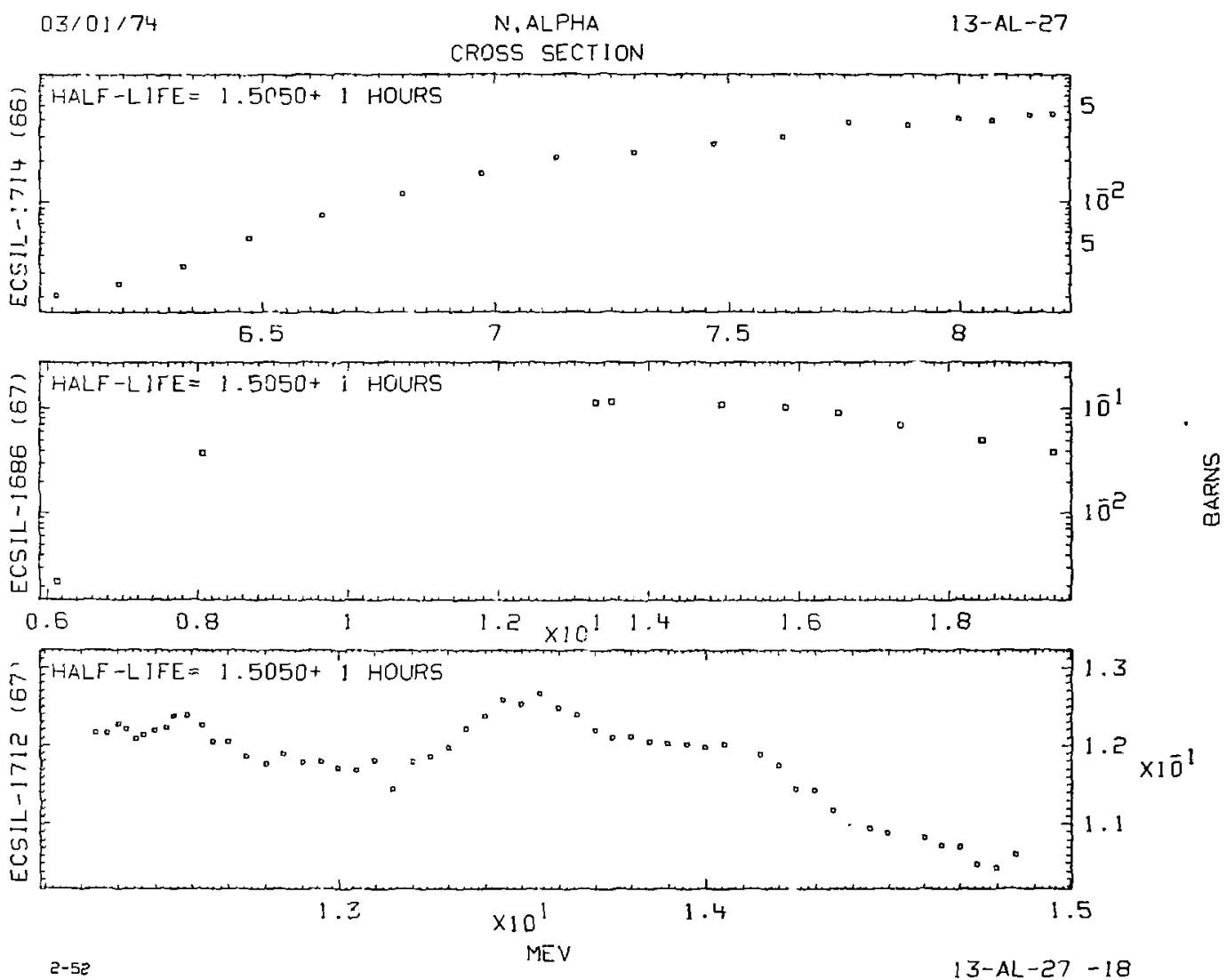

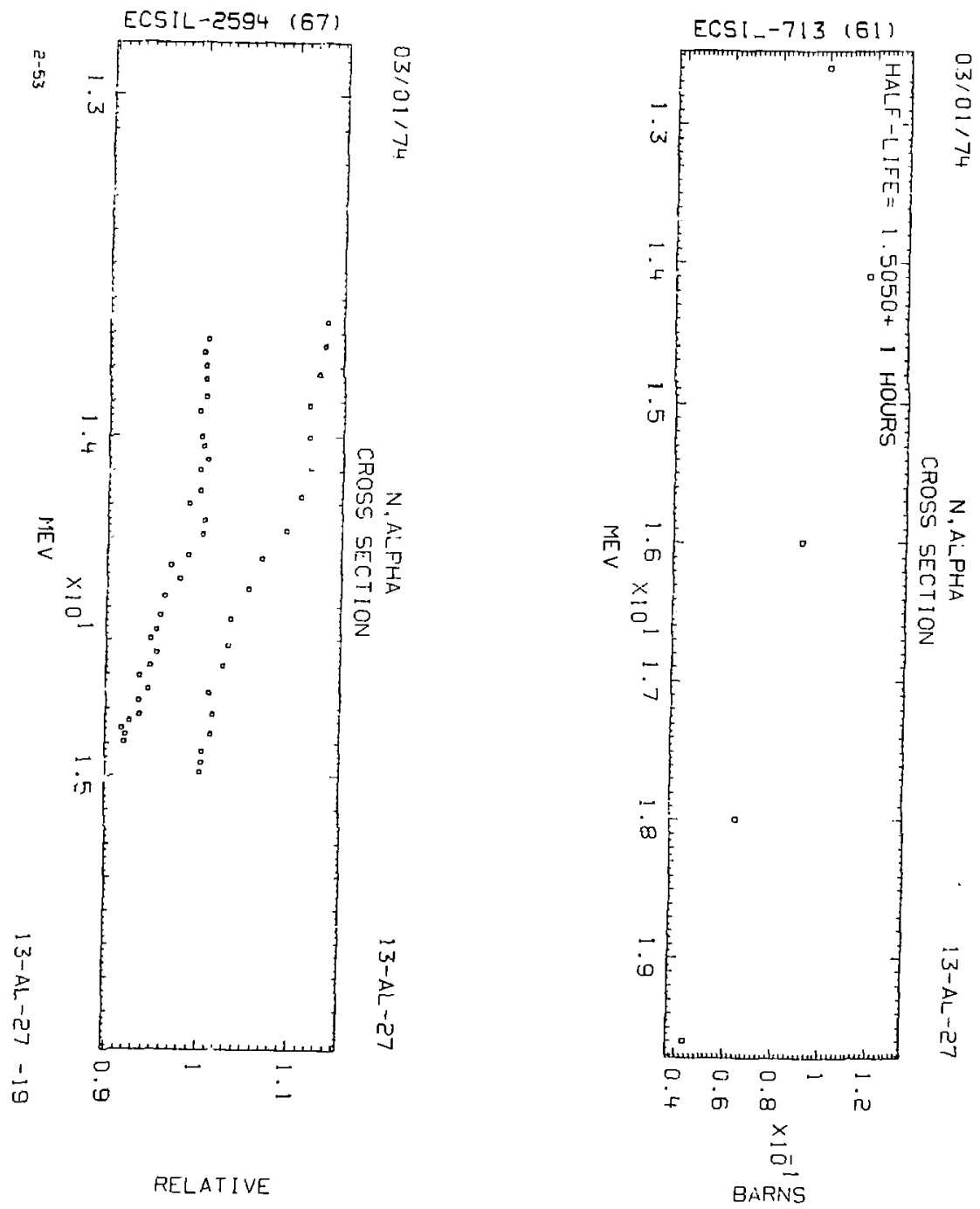
CROSS SECTION

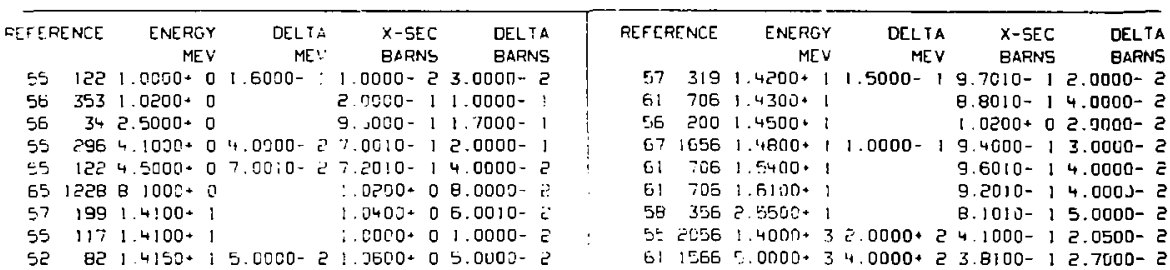

$03 / 01 / 74$

TOTAL SCATTERING

$13-A L-27$

$\begin{array}{rrrr}\text { REFERER.EE ENESGY DELTA } & \text { X-SEC } & \text { DÉLTA } \\ \text { MEV } & \text { MEV } & \text { BARNS } & \text { BARNS }\end{array}$

$63 \quad 8799.8000-15.0000-2$ 2 9200110 B .7600-

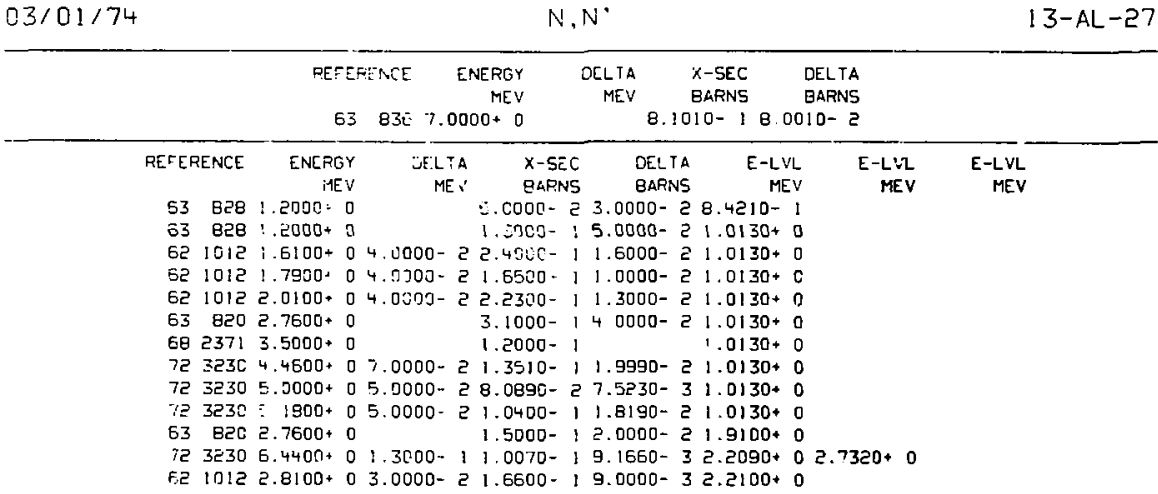


CROSS SECTION

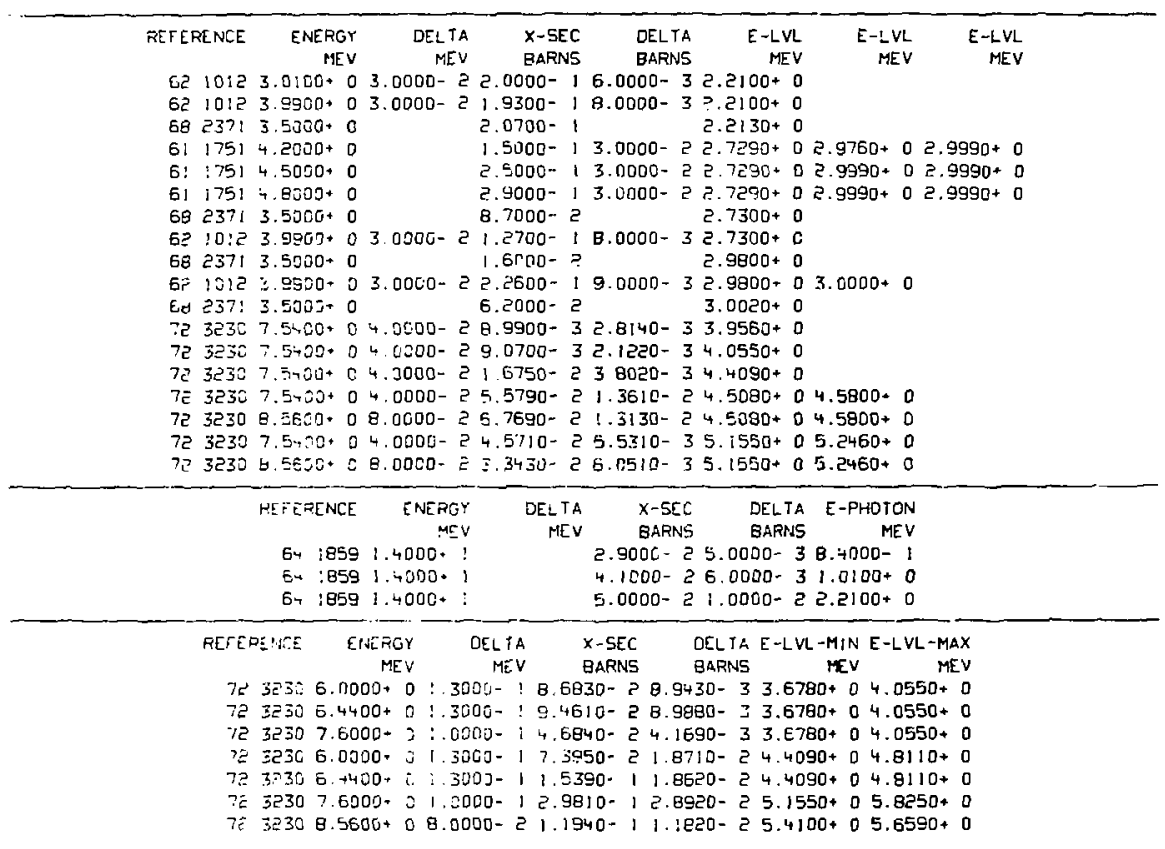


CROSS SECTION

\begin{tabular}{|c|c|c|c|c|c|c|c|c|c|c|c|}
\hline \multirow{2}{*}{\multicolumn{2}{|c|}{ REE ERENCE }} & ENERGY & DEL $Y_{A}$ & $x-\operatorname{SEC}$ & DELTA & \multicolumn{2}{|c|}{ REFERINCE } & EMERGY & DELTA & $x-5 E C$ & DELIA \\
\hline & & MEY & MEV & GARNS & BAFNS & & & MEV & MEV & BARNS & BAFNS \\
\hline $5^{-}$ & 217 & $4000+1$ & & $7.0010-2$ & $9.8010-3$ & 62 & 688 & $1.4400+1$ & -1 & $11.7000=2$ & $6.0010-3$ \\
\hline $6:$ & 361 & $1.4000+1$ & & $5.3010-2$ & $1.1000-2$ & 61 & 658 & $1.4800+1$ & & $1.5700-1$ & \\
\hline
\end{tabular}

$03 / 01 / 74 \quad$ ABSORPTION $\quad 13-A L-27$

\begin{tabular}{|c|c|c|c|c|c|c|c|c|c|c|}
\hline RE FERENCE & $\begin{array}{r}\text { ENERGY } \\
\text { MEV }\end{array}$ & $\begin{array}{l}\text { DEL IA } \\
\text { MEV }\end{array}$ & $\begin{array}{l}X-S E C \\
\text { BARNS }\end{array}$ & $\begin{array}{l}\text { DELIAA } \\
\text { BARNS }\end{array}$ & \multicolumn{2}{|c|}{ RETERENKE } & $\begin{array}{l}\text { ENGRGY } \\
\text { MEV }\end{array}$ & $\begin{array}{r}\text { DEL TA } \\
\text { MEV }\end{array}$ & $\begin{array}{l}x-5 E C \\
\text { BARNS }\end{array}$ & $\begin{array}{l}\text { DELTA } \\
\text { BARNS }\end{array}$ \\
\hline 612569 & $2.5300-8$ & & $2.3900-1$ & $11.4000-2$ & 58 & 364 & $2.5000-2$ & $4.0000-3$ & $1.7000-2$ & $=.0000-3$ \\
\hline 602932 & $2.5300-8$ & & $2.2000-1$ & $11,3000 \cdots 2$ & 58 & 3EH & $2.2000-1$ & $2.0000-2$ & $6.0000-3$ & $;-.0000-3$ \\
\hline $66 \quad 1491$ & $2 \div x-8$ & & $2.2900-1$ & $13.0000-3$ & 58 & 3EH & $8.3000-1$ & $4.0000-2$ & $1.6000-2$ & \\
\hline $58: 162$ & $2.5 .0-8$ & & 2. $+600-1$ & $13.0000-3$ & & & & & & \\
\hline
\end{tabular}

O3,01/74

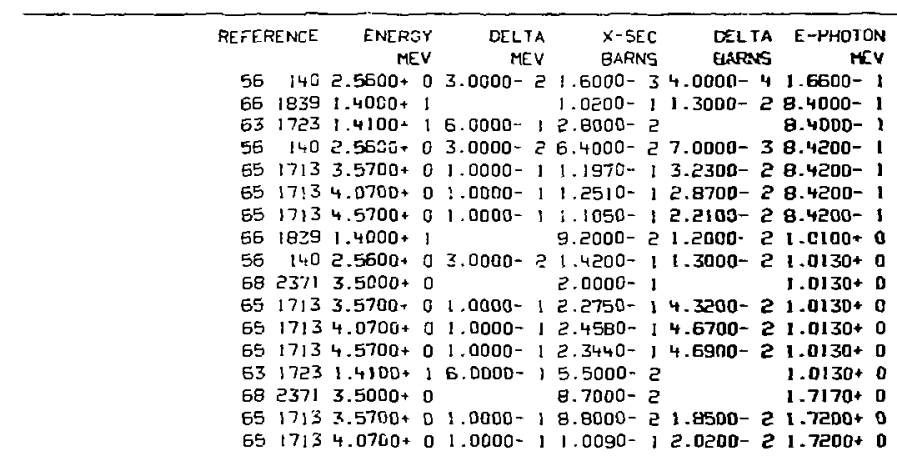


CROSS SECTION

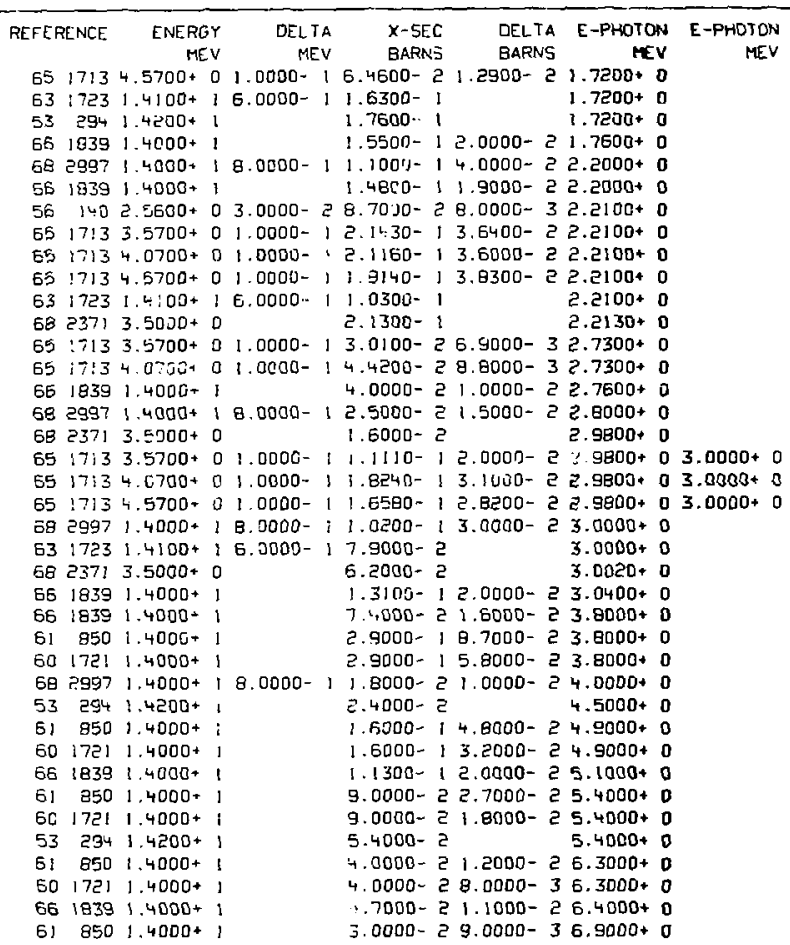


CROSS SECTION

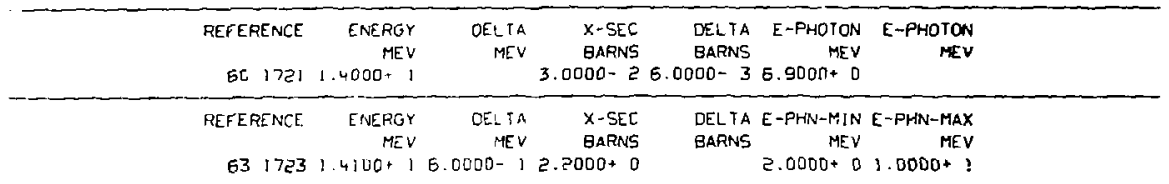

$03 / 01 / 74$

N.P

13-AL-27

\begin{tabular}{|c|c|c|c|c|c|c|c|c|c|c|c|}
\hline \multicolumn{2}{|c|}{ REFERENCE } & $\begin{array}{r}\text { ENERC } \\
1^{+1 E}\end{array}$ & & $\begin{array}{r}\text { DELTA } \\
\text { MEV }\end{array}$ & $\begin{array}{l}x-S[C \\
\text { BARNS }\end{array}$ & $\begin{array}{l}\text { CELLTA } \\
\text { BARNS }\end{array}$ & REFCRENCE & $\begin{array}{r}\text { ENEPGY } \\
\text { MEV }\end{array}$ & $\begin{array}{r}\text { DELTA } \\
\text { MEV }\end{array}$ & $\begin{array}{l}X \text {-SEL } \\
\text { GARNS }\end{array}$ & $\begin{array}{l}\text { DELTA } \\
\text { BARNS }\end{array}$ \\
\hline $5 !$ & 351 & 1.40004 & 1 & & $8.7010-2$ & $1.1000-2$ & 692050 & $1.4500+1$ & $2.0000-1$ & B. 1900- 2 & $7.0000-3$ \\
\hline 57 & 217 & $1.4000^{\circ}$ & 1 & & $7.0010-2$ & $1.0000-2$ & 53 & $1.4500+1$ & & $5.2410-2$ & $9.4010-3$ \\
\hline 50 & 837 & $1.4100+$ & 1 & $1.0000-1$ & $19.0013-2$ & $1.8000-2$ & $53 \quad 372$ & $1.4500+1$ & & $7.2010-2$ & \\
\hline 51 & 651 & $1,4100+$ & 1 & & B.:010- & $4.0000-3$ & $54 \quad 1848$ & ].4700+ 1 & $1.5000-1$ & $6.6000-2$ & $1.0000-3$ \\
\hline 57 & 159 & $1.4100^{+}$ & 1 & $1.0000+3$ & $37.9010-2$ & $? .5000-2$ & 62 & $1.4700+1$ & $1.5000-1$ & $8.2010-2$ & $1.0000-2$ \\
\hline 52 & $B 4$ & $1.4100+$ & 1 & & $7.90: 0-2$ & $E .8010-3$ & 65907 & $1.4800+1$ & $1.0000-1$ & $9.7000-2$ & $1.0000-2$ \\
\hline 57 & 535 & $1.4140+$ & 1 & $1.8000-1$ & $8.7010-2$ & $7.0010-5$ & 51860 & $1.4800+1$ & & $7.7010-2$ & $8.0010-3$ \\
\hline 58 & 1944 & $1.4200 *$ & 1 & $2.0000-!$ & ! 7.1500- 2 & $9.0000-3$ & 59 OEZ & $1.4800+1$ & $9.0010-1$ & $5.3010-2$ & $5.0000-3$ \\
\hline 59 & 2334 & $1.4200+$ & 1 & $2.0000-1$ & $17.7000-2$ & $7.0000-3$ & 703150 & $1.4800+1$ & 2.0000- ! & $7.3000-2$ & $5.0000-3$ \\
\hline 68 & 2695 & $1.4400+$ & 1 & $3.0000-i$ & $6.8003-2$ & $8.0000-3$ & $50 \quad 528$ & $1.5000+1$ & & $5.9010-2$ & $6.0010-3$ \\
\hline 62 & $68 \theta$ & $1.4400+$ & 1 & $2.0000-1$ & $19.3010-2$ & $\therefore 0000-2$ & & & & & \\
\hline & & & & & ME ${ }^{\prime}$ & $\begin{array}{l}\text { ELTR } \\
\text { MEV }\end{array}$ & & & MEV & MEV & \\
\hline
\end{tabular}

67 i914 7.9006-0 8.0000- $27.1000-37.0000-40.0000+03.1000-2$

$6719147.9000 \cdot 08.0000-29.8000-31.0000-39.8000-13.1000-2$

$5719 ! 47.9000+0$ B.0000- 22.4500-2 2.5000- $31.6900+01.9400+0$

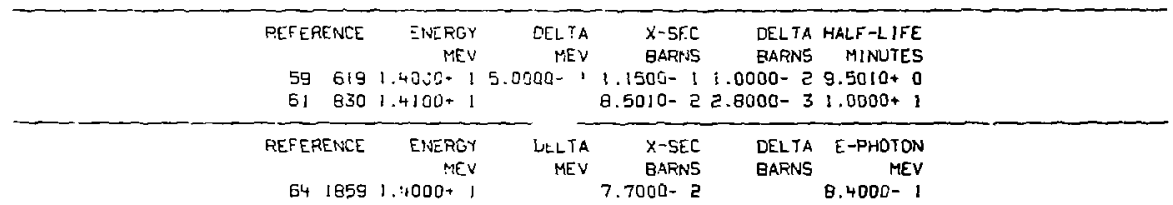




\section{CROSS SECTION}

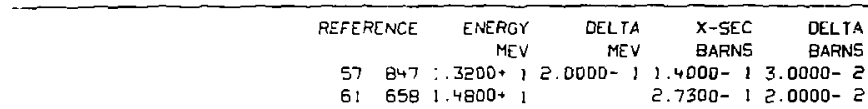

03/01/74

$60667+.4800+, 9.0010-15.0000-4$

$03 / 01 / 74$

$$
N, A L P H A
$$

$13-A L-27$

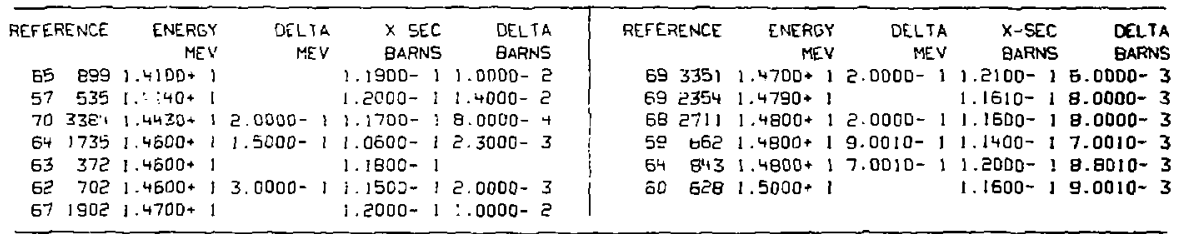

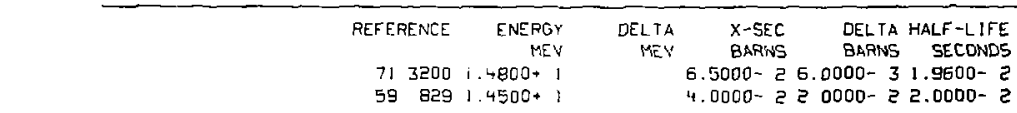

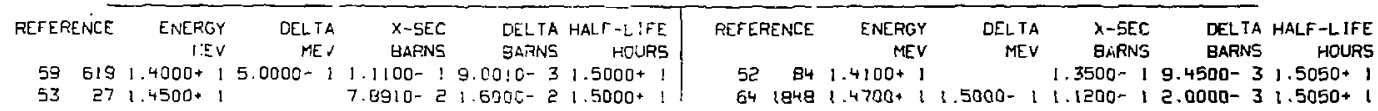




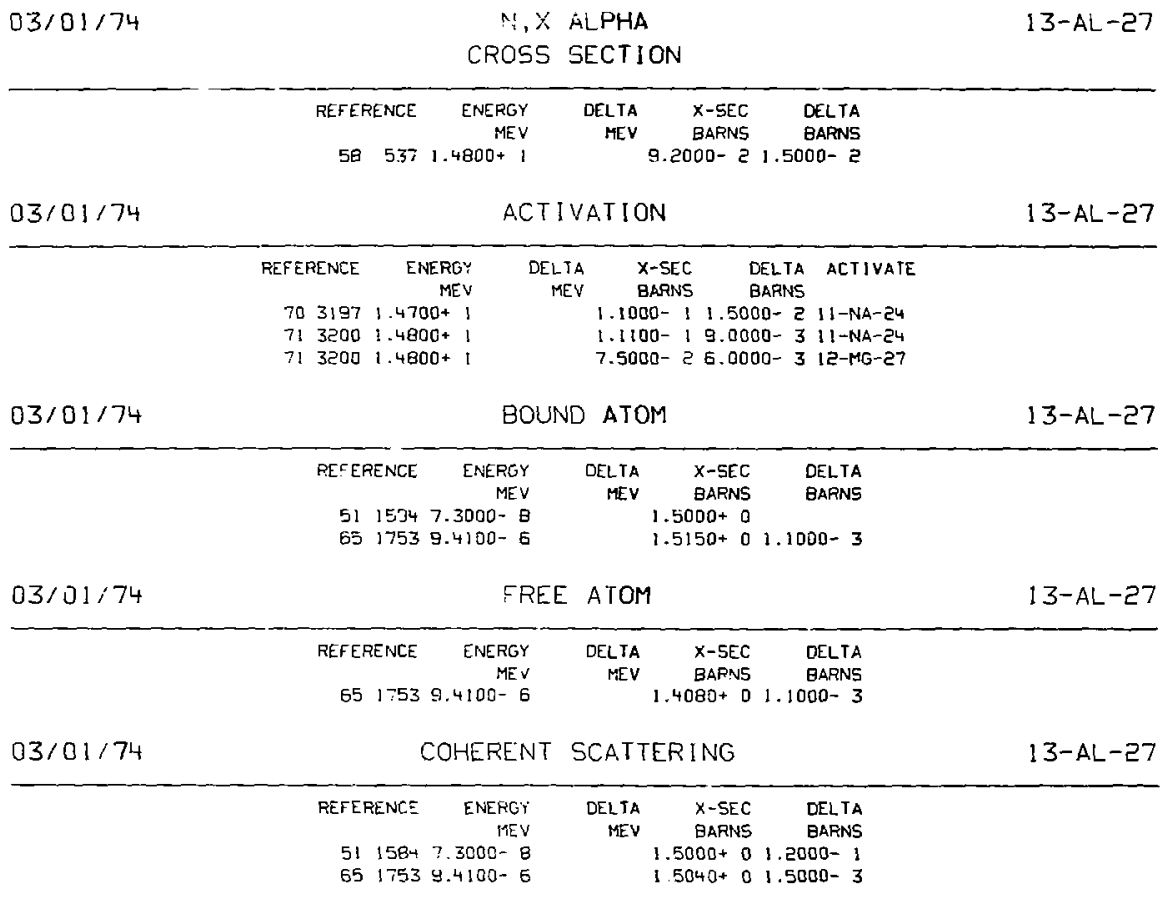




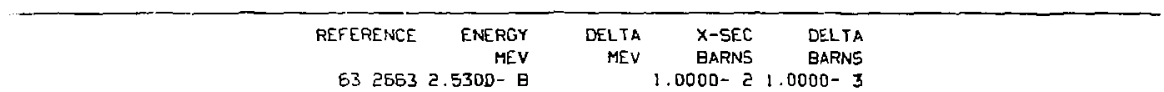

$6325632.5300-\mathrm{B}$ 1.0000- $21.0000-3$

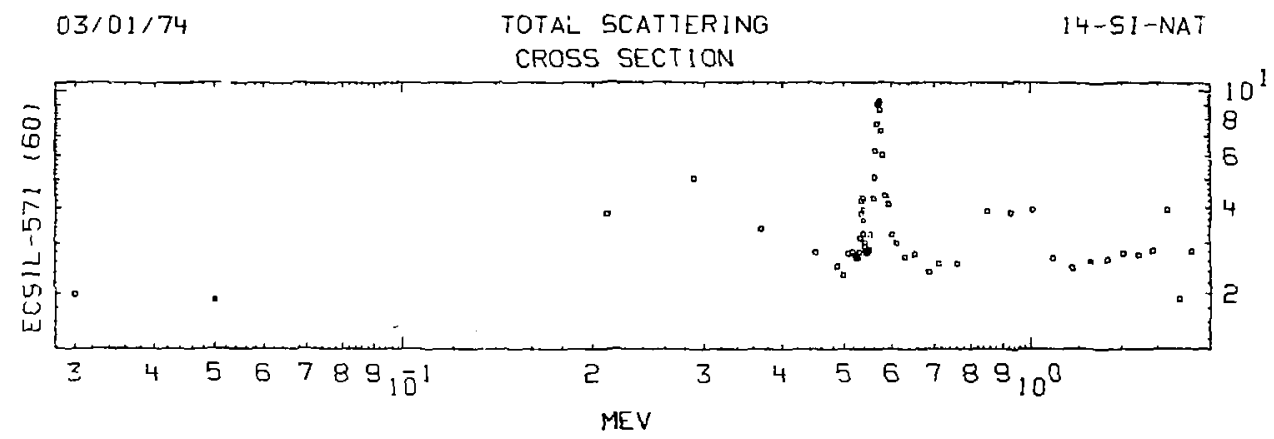




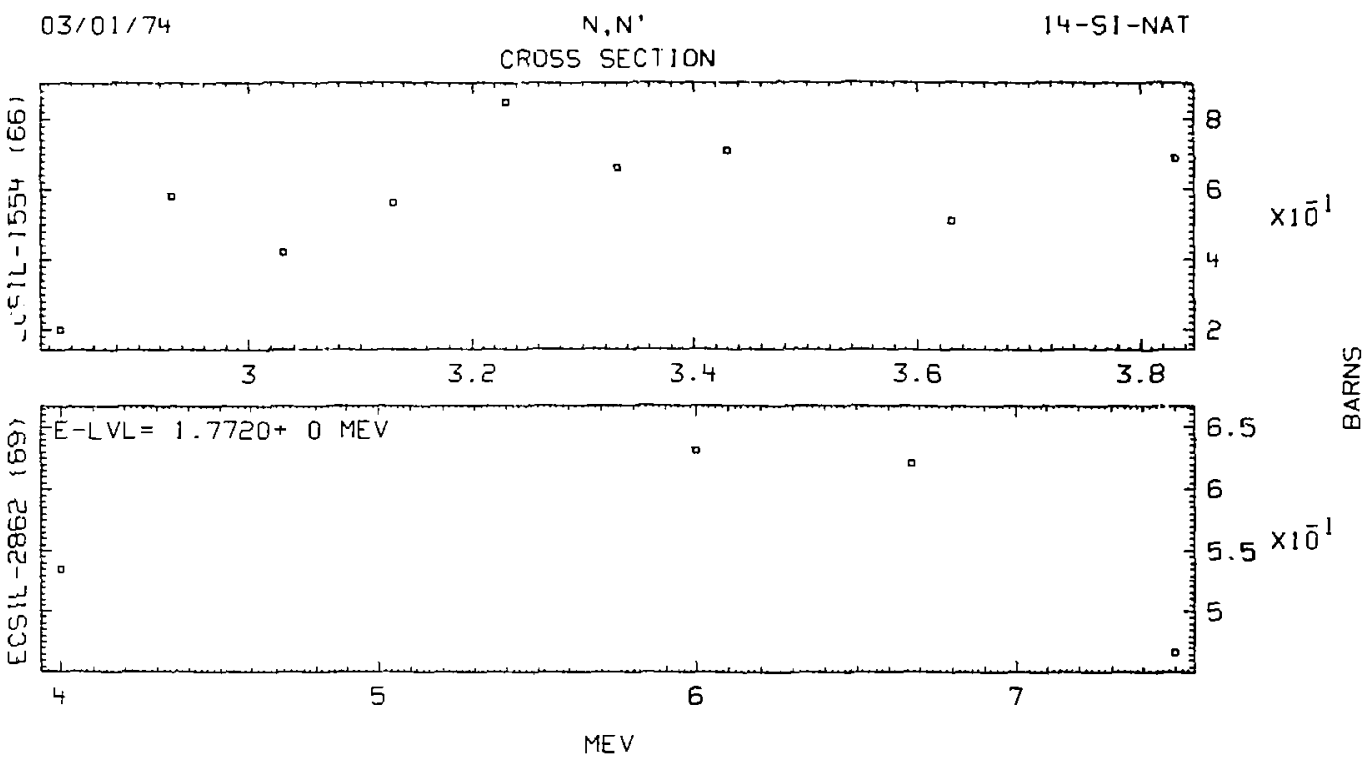



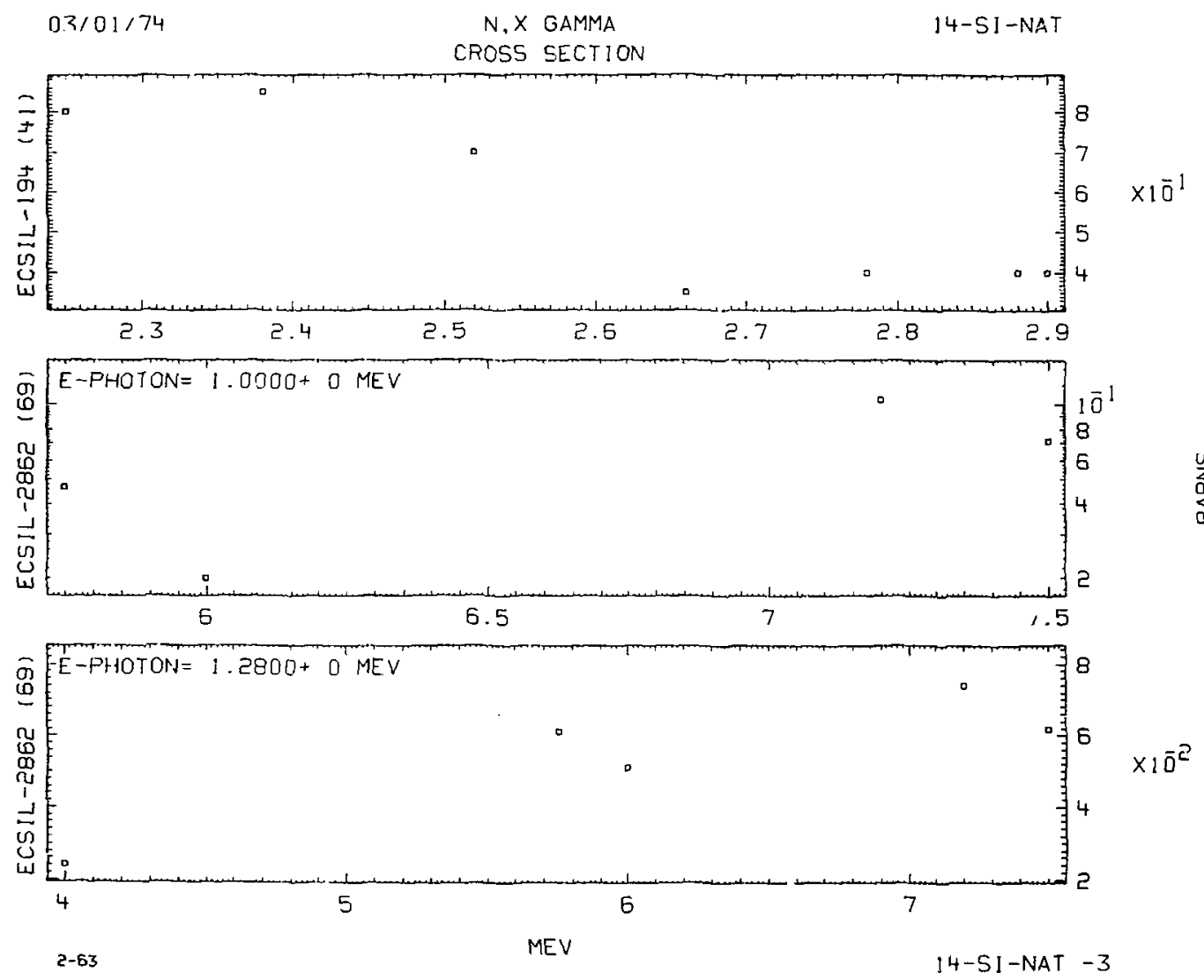


$\begin{array}{rr}N, X \text { GAMMA } & 14-5 I-N A T \\ \text { CROSS SECTION }\end{array}$
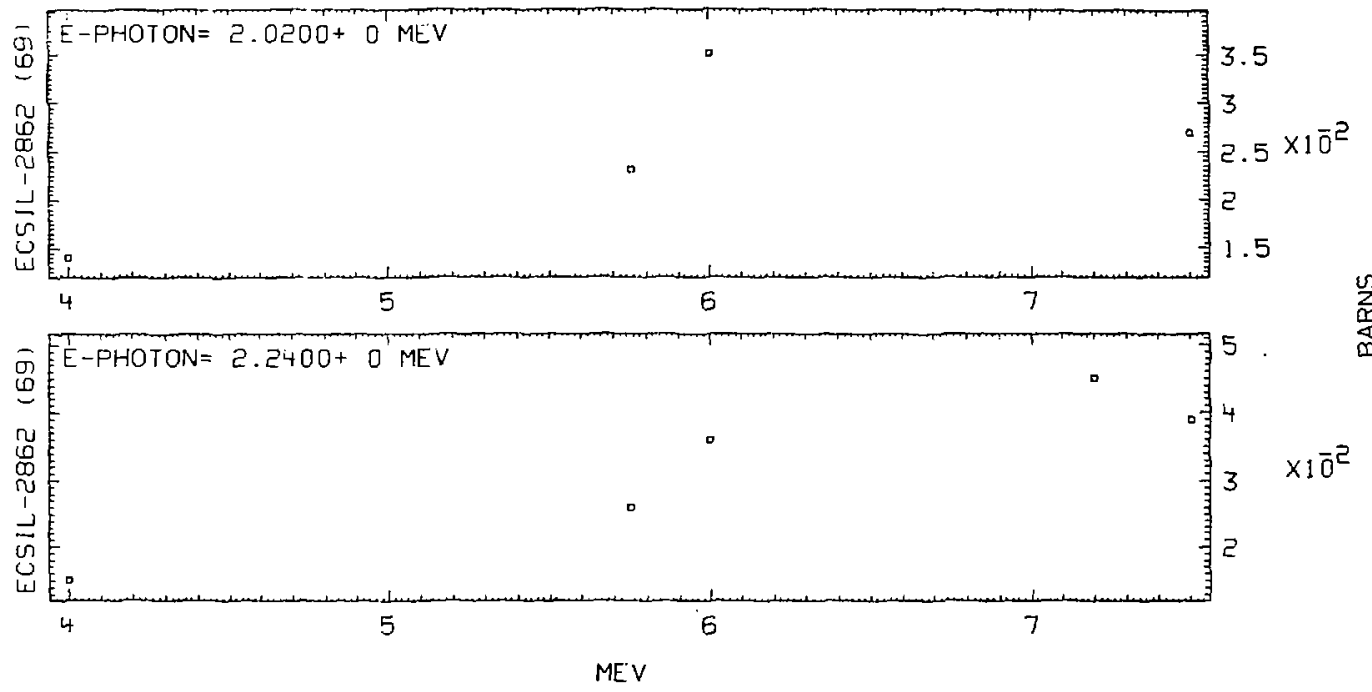

03/01,74

z-64 


\section{CROSS SECTION}

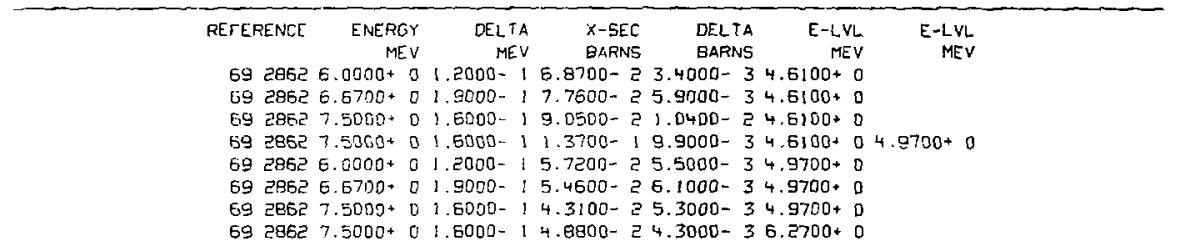

$03 / 01 / 74$

$N, X$ GAMMA

$14-5 I-N A T$

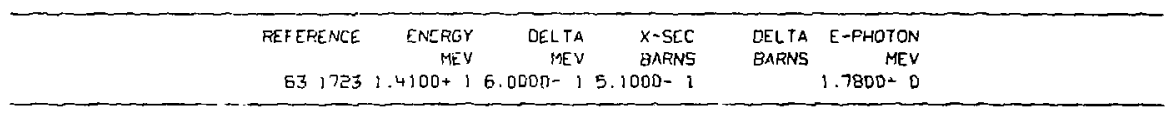

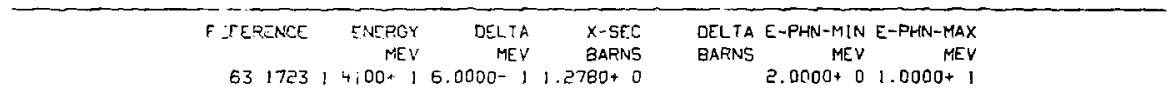

$03 / 01 / 74$

N.P

$14-5$ I -NAT

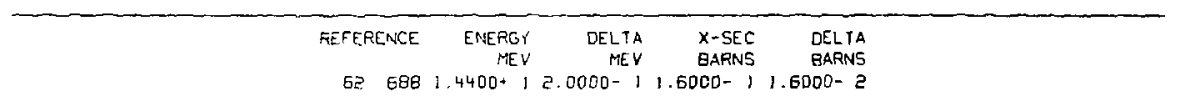

$03 / 01 / 74$

FREE ATOM

14-SI-NAT

REFEAENCE ENERGY

$6517599.4200-6$

$\begin{array}{lll}\text { DELTA } & X \text {-SEC } & \text { DELTA } \\ \text { MEV BARNS } & \text { BARNS }\end{array}$

$2.0220+03.0000-3$ 


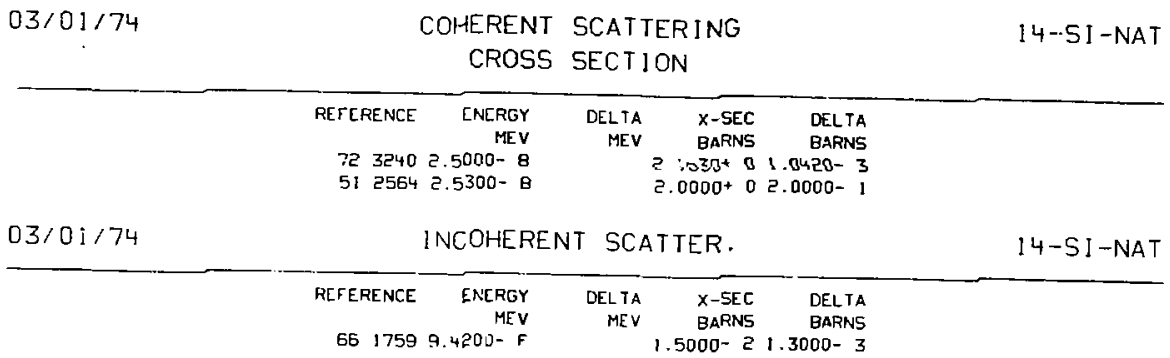

$6617599.4200-F \quad 1.5000-21.3000-3$

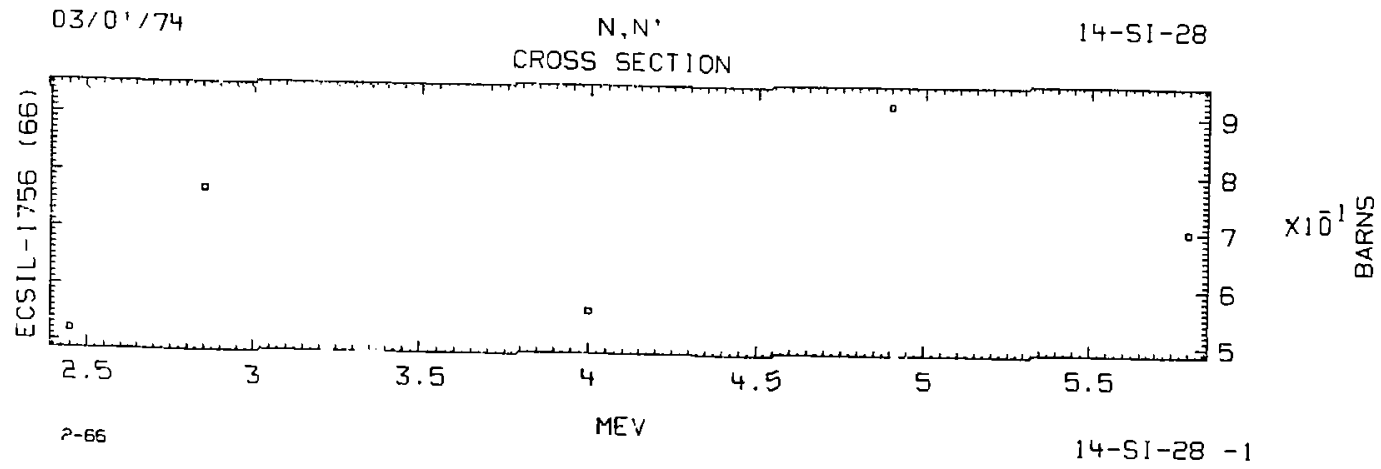




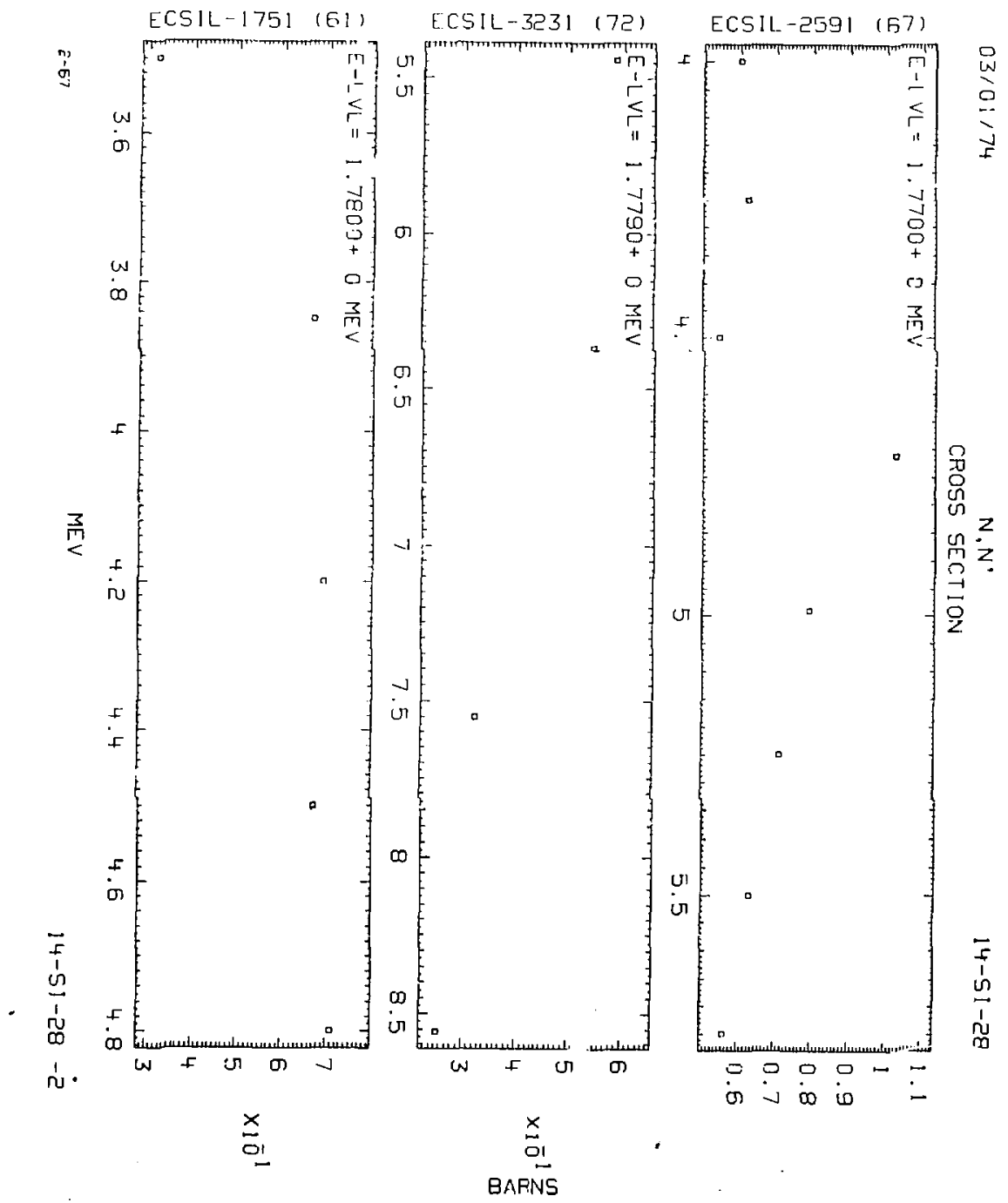



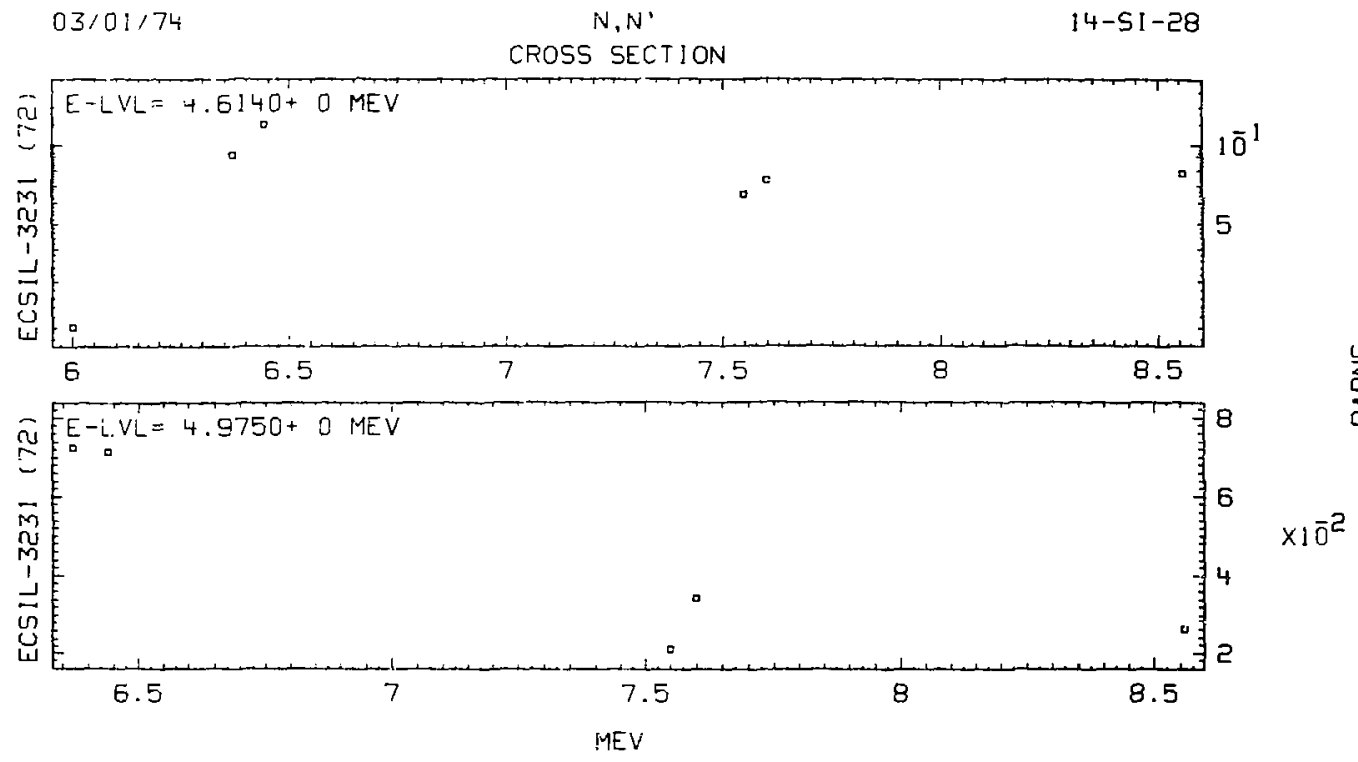

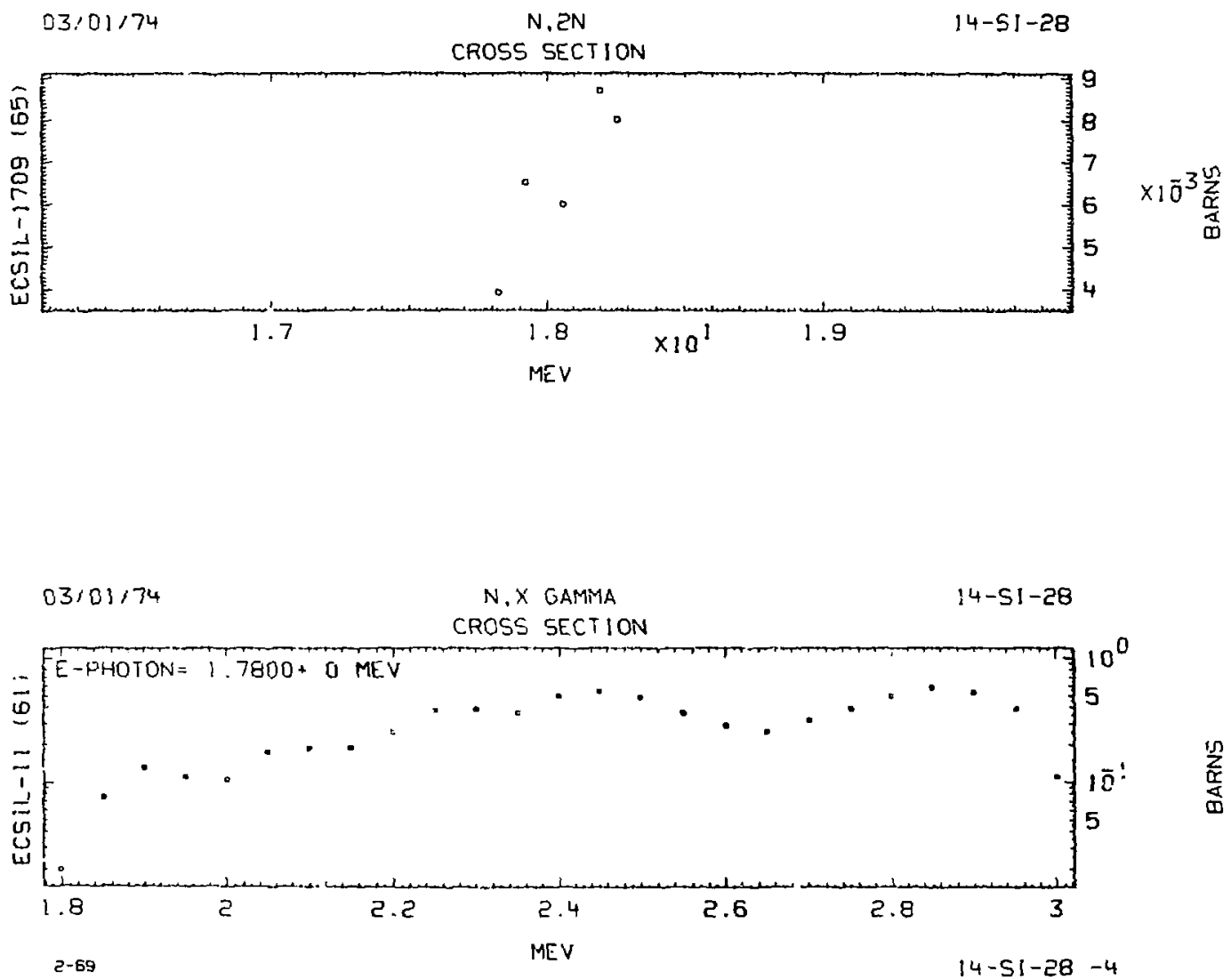

$\sum_{\substack{0 \\ 0}}^{\frac{10}{0}}$ 

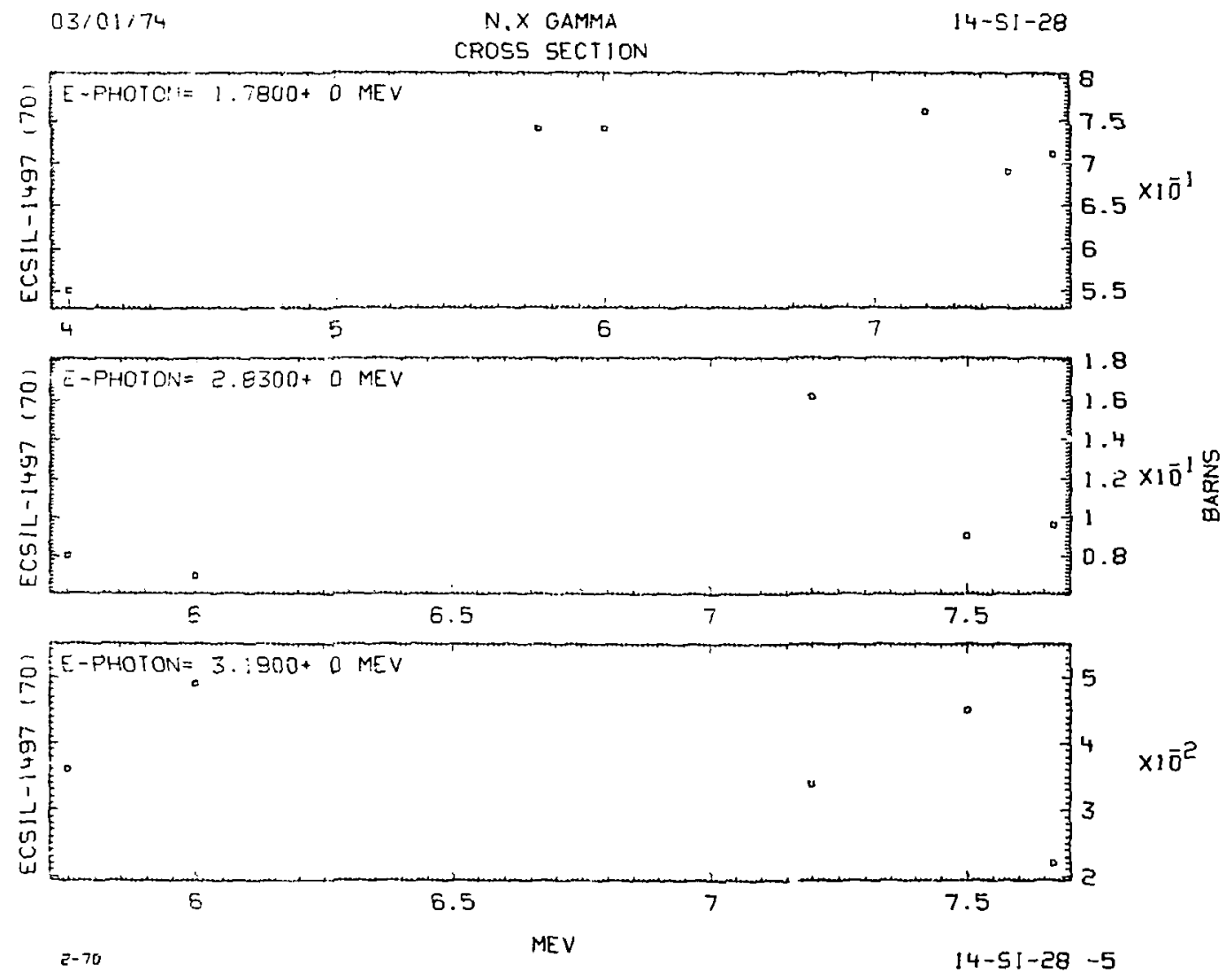

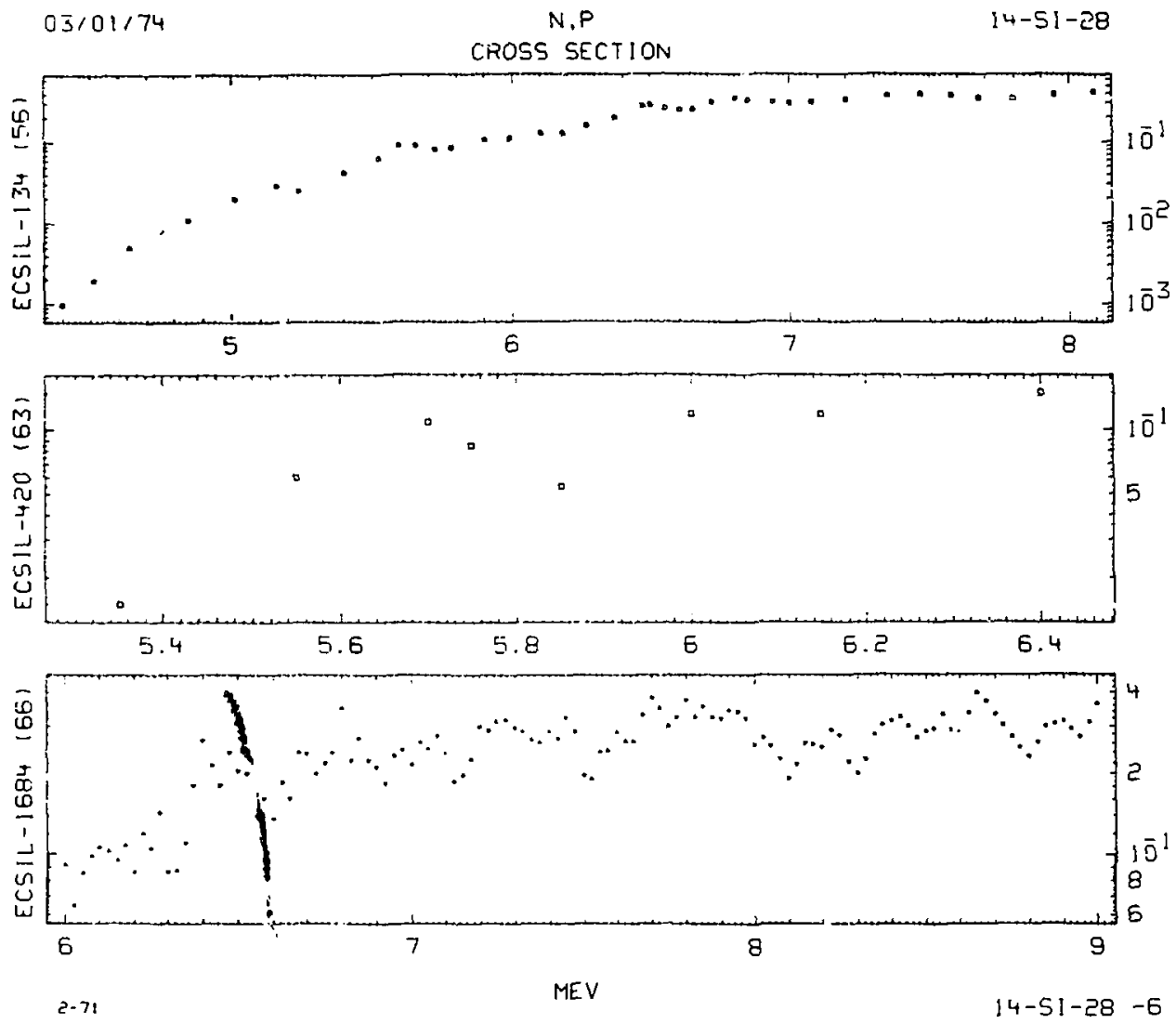

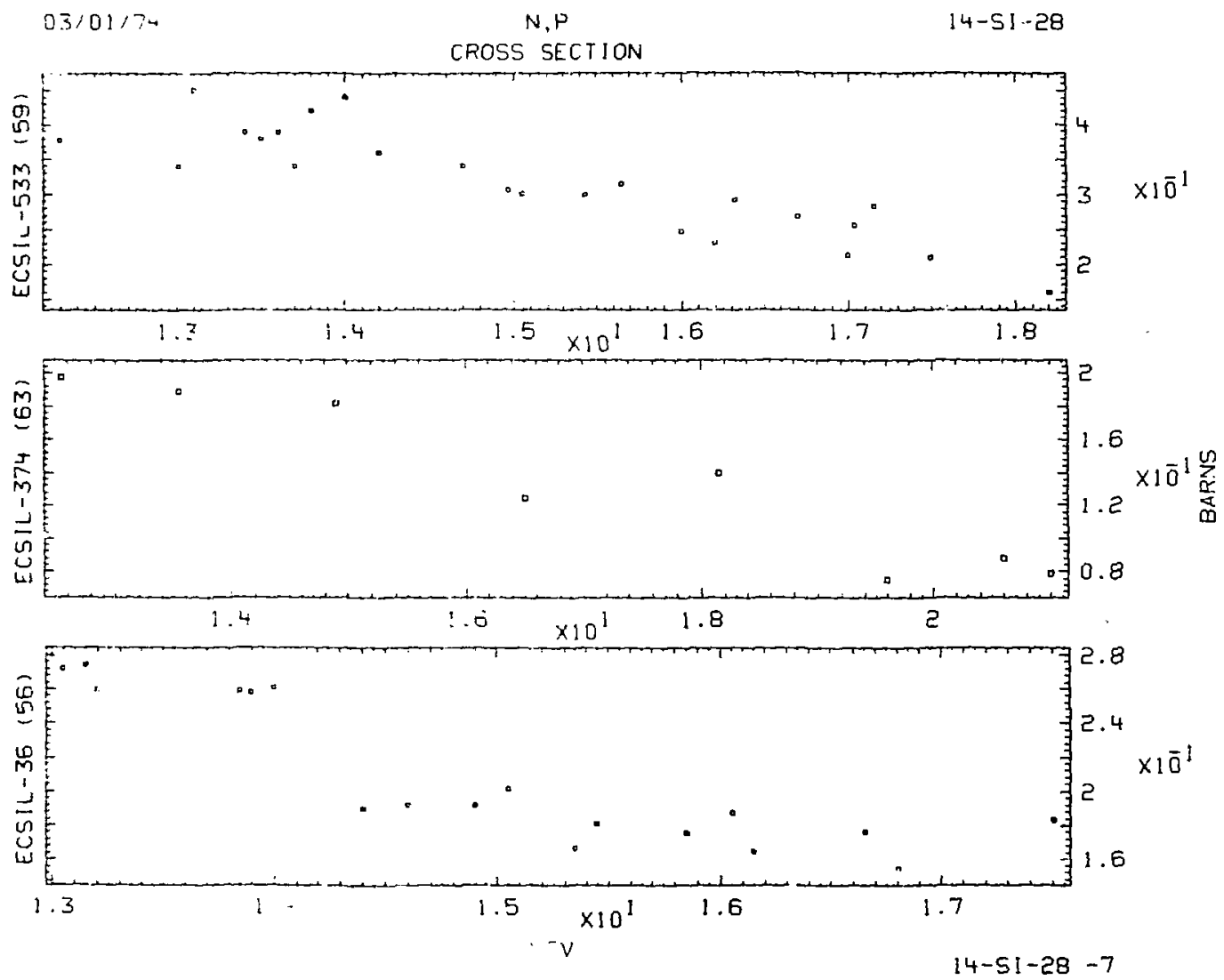


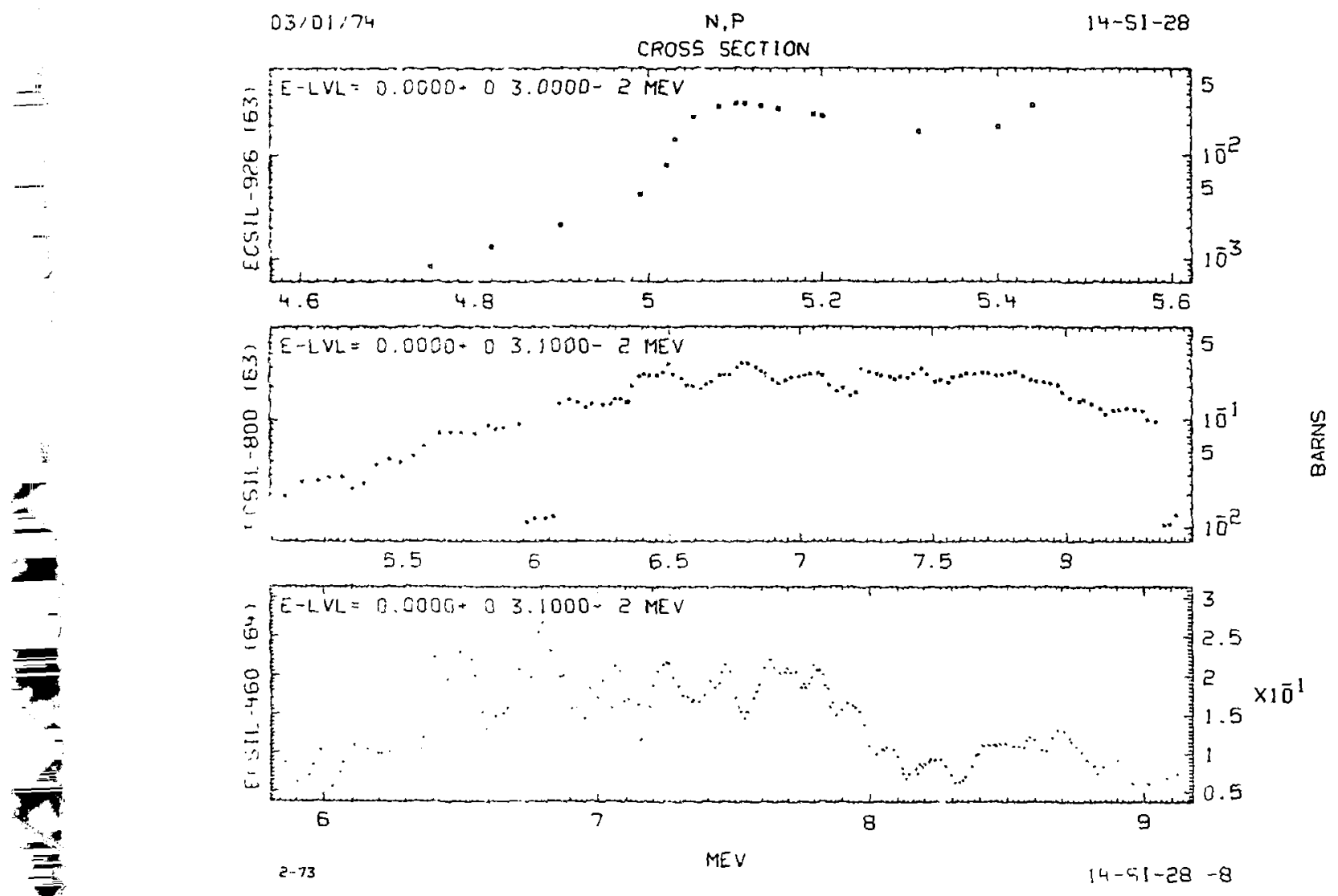




\section{SNAYG}

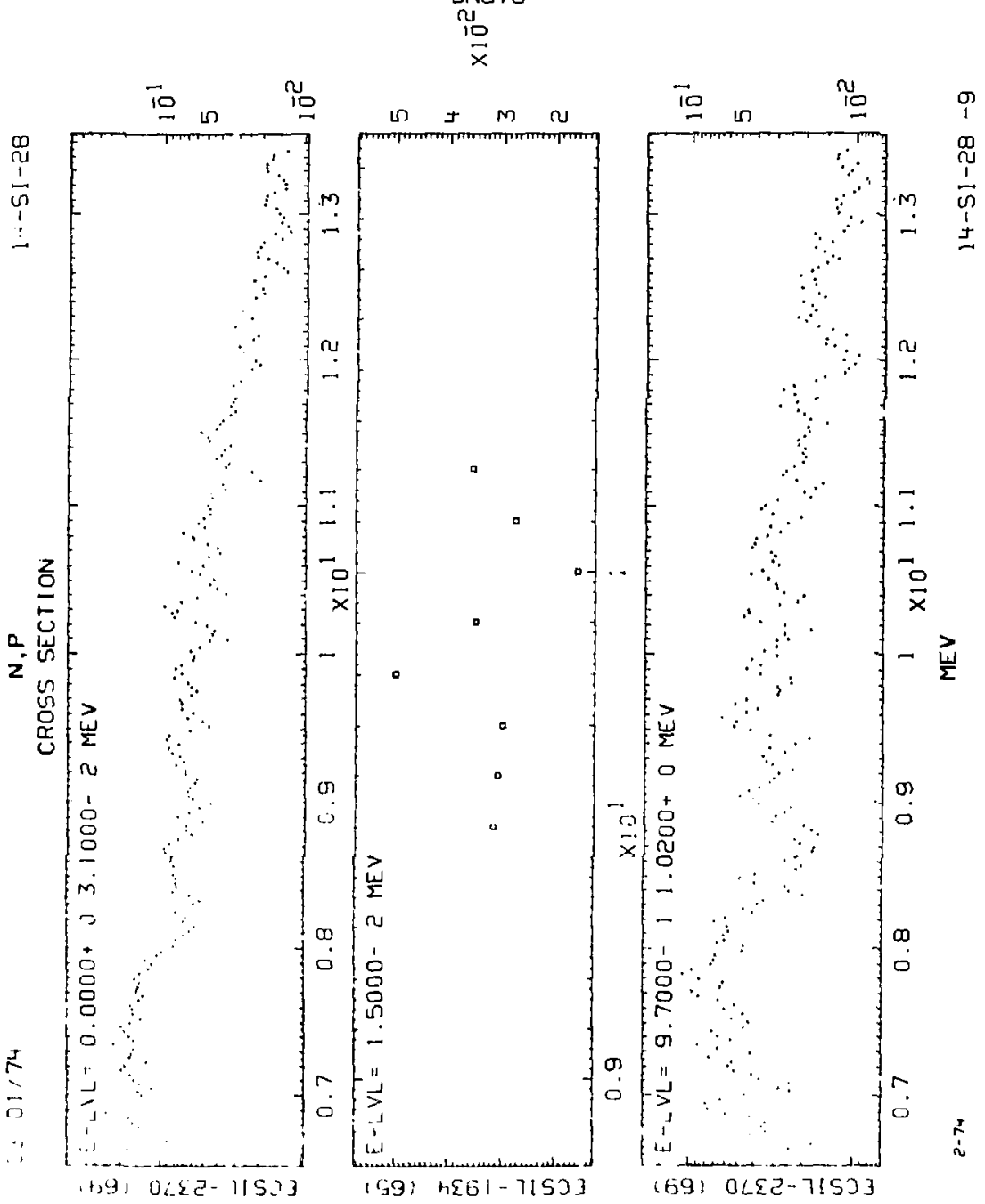



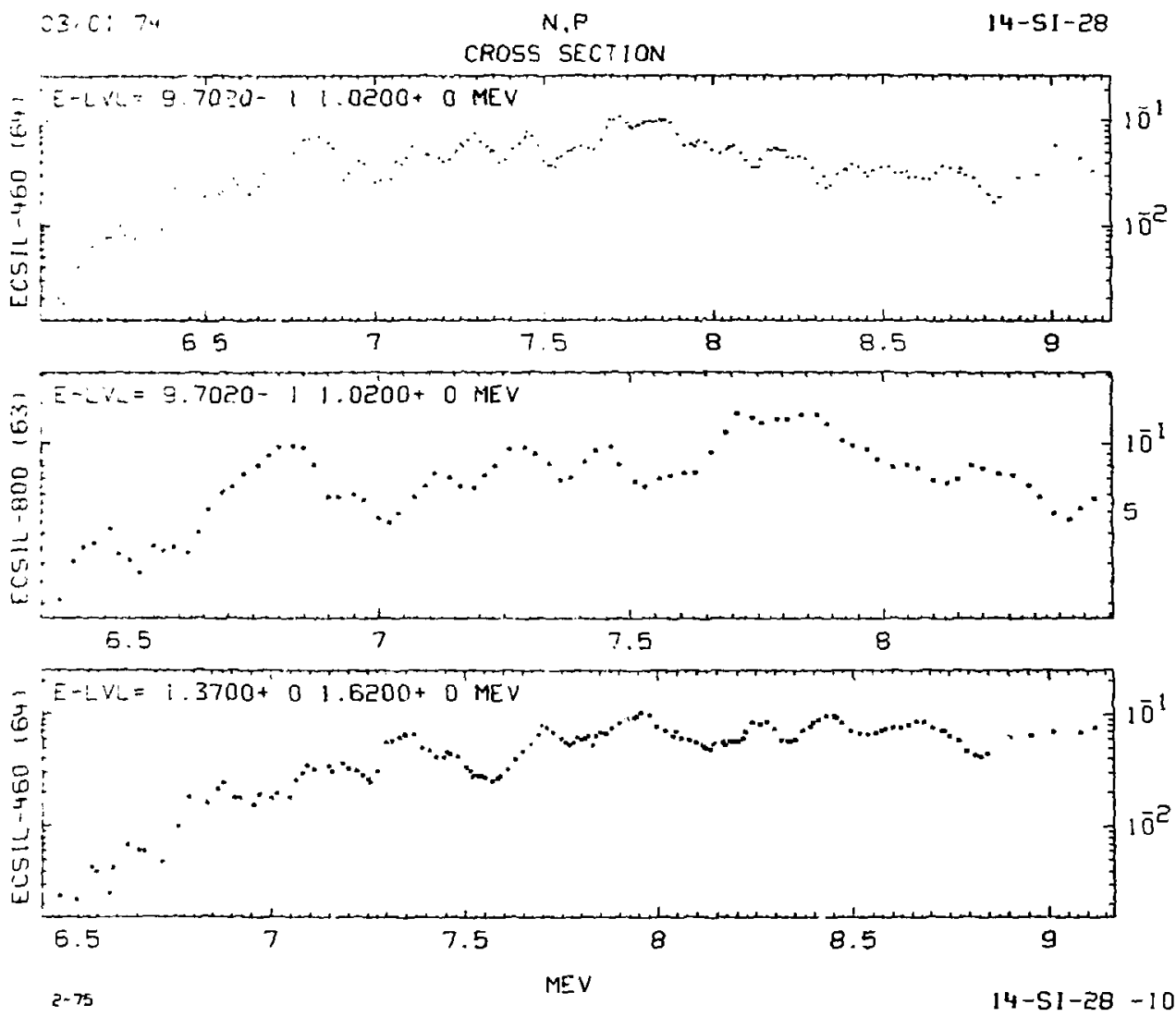

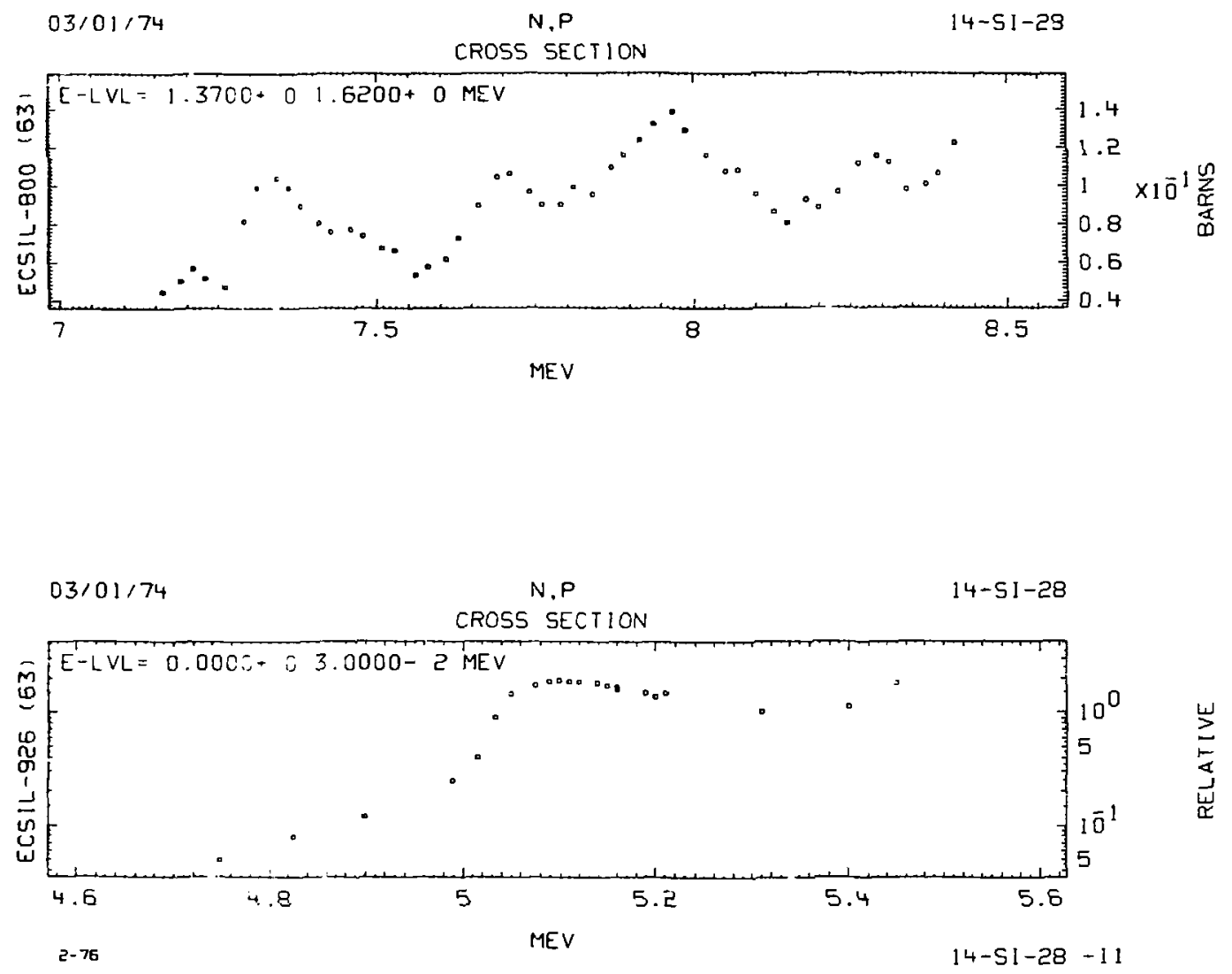


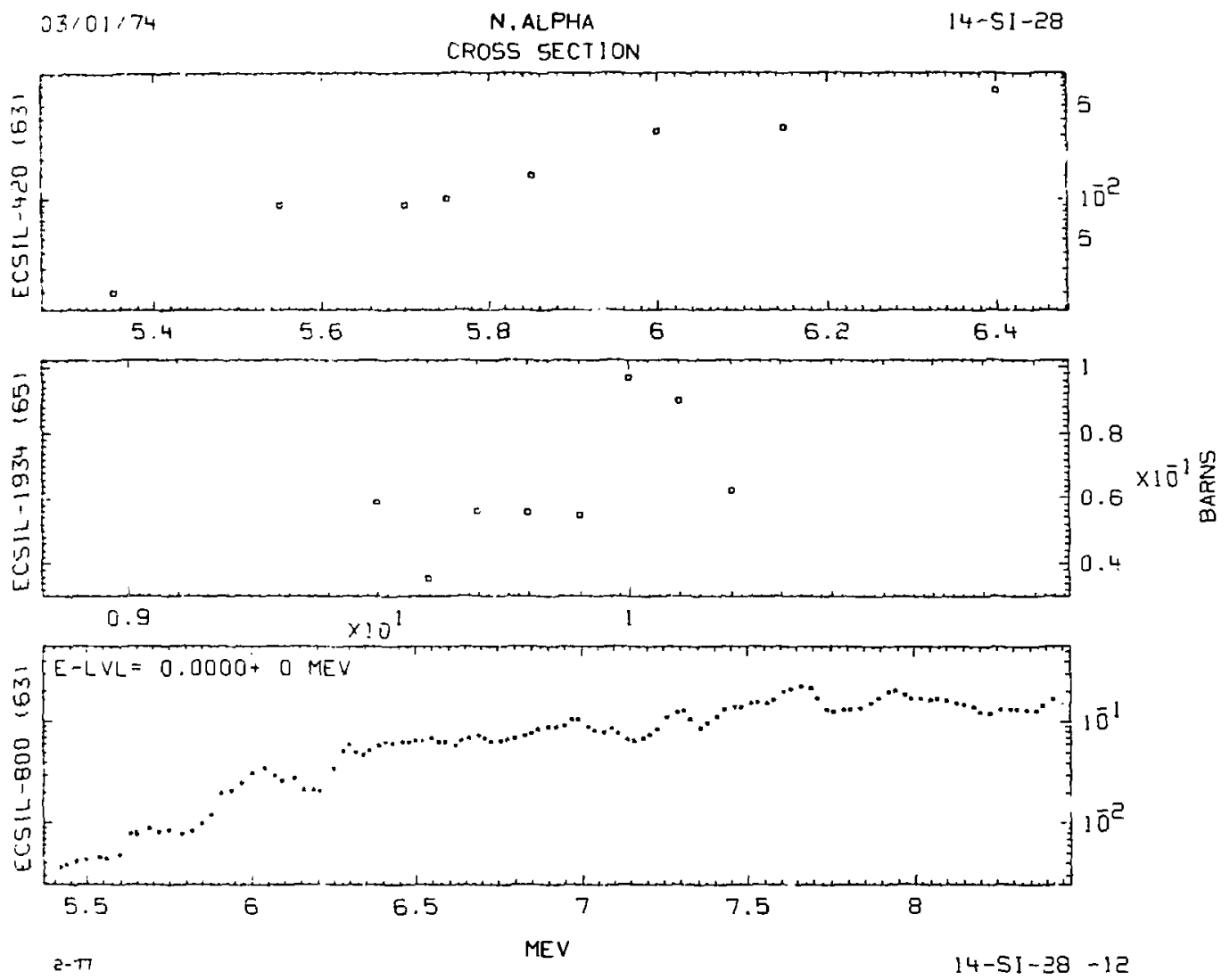



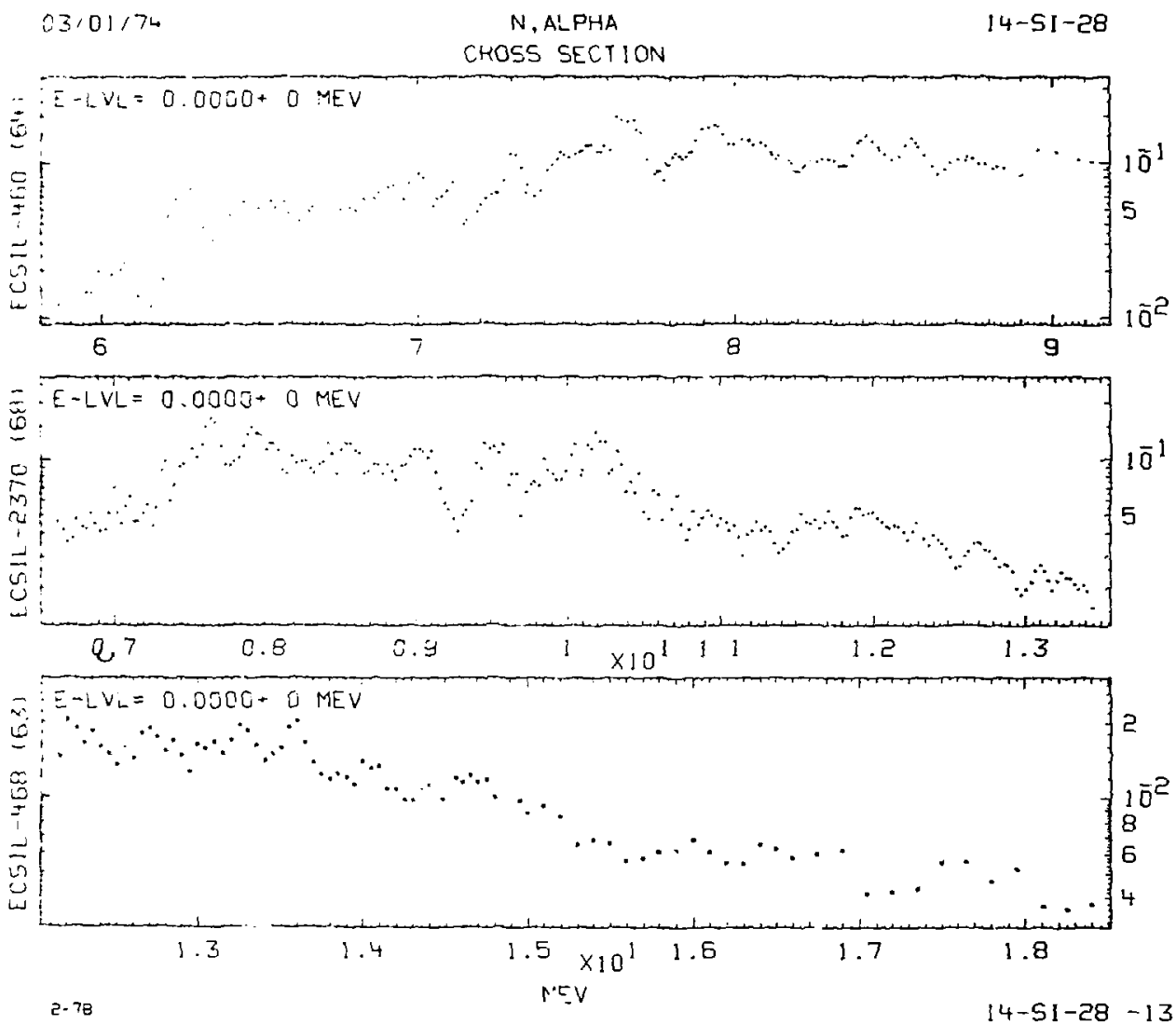

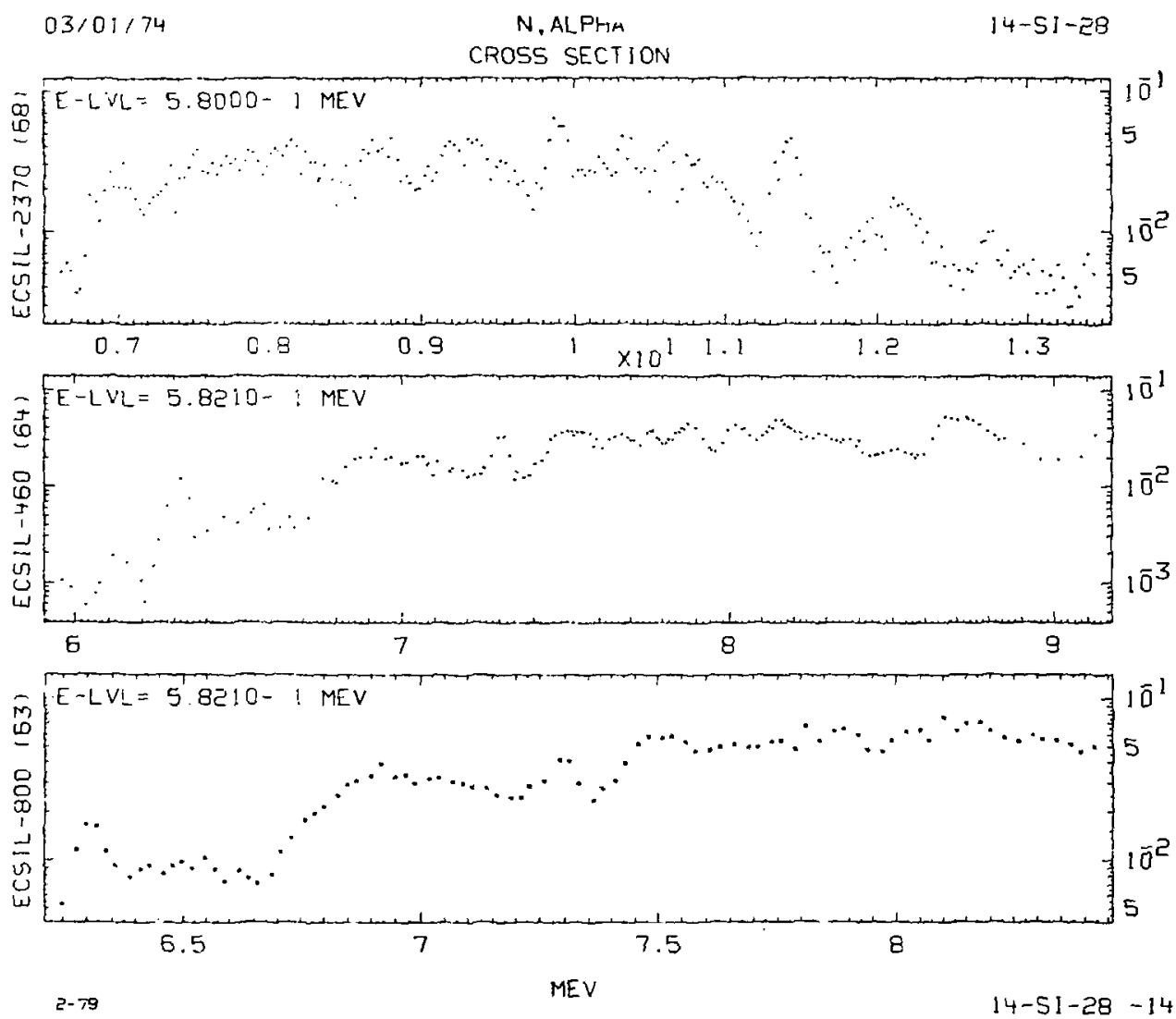
SNyㅂ

일

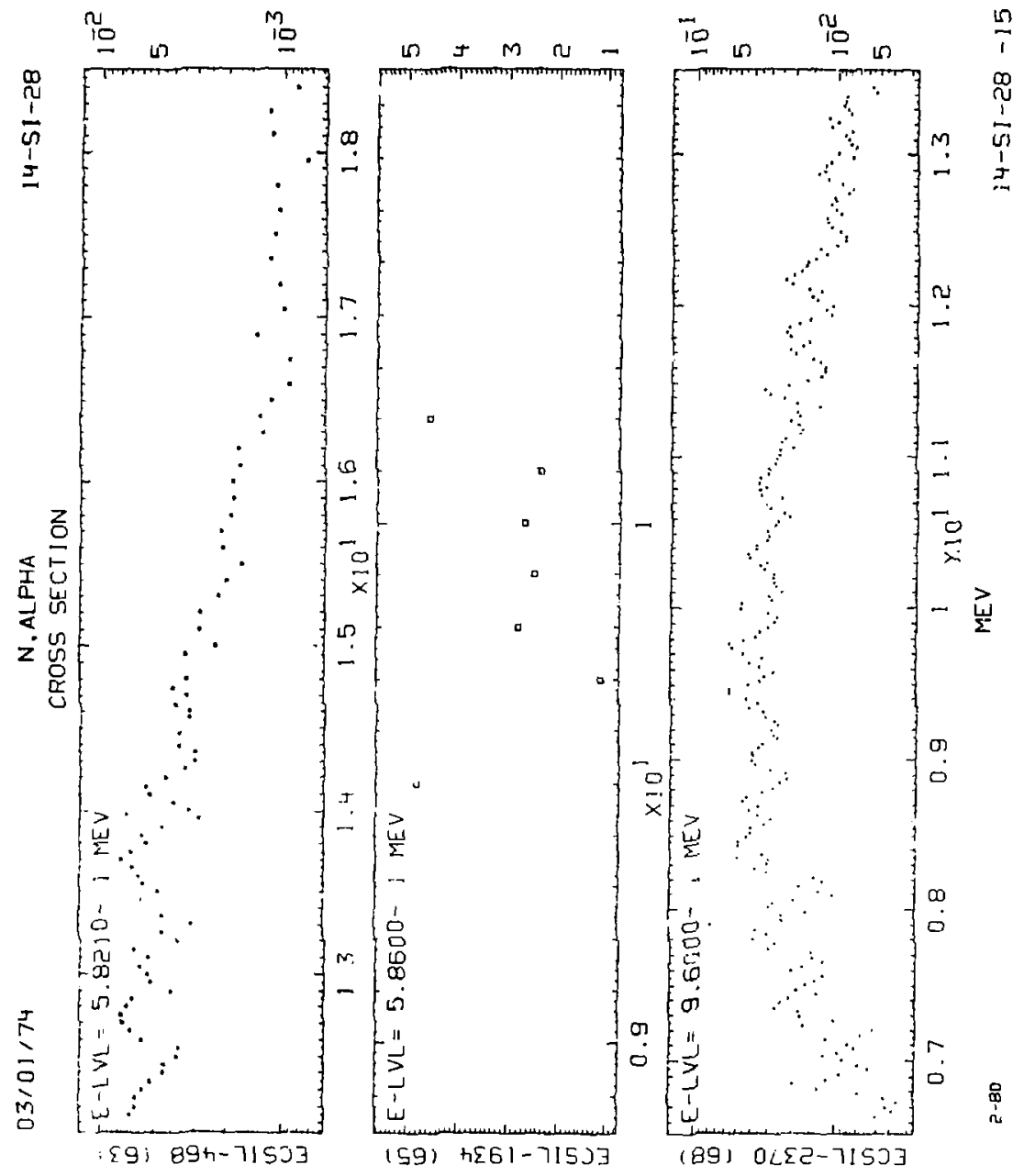




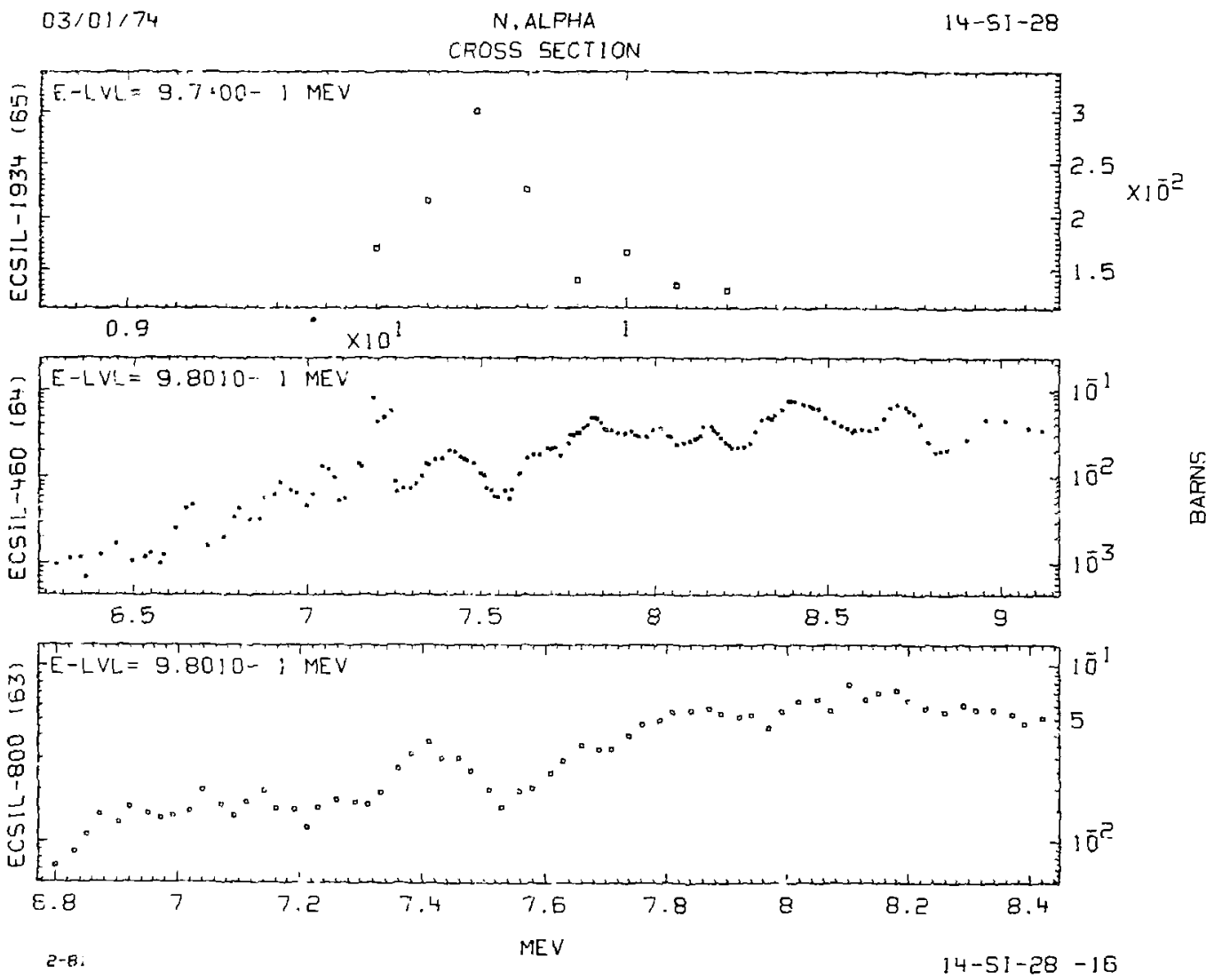


CROSS SECTION
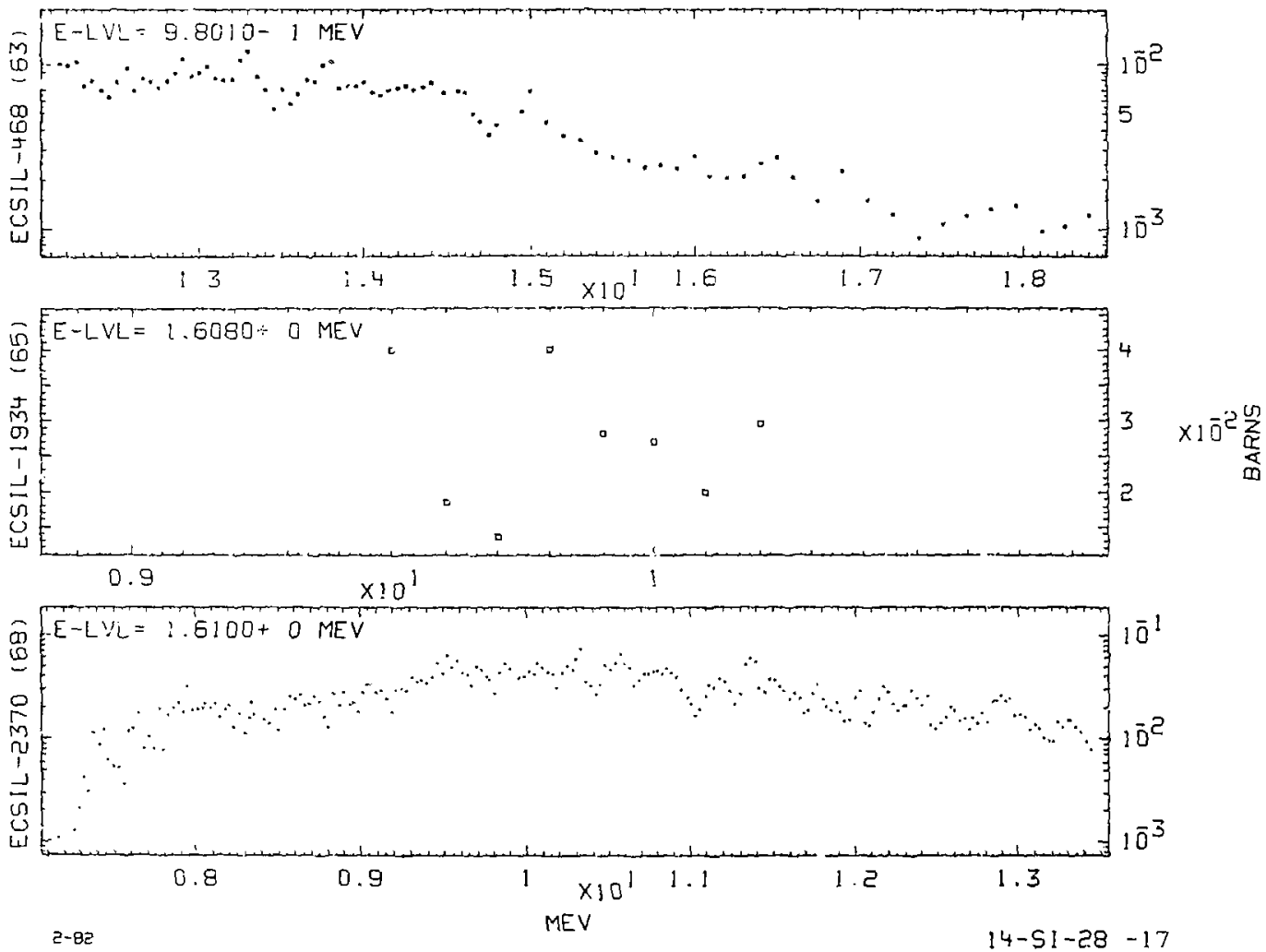

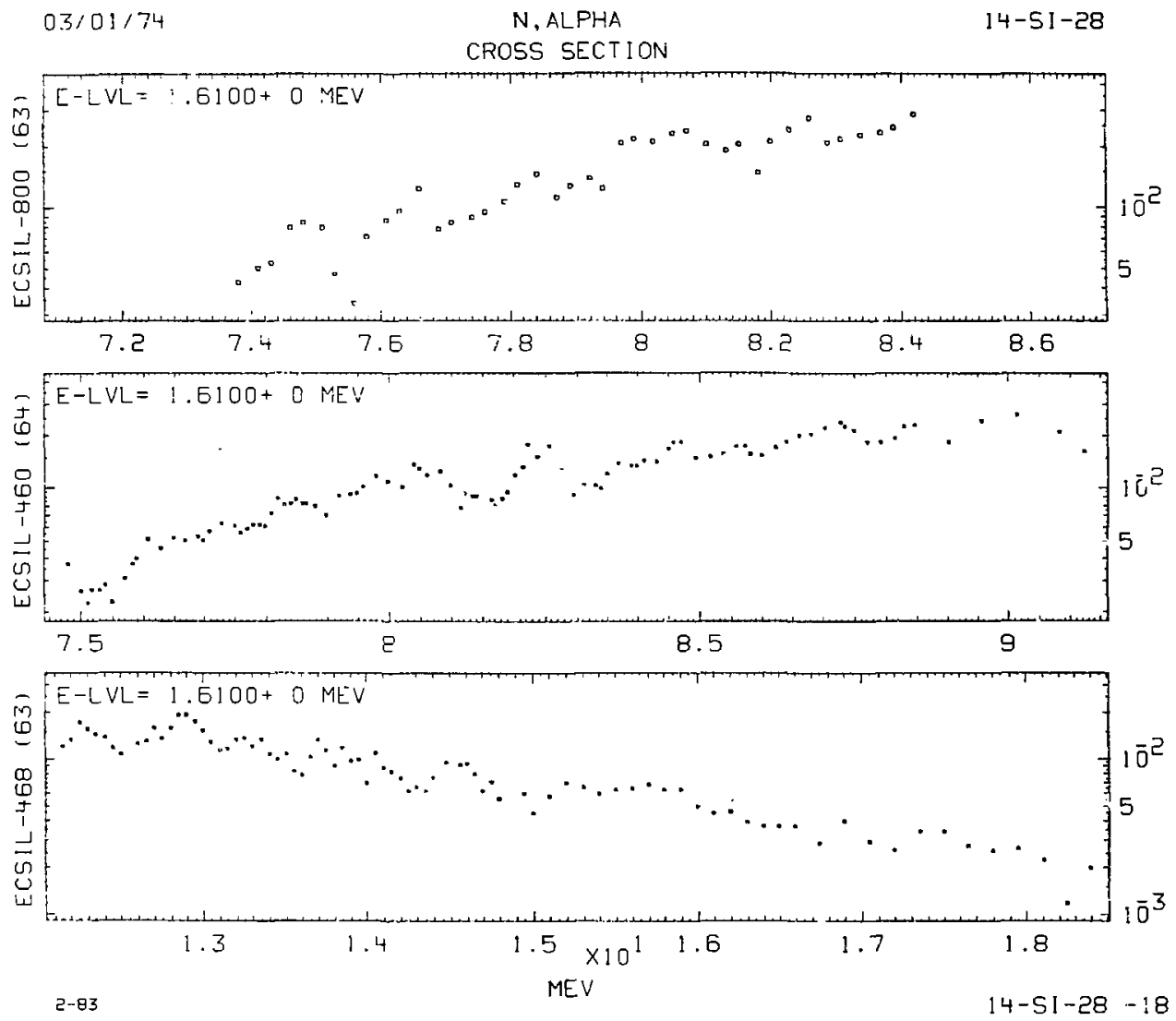

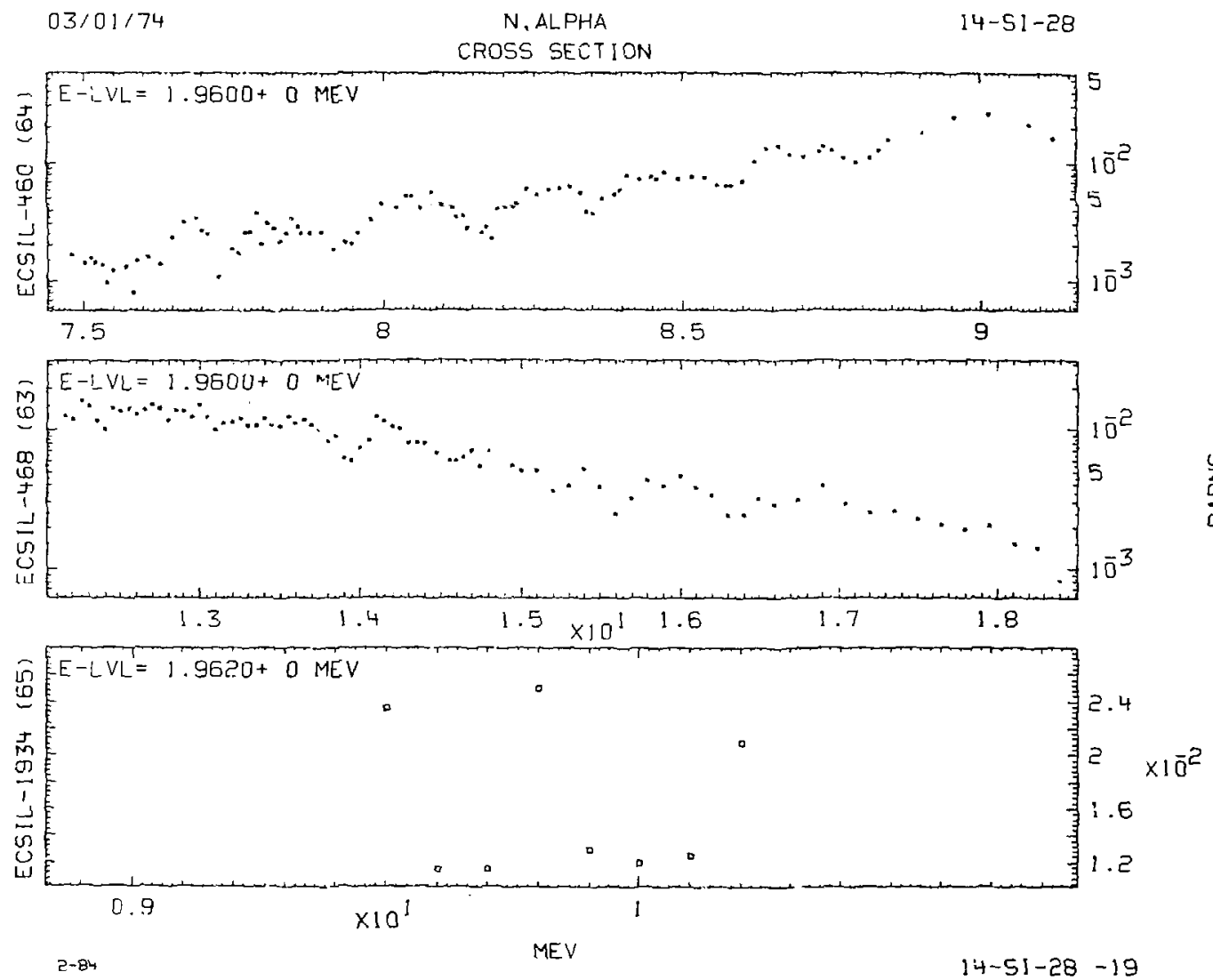


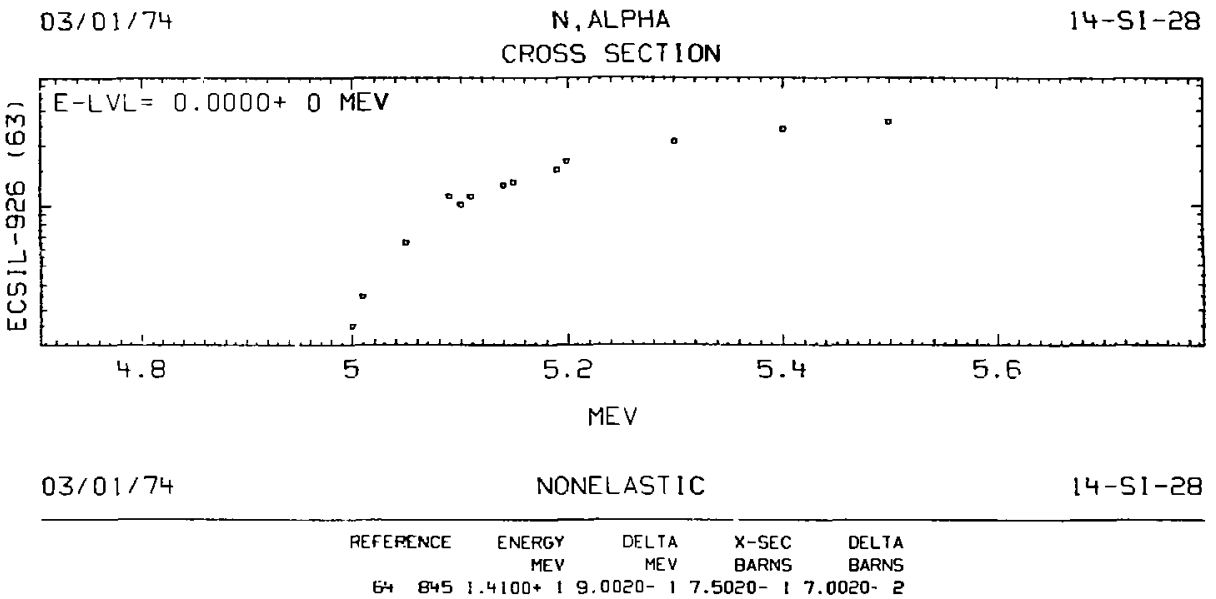

\begin{tabular}{|c|c|c|c|c|c|c|c|c|}
\hline \multirow[t]{2}{*}{$03 / 01 / 74$} & \multicolumn{8}{|c|}{$N, N^{\prime}$} \\
\hline & F:EFERENCE & $\begin{array}{r}\text { ENERGY } \\
\text { MEV }\end{array}$ & $\begin{array}{r}\text { DEL TA } \\
\text { MEY }\end{array}$ & $\begin{array}{l}X-5 E C \\
\text { BARNS }\end{array}$ & $\begin{array}{l}\text { DELTA } \\
\text { BARNS }\end{array}$ & E-LI & & $\begin{array}{r}E-L V L \\
\text { MEV }\end{array}$ \\
\hline & $64 \quad 845$ & $1.4 ! 00+1$ & $19.0000-1$ & $1.0900-1$ & $1.6000-2$ & $1.7900+$ & 0 & \\
\hline & 723231 & $6.3700+0$ & $01.3000-1$ & $1.5580-1$ & $11.9790-2$ & $4.6140+$ & 0 & $4.9750+0$ \\
\hline & 723231 & $7.5500+0$ & $04.0000-=$ & $1.1670-1$ & $12.1360-2$ & $4.6140+$ & 0 & $4.9750+0$ \\
\hline & 723231 & 7.EgOS- J & 3 1.0000- ! & $6,4640-$ & $\geq 1.7000-2$ & 6.Ë720* & 0 & \\
\hline & 723231 & $8.5600+3$ & J $E .0000-z$ & $8.7470-2$ & $29.1840-3$ & 6.2720 & 0 & \\
\hline & $72323 !$ & $8.56 \mathrm{CD}-=$ & $=3.0000-\bar{c}$ & $0.0410-?$ & 2 B.8450- 3 & 36.2720 * & 0 & $6.6900+0$ \\
\hline & 723231 & $8.5600+[$ & C $8.0000-2$ & $3,3400-2$ & $25.7110-3$ & 6.6900 & 0 & \\
\hline & 723231 & $\theta .5600+0$ & $08.0070-2$ & $2.0460-1$ & $13.9290-2$ & 6.6900 & 0 & \\
\hline & 723231 & $8.5600+0$ & 0 B.0000- 2 & 1.1 $1550-$ & $12.9450-2$ & 6.9780 & 0 & $6.8870+0$ \\
\hline
\end{tabular}




\section{CROSS SECTION}

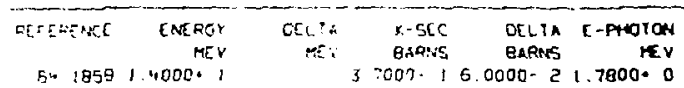

$03 / 01 / 74$

$N . N \cdot P$

$14-5 \mid-28$

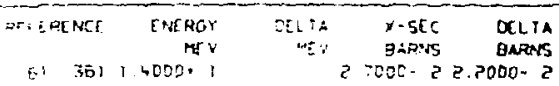

$03 / 01 / 74$

N. $\because$ Gomitis

$|4-5|-28$

\begin{tabular}{|c|c|c|c|c|c|c|c|c|c|c|c|}
\hline ETERENCE & $\begin{array}{r}\text { EArefo: } \\
28:\end{array}$ & $\begin{array}{l}\text { Oxtin } \\
\text { at: }\end{array}$ & $\begin{array}{l}5: 5 \\
5: 5: 5\end{array}$ & $\begin{array}{l}\text { OSLT: } \\
\text { GAPNS }\end{array}$ & 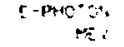 & ofratar & $\operatorname{sincog}$ & $\begin{array}{l}\text { OFE'h } \\
\text { PE' }\end{array}$ & $\begin{array}{l}x-\sec \\
\text { OAfives }\end{array}$ & $\begin{array}{l}\text { Cabit } \\
\text { Gaphes }\end{array}$ & $\begin{array}{r}\text { E-PNoton } \\
\text { KCV }\end{array}$ \\
\hline 55173 & $3.0000=$ & $5000: 1$ & $\therefore \therefore \quad$ & $\therefore .0202-1$ & 1, None = & $\because: \cdots$ & $\because 500 \cdot 0$ & $01.0020=1$ & $=.6000-2$ & $7.0000-3$ & 34.4900 .0 \\
\hline $55 \quad 1:: 3$ & $3.5602 . ?$ & $\therefore=000$. & $\therefore \leq 2 \cdots$ & $41000-?$ & :7900* = & $\because: 1+5$ & $\because .5000 \cdot 0$ & a $10000-1$ & $.0000-2$ & $8.0000-3$ & $35.1100 \cdot 0$ \\
\hline $65,17: 3$ & $+.02500=$ & $2000-$ & c. $\div:$ & $\therefore 2500-$ & 1.700: = & $\because \cdots$ & $\because 5700 \cdot 0$ & $01.0000-1$ & $3.0000-2$ & $5.0000-3$ & $35.1100+0$ \\
\hline 55169 & $14: 00:$ & & * $\rightarrow:: ?$ & $\because 0000-2$ & $\therefore: 000_{*}:$ & $\because .=g^{*}$ & $\because 5000.0$ & $01,0000-$ ! & $3.9000-2$ & $5.0000-3$ & $00=0$ \\
\hline $70 \quad 1497$ & ?.25:20 = & iover. & D. EA: : & $9.0000 \cdot 3$ & $+4900 \cdot=$ & $\because: \cdots 7^{*}$ & $7.5700 \cdot 0$ & $01.0000-1$ & $.5200-z$ & $4.0000 \cdot 3$ & $36.8000 \cdot 0$ \\
\hline$\therefore 1497$ & $7.5050=$ & 60. & 5 & $\theta .0000$ & $4,4900=c$ & & & & & & \\
\hline
\end{tabular}

$03: 01,74$

$M P$

$|4-5|-2 \theta$

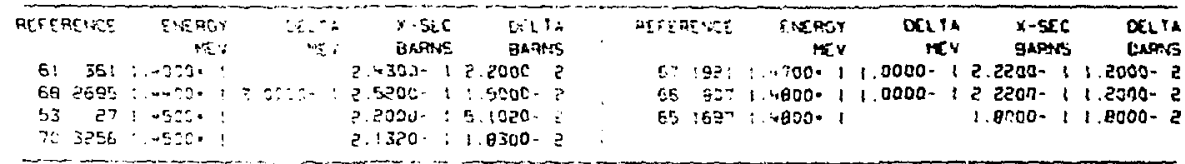

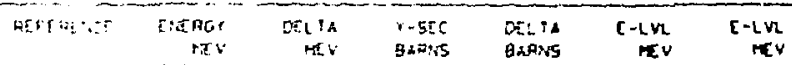

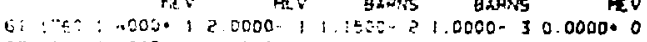

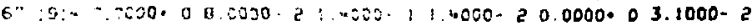

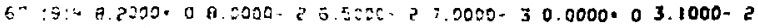

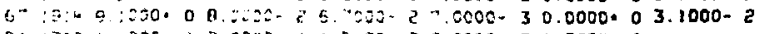

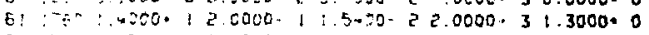

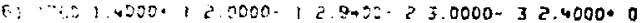




\section{CROSS SECTION}

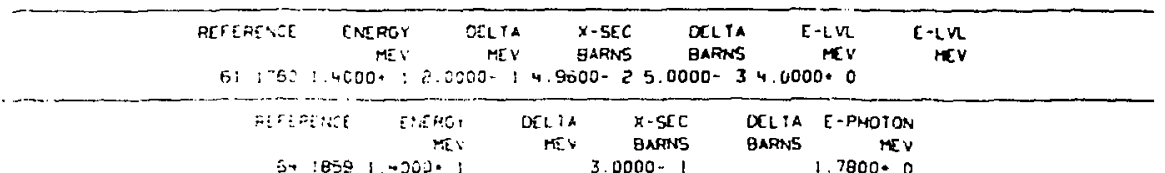
$33 / 01 / 74$
N. ALPHA
$14-51-28$

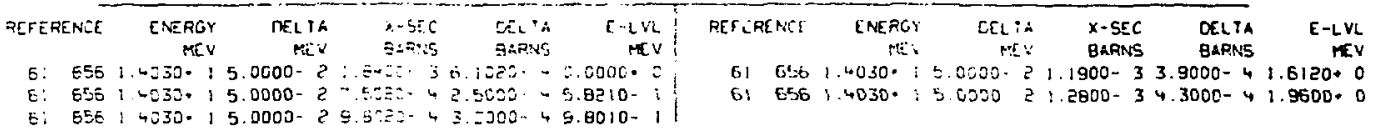

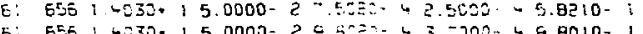

6) $656, .4030 *: 5.6050$ 2 :.2800-34.3000-41.9500*0

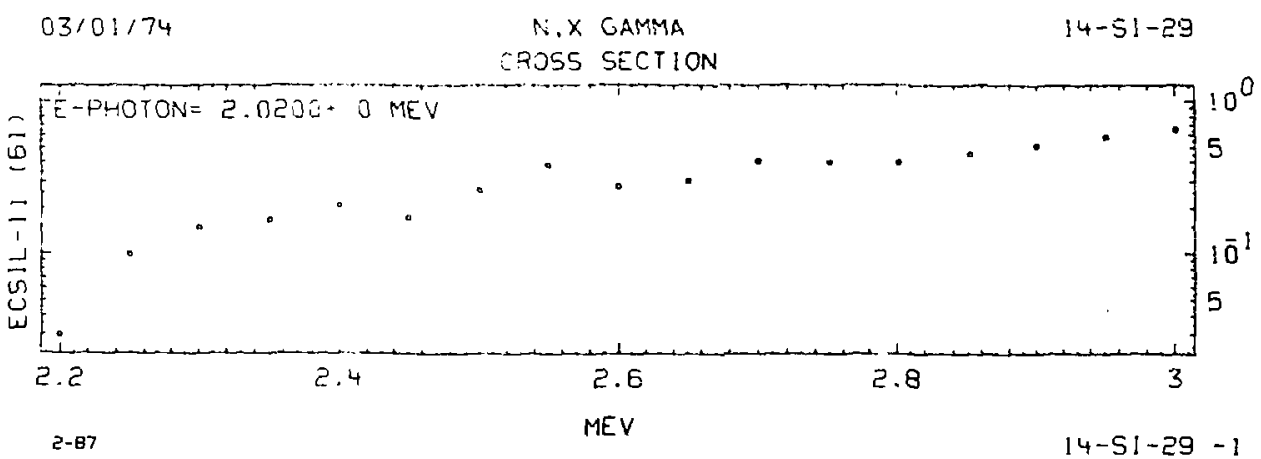



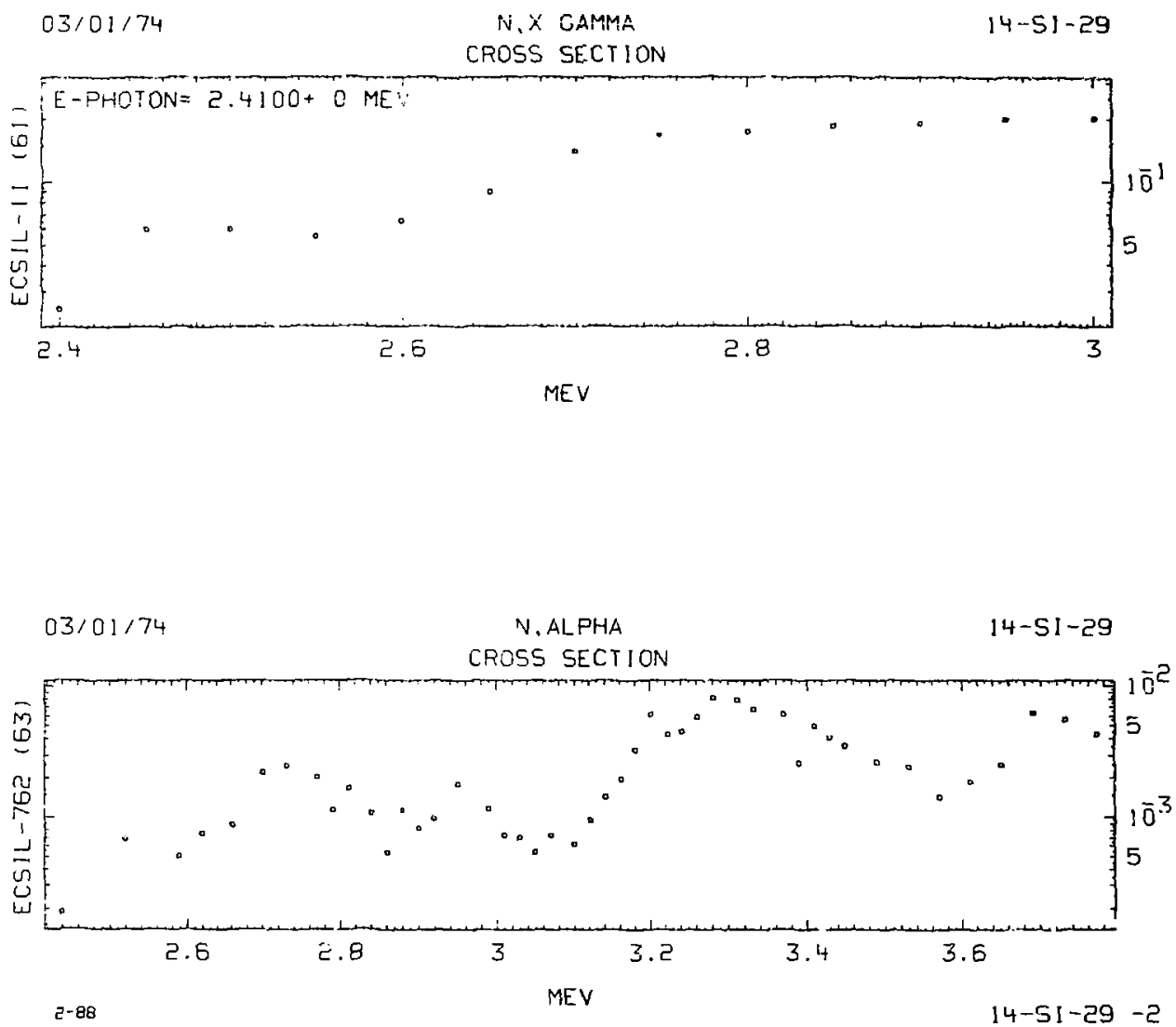


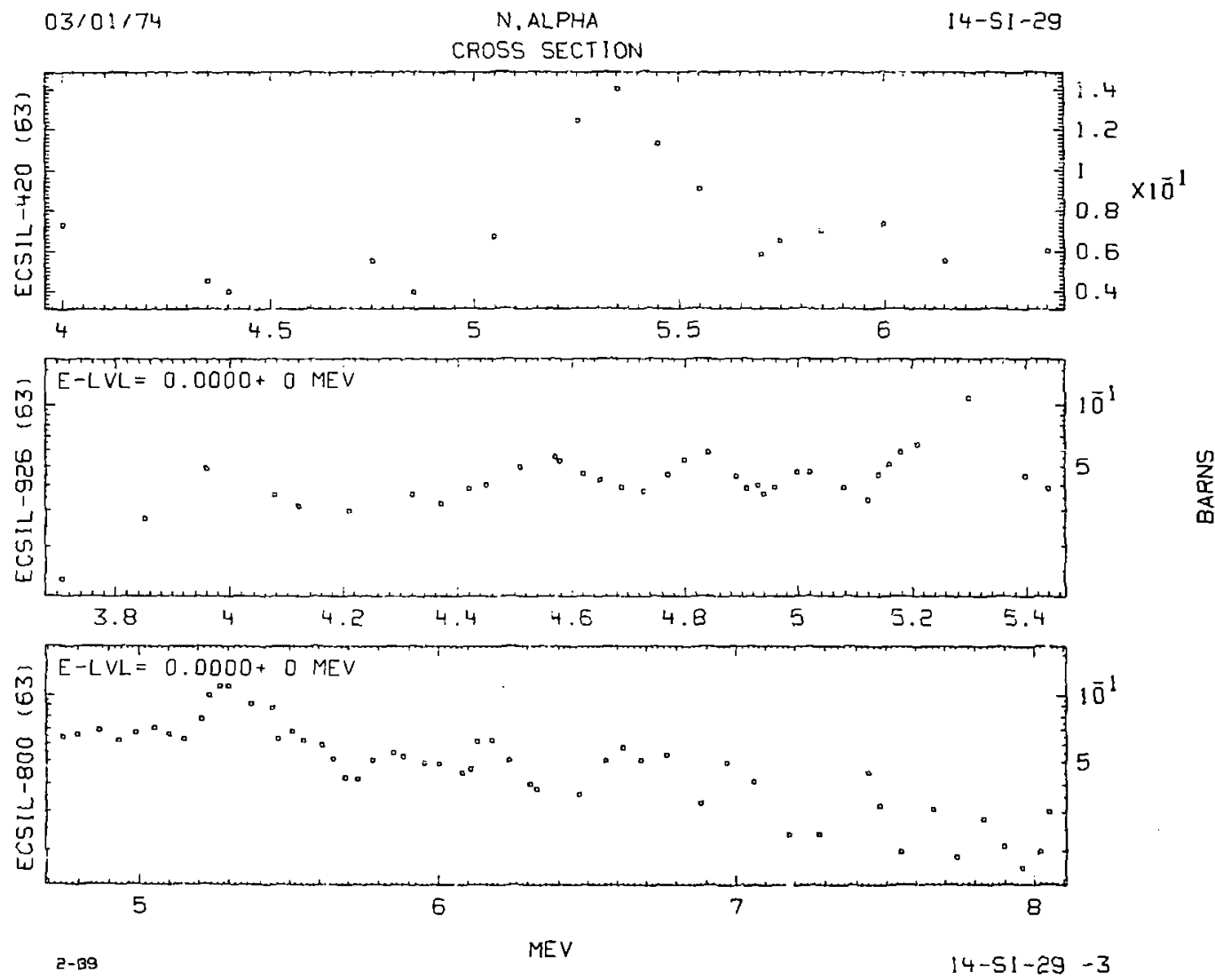


SNYYG

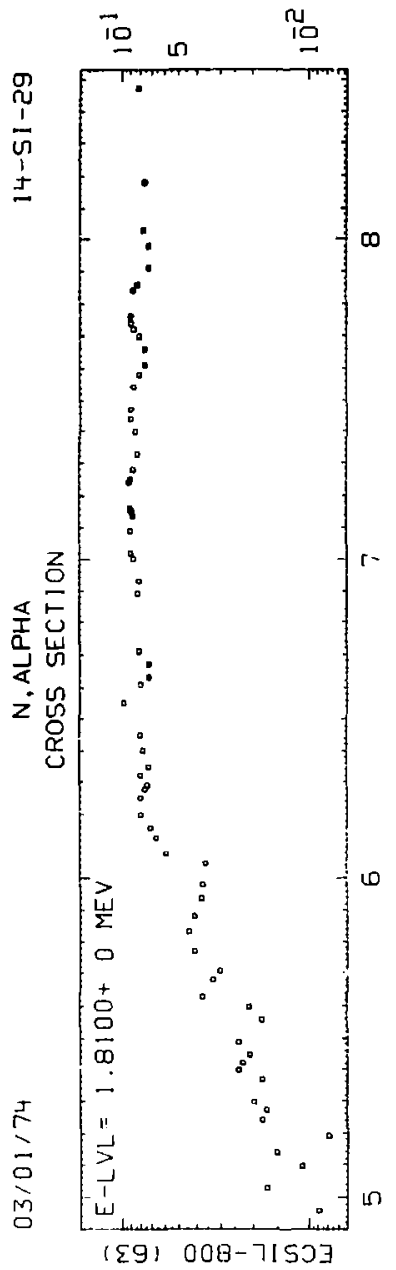

$\exists \wedge 1 \perp \vee 7 \exists y$

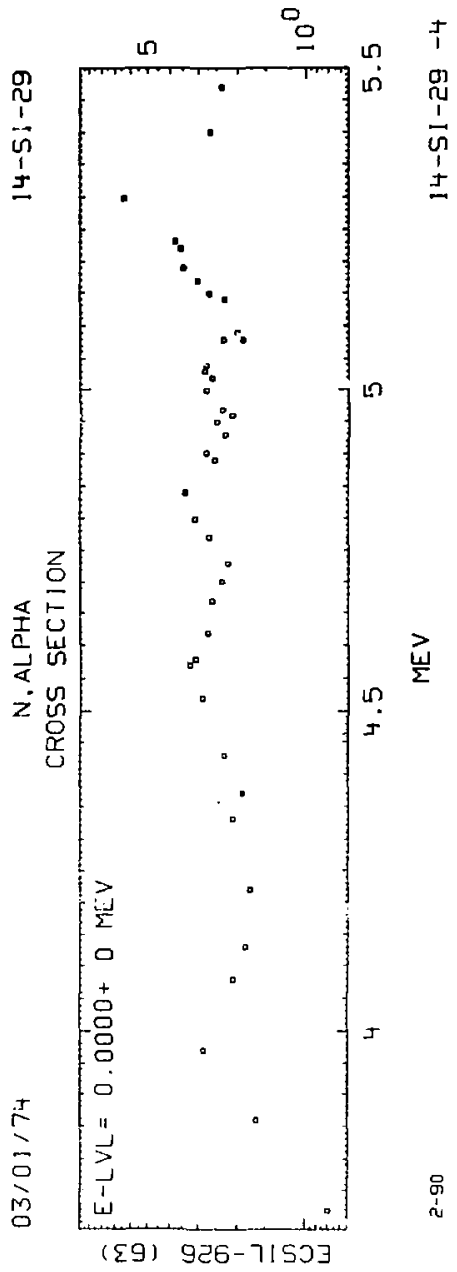




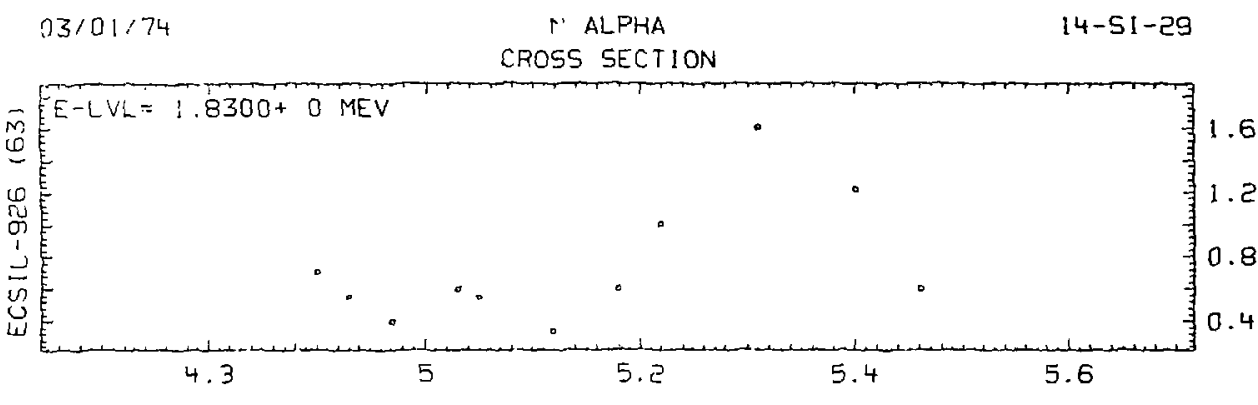

MEV

\begin{tabular}{|c|c|c|c|c|c|c|c|c|}
\hline $03 / 01 /$ & & & & & & & & $14-51-29$ \\
\hline REFERENCE & $\begin{array}{l}\text { ENERGY } \\
\text { MEV }\end{array}$ & OE: TA & $\begin{array}{l}X \text {-SEC } \\
\text { EARNS }\end{array}$ & $\begin{array}{l}\text { OELTA } \\
\text { BARNS }\end{array}$ & REFERENCE & $\begin{array}{l}\text { ENEROY } \\
\text { MEV }\end{array}$ & $\begin{array}{l}\text { DELTA } \\
\text { MEV }\end{array}$ & $\begin{array}{lr}x \text {-SEC } & \text { DELTH } \\
\text { BARNS } & \text { BAFNS }\end{array}$ \\
\hline
\end{tabular}
$5826951.4400+13.0000-11.3000-11.6000-2 \quad 7032581.4500-1 \quad 1.1250-11.6800-2$

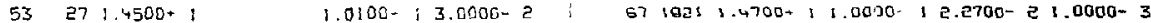
$03 / 01 / 74$
$N, X$ GAMMA
$14-51-30$
CROSS SECTION

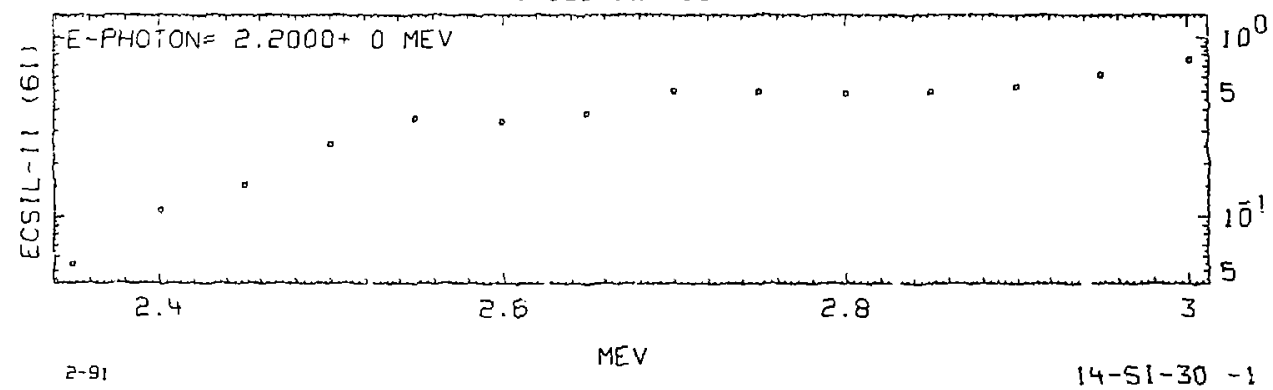


CROSS SECTION

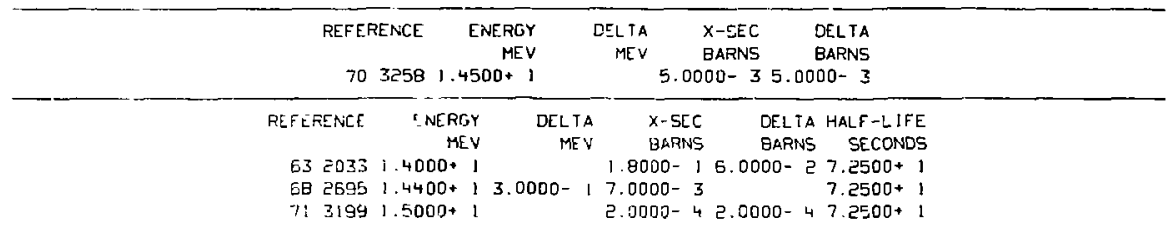

$03 / 01 / 74$

iv, ALPHA

$14-5 I-30$

\begin{tabular}{|c|c|c|c|c|c|c|c|c|c|}
\hline REFERENCE & $\begin{array}{r}\text { ENERGY } \\
\text { MEV }\end{array}$ & $\begin{array}{r}\text { DELTA } \\
\text { MEY }\end{array}$ & $\begin{array}{l}x-5[C \\
\text { BARNS }\end{array}$ & $\begin{array}{l}\text { DILTA } \\
\text { BARNS }\end{array}$ & REFERENCE & $\begin{array}{r}\text { ENERGY } \\
\text { MEV }\end{array}$ & $\begin{array}{r}\text { CEL TA } \\
\text { MEV }\end{array}$ & $\begin{array}{l}X \text {-SEC } \\
\text { BARNS }\end{array}$ & $\begin{array}{l}\text { DELTA } \\
\text { BARNS }\end{array}$ \\
\hline EB 2695 & $1.4400+1$ & 3.0000- I & $6 . B O C J-$ & $28.0000-3$ & 671921 & $: .4700+1$ & $1.0000-1$ & $1.7500-1$ & $1.8000-2$ \\
\hline $53 \quad 27$ & $1.4500+1$ & & $4.5900-2$ & $22.5000-2$ & 651597 & $1.4000+1$ & & $1.2300-1$ & $1.500 n-2$ \\
\hline 703258 & $1.4500+1$ & & $7.3600-2$ & $21.0300-5$ & & & & & \\
\hline
\end{tabular}

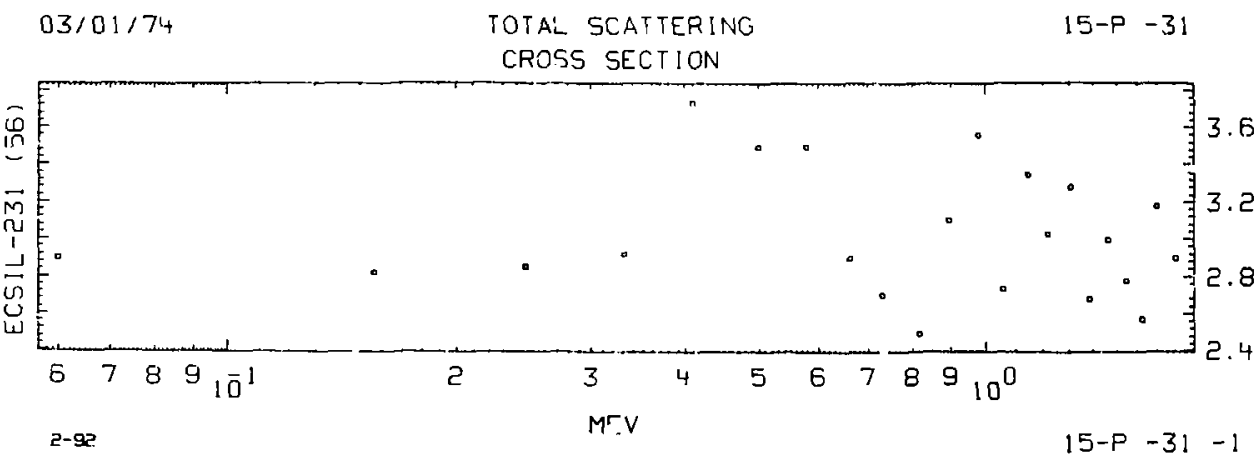



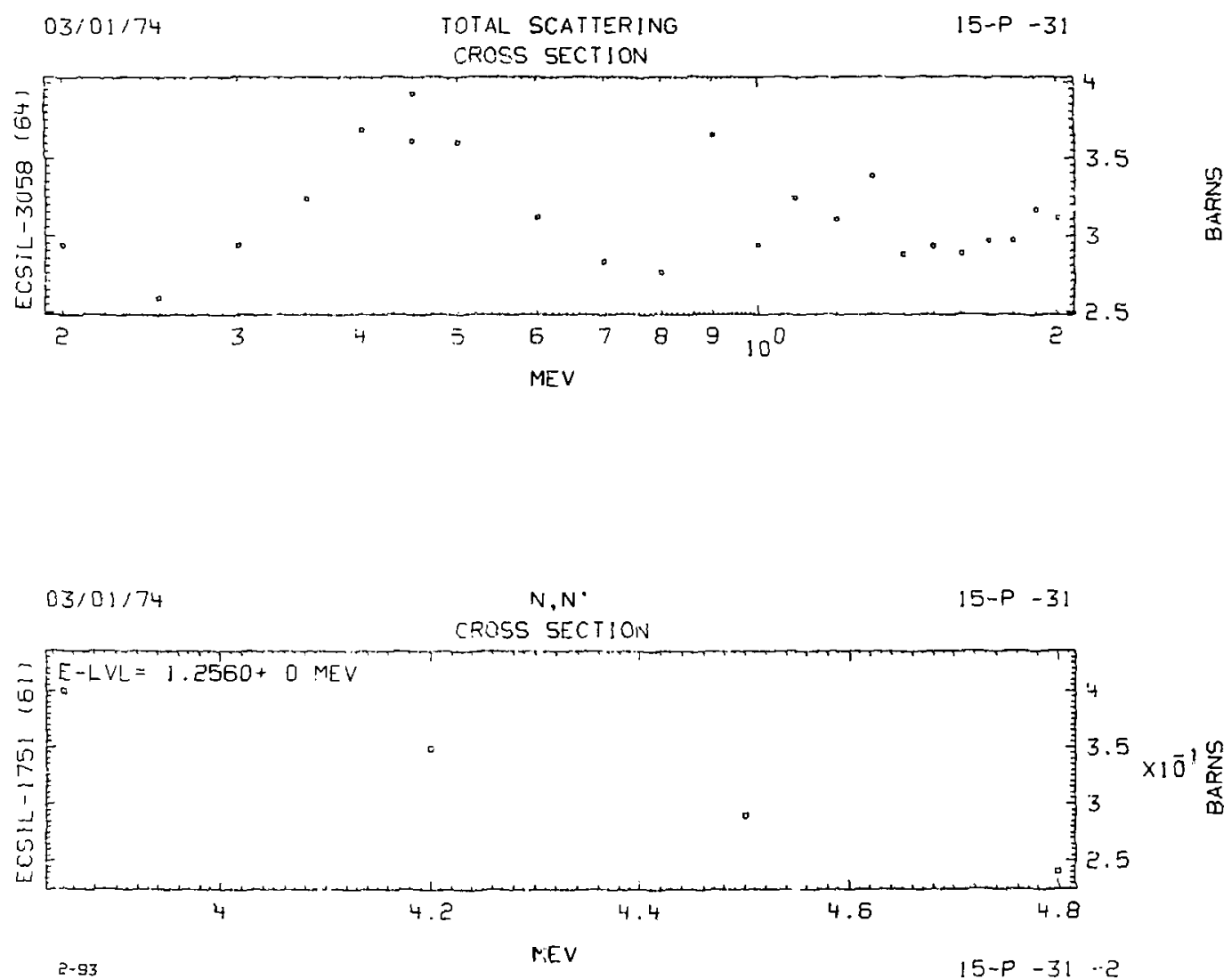



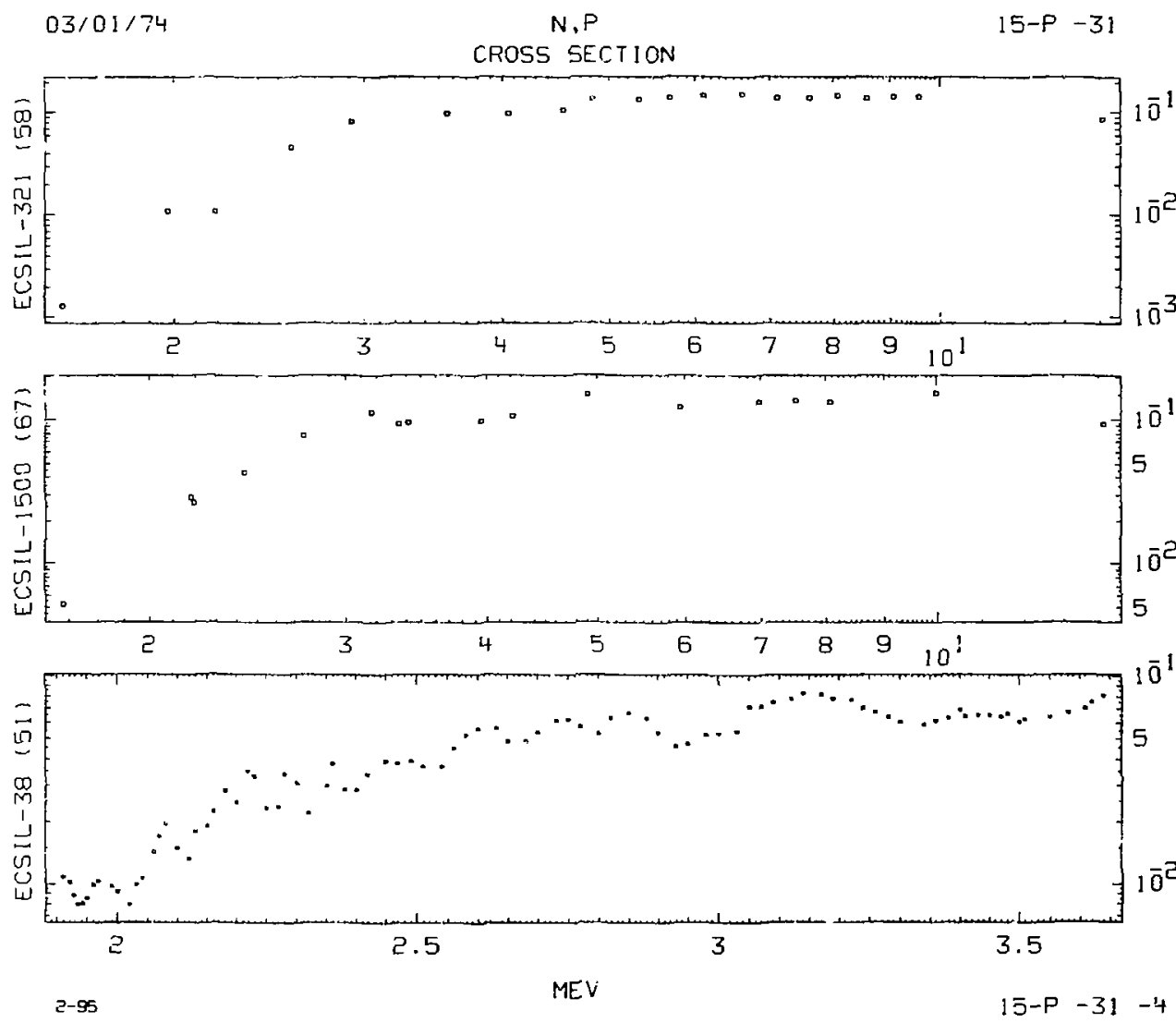




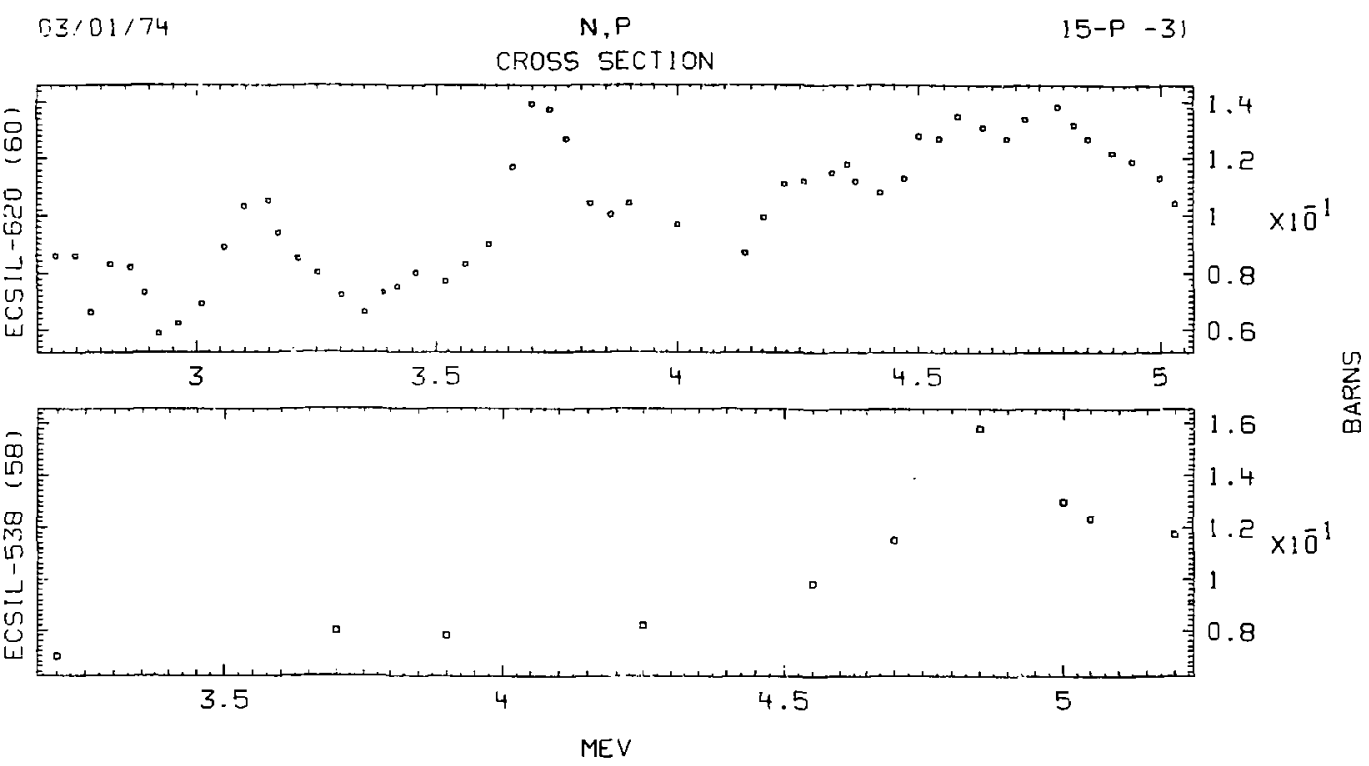




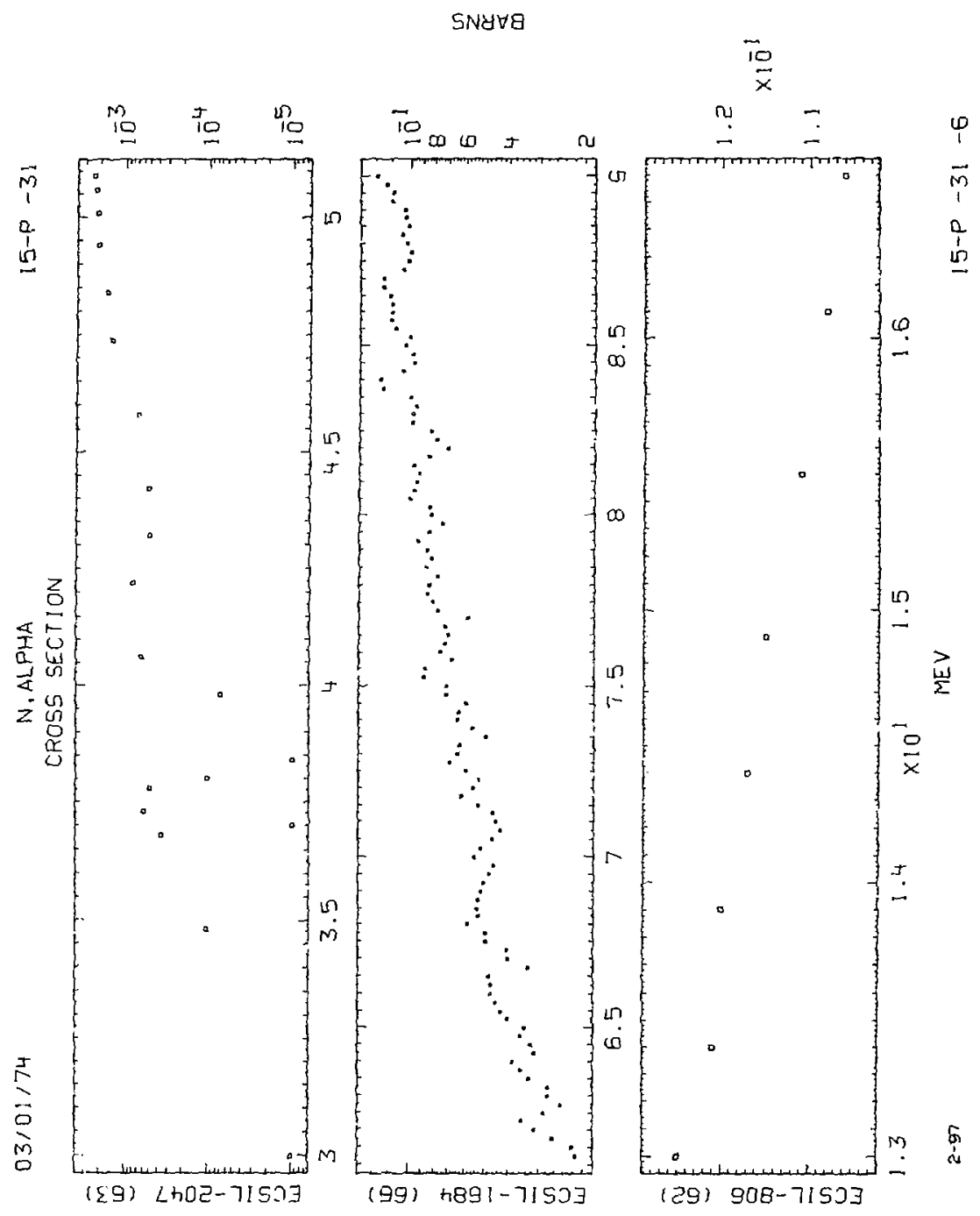




\section{CROSS SECTION}

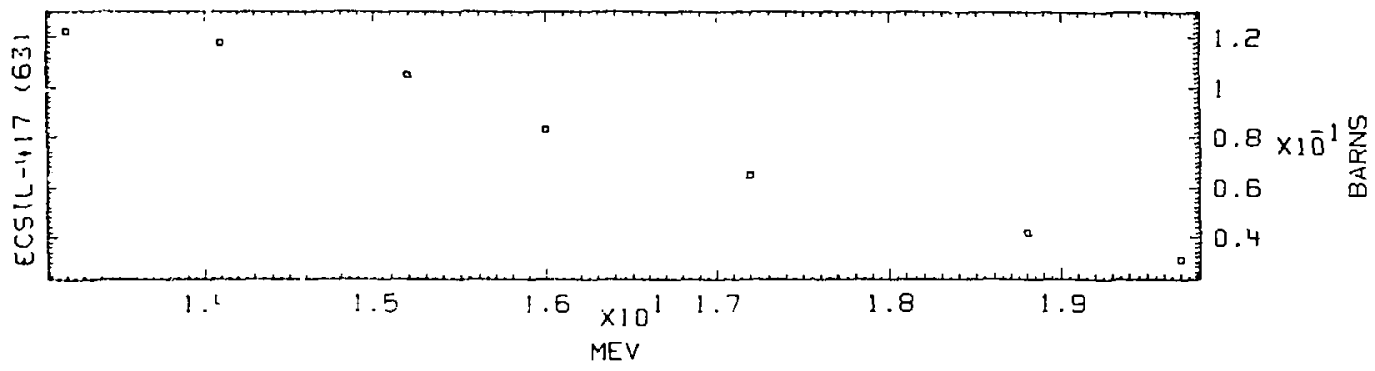

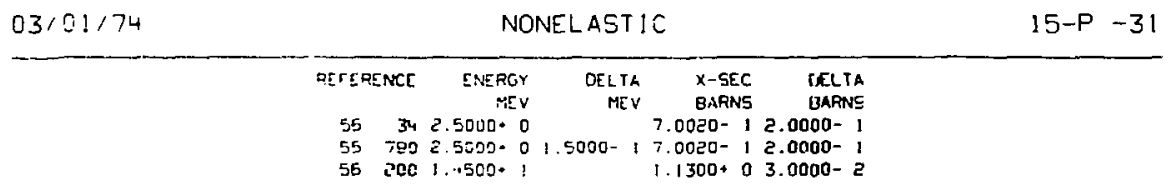

$03 / 0 ! 174 \quad$ N.2N $15-P-31$

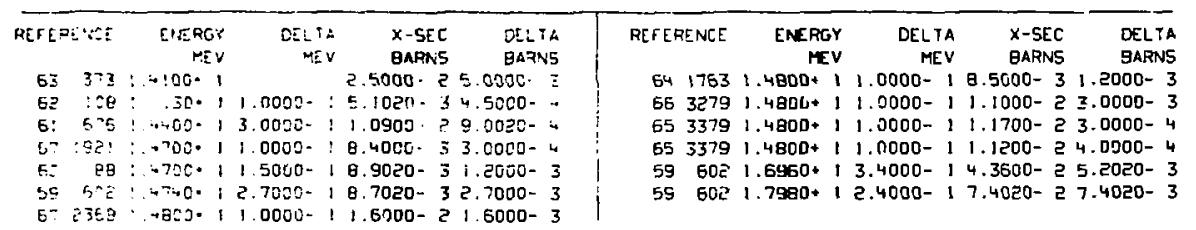




\section{CROSS SECTION}

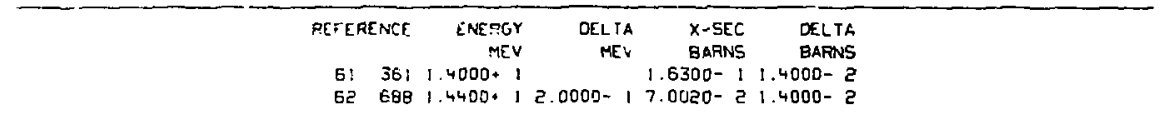

$03 / 01 / 74$

N.P

$15-P-31$

\begin{tabular}{|c|c|c|c|c|c|c|c|c|c|c|}
\hline \multicolumn{2}{|c|}{ RCFEAENEE } & 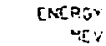 & $\begin{array}{c}\text { OEt is } \\
\text { rt: }\end{array}$ & $\begin{array}{l}x-55 \\
2 \neq 01\end{array}$ & $\begin{array}{l}\text { DELTIA } \\
\text { BARENS }\end{array}$ & PEFEAENCE & $\begin{array}{r}\text { ENERGY } \\
\text { HEY }\end{array}$ & $\begin{array}{r}\text { DELTA } \\
\text { MEV }\end{array}$ & $\begin{array}{l}X-S E C \\
\text { BARNS }\end{array}$ & $\begin{array}{l}\text { DELTA } \\
\text { BARNS }\end{array}$ \\
\hline $\begin{array}{l}61 \\
52\end{array}$ & $\begin{array}{r}351 \\
64\end{array}$ & $\begin{array}{l}1.5000: \\
1.41000:\end{array}$ & & $\begin{array}{l}\text { 1. } 9400- \\
\text { 9. } 1000-\end{array}$ & $\begin{array}{l}1.4000-2 \\
29.1000-3\end{array}$ & $\begin{array}{rr}67 & 192 ! \\
62 & 98\end{array}$ & $\begin{array}{l}1.4700+1 \\
1.4700+1\end{array}$ & $\begin{array}{l}1.0000-1 \\
1.5000-1\end{array}$ & $\begin{array}{l}6.4000-2 \\
\text { B.2020- }\end{array}$ & $\begin{array}{l}2.0000-3 \\
1.0000-2\end{array}$ \\
\hline $\begin{array}{l}62 \\
53\end{array}$ & $\begin{array}{r}689 \\
27\end{array}$ & $\begin{array}{l}1.4400 * 1 \\
1.4500 * 1\end{array}$ & $2.0000-i$ & $\begin{array}{l}\text { i !.5500- } \\
6 .+220-\end{array}$ & $\begin{array}{l}! \quad ! .5000-2 \\
28.3020-3\end{array}$ & 653379 & $1.4800+1$ & $1.0000-1$ & 100- & $00-$ \\
\hline
\end{tabular}

03/0!/74

E) E67 1.4800, $19.0020-17.0020-4$

$03 / 01 / 74$

N. ALPHA

$15-P-31$

\begin{tabular}{|c|c|c|c|c|c|c|c|c|c|c|}
\hline PETERE VEE & $\begin{array}{c}\text { EIEPSY } \\
\text { ME: }\end{array}$ & 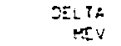 & $\begin{array}{l}x-55= \\
\text { Bxpis }\end{array}$ & $\begin{array}{l}\text { DEL IA } \\
\text { EARNS }\end{array}$ & $i$ & REFERENCE & $\begin{array}{r}\text { ENERGY } \\
\text { MEV }\end{array}$ & $\begin{array}{r}\text { DELTA } \\
\text { MEV }\end{array}$ & $\begin{array}{l}X \text { X-SEC } \\
\text { BARNS }\end{array}$ & $\begin{array}{l}\text { DELTA } \\
\text { BARNS }\end{array}$ \\
\hline 65 I 76 & $1.4500 \cdot:$ & $-0000-;$ & ! r ré̃o-! & $1.700 u+2$ & & $\mathrm{Eg}$ & $1.4700+1$ & $1.5000-1$ & $1.5300-!$ & $2.0000-2$ \\
\hline 53 & $1.4503=:$ & & $1.4600-1$ & $2.9000-2$ & & 553379 & $1.4000+1$ & $1.0000-1$ & $1.2900-1$ & $3.0000-3$ \\
\hline
\end{tabular}

$671921,4700 . ; 10090-196800-25.5000-3$

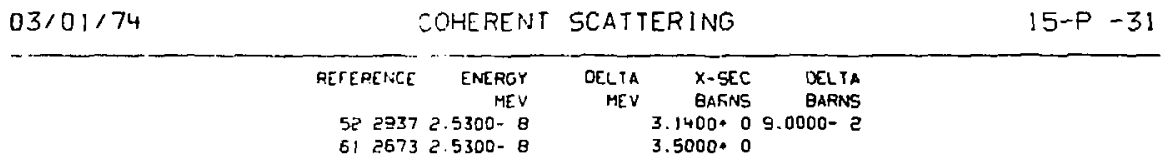



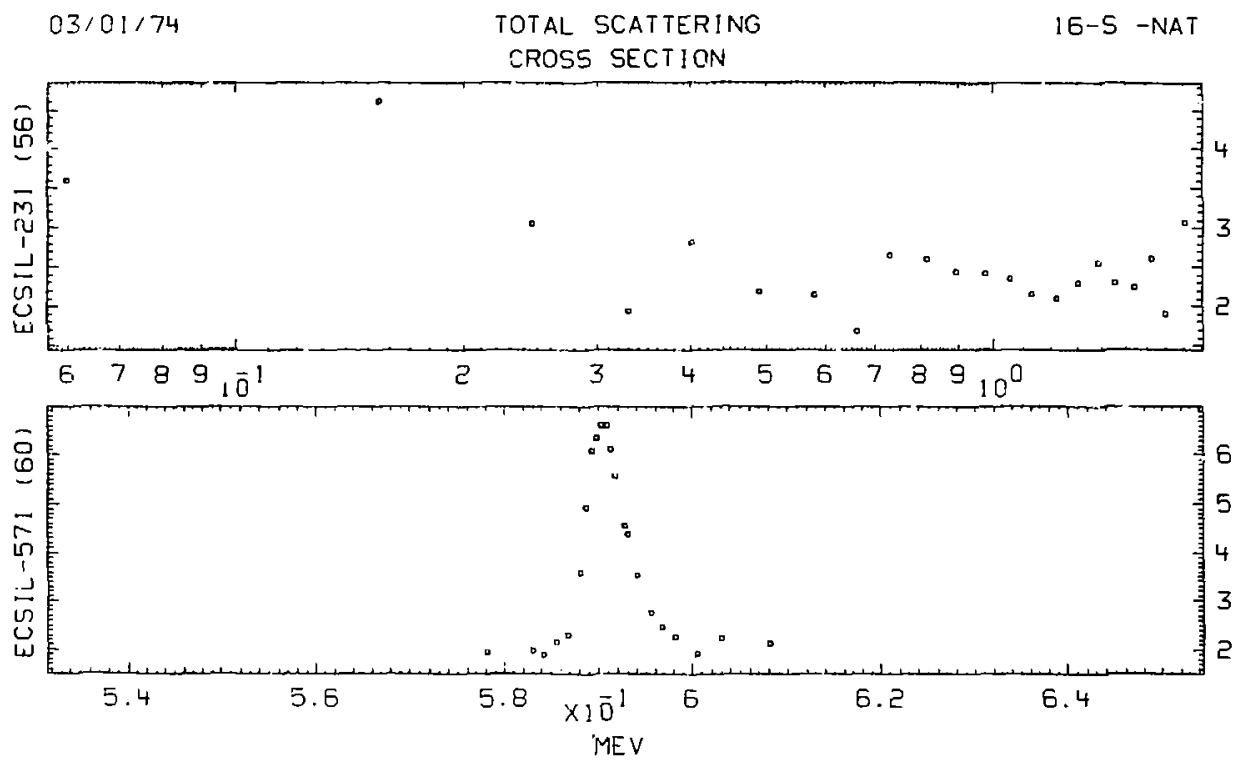

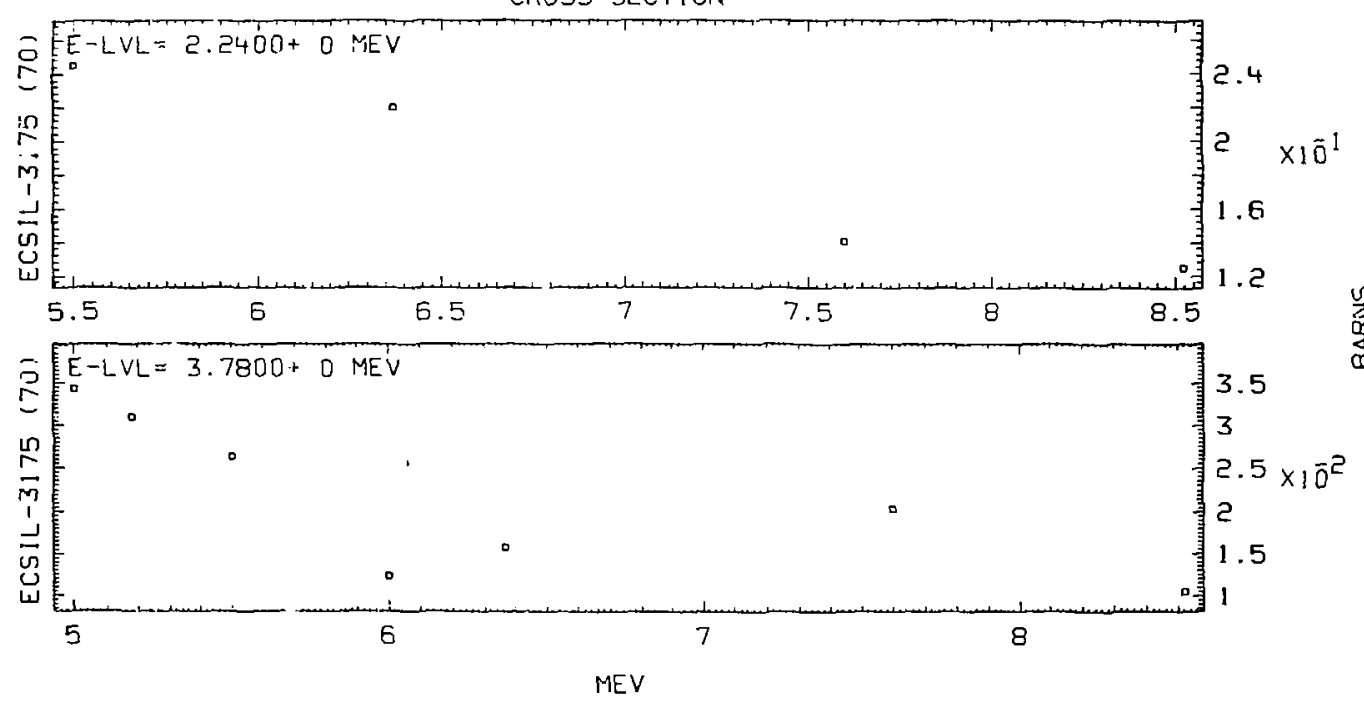

造 


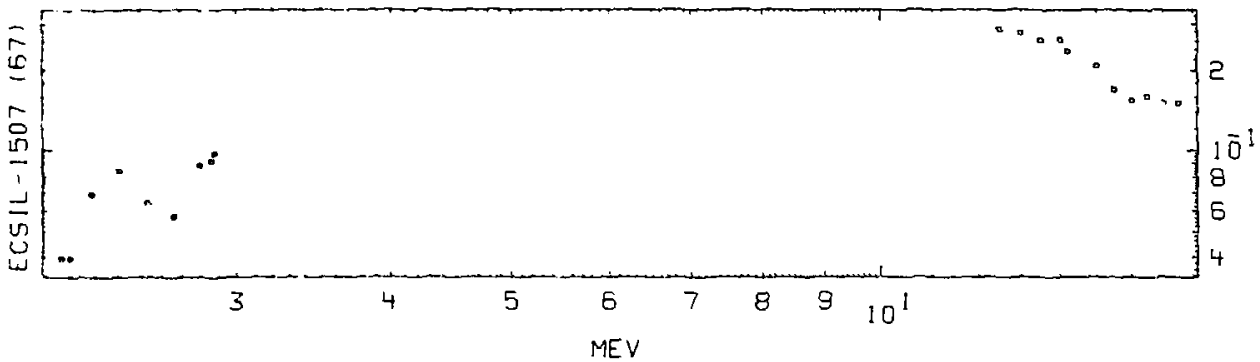

\section{$03,01 / 74$}

NONELASTIC

$$
16-5 \text { - NAT }
$$

\begin{tabular}{|c|c|c|c|c|c|}
\hline \multicolumn{2}{|c|}{ FEFERENCE } & $\begin{array}{l}\text { ENERGY } \\
\text { MEV }\end{array}$ & DE. A & $\begin{array}{l}x-5 E C \\
\text { BARINS }\end{array}$ & $\begin{array}{l}\text { DEL 1A } \\
\text { BARNS }\end{array}$ \\
\hline 56 & 34 & $2.5000+3$ & & $5.4020-1$ & $2.1000-1$ \\
\hline 55 & 790 & $2.5000+0$ & $1.5030-1$ & $5.4020-1$ & $2.1000-1$ \\
\hline 59 & 559 & $3.6600+0$ & 2.0000- 1 & $7.8020-1$ & $\therefore 2000-1$ \\
\hline 56 & 151 & $7.0000+0$ & $2.0000-1$ & $1.1400+0$ & $17.0020-2$ \\
\hline
\end{tabular}

$\begin{array}{rrr}\text { PETEPENCE } & \begin{array}{r}\text { ENERGY } \\ \text { MEV }\end{array} \\ 57 & 199 & 1.4100+1 \\ 57 & 319 & 1.4200+1\end{array}$

$\begin{array}{rrr}\text { DELTA } & X \text {-SEC } & \text { DELTA } \\ \text { MEV } & \text { BARNS } & \text { BARN5 }\end{array}$

319 1.4200+1 1.5000- $11.0800+08.0020-2$

$561517.0000+02.0000-11.1400+07.0020-2$

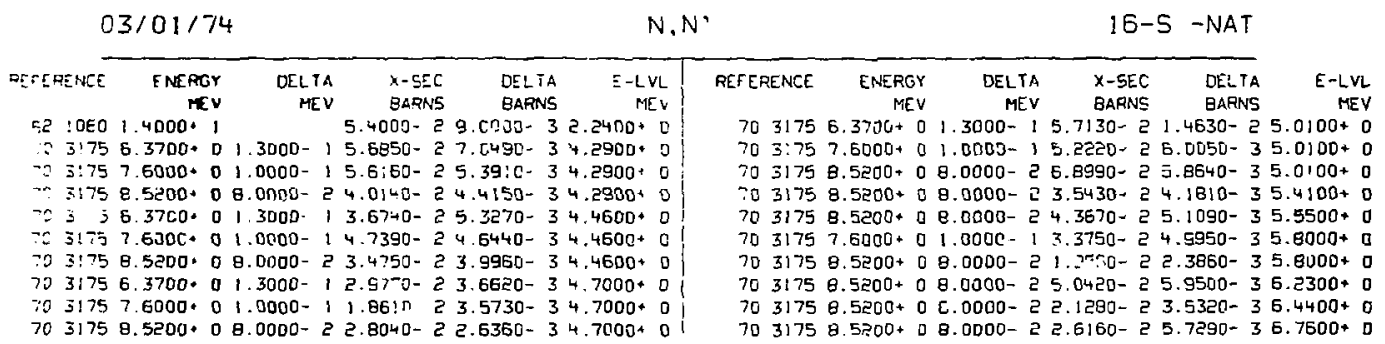




\section{CROSS SECTION}

\begin{tabular}{|c|c|c|c|c|c|c|c|}
\hline & REFERENCE & $\begin{array}{r}\text { ENERGY } \\
\text { MEV }\end{array}$ & $\begin{array}{c}\text { DELTA } \\
\text { MEV }\end{array}$ & $\begin{array}{l}x-5 E C \\
\text { RARNS }\end{array}$ & $\begin{array}{l}\text { DEL TA } \\
\text { BAFNS }\end{array}$ & $\begin{array}{r}E-L V L-M I N \\
M E V\end{array}$ & $\begin{array}{r}E-L V L-M A X \\
\text { MEV }\end{array}$ \\
\hline & 621060 & $1.4000+1$ & & $8.8000-2$ & $1.2000-2$ & $3.5000+0$ & $6.0000+0$ \\
\hline & 703175 & E. $0000+0$ & $8.0000-2$ & $9.3840-2$ & $1.1820-2$ & $4.2500+0$ & $4.4500+0$ \\
\hline & 703175 & $6.3700+0$ & $21.3000-1$ & I.2020- I & 1.094D- 2 & $4.2900+0$ & $4.4600+$ \\
\hline & $703: 75$ & $8.5200+0$ & $8.0000-2$ & B.2080- z & $7.0590-3$ & $4.2900+0$ & $4.4600+0$ \\
\hline & 763175 & $7.5000+0$ & $1.0000-1$ & 8.8000- ᄅ & $9.9440-3$ & $5.4100+0$ & $5.5500+0$ \\
\hline & 703175 & B. $5200+0$ & $8.0000-2$ & $7.5090-2$ & $6.8330-3$ & $5.4100+0$ & $5.5500+0$ \\
\hline & 621060 & $1.4000+1$ & & $4.8000-2$ & $9.0000-3$ & $6.0000+0$ & $8.0000+n$ \\
\hline & 703175 & $8.5200+0$ & $8.0000-2$ & E.8230- $\overline{c^{\prime}}$ & $7.9830-3$ & $6.2300+0$ & $6.4400+$ \\
\hline & 703175 & $8.5200+0$ & 8.0000- $\vec{r}$ & $3.9330-2$ & $6.5680-3$ & $6.6200+0$ & $6.6700+$ \\
\hline
\end{tabular}

$03 / 01 / 74$

$N, N \cdot P$

$16-S-N A T$

$\begin{array}{rrrrr}\text { RETEREAE } & \text { ENERGY } & \text { DELTA } & X-5 T C & \text { DELTA } \\ & \text { MLV } & \text { MEV } & \text { BARNS } & \text { BARNS }\end{array}$

$626881.4400+1$ 2.0000- $17.3020-21.5000-2$

\section{$03 / 01 / 74$}

REFLRENCE EIJERGY

5a 2566 ? $.5300-8$

\begin{tabular}{|c|c|c|}
\hline $\begin{array}{r}\text { DELTA } \\
\text { MEV }\end{array}$ & $\begin{array}{l}x-5=C \\
\text { BARNS }\end{array}$ & DELTA \\
\hline & $\begin{array}{l}500-1 \\
000-2\end{array}$ & $1.0000-?$ \\
\hline
\end{tabular}

$N, \times$ GAMMA
16-S -NAT

$\begin{array}{ll}X-5 E C & \text { DELTA } \\ \text { BAFNG } & \text { BAFNS }\end{array}$

58364 2. 2000

$583648.3000-14.0000-2$ 2.1000-

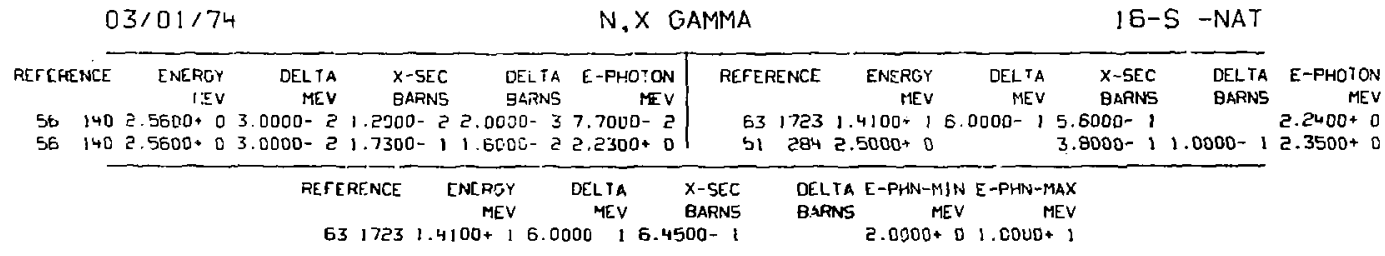




$03 / 01 / 74$
CFOSS SECTION

$\begin{array}{ccccc}\text { REFERENCE } & \text { ENERGY } & \text { DELTA } & x \text {-SEC } & \text { DCLTA } \\ & \text { MEV } & \text { MEV } & \text { BARNS } & \text { GARNS }\end{array}$

$626881 .+400+12.0000-12.0600-12.1000-2$

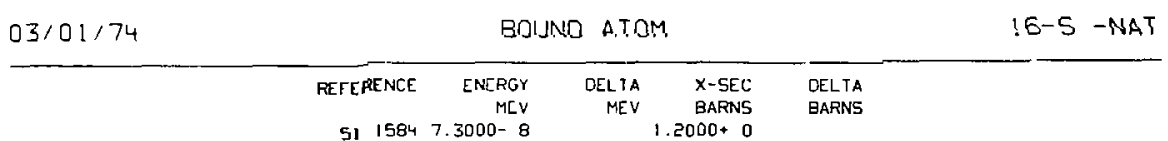

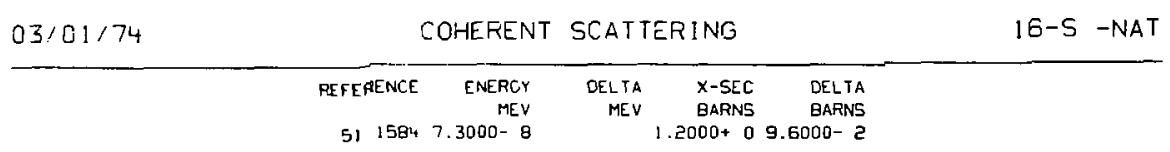

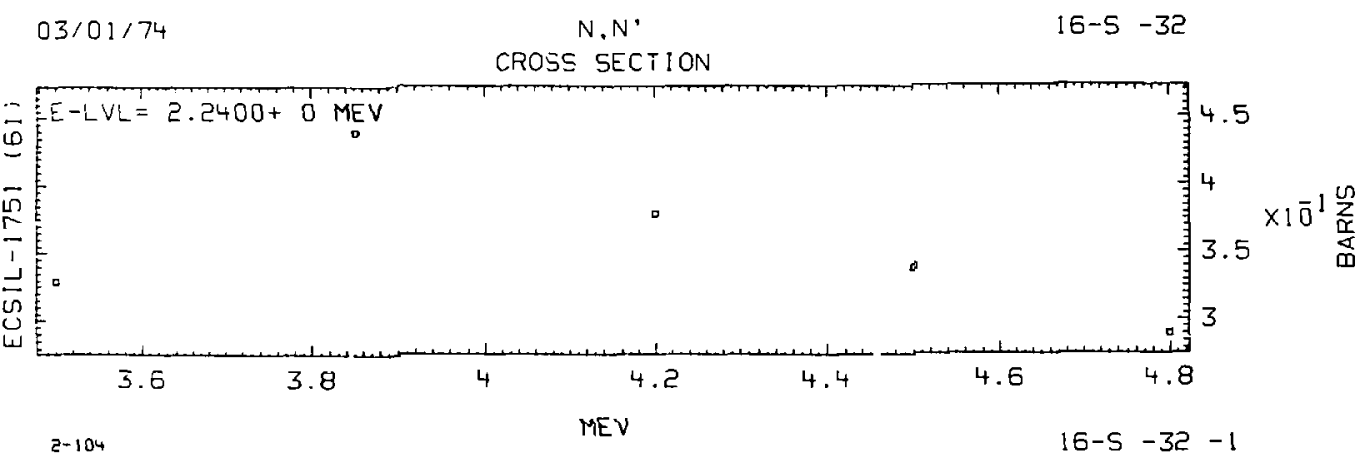



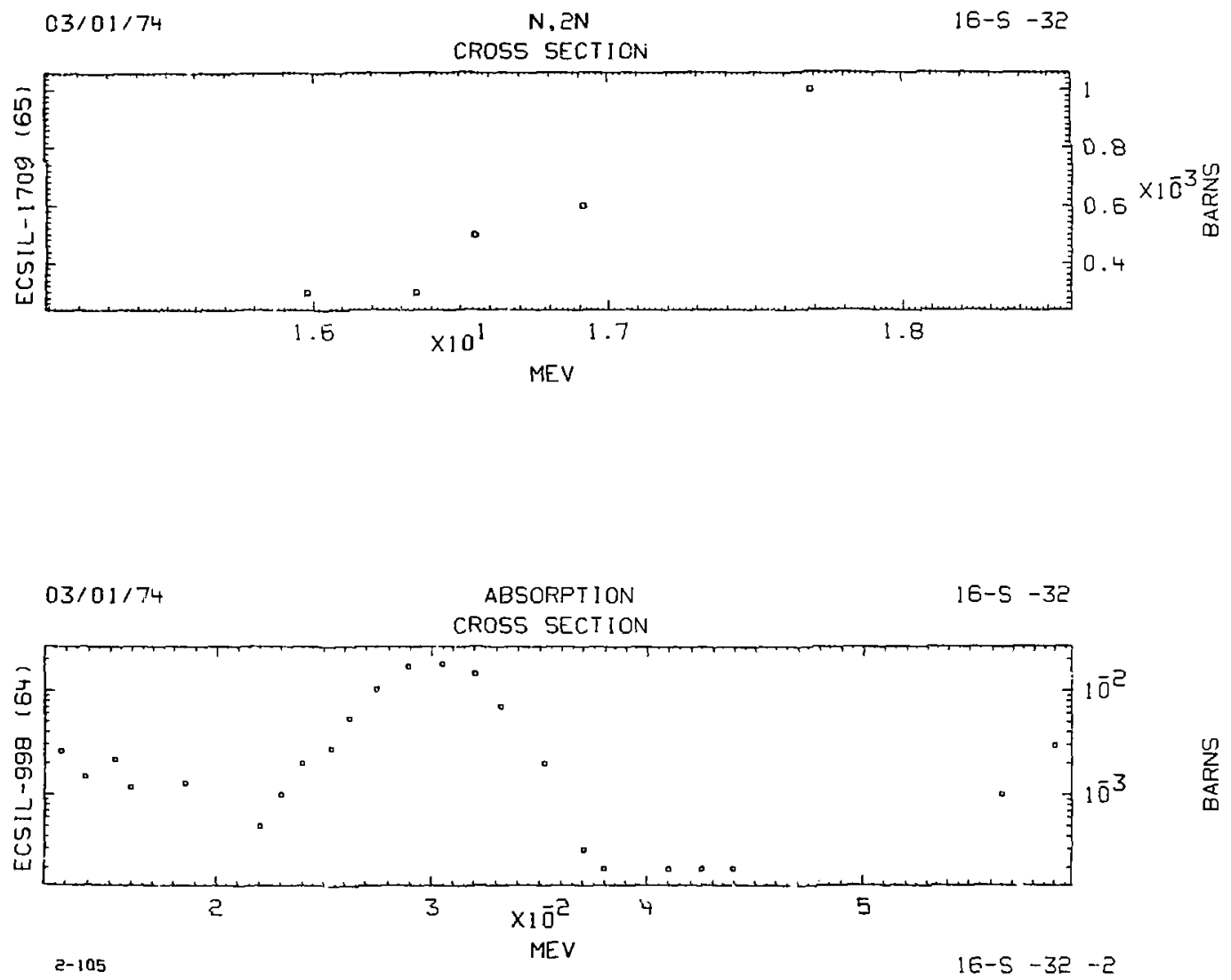

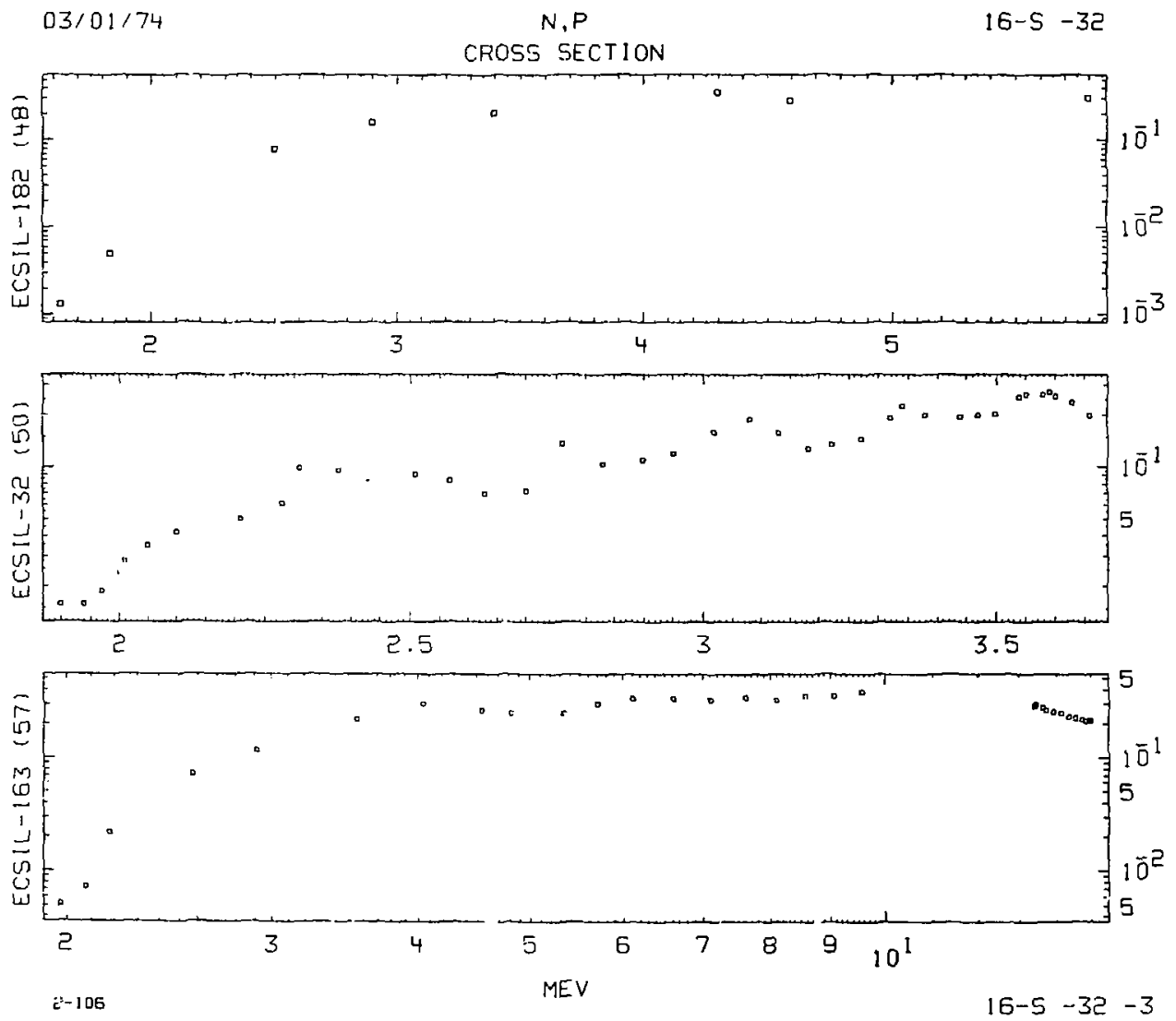

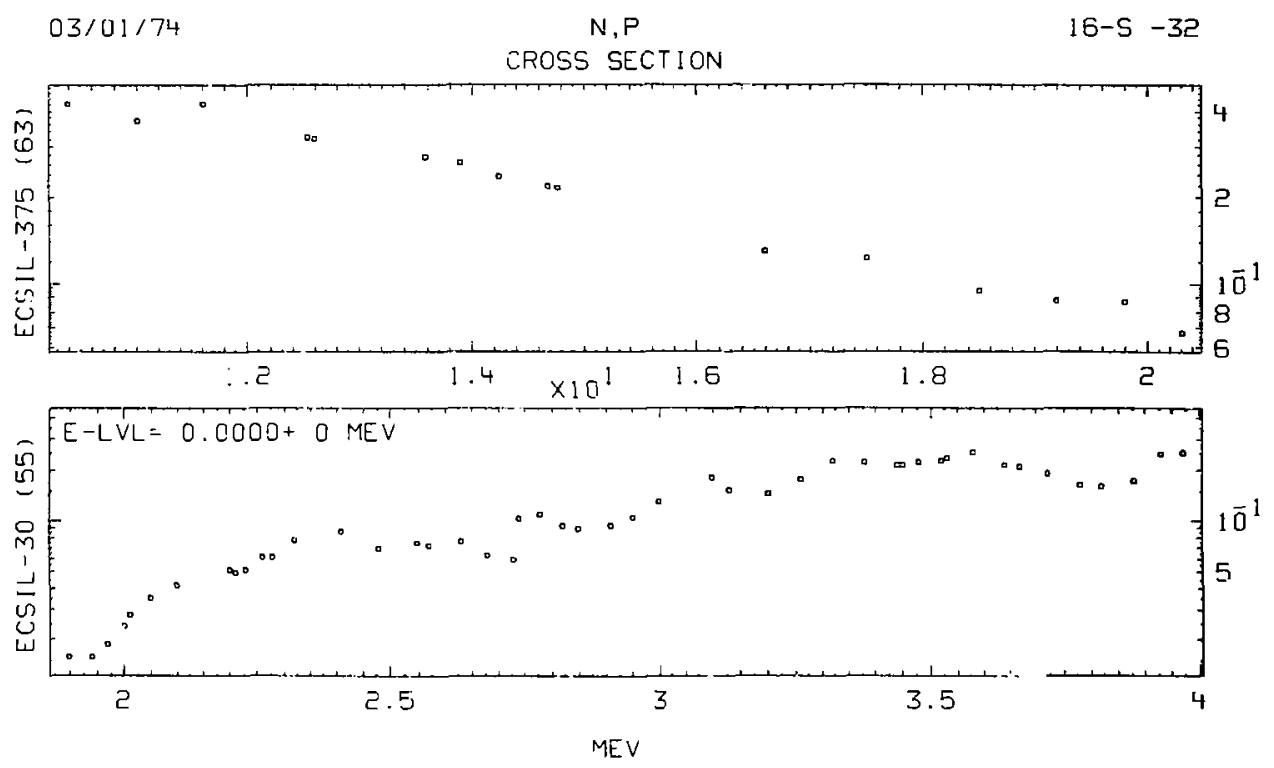

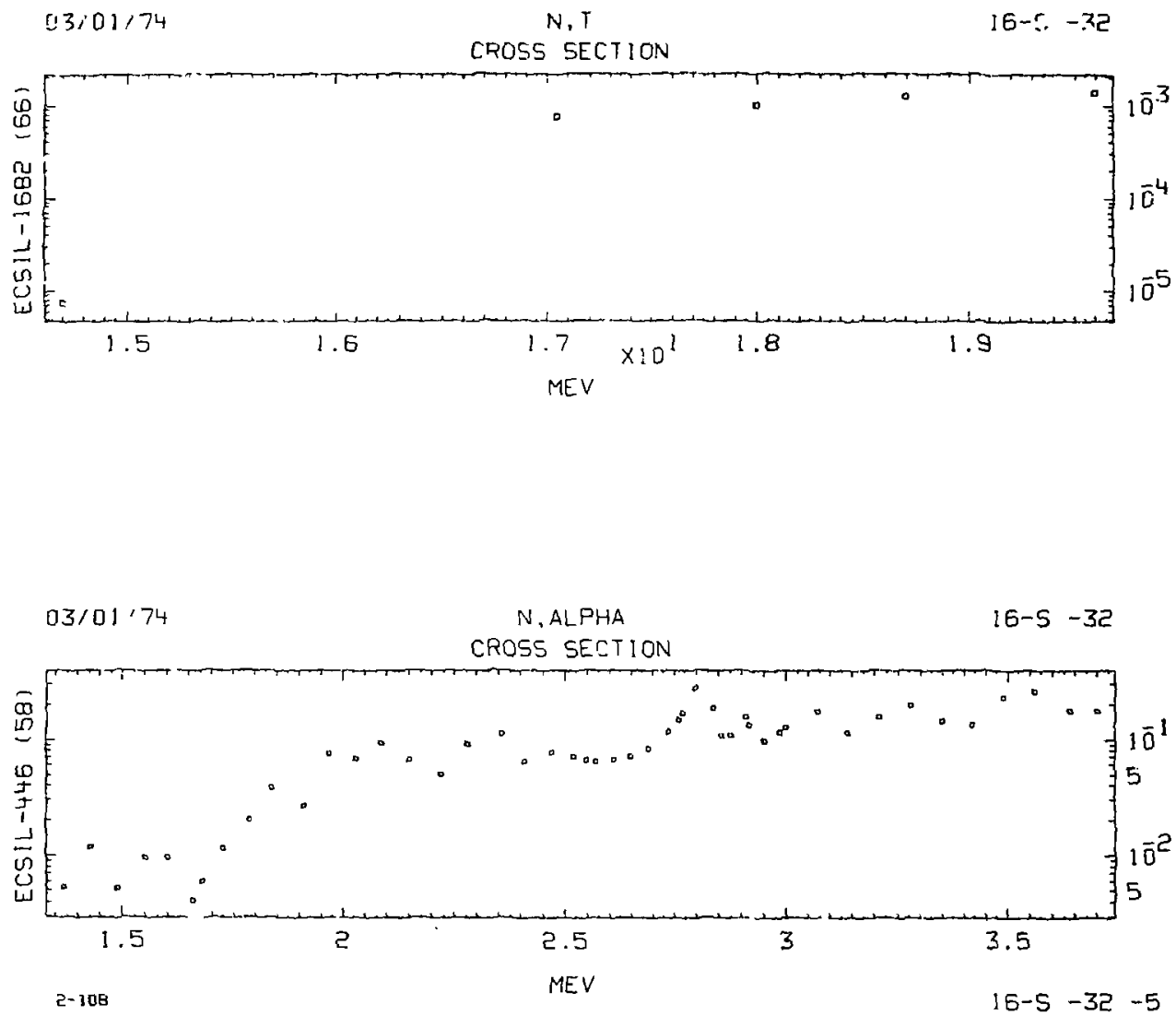


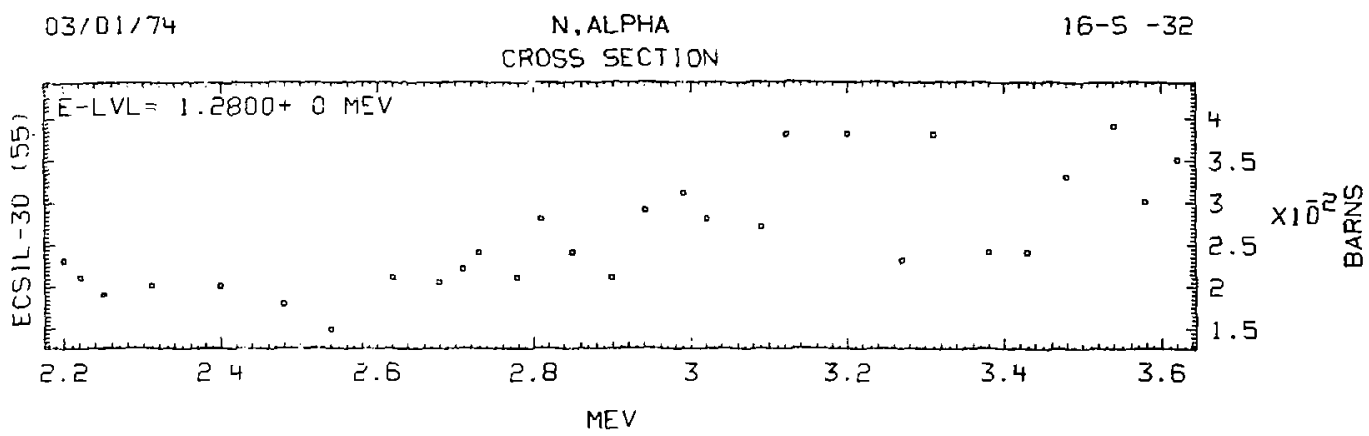

03/01/74

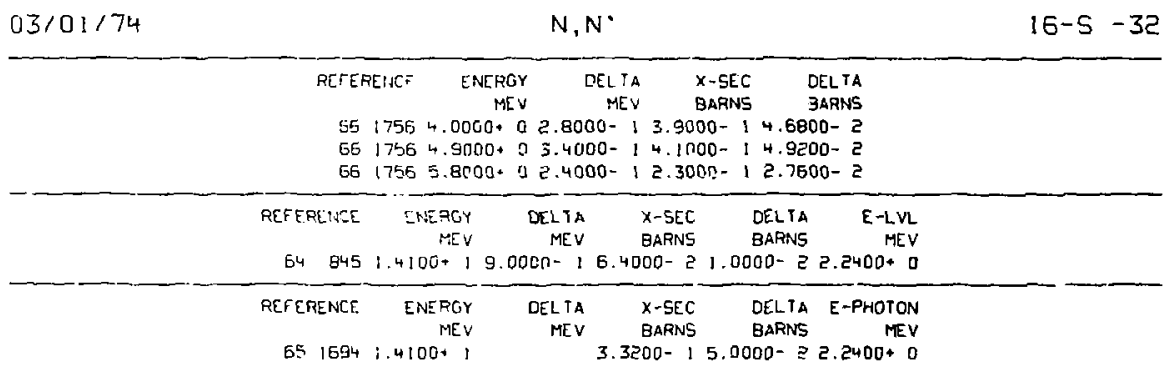




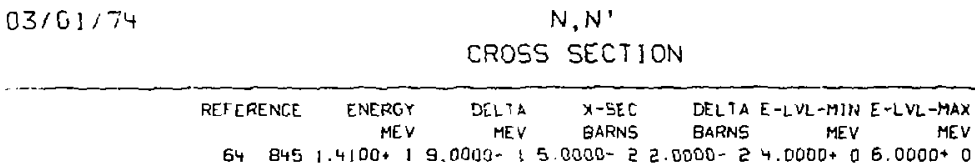

$648451.4100+19.0000-15.0000-22.0000-24.0000+06.0000+0$

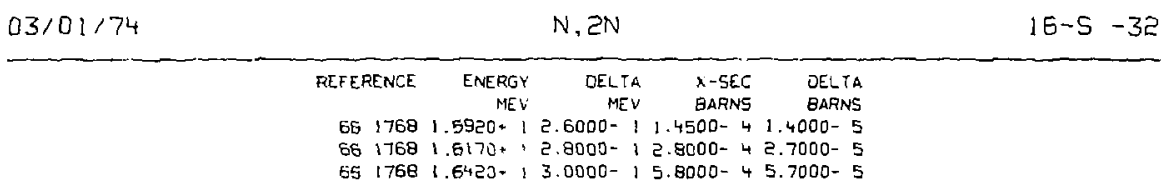

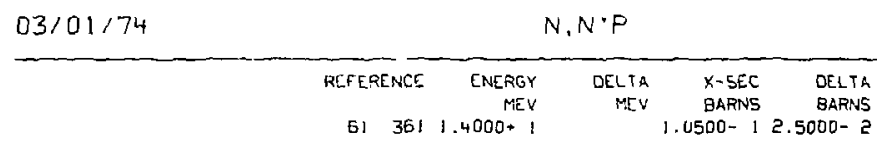

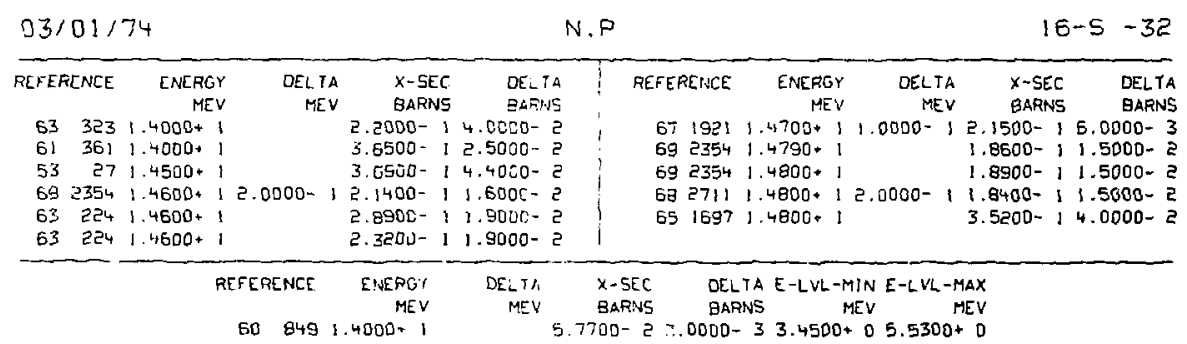




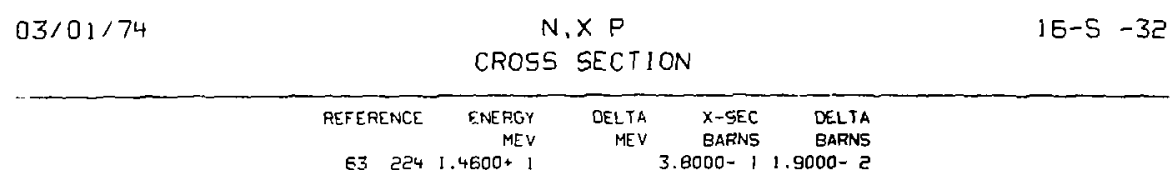

\begin{tabular}{|c|c|c|c|c|c|c|c|c|c|}
\hline $03 / 01$ & & & & & & & & 16 & $5-32$ \\
\hline REFERENC & $\begin{array}{c}\text { ENERGY } \\
\text { MEV }\end{array}$ & $\begin{array}{c}\text { DEL TA } \\
\text { MEV }\end{array}$ & $\begin{array}{l}x \text {-SEC } \\
\text { BARNS }\end{array}$ & $\begin{array}{l}\text { DELTA } \\
\text { BARNS }\end{array}$ & PEFERENCE & $\begin{array}{r}\text { ENERGY } \\
\text { MEV }\end{array}$ & $\begin{array}{l}\text { OELTA } \\
\text { MEV }\end{array}$ & $\begin{array}{l}x-5 E C \\
\text { BARMS }\end{array}$ & $\begin{array}{l}\text { DELTA } \\
\text { GAPNS }\end{array}$ \\
\hline $\begin{array}{rr}51 & 66 \\
62 & 1770\end{array}$ & $\begin{array}{l}.4600+1 \\
.4700+1\end{array}$ & $3.0000-1$ & $\begin{array}{l}.0000-5 \\
2.0000-5\end{array}$ & $\begin{array}{l}51.0000-E \\
5.0000-6\end{array}$ & $\begin{array}{ll}68 & 3369 \\
65 & 1697\end{array}$ & $\begin{array}{l}1.4700+1 \\
1.4000+1\end{array}$ & $2.0000-1$ & $\begin{array}{l}5.7000-5 \\
2.2000-3\end{array}$ & $\begin{array}{l}.9000-6 \\
.0000-4\end{array}$ \\
\hline
\end{tabular}

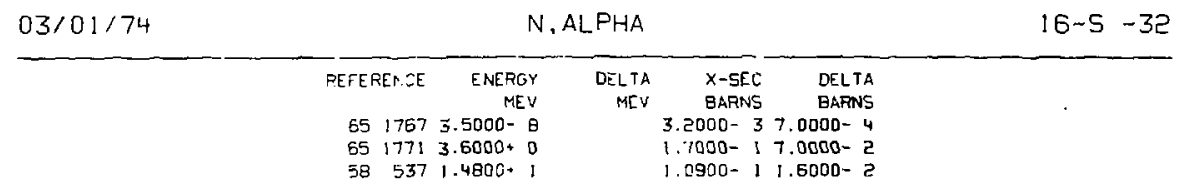

- $03 / 01 / 74$



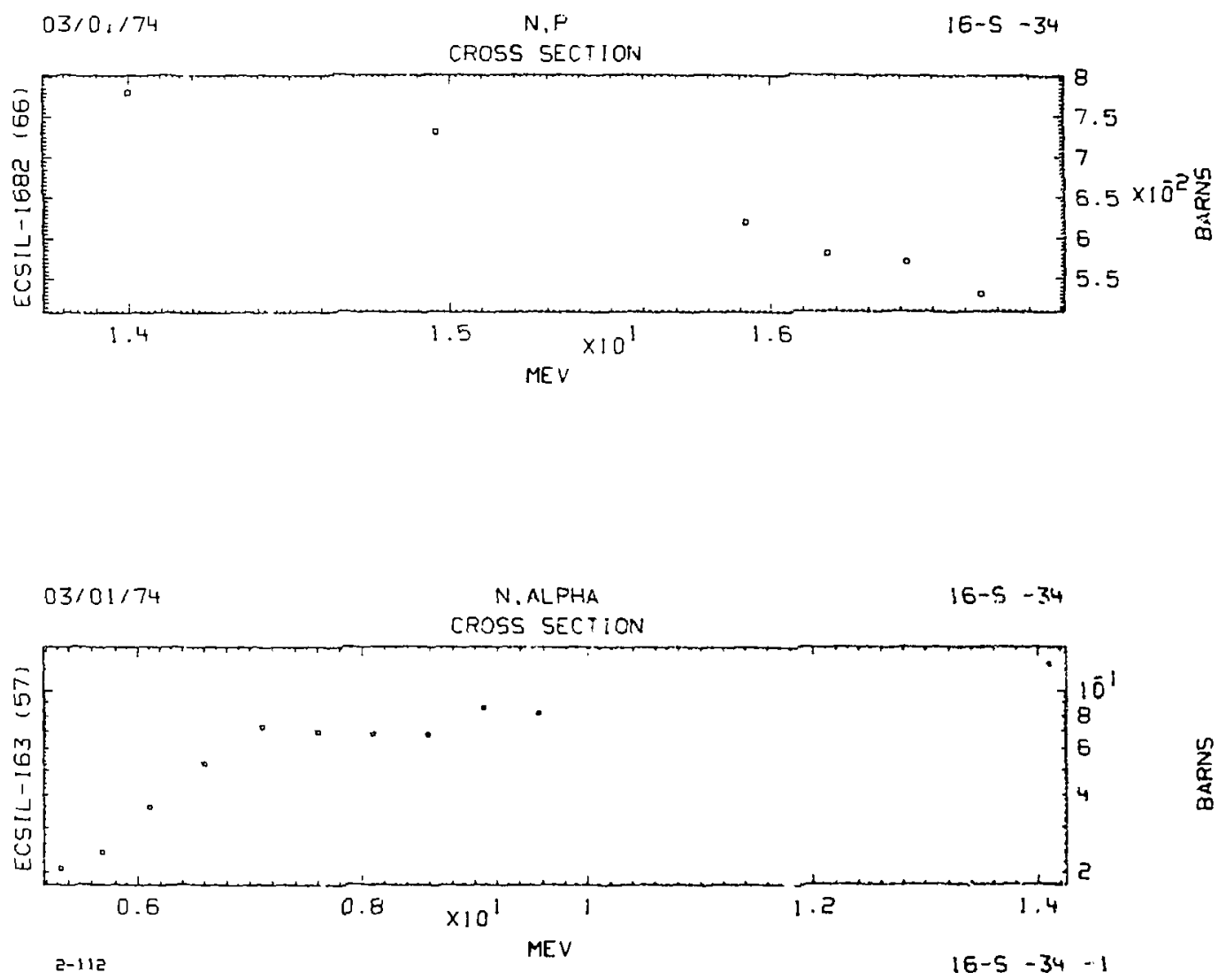


\section{CROSS SECTION}

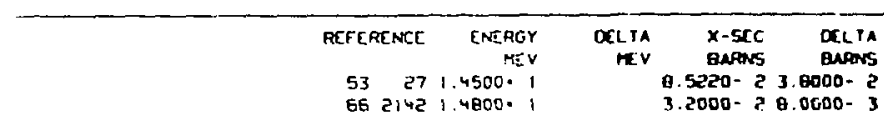

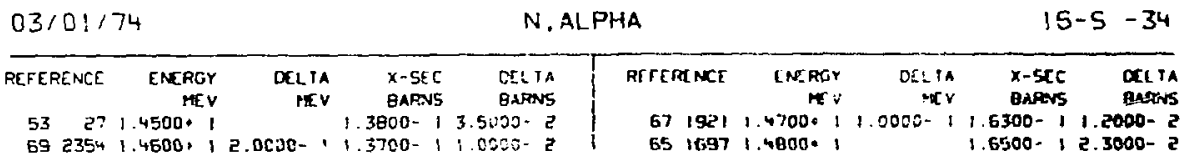

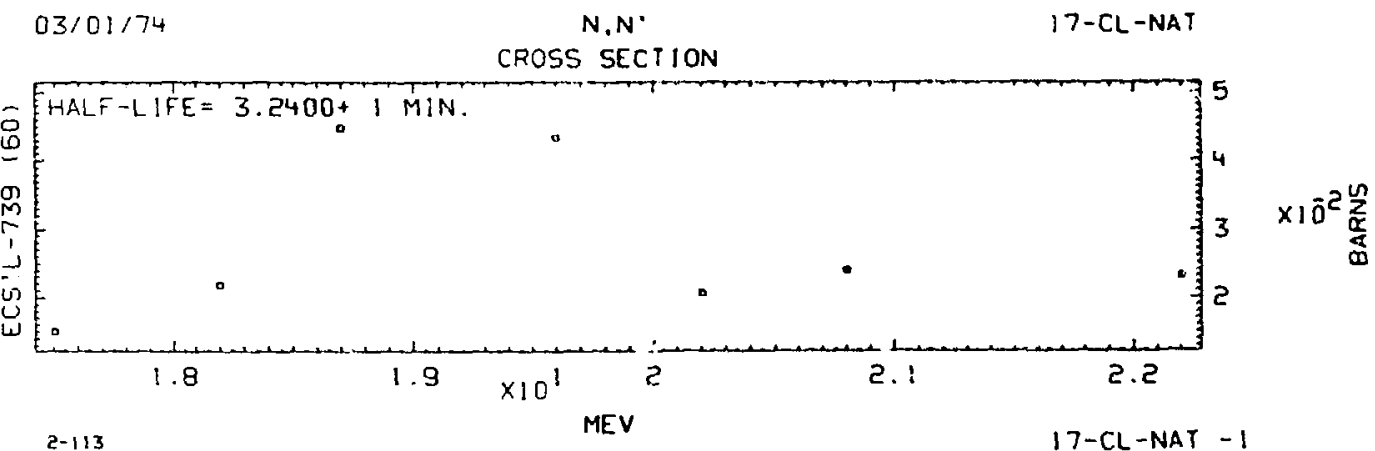




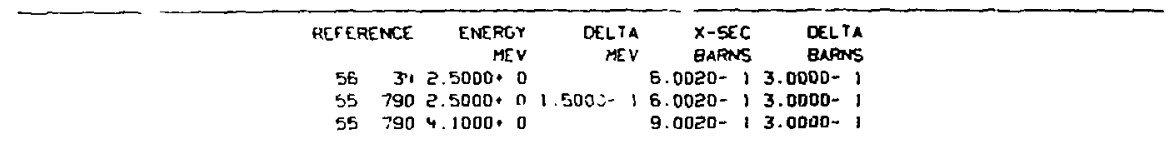

$03 / 0 ! / 74$ N.N 17-CL-NAT

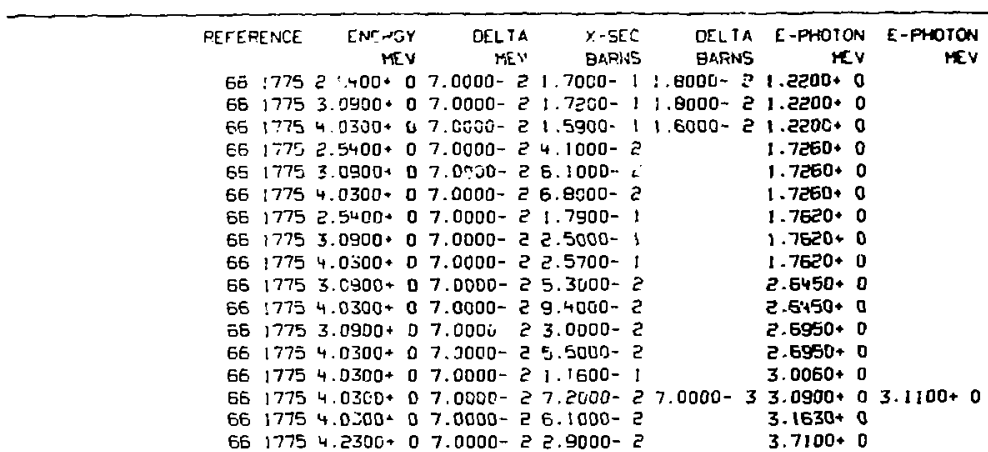

$\begin{array}{rrrrr}\text { REFERENCE } & \begin{array}{r}\text { CNERGY } \\ \text { MEV }\end{array} & \begin{array}{r}\text { DELTA } \\ \text { MEV }\end{array} & \begin{array}{r}\text { X-5EC } \\ \text { BARN5 }\end{array} & \begin{array}{r}\text { DELTA } \\ \text { BARN5 }\end{array} \\ 612934 & 2.5300-8 & 8.1000+1 & 2.0000+0 \\ 60 & 891 & 2.5300-8 & 8.0000-1\end{array}$




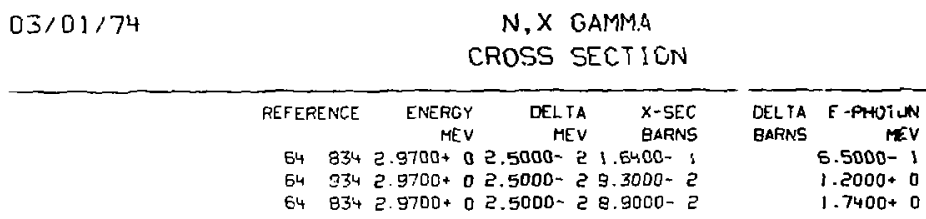

\begin{tabular}{|c|c|c|c|c|c|c|}
\hline $03 / 01 / 74$ & & $\mathrm{BC}$ & ATO & & & $17-C L-N A T$ \\
\hline & REFERENCE & $\begin{array}{r}\text { ENERGY } \\
\text { MEN }\end{array}$ & $\begin{array}{r}\text { DELT' } \\
\text { MEV }\end{array}$ & $\begin{array}{l}X \text { X-SEC } \\
\text { BARNS }\end{array}$ & $\begin{array}{l}\text { DELTA } \\
\text { BARNS }\end{array}$ & \\
\hline
\end{tabular}

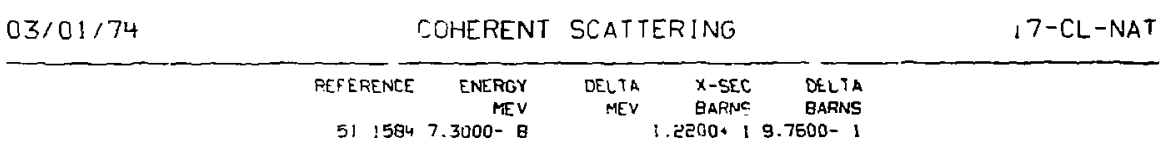

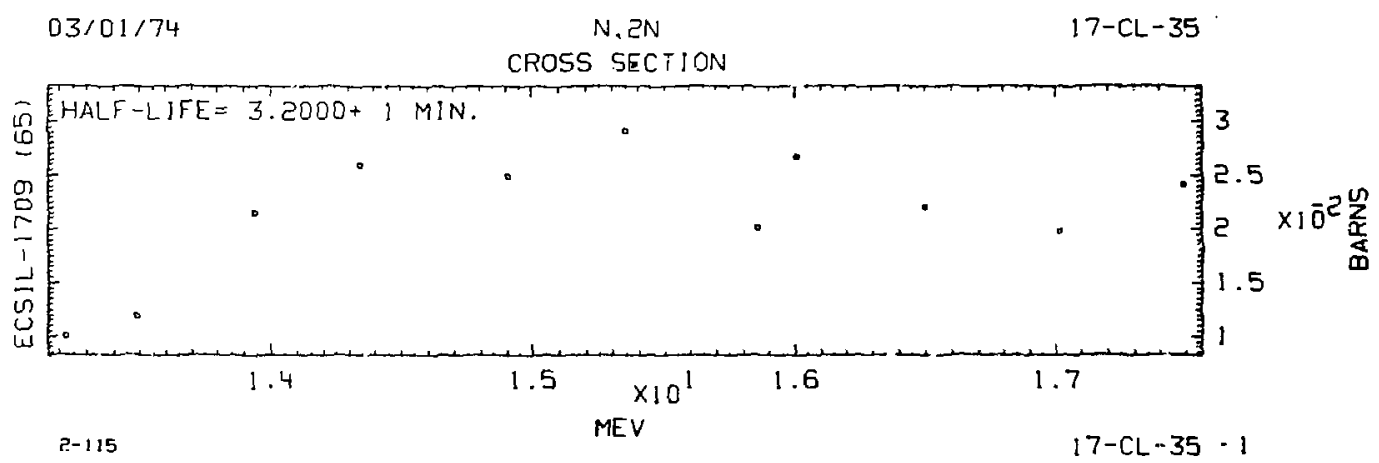




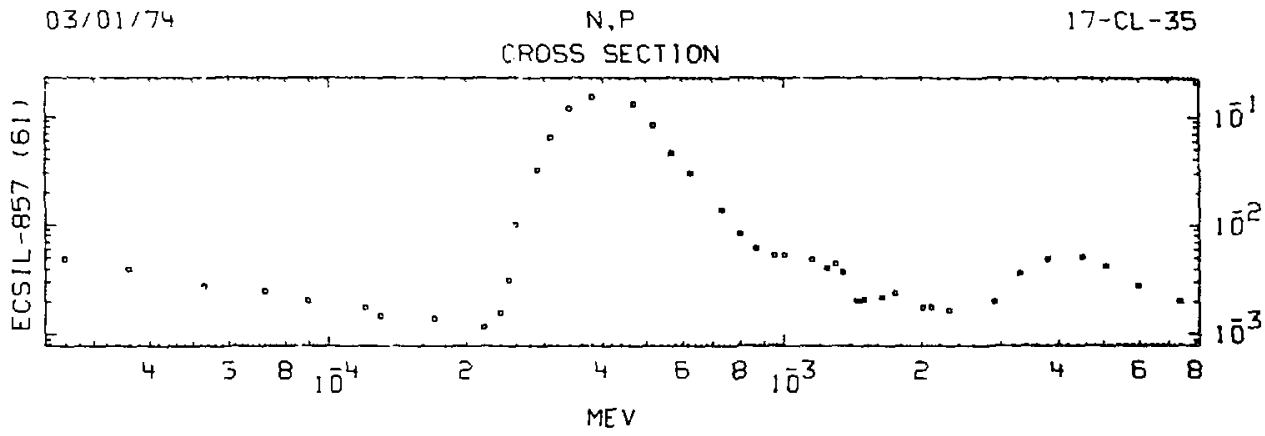

$\frac{w}{2}$

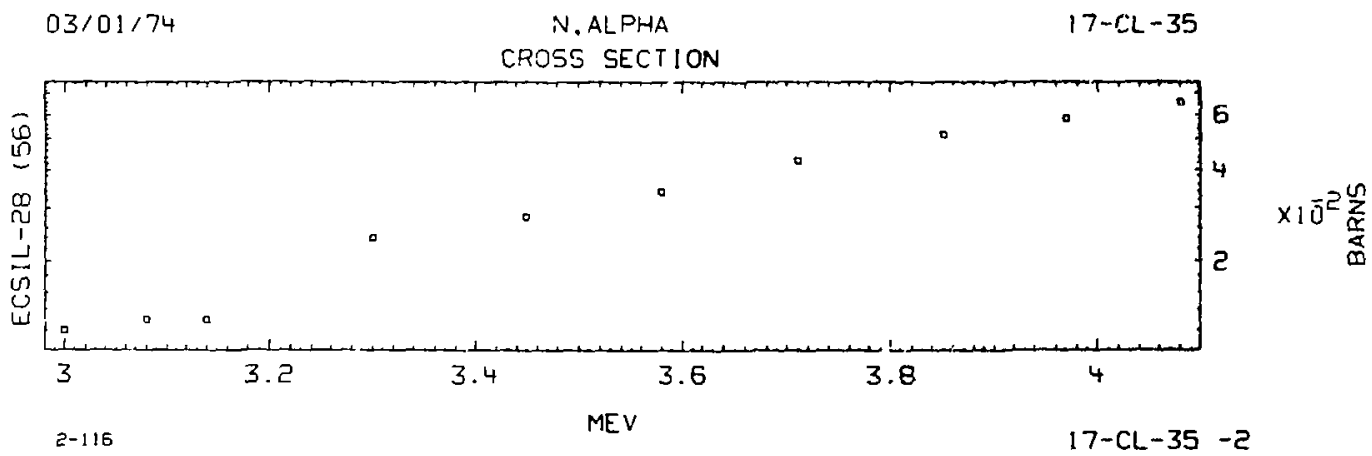




\section{CROSS SECTION}

\begin{tabular}{|c|c|c|c|c|c|c|c|c|c|c|c|}
\hline PEFERENCE & $\begin{array}{r}\text { ENERGY } \\
\text { MEV }\end{array}$ & $\begin{array}{r}\text { DEL TA } \\
\text { MEV }\end{array}$ & $\begin{array}{l}X \text {-SEC } \\
\text { BARNS }\end{array}$ & $\begin{array}{l}\text { JELTA } \\
\text { BARNS }\end{array}$ & $\begin{array}{r}\text { E-PHOTON } \\
\text { MEV }\end{array}$ & PEFERENCE & $\begin{array}{r}\text { ENERGY } \\
\text { MEV }\end{array}$ & $\begin{array}{l}\text { OELIA } \\
\text { MEV }\end{array}$ & & $\begin{array}{l}\text { DELIA } \\
\text { BARNS }\end{array}$ & E-PHETCN \\
\hline $66 \quad 1775$ & $03+0$ & $07.0000-2$ & $.2500-1$ & & & 66 1775 & $3.0900+0$ & $7.0000-2$ & $0000-2$ & & Z.E \\
\hline $65 \quad 1775$ & $3.0500+0$ & $07.0000-2$ & $2 B 00-1$ & & $0+0$ & $66 \quad 1775$ & 00.0 & $10 \cdot 2$ & $1.2500-1$ & 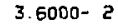 & $0+0$ \\
\hline $66: 775$ & $4.0300+0$ & $07.0000-2$ & E 2.1000- 1 & & $10+0$ & $66 \quad 1775$ & $00+0$ & $5-5$ & 4.DEDD - $\overrightarrow{2}$ & $\mathrm{DO}-2$ & $50+0$ \\
\hline $66 \quad 1775$ & $2.5400+3$ & $37.0000-2$ & $22.3700-1$ & & $1.762 n+0$ & $66: 775$ & $4.0300+0$ & $7.0000-2$ & $7.3000-2$ & 2 & $50 * 0$ \\
\hline $66 \quad 1775$ & $2.0900-0$ & $7.0000-2$ & $33.3100-1$ & & $1.76 \mathrm{cos} \cdot \mathrm{C}$ & $66 \quad 1775$ & $4.0300 \cdot 0$ & $7.0000-2$ & $1.5400-1$ & & 60+ \\
\hline $56 \quad 1775$ & $4.0300+0$ & $07.0000-2$ & $23.4000-1$ & & 1.7620 & $66 \quad 1775$ & 4. $0300+0$ & $7.0000-2$ & g. $1000-z$ & & 3.1630 \\
\hline
\end{tabular}
$03 / 01 / 75$
N, ZN
$17-\mathrm{CL}-35$

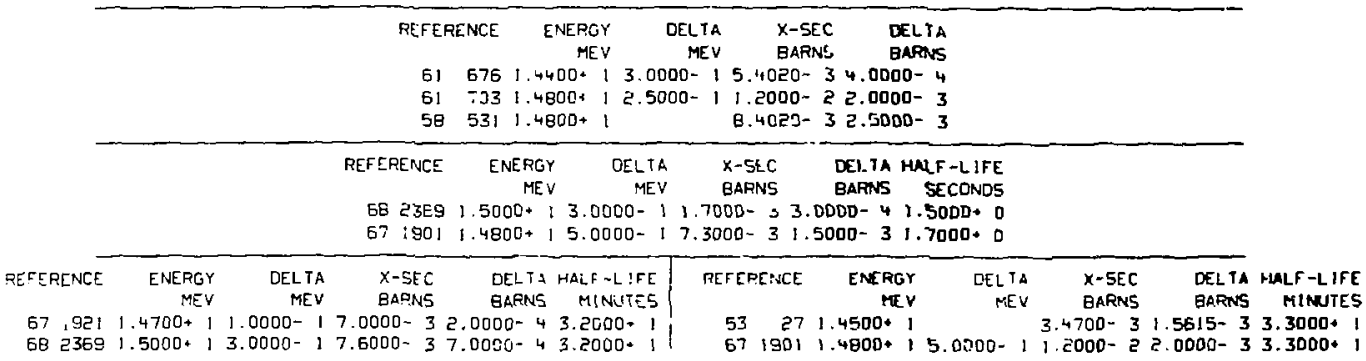

$03 / 01 / 74$

N.t

$17-C L-35$

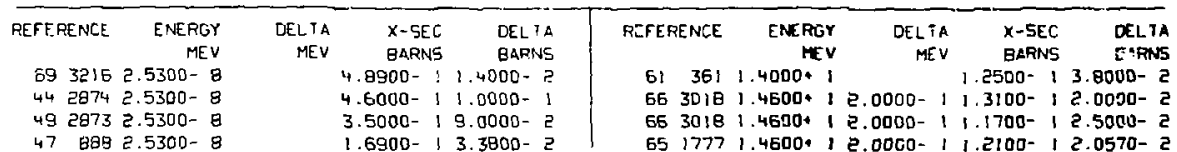




\section{CROSS SECTION}

\begin{tabular}{|c|c|c|c|c|c|c|c|c|c|}
\hline RT $r E R E N C E$ & $\begin{array}{r}\text { ENERGY } \\
\text { MEN }\end{array}$ & $\begin{array}{r}\text { DELTA } \\
\text { MEV }\end{array}$ & $\begin{array}{l}X \text { X-5EC } \\
\text { BARNS }\end{array}$ & $\begin{array}{l}\text { DELTA } \\
\text { BARNS }\end{array}$ & REFERENCE & $\begin{array}{r}\text { ENERSY } \\
\text { MEV }\end{array}$ & $\underset{\text { TEV }}{\operatorname{OELTA}}$ & $\begin{array}{l}X \text {-SEC } \\
\text { BARNS }\end{array}$ & $\begin{array}{l}\text { DELIAA } \\
\text { BARASS }\end{array}$ \\
\hline 61 2935 & $2.5300-8$ & & $8.0000-5$ & & 663018 & $1.4600 \cdot 1$ & e.0000- 1 & 1. $1700-1$ & $2.0000-2$ \\
\hline 323 & $1.4000 \cdot 1$ & & $1.0000-1$ & $2.0000-2$ & 563018 & $1.4500 \cdot 3$ & 2.0000- 1 & $1,2100-1$ & 2.00000- 2 \\
\hline 27 & 1.4500 & & $1.9100-1$ & $3.100 c-2$ & ES 1777 & $i 4600$ i & 2.0000- 1 & $1.0500-1$ & $1.6350-2$ \\
\hline 092354 & $\therefore 4600+1$ & $2.0000-1$ & $1.0000-1$ & $9.0000-2$ & $58 \quad 531$ & $14800+1$ & 1 & $1.2200-1$ & $5.5020-2$ \\
\hline
\end{tabular}

$\begin{array}{lll}03 / 01 / 74 & \text { N.P } & 17-C L-37\end{array}$

CROSS SECTION
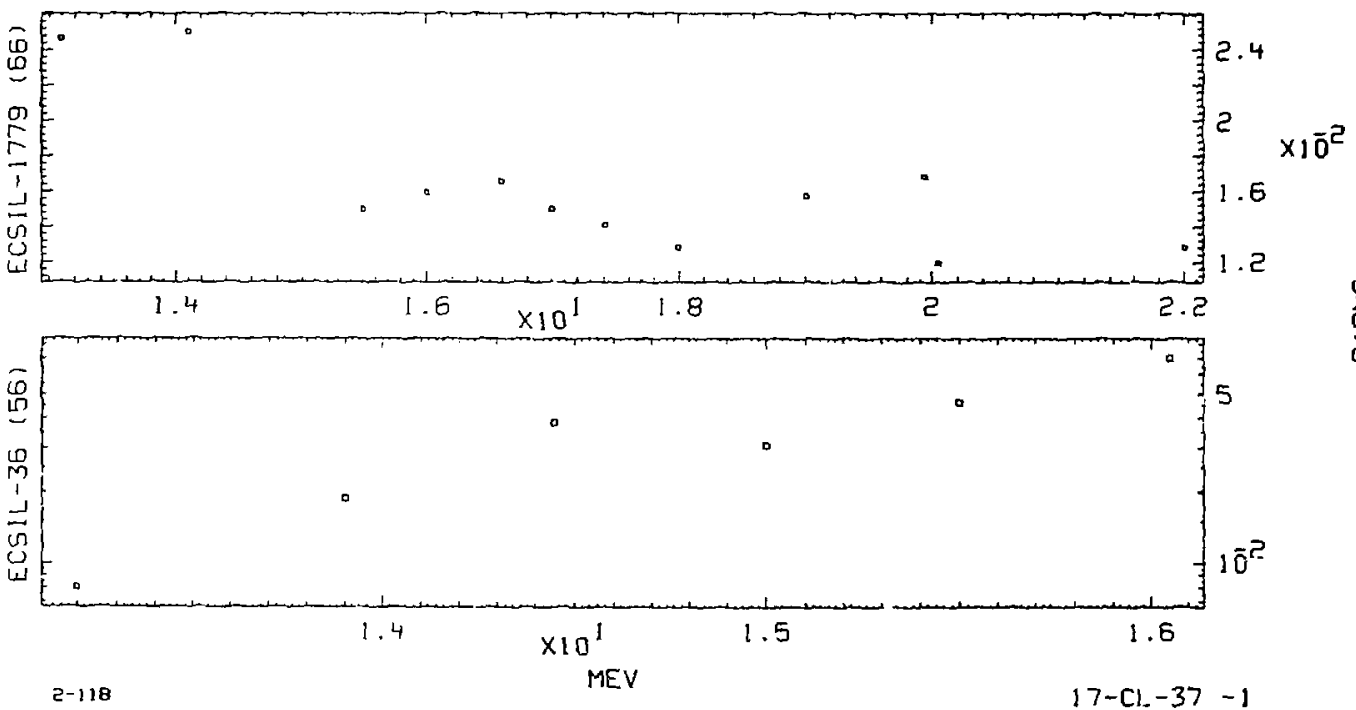
CROSS SECTION

\begin{tabular}{|c|c|c|c|c|c|c|c|c|c|c|c|}
\hline \multirow[b]{2}{*}{ REFEREISCR. } & & & & & & & & & & & \\
\hline & ENERGY & OF.L IA & $\begin{array}{l}x-5 \cdot E C \\
\text { BARNS }\end{array}$ & $\begin{array}{l}\text { DELTA } \\
\text { BARNS }\end{array}$ & E-PHOTON & REFERENCE & ENERGY & DELTA & $\begin{array}{l}x-\sec \\
\text { Bapans }\end{array}$ & DELTA & E-PHDTON \\
\hline & $\begin{array}{r}\text { MVY } \\
2.5400 \cdot 0\end{array}$ & $\begin{array}{r}\mathrm{M} \Gamma \mathrm{V} \\
7.0000-\mathrm{z}\end{array}$ & $\begin{array}{l}\text { BARNS } \\
\text { E I. } 6700-1\end{array}$ & BARNS & HEV & $66 \quad 1775$ & $4.0300+0$ & $7.0000-?$ & $.7800-1$ & & $\begin{array}{r}\text { MEV } \\
1.7260+0\end{array}$ \\
\hline $56 \quad 1775$ & $3.0900+0$ & $7.0000-2$ & $22.4900-1$ & & $1.7260+0$ & $66 \quad i 775$ & $4.2300 \cdot 0$ & $7.3000-2$ & $.1800-1$ & & 3.7100+ \\
\hline
\end{tabular}

$03 / 01 / 74 \quad$ N.P $17-\mathrm{Cl}-37$

\begin{tabular}{|c|c|c|c|c|c|c|c|c|c|c|}
\hline BEFERENCE & $\begin{array}{r}\text { ENERGY } \\
\text { MEV }\end{array}$ & $\begin{array}{l}\text { DELTA } \\
\text { MEV }\end{array}$ & $\begin{array}{l}X-S E C \\
\text { BARNS }\end{array}$ & $\begin{array}{l}\text { DELTA } \\
\text { BARNS }\end{array}$ & REFEF & ZENCE & $\begin{array}{r}\text { ENERGY } \\
\text { MEV }\end{array}$ & $\begin{array}{r}\text { DELIA } \\
\text { MEV }\end{array}$ & $\begin{array}{l}X \text {-SEC } \\
\text { BARESS }\end{array}$ & $\begin{array}{l}\text { OELTA } \\
\text { BAPWS }\end{array}$ \\
\hline 673307 & $1100+1$ & $1.8000-1$ & $2.1000-2$ & $3.0000-3$ & 58 & 531 & $.4800 \cdot 1$ & 1 & $2.5400-2$ & $22.1000-3$ \\
\hline $53 \geq 7$ & $1.4500+1$ & & $3.3400-2$ & $6.5800-3$ & 66 & 907 & $1.4800+1$ & $11.0000-1$ & 2. $1300-2$ & $2.1000-3$ \\
\hline 67,921 & $1.4700+1$ & $1.0000-$ & $2.5500-2$ & $1.2000-3$ & 67 & 3307 & $1.4800+1$ & $12.0000-2$ & $2.5000-2$ & $23.0000-3$ \\
\hline
\end{tabular}

\begin{tabular}{|c|c|c|c|c|c|}
\hline $03 / 01 / 74$ & \multicolumn{5}{|c|}{$N, A L P H A$} \\
\hline & REFERENCE & ENERGY & DELIA & $x-5 E C$ & DELTA \\
\hline & & MEV & MEV & BARNS & BARNS \\
\hline & 53 & $1.4500+1$ & & $5.2420-2$ & $2.6000-2$ \\
\hline & $652 ! 42$ & $1.4800+1$ & & $2.8000-2$ & $1.0000-2$ \\
\hline & $58 \quad 531$ & $1.4800+1$ & & $4.3800-2$ & $6.9020-3$ \\
\hline
\end{tabular}

$03 / 01 / 74$

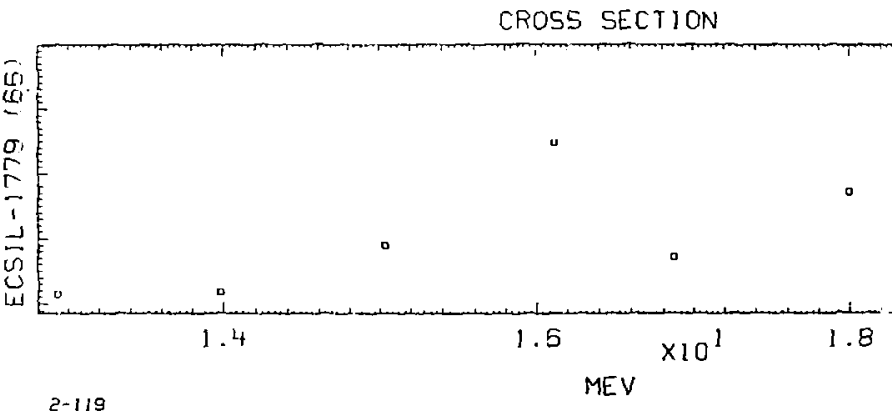

$\mathrm{N}, X$ ALPHA

\section{CROSS SECTION}

\section{MEV}

18-AR-NAT

$17-\mathrm{CL}-37$

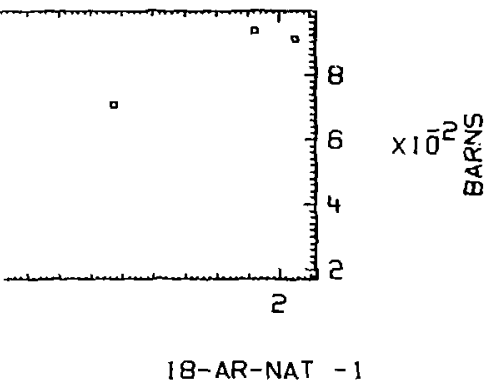




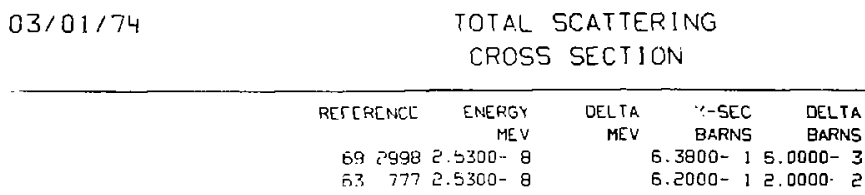

$03 / 01 / 74$ ABSORPTION

18-AR-NAT

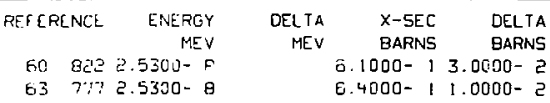

213/01/74

$46 \quad 17 ! 2.5000+0 ! .5000-11.0000-4$

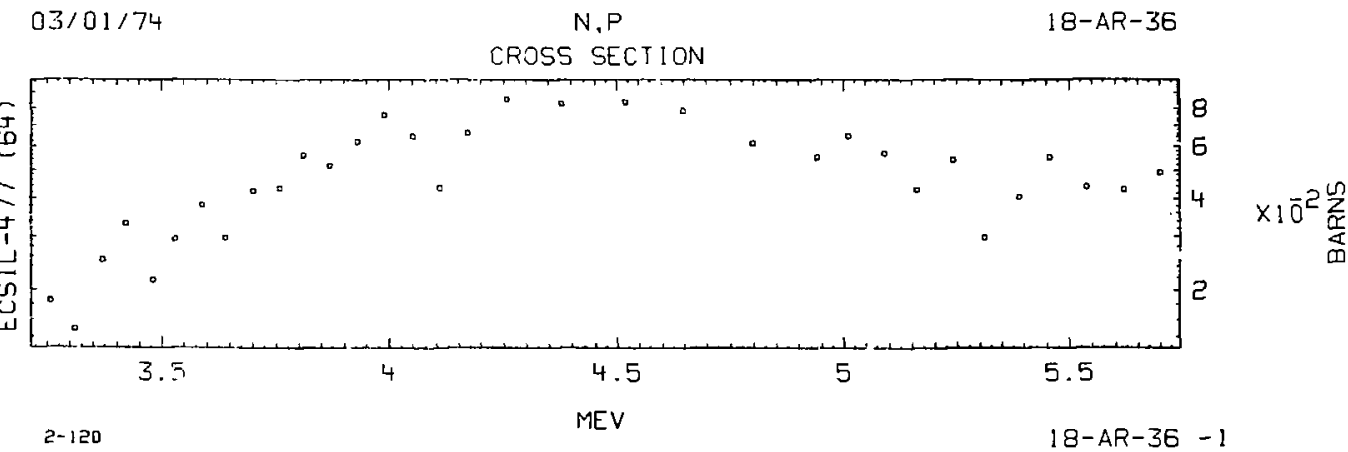


$03 / 01 / 74$

$N, P$

CROSS SECTION
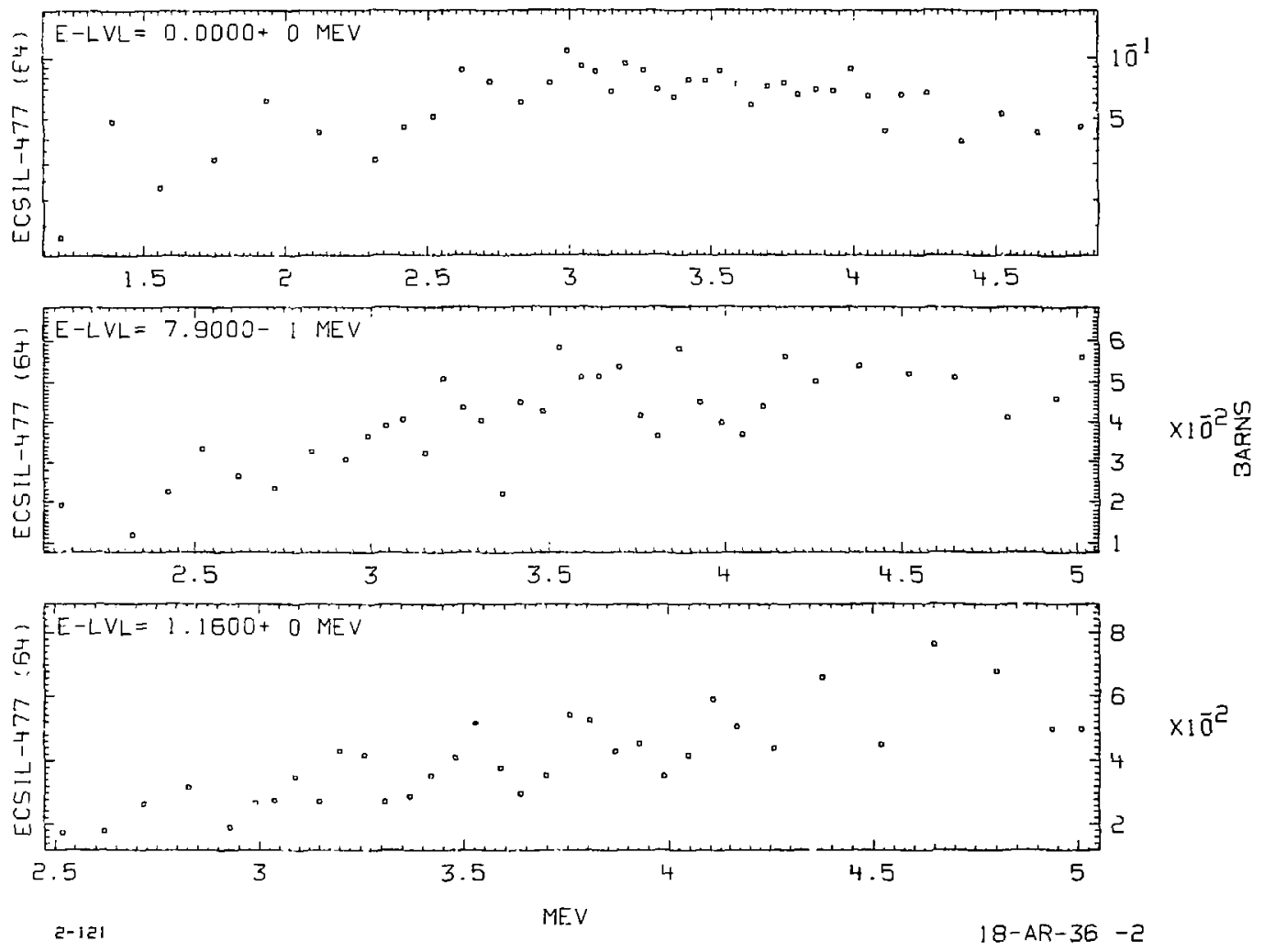

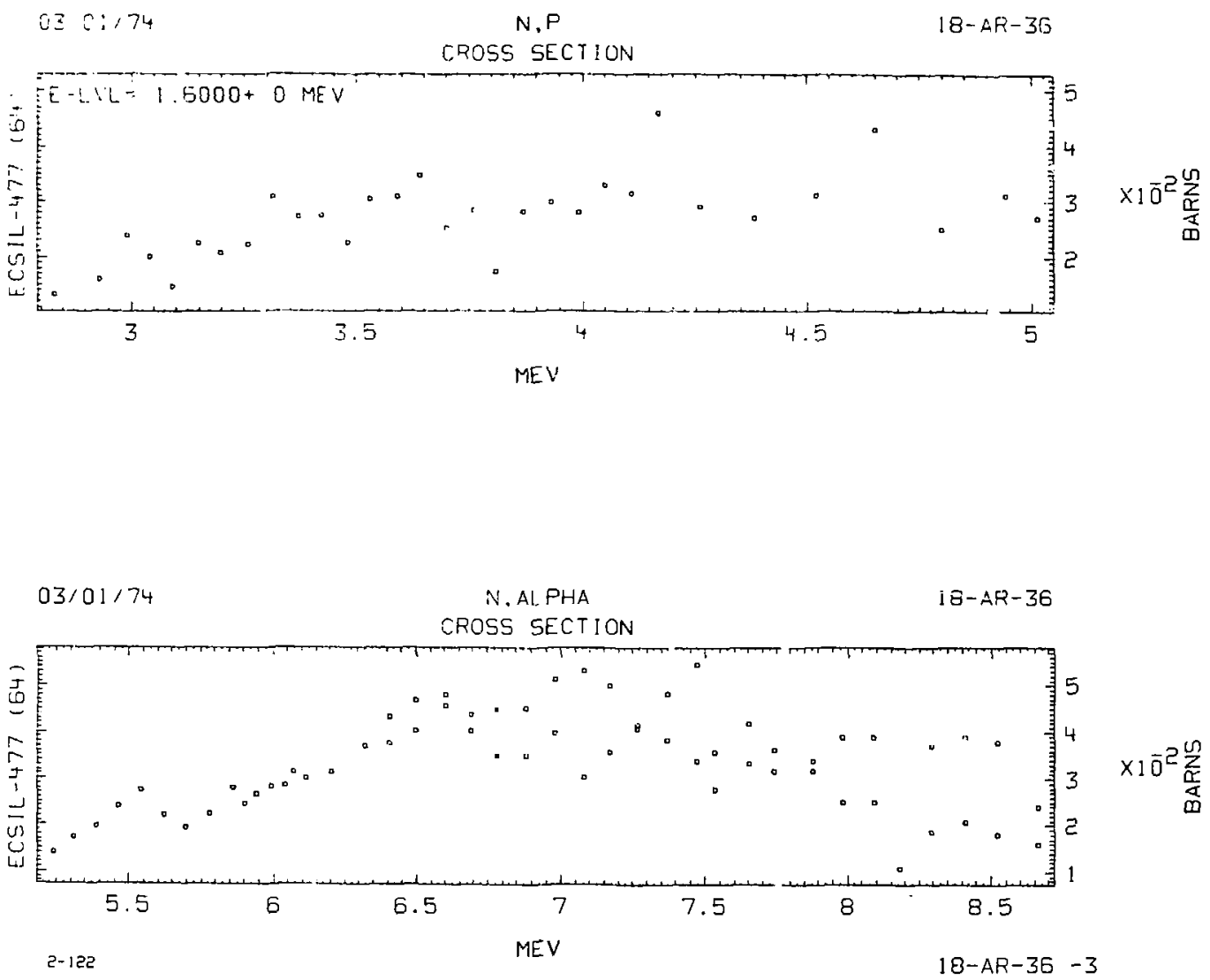

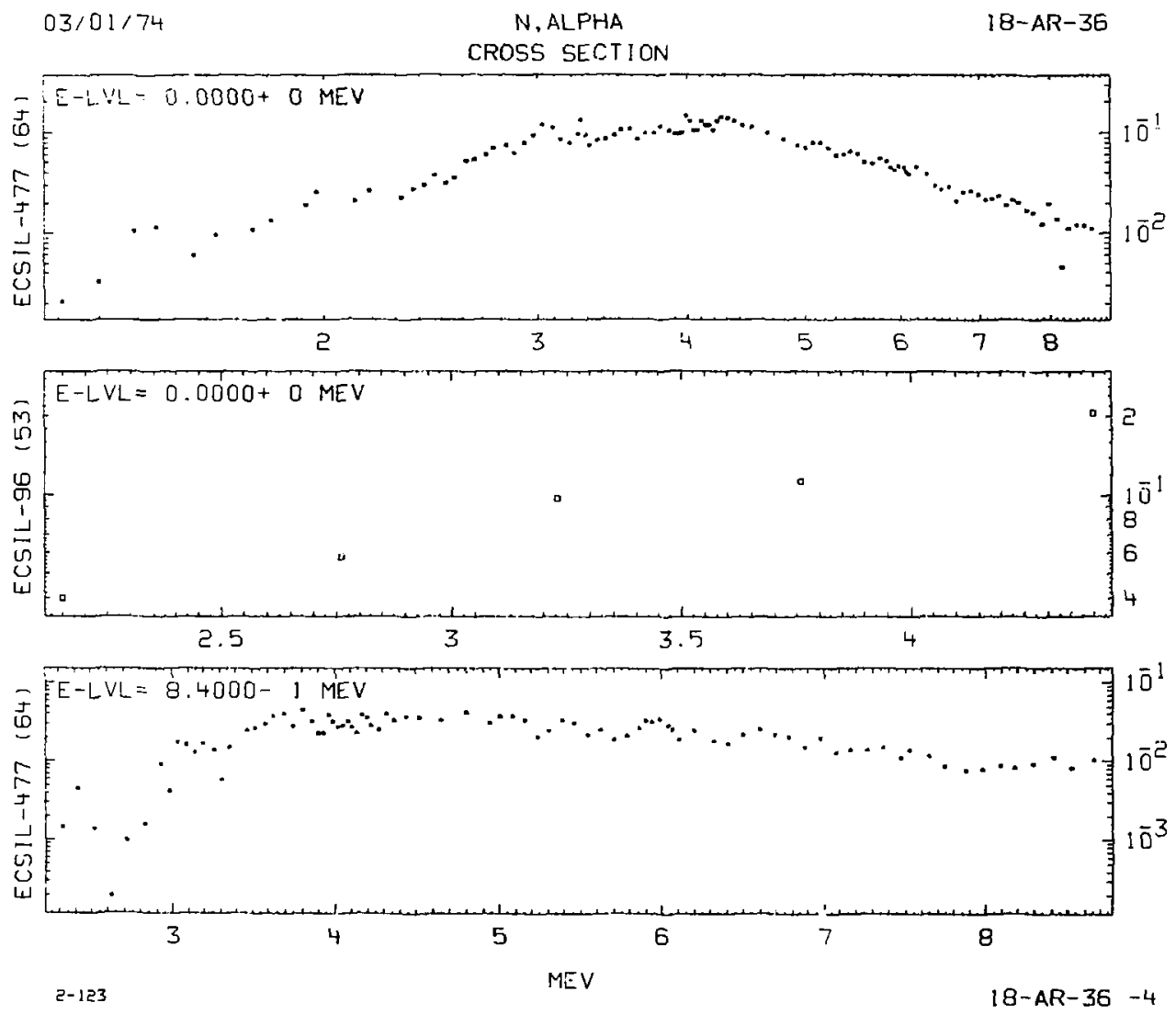


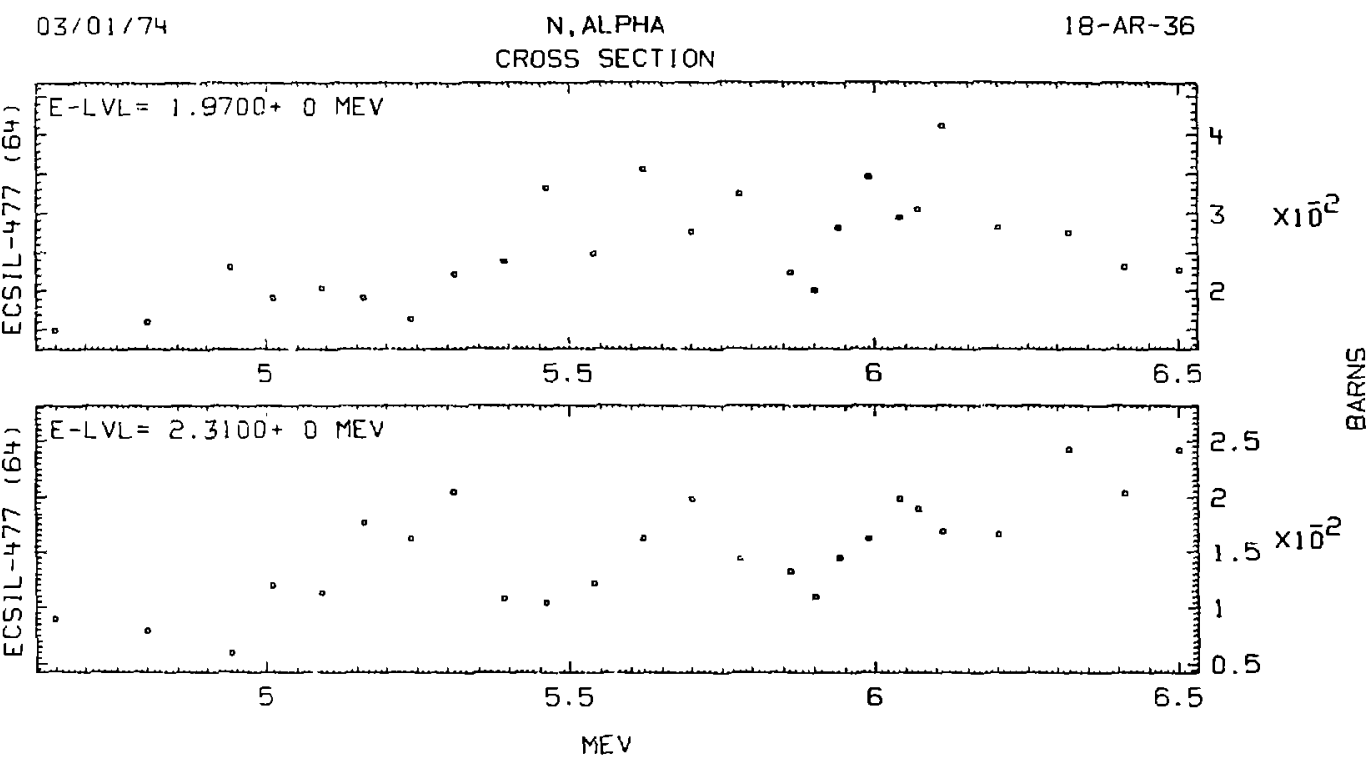

03/01/74




\section{CROSS SECTION}

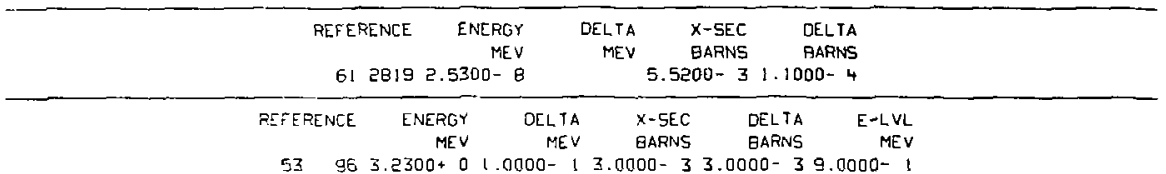

$53963.7600+01.0000-12.2000-213000-23.0000-$

$53964.4000+01.0000 \cdot 14.1000-22.5000-29.0000-1$

\begin{tabular}{|c|c|c|c|c|c|}
\hline \multirow{2}{*}{$03 / 01 / 74$} & \multicolumn{5}{|c|}{$N, P$} \\
\hline & PEFERENCE & $\begin{array}{r}\text { ENERGY } \\
\text { MEV }\end{array}$ & $\begin{array}{r}\text { DEL TA } \\
\text { MEY }\end{array}$ & $\begin{array}{l}X \text {-SEC } \\
\text { BARNS }\end{array}$ & $\begin{array}{l}\text { DELTAA } \\
\text { BARNS }\end{array}$ \\
\hline
\end{tabular}

$2819451.4800 .15 .0000-11.1000-15.5000-3$
$03 / 01 / 74$
iv, ALPHA
$18-A R-40$

\section{CROSS SECTION}

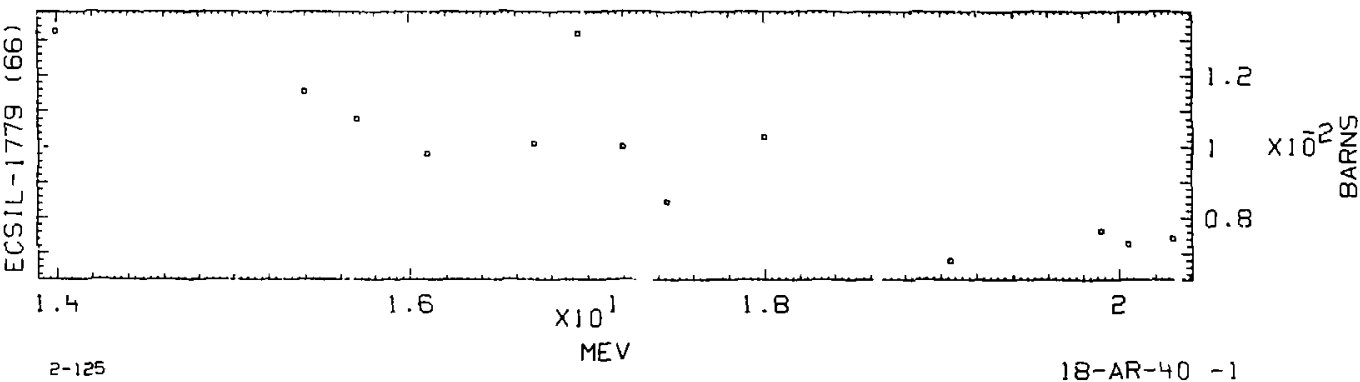



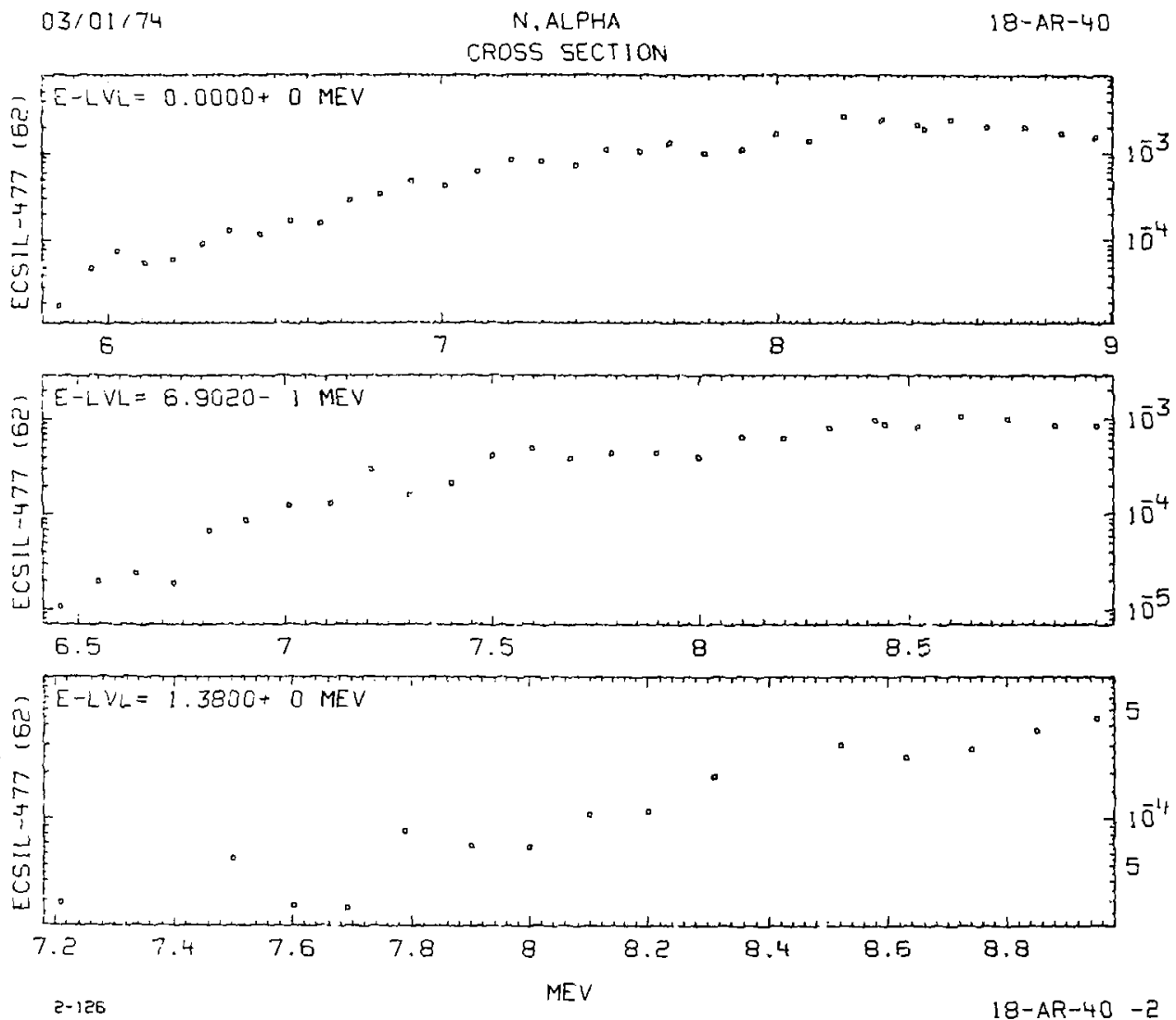


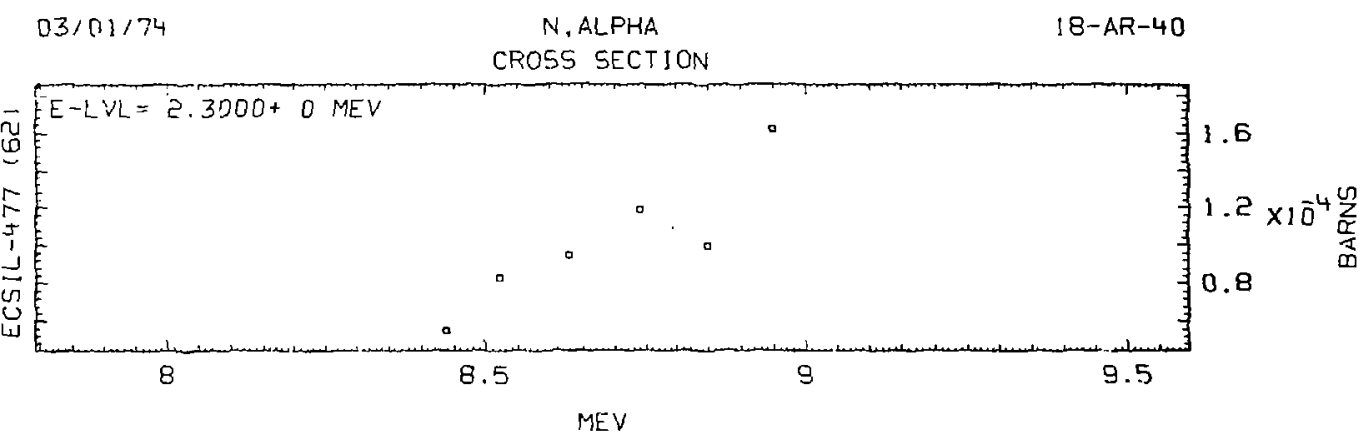

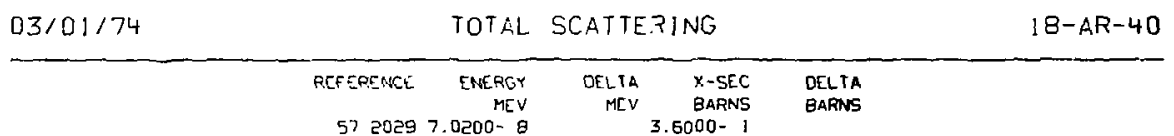

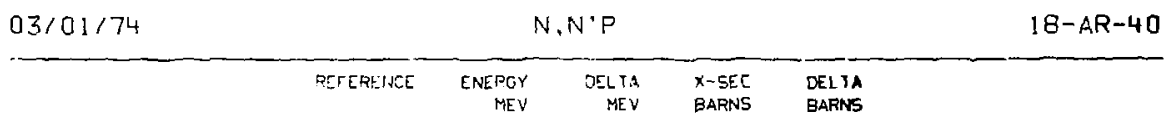

$6919451.4800^{*}, 2.0000-11.7000 \cdot 32.0000-4$

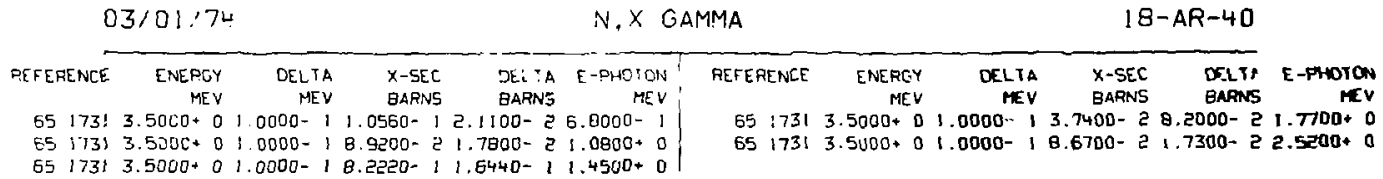




\section{CROSS SECTION}

\begin{tabular}{|c|c|c|c|c|c|}
\hline & $\begin{array}{l}\text { REFERE NCE } \\
\begin{array}{rl}69 & 2747 \\
65 & 1781 \\
68 & 1945\end{array}\end{array}$ & $\begin{array}{r}\text { ENERGY } \\
\text { MEV } \\
1.4400+1 \\
1.4700+1 \\
1.4800+1\end{array}$ & $\begin{array}{r}\text { DELTA } \\
\text { MEV } \\
3 .-900-1 \\
5.0000-1 \\
2.0000-1\end{array}$ & $\begin{array}{rrr}\text { X-SEC } & \text { DELTA } \\
\text { BARNS } & \text { BARNS } \\
1.5700-2 & 2.0000-3 \\
2.5000-2 & 2.0000-3 \\
1.5000-2 & 2.0000-3\end{array}$ & \\
\hline $03 / 01 / 74$ & & & N. $\square$ & & $18-A R-40$ \\
\hline
\end{tabular}

$65: 7811.4700+15.0000-12.9000-35.0000-4$

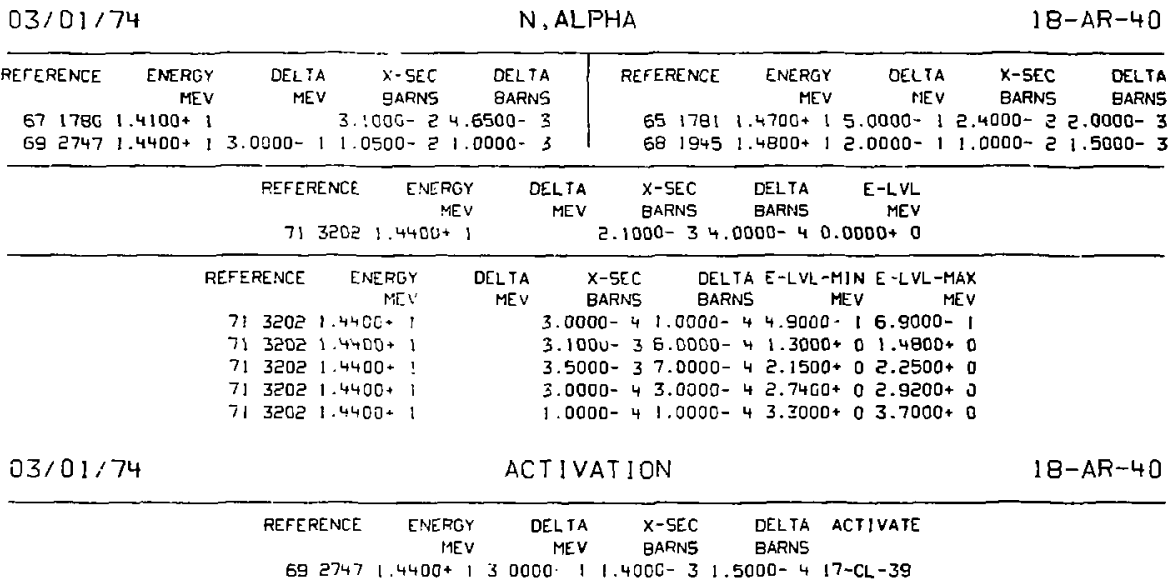




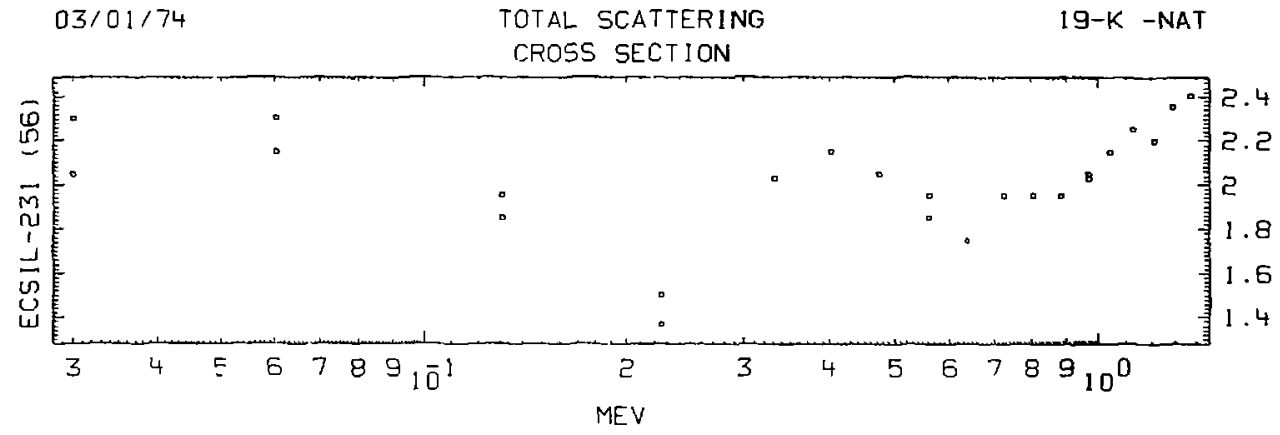

\section{$03 / 01 / 74$}

$N, X$ GAMMA

19-K -NAT

CROSS SECTION

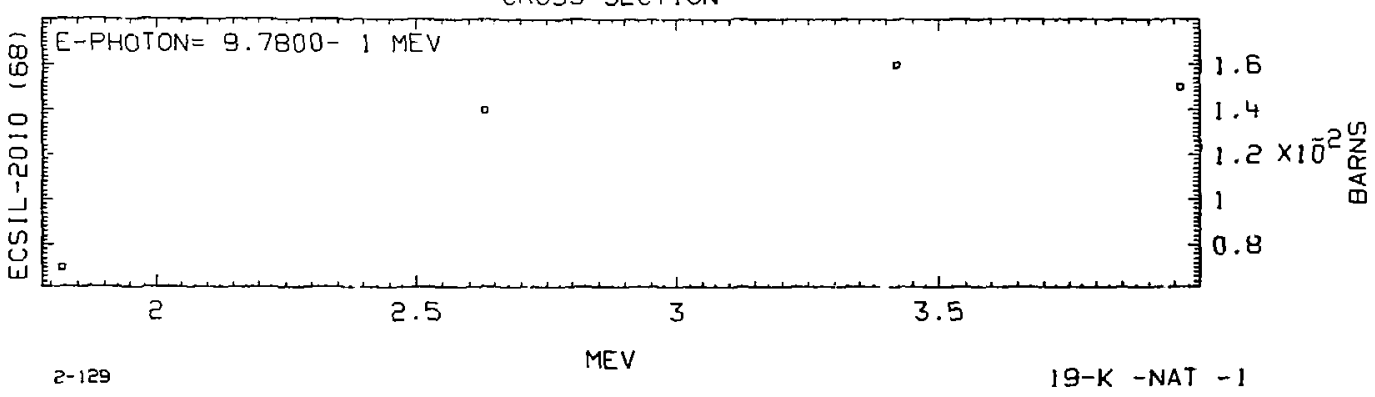


CROSS SECTION

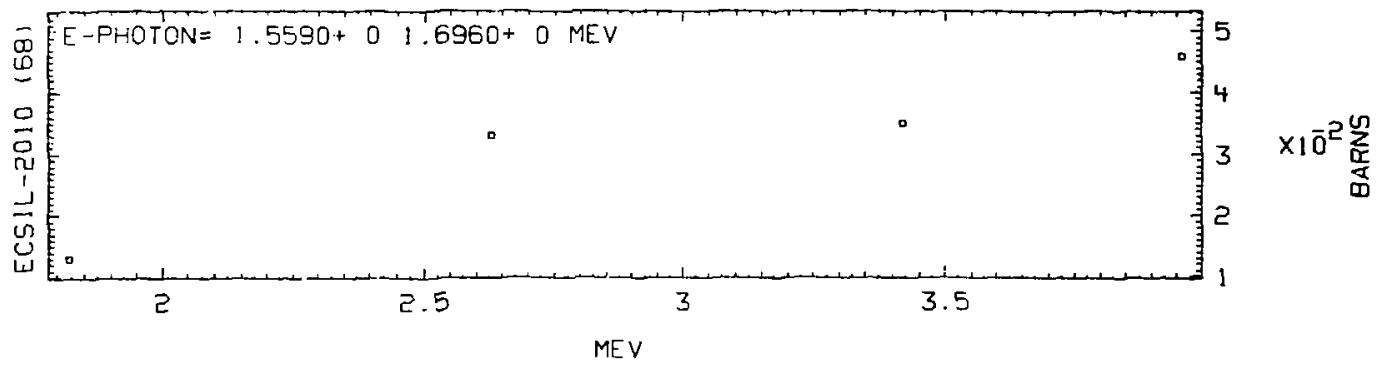

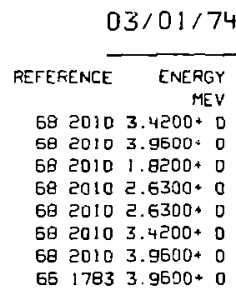

$03 / 01: 74$
$N, \times$ GAMMA

I9-K -NAT

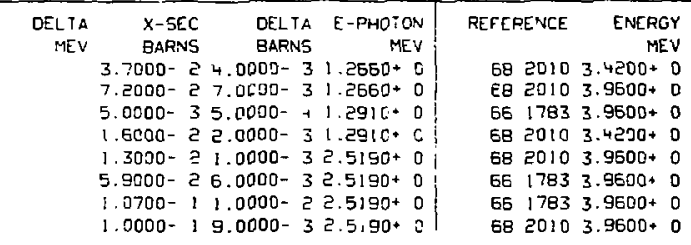

BOUND ATOM

19-K -NAT

REFERENCS

$511584 \quad 7.3000-$

$\begin{array}{rr}\text { DELTA } & X-5 E C \\ \text { MEV } & \text { BARNS } \\ 2.0000+0\end{array}$

LELTA

BARN'S

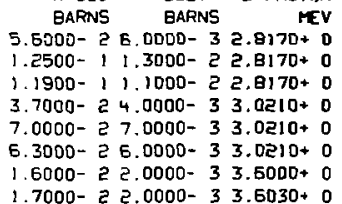


CROSS SECTION

$\begin{array}{rrrrr}\text { REFERENCE } & \text { ENERGY } & \text { DELTA } & \text { X-SEC } & \text { DELTA } \\ & \text { MEV } & \text { MEV } & \text { BAFNS } & \text { BARNS } \\ 532877 & 2.5300-8 & 1.4500+0 & \\ 51 & 15847.3000-8 & 1.5000+01.2000-1\end{array}$

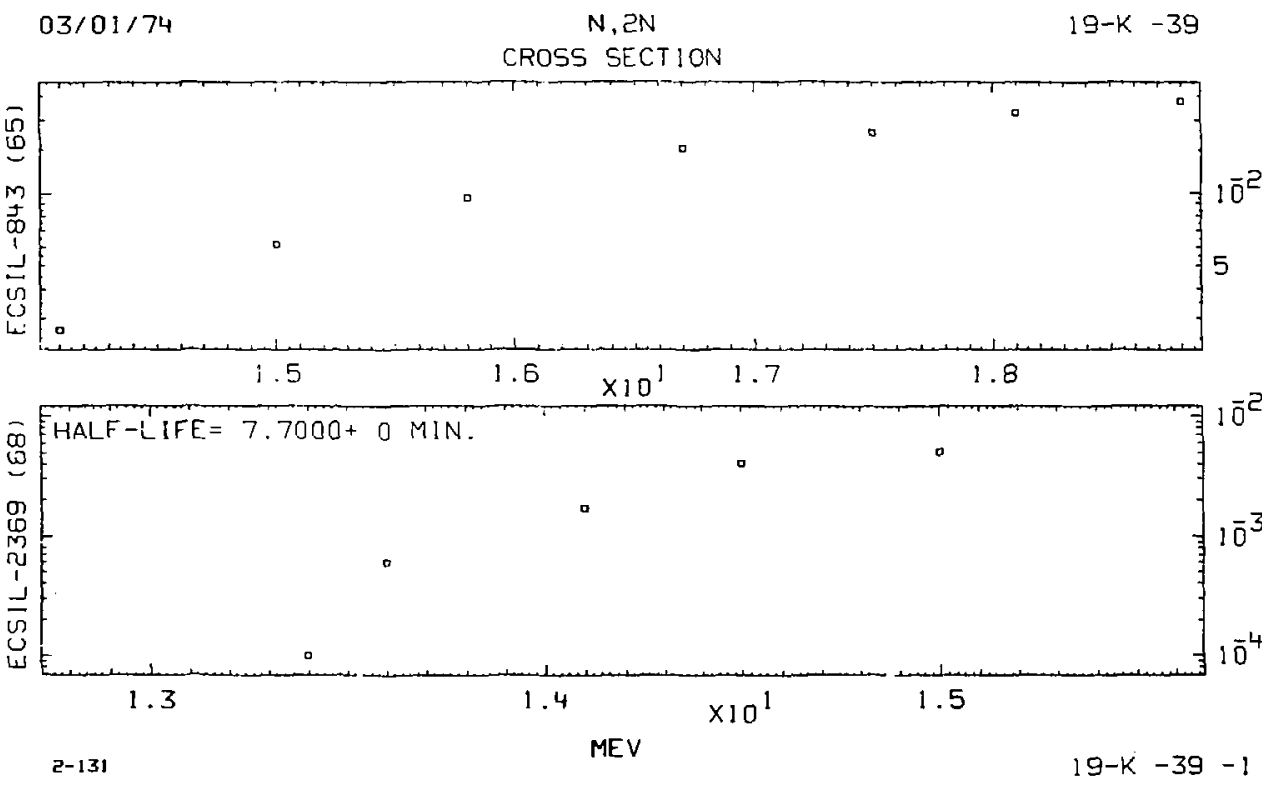



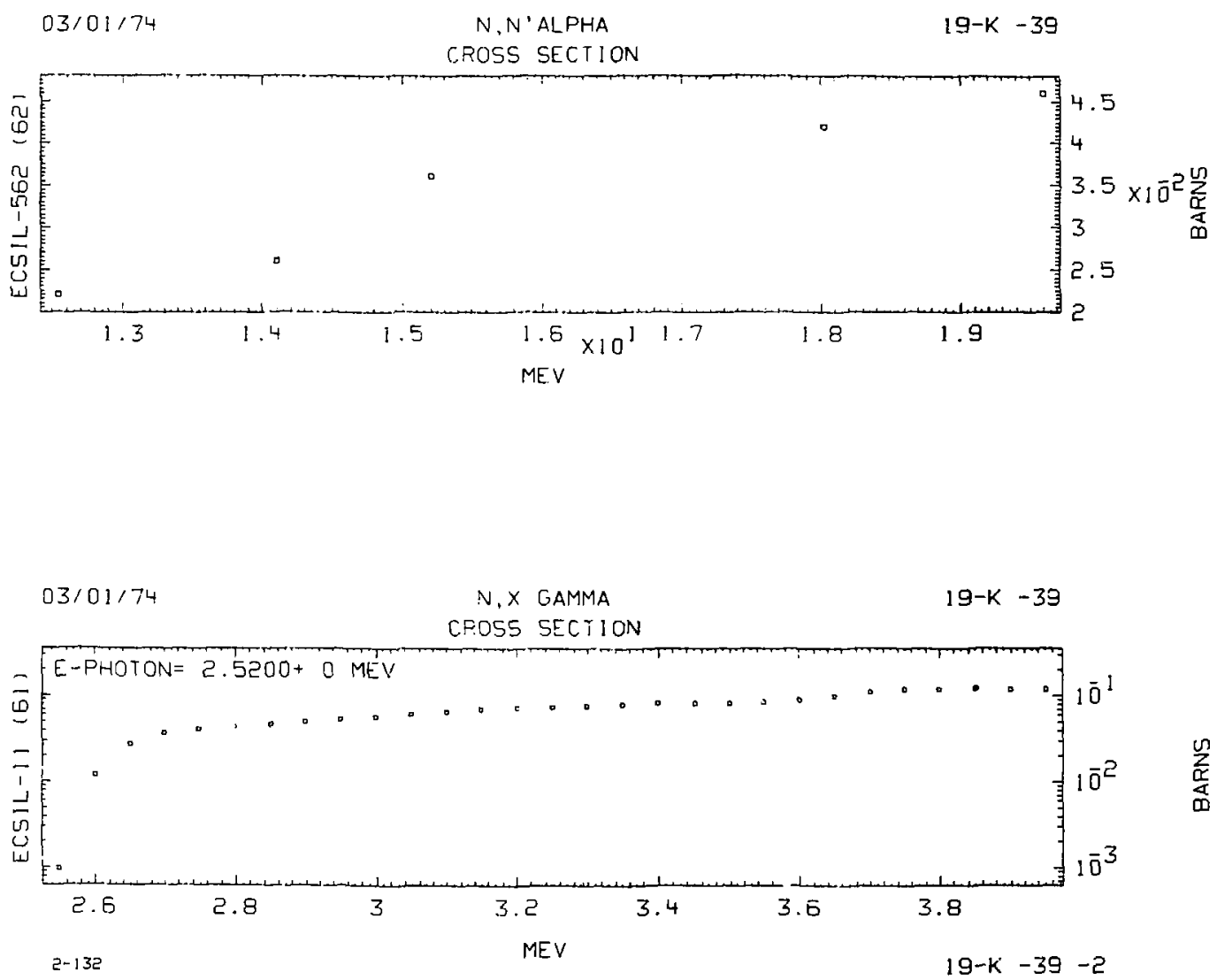


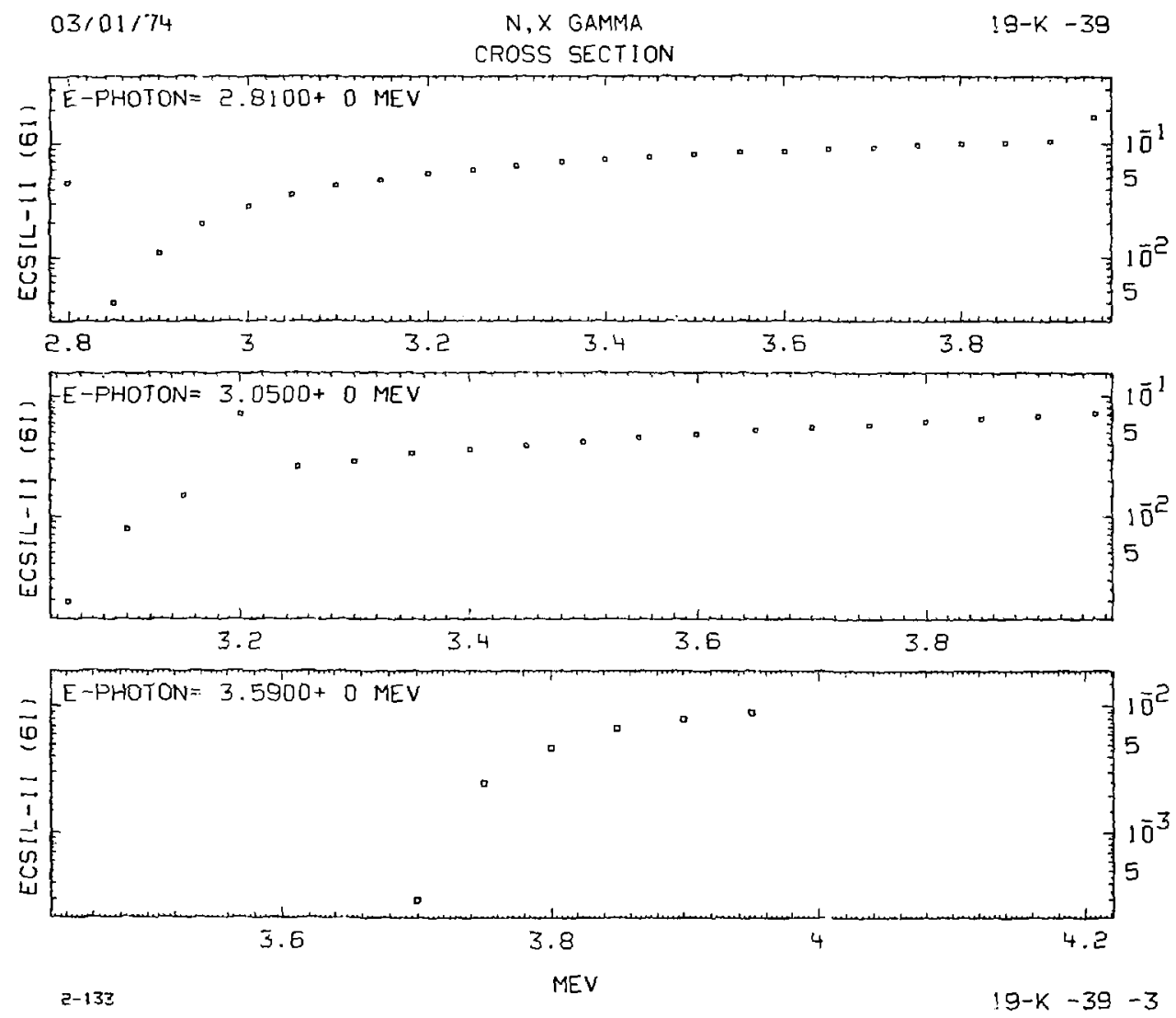




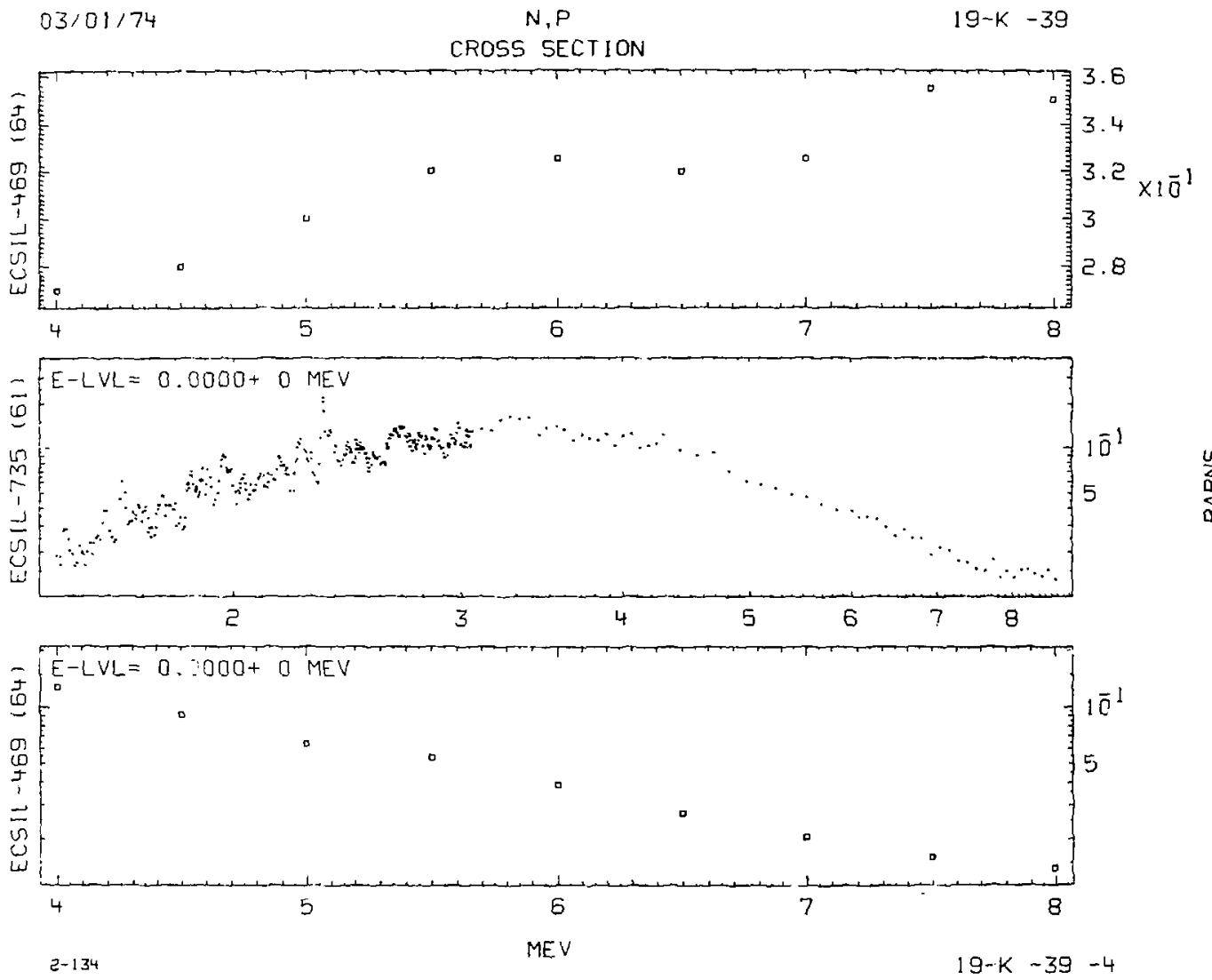




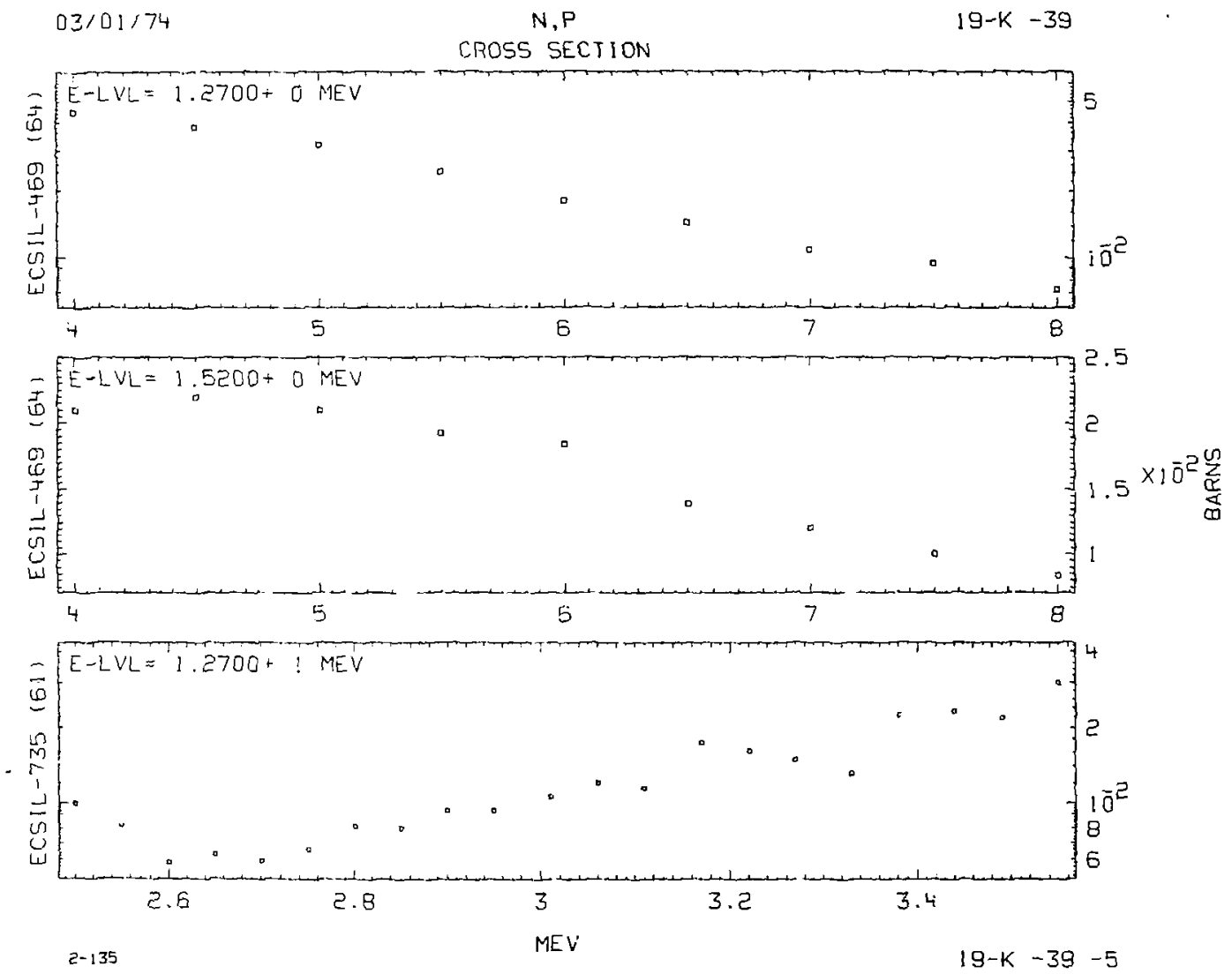




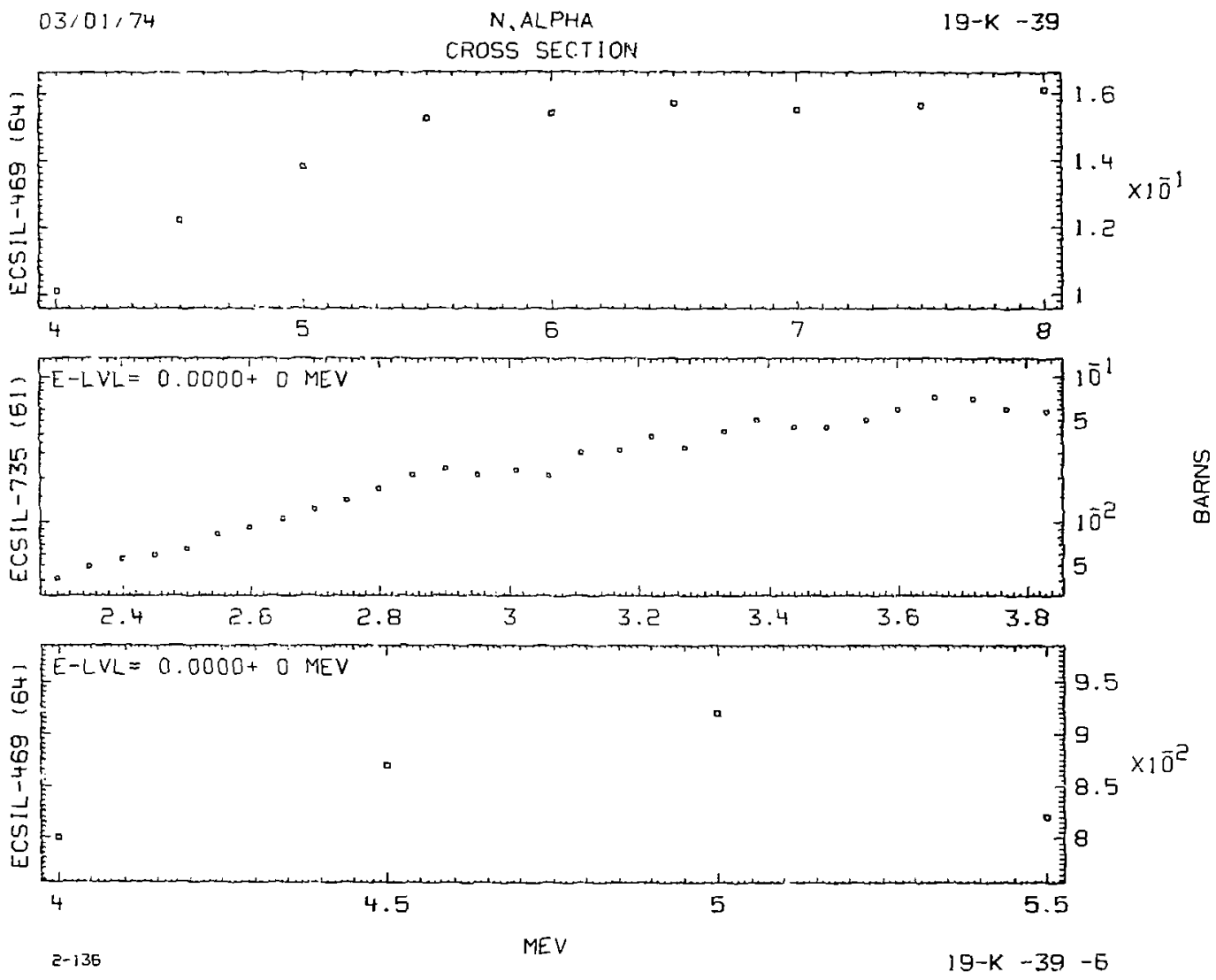




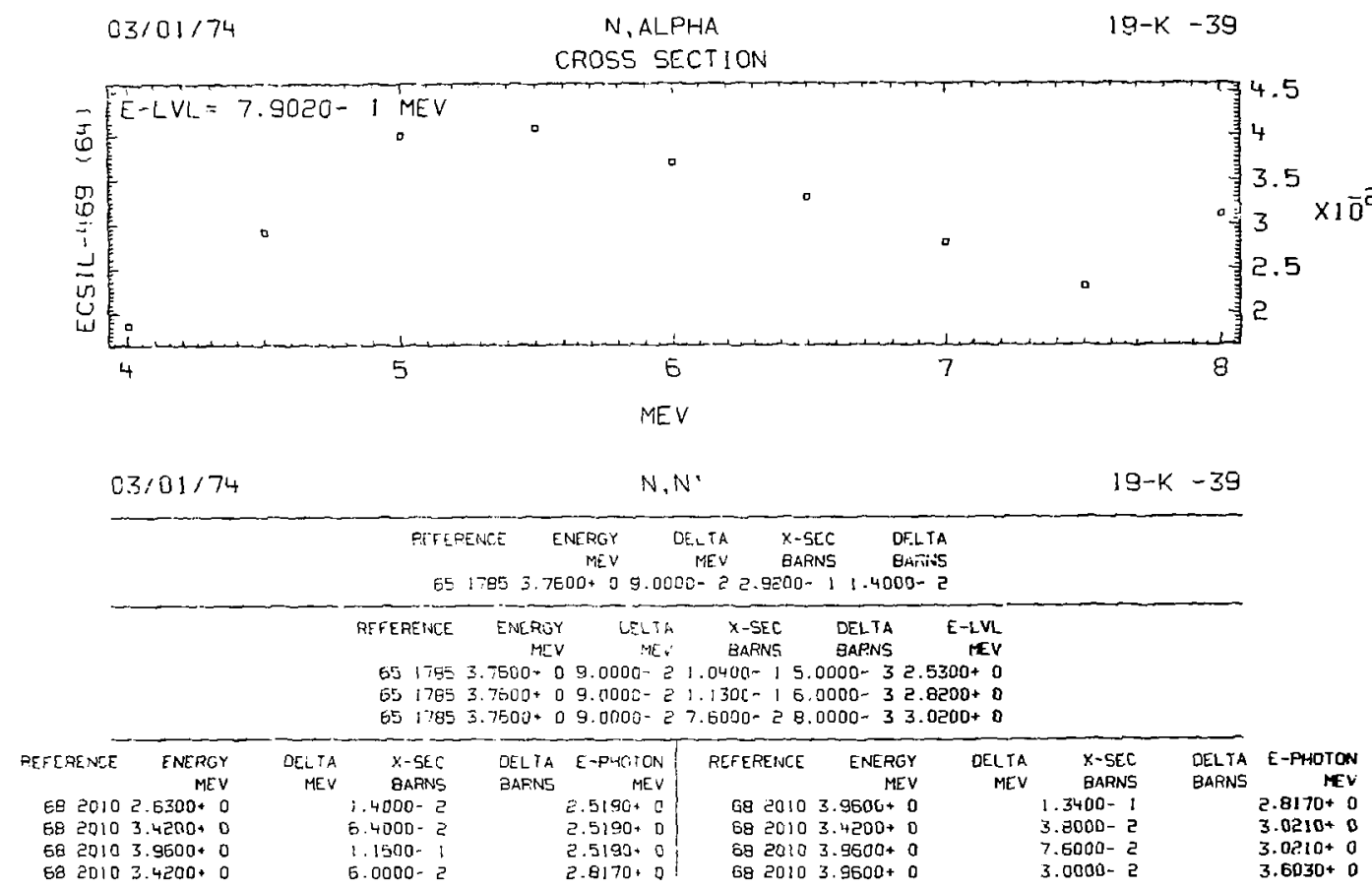




\section{CROSS SECTION}

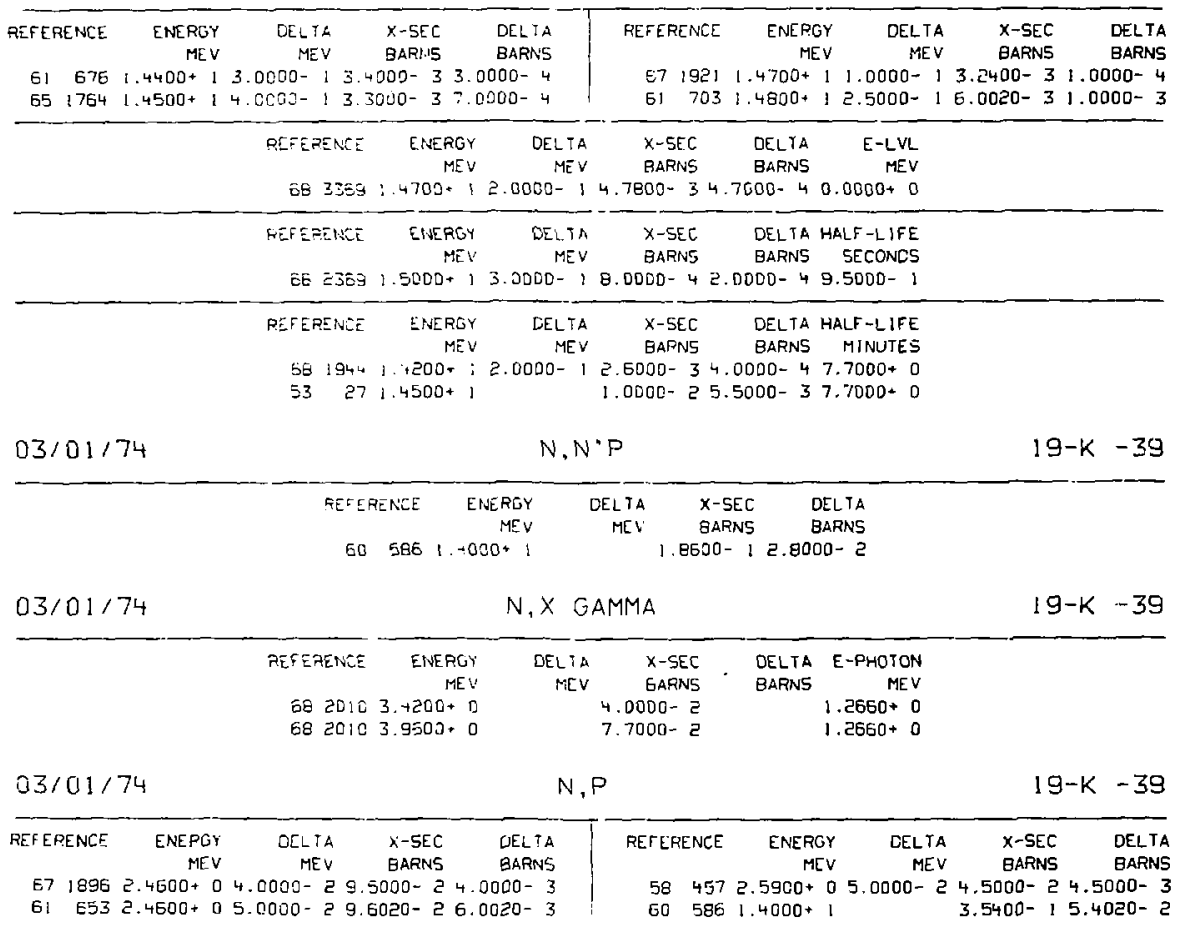


CROSS SECTION

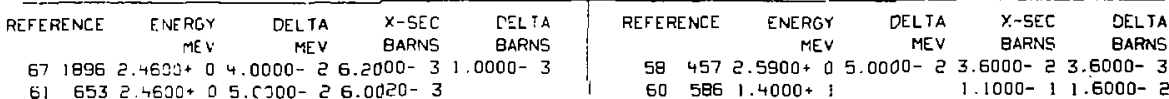

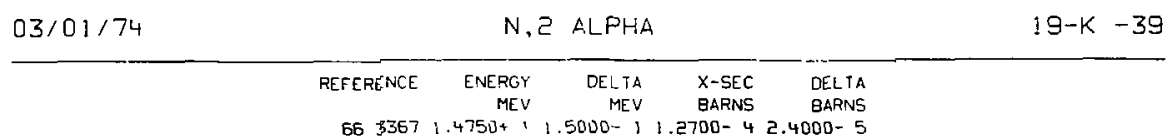

$6633671.4750+1.5000-11.2700-42.4000-5$

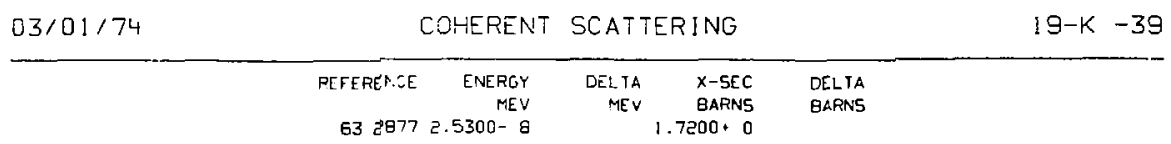

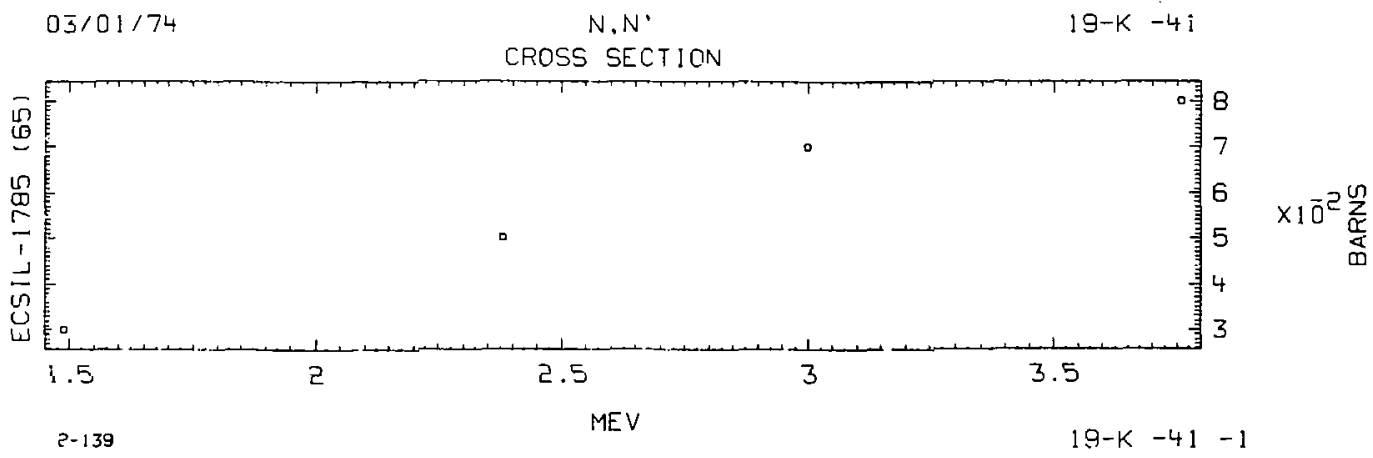



$03 / 01 / 74$
N, $N^{\prime}$
$19-K-41$
CROSS SECTION

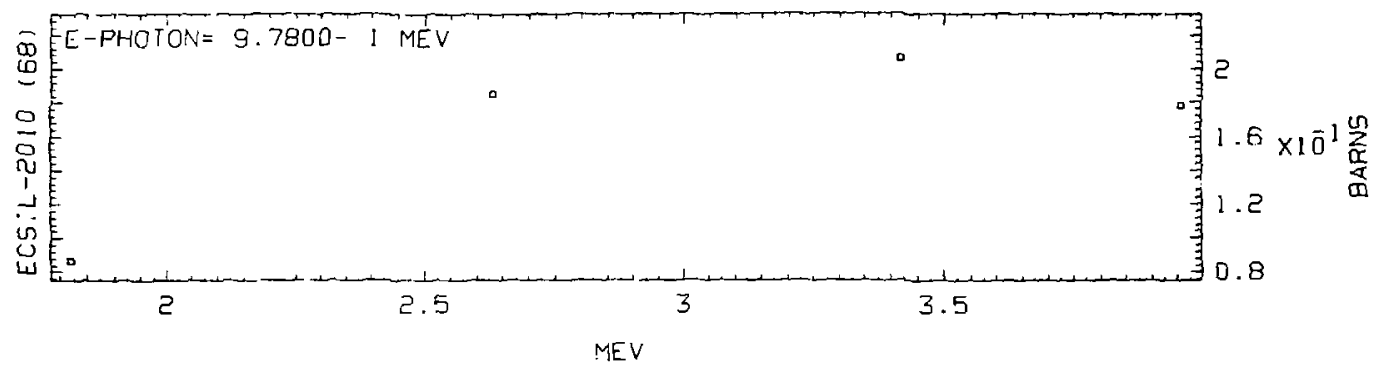

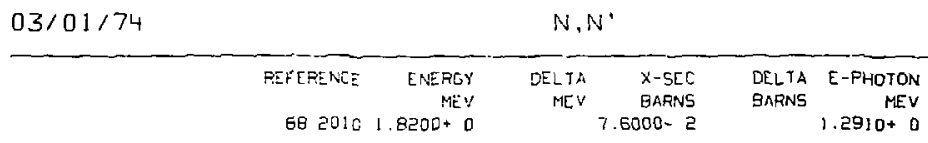

\begin{tabular}{|c|c|c|c|c|c|c|c|c|c|}
\hline $03 / 01$ & & & & & & & & 19 & $-k-4\}$ \\
\hline EFERENCE & $\begin{array}{l}\text { ENEROY } \\
\text { ME }\end{array}$ & $\begin{array}{r}\text { DELTA } \\
\text { MEV }\end{array}$ & & DELTA & FEFERENCE & $\begin{array}{r}\text { ENERGY } \\
\text { ME } V\end{array}$ & OEL TA & $\begin{array}{l}X \text {-SEC } \\
\text { BARNS }\end{array}$ & DELTA \\
\hline 681944 & i. - $200+i$ & $2.0000^{-1}$ & 5.0000- $己$ & $=6.0000-3$ & $65 \quad 1697$ & $1.4800+1$ & & $8.8000-2$ & $9.0000-3$ \\
\hline $53 \quad 27$ & $1.4500+1$ & & B. $7220-2$ & $3.5000-E$ & 63756 & $1.4800+1$ & 2. $0000-1$ & $6.9020-2$ & $1.7000-2$ \\
\hline
\end{tabular}

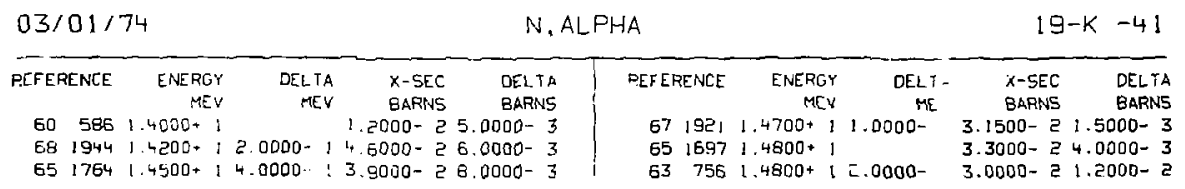


N, ALPHA

CROSS SECT!ON

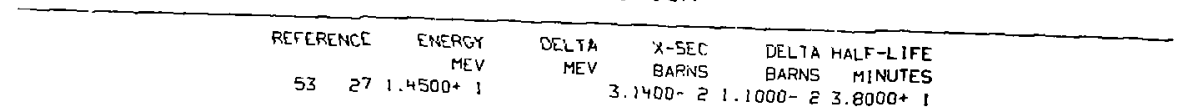

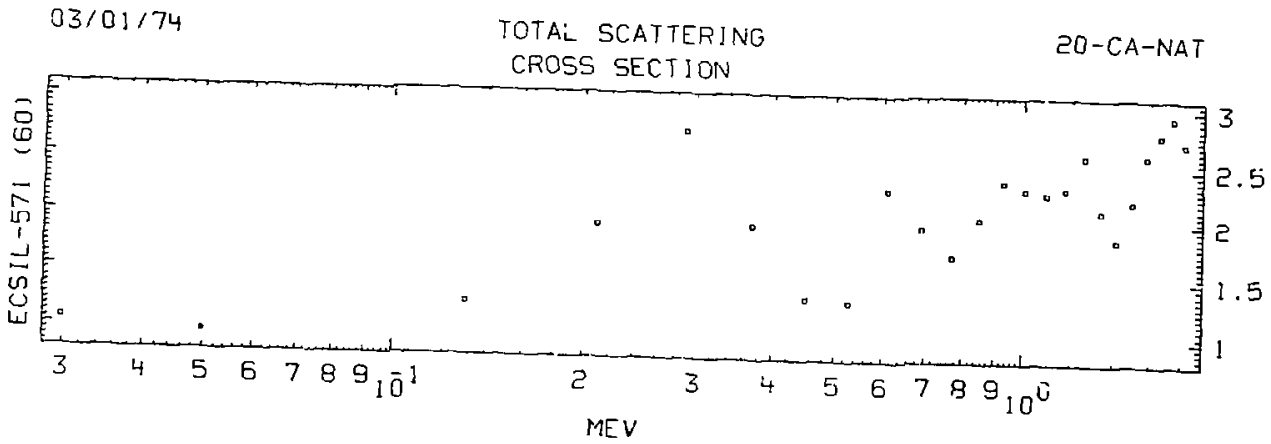

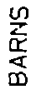


CROSS SECTION
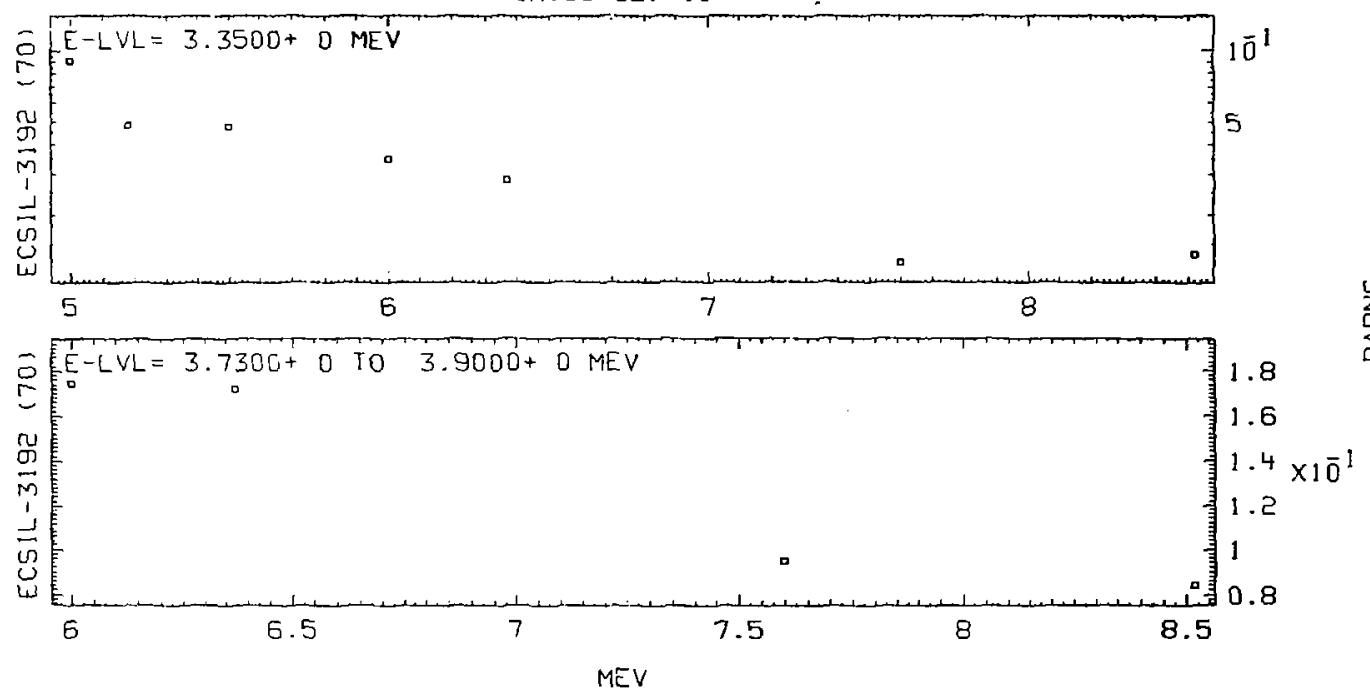

\begin{tabular}{|c|c|c|c|c|c|c|c|c|c|}
\hline \multicolumn{4}{|c|}{$03 / 01,74$} & \multicolumn{2}{|c|}{ NONEL AST IC } & \multicolumn{4}{|c|}{$20-C A-N A T$} \\
\hline KETERENCE & ENERGY & DELTA & $x-5 \pi C$ & DELTA & REF ERENCE & ENERGY & DEL 'A & $x-\operatorname{SEC}$ & DELTA \\
\hline & MEV & MEV & BARNS & GARNS & & MEV & MEV & BARNS & ; BAFANS \\
\hline $56 \quad 34$ & $2.5000+c$ & & $4.0000-1$ & $2.0000-1$ & $56 \quad 151$ & $7.0000+0$ & $2.0000-1$ & $1.1400+0$ & $7.0020-2$ \\
\hline 55790 & $2.5000+0$ & $1.5000=1$ & $4.0000-1$ & 2.0000- i & 55200 & $1.4500+1$ & & $1.3500+0$ & 2.0000- 2 \\
\hline
\end{tabular}


CROSS SECTION

\begin{tabular}{|c|c|c|c|c|c|c|c|c|c|c|c|}
\hline REFERENCE & $\begin{array}{r}\text { ENERGY } \\
M[V\end{array}$ & $\begin{array}{r}\text { DEL TA } \\
\text { MEV }\end{array}$ & $\begin{array}{l}x-5 E C \\
\text { BARNS }\end{array}$ & $\begin{array}{l}\text { DEL TA } \\
\text { BARNS }\end{array}$ & $\begin{array}{r}E-L V L \\
\text { MEV }\end{array}$ & REFERENCE & $\begin{array}{r}\text { ENERGY } \\
\text { MEV }\end{array}$ & $\begin{array}{r}\text { DELTA } \\
\text { MEV }\end{array}$ & $\begin{array}{l}x-5 E C \\
\text { BARNS }\end{array}$ & $\begin{array}{l}\text { DELTA } \\
\text { BARNS }\end{array}$ & $\begin{array}{r}E-L V L \\
\text { MEV }\end{array}$ \\
\hline 703192 & $0000+0$ & $5.0000-2$ & $2.0540-1$ & $5.6090-?$ & $3.7300+0$ & 703192 & $00+0$ & $1.3000-1$ & $3.5990-2$ & $4.0310-3$ & $+.4900+0$ \\
\hline 703192 & $5.1800 \cdot 0$ & $5.0000-2$ & $1.4000-1$ & $2.2680-2$ & $3.7300+0$ & 703192 & $7.6000+0$ & $1.0000-1$ & z. $2580-2$ & $2.1450-3$ & $+.4900+$ \\
\hline 703192 & $5.5000+0$ & $5.0000-2$ & : 6270- ! & 1.9040- ? & $3.7300+0$ & 703192 & $8.5200+0$ & $8.0000-2$ & 2.6660- 2 & $3.1990-3$ & $4.4900+$ \\
\hline 703192 & $5.1800+3$ & $5.0000-2$ & $1.8000-1$ & $4.7350-2$ & $3.9000+0$ & 703192 & B. $5200+0$ & $8.0000-2$ & $2.3120=$ & $4.5080-$ & \\
\hline
\end{tabular}

$7031925.5000+35.0000-21.5420-11.9450-23.9000+0$

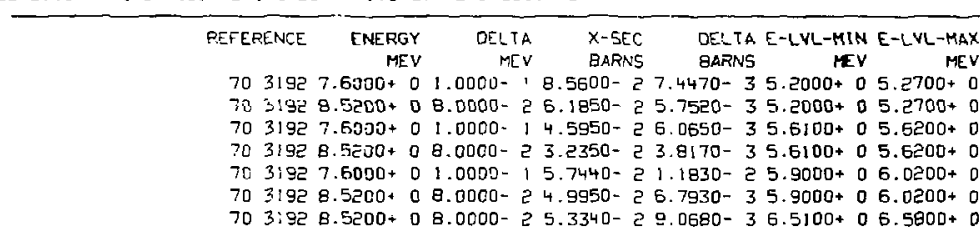

$03 / 01 / 74$ ABSORPT ION

2O-CA-NAT

\begin{tabular}{|c|c|c|c|c|c|}
\hline & \multirow[t]{3}{*}{ EN } & \multirow{2}{*}{$\begin{array}{r}\text { OELTA } \\
\text { MEV }\end{array}$} & \multirow{2}{*}{$\begin{array}{l}X-\text { SEC } \\
\text { 8ARNS }\end{array}$} & \multirow{2}{*}{$\begin{array}{l}\text { OELTA } \\
\text { BARNS }\end{array}$} \\
\hline \multicolumn{2}{|c|}{ REFERENCE } & & & & \\
\hline \multirow{2}{*}{\multicolumn{2}{|c|}{$\begin{array}{ll}58 & 364 \\
58 & 364\end{array}$}} & & $00-$ & $3000-$ & \multirow{3}{*}{$\begin{array}{l}1.0000-5 \\
1.0000-5 \\
1.0000-5\end{array}$} \\
\hline & & $2.2000-1$ & $100-2$ & $5.0000-3$ & \\
\hline \multicolumn{2}{|c|}{$58 \quad 364$} & $5000-1$ & $4.0000-2$ & $.0020-3$ & \\
\hline
\end{tabular}

$03 / 01 / 74$ $N, X$ GAMMA

$20-C A-N A T$

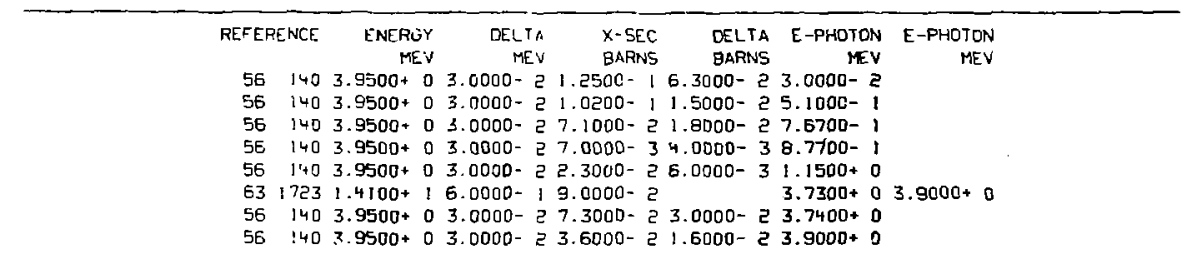




\section{CROSS SECTION}

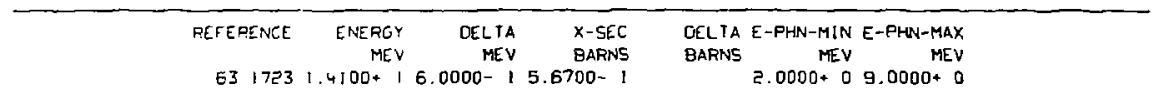

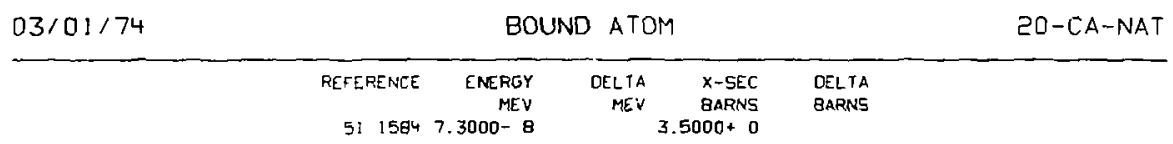

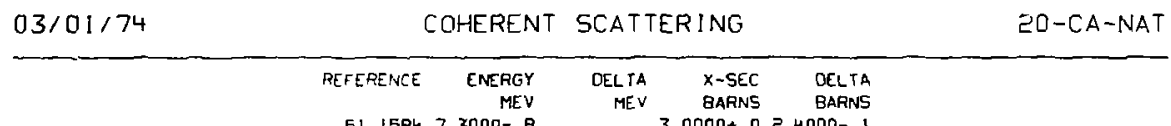

$5158473000-8$ $3.0000+0 \geq .4000-1$

\begin{tabular}{|c|c|c|c|c|c|}
\hline \multirow[t]{2}{*}{$03 / 01 / 74$} & \multicolumn{5}{|c|}{$N, N \cdot P$} \\
\hline & REF ERENCE & $\begin{array}{r}\text { ENERGY } \\
\text { MEV }\end{array}$ & $\begin{array}{r}\text { DELIA } \\
\text { MEV }\end{array}$ & $\begin{array}{l}X \text { X-SEC } \\
\text { BARNS }\end{array}$ & $\begin{array}{l}\text { DELTA } \\
\text { BARNS }\end{array}$ \\
\hline & $\begin{array}{l}5 ! 351 \\
58302 !\end{array}$ & $\begin{array}{l}1.4000+1 \\
1.4100+1\end{array}$ & $1.0000-1$ & $\begin{array}{l}2.0500-1 \\
1.8000-1\end{array}$ & $\begin{array}{l}3.8000-2 \\
3.2000-2\end{array}$ \\
\hline
\end{tabular}

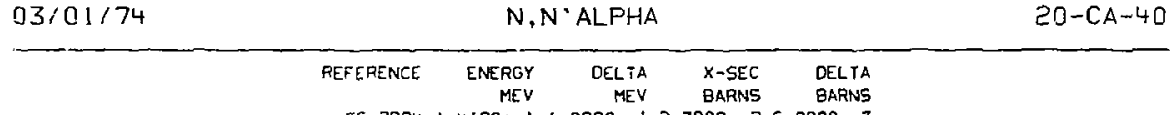

$6628941.4100+11.0000-\$ 2.3000-25.0000-$

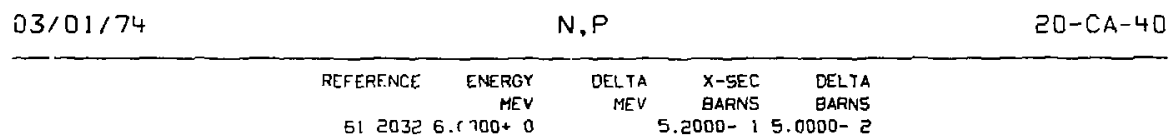


CROSS SECTION

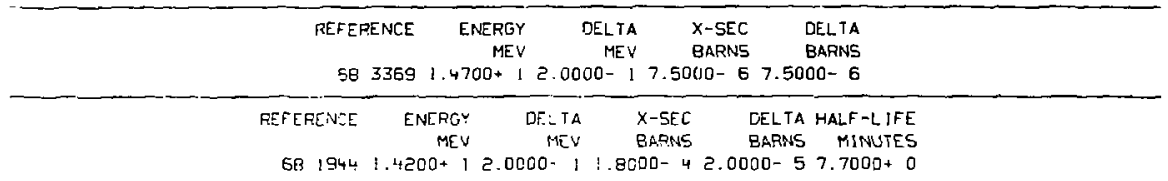

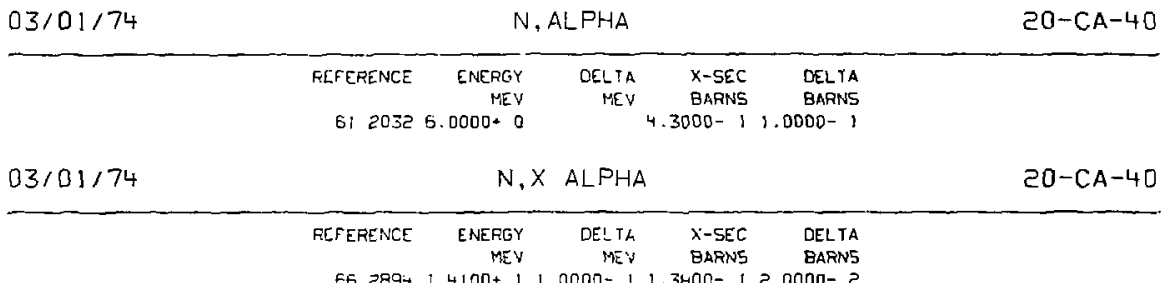

EE $289+1.4100+11.0000-11.3800-12.0000-2$

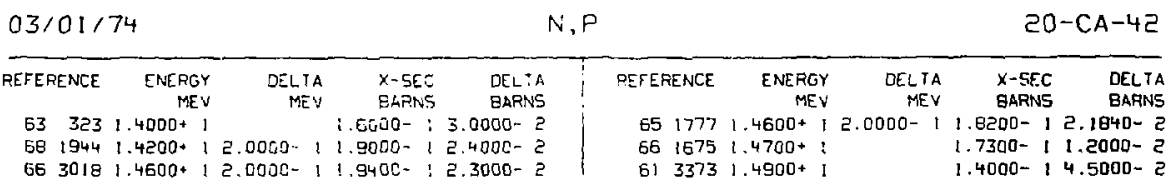

\begin{tabular}{|c|c|c|c|c|c|c|c|c|c|}
\hline \multicolumn{4}{|c|}{$03 / 01 / 74$} & \multicolumn{2}{|c|}{$N, P$} & \multicolumn{4}{|c|}{$20 \cdot C A-43$} \\
\hline REFF & $\begin{array}{l}\text { ENERGY } \\
\text { MEV }\end{array}$ & $\begin{array}{r}\text { OELTA } \\
\text { MEV }\end{array}$ & $\begin{array}{l}x-S E C \\
\text { GARNS }\end{array}$ & $\begin{array}{l}\text { DEL TA } \\
\text { BARNS }\end{array}$ & REFERENCE & $\begin{array}{r}\text { ENERGY } \\
\text { MEV }\end{array}$ & $\begin{array}{r}\text { OELTA } \\
\text { MEV }\end{array}$ & $\begin{array}{l}X \text { X-SEC } \\
\text { EARNS }\end{array}$ & $\begin{array}{l}\text { DELTA } \\
\text { BARNS }\end{array}$ \\
\hline $\begin{array}{ll}58 & 1944 \\
66 & 3018\end{array}$ & $\begin{array}{l}.4200+1 \\
.4600+1\end{array}$ & $.0000-1$ & $\begin{array}{l}9.3000- \\
1.3700-1\end{array}$ & $\begin{array}{l}21.2000-2 \\
13.0000-2\end{array}$ & $\begin{array}{ll}65 & 1777 \\
65 & 1675\end{array}$ & $\begin{array}{l}1.4600+1 \\
1.4700+1\end{array}$ & $1000-1$ & $\begin{array}{l}1.1000-1 \\
1.0100-1\end{array}$ & $\begin{array}{l}1.3200-2 \\
\text { 8.0000 - } 3\end{array}$ \\
\hline
\end{tabular}

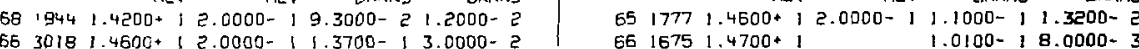


CROSS SECTION

\begin{tabular}{|c|c|c|c|c|c|c|c|c|c|}
\hline RE $=E R E N C$ & $\begin{array}{r}\text { ENERGY } \\
\text { MEV }\end{array}$ & $\begin{array}{r}\text { DELTA } \\
\text { MEV }\end{array}$ & $\begin{array}{l}X \text {-SEC } \\
\text { BARNS }\end{array}$ & $\begin{array}{l}\text { DEL TA } \\
\text { BAPAKS }\end{array}$ & REFERENCE & $\begin{array}{r}\text { ENERGY } \\
\text { MEV }\end{array}$ & $\begin{array}{r}\text { OELTA } \\
\text { MEV }\end{array}$ & & \\
\hline $\begin{array}{ll}57 & 2009 \\
68 & 1944\end{array}$ & $\begin{array}{l}1.3300+1 \\
1.4200+1\end{array}$ & $2.0000-1$ & $\begin{array}{l}8.6000-1 \\
9.0000-1\end{array}$ & $\begin{array}{l}1.2900-1 \\
1.0800-1\end{array}$ & $\begin{array}{l}62840 \\
61 \quad 3373\end{array}$ & $\begin{array}{l}1.4500+1 \\
1.4500+1\end{array}$ & $00-1$ & $\begin{array}{l}9.2020-1 \\
1.0700+0\end{array}$ & $\begin{array}{l}1.8000- \\
7.6000-\end{array}$ \\
\hline
\end{tabular}

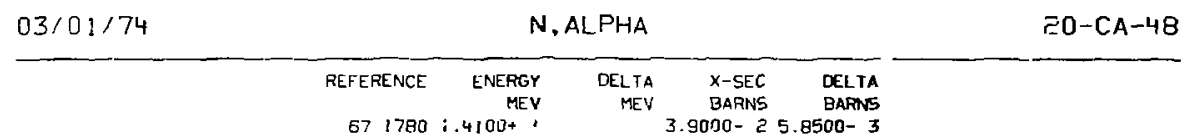
$03 / 01 / 74$
$N, Z N$
$21-5 C-45$ CROSS SECTION

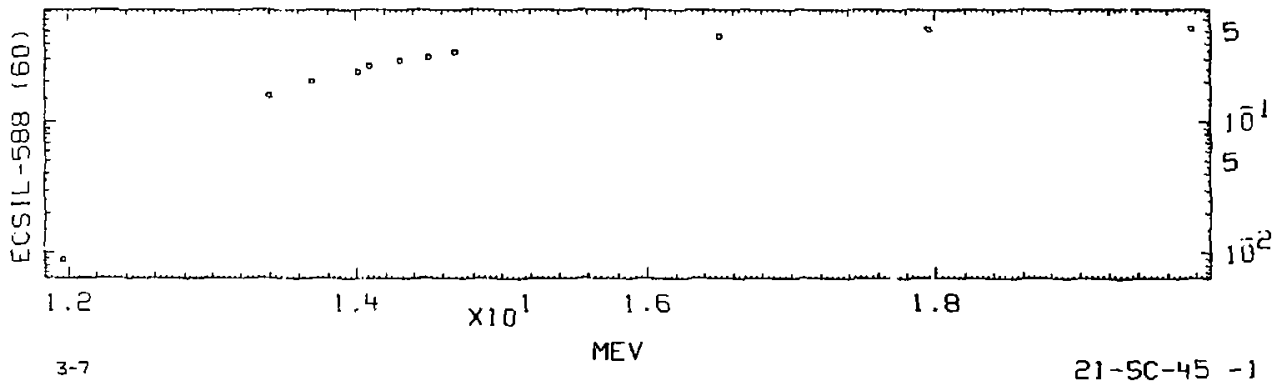




\section{CROSS SECTION}
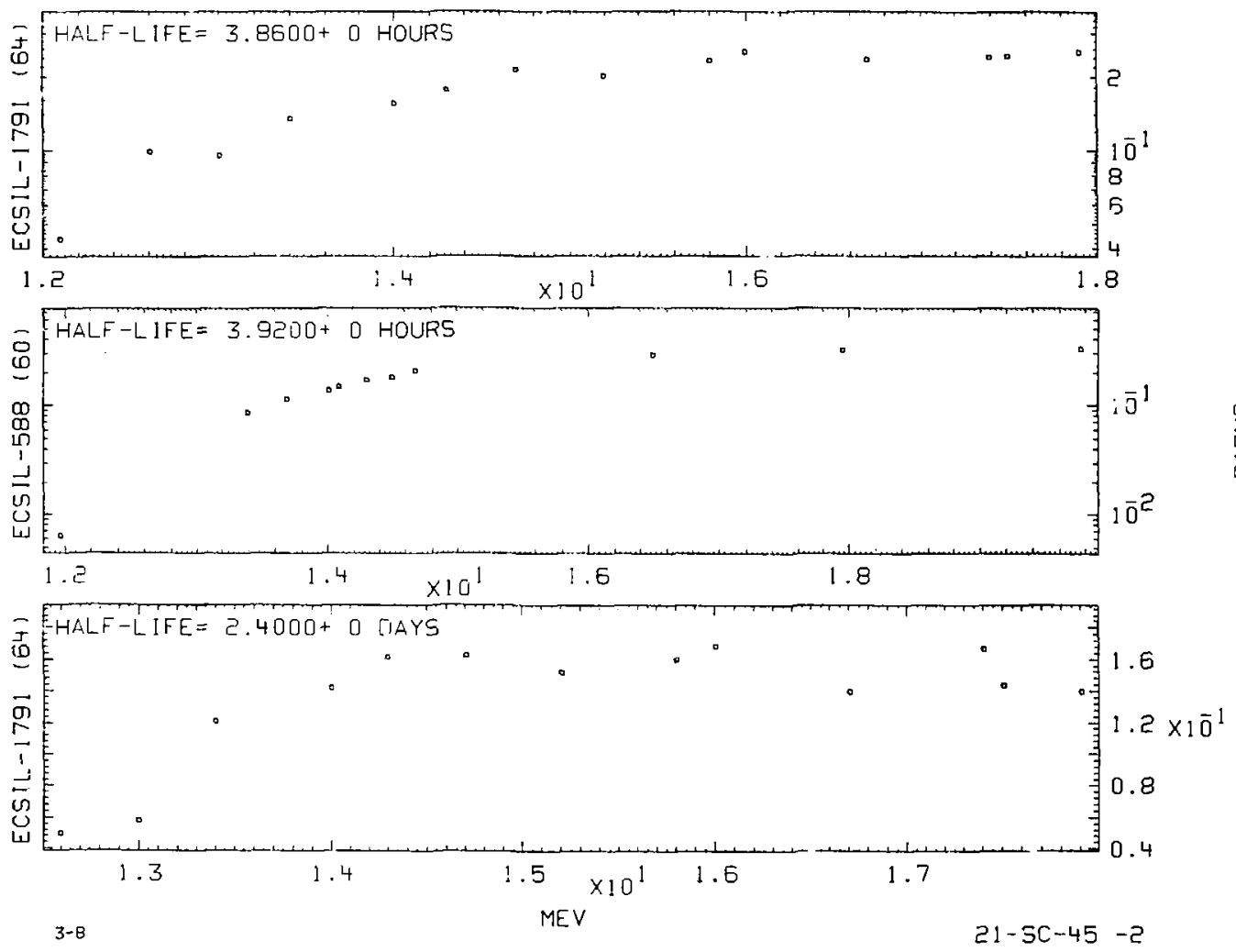


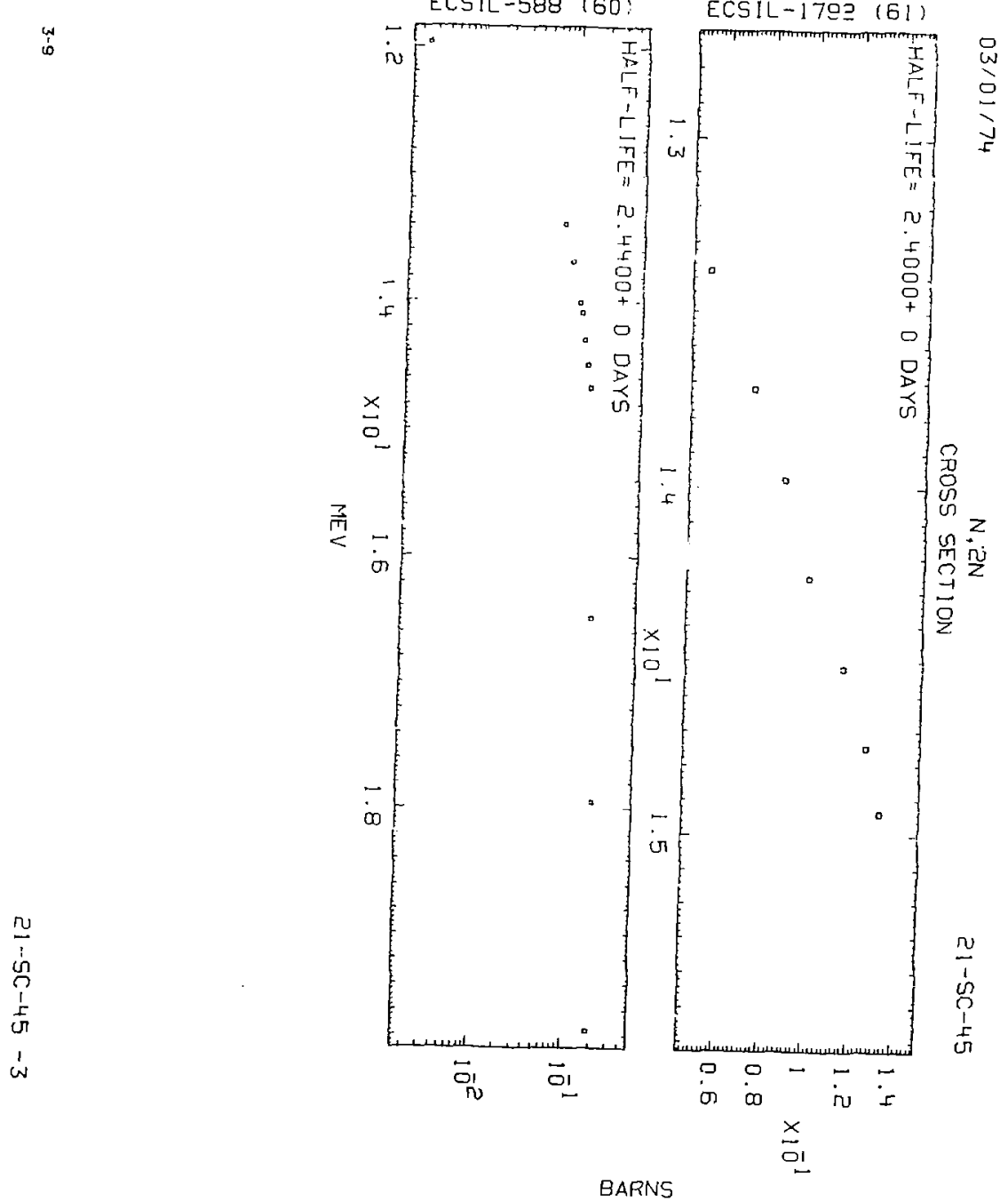



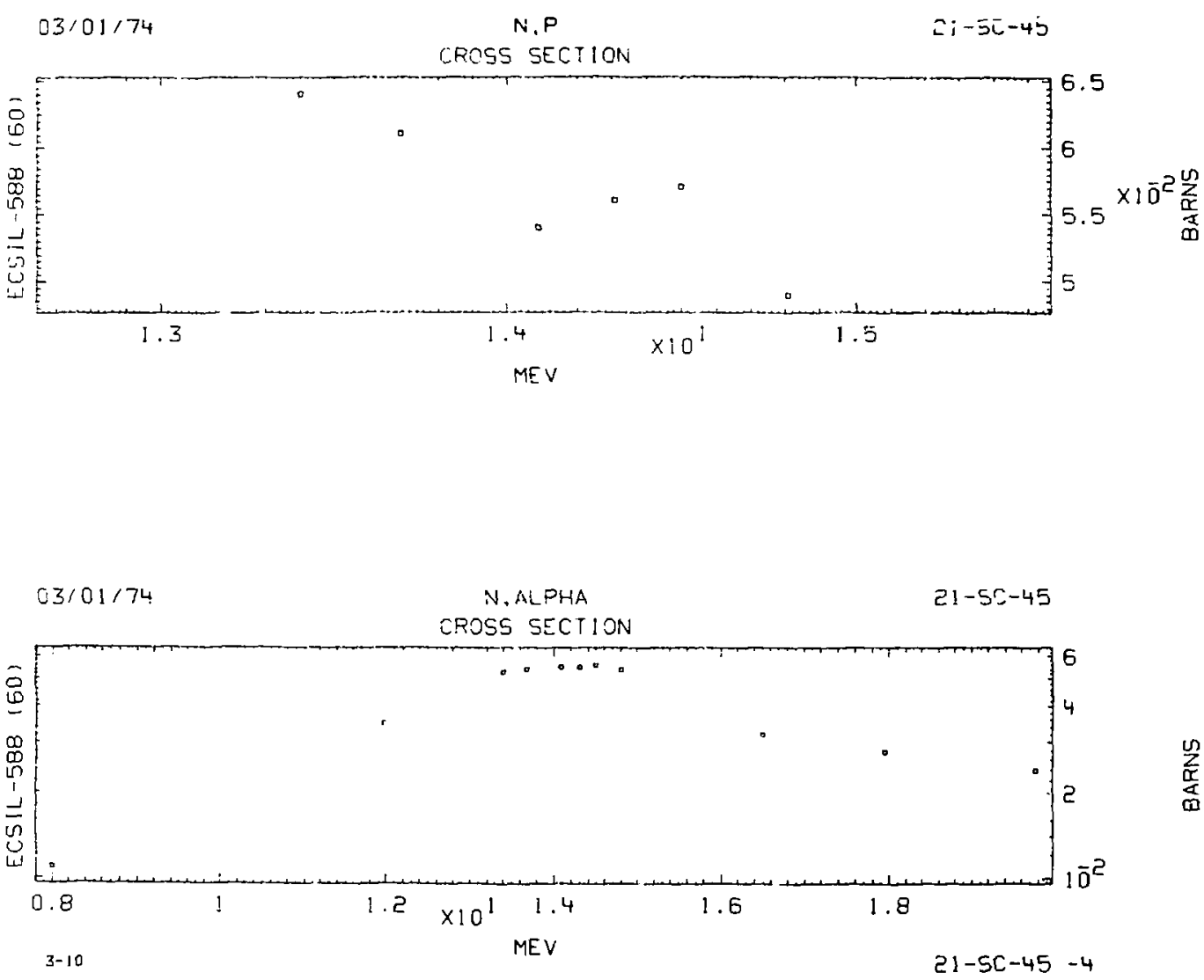


\section{CROSS SECTION}

\begin{tabular}{|c|c|c|c|c|c|c|c|c|c|c|}
\hline REFERENCE & $\begin{array}{r}\text { ENERGY } \\
\text { HEV }\end{array}$ & $\begin{array}{r}\text { DELTA } \\
\text { MEV }\end{array}$ & $\begin{array}{l}x-5 E C \\
\text { BARNS }\end{array}$ & $\begin{array}{ll}C & \text { DELTA } \\
S & \text { BARINS }\end{array}$ & REFEP & RENCE & $\begin{array}{r}\text { ENERG } \\
\text { ME }\end{array}$ & $\begin{array}{r}\text { OELTA } \\
\text { MEV }\end{array}$ & $\begin{array}{l}X \text {-SEC } \\
\text { BARNS }\end{array}$ & $\begin{array}{l}\text { DELTA } \\
\text { BARNS }\end{array}$ \\
\hline $\begin{array}{lr}6: & 676 \\
6 ? & 2009\end{array}$ & $\begin{array}{l}1.4400+1 \\
1.4600+1\end{array}$ & $13.0000-1$ & $\begin{array}{l}3.4700=1 \\
3.2000-1\end{array}$ & $\begin{array}{l}2.6000-2 \\
14.6000-5\end{array}$ & $\begin{array}{l}53 \\
61\end{array}$ & $\begin{array}{l}755 \\
660\end{array}$ & $\begin{array}{l}1.4800+ \\
1.4800+\end{array}$ & $12.0000=1$ & $\begin{array}{l}2.0400-1 \\
3.2800-1\end{array}$ & $\begin{array}{ll}12.5000-2 \\
14.9000-2\end{array}$ \\
\hline
\end{tabular}

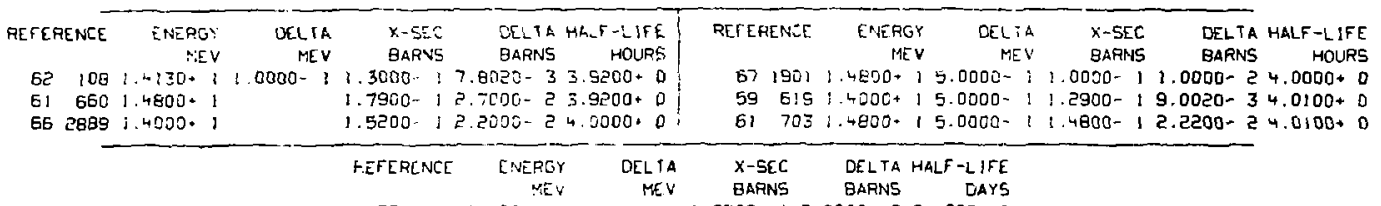

68 zgBS $1.4000+1 \quad 1.9500-13.0000-22.4000+0$

5) $6601.4800+1 \quad 14900-12.2000-22.4400+0$
$03 / 01 / 74$
$N, X$ GAMMA
$21-5 c-45$

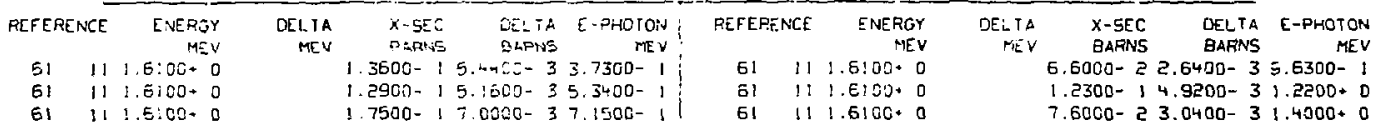

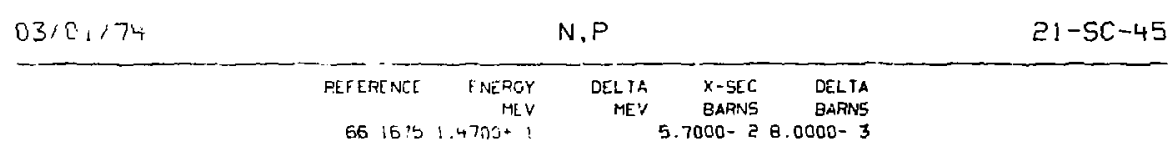

\begin{tabular}{|c|c|c|c|c|c|c|}
\hline $03 / 01 / 74$ & & & $N, A L P H A$ & & & $21-5 c-45$ \\
\hline & REFERENCE & ENEFGY & $\begin{array}{ll}V & \text { DELTA } \\
V & \text { MEV }\end{array}$ & $\begin{array}{l}x-\operatorname{sEC} \\
\text { BAFNS }\end{array}$ & $\begin{array}{ll}\text { DELTA } \\
\text { GARNS }\end{array}$ & \\
\hline & $\begin{array}{ll}63 & 756 \\
61 & 660\end{array}$ & $\begin{array}{l}1.4800+! \\
1.4800=\end{array}$ & $2.0000-1$ & $\begin{array}{l}6.3020- \\
6.3020-\end{array}$ & $\begin{array}{l}1.2000-2 \\
9.0020 \cdot 3\end{array}$ & \\
\hline
\end{tabular}




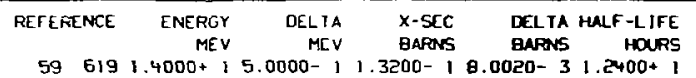

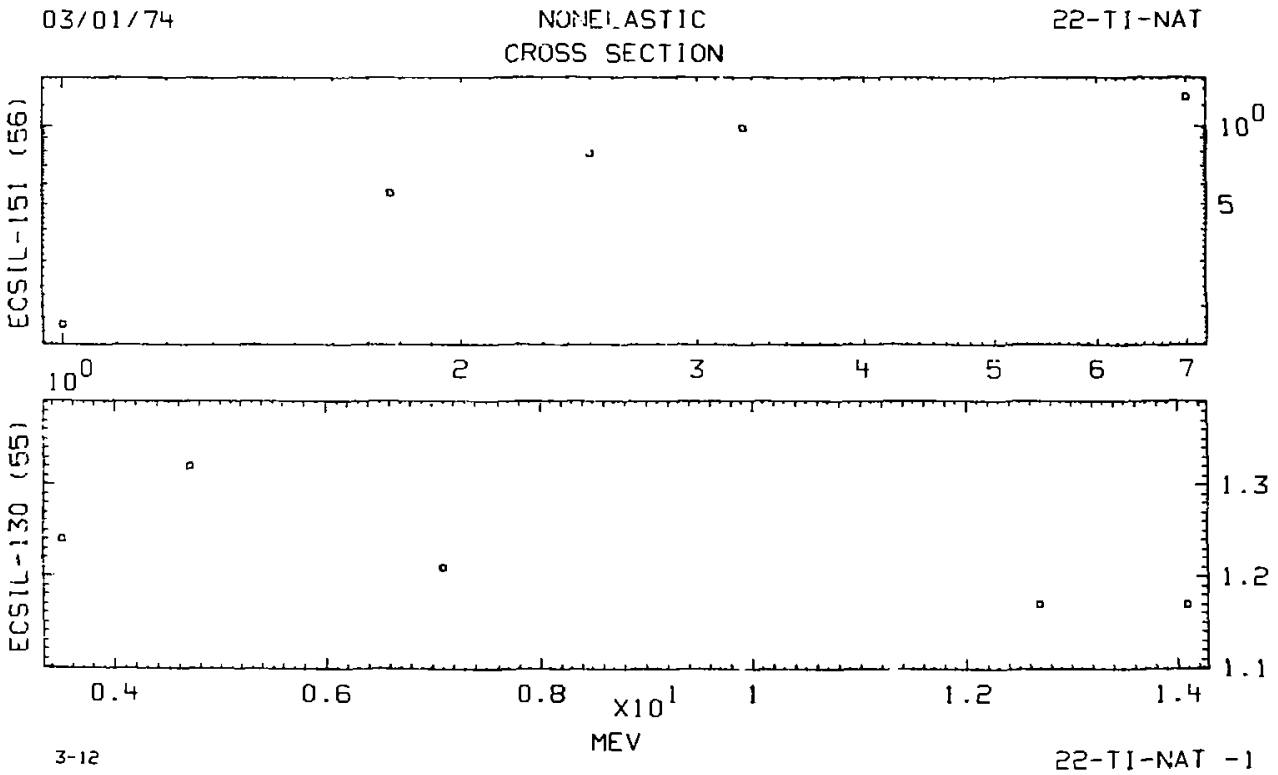




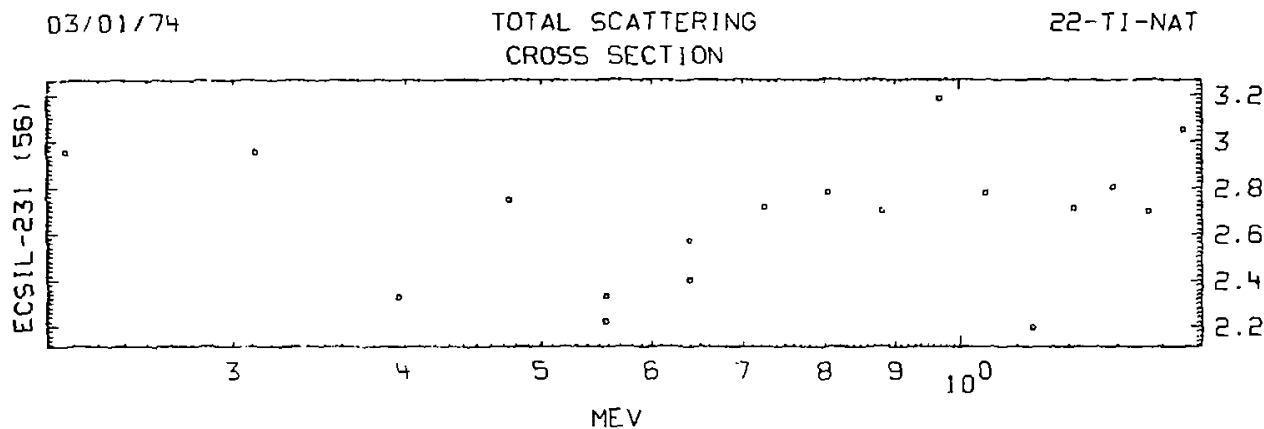

$03 / 01 / 74$

$N, N^{\circ}$

$22-T I-N A T$

CROSS SECTION

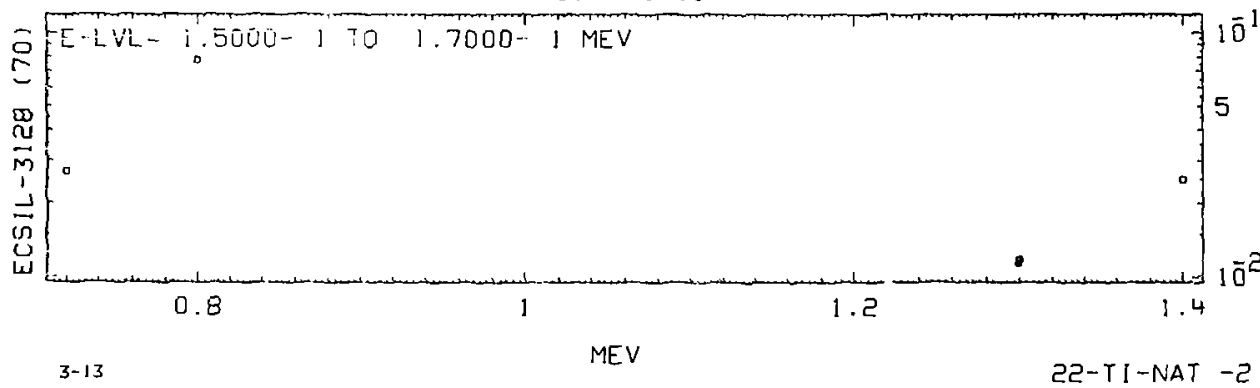




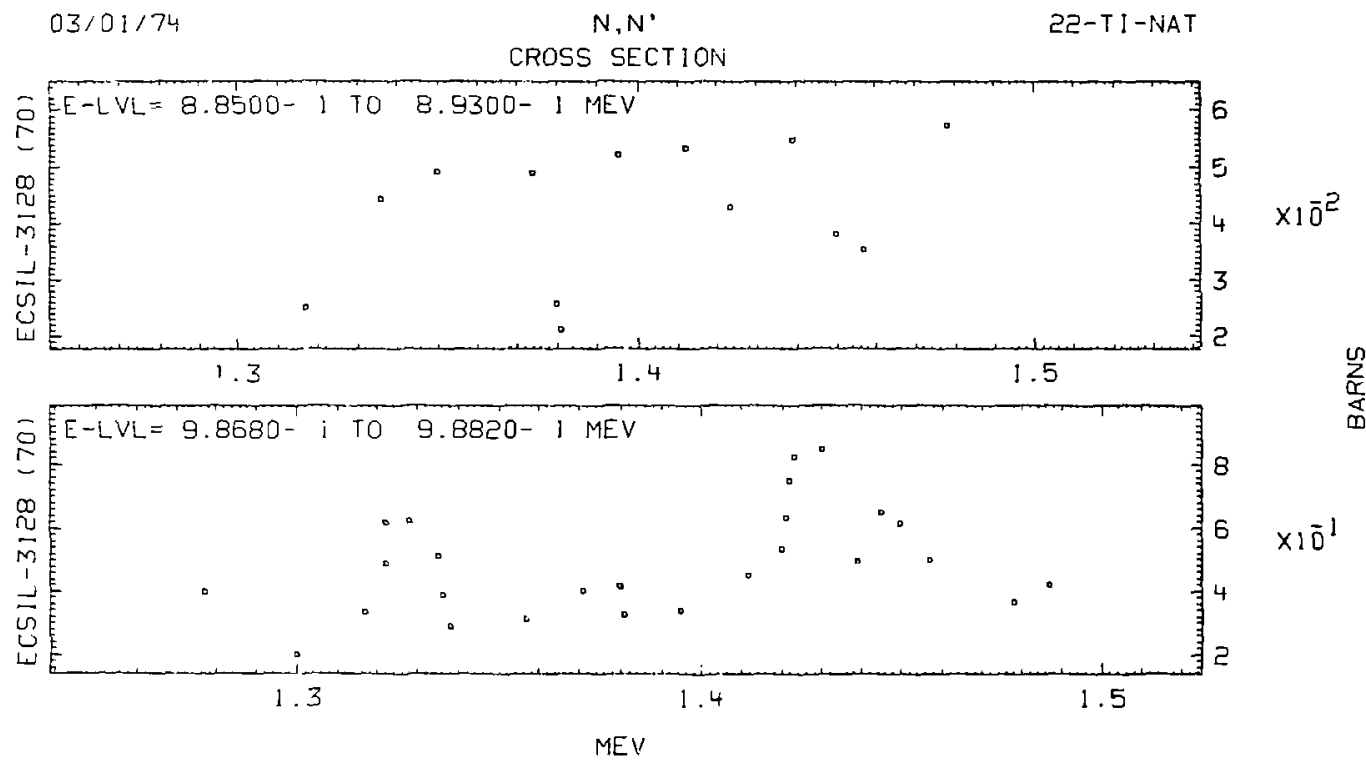


SNYYA

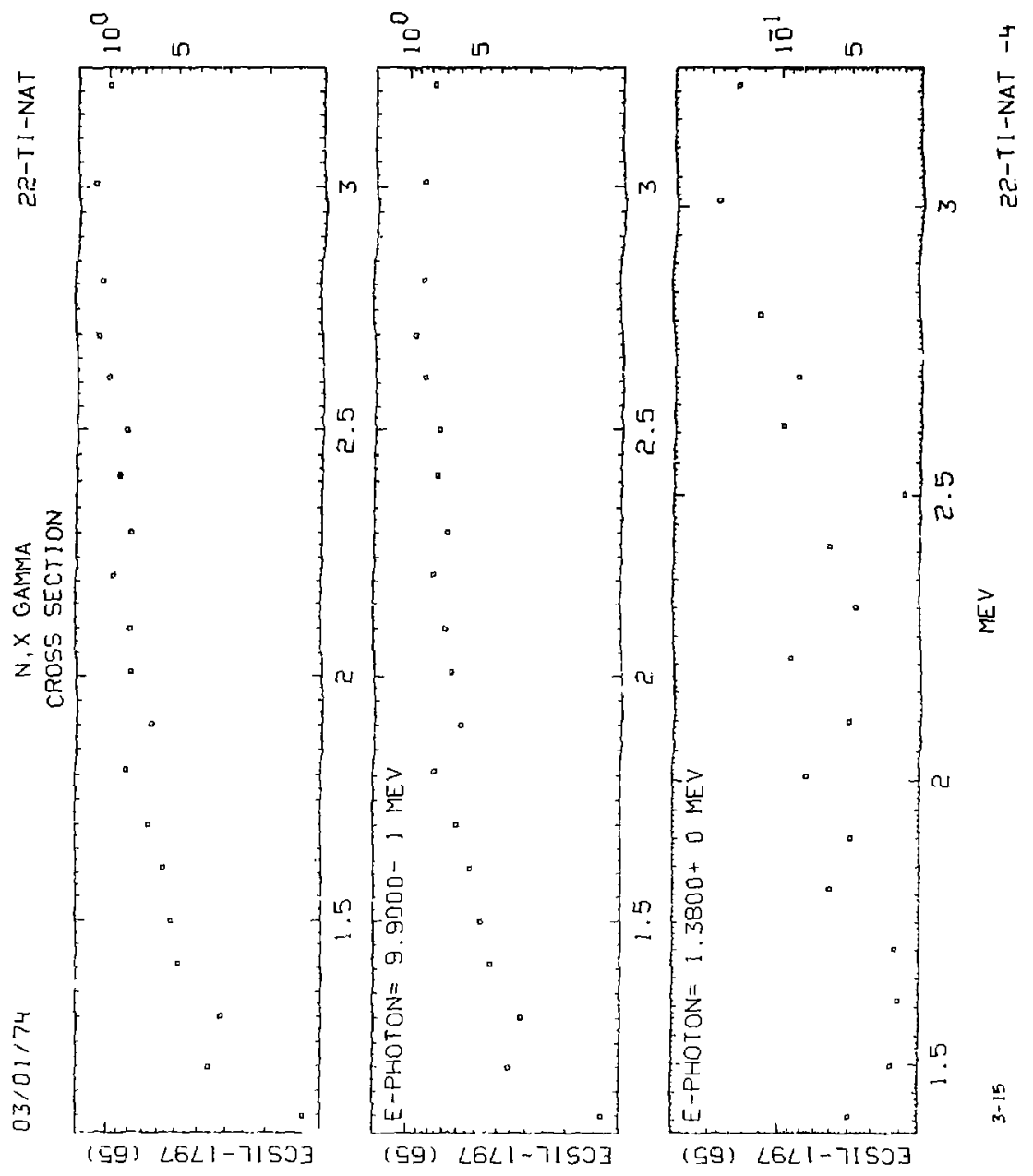




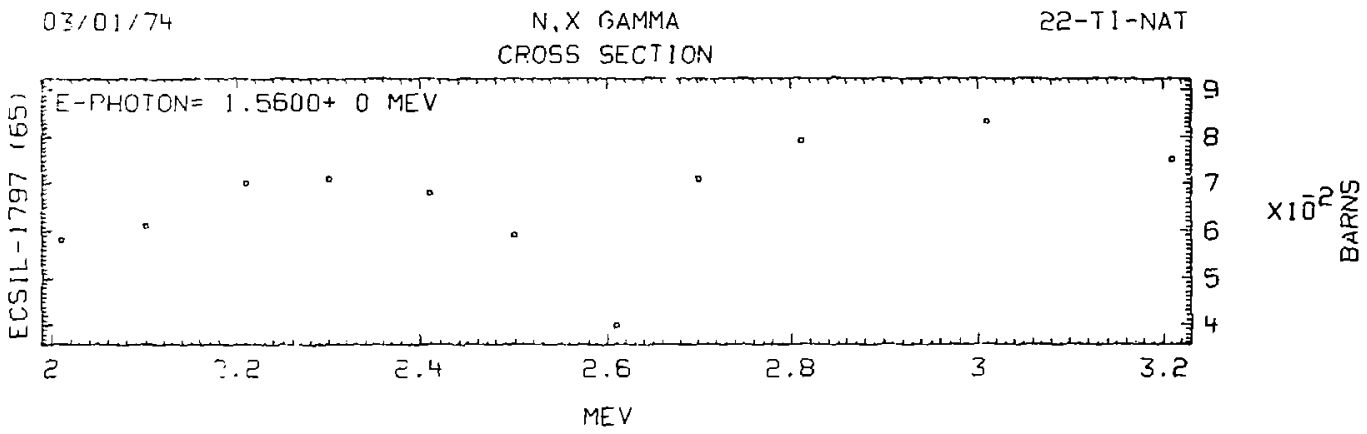

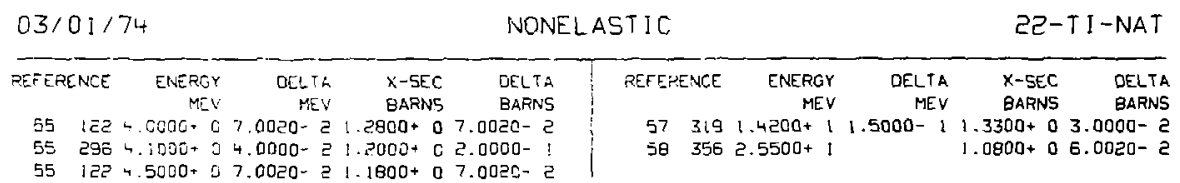

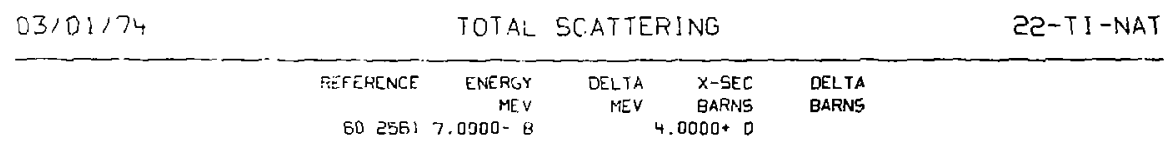

P3/01/74




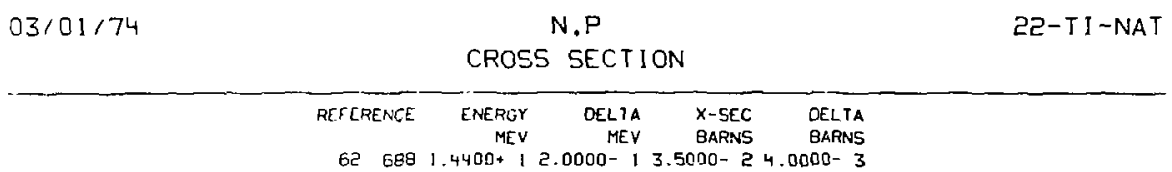

E2 $6881.4400+12.0000-13.5000-24.0000-3$

$03 / 01 / 74$

BOUND ATOM

$22-T I-N A T$

$\begin{array}{rrrrr}\text { REFERENCE } & \text { ENERGY } & \text { DELTA } & \text { X-SEC } & \text { DELTA } \\ & \text { MEV } & \text { MEV } & \text { BARNS } & \text { BARNS }\end{array}$

$03 / 01 / 74$

FREE ATOM

2E-TI-NAT

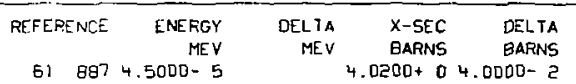

$03 / 01 / 74$

COHERENT SCATTERING

$25-T I-N A T$

REFE RENCE

ENERGY

OELTA

$X$ - SEC

$5125642.5300-$

$6 C 5617.0000=9$

$1.6000+03.0000-$

$1.4500+01.1500-1$

$5115847.3000-8$

$1.8000+01.4400-1$ 


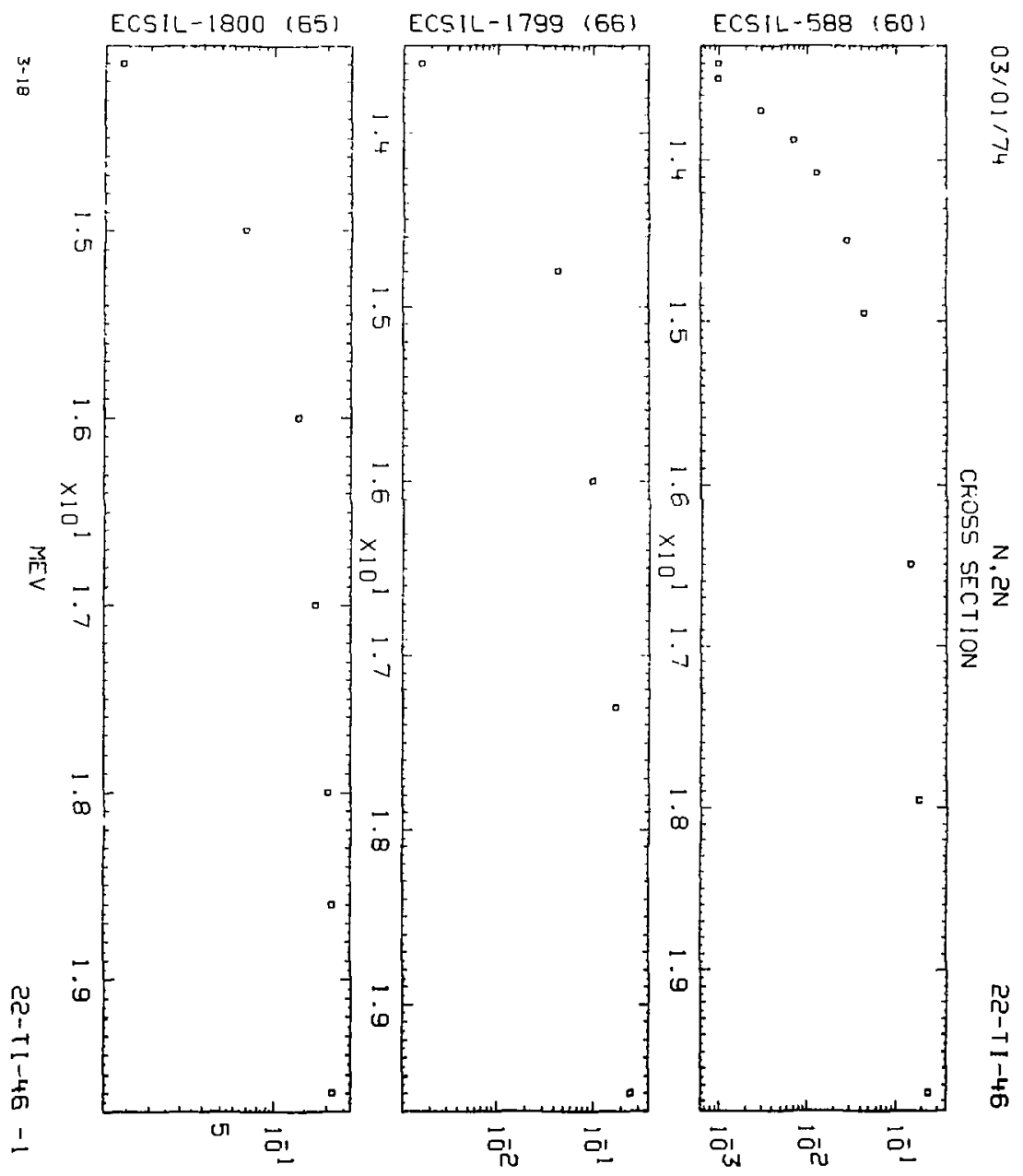

BARNS 

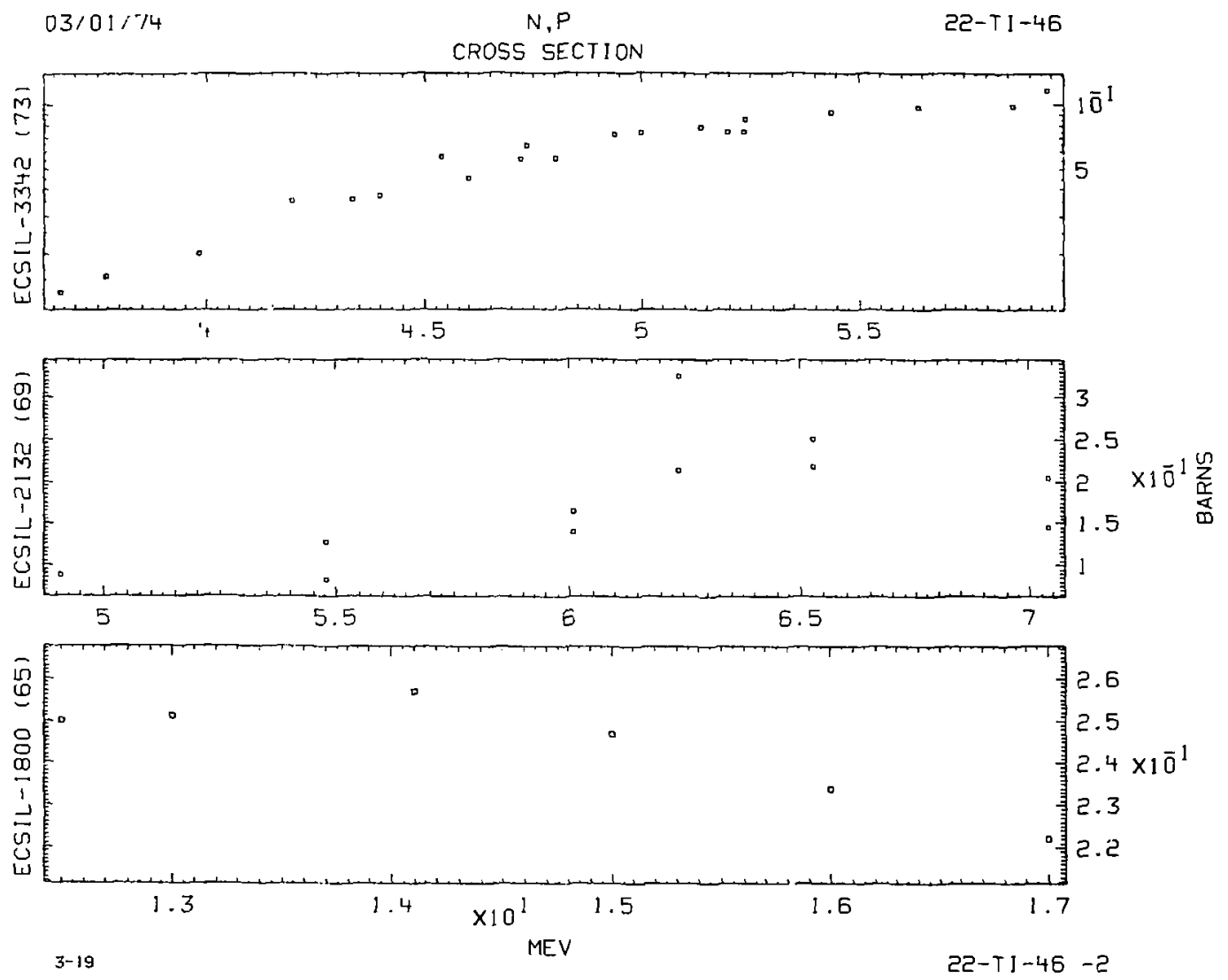

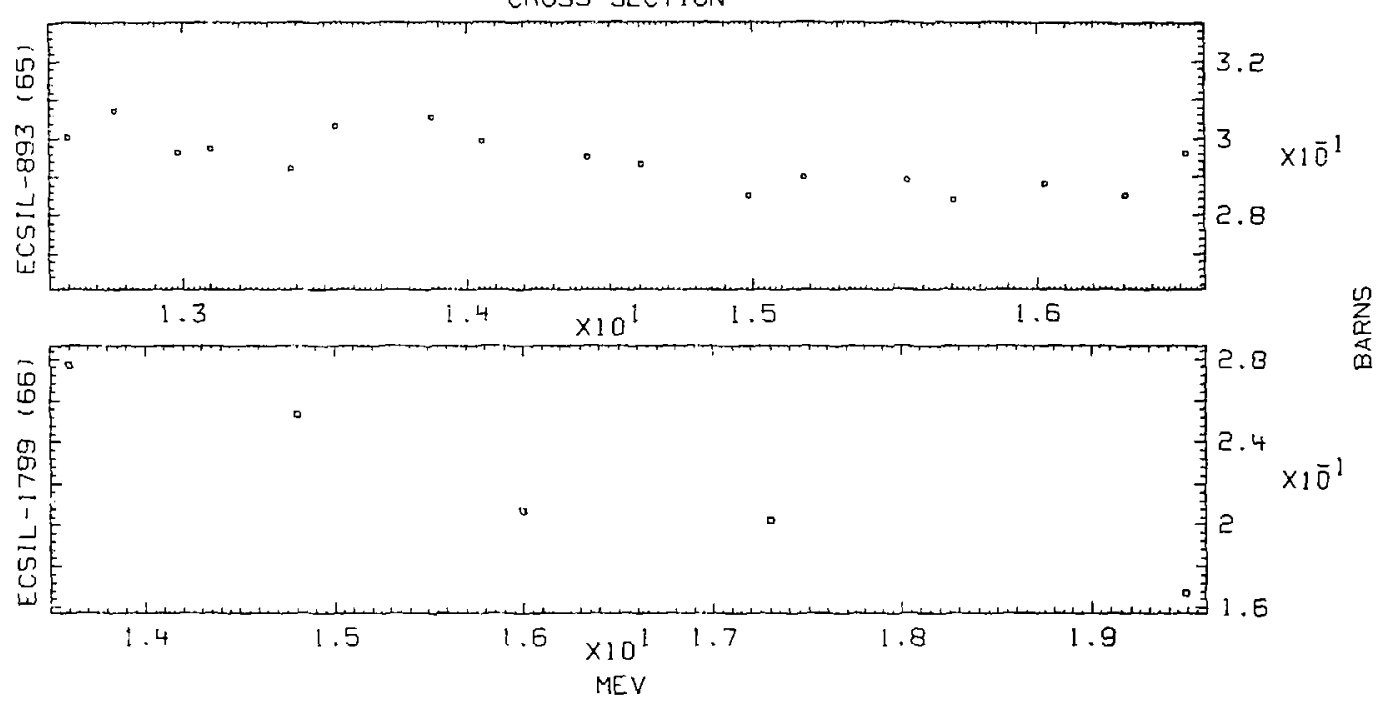

$03 / 01 / 74$

TOTAL SCATTERING

$22-T I-46$ 


\section{CROSS SECTION}

\begin{tabular}{|c|c|c|c|c|c|c|c|c|c|}
\hline REFERENCE & $\begin{array}{r}\text { ENERCY } \\
\text { MEV }\end{array}$ & $\begin{array}{r}\text { DELTA } \\
\text { MEV }\end{array}$ & $\begin{array}{l}x-S E C \\
\text { GARNS }\end{array}$ & $\begin{array}{l}\text { DELIA } \\
\text { GARNS }\end{array}$ & REFERENCE & $\begin{array}{r}\text { ENERGY } \\
\text { MEV }\end{array}$ & $\begin{array}{r}\text { DELTA } \\
\text { MEV }\end{array}$ & $\begin{array}{l}X-5 E C \\
\text { BARNS }\end{array}$ & $\begin{array}{l}\text { DELTA } \\
\text { EARNS }\end{array}$ \\
\hline $62 \quad 108$ & $130+1$ & $1.0000-1$ & $1.3300-2$ & $1.1000-3$ & 631009 & $1.4750+1$ & & $5.0000-?$ & \\
\hline 6: 675 & $+400+1$ & $3.0000^{-} \quad 1$ & $3.2000-2$ & 2.0000- 3 & $59 \quad 662$ & $1.4800+1$ & $9.0020-1$ & $5.0000-2$ & $8.0020-3$ \\
\hline
\end{tabular}

$5510721.4500+11.0000-15.5000-25.0000-3$

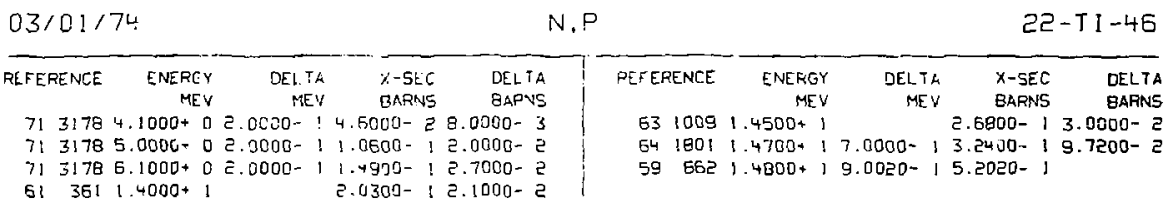

$03 / 01 / 74 \quad$ COHERENT SCATTERING 22-T1-46

$\begin{array}{rrrrr}\text { PEFIRENCE } & \text { ENEPGG } & \text { DELTA } & \text { X-SEC } & \text { OELTA } \\ & \text { MEV } & \text { MEV } & \text { BARNS } & \text { gARNS } \\ 502561 & 7.0000-B & & 2.9000+0 & 2.3200-1\end{array}$
$03 / 01 ; 74$
N,P
$22-T]-47$

\section{CROSS SECTION}

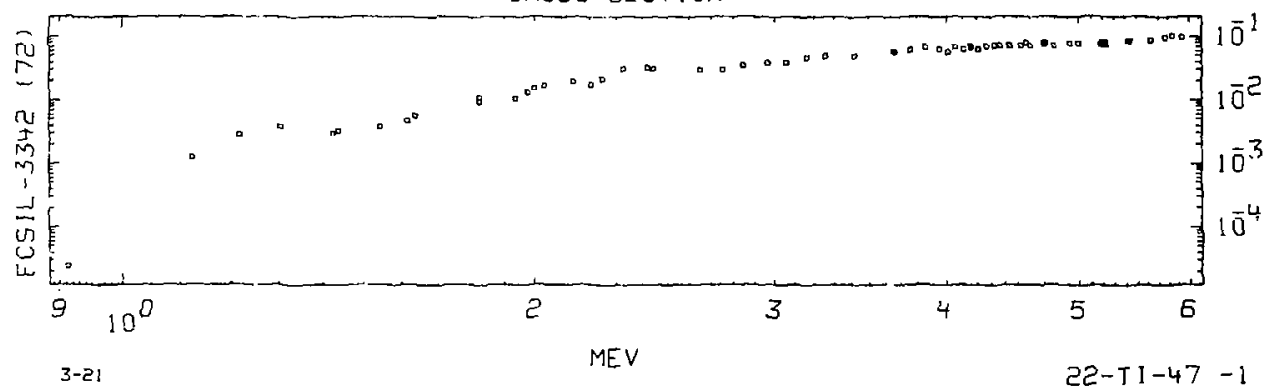




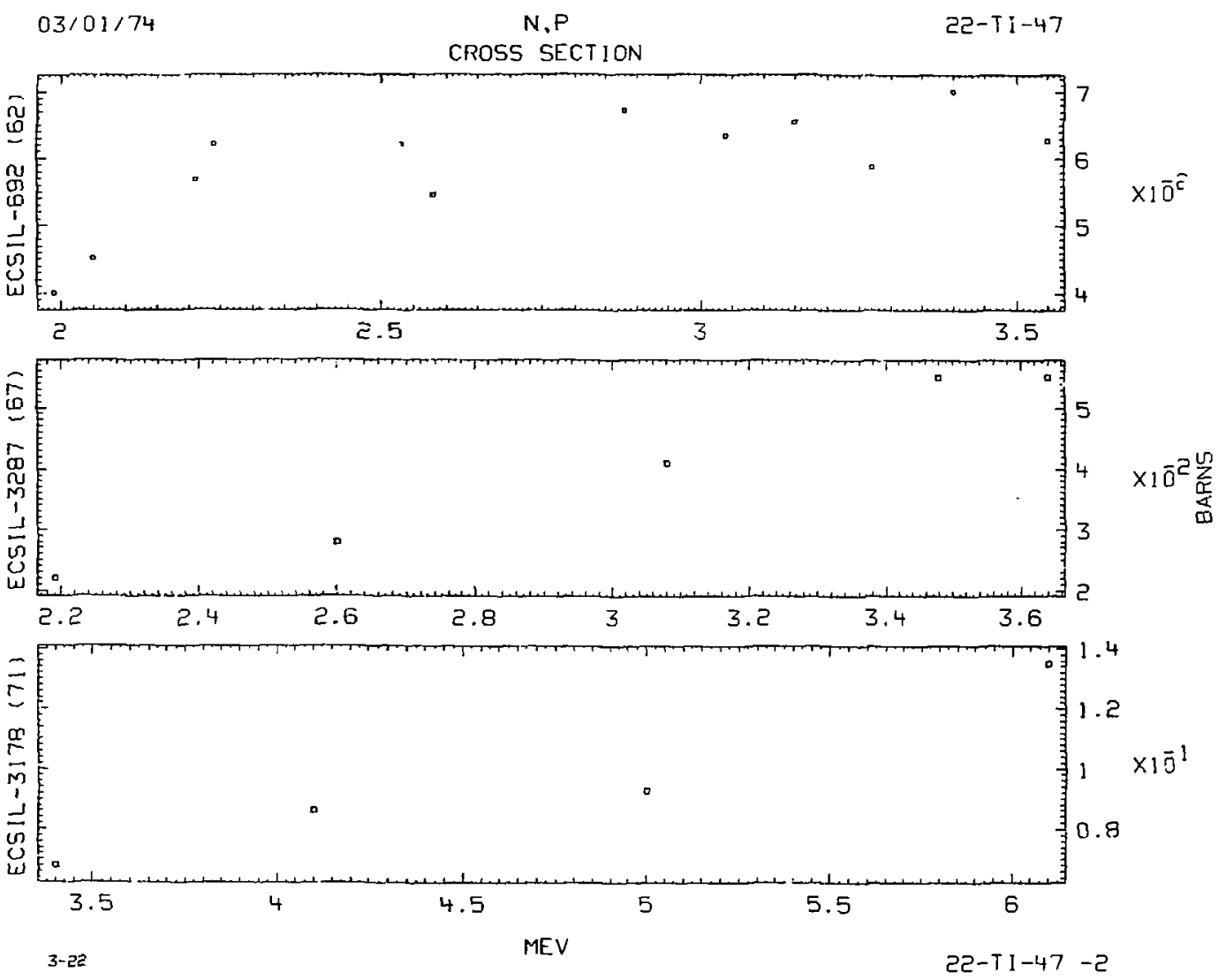



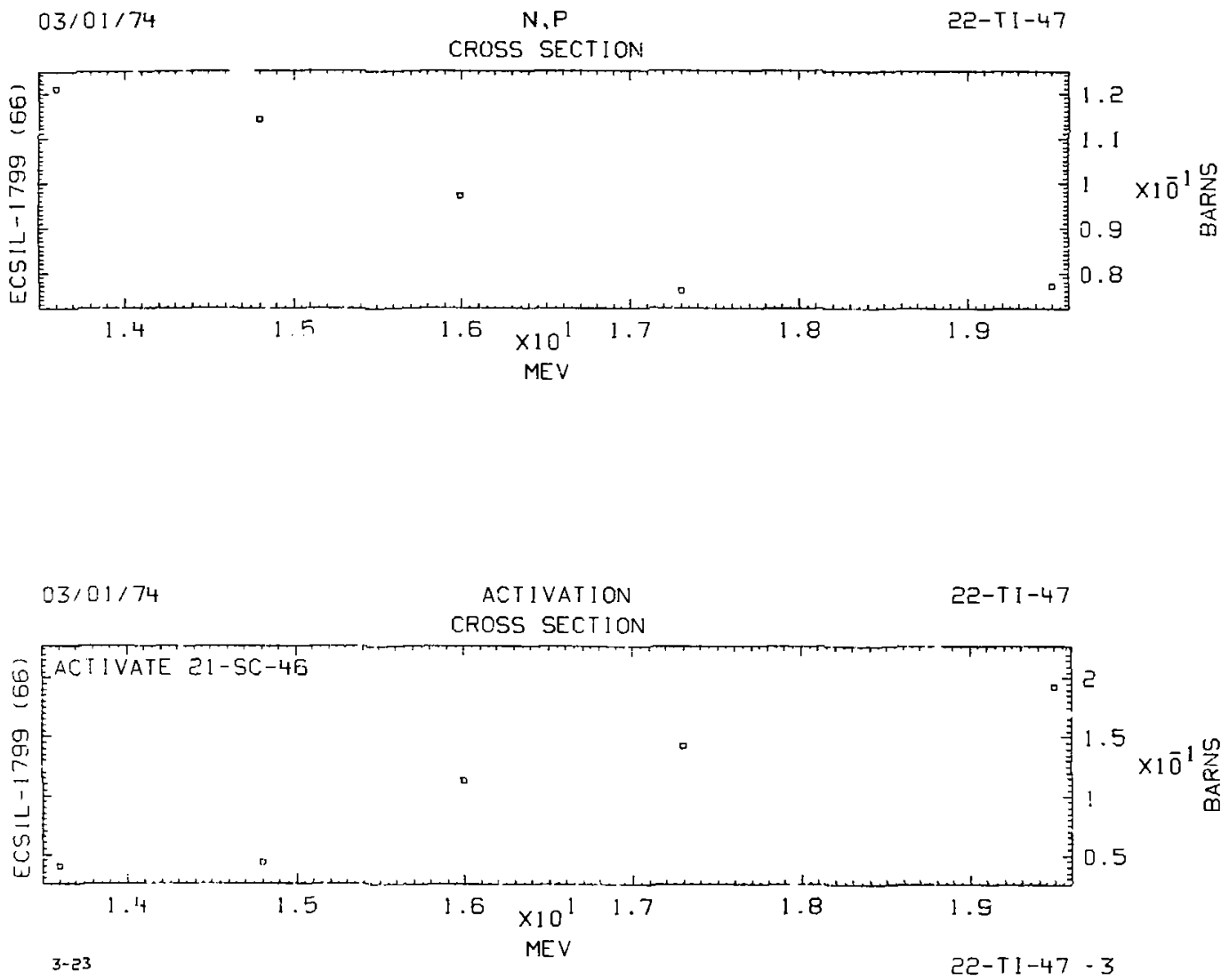
CROSS SEITION

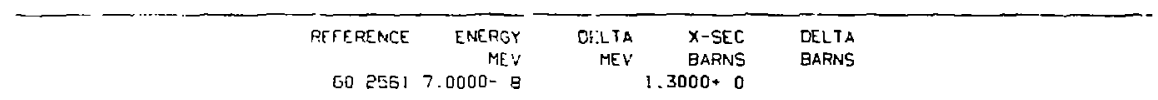

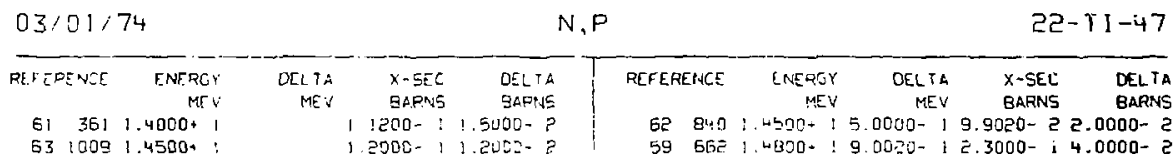

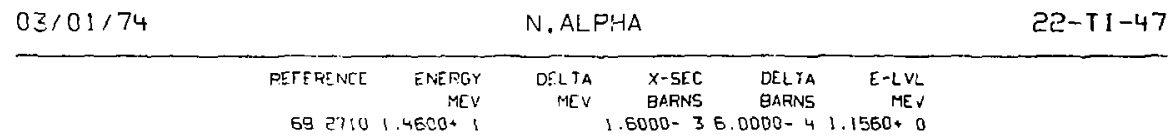

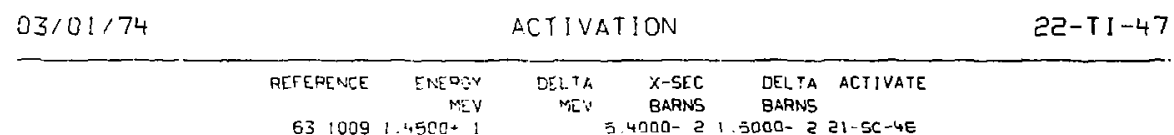

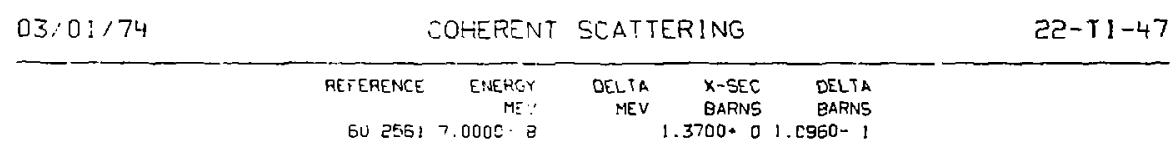


CROSS SECTION
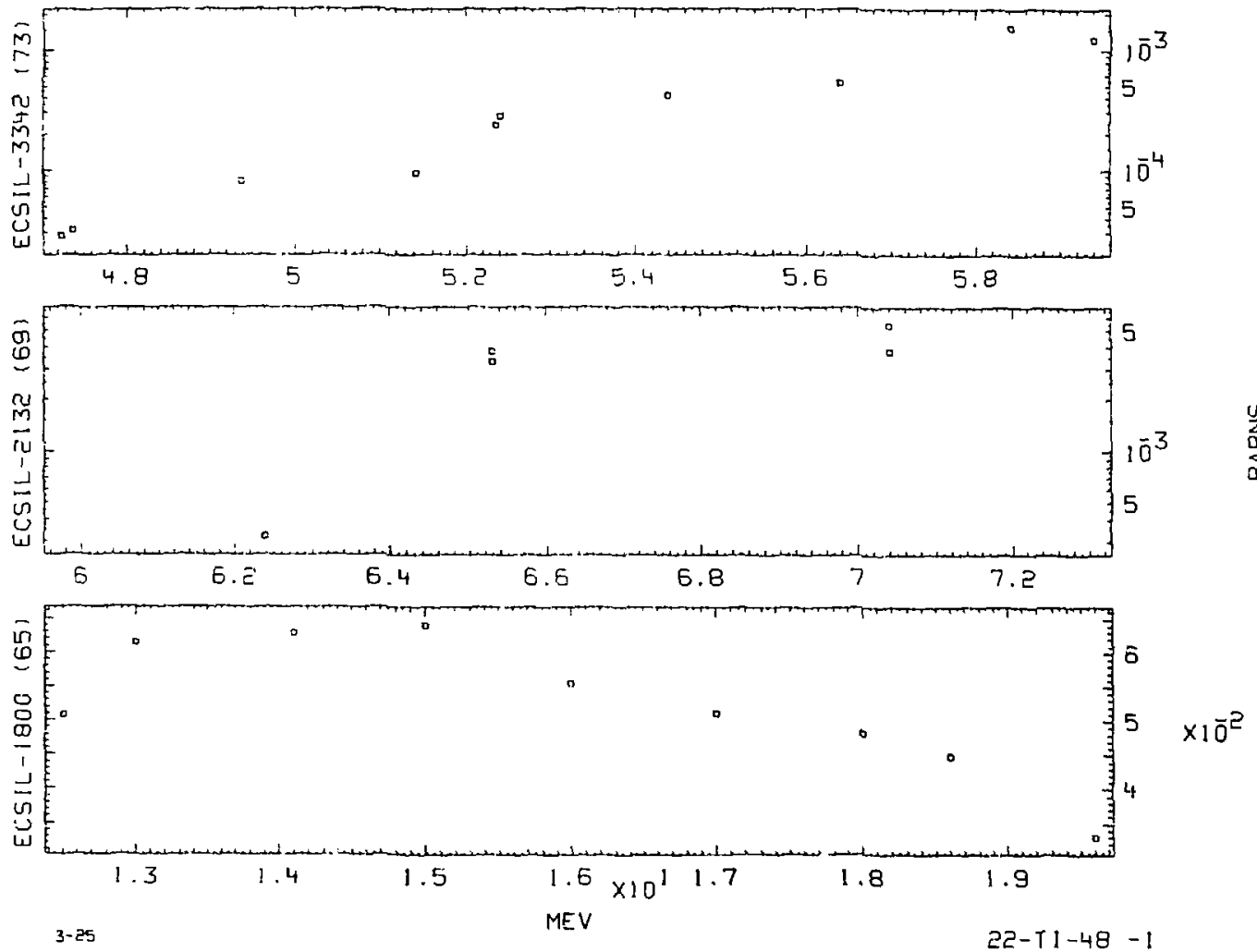


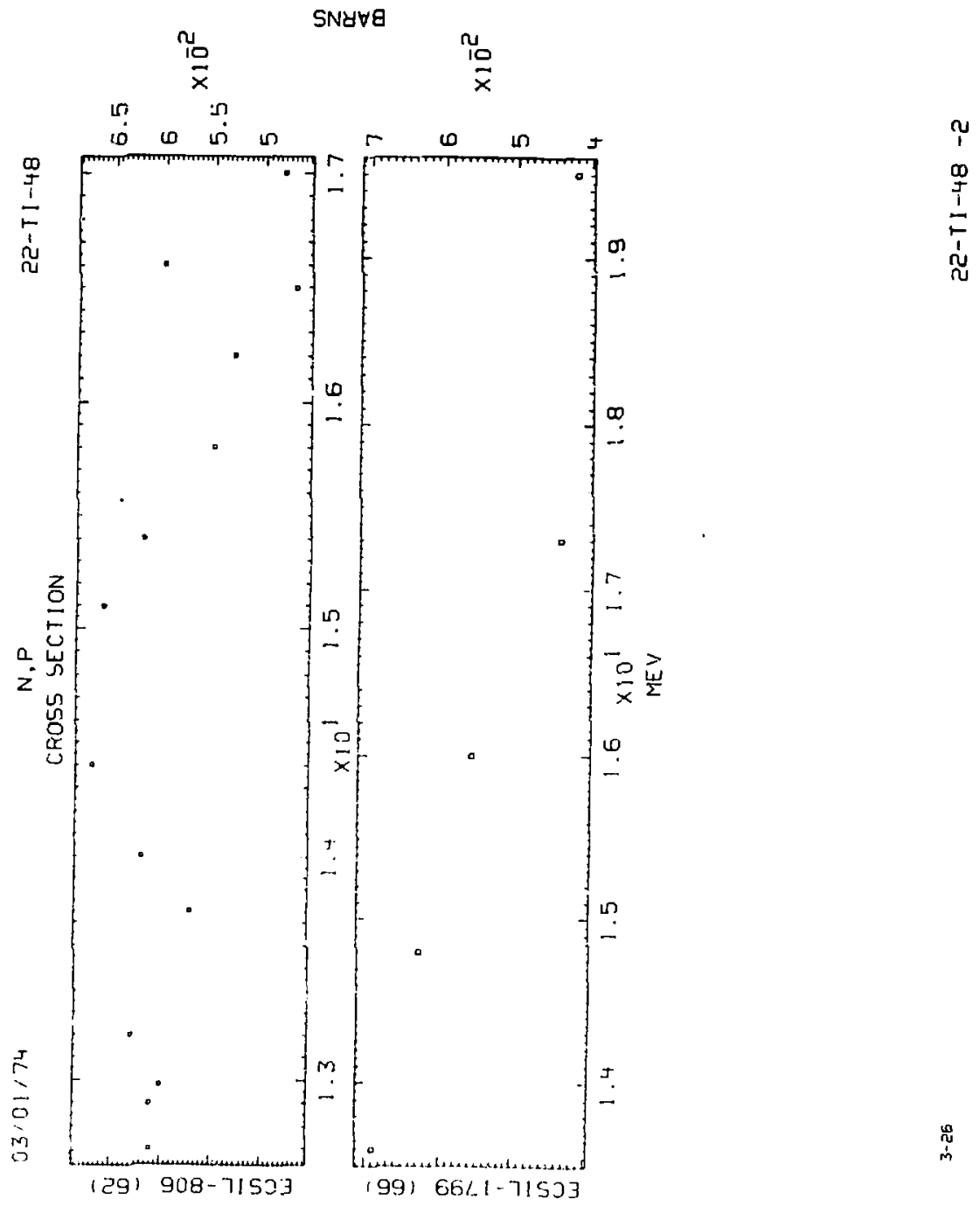



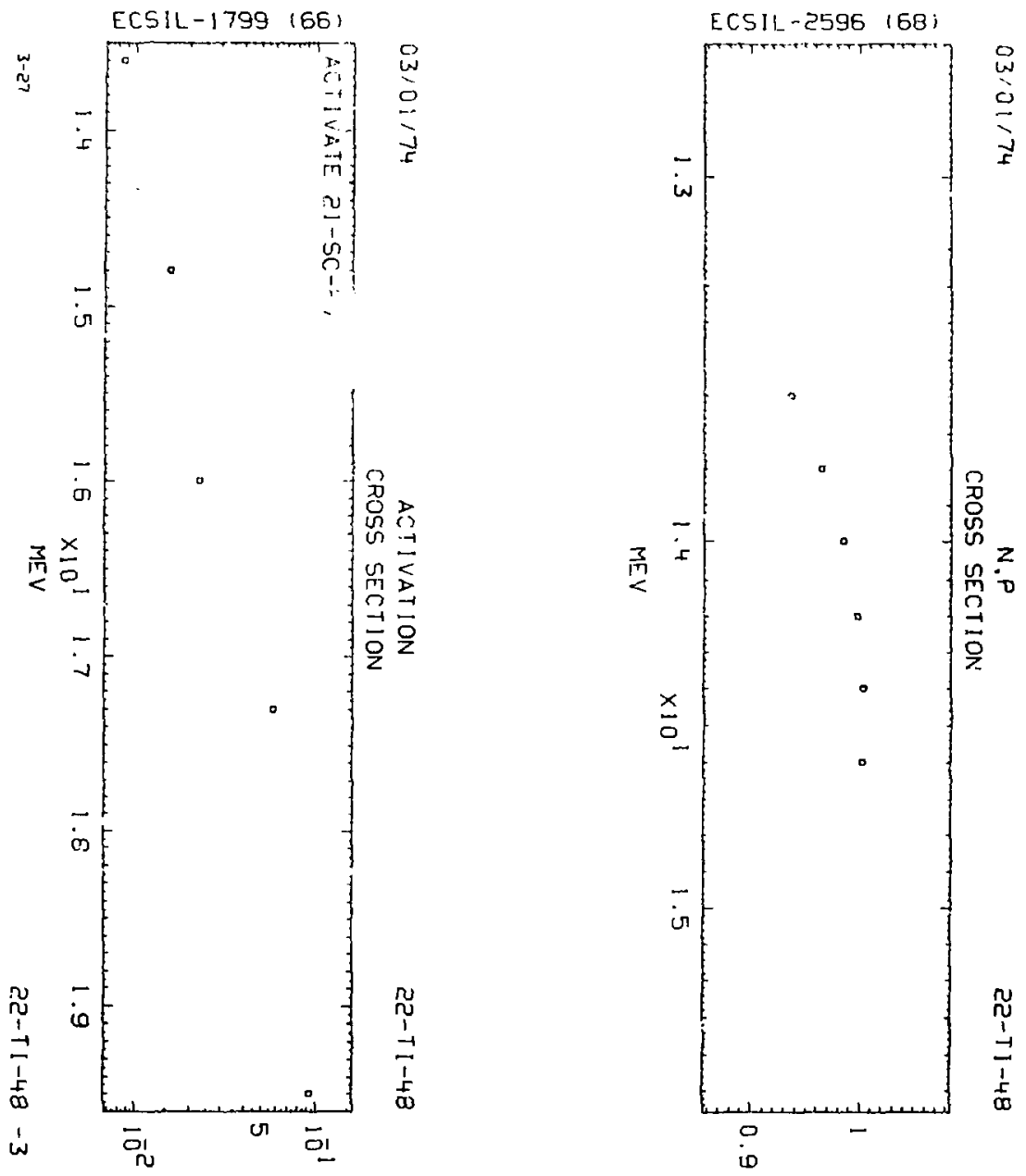

BARNS 
CRUSS SECTION

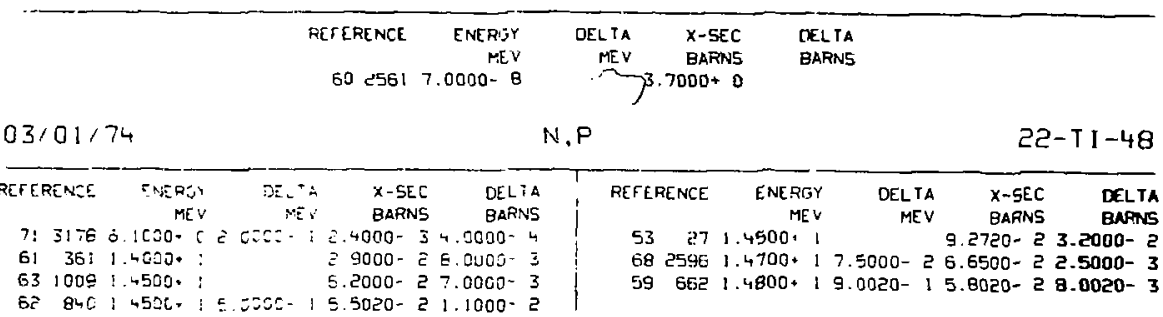

03/51,74

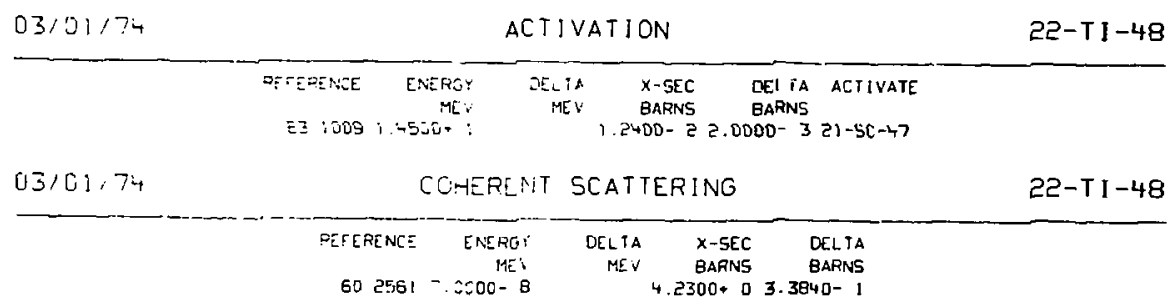



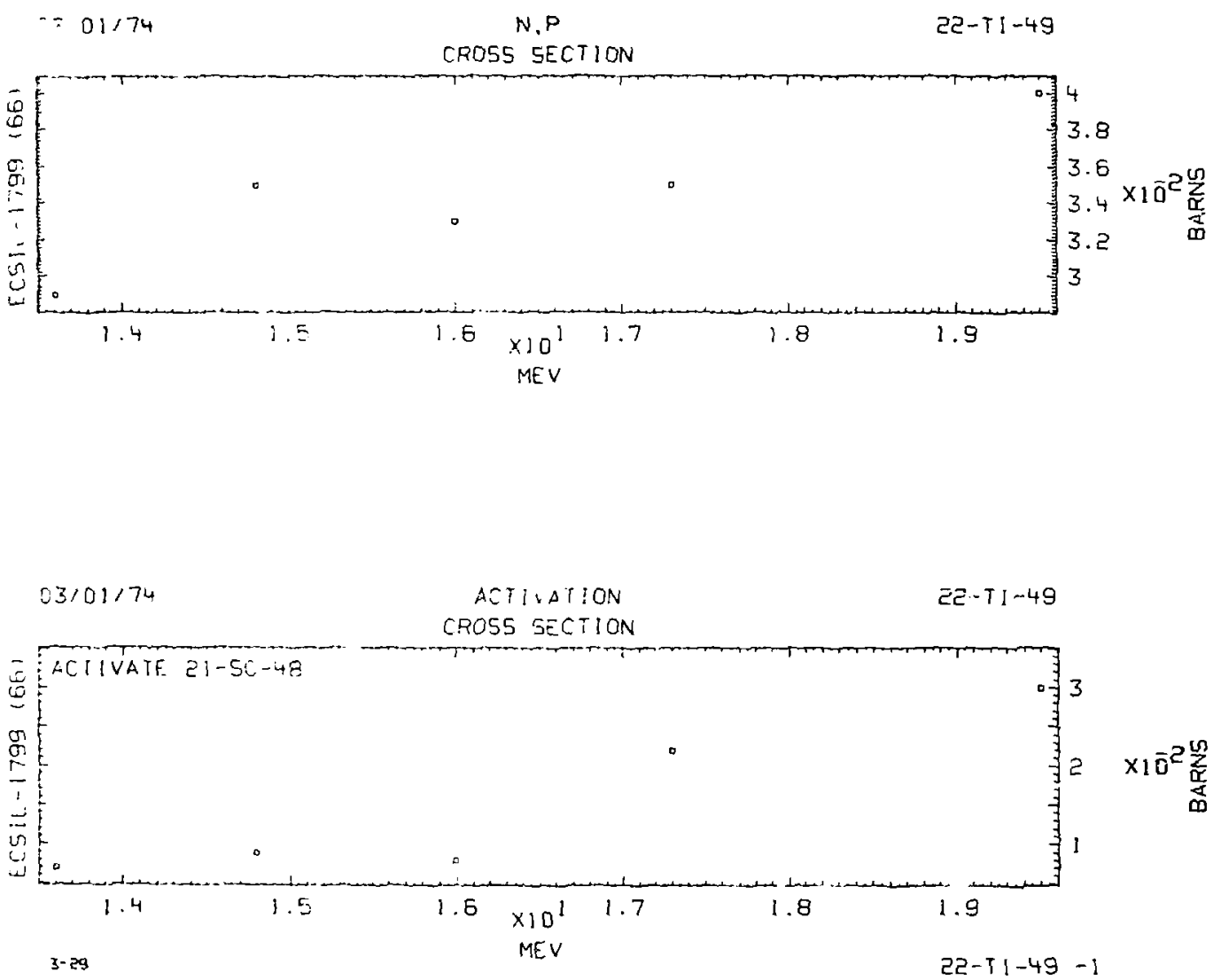


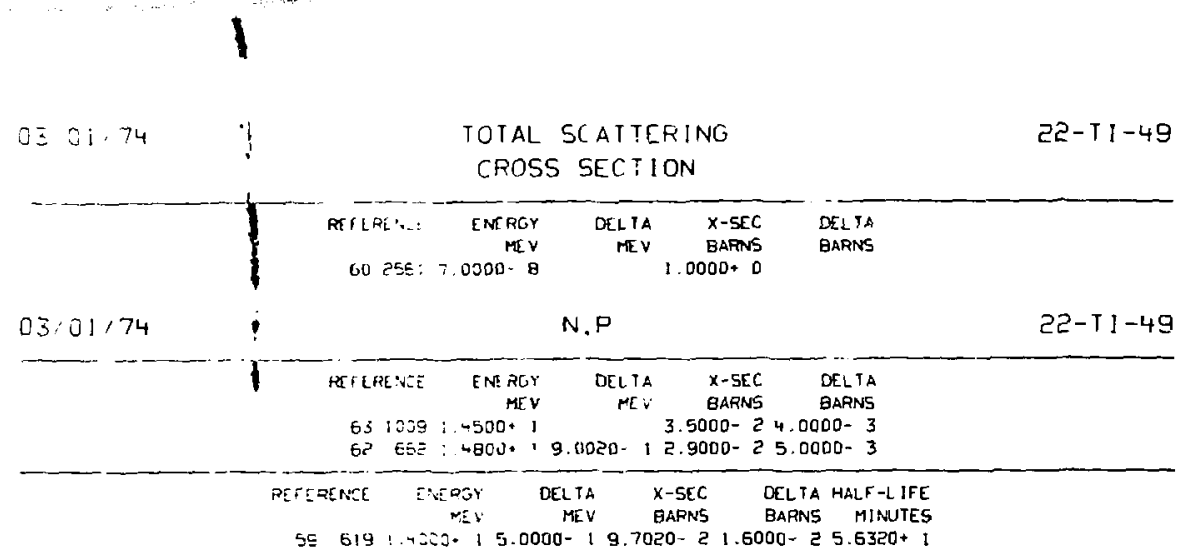

$03 / 01 / 74 \quad$ ACTIVATION

531005 :. 9000 : $\quad 9.0000-32.0000-321-5 C-48$

$03101 / 74$ CSHERENT SCATTERING 22-TI-49

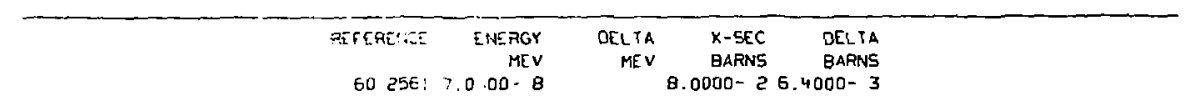




\section{CROSS SECTION}

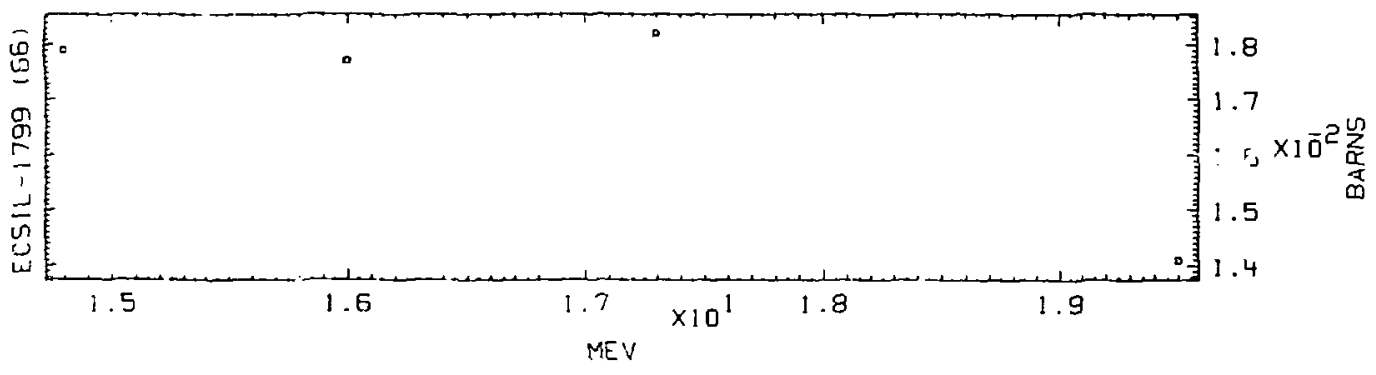

\begin{tabular}{|c|c|c|c|c|c|}
\hline \multirow[t]{2}{*}{$03101 / 74$} & \multicolumn{5}{|c|}{ TOTAL SCMTTERING } \\
\hline & $\begin{array}{l}\text { QETERENCE } \\
602561\end{array}$ & $\begin{array}{r}\text { ENEFGY } \\
\text { MEV } \\
0000-\theta\end{array}$ & $\begin{array}{r}\text { DELTA } \\
\text { MEV }\end{array}$ & $\begin{array}{r}x-\text { SEC } \\
\text { BARAYS } \\
\text { OOU+ } 0\end{array}$ & $\begin{array}{l}\text { DELTA } \\
\text { BARNS }\end{array}$ \\
\hline
\end{tabular}

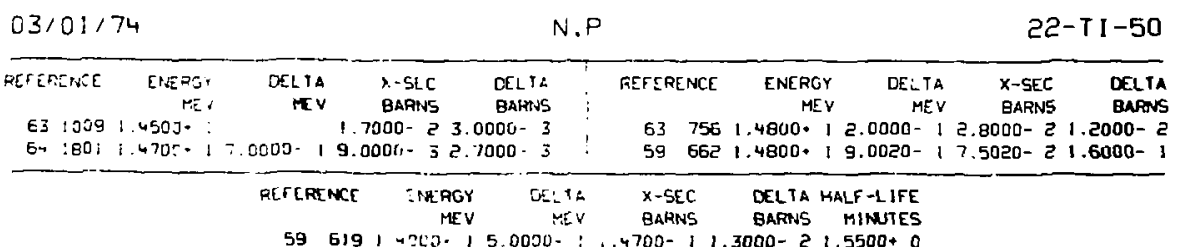

$59619,+200-15.0000-: \ldots 4700-1,1.3000-2, .5500+0$ 


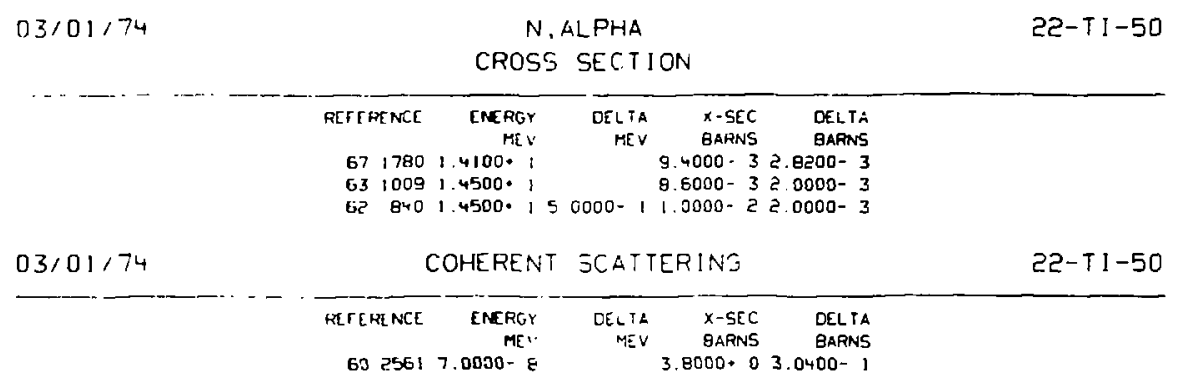

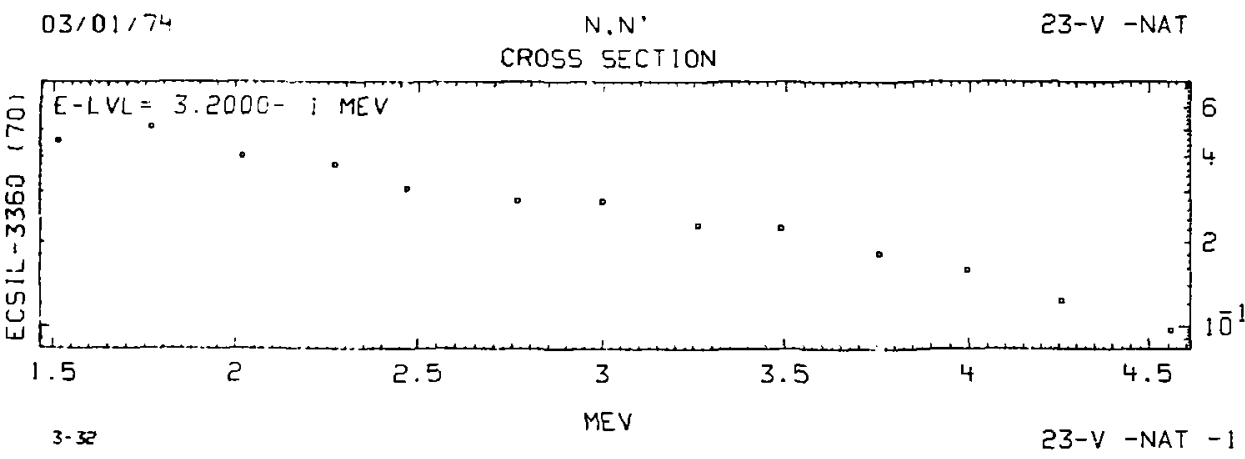




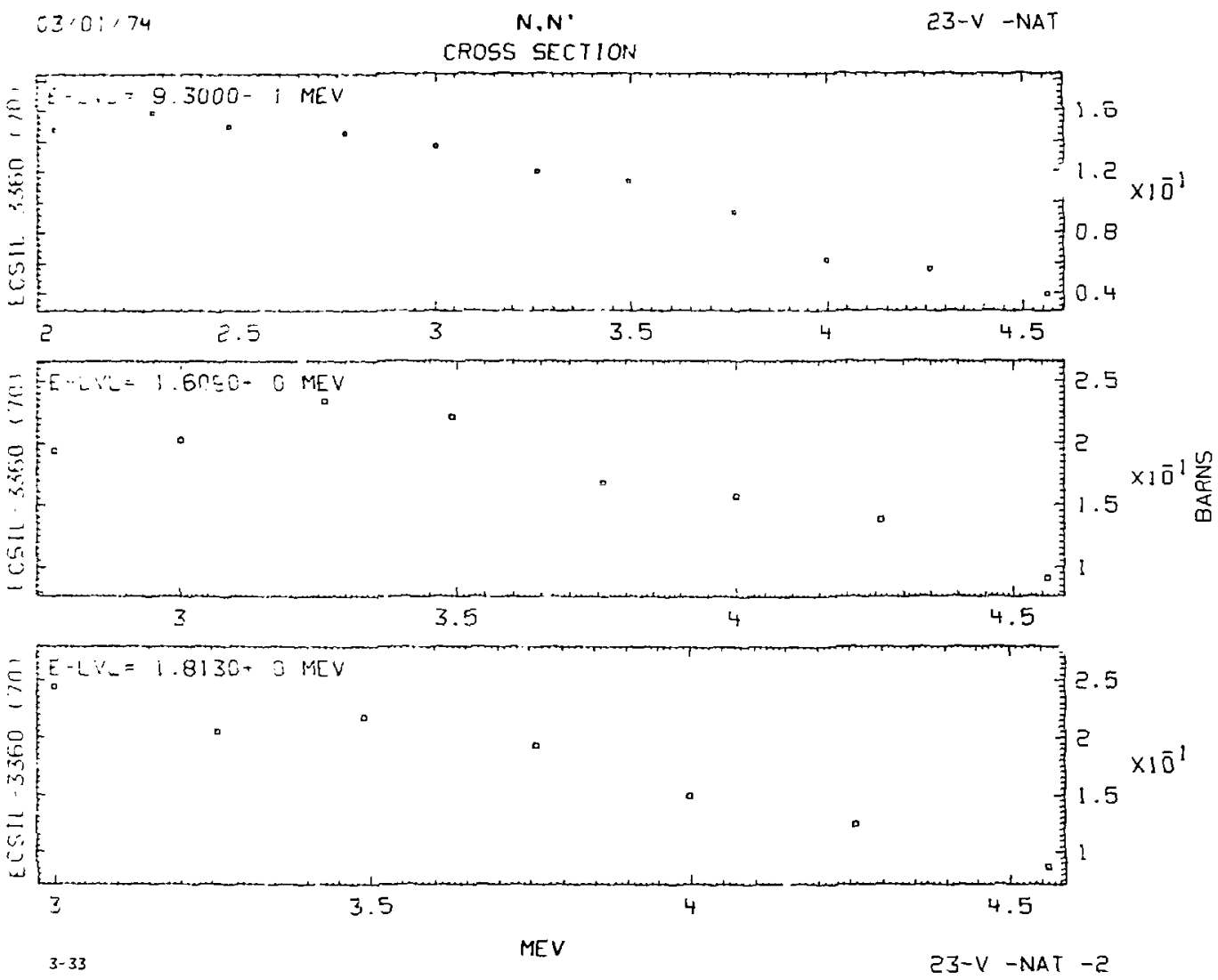


CROSS SECTION
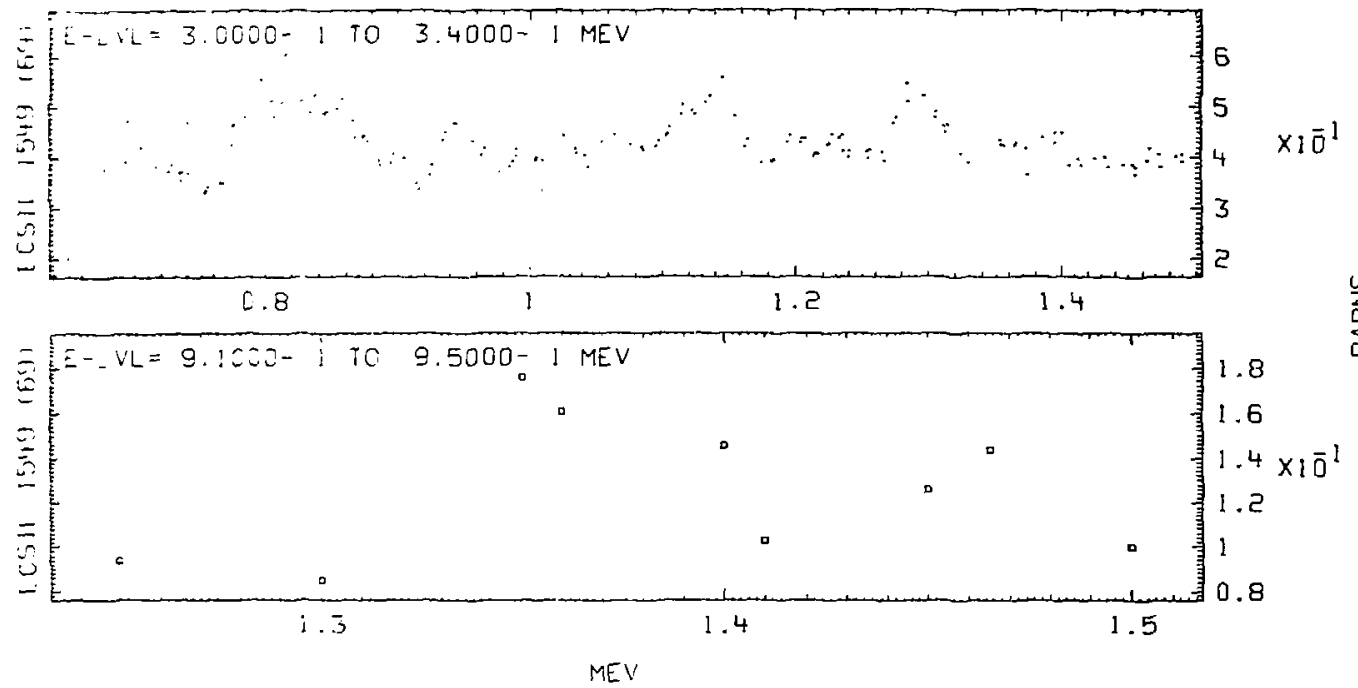

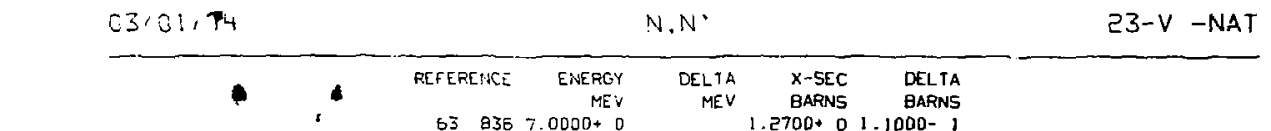

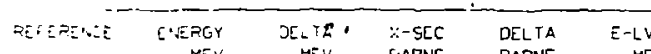

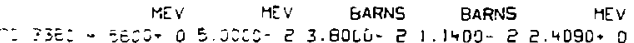

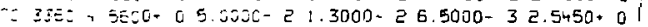
$1.2700+01.1000-$

\begin{tabular}{|c|c|c|c|}
\hline$\varepsilon$ & ENERGY & DELTA & $x-5 E C$ \\
\hline
\end{tabular}
$7033604.5600+05.0000-25.7000-21.7100-22.6750+0$ $7033604.5600+05.0000=25.7000-21.7100-22.6990+0$ 


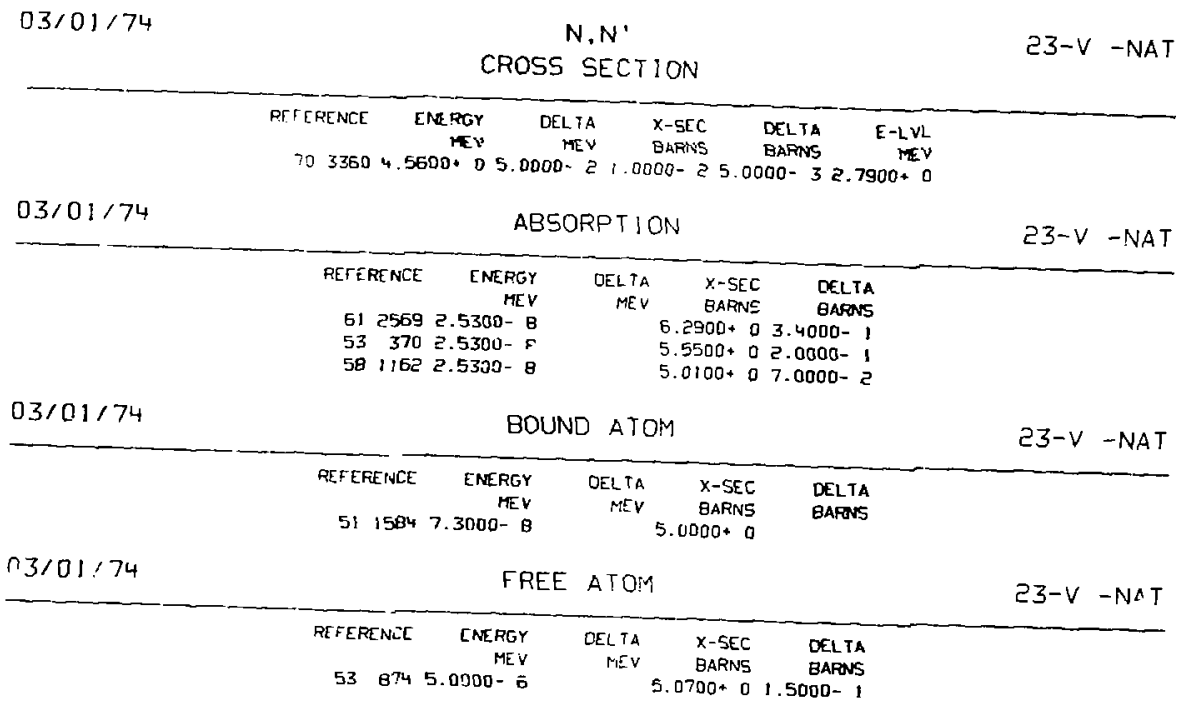



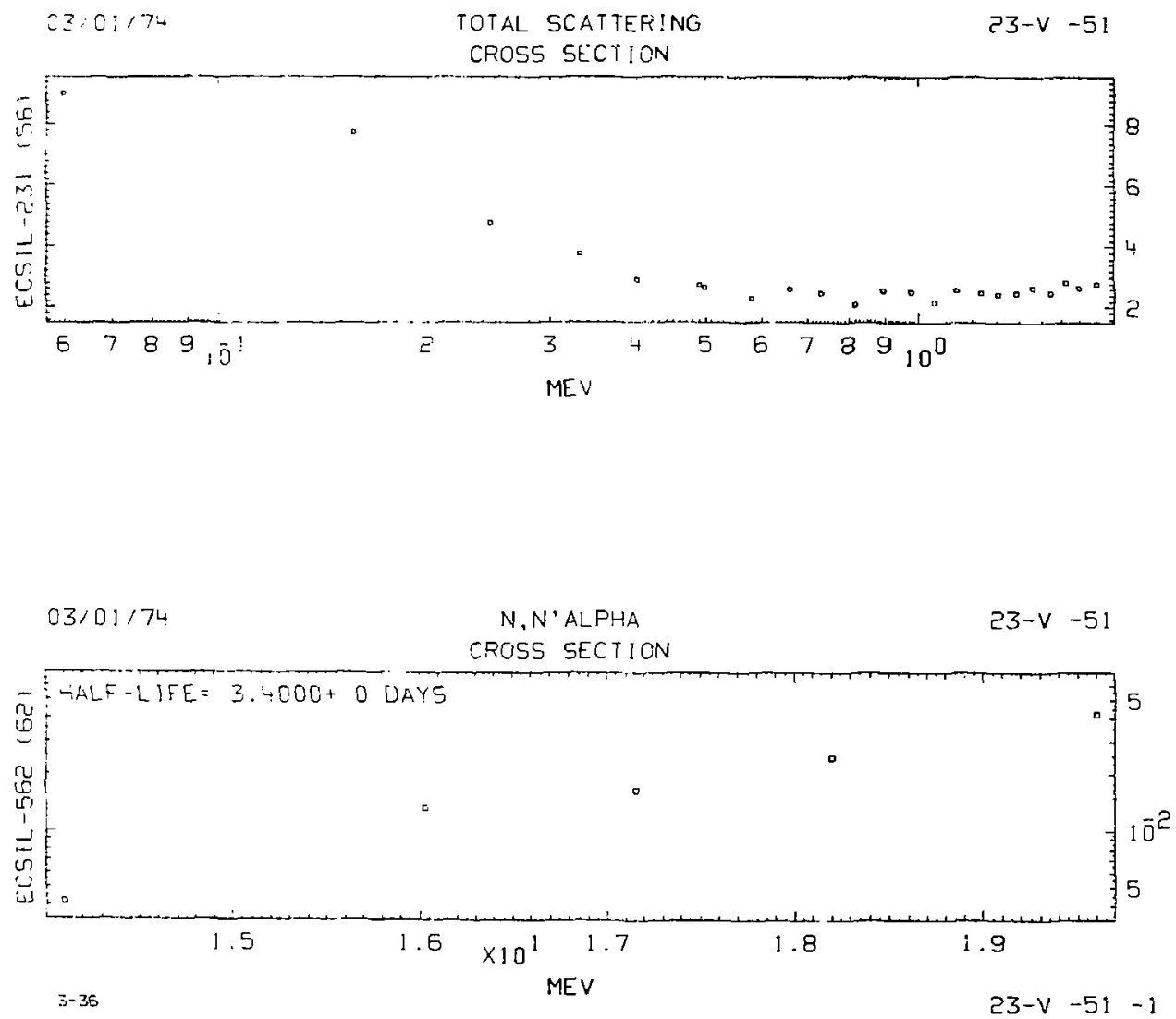

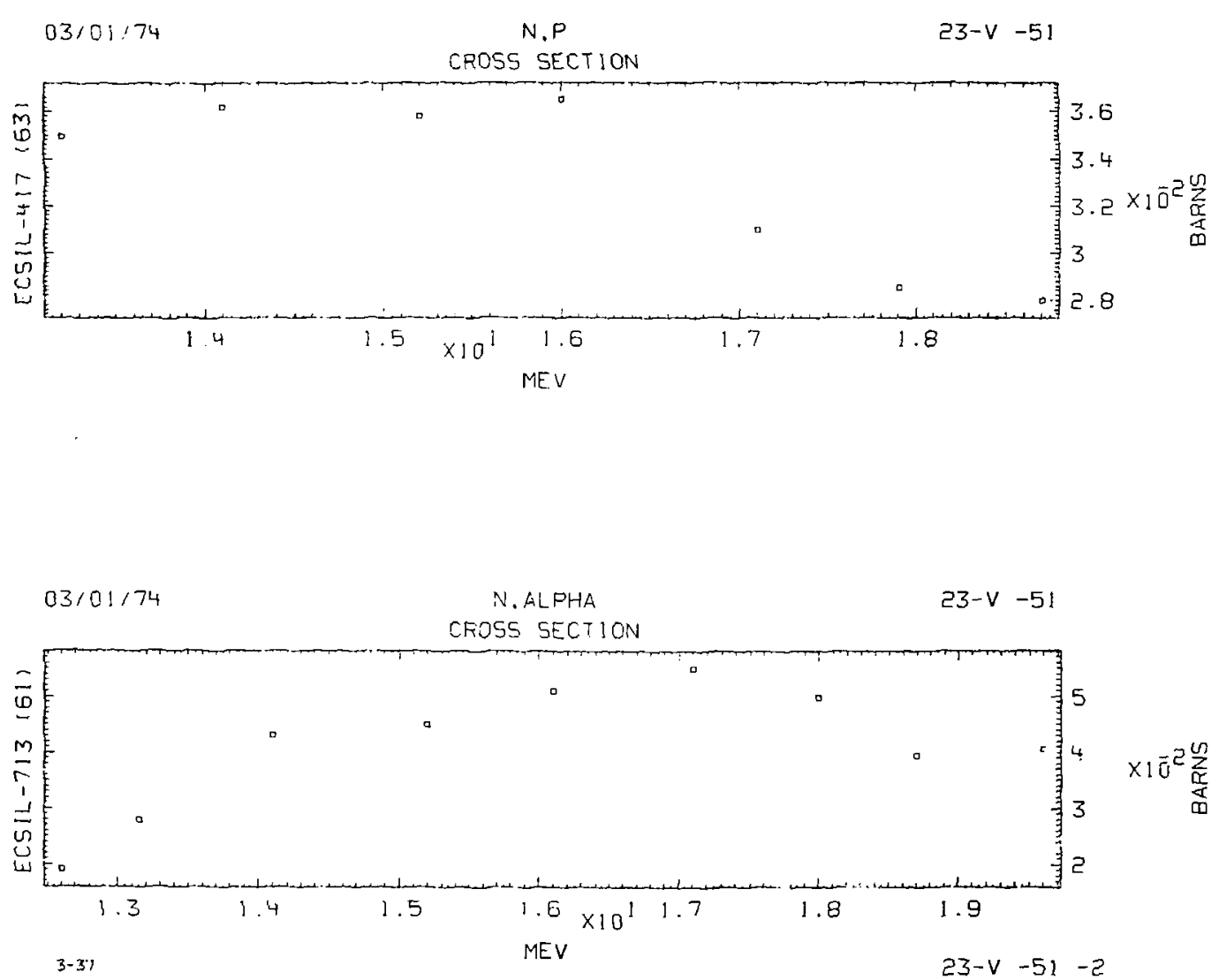


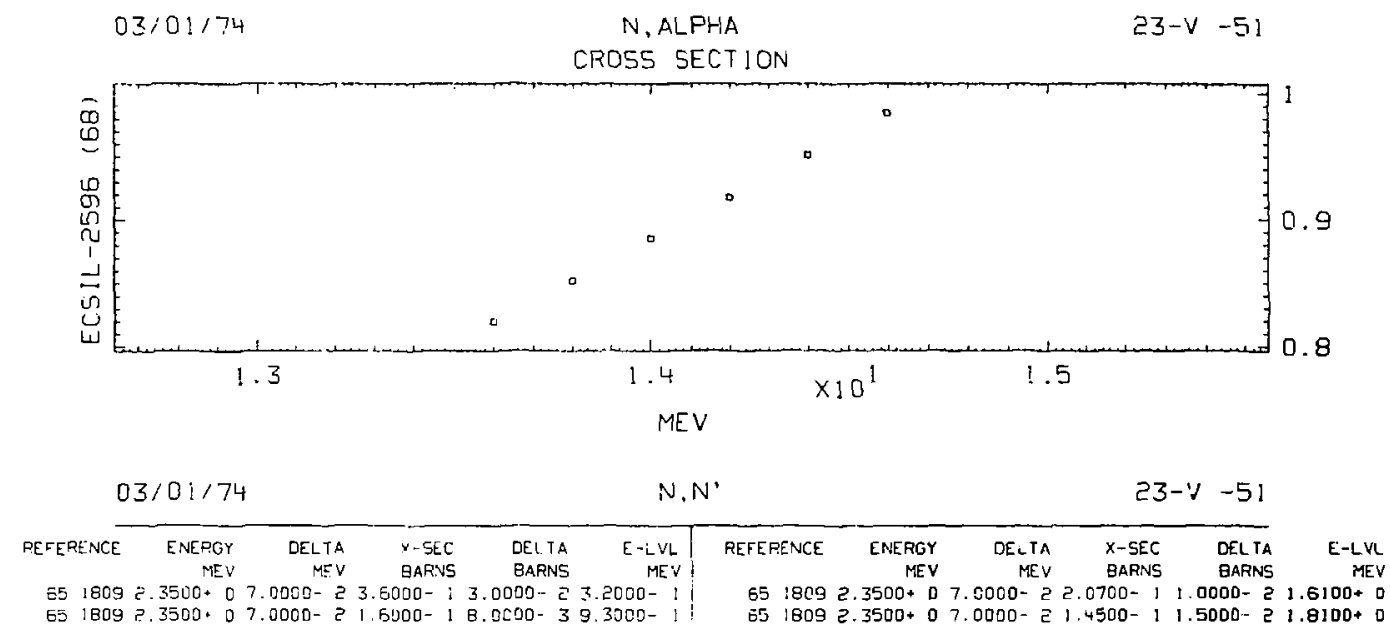

651809 z.3500+ $07.0000-23.6000-i 3.0000-23.2000-1 \quad 6518092.3500+07.6000-22.0700-11.0000-21.6100+0$ 651809 ?.3500+0 $7.0000-21.5000-1$ B.0500- $39.3000-1$ (1) $18092.3500+07.0000-21.4500-11.5000-21.8100+0$

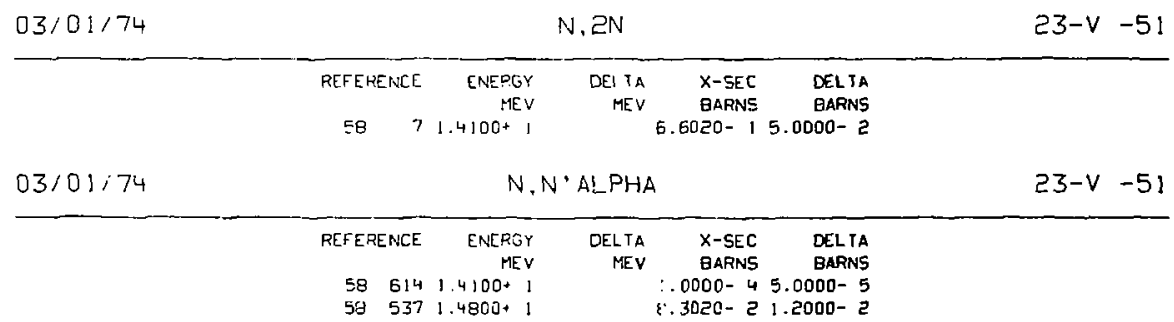

$3-3 B$ 
CROES SECTION

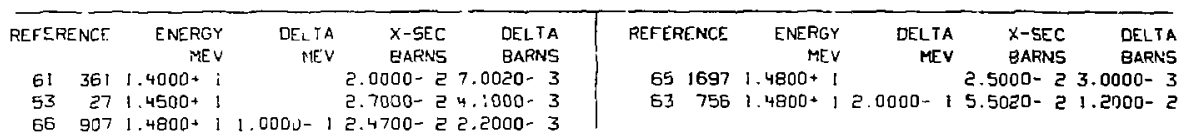

-

60667 1.4800+ | 9.0020- $18.0020-4$

\begin{tabular}{|c|c|c|c|c|c|c|c|c|c|c|}
\hline 031 & 011 & 74 & & & $N, A$ & & & & 23 & $3-V-5 i$ \\
\hline REFEF & ENCE & ENERGY & OELTA & $x-$ stc & DELTA & REFERENCE & ENERGY & DELTA & $x-$ SEC & OELTA \\
\hline & & MEV & MEV $V$ & SARNS & BARNS & & ME & MEV & BARNS & BARNS \\
\hline 58 & 614 & $1.4100+1$ & & 1. $3500-2$ & $1.4000-3$ & $68\ulcorner 596$ & $1.4700+1$ & $7.5000-2$ & $1.6400-2$ & 6.0000-4 \\
\hline 62 & 840 & $1.4500 * 1$ & $5.0000-1$ & $1.8000-2$ & $3.6000-3$ & 53756 & $1.4800+1$ & $2.0000-1$ & $2.3000-2$ & $4.0000-3$ \\
\hline 53 & 27 & $1.4500+1$ & & $=.8600-2$ & $1.2000-2$ & $58 \quad 537$ & $1.4900+1$ & & $4.3000=2$ & $6.0020-3$ \\
\hline
\end{tabular}

$03 / 01.74 \quad$ NONELASTIC
CROSS CECTION

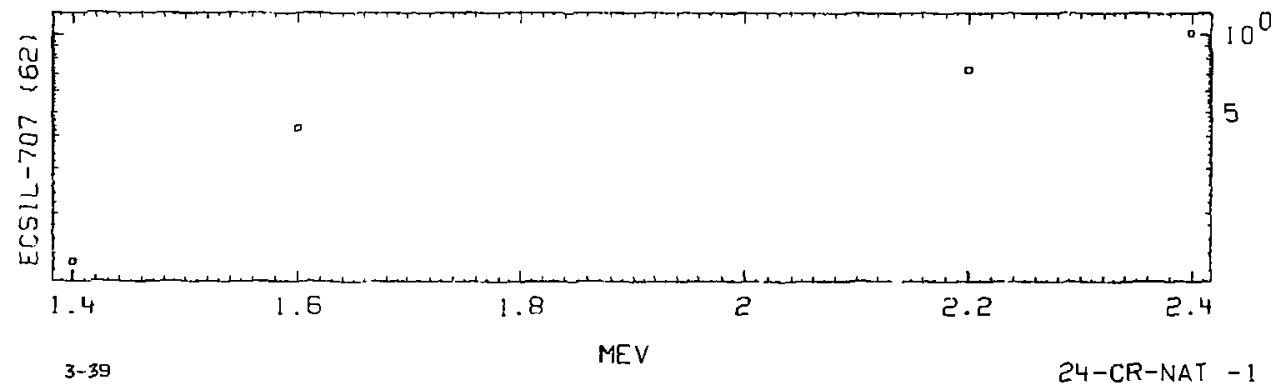




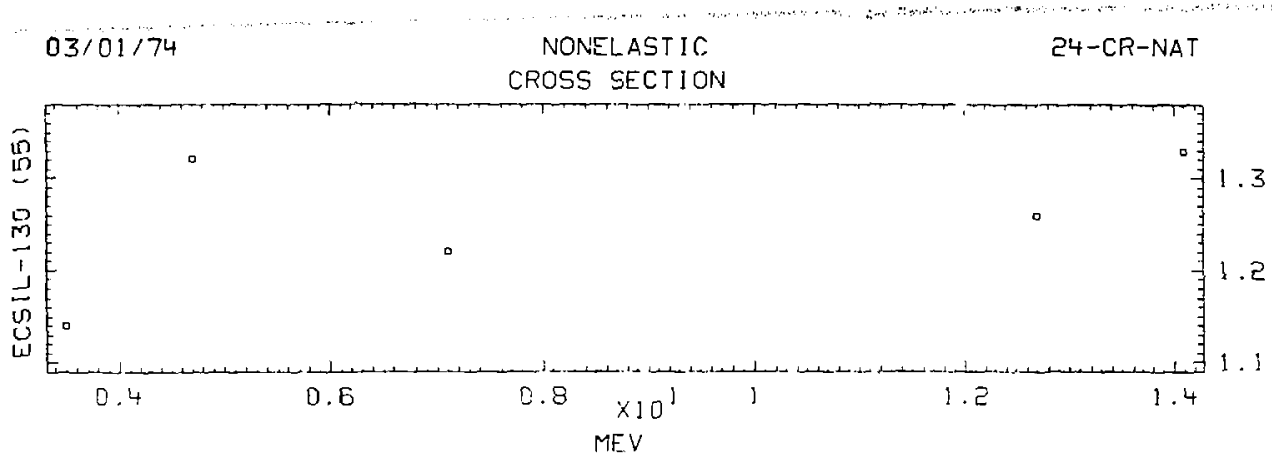

CROSS SECTION

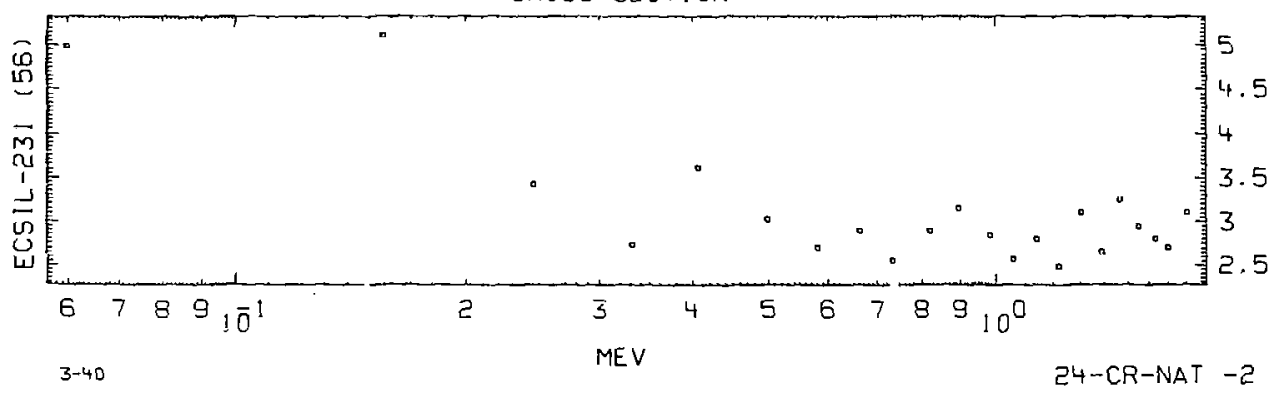



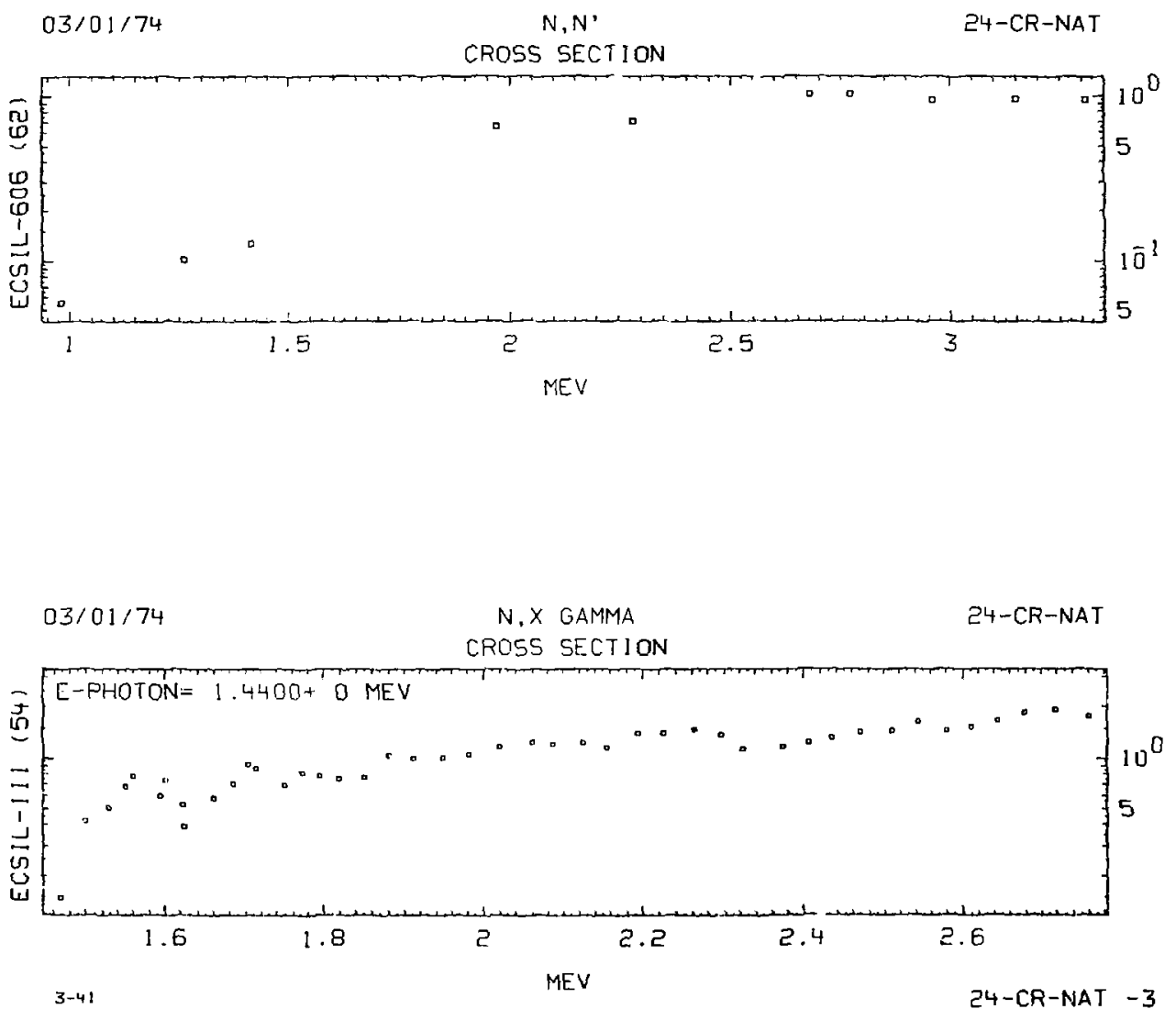


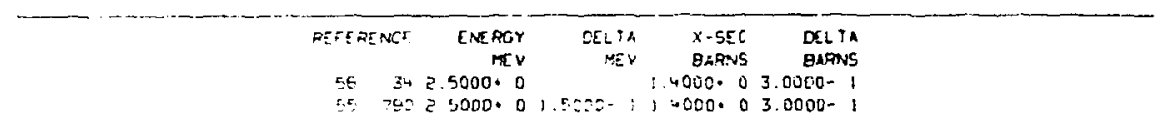

$03 / 01 / 74$

TOIAL SEATTEP!NG

$24-C R-N A T$

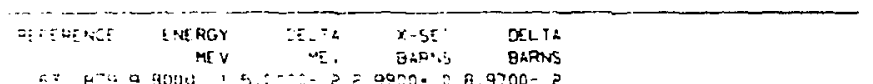

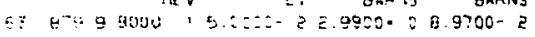

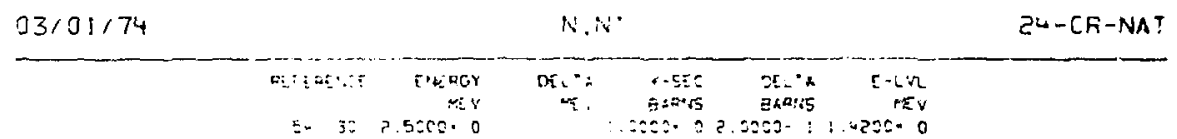

\begin{tabular}{|c|c|}
\hline $33 /[1 / 74$ & $A B S C=-: C \because$ \\
\hline
\end{tabular}

\begin{tabular}{|c|c|c|c|c|c|c|c|c|c|}
\hline$=E S E D F N C E$ & $\begin{array}{l}\text { EIERE: } \\
\text { पI: }\end{array}$ & $0:=$ & $\begin{array}{l}\text { yes } \\
\text { joives }\end{array}$ & $\begin{array}{l}\text { OE: TA } \\
\text { BAParS }\end{array}$ & AETEREST & 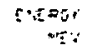 & $25: 11$ & $\begin{array}{l}x-5 \leq 6 \\
920-5\end{array}$ & $\begin{array}{l}\text { DLI:A } \\
\text { aAows }\end{array}$ \\
\hline
\end{tabular}

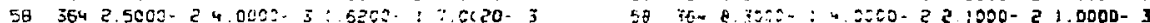

$33 / 01 / 74 \quad N \times$ OAM $24-C R-N A T$

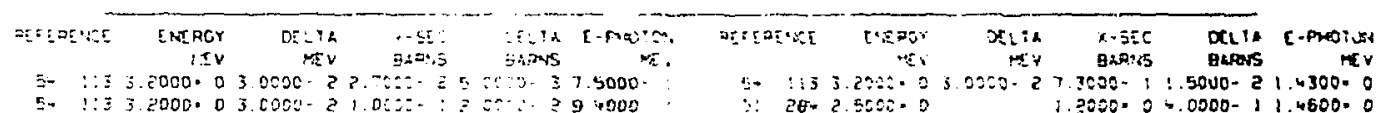




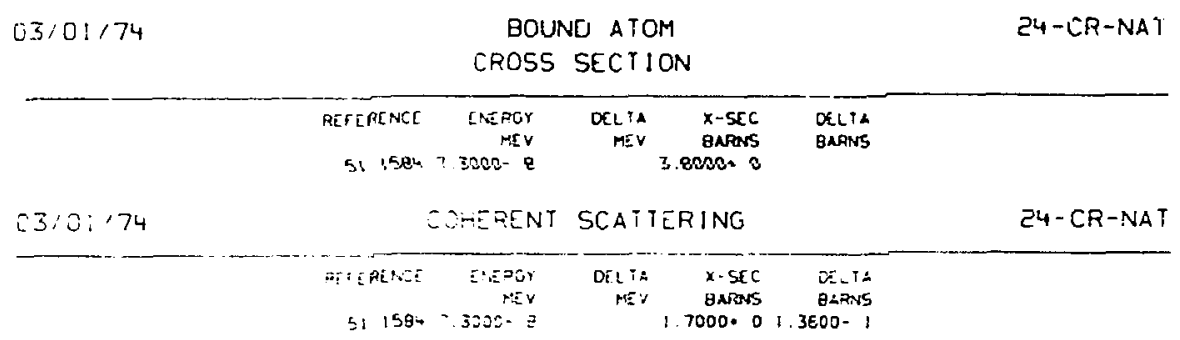

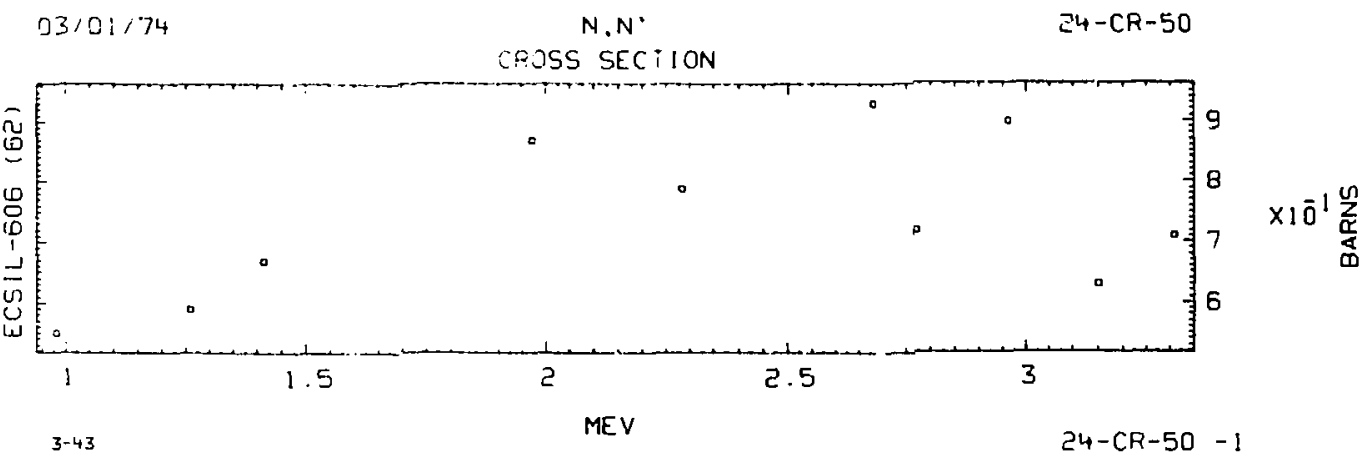




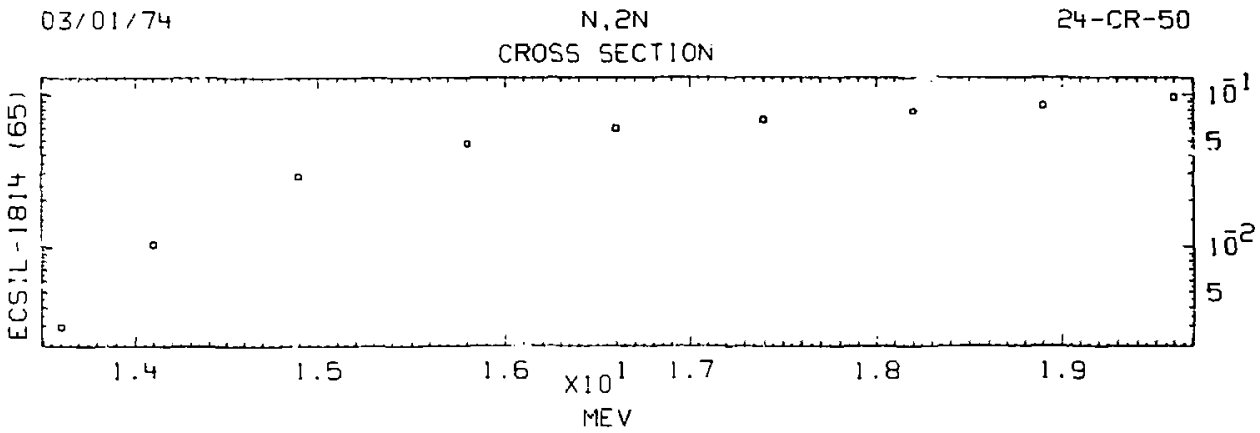

\begin{tabular}{|c|c|c|c|c|c|c|c|c|c|}
\hline \multicolumn{2}{|c|}{$03 / 01 / 74$} & \multicolumn{6}{|c|}{$N, Z N$} & \multicolumn{2}{|c|}{$24-C R-50$} \\
\hline PEEFERENCE & $\begin{array}{l}\text { ENERGY } \\
\text { MEY }\end{array}$ & $\begin{array}{l}\text { DEE TA } \\
\text { MEV }\end{array}$ & $\begin{array}{l}x-5 E S \\
\text { BARNS }\end{array}$ & $\begin{array}{l}\text { EZLTA } \\
\text { BARNS }\end{array}$ & PerrepENCE & $\begin{array}{r}\text { ENERGY } \\
\text { MEV }\end{array}$ & $\begin{array}{r}\text { DELTA } \\
\text { MEV }\end{array}$ & $\begin{array}{l}x-S E C \\
\text { BARNS }\end{array}$ & $\begin{array}{l}\text { DELTA } \\
\text { BARNS }\end{array}$ \\
\hline E! $\quad$ EาE & $1.4400+1$ & $3.0063-1$ & $\overrightarrow{2} .5400-\vec{c} a$ & $2.2000-3$ & E! 703 & $4800+1$ & $2.5000-1$ & $2.7000-2$ & $7.0020-3$ \\
\hline 61731 & $1,-600+1$ & & $1.0800-2$ & : $9000-3$ & Bi & $1.4800 \cdot 1$ & & $3.2000-2$ & $3.0000-3$ \\
\hline
\end{tabular}

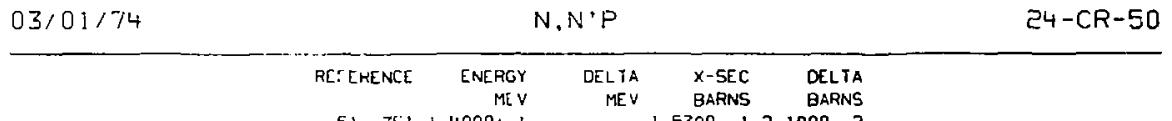

$613611.4000+1 \quad 1.5300-12.1000-2$

$03 / 01 / 74$

$N, P$

$24-C R-50$

$\begin{array}{rrrrr}\text { REFERENCE } & \text { ENEROY } & \text { DELTA } & \text { X-SEC } & \text { DELTA } \\ \text { MCV } & \text { MEV } & \text { BARNS } & \text { BAFINS } \\ \text { EI 361 } 1.4000+1 & & 2.6500-1 & 12.1000-2\end{array}$



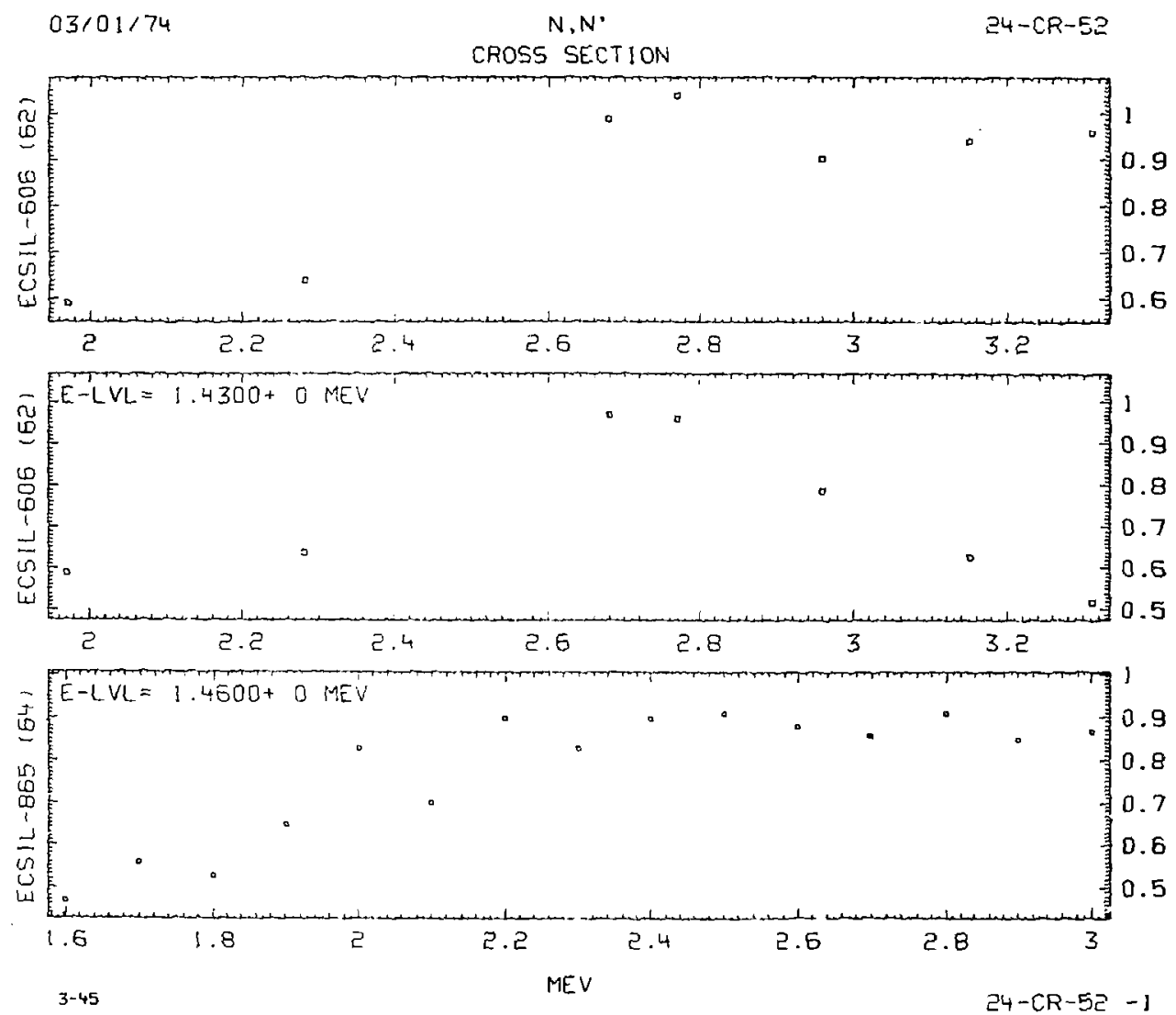


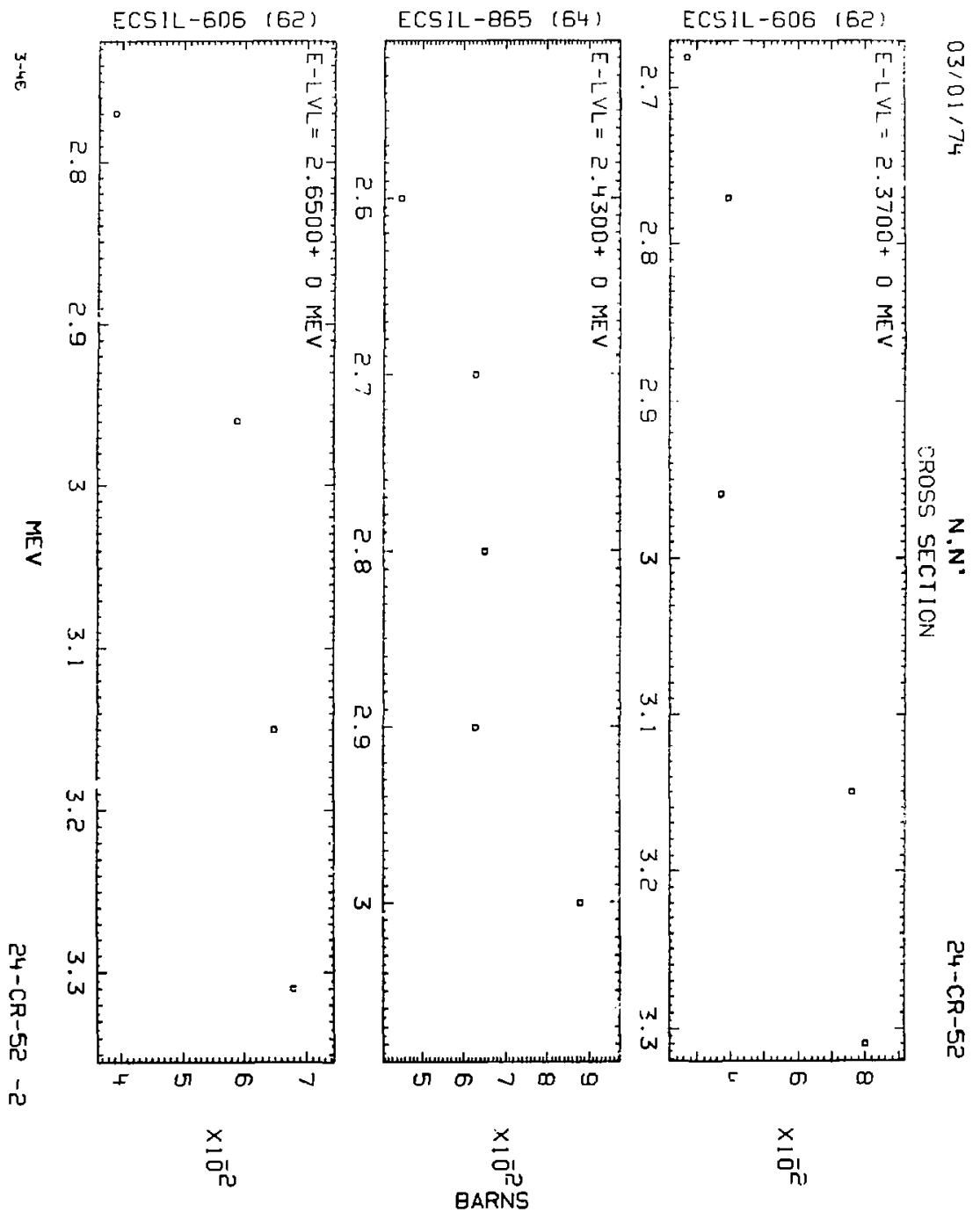




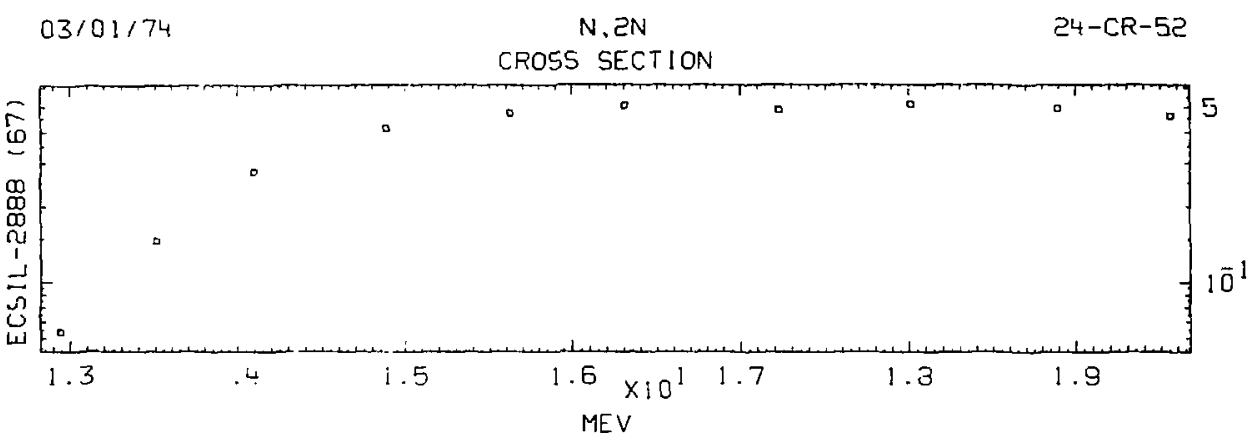

$03 / 01 / 74$

N.P

$24-C R-52$ CROSS SECTION

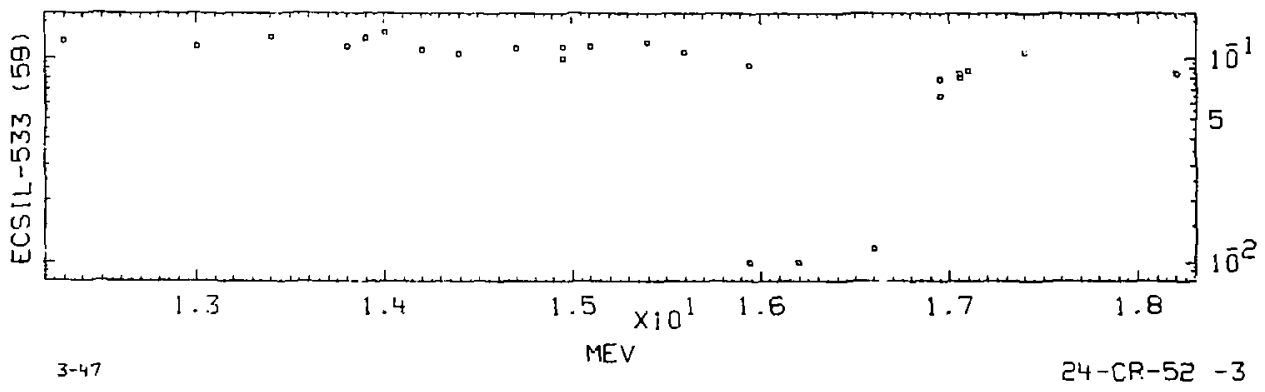




\section{CROSS SECTION}

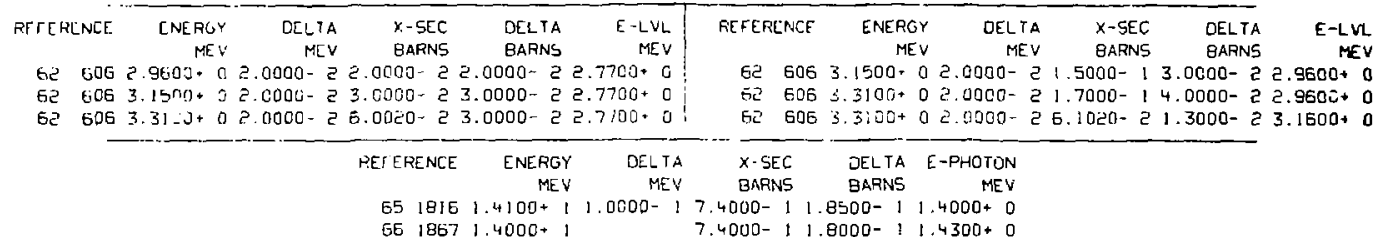

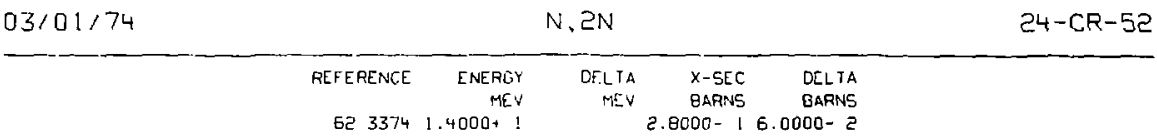

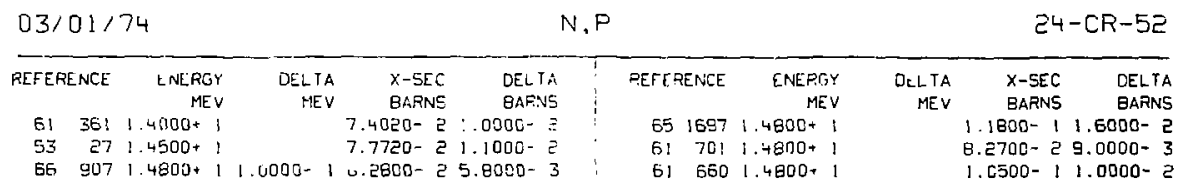


CROSE SECTION
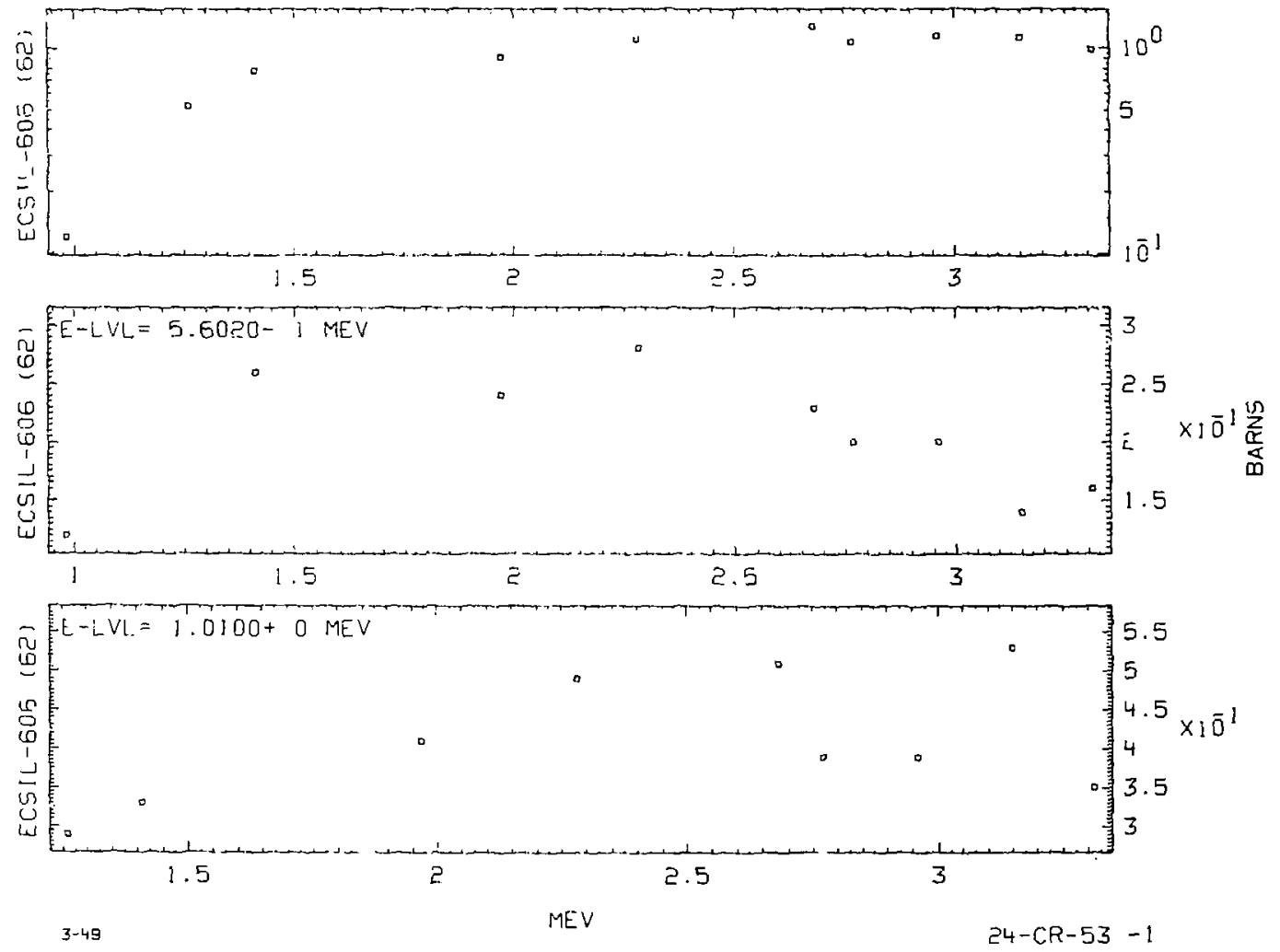

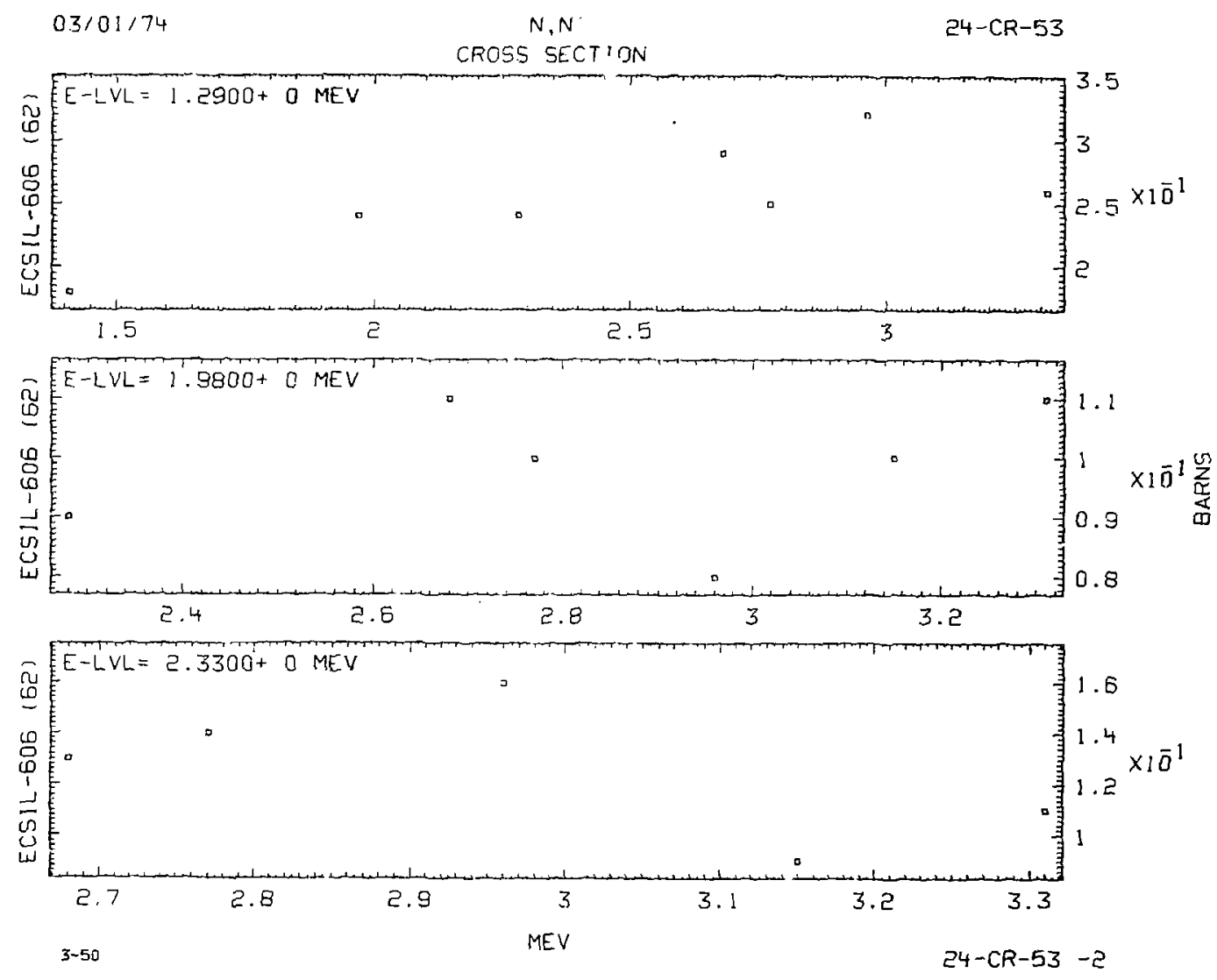
$03101 / 74$
CROSS SECTION

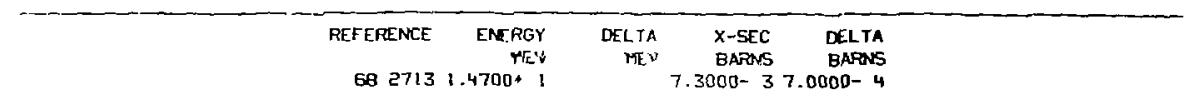

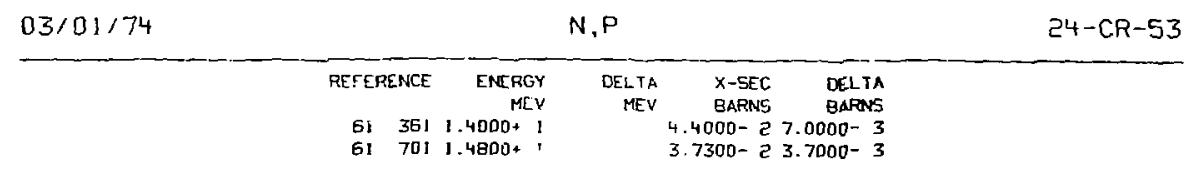

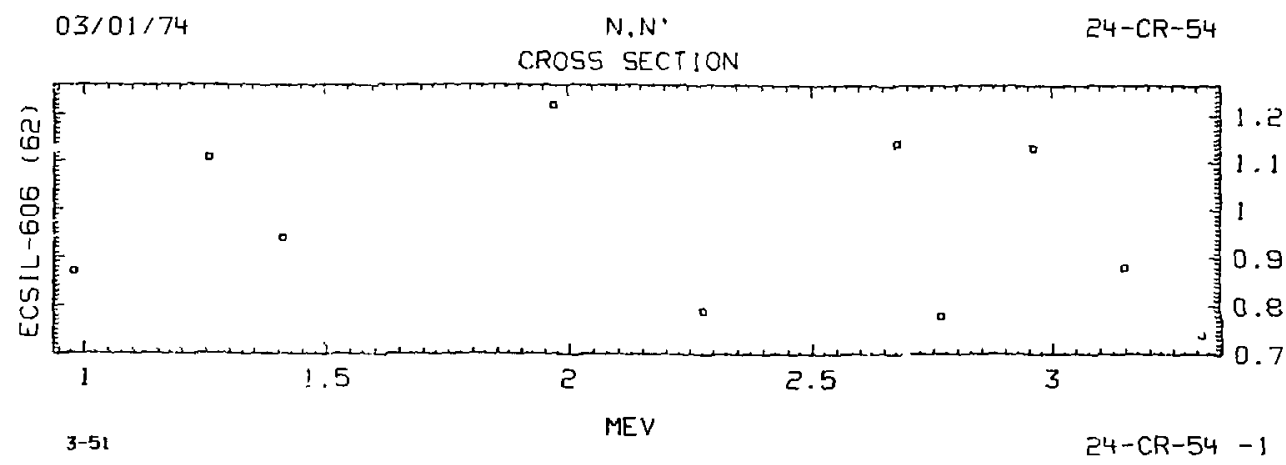




\section{CROSS SECTION}

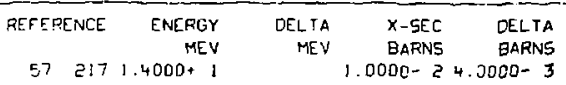
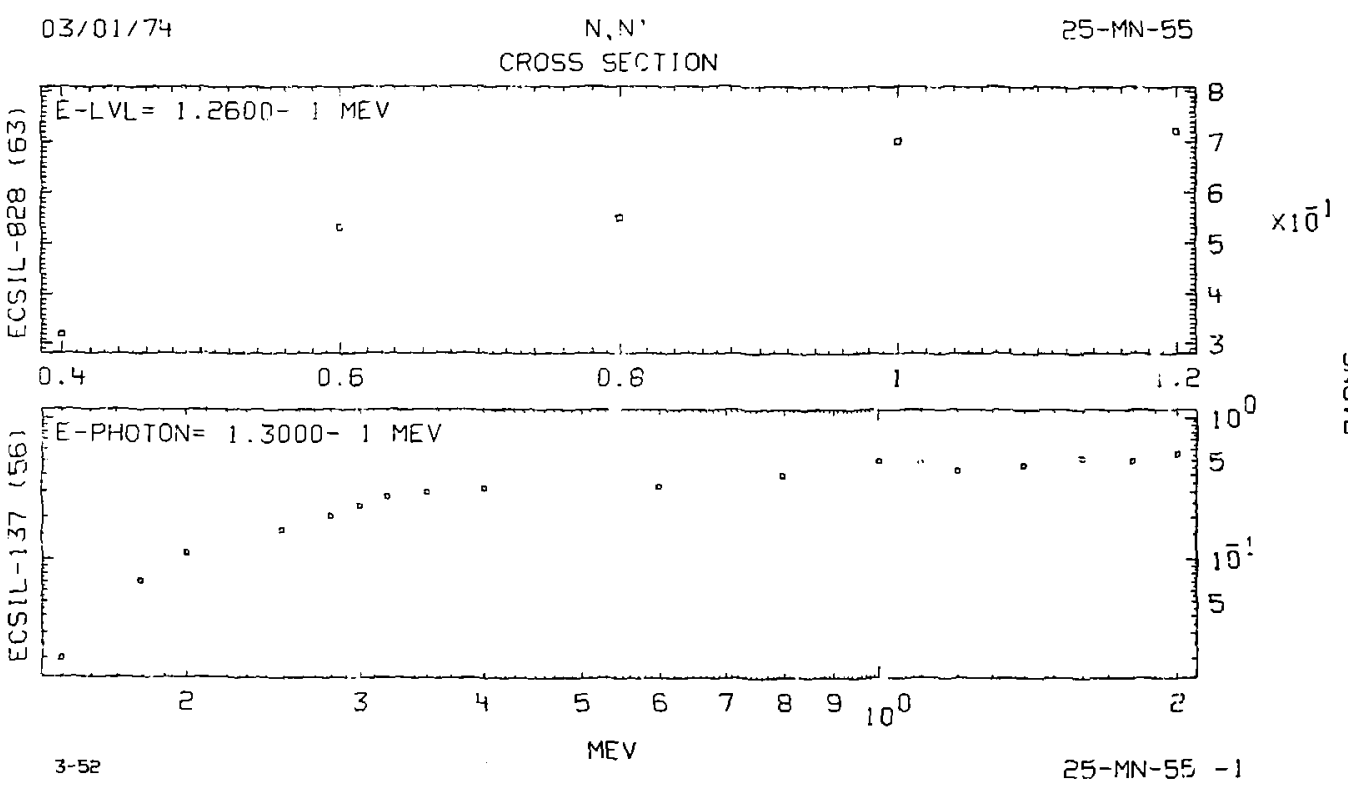


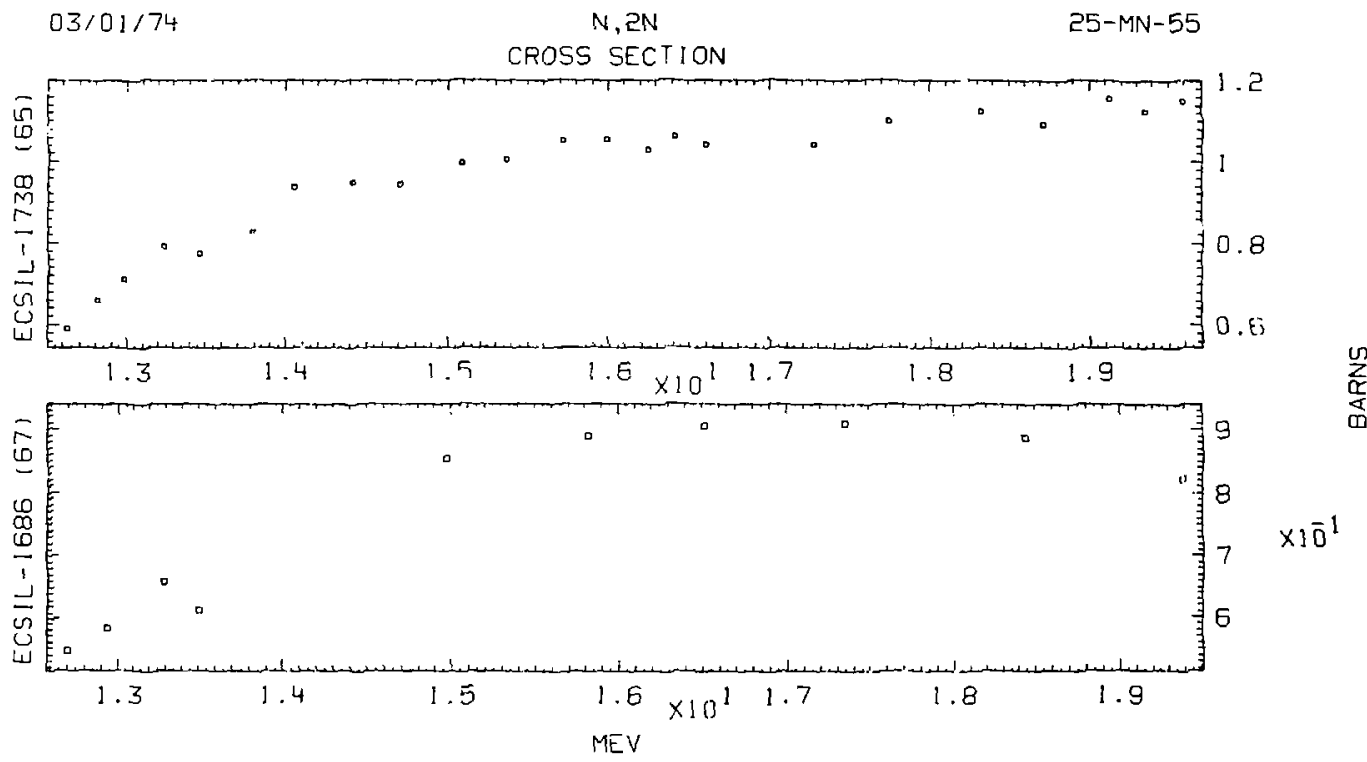



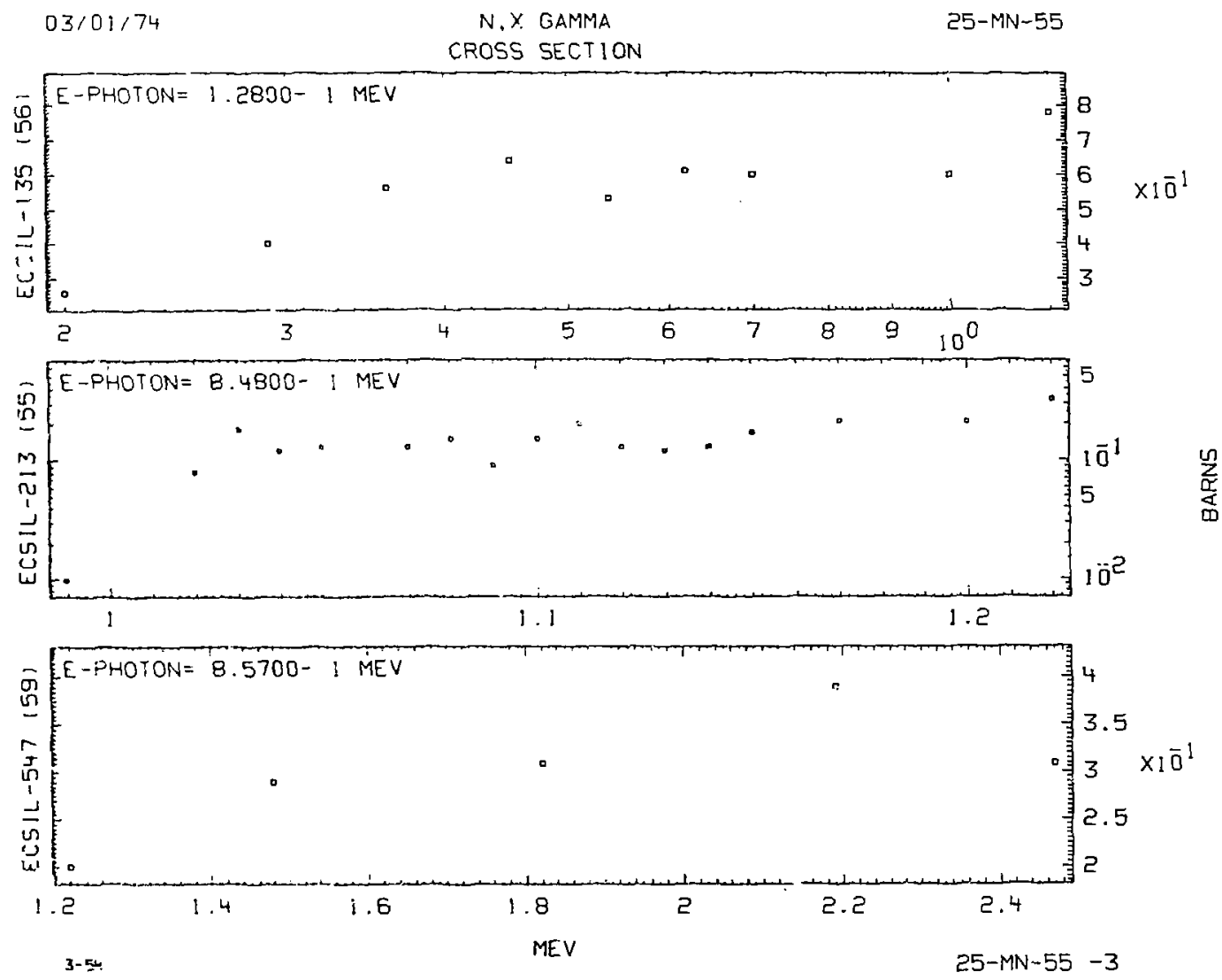

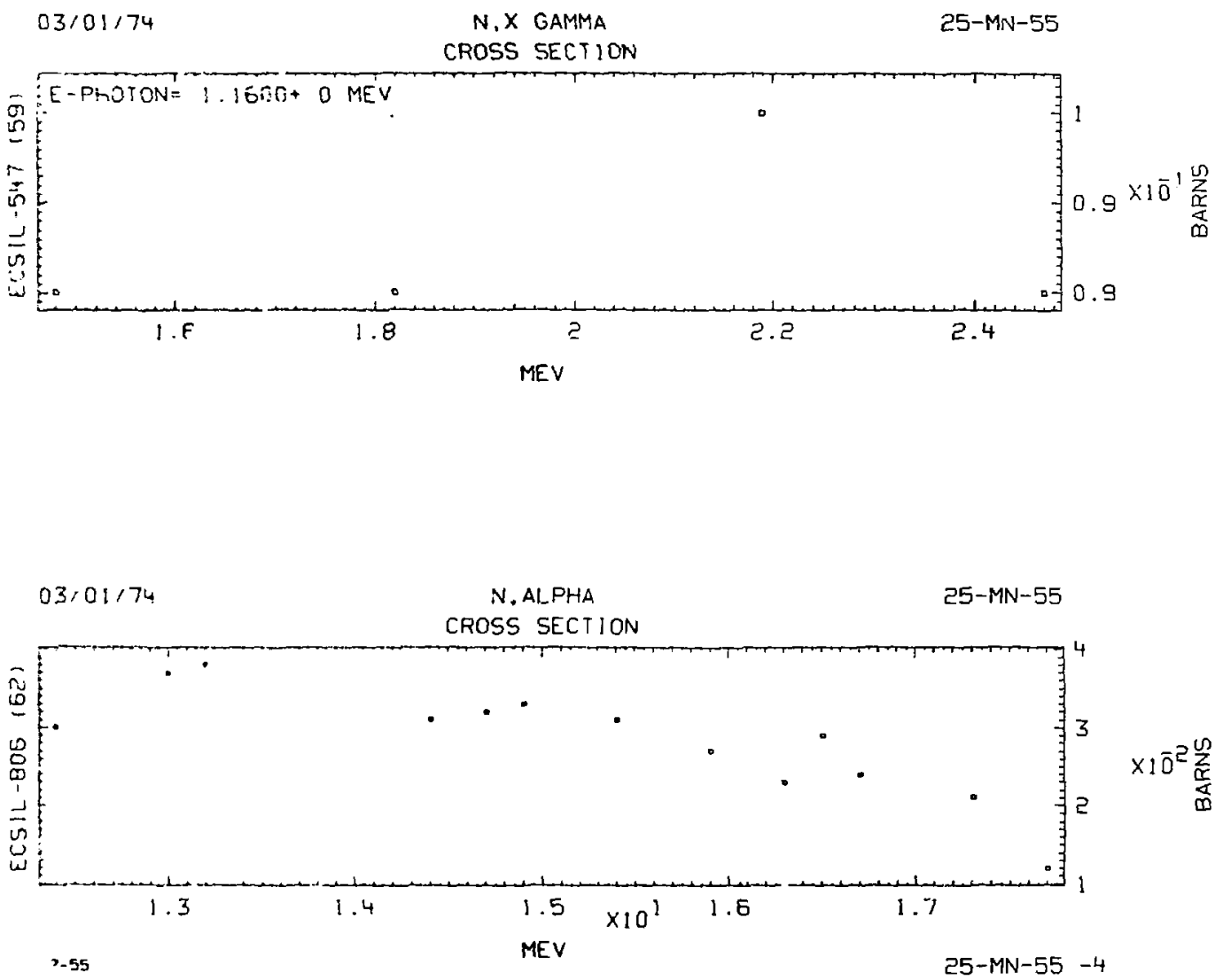


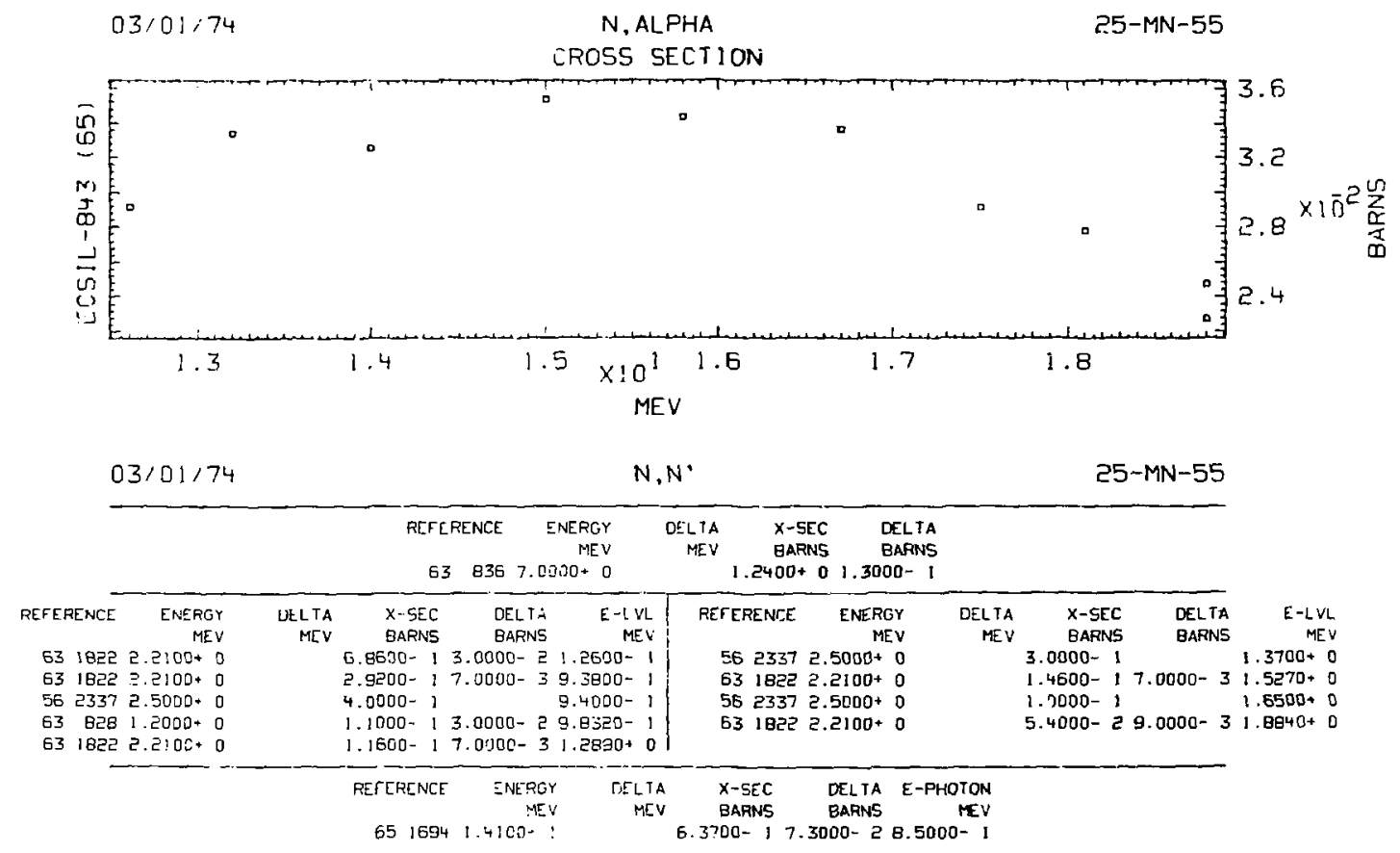


CROSS SECTION

\begin{tabular}{|c|c|c|c|c|c|c|c|c|c|}
\hline REFERENCE & $\begin{array}{r}\text { ENERGY } \\
\text { MEV }\end{array}$ & $\begin{array}{r}\text { DELTA } \\
\text { MEV }\end{array}$ & $\begin{array}{l}X \text {-SEC } \\
\text { BARNS }\end{array}$ & $\begin{array}{l}\text { DELIA } \\
\text { BARNS }\end{array}$ & RETERLNCE & $\begin{array}{r}\text { ENERGY } \\
\text { MEV }\end{array}$ & $\begin{array}{l}\text { OELTA } \\
\text { MEV }\end{array}$ & $\begin{array}{l}X \text {-SEC } \\
\text { GARNS }\end{array}$ & $\begin{array}{l}\text { DELTA } \\
\text { BARTSS }\end{array}$ \\
\hline 672009 & $1.3400+1$ & & $7.5000-1$ & $1.1250-1$ & $60 \quad 629$ & $1.4500+1$ & $15.0000-1$ & 1 8.2520- 1 & $1.8500-1$ \\
\hline $63 \quad 377$ & $1.4000+1$ & & $1.3100+0$ & $3.2750^{-} 1$ & 692354 & $1.4600+1$ & 1 2.0000. I & $17.8500-1$ & $8.0000-2$ \\
\hline GD 3374 & $1,4000+1$ & & $5.0000-1$ & $1.2000-1$ & 682711 & $1,4 \mathrm{A00}+1$ & $12.0000-1$ & $17.5000-1$ & $6.0000-2$ \\
\hline $58: \varepsilon z$ ! & $\therefore+100+1$ & & $9.0000-1$ & $7.0000-2$ & & & & & \\
\hline
\end{tabular}

$03 / 01 / 74$

ABSORPT I ON

$25-M N-55$

\begin{tabular}{|c|c|c|c|c|c|}
\hline \multirow{2}{*}{\multicolumn{2}{|c|}{ RETERENCE }} & ENERG & DEL TA & $X$-SEC & DELTA \\
\hline & & $M[V$ & $M \subseteq V$ & BARNS & BARNS \\
\hline ED & 897 & $2.5300-8$ & & $1.3250 \cdot 1$ & $1.5000-1$ \\
\hline 50 & $89 !$ & $2.5300-\theta$ & & $1.3200+1$ & $1.0000-1$ \\
\hline
\end{tabular}

$03 / 01 / 74$

$N, X$ GAMMA

$25-M N-55$

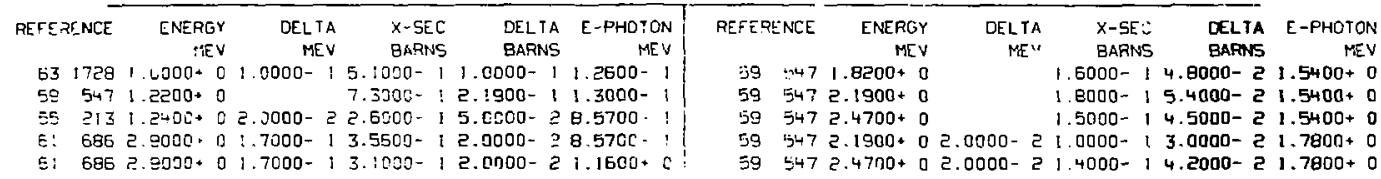

$\begin{array}{rrr}0.3: 5 i / 74 & \end{array}$




\section{CROSS SECTION}

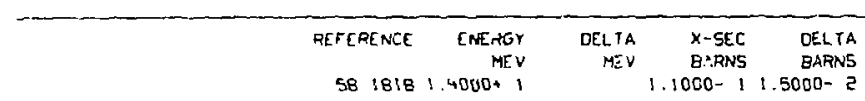

$03 / 01 / 74$

$$
N, 4 E-3
$$

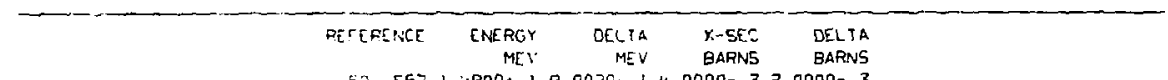

$635571 .+000+19.0020-14.0000-32.0000-3$

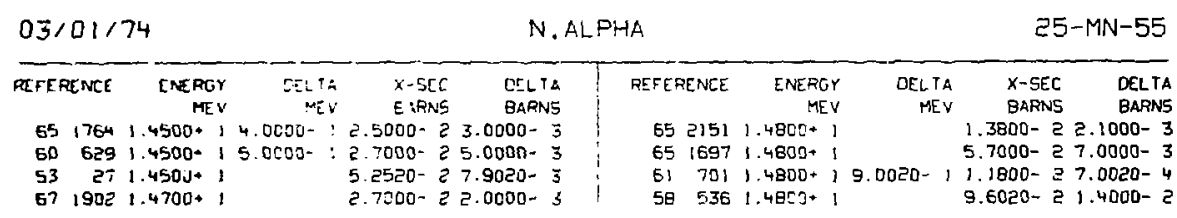

$03 / 01 / 74$ BCIND ATOM 25-MN-55

\begin{tabular}{|c|c|c|c|c|c|}
\hline & $\begin{array}{l}\text { OEFEFENCE } \\
511584\end{array}$ & $\begin{array}{r}\text { ENERGY } \\
\text { MEV } \\
7.3000-8\end{array}$ & $\begin{array}{rr}\text { DELTA } & X \text {-SEC } \\
\text { IVEV } & \text { BARNS } \\
2.2000+0\end{array}$ & $\begin{array}{l}\text { DELTA } \\
\text { BAFNS }\end{array}$ & \\
\hline $03 / 01 / 74$ & & COHERENT & SCATTERING & & $25-M N-55$ \\
\hline & $\begin{array}{l}\text { REFERENCE } \\
51158\end{array}$ & $\begin{array}{r}\text { ENEFGY } \\
\text { MEV } \\
-.3000-8\end{array}$ & $\begin{array}{rr}\text { DELTA } & x-S E C \\
\text { MEV } & \text { BARNS } \\
& 1.3500+0\end{array}$ & $\begin{array}{l}\text { DELTA } \\
\text { BARNS } \\
\text { BDO- ! }\end{array}$ & \\
\hline
\end{tabular}




\section{SNAVG}

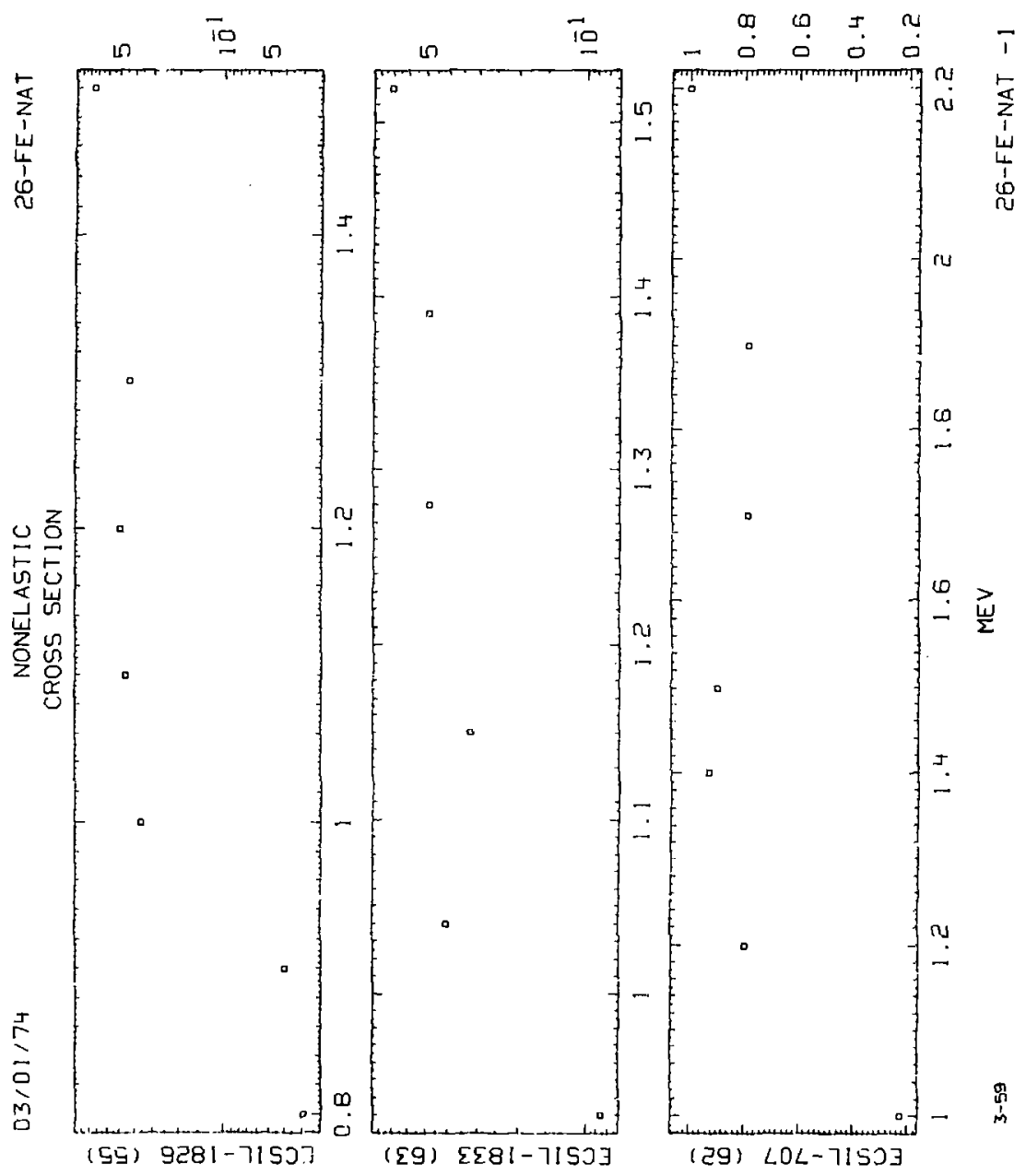




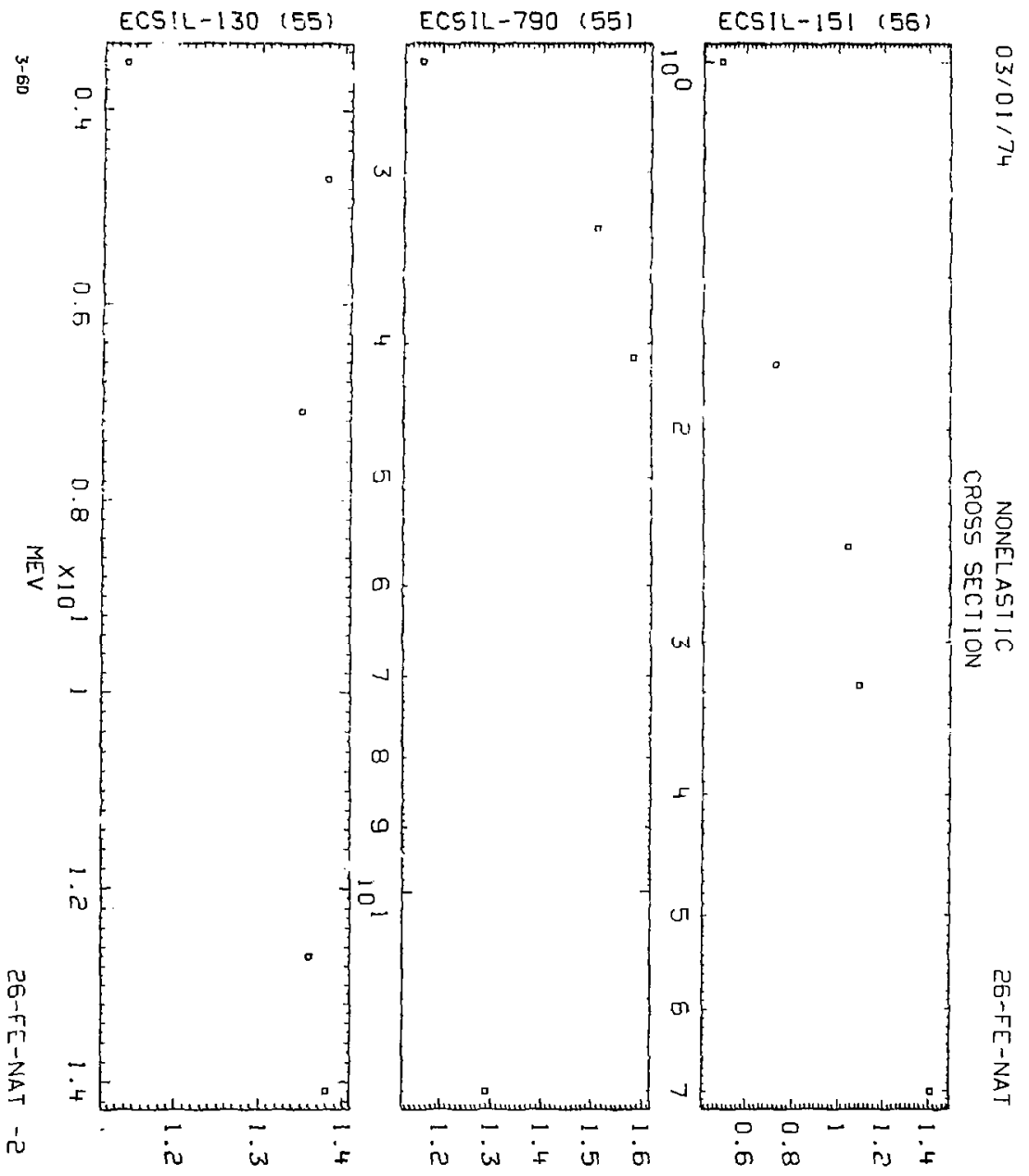

BARNS 


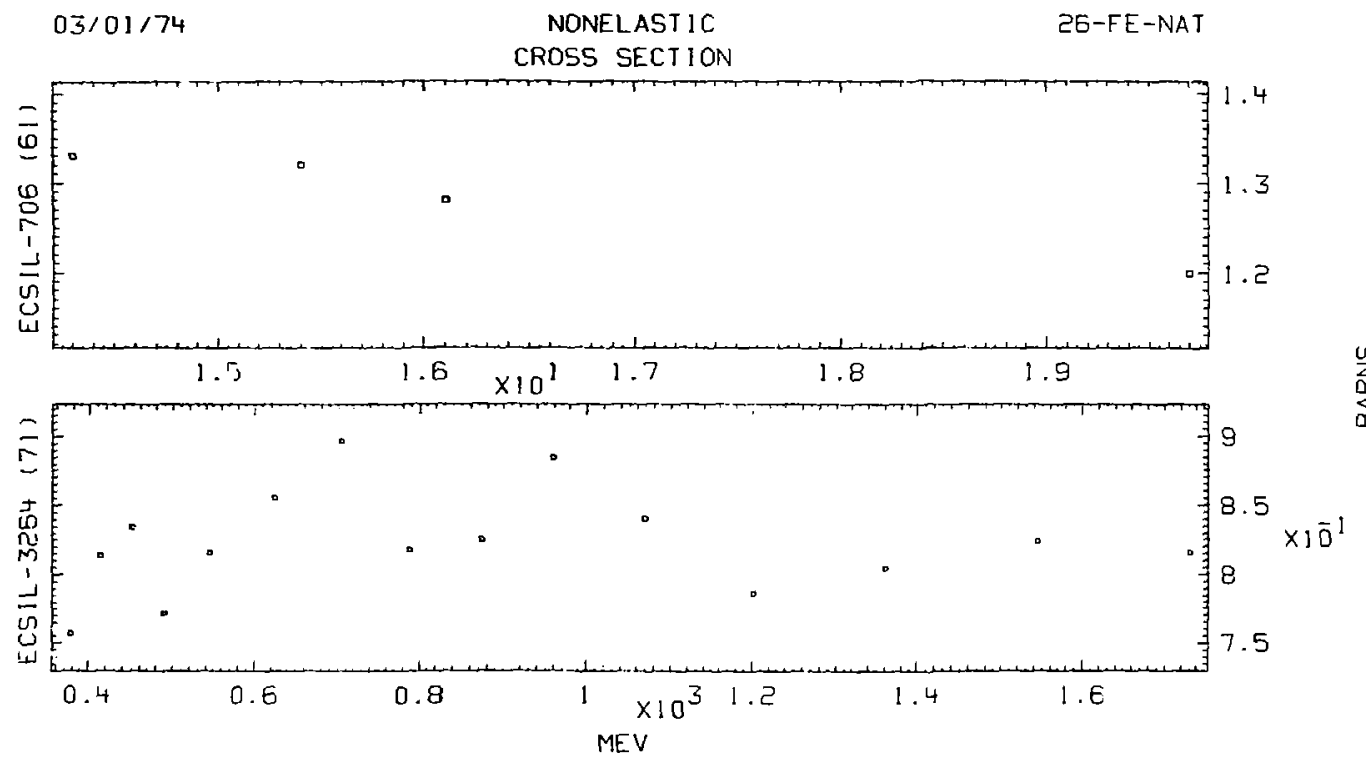

$\frac{n}{\frac{n}{a}}$ 

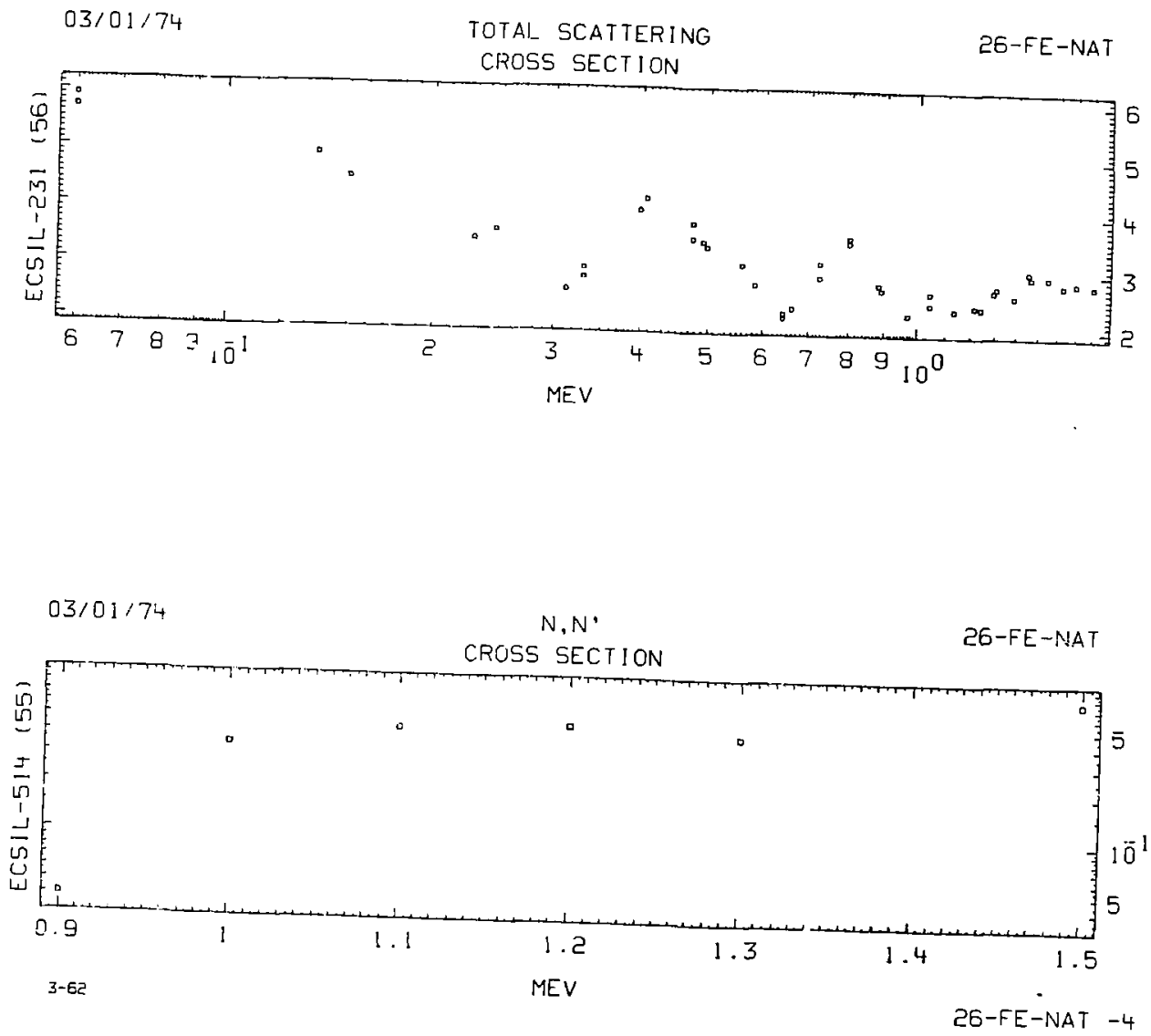

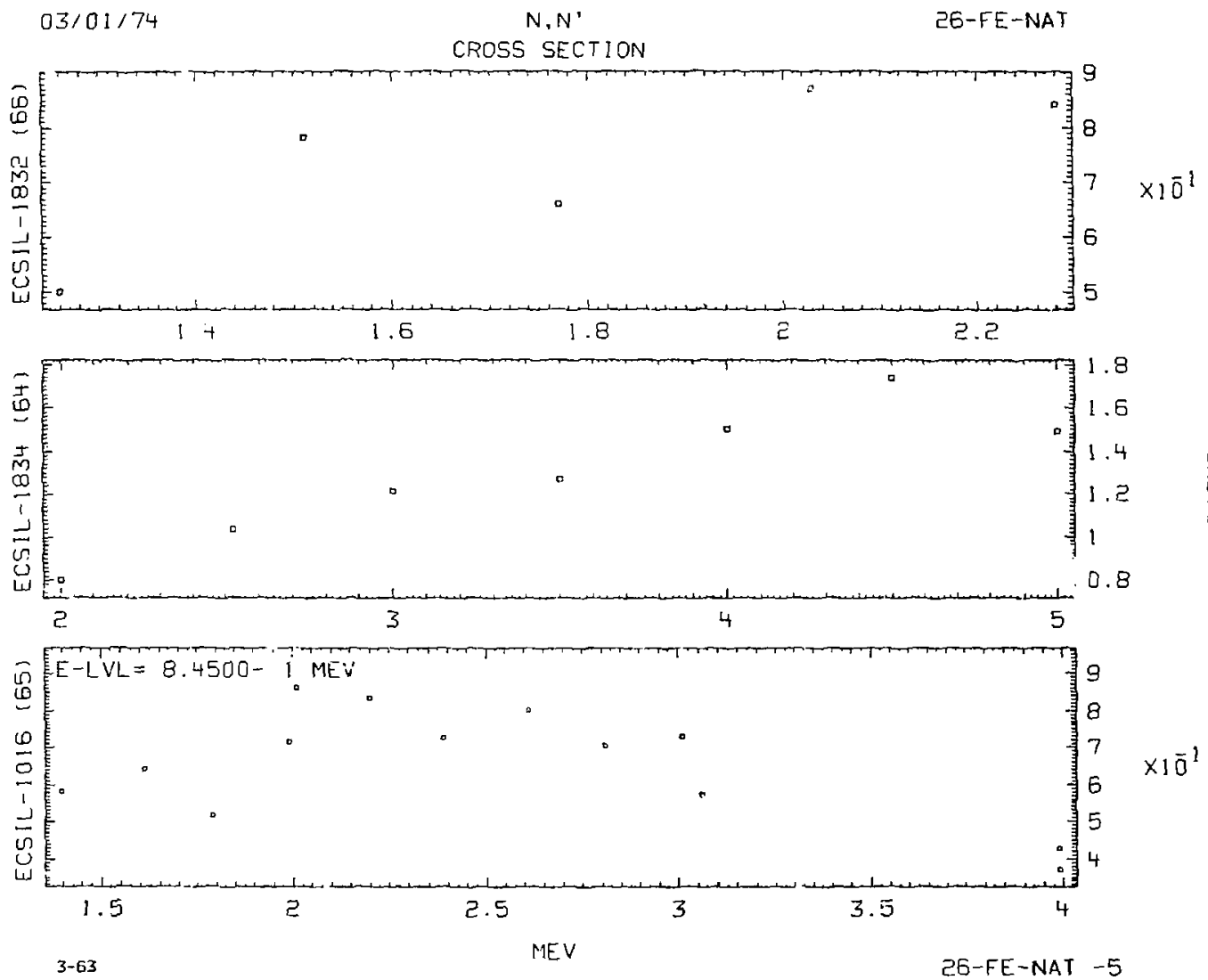


\section{CROSS SECTION}
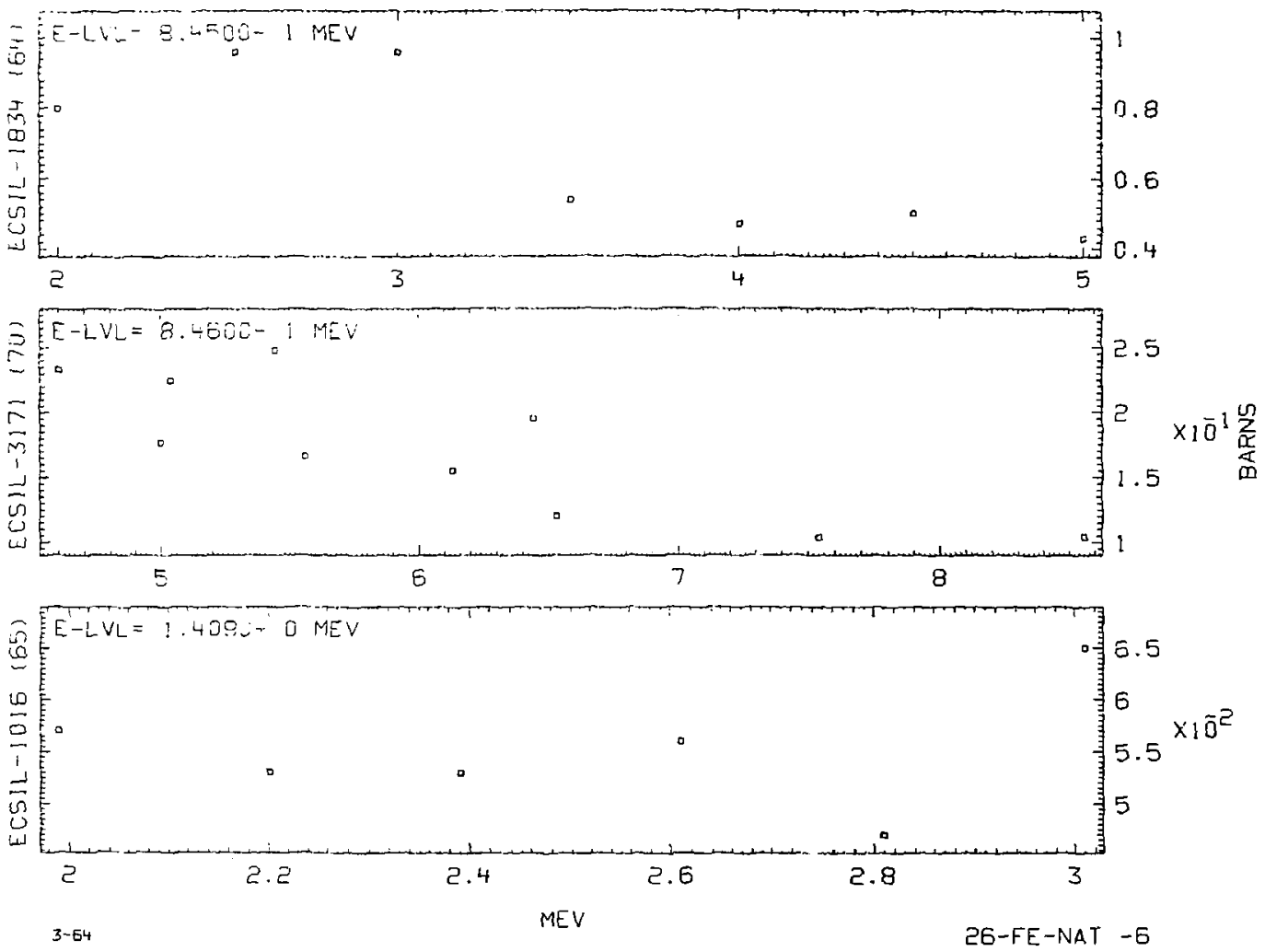

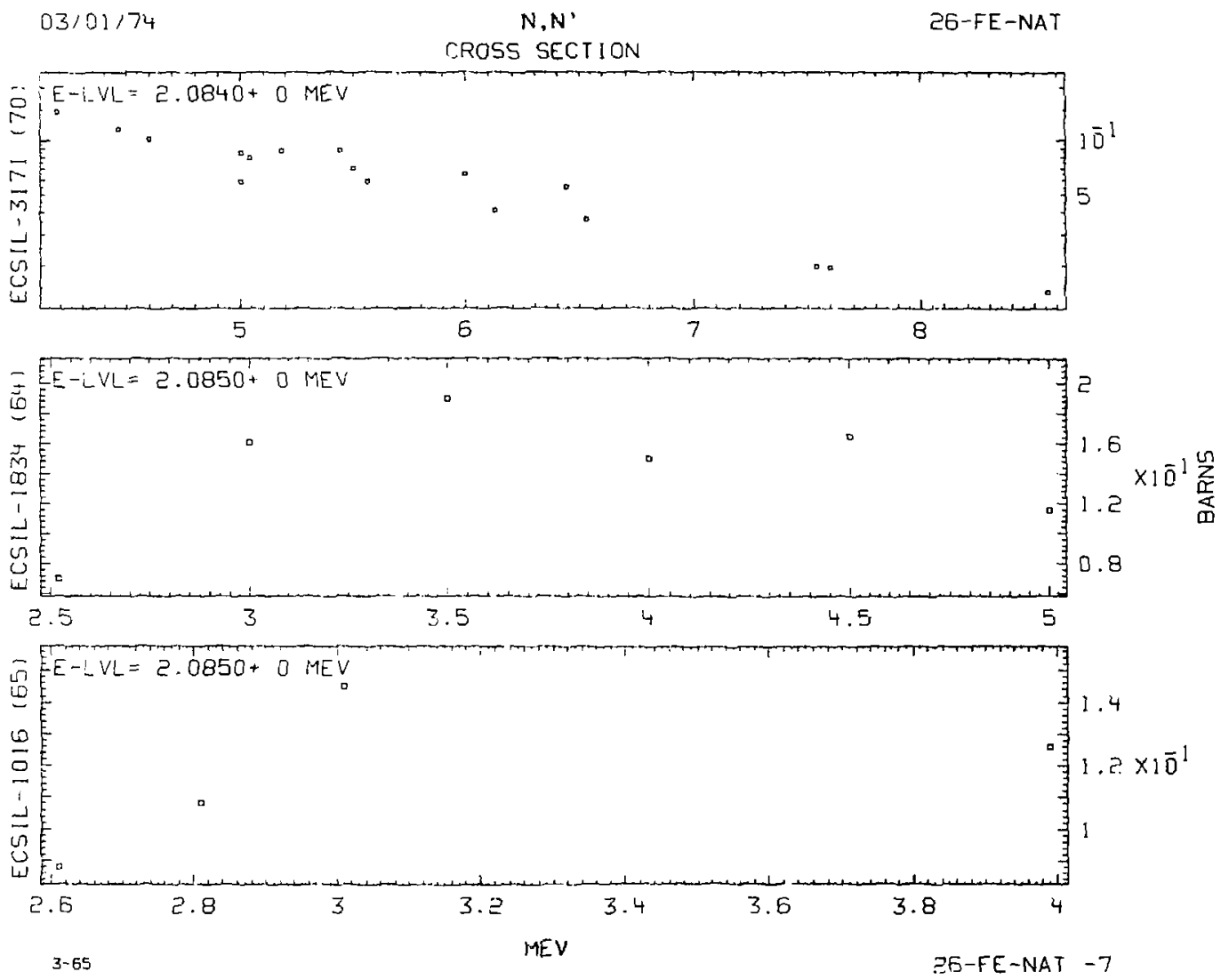
$03 / 01 / 74$

$N, N^{*}$

ZG-FE-NAT

CROSS SECTION
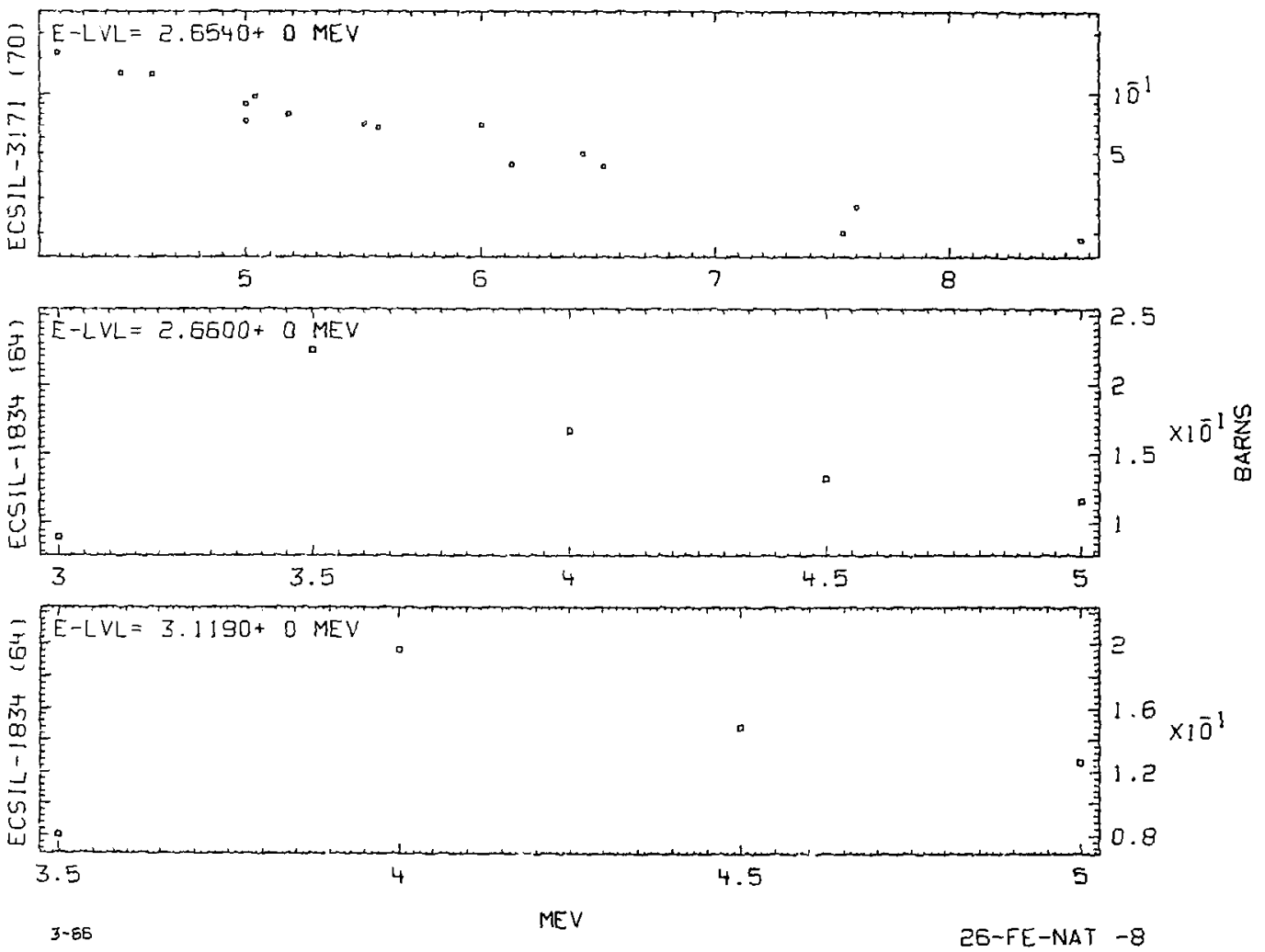

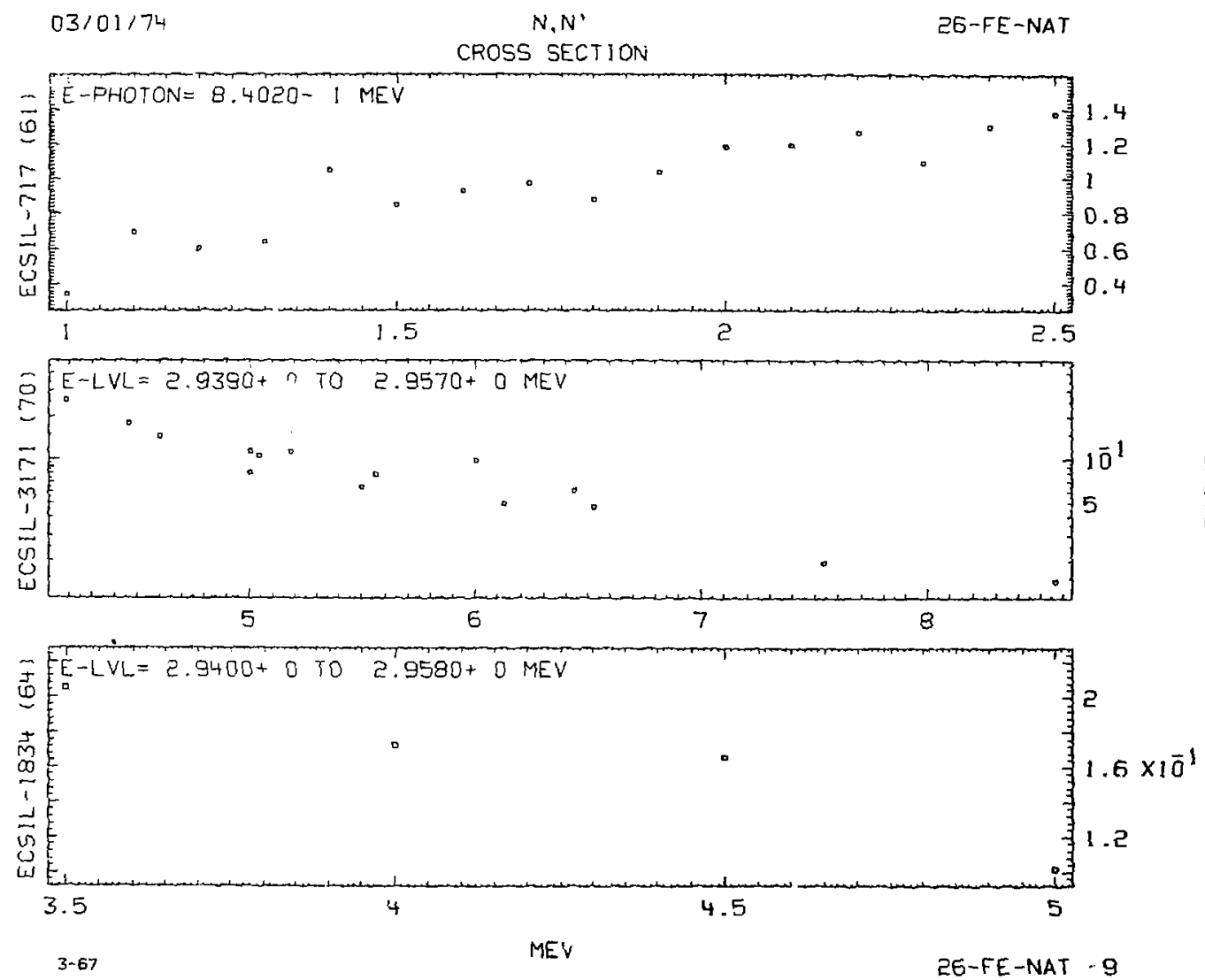

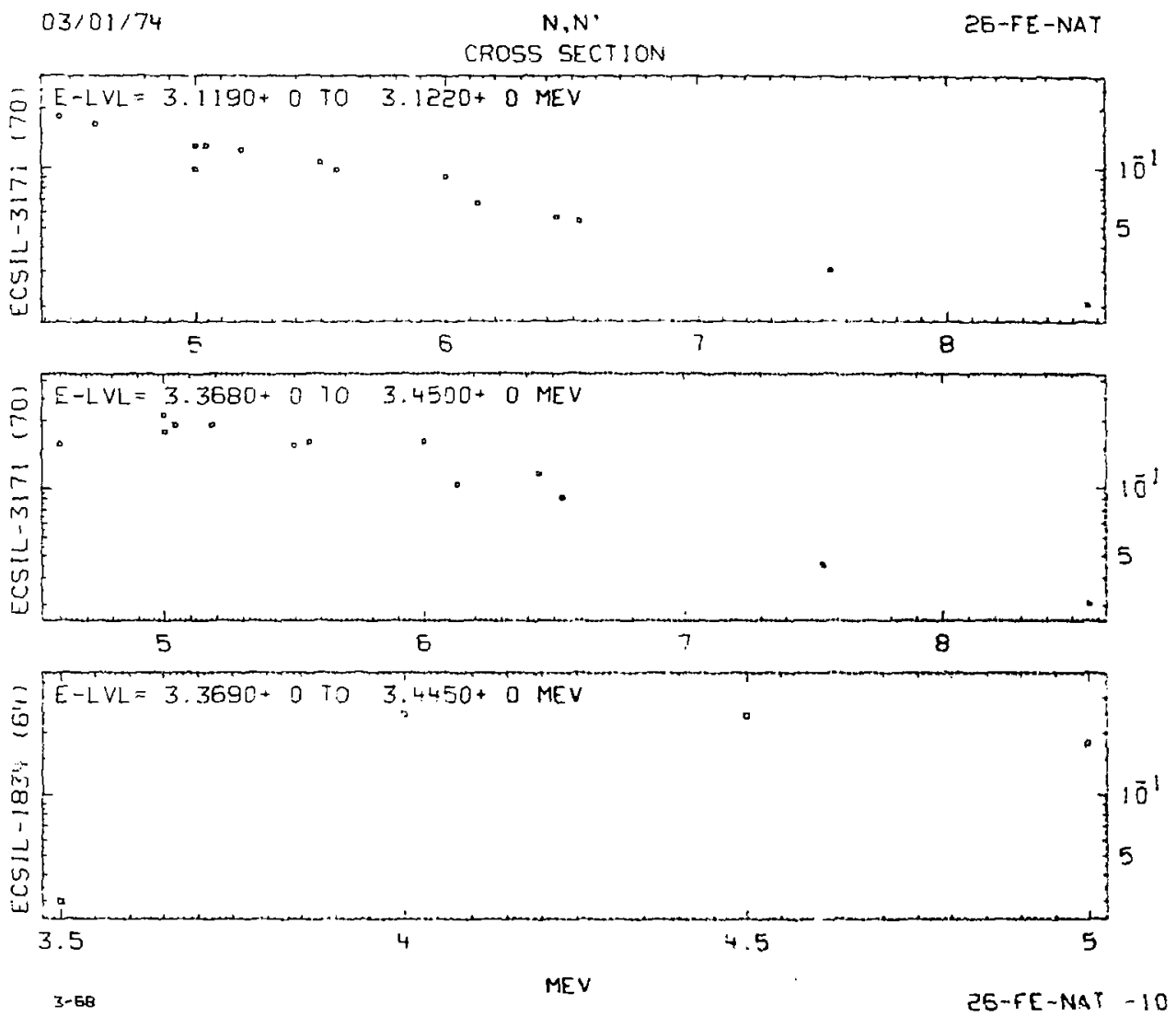

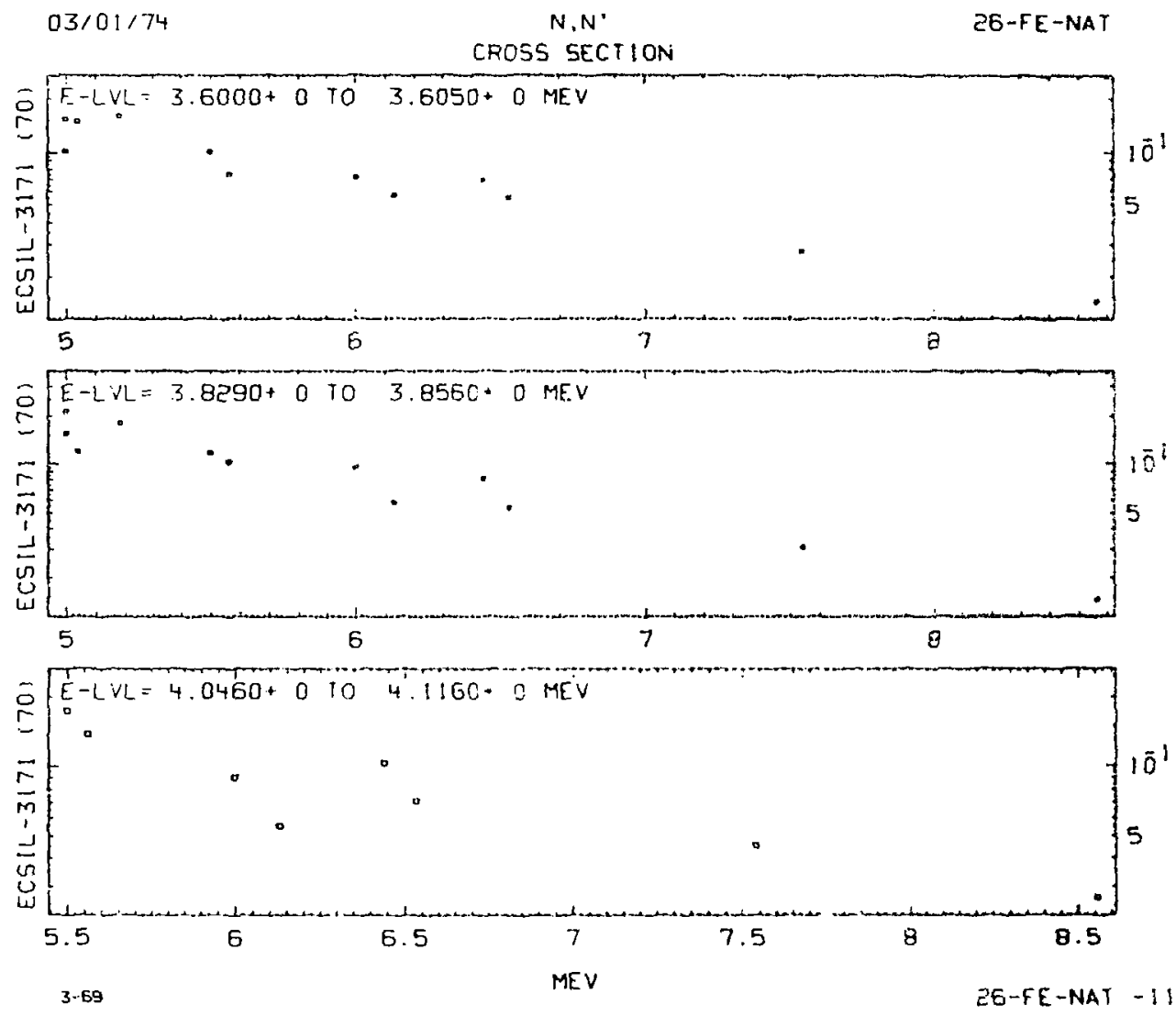

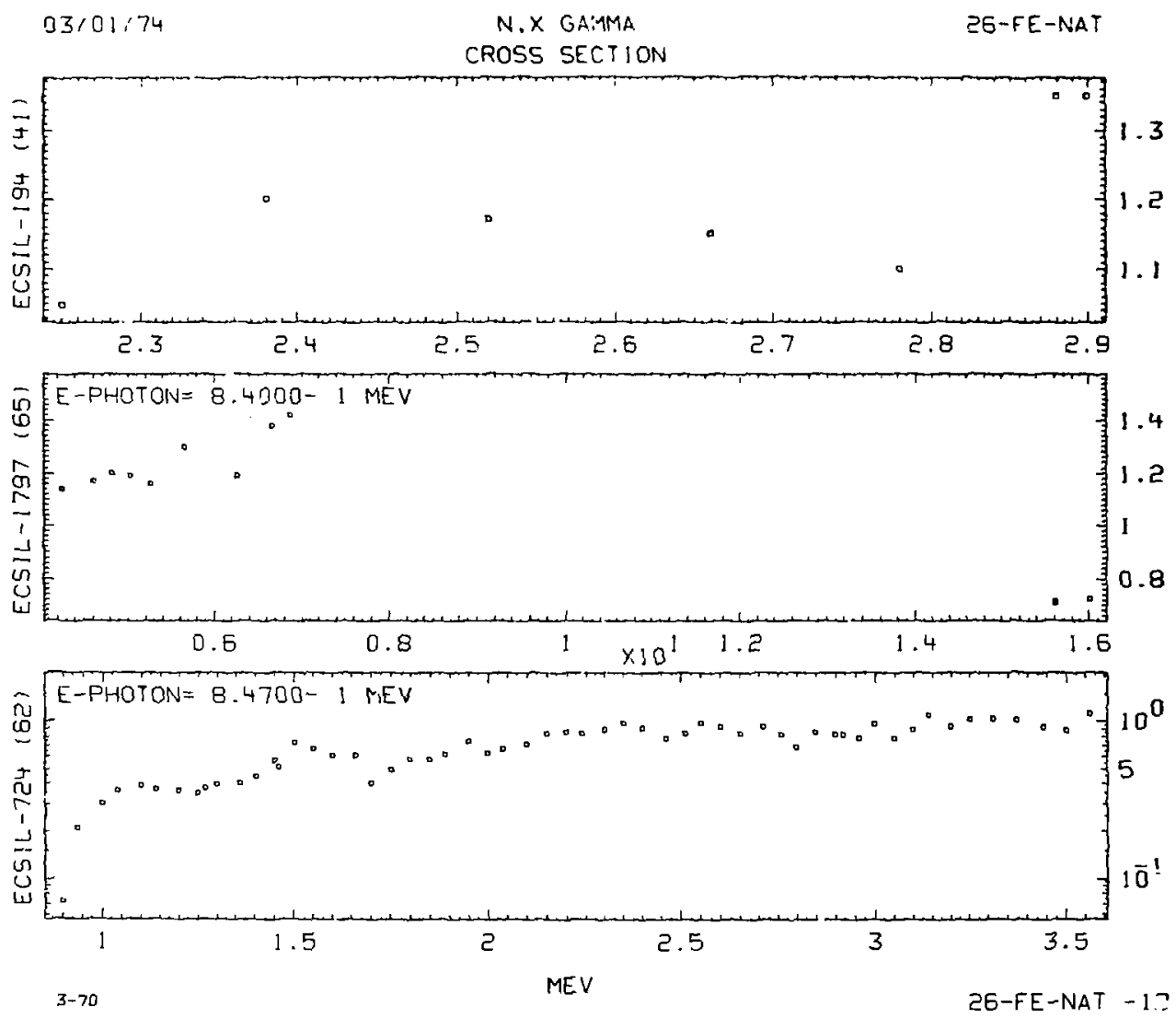

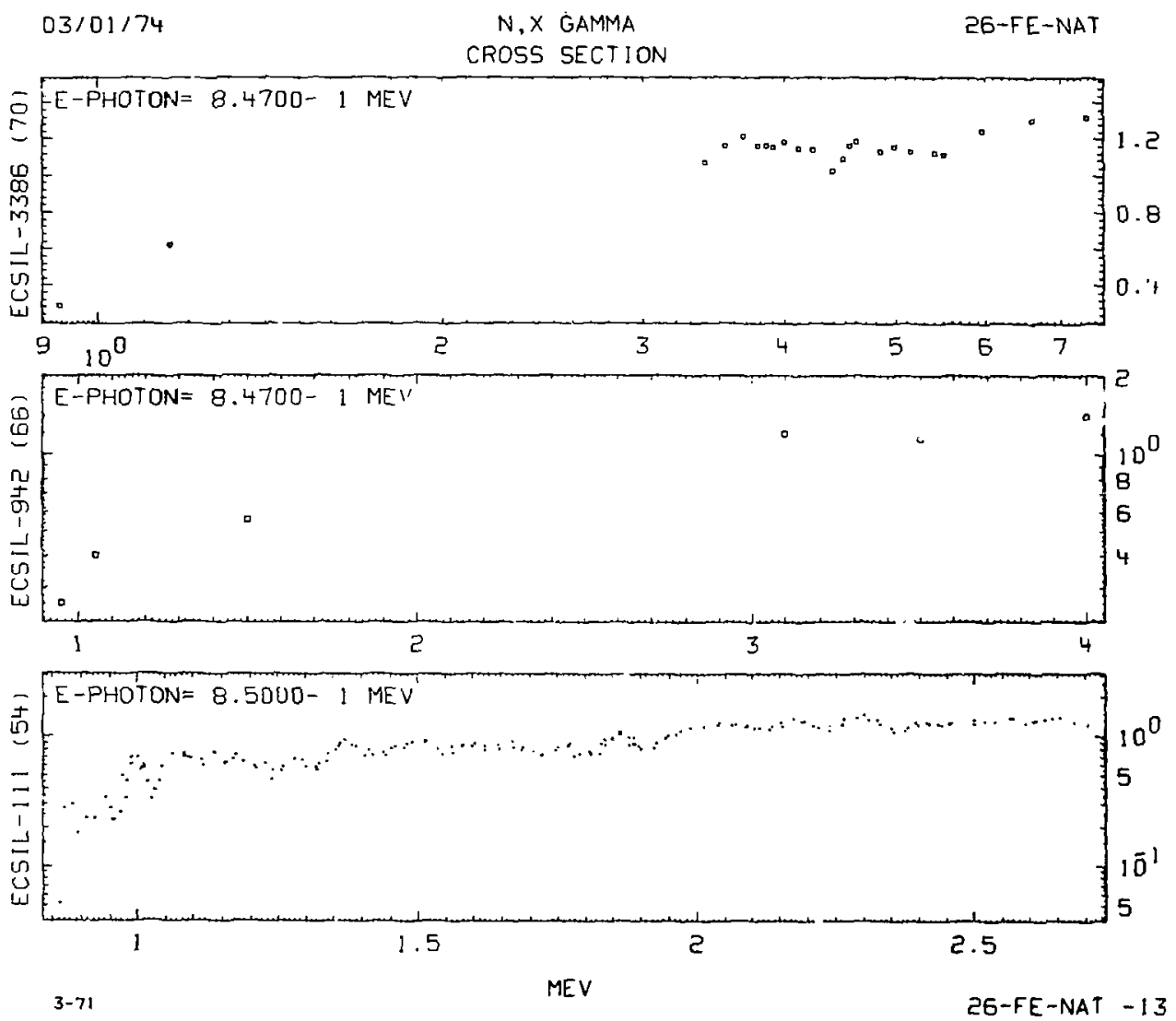

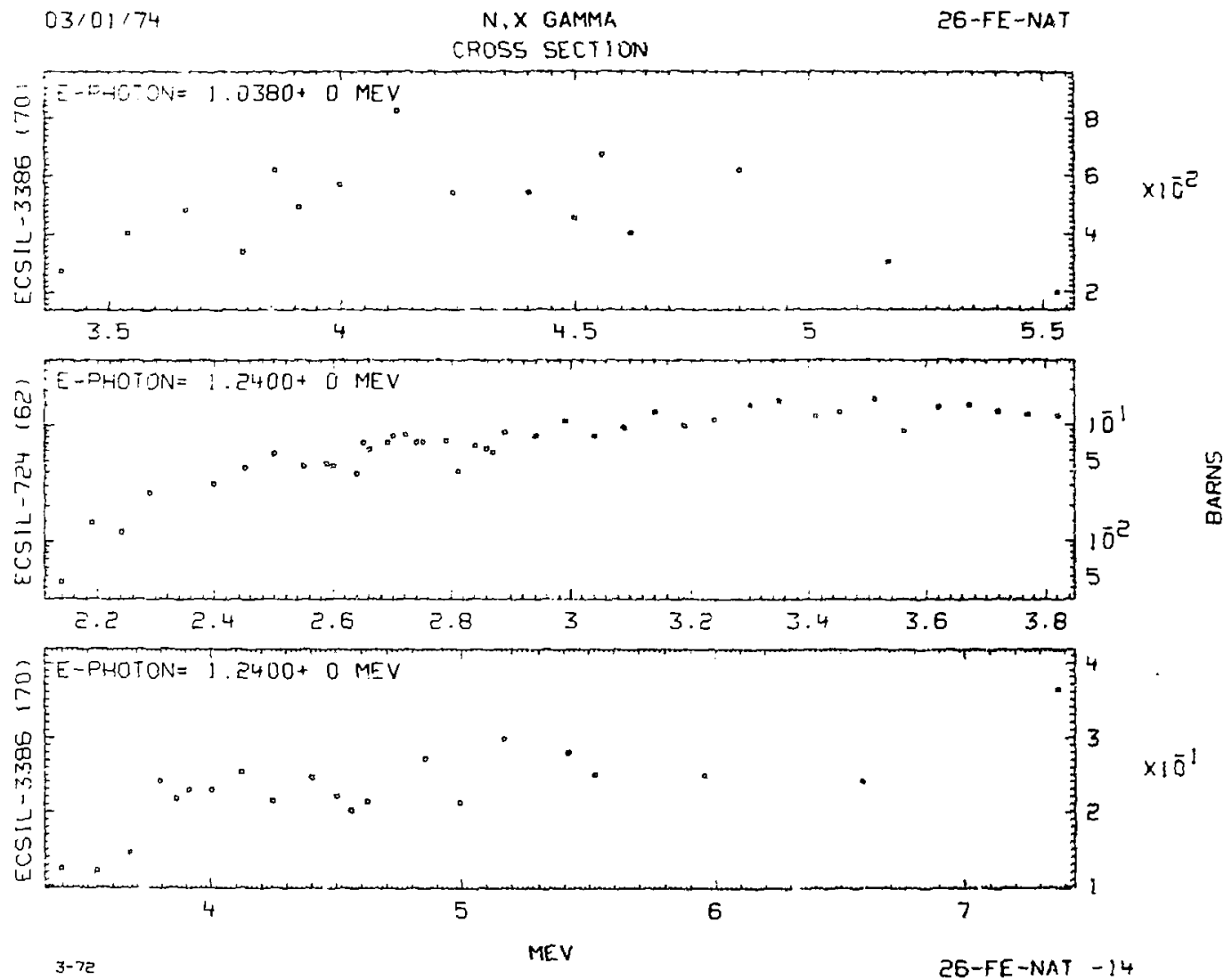

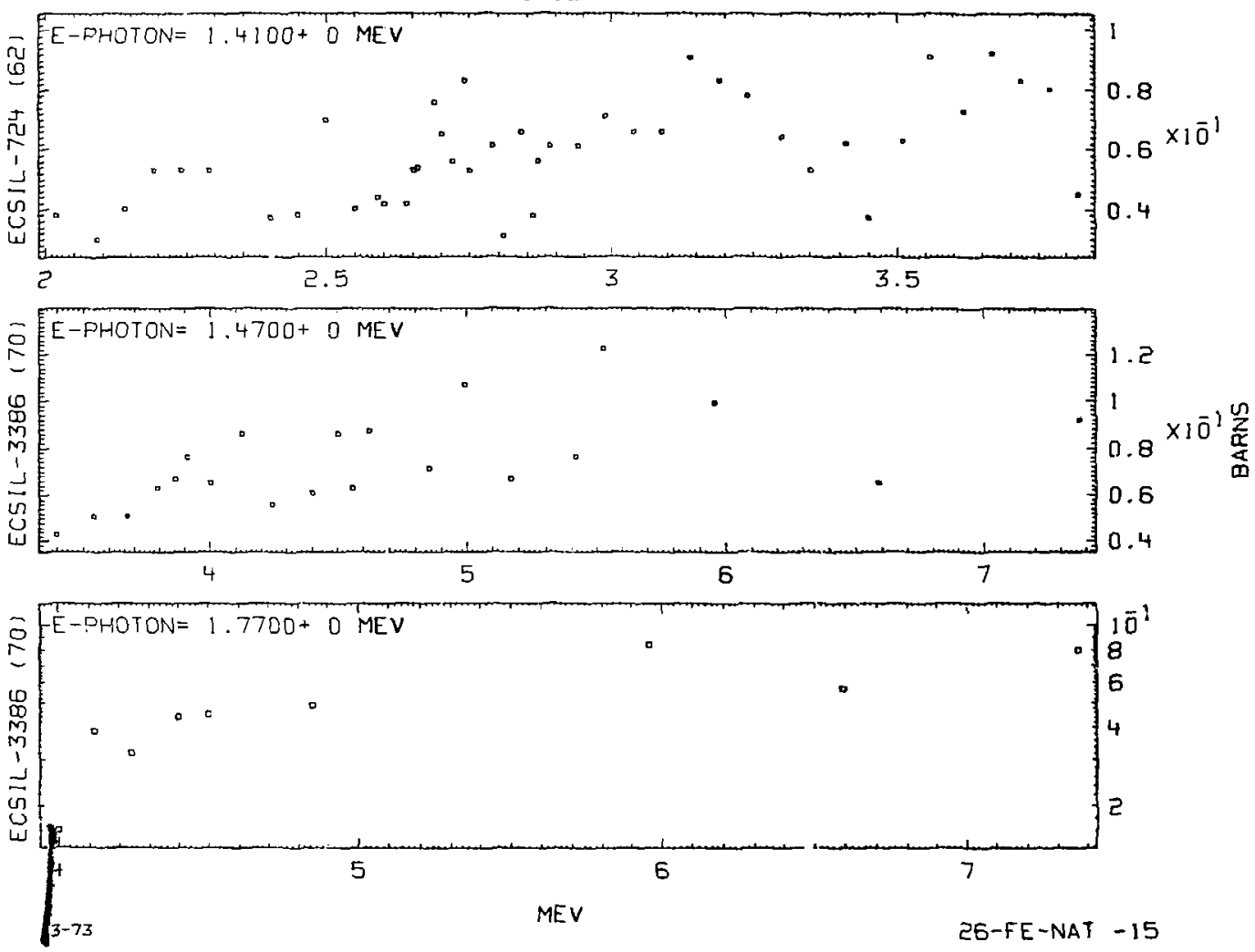


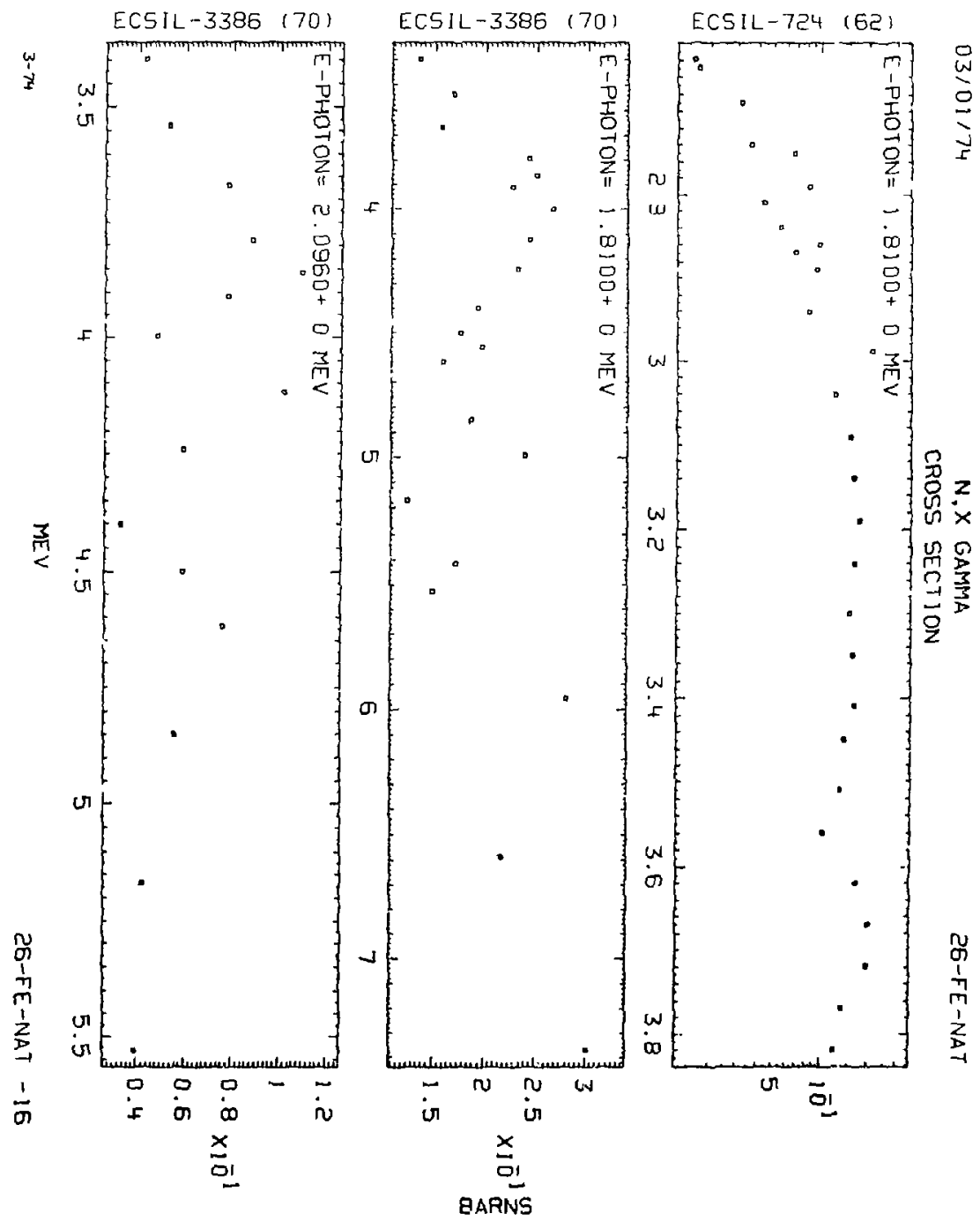




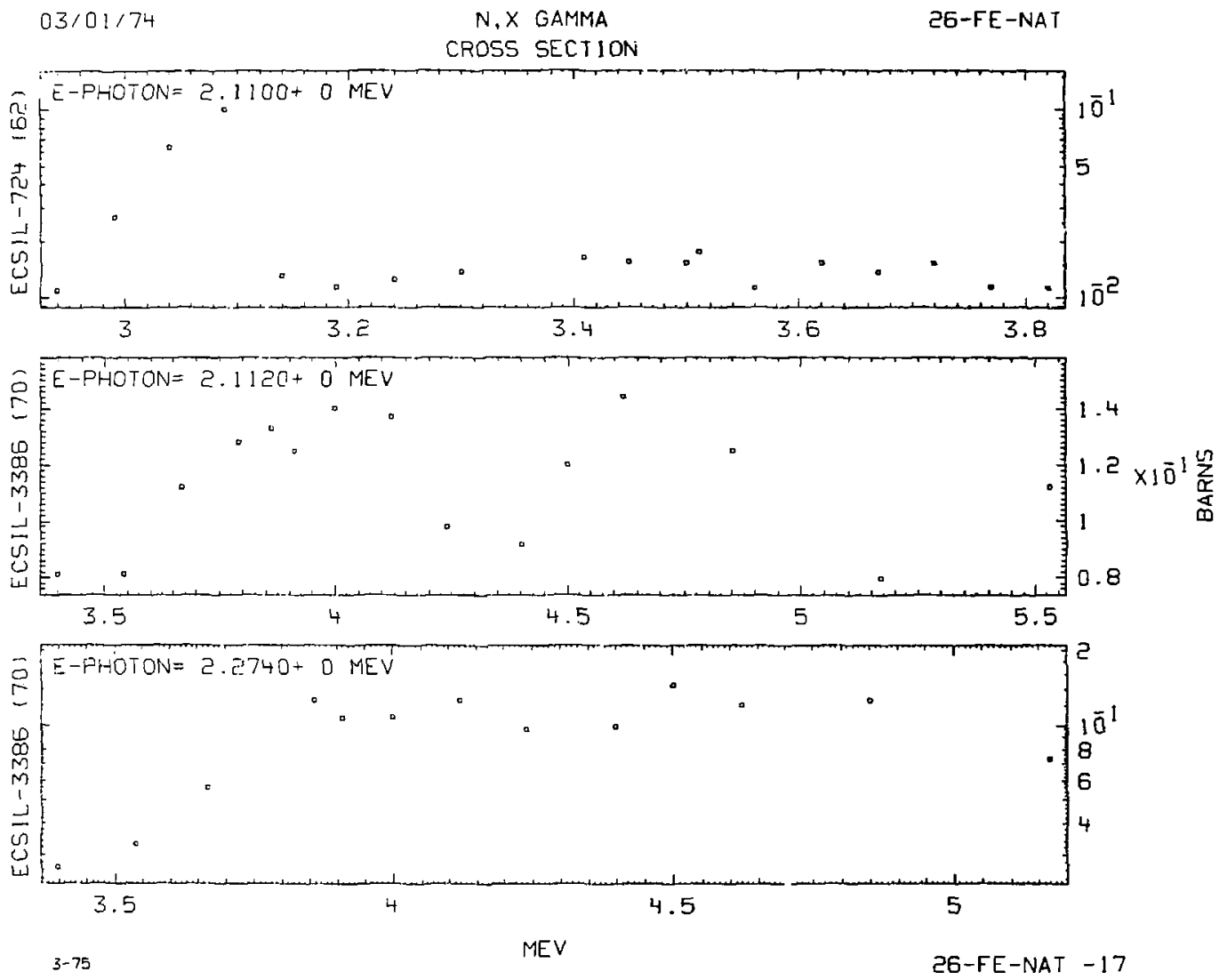



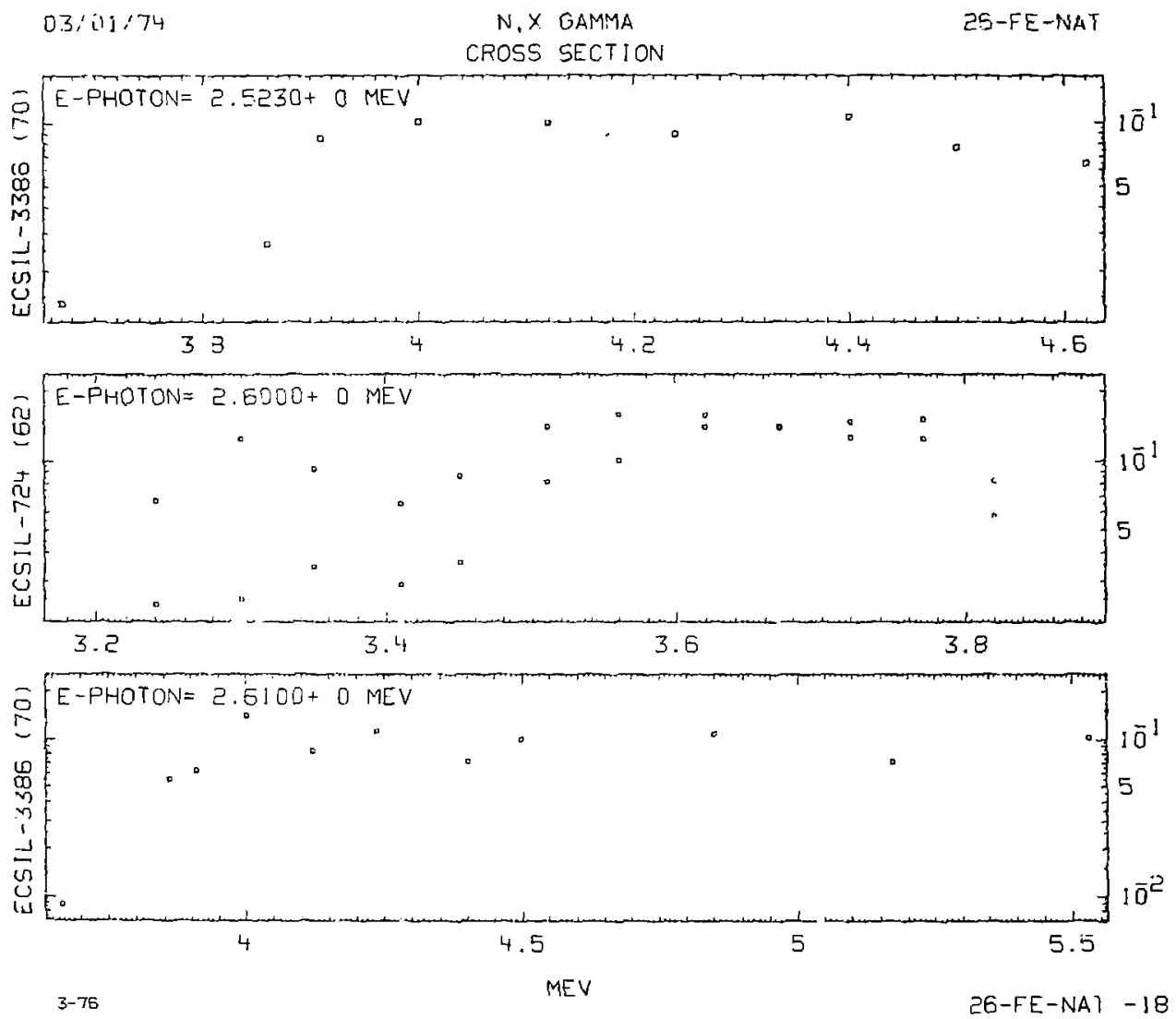


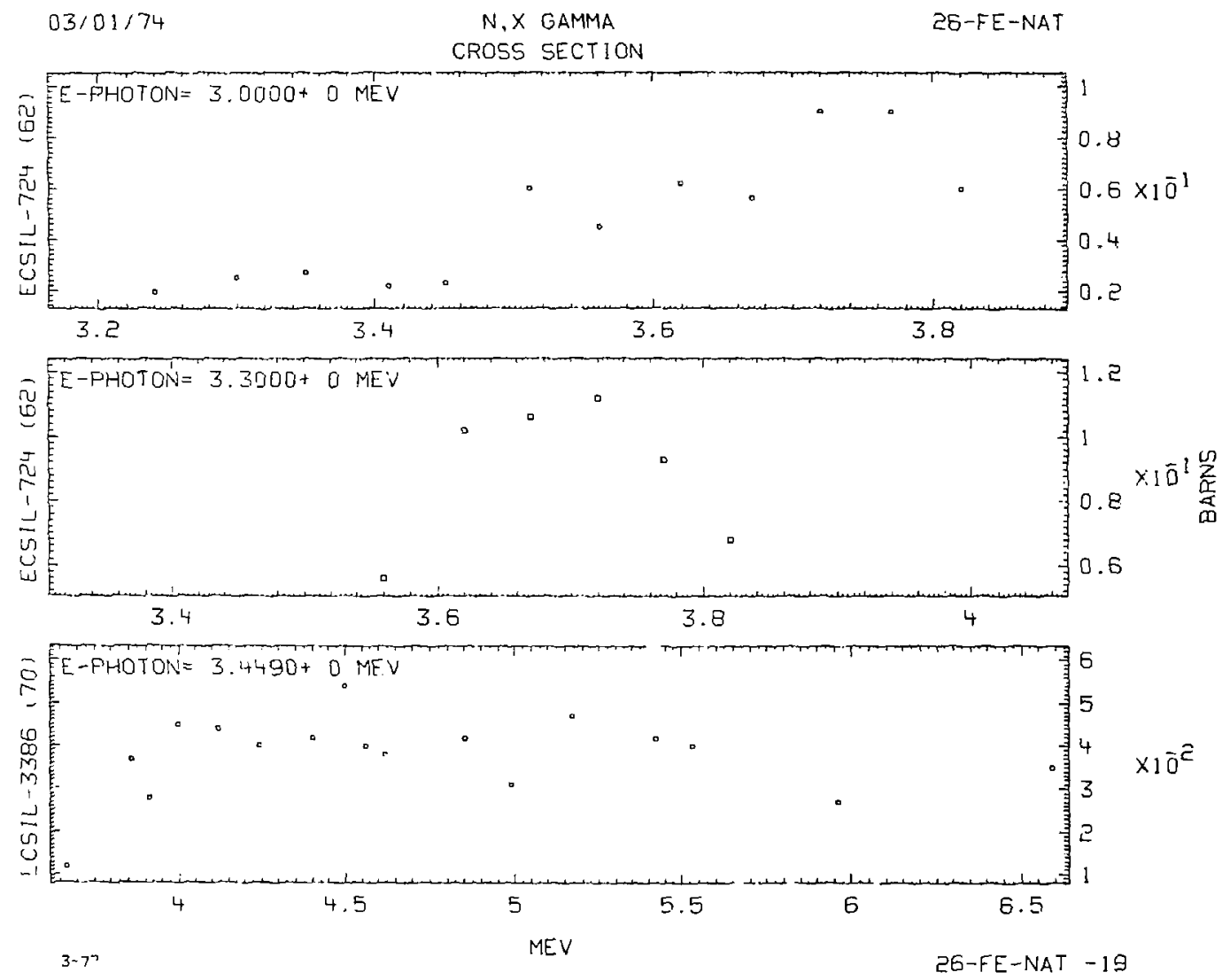



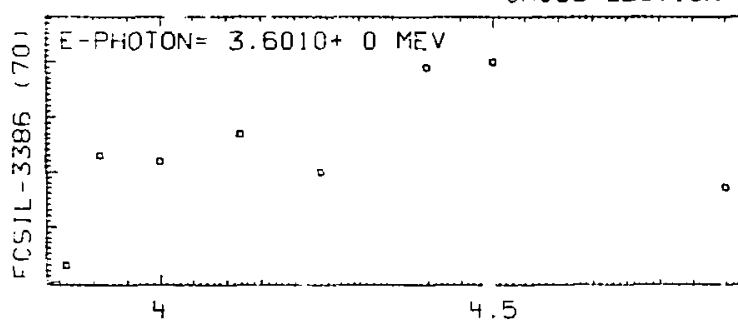

4

MEV

$03 / 01 / 74$

NGNELAST IC

26-FE-NAT

\begin{tabular}{|c|c|c|c|c|c|c|c|c|c|c|c|c|}
\hline \multicolumn{2}{|c|}{ FEEFERENCE } & $\begin{array}{r}\text { ENERC } \\
\text { ME }\end{array}$ & SY & $\begin{array}{r}\text { OEIAA } \\
\text { MEV }\end{array}$ & $\begin{array}{l}X-5 E \\
\text { BARN }\end{array}$ & $\begin{array}{l}\text { DELIA } \\
\text { BARNS }\end{array}$ & \multicolumn{2}{|c|}{ REF EP.ENCE } & $\begin{array}{r}\text { ENERGY } \\
\text { MEV }\end{array}$ & $\begin{array}{r}\text { DELTA } \\
\text { MEV }\end{array}$ & $\begin{array}{l}X \text { X-SEC } \\
\text { BARNS }\end{array}$ & $\begin{array}{l}\text { DELTA } \\
\text { GAFNS }\end{array}$ \\
\hline EO & 633 & $2.2000-$ & 1 & $2.0000-2$ & 8. $50 \supseteq 2$. & $32.0000-3$ & 55 & 1टट & $4.5000+0$ & $07.0020-2$ & $1.3300+0$ & $5.0000-2$ \\
\hline 56 & $35 z$ & $1.0200+$ & 0 & & $3.0000-$ & $1: .0000-1$ & 58 & 877 & $1.4000+!$ & $!$ & $1.4400+0$ & $4.0000-2$ \\
\hline $5 E$ & 164 & $1.2000+$ & 0 & & $5.0000-$ & $1 \ldots 0000-1$ & 55 & 117 & $1.4100+1$ & 1 & $1.2700+0$ & 0.0000- 2 \\
\hline 56 & 164 & $1.6000+$ & 0 & & $7.0020-$ & $11.0000-1$ & 57 & 199 & $1.4100+1$ & $!$ & $1.2900+0$ & $7.0020-2$ \\
\hline 56 & 164 & 2.0000+ & 0 & & $1.0000+$ & $02.0000-1$ & 52 & 82 & $1.4150+1$ & 1 E.0000- & $1.4500-1$ & 2.0000- \\
\hline 56 & 34 & $2.5000+$ & 0 & & i. . 6000 . & $01.2000-1$ & 57 & $3 i 9$ & $1 . t r 200+1$ & $11.5000-1$ & $1.3600+0$ & $3.0000-2$ \\
\hline 50 & 59 & $3.6600+$ & 0 & $2.0050-1$ & 1.5100 & $01.7000-1$ & 56 & 200 & $1.4500+1$ & $i$ & $1.3800-0$ & a.1.0000- \\
\hline 55 & 1.5 & $4.0000+$ & 0 & $7.0020-2$ & $1.4200+$ & $05.0000-2$ & 58 & 356 & $2.5500+i$ & $\mathrm{i}$ & $1.2100+0$ & $7.0020-2$ \\
\hline 55 & 295 & $4.1000+$ & 0 & $4.0000-2$ & $1.5000+$ & 0 c.c000- 1 & & & & & & \\
\hline
\end{tabular}

$03: 01 / 7+4$ TOTAL SCATTERING

26-FE-NAT

RE.FERENCE

ENEREY

MEV

DELTA X-SEC

B ARN5

DELTA

$639739.8000-15.0000=22.0200+06.0600-2$ 
CROSS SECTION

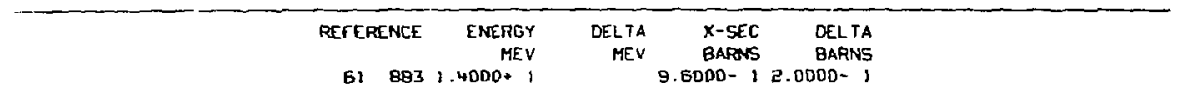

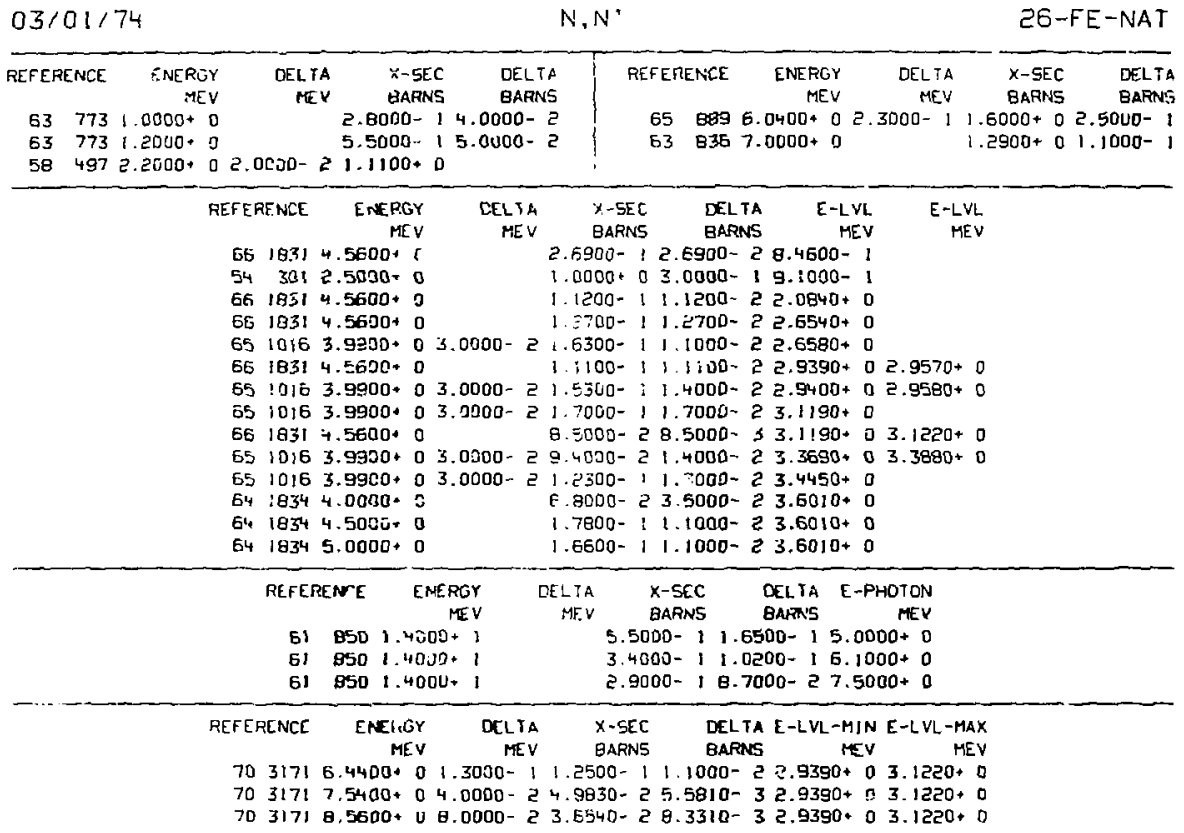




\section{CROSS SECTION}

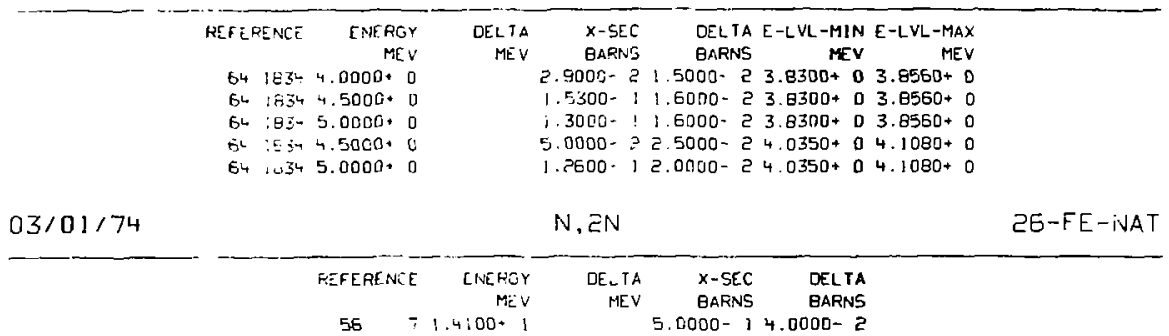

$03 / 01 / 74$

ABSORPT ION

2G-FE-NAT

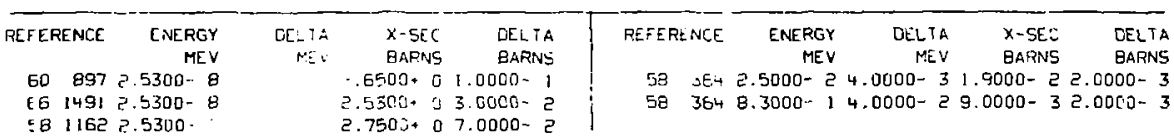

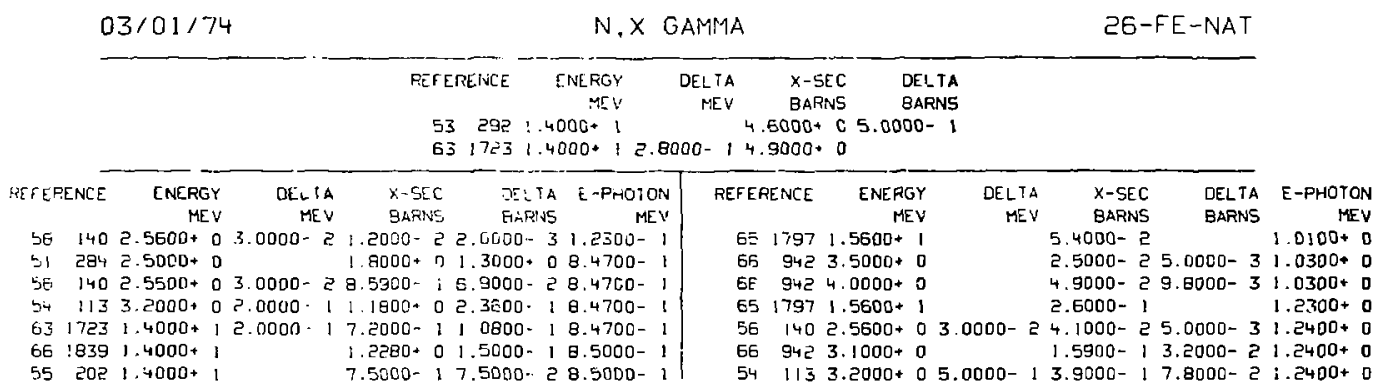




\section{CROSS SECTION}

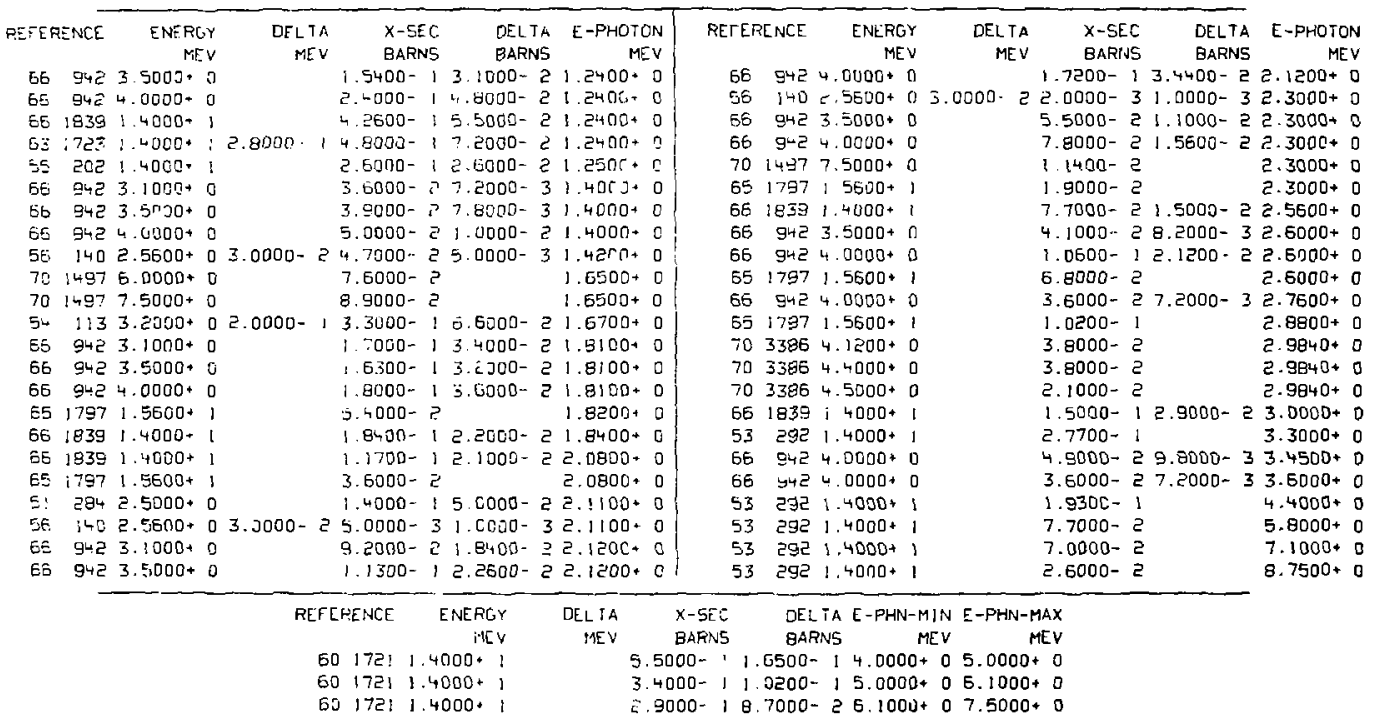

$03 / 01 / 74$

$N, P$

2E-FE-NAT

\begin{tabular}{|c|c|c|c|}
\hline REFERE NCE & $\begin{array}{r}\text { ENERGY } \\
\text { MEV }\end{array}$ & $\begin{array}{r}\text { DEL IA } \\
\text { MEV }\end{array}$ & $\begin{array}{l}x-5 E C \\
\text { BARN5 }\end{array}$ \\
\hline
\end{tabular}

$626881.4400,12.0000-11.0200-11.0000-2$ 


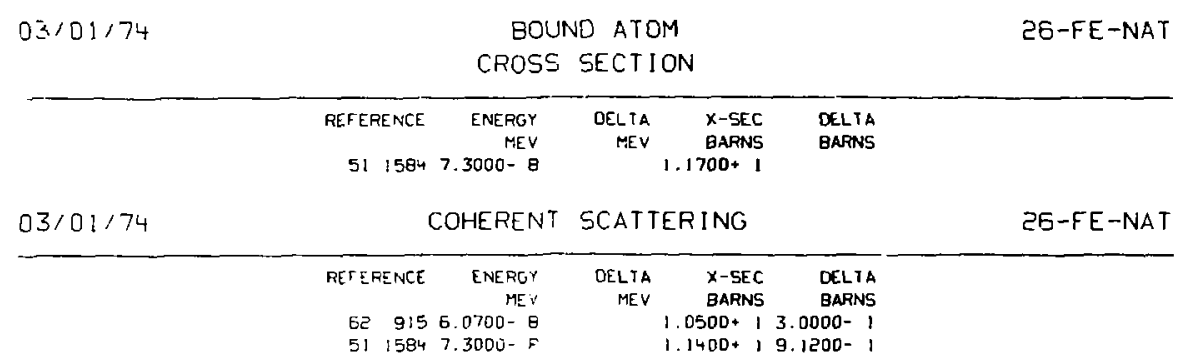

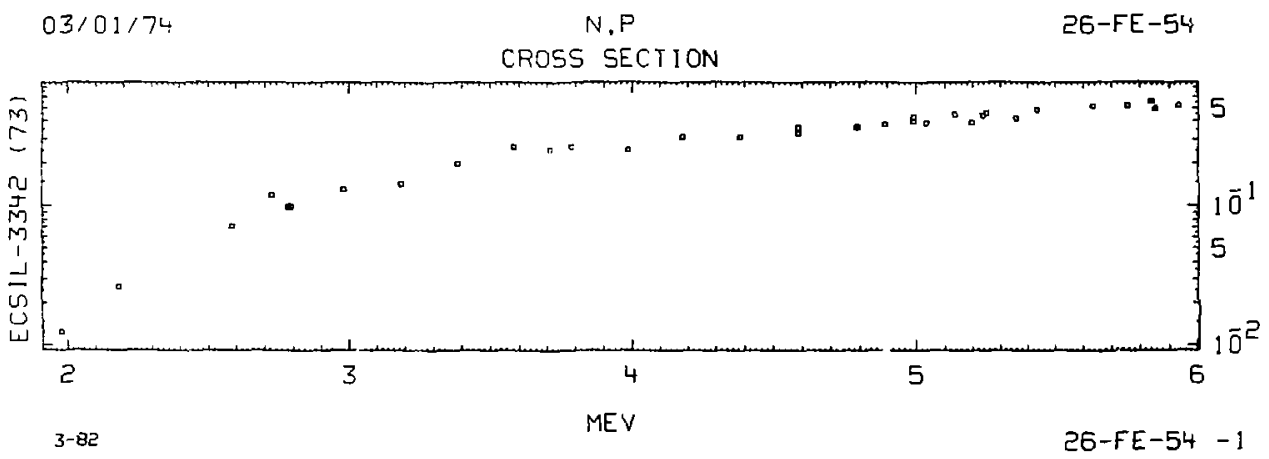




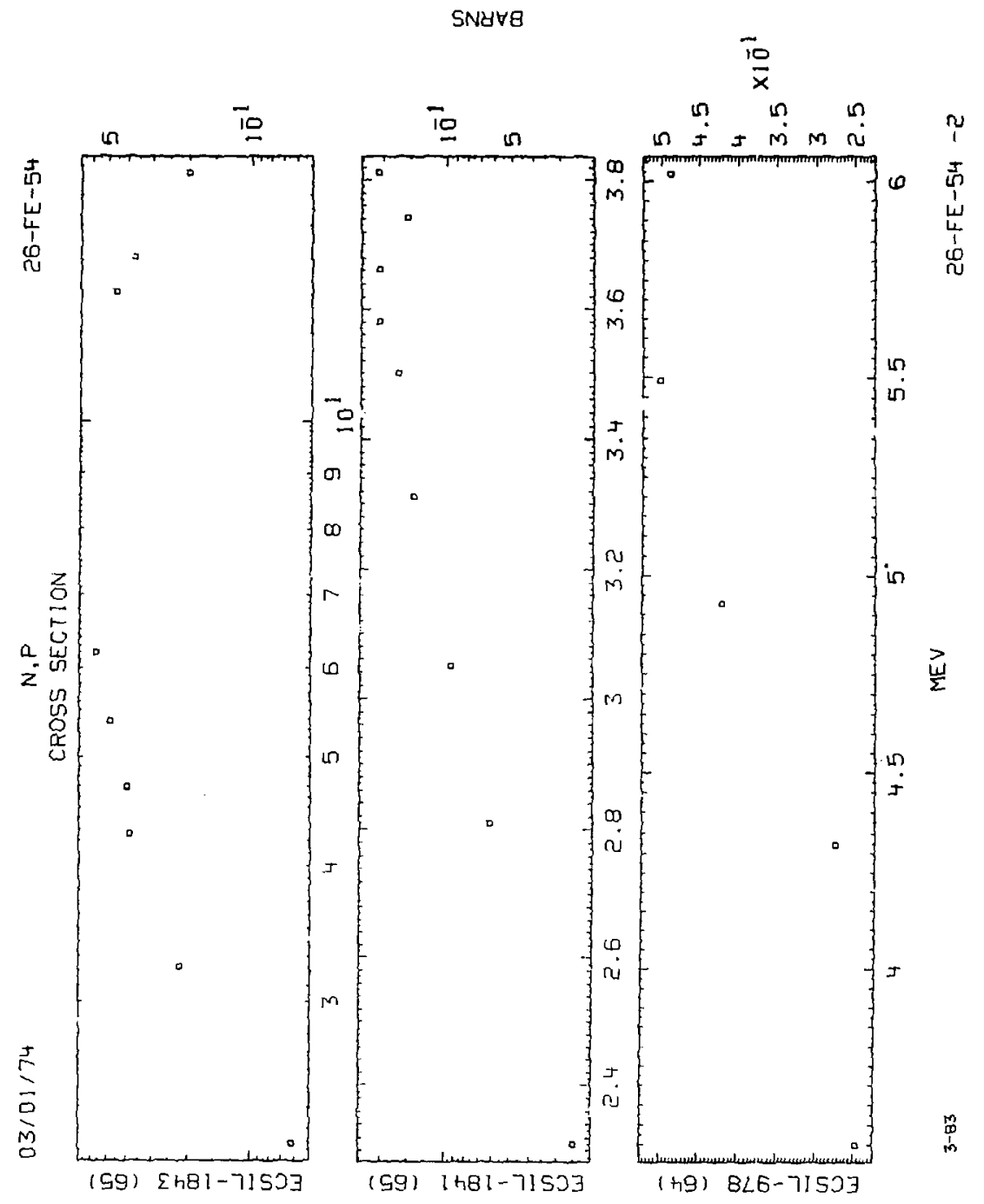



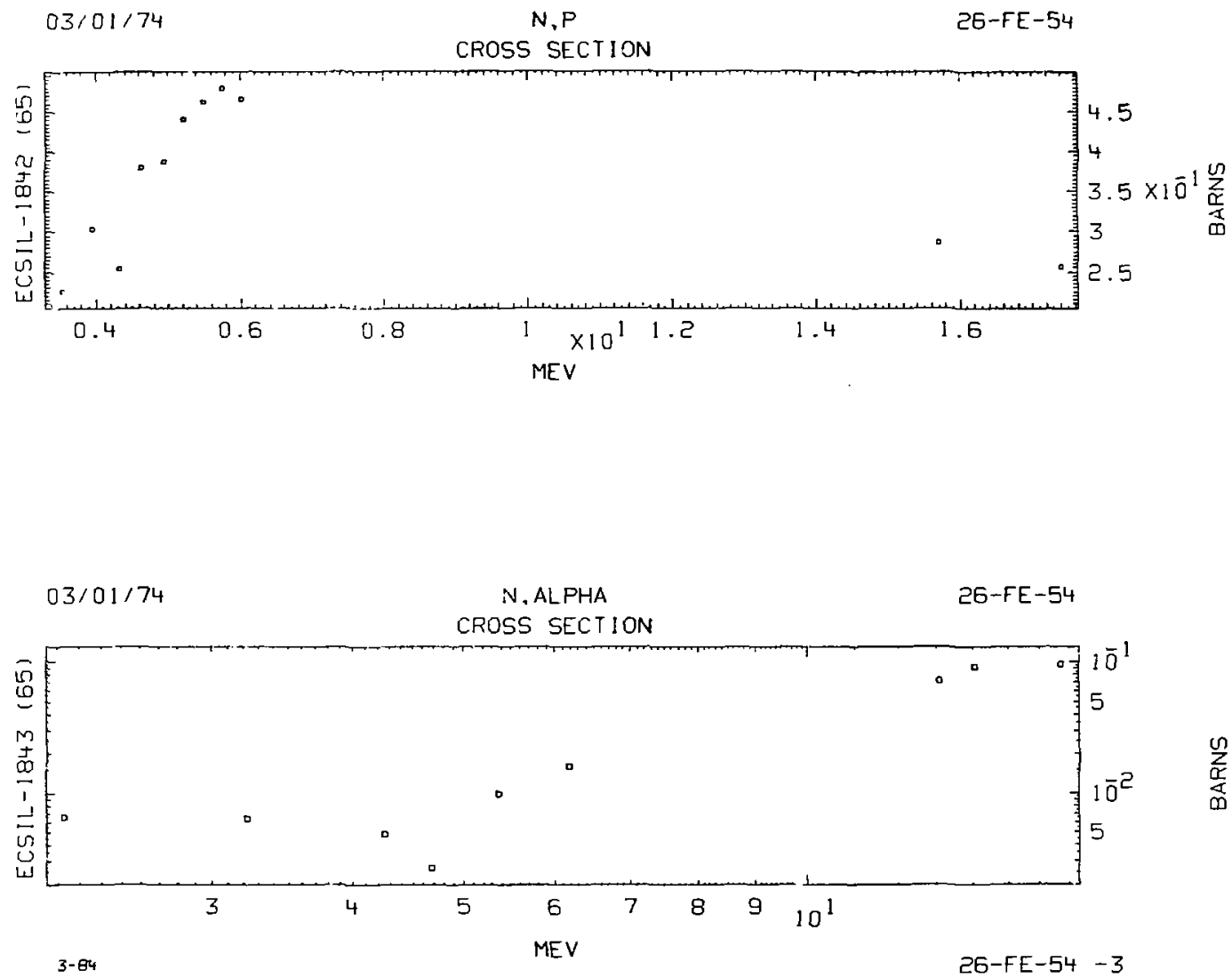
CROSS SECTION

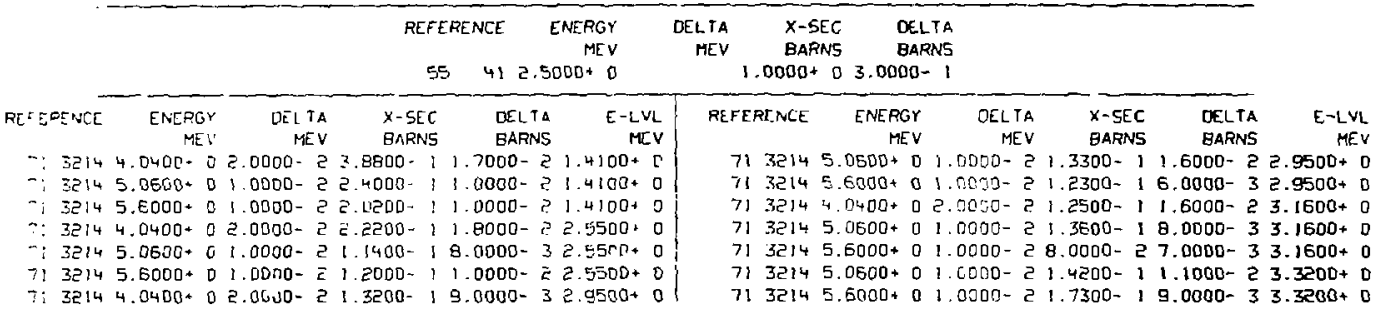

\begin{tabular}{|c|c|c|c|c|c|c|c|c|c|}
\hline \multicolumn{2}{|c|}{$03 / 01 / 74$} & \multicolumn{6}{|c|}{$N, 2 N$} & \multicolumn{2}{|c|}{$26-F E-54$} \\
\hline EFERENCE & ENERGY & OELTA & $x$ & A & REFERENCE & CNERG & DELTA & $c$ & A \\
\hline & MEV & MEV & BAPNS & BARNS & & $M E$ & MEV & EARNS & GAFNS \\
\hline $57 \quad 217$ & $1.4000 \cdot 1$ & & $1.0000-2$ & $24.0000-3$ & $65 \quad 1672$ & $1.4600 *$ & $11.0000-1$ & $11.6000-2$ & $3.0000-3$ \\
\hline $65 \quad 1843$ & $1.4050+1$ & $11.0500+0$ & $06.8300-3$ & $35.0000-5$ & El b79 & $1.4800+$ & $13.0010-1$ & $17.9010-3$ & $38.0010-4$ \\
\hline 6165 ! & $1.4100 * 1$ & & $1.1000-2$ & $22.0000-3$ & 80 628 & $1.5000+$ & & $7.0010-3$ & $31.3000-2$ \\
\hline E3 373 & $1.4100+1$ & & $1.0000-2$ & $25.5010-3$ & $5518+3$ & 1.67504 & 15.5000 & $15.0400-2$ & $5.0000-3$ \\
\hline EI 675 & $1.4400+1$ & $13.0000-1$ & $11.5000-2$ & $2: 0000-3$ & $58 \quad 326$ & $1.6890+$ & $13.2000-$ & $1.2000-$ & $3.6000-2$ \\
\hline $63: 039$ & $1.4500+1$ & & $8.5000-3$ & $38.0000-4$ & $58 \quad 326$ & $1.7890+$ & $18.0000-2$ & $1.7000-1$ & $5.1000-3$ \\
\hline
\end{tabular}

$03 / 01 / 74 \quad N, N \cdot P$

$26-F E-54$

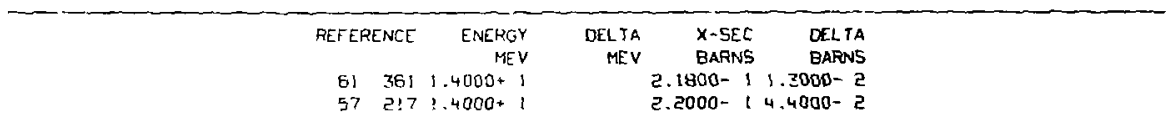

\begin{tabular}{|c|c|c|c|c|c|c|c|c|c|}
\hline $05 / 01$ & & & & & & & & & $-F E-54$ \\
\hline PEFEPENC & $\begin{array}{r}\text { ENERGY } \\
\text { MEV }\end{array}$ & $\begin{array}{r}\text { DELIS } \\
\text { MEV }\end{array}$ & $\begin{array}{l}k \text {-SEC } \\
\text { BARN5 }\end{array}$ & $\begin{array}{l}\text { OELTA } \\
\text { EARNS }\end{array}$ & REFERENCE & $\begin{array}{r}\text { ENERGY } \\
\text { MEV }\end{array}$ & $\begin{array}{r}\text { DELTA } \\
\text { MEV }\end{array}$ & $\begin{array}{l}X \text {-SEC } \\
\text { BARNS }\end{array}$ & $\begin{array}{l}\text { DELTA } \\
\text { BARNS }\end{array}$ \\
\hline $\begin{array}{ll}61 & 05 \\
61 & 65\end{array}$ & $\begin{array}{l}.5000 * 0 \\
.5000 \cdot 0\end{array}$ & $\begin{array}{l}2.0000-1 \\
1.0000-1\end{array}$ & $\begin{array}{l}1.5000- \\
1.9000^{-}\end{array}$ & $\begin{array}{l}1.5000-2 \\
2.0000-2\end{array}$ & $\begin{array}{rr}6 ! & 655 \\
6 ? & 1008\end{array}$ & $\begin{array}{l}3.6000 * 0 \\
1.3580 * 1\end{array}$ & $.0000-1$ & $\begin{array}{l}2.1000-1 \\
3.7000-1\end{array}$ & $\begin{array}{l}2.0000-2 \\
3.7000-2\end{array}$ \\
\hline
\end{tabular}


CROSS SECTION

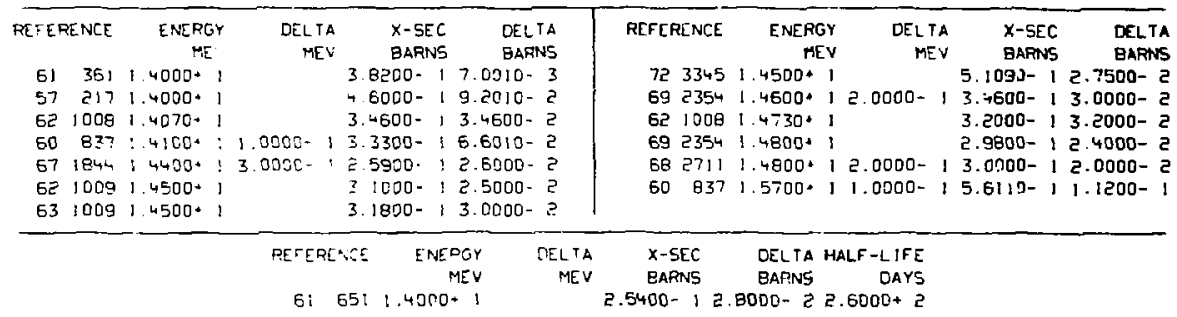

$03 / 01: 74$

$N, X P$

$26-F E-54$

\begin{tabular}{|c|c|c|c|c|}
\hline PEFERENCE & ENERGY & DELTA & $x-\operatorname{SEC}$ & OFLTA \\
\hline & MEV & MEV & BARNS & BARN5 \\
\hline
\end{tabular}

$03 / 01 / 74$

$N, T$

$26-F E-54$

$\begin{array}{rrrrr}\text { REFERENCE } & \text { ENEDGY } & \text { DELTA } & \text { X-SEC } & \text { DEI TA HALF-LIFE } \\ & 5 ! 679 & \text { MEV } & 4800+19.0010-16.0010-4 & 1.0000-42.1000+1\end{array}$

$03 / 01 / 74$

N. ALPHA

$26-F E-54$

\begin{tabular}{|c|c|c|c|c|c|c|c|c|c|}
\hline REFERENCE & $\begin{array}{r}\text { ENERGY } \\
\text { HEV }\end{array}$ & $\begin{array}{r}\text { DELTA } \\
\text { MEV }\end{array}$ & $\begin{array}{l}X \text { X-SEC } \\
\text { BARNS }\end{array}$ & $\begin{array}{l}\text { DELTA } \\
\text { BARNS }\end{array}$ & REFERENCE & $\begin{array}{r}\text { ENERGY } \\
\text { MEV }\end{array}$ & $\begin{array}{r}\text { DELTA } \\
\text { MEV }\end{array}$ & $\begin{array}{l}X \text { X-SEC } \\
\text { BARNS }\end{array}$ & $\begin{array}{l}\text { OEL.TA } \\
\text { BARNS }\end{array}$ \\
\hline 621008 & $.3580+1$ & & 6.7000-? & $0.7000-3$ & 631009 & $1.4500+1$ & & $9.4000-2$ & $1.0000-2$ \\
\hline 621008 & $1.4070+1$ & & $9.4000-2$ & $9.4000-3$ & 723345 & $1.4500+1$ & & $1.3950-1$ & $7.5000-3$ \\
\hline 61 551 & $1.4100+1$ & & $1.3100-1$ & $12.4000-2$ & 62,008 & $1.4730+1$ & & $9.6000-2$ & $9.6000-3$ \\
\hline $67: 844$ & $1.4400+1$ & $3.0000-1$ & $9.0000-2$ & $21.0000-2$ & 61679 & $1.4800+1$ & $9.0010-1$ & $2.7000-1$ & $1.3500-1$ \\
\hline
\end{tabular}




\begin{tabular}{|c|c|c|c|c|c|c|}
\hline \multirow[t]{3}{*}{$03 / 01 / 74$} & \multicolumn{4}{|c|}{ BGUND ATOM } & & \multirow[t]{2}{*}{$26-F E-54$} \\
\hline & & CROSS & SECT & & & \\
\hline & $\begin{array}{l}\text { REFERENCE } \\
51 \quad 1584\end{array}$ & $\begin{array}{r}\text { ENERGY } \\
\text { MEV } \\
7.3000-8\end{array}$ & $\begin{array}{r}\text { OELTA } \\
\text { MEV }\end{array}$ & $\begin{array}{r}X-5 E C \\
\text { BARNS } \\
000+0\end{array}$ & $\begin{array}{l}\text { DELTA } \\
\text { BARN5 }\end{array}$ & \\
\hline \multirow[t]{2}{*}{$03 / 01 / 74$} & & COHERENT & SCAT & ING & & $26-F E-54$ \\
\hline & $\begin{array}{r}\text { PEFFERENCE } \\
511584\end{array}$ & $\begin{array}{r}\text { ENERGY } \\
\text { MEV } \\
7.3000-8\end{array}$ & $\begin{array}{r}\text { DELTA } \\
\text { MEV }\end{array}$ & $\begin{array}{r}x-5 E C \\
\text { SARNS } \\
000+0\end{array}$ & $\begin{array}{l}\text { DEL TA } \\
\text { BARNS } \\
\text { GOD- } 1\end{array}$ & \\
\hline
\end{tabular}

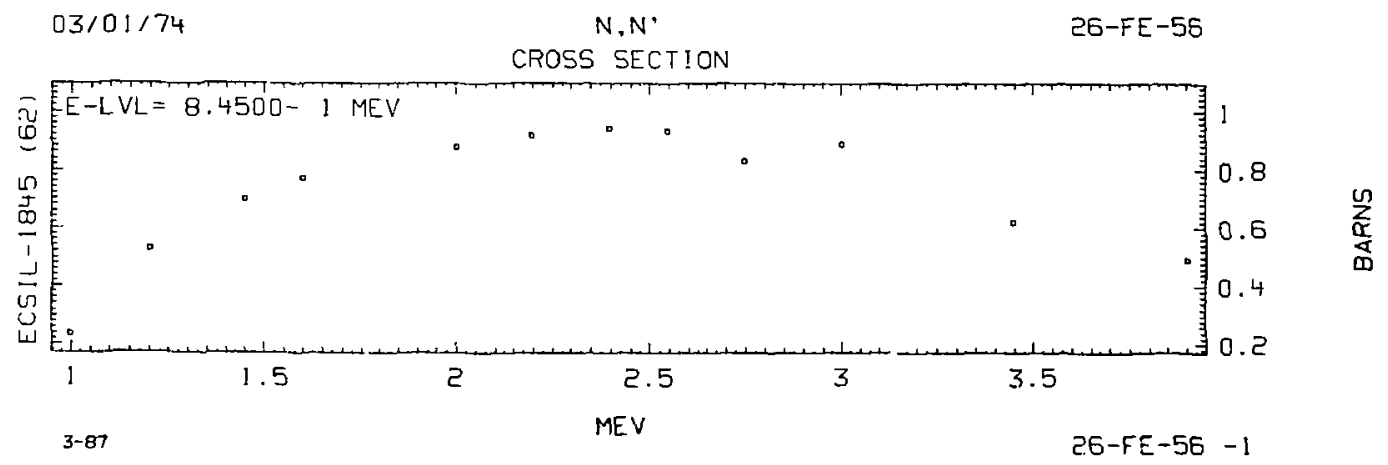



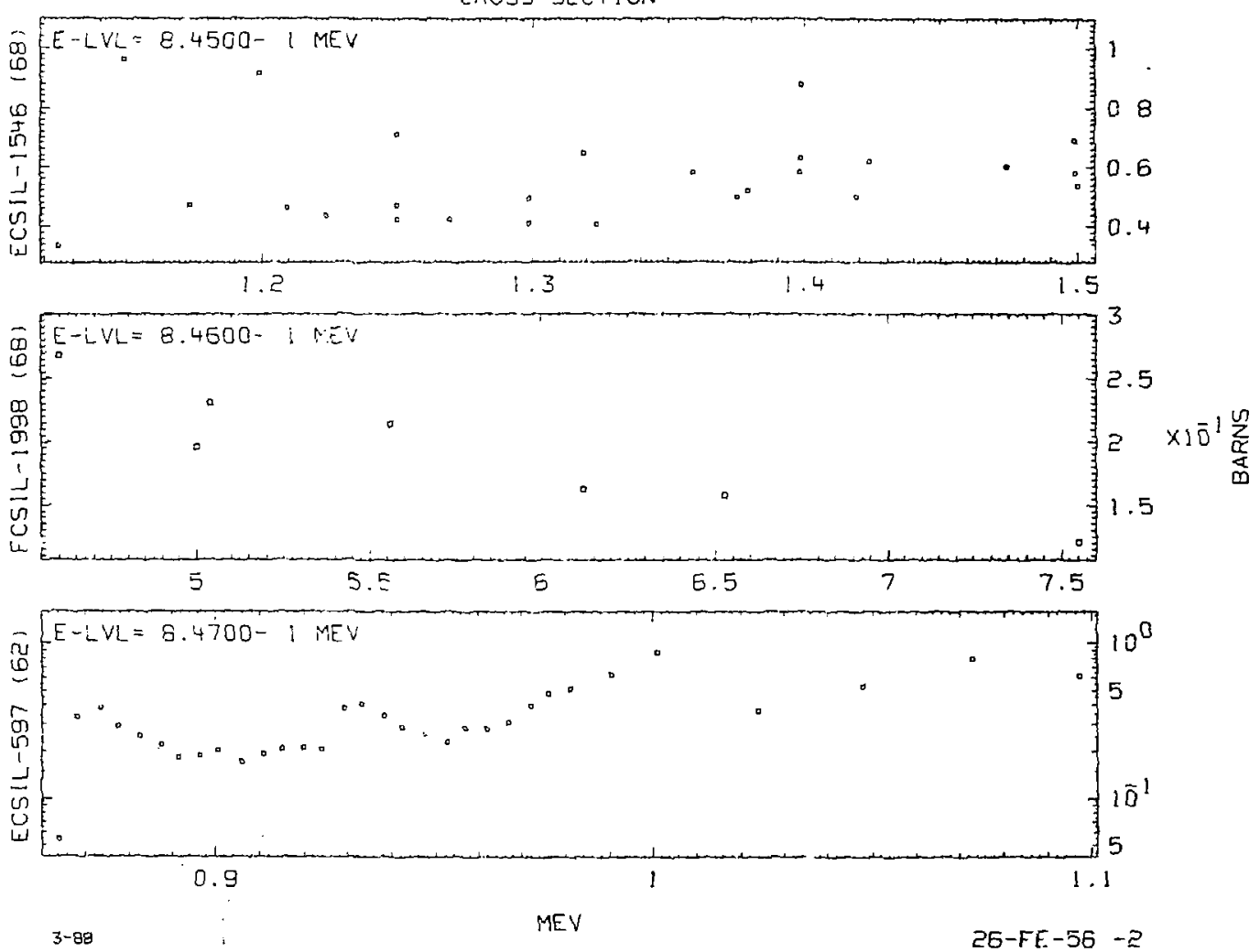

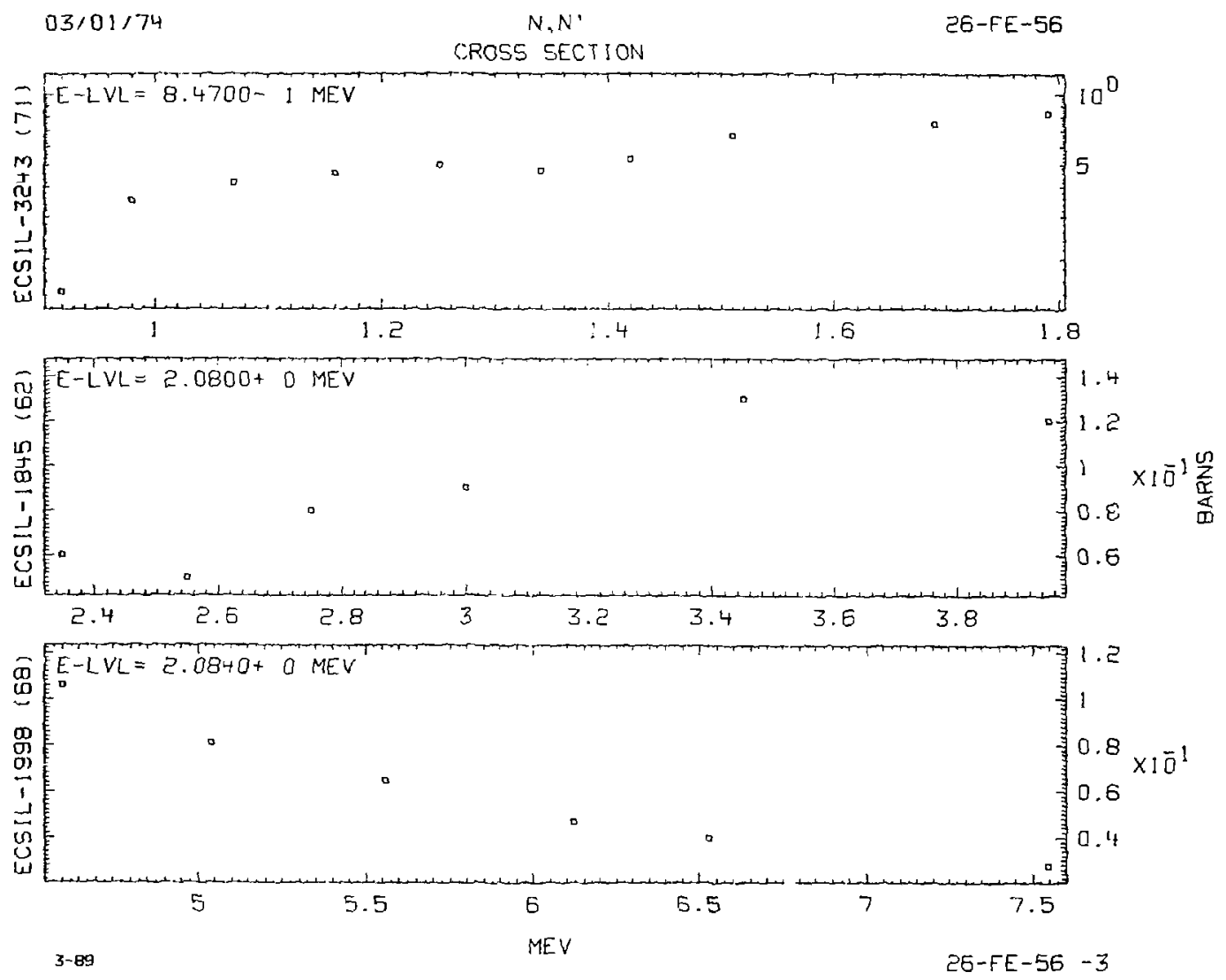

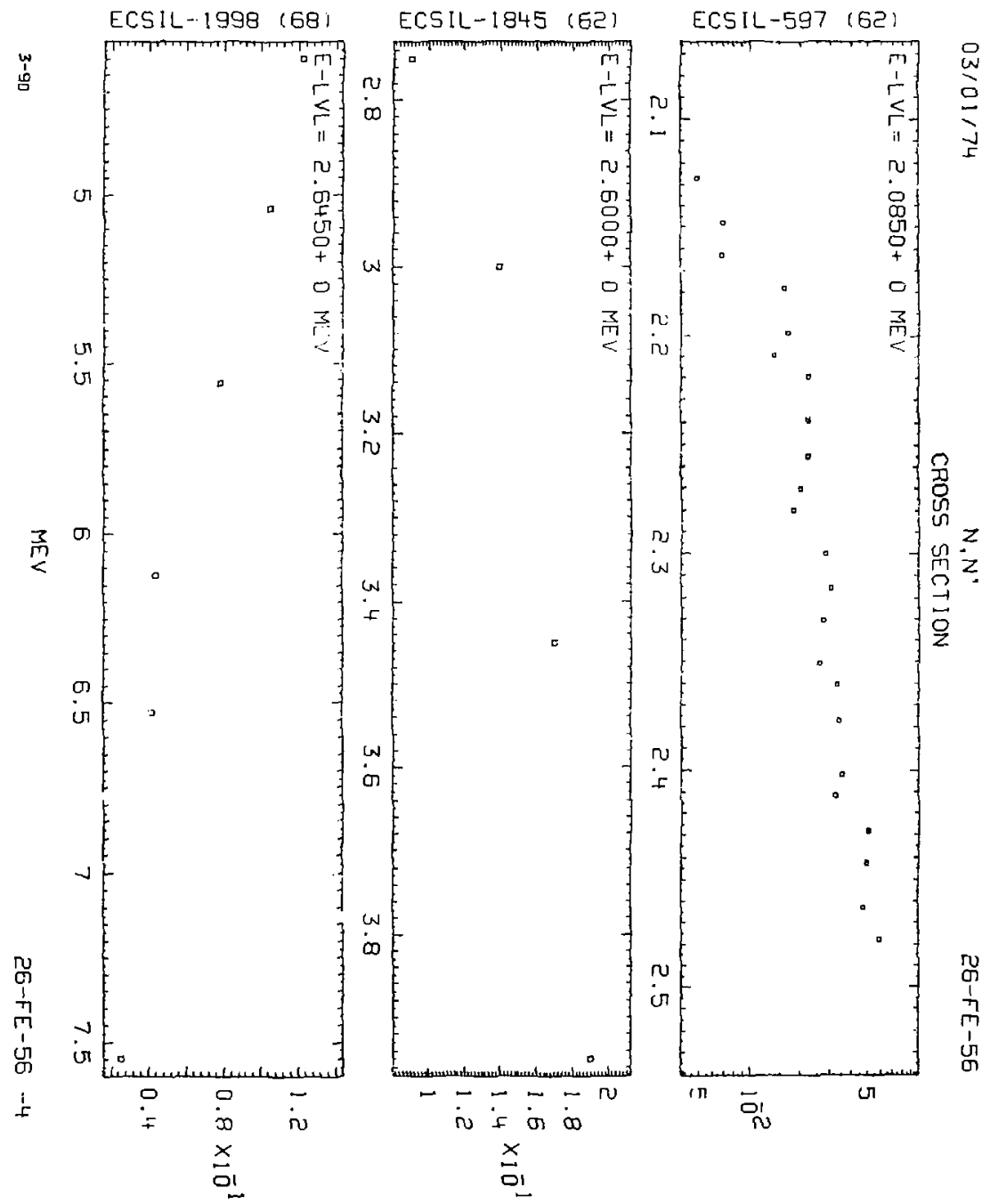

BARNS 

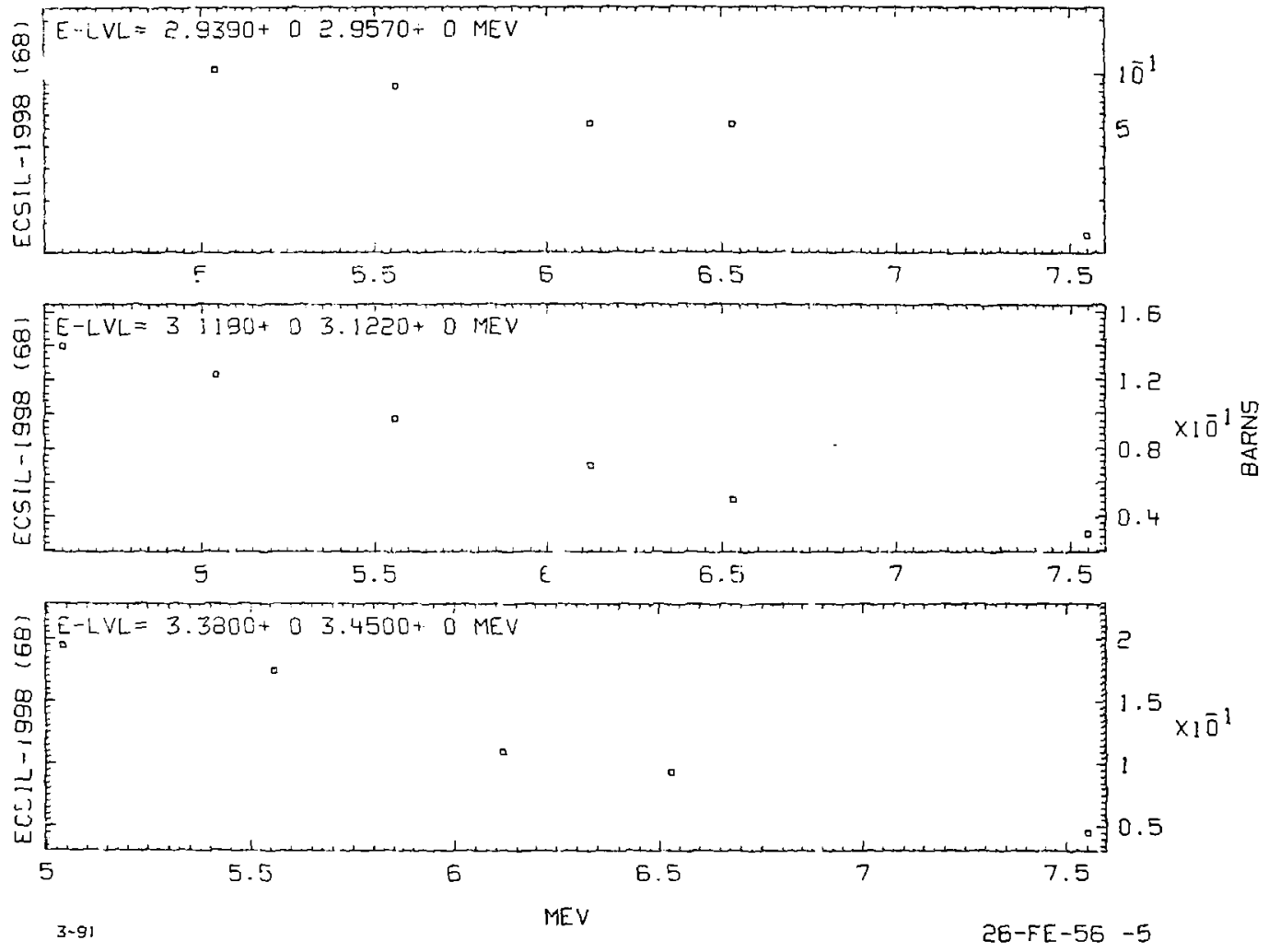

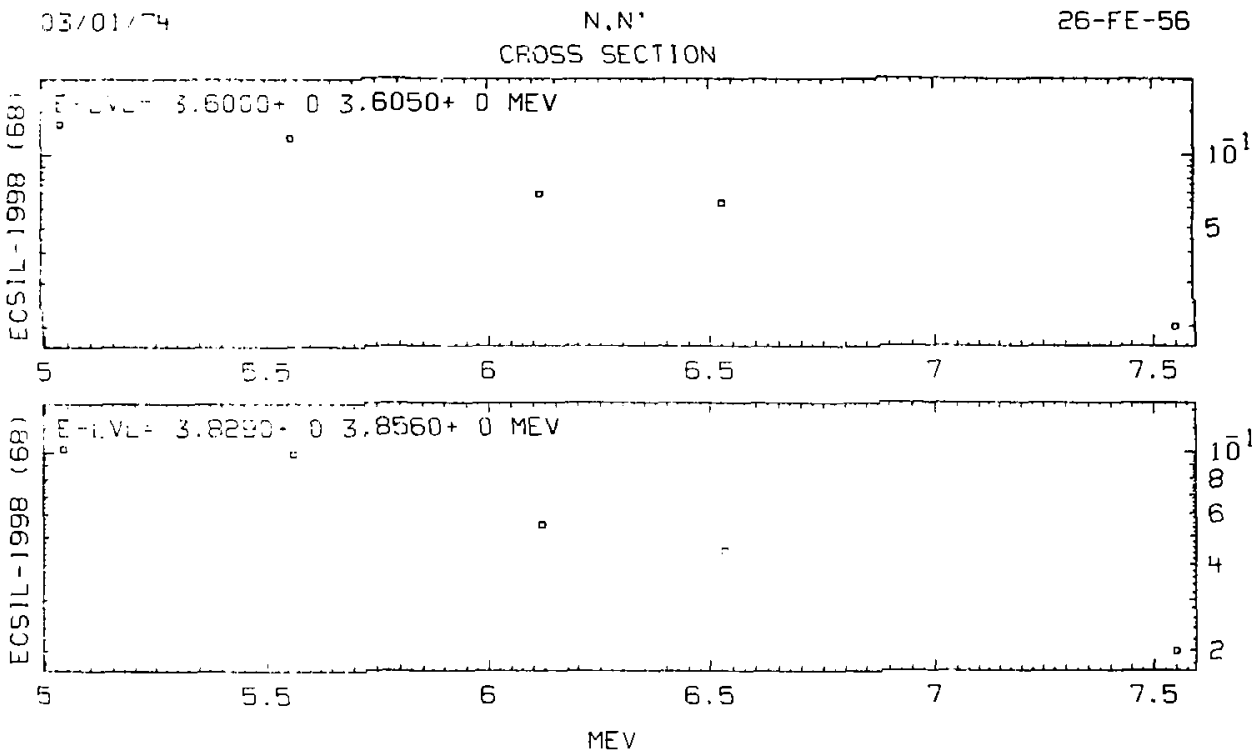

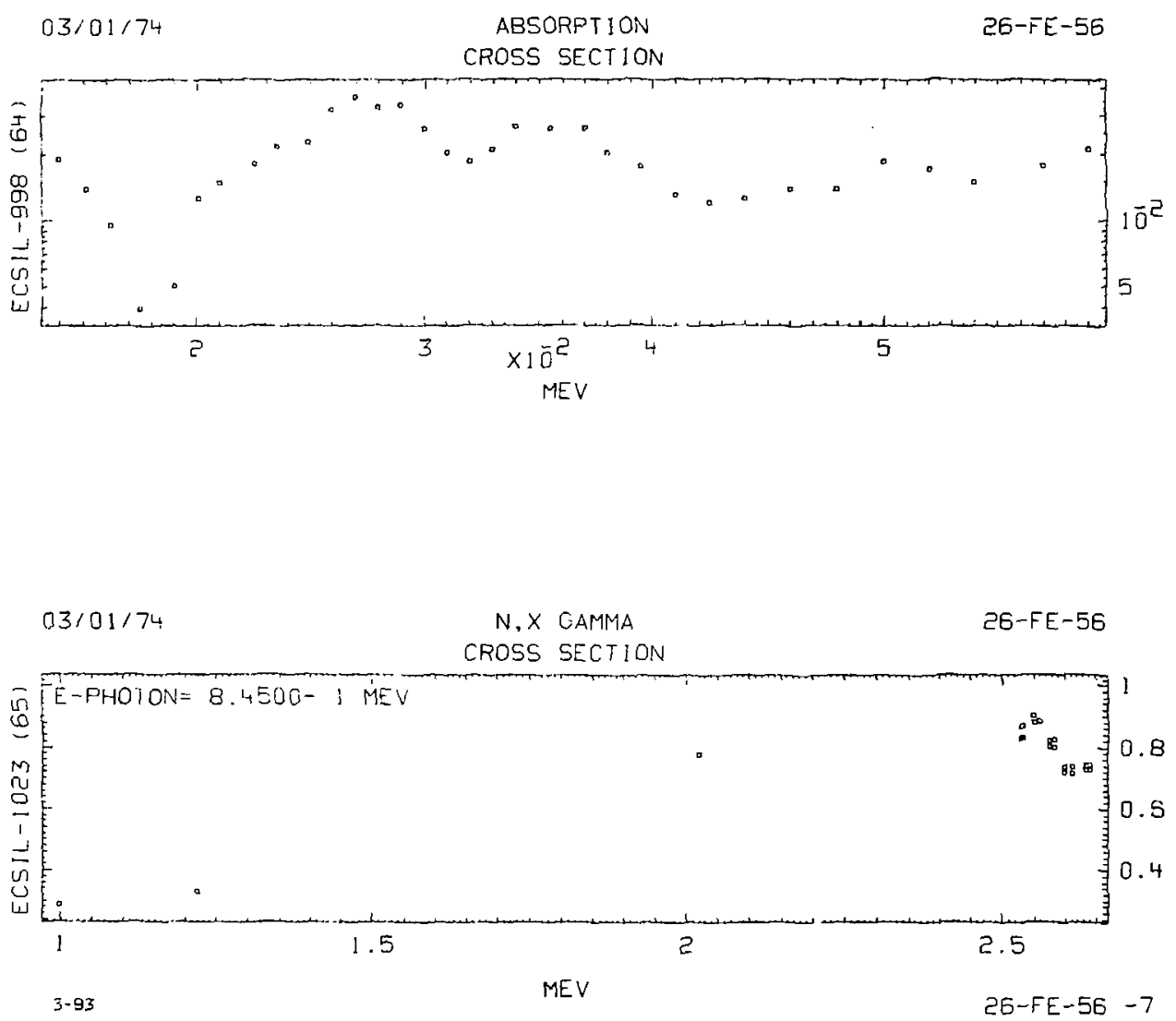

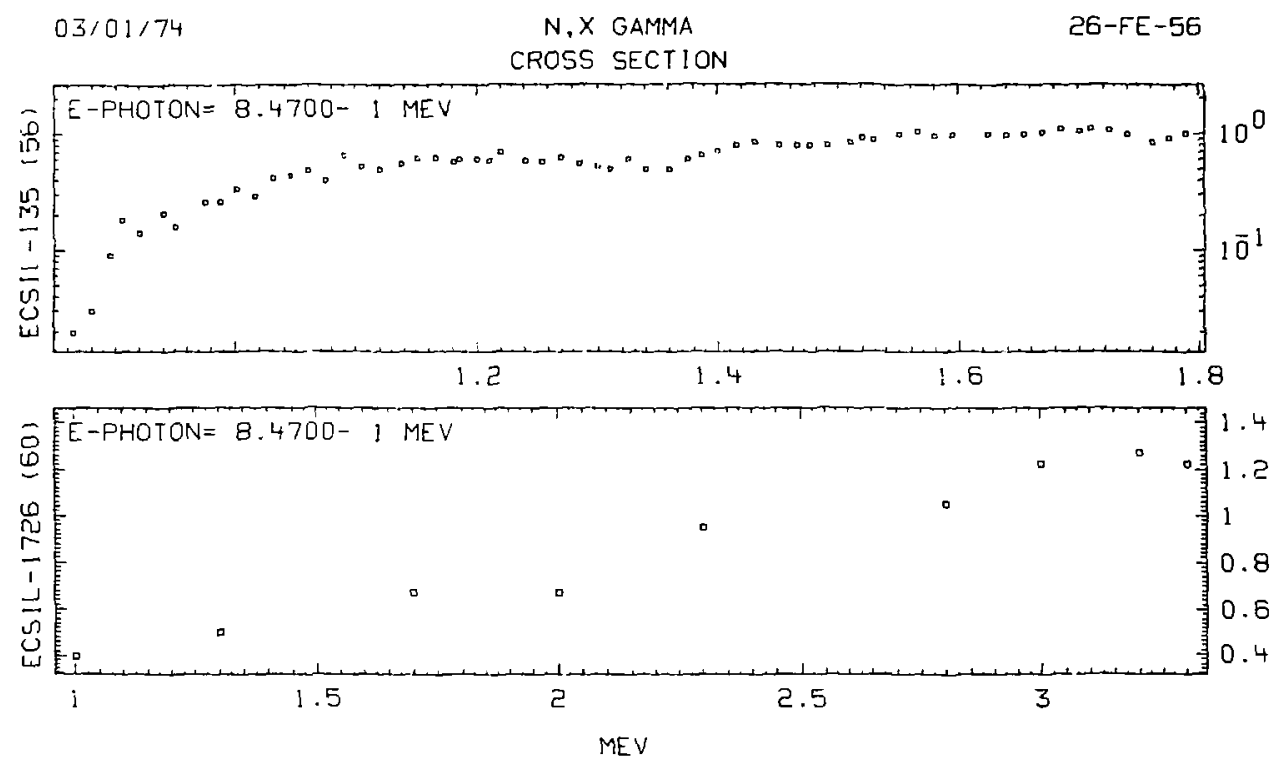

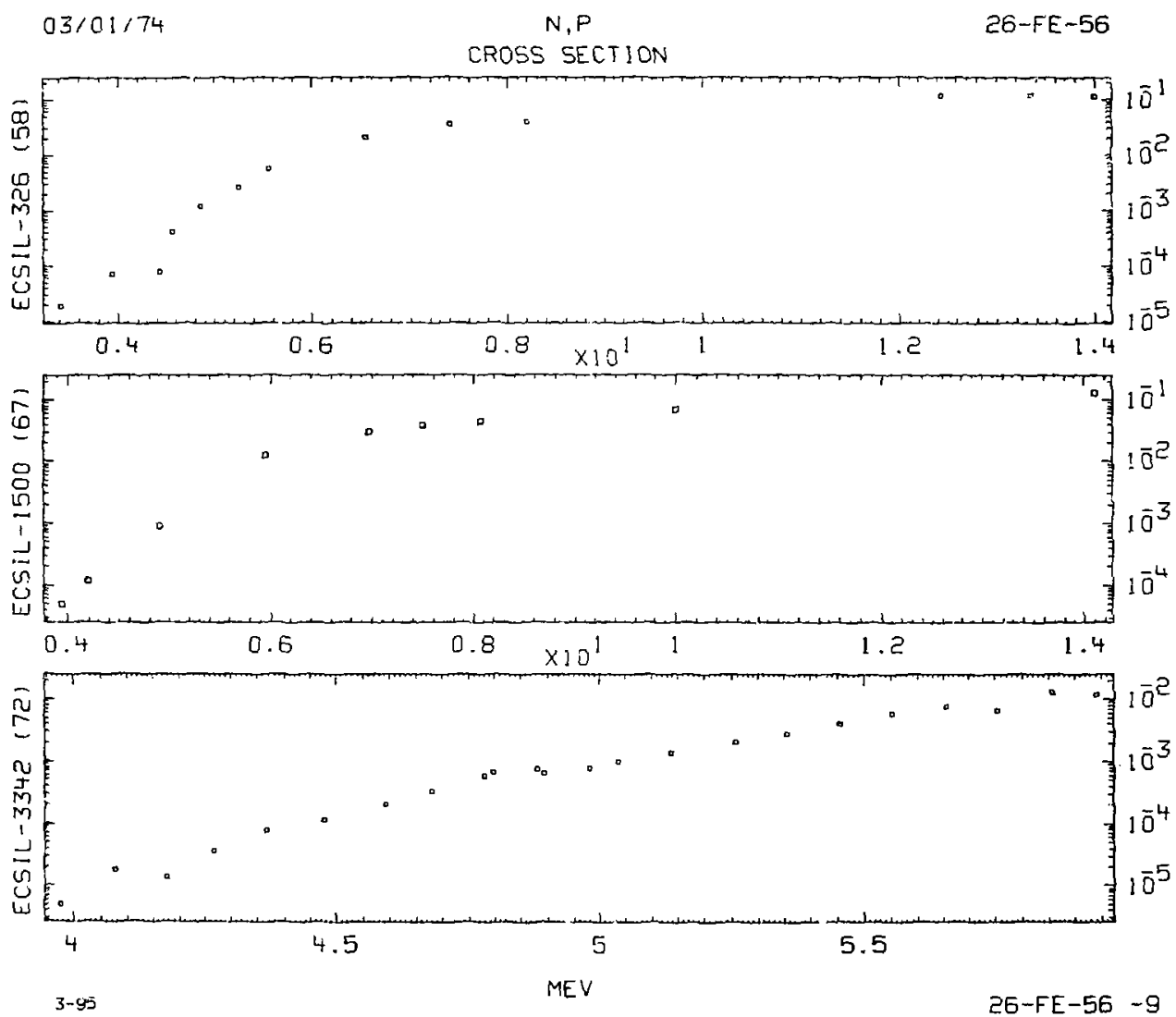


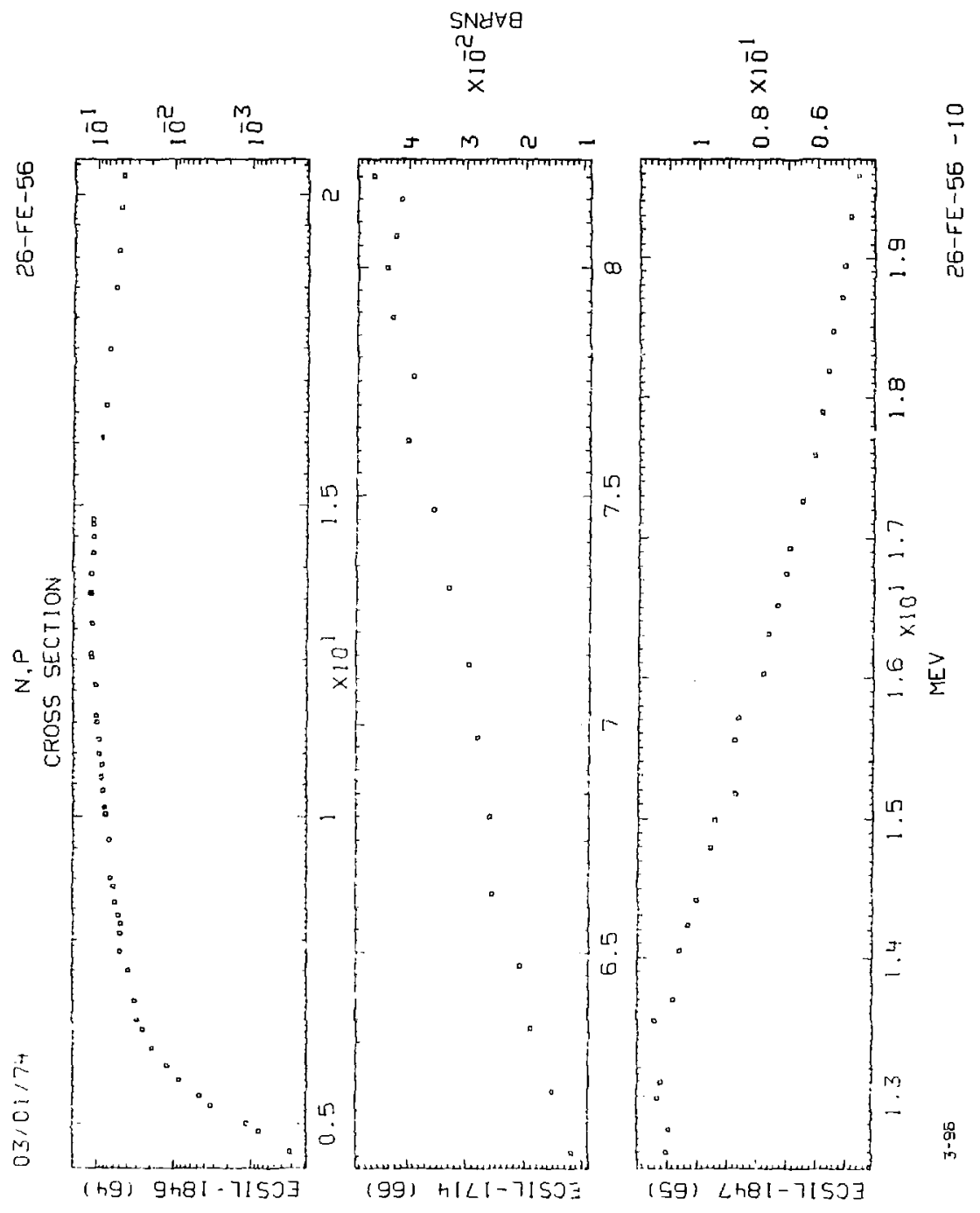



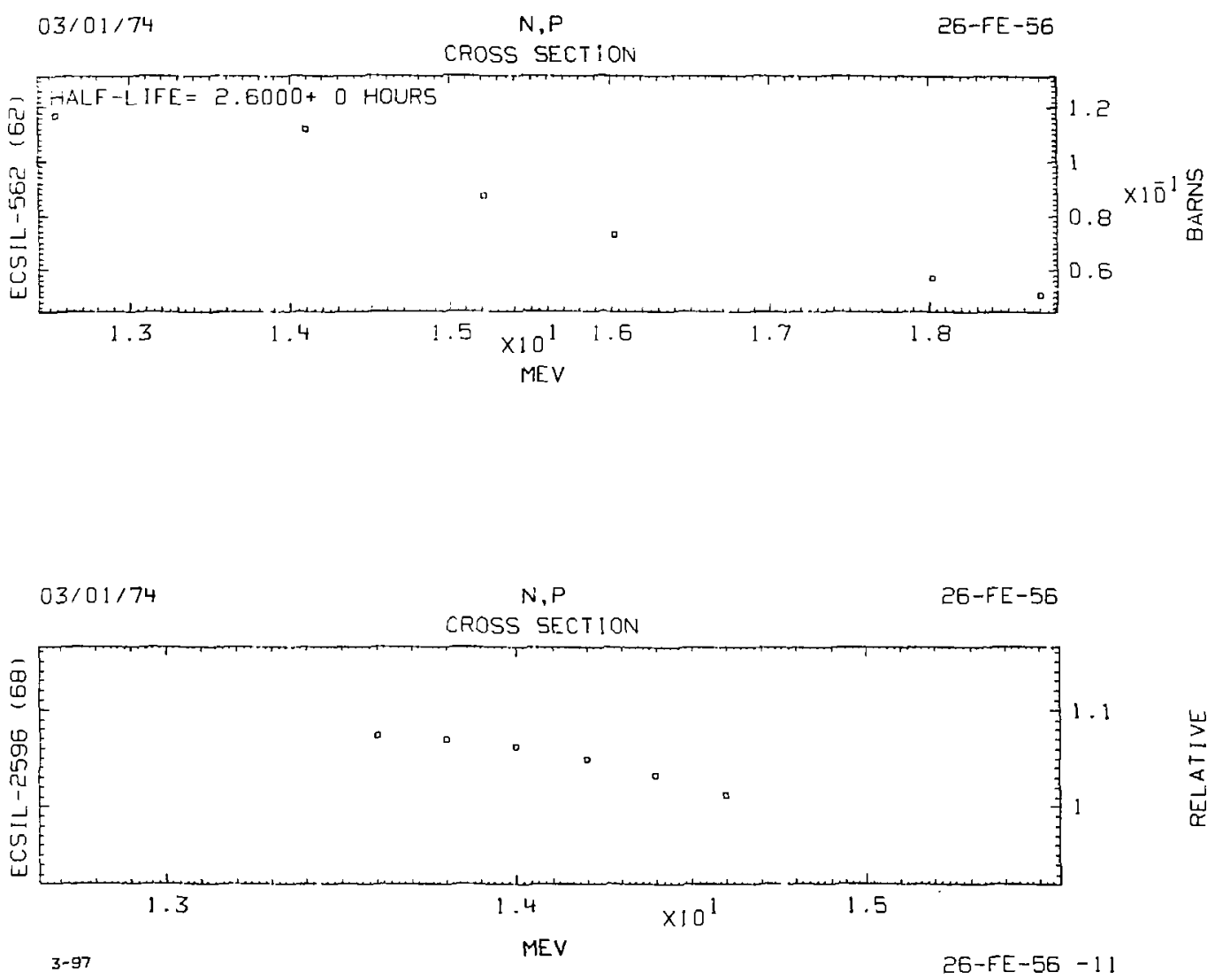

$\stackrel{w}{\stackrel{w}{\longleftarrow}}$ 


\section{CROSS SECTION}

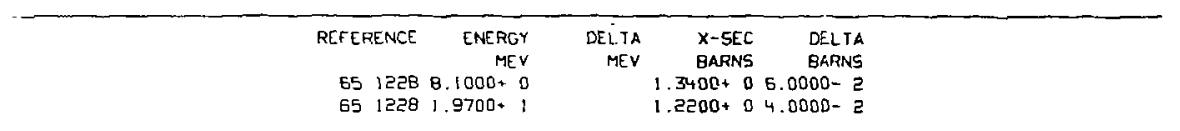

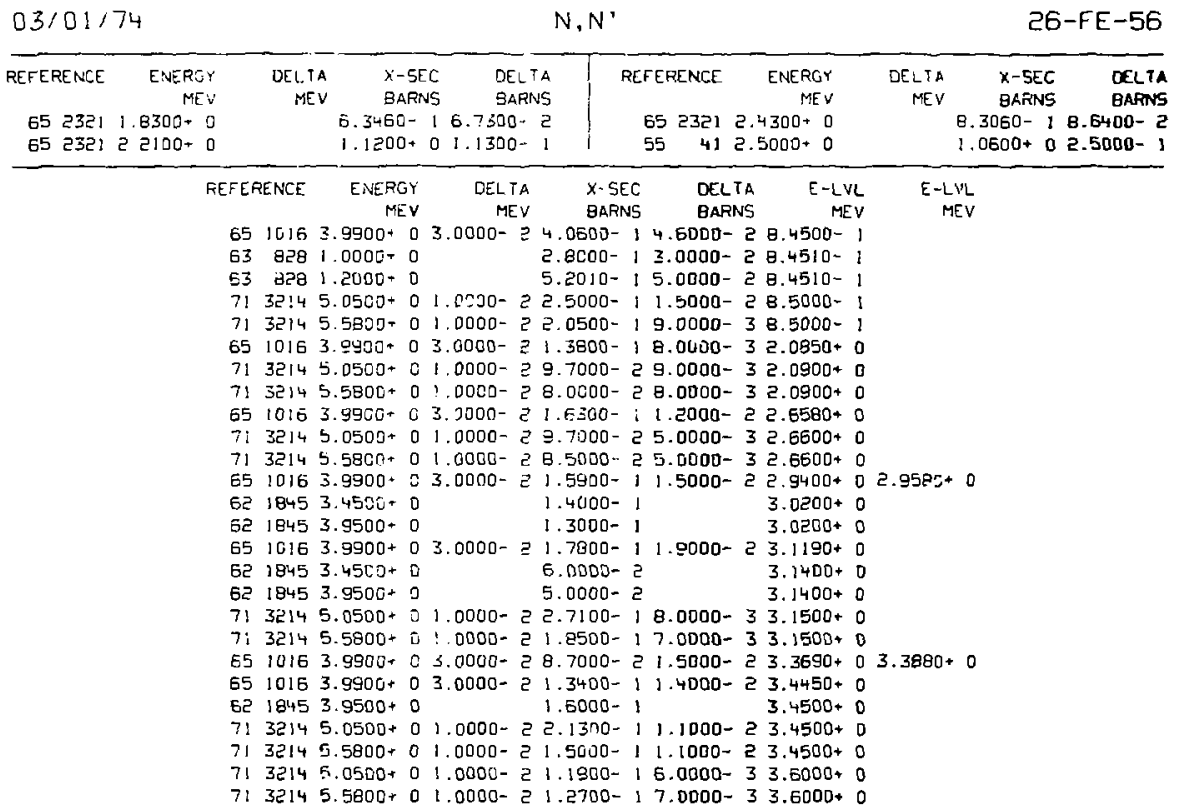




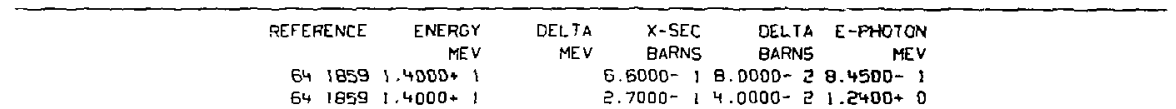

$03 / 01 / 74$

$N, 2 N$

$26-F E-56$

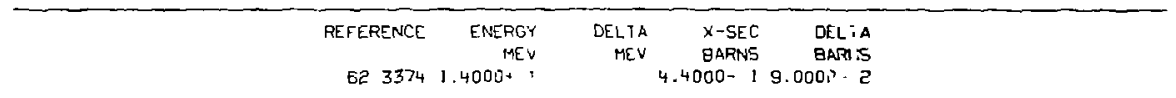

\section{$03 / 01 / 74$}

$N, N \cdot P$

$26-F E-56$

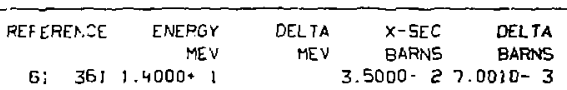

$03 / 01 / 74$

$N, X$ GAT' $1 A$

$26-F E-56$

$\begin{array}{rrrrr}\text { REFERENCE ENERGY } & \text { DELTA } & \text { X-SEC } & \text { DELTA E-PHOTON } \\ \text { MEV } & \text { MEV } & \text { BAFN5 } & \text { BARNS r MEV } \\ 61 \text { EJ5 } 2.9000+0 & 1.7000-: 1.2600+0 & 6.0000-28.4700-1\end{array}$

$03 / 01 / 74$

$N, P$

26-FE-56

\begin{tabular}{|c|c|c|c|c|c|c|c|c|c|c|}
\hline \multicolumn{2}{|c|}{ REFEF 'NCE } & $\begin{array}{r}\text { ENERGY } \\
\text { MEV }\end{array}$ & $\begin{array}{r}\text { DELT } \\
\text { ME }\end{array}$ & $\begin{array}{l}X \text { - SEC } \\
\text { BLRNS }\end{array}$ & $\begin{array}{l}\text { DEL TA } \\
\text { BMPNS }\end{array}$ & REFERENCE & $\begin{array}{r}\text { ENERGY } \\
\text { MEV }\end{array}$ & $\begin{array}{c}\text { DELTA } \\
\text { MEV }\end{array}$ & $\begin{array}{l}X-S E C \\
\text { BARNS }\end{array}$ & $\begin{array}{l}\text { DELTA } \\
\text { BARNS }\end{array}$ \\
\hline 62 & 1006 & $1.3580-1$ & 1 & $1.0600-i$ & $\therefore 1.0600-2$ & 621009 & $1.4500+1$ & & $1.0600-1$ & $6.0000-3$ \\
\hline 55 & 202 & $1.4000+1$ & 1 & $7.2000-2$ & $27.2000-3$ & 631009 & $1.4500+!$ & ! & $1.0700-1$ & $8.0000-3$ \\
\hline 57 & 217 & $1.4000+1$ & 1 & $1.9000-1$ & $13.8000-2$ & 53 & $1.4500+1$ & I & $9.6710-2$ & $000-2$ \\
\hline $6 !$ & 361 & $1.4000+1$ & 1 & $8.2010-2$ & $21.3000-2$ & 723345 & $1.4500+1$ & ! & $1.4840-1$ & $00-5$ \\
\hline $6 ?$ & 1008 & $1.4070+1$ & 1 & $1.0800-1$ & $11.0800-2$ & 592354 & $1.4600+1$ & $12.0000-1$ & $1.1300-1$ & $8.0000-2$ \\
\hline ' & 84 & $1.4300+1$ & 1 & $1.2400-1$ & $11.2400-2$ & 682596 & $1.4700+1$ & $17.5000-2$ & $=1.0000-1$ & $4.0000-3$ \\
\hline 60 & 837 & $1.4100+1$ & $11.0000-$ & $19.0010-a$ & $21.0000-2$ & $64 \quad 1848$ & $1.4700+1$ & $11.5000-1$ & $11.0500-1$ & $2.5000-3$ \\
\hline 51 & 651 & $1.4100+1$ & 1 & 1.1200-1 & 1 $5.6010-3$ & 621008 & $1.4730+1$ & & $1.0000-1$ & $1.0000-2$ \\
\hline 57 & 535 & $1.4148+1$ & $11.8000-$ & $11.4400=1$ & $11.8700-2$ & 692354 & $1.4600+1$ & 1 & $1.0520-1$ & $9.0000-3$ \\
\hline 62 & 806 & $1.4400+1$ & $12.5000-$ & 2 $1.0800-1$ & $11.0000-2$ & 582711 & $1.4800+1$ & $12,0000-1$ & $11.0900-1$ & $9.0000-3$ \\
\hline
\end{tabular}


CROSS SECTION

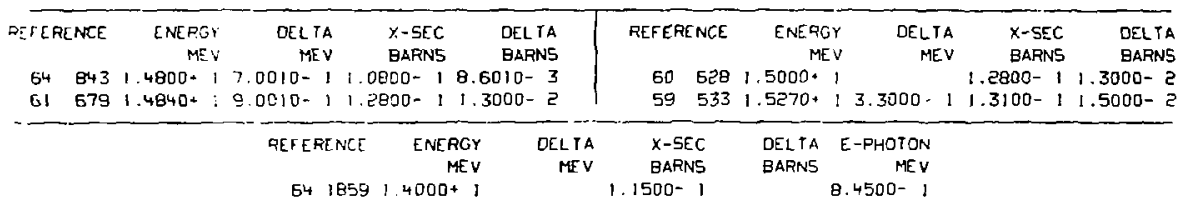

$543859,4000+1$

1. $1500-1$

26-FE-56

$03 / 01 / 74$

N. X P

RETTREINE ENERGY DELTA X-SEC DELTA

57 154 $73.3200 .12 .0000-11,2000-13.0000-2$

$03 / 01 / 74 \quad$ N.ALPHA 26-FE-56

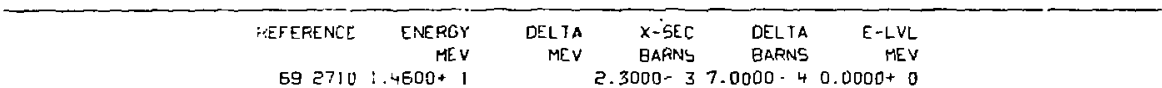

$03 / 01 / 74$

EOUND ATOM

$2 E-F E-56$

\begin{tabular}{|c|c|c|c|c|c|}
\hline & $\begin{array}{l}\text { REFERENCE } \\
\text { 51 } 1594\end{array}$ & $\begin{array}{r}\text { ENERGY } \\
\text { MEV } \\
7.3000-8\end{array}$ & $\begin{array}{rr}\text { DELTA } & x-\text { SEC } \\
\text { MEV } & \text { BARNS } \\
1,3000+1\end{array}$ & $\begin{array}{l}\text { CELTA } \\
\text { BARNS }\end{array}$ & \\
\hline $03 / 01 / 74$ & & COHEPEINT & SCAT TER ING & & $2 E-F E-56$ \\
\hline & REFEREWWE & $\begin{array}{r}\text { ENERGY } \\
\text { MEV }\end{array}$ & $\begin{array}{rr}\text { DELTA } & X \text {-SEC } \\
\text { MEV } & \text { BARNS }\end{array}$ & $\begin{array}{l}\text { DELTA } \\
\text { BARNS }\end{array}$ & \\
\hline
\end{tabular}

$5115847.3000-9$ 


\begin{tabular}{|c|c|c|c|c|c|}
\hline \multirow[t]{2}{*}{$03 / 01 / 74$} & \multicolumn{5}{|c|}{$N, N^{\prime} P$} \\
\hline & & CROSS & SECTION & & \\
\hline & REF ERENCE & $\begin{array}{l}\text { ENFEGGY } \\
\text { HEEY }\end{array}$ & $\begin{array}{r}\text { DELTA } \\
\text { MEV }\end{array}$ & $\begin{array}{l}x-\text { SEC } \\
\text { GARNS }\end{array}$ & $\begin{array}{l}\text { DELTA } \\
\text { BAPNSS }\end{array}$ \\
\hline
\end{tabular}

\begin{tabular}{|c|c|c|c|c|c|c|c|c|c|}
\hline $03 / 01$ & & & & & & & & 26 & $-F E-57$ \\
\hline$P E=E A E N C$ & ENERGY & $D E: T A$ & $x-5 E C$ & DELTA & REF ERENCE & ENLRGY & DELTA & $x$-SEC & $\begin{array}{l}\text { DELTA } \\
\text { GARNS }\end{array}$ \\
\hline $51 \quad 65$ & $\begin{array}{r}\text { MEV } \\
.4100+1\end{array}$ & MEV & $\begin{array}{l}\text { BARN5 } \\
\text { DOD- } ?\end{array}$ & $\begin{array}{r}\text { BAFNS } \\
000 \text { - }\end{array}$ & $72 \quad 3345$ & $\begin{array}{r}\text { MEY } \\
.4500+1\end{array}$ & MEV & $\begin{array}{r}\text { BARNS } \\
3.1500-2\end{array}$ & $\begin{array}{r}\text { BARNS } \\
2.0000=3\end{array}$ \\
\hline$E 3100$ & $.4500+1$ & & $600-\geqq$ & $0000-3$ & E) 579 & $.4800+1$ & $1010-1$ & $7.1010-2$ & $7.0000-3$ \\
\hline
\end{tabular}

$03 / 01 / 74 \quad$ BOUND ATOM 26-FE-57

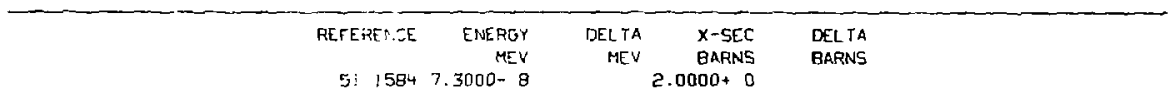

$03 / 01 / 74$

COHERENT SCATTER:NG

$26-F E-57$

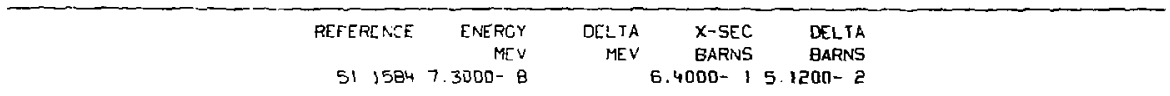

$03 / 01 / 74$

$N, P$

$2 G-F E-58$

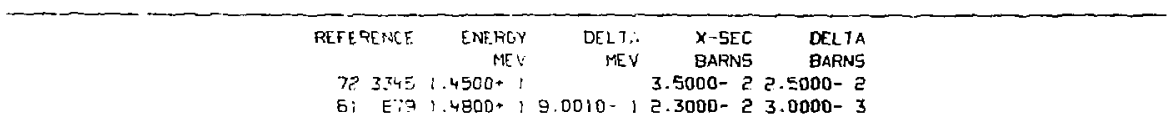

$05 / 01 / 74$

$$
\text { N, ALPHA }
$$

$26-F E-58$

$\begin{array}{rrrr}\text { REFERENCE ENERGY DELTA } & \text { X-SEC } & \text { DELTA } \\ & \text { MEV MARNS }\end{array}$

3-101 

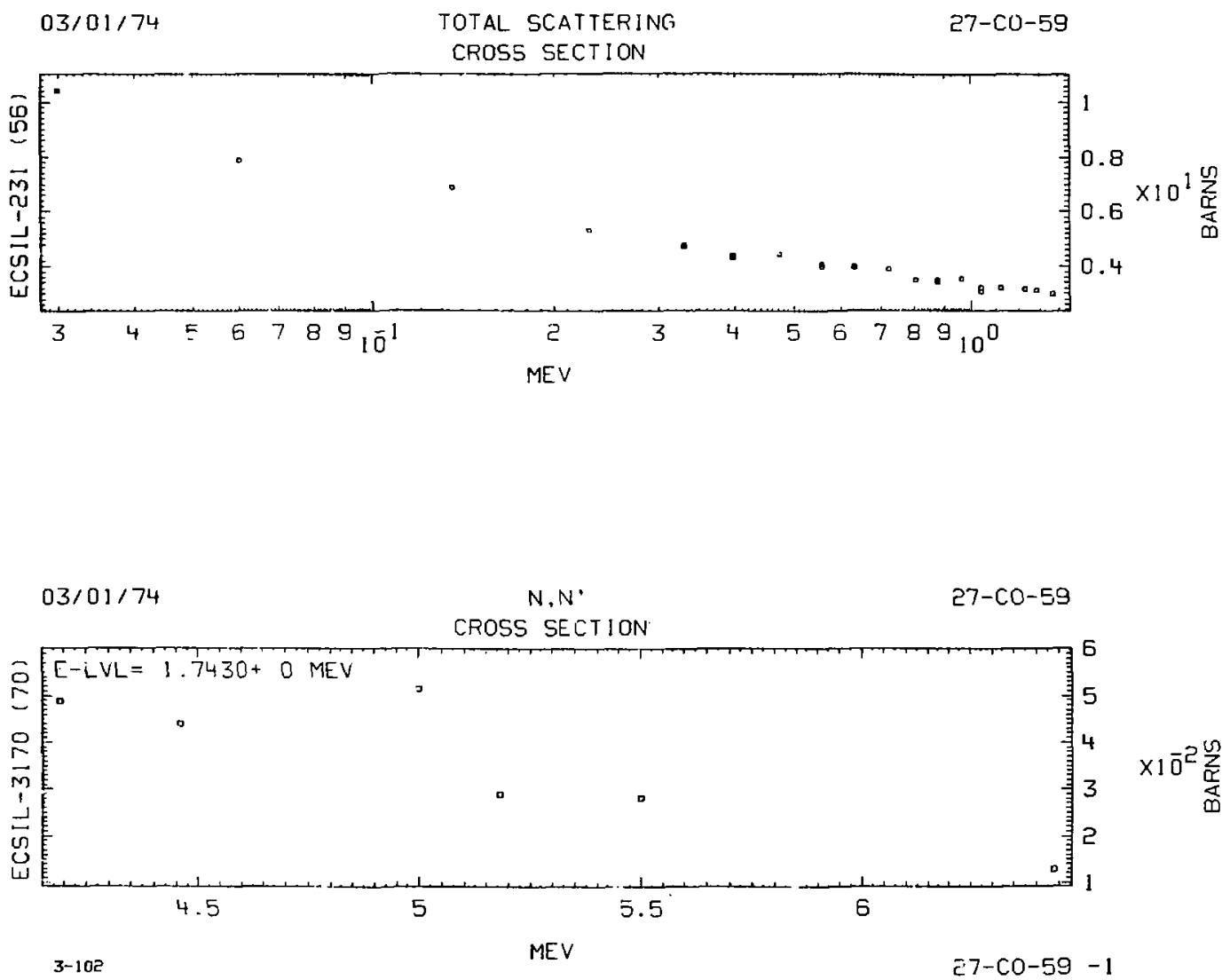


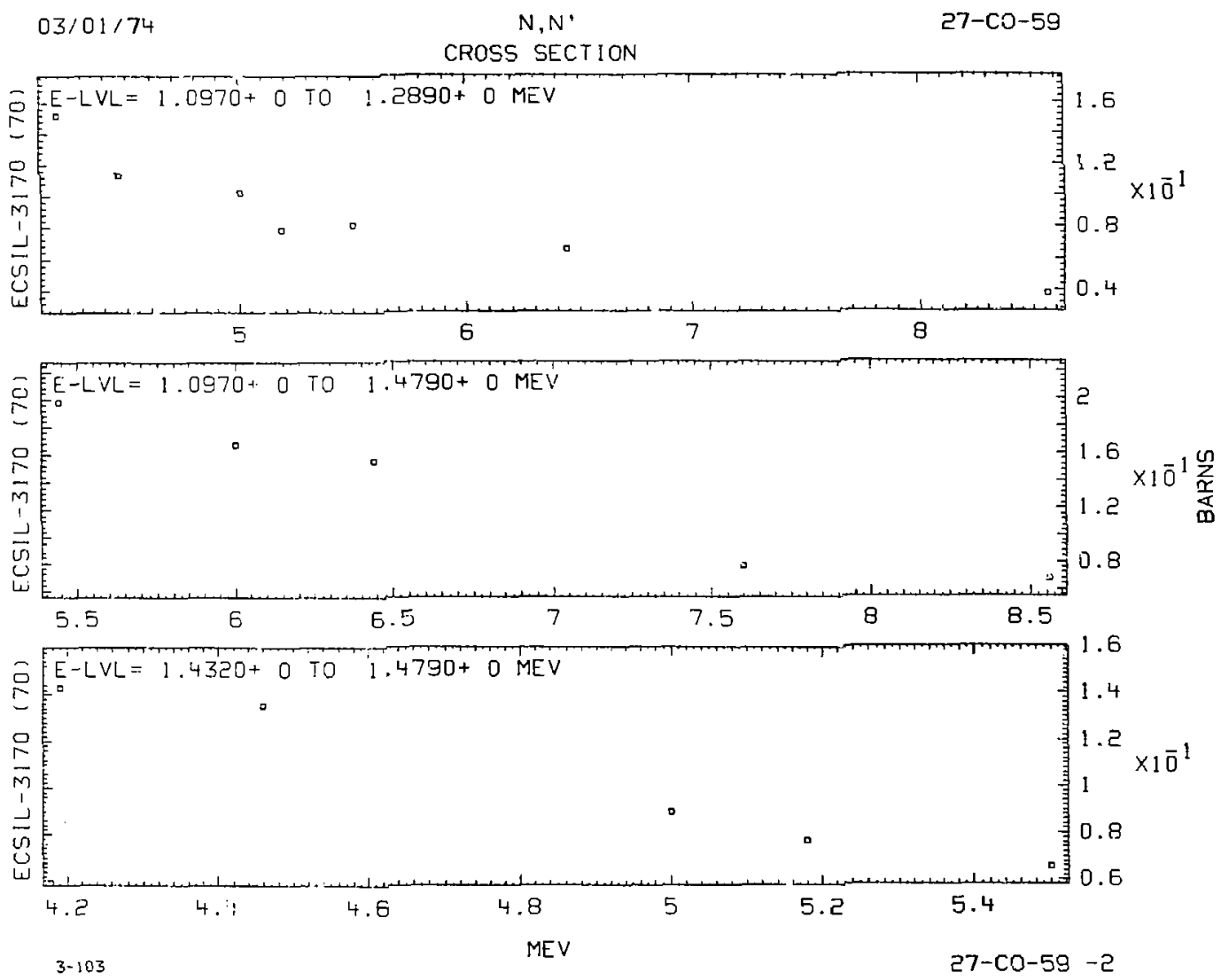



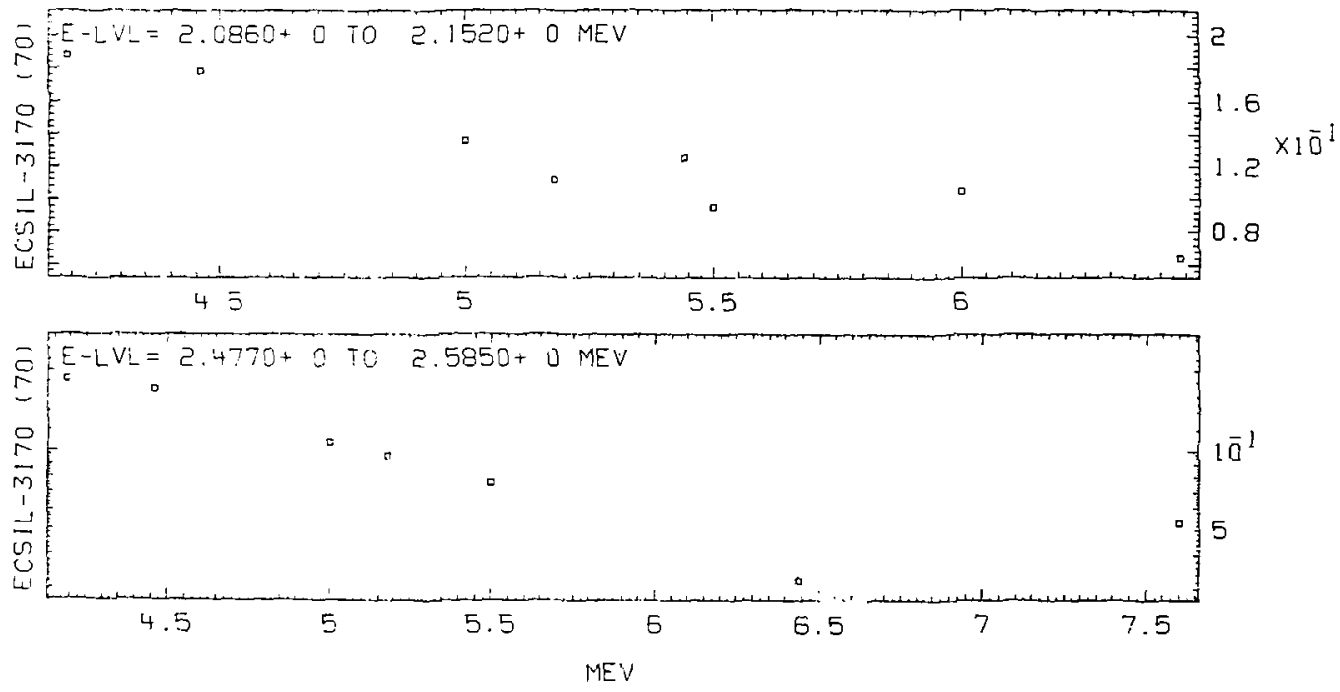


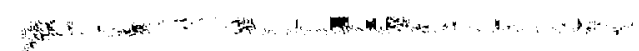

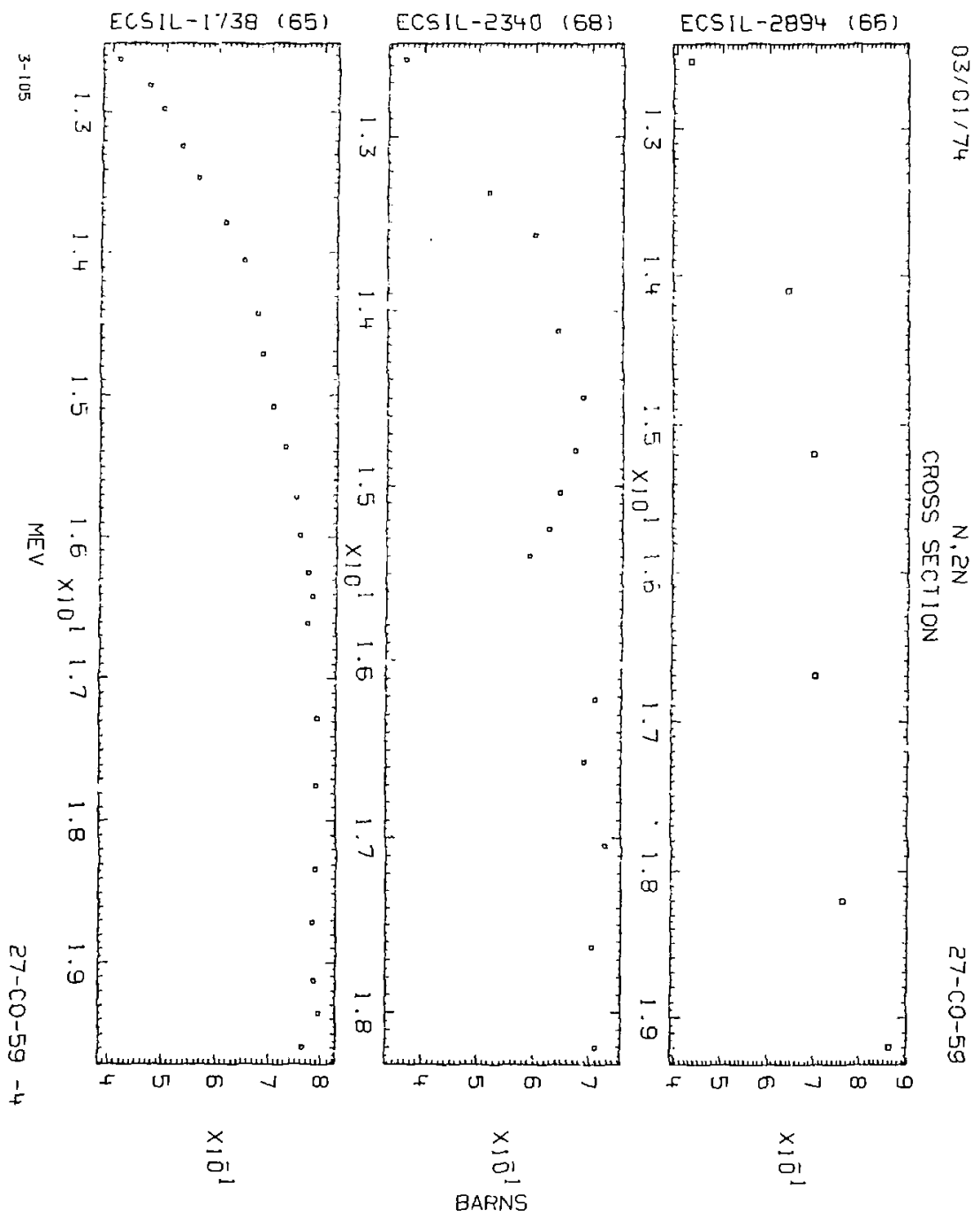



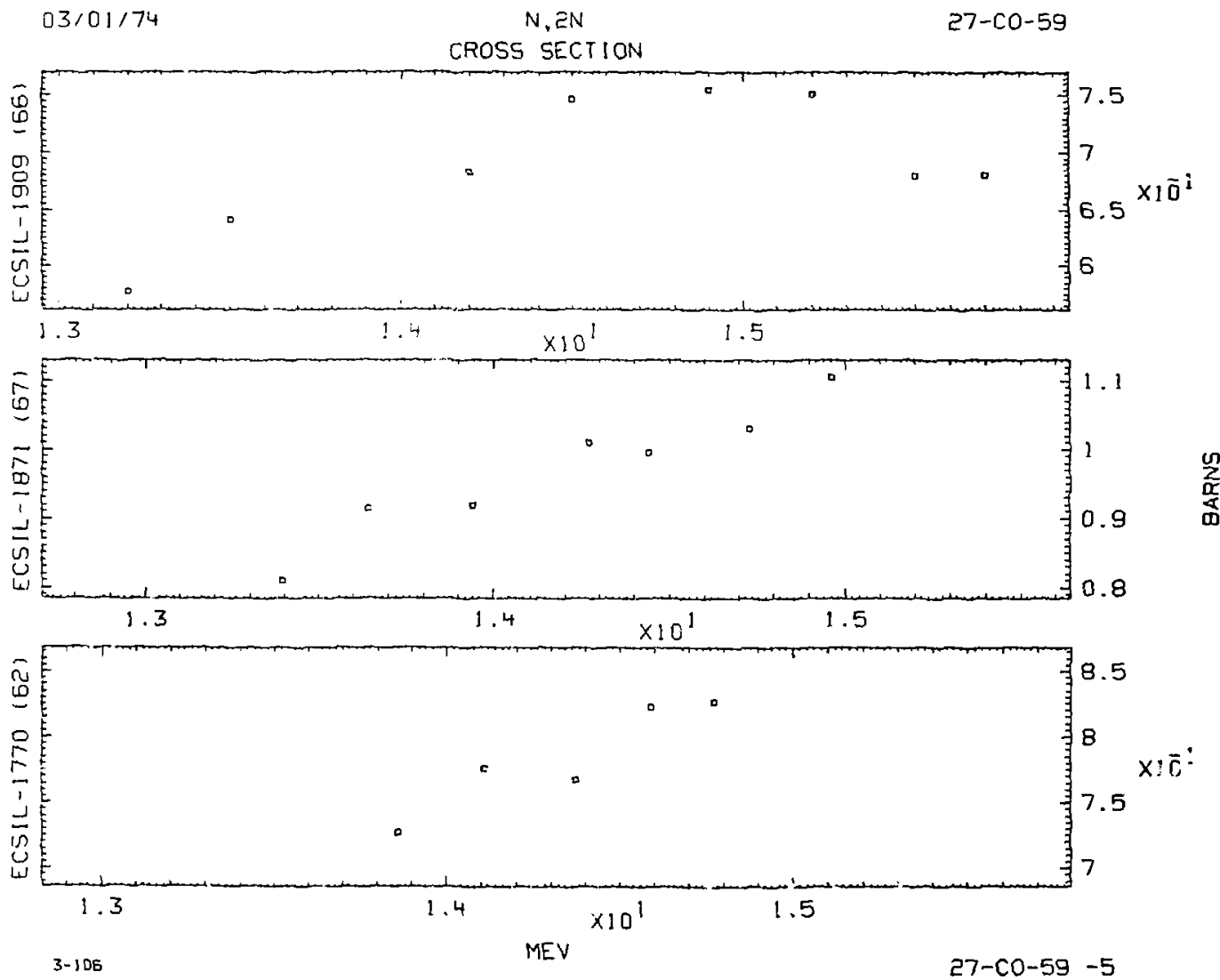


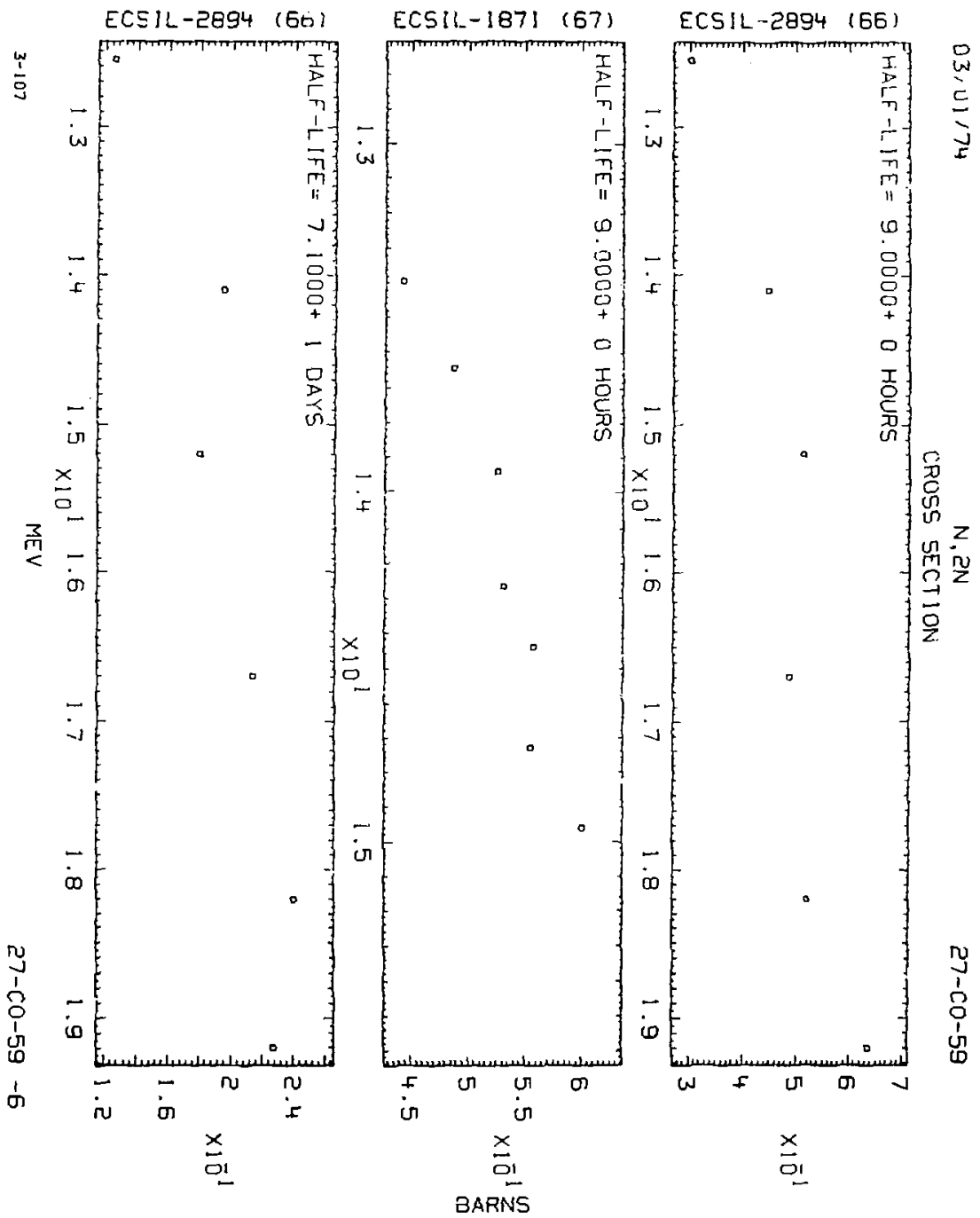




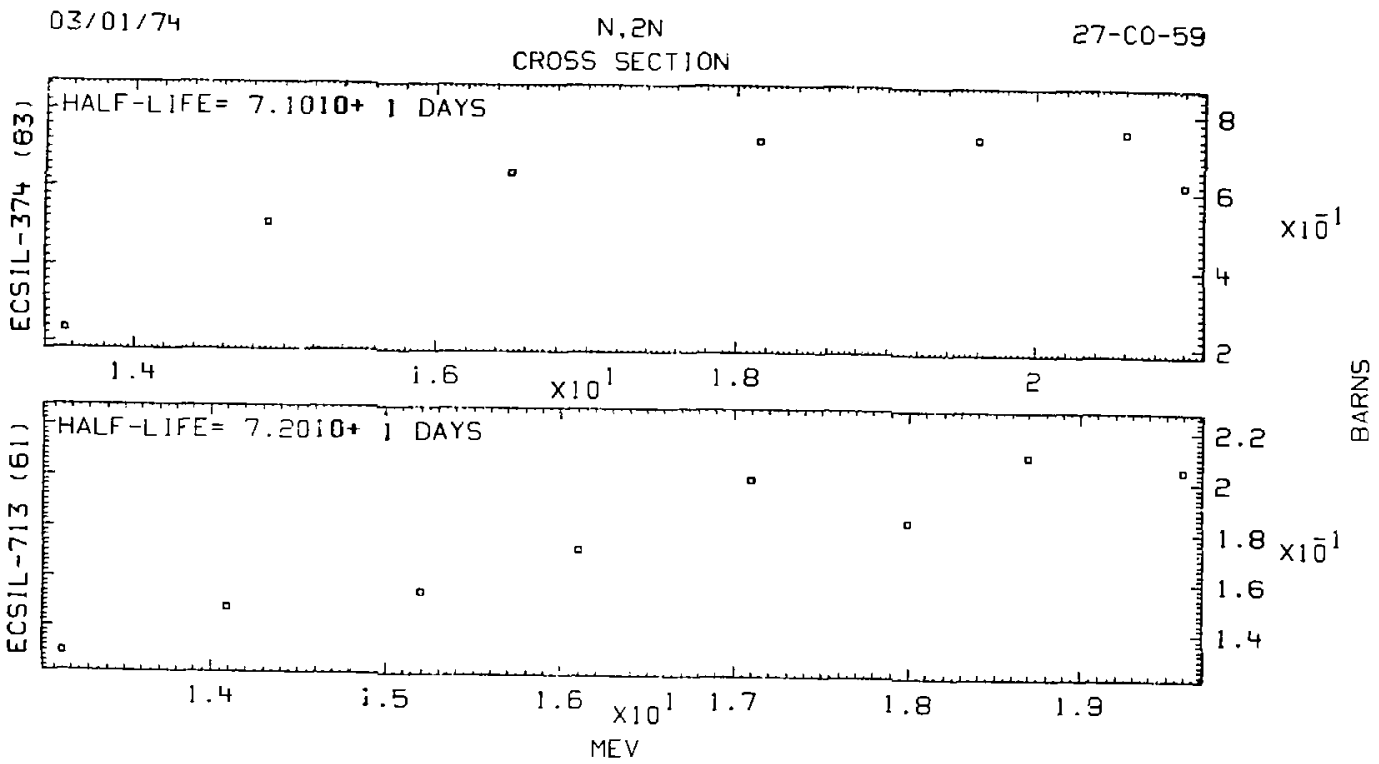



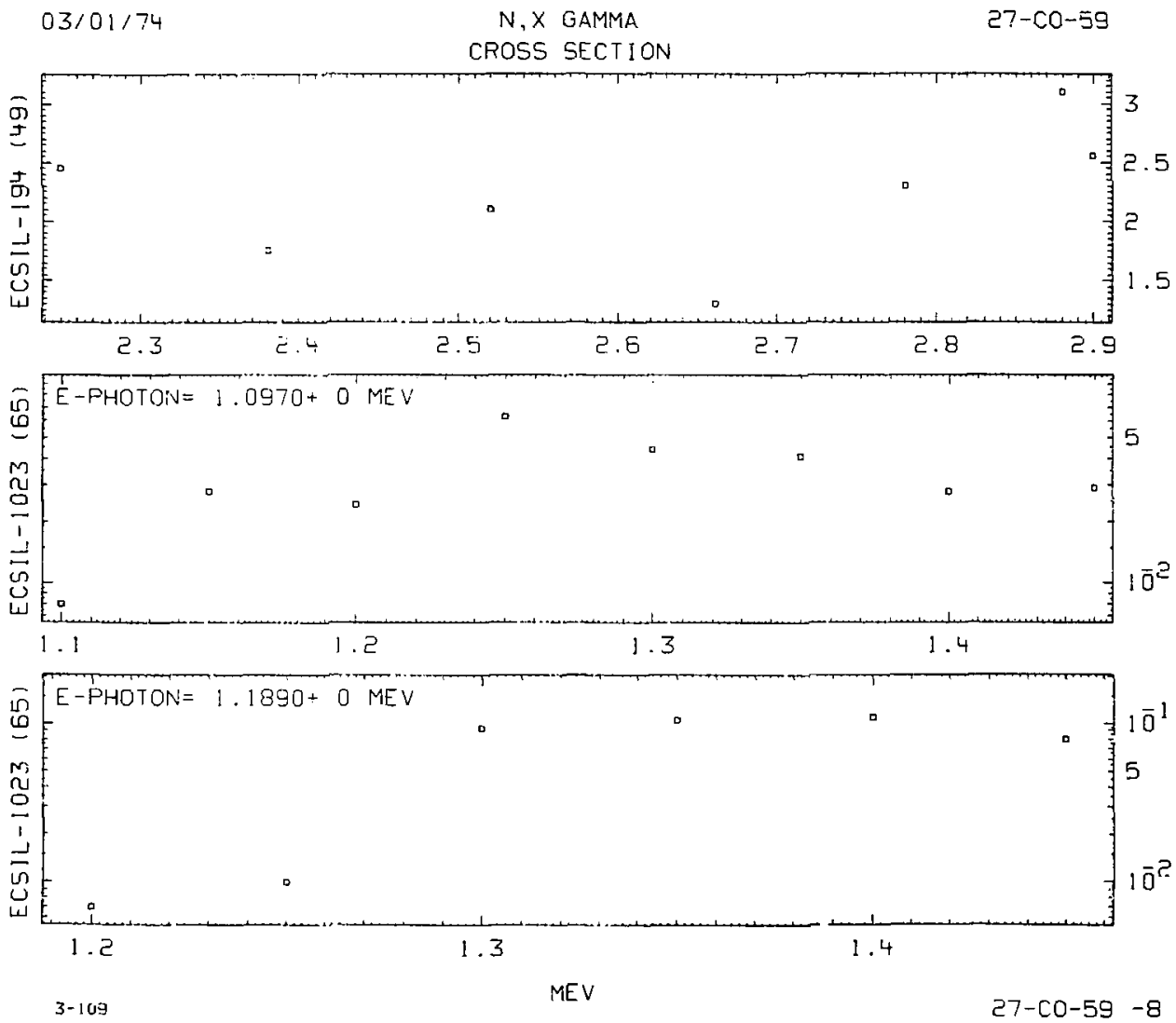


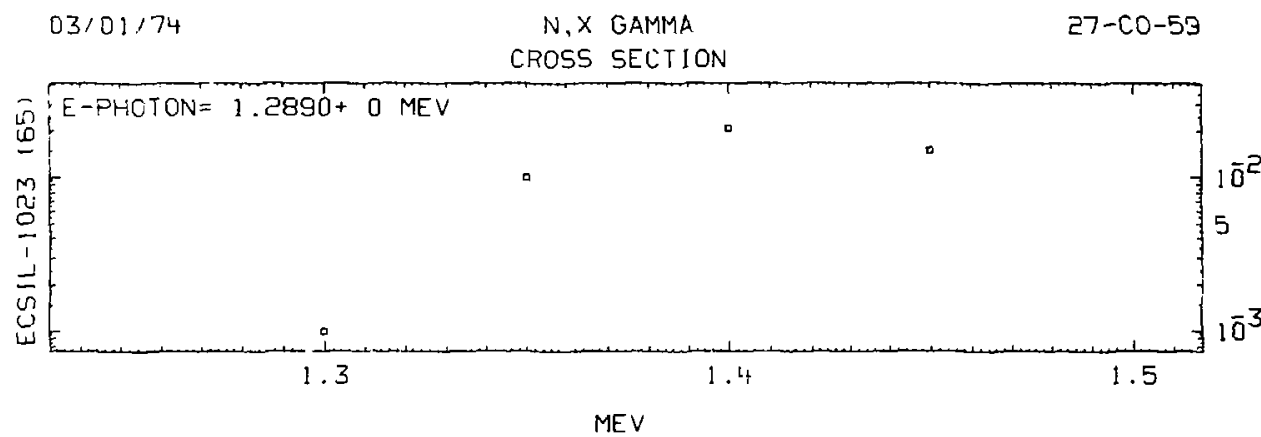

$05 / 01 / 74$

$N, P$

$27-\mathrm{CO}-59$

\section{CROSS SECTION}

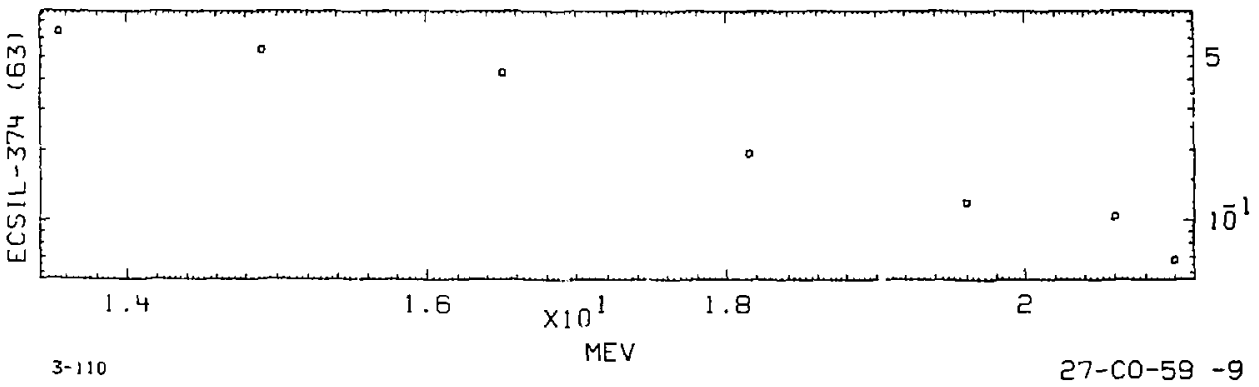

$\underset{\substack{\frac{\pi}{2} \\ \frac{\pi}{2}}}{\stackrel{n}{2}}$ 

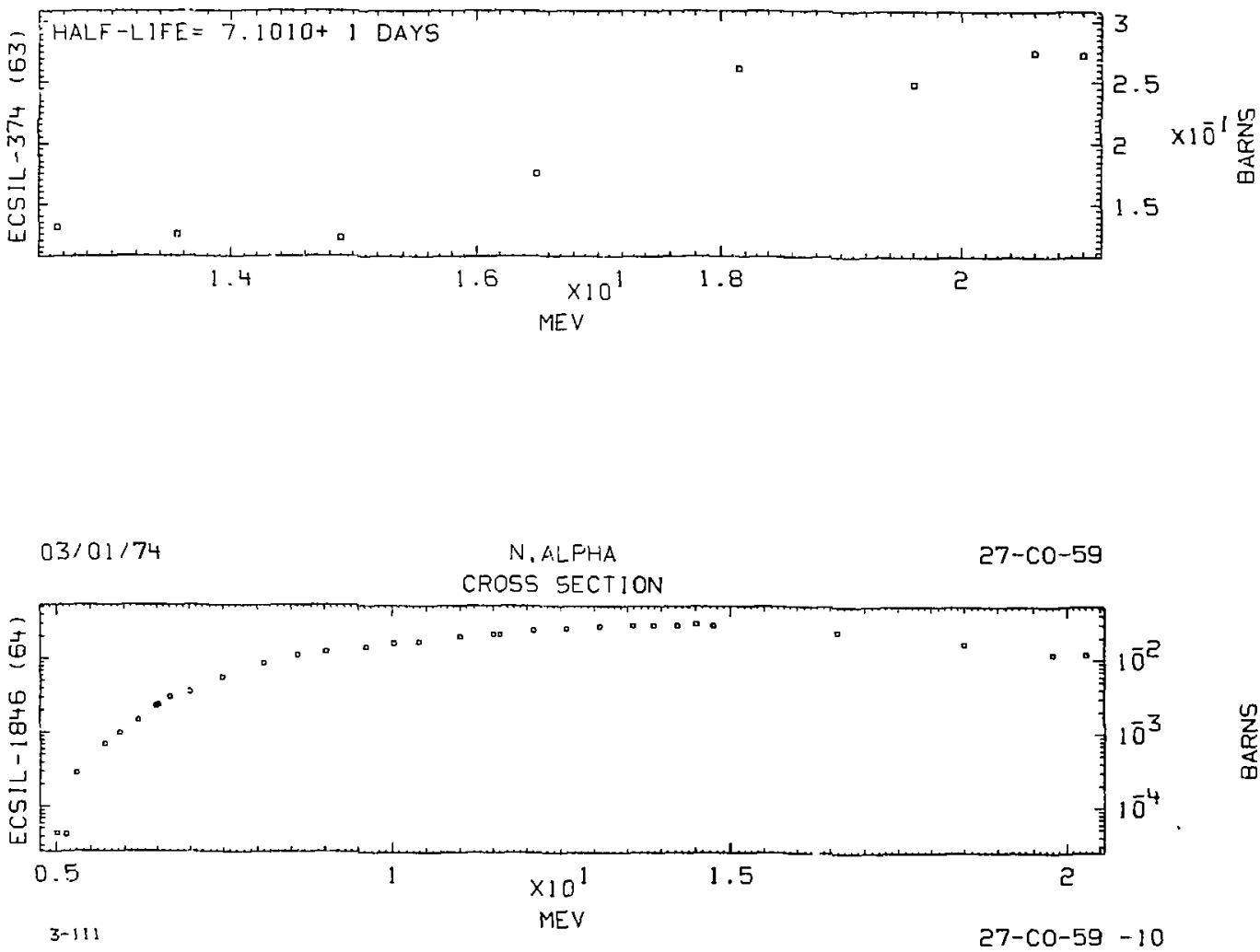


\section{CROSS SECTION}
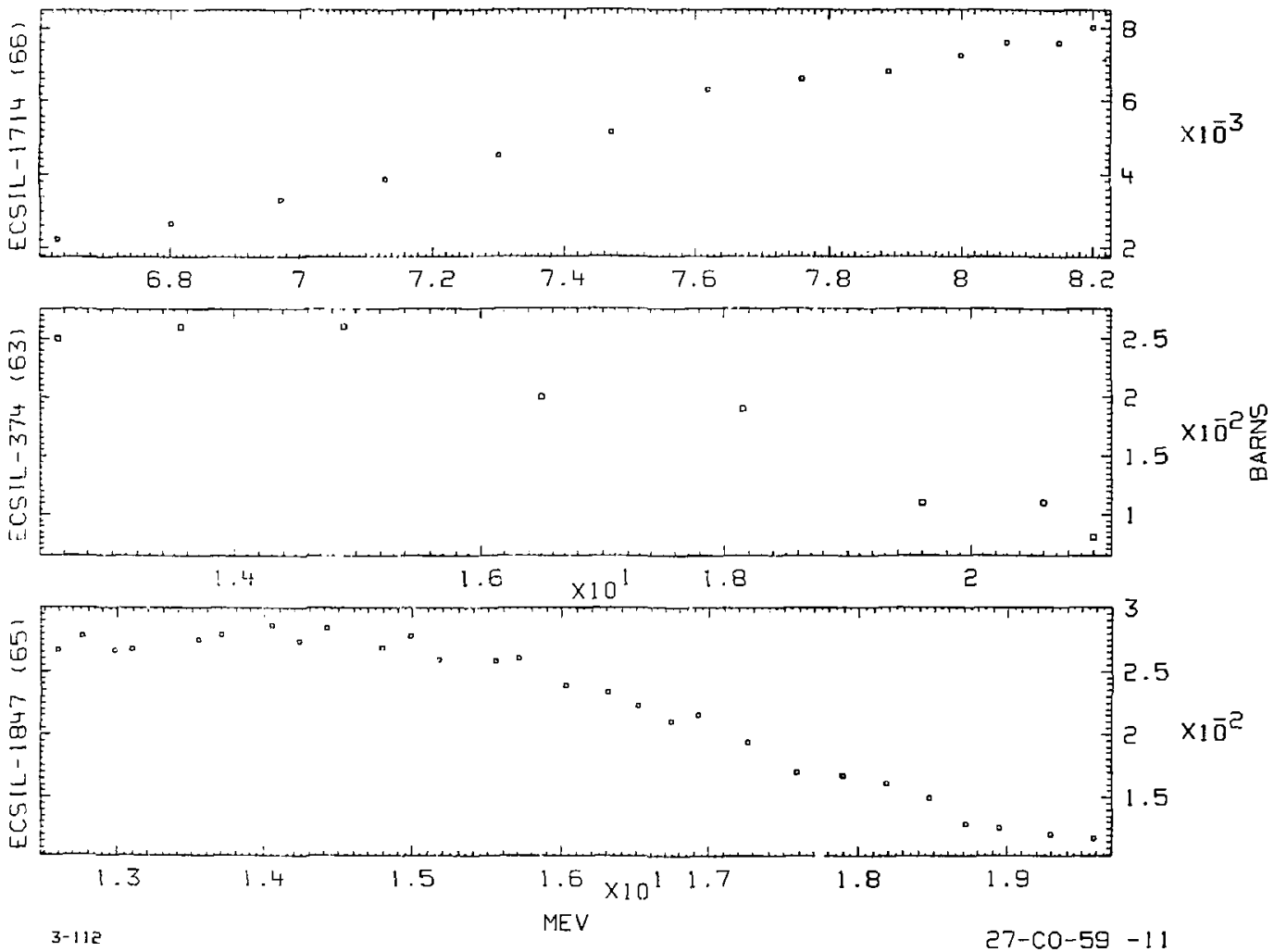


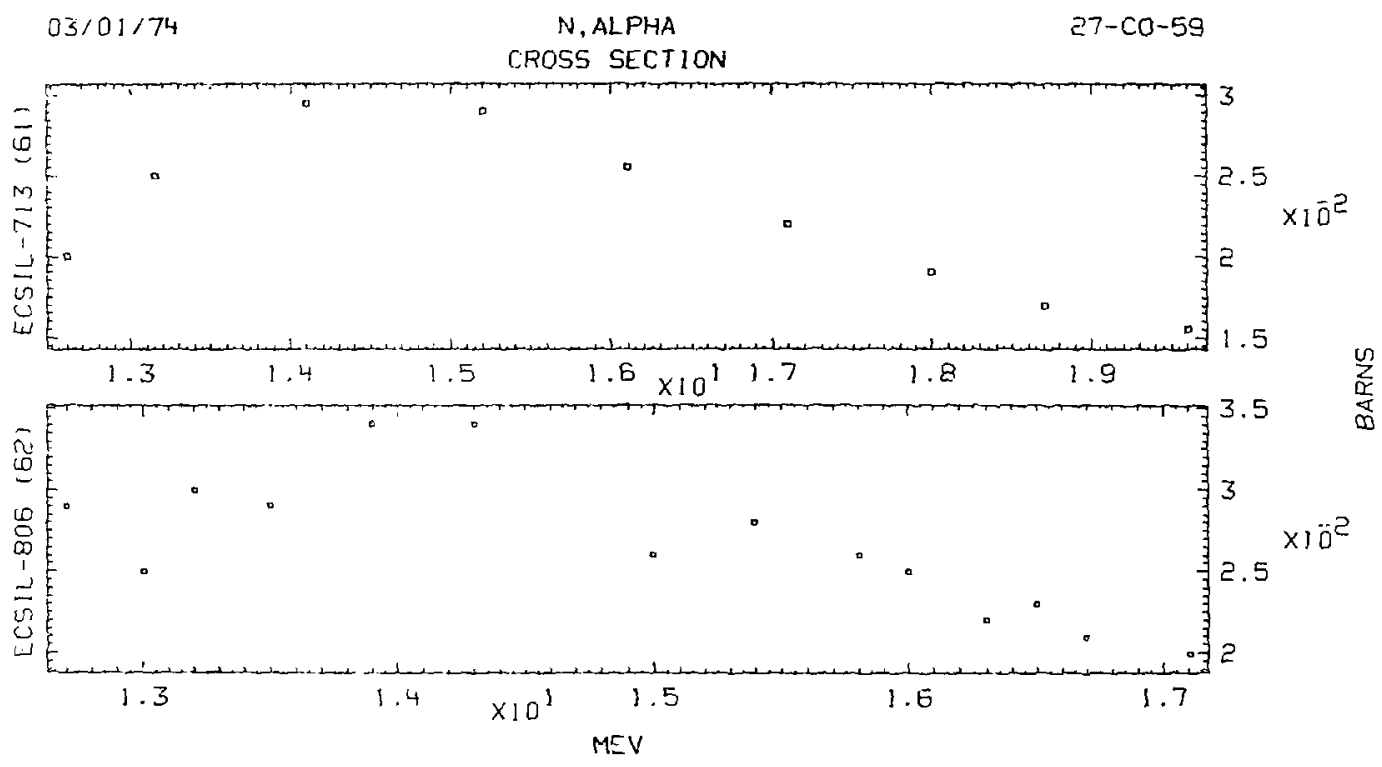

\begin{tabular}{|c|c|c|c|c|c|c|c|c|c|c|}
\hline \multicolumn{2}{|c|}{$03 / 01,74$} & \multicolumn{7}{|c|}{ NDNELASTIC } & \multicolumn{2}{|c|}{$27-\mathrm{CO}-59$} \\
\hline RENCE & $\begin{array}{l}\text { ENERGY } \\
\text { MEV }\end{array}$ & $\begin{array}{l}\text { DELLTA } \\
\text { MEV }\end{array}$ & $\begin{array}{l}X \text {-SEE } \\
\text { BARNS }\end{array}$ & $\begin{array}{l}\text { DEL TA } \\
\text { BARNS }\end{array}$ & RETERE & NCE & $\begin{array}{l}\text { ENERGY } \\
\text { MEV }\end{array}$ & $\begin{array}{r}\text { DELTA } \\
\text { MEV }\end{array}$ & $\begin{array}{l}x \text {-SEC } \\
\text { GAPNS }\end{array}$ & $\begin{array}{l}\text { DELTA } \\
\text { BARNS }\end{array}$ \\
\hline $\begin{array}{ll}54 & 103 \\
55 & 34\end{array}$ & $\begin{array}{l}.0000+c \\
.5000+0\end{array}$ & $=0000-2$ & $\begin{array}{l}.0000-1 \\
.4000+0\end{array}$ & $\begin{array}{l}9.0010-2 \\
1.1000-1\end{array}$ & $\begin{array}{l}59 \\
5 \hat{i}\end{array}$ & $\begin{array}{l}559 \\
319\end{array}$ & $\begin{array}{r}3.6500+0 \\
.4200+1\end{array}$ & $\begin{array}{l}0000-1 \\
5000-1\end{array}$ & $\begin{array}{l}1.6200+0 \\
1.3700+0\end{array}$ & $\begin{array}{l}1.8000-1 \\
3.0000-2\end{array}$ \\
\hline
\end{tabular}




\section{CROSS SECTION}

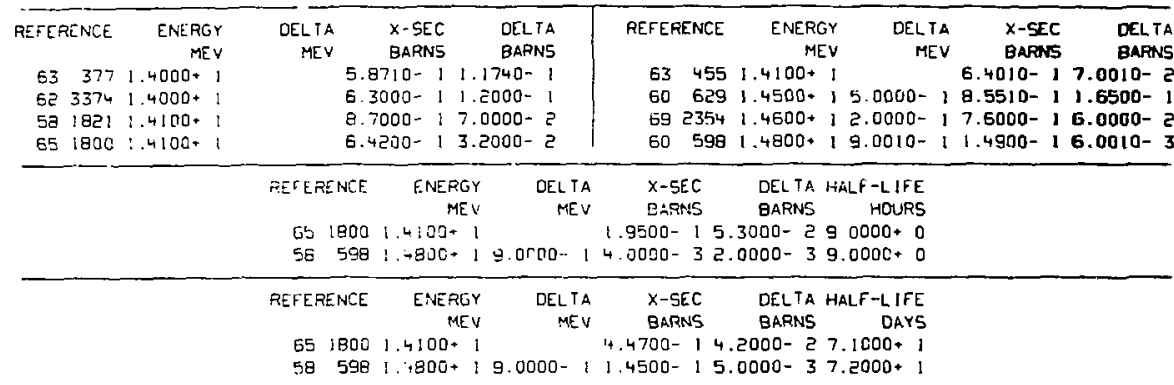

$03 / 01 / 74$ $N, N ' P$ $27-\mathrm{CC}-59$

$\begin{array}{rrrrr}\text { REFERENCE ENERGY } & \text { DELTA } & \text { X-SEC } & \text { DELTA } \\ & \text { MEV } & \text { MEV } & \text { BARNS } & \text { BARNS }\end{array}$

$626961.4400+12.0000-11.1000-2$

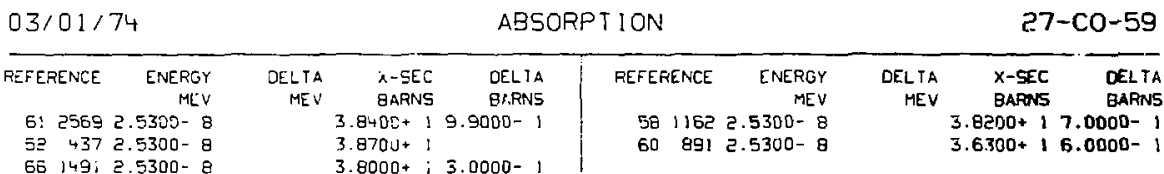
$03 / 01 / 74$
$N, X$ GAMMA
27-c0-59

\begin{tabular}{|c|c|c|c|c|c|c|c|c|c|c|c|c|c|}
\hline \multirow{2}{*}{\multicolumn{2}{|c|}{ REFERENCE }} & ENERG & DELIA & $X-5 E C$ & DELTA & E-PHOTDN & REFEREN & NCE & ENEFGY & CEL TA & $x-5 E C$ & DELTA & E-PHOTON \\
\hline & & MI & MEV & BARNS & BARNS & MEV & & & MEV & MEV & GARNS & BARNS & MEV \\
\hline 54 & 113 & $3.2000 \cdot$ & $02.0000-1$ & $2.0000-1$ & $4.0000-2$ & $6.0000-1$ & $54 \quad 1$ & $113=$ & $3.2000+0$ & $2.0000-1$ & $1.5000-1$ & $3.0000-2$ & $1.7000+0$ \\
\hline 54 & $1: 3$ & 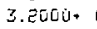 & $02.0000-1$ & $8.2000-1$ & $1.6000-1$ & $1.1500+0$ & $54 \quad 1$ & 113 & $3.2000+0$ & $2.0000-1$ & 1.9000-i & $4.0000-2$ & $2.5000+0$ \\
\hline 54 & 113 & 3.2000 & $02.0000-1$ & $5.3000-1$ & $1.1000-1$ & $1.4900+0$ & & & & & & & \\
\hline
\end{tabular}




\begin{tabular}{|c|c|c|c|c|c|c|c|c|c|}
\hline $03 / 01$ & & . & & CROS & TION & & & & $7-c 0-59$ \\
\hline ETERENC & $\begin{array}{c}\text { ENERQ } r \\
i=V\end{array}$ & $\begin{array}{r}\text { DELIA } \\
\text { MEV }\end{array}$ & & & REFERE,NCE & $\begin{array}{r}\text { ENERGY } \\
\text { MEV }\end{array}$ & $\begin{array}{r}\text { DELTA } \\
\text { MEV }\end{array}$ & $\begin{array}{l}x-5 E C \\
\text { BARNS }\end{array}$ & \\
\hline $\begin{array}{ll}61 & 36 \\
60 & 83\end{array}$ & $\begin{array}{l}.4000+1 \\
.4100+1\end{array}$ & & $\begin{array}{l}010-2 \\
010-2\end{array}$ & $\begin{array}{l}7.0010-3 \\
1.5000-2\end{array}$ & $\begin{array}{rr}60 & 629 \\
65 & 1855\end{array}$ & $\begin{array}{l}4500 * 1 \\
4800 * 1\end{array}$ & $0000-1$ & $010-2$ & \\
\hline 5268 & $.4400+1$ & 1 2.0000- 1 & 4.8000- & $5.0000-3$ & $60 \quad 598$ & $1.4800+1$ & $19.0010-1$ & $8.2010-2$ & $8.0010-$ \\
\hline
\end{tabular}

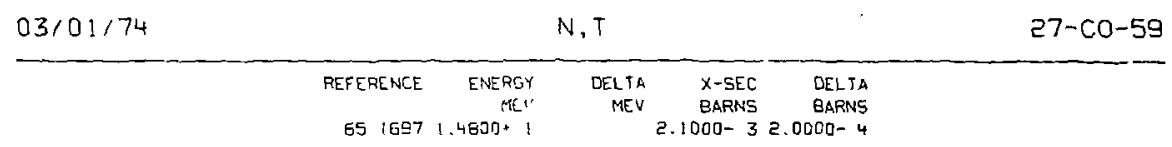

$03 / 01 / 74$

N.HE-3

$27-\mathrm{CO}-59$

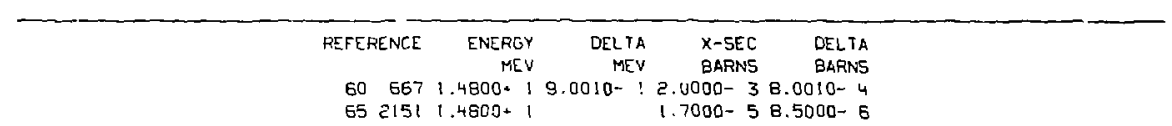

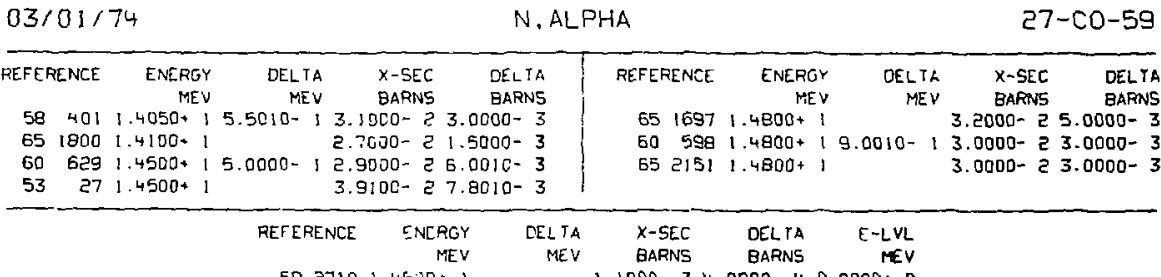

$6927101.4600+1 \quad 1.1000-34.0000-40.0000+0$ 
CROSS SECTION

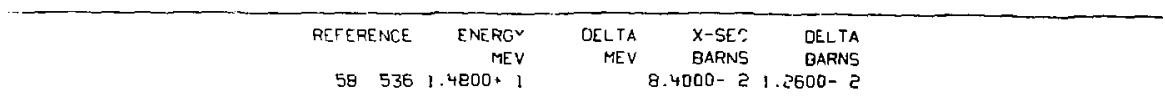

03/01/74

$03 / 01 / 74$ COHERENT SCATTERING

27-C0-59

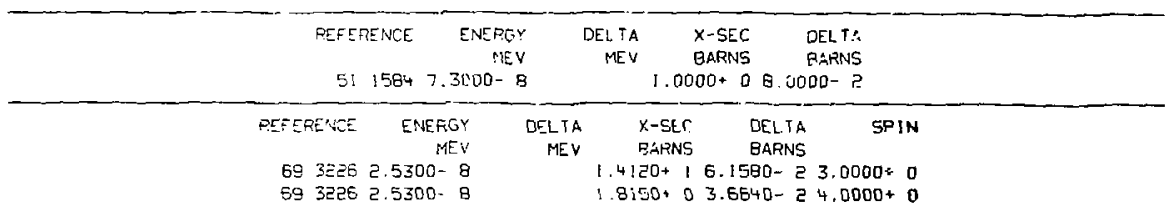

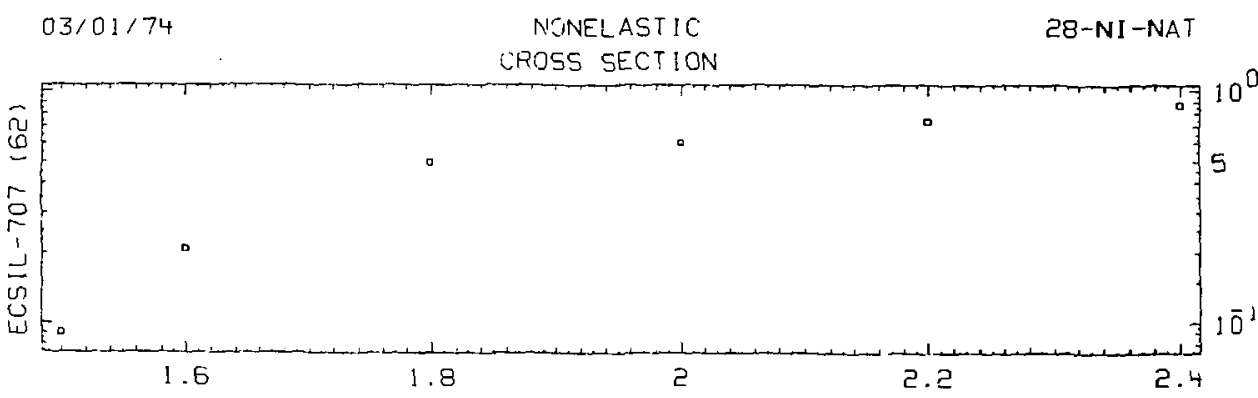



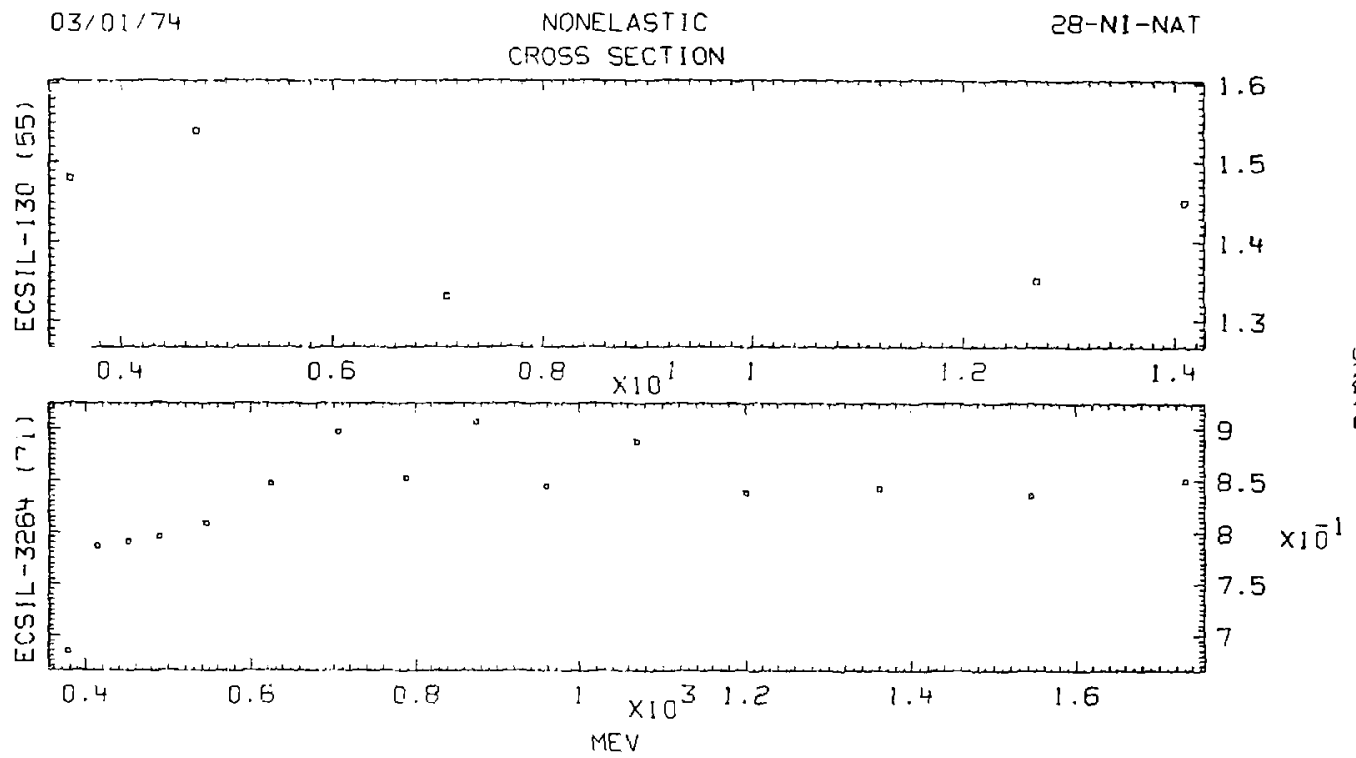

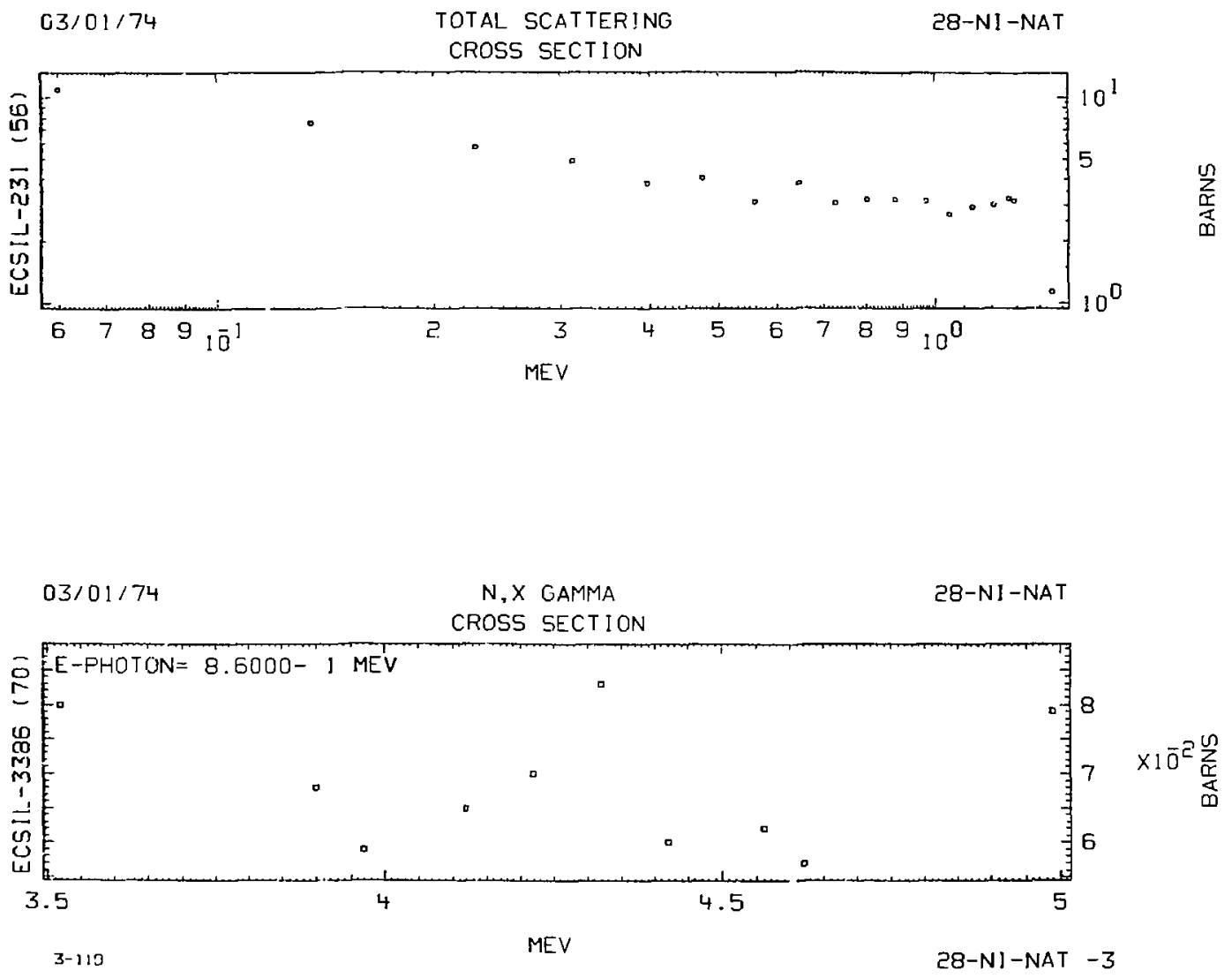

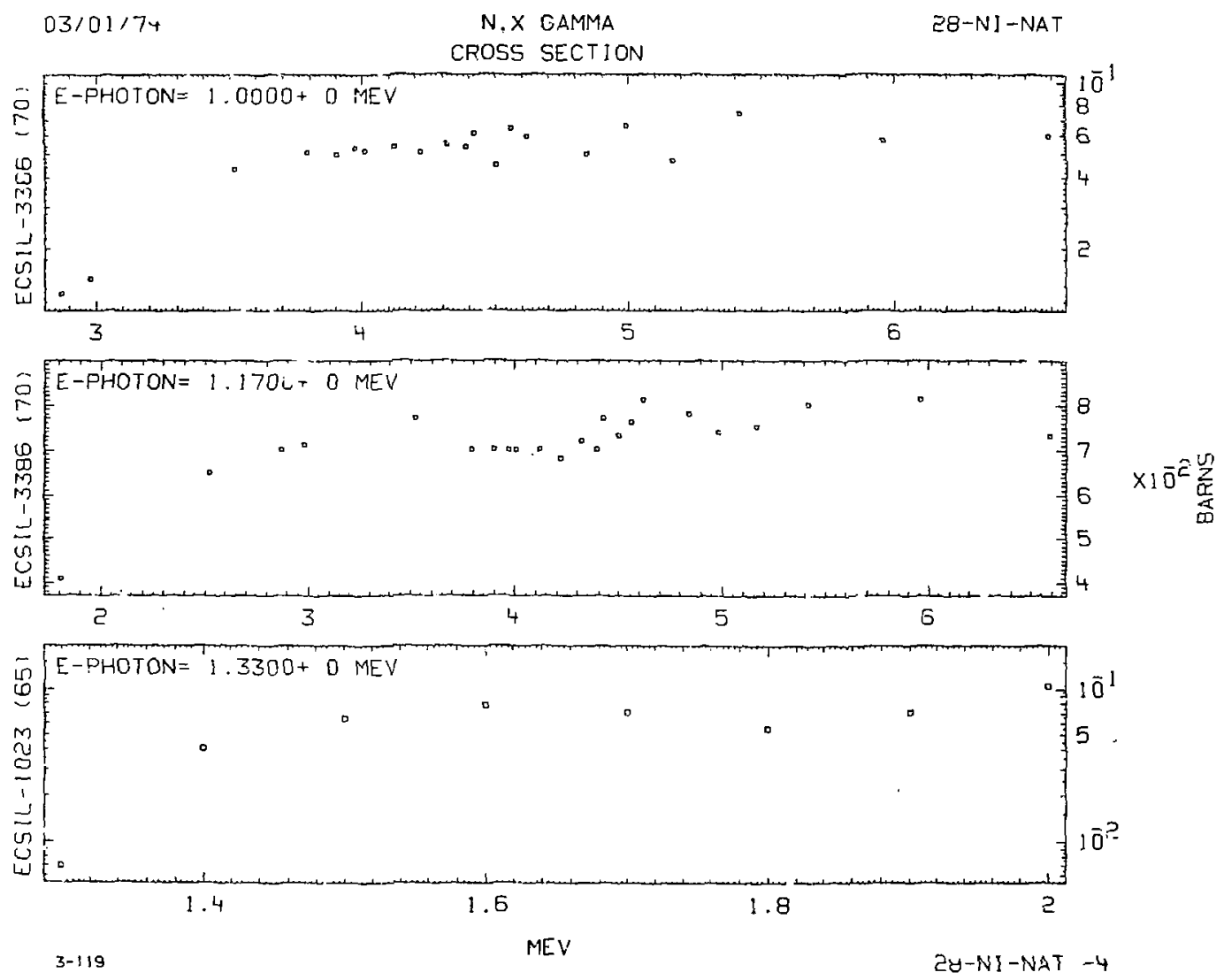

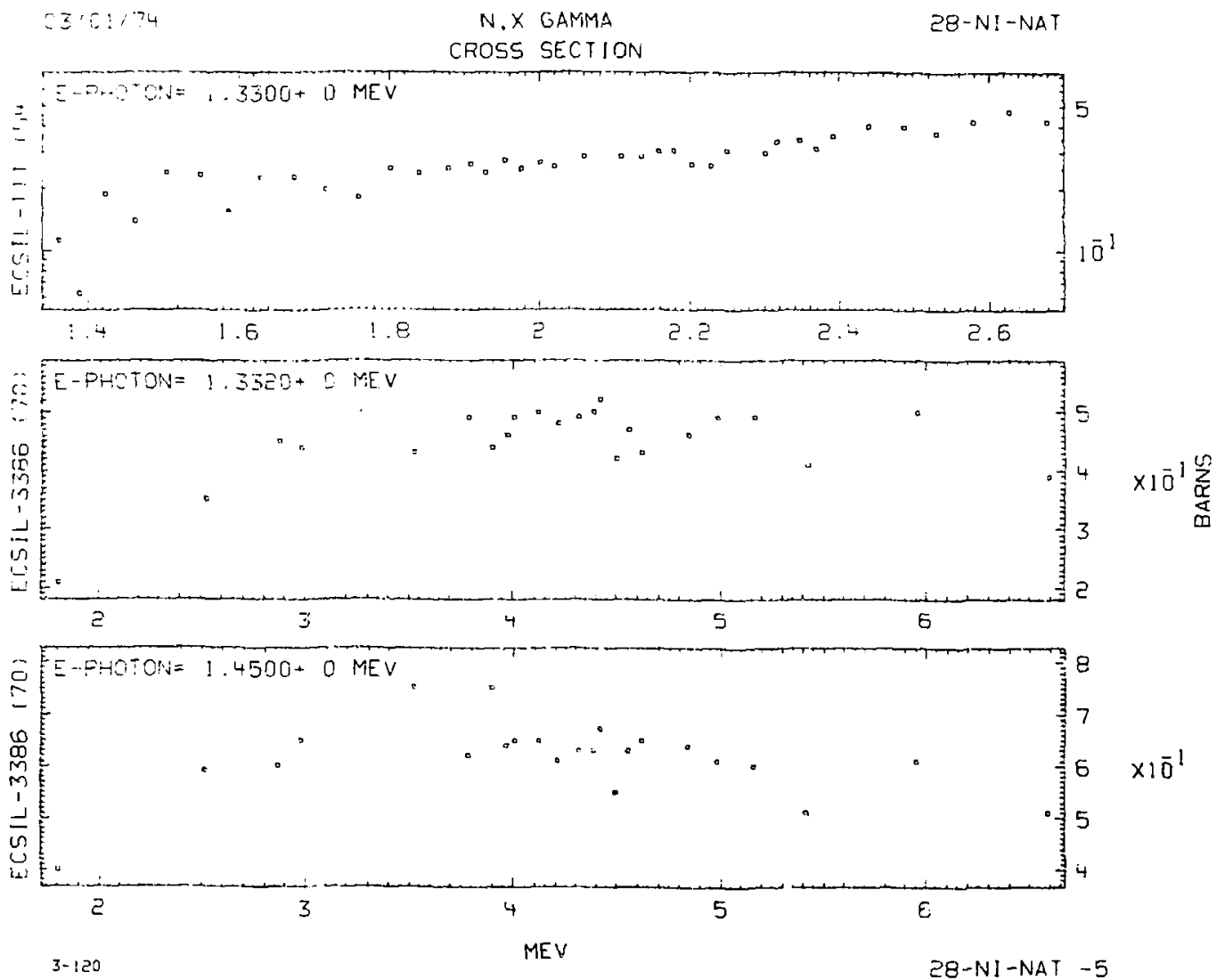


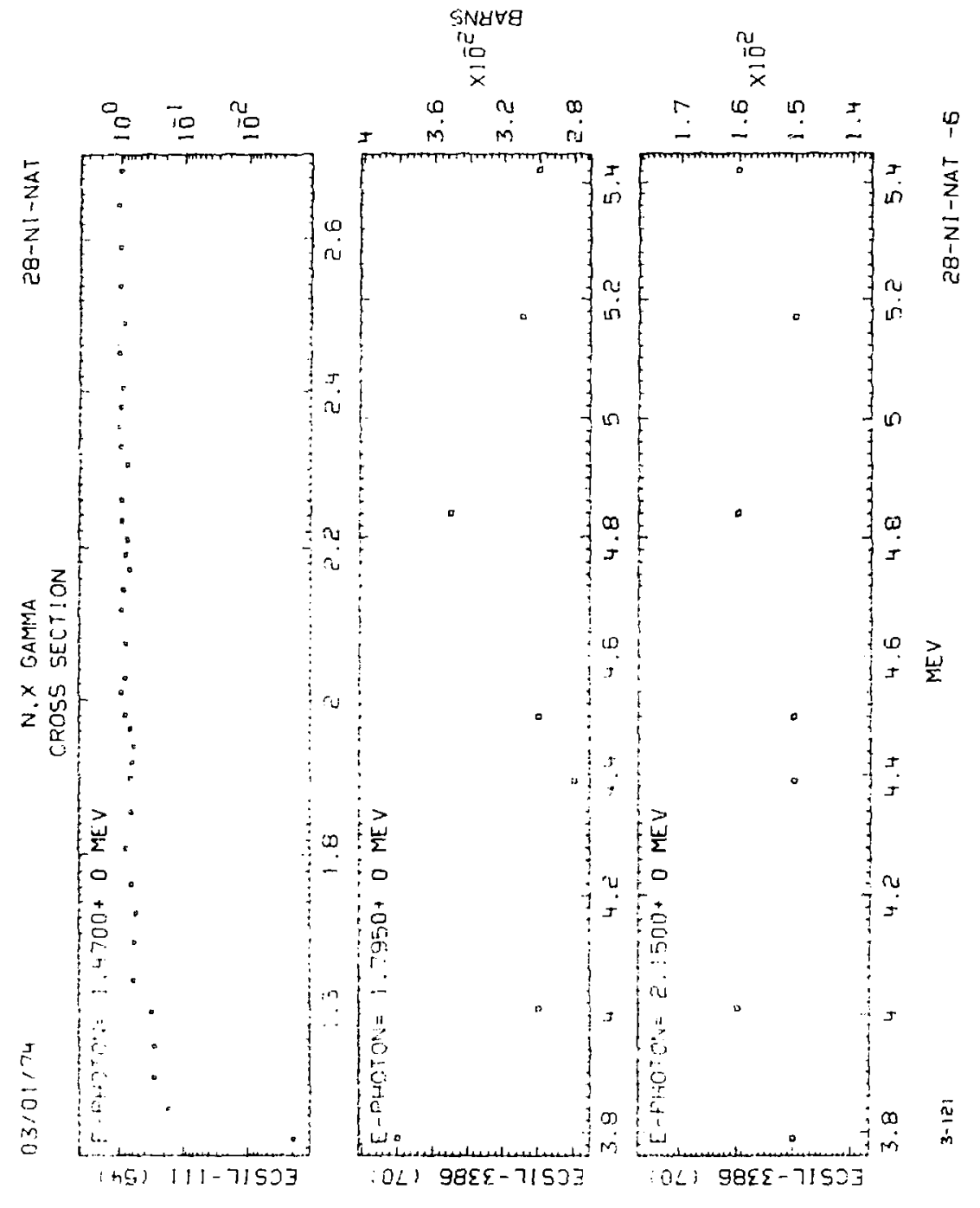



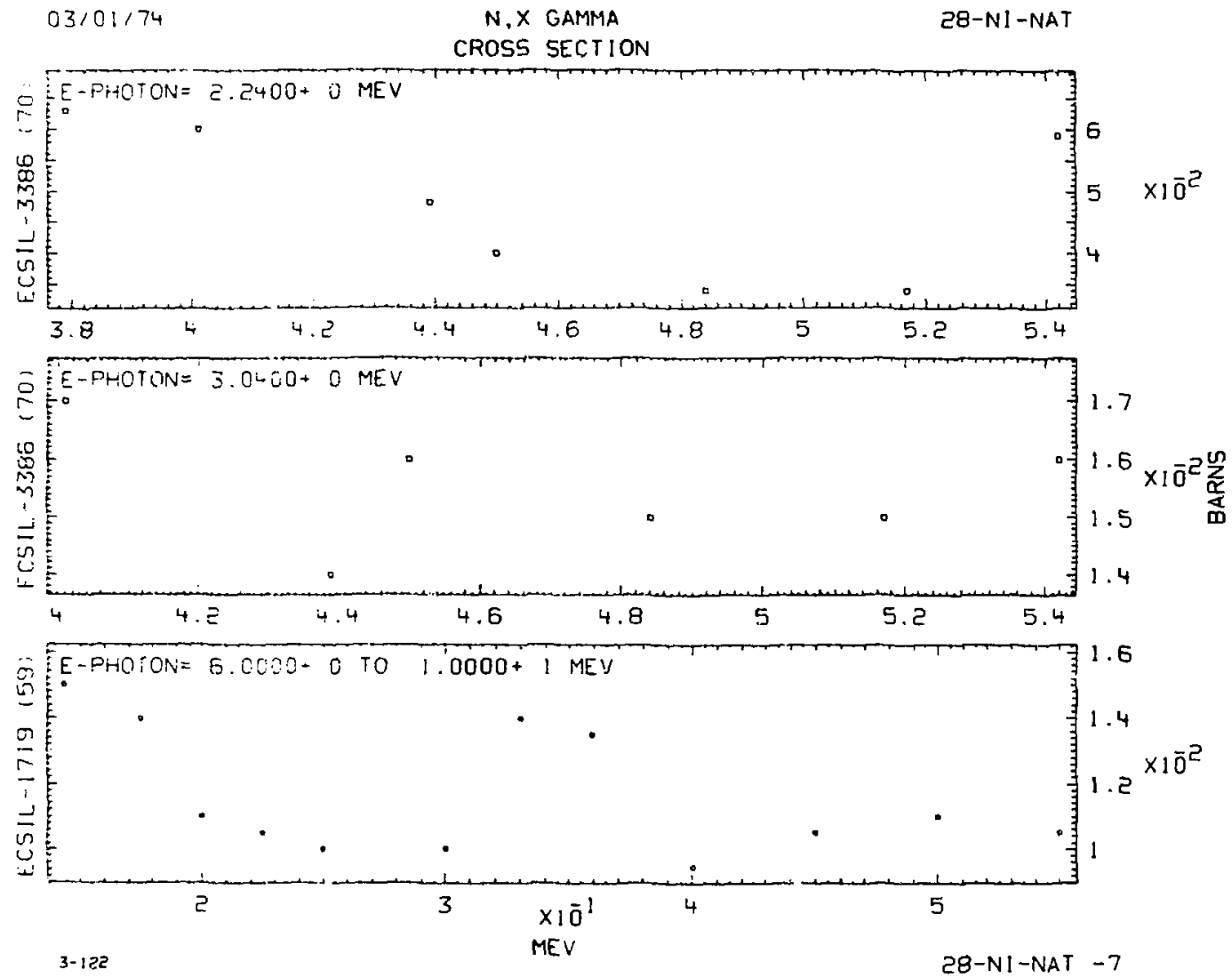


\section{CROSS SECT:ON}

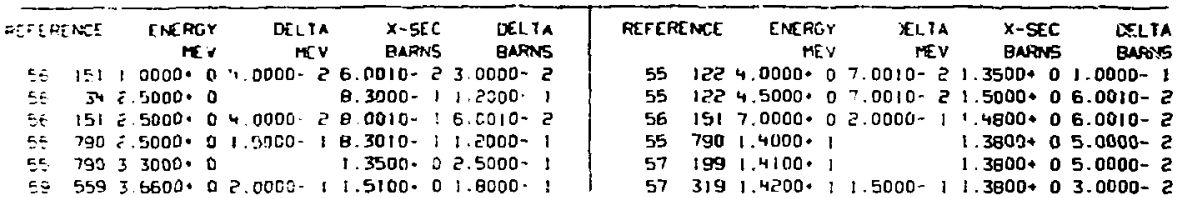

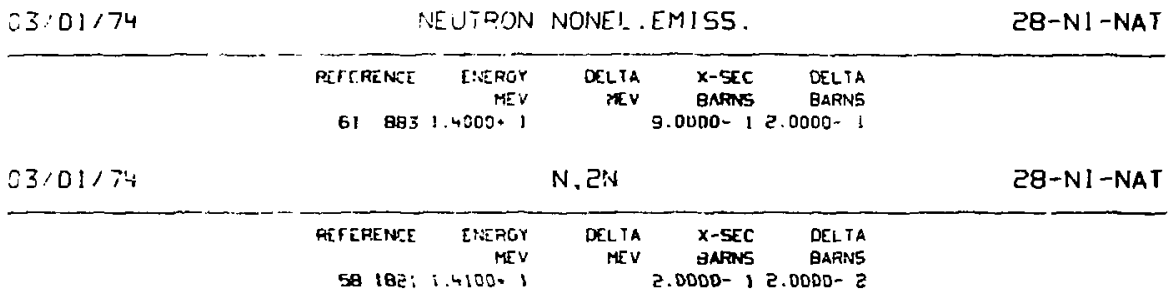

ב3/01/74

\begin{tabular}{|c|c|c|c|c|c|c|c|c|c|}
\hline \multicolumn{4}{|c|}{$53 / 01 / 74$} & \multicolumn{2}{|c|}{ ABSORPTION } & \multicolumn{4}{|c|}{$2 B-N I-N A T$} \\
\hline PE=ERENCE & $\begin{array}{r}\text { ENERGY } \\
\text { MTV }\end{array}$ & DELTA & $\begin{array}{l}x-5 L ? \\
\text { GARNS }\end{array}$ & $\begin{array}{l}\text { DELIA } \\
\text { BARNS }\end{array}$ & REFERENCE & $\begin{array}{r}\text { ENERGY } \\
\text { MEV }\end{array}$ & DELTA & $\begin{array}{l}x-5 E C \\
\text { BARANS }\end{array}$ & $\begin{array}{l}\text { OELTA } \\
\text { BARNS }\end{array}$ \\
\hline 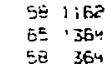 & $\begin{array}{l}\text { ?. } 5300-8 \\
\text { ?. } 4000-? \\
\text { ?. } 5000-\text { ? }\end{array}$ & $0000-3$ & $\begin{array}{l}4.6000+0 \\
2.3000-? \\
5.0000-2\end{array}$ & $\begin{array}{ll}1.0000-1 \\
2 & 6.0020-3 \\
2 & 1.0000-3\end{array}$ & $\begin{array}{ll}58 & 354 \\
58 & 364\end{array}$ & $\begin{array}{l}\text { ב.2000- } 1 \\
\text { a.3000- }\end{array}$ & $\begin{array}{l}2.0000-2 \\
4.0000-2\end{array}$ & $\begin{array}{l}2.6000-2 \\
1.9000-2\end{array}$ & $\begin{array}{l}2.0000-3 \\
6.0010-3\end{array}$ \\
\hline
\end{tabular}




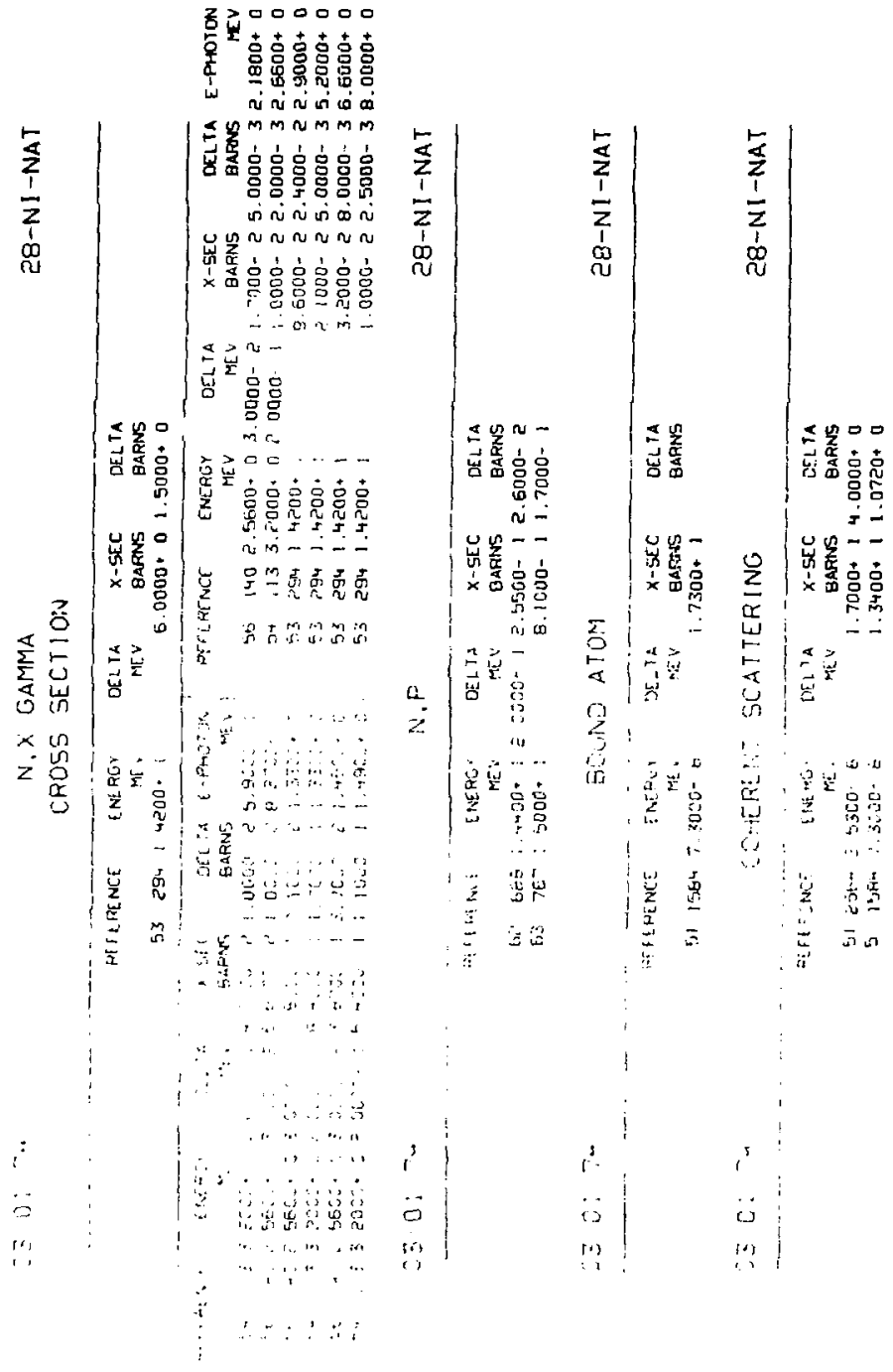

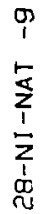


$03 / 01 / 74$

N.N'

$28-N I-58$
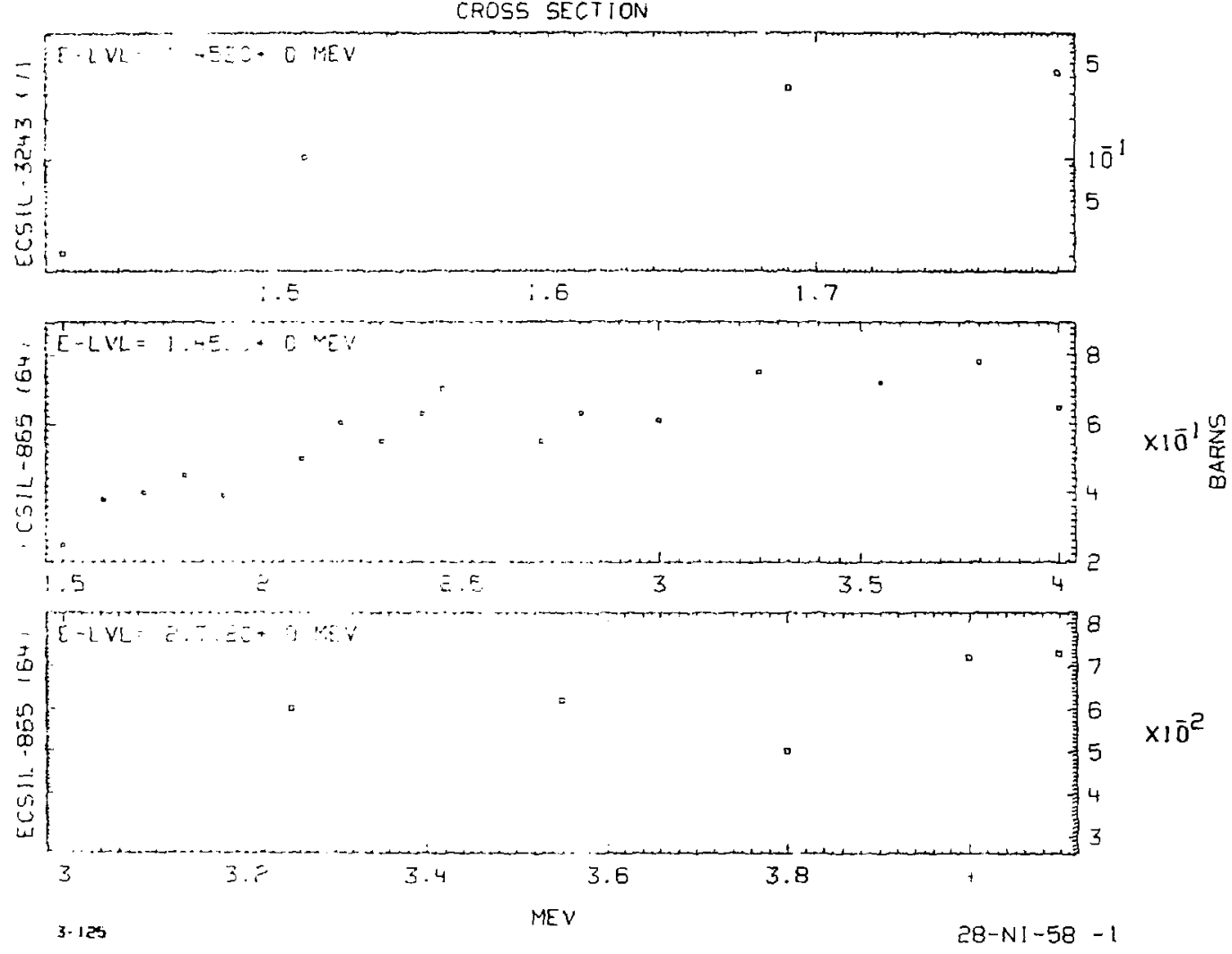

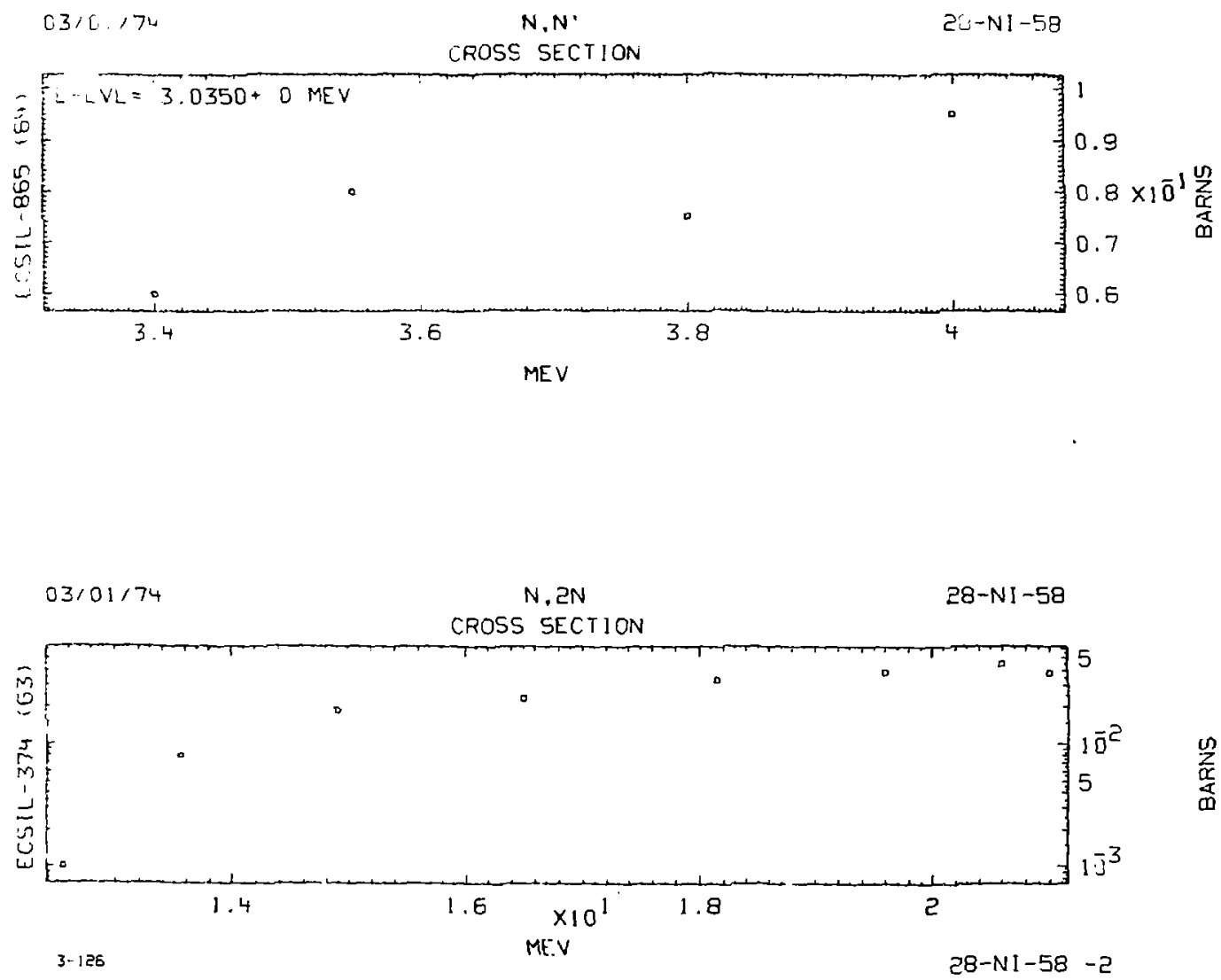

$o n$
$z_{\alpha}$
ax
wi 


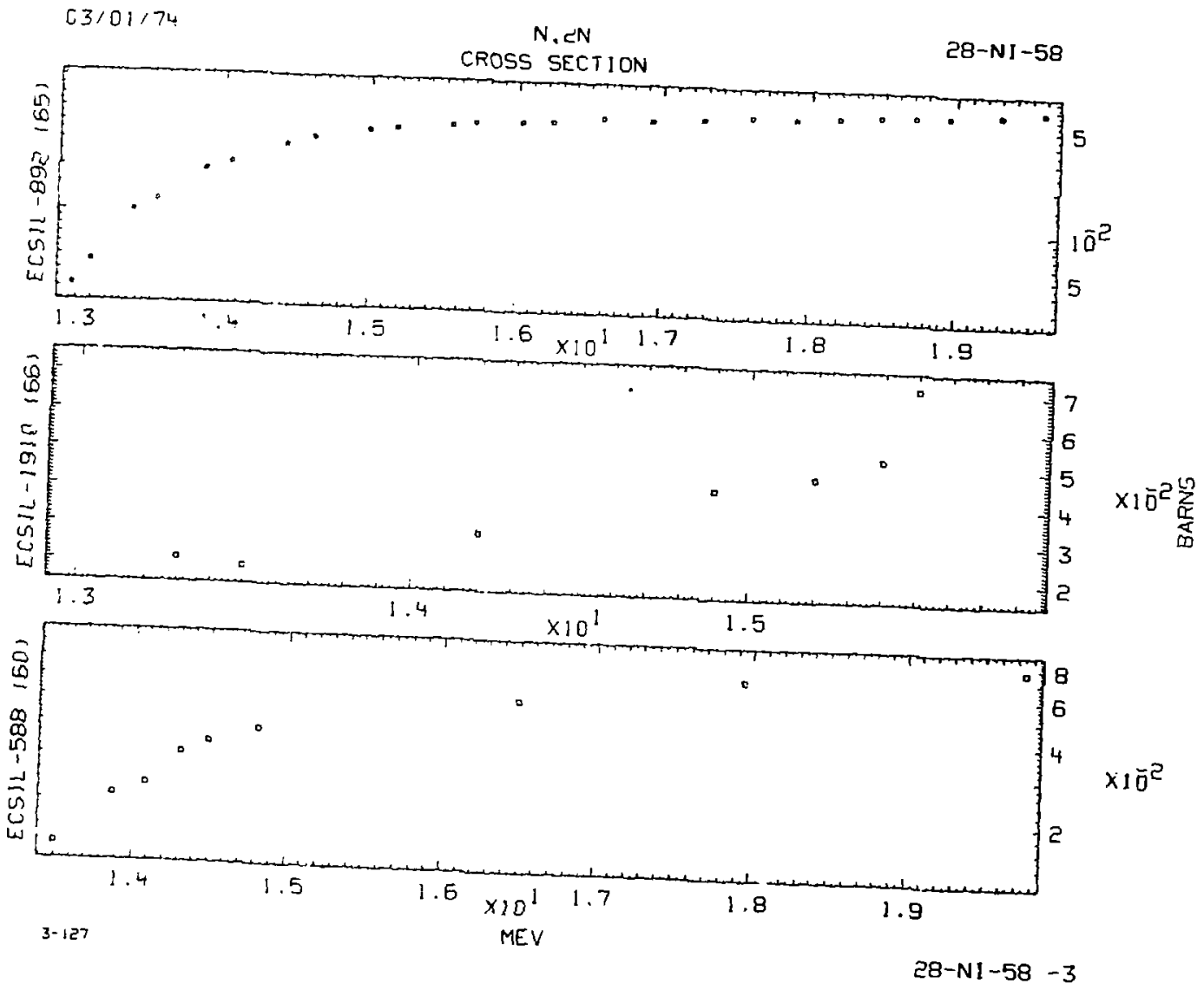




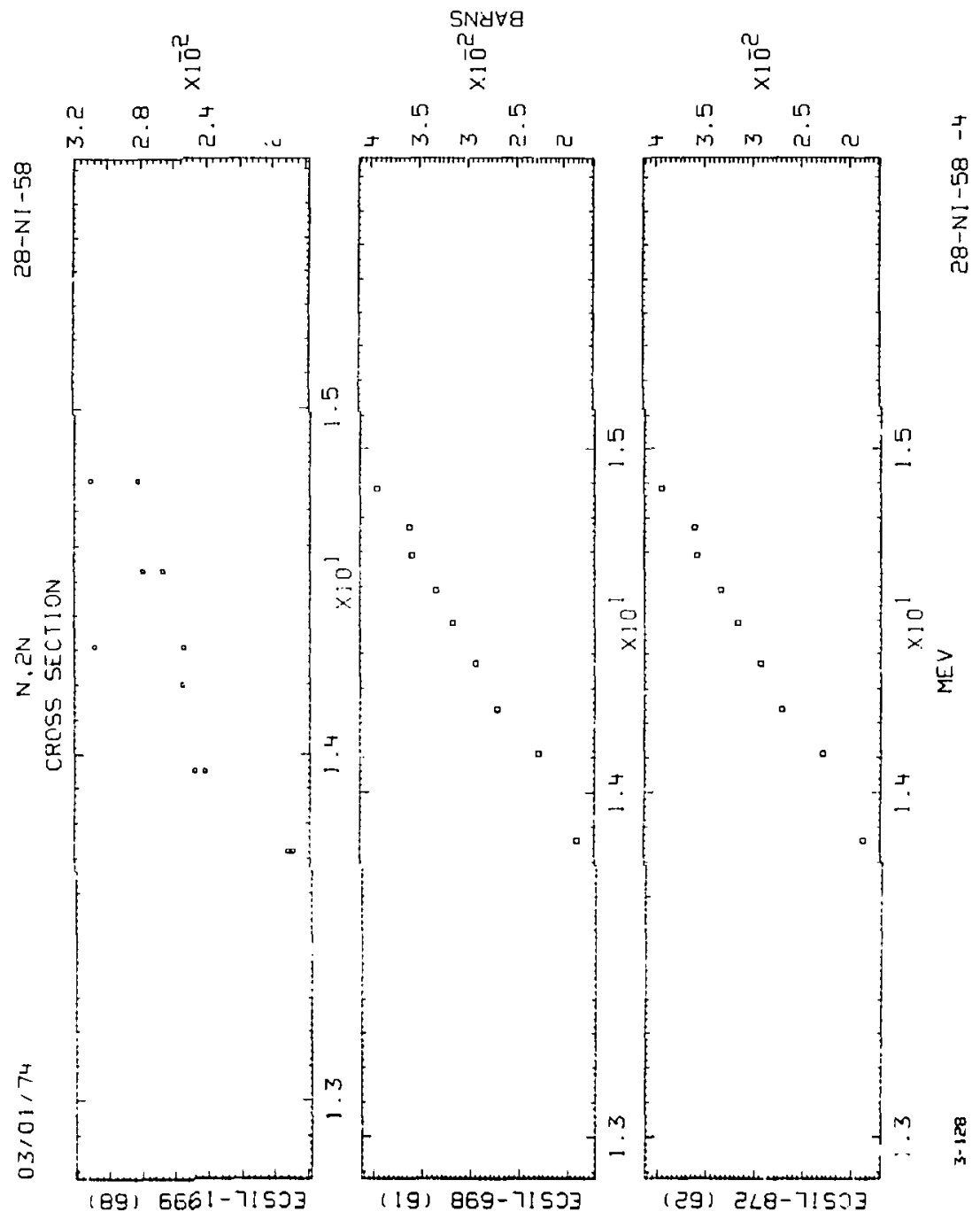


$\exists \wedge 1 \perp \forall า \exists y$
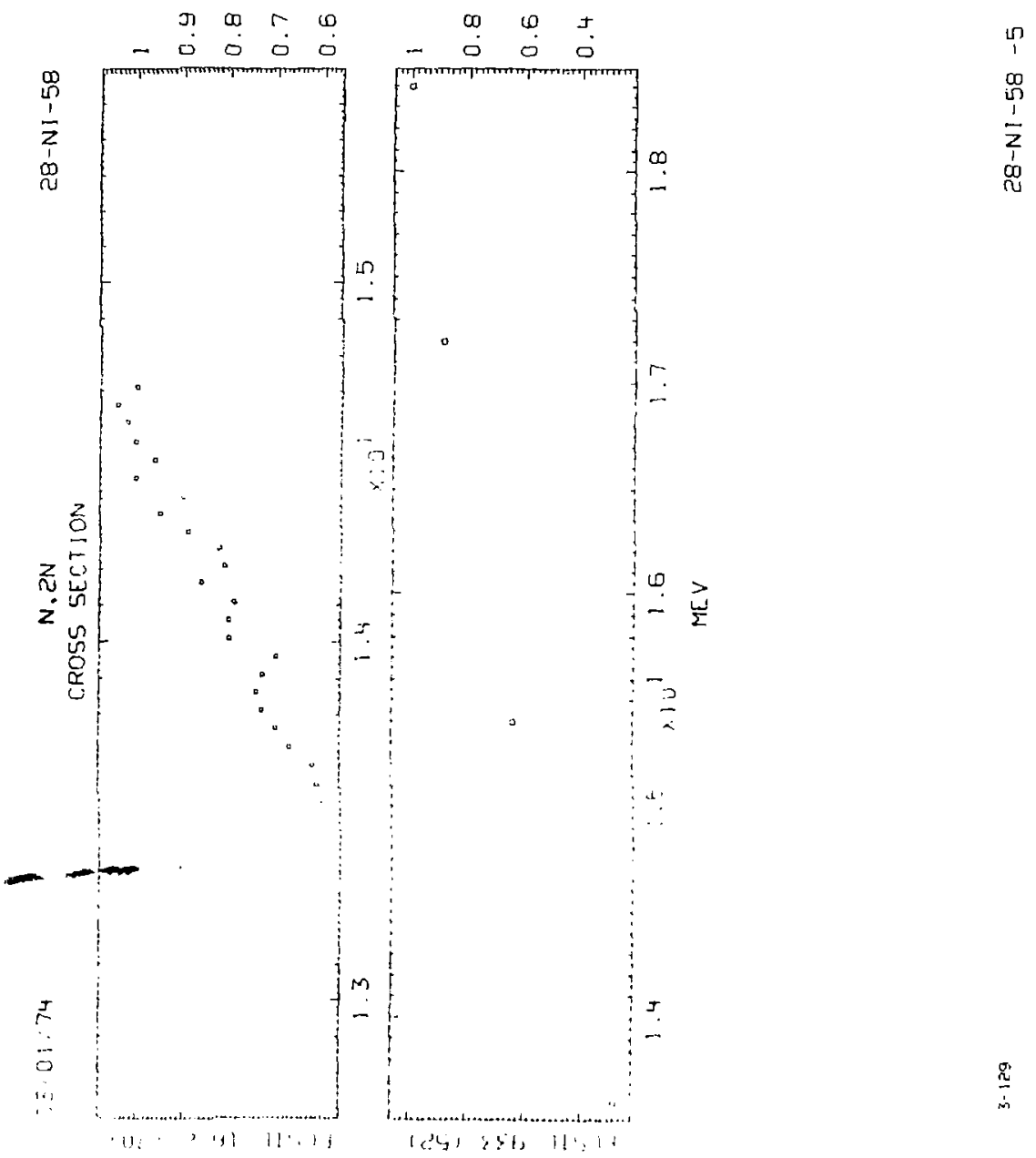


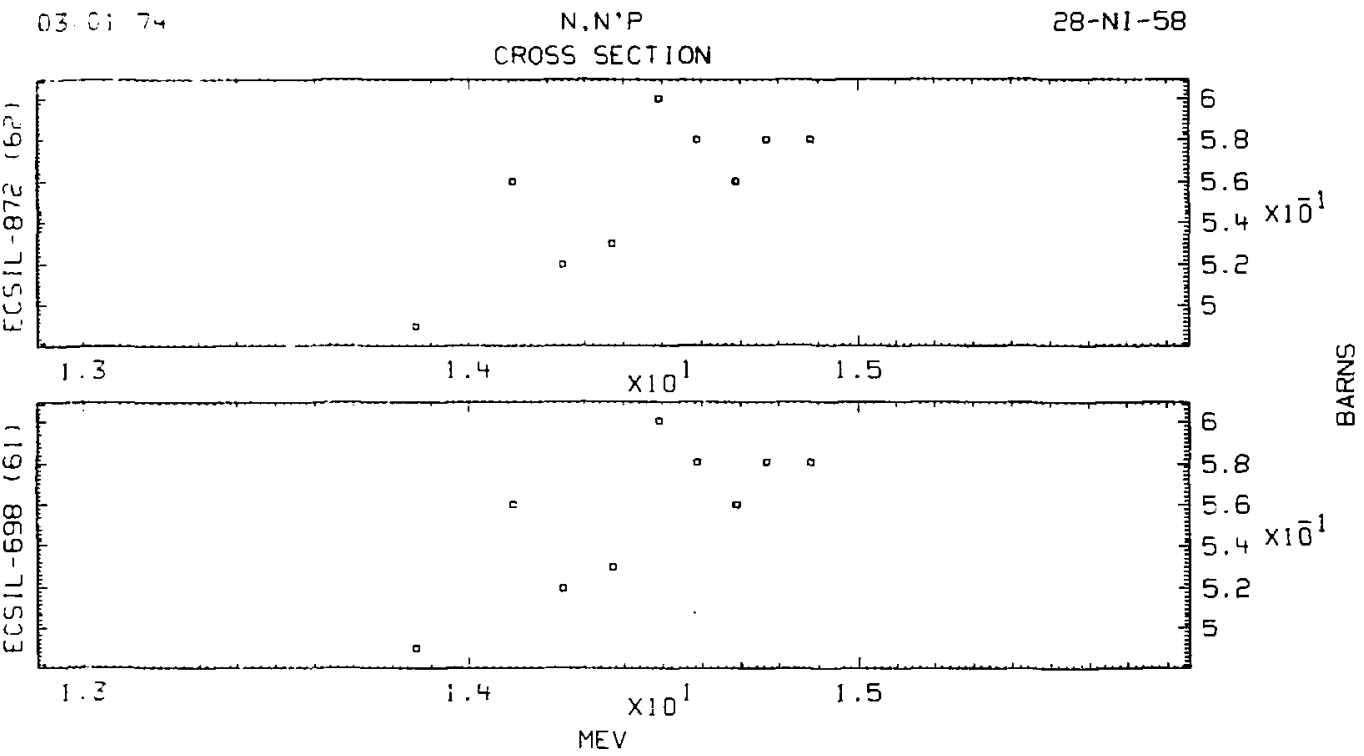



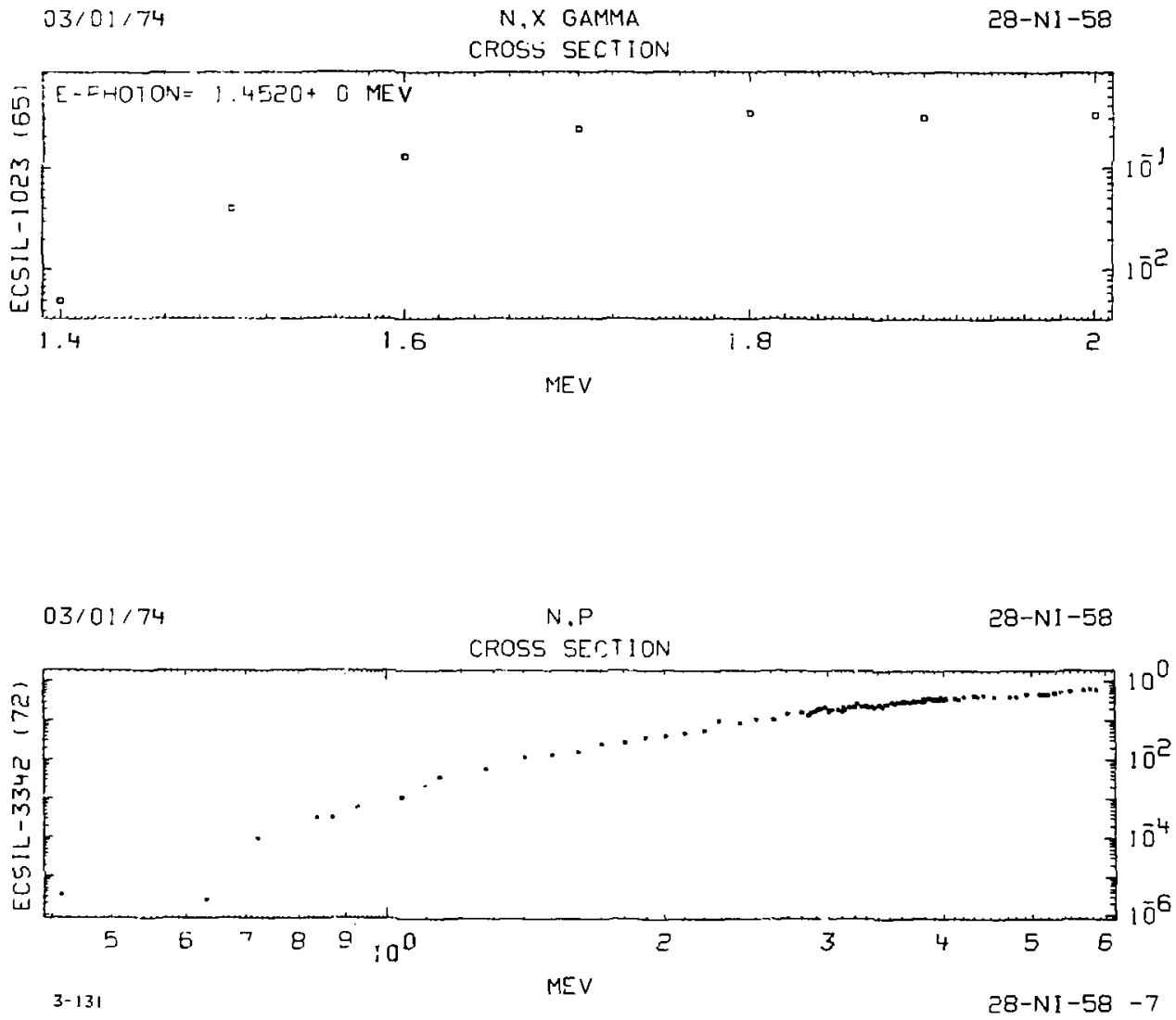
SNY

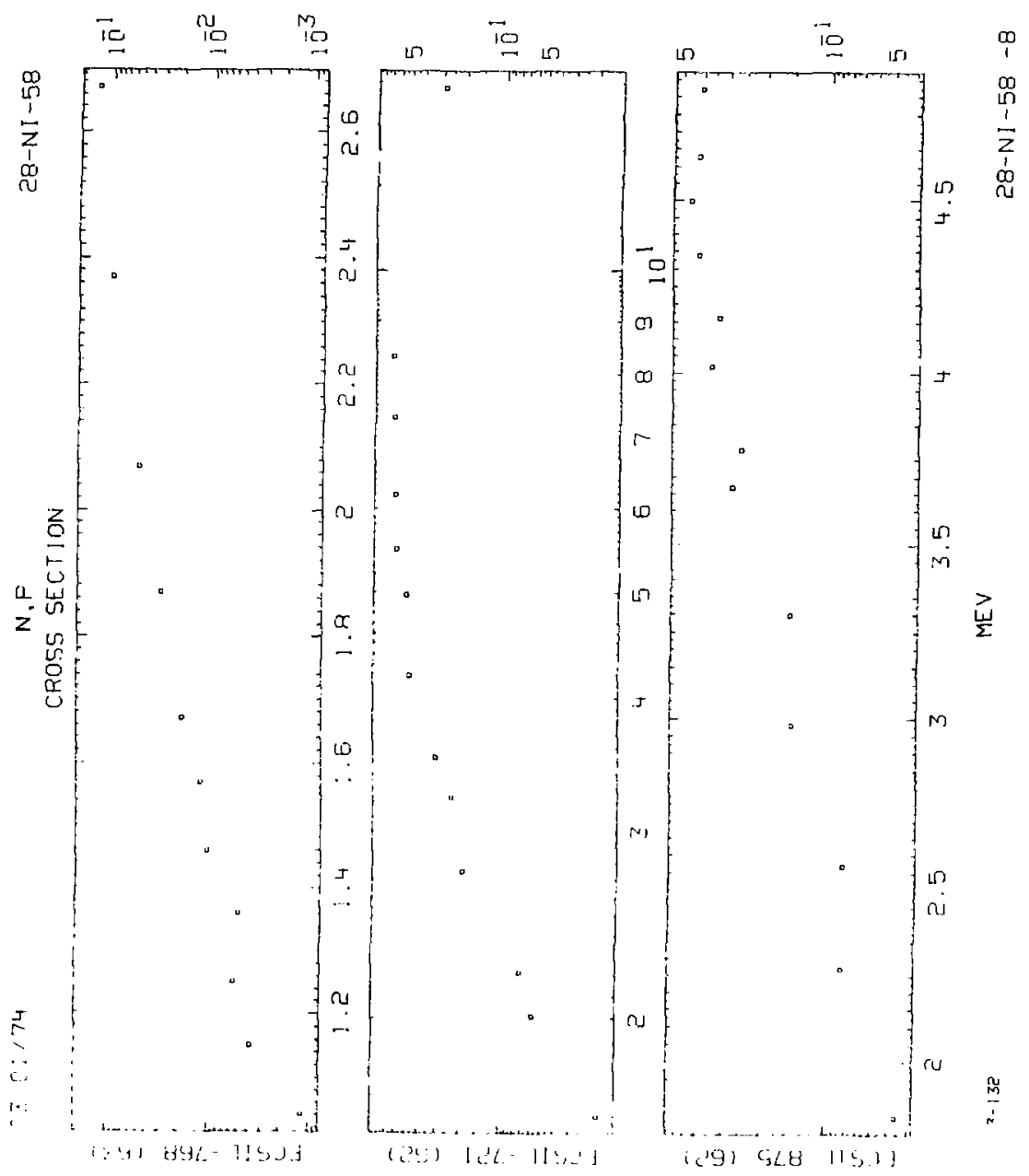




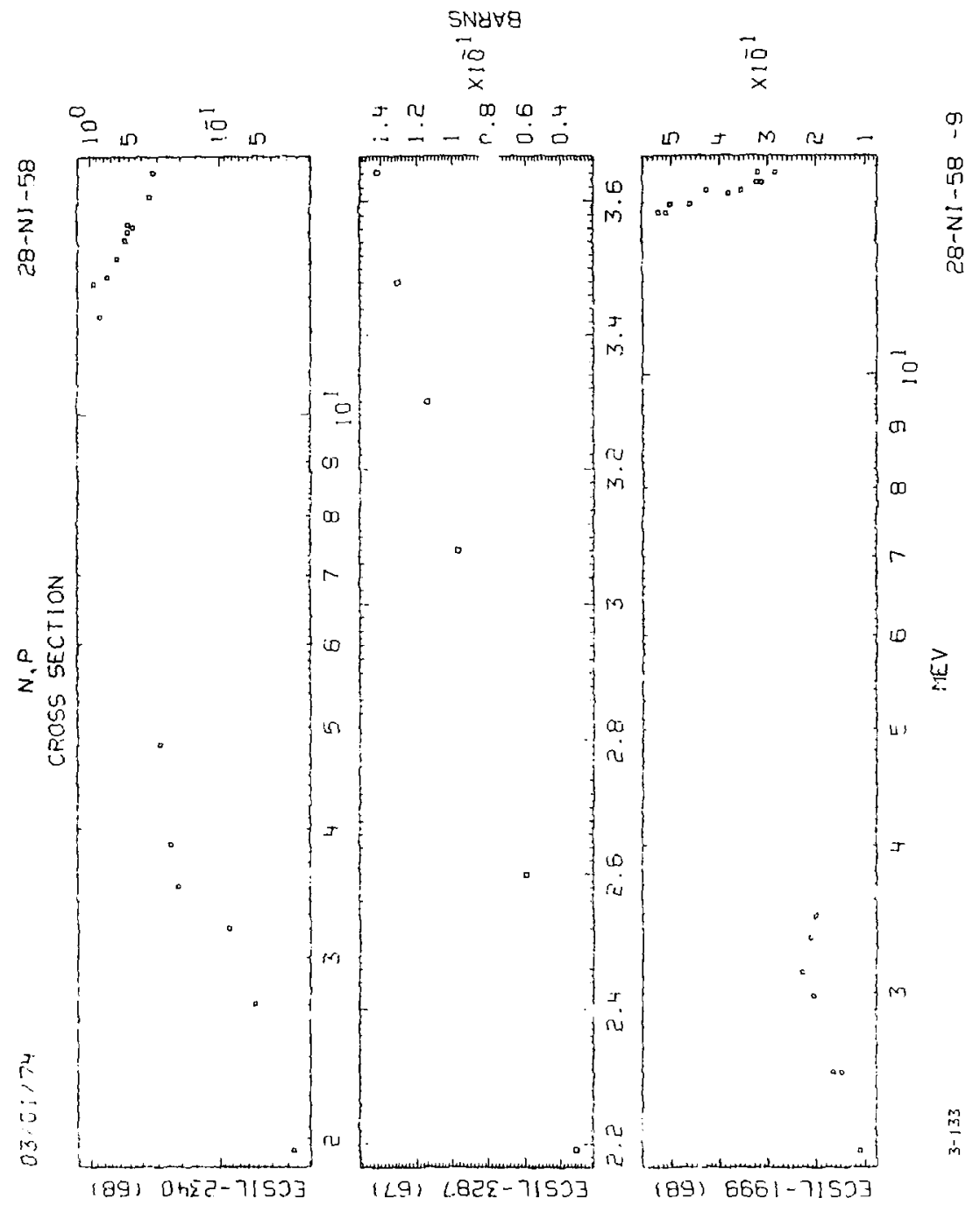



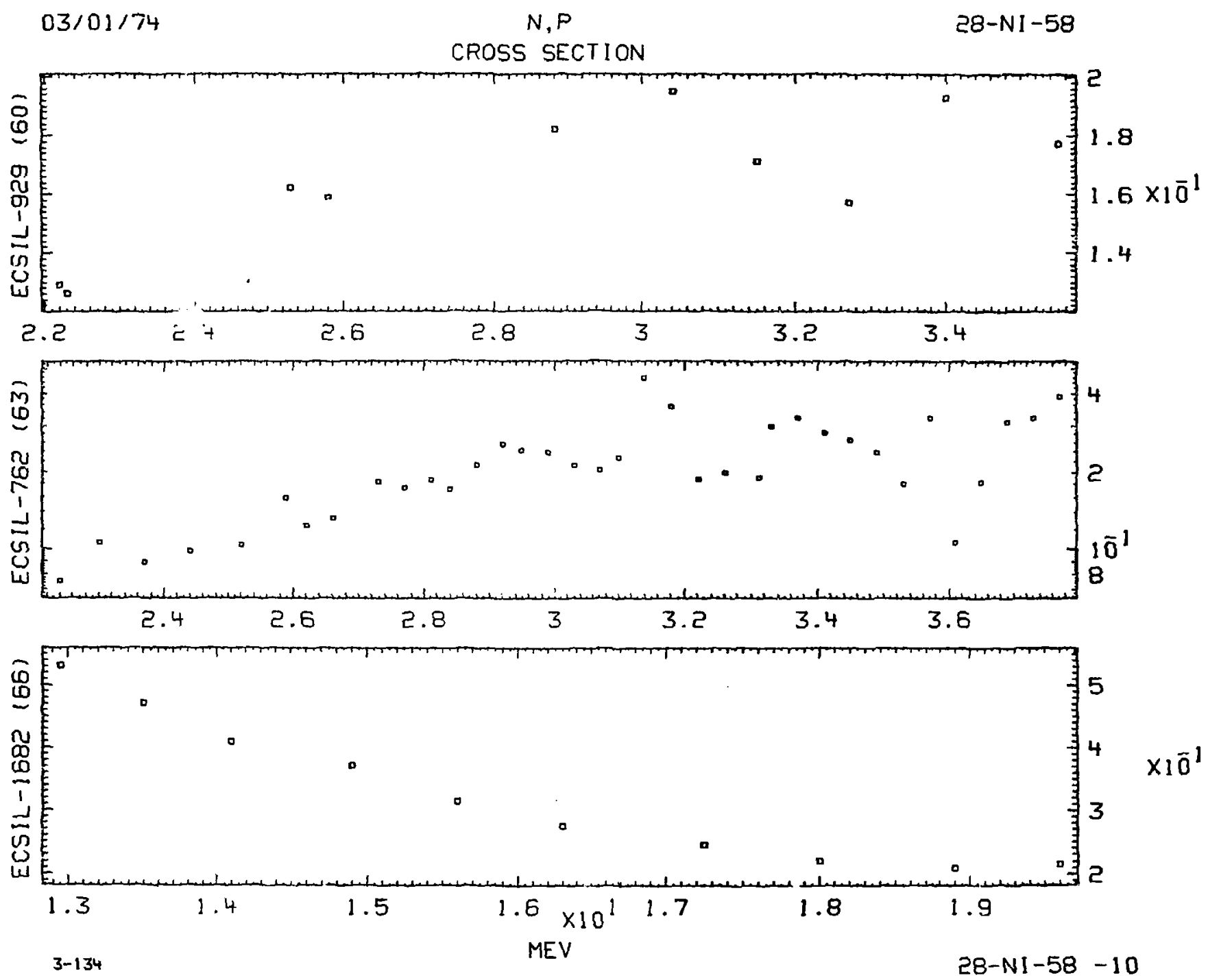


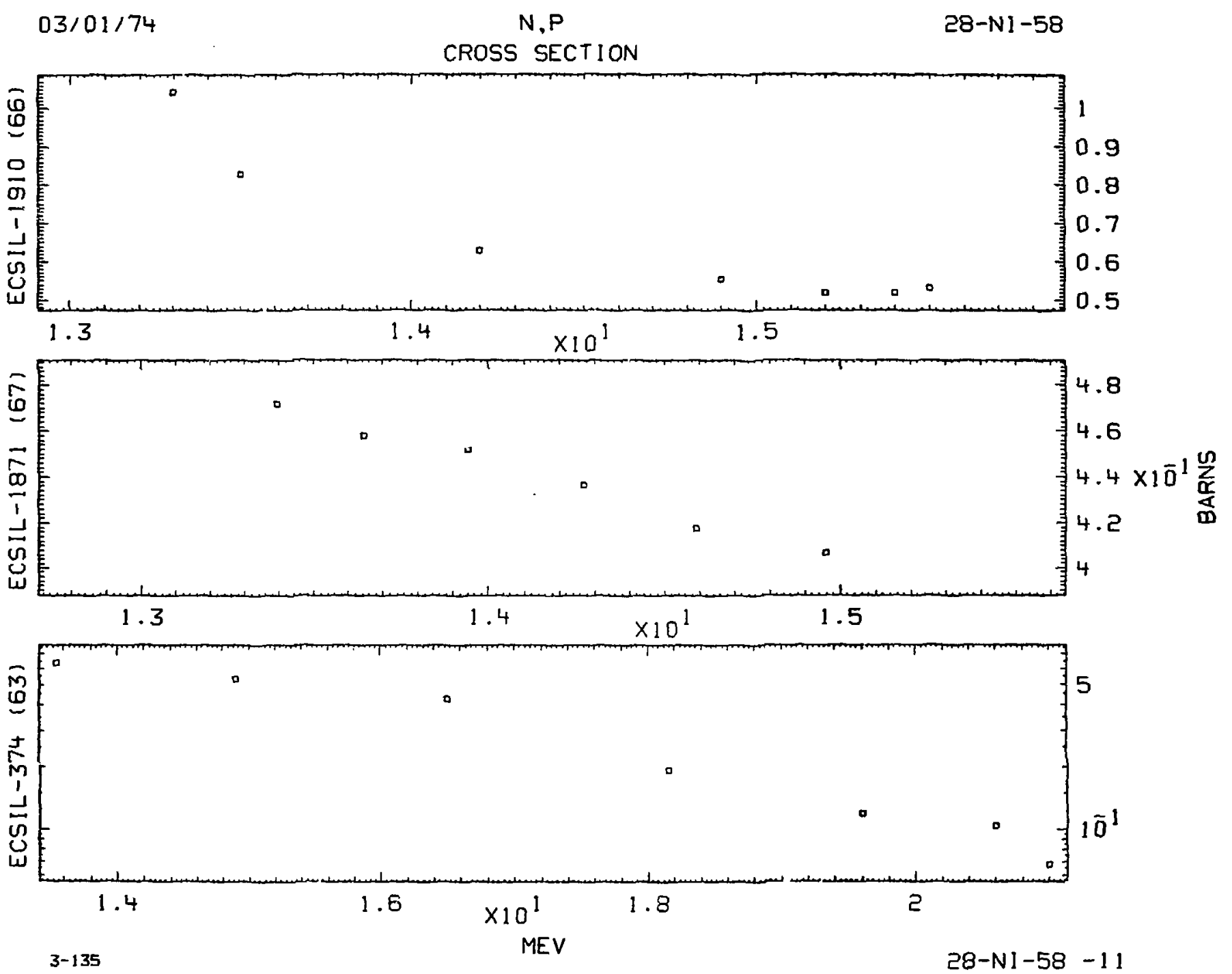




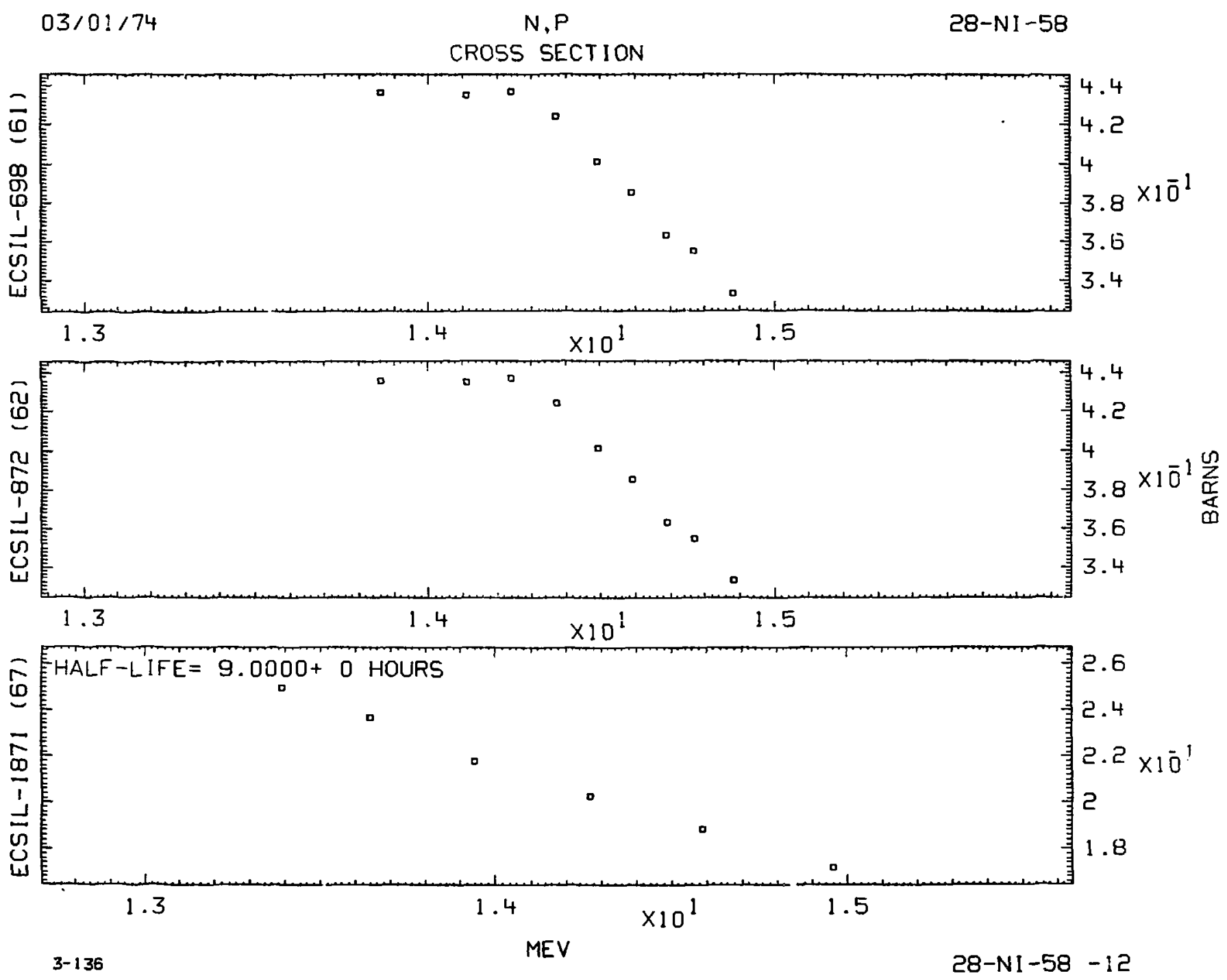




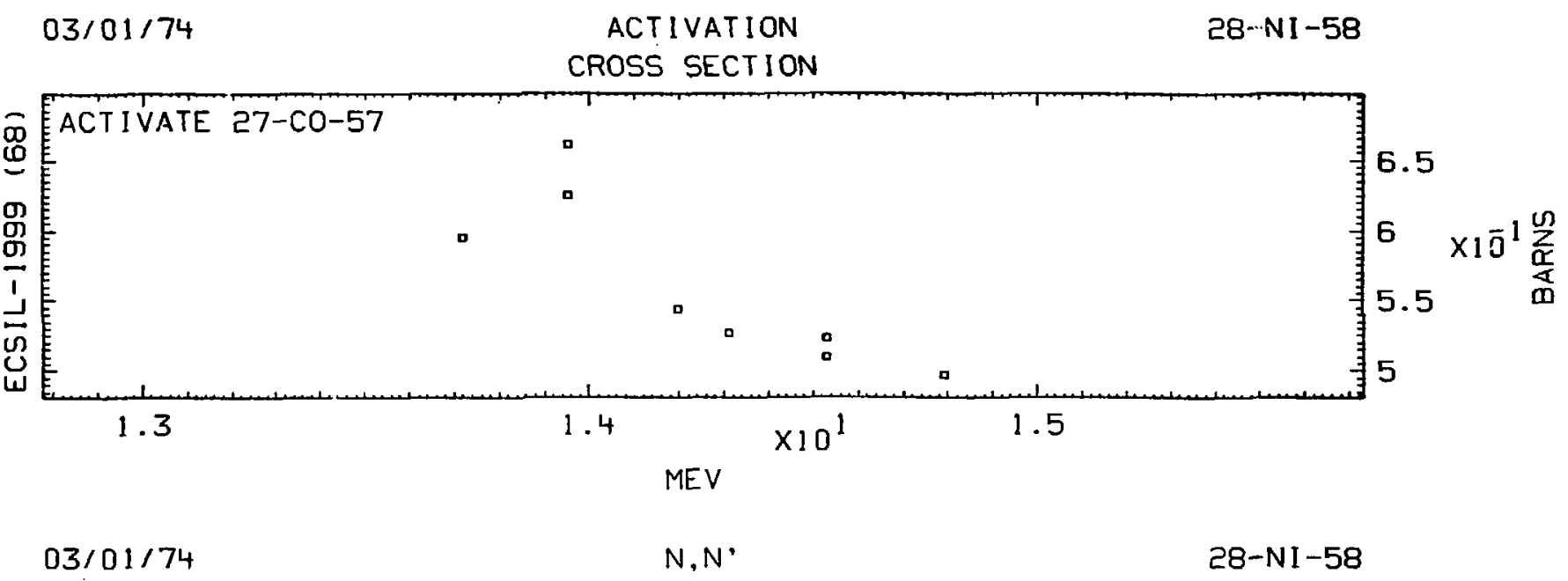

\begin{tabular}{|c|c|c|c|c|c|c|c|c|c|c|c|}
\hline REFERENCE & $\begin{array}{r}\text { ENERGY } \\
\text { MEV }\end{array}$ & $\begin{array}{r}\text { DELTA } \\
\text { MEV }\end{array}$ & $\begin{array}{l}X \text { X-SEC } \\
\text { BARNS }\end{array}$ & $\begin{array}{l}\text { DELTA } \\
\text { BARNS }\end{array}$ & $\begin{array}{r}E-L V L \\
M E V\end{array}$ & REFERENCE & $\begin{array}{r}\text { ENERGY } \\
\text { MEV }\end{array}$ & $\begin{array}{r}\text { DELTA } \\
\text { MEV }\end{array}$ & $\begin{array}{l}X \text {-SEC } \\
\text { BARNS }\end{array}$ & $\begin{array}{l}\text { DELTA } \\
\text { BARNS }\end{array}$ & $\begin{array}{r}E-L V L \\
\text { MEV }\end{array}$ \\
\hline 713214 & $00+0$ & $100-2$ & $9500-1$ & $9.0000-3$ & & 713214 & $0+0$ & $10-2$ & & & \\
\hline 713214 & $0+0$ & $300-2$ & $6500-1$ & 8.0050- 3 & +0 & 713214 & $0+0$ & & - & D- & $1+0$ \\
\hline 865 & $2.7000+0$ & $3.0000-2$ & $1.4000-1$ & $5000-2$ & $0+0$ & 713214 & $30+0$ & 1. & $0-1$ & $0-$ & $0+0$ \\
\hline 865 & $2.8000+0$ & $3.0000-2$ & $1.5000-1$ & $3.7500-2$ & $80+0$ & 855 & $10+0$ & & $0-2$ & $0-$ & $10+0$ \\
\hline $64 \quad 865$ & $3.0000+0$ & $3.0000-2$ & $1.7000-1$ & $4.2500-2$ & $4580+0$ & 713214 & $1500+0$ & $1.0000-2$ & $100-1$ & Do- & $400+0$ \\
\hline 713214 & $5.0500+0$ & $1.0000-2$ & $7.3000-2$ & $6.0000-3$ & $32.4600+0$ & 713214 & $5.5800+0$ & $1.0000-2$ & $1.1800-1$ & $1.2000-2$ & $3.3400+D$ \\
\hline
\end{tabular}

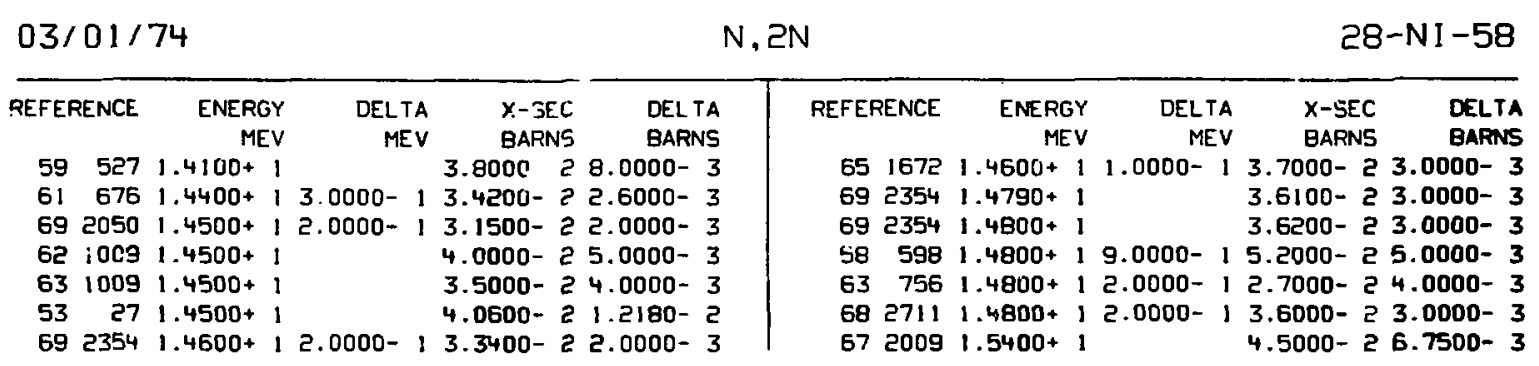




\section{CROSS SECTION}

\begin{tabular}{|c|c|c|c|c|c|c|c|c|c|c|}
\hline FEFER & ENCE & $\begin{array}{r}\text { ENERGY } \\
\text { MEV }\end{array}$ & $\begin{array}{l}\text { DEL IA } \\
\text { MEV }\end{array}$ & $\begin{array}{l}\text { X-SEC } \\
\text { BARNS }\end{array}$ & $\begin{array}{l}\text { OELTA } \\
\text { EARINS }\end{array}$ & REFERINCE & $\begin{array}{r}\text { ENERGY } \\
\text { MEV }\end{array}$ & $\begin{array}{c}\text { DELTA } \\
\text { MEV }\end{array}$ & $\begin{array}{l}x \text {-SEC } \\
\text { BAFNS }\end{array}$ & $\begin{array}{l}\text { DELTA } \\
\text { BNANS }\end{array}$ \\
\hline $\begin{array}{l}61 \\
57 \\
59\end{array}$ & $\begin{array}{l}361 \\
217 \\
527\end{array}$ & $\begin{array}{l}1.4000 \cdot 1 \\
1.4000 * 1 \\
1.4100+1\end{array}$ & & $\begin{array}{l}3.4500-1 \\
2.2000-1 \\
1.6000-1\end{array}$ & $\begin{array}{l}2.7000-2 \\
4.4000-2 \\
4.0000-2\end{array}$ & $\begin{array}{lr}69 & 2050 \\
\text { 81 } & 654\end{array}$ & $\begin{array}{l}1.4500 * 1 \\
1.4800 \cdot 1\end{array}$ & $\begin{array}{l}2.0000-1 \\
3.0000-1\end{array}$ & $\begin{array}{l}7.5000-1 \\
3.4000-!\end{array}$ & $\begin{array}{l}7.0000-2 \\
7.0000-z\end{array}$ \\
\hline
\end{tabular}
$03 / 01 / 74$
N, N ALPHA
$28-N \mid-58$

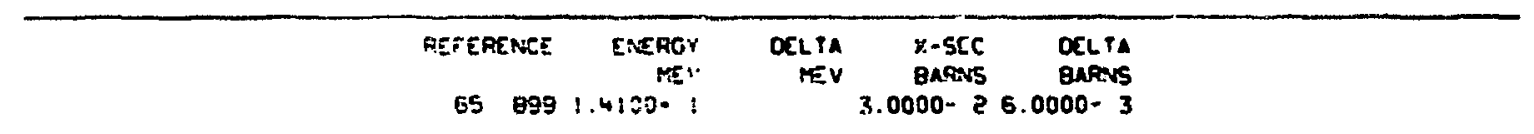

\section{$03 / 01 / 74$}

$N, P$

$28-N I-58$

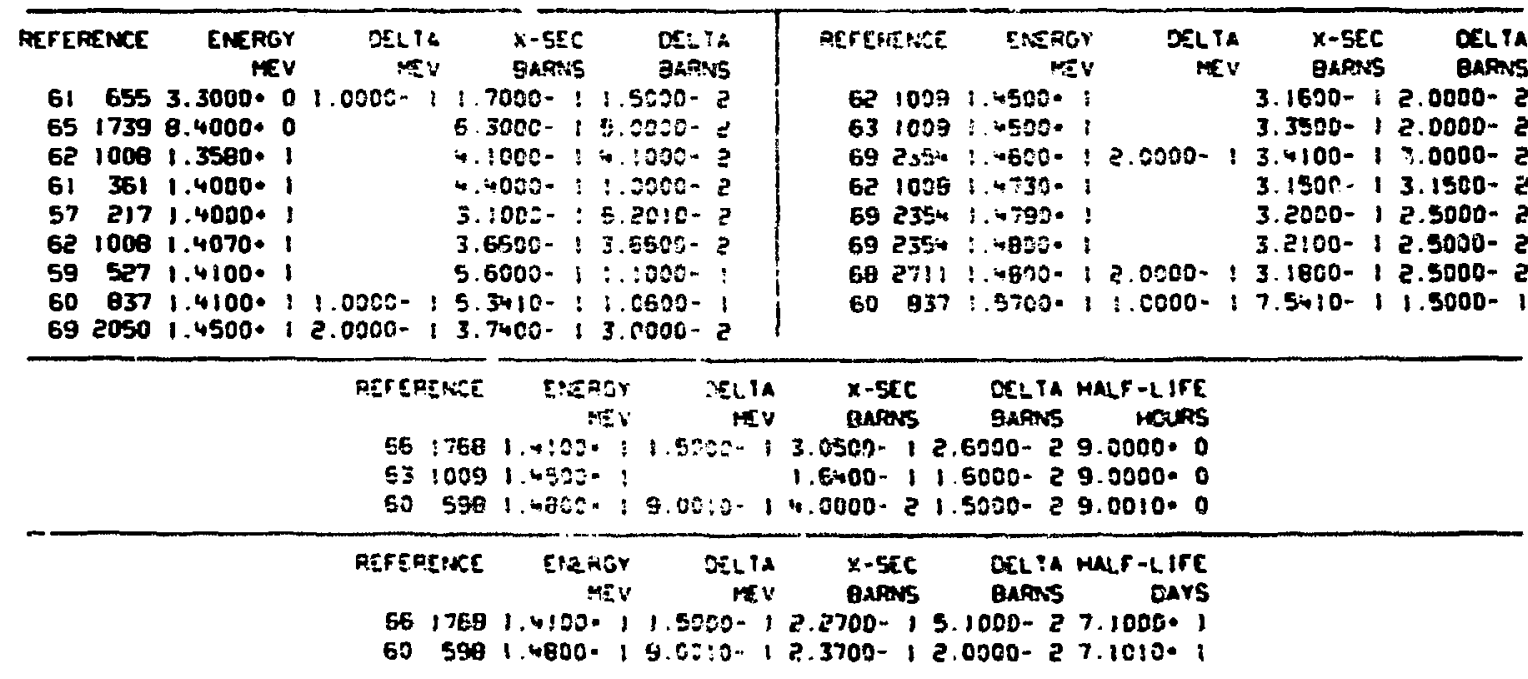




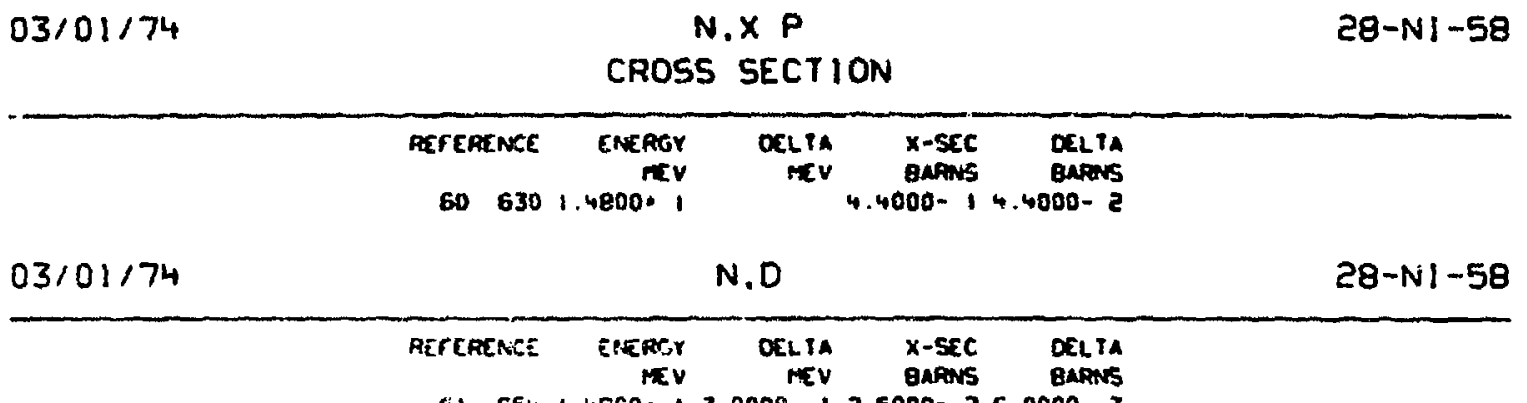

$61554: .4800 \cdot 13.0000-12.5000-26.0000-3$

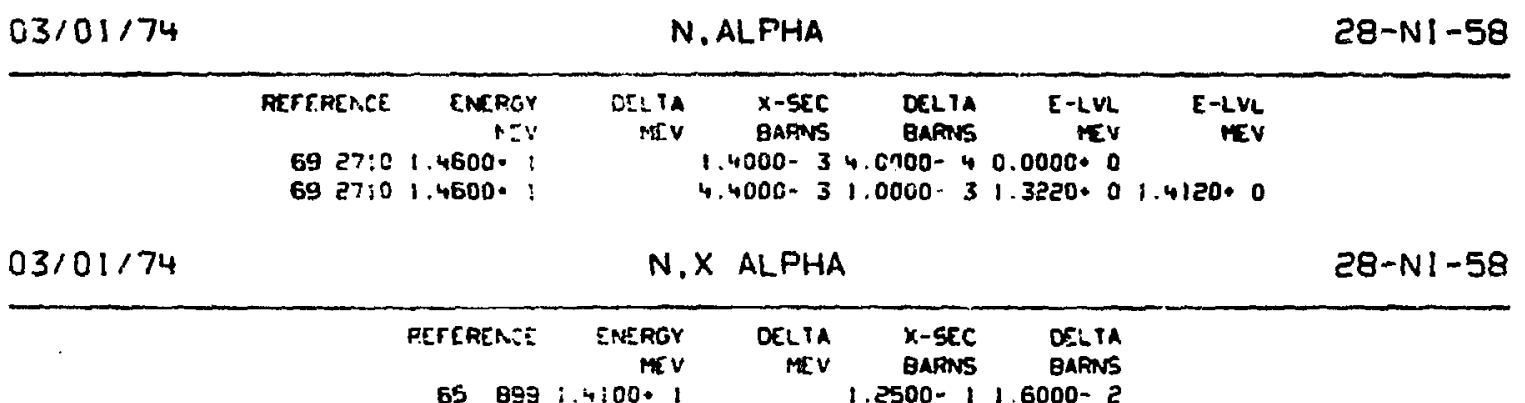

$03 / 01 / 74 \quad$ ACTIVATION E $8-N !-58$

\begin{tabular}{|c|c|c|c|c|c|c|c|c|c|c|c|}
\hline EFEREN & $\begin{array}{r}\text { ENERGY } \\
\text { MEV }\end{array}$ & $\underset{M E V}{\text { DELTA }}$ & $\begin{array}{l}x-S E C \\
\text { BARNS }\end{array}$ & $\begin{array}{l}\text { DELIA } \\
\text { BRFNS }\end{array}$ & IS ACTIVATE & REFERENCE & $\begin{array}{c}\text { ENEROY } \\
\text { MEV }\end{array}$ & $\begin{array}{l}\text { DELIA } \\
\text { MEV }\end{array}$ & & $\begin{array}{l}\text { DELTA } \\
\text { BARNS }\end{array}$ & Ctivate \\
\hline $\begin{array}{ll}62 & 1009 \\
63 & 1009 \\
69 & 2354\end{array}$ & $\begin{array}{l}1.4500 \\
1.4500+1 \\
1.4600+1\end{array}$ & & $\begin{array}{l}6.8000- \\
6.6500- \\
7.3000-\end{array}$ & $\begin{array}{l}16.0000 \cdot 2 \\
6.0000-2 \\
16.0000-2\end{array}$ & & $\begin{array}{lr}69 & 2354 \\
63 & 756 \\
68 & 2711\end{array}$ & $\begin{array}{l}1.4790 \\
1.4800 \\
1.4800\end{array}$ & $\begin{array}{l}1 \\
12.0000-1\end{array}$ & $\begin{array}{l}7.6400- \\
5.2000= \\
7.5000\end{array}$ & $\begin{array}{ll}1 & 6 . \\
1 & 1 . \\
1 & 6\end{array}$ & $\begin{array}{ll}2 & 27-00-57 \\
1 & 27-00-57 \\
2 & 27-00-57\end{array}$ \\
\hline
\end{tabular}




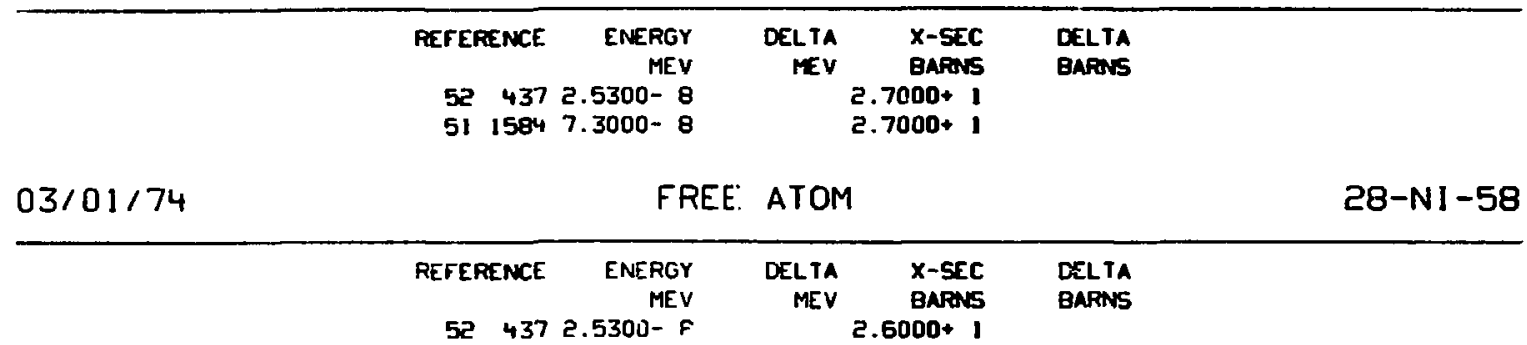

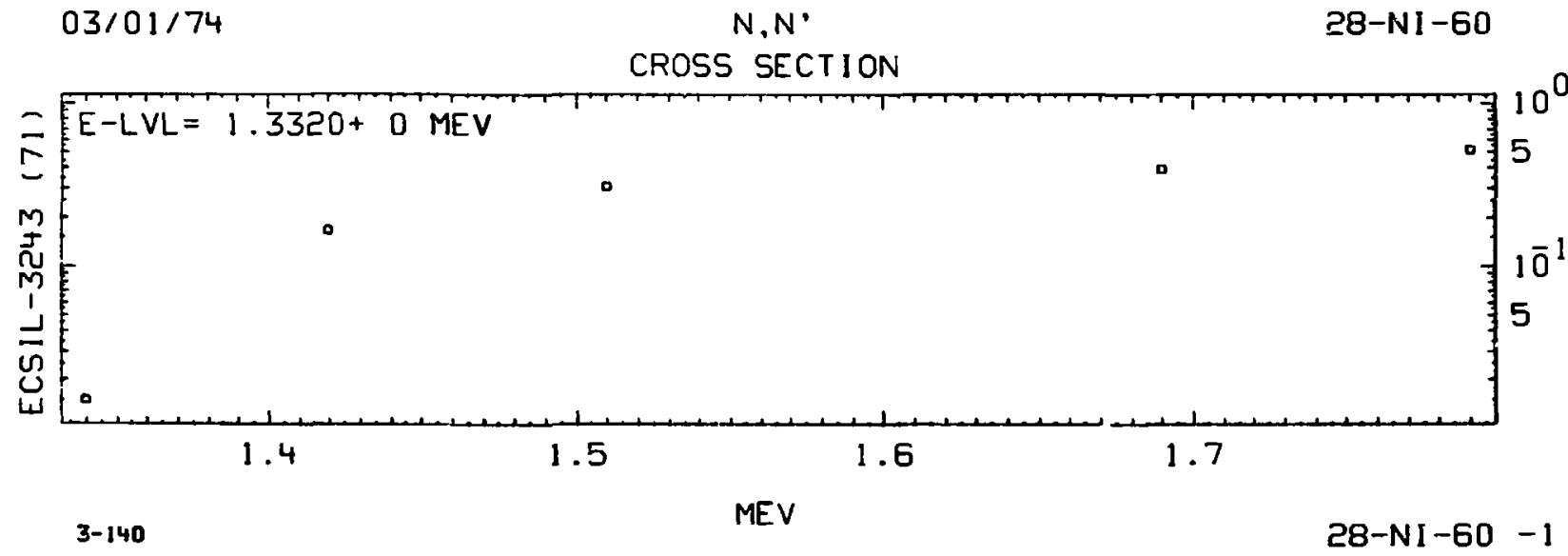



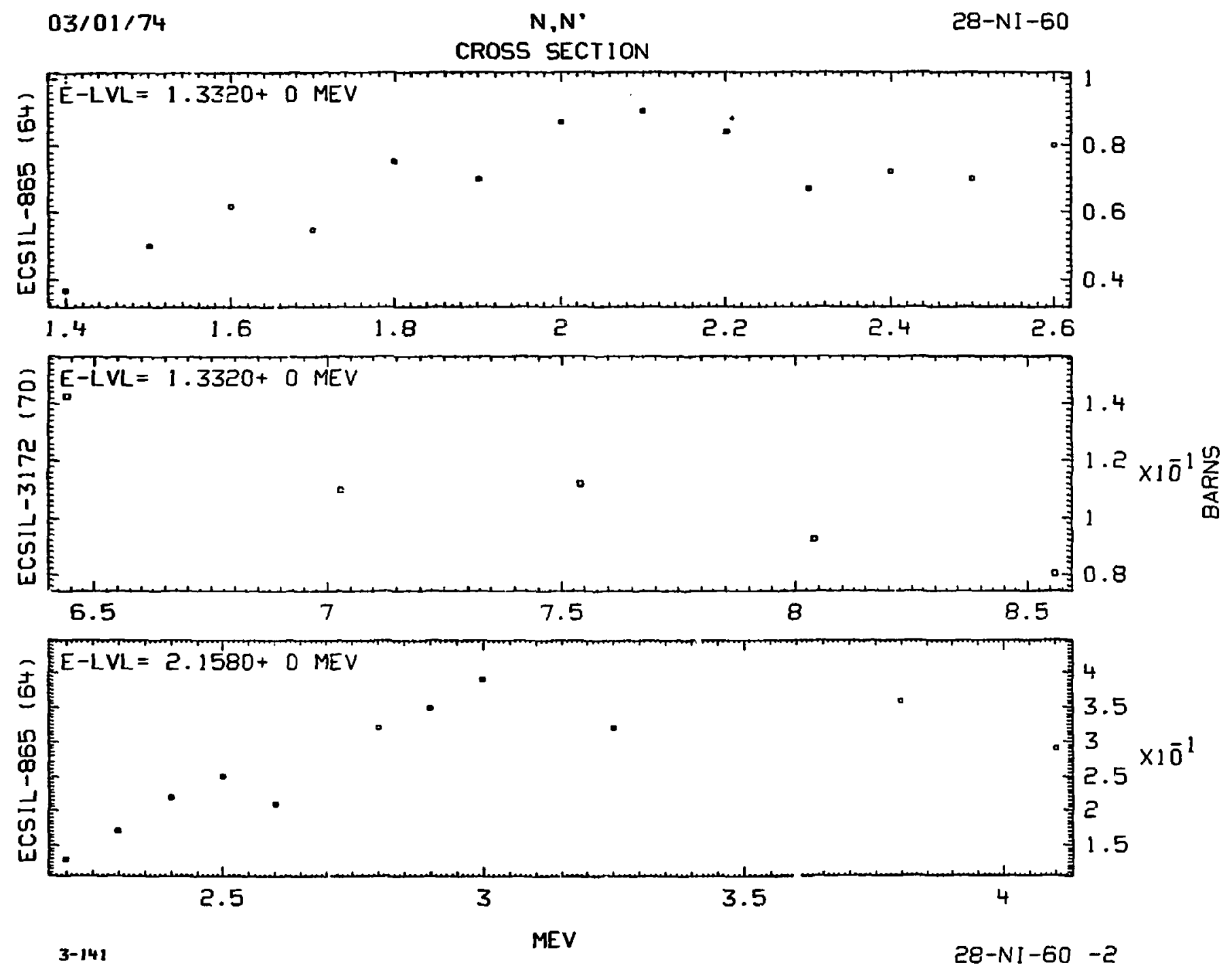


\section{CROSS SECTION}
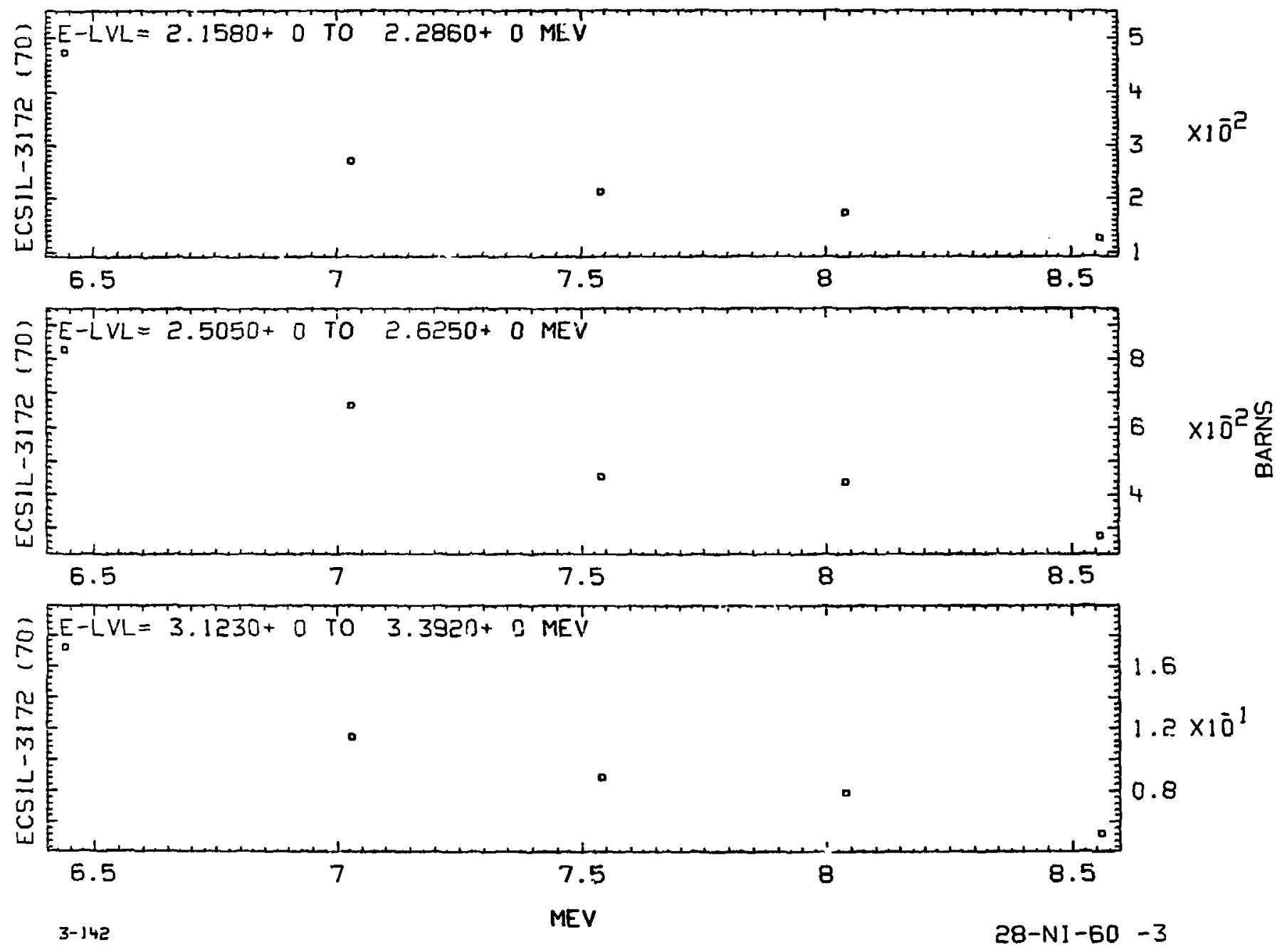

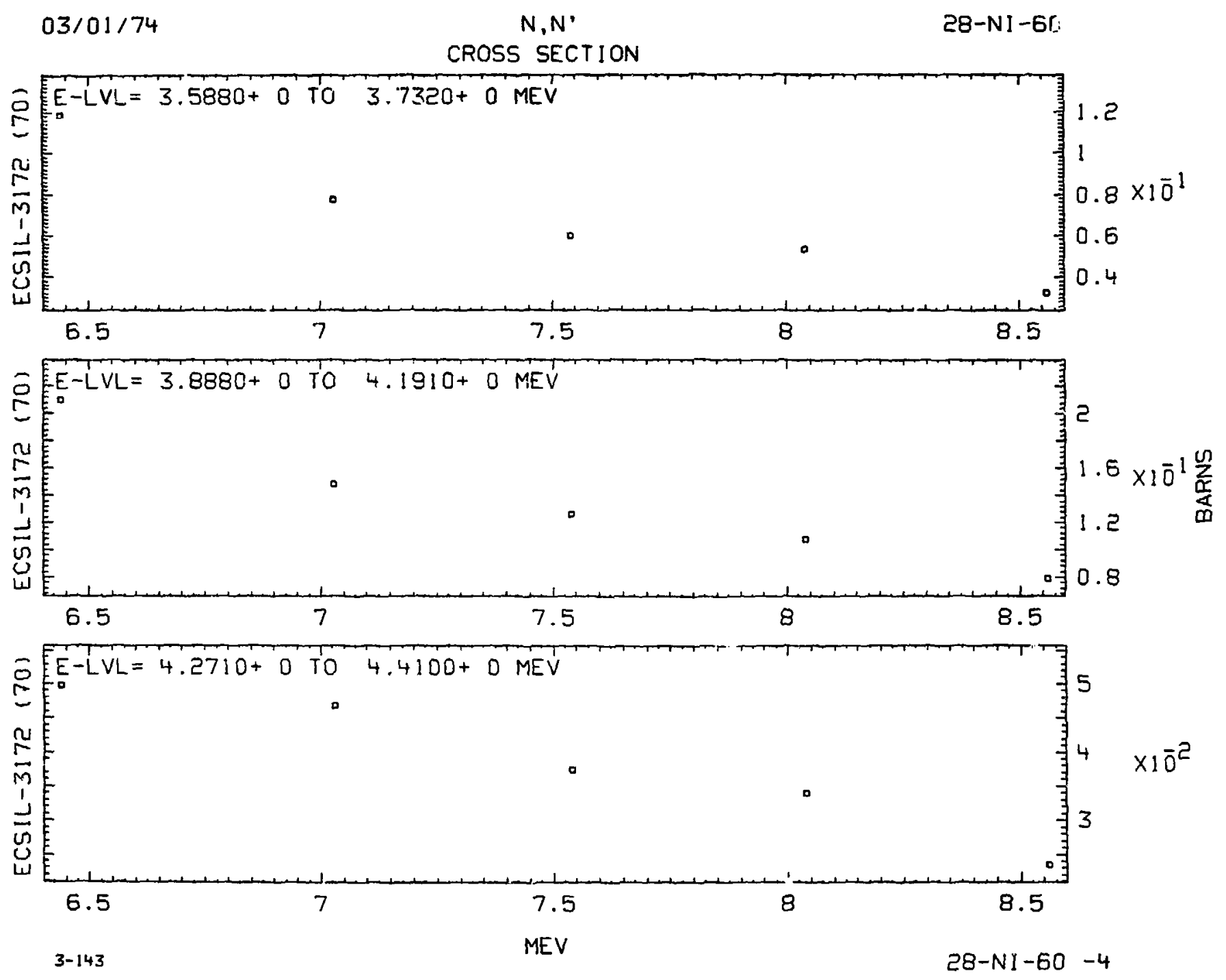

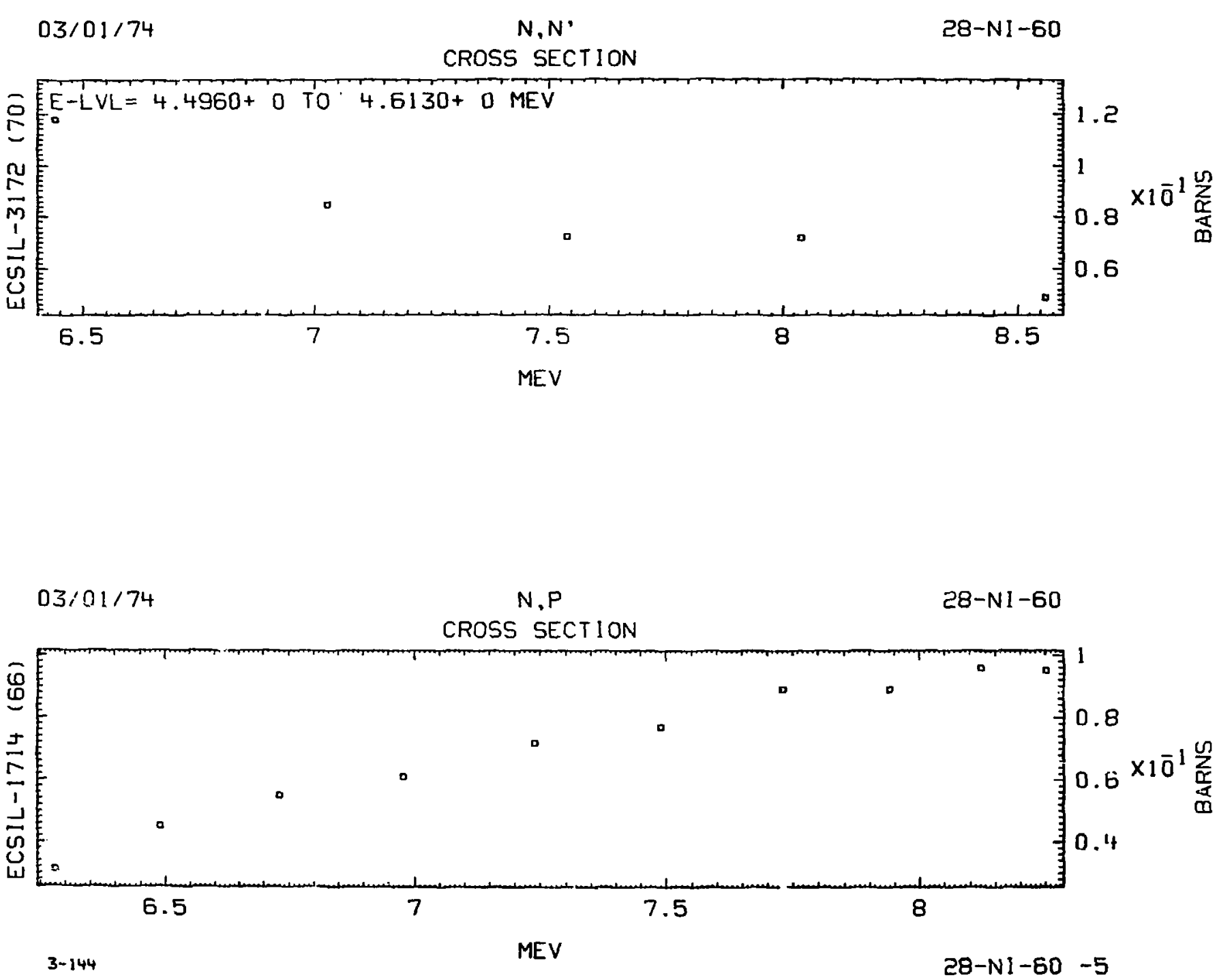


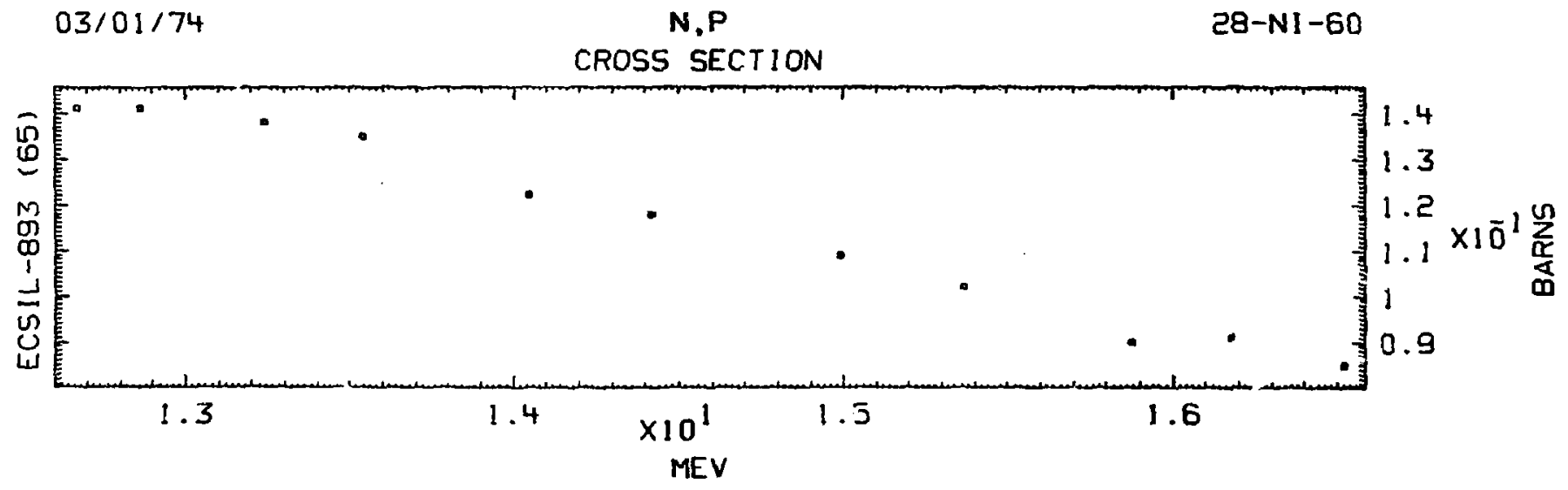

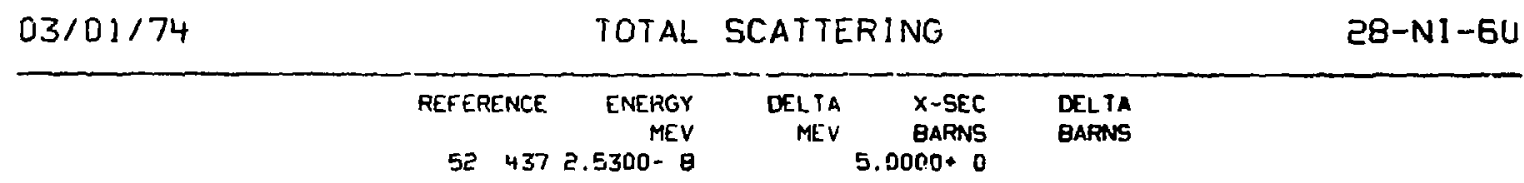

$03 / 01 / 74 \quad$ N.N $28-N I-60$

\begin{tabular}{|c|c|c|c|c|c|c|c|c|c|c|}
\hline REFERENCE & $\begin{array}{r}\text { ENERGY } \\
\text { MEV }\end{array}$ & $\begin{array}{r}\text { OELTAA } \\
\text { MEV }\end{array}$ & $\begin{array}{l}X-S F C \\
\text { BARNS }\end{array}$ & $\begin{array}{l}\text { DELTA } \\
\text { GARNS }\end{array}$ & $\begin{array}{r}E-L V L \\
F E V\end{array}$ & PEFERENCE & $\begin{array}{r}\text { ENERGY } \\
\text { MEV }\end{array}$ & $\begin{array}{r}\text { DELTA } \\
\text { MEV }\end{array}$ & $\begin{array}{l}x \text {-SEC } \\
\text { BARNS }\end{array}$ & $\begin{array}{l}\text { DELTA } \\
\text { BARNS }\end{array}$ \\
\hline
\end{tabular}

$7332145.0500+01.0000-22.4100-19.0000-3 ! .3300+0 \quad 7132145.0500+01.0000-21.7000-18.0000-32.5700+0$

$7132145.5800+01.0000-22.1000-11.5902-21.3320+0 \quad 7132145.5800+01.0000-21.3000-19.0000-32.5700+0$

$7132145.0500+0$ i.0000- $21.3200-11.2000-22.2200-0 \mid 7132145.0500+01.0000-23.9900-12.2000-23.2500+0$

$7132145.5800+01.0000-21.0400-11.1000-22.2200+0 \mid 7132145.5300+01.0000-23.0500-11.9000-23.2500+0$

\begin{tabular}{|c|c|c|c|c|c|}
\hline \multirow[t]{2}{*}{$03 / 01 / 74$} & \multicolumn{5}{|c|}{$N \cdot N \cdot P$} \\
\hline & REFERENCE & $\begin{array}{l}\text { ENERGY } \\
\text { MEV }\end{array}$ & $\begin{array}{r}\text { DELLTA } \\
\text { MEV }\end{array}$ & $\begin{array}{l}x \text {-SEC } \\
\text { BARNS }\end{array}$ & $\begin{array}{l}\text { DELTA } \\
\text { BARNS }\end{array}$ \\
\hline & $\begin{array}{ll}61 & 351 \\
57 & 217\end{array}$ & $\begin{array}{l}1.4000+1 \\
1.4000+1\end{array}$ & & $\begin{array}{l}5.1010-2 \\
6.0010-2\end{array}$ & $\begin{array}{l}9.0010-3 \\
1.2000-2\end{array}$ \\
\hline
\end{tabular}




\section{CROSS SECTION}

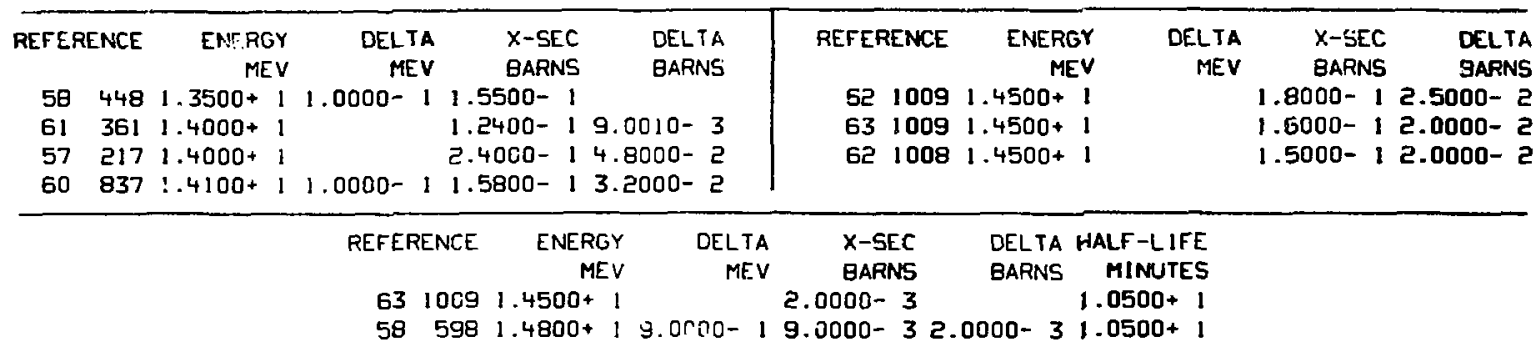

$585981.4800+13.0500-19.0000-32.0000-31.0500+1$

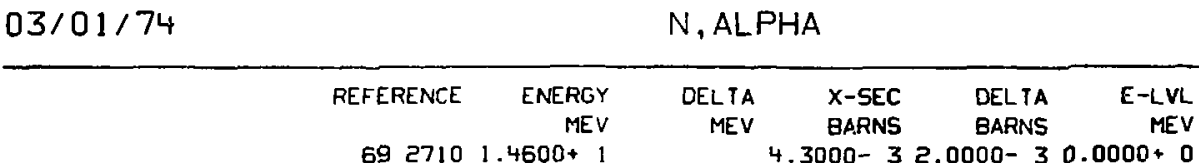

$03 / 01 / 74$

BOUND ATOM

$28-N I-60$

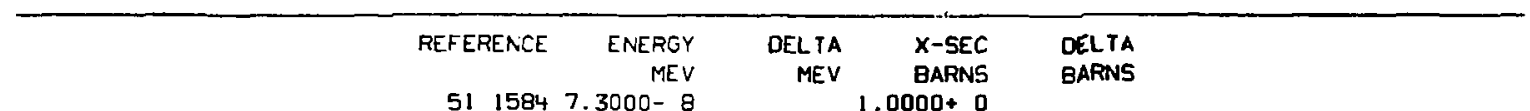

$5115847.3000-8$

$.0000+0$

$03 / 01 / 74$

COHERENT SCATTERING

$28-N I-60$

$\begin{array}{rrrrr}\text { REFERENCE } & \text { ENERGY } & \text { DELTA } & \text { X-5EC } & \text { DELTA } \\ \text { MEV } & \text { MEV } & \text { BARNS } & \text { BARNS } \\ 511584 & 7.3000-8 & & 9.7000-17.7600-2\end{array}$

$03 / 01 / 74$

$N, N \cdot P$

$28-N I-61$

$\begin{array}{lrrrr}\text { REFERENCE ENERGY } & \text { DELTA } & \text { X-SEC } & \text { DELTA } \\ & \text { MEV } & \text { MEV } & \text { BARNS } & \text { BARIS }\end{array}$

$585981.4800+19.0000-13.8000-31.0000-3$ 
$03 / 01 / 74$

$N, P$

$28-N I-61$

CROSS SECTION

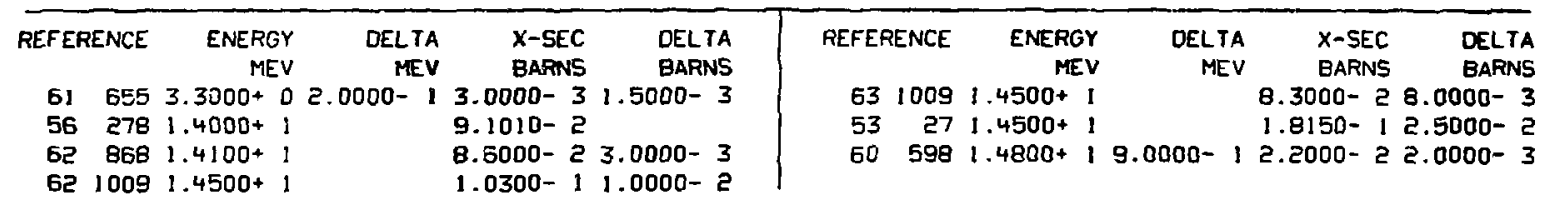
$03 / 01 / 74$
N, ALPHA
$28-N 1-61$

$\begin{array}{rrrrrr}\text { REFERENCF } & \text { ENERGY } & \text { DELTA } & \text { X-SEC } & \text { DELTA } & \text { E-LVL } \\ & \text { MEV } & \text { MEV } & \text { BARNS } & \text { BARNS } & \text { MEV } \\ 692710 & 1.4600+1 & & 7.0000-4 & 2.0000-4 & 0.0000+0 \\ 692710 & 1.4600+1 & & 1.1000-34.0000-48.1000-1\end{array}$

$03 / 01 / 74 \quad N, N^{\circ} \quad 28-N I-62$ CROSS SECTION

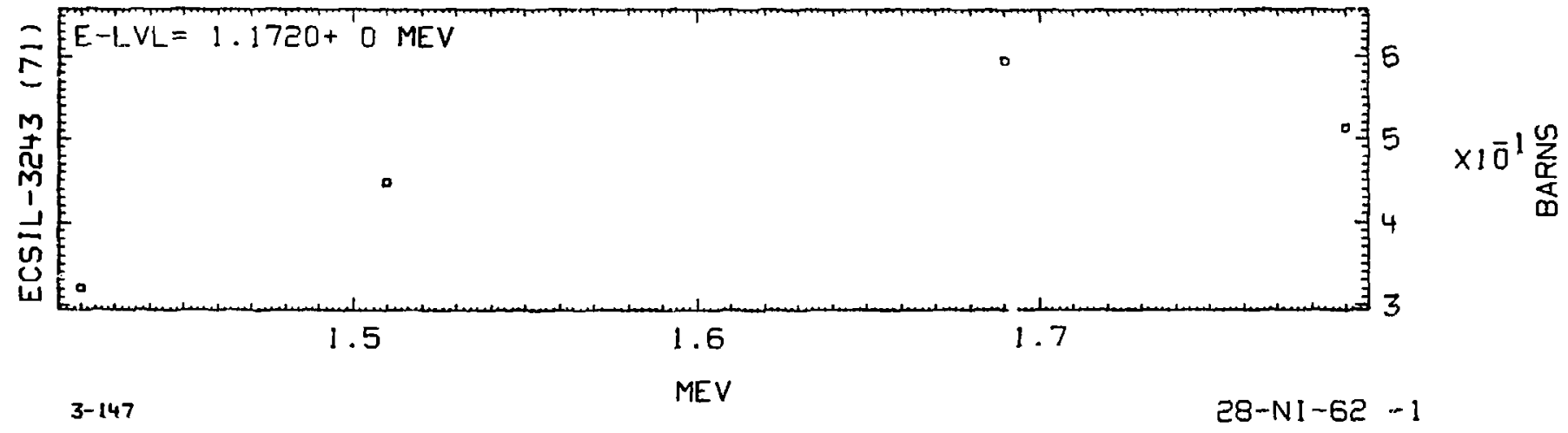




\section{CROSS SECTION}

$\begin{array}{rrrrr}\text { REFERENCE } & \text { ENERGY } & \text { DELTA } & x-5 E C & \text { DELTA } \\ \text { MEV } & \text { MEV } & \text { BARNS } & \text { BARNS }\end{array}$

$7132431.3400+0$ 3.4200- 1

$03 / 01 / 74$

$N, N \cdot P$

$\operatorname{sen}-N I-\mathrm{CS}^{2}$

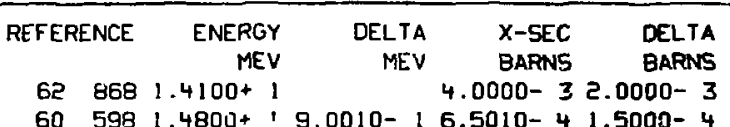

$605981.4800+19.0010-16.5010-41.5000-4$

$03 / 01 / 74$

$N, P$

$28-N I-62$

$\begin{array}{rrrrr}\text { REFERENE } & \text { ENERGY } & \text { DELTA } & \text { X-SEC } & \text { DELTA } \\ \text { MEV } & \text { MEV } & \text { BARNS r BARNS } \\ & 6210591.4500+1 & 2.4000-26.0000-3 \\ 6310091.4500+1 & 3.9000-26.0000-3\end{array}$

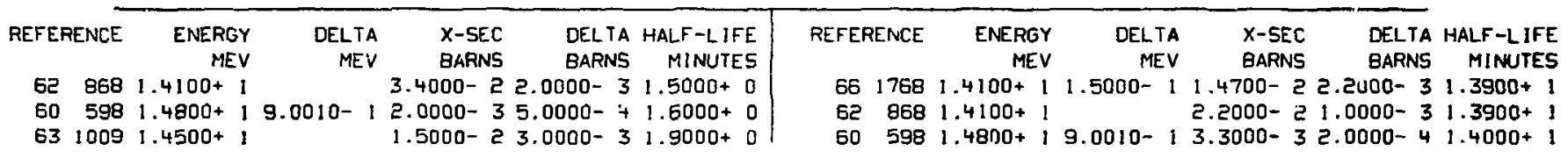

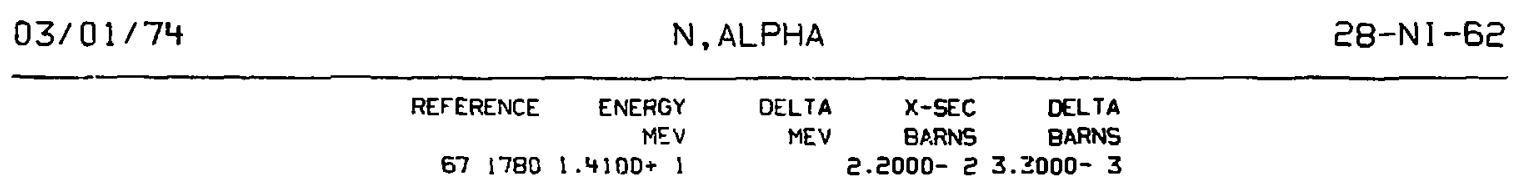

$03 / 01 / 74$

ACTIVATION

$28-N I-62$

$\begin{array}{rrrrr}\text { REFERENCE } & \text { ENERGY } & \text { DELTA } & \text { X-SEC } & \text { DELTA ACTIVATE } \\ & \text { MEV } & \text { MEV } & \text { BARNS } & \text { BARNS } \\ 6310091.4500+1 & & 4.4000-31.0000-327-C 0-61\end{array}$


CROSS SECTION

\begin{tabular}{|c|c|c|c|c|c|c|}
\hline & $\begin{array}{l}\text { REFERENCE } \\
511584\end{array}$ & $\begin{array}{r}\text { ENEFGY } \\
\text { MEV } \\
.3000-8\end{array}$ & $\begin{array}{l}\text { DELTA } \\
\text { MEV }\end{array}$ & $\begin{array}{l}X-5 E C \\
\text { BARNS } \\
000+0\end{array}$ & $\begin{array}{l}\text { DELTA } \\
\text { BAFNSS }\end{array}$ & \\
\hline $03 / 01 / 74$ & & OHERENT & SCATT & ING & & $28-N I-62$ \\
\hline
\end{tabular}

$5115847.3000-8$

$9.1000+07.2800-$

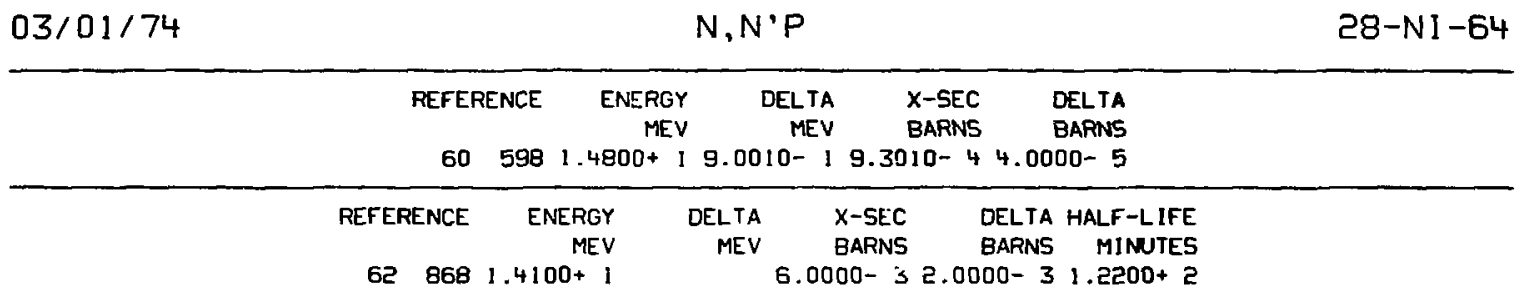

$03 / 01 / 74$

$N, P$

$28-N I-64$

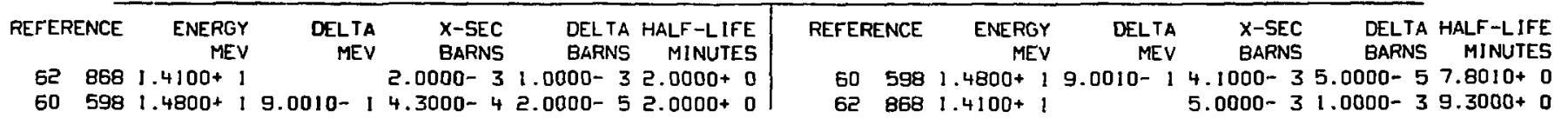



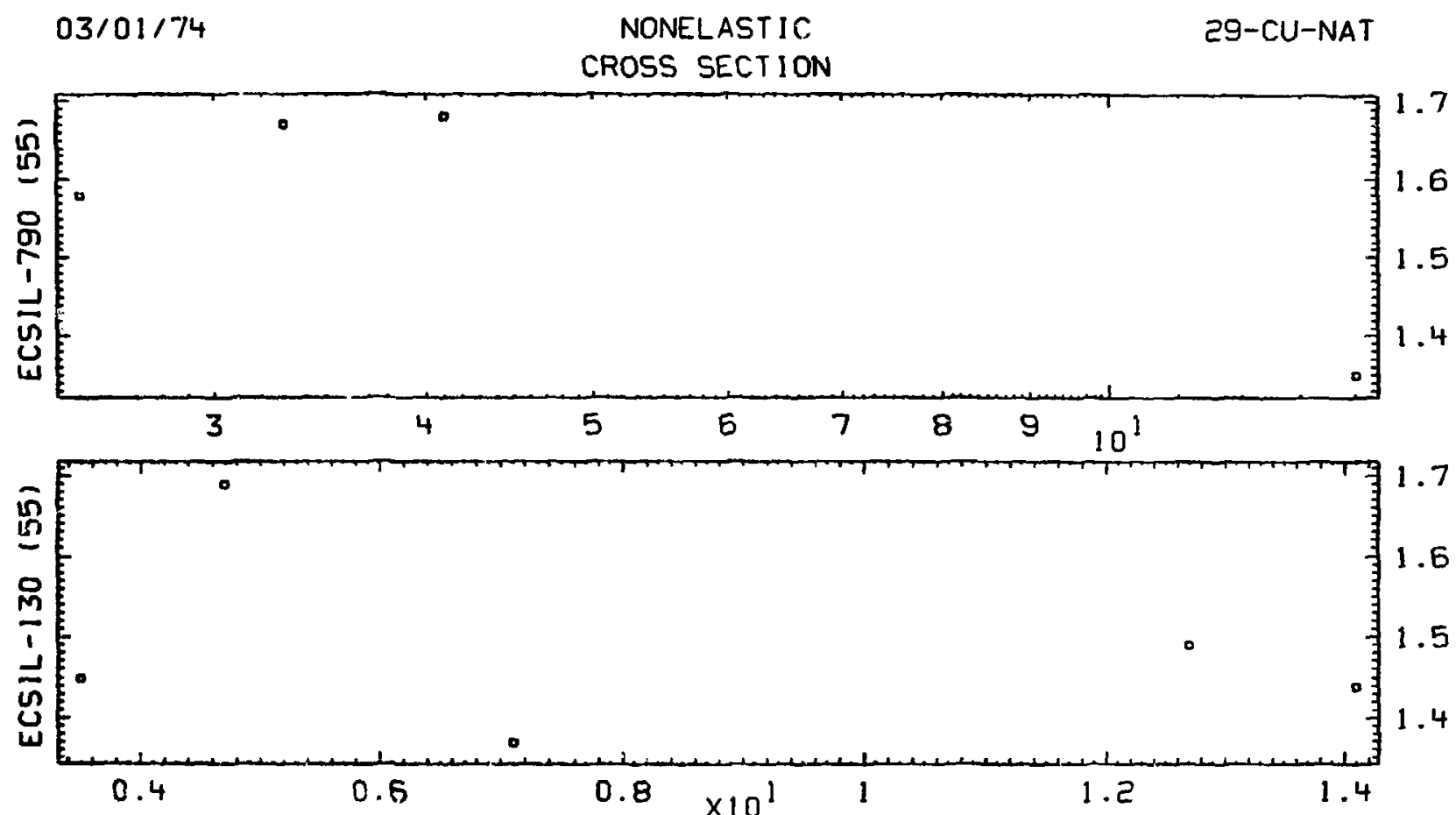

$\underset{\substack{n \\ \text { no }}}{\frac{n}{2}}$

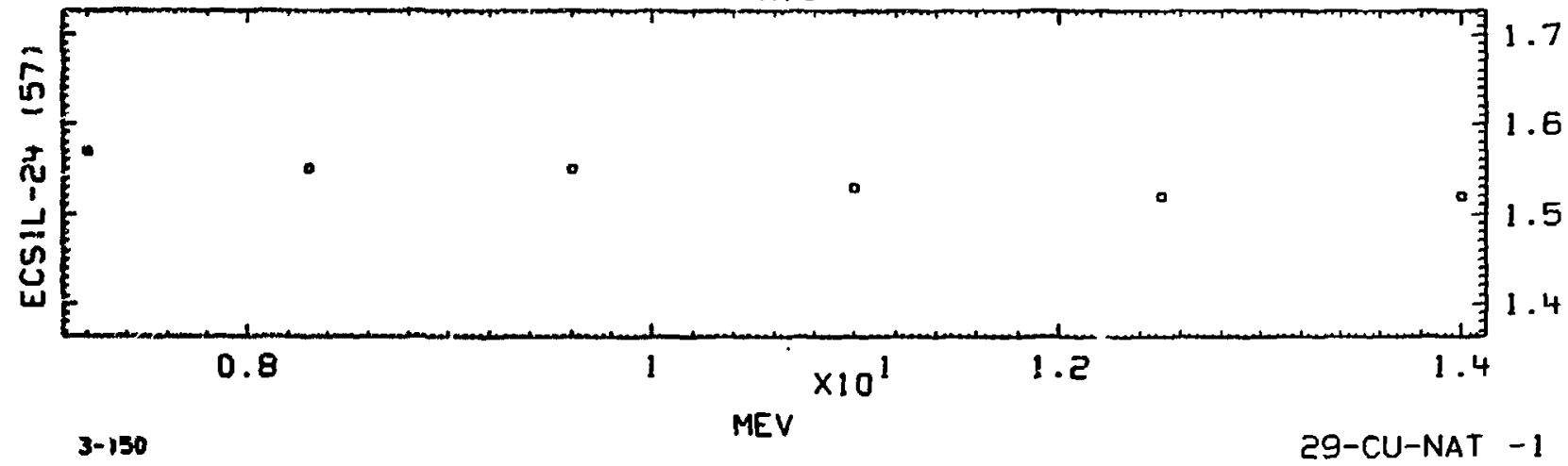



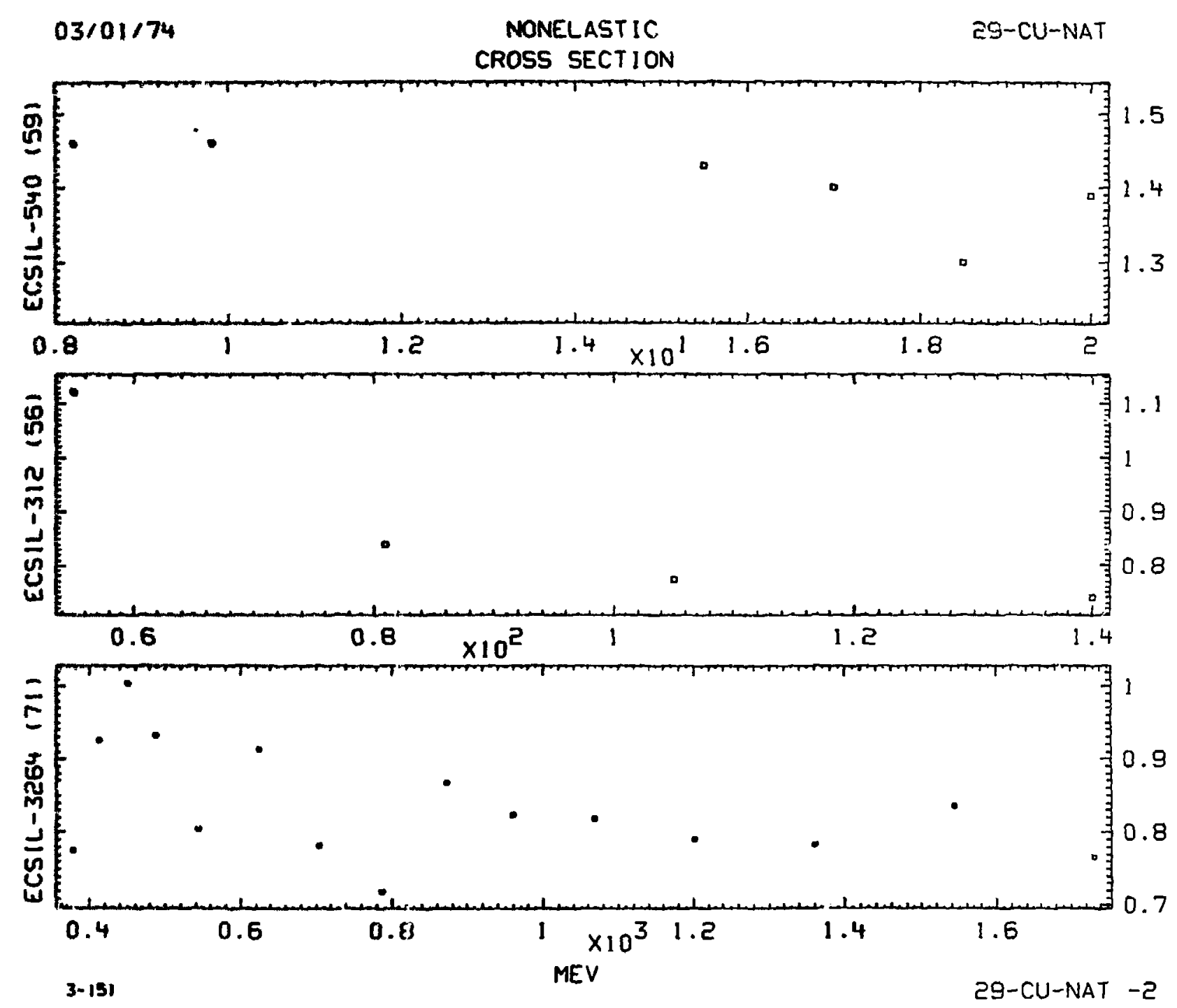


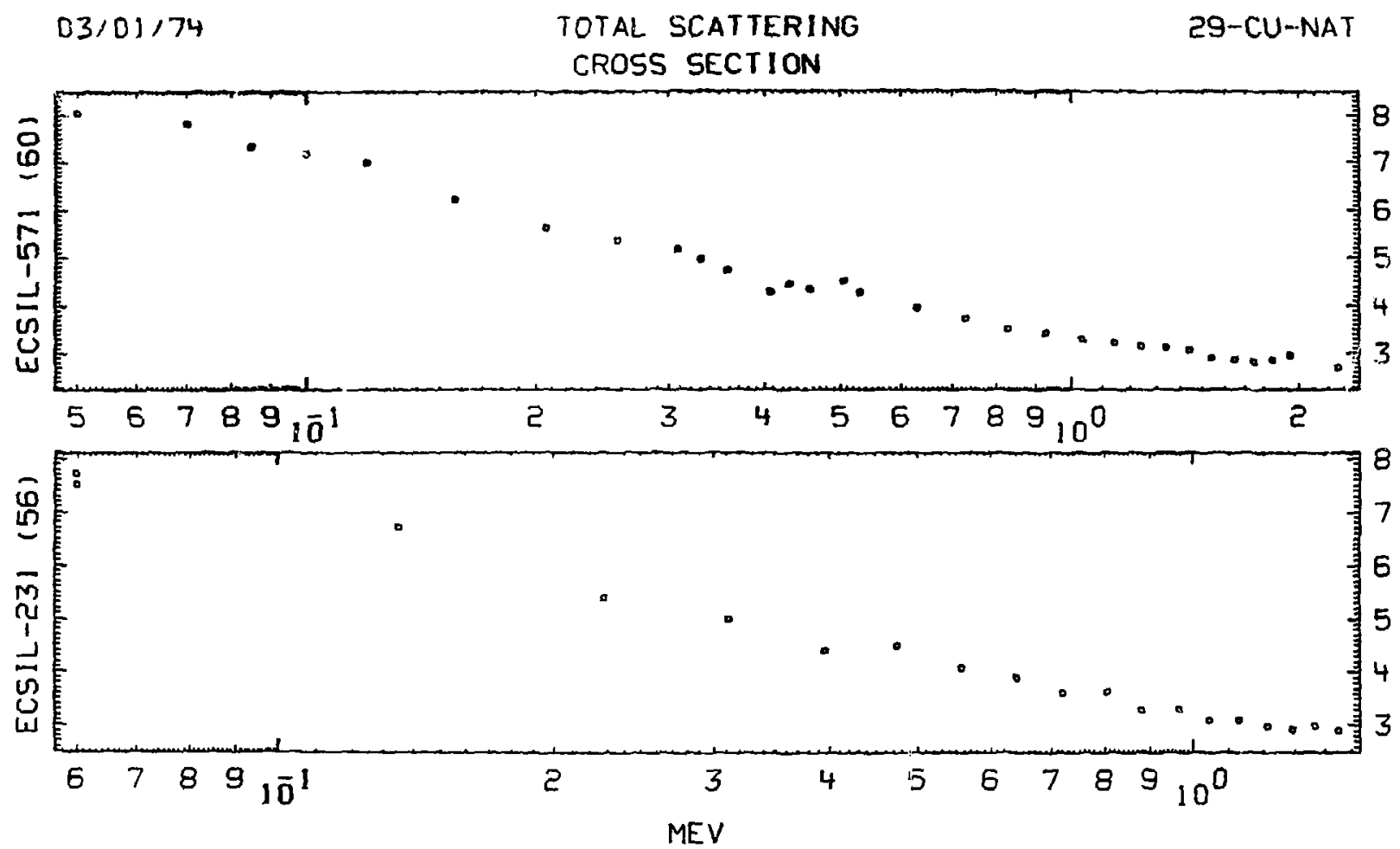




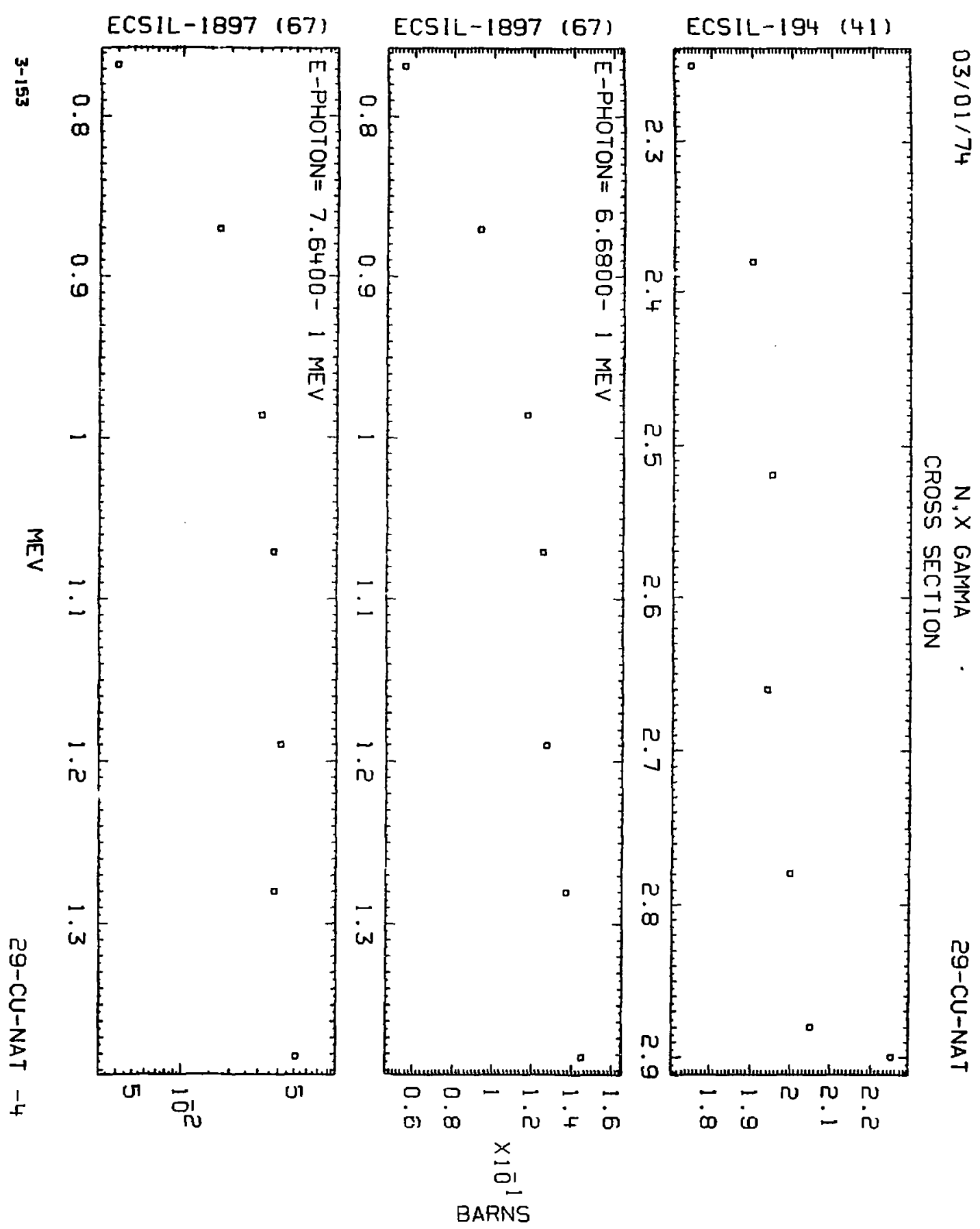


CROSS SECTION

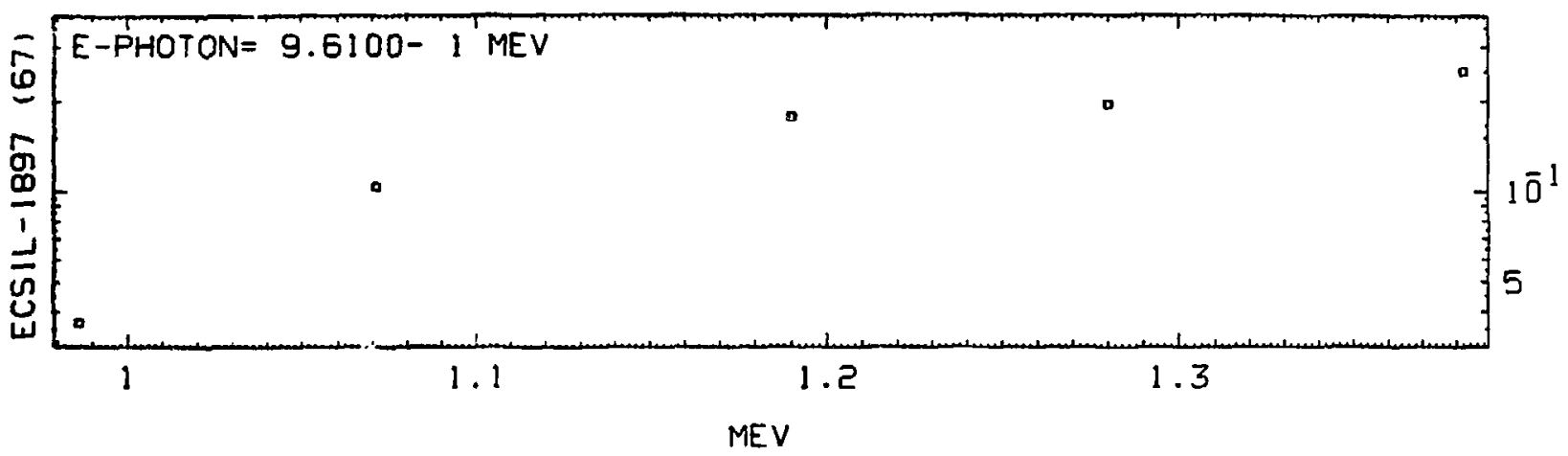

$03 / 01 / 74$

NONELASTIC

29-CU-NAT

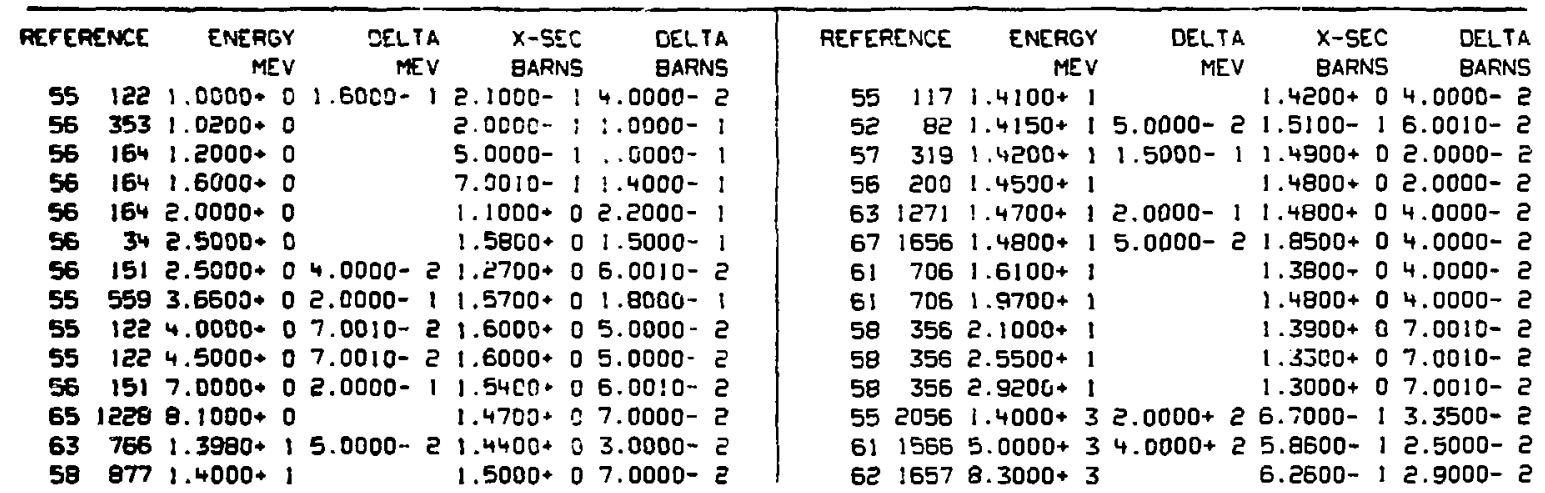


CROSS SECTION

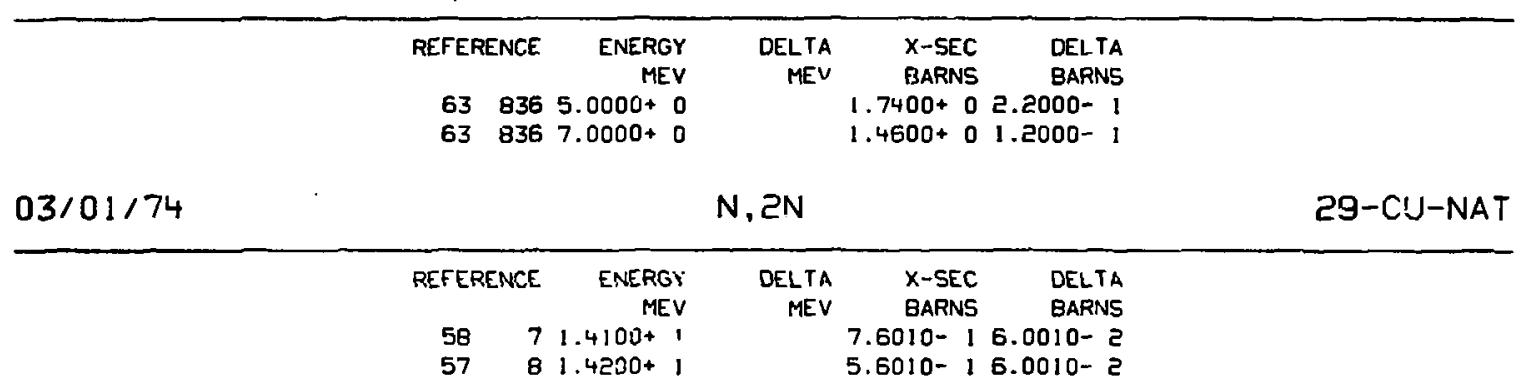

$03 / 01 / 74$

$N, N \cdot P$

29-CU-NAT

\begin{tabular}{rrrrr}
\hline REFERENCE & ENERGY & DELTA & X-SEC & DELTA \\
& MEV & MEV & BARNS & BARNS \\
$5920531.4000+1$ & & $8100-1$ & $8100-2$
\end{tabular}

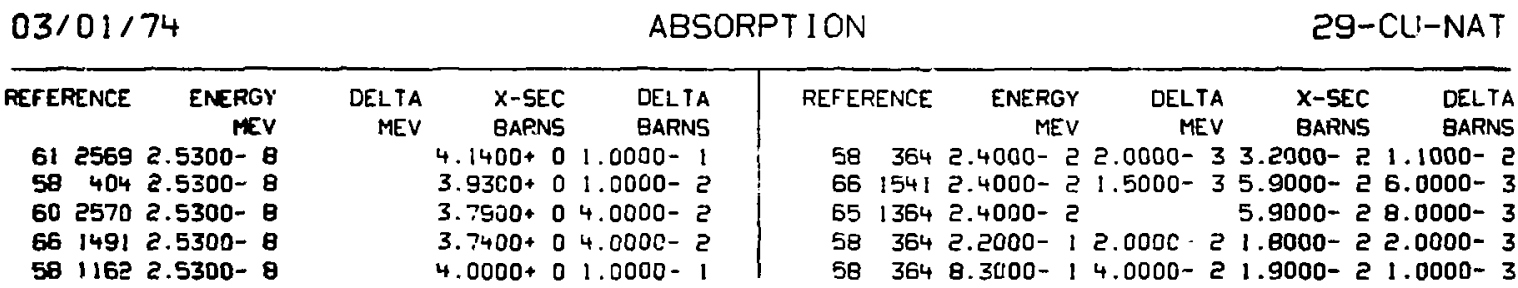

$03 / 01 / 74$

$N, X$ GAMMA

29-CU-NAT

\begin{tabular}{|c|c|c|c|c|c|}
\hline \multicolumn{2}{|l|}{ REFERENCE } & $\begin{array}{r}\text { DELTA } \\
\text { MEV }\end{array}$ & $\begin{array}{l}X \text { X-SEC } \\
\text { BARNS }\end{array}$ & & $\begin{array}{r}\text { ENERG } \\
\text { ME }\end{array}$ \\
\hline
\end{tabular}




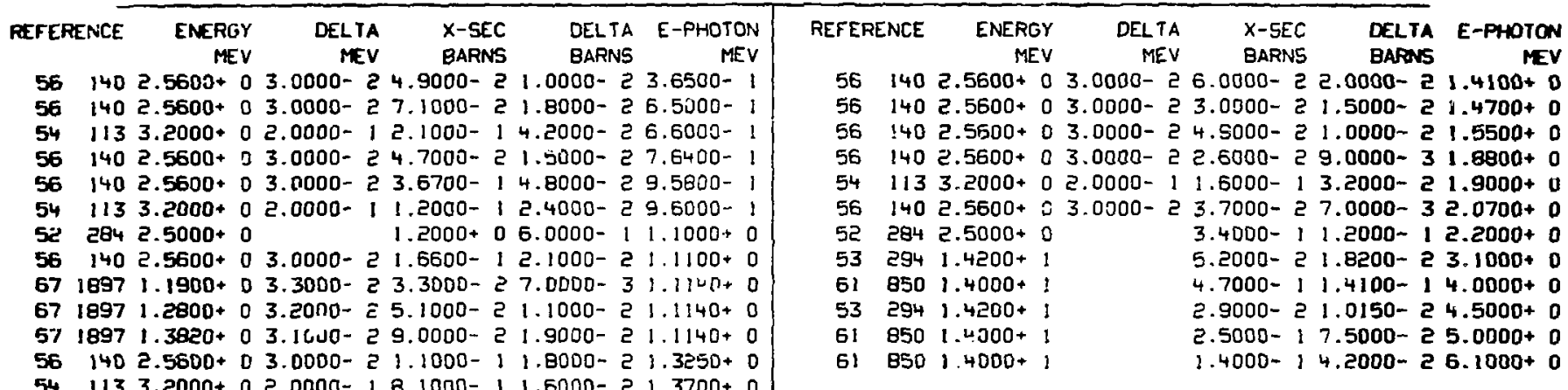

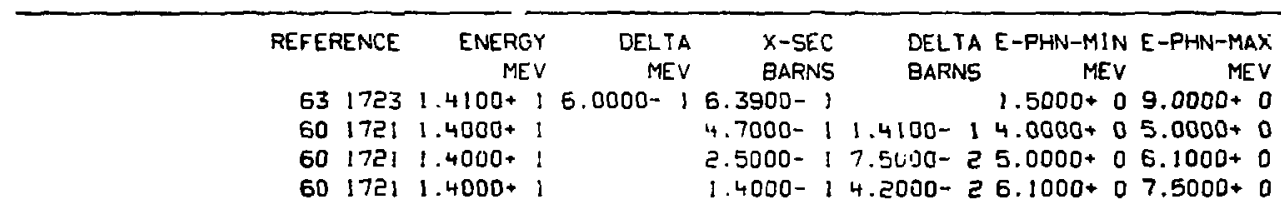

$03 / 01 / 74$

$N, X P$

29-CU-NAT

\begin{tabular}{|c|c|c|c|c|c|}
\hline & $\begin{array}{r}\text { REFERENCE } \\
\begin{array}{rr}59 & 1840 \\
58 & 441\end{array}\end{array}$ & $\begin{array}{r}\text { ENERGY } \\
\text { MEV } \\
1.4000+1 \\
1.4000+1\end{array}$ & $\begin{array}{rr}\text { DELTA } & \text { X-SEC } \\
\text { MEV } & \text { BARNS } \\
2.4600-1 \\
1.7300-1\end{array}$ & $\begin{array}{r}\text { DELTA } \\
\text { BARNS } \\
1.0000-2\end{array}$ & \\
\hline $03 / 01 / 74$ & & BOUND & ATOM & & 29-CU-NAT \\
\hline
\end{tabular}


CROSS SECTION

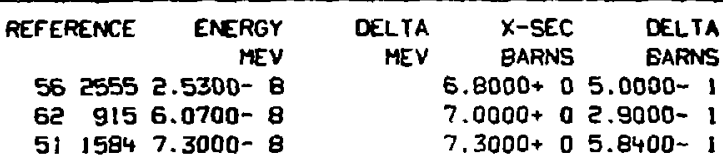
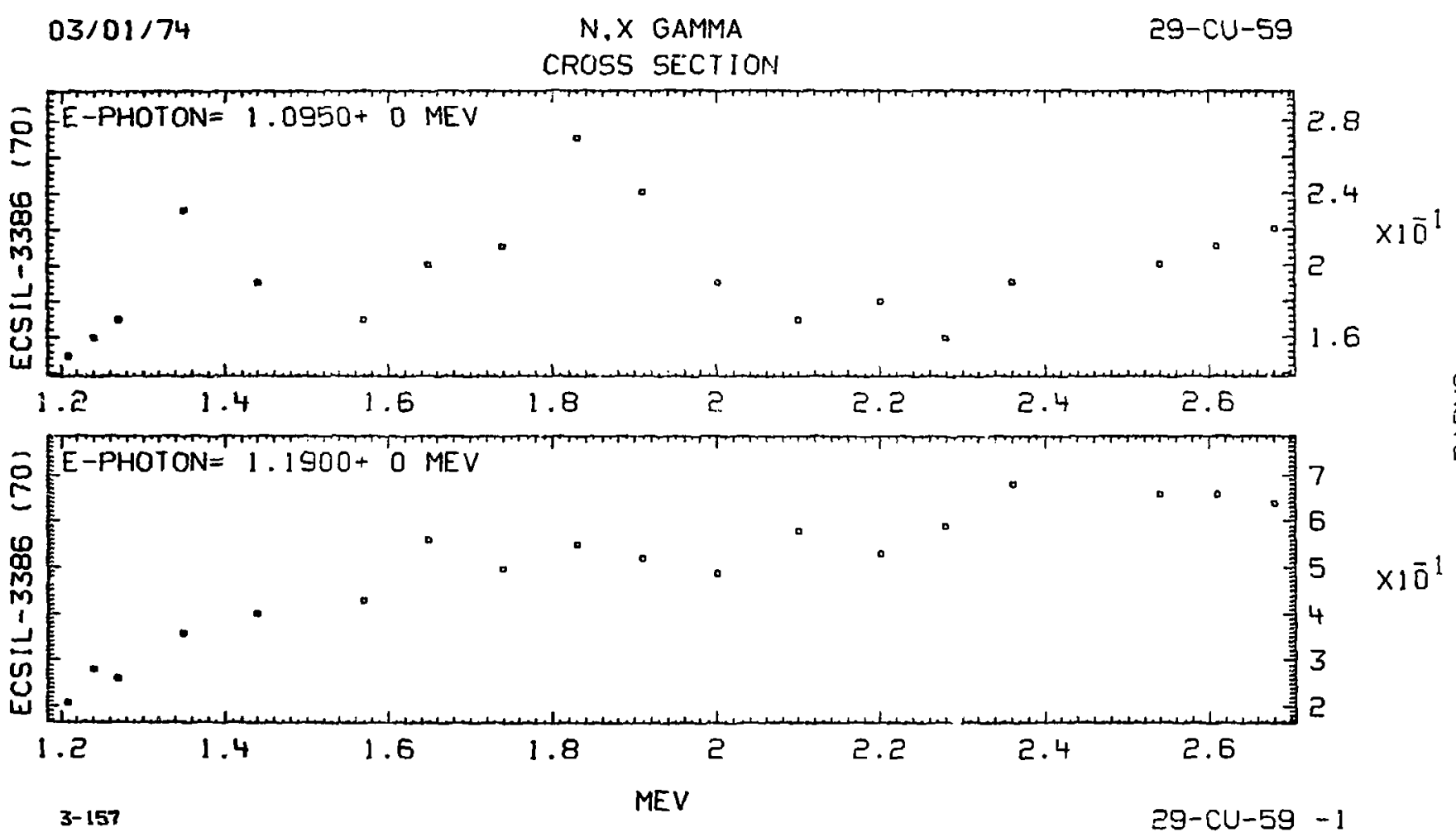


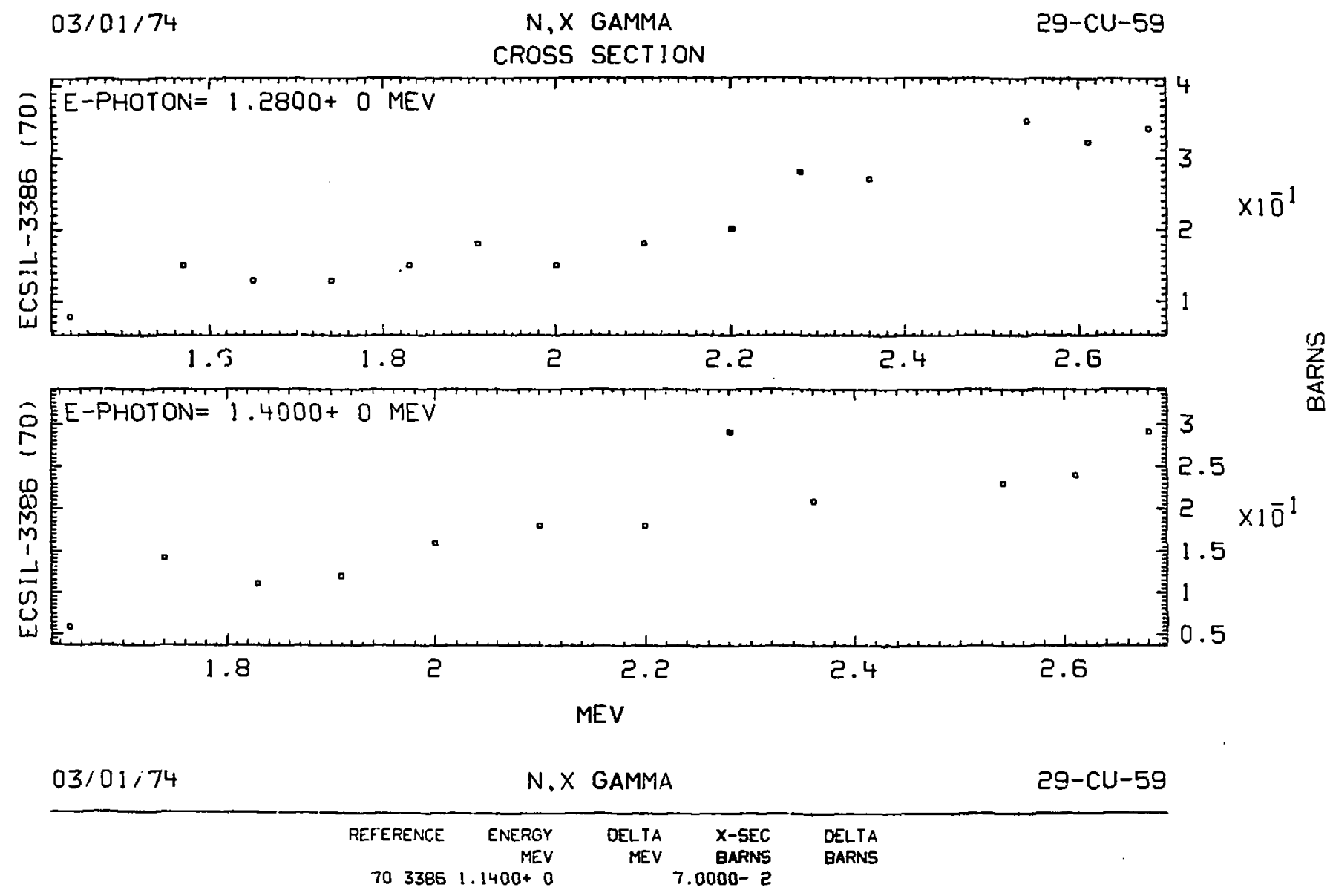




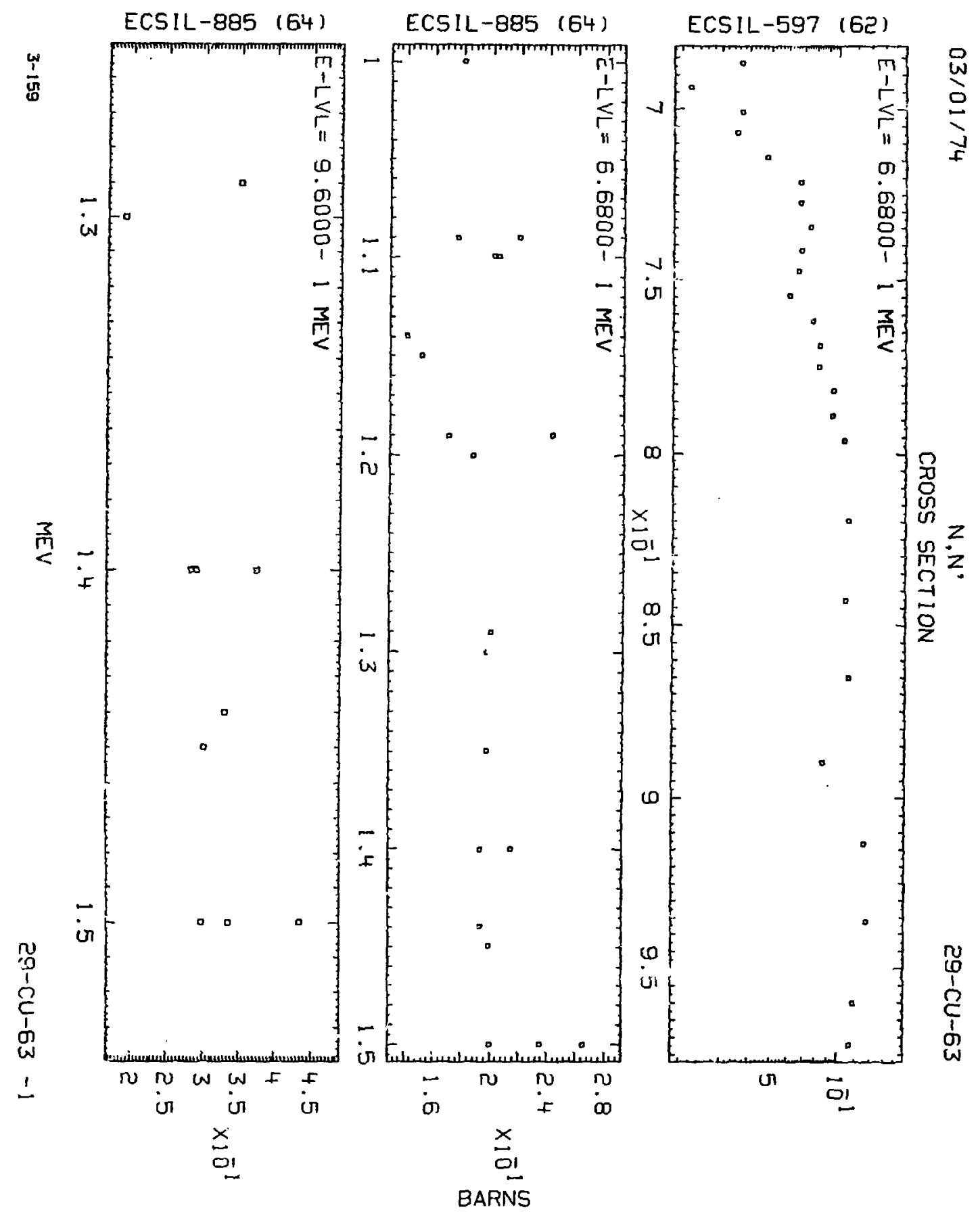




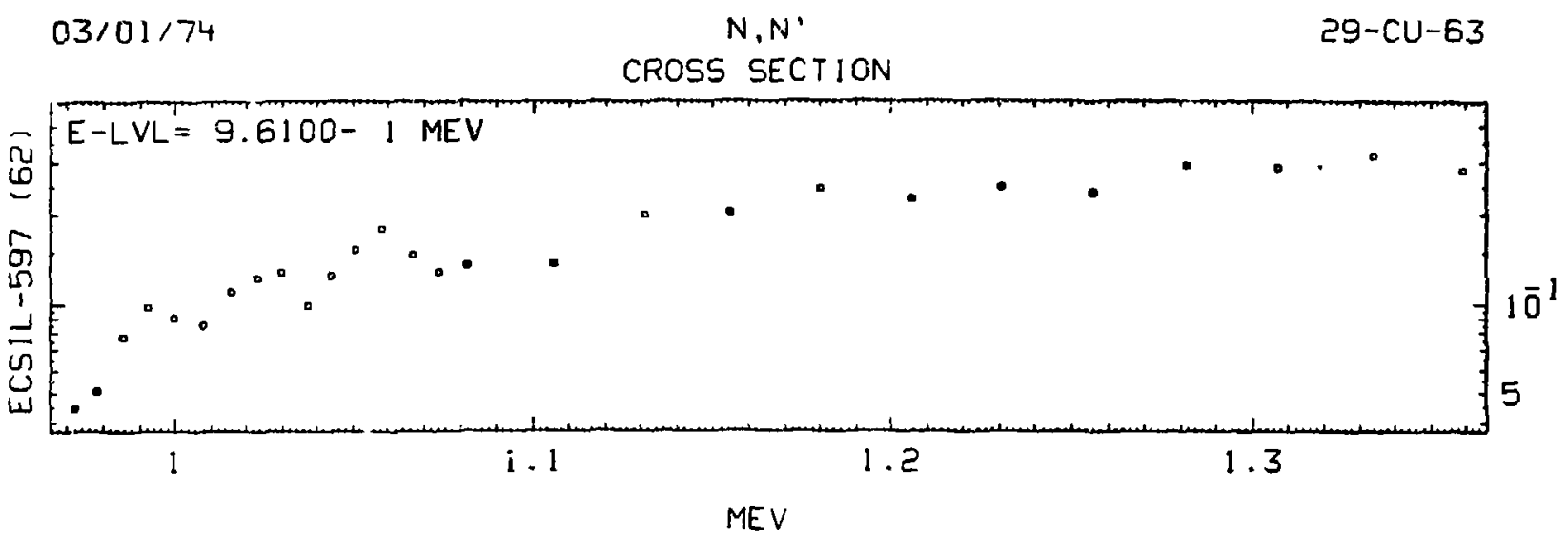

MEV

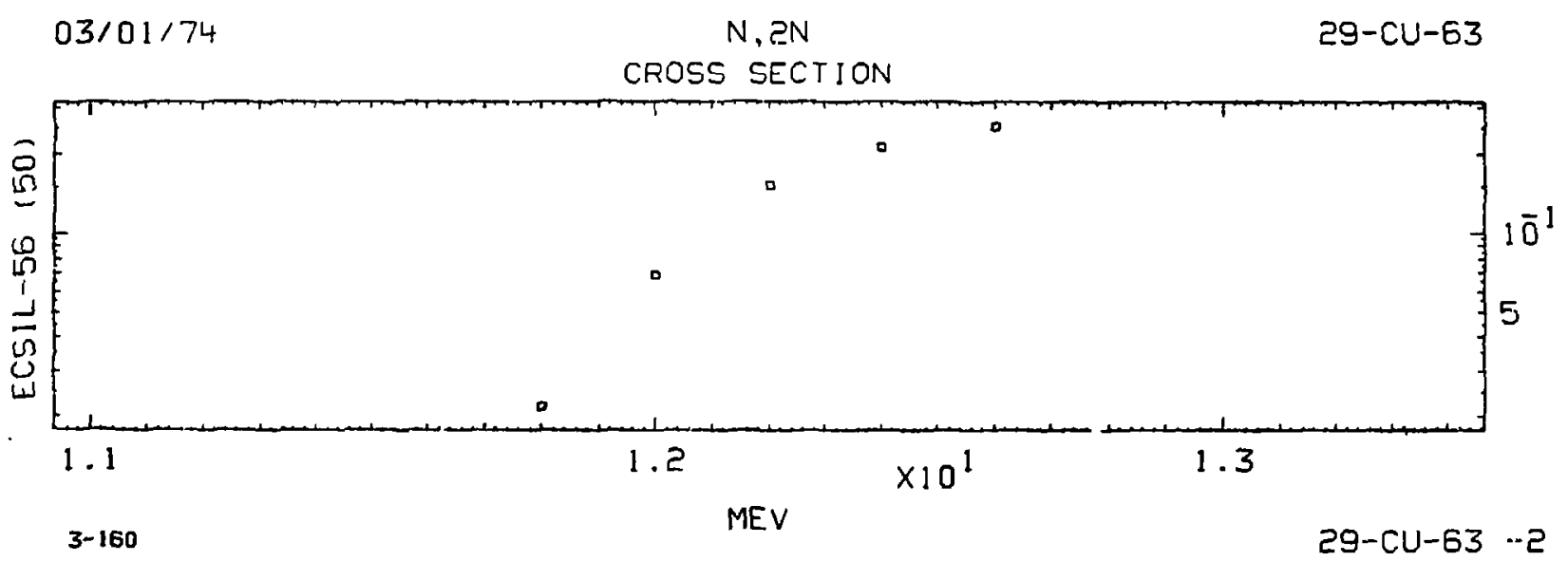



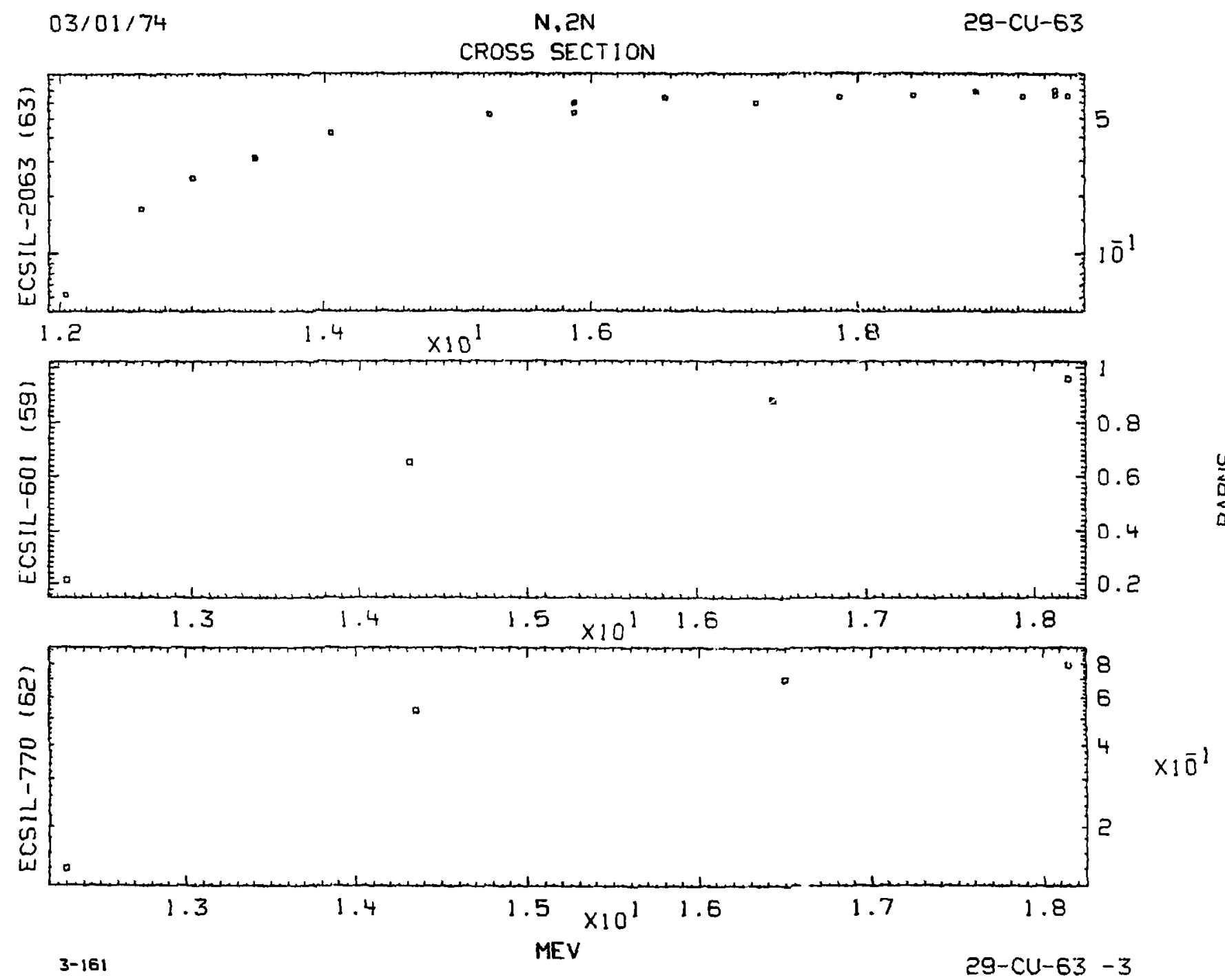


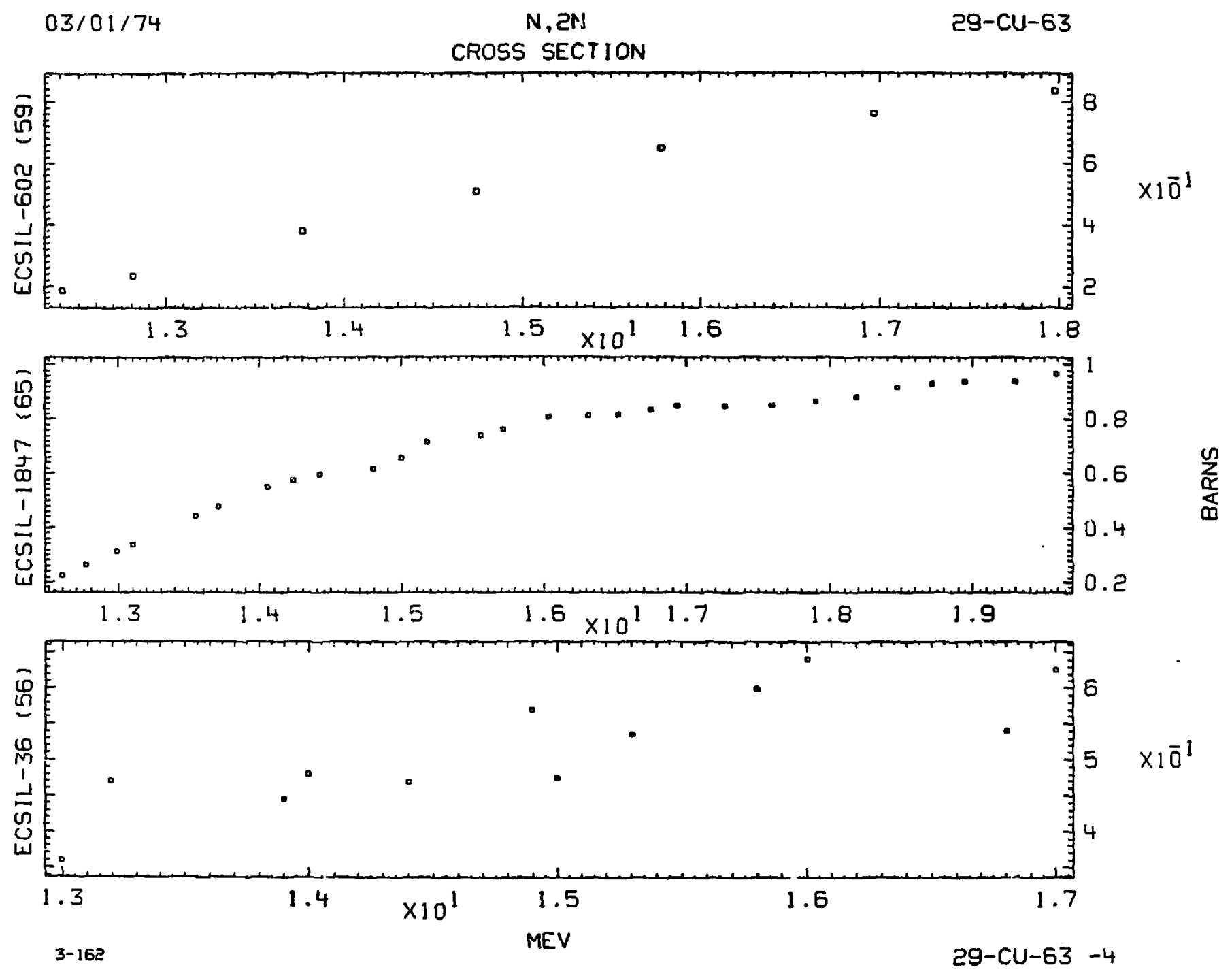




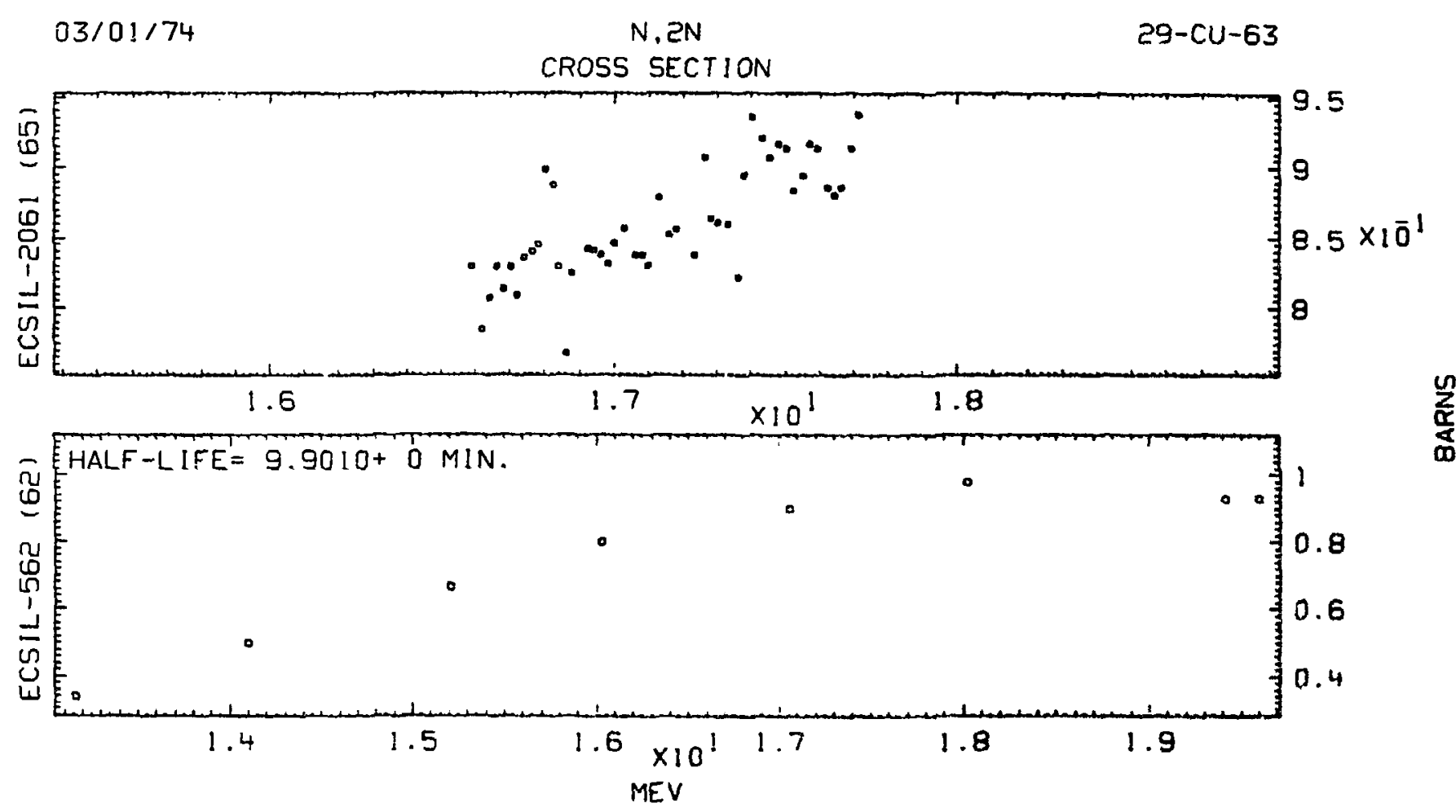


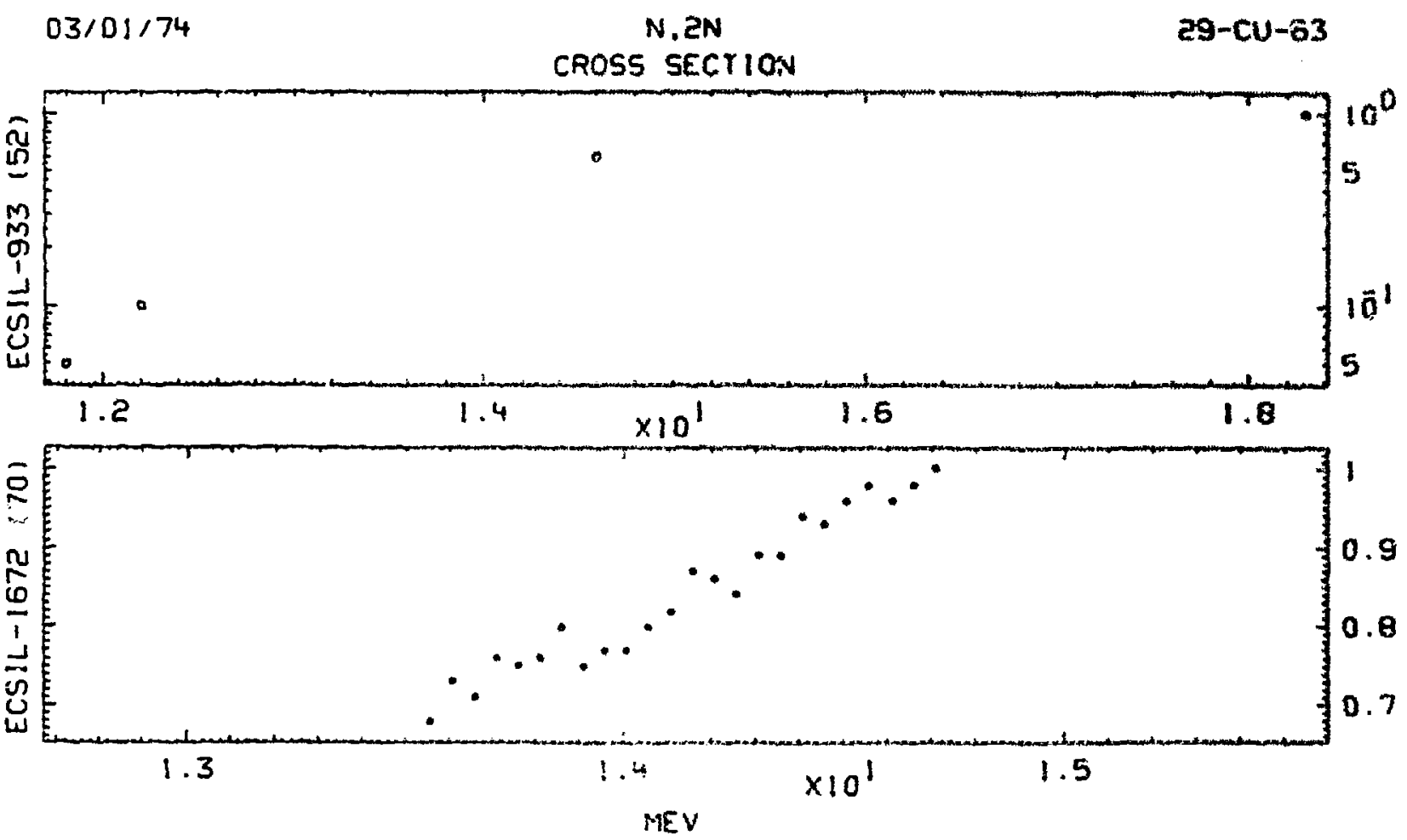


$03 / 01 / 74$
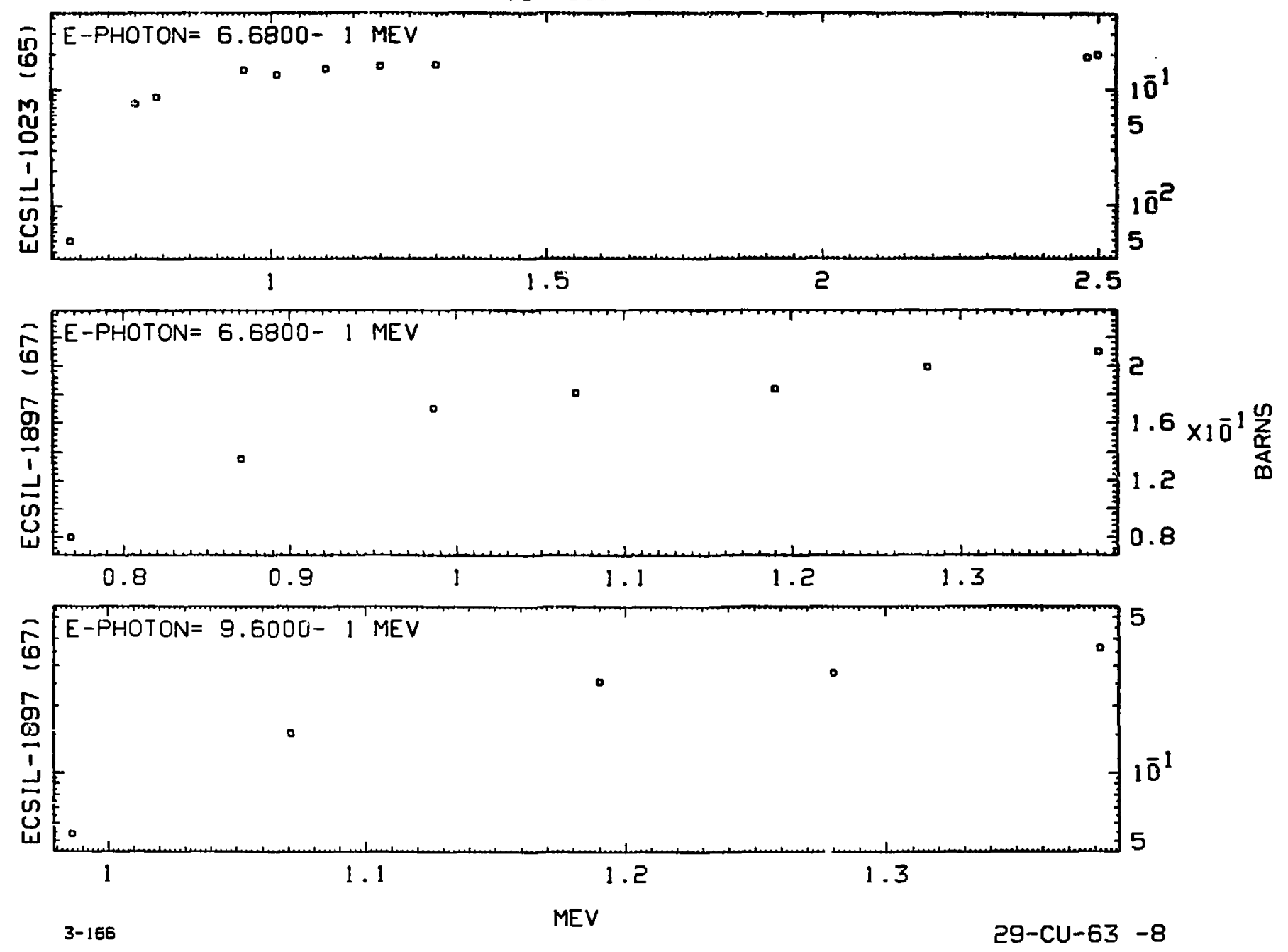

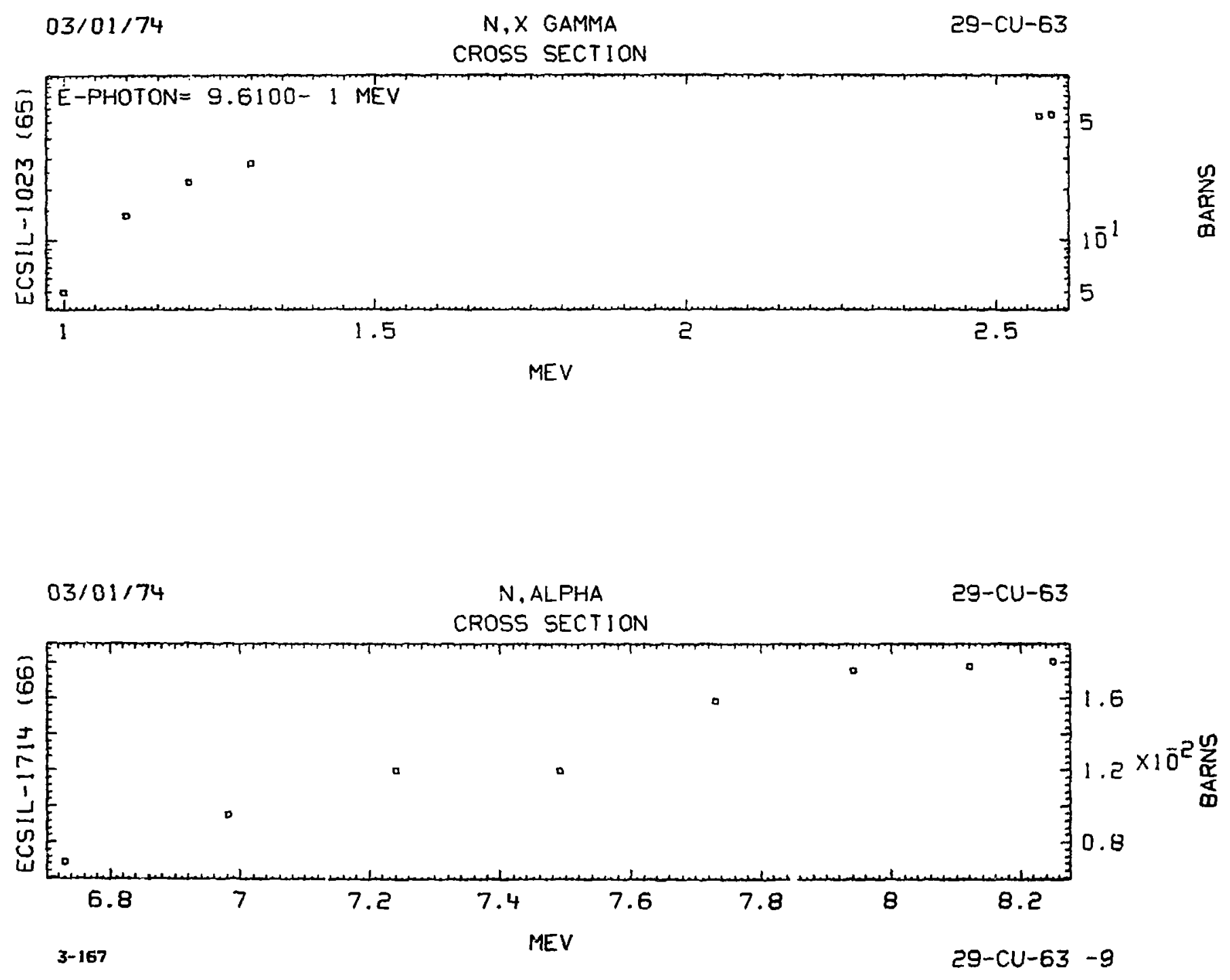


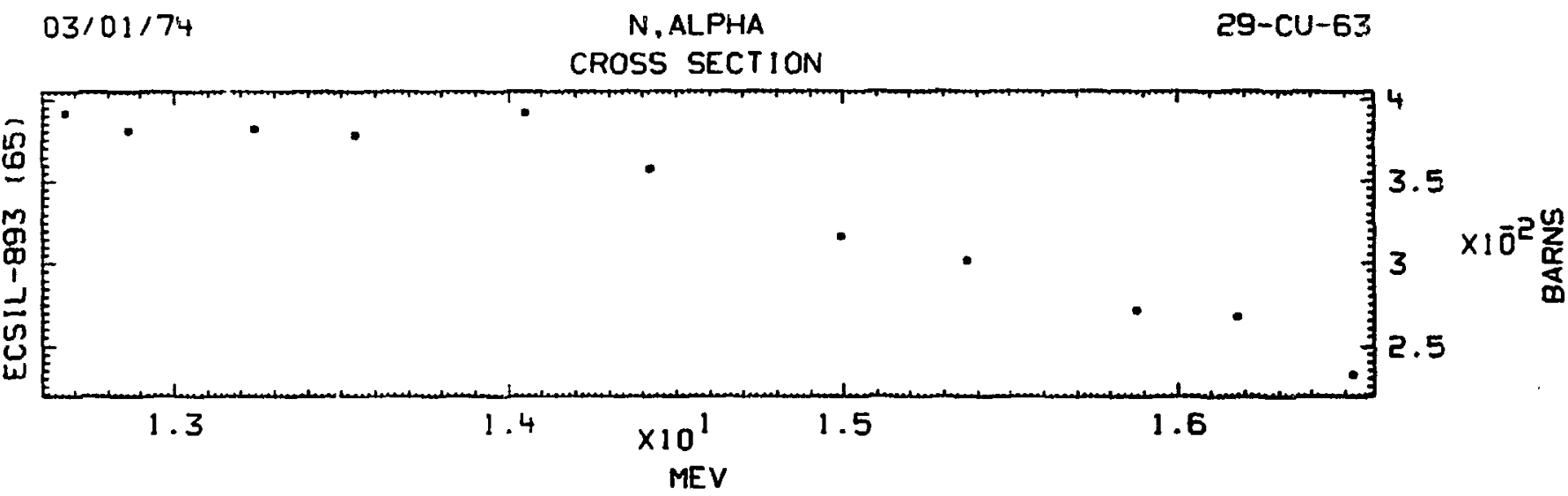

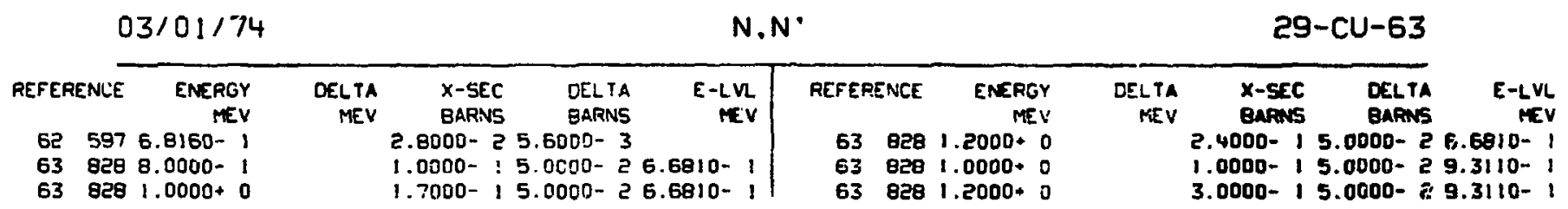

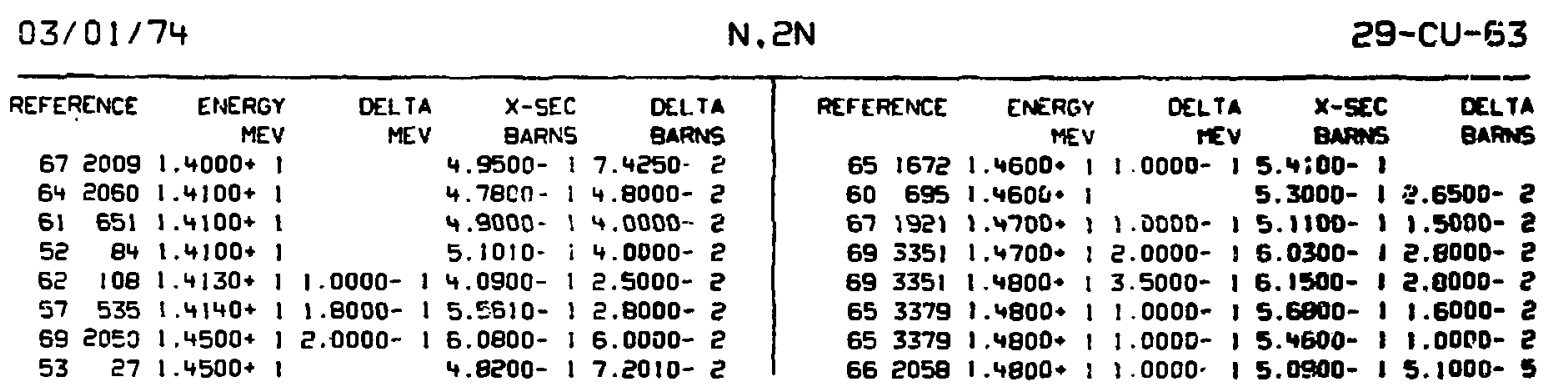


CROSS SECTION

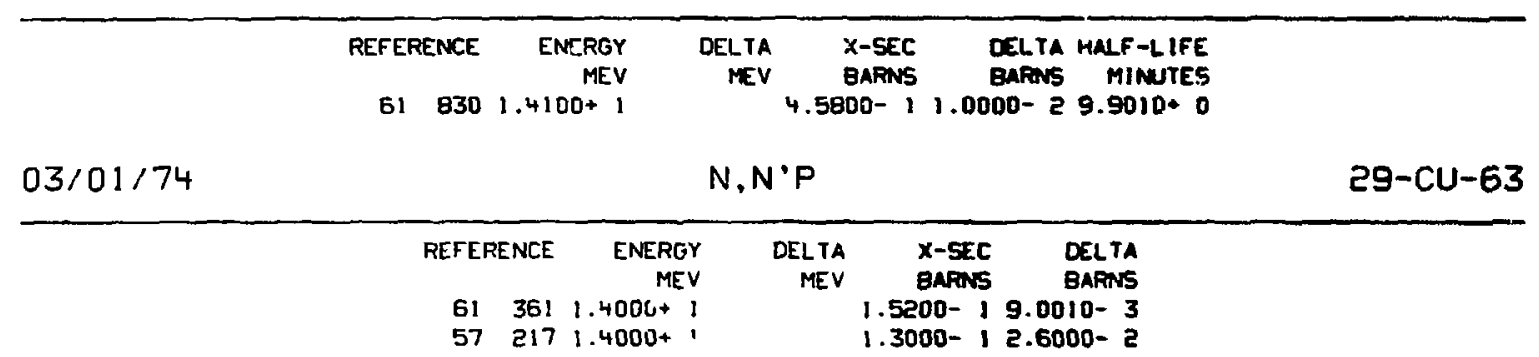

\begin{tabular}{|c|c|c|c|c|c|}
\hline $03 / 01 / 74$ & & & $N, P$ & & $29-C U-63$ \\
\hline & $\begin{array}{l}\text { REFERER:CE } \\
\begin{array}{rr}57 & 217 \\
61 & 361 \\
60 & 837\end{array}\end{array}$ & $\begin{array}{r}\text { ENERGY } \\
\text { MEV } \\
1.4000+1 \\
1.4000+1 \\
1.4100+1\end{array}$ & $\begin{array}{r}\text { DELTA } \\
\text { MEV } \\
1.0000-1\end{array}$ & $\begin{array}{rr}\text { X-SEC } & \text { DELTA } \\
\text { BAFNS } & \text { BAFNS } \\
1.2000-1 & 2.4000-2 \\
1.1800-1 & 9.0010-3 \\
1.4900-1 & 3.0000-2\end{array}$ & \\
\hline
\end{tabular}

$03 / 01 / 74 \quad$ N.HE-3 29-CU-63

$\begin{array}{rrrrrr}\text { REFERENCE } & \text { ENERGY } & \text { DELTA } & \text { X-SEC } & \text { DELTA } \\ & & \text { MEV } & \text { MEV } & \text { BARNS } & \text { BARNS } \\ & 61 & 1.4100+1 & & 3.0000-3 & 1.0000-3\end{array}$

$03 / 01 / 74$

N, ALPHA

$29-\mathrm{CU}-63$

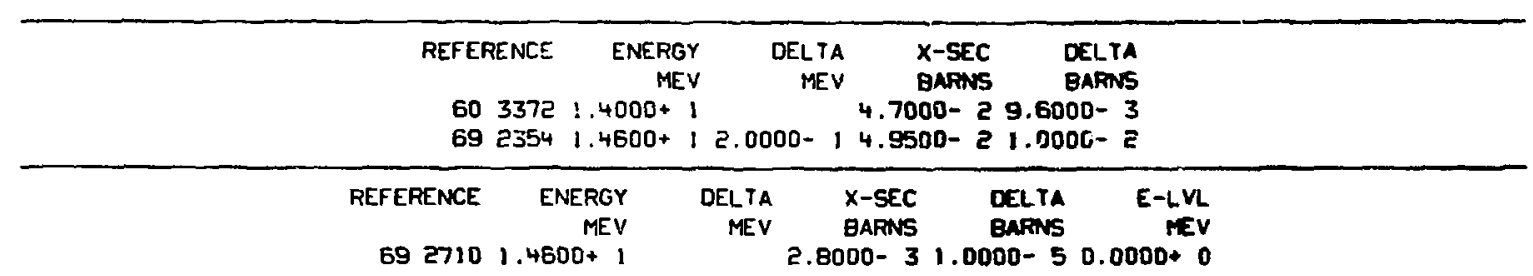


CROSS SECTION

$\begin{array}{ccccc}\text { REFERENCE } & \text { ENERGY } & \text { DELTA } & \text { X-SEC } & \text { DELTA HNLF-LIFE } \\ & \text { MEV } & \text { MEV } & \text { BARNS } & \text { BARNS MISUTES }\end{array}$

$03 / 01 / 74$

$N, N$ :

$29-C U-65$ CROSS SECTION

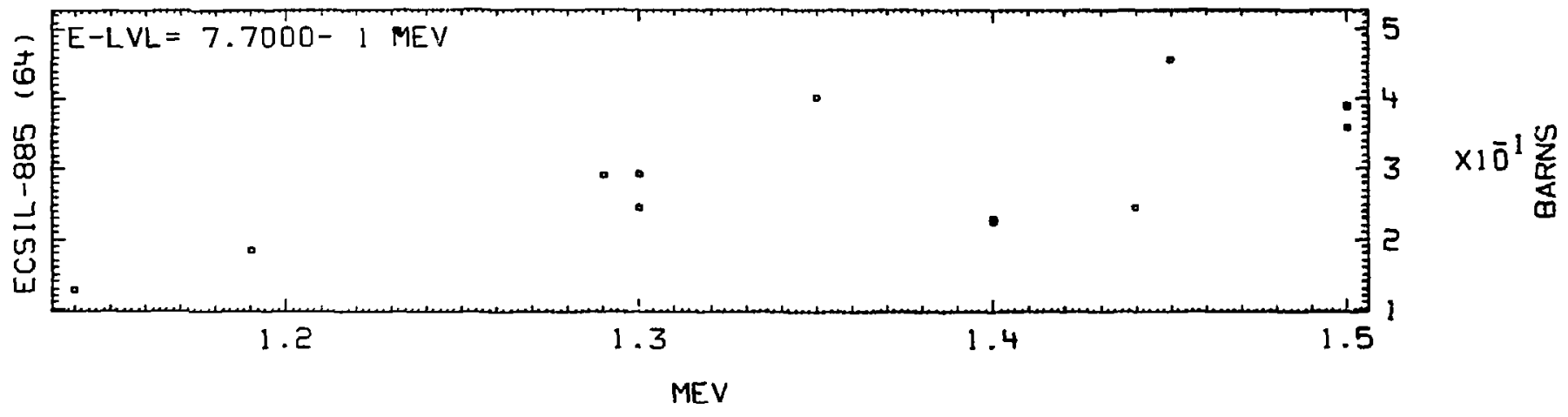



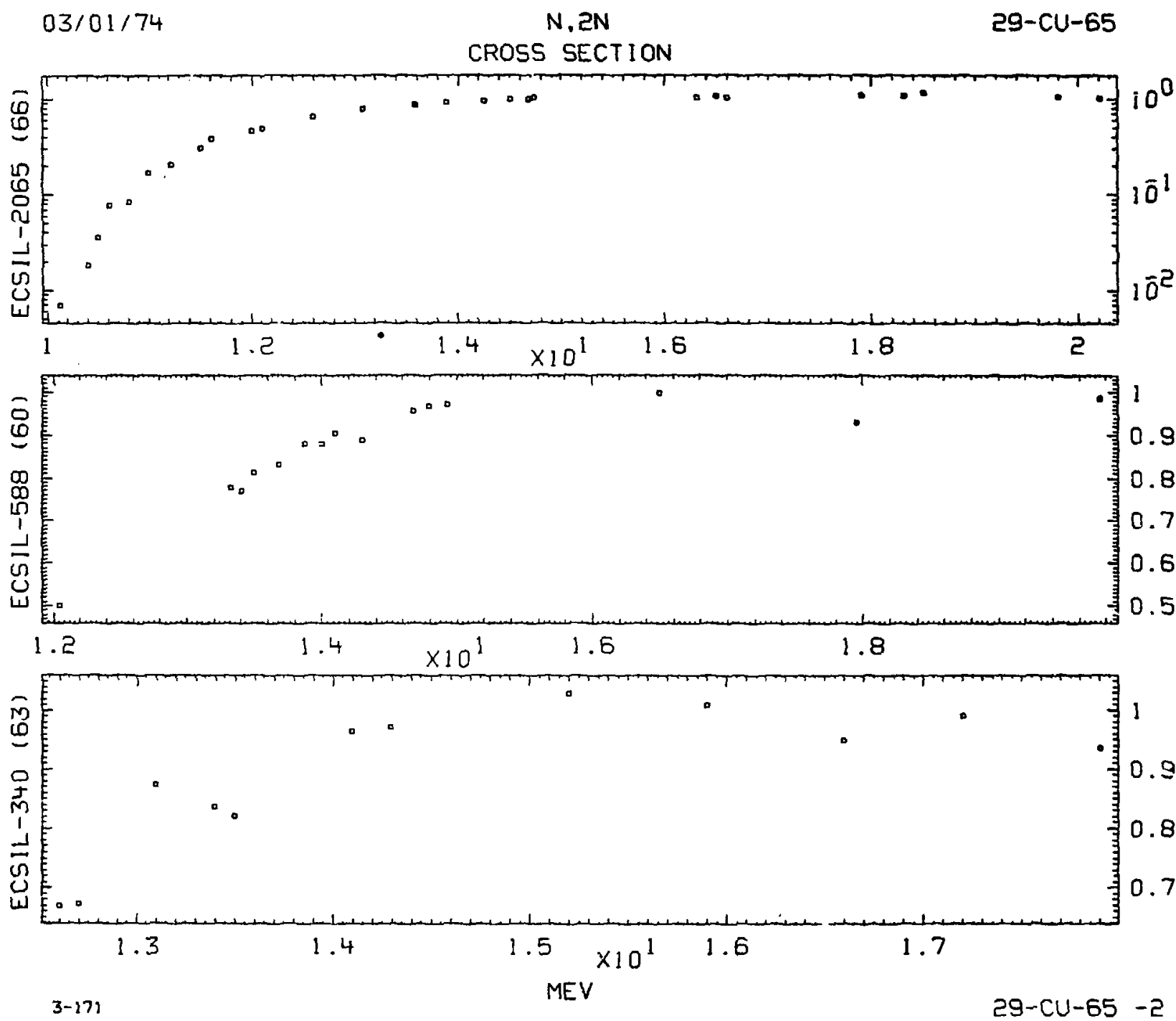

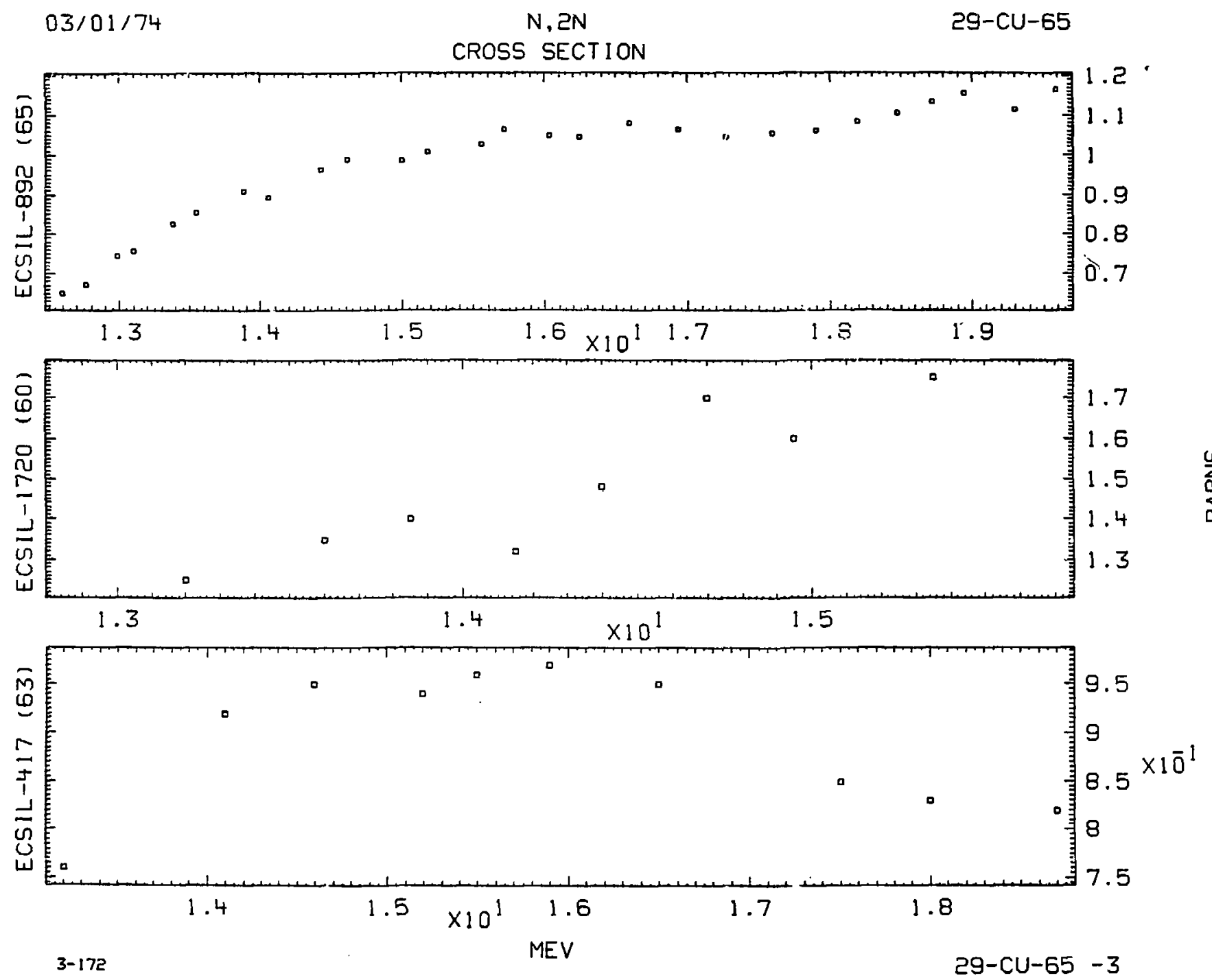


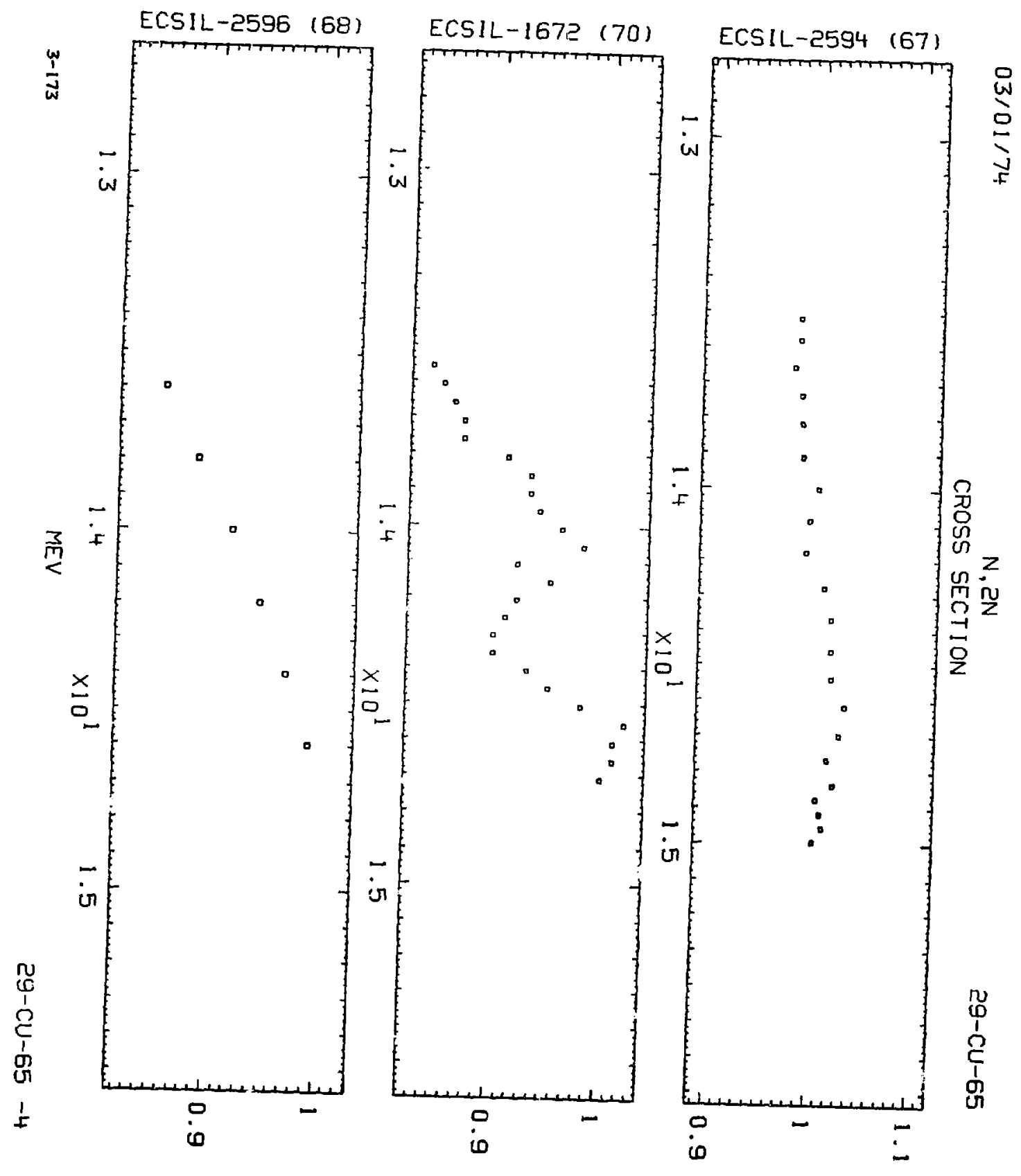

RELATIVE 


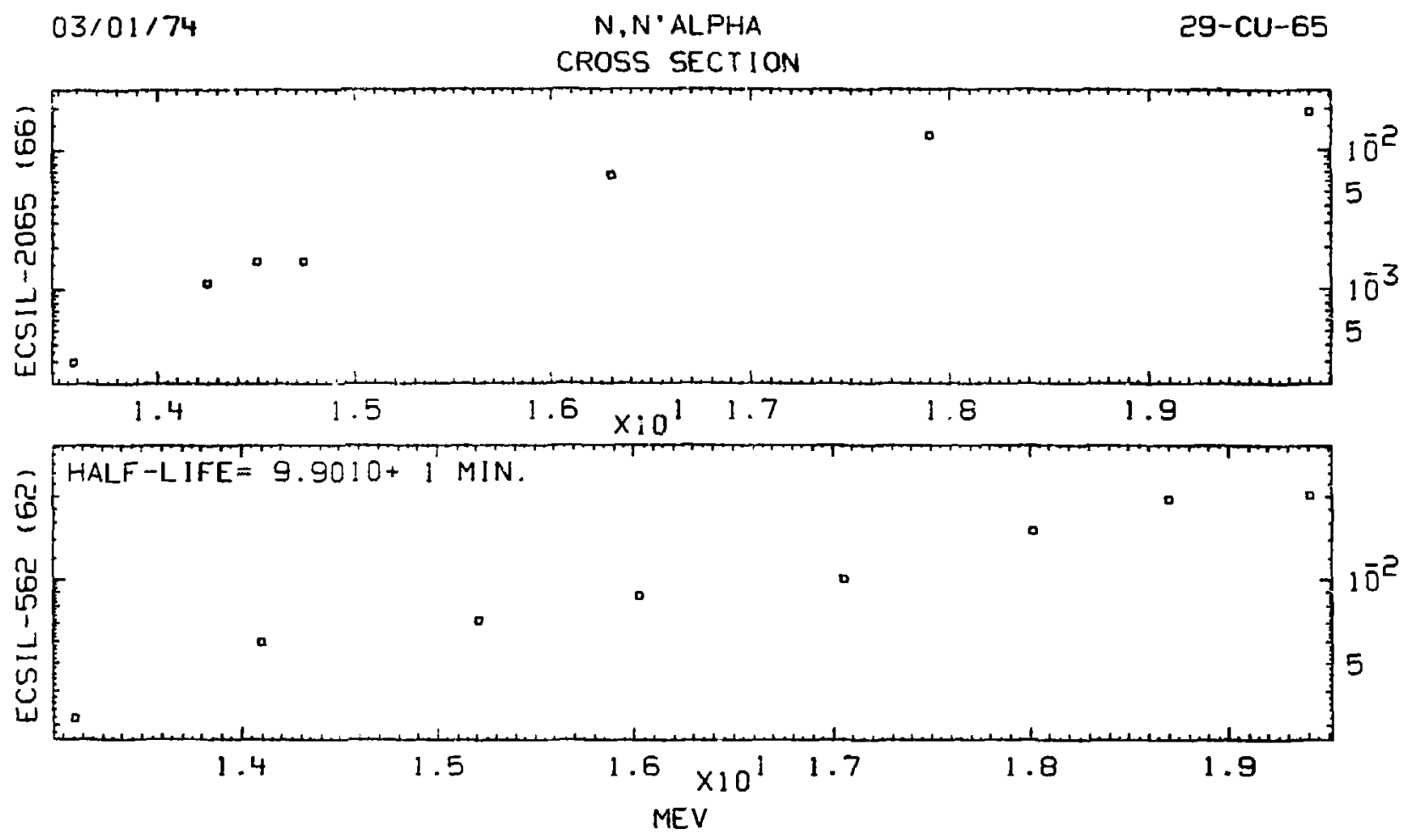

$\underset{\substack{0 \\ \frac{1}{\alpha}}}{\substack{0 \\ 0}}$ 

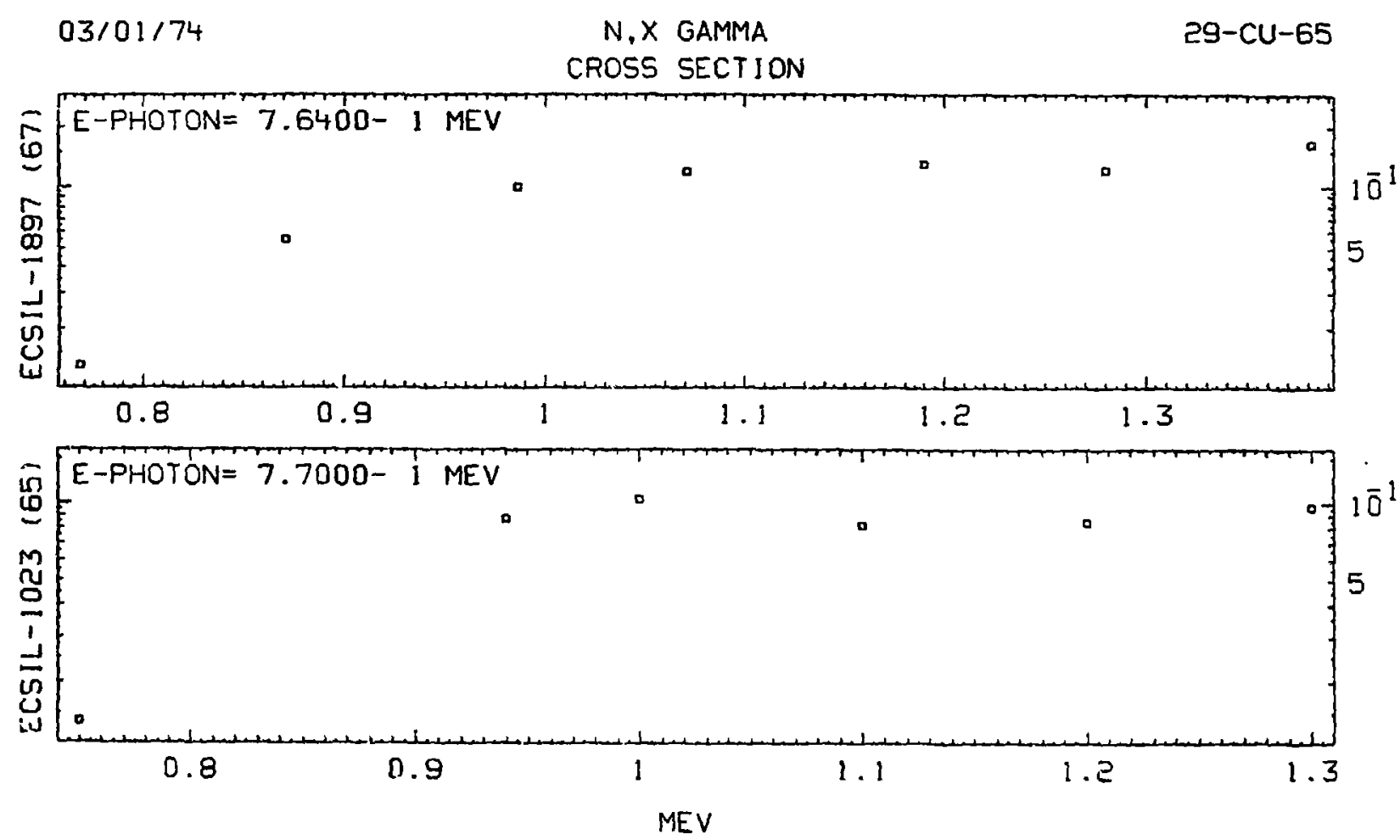


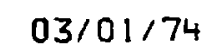

$N, P$

$29-\mathrm{cu}-65$

CROSS SECTION
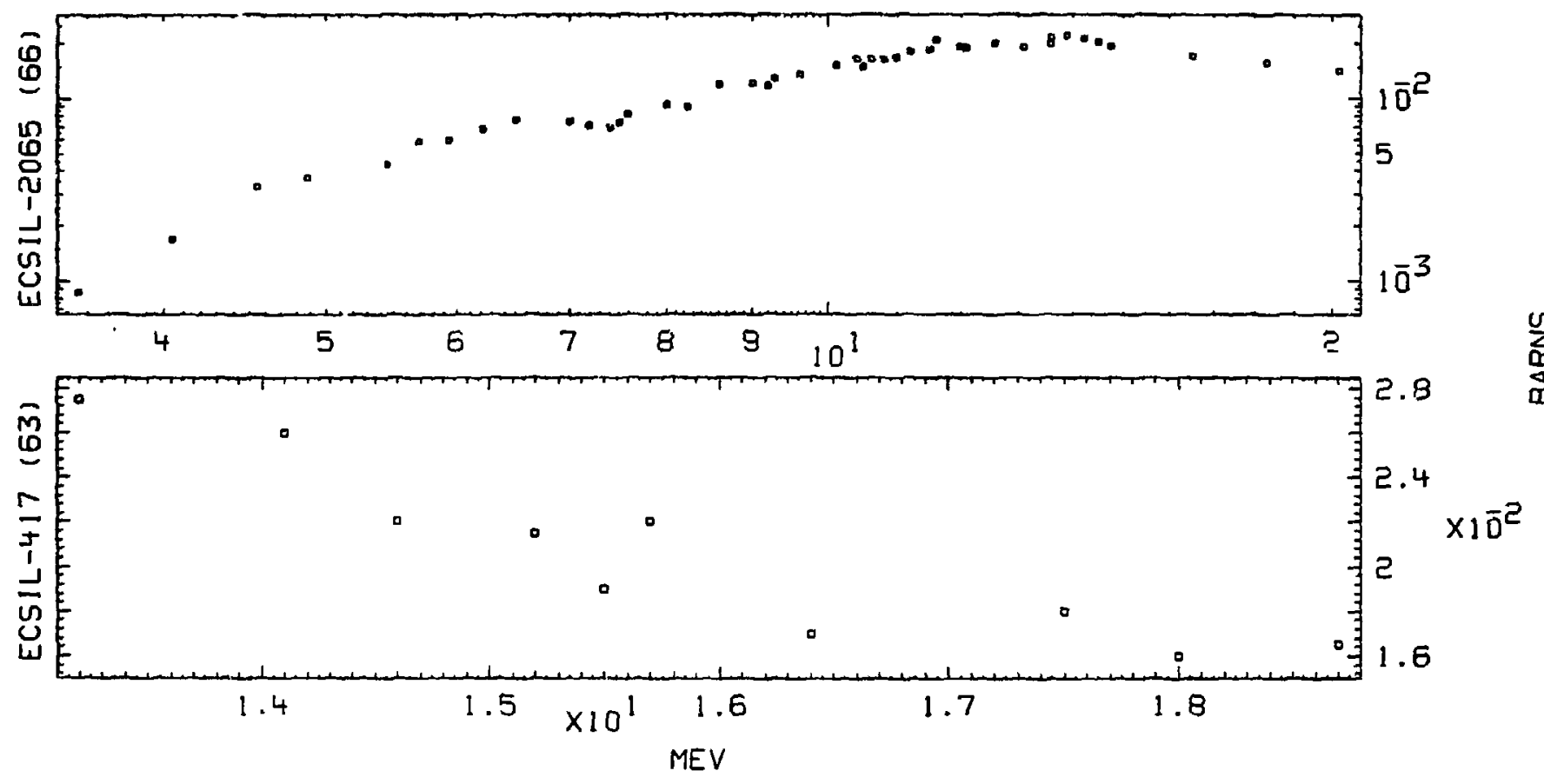

\begin{tabular}{|c|c|c|c|c|c|c|c|c|c|c|c|}
\hline \multirow[b]{2}{*}{ REFERENCL } & \multicolumn{2}{|l|}{$03 / 01 / 74$} & \multicolumn{5}{|c|}{$N, N^{\prime}$} & \multicolumn{3}{|c|}{$29-C U-65$} & \\
\hline & $\begin{array}{r}\text { ENERGY } \\
\text { MEV }\end{array}$ & $\begin{array}{r}\text { DELTA } \\
\text { MEV }\end{array}$ & $\begin{array}{l}X-S E C \\
\text { BARNS }\end{array}$ & $\begin{array}{l}\text { DE:TA } \\
\text { BARNS }\end{array}$ & $\begin{array}{c}E-L V L \\
M E V\end{array}$ & REFERENCE & $\begin{array}{l}\text { ENERGY } \\
\text { MEV }\end{array}$ & $\begin{array}{r}\text { DELTA, } \\
\text { MEV }\end{array}$ & $\begin{array}{l}X \text { X-SEC } \\
\text { BARNS }\end{array}$ & $\begin{array}{l}\text { DELTA } \\
\text { BARNS }\end{array}$ & $\begin{array}{r}\text { E-LVL } \\
\text { MEV }\end{array}$ \\
\hline $\begin{array}{ll}54 & 88 \\
64 & 88\end{array}$ & $\begin{array}{ll}85 & 1.1000+0 \\
85 & 1.4000+0\end{array}$ & & $\begin{array}{l}9.4000-2 \\
4.6800-1\end{array}$ & $4.8000-2$ & $.1140+0$ & $\begin{array}{ll}64 & 885 \\
64 & 685\end{array}$ & $\begin{array}{l}1.4400+0 \\
1.5000+0\end{array}$ & & $\begin{array}{l}3.8100-1 \\
7.1100-1\end{array}$ & $\begin{array}{l}1.1300-1 \\
1.2900-1\end{array}$ & $\begin{array}{l}1.1140+0 \\
1.1140+0\end{array}$ \\
\hline
\end{tabular}


CROSS SECTION

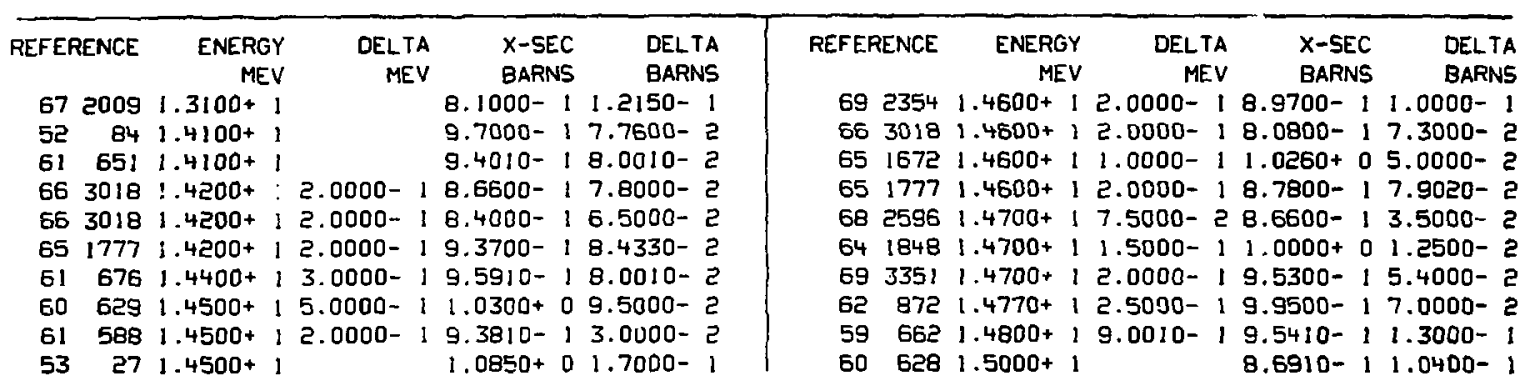

\section{$03 / 01 / 74$}

$N, N$ 'P
$29-C U-65$

$\begin{array}{rrrrr}\text { REFERENCE } & \begin{array}{r}\text { ENERGY } \\ \text { MEV }\end{array} & \begin{array}{r}\text { DELTA } \\ \text { MEV }\end{array} & \begin{array}{r}\text { X-SEC } \\ \text { BARNS }\end{array} & \begin{array}{r}\text { DELTA } \\ \text { BARNS }\end{array} \\ 592053 & 1.4000+1 & 2.5000-1 & 2.5000-2 \\ 57 & 217 & 1.4000+1 & & 4.0000-28.0010-3\end{array}$

$03 / 01 / 74$

$N, N^{\prime}$ ALPHA

$29-C U-65$

$\begin{array}{rrrrrr}\text { REFERENCE } & \begin{array}{r}\text { ENERGY } \\ \text { MEV }\end{array} & \begin{array}{r}\text { DELTA } \\ \text { MEV }\end{array} & \begin{array}{r}\text { X-SEC } \\ \text { BARNS }\end{array} & \begin{array}{r}\text { DELTA } \\ \text { BARNS }\end{array} \\ 62 & 757 & 1.4500+1 & 9.0000-1 & 2.3000-3 & 1.3000-3 \\ 62 & 88 & 1.4700+1 & 1.5000-1 & 2.8000-3 & 3.0000-4 \\ 63 & 756 & 1.4800+1 & 2.0000-1 & 2.9000-3 & 8.0010-4\end{array}$

$03 / 01 / 74 \quad N, \times$ GAMMA 29-CU-65

\begin{tabular}{|c|c|c|c|c|c|c|c|c|c|c|c|}
\hline REFERENCE & $\begin{array}{r}\text { ENERGY } \\
\text { MEV }\end{array}$ & $\begin{array}{c}\text { DELTA } \\
\text { MEV }\end{array}$ & $\begin{array}{l}X \text {-SEC } \\
\text { BARNS }\end{array}$ & $\begin{array}{l}\text { DELTA } \\
\text { BARNS }\end{array}$ & $\begin{array}{r}\text { E-PHOTON } \\
\text { MEV }\end{array}$ & REFERENCE & $\begin{array}{r}\text { ENERGY } \\
\text { MEV }\end{array}$ & $\begin{array}{r}\text { DELTA } \\
\text { MEV }\end{array}$ & $\begin{array}{l}X \text {-SEC } \\
\text { BARNS }\end{array}$ & $\begin{array}{l}\text { DELTA } \\
\text { BARNS }\end{array}$ & $\begin{array}{r}\text { E-PHOTON } \\
\text { MEV }\end{array}$ \\
\hline $\begin{array}{ll}67 & 1897 \\
65 & 1023 \\
67 & 1897\end{array}$ & $\begin{array}{l}1.1900+0 \\
1.2300+0 \\
1.2800+0\end{array}$ & $3.0000-2$ & $\begin{array}{l}1.0700-1 \\
1.0000-1 \\
1.6500-1\end{array}$ & $\begin{array}{l}2.3000-2 \\
3.6000-2\end{array}$ & $\begin{array}{l}1.1140+0 \\
1.1140+0 \\
1.1140+0\end{array}$ & $\begin{array}{ll}65 & 1023 \\
67 & 1897\end{array}$ & $\begin{array}{l}1.3000+0 \\
1.3820+0\end{array}$ & $3.0000-2$ & $\begin{array}{l}1.2000-1 \\
2.9100-1\end{array}$ & $6.1000-2$ & $\begin{array}{l}1.1140+0 \\
1.1140+0\end{array}$ \\
\hline
\end{tabular}




\section{CROSS SECTION}

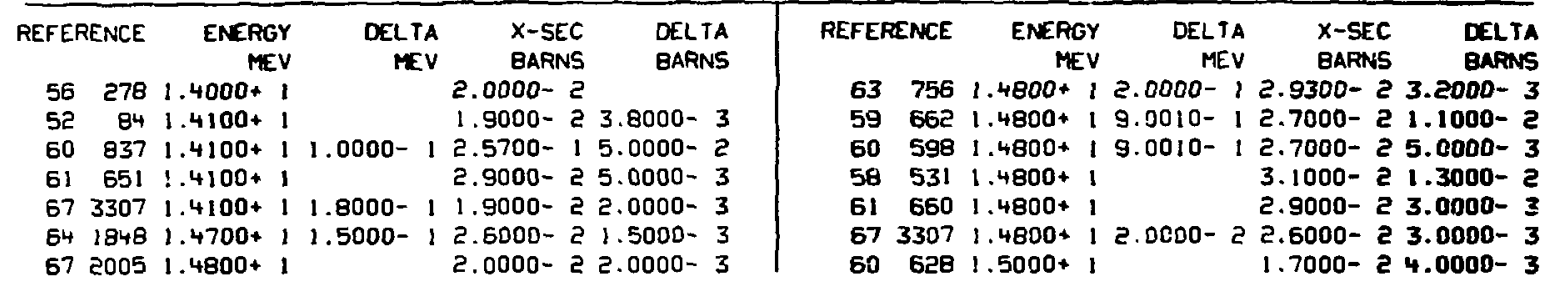

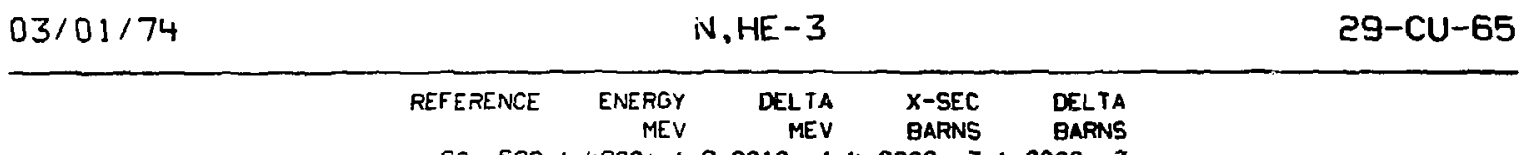

$605381.4800+19.0010-14.0000-31.0000-3$

$03 / 01 / 74$

N. ALPHA

29-Cu-65

$\begin{array}{rrrrrr}\text { REFERENCE } & \text { ENERGY } & \text { DELTA } & \text { X-SEC } & \text { DELTA } \\ 60 & 598 & 1.4800+1 & \text { MEV } & \text { BARNS } & \text { BARNS } \\ 63 & 756 & 1.4800+10-1 & 2.0000-2 & 7.0010-3 \\ & 2.0000-1 & 1.4000-2 & 1.0000-2\end{array}$

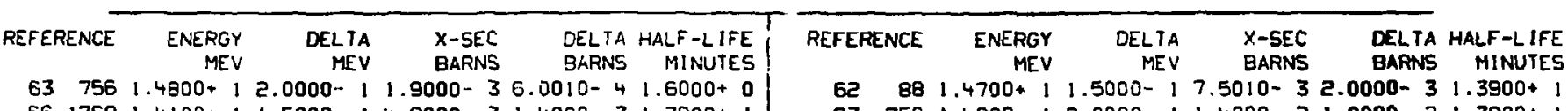

$1.5000-17.5010-32.0000-31.3900+$

$637561.4800+12.0000-11.4000-21.0000-21.3900+$ 

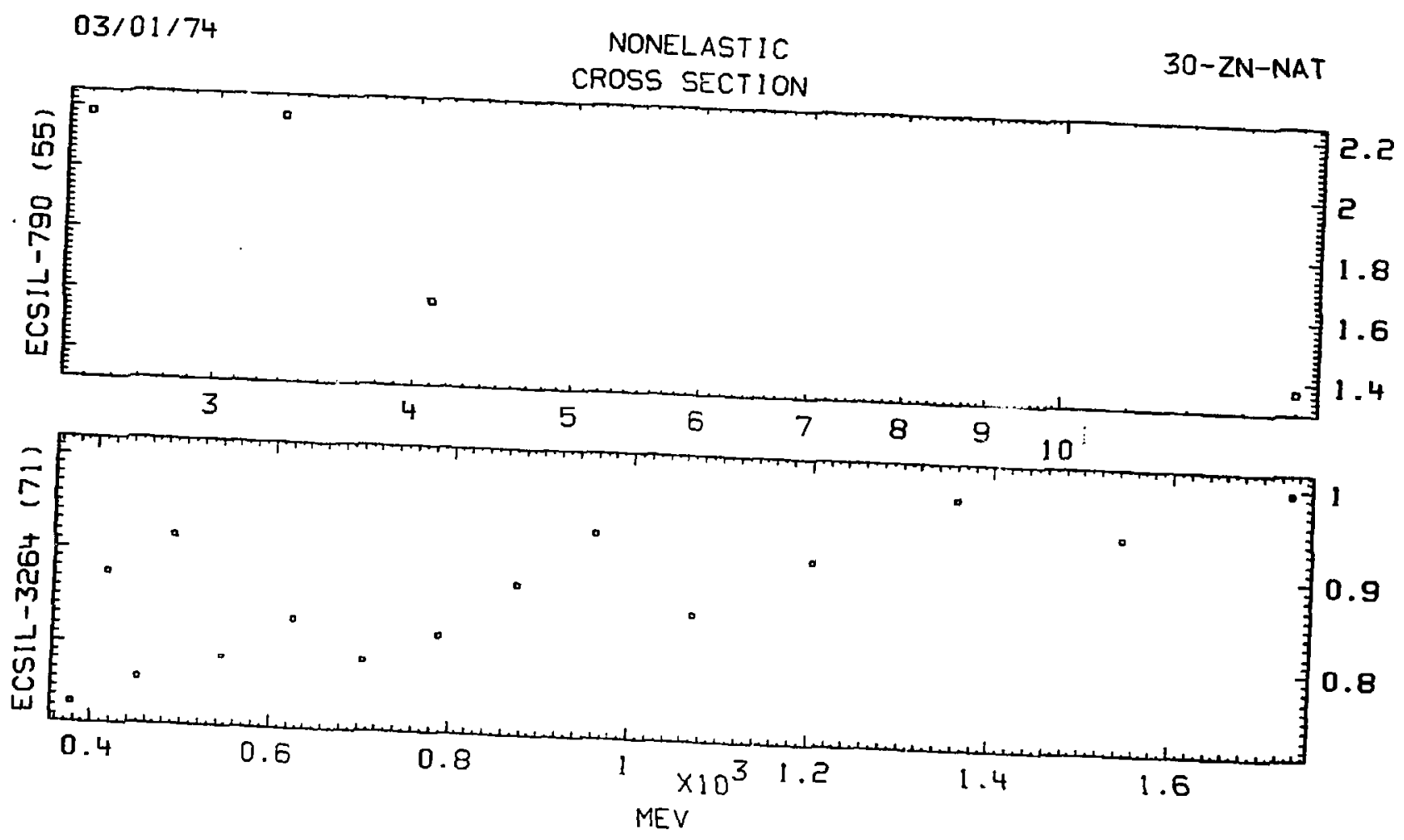

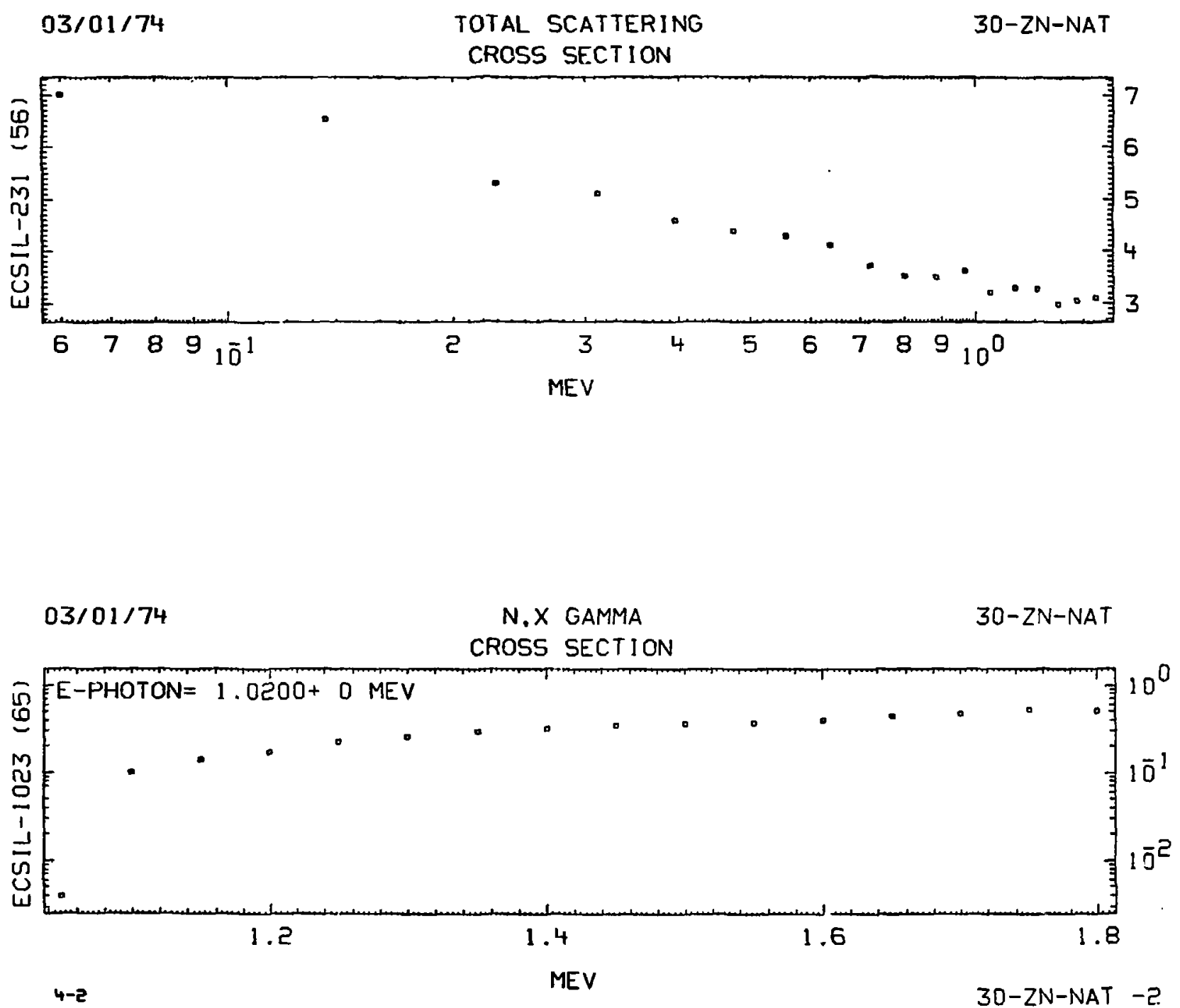
CROSS SECTION

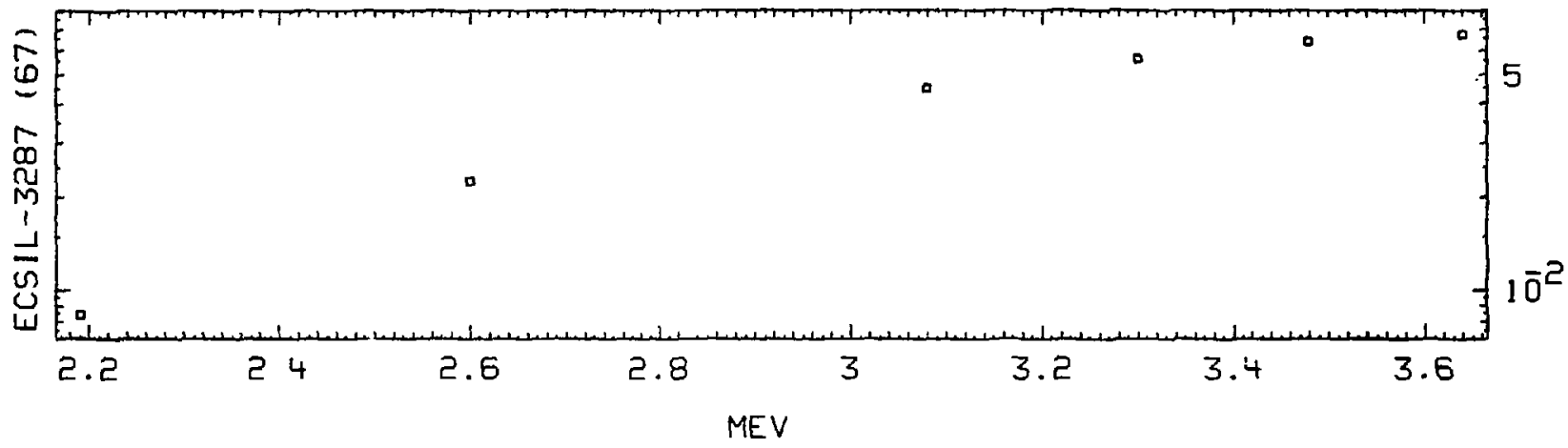

\begin{tabular}{rrrrrrr}
\hline REFERENCE & $\begin{array}{r}\text { ENERGY } \\
\text { MEV }\end{array}$ & $\begin{array}{r}\text { DELTA } \\
\text { MEV }\end{array}$ & $\begin{array}{r}\text { X-SEC } \\
\text { BARNS }\end{array}$ & $\begin{array}{r}\text { DELTA } \\
\text { BARN5 }\end{array}$ \\
54 & 103 & $1.0000+0$ & $5.0000-2$ & $3.0000-1$ & $1.0000-1$ \\
56 & 34 & $2.5000+0$ & & $1.8800+0$ & $1.5000-1$ \\
56 & 151 & $2.5000+0$ & $4.0000-2$ & $1.3000+0$ & $1.0000-1$ \\
59 & 559 & $3.6600+0$ & $2.0000-1$ & $1.8400+0$ & $2.0000-1$ \\
55 & 122 & $4.0000+0$ & $7.0010-2$ & $1.6900+0$ & $5.0000-2$ \\
55 & 296 & $4.1000+0$ & $4.0000-2$ & $1.7000+0$ & $2.0000-1$
\end{tabular}

$$
03 / 01 / 74 \quad N, 2 N
$$

$03 / 01 / 74 \quad N, 2 N$

\section{REFERENICE ENERGY}

$5818211.4100+$

\section{DELTA
MEV}

$X$-SEC BARN5,

DELTA

$0000-2$ 
CROSS SECTION

\begin{tabular}{|c|c|c|c|c|c|c|c|c|c|c|}
\hline REFERENCE & $\begin{array}{r}\text { ENERGY } \\
\text { MEY }\end{array}$ & $\begin{array}{r}\text { DELTA } \\
\text { MEV }\end{array}$ & $\begin{array}{l}X-5 E C \\
\text { BARNS }\end{array}$ & $\begin{array}{ll}\text { DELTA } \\
\text { BARNS }\end{array}$ & REFEREI & ENCE & $\begin{array}{r}\text { ENERGY } \\
\text { MEV }\end{array}$ & $\begin{array}{l}\text { DELTA } \\
\text { MEV }\end{array}$ & $\begin{array}{l}X \text { X-SEC } \\
\text { BAFANS }\end{array}$ & $\begin{array}{l}\text { DELTA } \\
\text { BNoNS }\end{array}$ \\
\hline $\begin{array}{lr}58 & 1162 \\
58 & 364 \\
65 & 1364\end{array}$ & $\begin{array}{l}2.5300-8 \\
2.4000-2 \\
2.4000-2\end{array}$ & $2.0000-$ & $\begin{array}{r}1.0900+0 \\
2.9000-2 \\
6.4000-2\end{array}$ & $\begin{array}{l}2.0000-2 \\
2.0000-3 \\
7.0000-3\end{array}$ & $\begin{array}{l}58 \\
58\end{array}$ & $\begin{array}{l}364 \\
364\end{array}$ & $\begin{array}{l}2.2000-1 \\
\text { 8.3000- }\end{array}$ & $\begin{array}{l}2.0000-2 \\
4.0000-2\end{array}$ & $\begin{array}{l}2.1000-2 \\
1.8000-2\end{array}$ & $\begin{array}{l}2.0000-3 \\
3.0000-3\end{array}$ \\
\hline
\end{tabular}

\begin{tabular}{|c|c|c|c|c|c|c|c|}
\hline \multirow[t]{2}{*}{$03 / 01 / 74$} & \multicolumn{7}{|c|}{$N, X$ GAMMA } \\
\hline & FEFERS & NCE & $\begin{array}{r}\text { ENERGY } \\
\text { MEV }\end{array}$ & $\begin{array}{r}\text { DELTA } \\
\text { MEV }\end{array}$ & $\begin{array}{l}X \text {-SEC } \\
\text { BARNS }\end{array}$ & $\begin{array}{l}\text { OELTA } \\
\text { BARNS }\end{array}$ & $\begin{array}{r}\text { E-PHOTON } \\
\text { MEV }\end{array}$ \\
\hline & $\begin{array}{l}54 \\
54 \\
54\end{array}$ & $\begin{array}{l}113 \\
113 \\
113\end{array}$ & $\begin{array}{l}3.2000+0 \\
3.2000+0 \\
3.2000+0\end{array}$ & $\begin{array}{l}2.0000-1 \\
2.0000-1 \\
2.0000-1\end{array}$ & $\begin{array}{l}1.3000+0 \\
3.0000-2 \\
2.0000-2\end{array}$ & $\begin{array}{l}2.6000-1 \\
6.0000-3 \\
4.0000-3\end{array}$ & $\begin{array}{l}1.0200+0 \\
1.3000+0 \\
1.5000+0\end{array}$ \\
\hline
\end{tabular}

$03 / 01 / 74$

$N, \times P$

30-ZN-NAT

\begin{tabular}{rrrrr}
\hline REFERENCE & ENERGY & DELTA & X-SEC & DELTA \\
& MEV & MEV & GARNS & BARNS
\end{tabular}

62. $6881.4400+12.0000-11.7000-12.0000-2$

$03 / 01 / 74$

BOUND ATOM

30-ZN-NAT

\begin{tabular}{|c|c|c|c|c|c|c|}
\hline & $\begin{array}{l}\text { REFERENCE } \\
511584\end{array}$ & $\begin{array}{r}\text { ENERGY } \\
\text { MEV } \\
47.3000-8\end{array}$ & $\begin{array}{l}\text { DELTA } \\
\text { MEV }\end{array}$ & $\begin{array}{l}X \text {-SEC } \\
\text { BARNS } \\
300 * 0\end{array}$ & $\begin{array}{l}\text { DELTA } \\
\text { BARNS }\end{array}$ & \\
\hline $03 / 01 / 74$ & & COHERENT & SCATT & ING & & $30-Z N-N A T$ \\
\hline
\end{tabular}



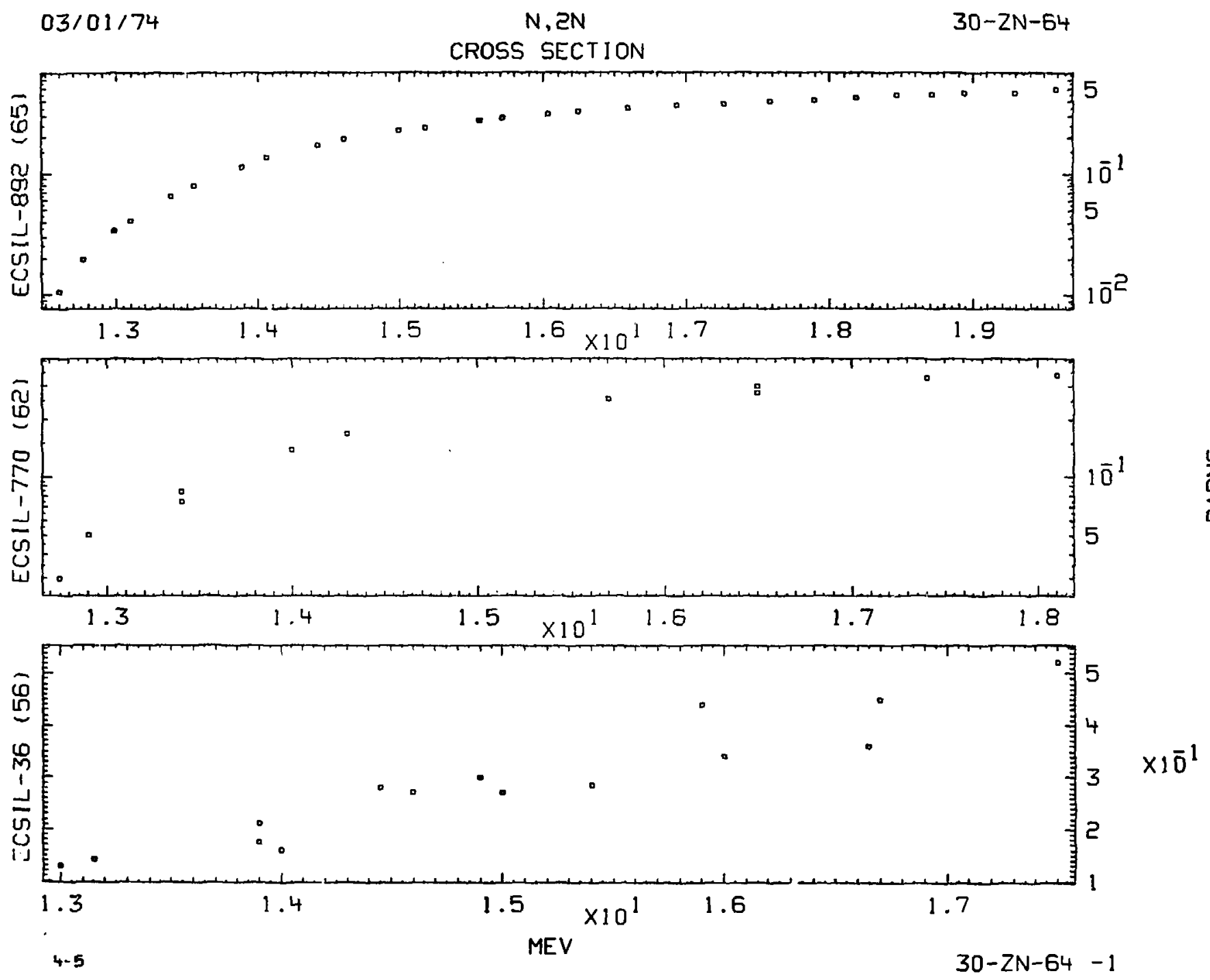


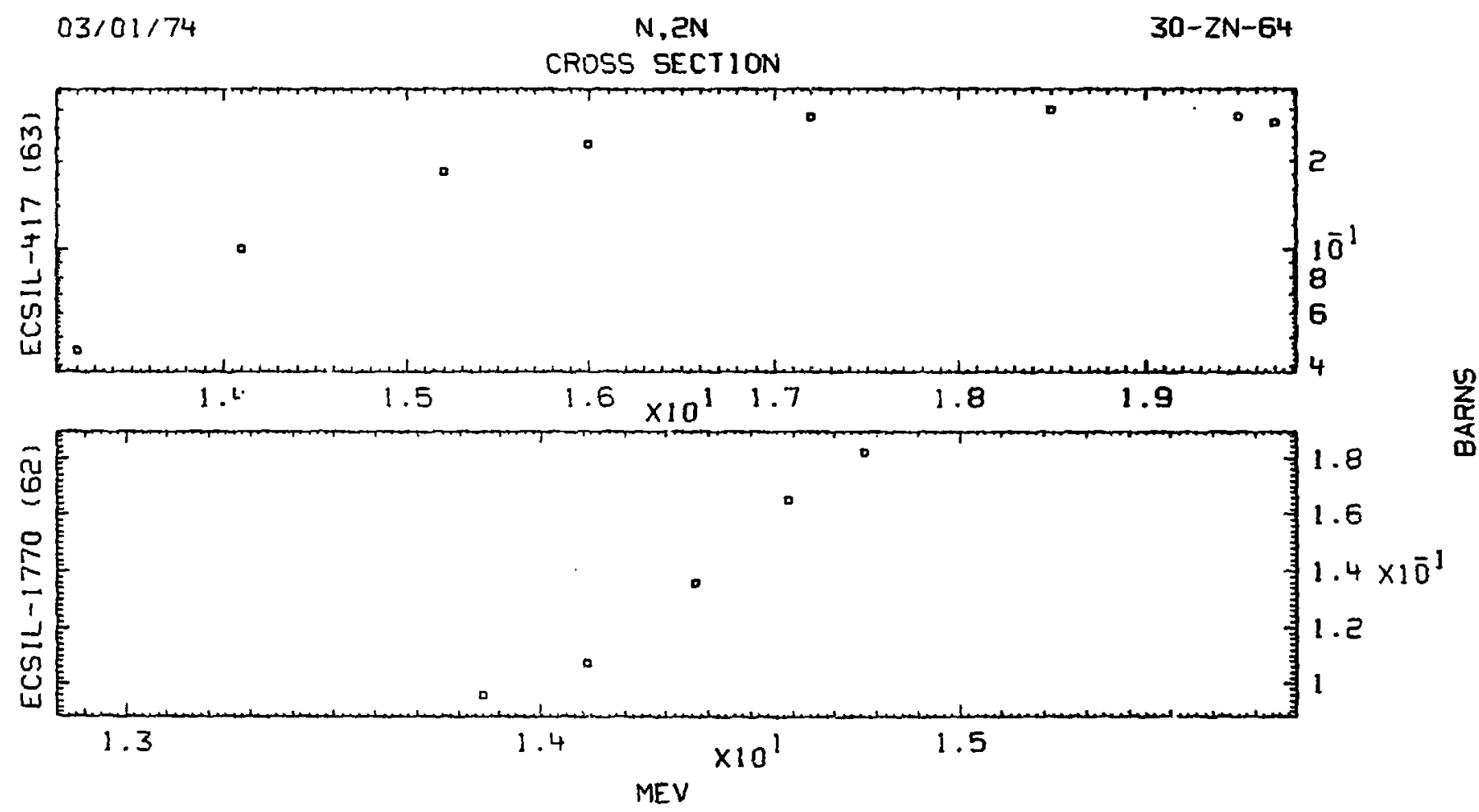



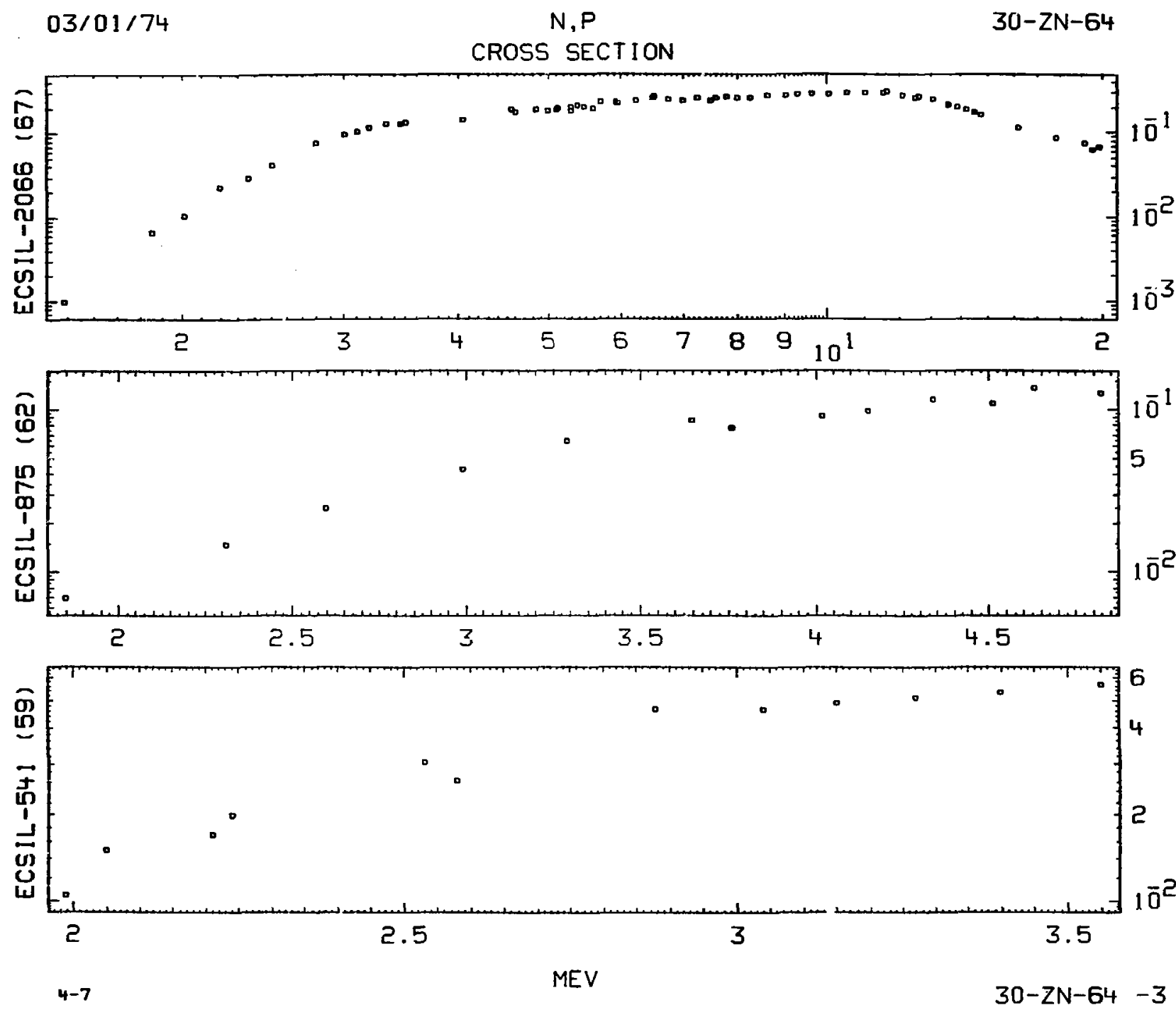


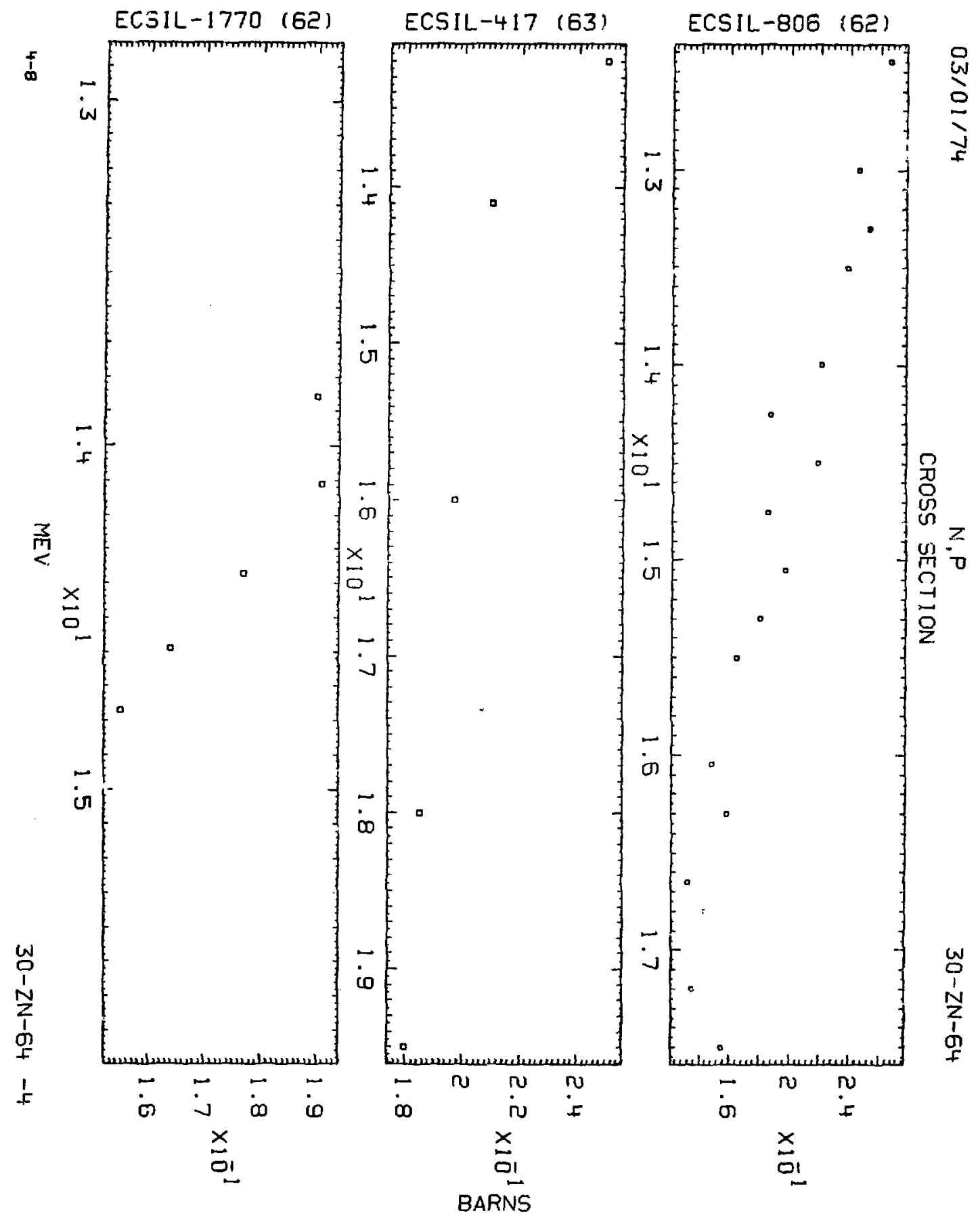


CROSS SECTION

\begin{tabular}{|c|c|c|c|c|c|c|c|c|c|c|c|c|}
\hline \multicolumn{2}{|c|}{ REFERENCE } & $\begin{array}{r}\text { ENERGY } \\
\text { MEV }\end{array}$ & $\begin{array}{r}\text { DELTA } \\
\text { MEV }\end{array}$ & $\begin{array}{l}X \text { X-SE } \\
\text { BARI }\end{array}$ & $\begin{array}{l}\text { DELTA } \\
\text { GARNS }\end{array}$ & REFEF & RENCE & $\begin{array}{r}\text { ENER } \\
M E\end{array}$ & $\begin{array}{l}\text { GY } \\
\text { EV }\end{array}$ & $\begin{array}{r}\text { DELTA } \\
\text { MEV }\end{array}$ & $\begin{array}{l}x \text {-SEC } \\
\text { BARNS }\end{array}$ & $\begin{array}{l}\text { DELTA } \\
\text { BARNS }\end{array}$ \\
\hline 59 & 601 & $3500+1$ & $3.0000-1$ & $16.5010^{-}$ & $26.0010-3$ & 67 & 2009 & $1.4700+$ & 1 & & $2.2500-1$ & $12.5000-2$ \\
\hline 58 & 425 & $.4000+1$ & & I. $5900-$ & 1 & 67 & 2368 & $1.4800+$ & 1 & $1.0000 \sim 1$ & $1.0200-1$ & - \\
\hline 62 & 108 & $1.4130+1$ & $1.0000-1$ & $1.0500-$ & $17.0010-3$ & 58 & 598 & $1.4800+$ & 1 & $.0000-1$ & $2.5400-1$ & $30-$ \\
\hline 57 & 535 & $1.4140+1$ & $1.8000-1$ & $1.1900-$ & $11.4000-2$ & 63 & 756 & $1.4800+$ & & $2.0000-1$ & $1.5300-1$ & $13.6000=$ \\
\hline 68 & 2695 & $1.4400+1$ & $3.0000-1$ & $11.5000-$ & $11.2000-2$ & 66 & 2058 & $1.4800+$ & 1 & $1.0000-1$ & $1.6500-1$ & 11. \\
\hline 61 & 675 & $1.4400+2$ & $3.0000-1$ & $1.6700-$ & $11.3000-2$ & 67 & 2009 & $1.5000+$ & 1 & & $1800-1$ & $200-$ \\
\hline 53 & 27 & $1.4500+1$ & & $2.2400^{-}$ & $4.4800-2$ & 59 & 601 & $1.5600+$ & 1 & $0000-$ & $2.2500-1$ & $12.0000-2$ \\
\hline 65 & 572 & $20+1$ & . & $0-$ & $00-$ & 59 & 601 & 001 & & חחתחס & $0-$ & 100 \\
\hline
\end{tabular}

$03 / 01 / 74$

$N, N \cdot P$

$30-2 N-64$

$\begin{array}{rrrrr}\text { REFERENCE } & \text { ENERGY } & \text { DELTA } & \text { X-SEC } & \text { DELTA } \\ & \text { MEV } & \text { MEV } & \text { BARNS } & \text { BARNS } \\ \text { E) } 351 & 1.4000+1 & & 2.8100-1 & 1.8000-2\end{array}$

$03 / 01 / 74$

$N, N \cdot A L P H A$

$30-2 N-64$

$\begin{array}{rrrrr}\text { REFERENCE } & \text { ENERGY } & \text { DELTA } & X-S E C & \text { DELTA } \\ & \text { MEV } & \text { MEV } & \text { BARNS } & \text { BARNS }\end{array}$

$5628941 .+100+11.0000-17.3000-27.0000-3$

$03 / 01 / 74$

$N, P$

$30-2 N-64$

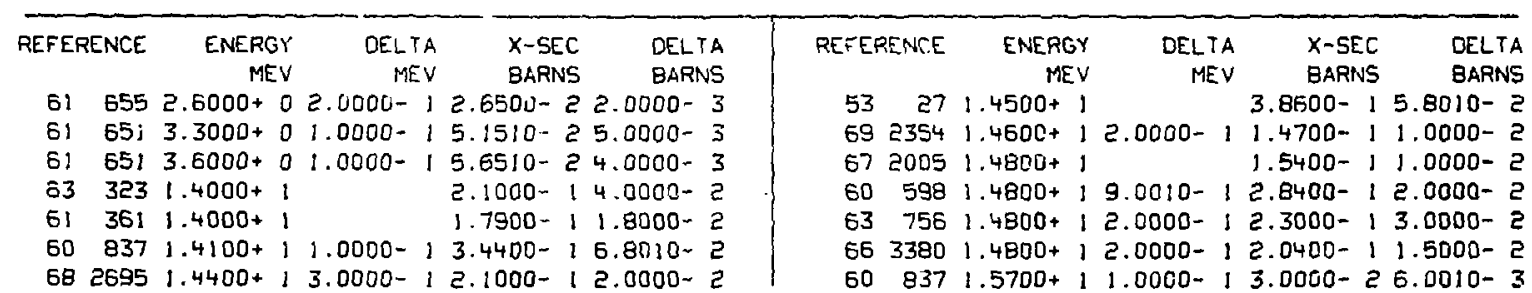


$03 / 01 / 74$

$N, X P$

$30-Z N-64$

CROSS SECTION

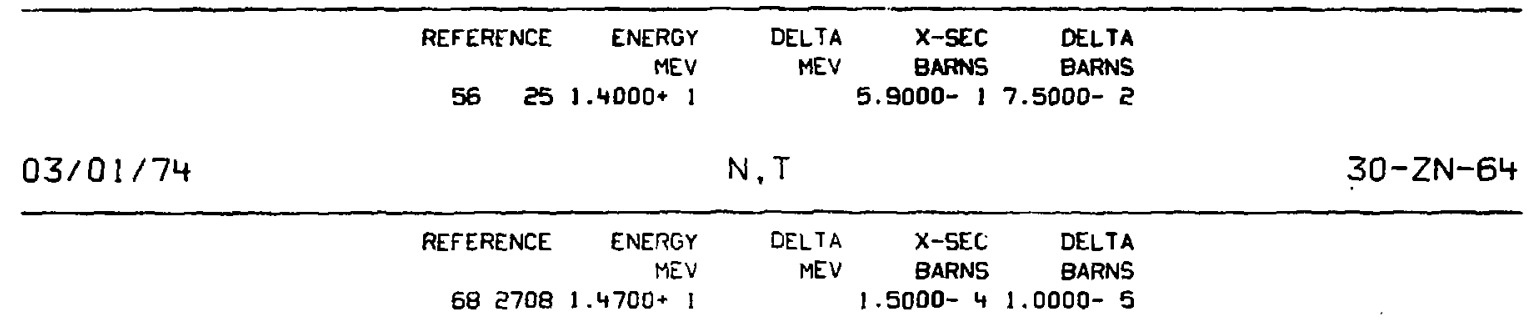

\begin{tabular}{llllll}
$03 / 01 / 74$ & $N$, ALPHA & $30-Z N-64$ \\
\hline REFERENCE & ENERGY & DELTA & $x$-SEC & DELTA & E-LVL \\
MEV & MEV & BARNS & BARNS & MEV
\end{tabular}

$6927101.4600+1 \quad 6.6000-32.0000-30.0000+0$

$03 / 01 / 74 \quad N, X$ ALPHA $\quad 30-2 N-64$

$\begin{array}{rrrrrr}\text { REFERENCE } & \text { ENERGY } & \text { DELTA } & X \text {-SEC } & \text { DELTA } \\ \text { GE } & & \text { MEV } & \text { MEV } & \text { BARNS } & \text { BARNS } \\ & 1.4100+1 & 1.0000-1 & 1.6 B D 0-1 & 1.6000-2\end{array}$

$6628941.4100+11.0000-11.6800-11.6000-2$

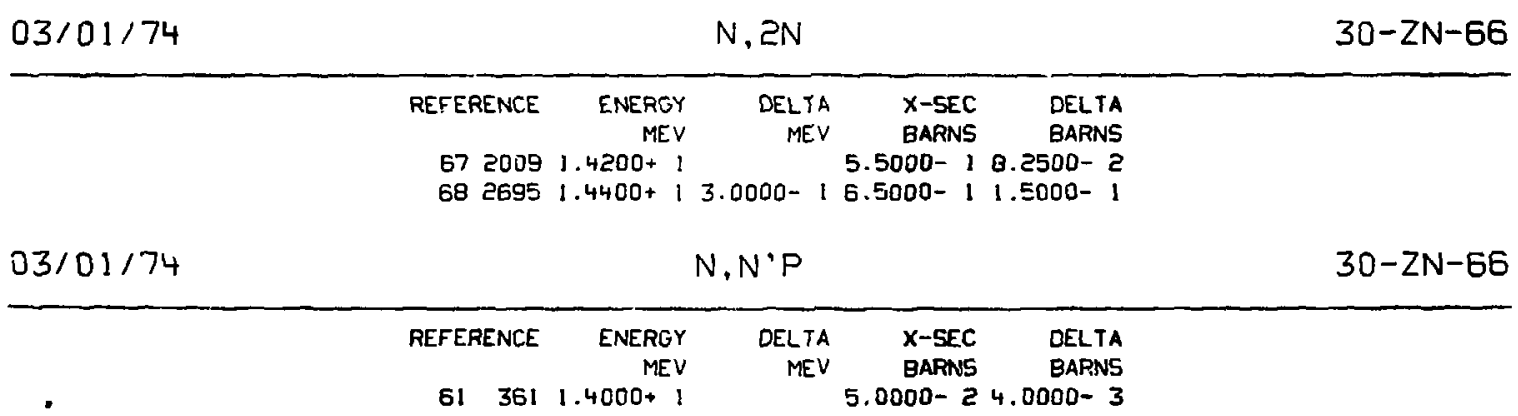


CROSS SECTION

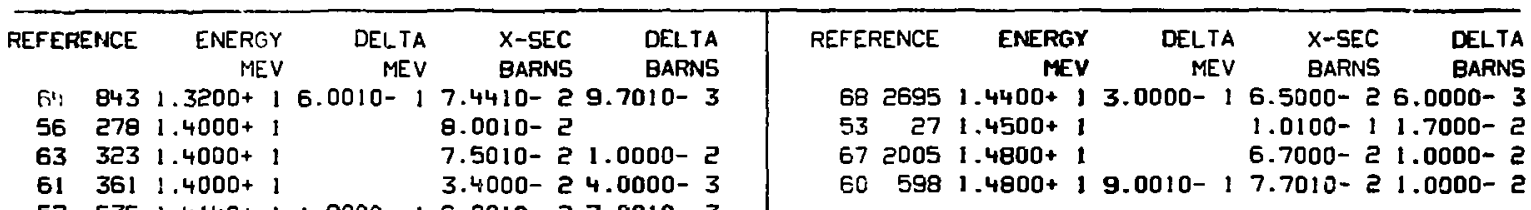

$575351.4140+11.8000-16.0010-27.0010-3$

$03 / 01 / 74 \quad N, P$

$30-Z N-67$

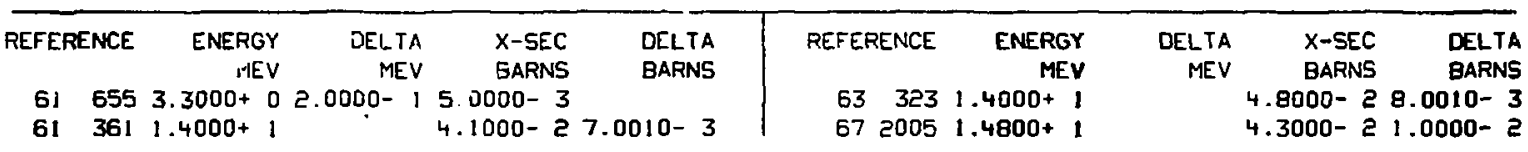

$\begin{array}{lll}03 / 01 / 74 & N, 2 N & 30-Z N-68\end{array}$

$\begin{array}{rrrrr}\text { REFERENCE } & \text { ENERGY } & \text { DELTA } & \text { X-SEC } & \text { DELTA } \\ & \text { MEV } & \text { MEV } & \text { BARNS } & \text { BARNS } \\ 62 & 3374 & 1.4000+1 & 5.3000-11.0000-1\end{array}$

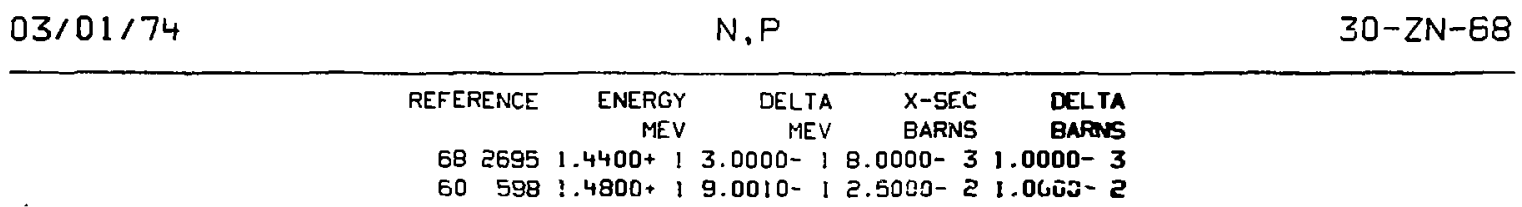

\begin{tabular}{|c|c|c|c|c|c|c|c|c|c|}
\hline \multicolumn{3}{|c|}{$03 / 01 / 74$} & \multicolumn{3}{|c|}{$N, A L P H A$} & \multicolumn{4}{|c|}{$30-Z N-68$} \\
\hline REFERENCE & $\begin{array}{r}\text { ENERGY } \\
\text { MEV }\end{array}$ & $\begin{array}{l}\text { DELTA } \\
\text { MEV }\end{array}$ & $\begin{array}{l}x-\text { SEC } \\
\text { BARNS }\end{array}$ & $\begin{array}{l}\text { DELTA } \\
\text { BARNS }\end{array}$ & REFERENCE & $\begin{array}{r}\text { ENERGY } \\
\text { MEV }\end{array}$ & $\begin{array}{r}\text { DELTA } \\
\text { MEV }\end{array}$ & $\begin{array}{l}\text { X-SEC } \\
\text { BARNS }\end{array}$ & $\begin{array}{l}\text { DELTA } \\
\text { EARNS }\end{array}$ \\
\hline $\begin{array}{rr}55 & 131 \\
58 & 401 \\
68 & 2695\end{array}$ & $\begin{array}{l}1.4000+1 \\
1.4050+1 \\
1.4400+1\end{array}$ & $\begin{array}{l}5.5010-1 \\
3.0000-1\end{array}$ & $\begin{array}{l}7.6000-3 \\
7.6010-3 \\
9.0000-3\end{array}$ & $\begin{array}{l}\text { 8.0000- } 4 \\
\text { 8.0010- } 4 \\
1.0000-3\end{array}$ & $\begin{array}{lr}67 & 2005 \\
63 & 756 \\
60 & 598\end{array}$ & $\begin{array}{l}1.4800+1 \\
1.4800+1 \\
1.4800+1\end{array}$ & $\begin{array}{l}2.0000-1 \\
9.0010-1\end{array}$ & $\begin{array}{l}1.0000-2 \\
1.8000-2 \\
5.1010-2\end{array}$ & $\begin{array}{l}1.0000-3 \\
5.0000-3 \\
1.0000-2\end{array}$ \\
\hline
\end{tabular}




\section{CROSS SECTION}

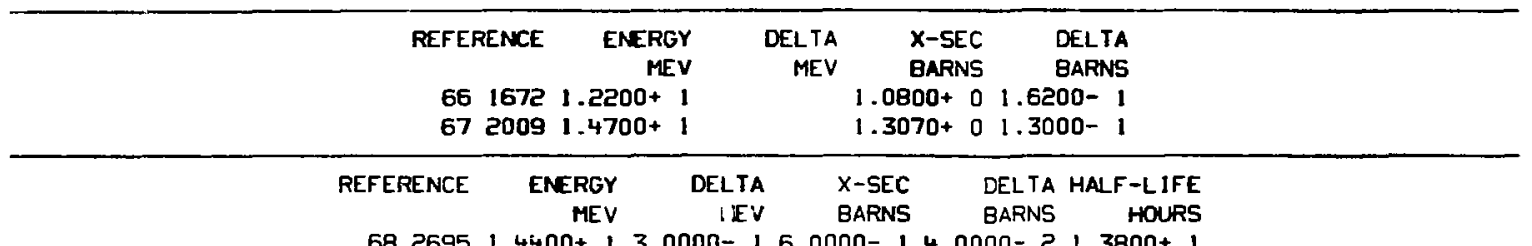

$6826951.4500+13.0000-16.0000-14.0000-21.3800+1$

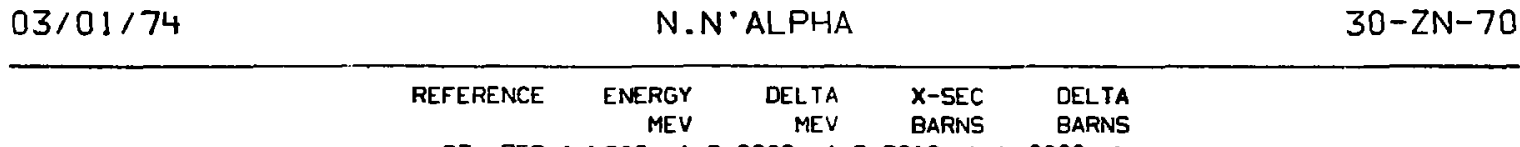

$637561.4800+12.0000-18.9010-44.0000-4$

$\begin{array}{lll}03 / 01 / 74 & N, N^{\circ} & 30-Z N-74\end{array}$

\begin{tabular}{|c|c|c|c|c|c|c|c|c|c|c|c|}
\hline REFERENCE & $\begin{array}{r}\text { ENERGY } \\
\text { MEV }\end{array}$ & $\begin{array}{r}\text { DELIA } \\
\text { MEV }\end{array}$ & $\begin{array}{l}X \text {-SEC } \\
\text { BARNS }\end{array}$ & $\begin{array}{l}\text { DEL TA } \\
\text { BAPNS }\end{array}$ & $\begin{array}{r}E-L V L \\
\text { MEV }\end{array}$ & REFEPENCE & $\begin{array}{r}\text { ENERGY } \\
\text { MEV }\end{array}$ & $\begin{array}{r}\text { DELTA } \\
\text { MEV }\end{array}$ & $\begin{array}{l}X \text { X-SEC } \\
\text { BARNS }\end{array}$ & $\begin{array}{l}\text { DELTA } \\
\text { BARNS }\end{array}$ & $\begin{array}{r}E-L V L \\
M E V\end{array}$ \\
\hline 702753 & $1.7500+0$ & $5.5000-2$ & $7.6500-1$ & & & 702763 & $2.5500+0$ & $5.5000-2$ & $1.5100-1$ & & $1.46+0+0$ \\
\hline 702763 & $2.1300+0$ & $5.5000-$ & $6.8800-1$ & & $5.9600-\quad !$ & 702763 & $1.7500+0$ & $5.5000-2$ & $5.4000-2$ & & $1.4840+$ \\
\hline 702763 & $2.5500+0$ & $5.5000-2$ & $6.7200-1$ & & $5.960 \mathrm{c}-1$ & 702763 & $2.1500+0$ & $5.5000-2$ & $9.2000-2$ & & $1.4840+$ \\
\hline 702763 & $1.7500+0$ & $5.5000-2$ & $3.4100-1$ & & $1.2050+0$ & 702763 & $2.5500+0$ & $5.5000-2$ & $1.2300-1$ & & $1.4840+r$ \\
\hline $\begin{array}{ll}70 & 2763 \\
70 & 2763\end{array}$ & $\begin{array}{l}2.1300+0 \\
2.5500+0\end{array}$ & $\begin{array}{l}5.5000-2 \\
5.5000-2\end{array}$ & $3.1500-1$ & & $1.2050+0$ & $\begin{array}{l}702763 \\
702763\end{array}$ & $\begin{array}{l}1.7500+0 \\
2.300+0\end{array}$ & $\begin{array}{l}5.5000-5 \\
5.5000-5\end{array}$ & 1.0000- 5 & & $1.6980+$ \\
\hline 702763 & $\begin{array}{l}2.5500+0 \\
1.7500+0\end{array}$ & $5.5000-2$ & $\begin{array}{l}3.7700-1 \\
6.5000-2\end{array}$ & & $\begin{array}{l}1.2050+0 \\
1.4640+0\end{array}$ & $\begin{array}{l}702763 \\
702763\end{array}$ & $\begin{array}{l}2.1300+0 \\
2.5500+0\end{array}$ & $\begin{array}{l}5.5000-2 \\
5.5000-2\end{array}$ & $\begin{array}{l}1.2900-1 \\
2.3800-1\end{array}$ & & $\begin{array}{l}1.6980+ \\
1.6980+\end{array}$ \\
\hline 702763 & $2.1300+0$ & $5.5000-2$ & $1.0900-1$ & & $1.4640+0$ & 702763 & $2.5500+0$ & $5.5000-2$ & $1.6000-2$ & & $2.1980+$ \\
\hline
\end{tabular}




\section{$03 / 01 / 74$}

$N, P$

$31-G A-69$

CROSS SECTION

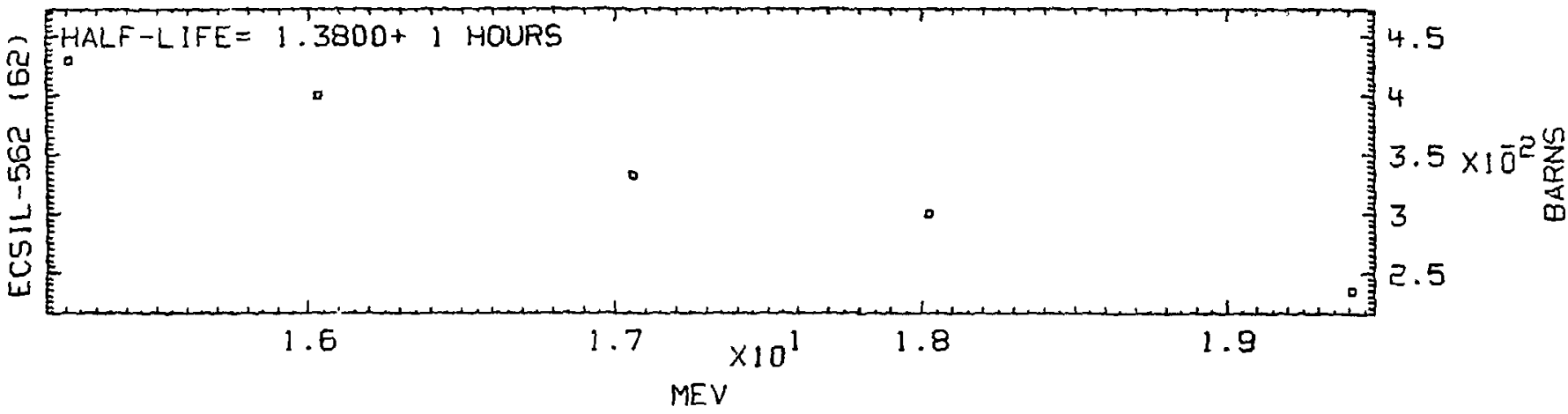

$03 / 01 / 74 \quad$ N.2N 31-GA-69

\begin{tabular}{|c|c|c|c|c|c|c|c|c|c|}
\hline REFERENCE & $\begin{array}{r}\text { ENERGY } \\
\text { MEV }\end{array}$ & $\begin{array}{r}\text { DELTA } \\
\text { MEV }\end{array}$ & $\begin{array}{l}X-5 E C \\
\text { BARNS }\end{array}$ & $\begin{array}{l}\text { DELTA } \\
\text { BARNS }\end{array}$ & REFERENCE & $\begin{array}{r}\text { ENERGY } \\
\text { MEV }\end{array}$ & $\begin{array}{r}\text { DELTA } \\
\text { MEV }\end{array}$ & $\begin{array}{l}X \text {-SEC } \\
\text { SARNS }\end{array}$ & $\begin{array}{l}\text { OELTA } \\
\text { BARNS }\end{array}$ \\
\hline $\begin{array}{lr}E 2 & 108 \\
61 & 676 \\
53 & 27\end{array}$ & $\begin{array}{l}1.4130+1 \\
1.4400+1 \\
1.4500+1\end{array}$ & $\begin{array}{l}1.0000 \\
3.0000\end{array}$ & $\begin{array}{l}17.3510-1 \\
19.2310-1 \\
5.5210-1\end{array}$ & $\begin{array}{l}4.4000-2 \\
6.9010-2 \\
: .7000-1\end{array}$ & $\begin{array}{rr}67 & 2368 \\
61 & 703 \\
66 & 2058\end{array}$ & $\begin{array}{l}1.4800+1 \\
1.4800+1 \\
1.4800+1\end{array}$ & $\begin{array}{l}1.0000-1 \\
2.5000-1 \\
1.0000-1\end{array}$ & $\begin{array}{l}9.8300-1 \\
1.0700+.0 \\
9.5000-1\end{array}$ & $\begin{array}{l}1.5000-1 \\
1.1000-1 \\
9.5000-5\end{array}$ \\
\hline
\end{tabular}

$6720091.4700+13.0000-11.0800+01.0000-1$

$03 / 01 / 74 \quad$ N.P $31-G A-69$

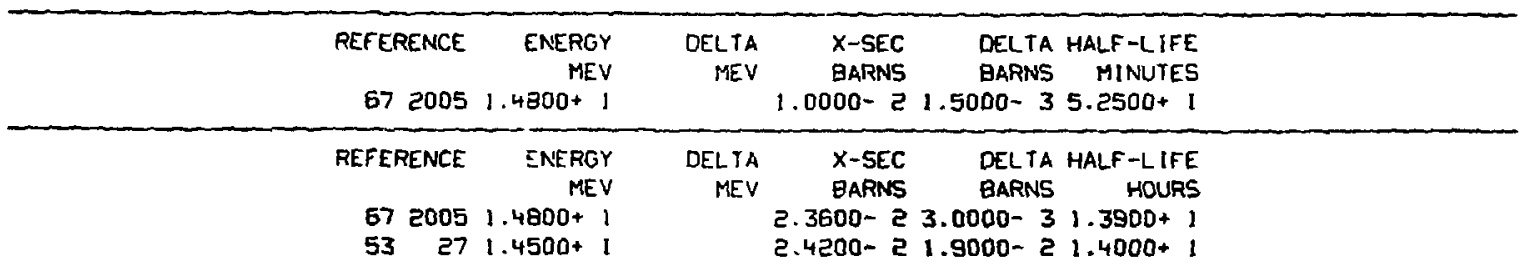


CROSS SECTION

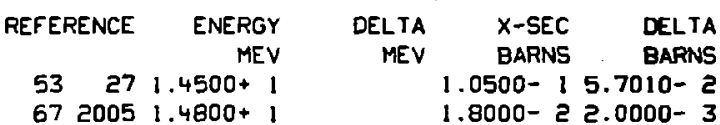

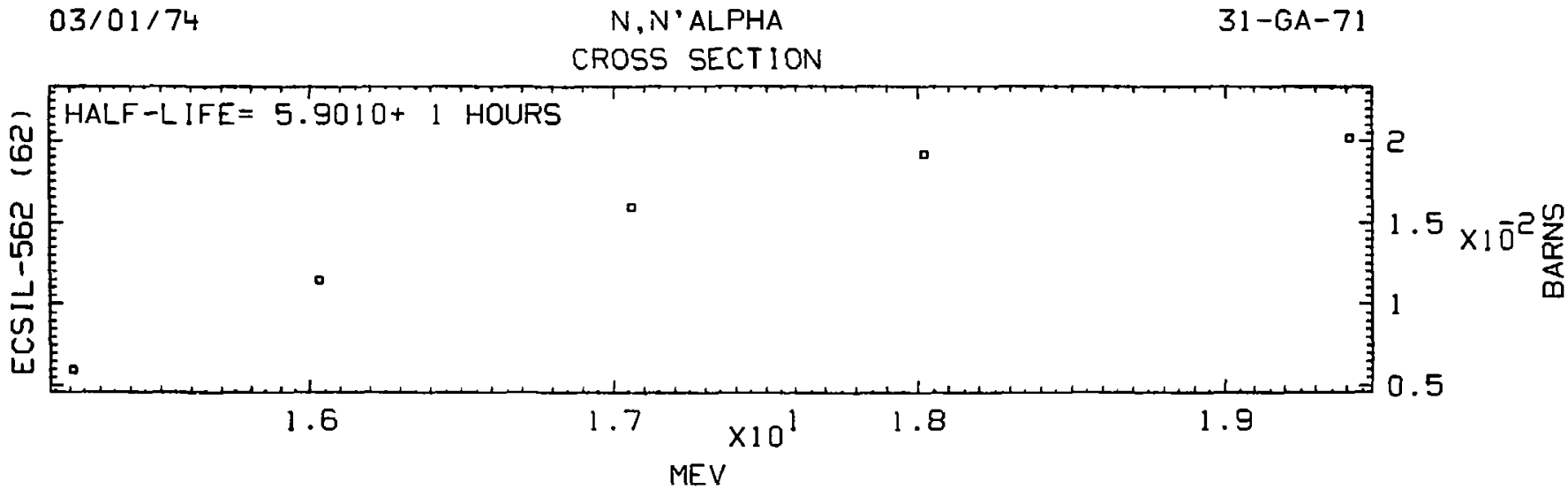

\begin{tabular}{|c|c|c|c|c|c|c|c|c|c|}
\hline \multicolumn{2}{|c|}{$03 / 01 ; 74$} & \multicolumn{5}{|c|}{$N, 2 N$} & \multicolumn{3}{|c|}{$31-6 A-71$} \\
\hline GEFERENCE & $\begin{array}{r}\text { ENERGY } \\
\text { MEV }\end{array}$ & $\begin{array}{l}\text { DELTA } \\
\text { MEV }\end{array}$ & $\begin{array}{l}X-\text { SEC } \\
\text { BARNS }\end{array}$ & $\begin{array}{l}\text { DELTA } \\
\text { BARNS }\end{array}$ & REFERENCE & $\begin{array}{r}\text { ENERGY } \\
\text { MEV }\end{array}$ & $\begin{array}{l}\text { DELTA } \\
\text { MEV }\end{array}$ & $\begin{array}{l}X-S E C \\
\text { BARNS }\end{array}$ & $\begin{array}{l}\text { DELTA } \\
\text { BARNS }\end{array}$ \\
\hline $\begin{array}{rr}66 & 1672 \\
53 & 27\end{array}$ & $\begin{array}{l}1.2320+1 \\
1.4500+1\end{array}$ & & $\begin{array}{l}8.0600-1 \\
7.0010-1\end{array}$ & $\begin{array}{l}1.2100-1 \\
1.1000-1\end{array}$ & $\begin{array}{rr}67 & 2009 \\
61 & 703\end{array}$ & $\begin{array}{l}1.4700+1 \\
.4800+1\end{array}$ & $\begin{array}{l}3.0000-1 \\
2.5000-1\end{array}$ & $\begin{array}{l}9.6100-1 \\
2.1800+0\end{array}$ & $\begin{array}{l}1.0000-1 \\
2.2000-1\end{array}$ \\
\hline
\end{tabular}


CROSS SECTION

$\begin{array}{rrrrr}\text { REFERENCE } & \text { ENERGY } & \text { DELTA } & \text { X-SEC } & \text { DELTA } \\ & \text { MEV } & \text { MEV } & \text { BARNS } & \text { BARNS }\end{array}$

$637551.4800+12.0000-12.1000-31.8000-3$

$03 / 01 / 74$

$$
N, P
$$

$31-G A-71$

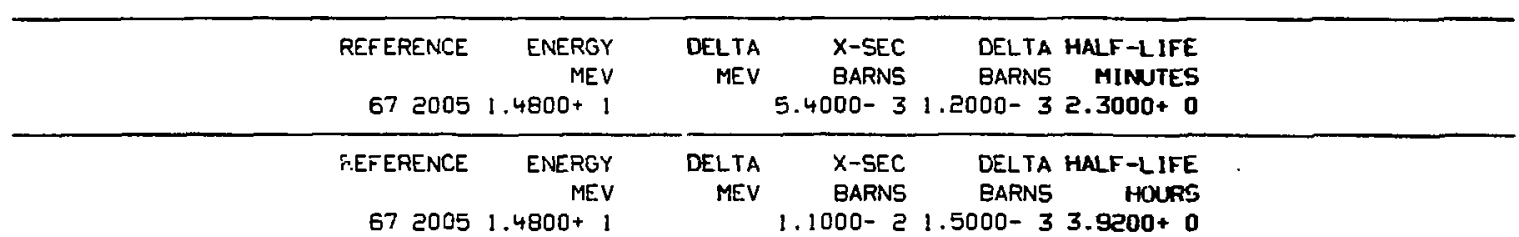

$03 / 01 / 74$

N, ALPHA

$31-G A-71$

$\begin{array}{rrrrr}\text { REFERENCE } & \text { ENERGY } & \text { DELTA } & \text { X-SEC } & \text { DELTA } \\ & \text { NEV } & \text { MEV } & \text { BARNS } & \text { BARNS } \\ 662142 & 1.4800+1 & 6.0400-24.0000-3\end{array}$

$6621421.4800+1$ $6.0000-24.0000-3$

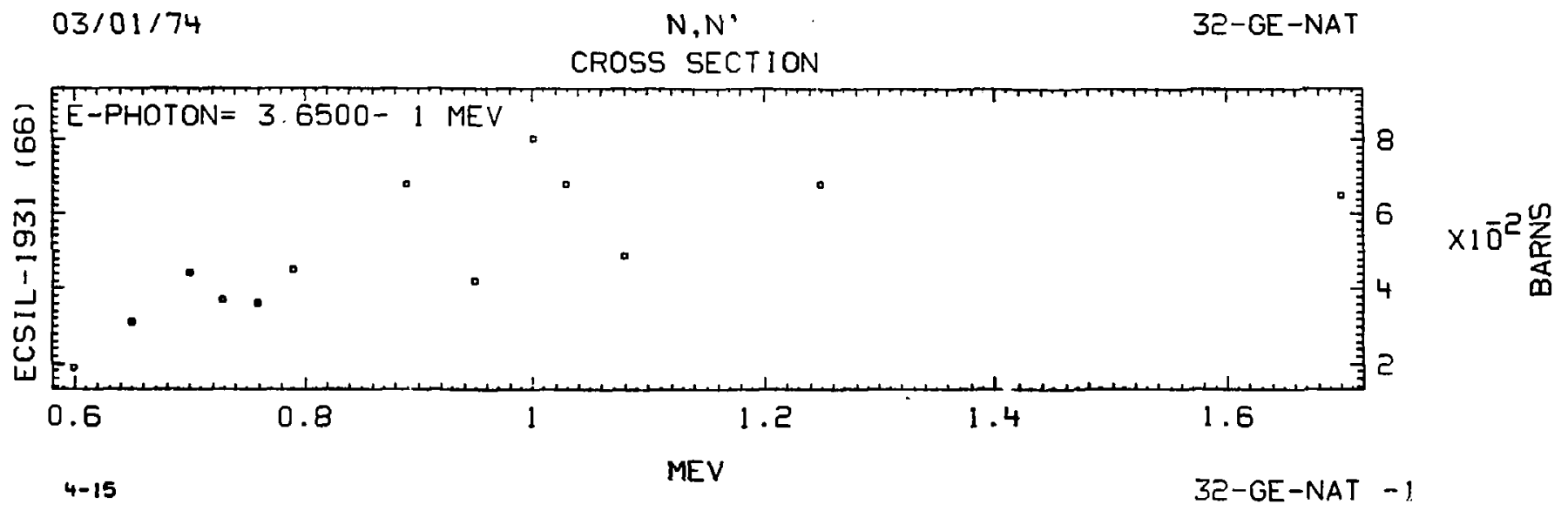




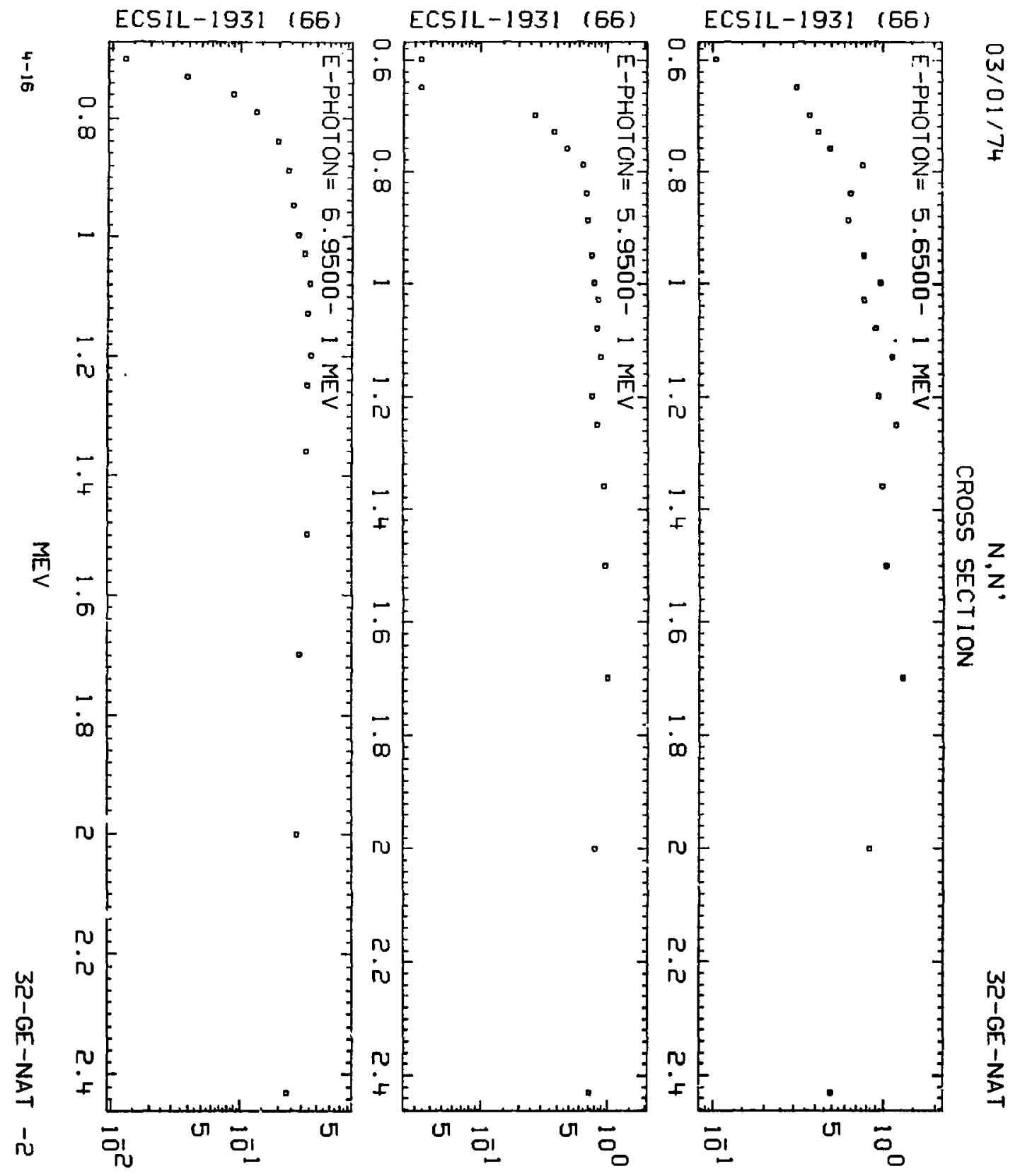

BARNS 

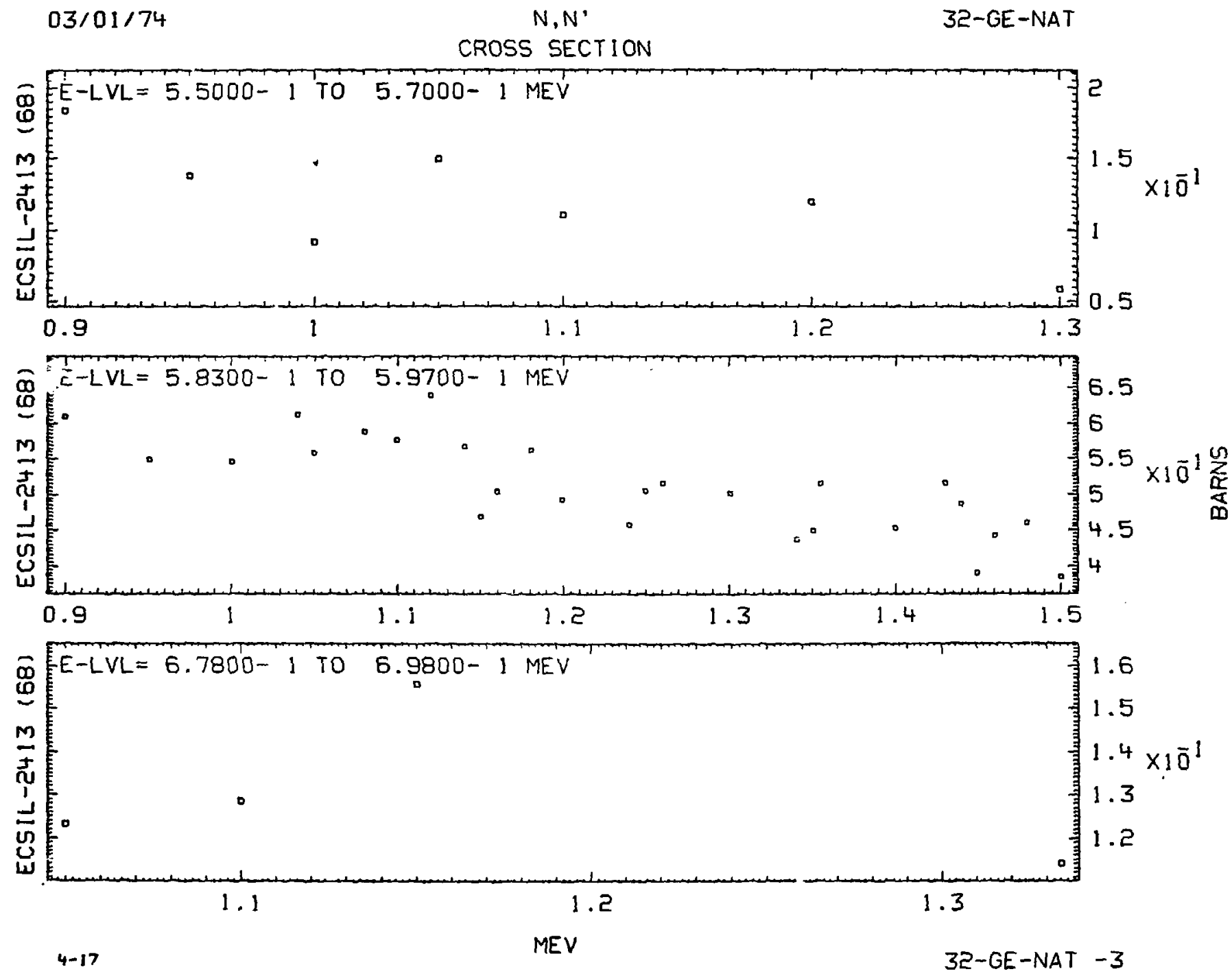


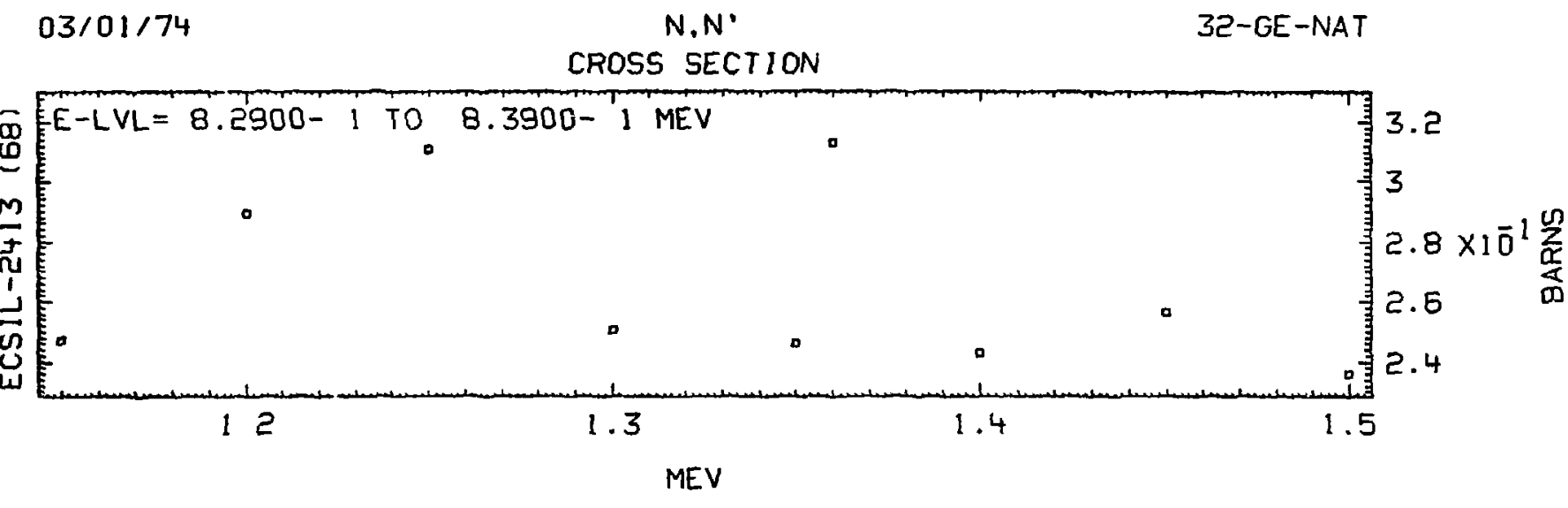

03/01/74

$6928507.5500+01.3000-11.6800+01.7000-1$

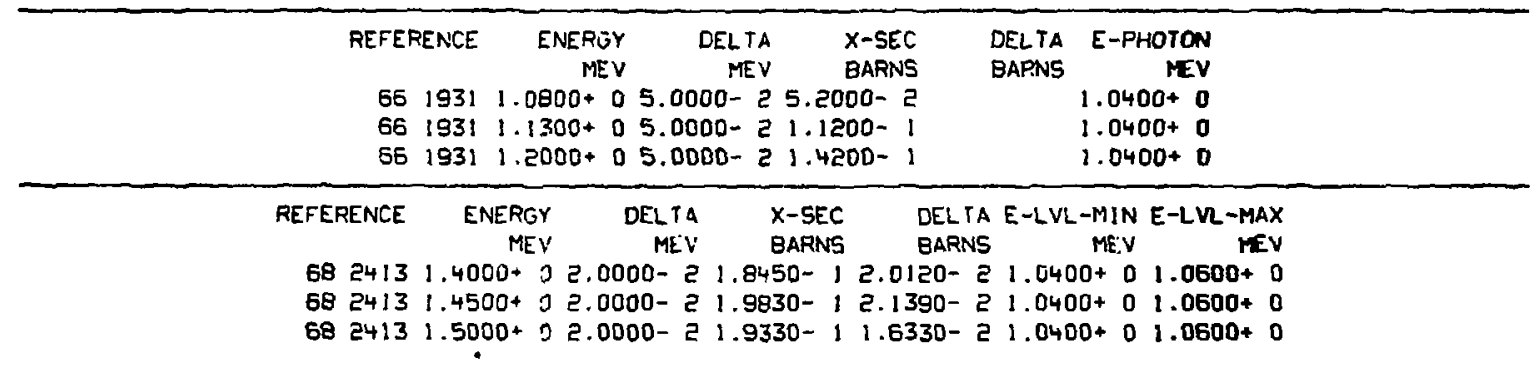


CROSS SECTION

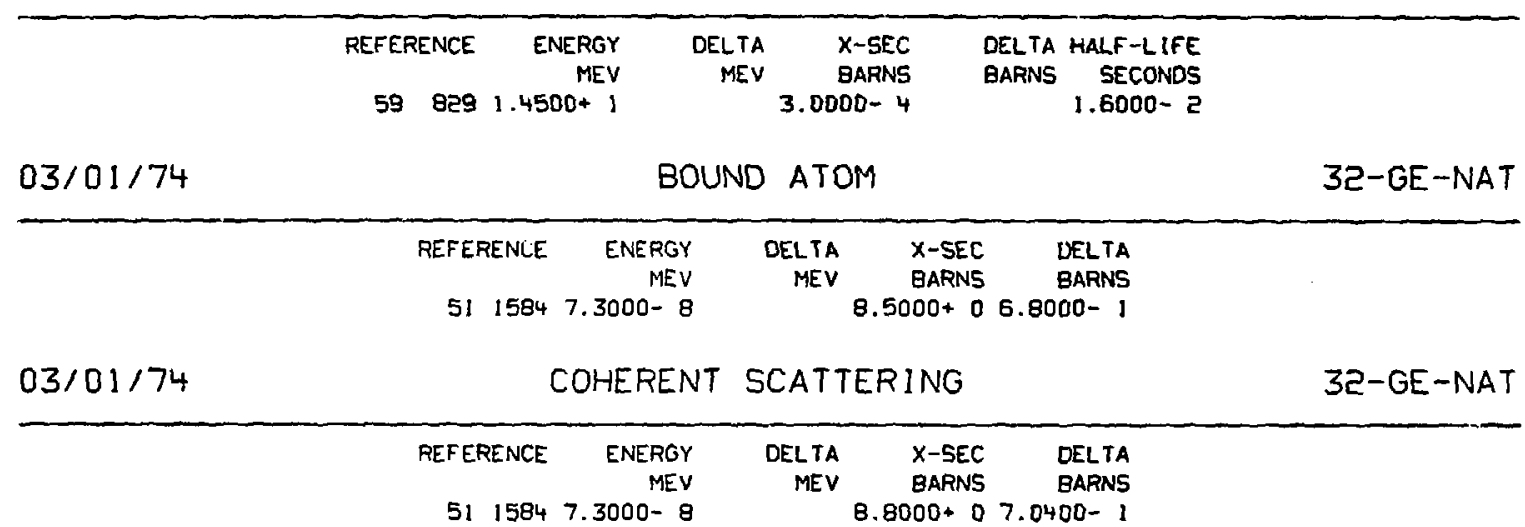

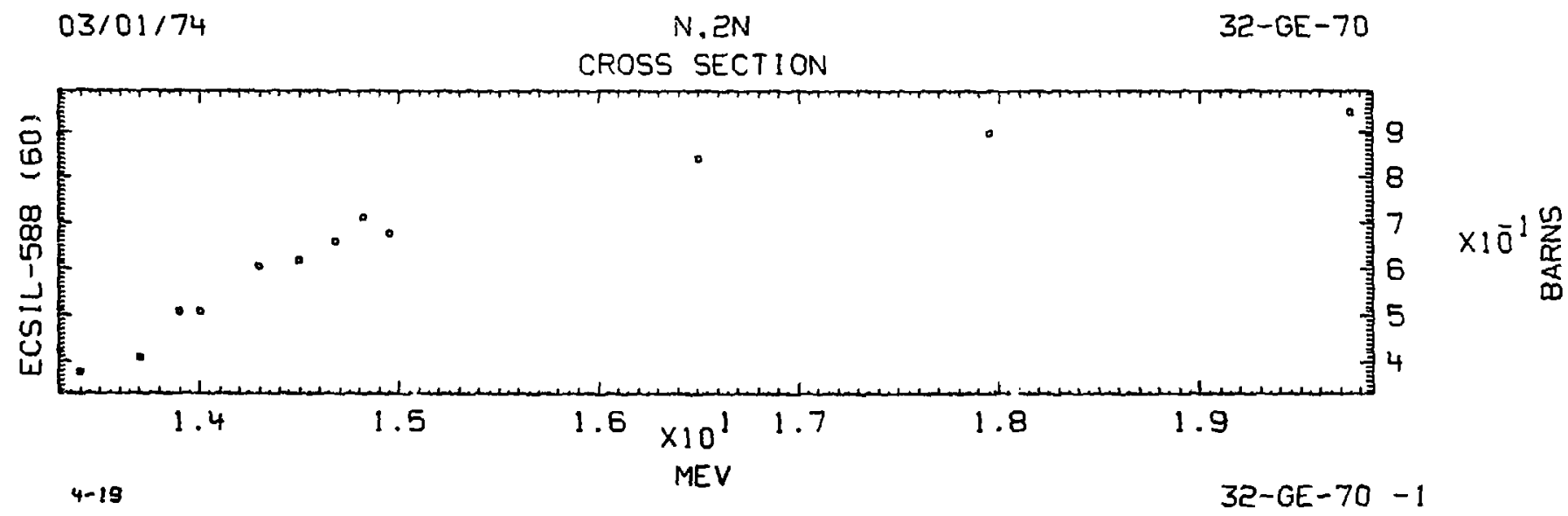




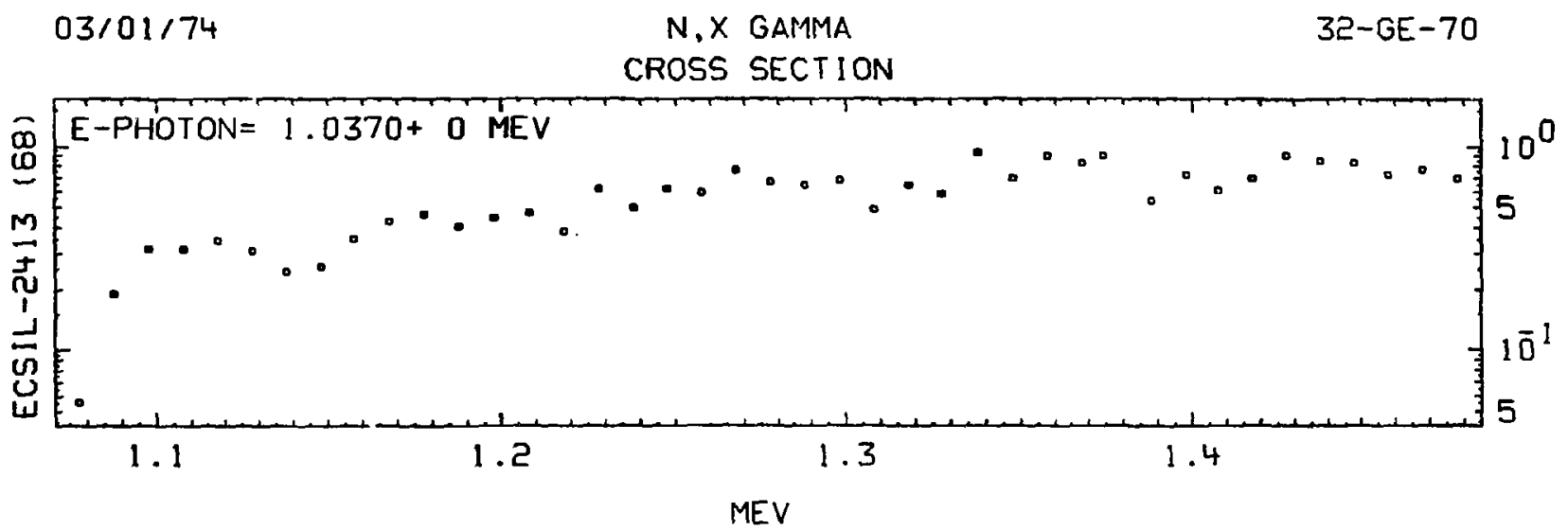

\begin{tabular}{|c|c|c|c|c|c|c|c|c|c|c|c|}
\hline \multirow[b]{2}{*}{ REFERENCE } & \multicolumn{3}{|l|}{$03 / 01 / 74$} & \multicolumn{3}{|c|}{$N, N^{\circ}$} & & & \multicolumn{2}{|c|}{$32-G E-70$} & \multirow[b]{2}{*}{$\begin{array}{l}\text { E-LVL } \\
\text { MEV }\end{array}$} \\
\hline & $\begin{array}{r}\text { ENERGY } \\
\text { MEV }\end{array}$ & $\begin{array}{c}\text { DELTAA } \\
\text { MEV }\end{array}$ & $\begin{array}{l}X-5 E C \\
\text { BARNS }\end{array}$ & $\begin{array}{l}\text { DEL TA } \\
\text { BARNS }\end{array}$ & $\begin{array}{c}E-L V L \\
M E V\end{array}$ & REFE.PENCNE & $\begin{array}{r}\text { ENERGY } \\
\text { MEV }\end{array}$ & $\begin{array}{r}\text { DELTA } \\
\text { MEV }\end{array}$ & $\begin{array}{l}X \text {-SEC } \\
\text { BARNS }\end{array}$ & $\begin{array}{l}\text { DELTA } \\
\text { BARNS }\end{array}$ & \\
\hline $\begin{array}{ll}70 & 2763 \\
70 & 2763 \\
70 & 2763\end{array}$ & $\begin{array}{l}1.7500+0 \\
2.1300+0 \\
2.5500+0\end{array}$ & $\begin{array}{l}1000-2 \\
000-2 \\
000-2\end{array}$ & $\begin{array}{l}8200-1 \\
0900-1 \\
3300-1\end{array}$ & & $\begin{array}{l}3400+0 \\
3400+0\end{array}$ & $\begin{array}{ll}70 & 2763 \\
70 & 2763\end{array}$ & $\begin{array}{l}1300+0 \\
5500+0\end{array}$ & $\begin{array}{r}5000-5 \\
5000-5\end{array}$ & $\begin{array}{l}9700-1 \\
1700-1\end{array}$ & & $\begin{array}{l}1.7090+0 \\
1.7090+0\end{array}$ \\
\hline
\end{tabular}

\begin{tabular}{|c|c|c|c|c|c|}
\hline \multirow[t]{2}{*}{$03 / 01 / 74$} & \multicolumn{5}{|c|}{$N, 2 N$} \\
\hline & REFERENCE & $\begin{array}{r}\text { ENERGY } \\
\text { MEV }\end{array}$ & $\begin{array}{r}\text { OELTA } \\
\text { MEV }\end{array}$ & $\begin{array}{l}x \text {-SEC } \\
\text { BAFNS }\end{array}$ & $\begin{array}{l}\text { OELTA } \\
\text { BARNS }\end{array}$ \\
\hline & $\begin{array}{rr}61 & 676 \\
53 & 27 \\
61 & 703\end{array}$ & $\begin{array}{l}1.4400+: \\
1.4500+1 \\
1.4800+1\end{array}$ & & $\begin{array}{l}5.9810-1 \\
6.6670-1 \\
1.6000+\end{array}$ & $\begin{array}{l}4.5000-2 \\
2.3000-1\end{array}$ \\
\hline
\end{tabular}

$03 / 01 / 74$

$N, X$ GAMMA

$32-G E-70$

\begin{tabular}{|c|c|c|c|c|c|c|c|c|c|c|}
\hline REFERENCE & $\begin{array}{r}\text { ENERGY } \\
\text { MEV }\end{array}$ & $\begin{array}{r}\text { DELTA } \\
\text { MEV }\end{array}$ & $\begin{array}{l}X \text {-SEC } \\
\text { BARINS }\end{array}$ & $\begin{array}{l}\text { DELTA } \\
\text { BARNS }\end{array}$ & $\begin{array}{r}\text { E-PHOTON } \\
\text { MEV }\end{array}$ & REFERENCE & $\begin{array}{r}\text { ENERSYY } \\
\text { MEV }\end{array}$ & $\begin{array}{r}\text { DELTA } \\
\text { MEV }\end{array}$ & $\begin{array}{l}x \text {-SEC } \\
\text { BARNS }\end{array}$ & $\begin{array}{l}\text { DELTA } \\
\text { BARNS }\end{array}$ \\
\hline
\end{tabular}

$7027632.1300+05.5000-21.0500-11.1000-26.6800-1 \quad 7027631.7500+05.5000-26.8200-16.8000-21.0410+0$

$7027632.5500+05.5000-21.5400-11.6000-26.6800-1 \mid 7027632.1300+05.5000-28.1400-18.1000-21.0410+0$ 
CROSS SECTION

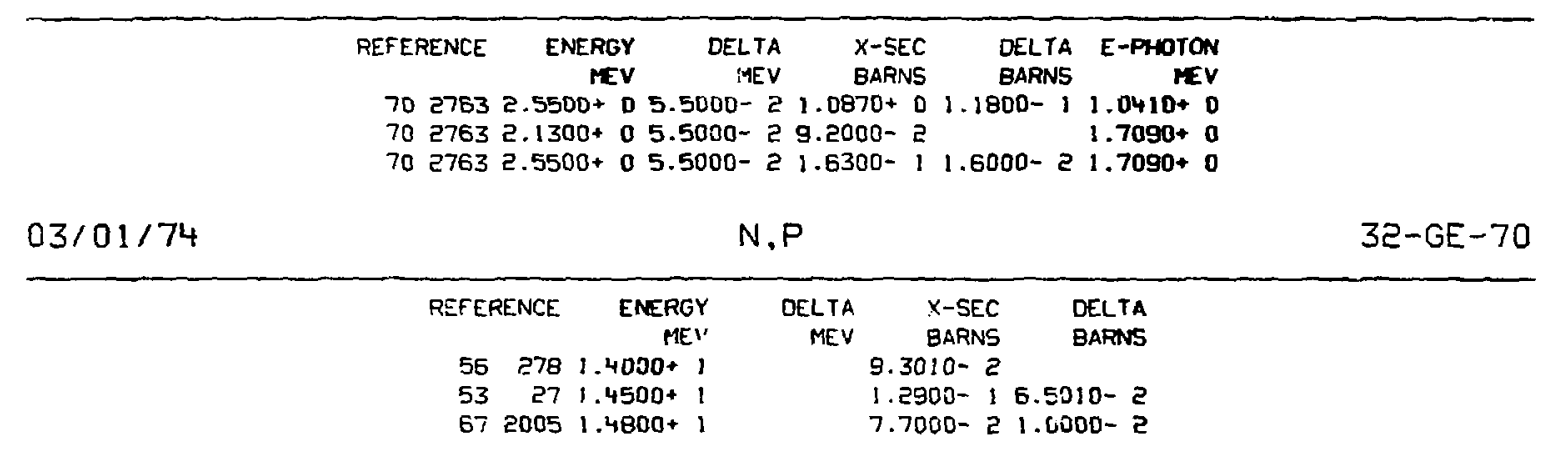

\section{$03 / 01 / 74$}

\section{CROSS SECTION}

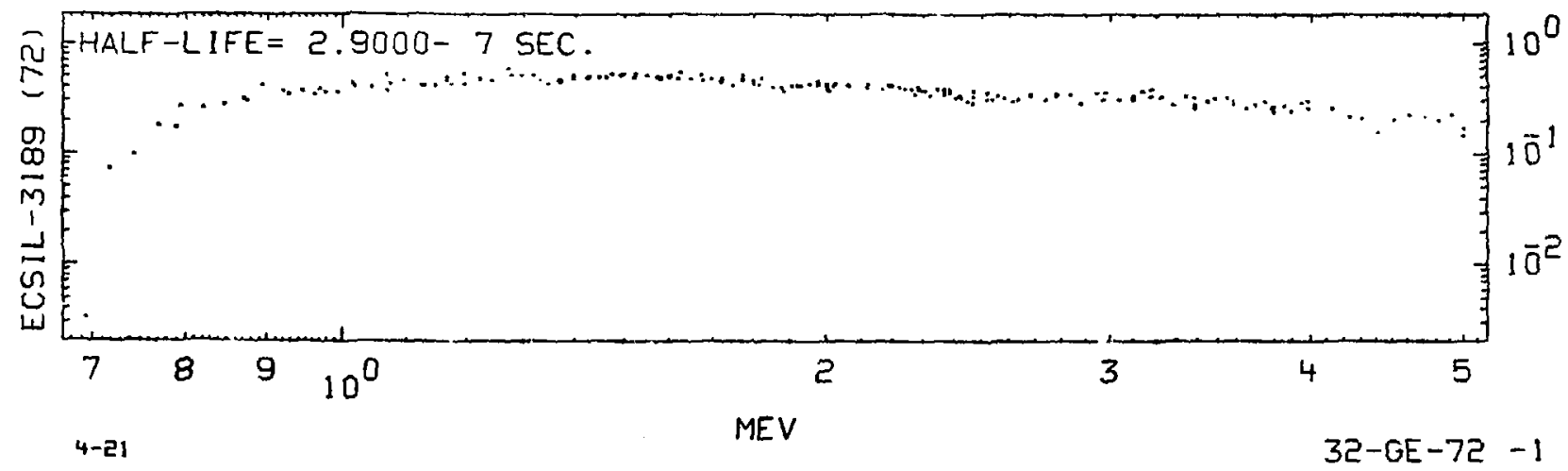




\section{CROSS SECTION}
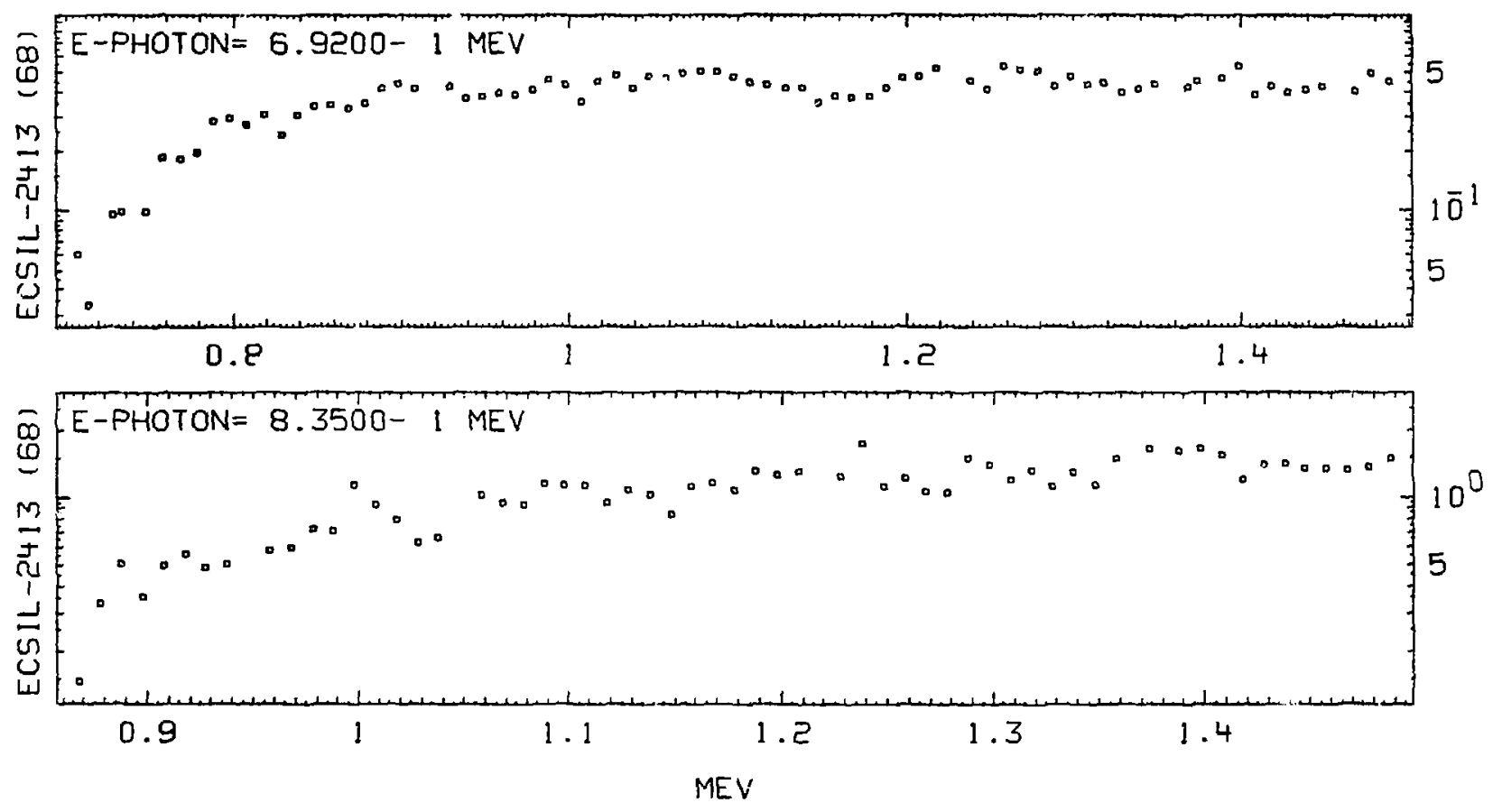

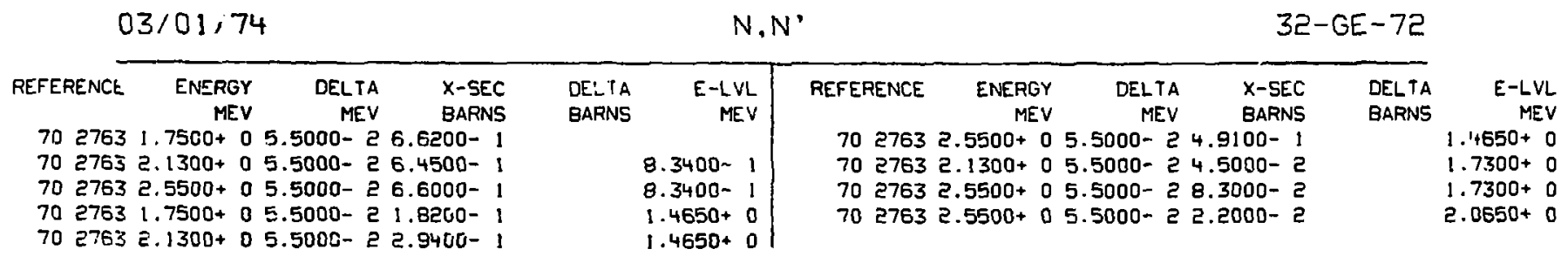




\section{CROSS SECTION}

$\begin{array}{rrrrr}\text { REFERENCE } & \text { ENERGY } & \text { DELTA } & \text { X-SEC } & \text { DELTA HALF-LIFE } \\ & \text { MEV } & \text { MEV } & \text { BARNS } & \text { BARNS } \\ \text { SECONDS }\end{array}$

$6929101.4800+1 \quad 4.8700-15.0000-22.0000-2$

$03 / 01 / 74 \quad N, X$ GAMMA $\quad 32-G E-72$

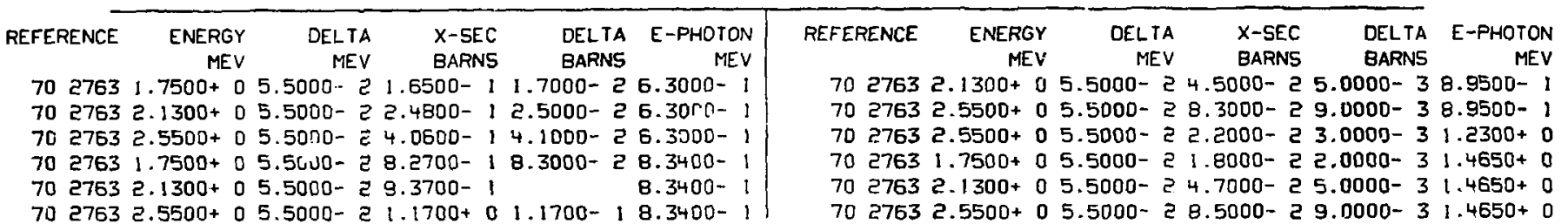

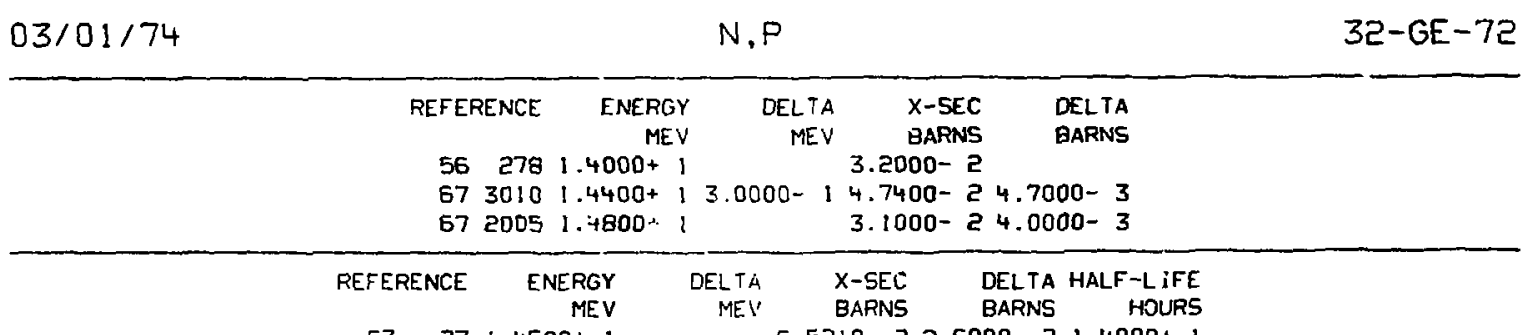

$53271.4500+1 \quad 6.5210-22.6000-21.4000+1$

\begin{tabular}{|c|c|c|c|c|c|c|}
\hline $03 / 01 / 74$ & \multicolumn{4}{|c|}{ N, ALPHA } & & $32-G E-72$ \\
\hline & $\begin{array}{r}\text { REFERENCE } \\
673010\end{array}$ & $\begin{array}{r}\text { ENERGY } \\
\text { MEV } \\
.4400+1\end{array}$ & $\begin{array}{r}\text { DELTA } \\
\text { MEV } \\
.0000-1\end{array}$ & $\begin{array}{r}X \text {-SEC } \\
\text { BAFNS } \\
1.5200-2\end{array}$ & $\begin{array}{r}\text { DELTA } \\
\text { BARNS } \\
.5200-3\end{array}$ & \\
\hline
\end{tabular}

$\begin{array}{rrrrr}\text { REFERENCE } & \text { ENERGY } & \text { DELTA } & \text { X-SEC } & \text { DELTA HALF-LIFE } \\ \text { MEV } & \text { MEV } & \text { BARNS } & \text { BARNS } \\ & \text { MINUTES }\end{array}$


CROSS SECTION

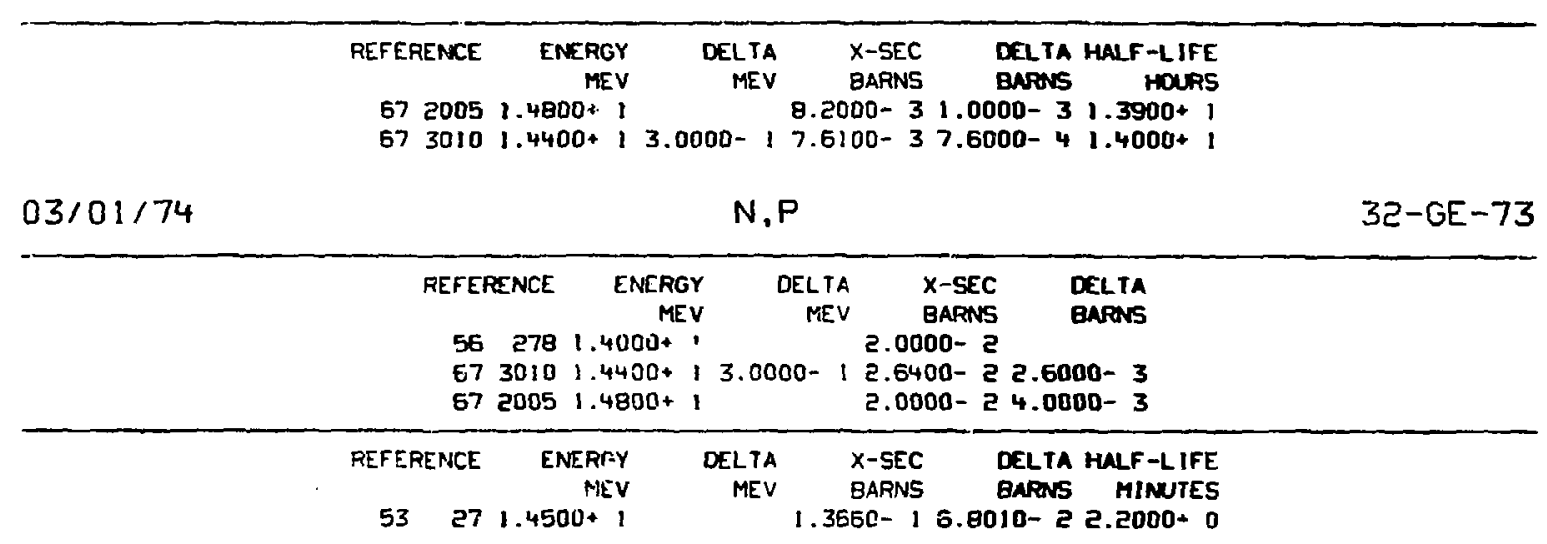

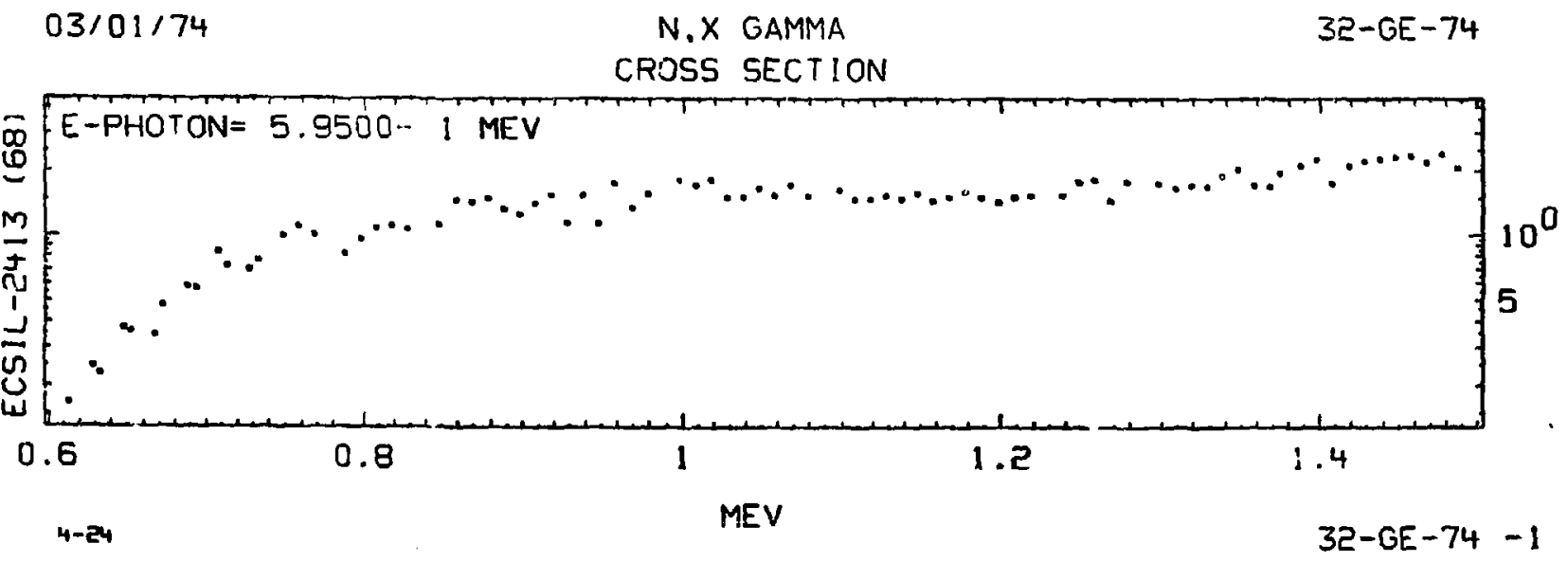


CROSS SECTION

\begin{tabular}{|c|c|c|c|}
\hline REFERENCE & $\begin{array}{r}\text { ENERGY } \\
\text { MEV } \\
4700+1\end{array}$ & $\begin{array}{r}\text { OELTA } \\
\text { MEV }\end{array}$ & $\begin{array}{r}X-5 E C \\
\text { BARNS } \\
000-4\end{array}$ \\
\hline
\end{tabular}

$03 / 01 / 74$

$N, X$ GAMMA

$32-G E-74$

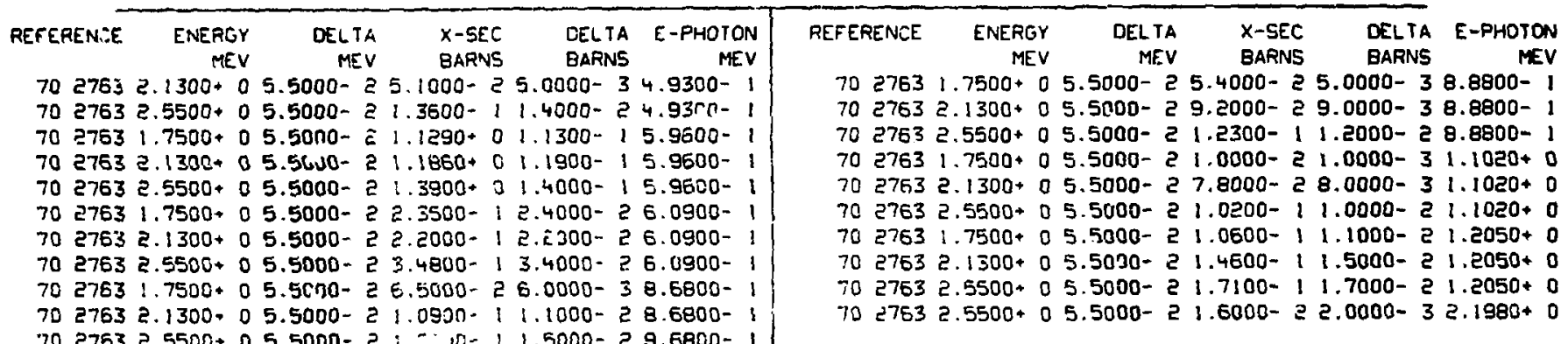

$03 / 01 / 74$

$N, P$

$32-G E-74$

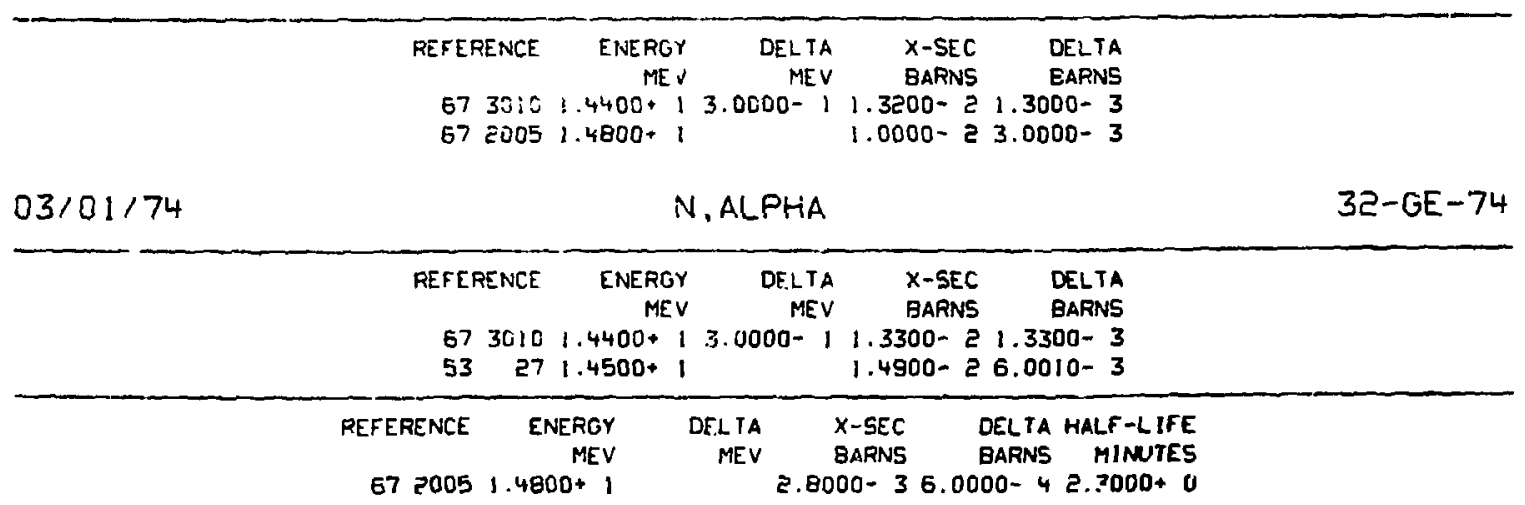




\section{CROSS SECTION}

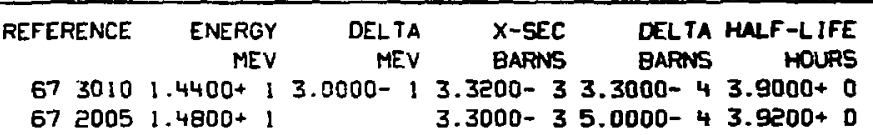

$03 / 01 / 74$

$N, 2 N$

$32-G E-76$
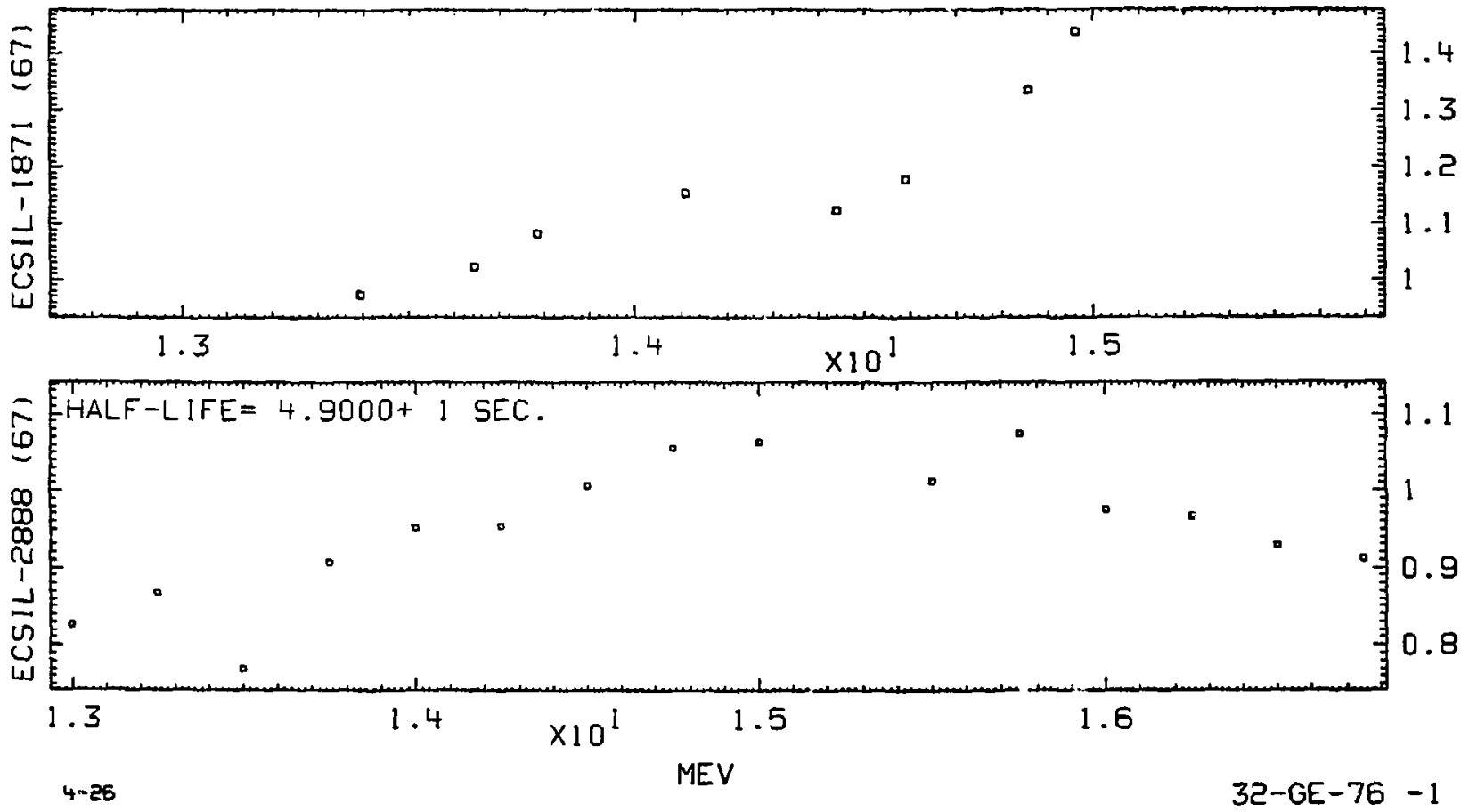

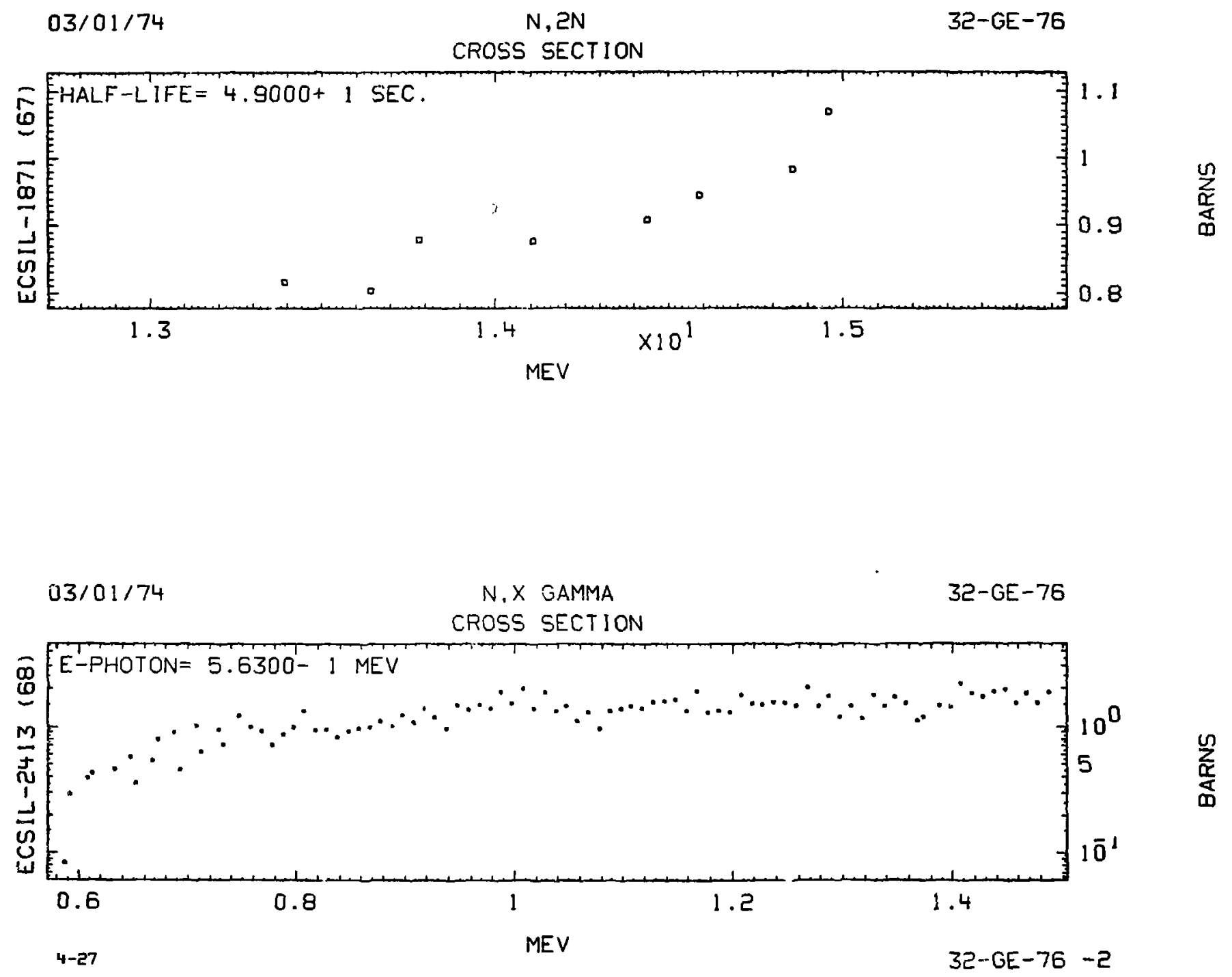
CROSS SECTION

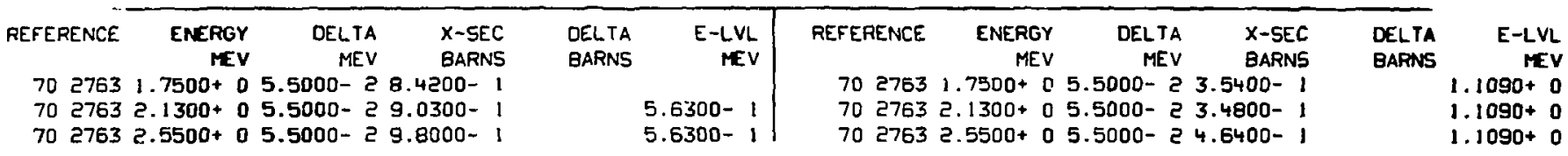

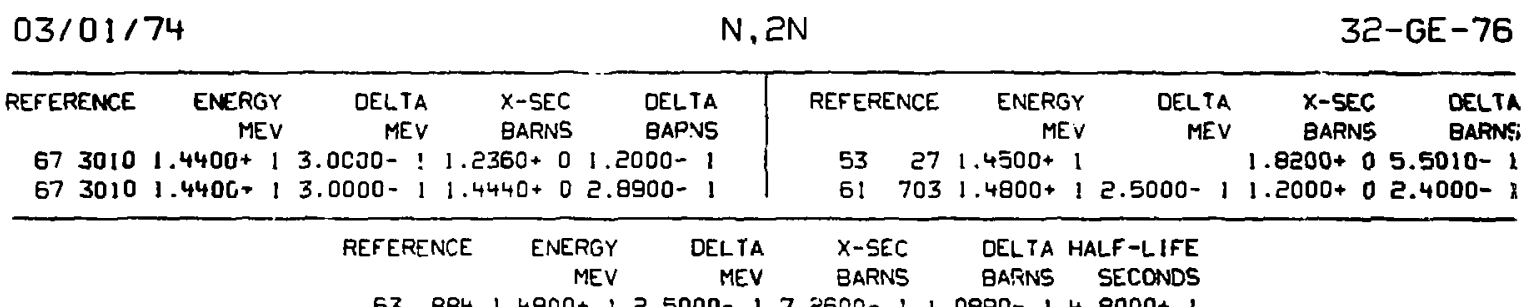

$638841.4800+12.5000-17.2600-11.0890-14.8000^{2} 1$

$03 / 01 / 74$

$N, X$ GAMMA

$32-G E-76$

\begin{tabular}{|c|c|c|c|c|c|c|c|c|c|c|c|}
\hline REFERENCE & $\begin{array}{r}\text { ENERGY } \\
\text { MEV }\end{array}$ & $\begin{array}{l}\text { DEL.TA } \\
\text { MEV }\end{array}$ & $\begin{array}{l}x-S E C \\
\text { BARNS }\end{array}$ & $\begin{array}{l}\text { DELTA } \\
\text { BARNS }\end{array}$ & $\begin{array}{r}\text { E-PHOTON } \\
\text { MEV }\end{array}$ & REFERENCE & $\begin{array}{r}\text { ENEPRGY } \\
\text { MEV }\end{array}$ & $\begin{array}{r}\text { DELTA } \\
\text { MEV }\end{array}$ & $\begin{array}{l}X \text { X-SEC } \\
\text { BARNS }\end{array}$ & $\begin{array}{l}\text { DELTA } \\
\text { BARNS }\end{array}$ & $\begin{array}{r}\text { E-PHOTON } \\
\text { MEV }\end{array}$ \\
\hline $\begin{array}{ll}70 & 2763 \\
70 & 2763 \\
70 & 2763 \\
70 & 2763\end{array}$ & $\begin{array}{l}7500+0 \\
1300+0 \\
5500+0 \\
7500+0\end{array}$ & $\begin{array}{l}5.5000-2 \\
5.5000-2 \\
5.5000-2 \\
5.5000-2\end{array}$ & $\begin{array}{l}2.0200-1 \\
2.0600-1 \\
2.2000-1 \\
, 0440+0\end{array}$ & $\begin{array}{l}2.0000-2 \\
2.1000-2 \\
2.2000-2 \\
1.1400-1\end{array}$ & $\begin{array}{l}5.4500-i \\
5.4500-i \\
5.4500-1 \\
5.6300-i\end{array}$ & $\begin{array}{ll}70 & 2763 \\
70 & 2763 \\
70 & 2763 \\
70 & 2763\end{array}$ & $\begin{array}{l}2.5500+0 \\
1.7500+0 \\
2.1300+0 \\
2.5500+0\end{array}$ & $\begin{array}{l}5.5000-2 \\
5.5000-2 \\
5.5000-2 \\
5.5000-2\end{array}$ & $\begin{array}{l}1.2000+0 \\
1.5200-1 \\
1.4200-1 \\
2.4400-1\end{array}$ & $\begin{array}{l}1.2000-1 \\
1.5000-2 \\
1.4000-2 \\
2.5000-2\end{array}$ & $\begin{array}{l}5.6300-1 \\
1.1090+0 \\
1.1090+0 \\
1.1090+0\end{array}$ \\
\hline
\end{tabular}

$7027632.1300+05.5000-2,1090+0,1100-15.6300-1$

$27632.5500+05.5000-25.4400-12.5000-31.1090+0$ 

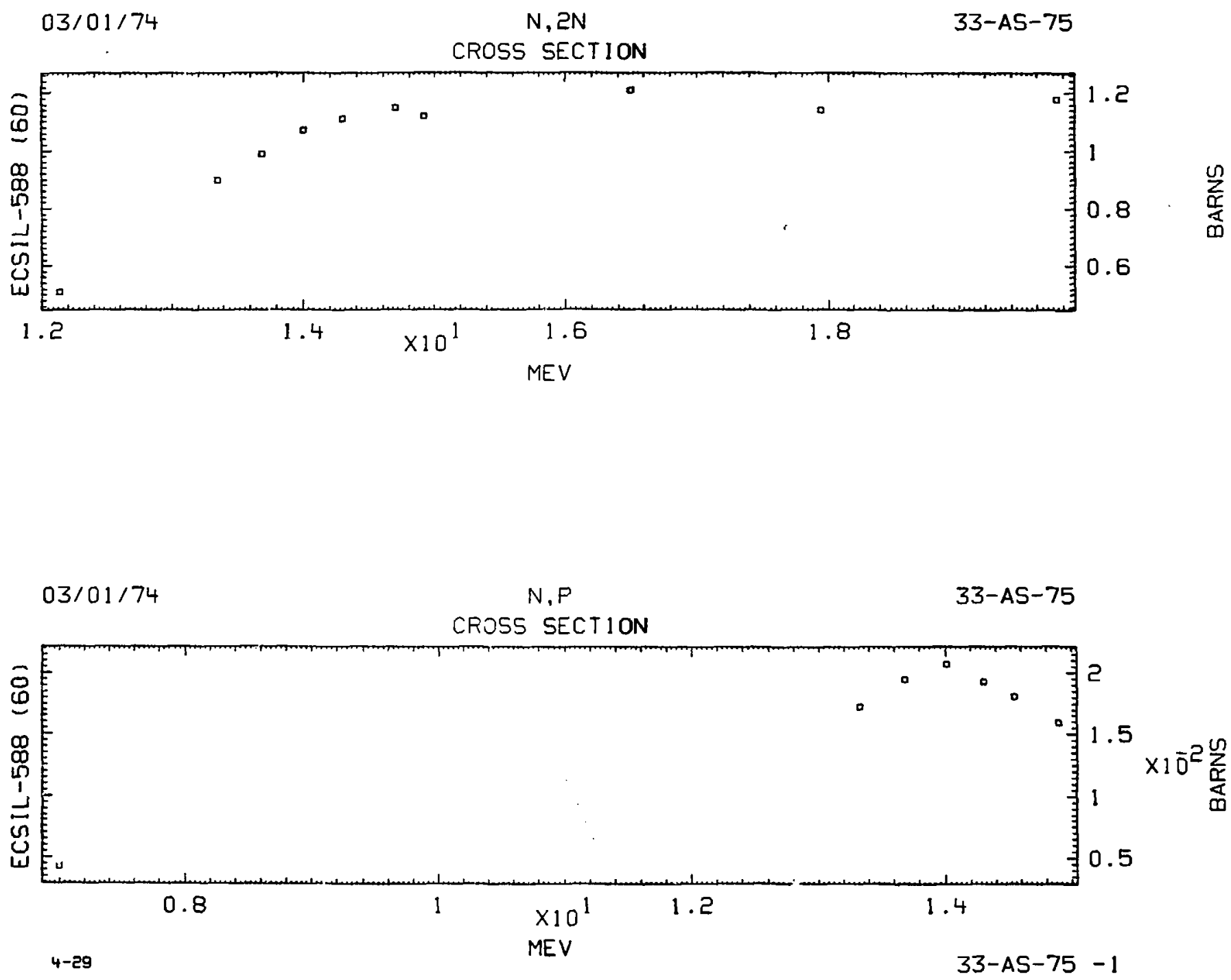


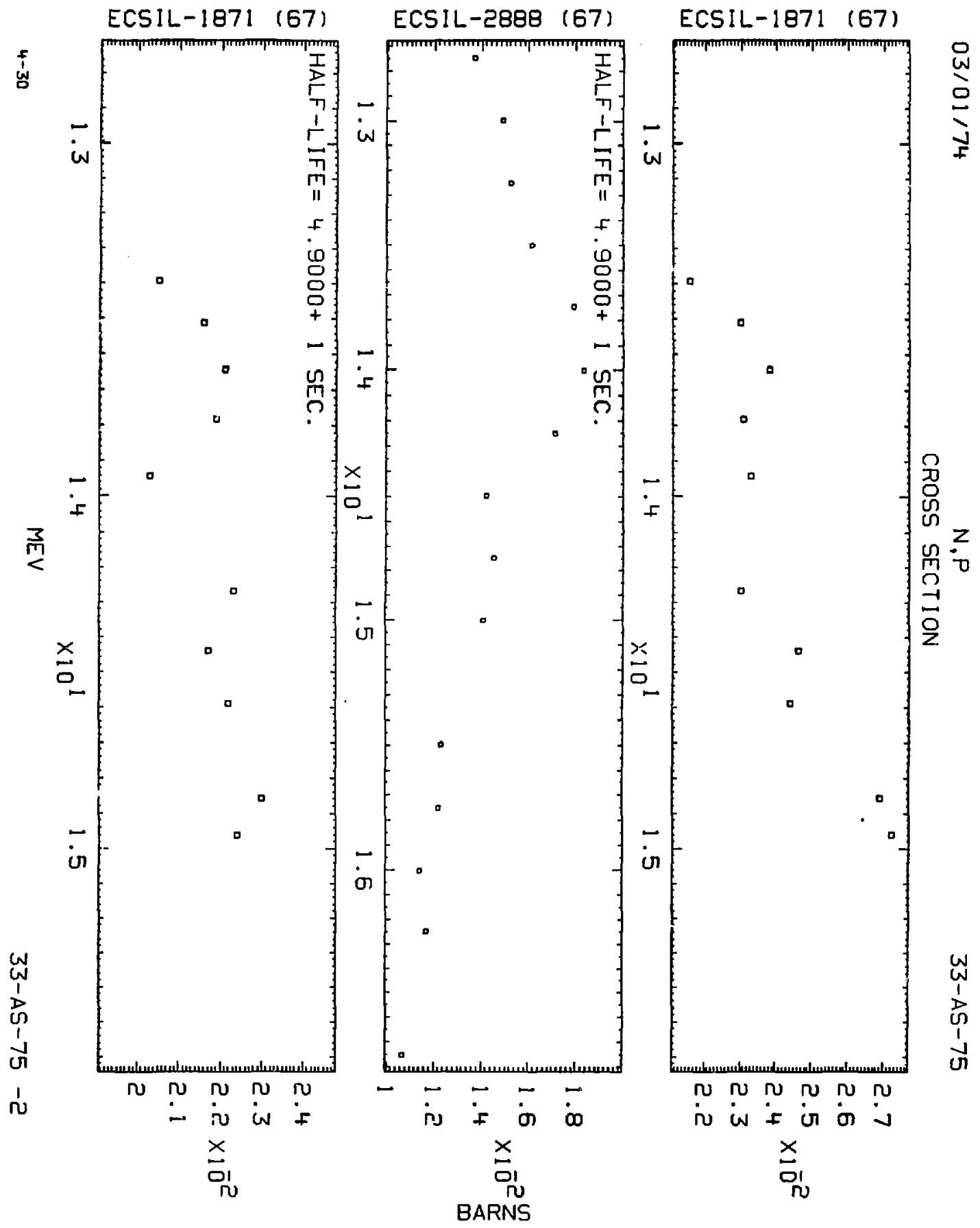




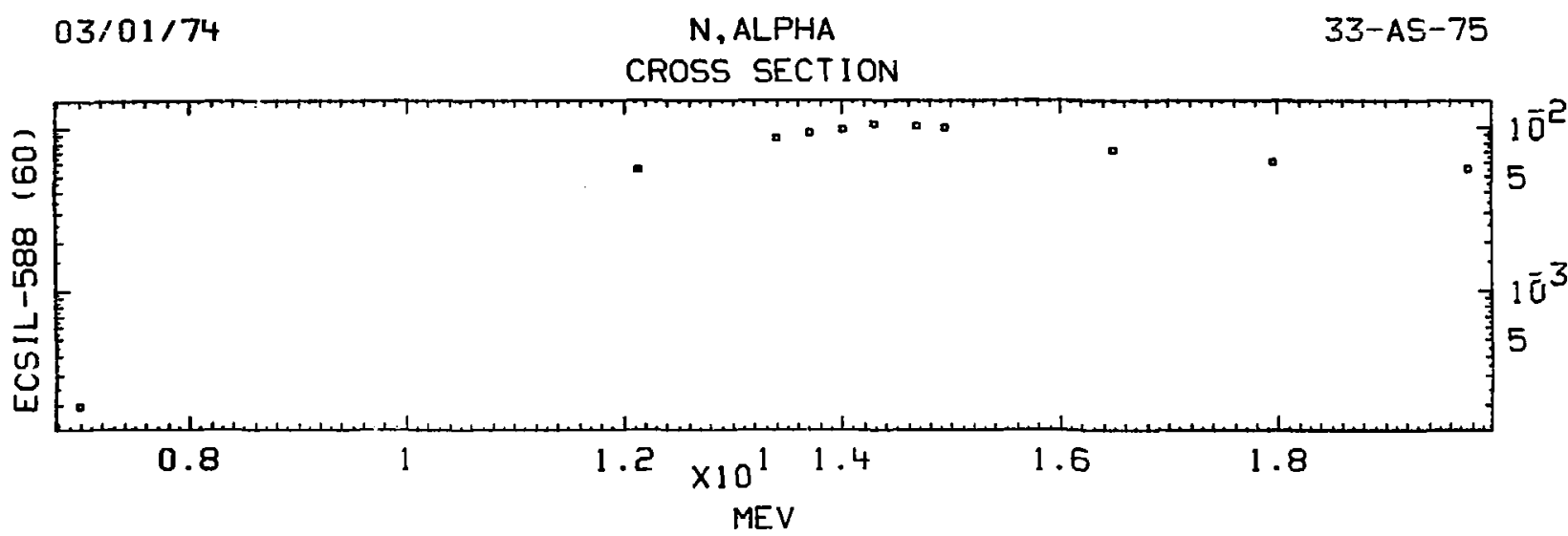

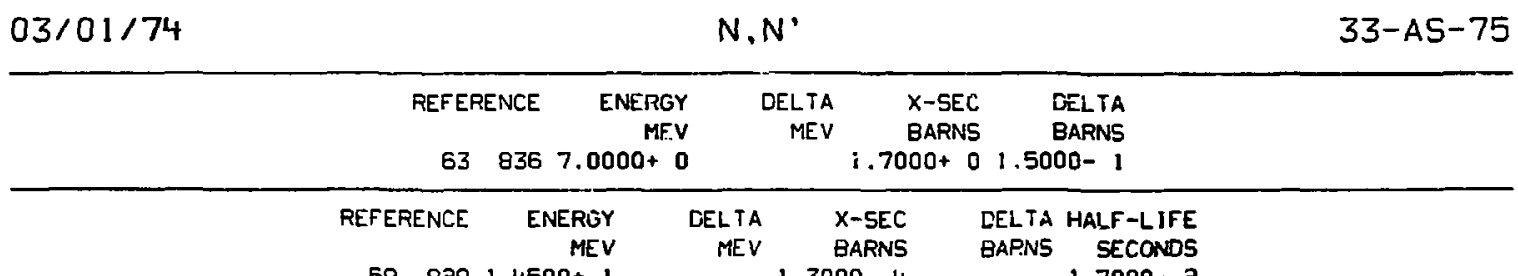

$598291.4500+1$

$$
N, 2 N
$$

\begin{tabular}{|c|c|c|c|c|c|c|c|c|}
\hline REFERENCE & $\begin{array}{r}\text { ENERGY } \\
\text { MEV }\end{array}$ & $\begin{array}{r}\text { DELTA } \\
\text { MEV }\end{array}$ & $\begin{array}{l}X-5 E C \\
\text { EARNS }\end{array}$ & $\begin{array}{l}\text { DELTA } \\
\text { BARNS }\end{array}$ & REFERENCE & $\begin{array}{r}\text { ENERGY } \\
\text { MEV }\end{array}$ & $\begin{array}{r}\text { DELTA } \\
\text { MEV }\end{array}$ & $\begin{array}{l}X-S E C \\
\text { BARNS }\end{array}$ \\
\hline
\end{tabular}

$633771.4000+1 \quad 8.4310-12.5290-$

$6618741.4050+11.0000-19.6500-16.7550-?$ $6923341.4200+12.0000-11.1700+01.1700-1$

\section{REFERENCE ENERGY}

53
DELTA MEV

$67200914700+13.0000-11.0920+01.2000-1$ $6618741.4750+11.0000-11.0380+07.2660-$

\section{X-SEC DELTA HALF-LIFE}

BARNS BARNS HOURS

$5.4510-11.6000-11.7000+1$ 

CIROSS SECTION

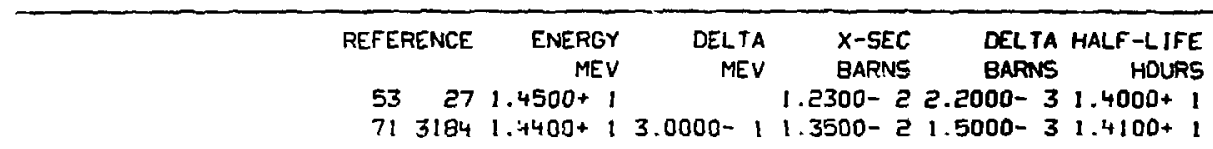

$03 / 01 / 74$

BOUND ATOM

33-AS-75

$\begin{array}{ccrrr}\text { REFERENCE } & \text { ENERGY } & \text { DELTA } & \text { X-SEC } & \text { DELTA } \\ \text { MEV } & \text { MEV } & \begin{array}{r}\text { BARS } \\ \text { BARNS }\end{array} & \text { B.0000+ } 0\end{array}$

$03 / 01 / 74$ COHERENT SCATTERING

$33-A S-75$

\begin{tabular}{|c|c|c|c|c|}
\hline REFERER: :E & $\begin{array}{r}\text { ENERGY } \\
\text { MEV }\end{array}$ & $\begin{array}{c}\text { DELTA } \\
\text { MEV }\end{array}$ & $\begin{array}{l}X-S E C \\
\text { GARNS }\end{array}$ & $\begin{array}{l}\text { DELTA } \\
\text { BARN' }\end{array}$ \\
\hline $\begin{array}{ll}50 & 2564 \\
51 & 1584\end{array}$ & $\begin{array}{l}5300-8 \\
3000-8\end{array}$ & & $\begin{array}{l}000+0 \\
000+0\end{array}$ & $\begin{array}{l}5.0000-1 \\
4.0000-1\end{array}$ \\
\hline
\end{tabular}

$\begin{array}{llll}502564 & 2.5300-8 & 4.6000+0 & 5.0000-1 \\ 51 & 1584 & 7.3000-8 & 5.0000+04.0000-1\end{array}$

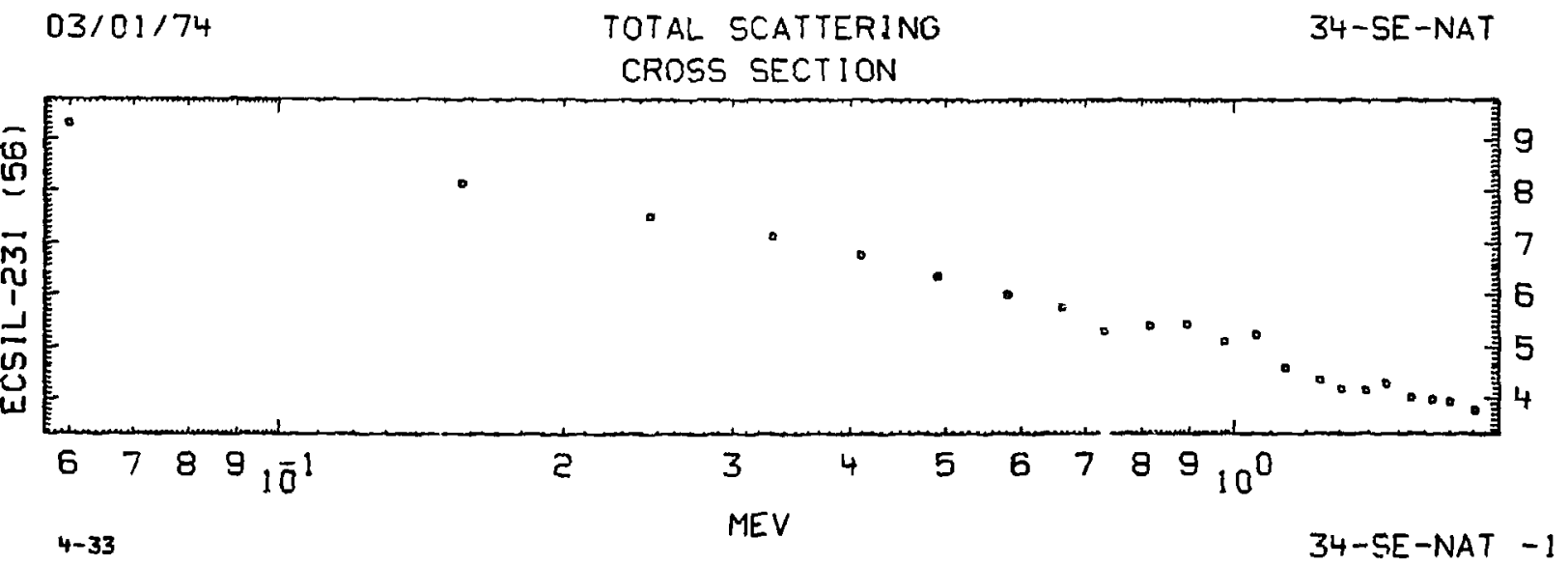




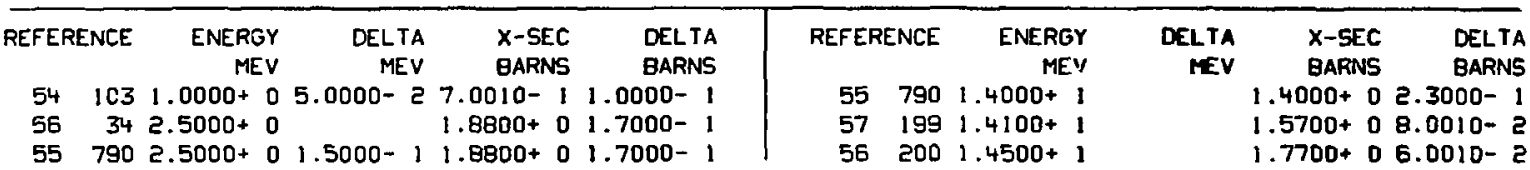

$03 / 01 / 74 \quad N, N^{*} \quad 34-5 E-N A T$

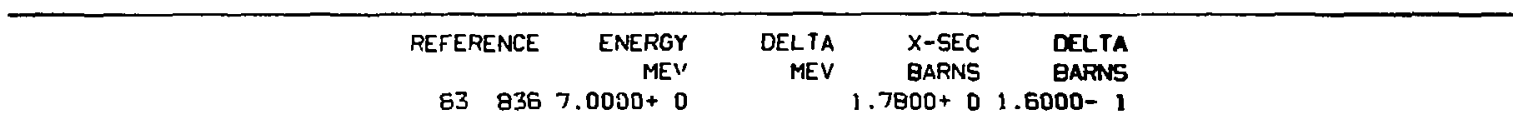

$03 / 01 / 74$

ABSORPT ION

34-SE-NAT

\begin{tabular}{|c|c|c|c|c|c|c|c|c|c|c|}
\hline REFERENCE & $\begin{array}{r}\text { ENERGY } \\
\text { MEV }\end{array}$ & $\begin{array}{l}\text { DELTA } \\
\text { MEV }\end{array}$ & $\begin{array}{l}X \text { X-SEC } \\
\text { BARNS }\end{array}$ & $\begin{array}{l}\text { DELTA } \\
\text { BARNS }\end{array}$ & REFER & ENCE & $\begin{array}{r}\text { ENERGY } \\
\text { MEV }\end{array}$ & $\begin{array}{l}\text { DELTA } \\
\text { MEV }\end{array}$ & $\begin{array}{l}\text { X-SEC } \\
\text { BARNS }\end{array}$ & $\begin{array}{l}\text { DELTA } \\
\text { BARNS }\end{array}$ \\
\hline $\begin{array}{ll}53 & 37 \\
60 & 85\end{array}$ & $\begin{array}{l}.5300-8 \\
.5300-8\end{array}$ & & $\begin{array}{l}1.2400+1 \\
1.1700+1\end{array}$ & $\begin{array}{l}5.0000-1 \\
1.0000-1\end{array}$ & $\begin{array}{l}58 \\
58\end{array}$ & $\begin{array}{l}364 \\
364\end{array}$ & $\begin{array}{l}2.2000-1 \\
8.3000-1\end{array}$ & $\begin{array}{l}2.0000-2 \\
4.0000-2\end{array}$ & $\begin{array}{l}8.3010-2 \\
5.8010-2\end{array}$ & $\begin{array}{l}1.3000-2 \\
1.6000-2\end{array}$ \\
\hline
\end{tabular}

$03 / 01 / 74 \quad$ BOUND ATOM

34-SE-NAT

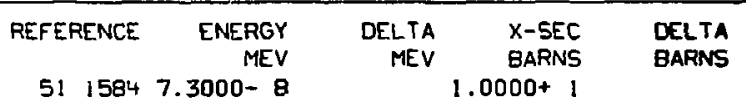

$5115847.3000-8$

$34-S E-N A T$

$03 / 01 / 74$

COHERENT SCATTERING

DELTA

$\begin{array}{ccccc}\text { REFERENCE ENERGY } & \text { DELTA } & \text { X-SEC } & \text { DELTA } \\ & \text { MEV } & \text { MEV } & \text { BARNS } & \text { BARNS }\end{array}$

$5115847.3000-8 \quad 1.0000+18.0000-1$ 


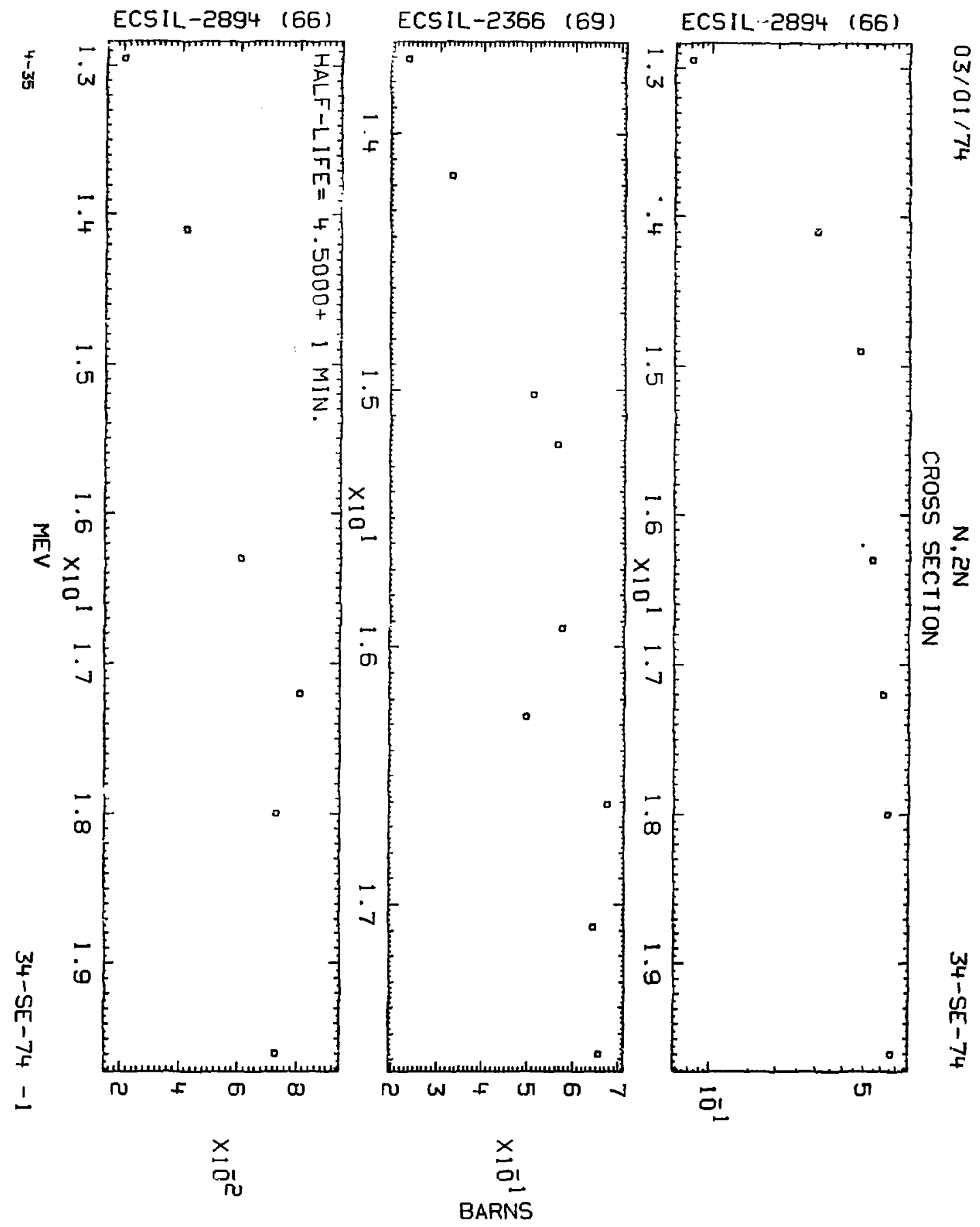



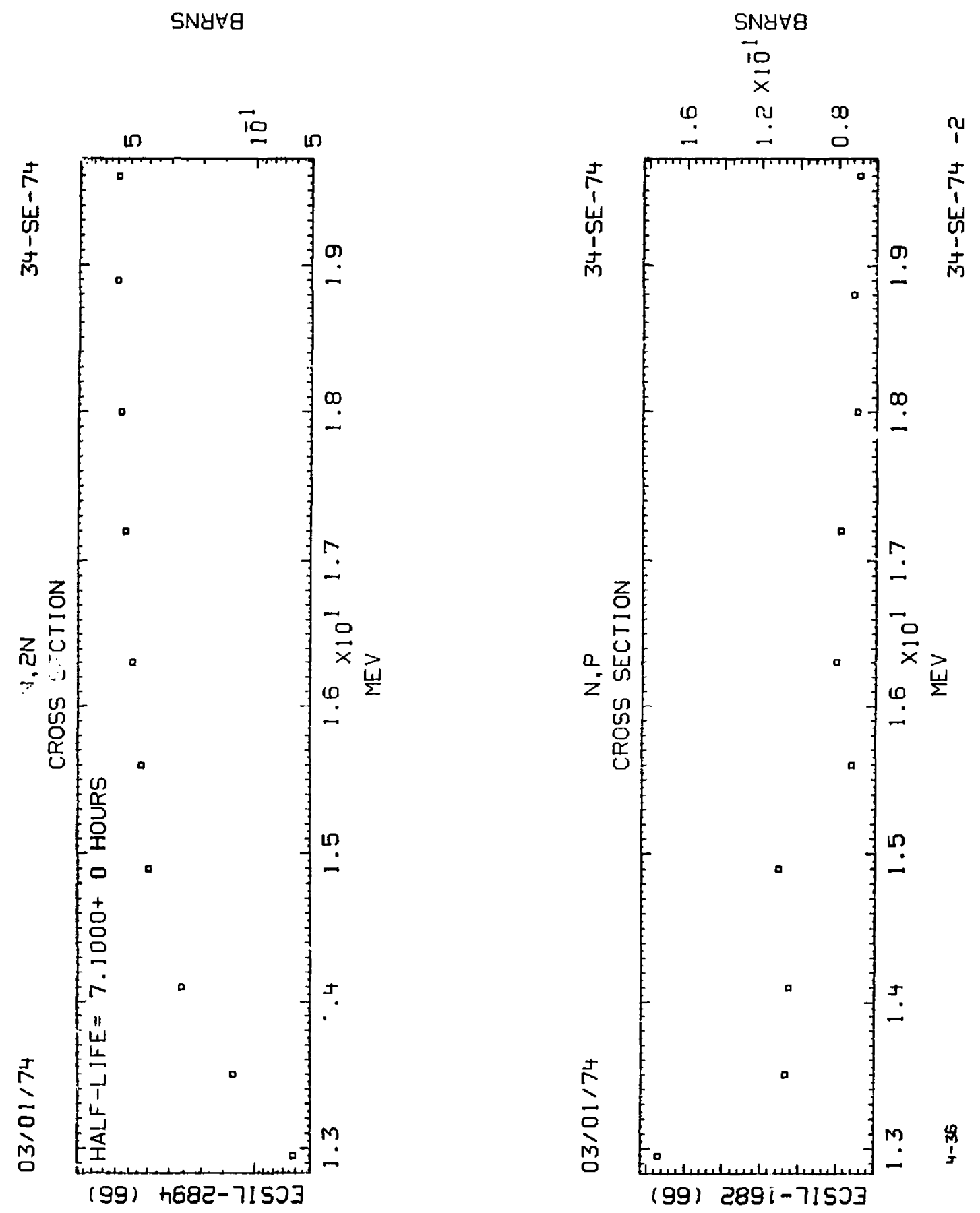
CROSS SECTION

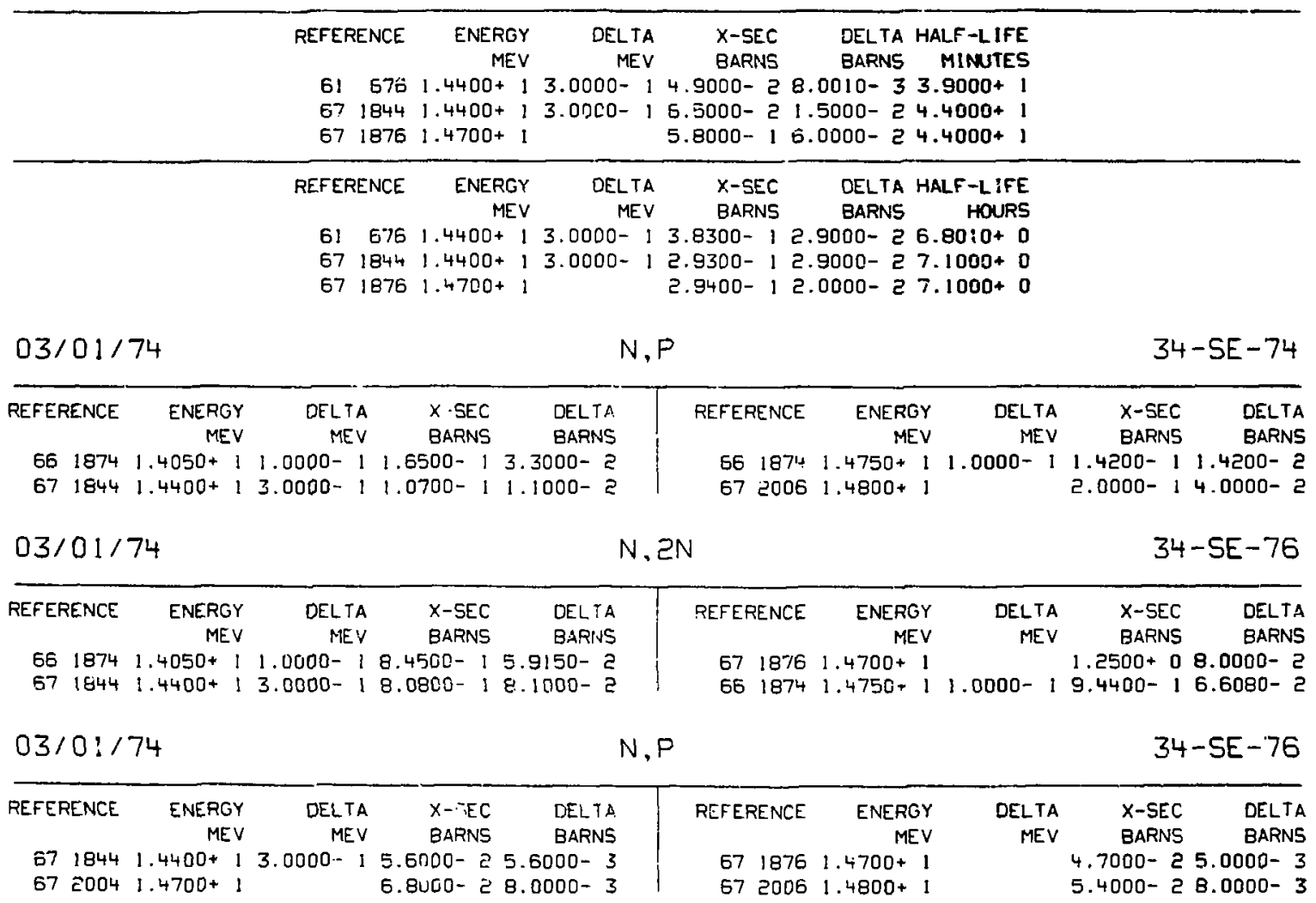




\section{CROSS SECTION}

$\begin{array}{rrrrr}\text { REFERENCE ENERGY } & \text { DELTA } & \text { X-SEC } & \text { DELTA } \\ & \text { MEV } & \text { MEV } & \text { BARNS } & \text { BARNS }\end{array}$

$6726022.8000+07.0000-21.0000+01.3000-1$

$03 / 01 / 74$

$N, P$

$34-S E-77$

REFERENCE ENERGY

$5327 \div .4500+$

6720061,4800 .

$\begin{array}{rrr}\text { DELTA } & \text { X-SEC } & \text { DELTA } \\ \text { MEV } & \text { BARNS } & \text { BARNS } \\ 4.5200-2 & 2.3000-2 \\ 3.6000-2 & 1.0000-2\end{array}$

$03 / 01 / 74$

ACTIVATION

$34-5 E-77$

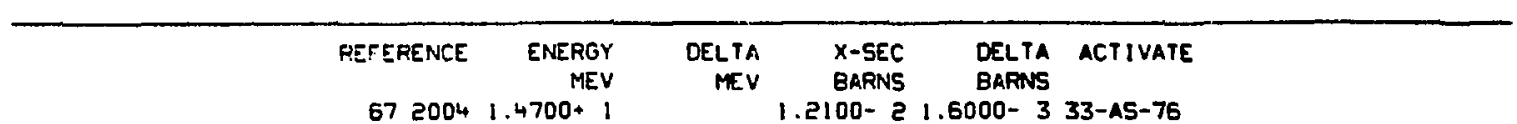

$672004 \quad 1.47004$

$1.2100-21.6000-3$ 33-AS-76

$03 / 01 / 74$

N. ZN

$34-S E-78$

REFERENCE ENERGY

DELTA

$x-5=2$

MEV BARNS

DELTA

$671876 \quad 1.4700+1$

$N, P$

$34-S E-78$

$03 / 01 / 74$

ENERGY

DELTA

MEV MEV BARNS

X-SEC DELTA

$6718441.4400 * 13.0000-12.4000-22.4000-3$

$\begin{array}{rrrrr}\text { REFERENCE } & \text { EINEPGY } & \text { DELTA } & \text { X-SEE } & \text { DELTA HALF-LIFE } \\ & \text { MEV } & \text { MEV } & \text { BARNS } & \text { BAFNS MINUTES } \\ 671876 & 1.4700 * 1 & 9.3000-49.0000-56.0000 * 0 \\ 671876 & 1.4700 * 1 & & 9.1000-22.0000-39.1000+1 \\ 672006 & 1.4800 * 1 & & 1.4000-22.0000-39.5000+1\end{array}$




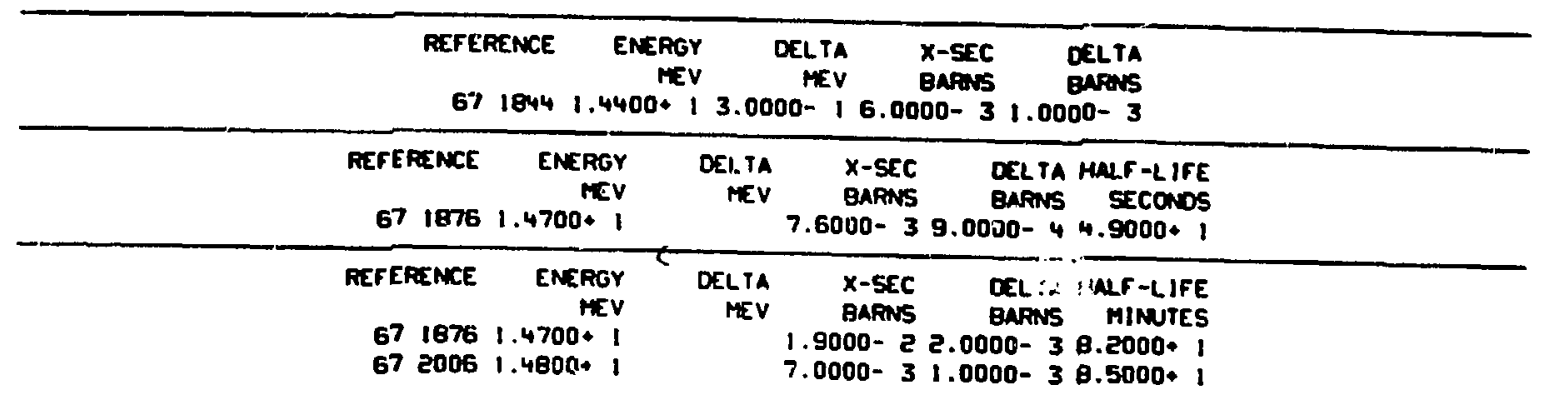

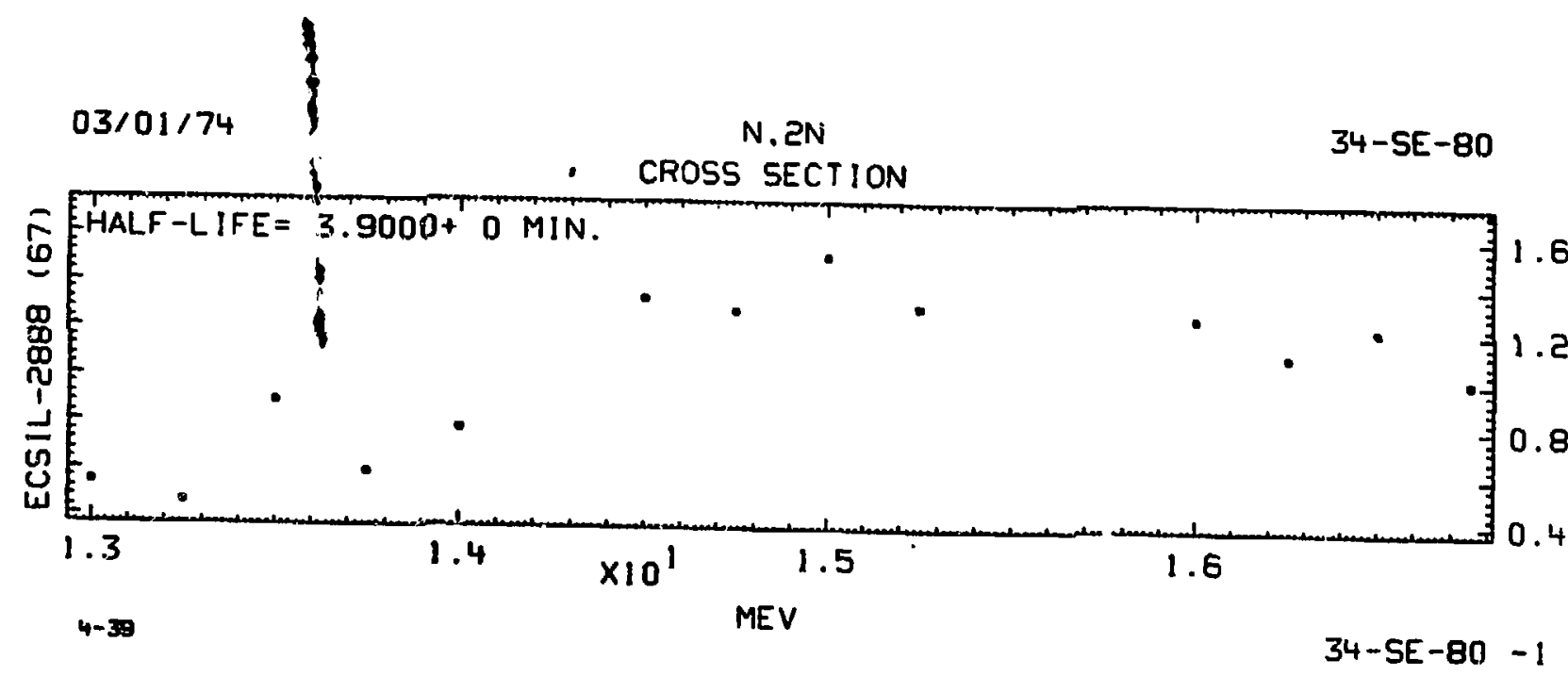


$03 / 01 / 74$

$N, 2 N$

$34-5 E-80$

\section{CROSS SECTION}

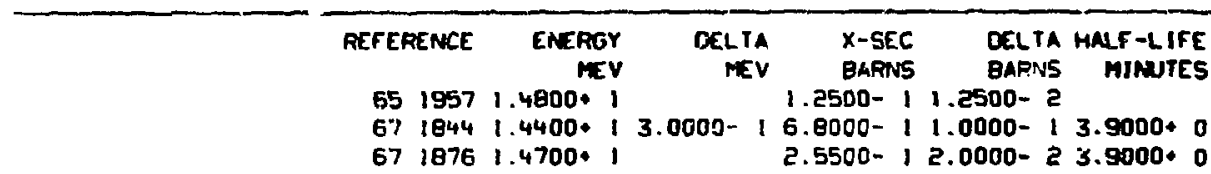

$03 / 01 / 74$

$N, P$

$34-5 E-80$

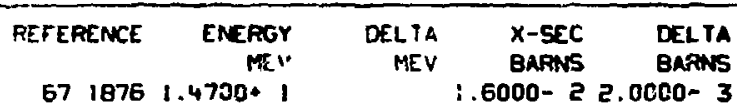

$03 / 01 / 74$

N. ALPHA

$34-5 E-80$

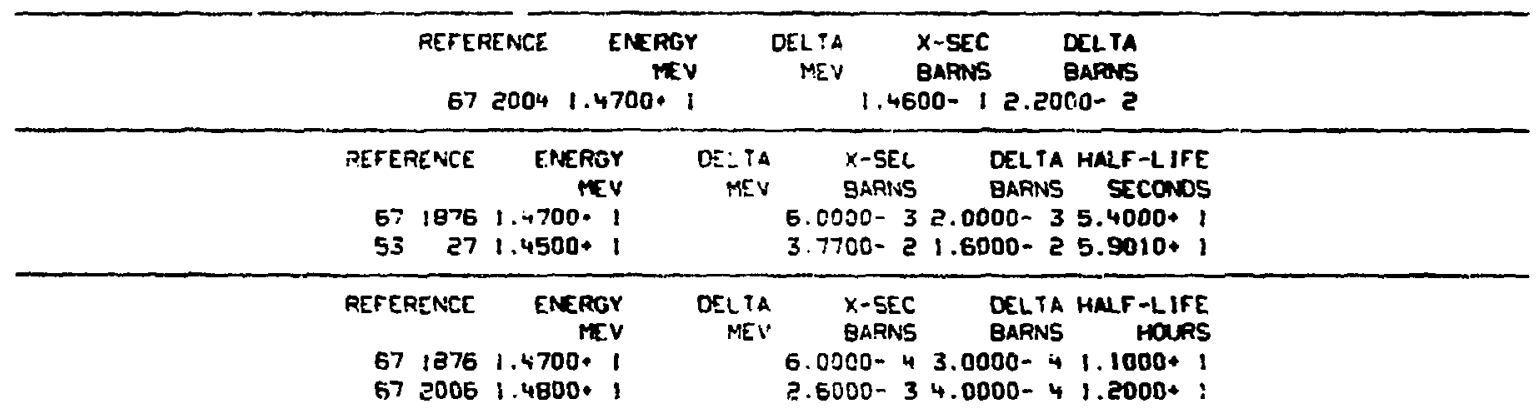

$03 / 01 / 74$

N.2N

$34-5 E-82$

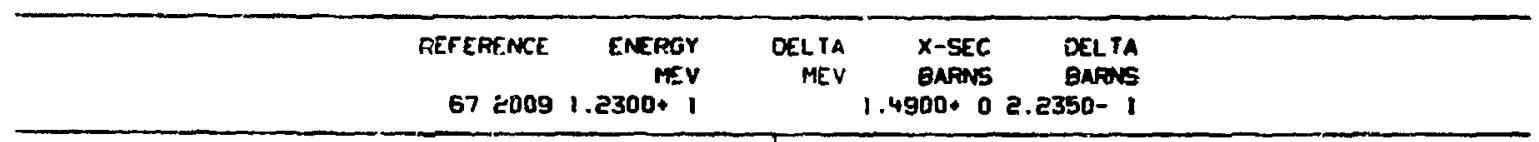

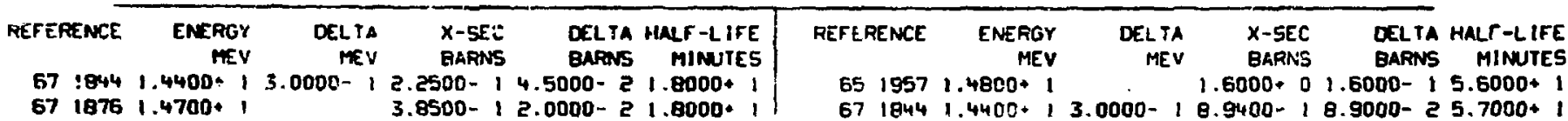




\section{CROSS SECTION}

$\begin{array}{rrrrrr}\text { REFERENCE } & \text { ENERGY } & \text { DELTA } & \text { X-SEC } & \text { DELTA HNLF-LIFE } \\ \text { MEV } & \text { MEV } & \text { BARNS } & \text { BARNS MINUTES } \\ 671876 & 1.4700+1 & & 1.0 \%+70+0 & 3.0000-25.7000+1 \\ 53 & 27 & 1.4500+1 & & 1.5000+0 & 5.0000-15.5010+1\end{array}$

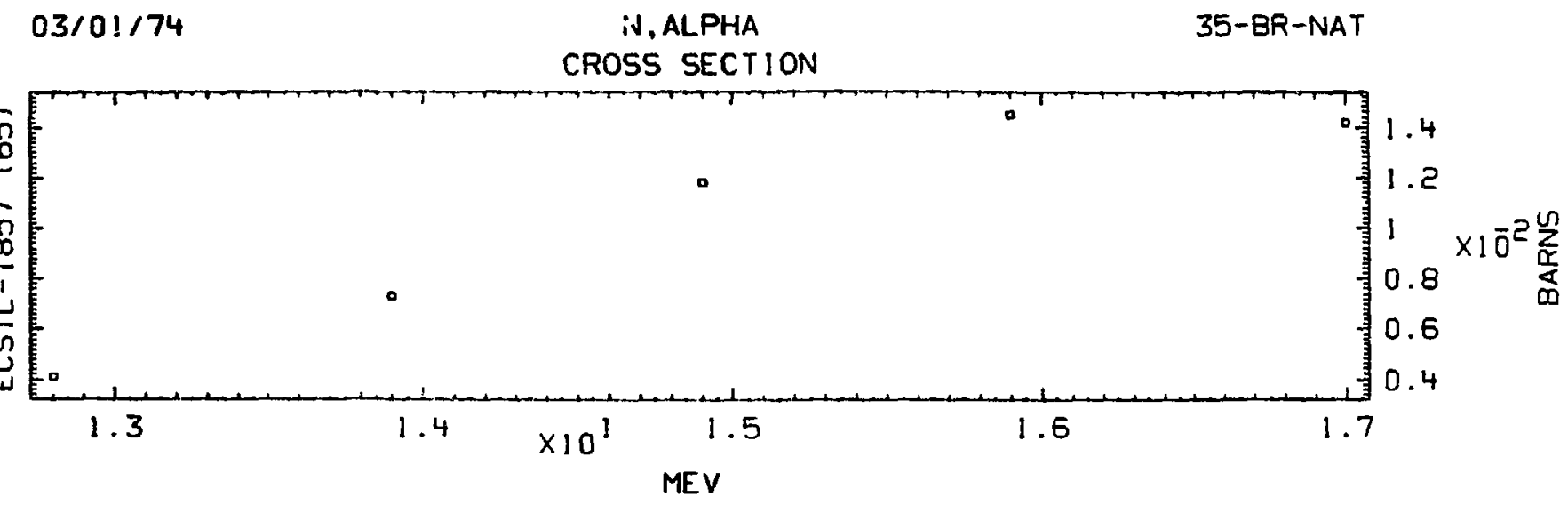

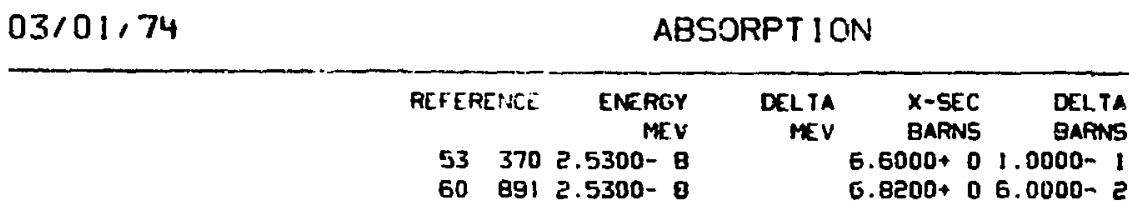




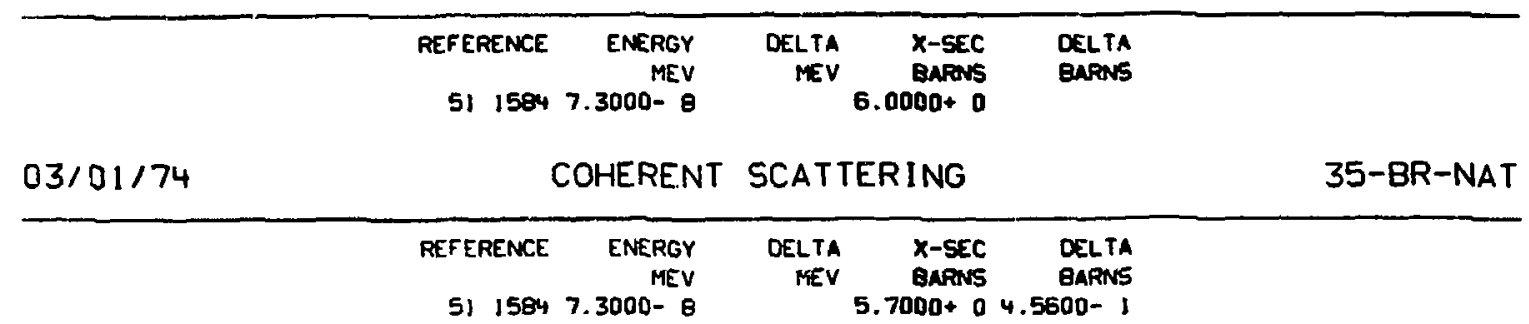

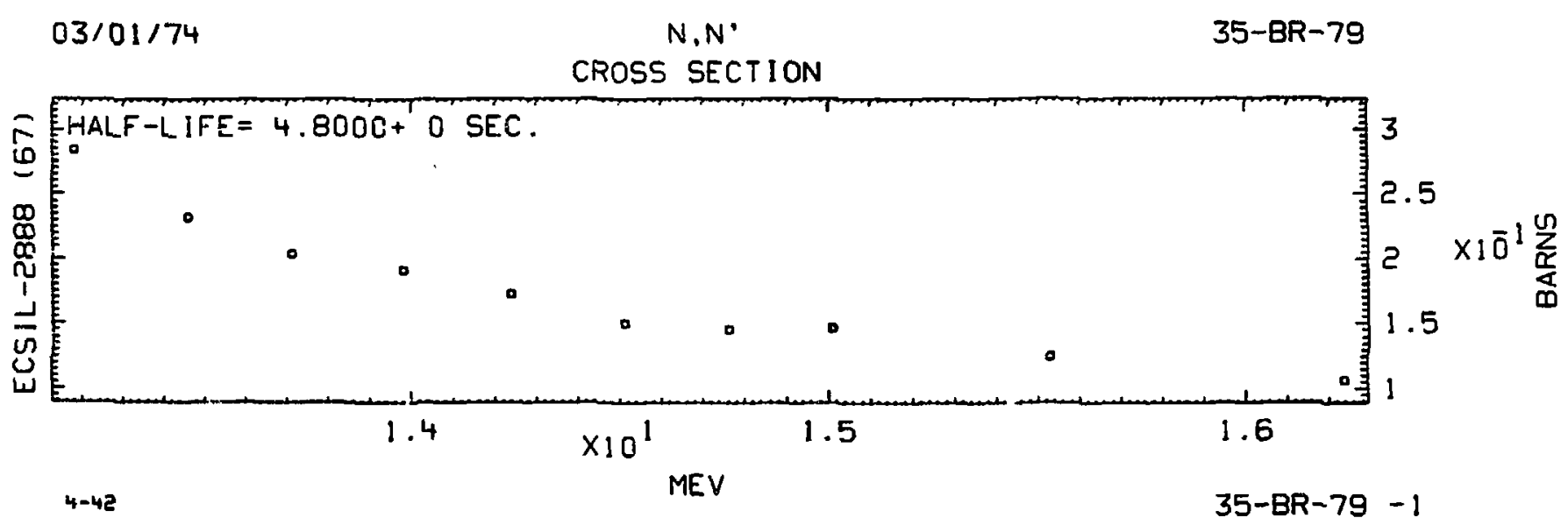




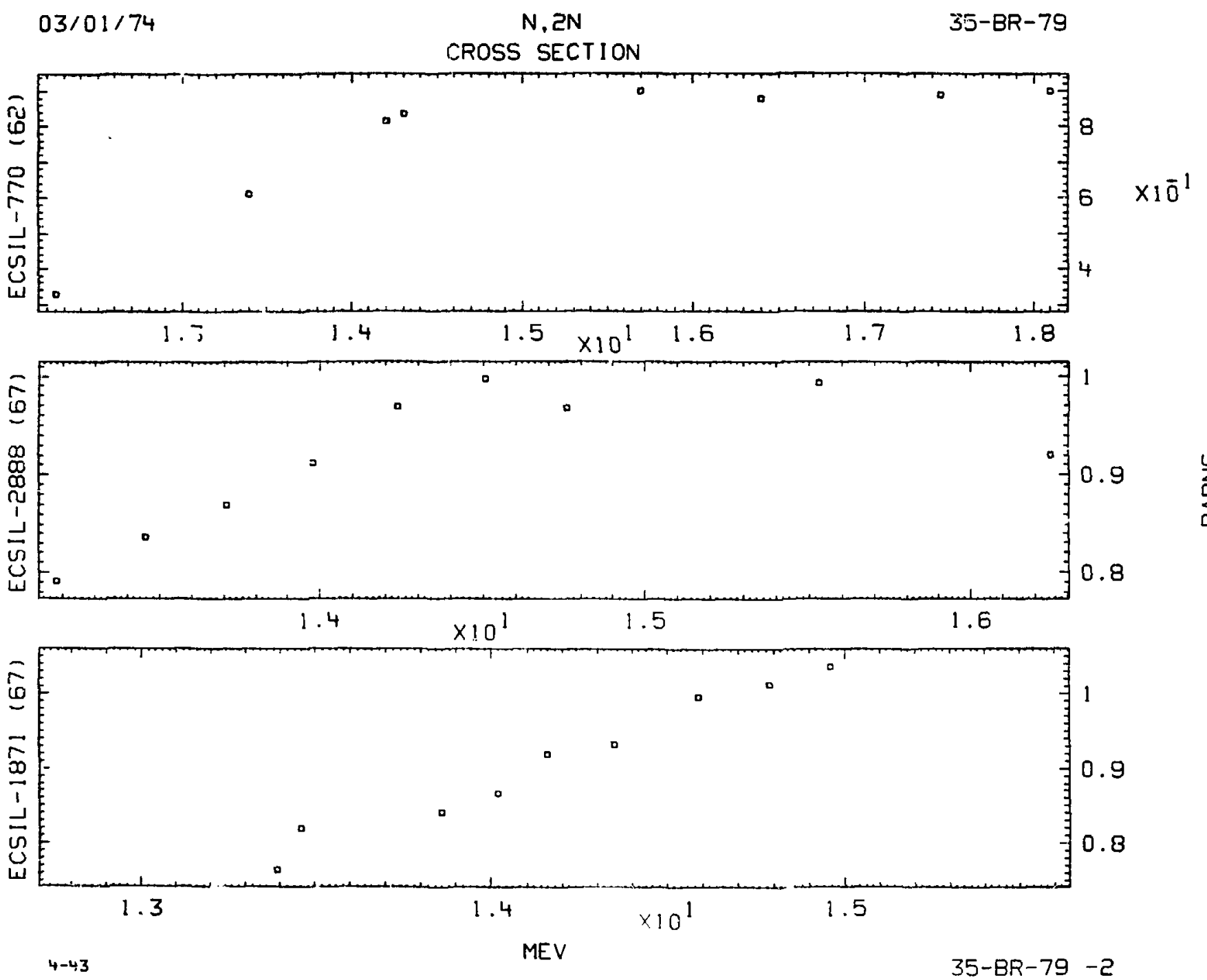




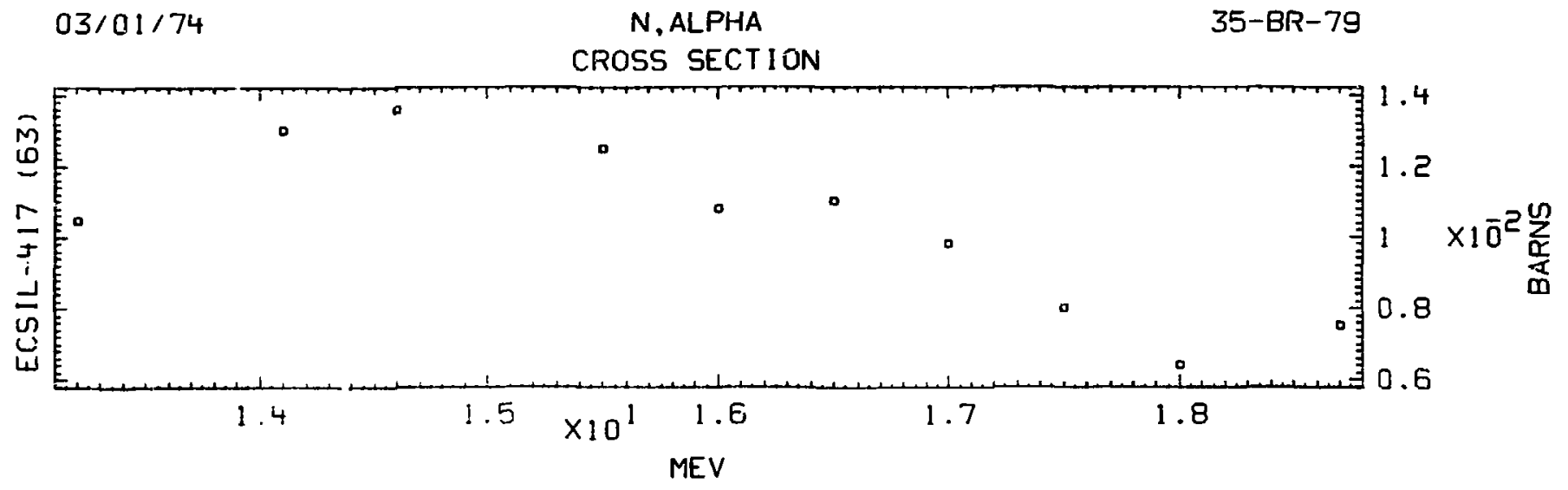

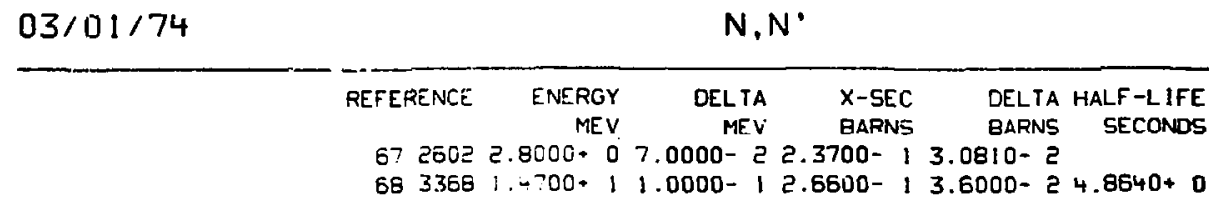

$03 / 01 / 74$

$N, 2 N$

35-BR-79

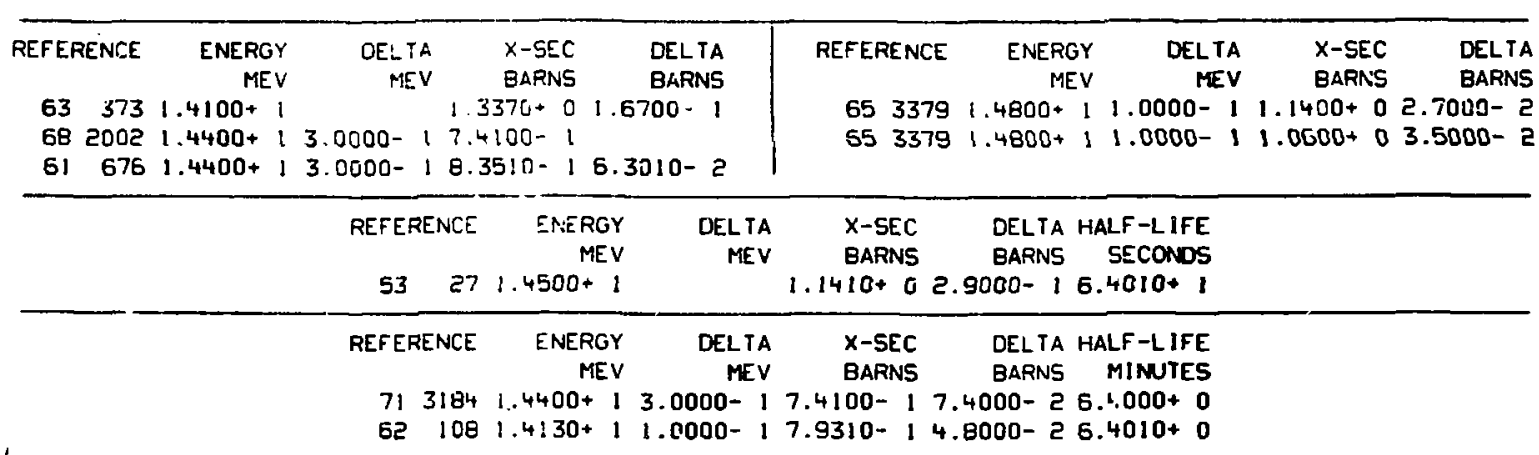


CROSS SECTION

$\begin{array}{lrll}\text { REFERENCE ENERGY } & \text { DELTA } & X \text {-SEC } & \text { DELTA HALF-LIFE } \\ \text { MEV } & \text { MEV } & \text { BARNS } & \text { BARANS MINUTES }\end{array}$

$563380,4000+1$ MEV BARNS BAPNS MINUTES

$03 / 01 / 74$

N, ALPHA

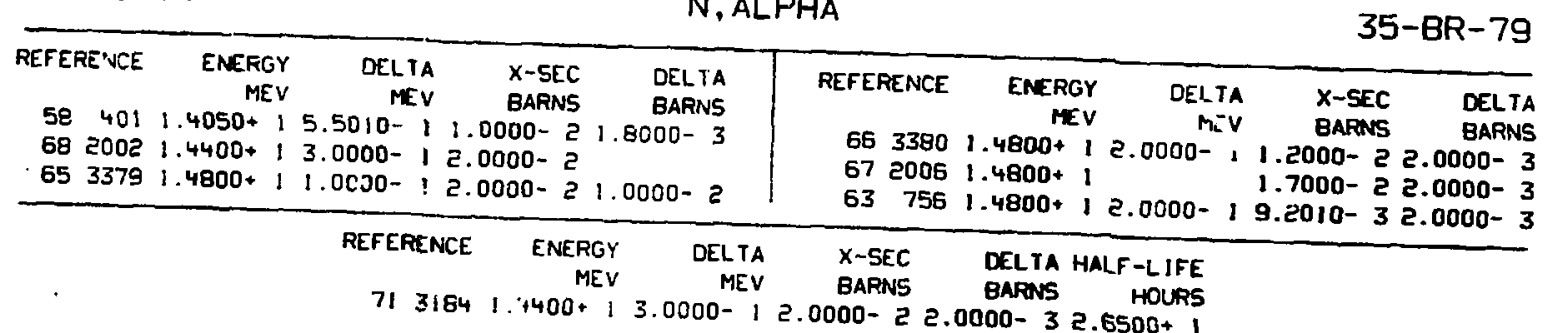

$7131841 .+400+13.0000-12.0000-22.0000-32.6500+1$

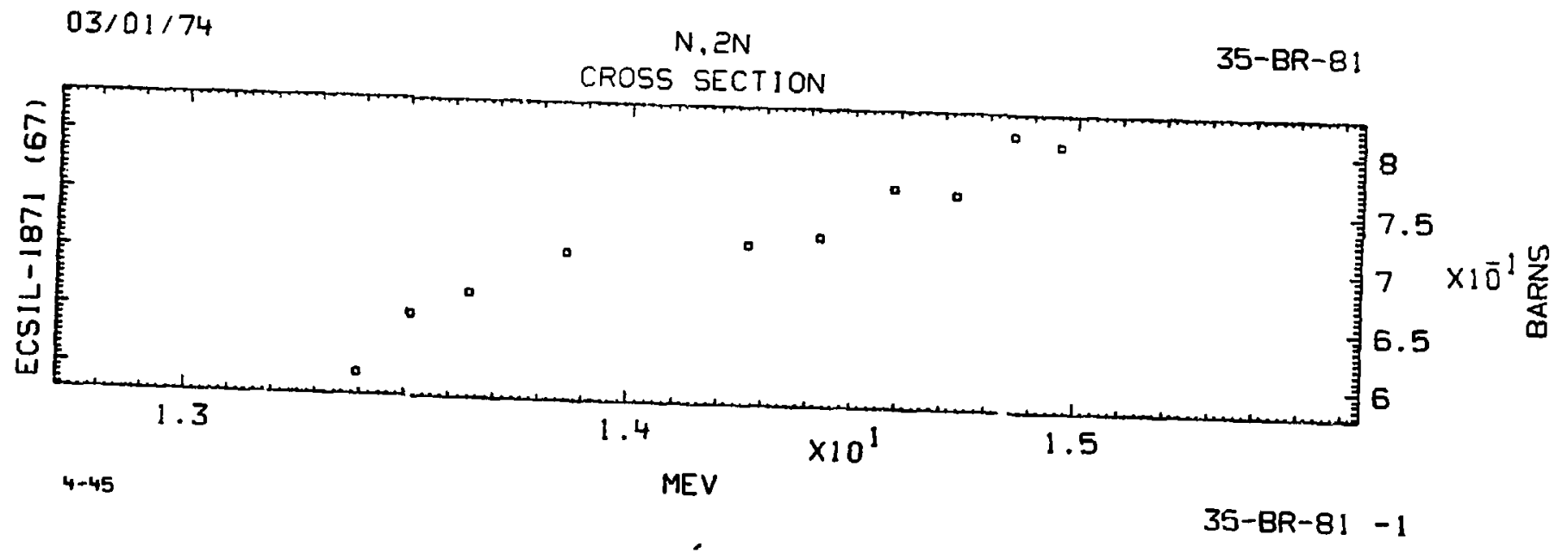




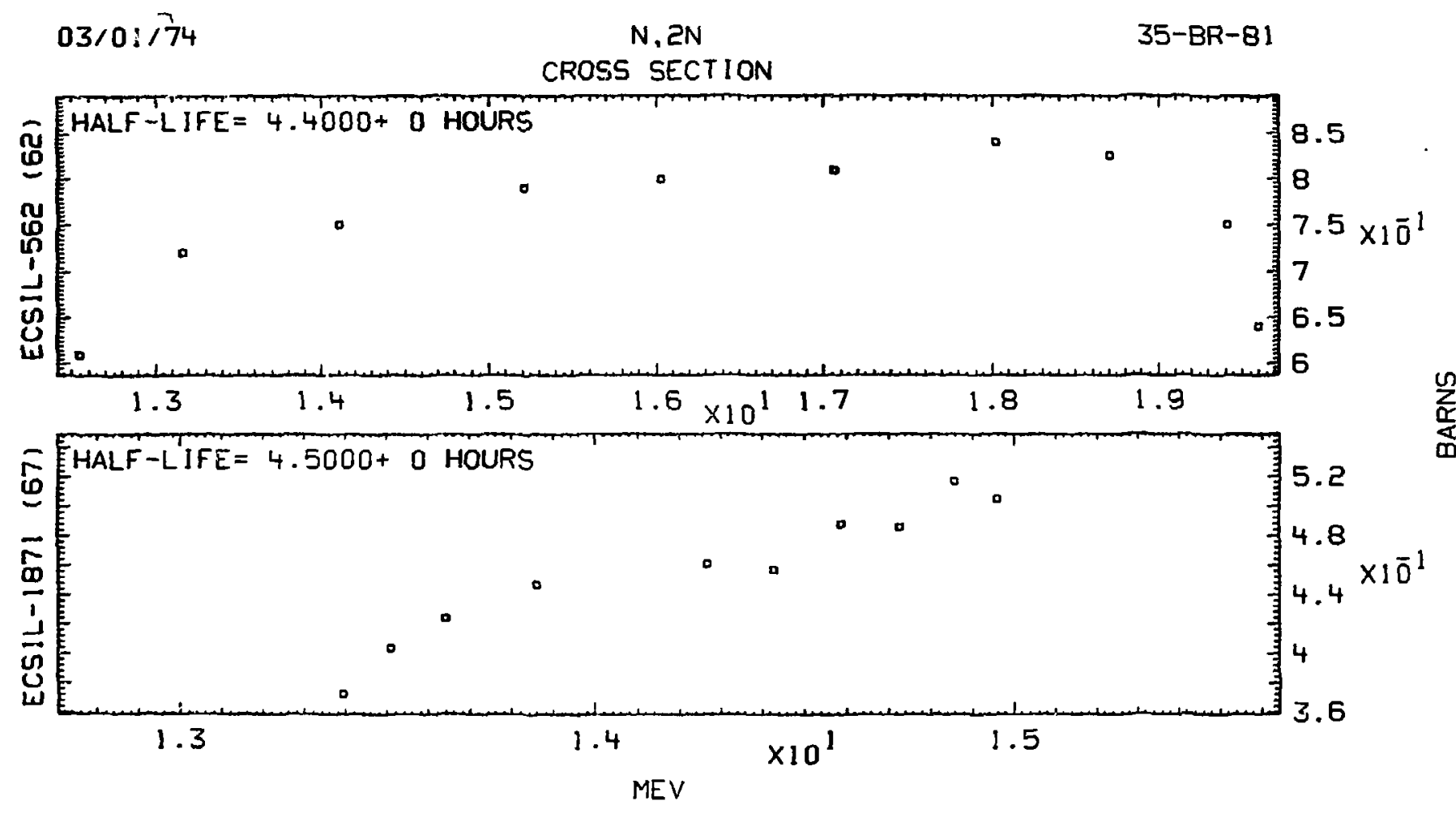

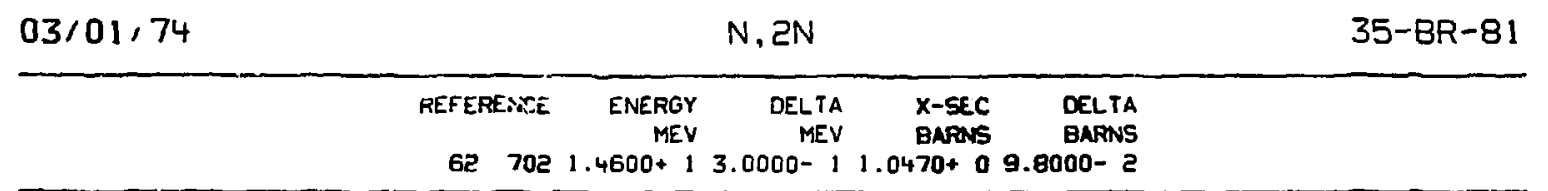

\begin{tabular}{|c|c|c|}
\hline NCE & ENERGY & DELTA \\
\hline
\end{tabular}

$6533791.4800+11.0000-14.6400-13.6000-23.5080+4$ 
CROSS SECTION

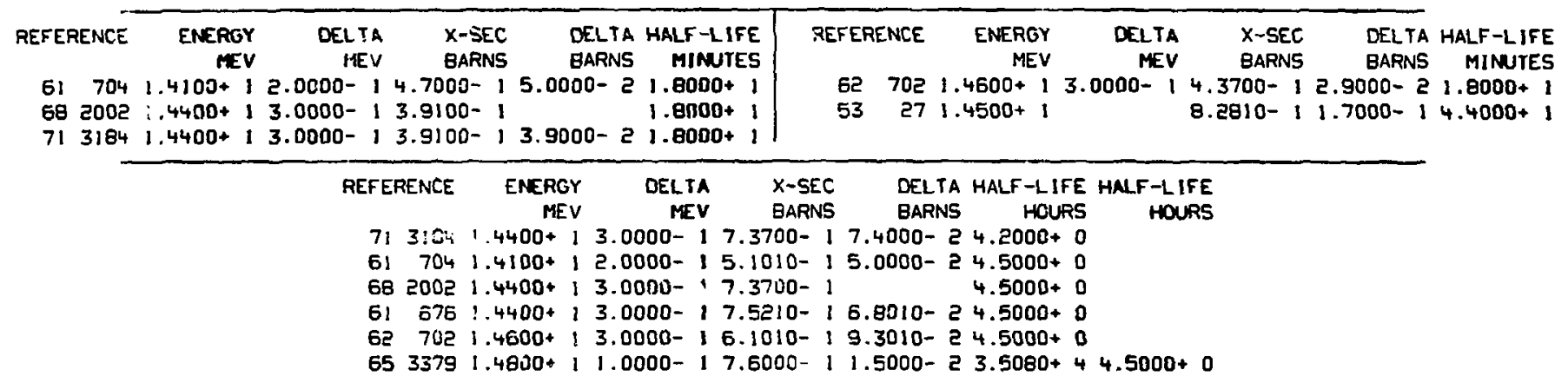

$03 / 01 / 74$

N.P

35-BR-81

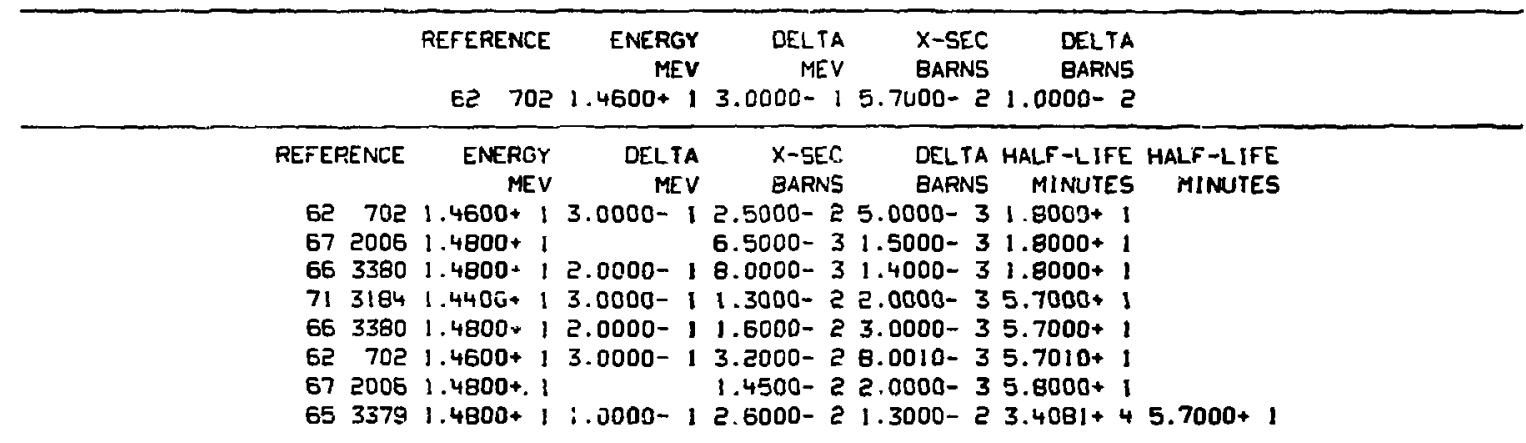

$03 / 01 / 74$

N, ALPHA

$35-B R-81$

\begin{tabular}{|c|c|c|c|c|c|c|c|c|c|}
\hline $\begin{array}{rr}\text { REFERE } i \text { CE } \\
\text { 6B } & 2002 \\
62 & 702 \\
33 & 756\end{array}$ & $\begin{array}{r}\text { ENERGY } \\
\text { MEV } \\
1.4400+1 \\
1.4600+1 \\
1.4800+1\end{array}$ & $\begin{array}{r}\text { DELTA } \\
\text { MEV } \\
3.0000-1 \\
3.0000-1 \\
2.0000-1\end{array}$ & $\begin{array}{r}\text { X-SEC } \\
\text { BARNS } \\
1.9000-2 \\
1.0700-1 \\
6.6010-3\end{array}$ & $\begin{array}{r}\text { DELTA } \\
\text { BARNS } \\
2.0000-2 \\
1.4000-3\end{array}$ & 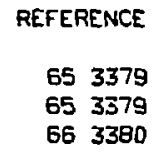 & $\begin{array}{r}\text { ENERGY } \\
\text { MEV } \\
1.4800+1 \\
1.4800+1 \\
1.4800+1\end{array}$ & $\begin{array}{r}\text { CELTA } \\
\text { MEV } \\
1.0000-1 \\
.0000-1 \\
2.0000-1\end{array}$ & $\begin{array}{r}\text { X-SEC } \\
\text { BARNS } \\
7.0000-3 \\
1.4000-2 \\
3.8000-3\end{array}$ & $\begin{array}{r}\text { DELTA } \\
\text { 8ARNS } \\
3.0000-3 \\
1.0000-2 \\
1.0000-3\end{array}$ \\
\hline
\end{tabular}


CROSS SECTION

$\begin{array}{ccccc}\text { REFERENCE } & \text { ENERGY } & \text { DELTA } & X \text {-SEC } & \text { DELTA HALF-LIFE } \\ & \text { MEV } & \text { MEV } & \text { BARNS } & \text { BARNS MINUTES }\end{array}$

$7131841.4400+13.0000-11.9000-22.0000-39.0000+$

$53 \quad 271.4500+1 \quad 1.0300-12.1000-29.0010+1$

$6720051.4800+i \quad 6.5000-31.2000-39.5000+1$

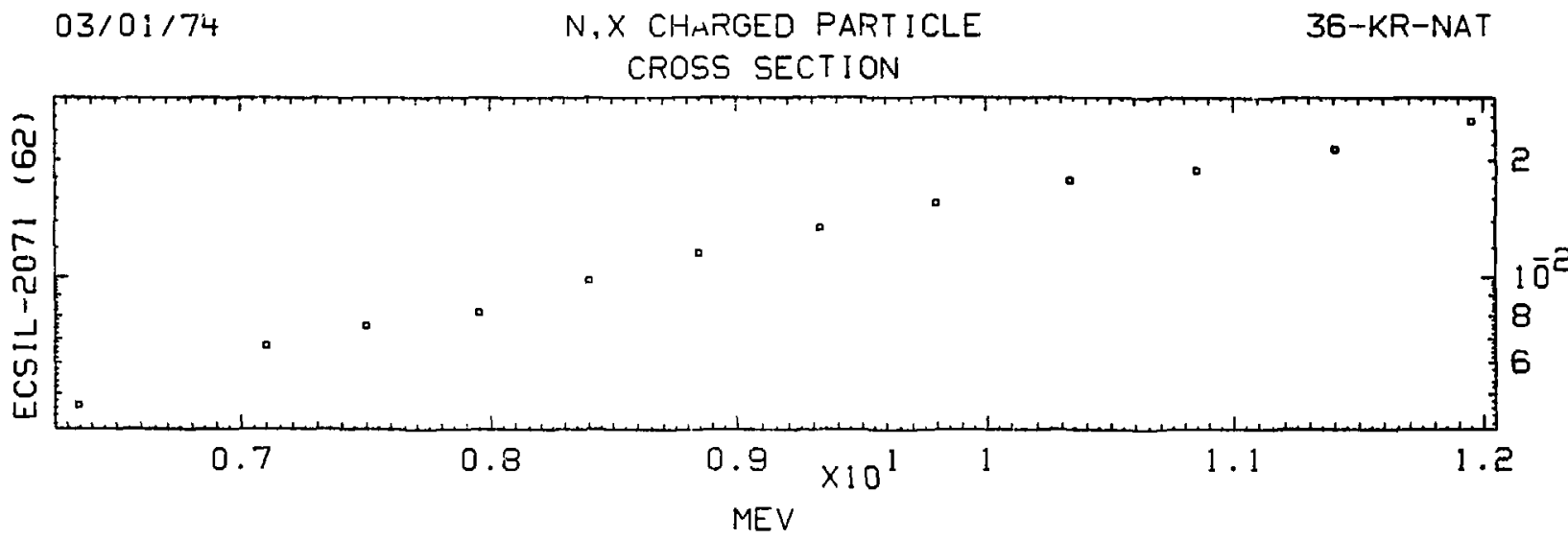




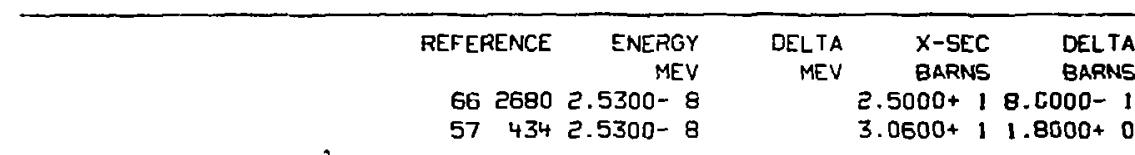

$03 / 01 / 74$

FREE ATOM

36-KR-NAT

$\begin{array}{rrrrr}\text { REFERENCE } & \text { ENERGY } & \text { DELTA } & \text { X-SEC } & \text { DELTA } \\ & \text { MEV } & \text { MEV } & \text { BARNS } & \text { BARNS } \\ 662680 & 2.5300-F & & 7.5000+0 & 1.3000-1\end{array}$

$03 / 01 / 74$

$N, 2 N$

$36-K R-78$

REFEREN:CE ENERGY DELTA X-SEC DELTA

MEV MEV BARNS GARNS

682842 ! $.4400+13.0000-12.4500-12.0000-$ ?

$03 / 01 / 74$

$N, 2 N$

$36-K R-80$

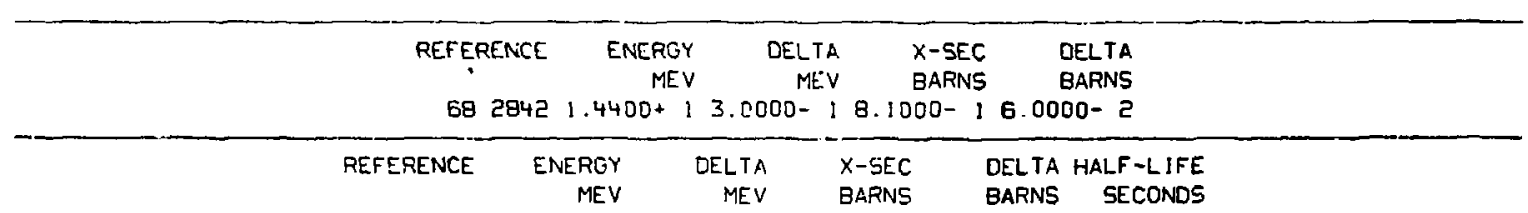

6829421.4400

$03 / 01 / 74$

$N, P$

$36-K R-80$

$\begin{array}{rrrrr}\text { RE.FERENCE } & \text { ENERGY } & \text { DELTA } & \text { X-5EC } & \text { OELTA HALF-LIFE } \\ & M E V & M E V & \text { BARNS } & \text { BARNS HOURS }\end{array}$

$682842+.4400+13.0000-15.5000-29.0000-34.5000+0$ 
CROSS SECTION

\begin{tabular}{|c|c|c|c|c|c|c|}
\hline & $\begin{array}{r}\text { REFERENCE } \\
682842\end{array}$ & $\begin{array}{r}\text { ENERGY } \\
\text { MEV } \\
4400+1\end{array}$ & $\begin{array}{r}\text { DELTA } \\
\text { MEV } \\
000-1\end{array}$ & $\begin{array}{l}\text { X-SEC } \\
\text { BARNS } \\
000-1\end{array}$ & $\begin{array}{l}\text { DELTA } \\
\text { BARNS } \\
000-2\end{array}$ & \\
\hline $03 / 01 / 74$ & & & $p$ & & & $38-K R-82$ \\
\hline
\end{tabular}

$6828421.4400+13.0000-12.3000-24.0000-3$

$\begin{array}{llllll}03 / 01 / 74 & N, P & & 36-K R-84 \\ \text { REFERENCE } & \text { ENERGY } & \text { DELTA } & \text { X-5EC } & \text { DELTA } \\ \text { BARNS } & \text { MEV } & \text { BARNS } & \text { BARNS }\end{array}$

$5828421.4400+13.0000-18.5000-31.5000-3$

$03 / 01 / 74 \quad N, 2 N \quad 36-19-86$

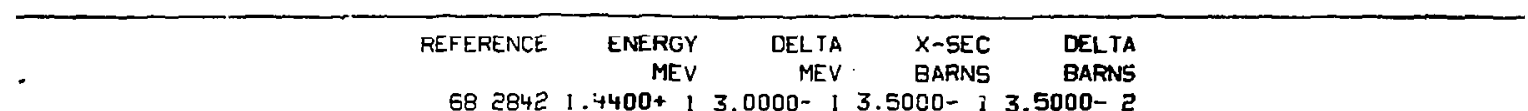

$6828421.4400+13.0000-13.5000-i 3.5000-2$

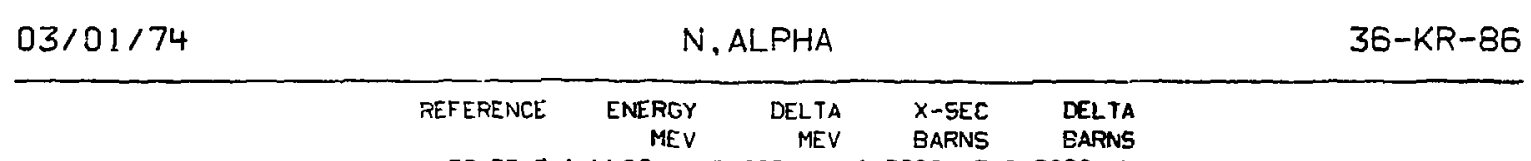

$5828+\vec{c} 1.4400+13.0000-11.2000-32.0000-4$ 
$03 / 01 / 74$

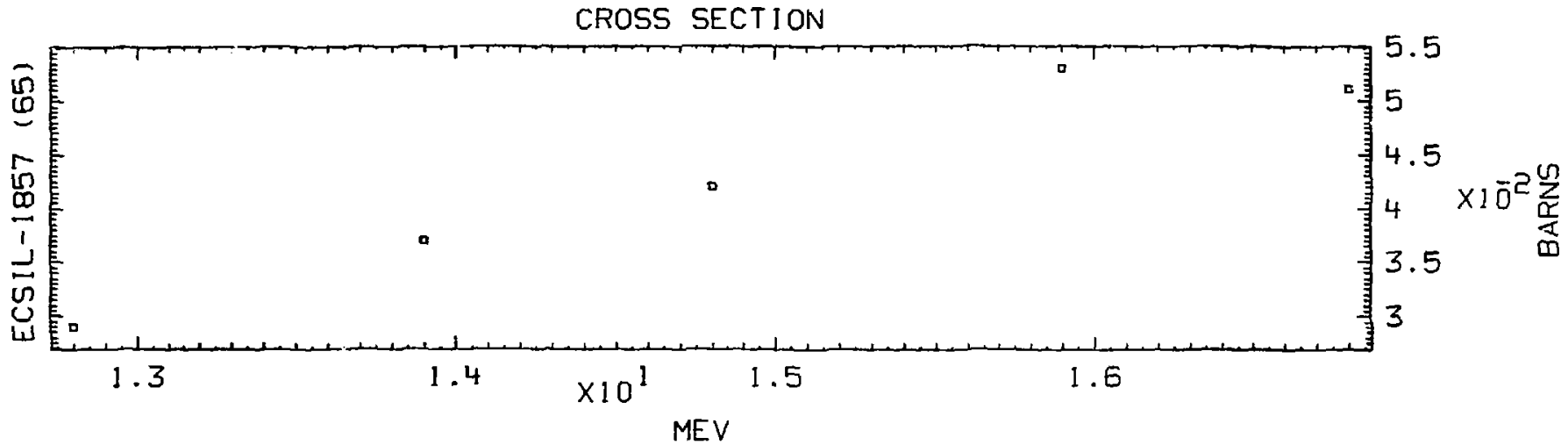

$03 / 01 / 74$

N, ALPHA CROSS SECTION

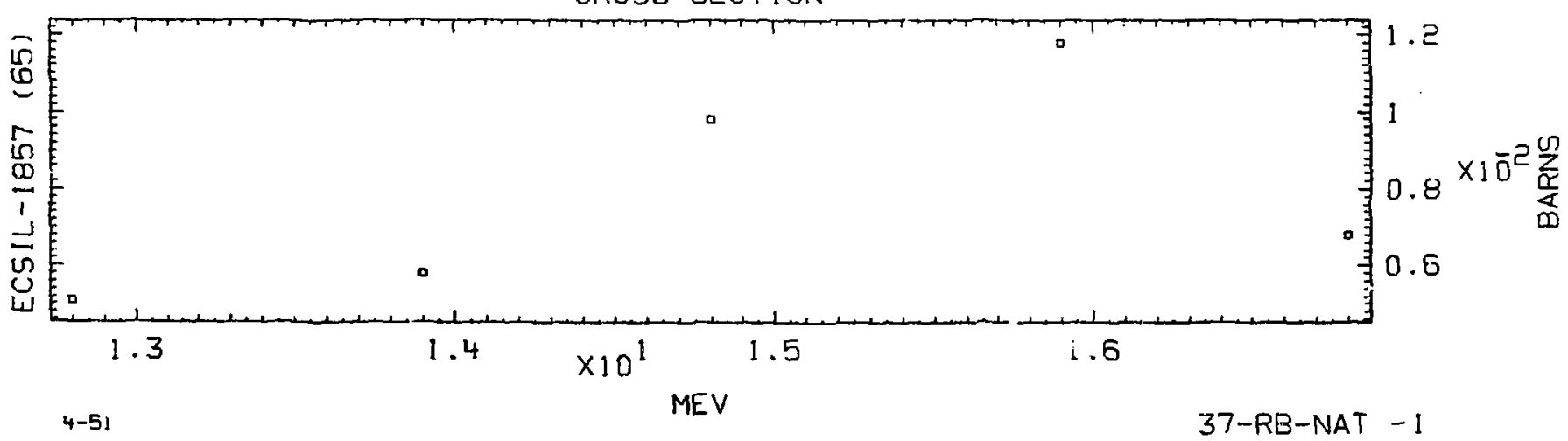




\section{CROSS SECTION}

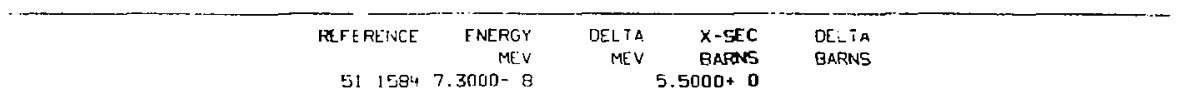

$03 / 01 / 74$ COHERENT SCATTERING

37-RB-NAT

\begin{tabular}{|c|c|c|c|c|}
\hline \multirow[t]{2}{*}{ gatefit: } & TNERGY & DELTA & $x-5 \Gamma c$ & DEL 1A \\
\hline & MEV & MEV & BARNS & BARNS \\
\hline 5,3 PET & $P .5300-9$ & & $9.0800+0$ & 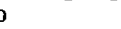 \\
\hline 701006 & c. $5300-8$ & & $5.9000+0$ & $2.0000-$ \\
\hline 51158 & $7.3000-9$ & & $3.8000+0$ & $03.0400-$ \\
\hline
\end{tabular}
$03 / 01 / 74$
N. $2 N$
$37-R B-85$
CROSS SECTIDN

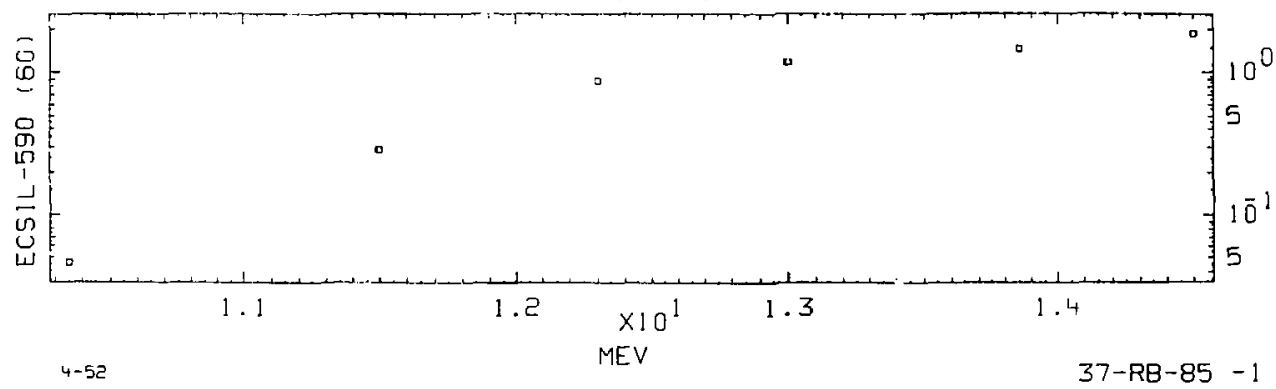




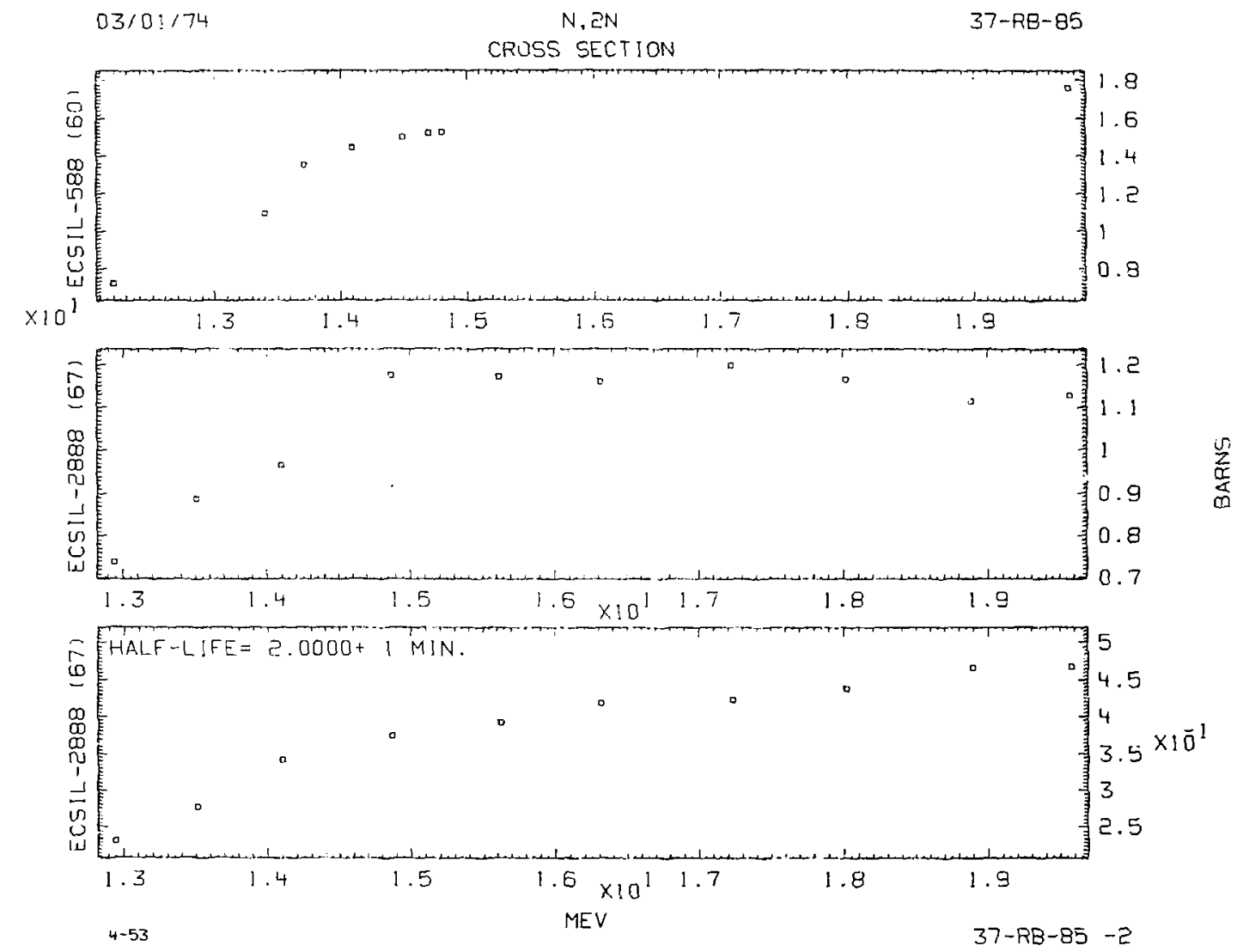



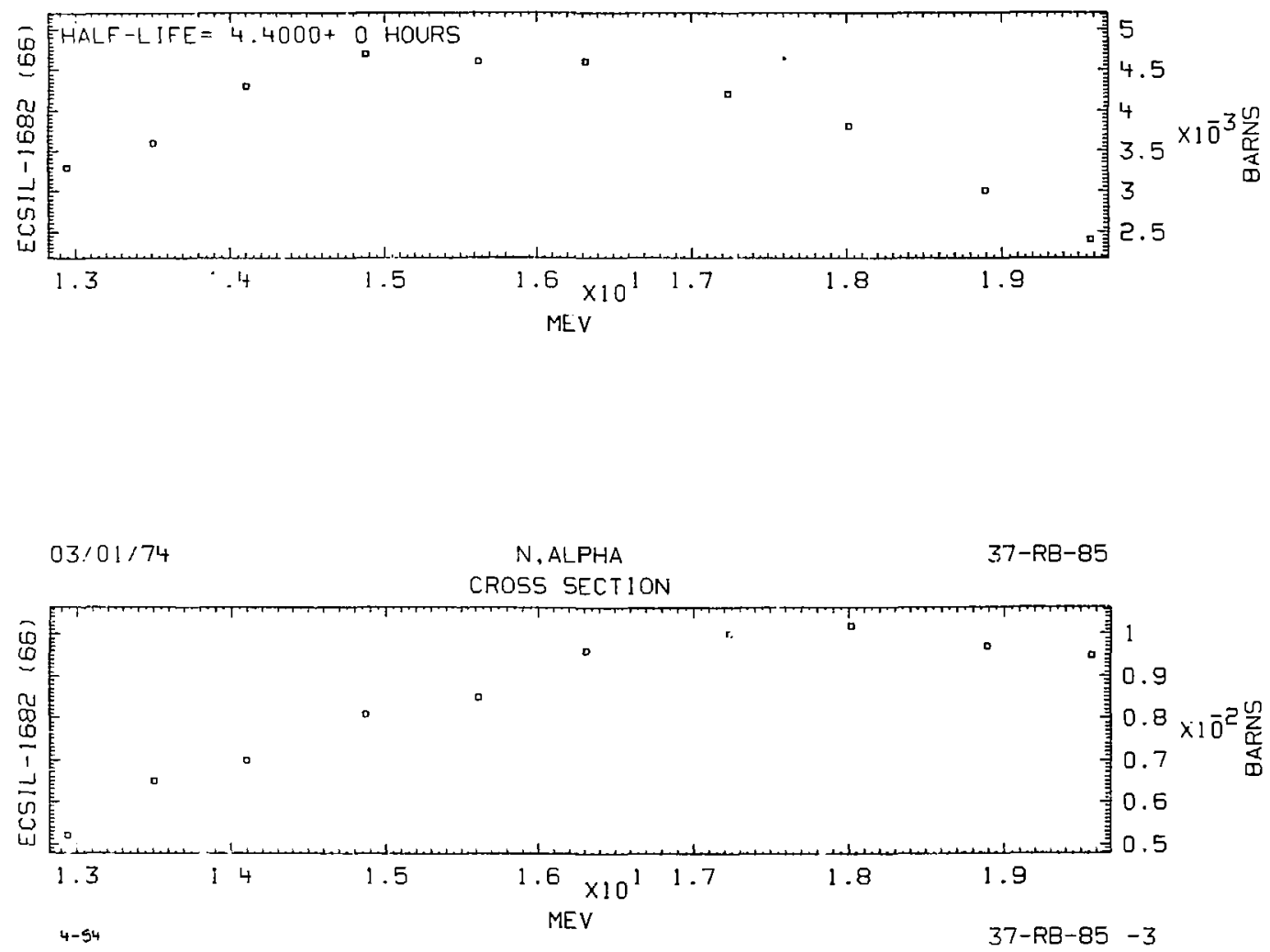
CROSS SECTION

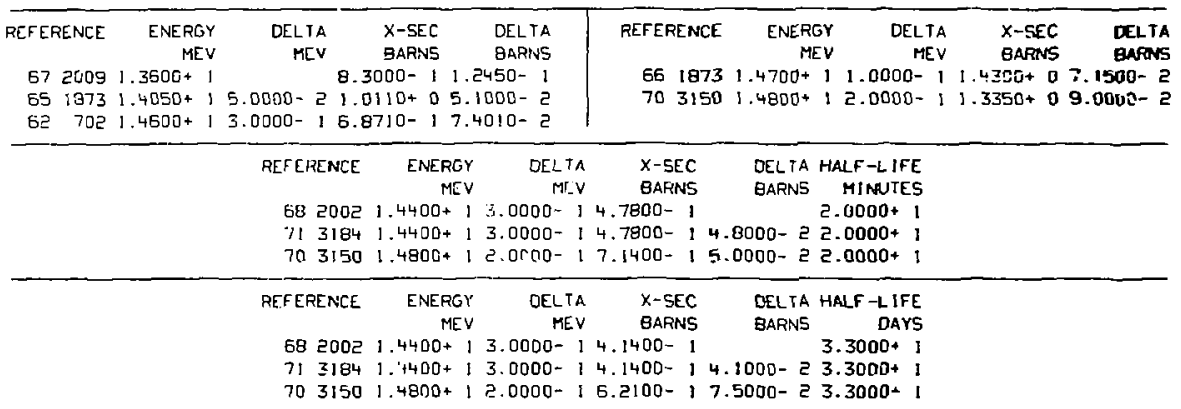

$03 / 01 / 74$

$N, P$

37-RB-85

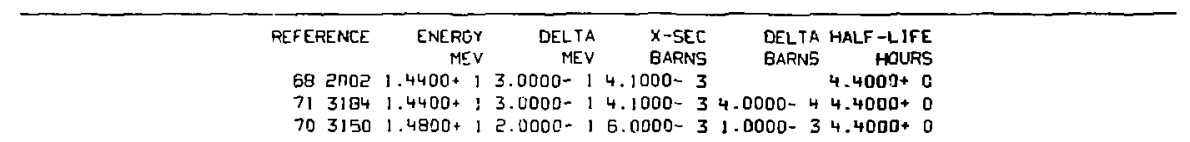

$03 / 01 / 74$

N, ALPHA

37-RB-85

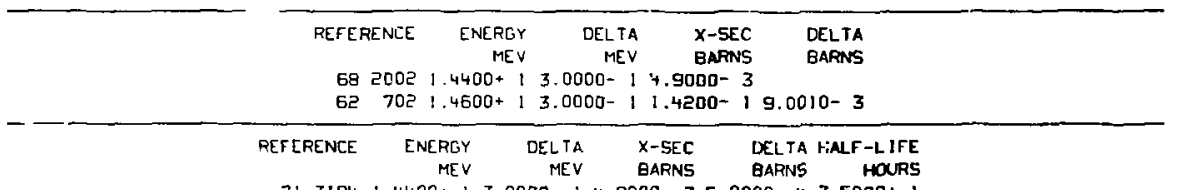

$7131841.4400 * 13.0000-14.9000-35.0000-43.5000 * 1$ 
$\begin{array}{cc}03 / 01 / 74 & \text { COHEPENT SCATTER!NOS } \\ \text { CEOSS SECTION } & \text { 37-RB-85 }\end{array}$

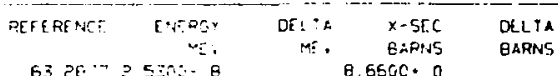

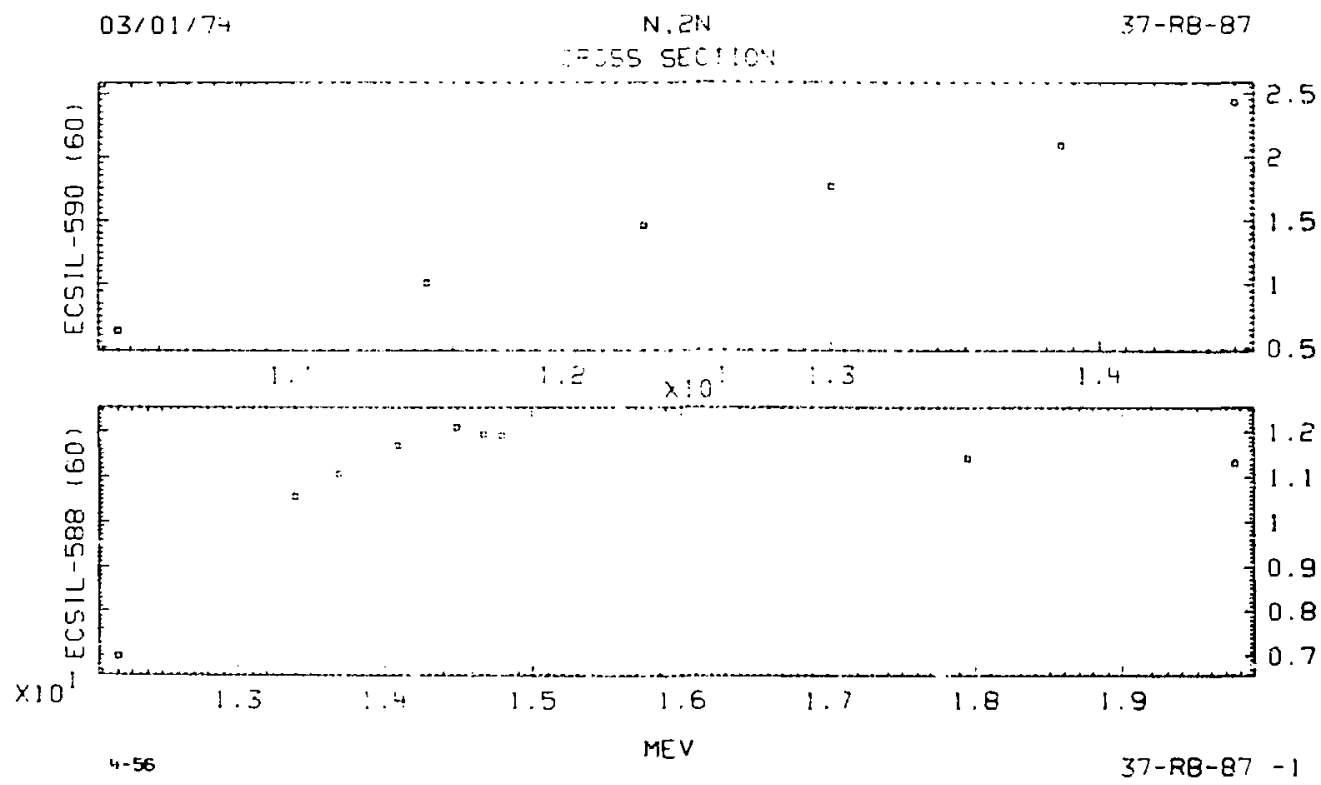


CPOSS SECTION

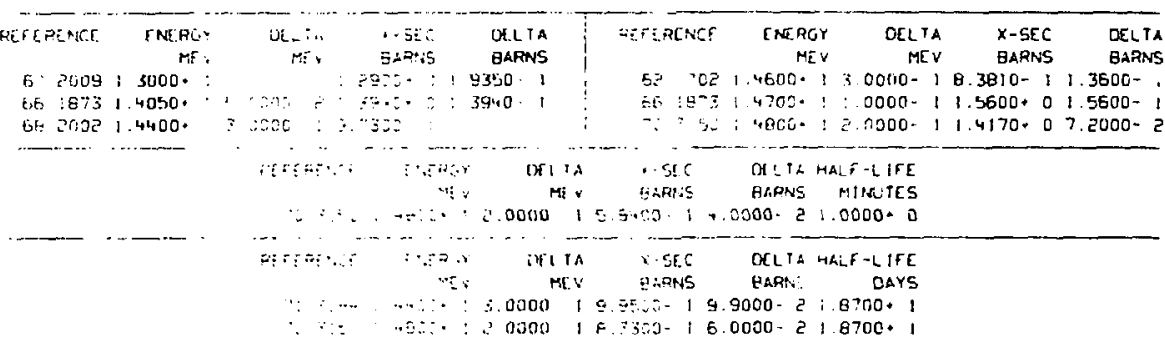

$03 / 01 / 74$

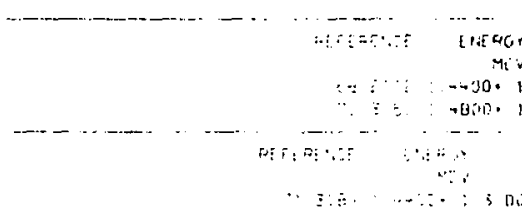

$03: 01 / 74$

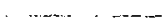

\section{$N, P$}

$\Xi 7-R B-B 7$

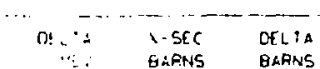

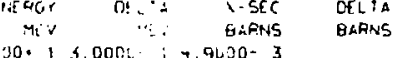

P.00n: $7.0000-31.0000-3$

[?!: :

OCLIA HALF-LIFC

BARNS MINUICS

i $5.90 .35 .0000 \cdot 47.6000$. 


\section{CROSS SECTION}

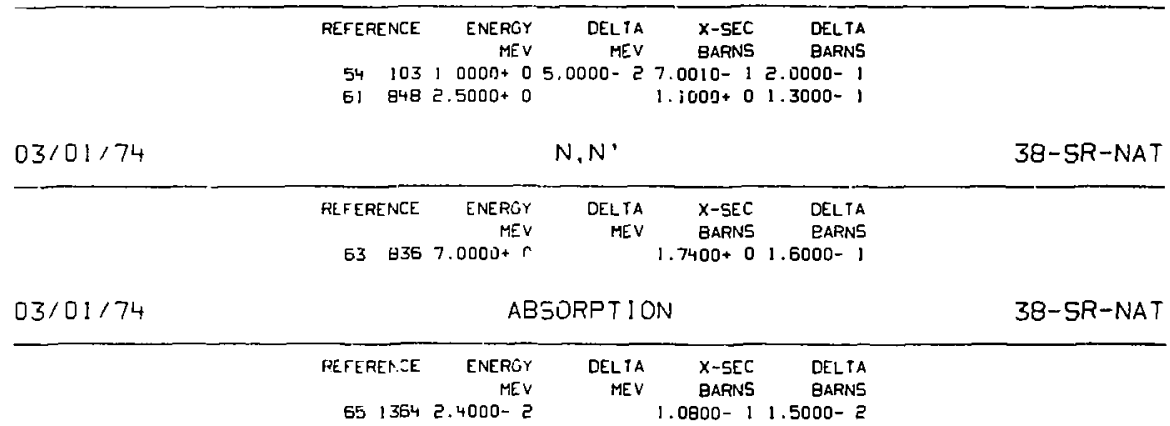

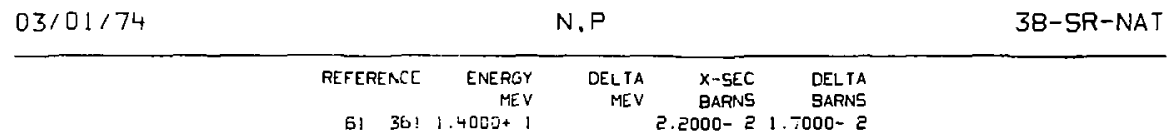

$03 / 01 / 74$

BOUND ATOM

3B-SR-NAT

$\begin{array}{rrrrr}\text { REFERENCE } & \text { EN:RGY } & \text { DELTA } & \text { X-SEC } & \text { DELTA } \\ & \text { MEV } & \text { MEV } & \text { EARNS } & \text { BARNS }\end{array}$

51 158-7.3000-8 $9.5000+0$

$03 / 01 / 74$

COHF.RENT SCATTERING

38-SR-NAT

$\begin{array}{rrrrr}\text { REFERENCE } & \begin{array}{r}\text { ENERGY } \\ \text { MEV }\end{array} & \begin{array}{r}\text { DELIA } \\ \text { MEV }\end{array} & \begin{array}{r}x \text {-SEC } \\ \text { BARNS }\end{array} & \begin{array}{r}\text { DELTA } \\ \text { BARNS }\end{array} \\ 511584 & 7.3000-8 & & 4.1000+0 & 3.2800-1\end{array}$


CFOSS SECTION
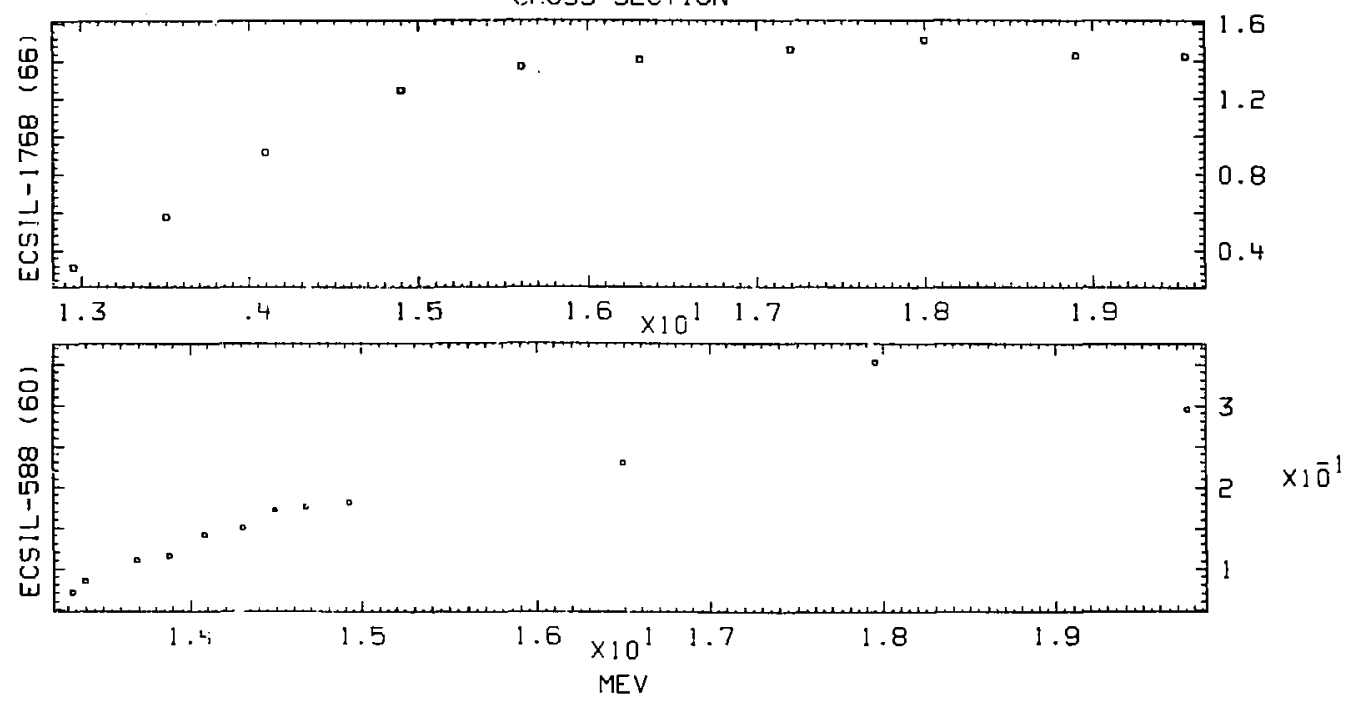

$03 / 01,74$

$N, 2 N$

$38-S R-84$

$\begin{array}{rrrrr}\text { REFERENCE } & \text { ENERGY } & \text { DELTA } & X \text {-SEC } & \text { DELTA } \\ & \text { MEV } & \text { MEV } & \text { BARNS } & \text { BARNS }\end{array}$

$627021.4600+13.0000-13.0000-1$

$617031.4800+15.0000-11.7700+01.7700-1$

$7031501.4800+12.0000-13.9500-17.5000-2$ 
CROSS SECTION

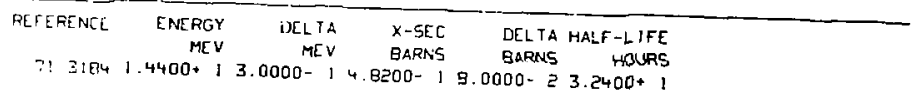

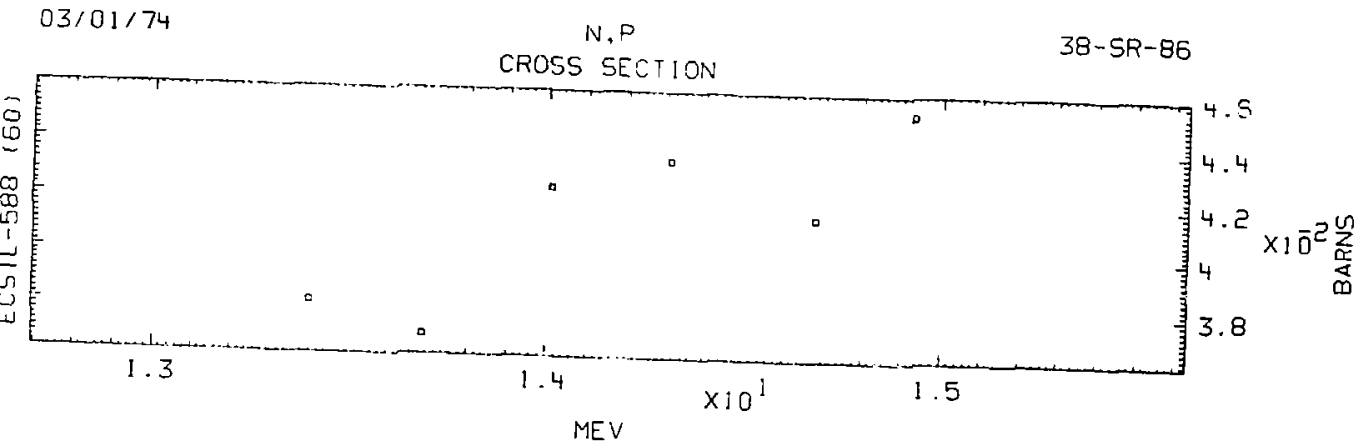

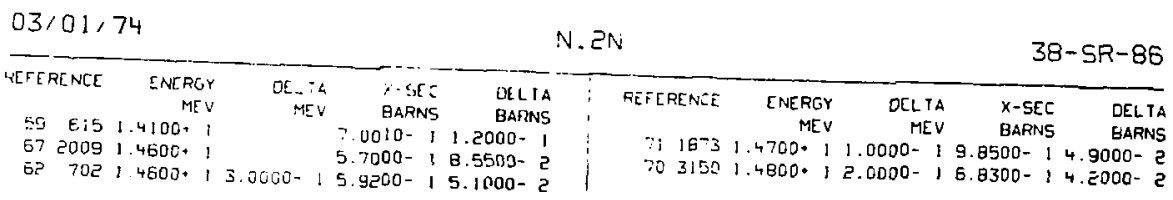


CROSS SECTION

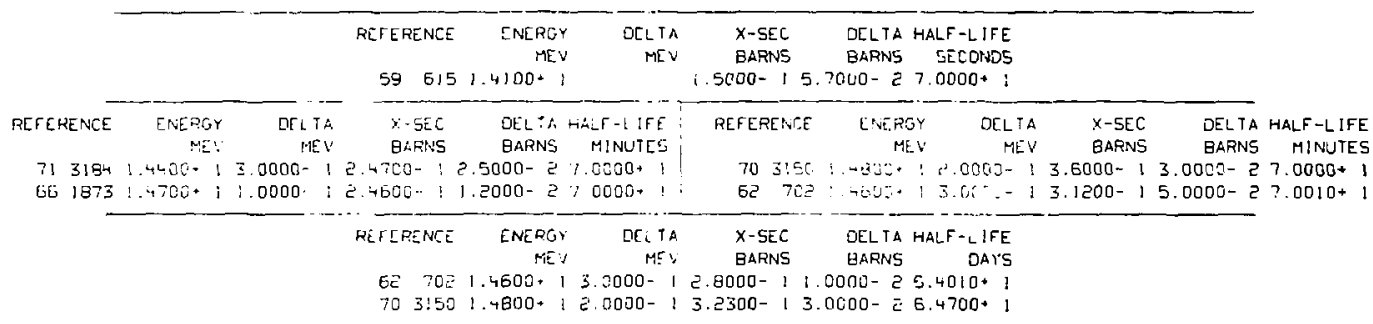

$0 \overline{5} / 01 / 74$

N.P

$38-5 R-86$

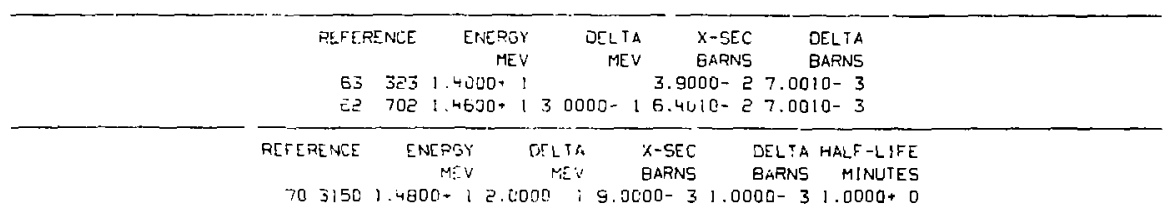

$7031501.4800+2.6000 ; 9.0000-31.0000-31.0000+0$ 


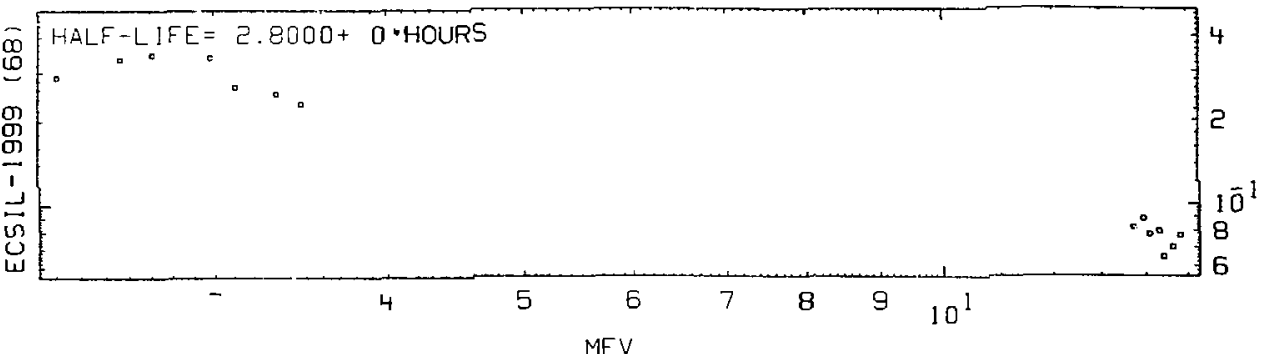

MEV

$03 / 01 / 74$

$N, N^{*}$

$38-S R-87$

REFERENCE

ENERGY

MEV

DELTA

MEV X-SEC

XELTA

SR $19992.2000+07.0000-2$ 2.8600- $13.4000-2$

$03 / 01 / 74$

N. $2 N$

$38-5 R-88$

\section{CROSS SECTION}

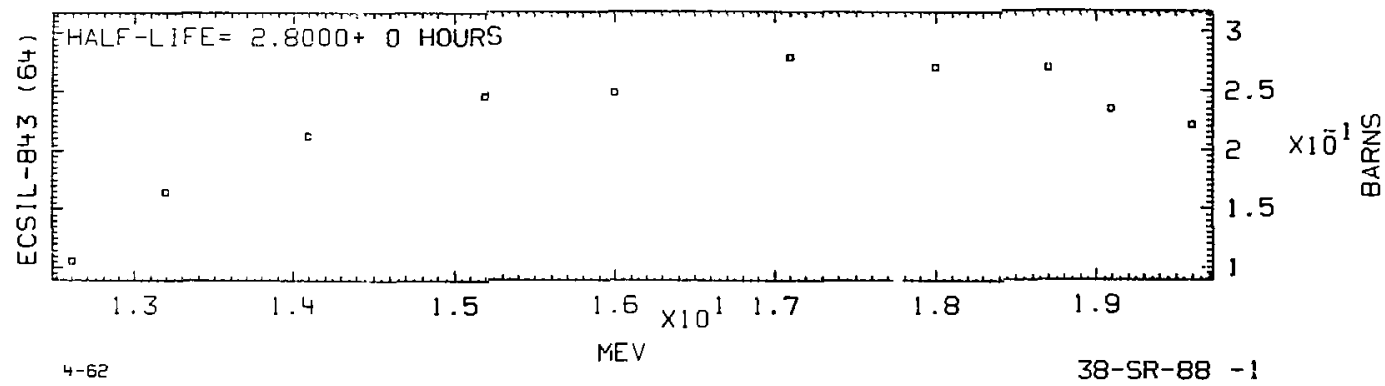




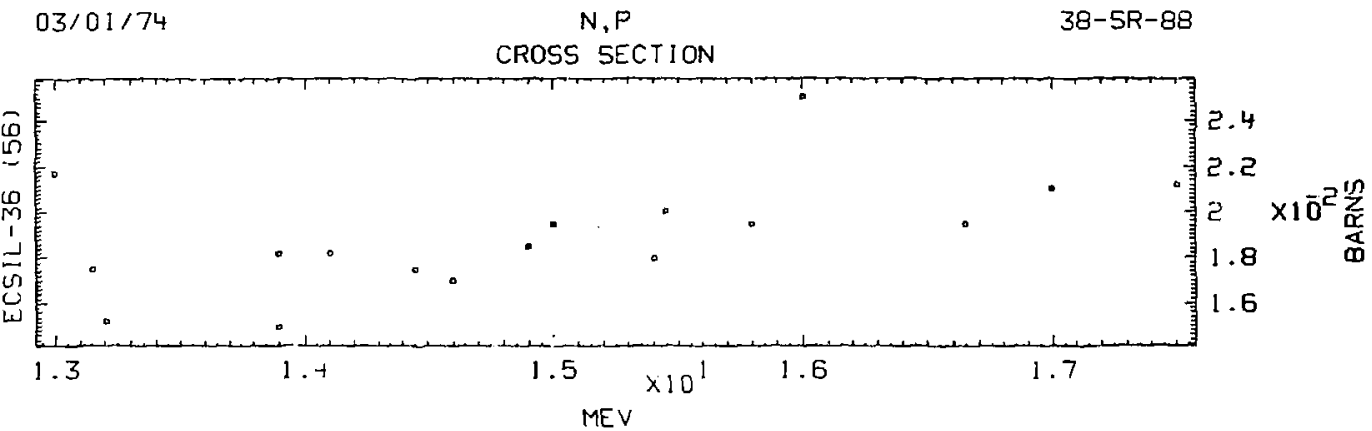

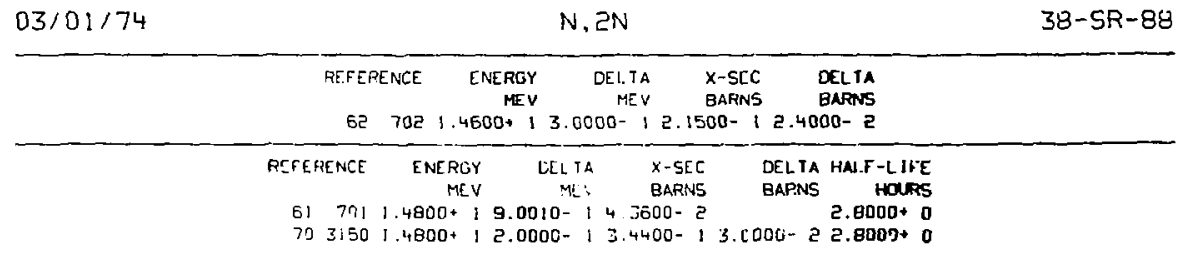

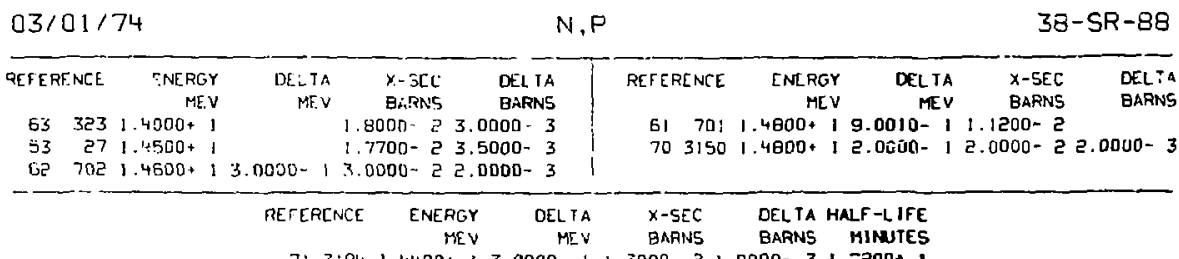

$7121841.4400+13.0000-1,1.3000-21.0000-31.700001$ 


HETCRENGE ETIERGY OELTA X-SEC DFLTA HALF-LIFE

Le 702, $4600+13.0000-18.7000-23.1000-24.4000+0$

sj $271.4500+1 \quad 6.4010-21.9000-24.5000+0$
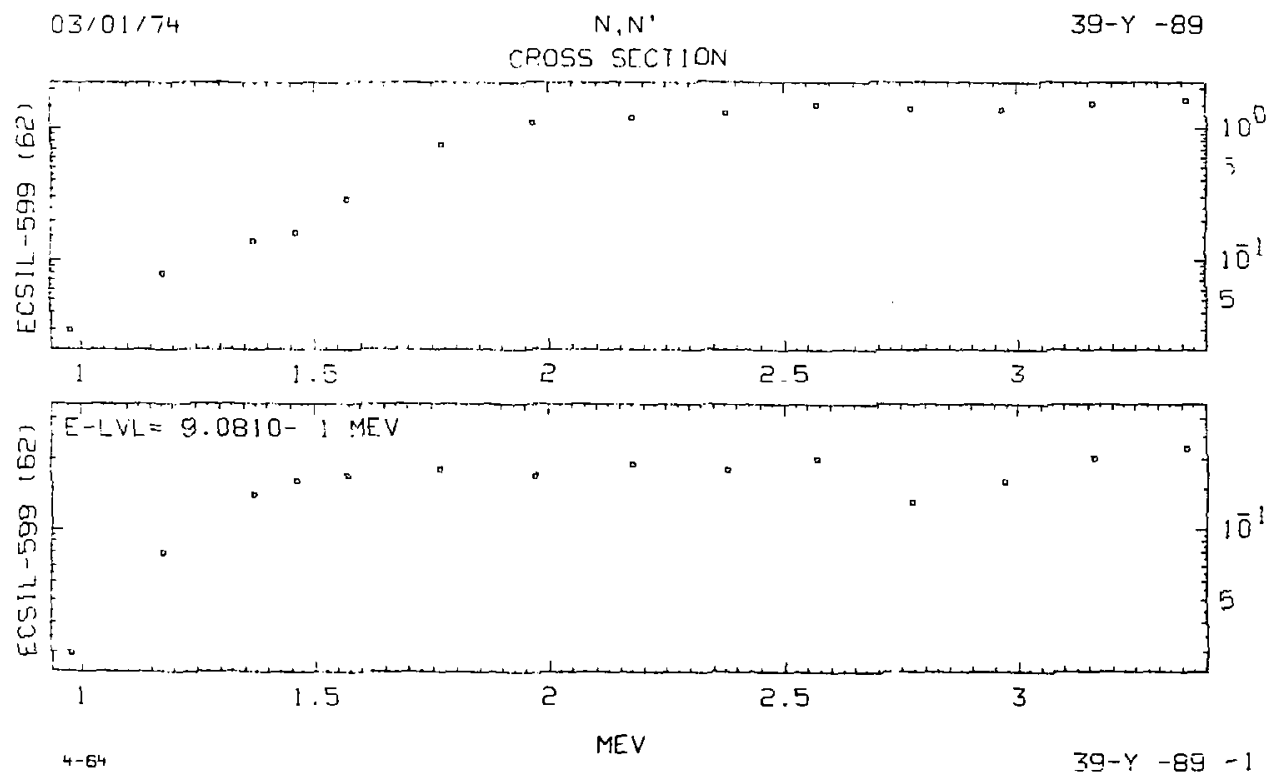


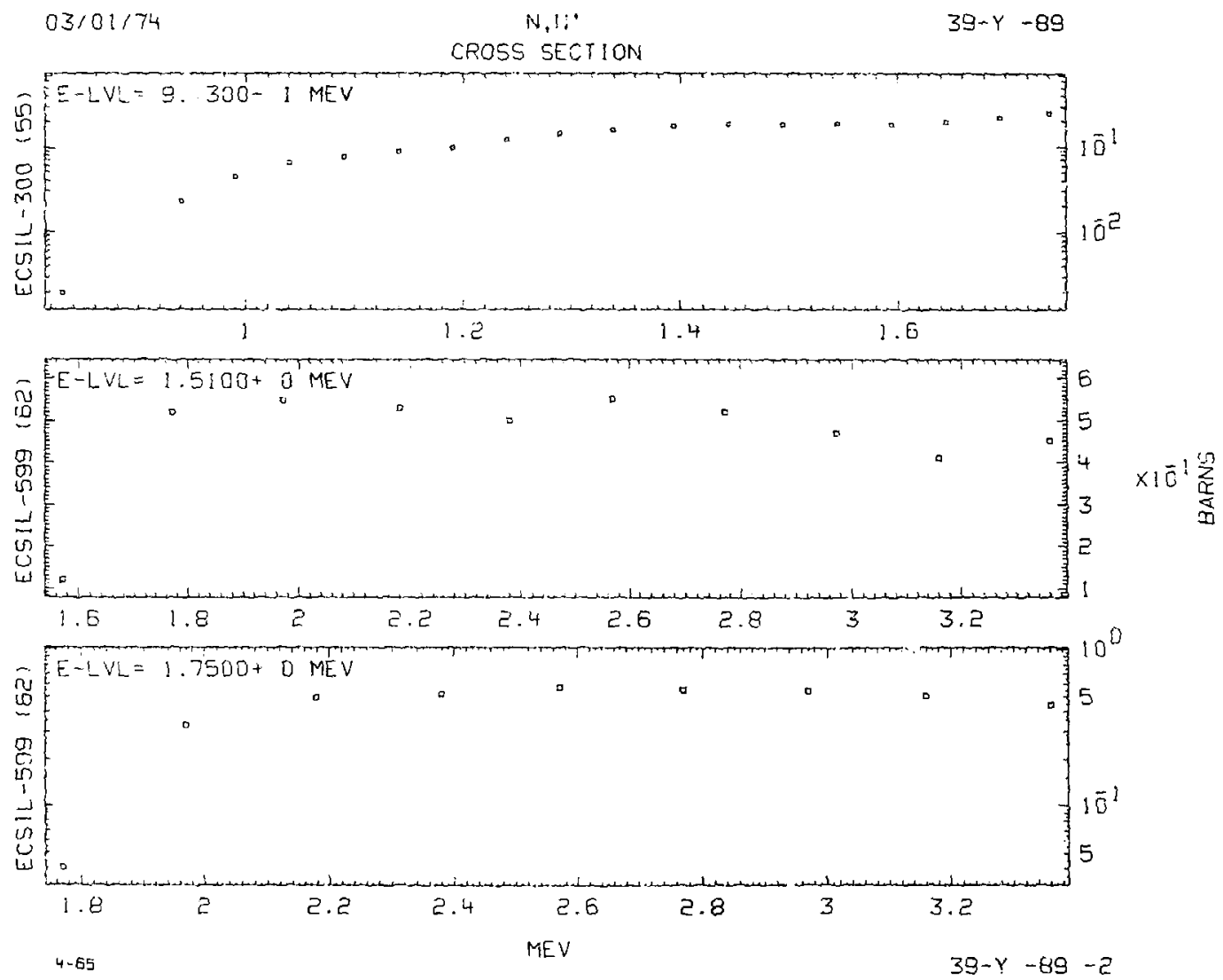




\section{CROSS SECTION}

$39-Y-89$
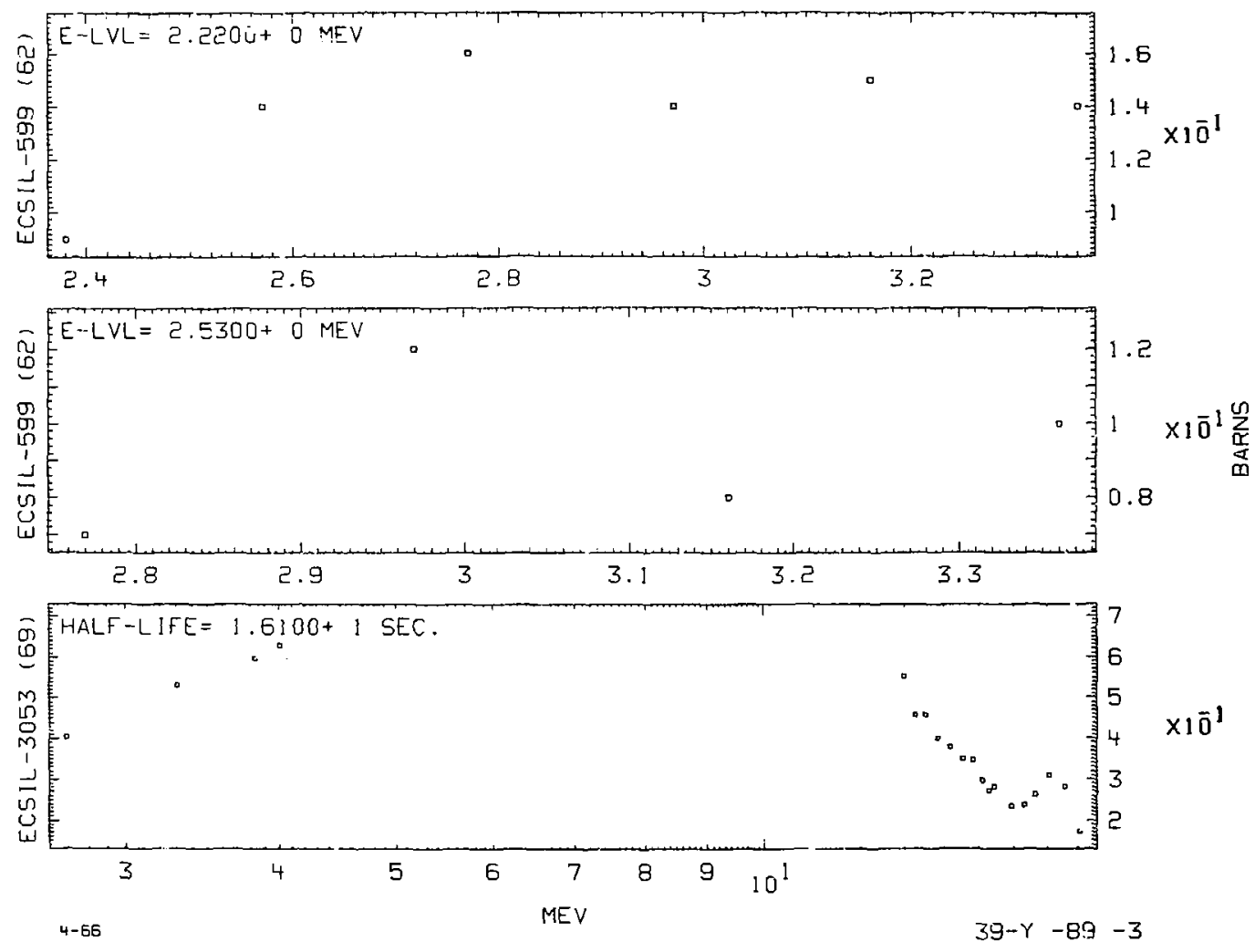


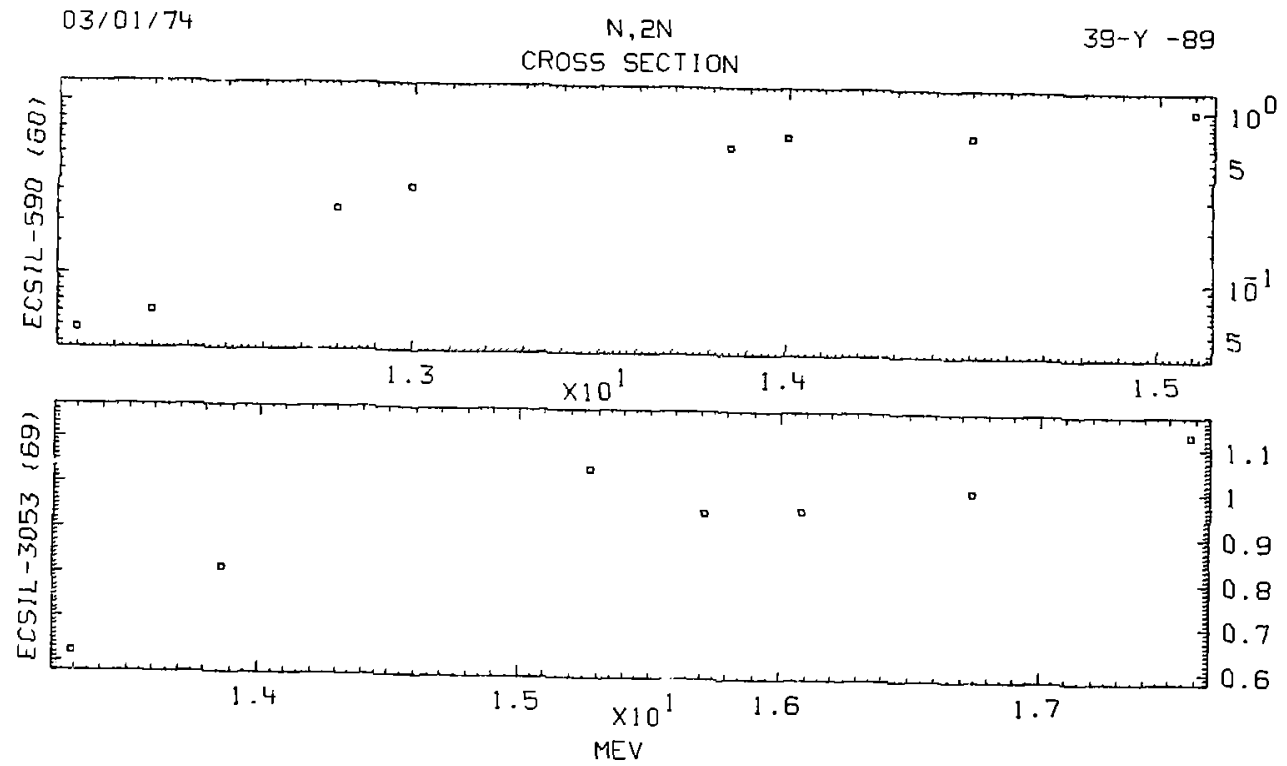



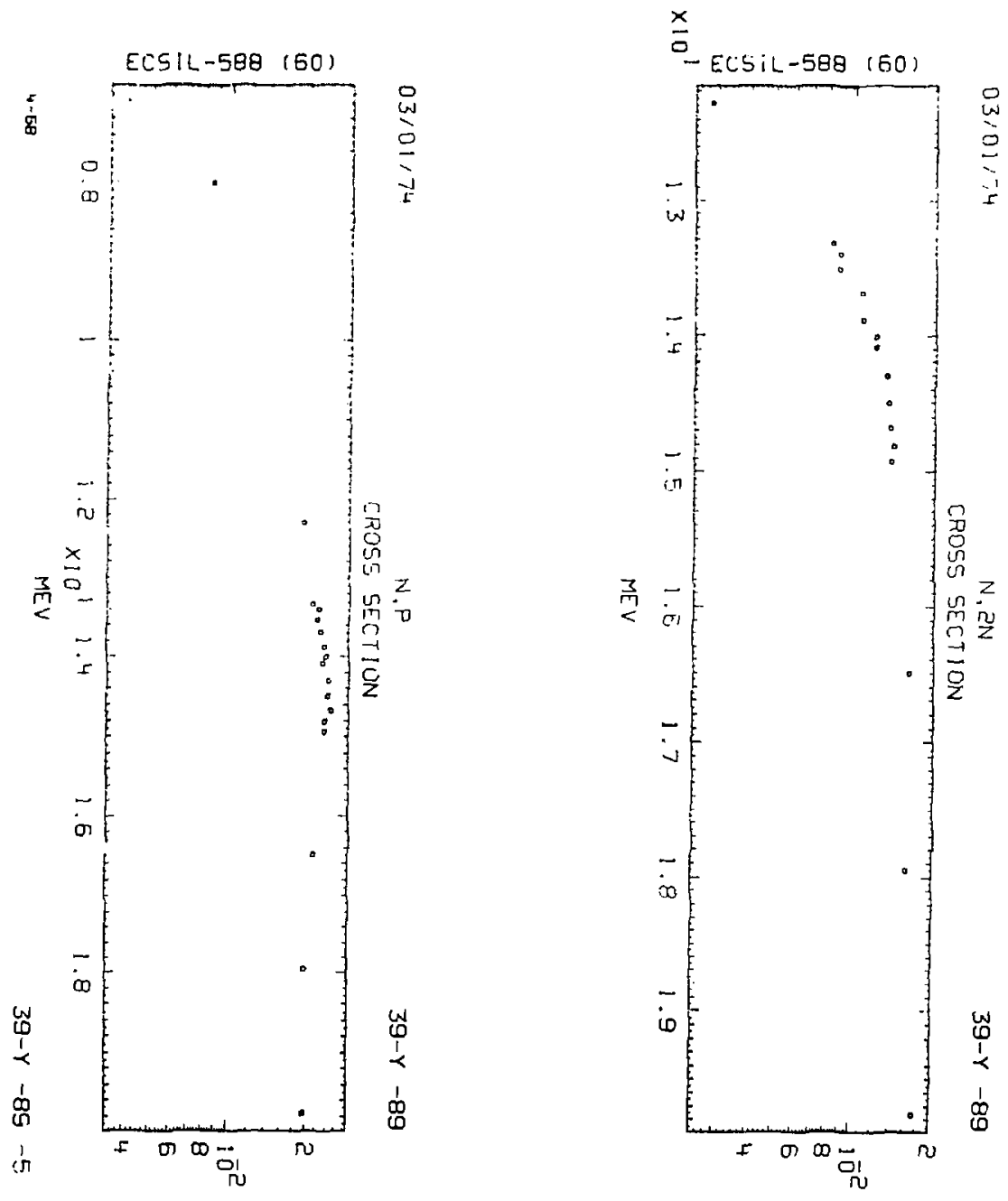

BARNS

RF-LATIVE 

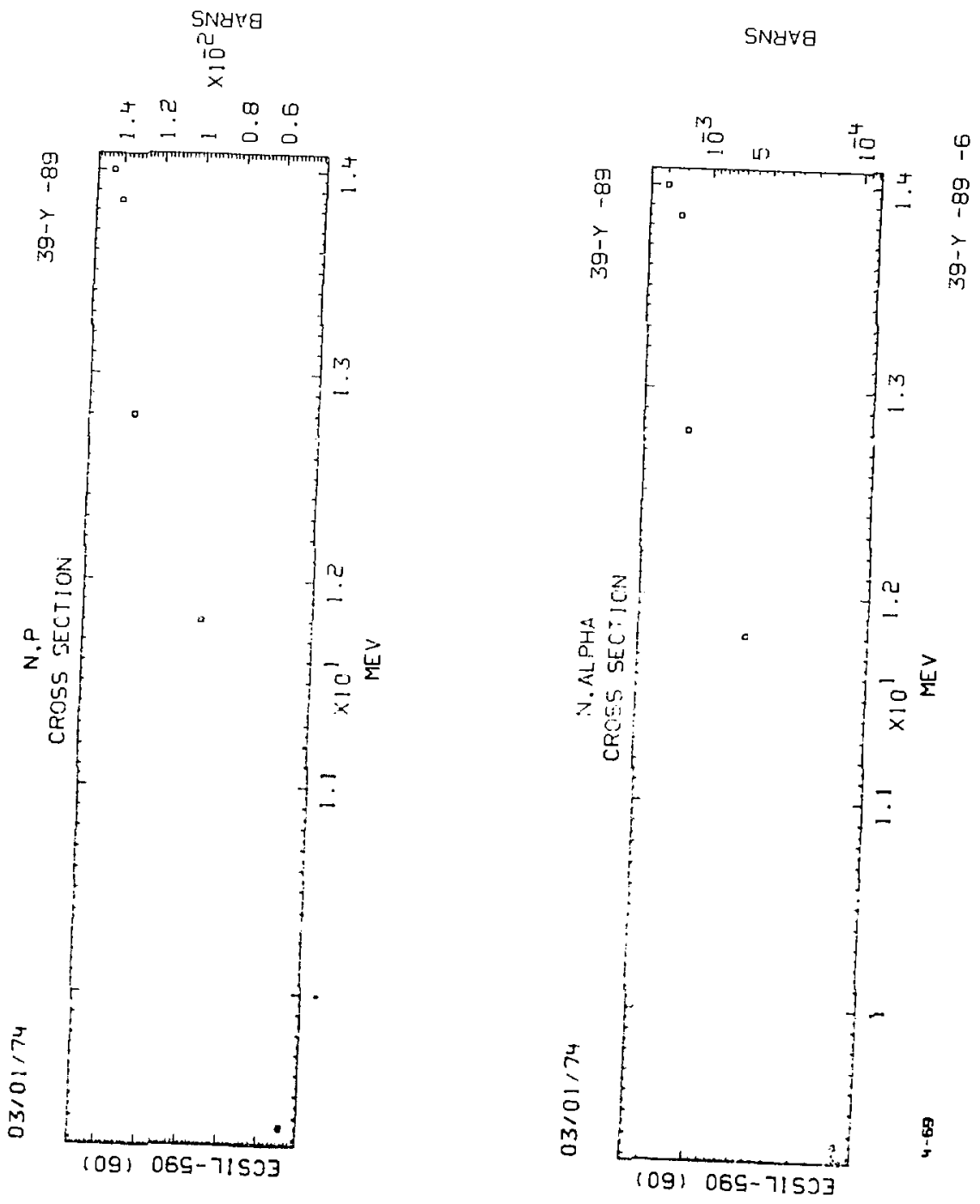


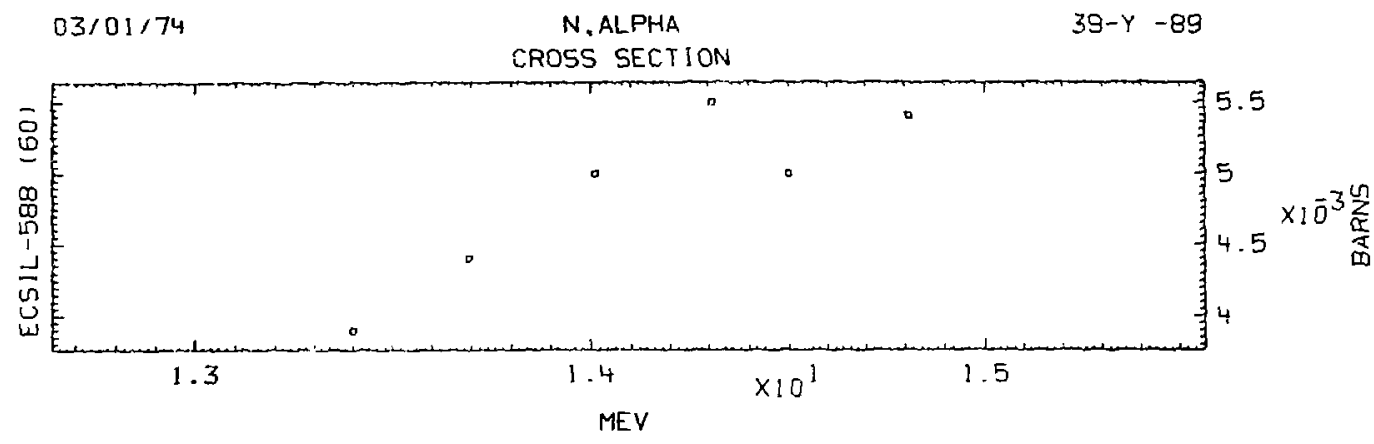

13/01/74

ES $8896.0400+02.3000-12.3000+03.0000-1$

\begin{tabular}{|c|c|c|c|c|c|c|c|c|c|c|c|}
\hline REFERETICE & $\begin{array}{r}\text { ENERGY } \\
\text { MEY }\end{array}$ & $\begin{array}{r}\text { DELTA } \\
\text { MEV }\end{array}$ & $\begin{array}{l}X-5 E C \\
\text { BARNS }\end{array}$ & $\begin{array}{l}\text { CELTA } \\
\text { BARNS }\end{array}$ & $\begin{array}{r}\dot{E}-L V L \\
M E V\end{array}$ & REFERENCE & $\begin{array}{r}\text { ENEFGY } \\
\text { MEY }\end{array}$ & $\begin{array}{r}\text { OELTA } \\
\text { MEV }\end{array}$ & $\begin{array}{l}x \text {-SEC } \\
\text { BARNS }\end{array}$ & $\begin{array}{l}\text { DELTA } \\
\text { BARNS }\end{array}$ & $\begin{array}{r}E-L V L \\
\text { MEV }\end{array}$ \\
\hline 651809 & $3.7700+0$ & $7.0000-z$ & $1.4000-?$ & $=.0500-2$ & $5.0800-1$ & $65 \quad 1809$ & $3.7700 \cdot 0$ & $7.0000-2$ & $1.9500-1$ & J.0000- $\bar{E}$ & $2.8400+0$ \\
\hline 651809 & $3.7700+0$ & $7.0000-2$ & $1.4000-1$ & $7.0000-3$ & $2.2200+0$ & 62599 & $3.1600+0$ & & $3.0000-2$ & $1.0000-2$ & $3.0500+0$ \\
\hline $62 \quad 599$ & $3.9700+0$ & & 2. $0000-2$ & $1.0000-2$ & $2.8400+0$ & $62 \quad 599$ & $3.3600+0$ & & $1.1000-1$ & $2.0000-\bar{z}$ & $3.0500+0$ \\
\hline $62 \quad 599$ & $3.1600+0$ & & $1.3000-1$ & $4.0000-2$ & $2.8400+0$ & $65 \quad 1809$ & $3.7700+0$ & $7.0000-2$ & $3.6500-1$ & 2.0000- 2 & $3.0500+0$ \\
\hline $62 \quad 599$ & $3.3 E D C+0$ & & $1.0000-1$ & 2.0000- & $2.9400+0$ & & & & & & \\
\hline
\end{tabular}

\begin{tabular}{|c|c|c|c|c|c|c|c|c|c|}
\hline REFERENCE & $\begin{array}{r}\text { ENEFËY } \\
\text { MEV }\end{array}$ & $\begin{array}{l}\text { DELTA } \\
\text { MEV }\end{array}$ & $\begin{array}{l}x-S E C \\
\text { BARNS }\end{array}$ & $\begin{array}{l}\text { JELTA HALF-LITE } \\
\text { SAENS SECONOS }\end{array}$ & REFERENCE & $\begin{array}{r}\text { ENERGY } \\
\text { HEV }\end{array}$ & $\begin{array}{l}\text { OELTA } \\
\text { MEV }\end{array}$ & $\begin{array}{l}x \text {-SEC } \\
\text { GAFivS }\end{array}$ & DELTA HKLF-LIFE \\
\hline
\end{tabular}

$6833681.4700+11.0000-15.2400-15.8050-21.5780+1 \quad 6521201.4600+13.0000-14.0000-14.7000-21.6800+1$

$6726022.8000+07.0000-22.5100+23.2630+11.6000+1$

$5.9400-1 ? 3000-11.5000+114$

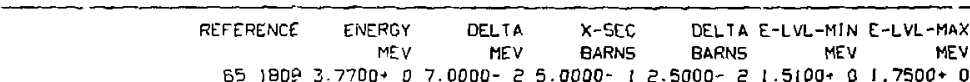

$5518003.7700+07.0000-25.0000-12.5000-21.5100+01.7500+0$

$6518093.7700+07.0000-21.6500-18.0000-32.5300+02.6100+0$ 
CROSS SECTION

\begin{tabular}{|c|c|c|c|c|c|c|c|c|c|}
\hline REFERENCE & $\begin{array}{r}\text { ENERGY } \\
\text { MEV }\end{array}$ & $\begin{array}{r}\text { DELTA } \\
\text { MEV }\end{array}$ & $\begin{array}{l}X \text {-SEC } \\
\text { BARNS }\end{array}$ & $\begin{array}{l}\text { DELTA } \\
\text { BARNS }\end{array}$ & REFERENCE & $\begin{array}{r}\text { ENERGY } \\
\text { MEV }\end{array}$ & $\begin{array}{r}\text { DELTA } \\
\text { MEV }\end{array}$ & $\begin{array}{l}X \text { X-SEC } \\
\text { BARNS }\end{array}$ & $\begin{array}{l}\text { DEL TA } \\
\text { BARNS }\end{array}$ \\
\hline $63 \quad 377$ & $1.4000+1$ & & $1.3500+0$ & $3.3750-1$ & 661873 & $1.4700+1$ & $1.0000-1$ & $1.0150+0$ & $05.0750-2$ \\
\hline 65,873 & $1.4050+1$ & $5.0000-2$ & $=9.1500-1$ & $4.5750 \sim 2$ & 67 2009 & $1.5000+1$ & & $1,0,00+0$ & $0,1.5150-3$ \\
\hline $59 \quad E^{15}$ & $1.4100+1$ & & $5.4010-1$ & B.0010 - & 612116 & $1.6000+1$ & & $1.1250-3$ & $32.9250-4$ \\
\hline $7 C ?$ & $\therefore 4600+$ & $3.0000-$ & $5.4210-$ & $5.8010-2$ & & & & & \\
\hline
\end{tabular}

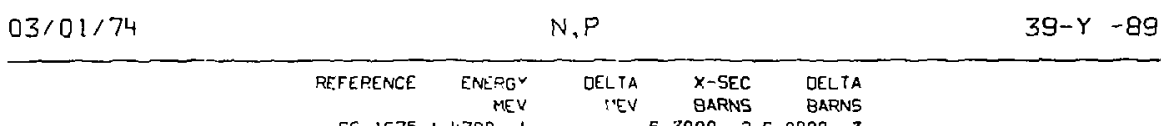

$6616751.4700+1 \quad 5.3000-25.0000-3$

$03 / 0 j / 74$

N. ALPHA

$39-Y-89$

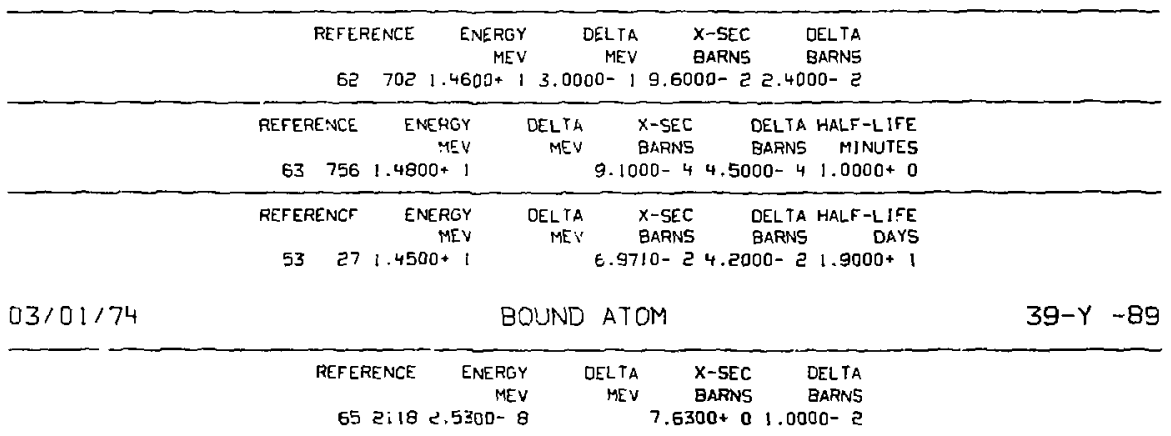


FS:01:74 FRE ATOM
CROSS SECTION

$39-Y-89$

$\begin{array}{rrrrr}\text { FEFERENCE } & \text { ENERGY } & \text { DELTA } & X \text {-SEC } & \text { DELTA } \\ & \text { MEV } & \text { MEV } & \text { BARNS } & \text { BARNS } \\ \text { G5 } 2118 & 2.5300-8 & & 7.4600+0 & 1.0000-?\end{array}$

$03.8:-$ COHERENT SCATIERING

$39-Y-89$

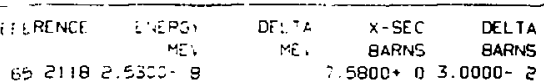

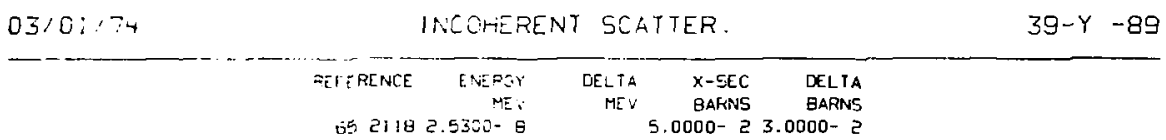

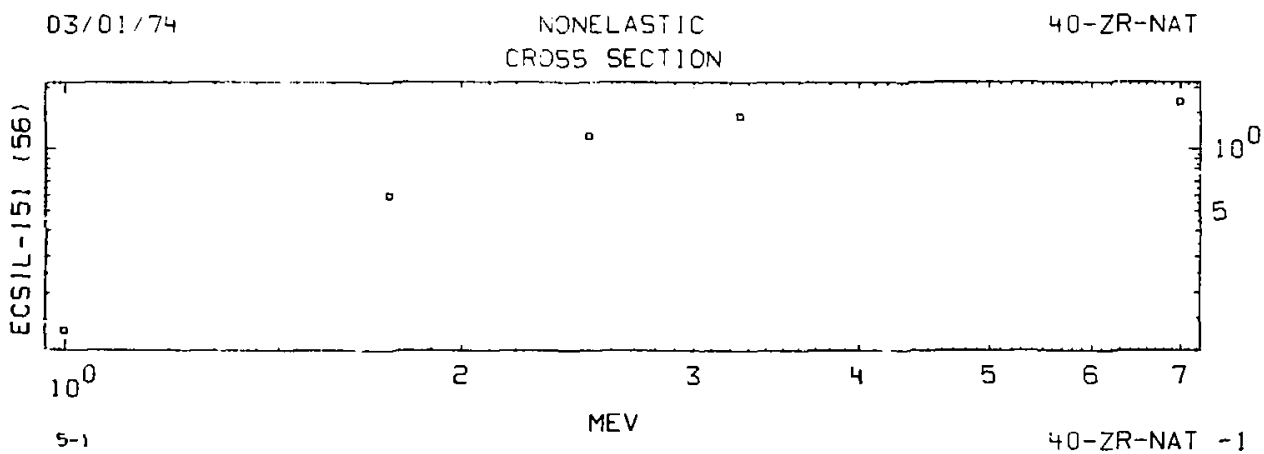



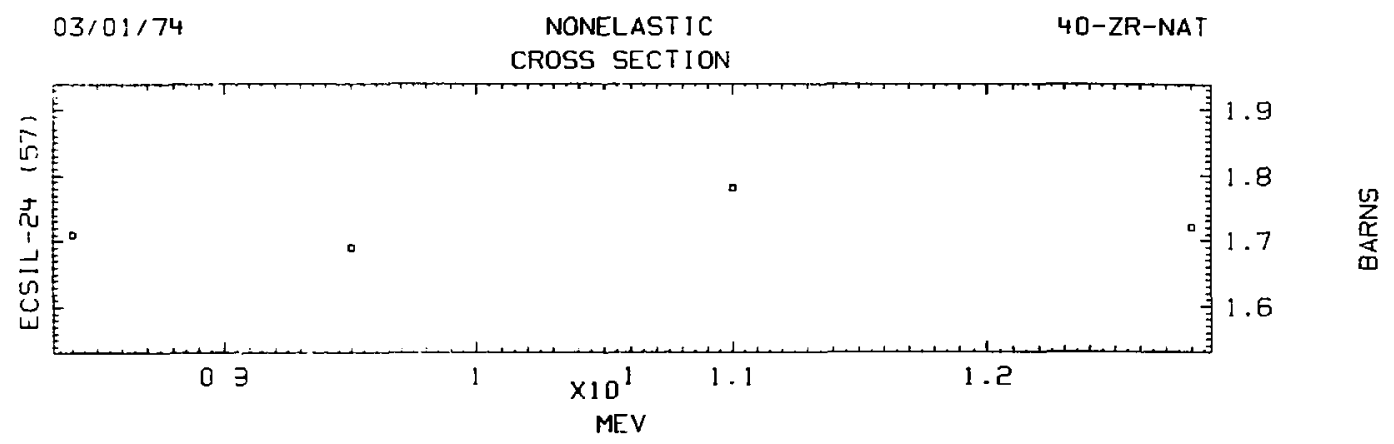

6

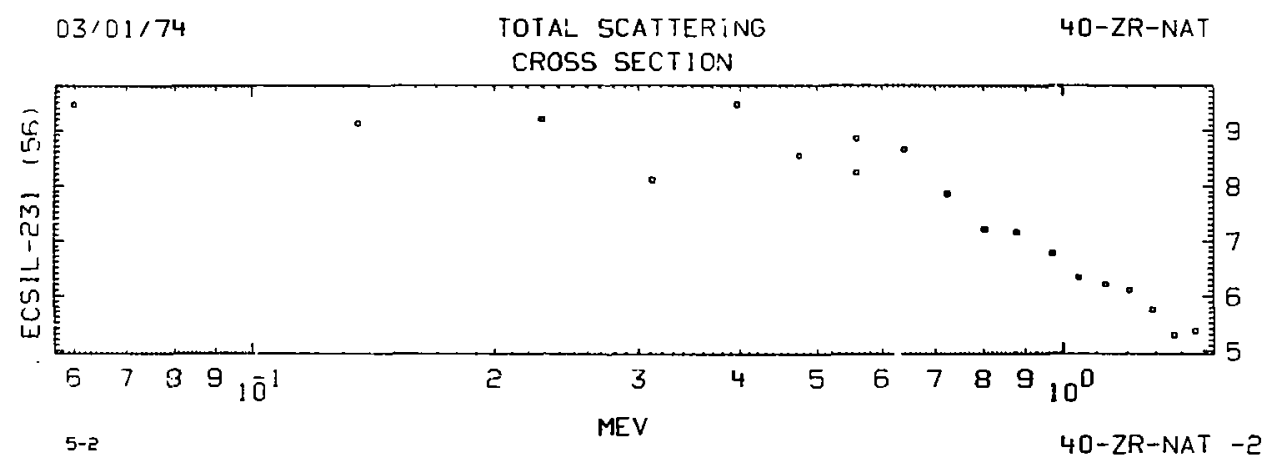

$\underset{\substack{n \\ \frac{n}{n}}}{\frac{n}{4}}$ 


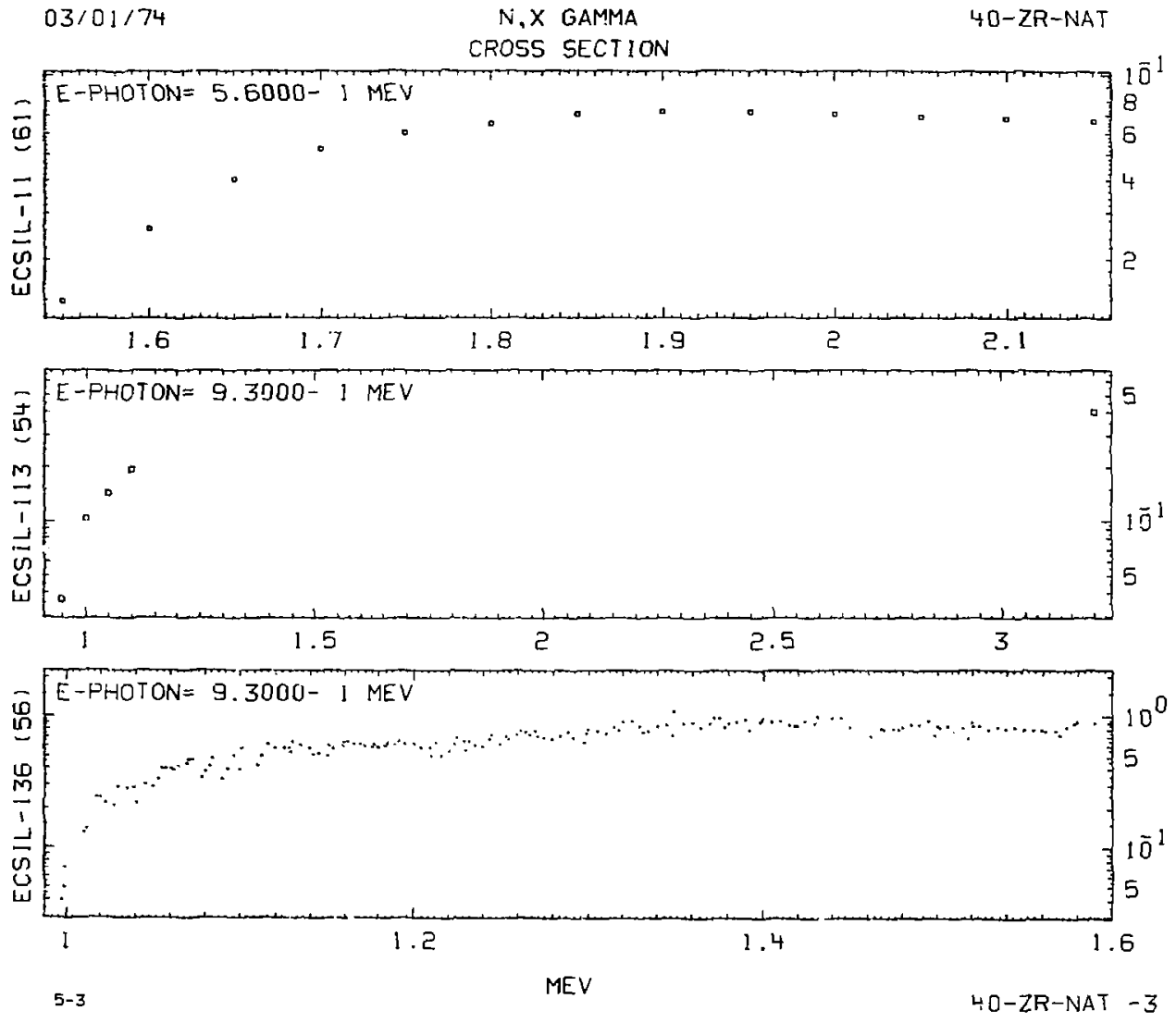




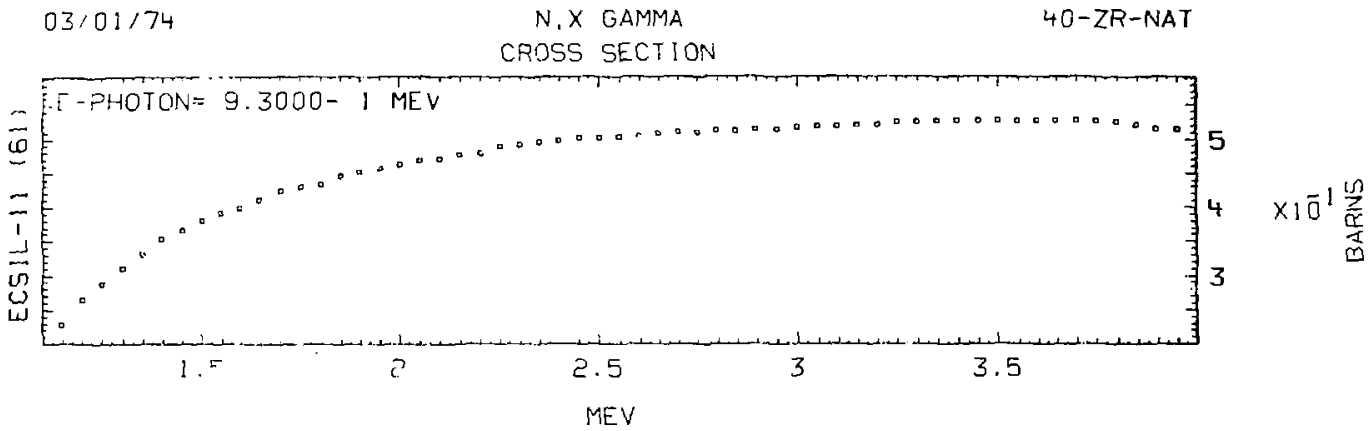

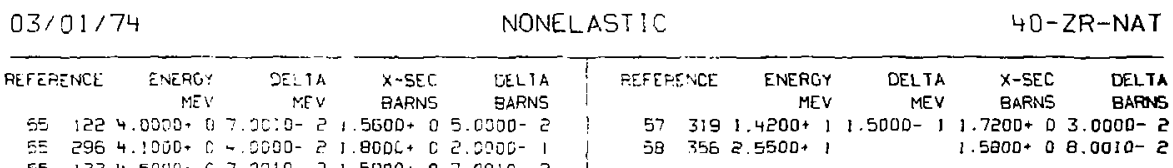

55 1हट $4.5000-07.0010-21.5000+07.0010-8$

03/01/74

69 2518 $5.3900 \cdot 10$

63 0199.8050 1 5.0000 $25.5600+01.5680-1$

$03 / 01 / 74$

$N, N^{\prime}$

40-ZR-NAT

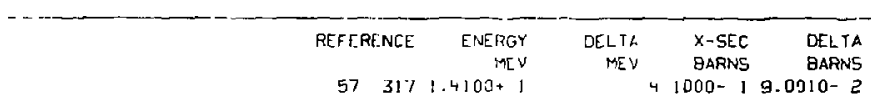




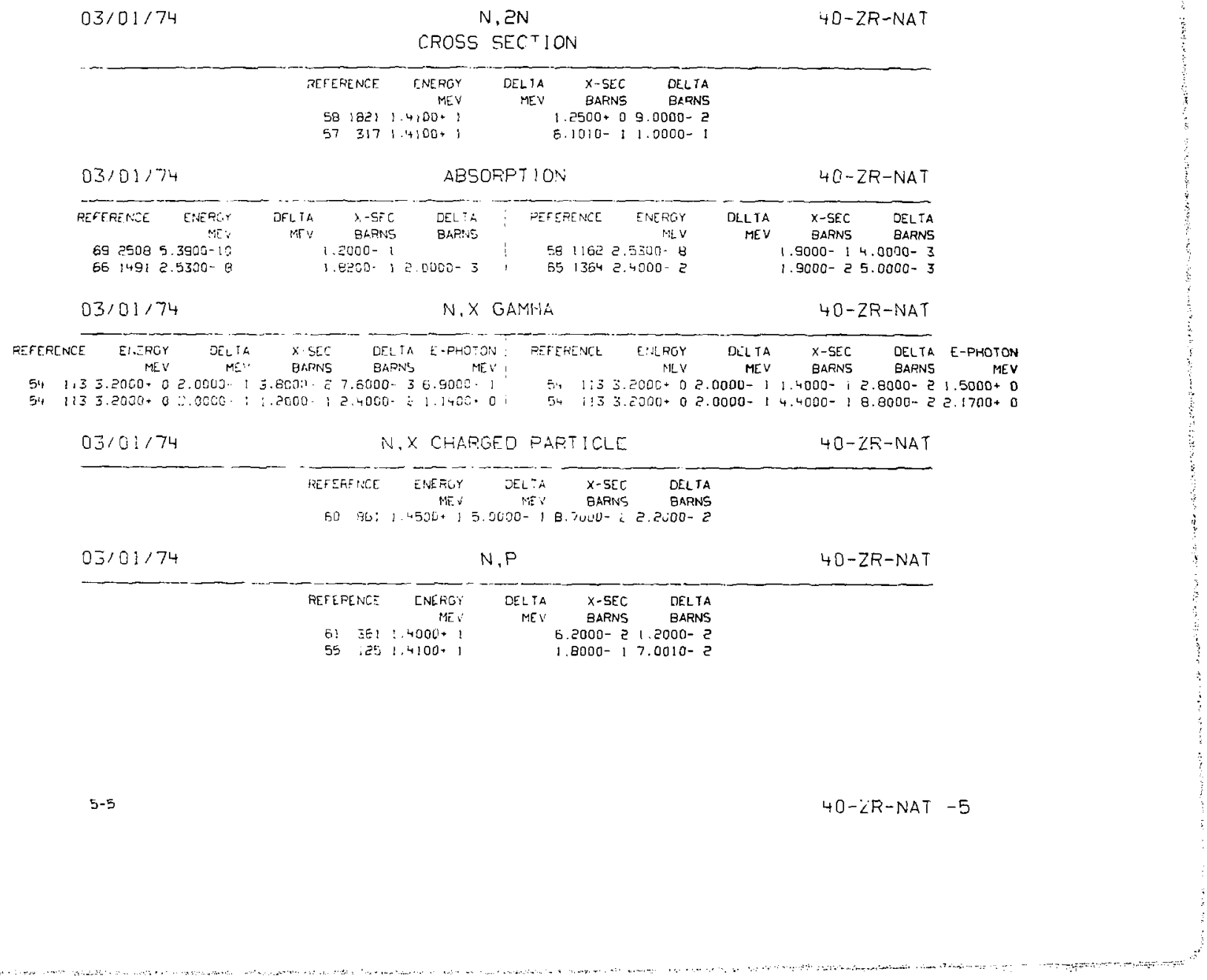




0310174
03101174
0

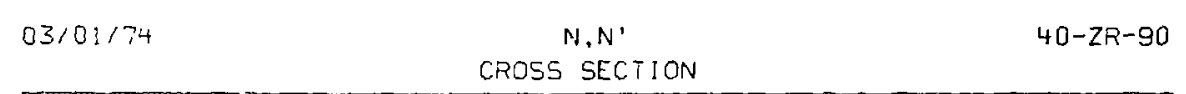

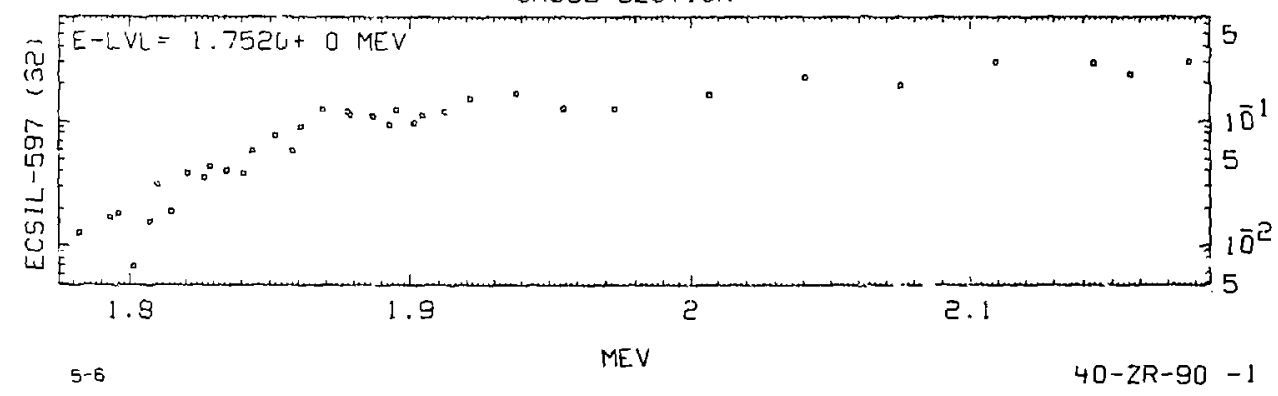



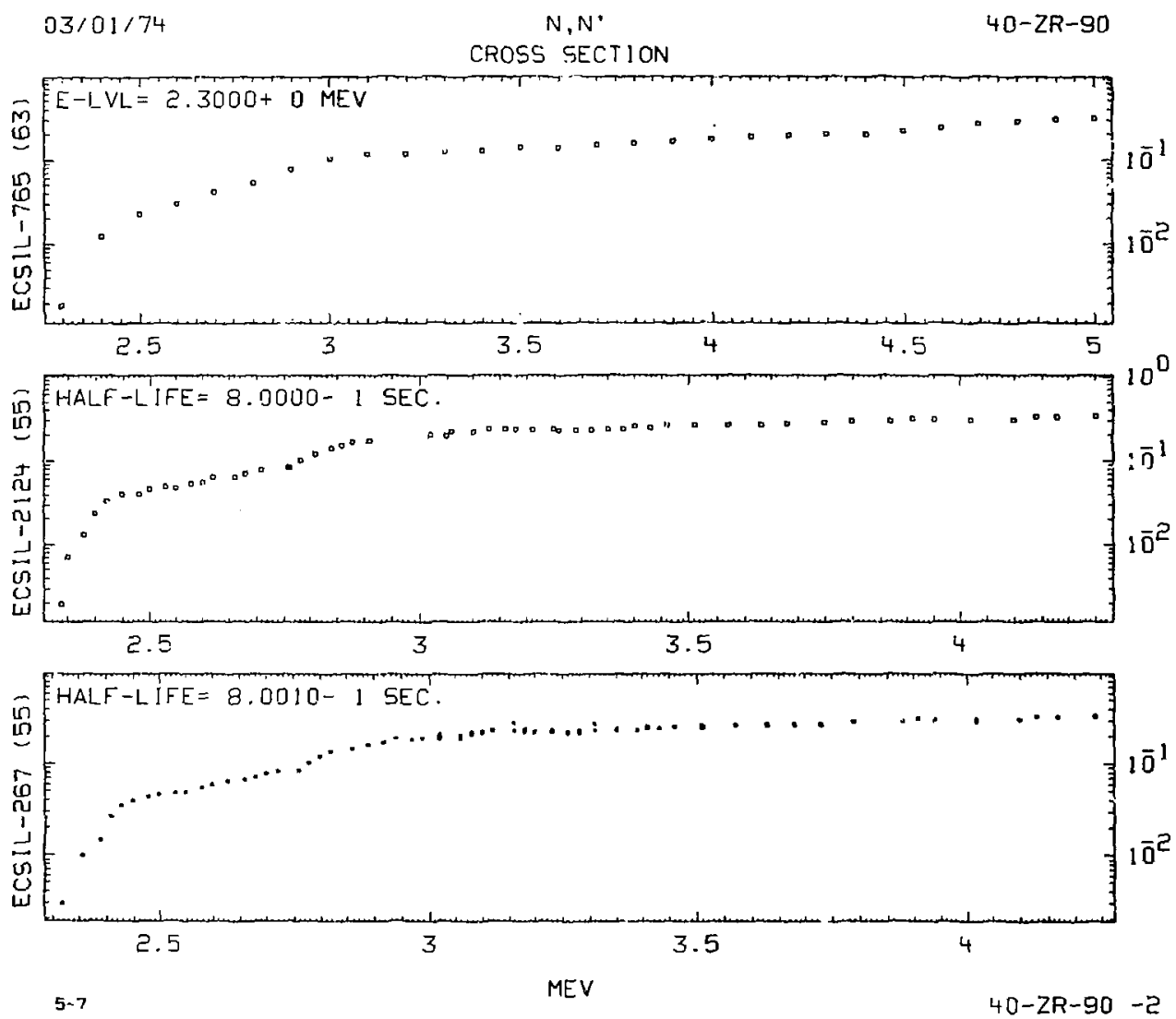
SNd 89
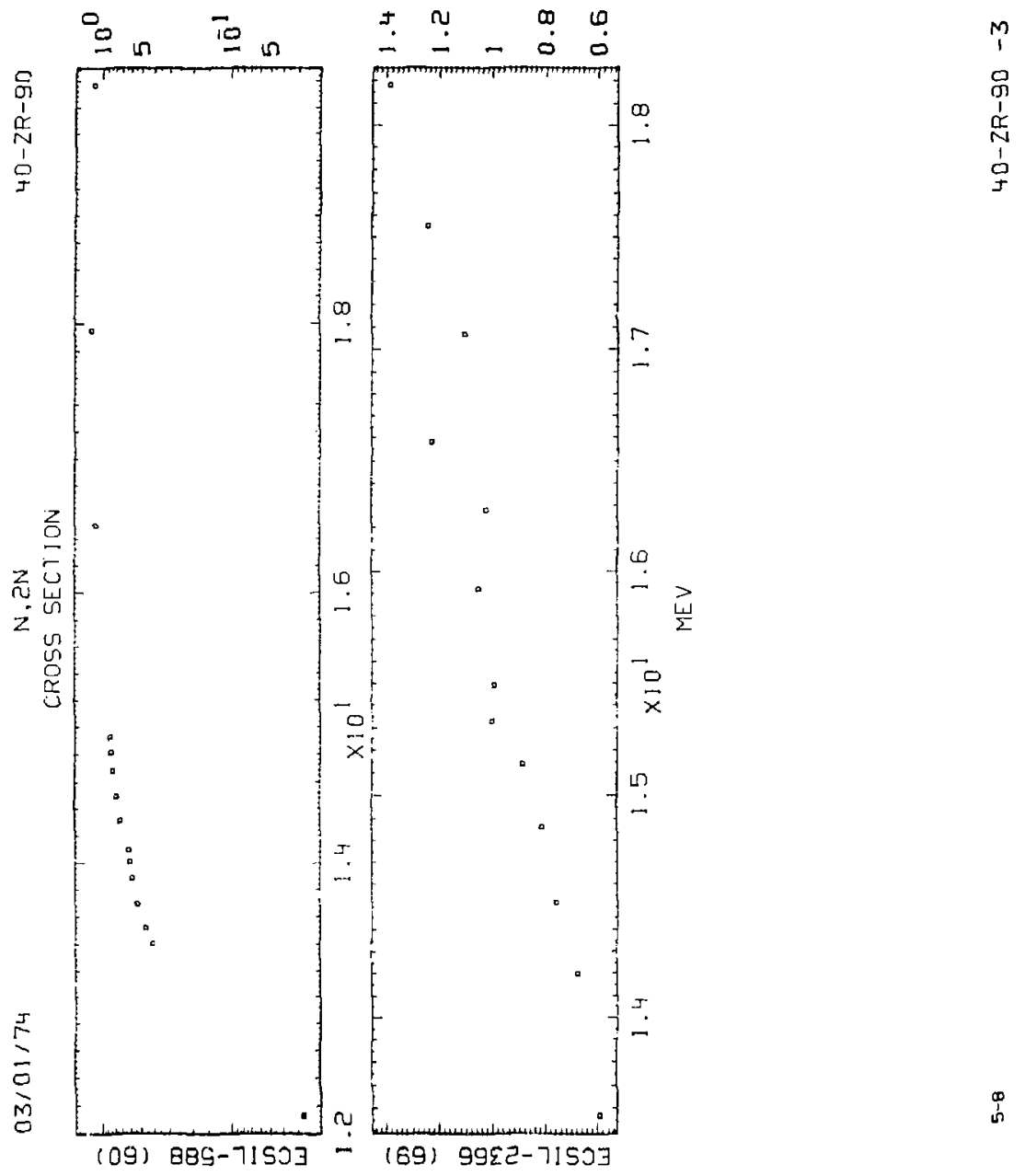

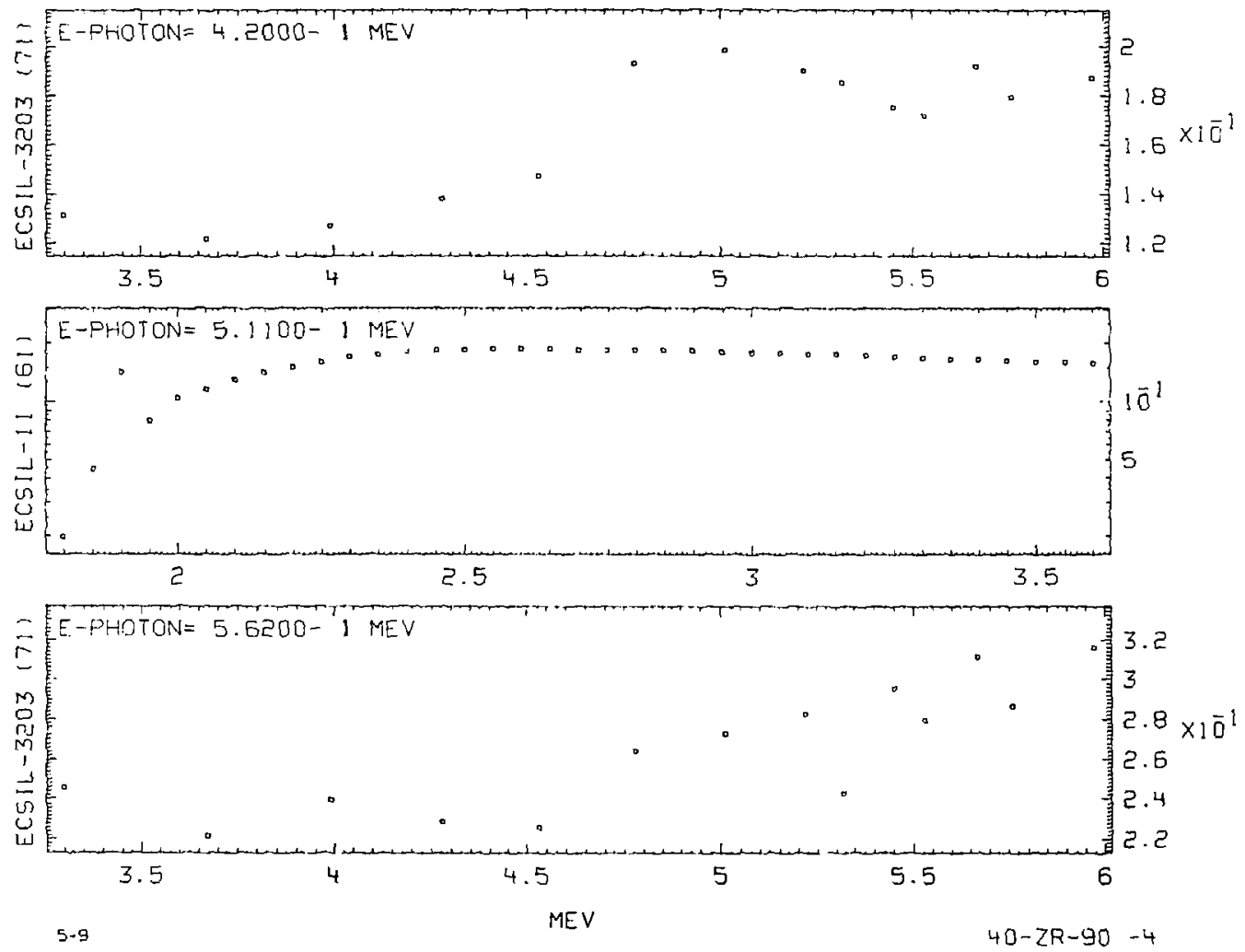


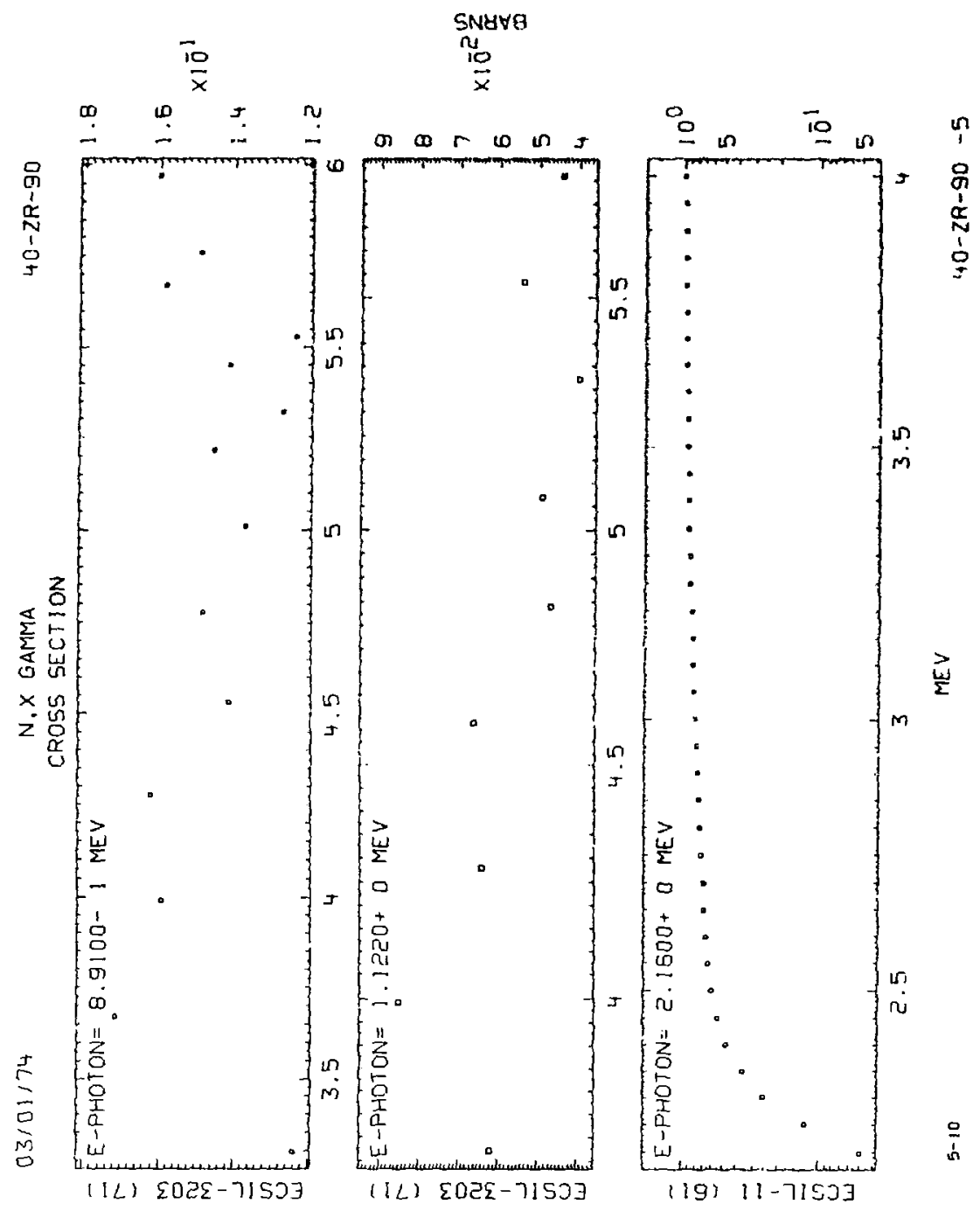




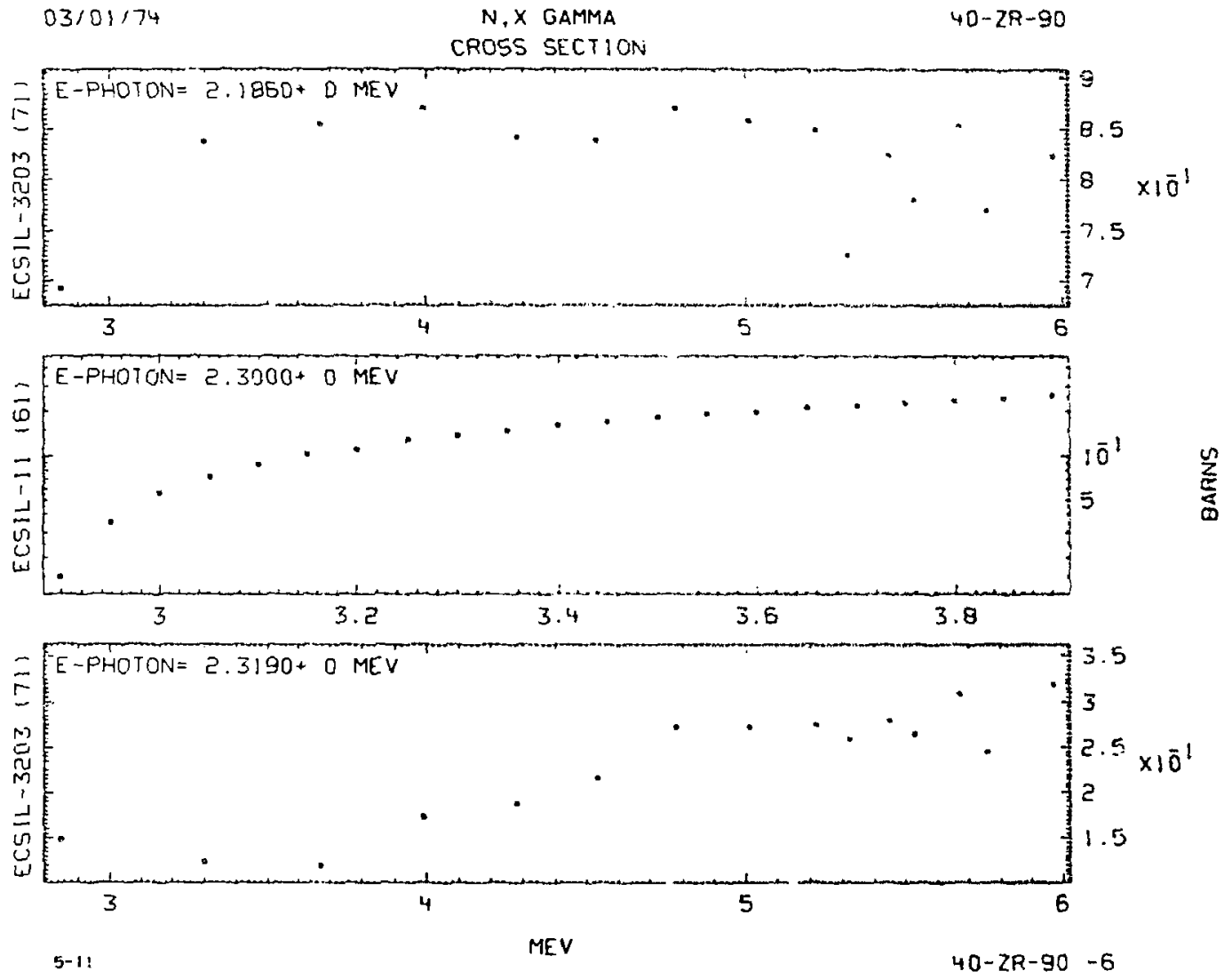




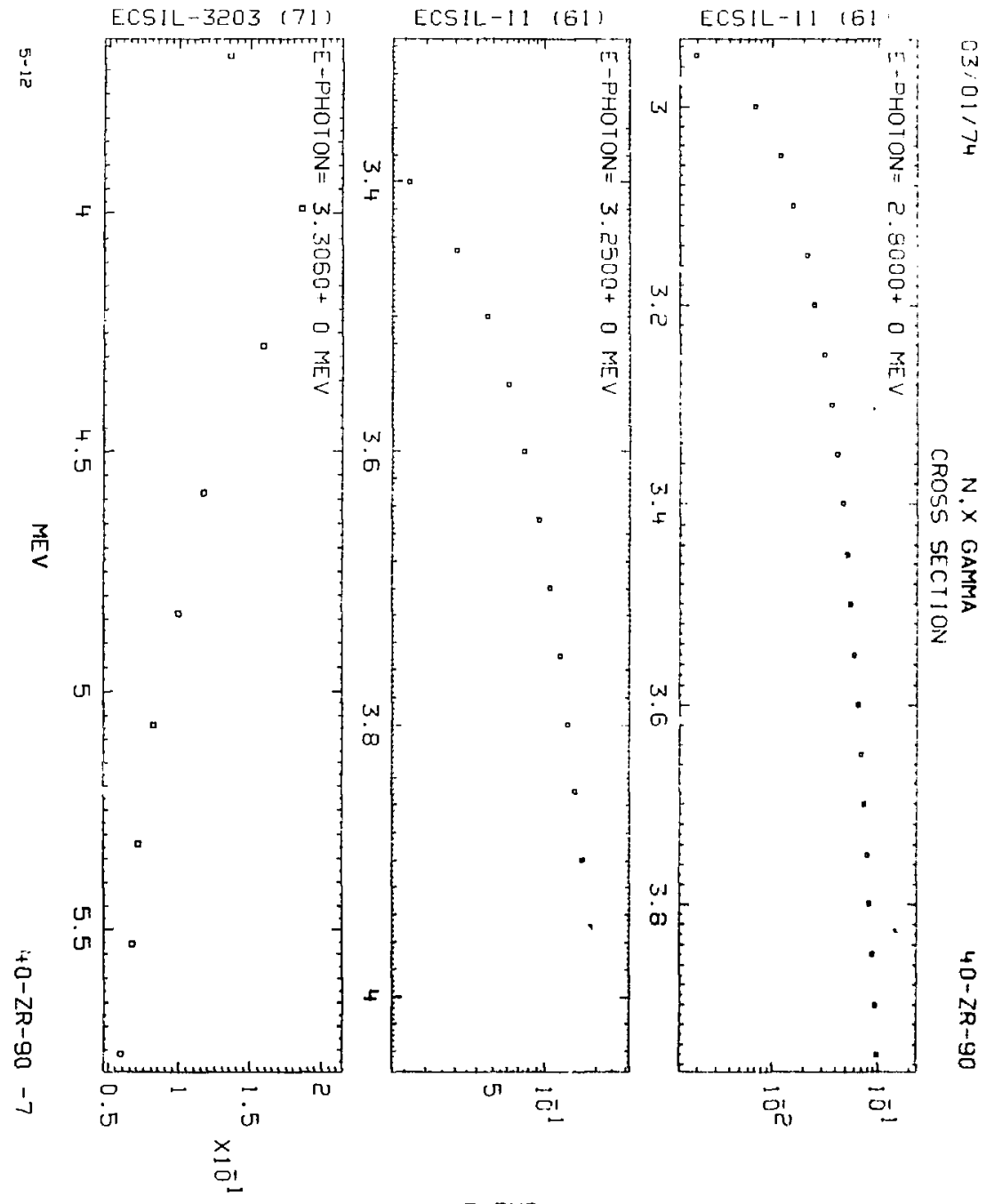

BARNS 

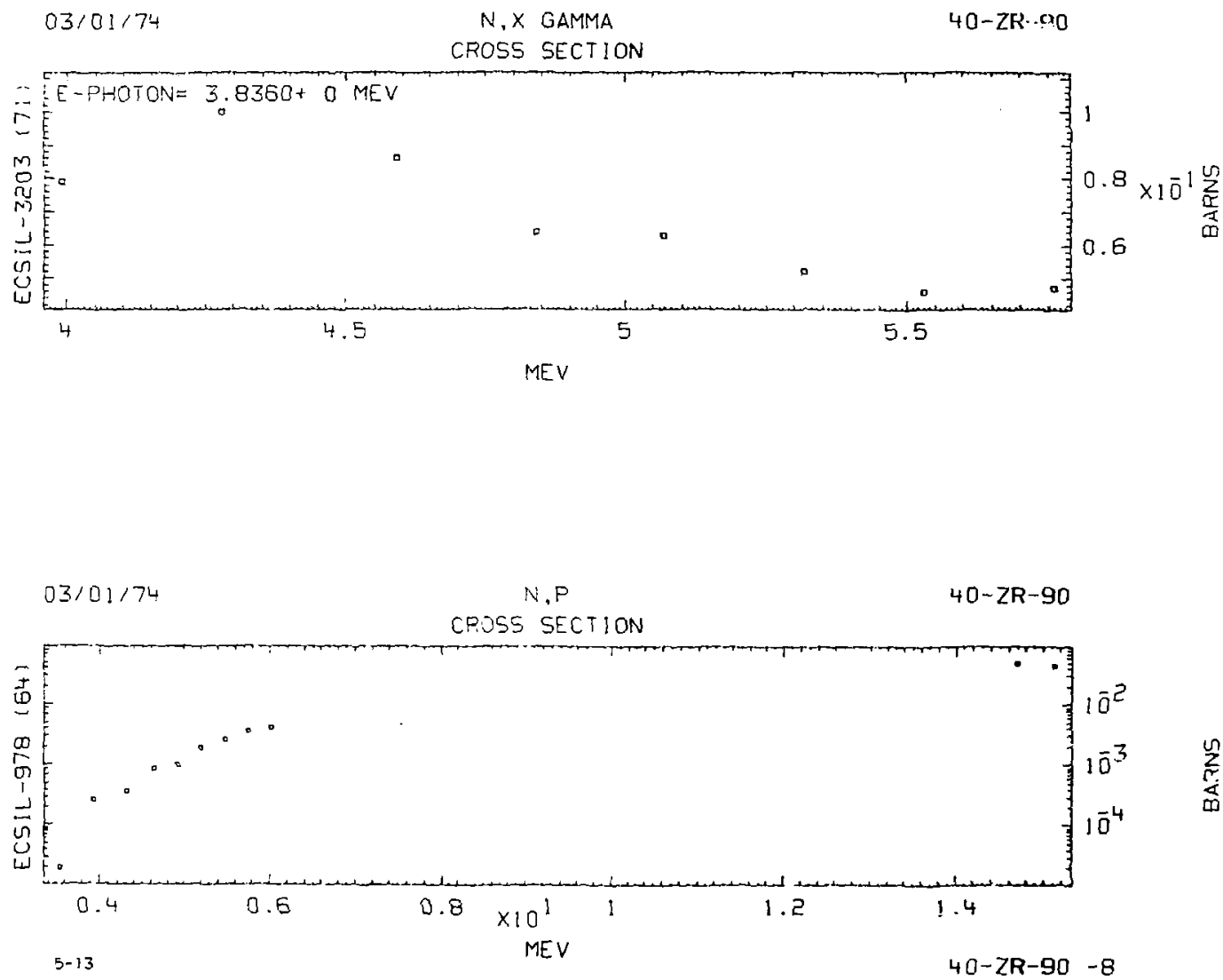
CROSS SECTION

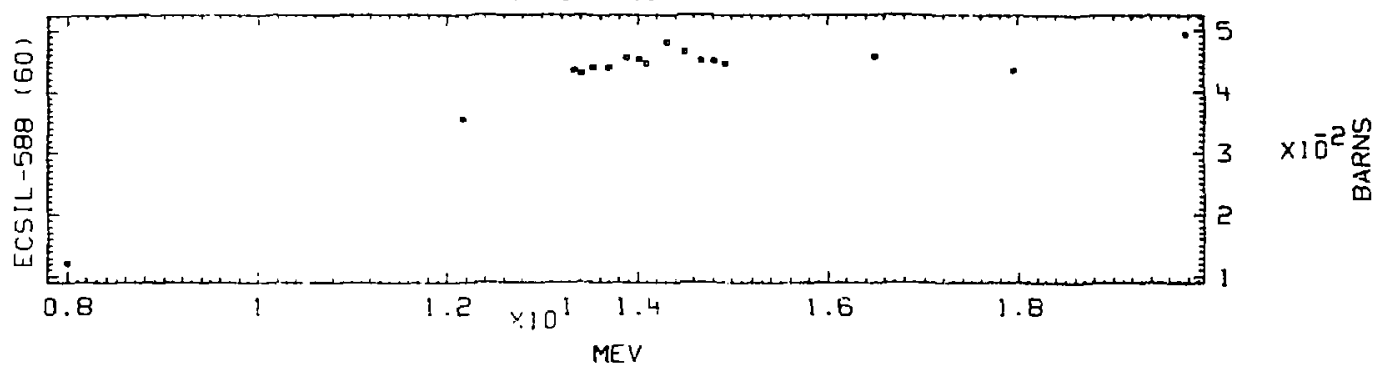

\section{$03 / 01 / 74$}

$N, 2 N$

$40-2 R-90$

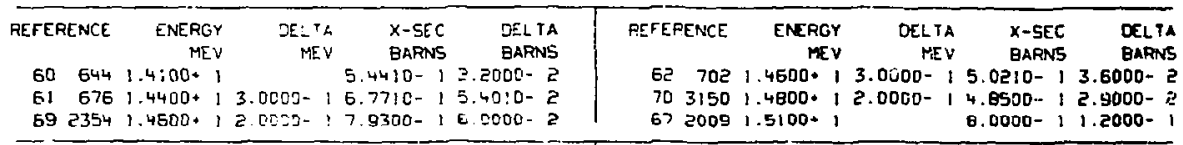

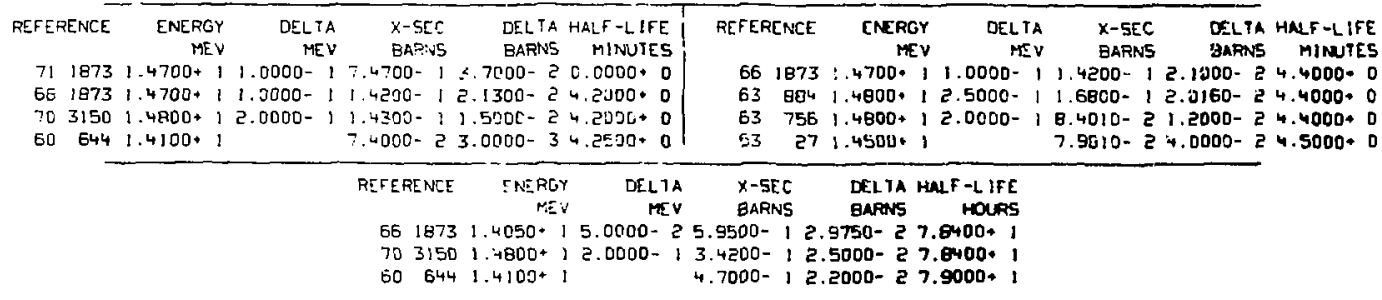


CROSS SECTION

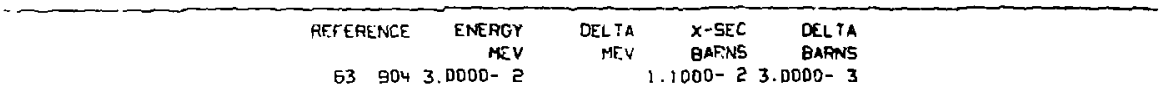

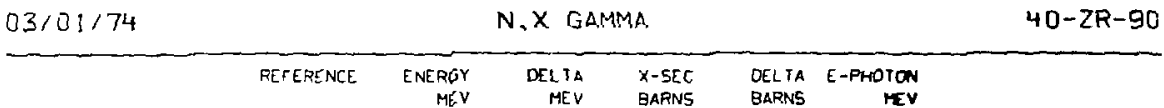

E) $\quad 113.7000+02.0000-a^{3} 6.8500-11.7100-11.4600+0$

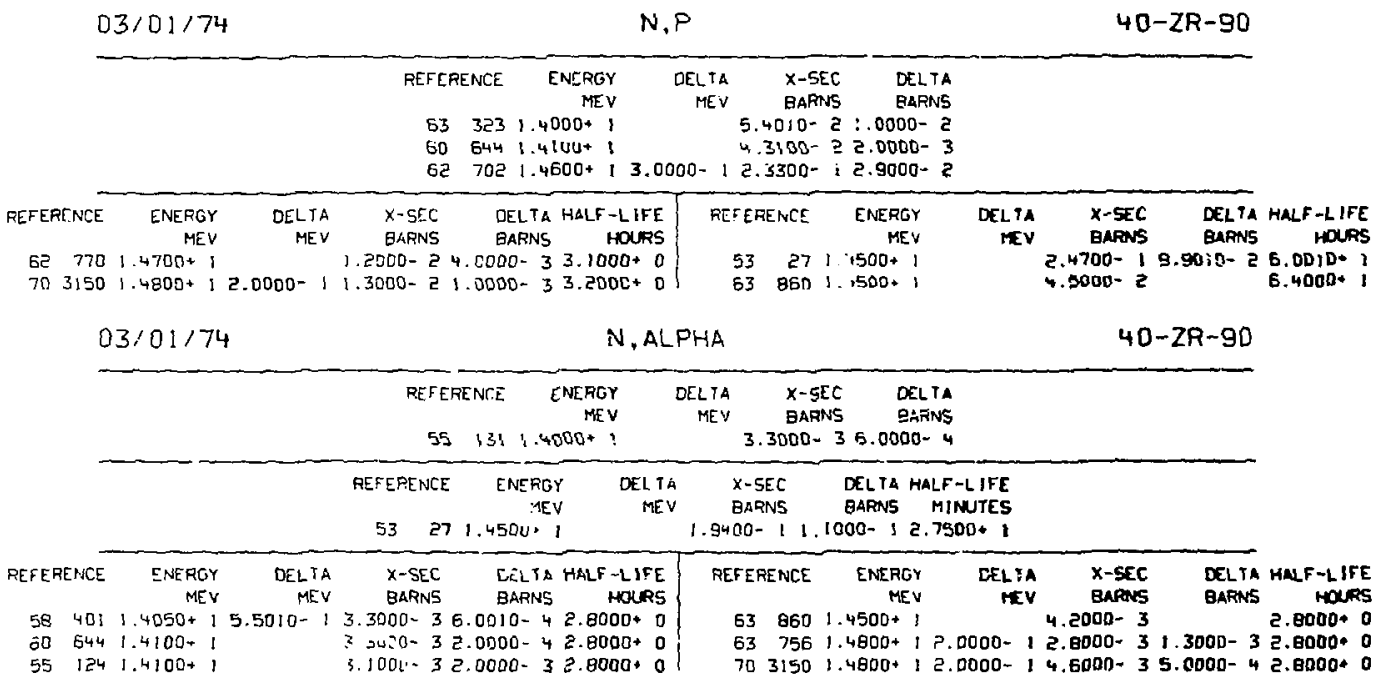




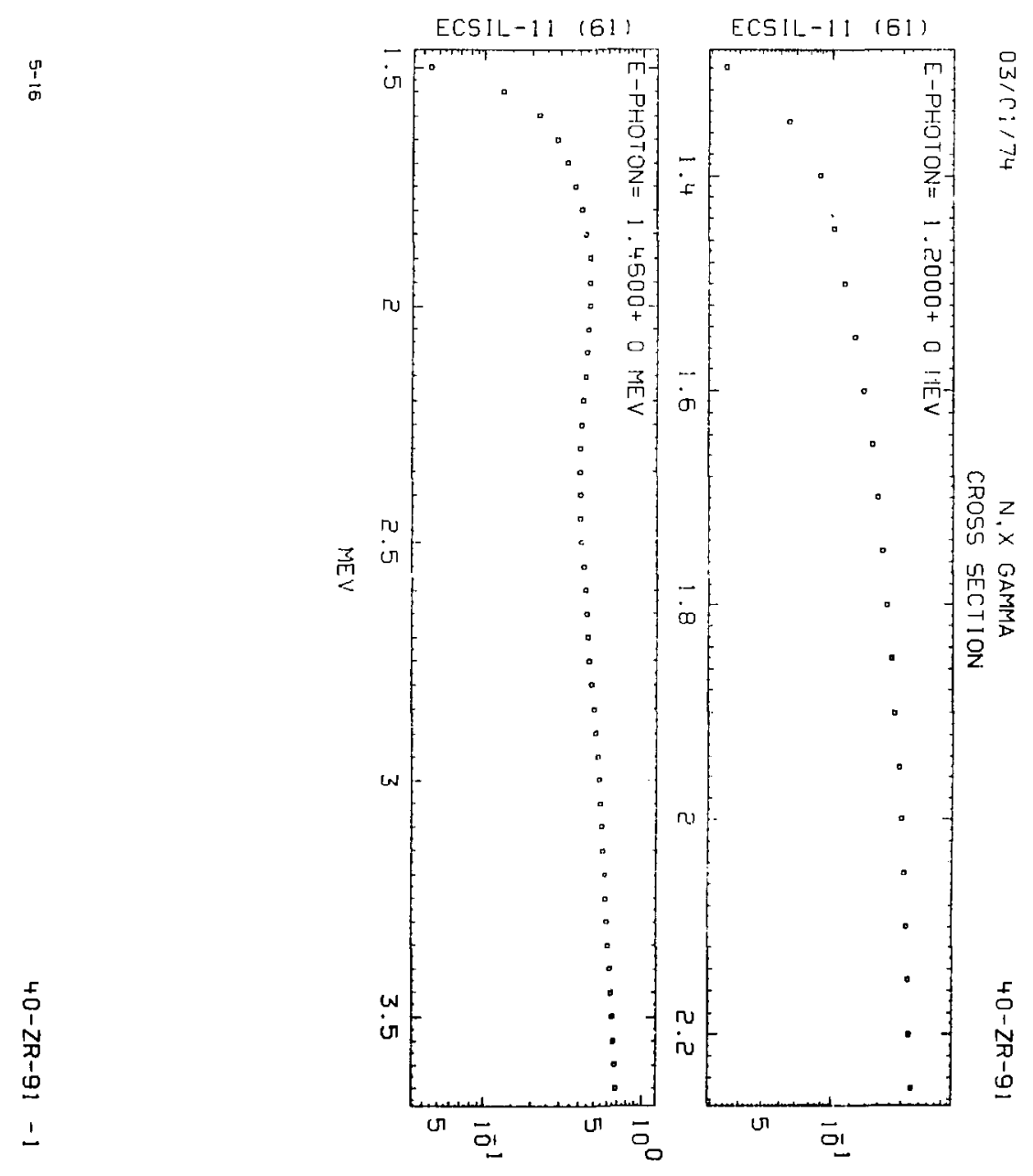

BARNS 


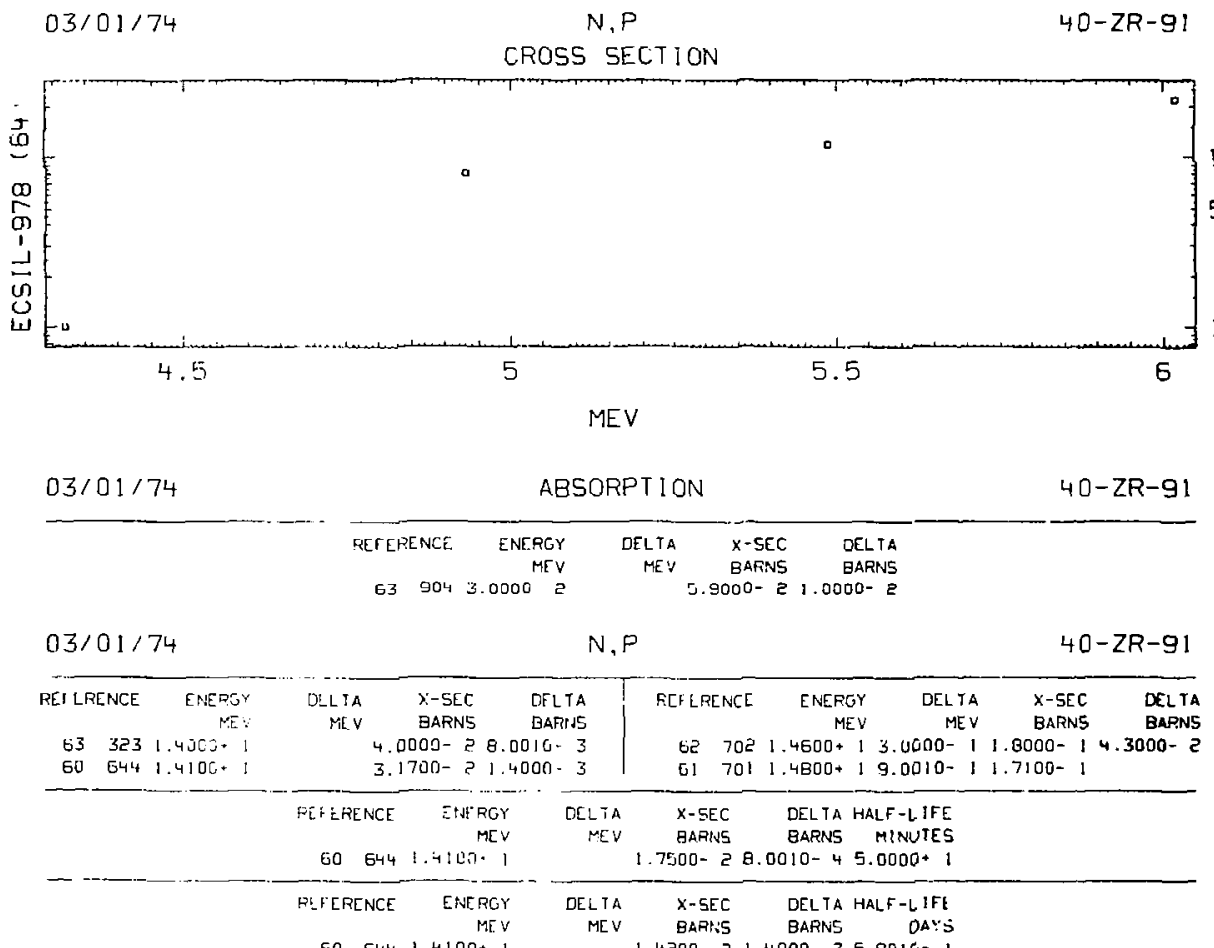

50 $6441.4100+1 \quad$ MEV $1.4200-21.4000-35.801 \% 1$ 

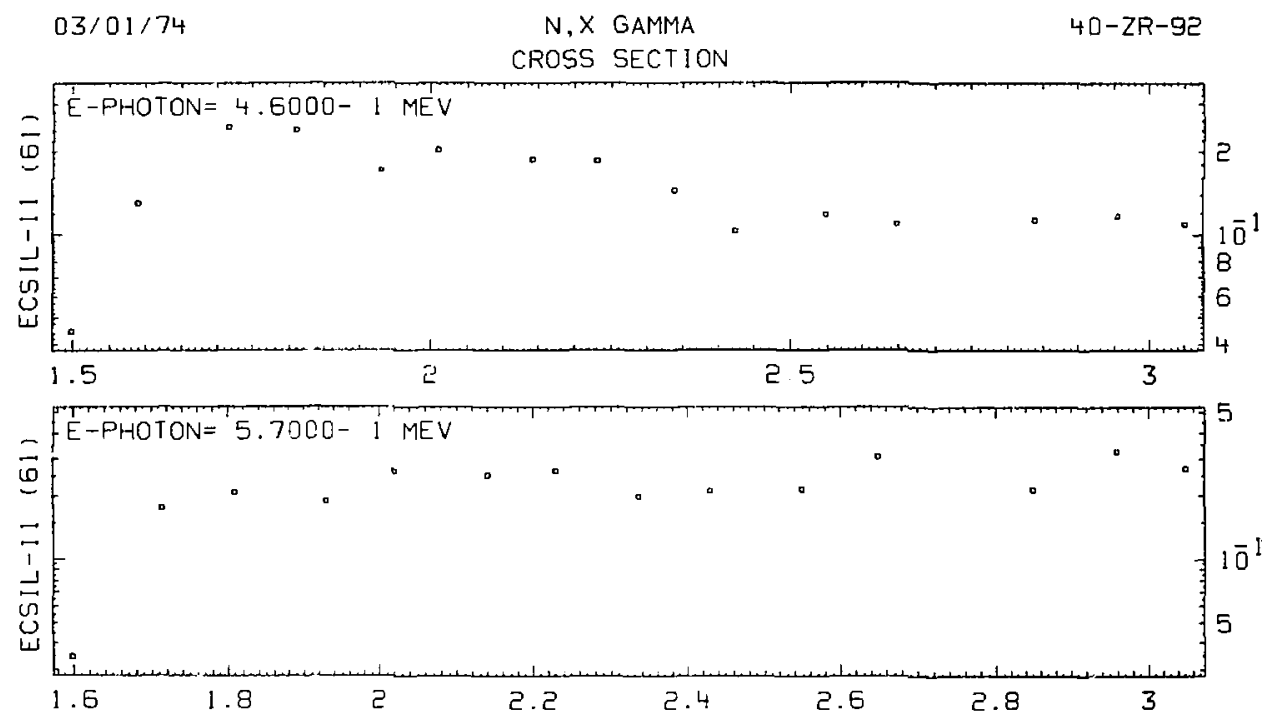

$\frac{n}{\frac{\pi}{0}}$

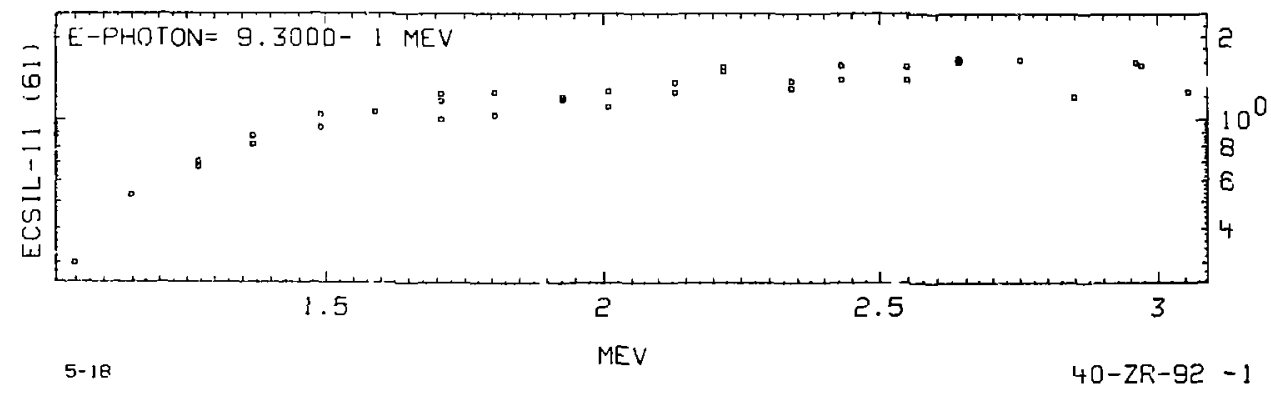




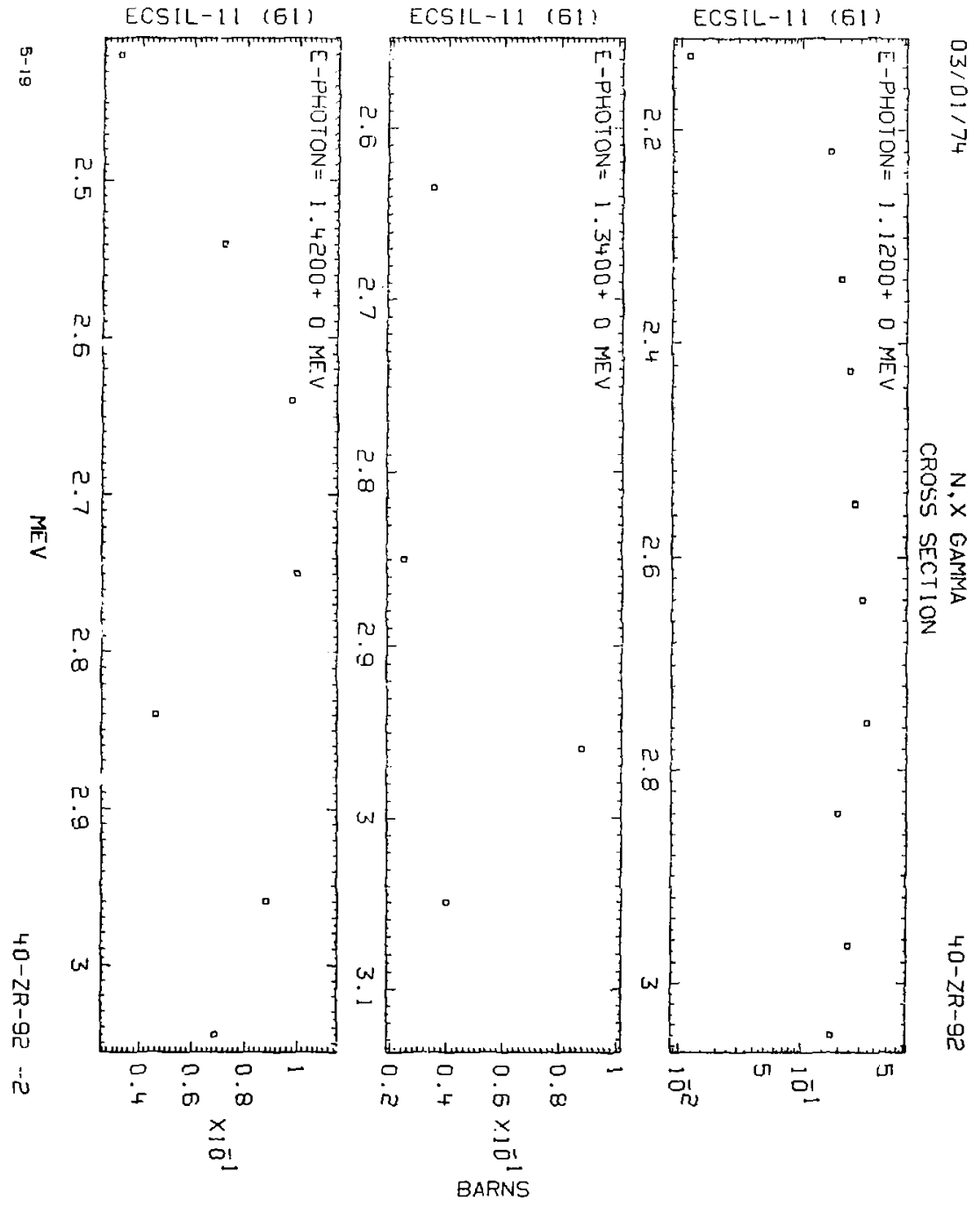




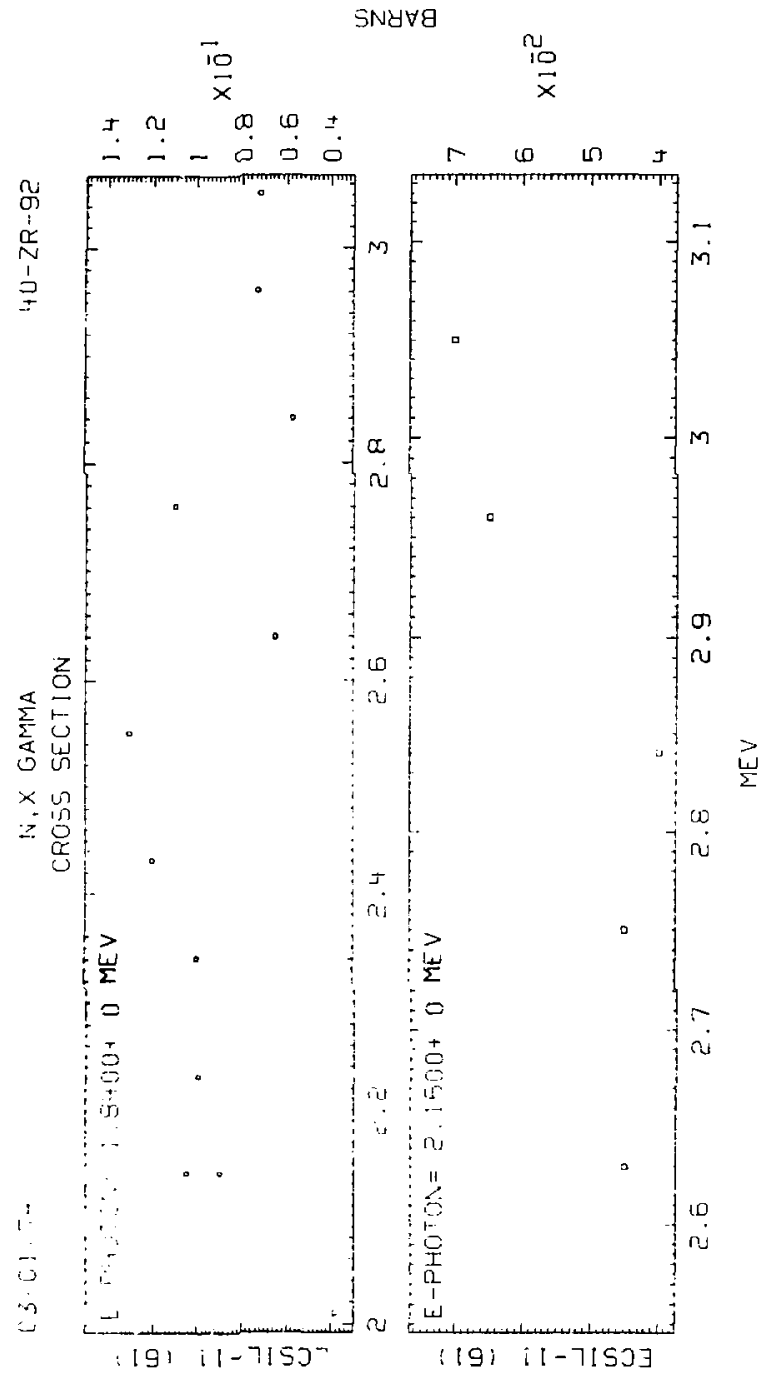

$M$
1
$\widetilde{W}$
1
1
$\mathbb{N}$
1
0
$\mathcal{J}$

品 

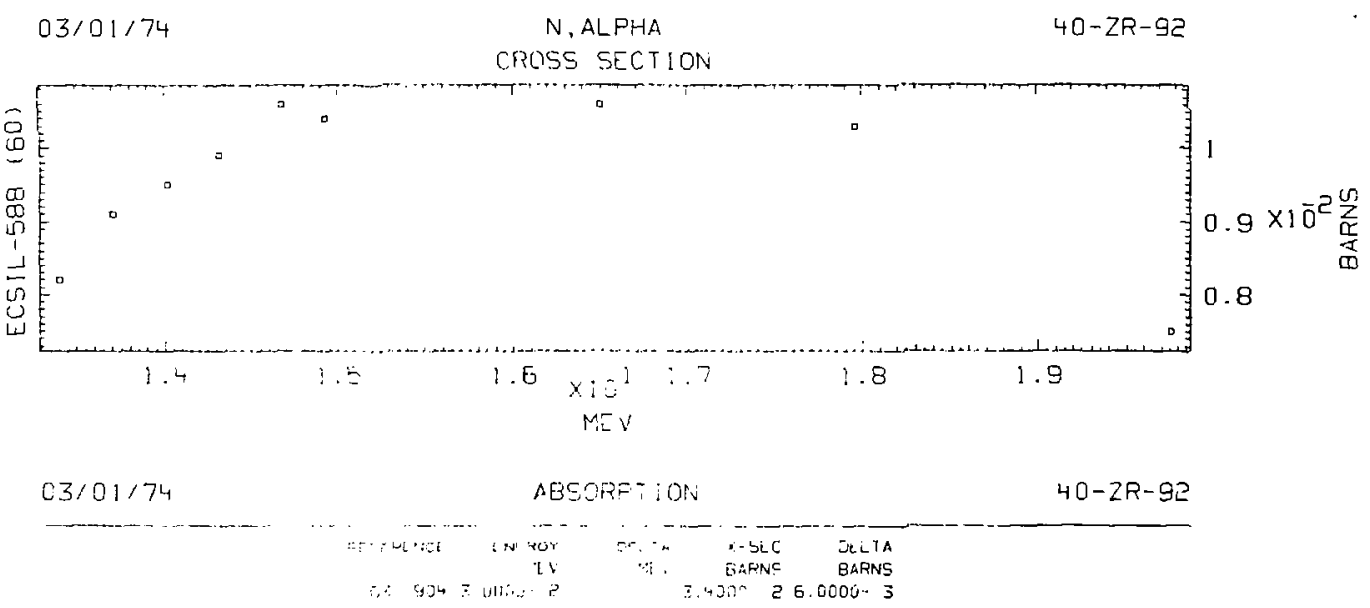

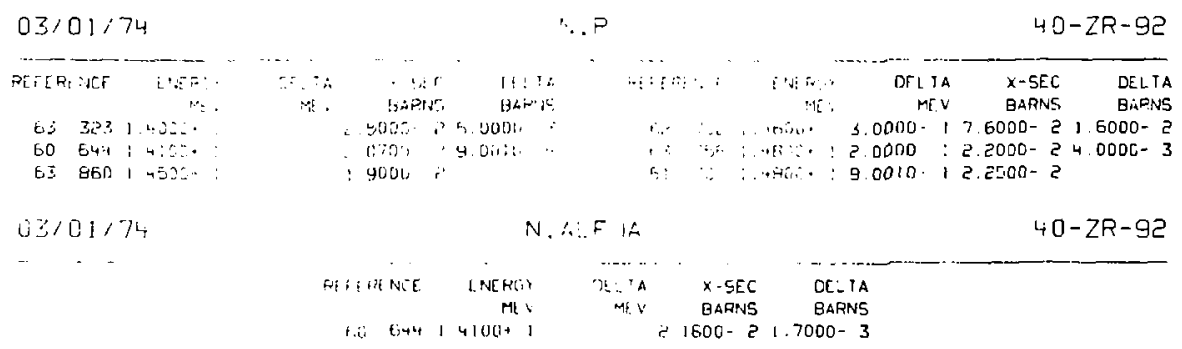




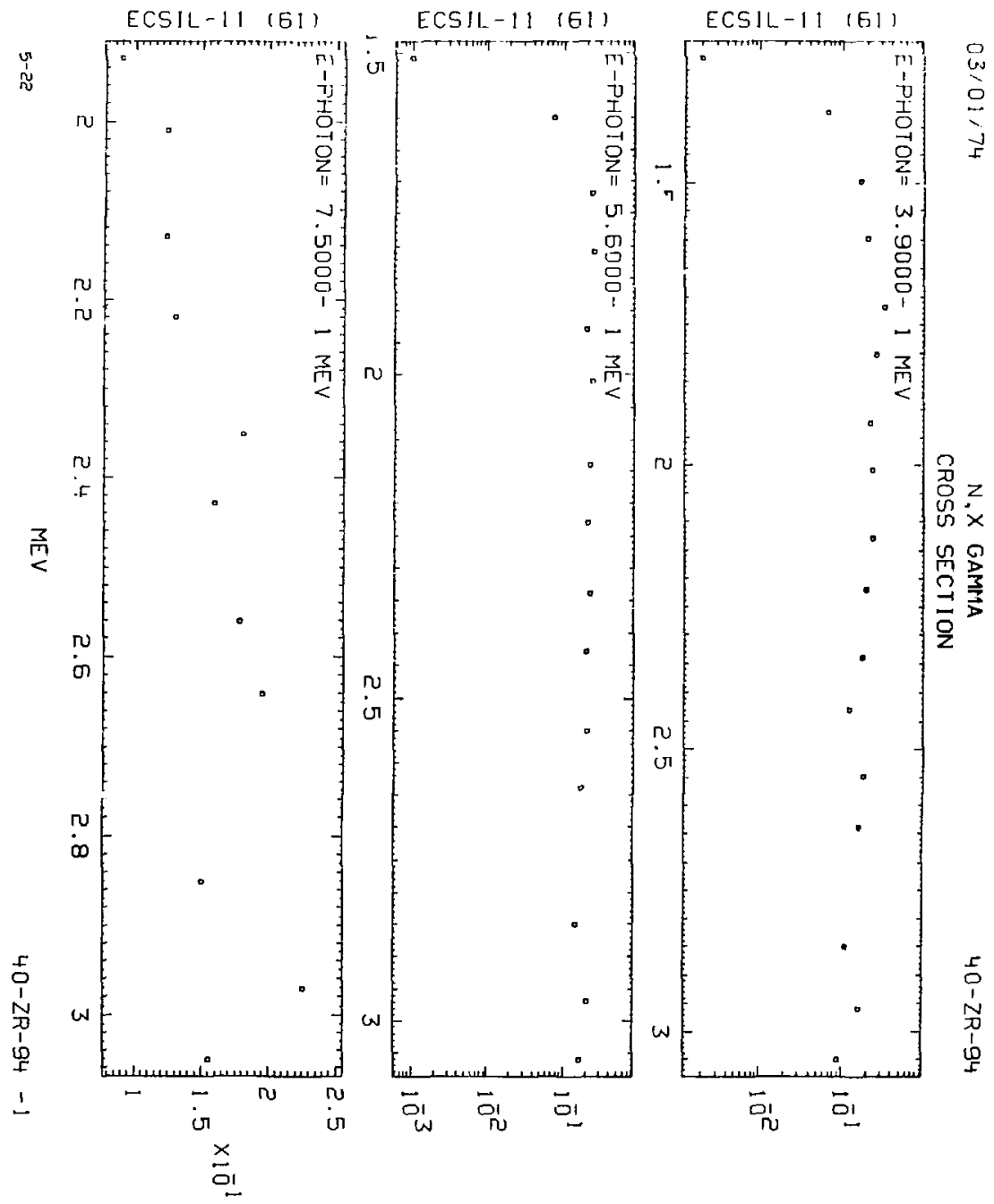

BARNS 

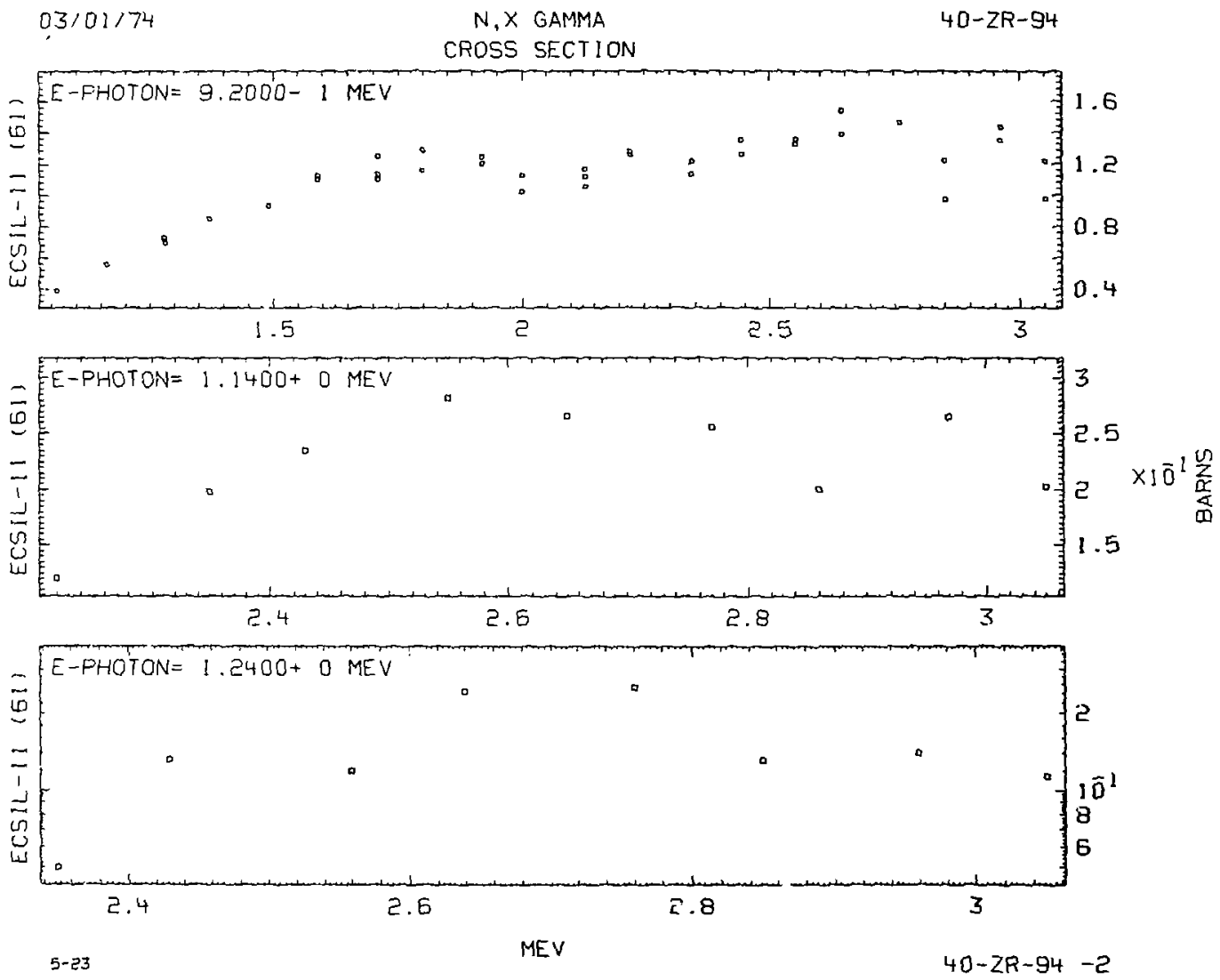


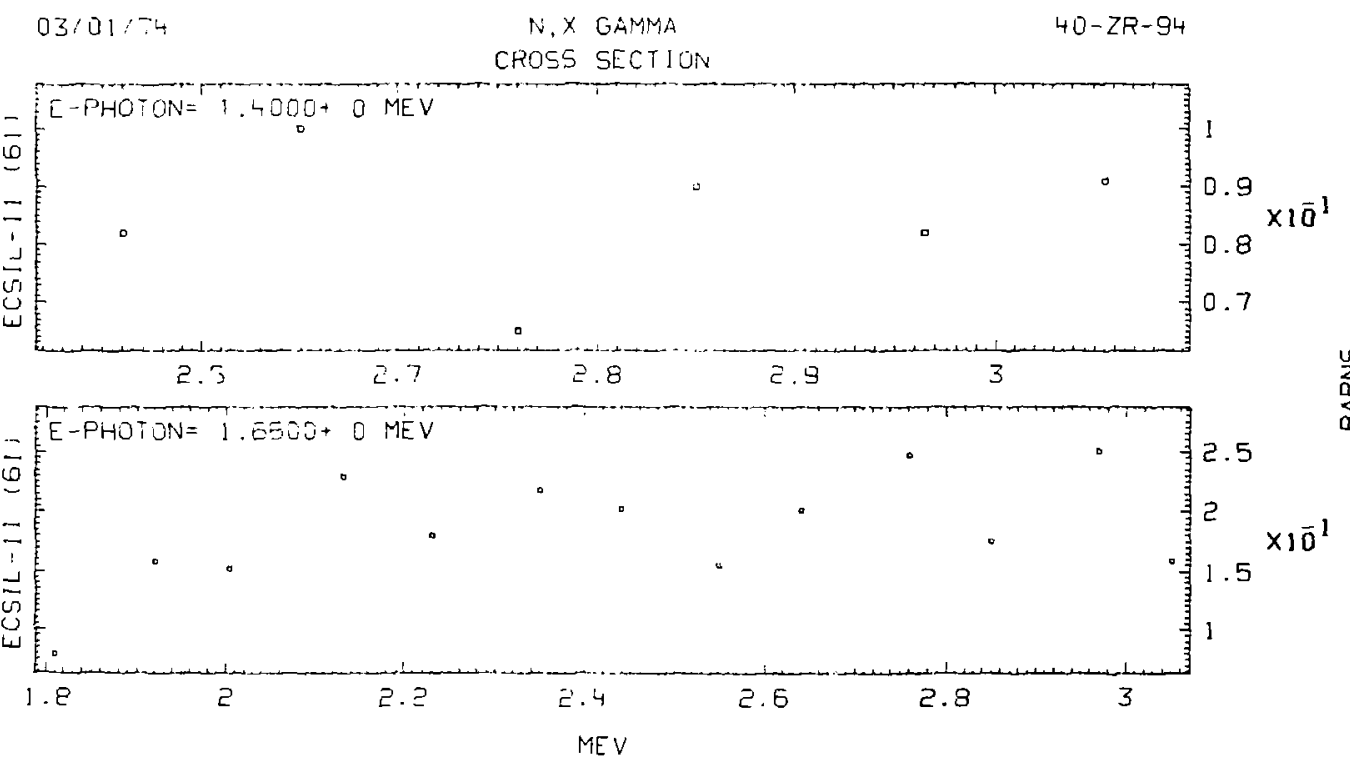

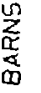




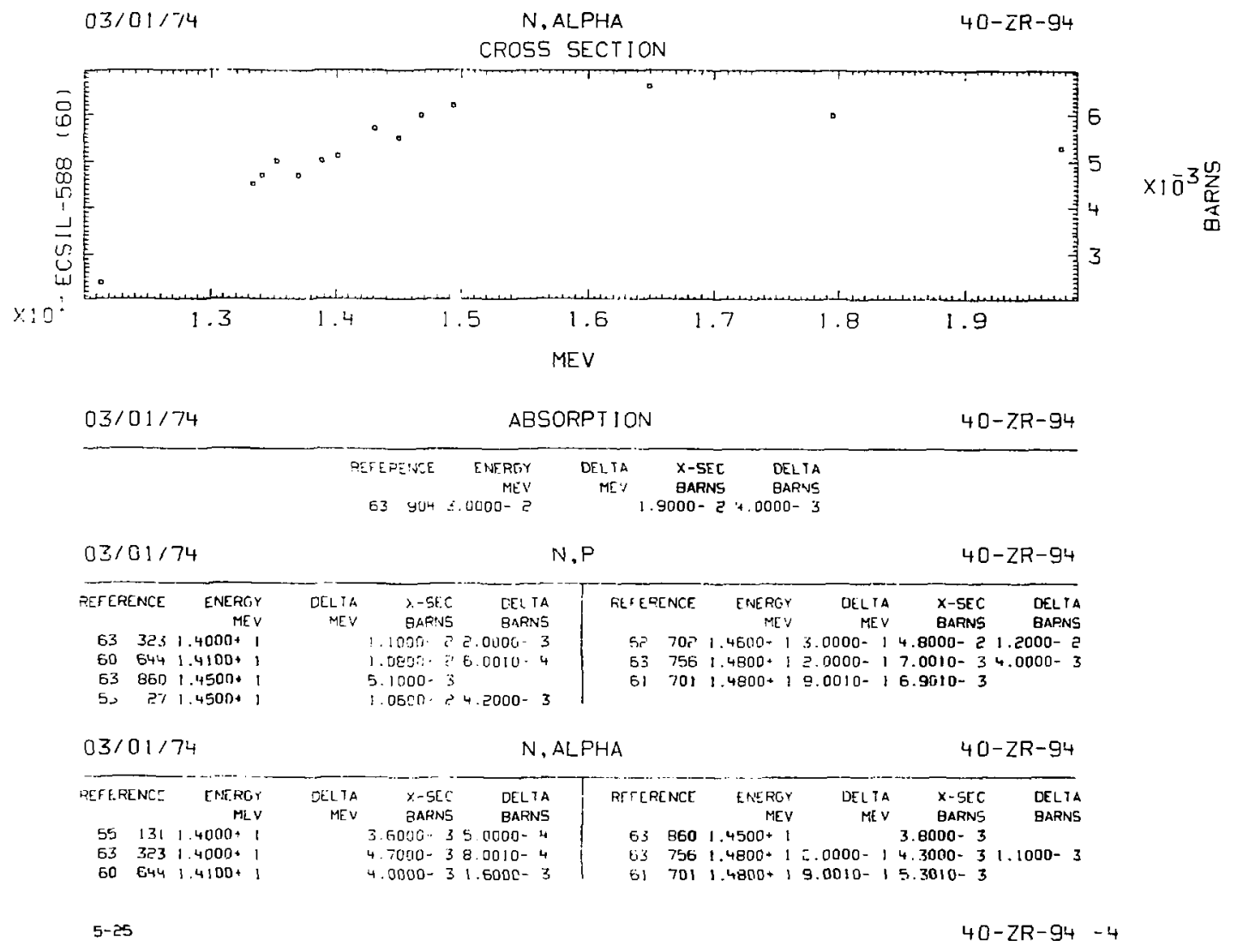


ABSORPTION
CROSS SECTION

$40-Z R-96$

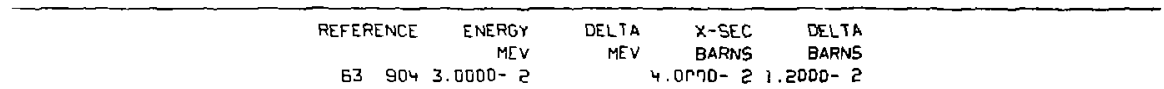

$639043.0000=$ 4. ORnO- $21.2000-2$

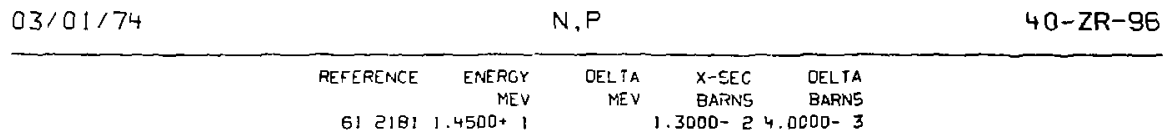

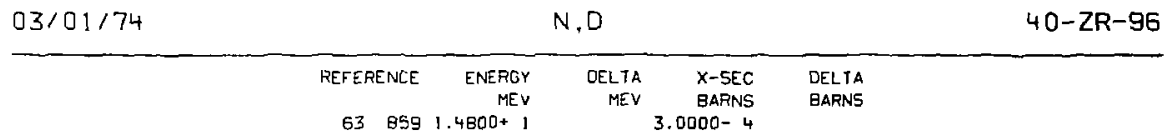

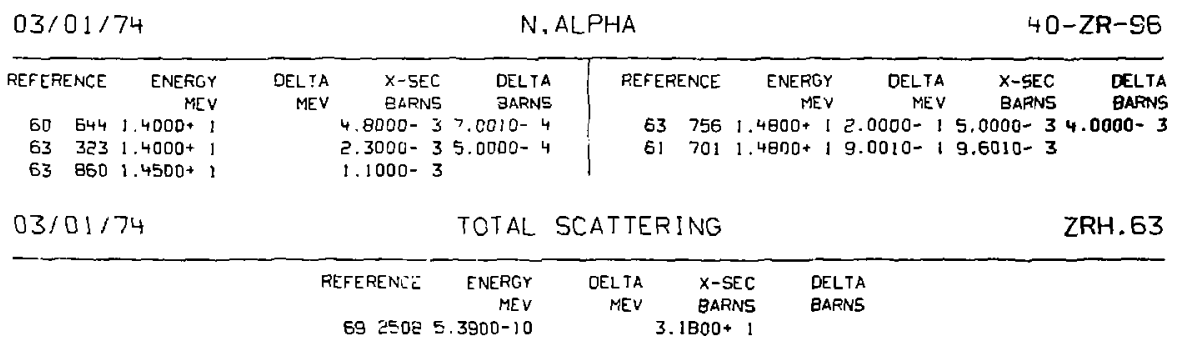

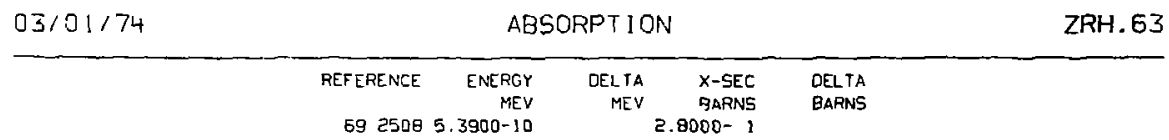




\section{$03 / 01 / 74$}

TOTAL SCATTERING

CROSS SECTION

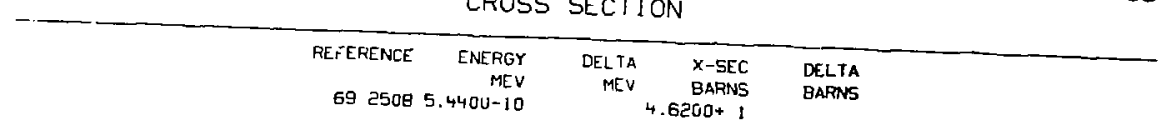

O3/01/74

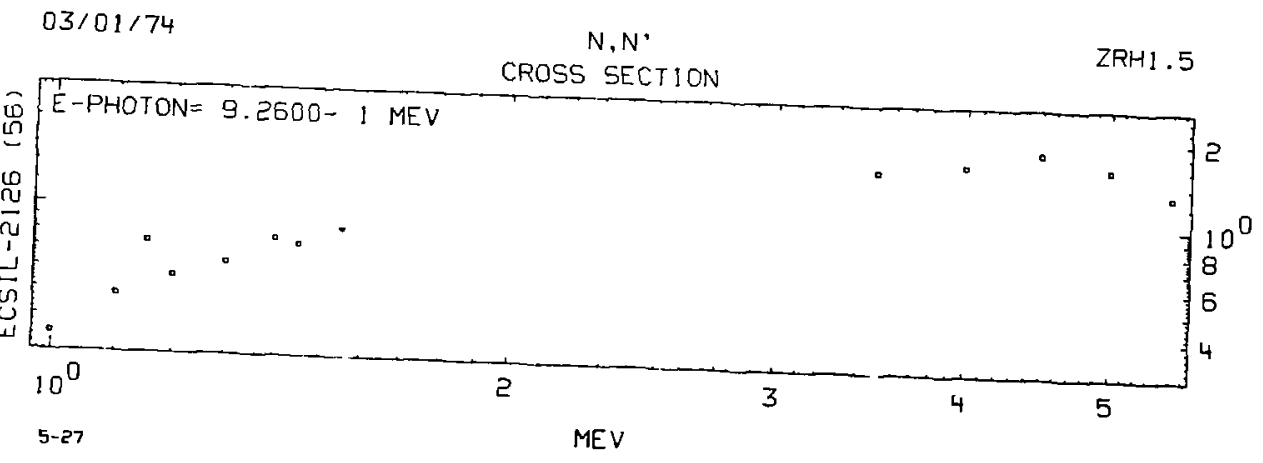


CHOSS SECTION

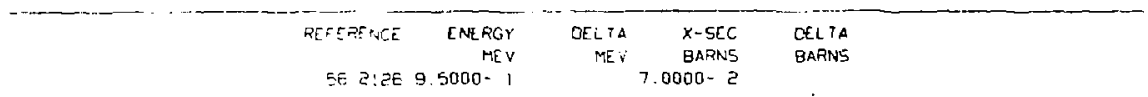

03/01/74

\begin{tabular}{|c|c|c|c|c|c|c|}
\hline $03 / 01 / 74$ & \multicolumn{4}{|c|}{ ABSORPT ION } & & ZPH J.998 \\
\hline & $\partial_{E}=-D_{E}$ & $\begin{array}{r}\text { ENERGY } \\
\text { MEV }\end{array}$ & $\begin{array}{l}\text { DELTA } \\
\text { MEV }\end{array}$ & $\begin{array}{l}x-5 E C \\
\text { BARISS }\end{array}$ & $\begin{array}{l}\text { DELIA } \\
\text { PAENS }\end{array}$ & \\
\hline
\end{tabular}

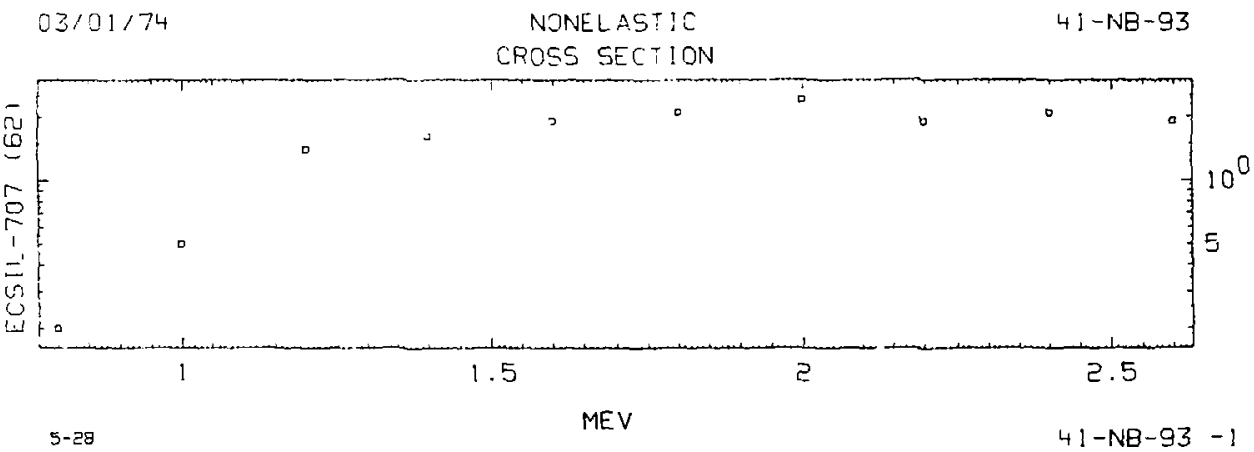




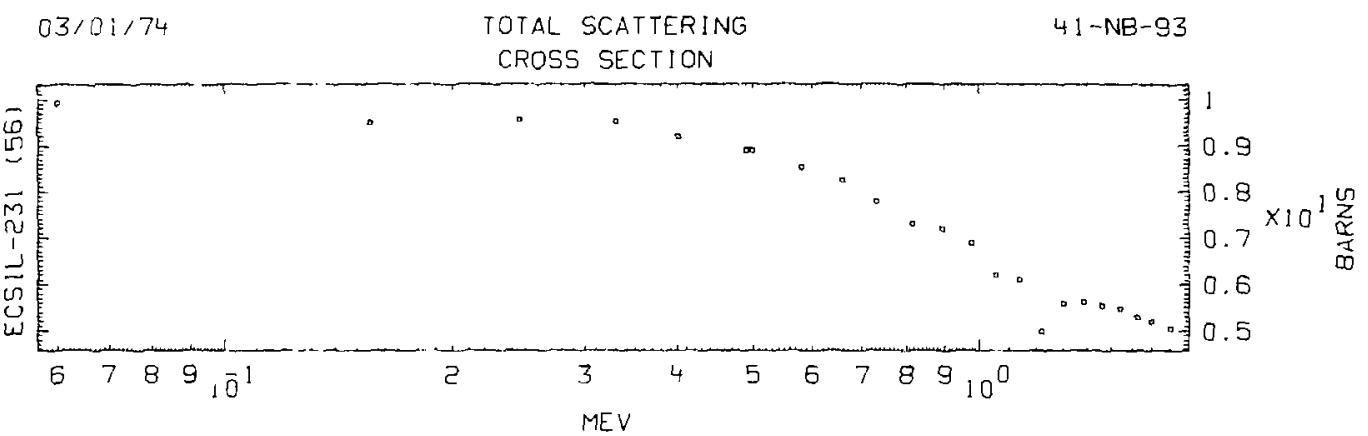
$03 / 01 / 74$
N.N
$41-N B-93$
CROSS SECTION

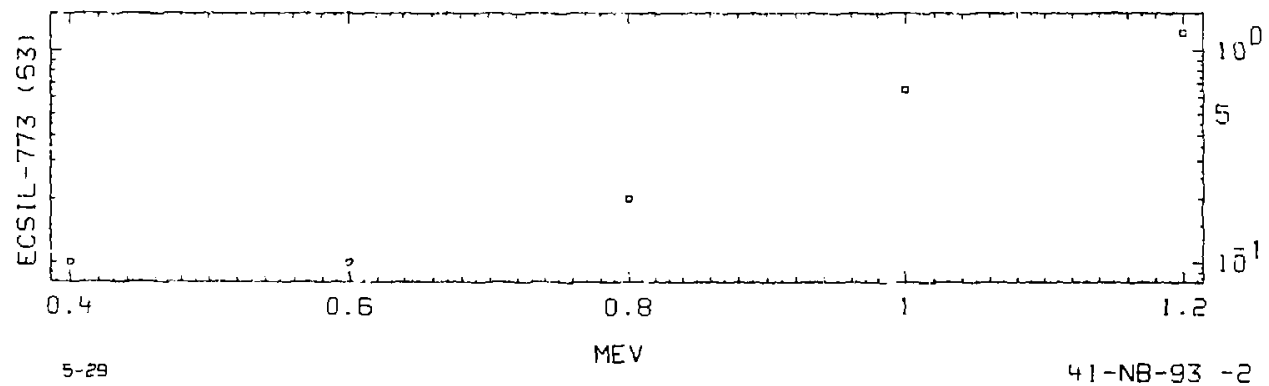



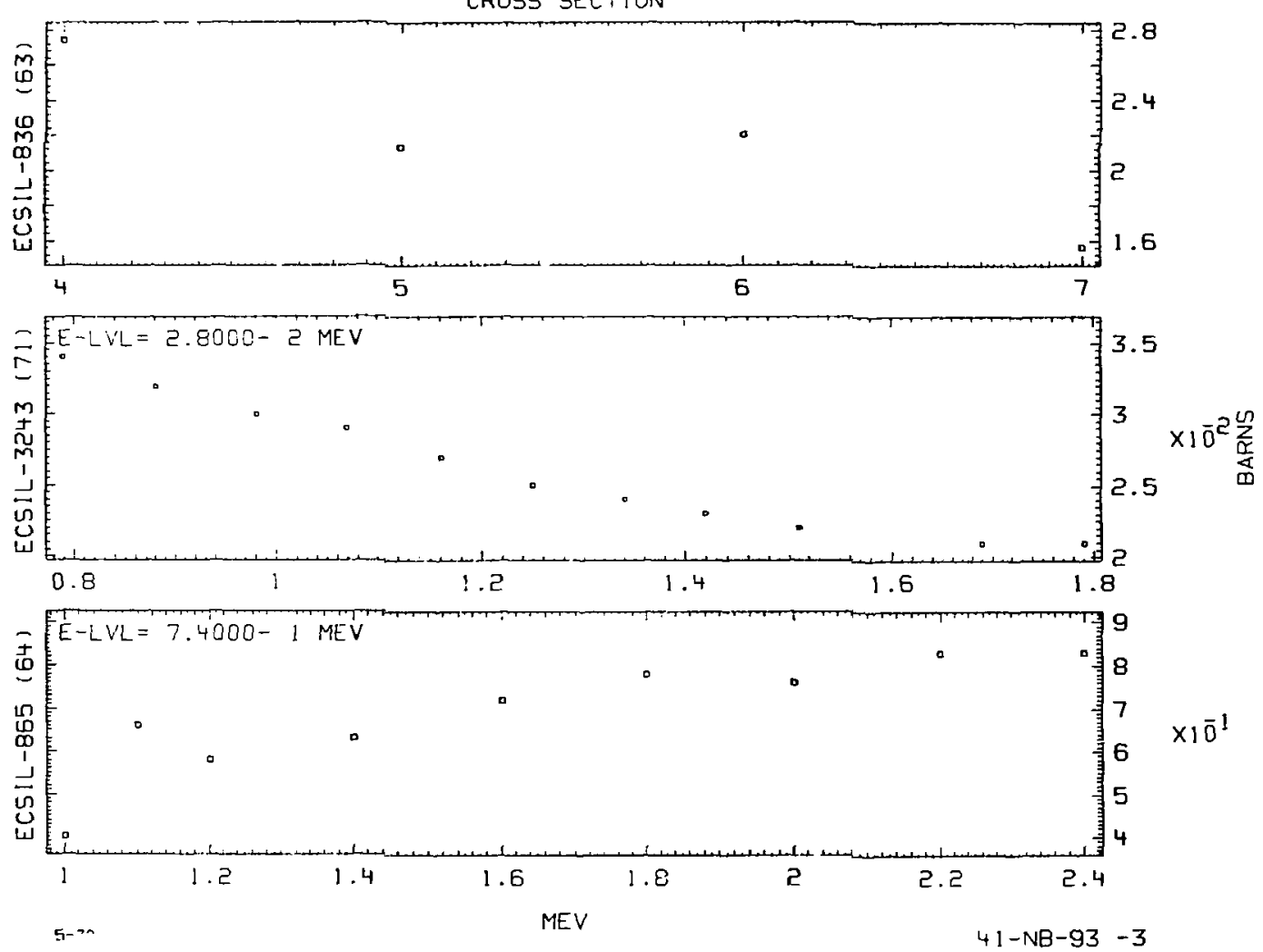

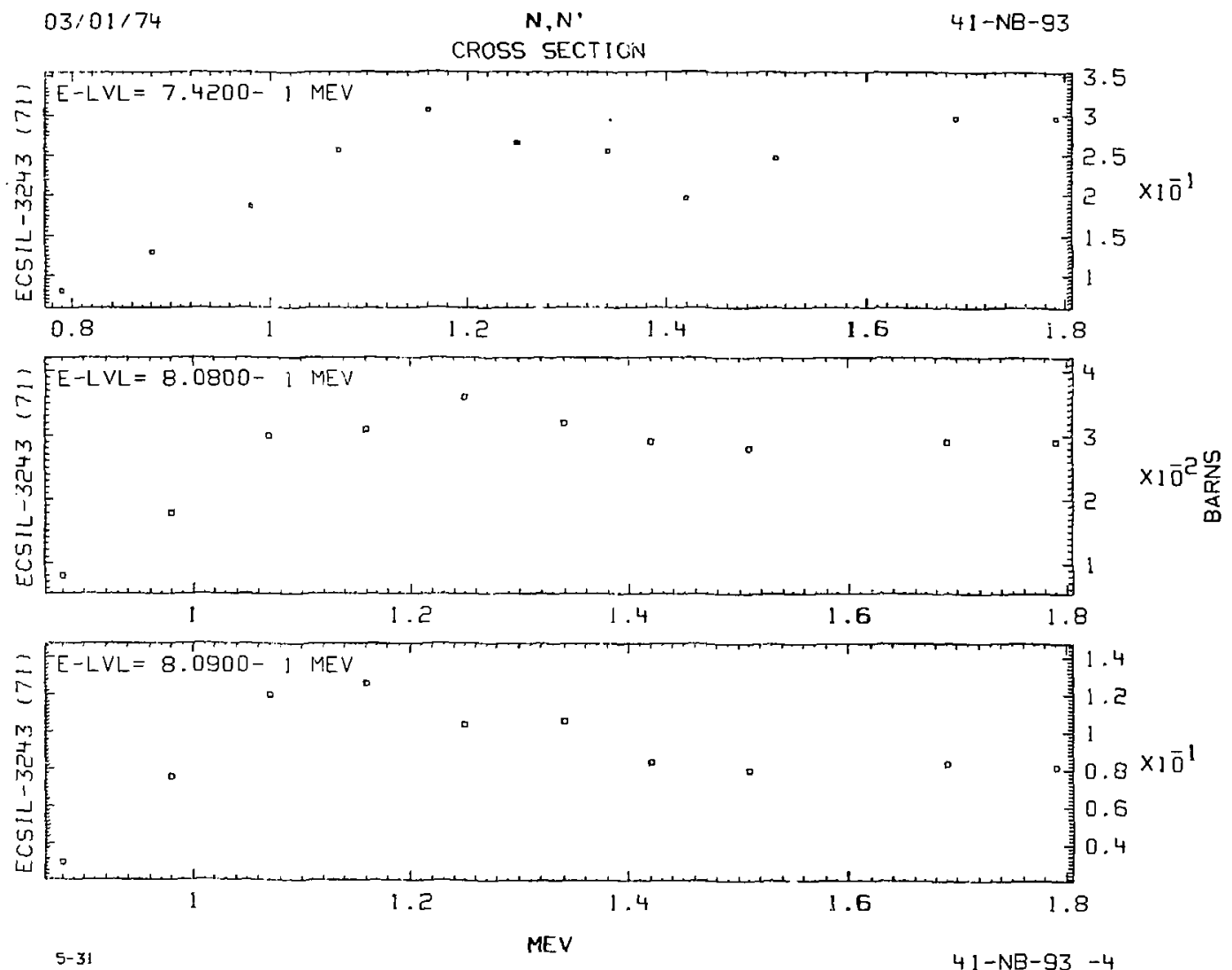


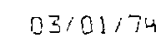

$N, N^{\prime}$

$41-N B-93$

\section{CROSS SECTION}
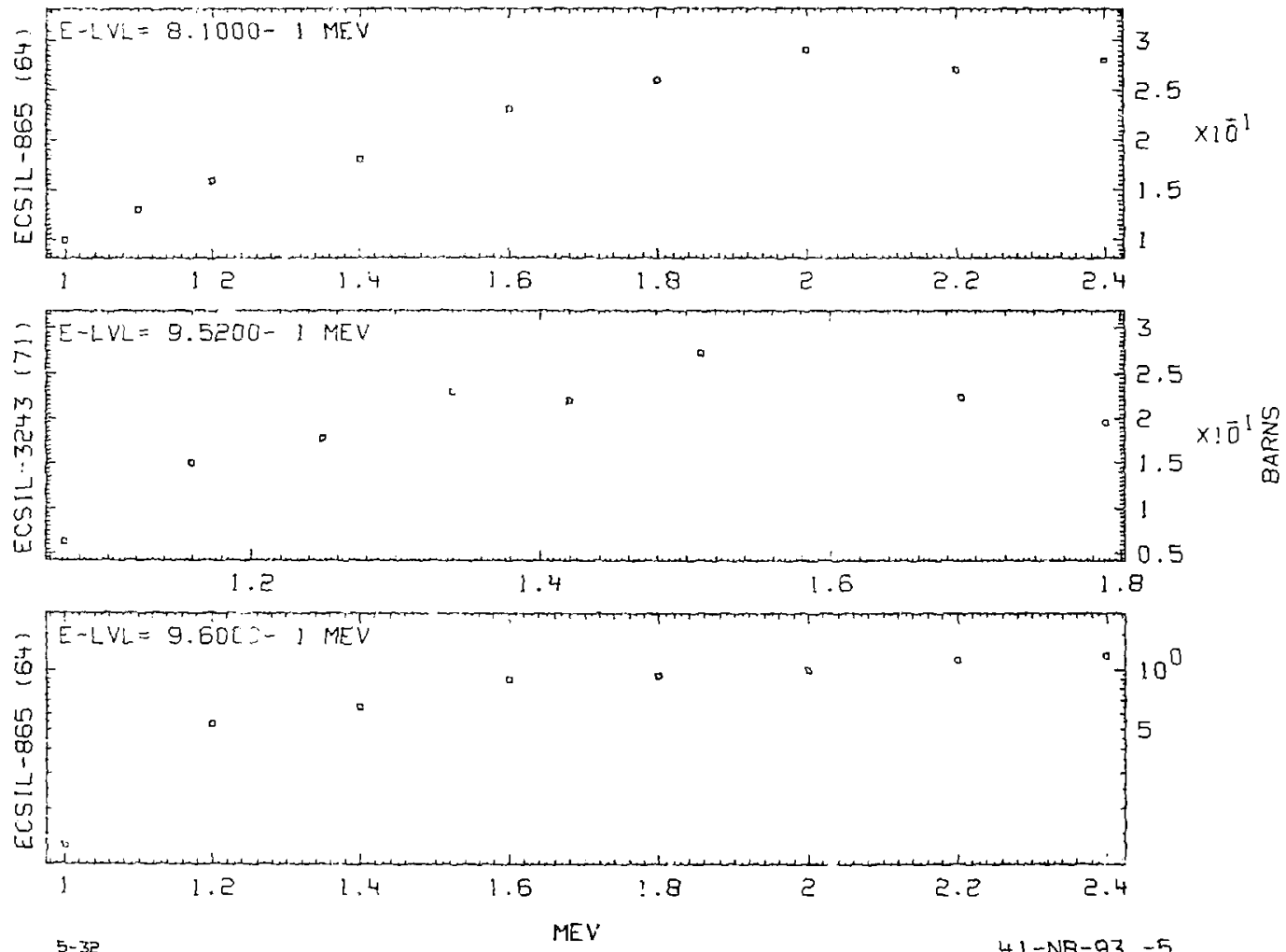

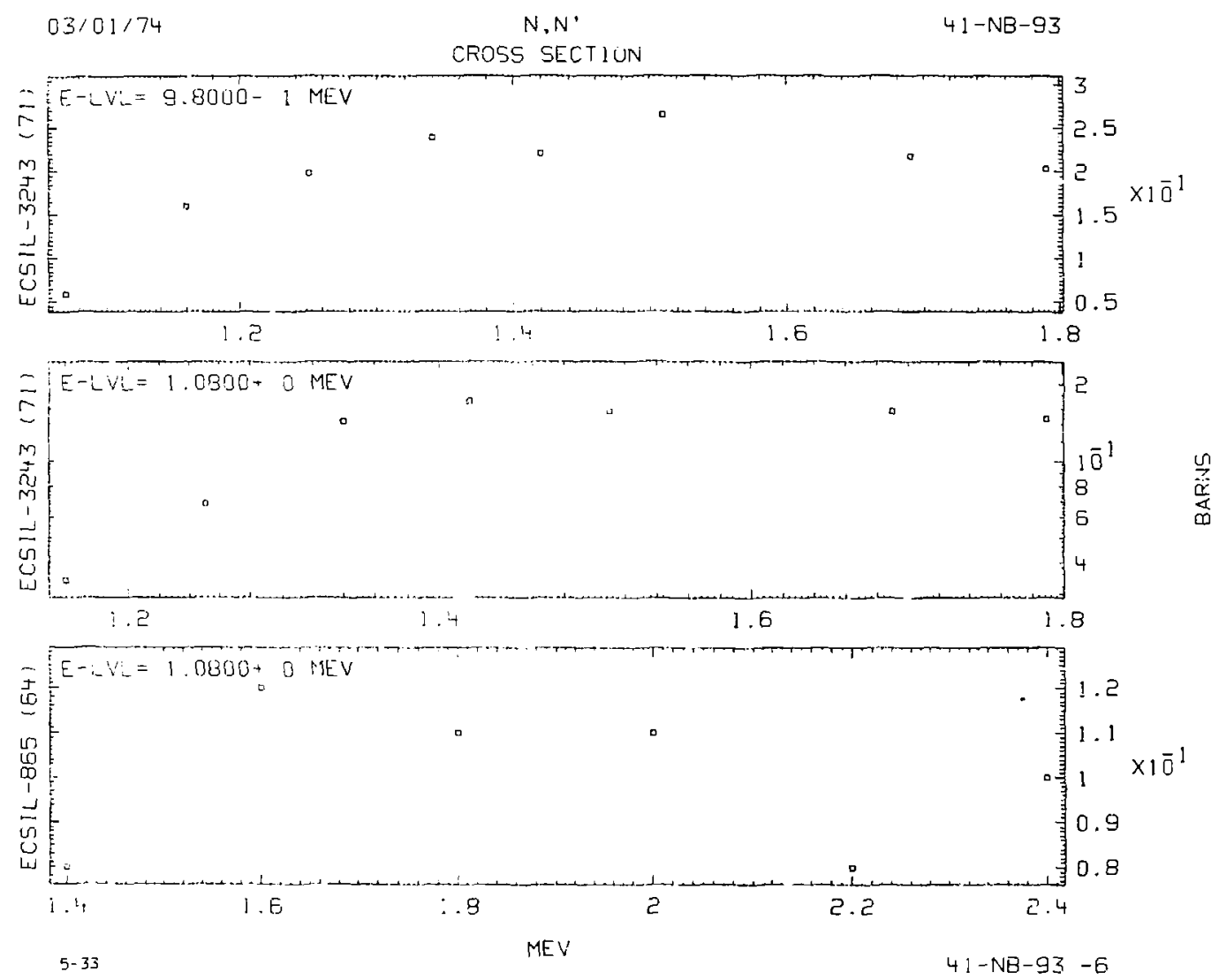

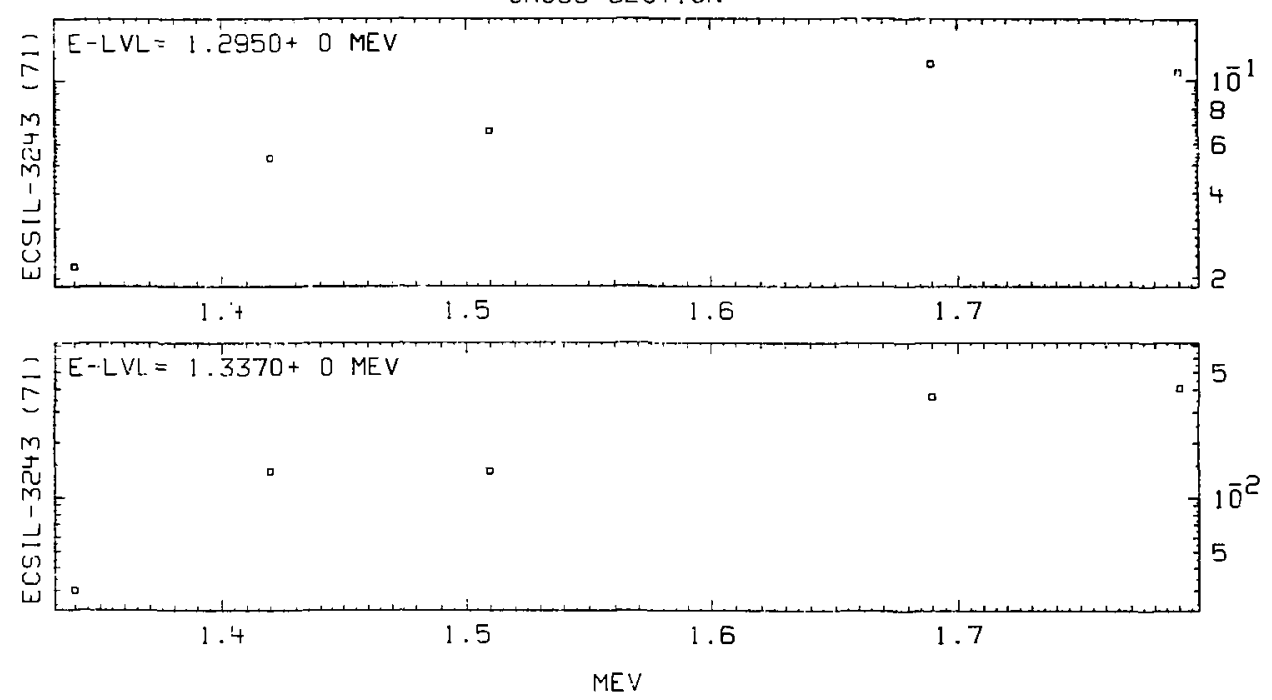

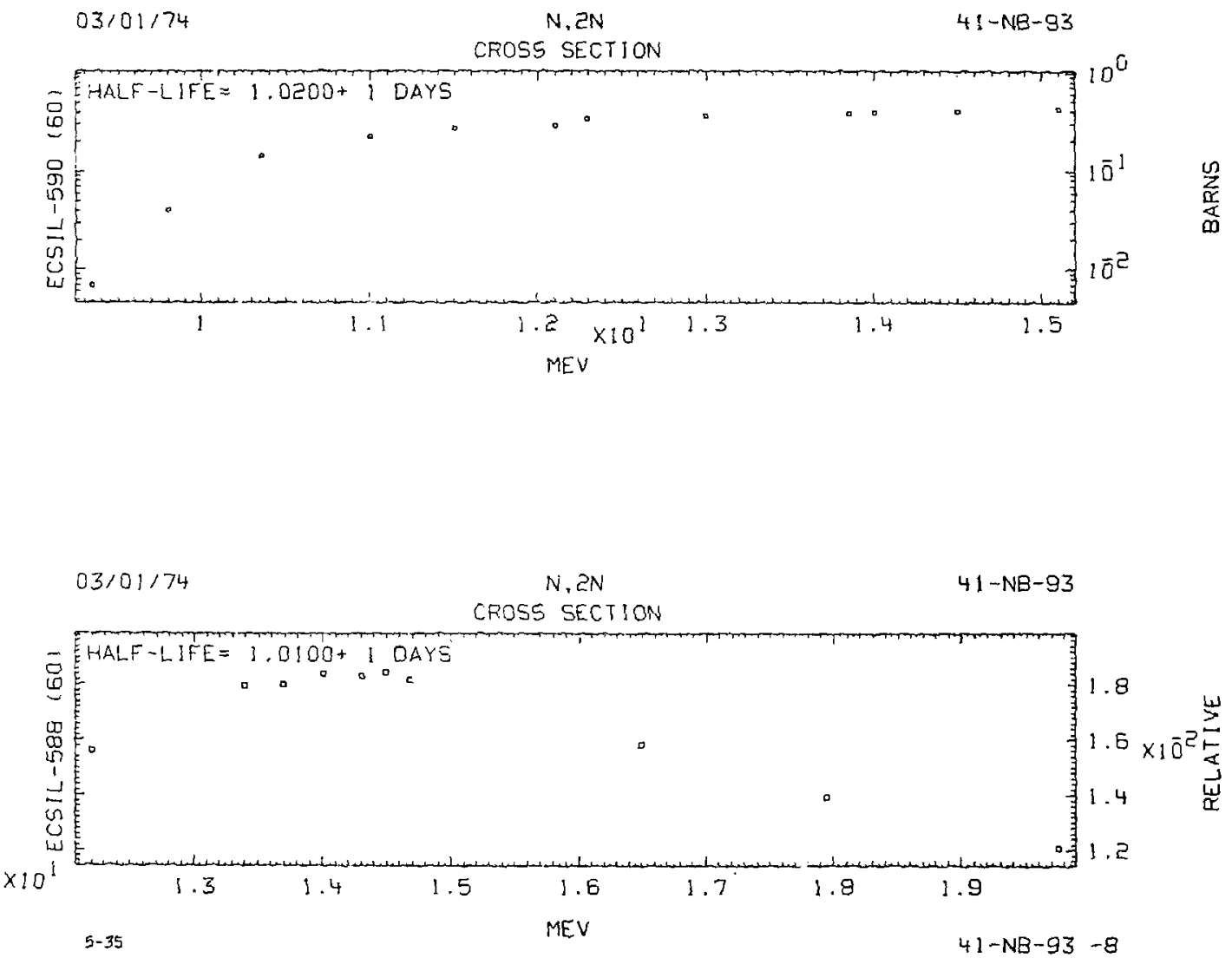

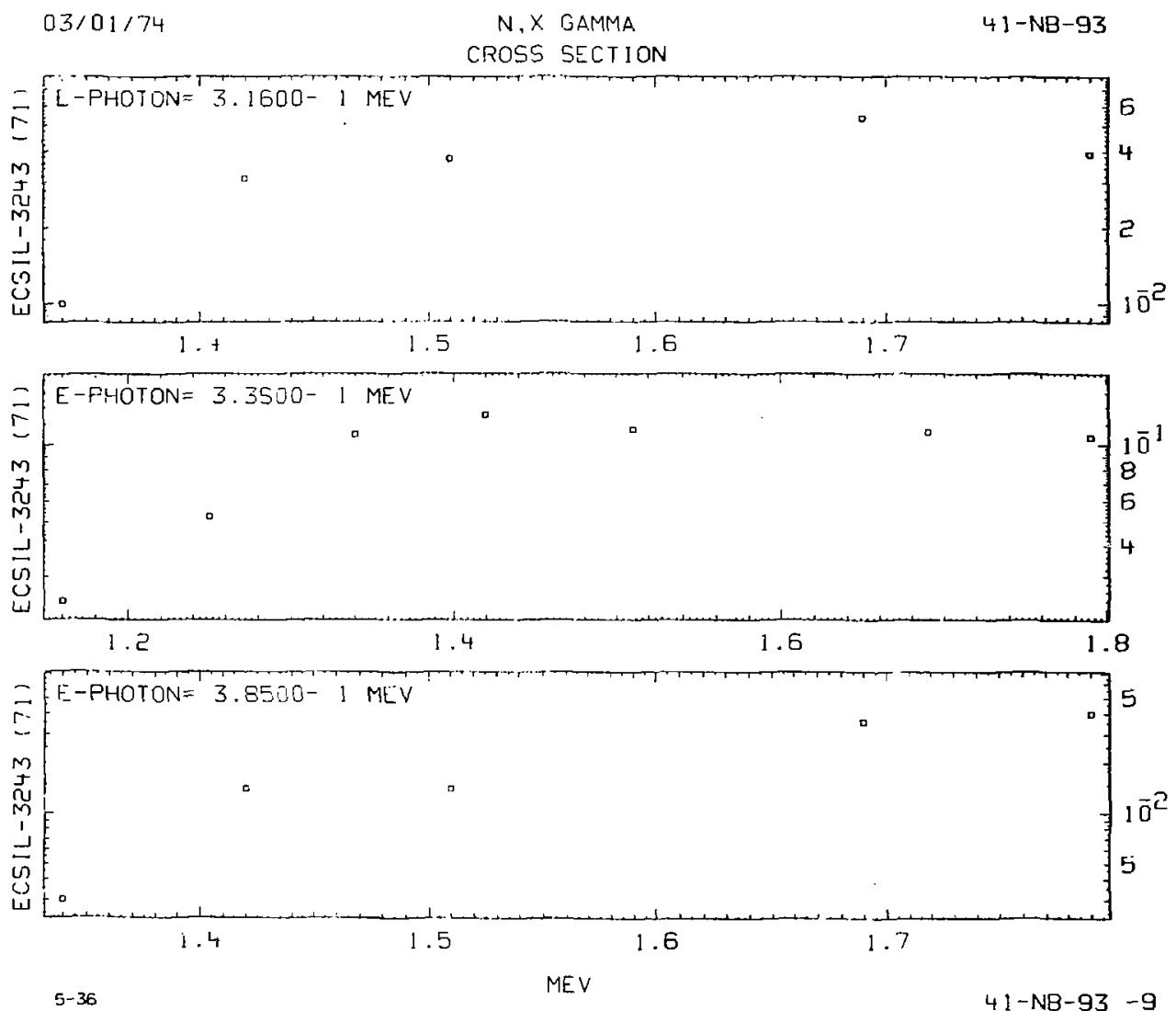

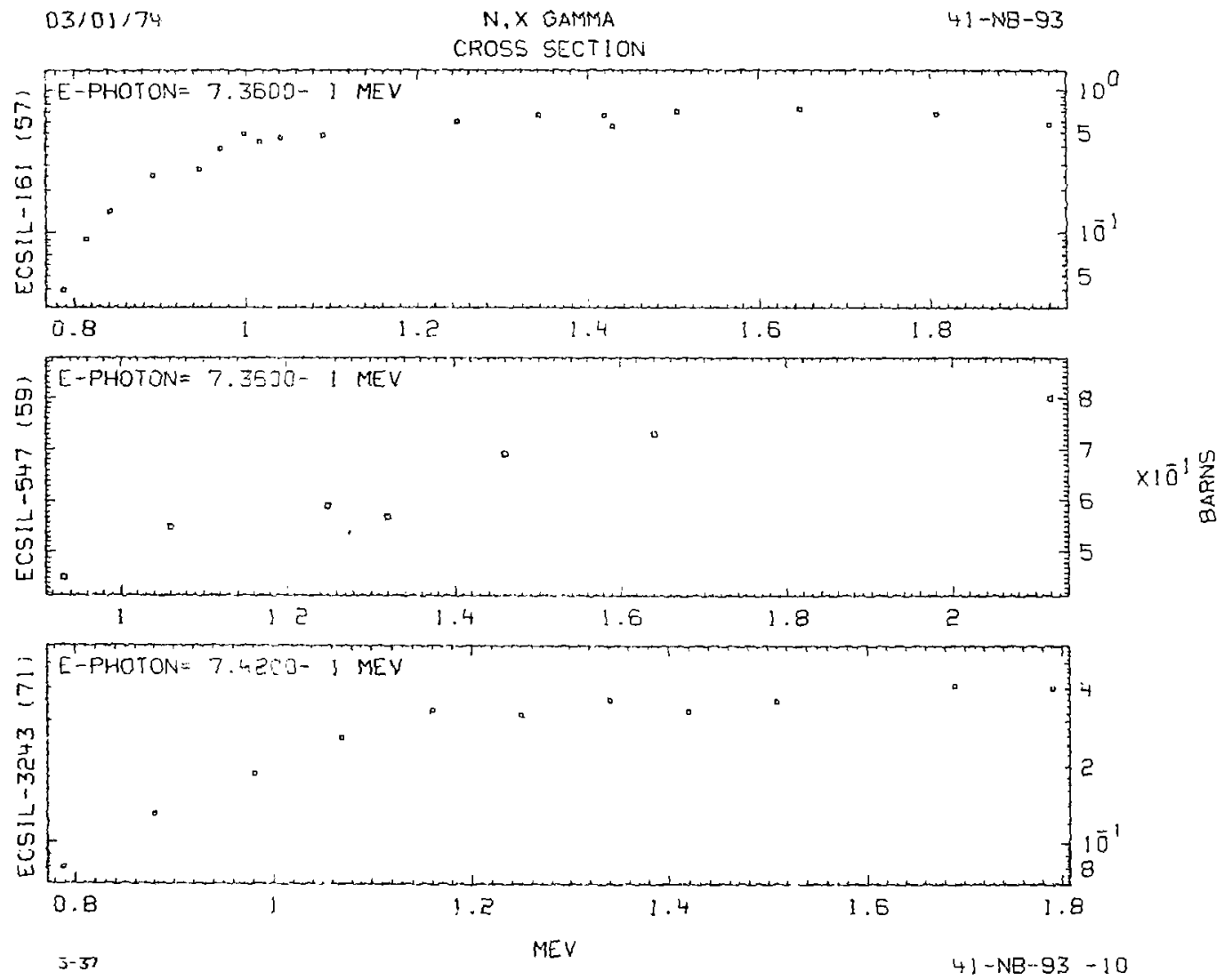

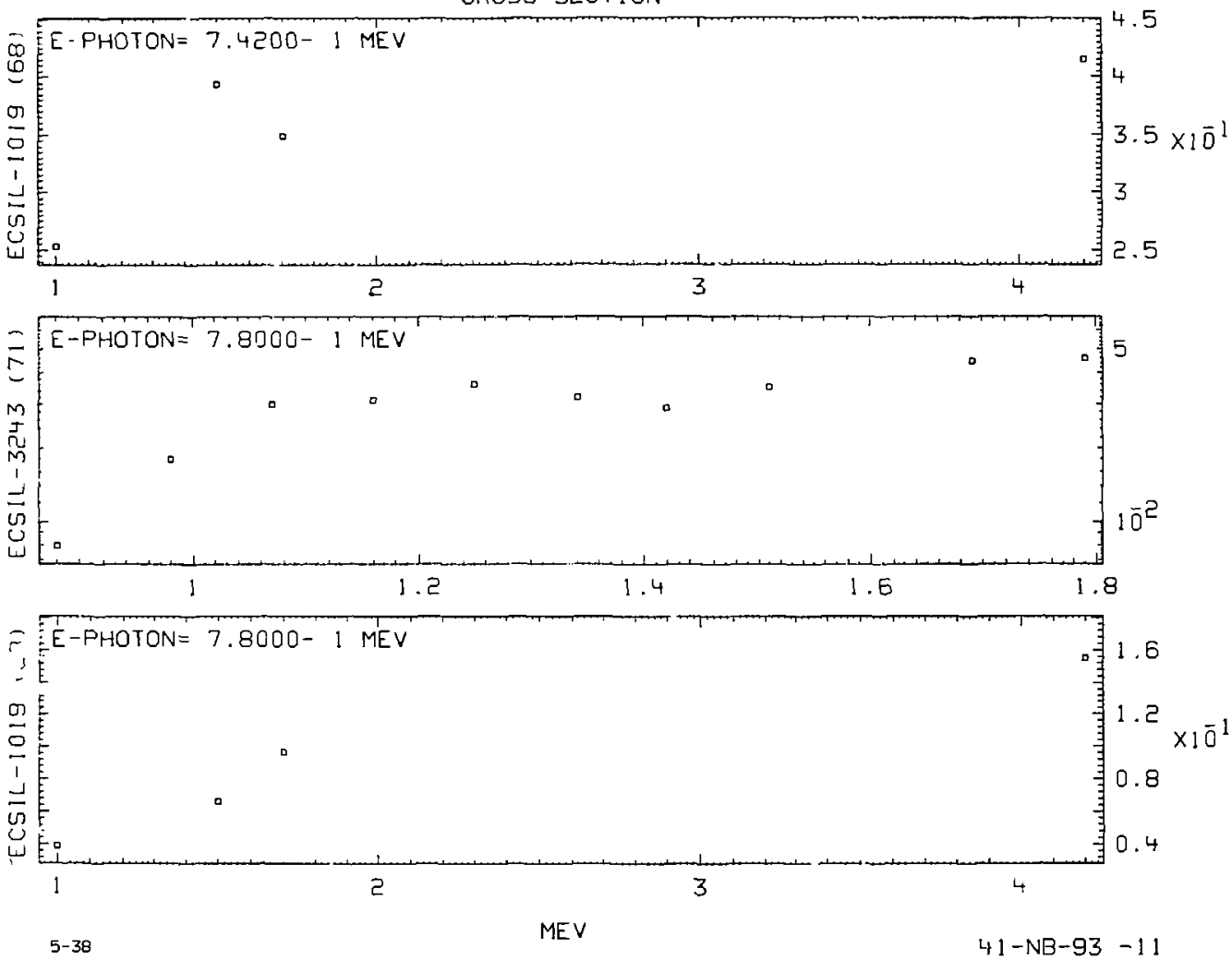

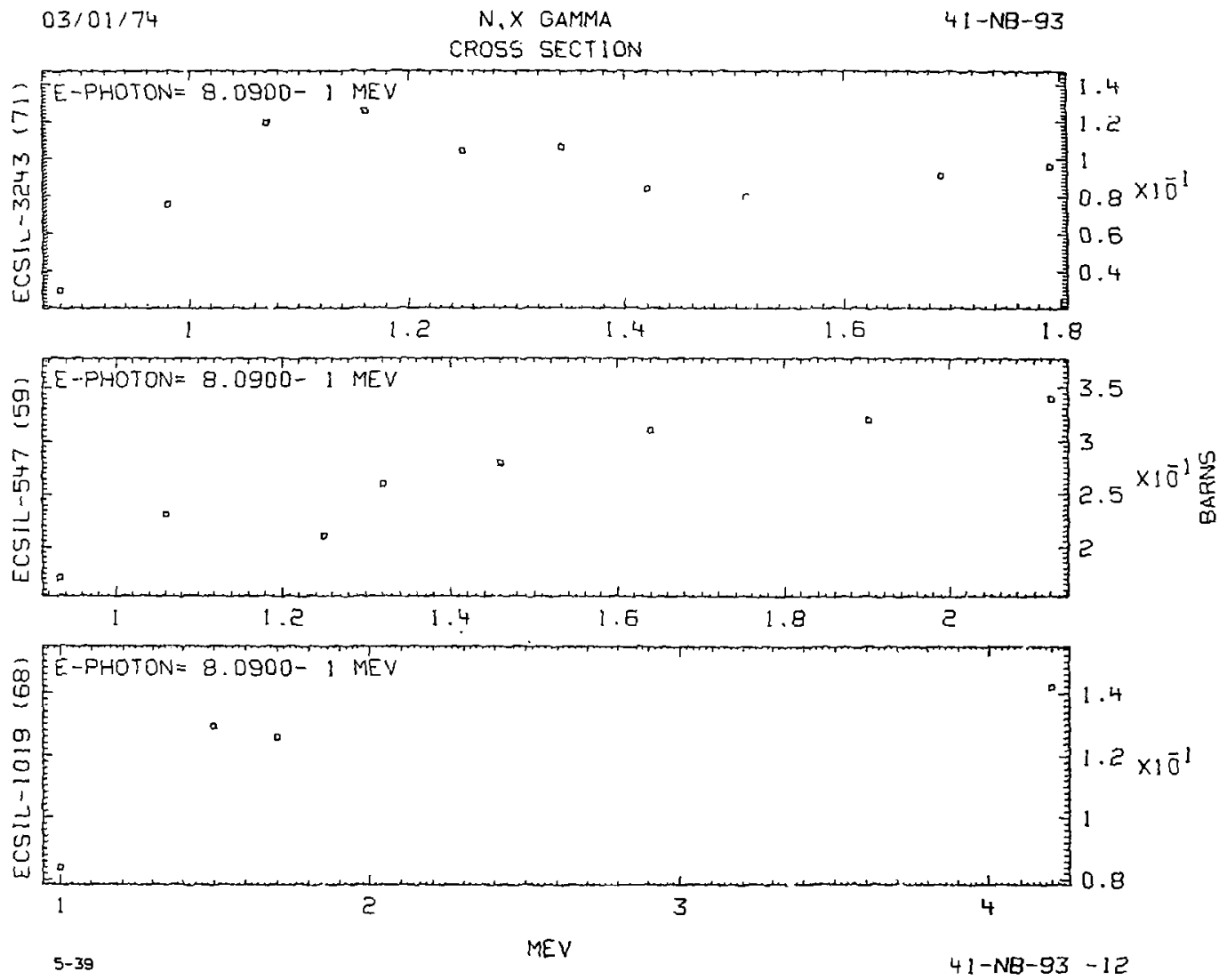


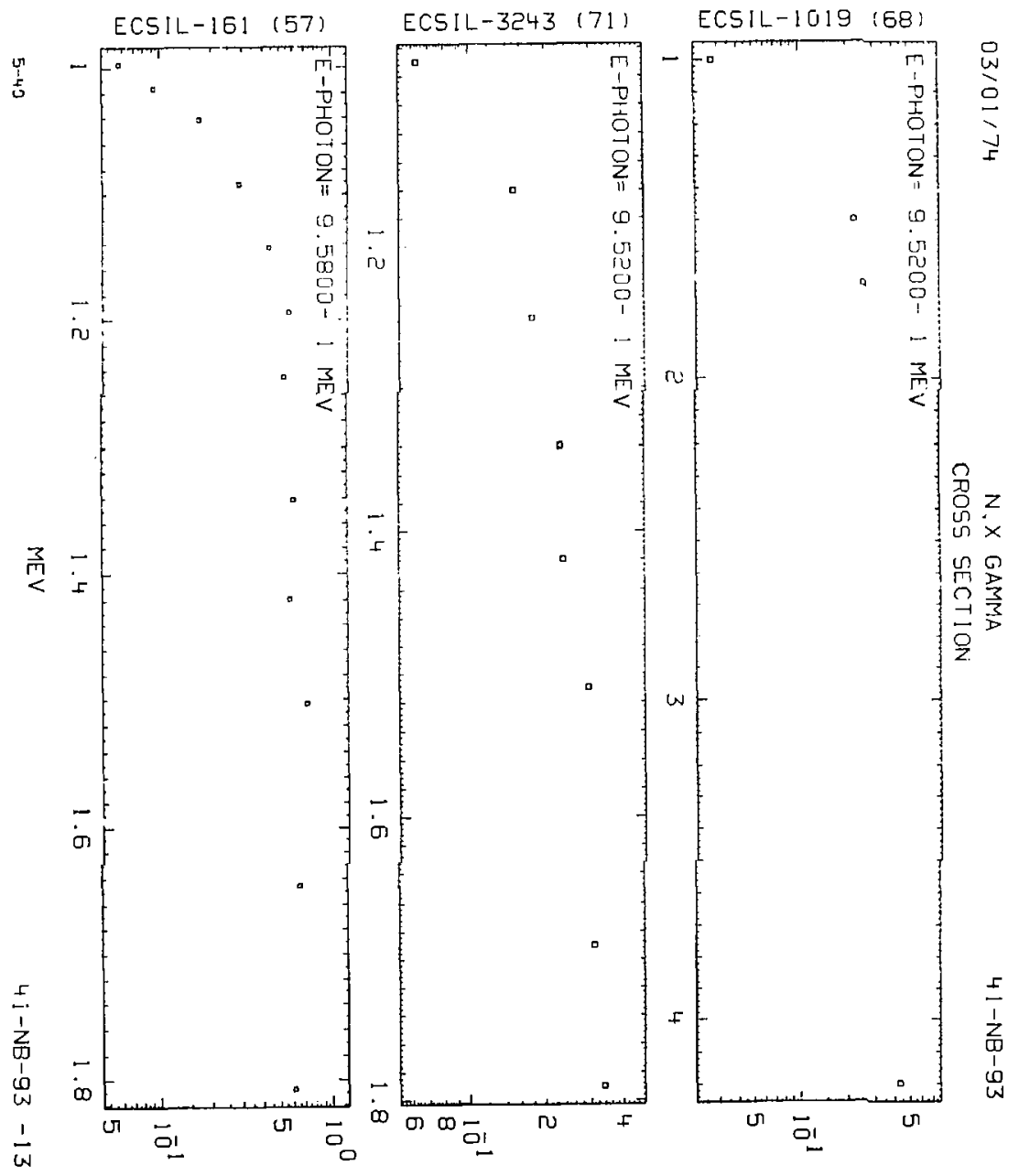

BARNS 

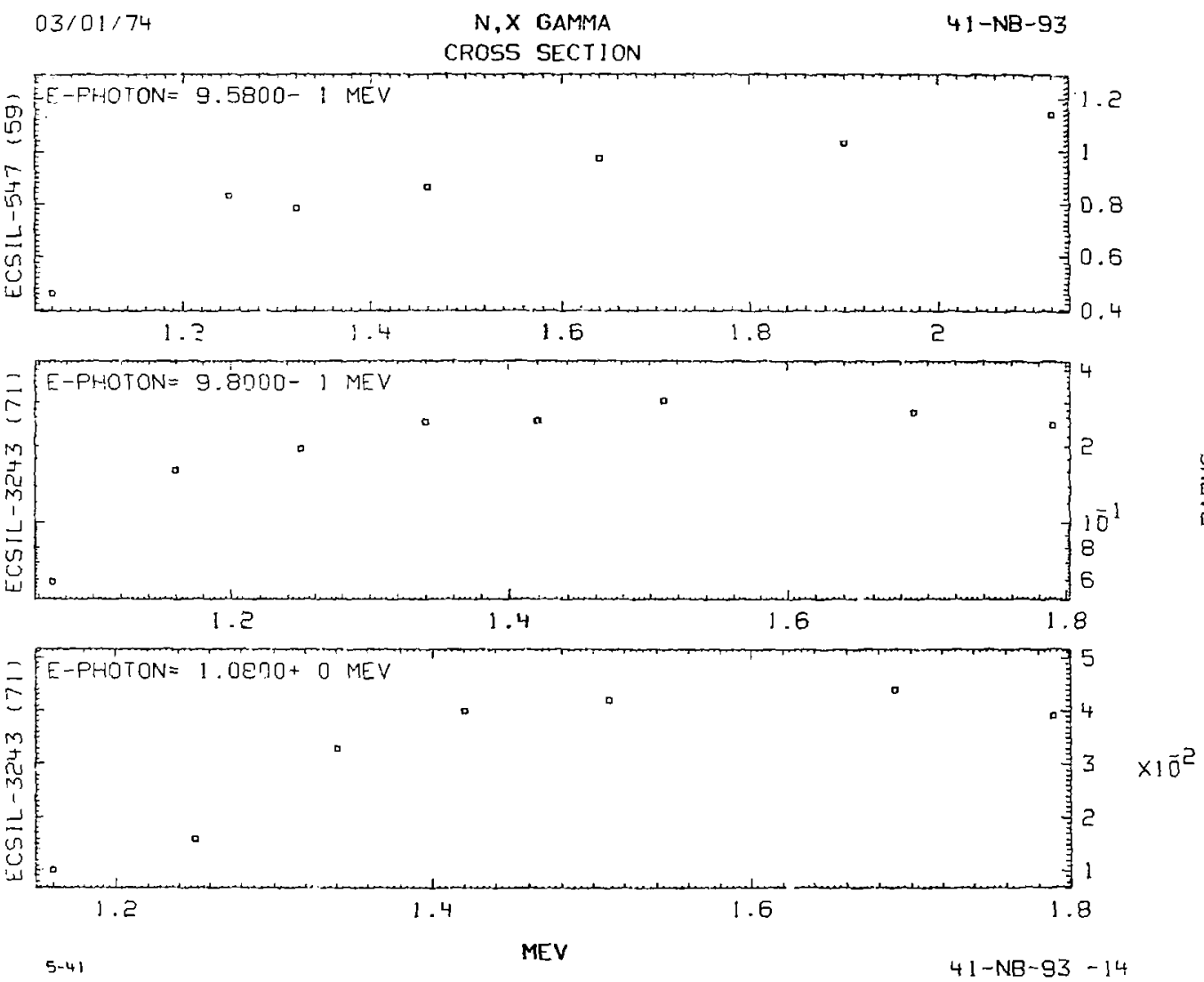

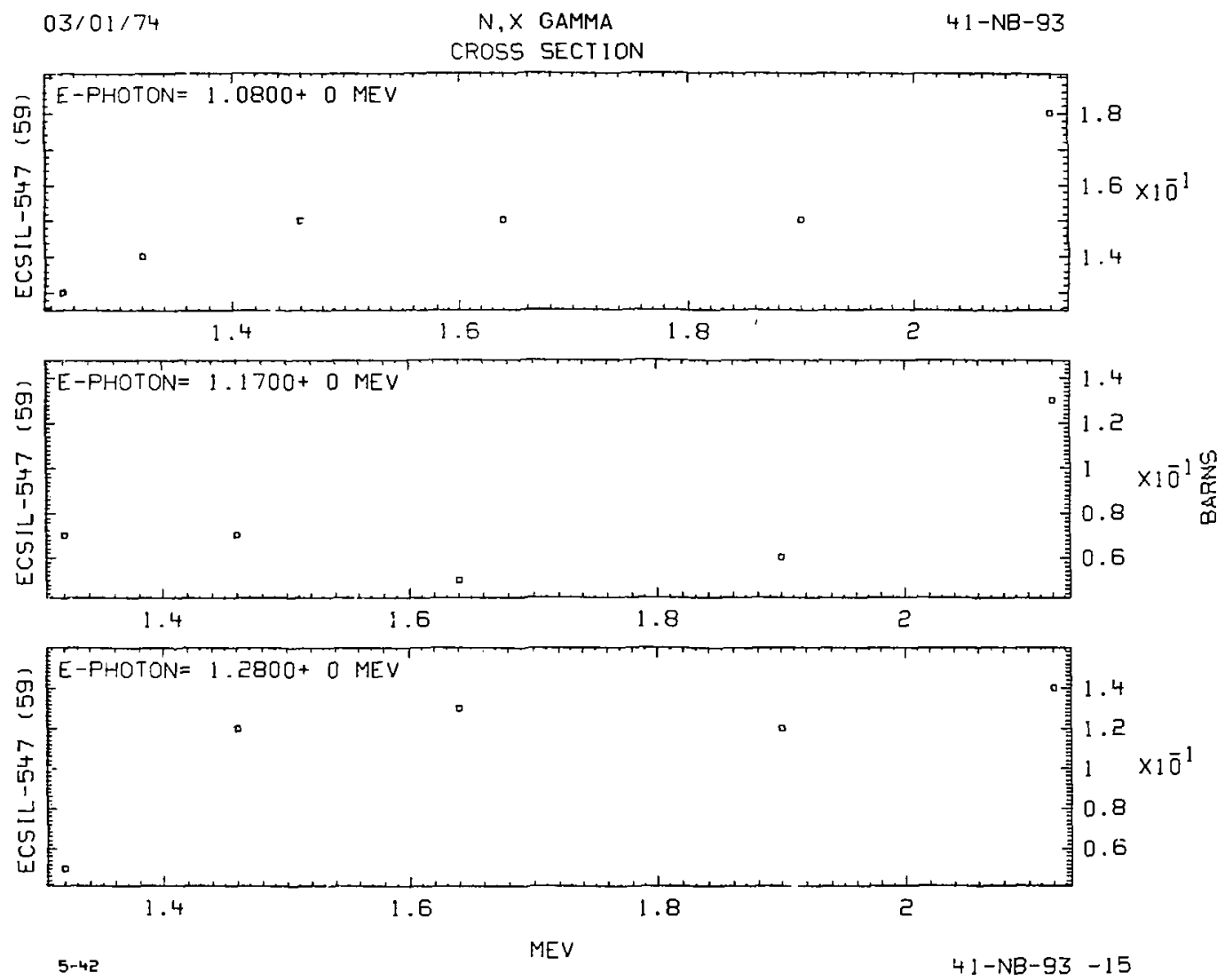


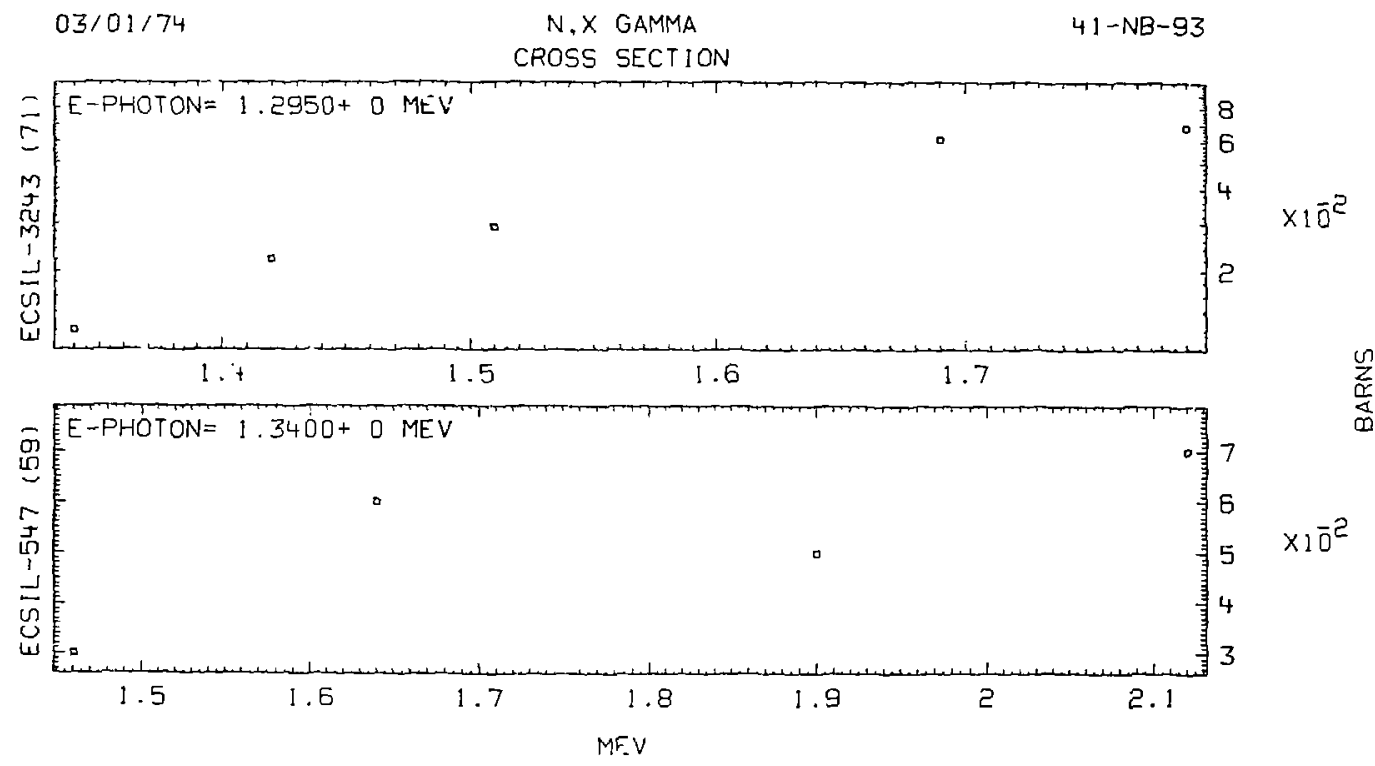




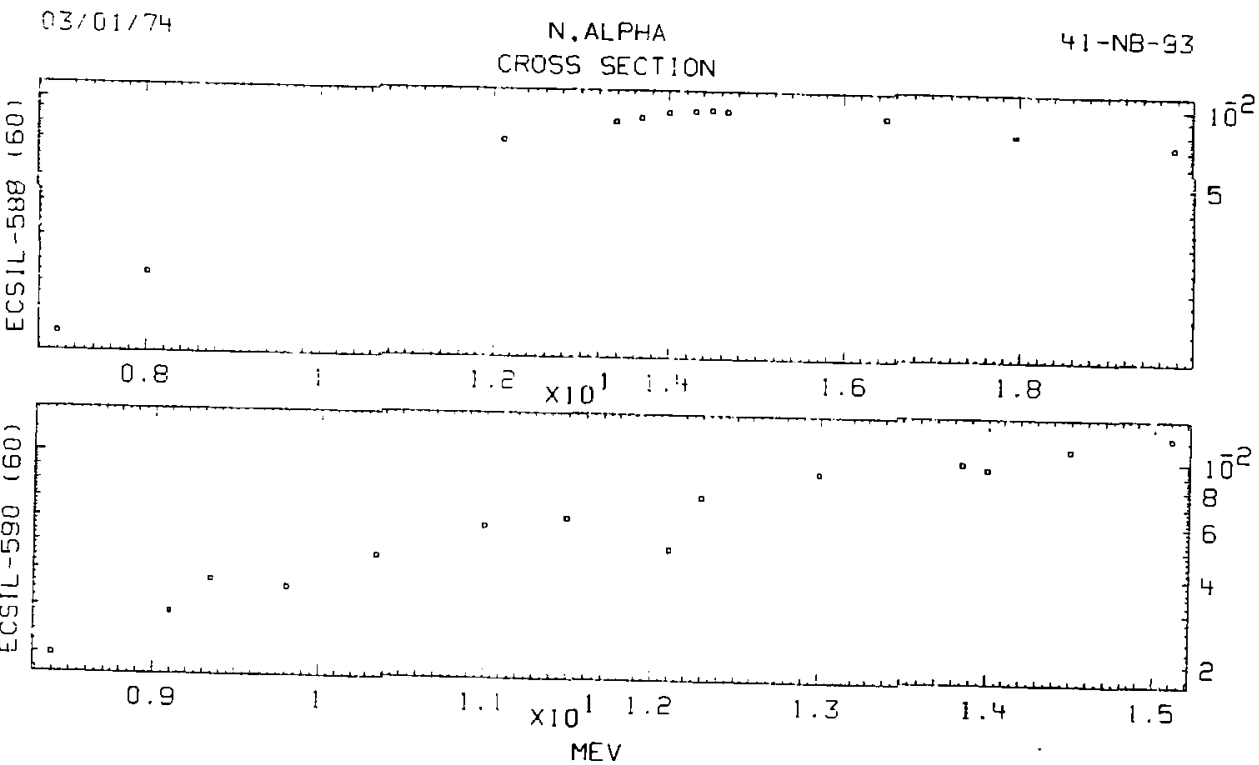

$03 / 01,74$

NONEL_ASTIC

4 I $-N B-93$

$\begin{array}{rrrr}\text { REFERENCE TNIERGY } & \text { DELTA } & x-S T C & \text { DELIA } \\ \text { MEV } & \text { MEV } & \text { BARNS } & \text { BARNS }\end{array}$

$541133: 0000+05.0000-2 ? .0010-11.0000-1$ 


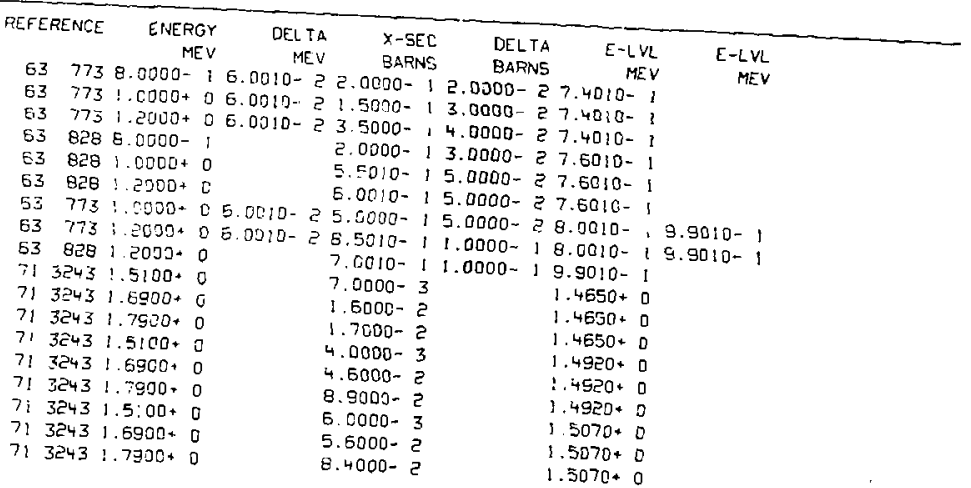

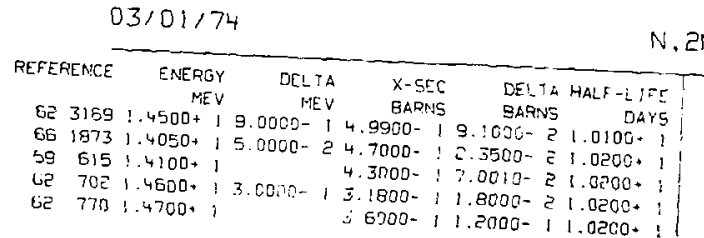

N. $2 N$ $36000-1,1.8000-21.0200+$
$41-N B-93$

REFERENCE

ERIERGY

66 $1873,1.4700+1,0000-14$

661873,4700 MEV $1.0000-14.5400-1$

6) $657 \quad 1.4700+1$ $11.0000-14$ BARNS BARNS

UELTA HALF-LIFE

30 1.4.00+ 1 5.600- 1 2.3200- 2 1.0200+ 1

$31501.4800+12.0000-14.5000-16.0000-21.0200+1$

$637561.4800+12.0000-14.5500-13.2000-\geq 1.0200+1$

$$
N, 3 N
$$

REFERENCE ENERGY DELTA X-SEC

$6718931.9500+12.0000-16.0000-2$
$41-N B-93$

DE: TA HALF -L IFE

HOURS

ธ. $2000+1$ 
CROSS SECTION

$\begin{array}{rrrrr}\text { REFERENCE } & \text { ENERGY } & \text { DELTA } & \text { X-SEC } & \text { DELTA HALF-LIFE } \\ & \text { MEV } & \text { MEV } & \text { BARNS } & \text { BAFN5 } \\ \text { SECONDS }\end{array}$

$03 / 01 / 74$

ABSORPT ION

$41-N B-93$

$\begin{array}{rrrrr}\text { REFERENCE } & \text { ENERGY } & \text { DELTA } & \text { X-SEC } & \text { DELTA } \\ & \text { MEV } & \text { MEV } & \text { BARNS } & \text { BARNS } \\ & 581162 & 2.5300-F & 1.1700+02.0000-2 \\ 651364 & 2.4000-2 & 2.7000-11.5000-2\end{array}$

\begin{tabular}{|c|c|c|}
\hline \multicolumn{2}{|c|}{ REFERENCE } & $\begin{array}{r}\text { ENERGY } \\
\text { ME }\end{array}$ \\
\hline 68 & 1019 & $1.5000+0$ \\
\hline 68 & 1019 & $1.7000+$ \\
\hline 68 & 1019 & ب. $2000+$ \\
\hline 68 & 1019 & I. $5000+$ \\
\hline $6 \theta$ & 1019 & $1.7000^{+}$ \\
\hline G8 & 1019 & 4.2000+ \\
\hline 68 & 1019 & $4.2000+$ \\
\hline 68 & 1019 & $1.7000+$ \\
\hline 68 & 1019 & 4. $2000+$ \\
\hline 68 & 1019 & $4.2006+$ \\
\hline 71 & 3243 & $1.6900+$ \\
\hline 68 & 1019 & $1.7000+$ \\
\hline 71 & 3243 & $1.7900^{+}$ \\
\hline$\overline{\sigma \theta}$ & 1019 & 4.2000 \\
\hline 70 & 1127 & $6.0000+$ \\
\hline 68 & 1019 & $1.5000+$ \\
\hline 68 & 1019 & $1.7000+$ \\
\hline 68 & 1019 & 4. $20000+$ \\
\hline 71 & 3243 & $1.5100+$ \\
\hline 71 & 3243 & $1.6900+$ \\
\hline 71 & 5.43 & $1.7900+$ \\
\hline E9 & 1019 & $1.7000^{*}$ \\
\hline 68 & 1019 & $4.5000+$ \\
\hline
\end{tabular}

\section{$N, X$ GAMMA}

$41-N B-93$

DELTA X-SEC

EARNS BARNS E-PHOION

$1.4000-2$ 2.EOOO- $33.1500-1$ $5.6000-51.1=00-23.1500-$ $5.4000-21.0800-23.1500-$ $1.0000-12.0000-23.3800-1$ $1.2400-12.4800-23.3800-$ 9.0000- $21.9000-\geq 3.3800-1$ 2.9000- $25.8000-33.5900-1$ $3.7000-27.4000-33.8400-$ 7.7000" $21.5400-23.6400-$ 3. $4000-26.8000-34.7800-$ ร. $2000-5$ $5.4 \div 00-1$

2.9000- $25.9000-35.4100-1$ 5. 5000- 2 $5 .+190^{-} \quad 1$ $1.2900-1$ 2.5860- $25.4100-1$
$8.5000-1$
$5.5000-$ । $5.5000-1$

$3.5000-27.0000-35.5300-$ !

7.6000- $21.5200-25.5500-1$

ट.6000- $25.2000-35.5300-1$

$4.0000-3$ $5.5400-1$

5.7000$5.5400=1$

$4.4000-2$ $5.5400-1$

$4.7000-23.4000-35.7200-i$

$3.9000-27.8000-35.7200-1$

$\begin{array}{rrr}\text { REFERENCE } & \begin{array}{r}\text { CNERGY } \\ \text { MEV }\end{array} \\ 58 & 1019 & 4.2000+0 \\ 71 & 3243 & 1.5100+0 \\ 71 & 3543 & 1.6900+0 \\ 71 & 3243 & 1.7900+0 \\ 68 & 1019 & 4.2000+0 \\ 68 & 1019 & 4.2000+0 \\ 71 & 3243 & 1.6900+0 \\ 71 & 3243 & 1.7900+0 \\ 70 & 1497 & 1.0000+0 \\ 70 & 1497 & 6.0000+0 \\ 68 & 1019 & 1.5000+0 \\ 68 & 1019 & 1.7000+0 \\ 56 & 1019 & 4.2000+0 \\ 68 & 1019 & 4.2000+0 \\ 68 & 1019 & 1.5000+0 \\ 68 & 1019 & 1.7000+0 \\ 68 & 1019 & 4.2000+0 \\ 68 & 1019 & 4.2000+0 \\ 68 & 1019 & 1.5000+0 \\ 68 & 1019 & 1.7000+0 \\ 68 & 1019 & 4.2000+0 \\ 59 & 547 & 1.6400+0 \\ 59 & 547 & 1.9000+0\end{array}$

\begin{tabular}{|c|c|c|c|}
\hline DEL.TA & $X$-SEC & DELTA & E-PHOTON \\
\hline MEV & BARN5 & BARNS & MEV \\
\hline & $4.4000-2$ & $8.8000-3$ & 5. B600- \\
\hline & $7.0000-3$ & & $6.5600-1$ \\
\hline & $1.6000-2$ & & $6.5600-1$ \\
\hline & $1.7000-2$ & & $6.5600-1$ \\
\hline & $9.3000-2$ & $1.8600-2$ & $00-I$ \\
\hline & $4.6000-2$ & $9.2000-$ & $0-1$ \\
\hline & $8.0000-3$ & & $00-1$ \\
\hline & $1.5000-2$ & & $0-1$ \\
\hline & $1.2800+0$ & & $0-1$ \\
\hline & $1.2000+0$ & & $30-1$ \\
\hline & $2.5500-1$ & $5.1000-2$ & $00-1$ \\
\hline & $2.3900-1$ & $4.7800-2$ & $0-1$ \\
\hline & E. $2^{1} 00-1$ & $4.4200-2$ & $9.8000-1$ \\
\hline & $2.1000-2$ & $4.2000-3$ & $1.0530+0$ \\
\hline & $3.8000-2$ & $7.6000-3$ & $1.0820+0$ \\
\hline & $4.1000-2$ & 8.2000- 3 & $1.0820+0$ \\
\hline & $4.6000-2$ & $9.2000-3$ & $1.0820+0$ \\
\hline & $1.7000-2$ & $3.4000-3$ & $1.0940+0$ \\
\hline & $2.3000-2$ & $4.6000-3$ & $1.2940+0$ \\
\hline & $5.3000-2$ & $1.0600-z$ & $1.2340+0$ \\
\hline & $3.4000-E$ & $6.8000-3$ & $1.2940+0$ \\
\hline & $1.2000-1$ & $3.6000-2$ & $1.4800+0$ \\
\hline & $1.6000-1$ & $4.8000-2$ & $1.4800+$ \\
\hline
\end{tabular}

$$
41-N E-93-19
$$




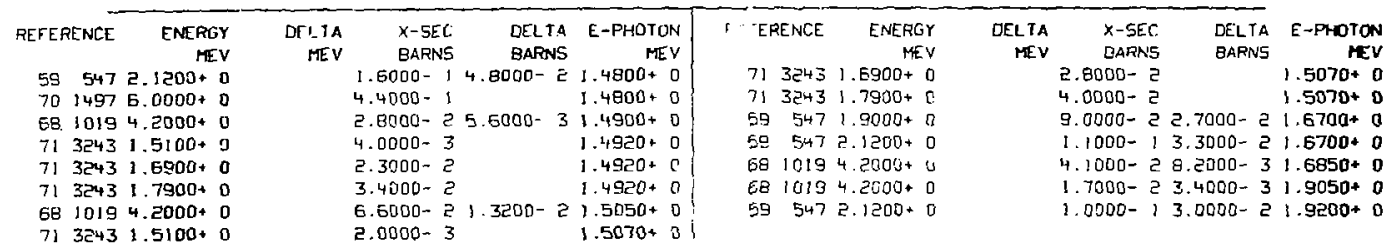

\section{$03 / 01 / 74$}

N. A:PHA

$41-N B-93$

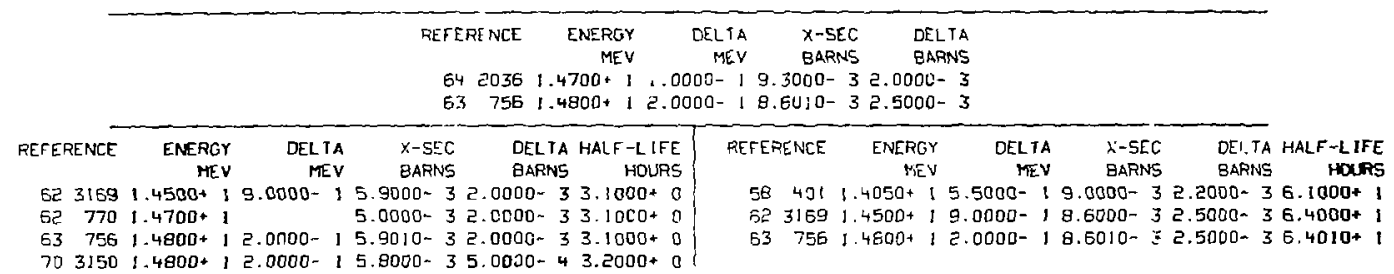

$03 / 01 / 74$

BOUNO ATUA:

$41-N B-93$

\begin{tabular}{|c|c|c|c|c|c|}
\hline & $\begin{array}{l}\text { REFERENCE } \\
511584\end{array}$ & $\begin{array}{r}\text { ENERGY } \\
\text { MFV } \\
7.3000-8\end{array}$ & $\begin{array}{rr}\text { DELTA } & \text { X-SEC } \\
\text { MEV } & \text { BARNS } \\
6.2000 * 0\end{array}$ & $\begin{array}{l}\text { DELTA } \\
\text { BARN5 }\end{array}$ & \\
\hline $03 / 01: 74$ & & I. DHERENT & SCATTERING & & $41-N B-93$ \\
\hline & $\begin{array}{r}\text { REFEAENCE } \\
5 ; 1584\end{array}$ & $\begin{array}{r}\text { ENCRGY } \\
\text { MEV } \\
7.3000-8\end{array}$ & $\begin{array}{rr}\text { DELTA } & \text { X-SEC } \\
\text { MEV } & \text { BARHAS } \\
5.0000+0\end{array}$ & $\begin{array}{l}\text { DELTA } \\
\text { BARNS } \\
\text { OUB- } 1\end{array}$ & \\
\hline
\end{tabular}


$03 / 01 / 74$

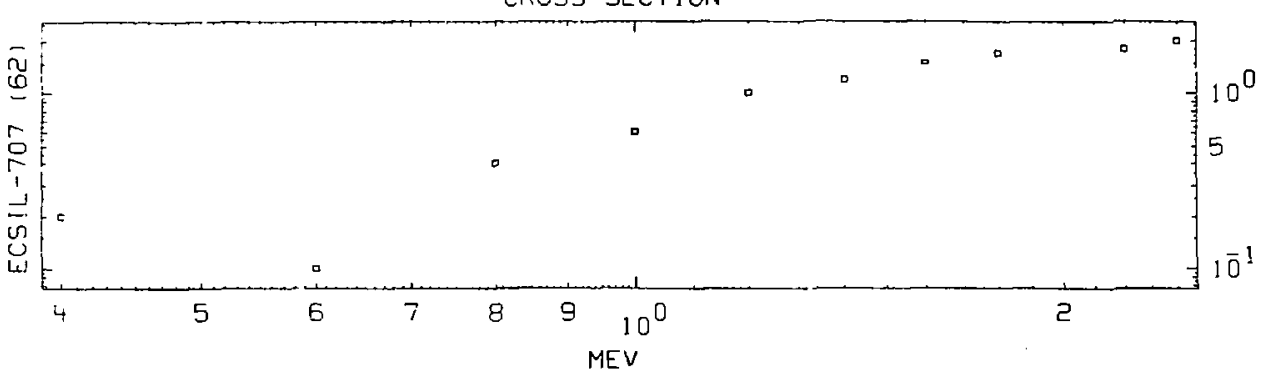

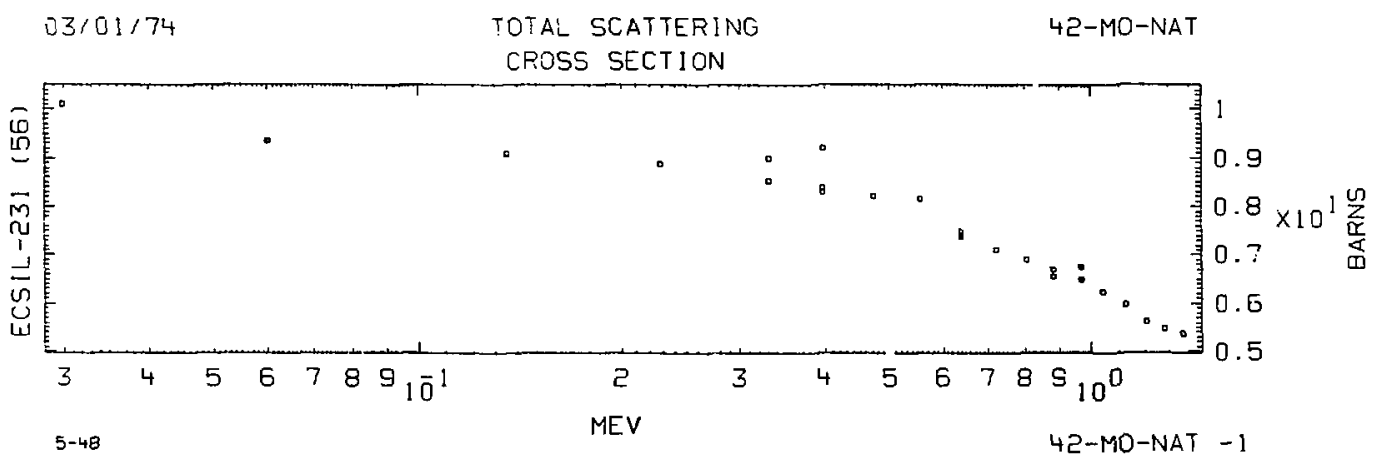




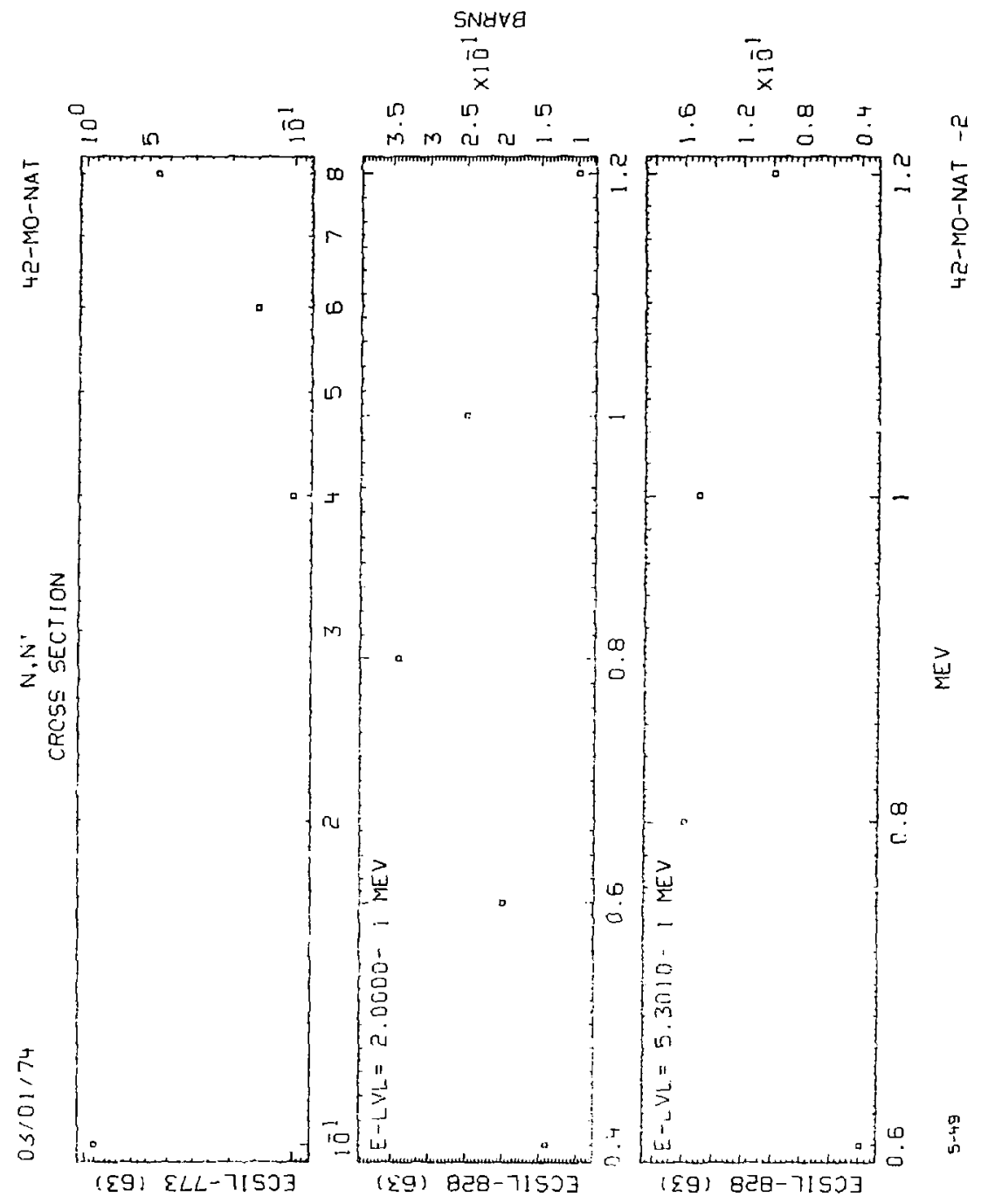



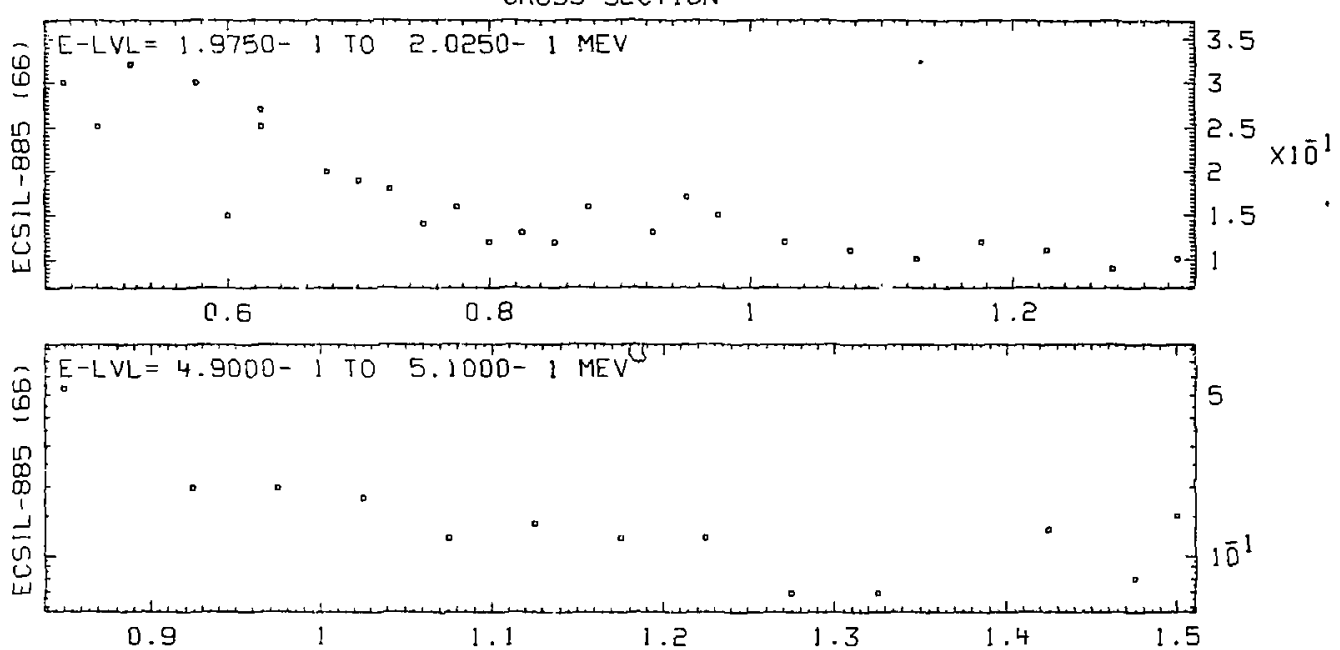

$\underset{\frac{10}{2}}{\frac{1}{\alpha}}$

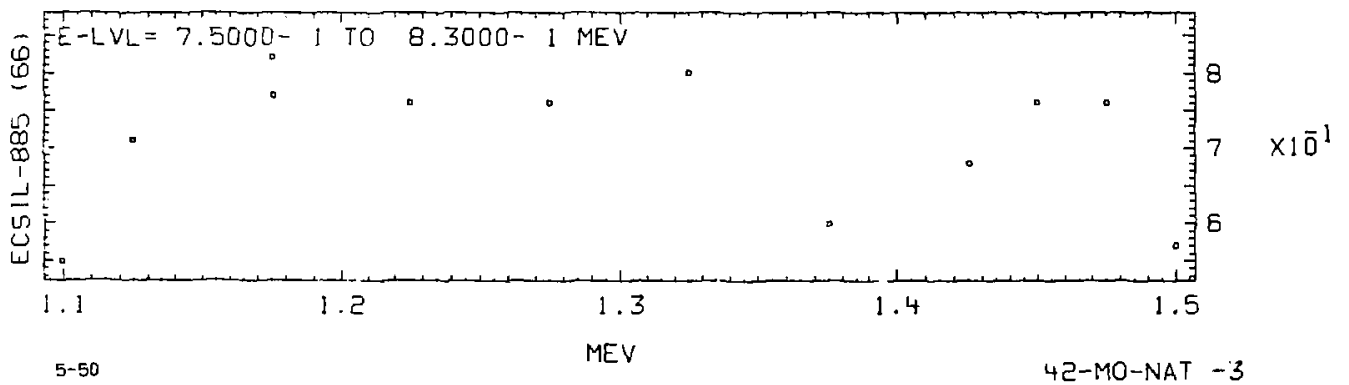



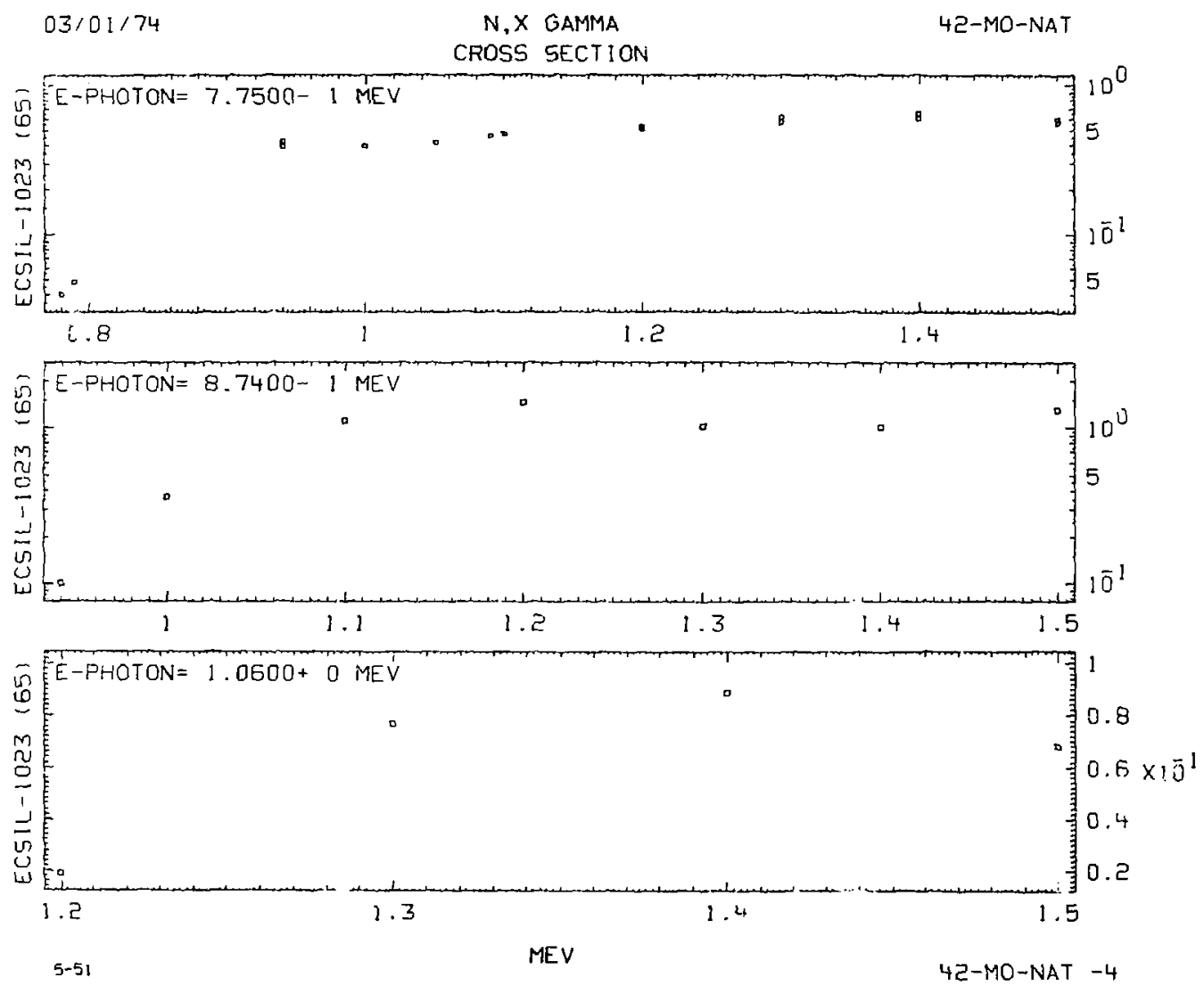


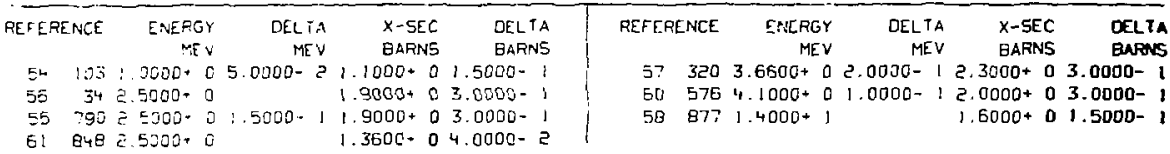

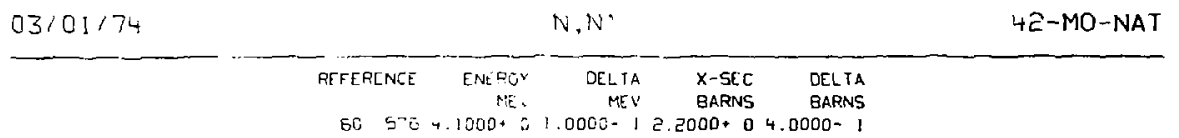

5C 570 $41000+210000-12.2000 * 04.0000-1$

65 6ES $6.0400+02.3000-12.2000+03.0000-1$

$03 / 01 / 74$

N. 2N

L2-MO-NAT

FITERENCE ENEPEY DELTA X-SEC DELTA

5日 $18211.4100+1 \quad 1.5900+01.2000=1$

$03 / 01 / 74$

$N, N \cdot P$

42-MO-NAT

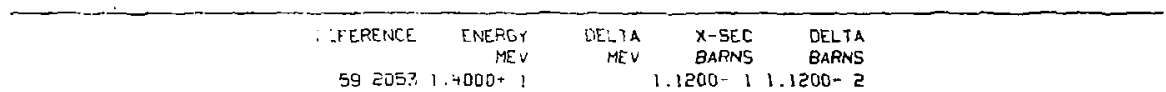

59 2053 $1.4000+$

\begin{tabular}{|c|c|c|c|c|c|c|c|c|c|}
\hline $03 / 01 /$ & 74 & & & $A 35$ & TION & & & $42-$ & -MO-NAT \\
\hline REFERENCE & $\begin{array}{r}\text { ENERGY } \\
\text { MEY }\end{array}$ & $\begin{array}{r}\text { DELTA } \\
\text { MEV }\end{array}$ & $\begin{array}{l}x-5 E C \\
\text { BAPNAS }\end{array}$ & OELIA & REFERLNCE & ENERGY & $\begin{array}{r}\text { DELTA } \\
\text { MEV }\end{array}$ & $\begin{array}{l}X \text { SEC } \\
\text { BARNS }\end{array}$ & DELTA \\
\hline $\begin{array}{ll}53 & 370 \\
66 & 1491 \\
58 & 1162\end{array}$ & $\begin{array}{l}2.5300-8 \\
2.5300-8 \\
2.5300-8\end{array}$ & & $\begin{array}{l}2.5500+u \\
2.6000 \cdot 0 \\
2.7000+0\end{array}$ & $\begin{array}{l}1.0000-3 \\
5.0000-2 \\
4.0000-2\end{array}$ & $\begin{array}{ll}66 & 1541 \\
65 & 1364\end{array}$ & $\begin{array}{l}2.4000-2 \\
2.4000-2\end{array}$ & $1.5000-3$ & $\begin{array}{l}1.8900-1 \\
1.9200-1\end{array}$ & $\begin{array}{l}1.5000-2 \\
1.2000-2\end{array}$ \\
\hline
\end{tabular}




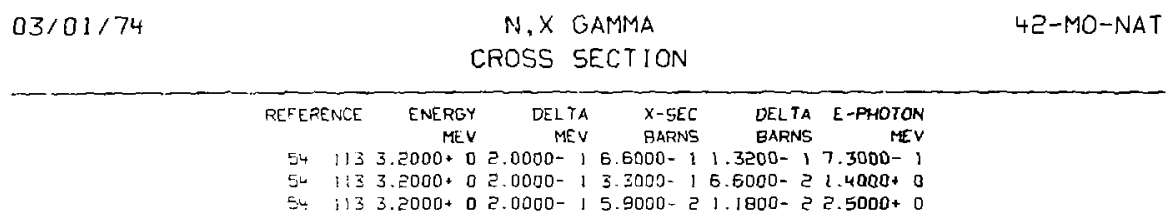

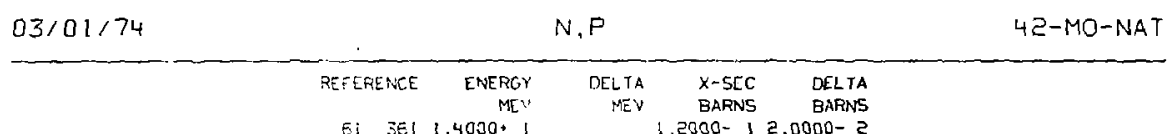

Ei SEl $1.4000+1 \quad 1.2030-12.0000-2$

\begin{tabular}{|c|c|c|c|c|c|c|}
\hline \multirow[t]{2}{*}{$03 / 01 / 74$} & \multicolumn{5}{|c|}{ BOUND ATOM } & 4Z-MO-NAT \\
\hline & $\begin{array}{l}\text { FEFEPENCE } \\
\text { S! } 1584\end{array}$ & $\begin{array}{r}\text { ENERGY } \\
\text { MEV } \\
.3000-8\end{array}$ & $\begin{array}{r}\text { DELTA } \\
\text { MEV }\end{array}$ & $\begin{array}{r}x-S E C \\
\text { BARNS } \\
4000+0\end{array}$ & $\begin{array}{l}\text { DELTA } \\
\text { GARNS }\end{array}$ & \\
\hline $03 / 01 / 74$ & & OHERENT & SCATT & RING & & $42-M O-N A T$ \\
\hline
\end{tabular}




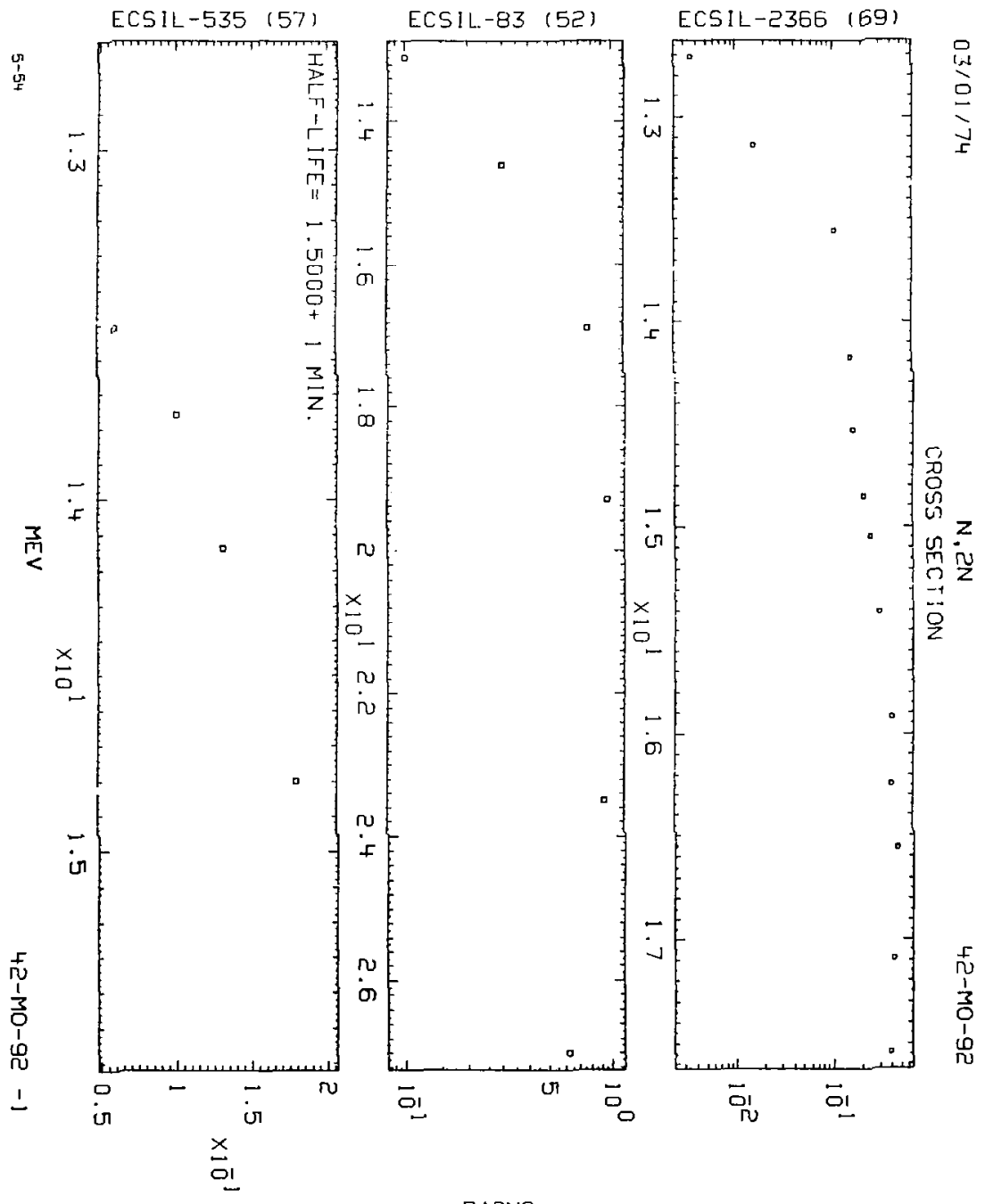

BARNS 
CROSS SECTION

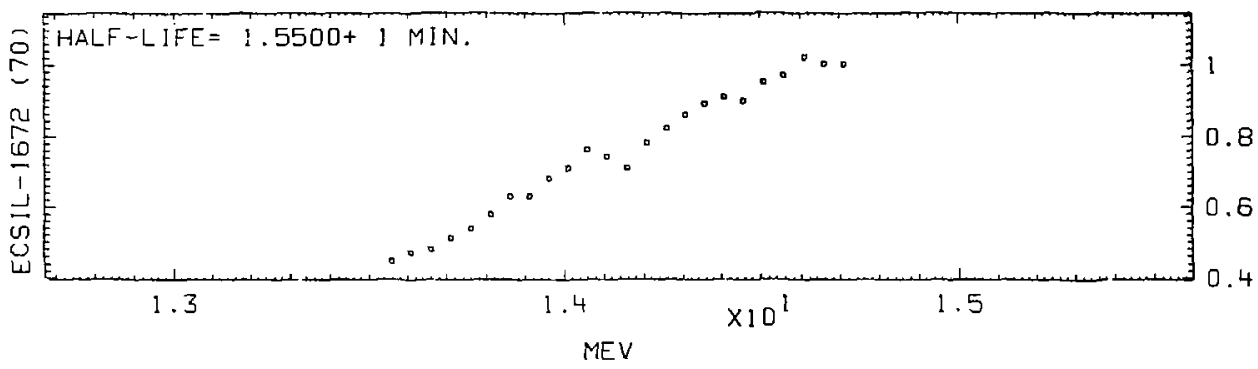

$03 / 01 / 74$

$N, 2 N$

$42-10-92$

\begin{tabular}{|c|c|c|c|c|c|c|c|c|c|c|}
\hline REFERENCE & $\begin{array}{r}\text { ENERGY } \\
\text { MEY }\end{array}$ & $\begin{array}{r}\text { DELTA } \\
\text { MEV }\end{array}$ & $\begin{array}{l}X-5 E \hat{~} \\
\text { GARNS }\end{array}$ & $\begin{array}{l}\text { DELTA } \\
\text { BARNS }\end{array}$ & REFEPENCE & $\begin{array}{r}\text { ENERGY } \\
\text { MEY }\end{array}$ & DELT & & $\begin{array}{l}X-\text { SEC } \\
\text { BARNS }\end{array}$ & $\begin{array}{l}\text { DELTA } \\
\text { BARN5 }\end{array}$ \\
\hline $67 \quad 1887$ & $1.4100+1$ & 2.0000- 1 & $1.5800-1$ & $5.0000-3$ & 693351 & $1.4700+1$ & 2.0000- & $1 a$ & $2.2200-1$ & $1.0000-2$ \\
\hline 651672 & $1.4600+1$ & $1.0000-1$ & $1.750 ?-1$ & $1.0000-2$ & 693351 & $1.4800+1$ & $3.5000-$ & 1 & $2.2700-1$ & $1.0000-2$ \\
\hline 62702 & $1.4600+1$ & $3.0000-1$ & $3.1500-1$ & $3.5000-2$ & 672009 & $1.6300+1$ & & & $2.8000-1$ & $4.2000-2$ \\
\hline
\end{tabular}

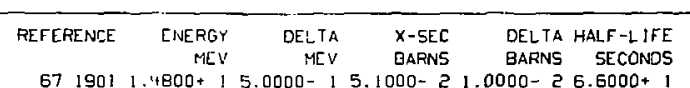

$6719011.4800+15.0000-15.1000-21.0000-26.6000+1$

$53271.4500+1 \quad 1.9000-12.9000-27.5010+1$

\begin{tabular}{|c|c|c|c|c|c|c|c|c|c|c|c|}
\hline REFERENCE & ENERGY & DELTA & $x-5 E C$ & DELTA & HALF LLIFE & REFERENCE & ENERGY & DELTA & $x-5 E C$ & DEL TA & HALF-LIFE \\
\hline & MEE & MEV & BARNS & BARN5 & MINUTES & & MEV & MEY & BARNS & BARNS & MINUTES \\
\hline $62 \quad 108$ & $1,4130 * 1$ & $11.0000-1$ & $1.0600-1$ & $7.5010-3$ & $1.5700+1$ & 756 & $1.4800+1$ & $2.0000-1$ & $1.9800=1$ & $4.0000-2$ & $1.6000+1$ \\
\hline 652136 & $1.4800+$ & & $1.5900-1$ & & $1.5700+1$ & 65 2136 & $1.4800+1$ & & $1.5000-z$ & & $6.0400+1$ \\
\hline 671901 & $1,4800+1$ & $15.0000-1$ & $2.0500-1$ & $2.5000-2$ & $1.5000+1$ & 651672 & $1.4600+1$ & $1.0000-1$ & $1.7500-1$ & $1.0000-2$ & $1.5500+4$ \\
\hline
\end{tabular}




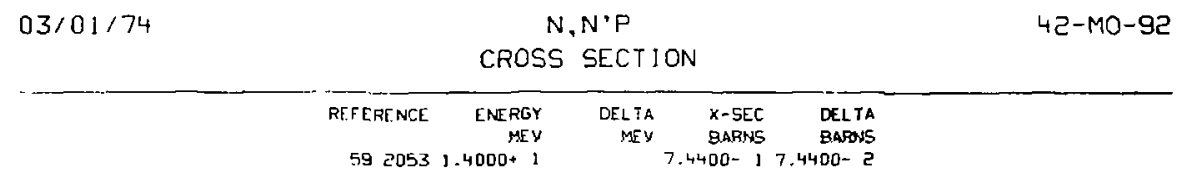

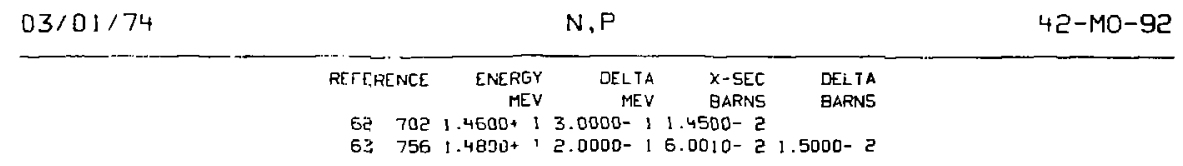

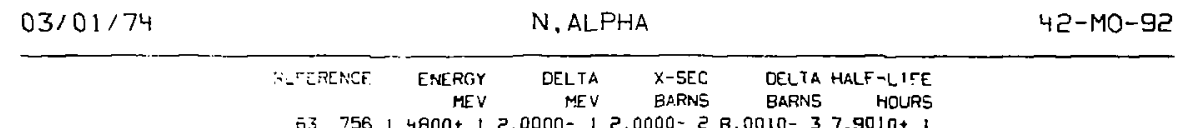

$537561.4800+12.0000-12.0000-28.0010-37.9010+1$

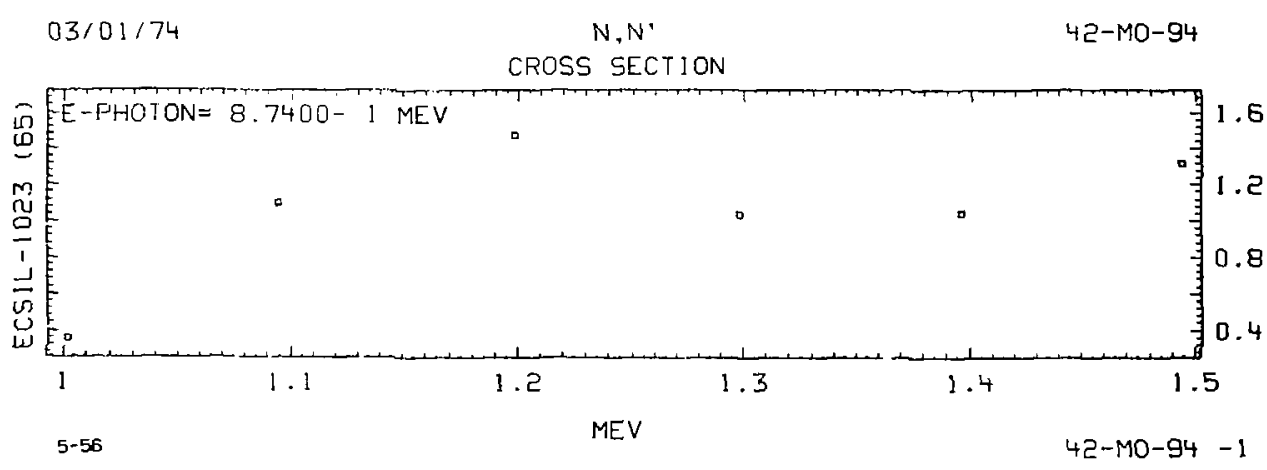




\section{CROSS SECTION}

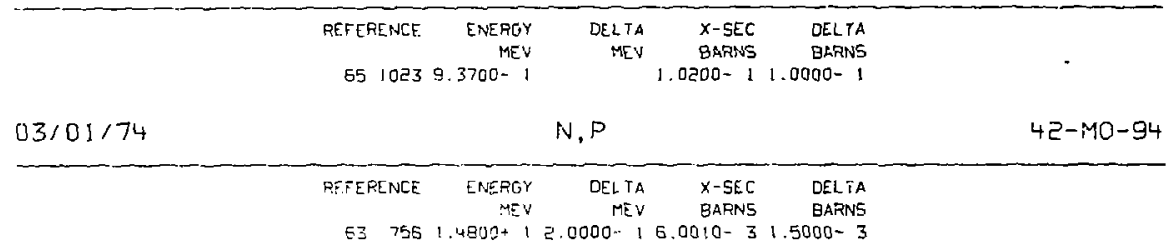

$03 / 01 / 74$ ABSORPTION

$42-M 0-95$

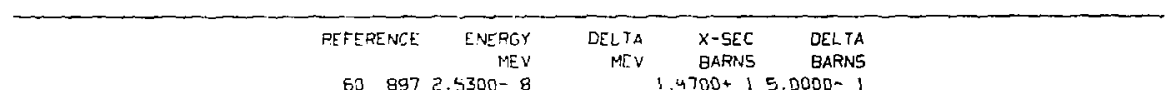

53897 2.5300-

\begin{tabular}{|c|c|c|c|c|c|c|}
\hline $03 / 01 / 74$ & & & $N, P$ & & & $42-10-96$ \\
\hline & PREFEPENCE & $\begin{array}{r}\text { ENERGY } \\
\text { MEV }\end{array}$ & $\begin{array}{r}\text { DELTA } \\
M[V\end{array}$ & $\begin{array}{l}X \text {-SEC } \\
\text { BARNS }\end{array}$ & $\begin{array}{l}\text { DELTA } \\
\text { BARNS }\end{array}$ & \\
\hline & $57 \quad 1887$ & $1+100 \times 1$ & $12.0000-i$ & $1.5000-2$ & $3.0000-3$ & \\
\hline & se 702 & $i .4 E 00+1$ & $13.0000-!$ & ! 2.1000- 2 & $7.0010-3$ & \\
\hline & 63756 & $1.4800+1$ & $12.0000-1$ & $13.7000-2$ & $9.0010-3$ & \\
\hline
\end{tabular}

$03 / 01 / 74$

$N, P$

$4 z-190-97$

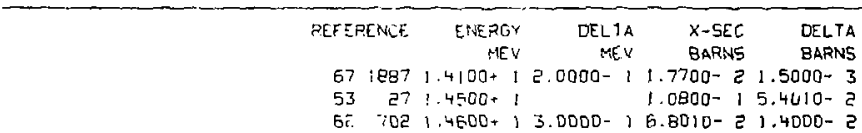




\section{CROSS SECTION}

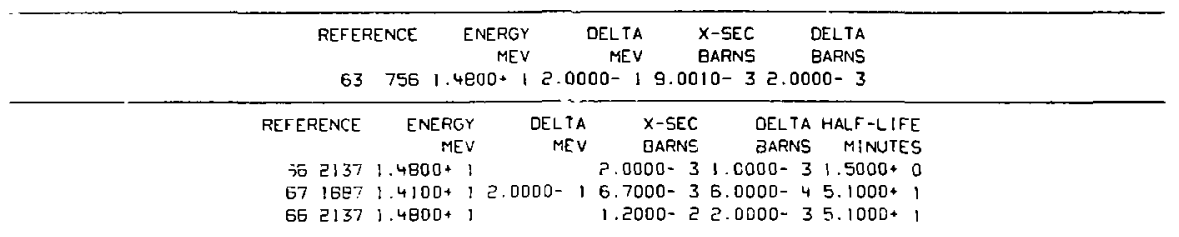

$03 / 01 / 74$

$N, 2 N$

$42-90-100$

\begin{tabular}{|c|c|c|c|c|c|c|c|c|c|}
\hline REFERENCE & $\begin{array}{r}\text { ENERGY } \\
\text { MEV }\end{array}$ & $\begin{array}{r}\text { DELTA } \\
\text { MLV }\end{array}$ & $\begin{array}{l}X-5 E C \\
\text { BARNS }\end{array}$ & $\begin{array}{l}\text { DELTA } \\
\text { BARNS }\end{array}$ & REFERENCE & $\begin{array}{r}\text { ENERGY } \\
\text { MEV }\end{array}$ & $\begin{array}{r}\text { DELTA } \\
\text { MEV }\end{array}$ & $\begin{array}{l}X \text {-SEC } \\
\text { BARNS }\end{array}$ & $\begin{array}{l}\text { DELTA } \\
\text { BARN5 }\end{array}$ \\
\hline 671887 & $4100+1$ & $12.0000-1$ & $11.51[0+0$ & $1.8000-1$ & 702 & $600+1$ & $3.0000-1$ & $2.0390+0$ & $000-$ \\
\hline $69 \quad 2 B 37$ & $1.4400+1$ & $3.0000-1$ & $11.42 \mathrm{i} 0+0$ & & 672009 & $1.4700+1$ & $3.0000-1$ & $1.7620+0$ & $.0000-$ \\
\hline 53 & $1.4500+1$ & & $3.7900+0$ & $1.9000+0$ & 703 & $1.4800+1$ & $2.5000-1$ & $1.9100+0$ & $1.9100-$ \\
\hline
\end{tabular}

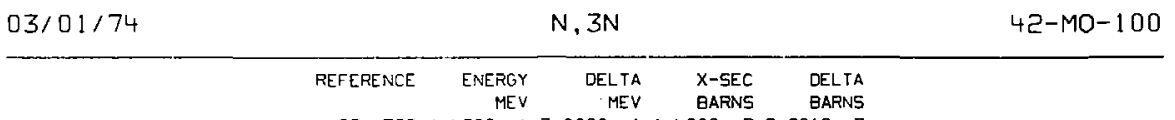

$627021.4600+13.0000-11.4000-25.0010-3$

\begin{tabular}{|c|c|c|c|c|c|}
\hline $03 / 0: / 74$ & & h & PHA & & \\
\hline & & ENERGY & $\begin{array}{l}\text { OELTA } \\
\text { MEV }\end{array}$ & $\begin{array}{l}X-S E C \\
\text { BARNS }\end{array}$ & $\begin{array}{l}\text { DELTA } \\
\text { BARNS }\end{array}$ \\
\hline
\end{tabular}

$05 / 01 / 74$

TOTAL SCATTERING

43-TC-99

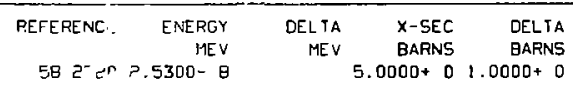


CROSS SECTION

$\begin{array}{rrrr}\text { REFERENCE ENFRGY } & \text { DELTA } & x-S E C & \text { DELTA HALF LIFE } \\ 652140 & 1.4100+1 & \text { MEV } & \text { BARNS } \\ \text { BARNS HOURS }\end{array}$

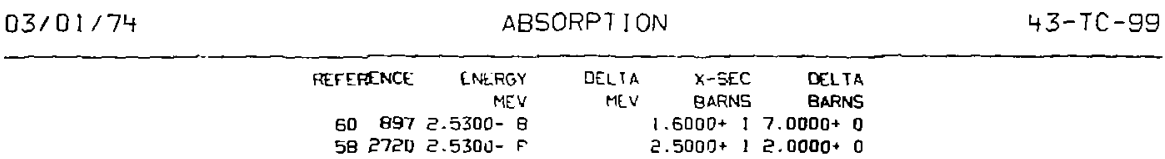

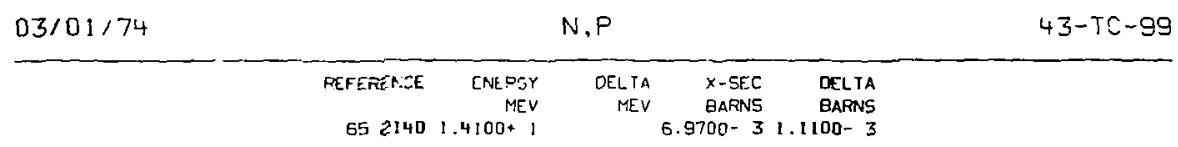

13/01/74

$03 / 01 / 74$ COHERENT SCATTERING

$43-T C-99$

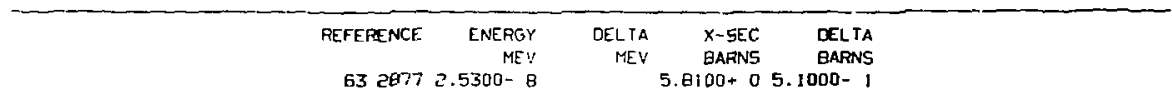

\section{$03 / 01 / 74$}

N. ZN

44 -RU - 96

\begin{tabular}{|c|c|c|c|c|c|c|c|c|c|}
\hline REIERENCE & $\begin{array}{r}\text { ENERGY } \\
\text { MEV }\end{array}$ & $\begin{array}{c}\text { DEL.TA } \\
\text { MEY }\end{array}$ & $\begin{array}{l}X \text {-SEC } \\
\text { GAFNS }\end{array}$ & $\begin{array}{l}\text { DELIA } \\
\text { BARNS }\end{array}$ & REFERENCE & $\begin{array}{r}\text { ENERGY } \\
\text { HEV }\end{array}$ & $\begin{array}{r}\text { EELTA } \\
\text { MEV }\end{array}$ & $\begin{array}{l}X-S E C \\
\text { BARNS }\end{array}$ & $\begin{array}{l}\text { DELTA } \\
\text { BARN5 }\end{array}$ \\
\hline 703340 & $1.4100+1$ & $5.0000-1$ & I $6.0000-1$ & $7.0000-2$ & 662141 & $1.4700+1$ & $5.0000-1$ & E.6000*0 & $3.0000-1$ \\
\hline $\begin{array}{rr}61 & E 76 \\
53 & 27\end{array}$ & $\begin{array}{l}1.4400+1 \\
1.4500+1\end{array}$ & $3,0000-1$ & $\begin{array}{l}6.3410-: \\
4.7800-1\end{array}$ & $\begin{array}{l}5.1010-2 \\
9.1010-2\end{array}$ & $66 \quad 1373$ & $1.4700+1$ & $1.0000-1$ & $8.6000-1$ & $4.3000-2$ \\
\hline
\end{tabular}


CROSS SECTION

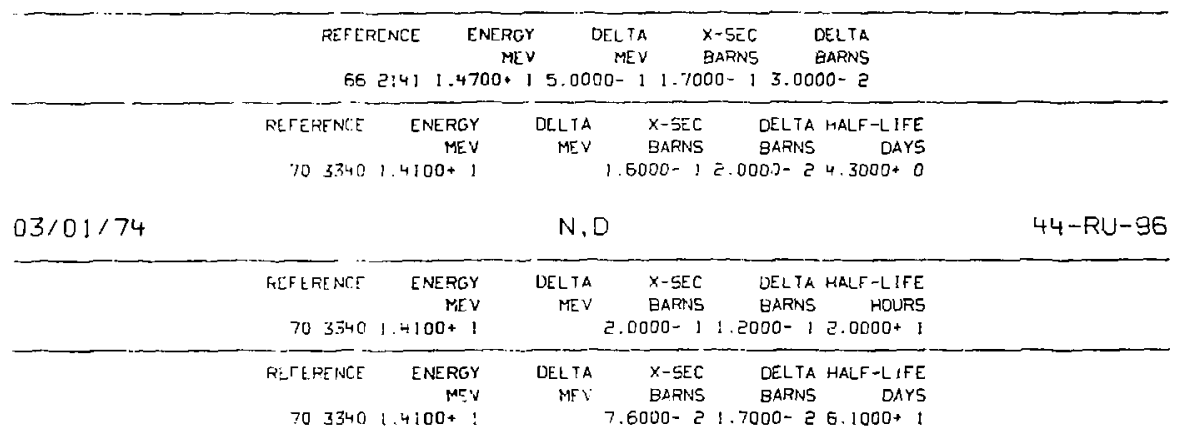

O3/01/74

$03: 01 / 74$

$N, 2 N$

$44-R U-98$

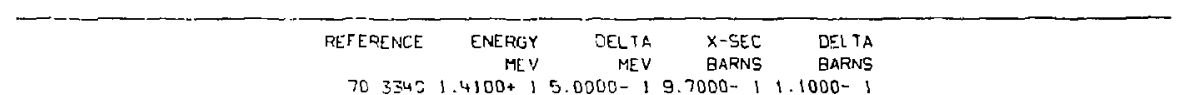

$70334=1.4100+15.0000-19.7000-11.1000-1$

33101/74


CROSS SECTION

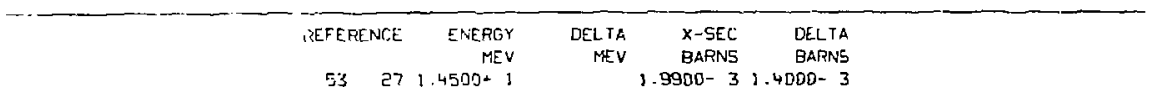

$03 / 01 / 74$

$N, P$

$44-R U-102$

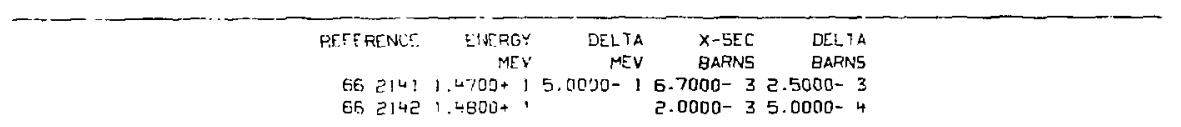

-

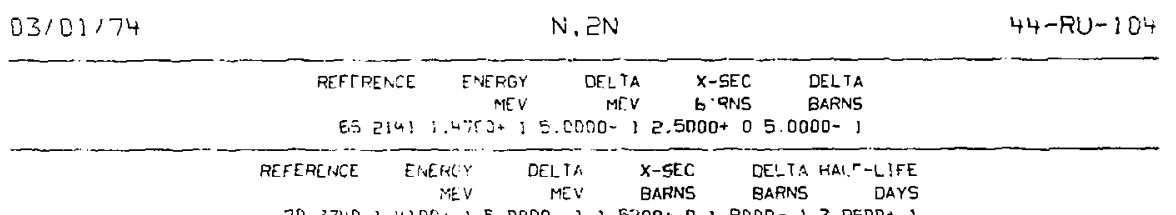

$7033401.4100+15.0000-1,1.5 \% 00+01.0000-13.9600+1$

S3/01/74




\section{CROSS SECTION}

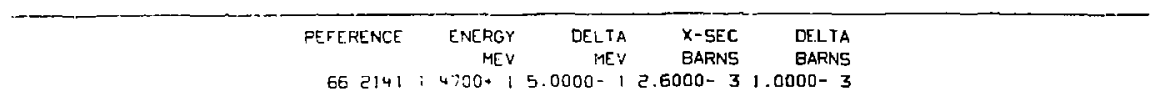

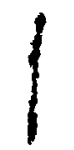

$662141: 4700+15.0000-12.6000-31.0000-3$

$03 / 01 / 74$

$N, N^{\prime}$

$45-\mathrm{RH}-103$

CROSS SECTION

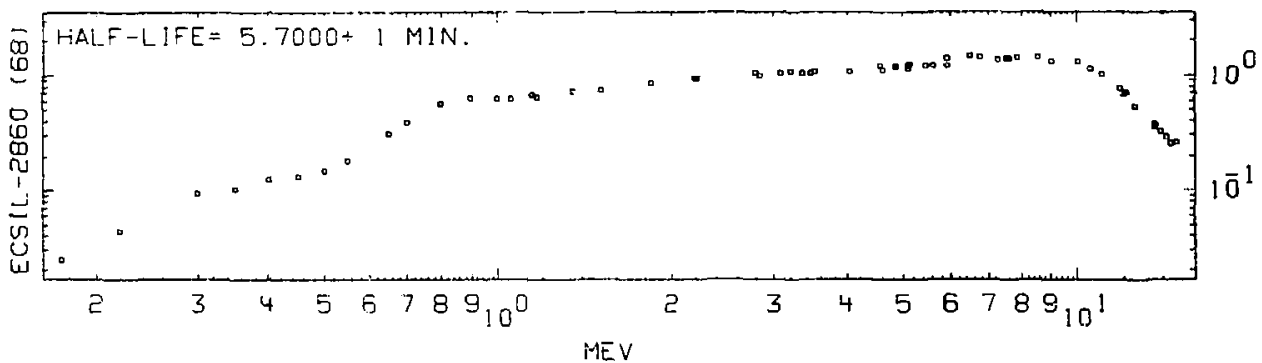

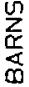


ll
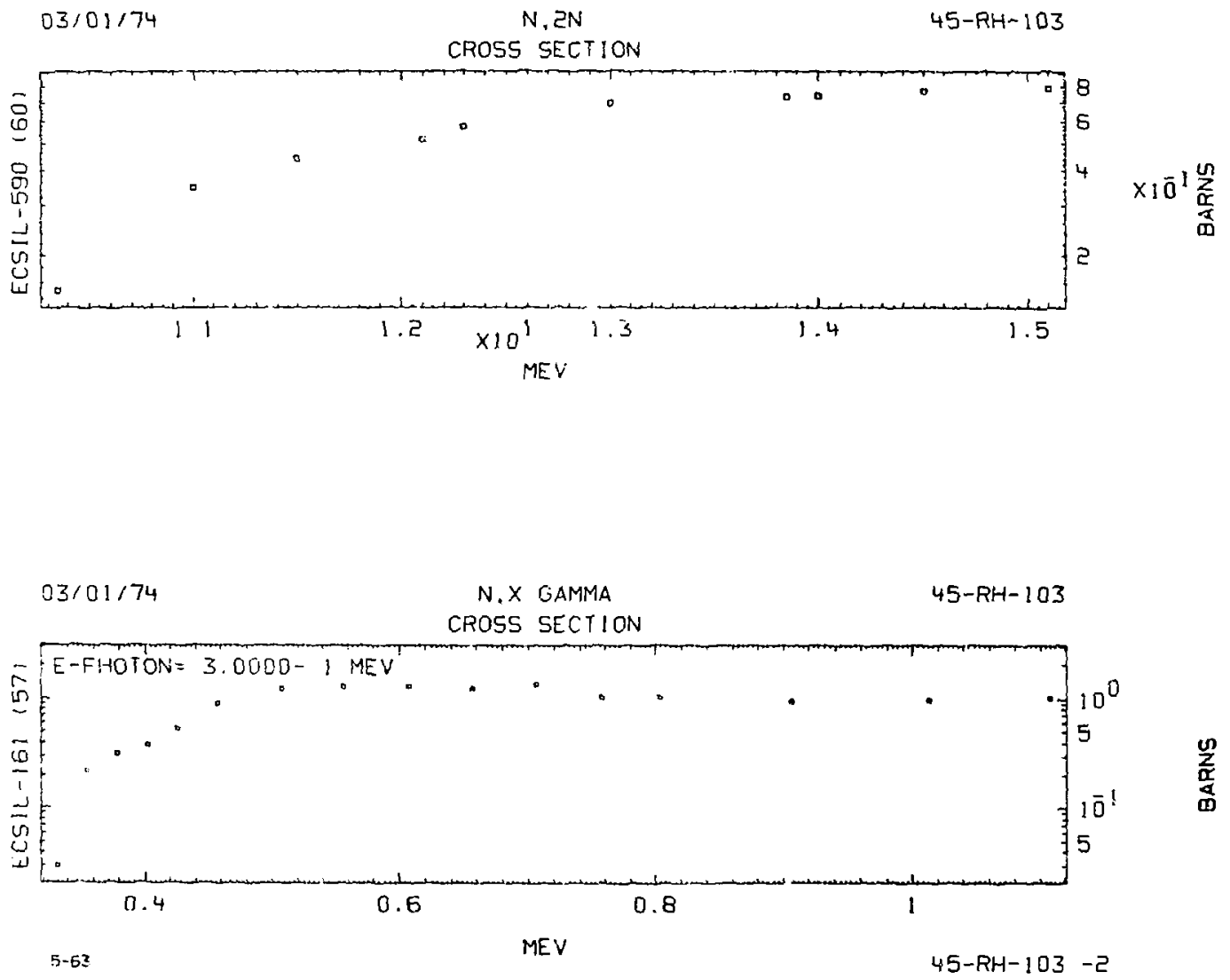


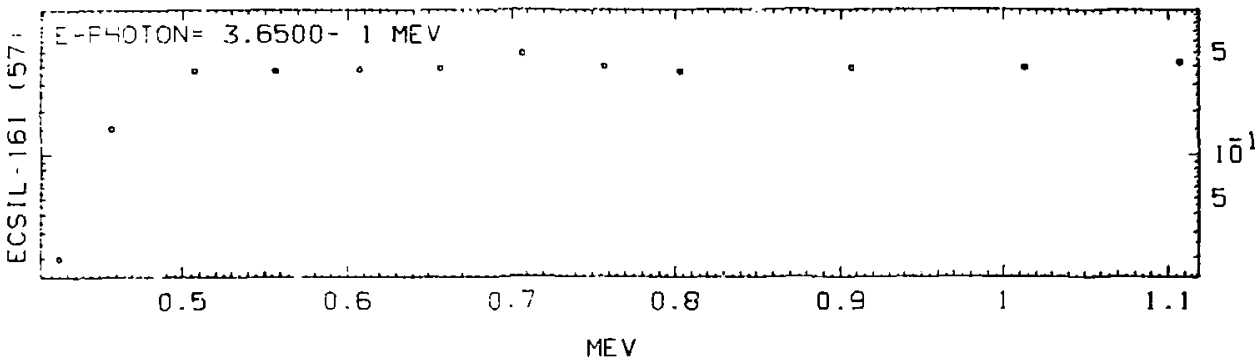

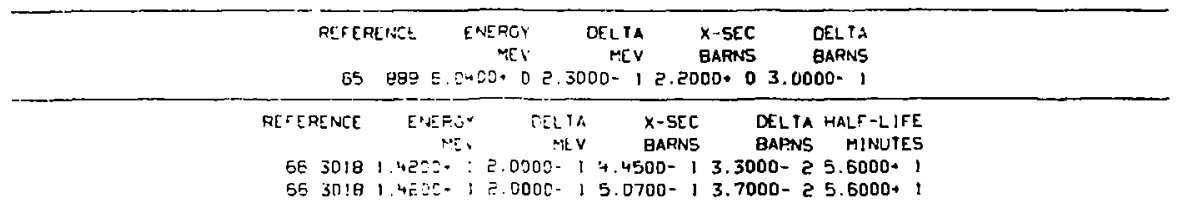

$03 / 01: 74$

$$
N, 3 N
$$

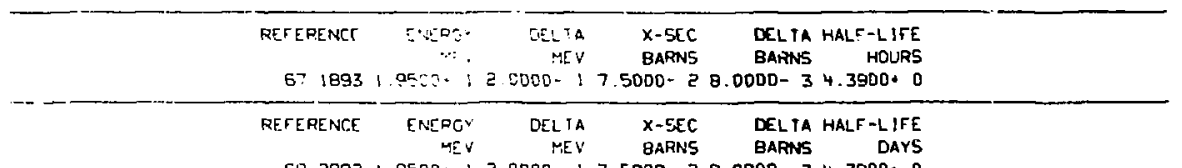

69 2992 $1.9500 \cdot 12.0000-17.5000-2$ B. $0000-34.3900+0$ 
CROSS SECTIGN

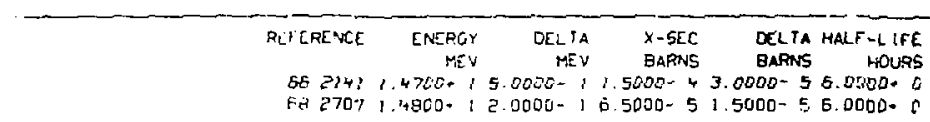

$0.5 / 01 / 74$

ABSORPTION

45- $\mathrm{RH}-103$

RETERENCE ENEAGY OELTS XIS XEC DELTA

$03 / 01 / 74$

N,P

45-RH-103

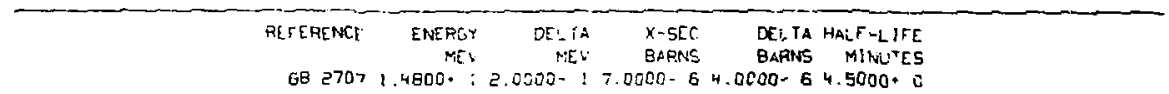

G8 $27071.4800 \cdot: 2.0000-17.0000-64.0000-64.5000 * 0$

$03 / 01 / 74$

N. $\times P$

$45-\mathrm{RH}-103$

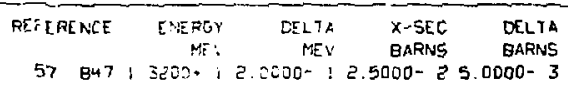

$03: 01 / 74$

N. HE $\rightarrow 3$

$45-R H-103$

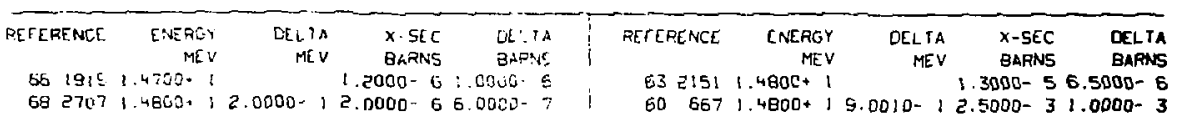

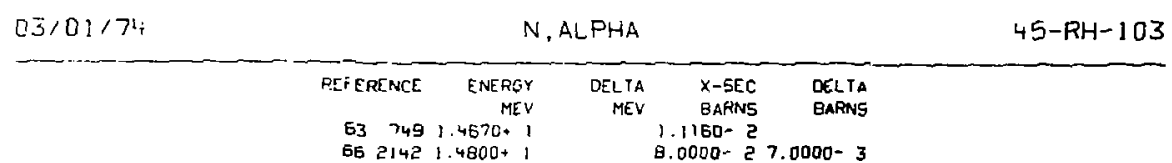




\begin{tabular}{|c|c|c|}
\hline $03 / 01 / 74$ & N, ALPHA & $45-\mathrm{RH}-103$ \\
\hline & CROSS SECTION & \\
\hline
\end{tabular}

REFERENCE ENTACY $53 \quad 2734500+1$ DELTK X-SEC MEV BARNS

DELTA HALF-LIFE $6.3010-2$
$2.5000-28.0010+1$

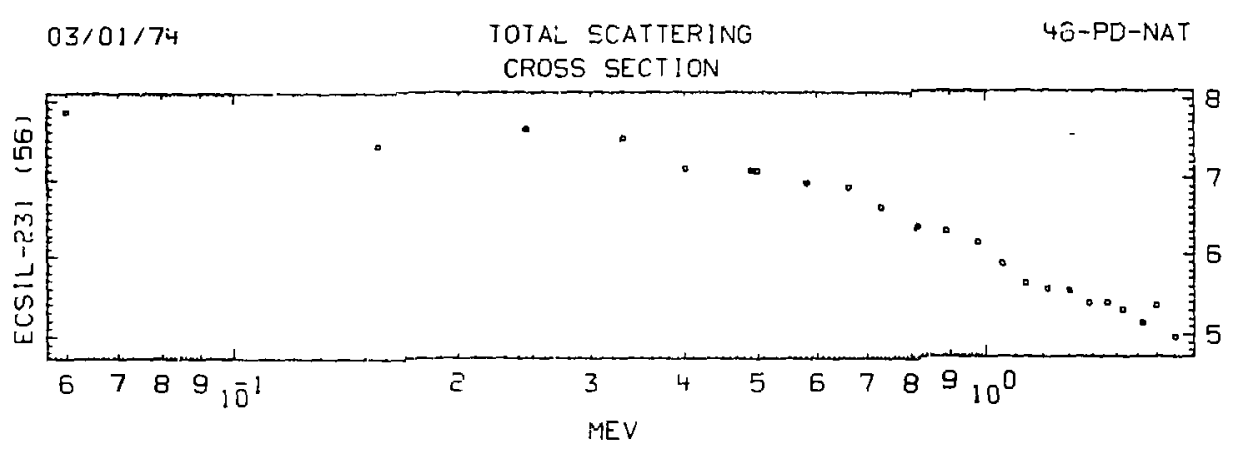



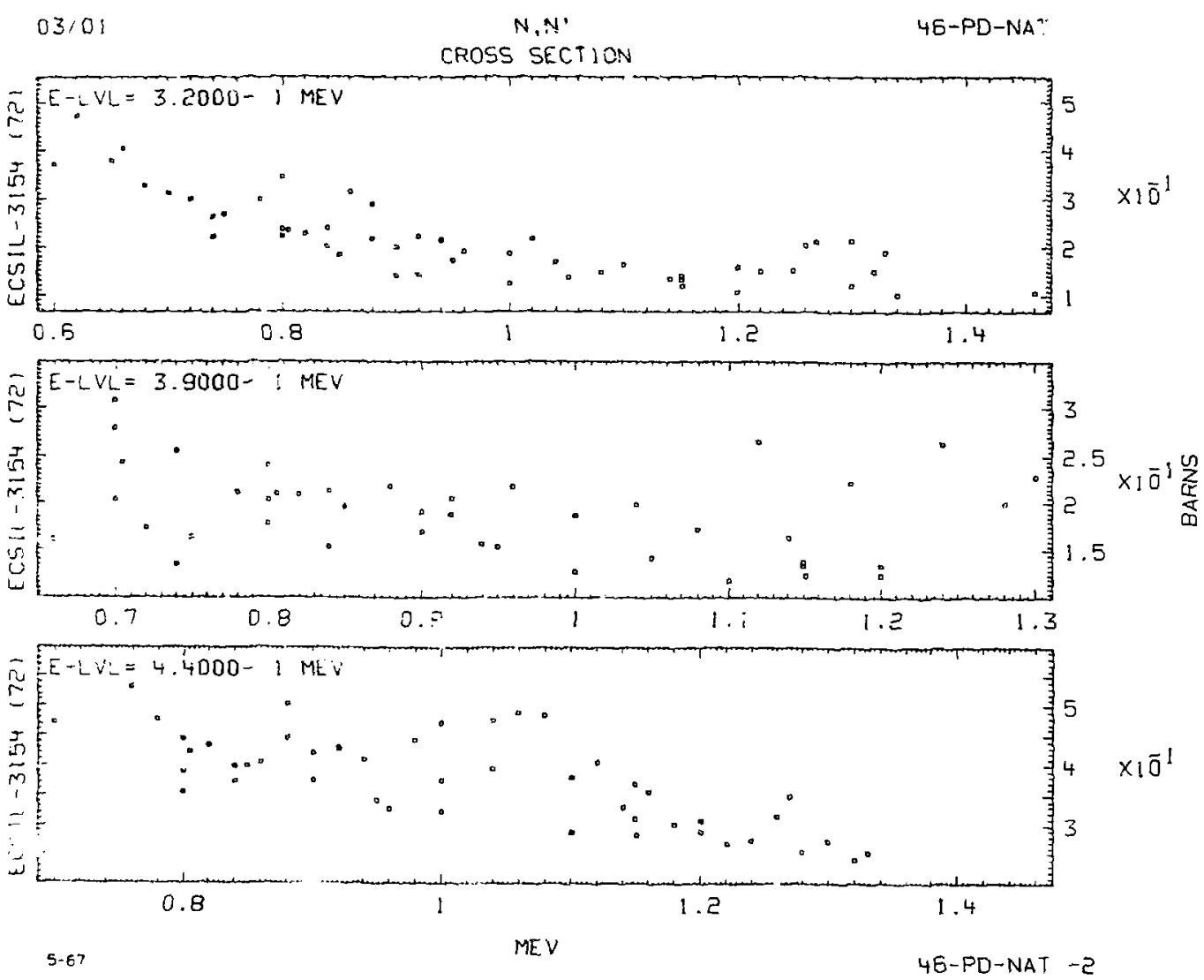


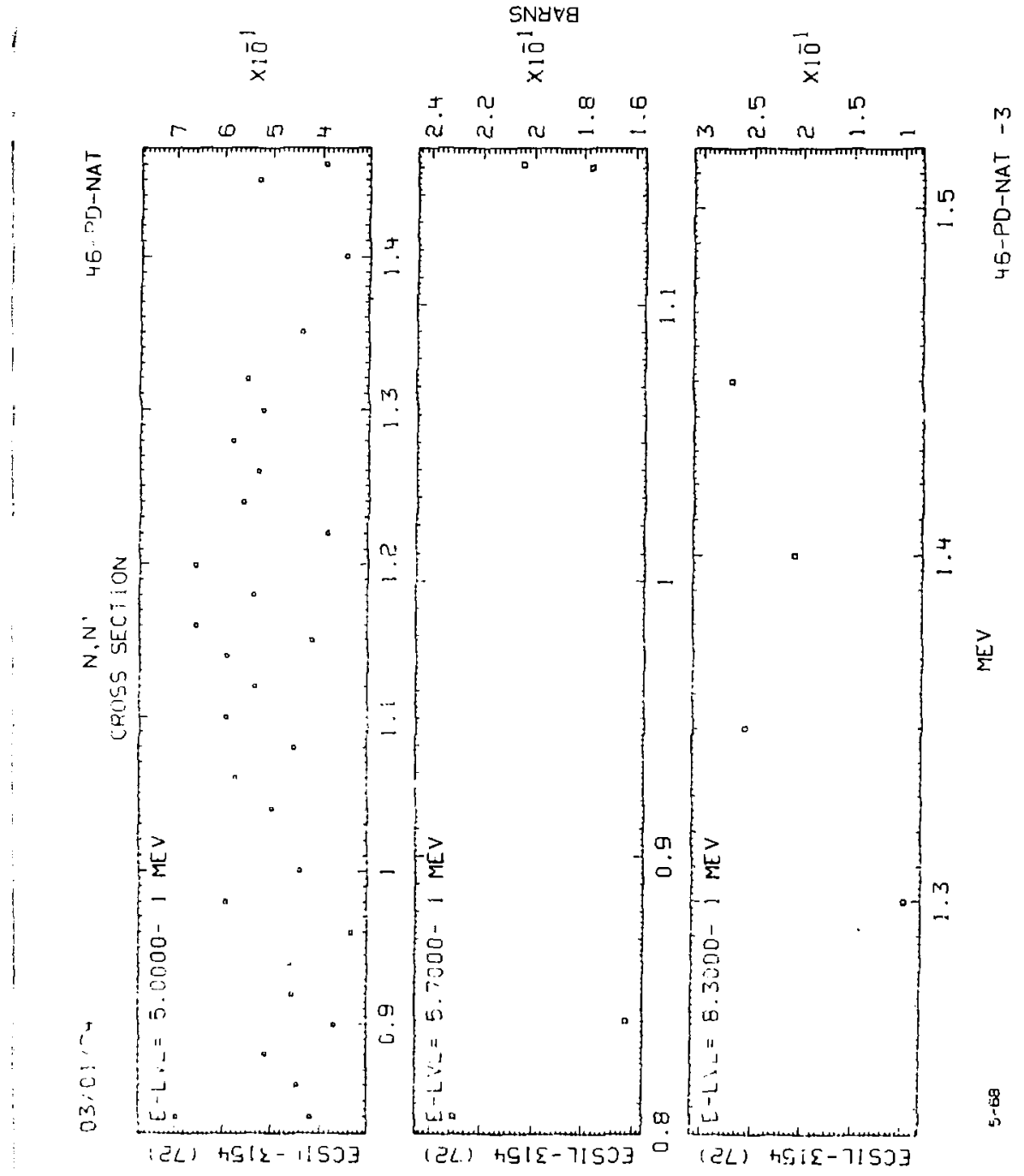




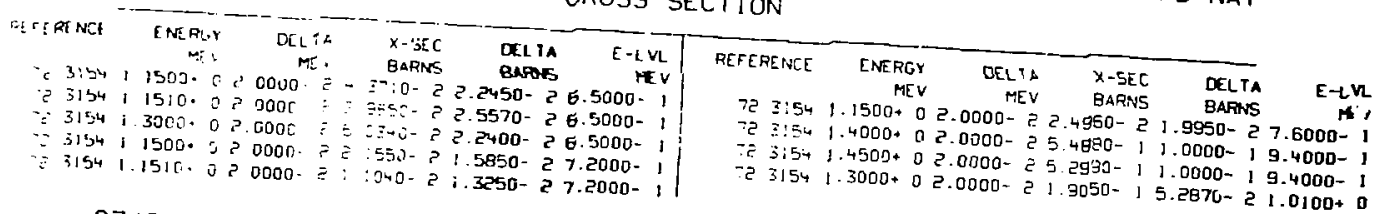

SLFEENC

$03 / 01 / 74$ COHERENT SCATTESING

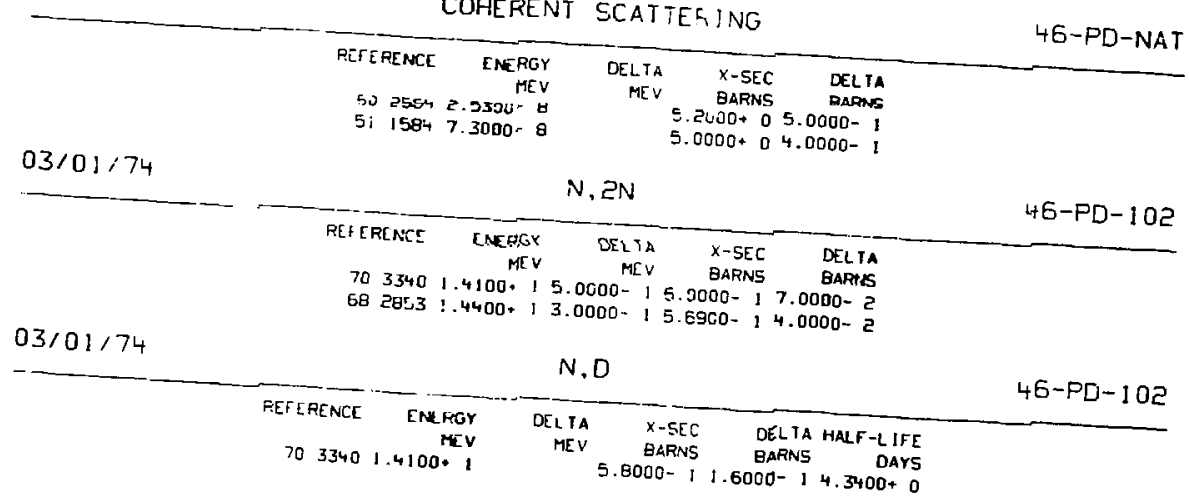


CROSS SECTION

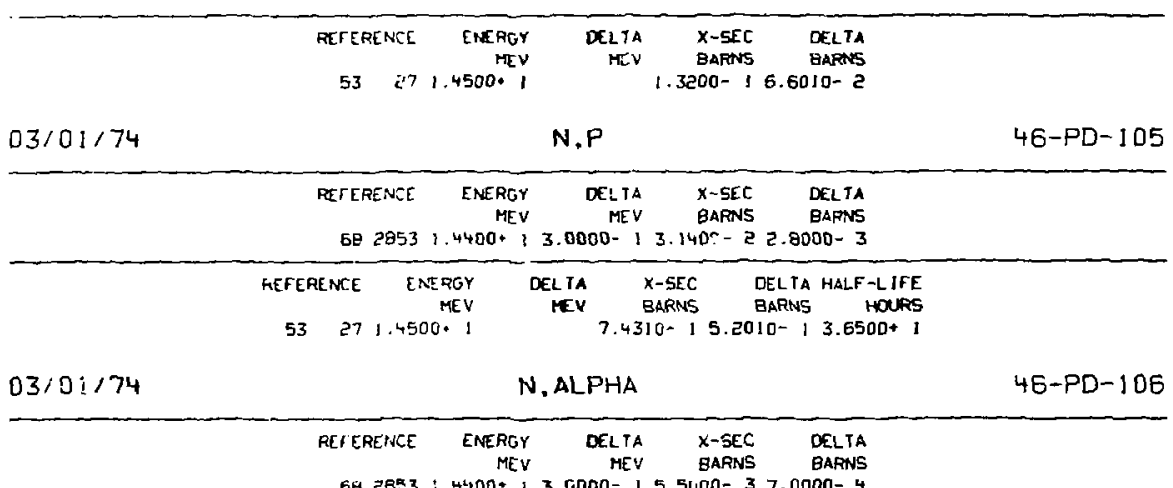

68 टBR $3: 4^{1400+} 3.6000-15.5000-37.0000-4$

03/01/74

$682353,4400+13.0000-14.4800-13.2000-2$

-

$596261.4500 * 14.0000-14.0000-38.0010-4$ 
CROSS SECTION

\begin{tabular}{|c|c|c|c|c|c|c|}
\hline & $\begin{array}{r}\text { REFERENCE } \\
63 \quad 859\end{array}$ & $\begin{array}{r}\text { ENEAGY } \\
\text { AEY } \\
1.4800 \cdot 1\end{array}$ & $\begin{array}{r}\text { DELTA } \\
\text { MEV }\end{array}$ & $\begin{array}{r}x \text {-SEC } \\
\text { BARINS } \\
e, 0000-5\end{array}$ & $\begin{array}{l}\text { DELTA } \\
\text { BARNS }\end{array}$ & \\
\hline $03 / 0: / 74$ & \multicolumn{5}{|c|}{$N, A L$} & $46-P D-108$ \\
\hline & $\begin{array}{l}\text { REFEFENCE } \\
58 \quad 401 \\
682853 \\
63 \quad 860\end{array}$ & $\begin{array}{r}\text { ENERGY } \\
\text { MEV } \\
1.4050^{\circ} \text { ! } \\
1.4600+ \\
1.4500^{\circ} \text { ? }\end{array}$ & $\begin{array}{r}\text { C.TA } \\
\text { MEV } \\
3.5010-1 \\
\text { M.0000- } 1\end{array}$ & $\begin{array}{r}\text { X- SEC } \\
\text { BARNS } \\
2.3000-3 \\
2.5000+0 \\
3.1000-3\end{array}$ & $\begin{array}{r}\text { DELTA } \\
\text { BAFNS } \\
4.0000-4 \\
3.0000-1\end{array}$ & \\
\hline
\end{tabular}

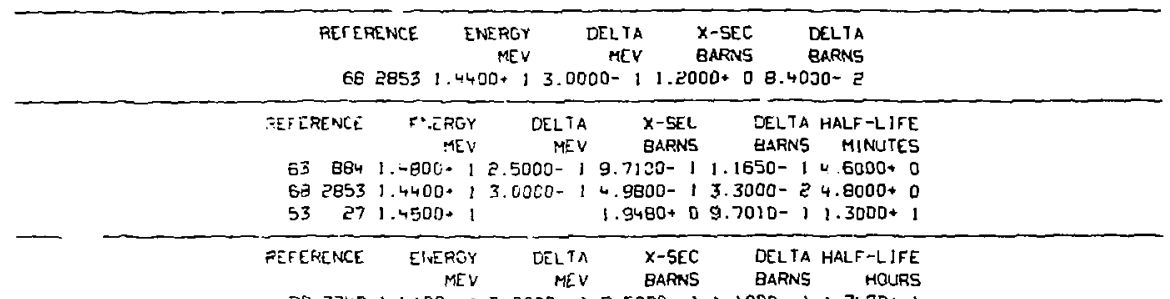

$7033401.4100+15.0000-19.5000-11.1000-11.3470+1$

$6=18481.4700,: 1.5060-12.5300+08.0000-21.3600+1$

$03 / 01 / 74$ N.O $46-P D-11 C$

$\begin{array}{rrrrr}\text { REFERENCE ENERGY } & \text { DELTA } & \text { X-SEC } & \text { DELTA HALF-LIFE } \\ & 638591.4000+1 & \text { MEV } & 1.7000-3 & \text { BEARS }\end{array}$



$53 \cdot i-4$
N, ALPHA
CROSS SECTION

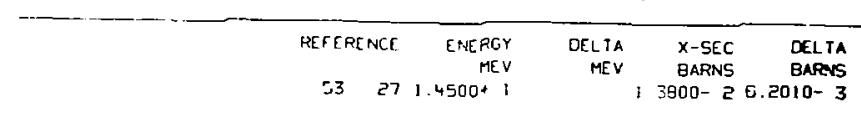

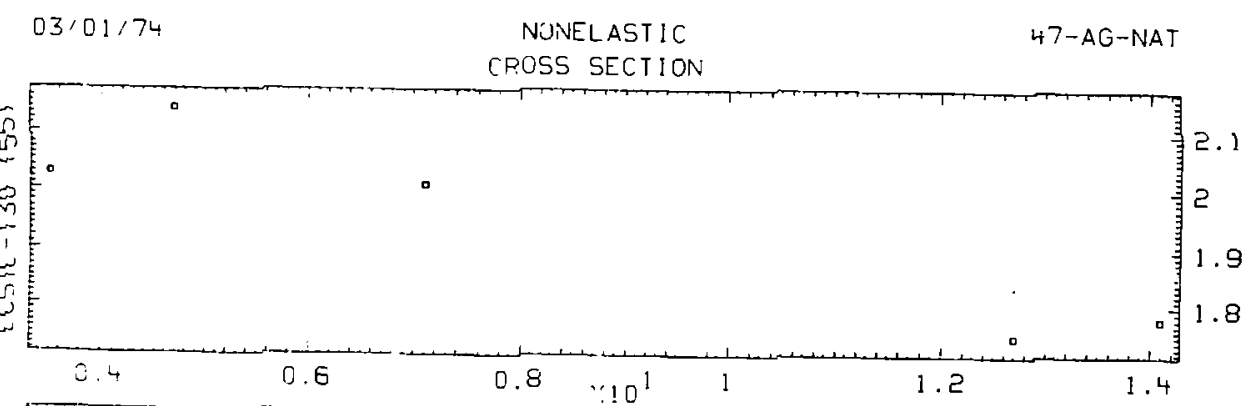

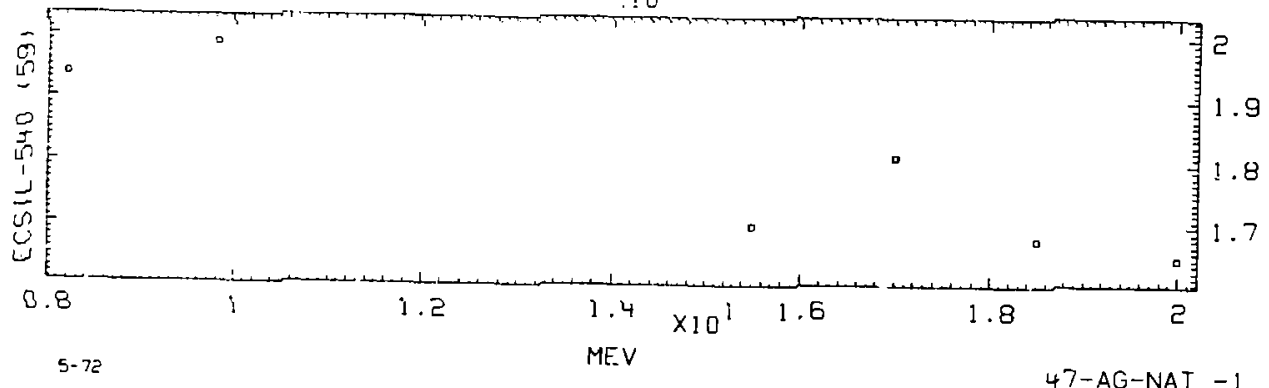




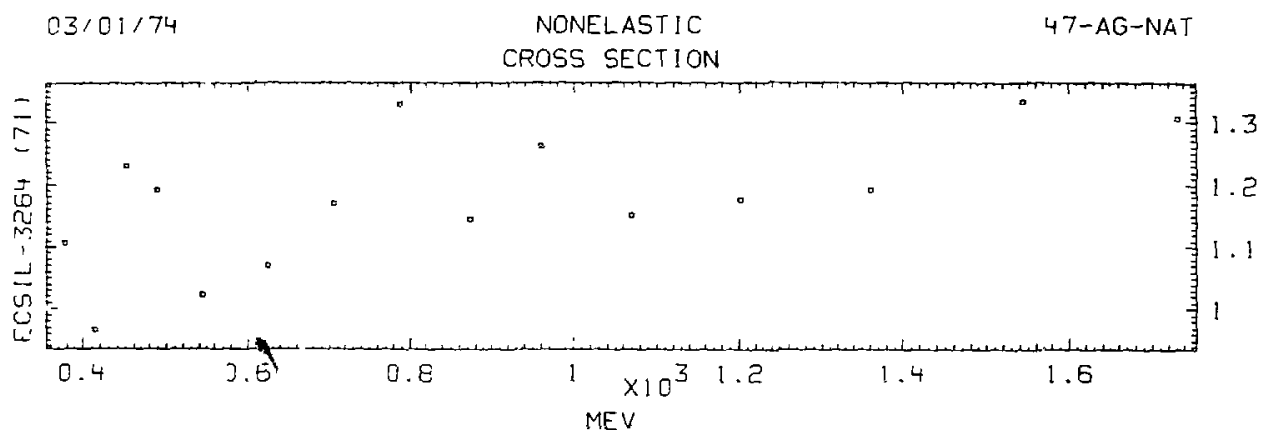

1

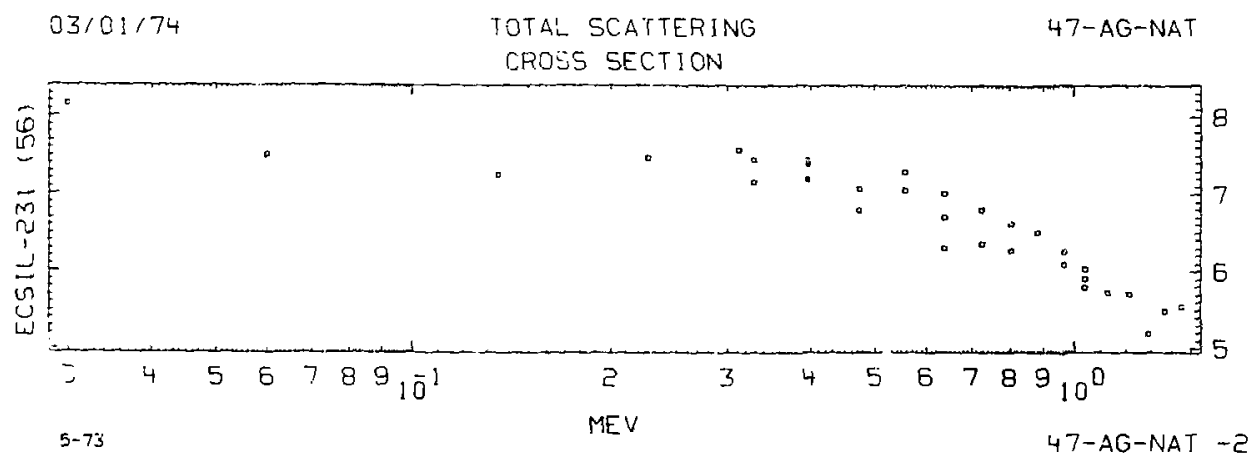



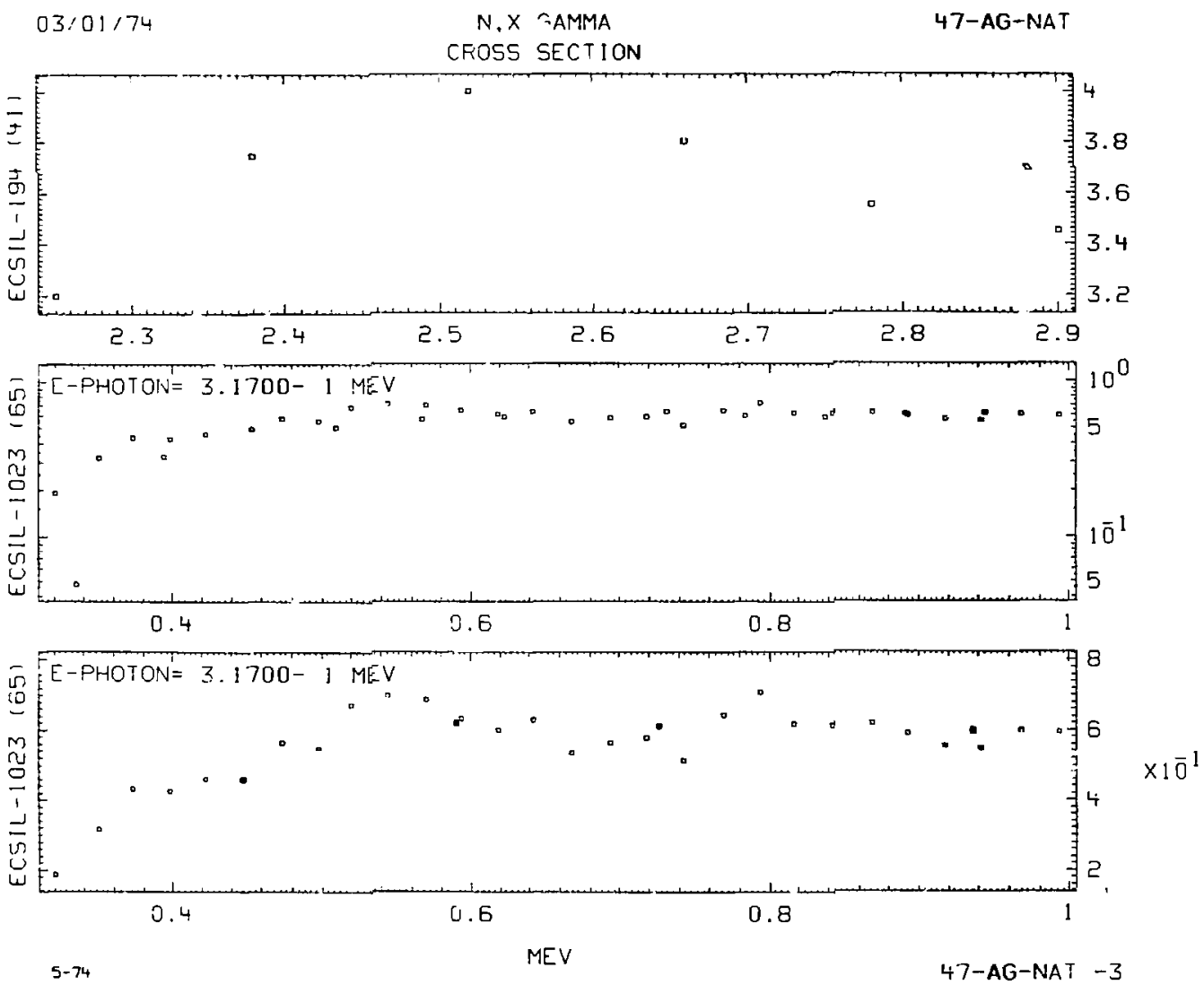

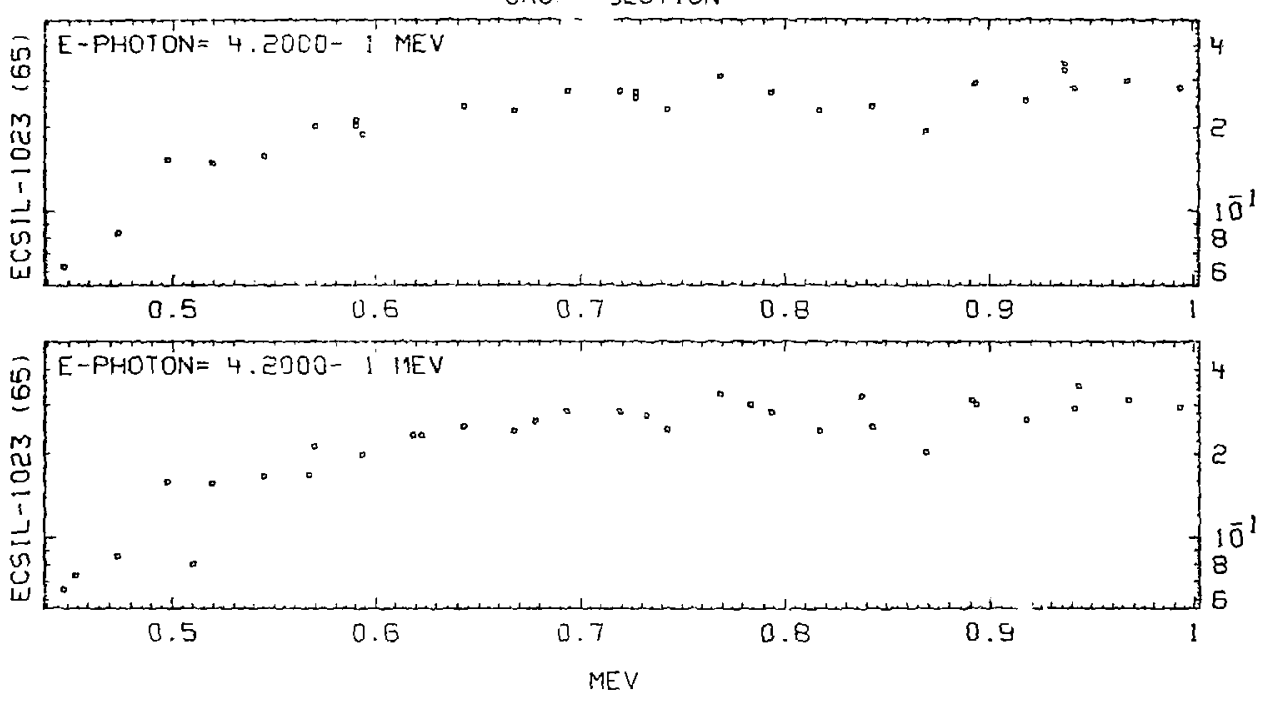

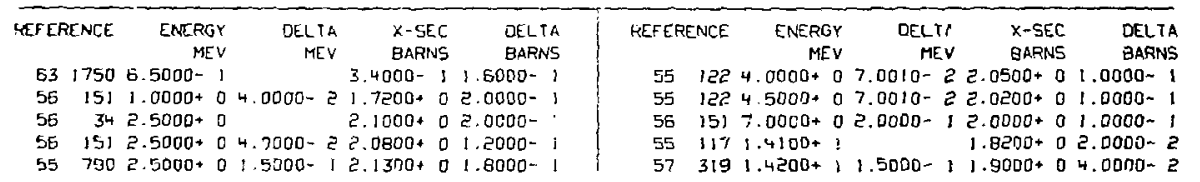


CROSS SECTION

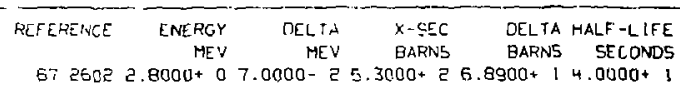

$03 / 01 / 74$

$N$, ¿N

47-AG-NAT

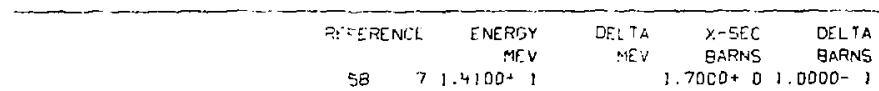

$03 / 01 / 74$

ABSORPTION

47-AG-NAT

\begin{tabular}{|c|c|c|c|c|c|c|c|c|c|}
\hline REFERENCF. & $\begin{array}{r}\text { ENEAGSY } \\
\text { MEY }\end{array}$ & $\begin{array}{r}\text { EELSA } \\
\text { MEV }\end{array}$ & $\begin{array}{l}X-S E C \\
E \text { TRNS }\end{array}$ & $\begin{array}{l}\text { DELIAA } \\
\text { BARNS }\end{array}$ & FEFERENCE & $\begin{array}{r}\text { ENEPSY } \\
\text { MEY }\end{array}$ & $\begin{array}{r}\text { DELTA } \\
\text { MEV }\end{array}$ & $\begin{array}{l}x-S E C \\
\text { BARNS }\end{array}$ & $\begin{array}{l}\text { DLLTA } \\
\text { GARN?. }\end{array}$ \\
\hline 897 & $2.5300-8$ & & $5.3+00+1$ & $1.2000+0$ & 673 & $2.5300-\mathrm{e}$ & & $6.4000 \cdot 1$ & $5.0000-1$ \\
\hline 54 ट?टR & $2.5300-8$ & & $5.3800+1$ & $4.0000-1$ & Eo ea! & $\tilde{C}^{\prime}=3200-8$ & & $6.4800+1$ & $4.0000-1$ \\
\hline $54 \quad 2730$ & $2.5300-8$ & & $5.8000+1$ & $12.0000 \cdot 0$ & $5=1354$ & $2.4000-?$ & & $9.8000-1$ & $6.0000-2$ \\
\hline
\end{tabular}

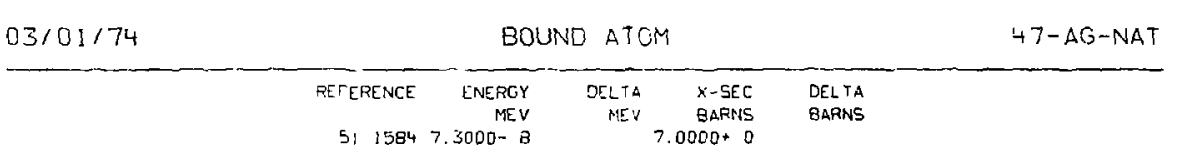

$03 / 01 / 74$

COHERENT SCATTEFING

47-AG-NAT

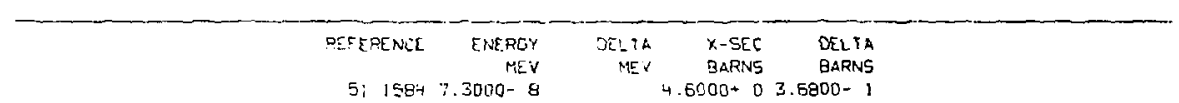




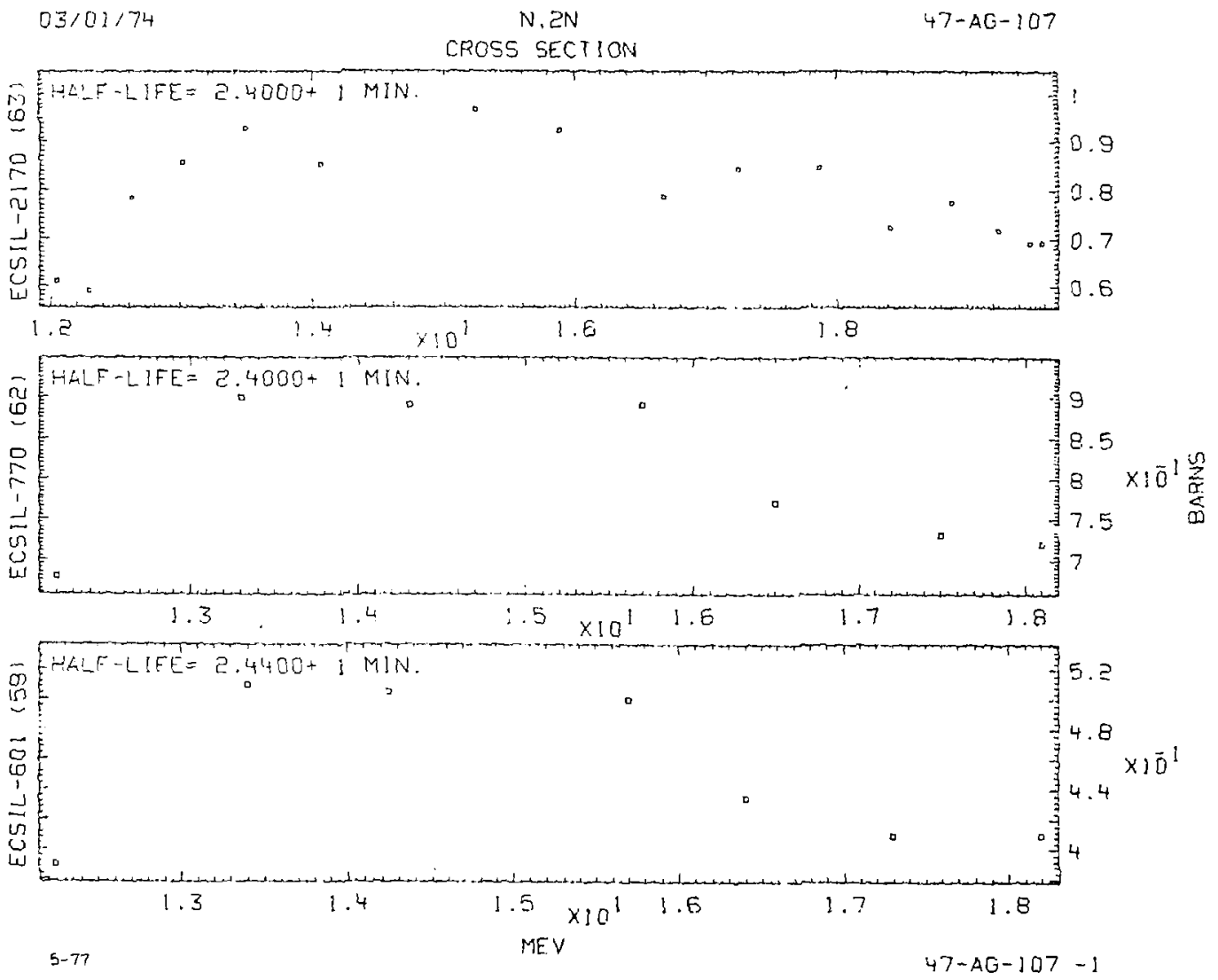



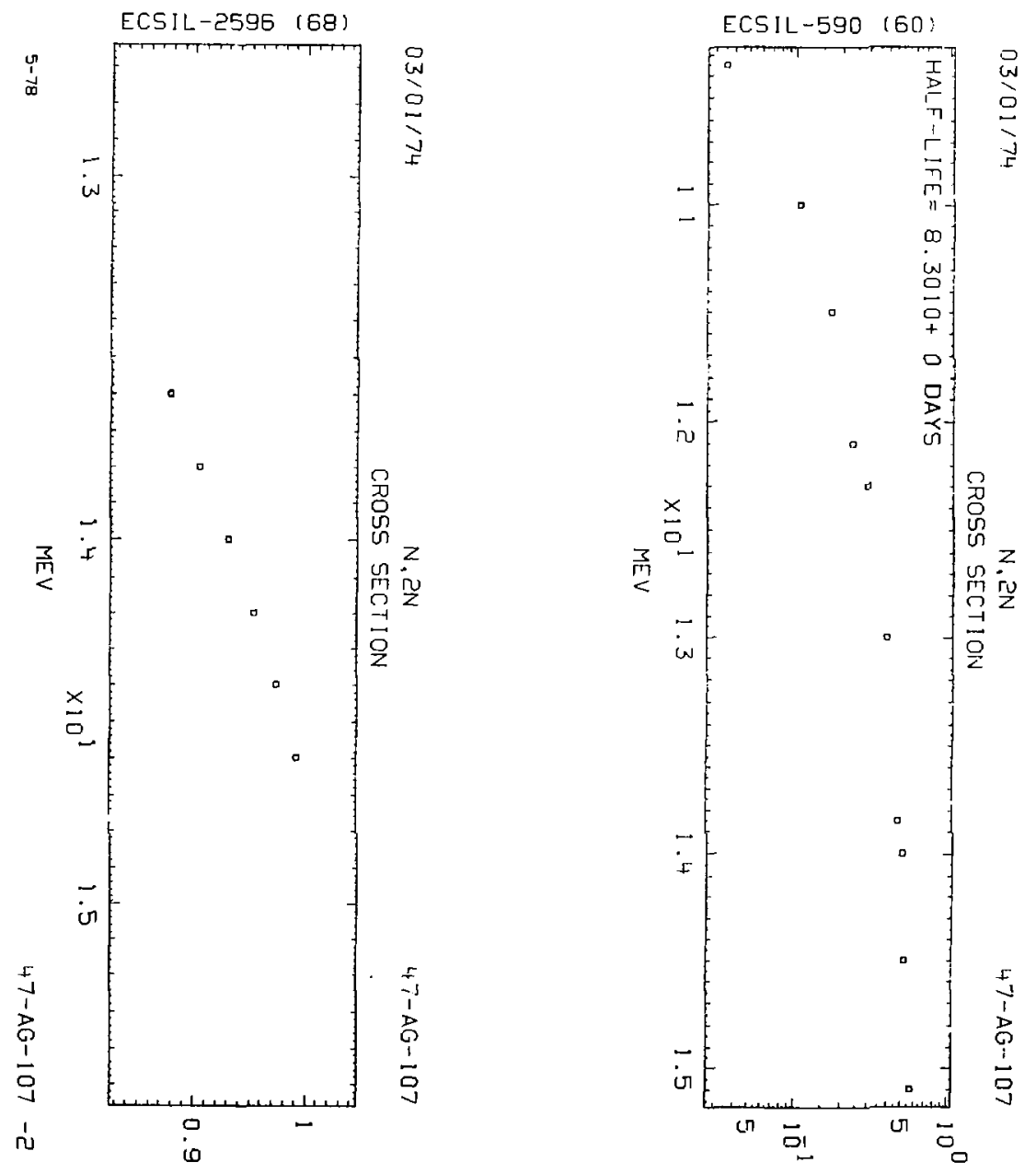

REL AT I VE

BARNS 

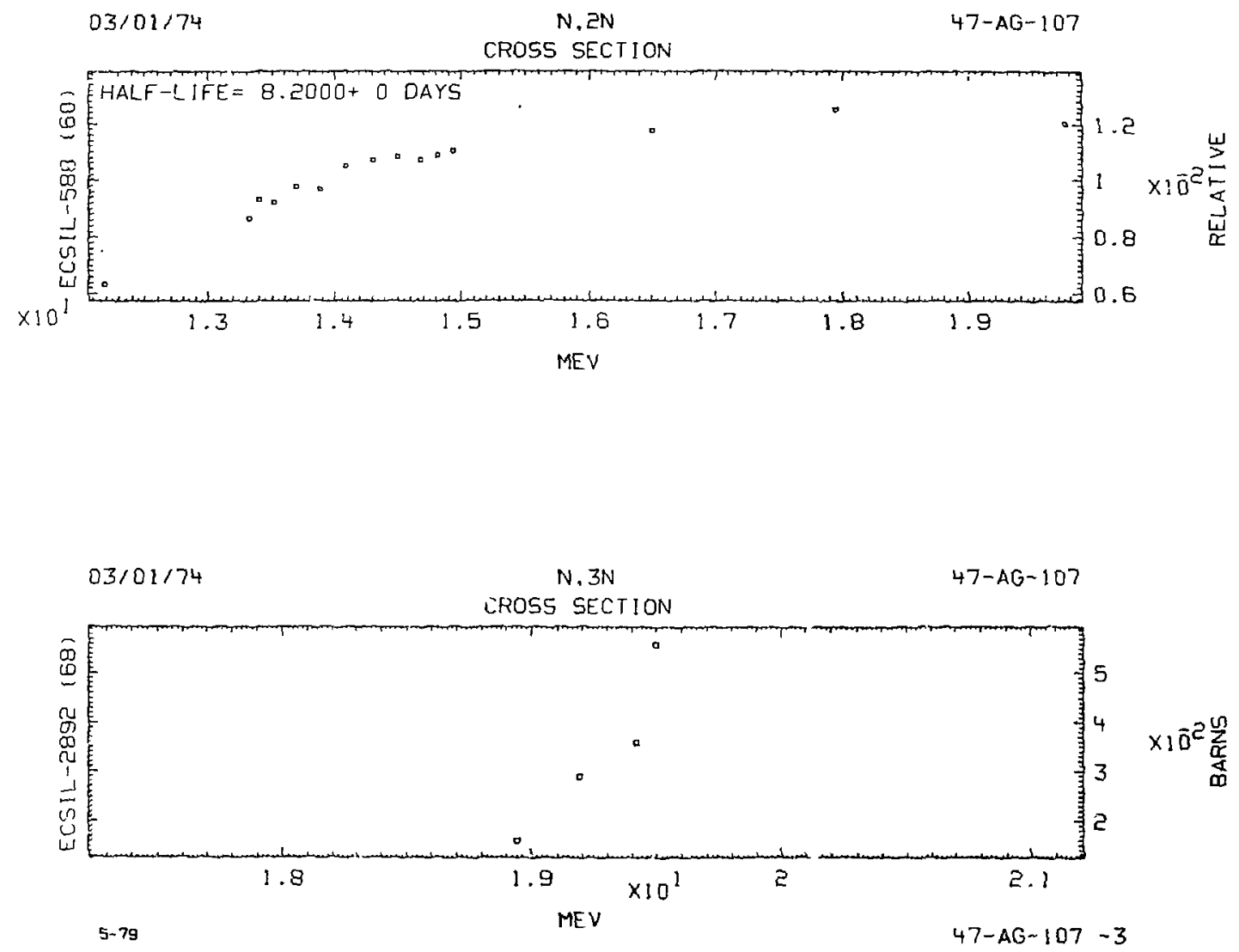
CROSS SECIION

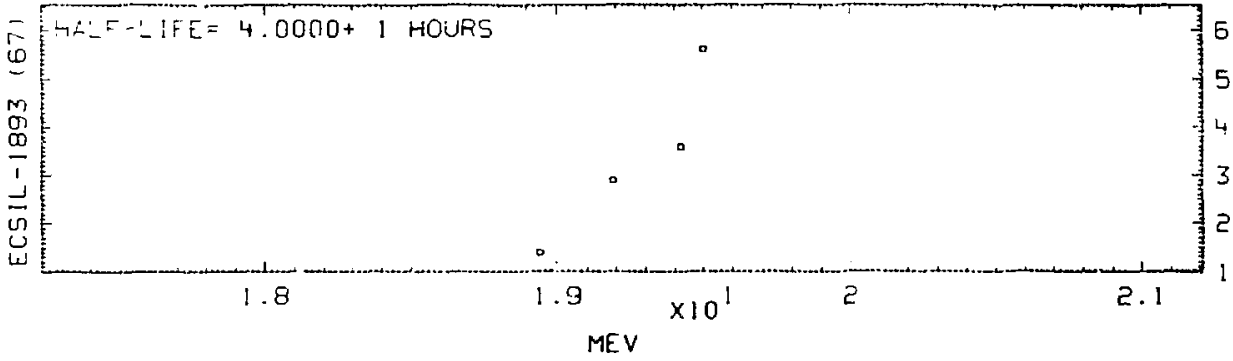

$03 / 01 / 74$

N. $2 N$

47-AG-107

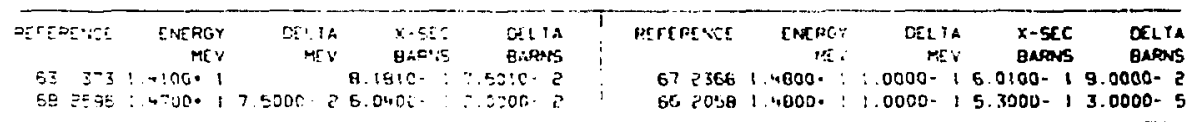

\begin{tabular}{|c|c|c|c|c|c|c|c|c|c|c|}
\hline \multicolumn{2}{|c|}{ PEFERENE: } & $=\because 5$ & & $\begin{array}{l}x-5 \\
\text { and }\end{array}$ & $a$. & 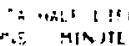 & fiefch & s mes & $\begin{array}{c}\text { EIEno } \\
\text { ME }\end{array}$ & DẼ. \\
\hline $6 !$ & 2JEE & 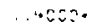 & : & -.600 & : $1.00: 2$ & $\therefore$ LOUto & $6:$ & $\because 35$ & $\therefore .0000$. & : 2.5000 \\
\hline 62 & $215^{-}$ & $: 4:: 2$ & $:: 0000$ & $1: B 0 \leqslant 0$. & 11.5082 & $\therefore \therefore 000$. & G! & 600 & 1.4800. & : \\
\hline $6 \mathrm{e}$ & 168 & $\therefore \cdots: \div$ & $: \quad \therefore 3300$ & $1 \% 34.19$ & $14.4008-$ & 22.4300 & $r x^{2}$ & A:, & $14100 \%$ & : \\
\hline 57 & 535 & $\therefore 6: 0$ & $: 1.0000 \mathrm{~m}$ & $14.5800-$ & $15.0 \% 0 \%-$ & $=? 2.4+130$ & 61 & 830 & 1.4100 & : \\
\hline 6) & G:E & 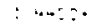 & $: 3.0000$ & $18.8910^{-}$ & $16.20: 2$ & $? 2 . \cdots 30$. & 55 & $? 7$ & 1.4500. & : \\
\hline
\end{tabular}




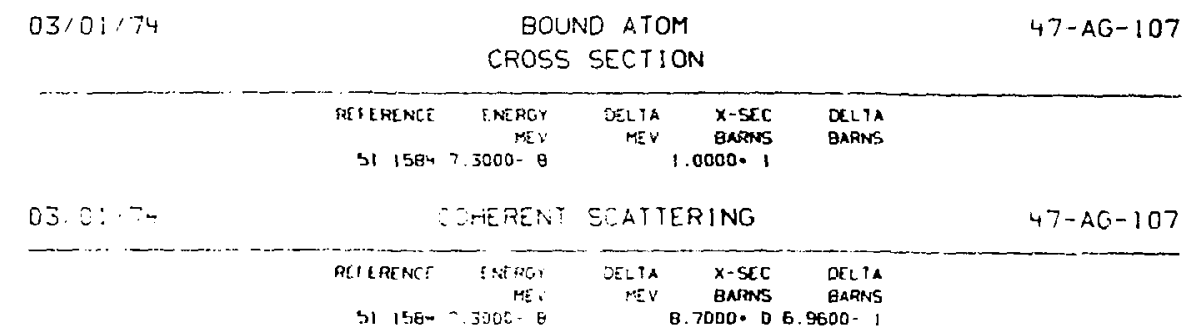

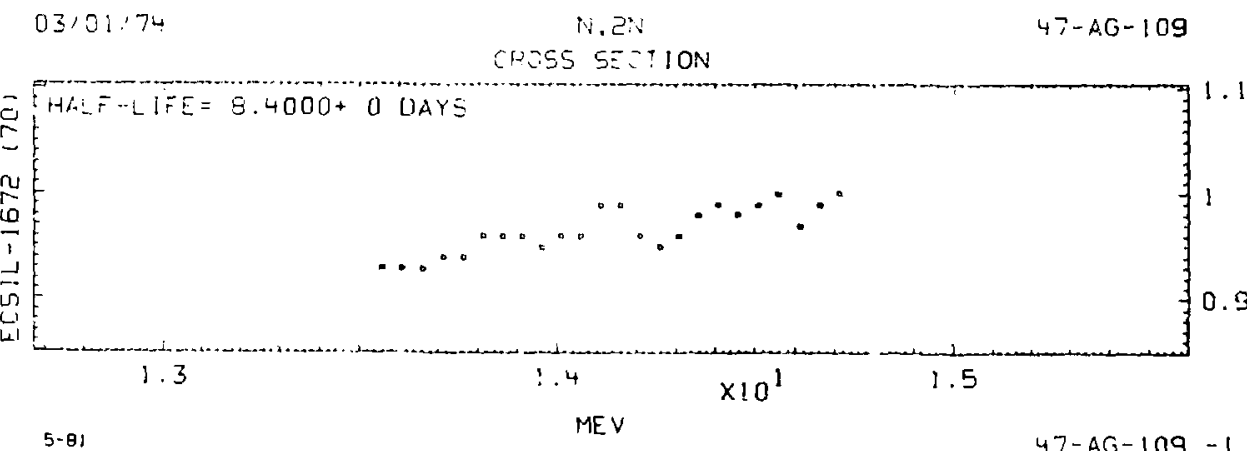




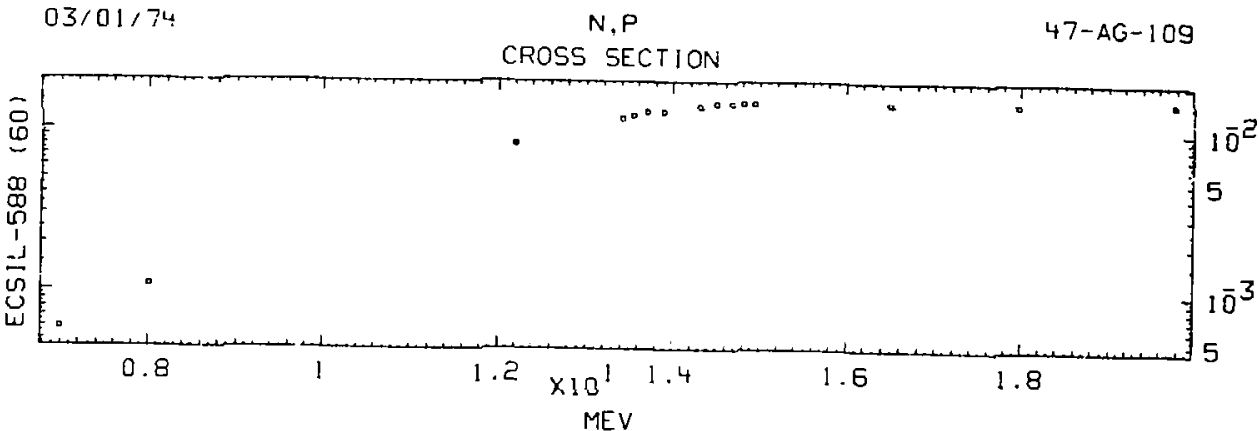

$03 / 01 / 74$

N. $2 N$

47-AG-109

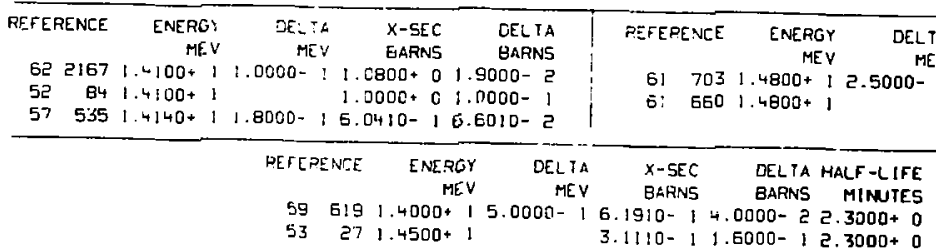

$03 / 01: 74$ ABSORPT ION

47-AG-109

$\begin{array}{rrrrr}\text { RETEPENCE } & \text { ENERRY } & \text { DELTA } & \text { X-5EC } & \text { CELTA } \\ \text { MEV } & \text { MEV } & \text { BARNS } & \text { EARNS } \\ 608972.530 t-8 & & 9.2000+12.0000+0\end{array}$




\section{CROSS SECTION}

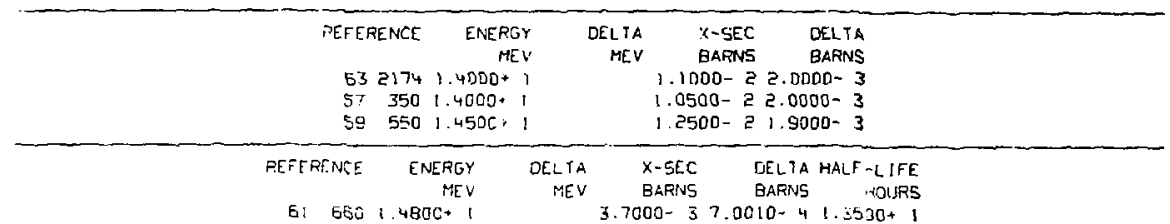

$03 / 01 / 74$ IV, ALPHA

47-AG-109

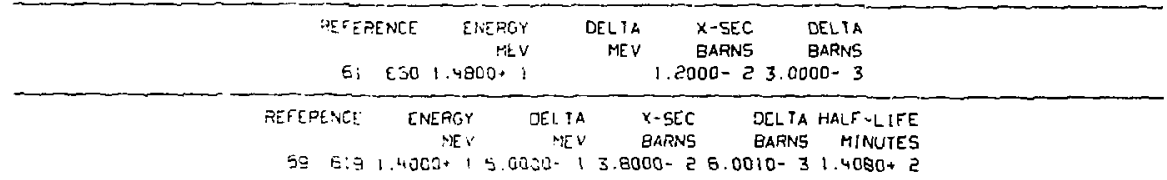

$03: 01 / 74$ BOUND ATOM

$47-A G-109$

DEFTRENCE

5) $15 \theta^{\prime}+7.3000-$

$03 / 01: 74$ COHERENT SCATTERING

DELTA

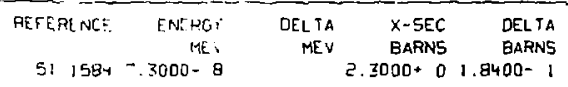




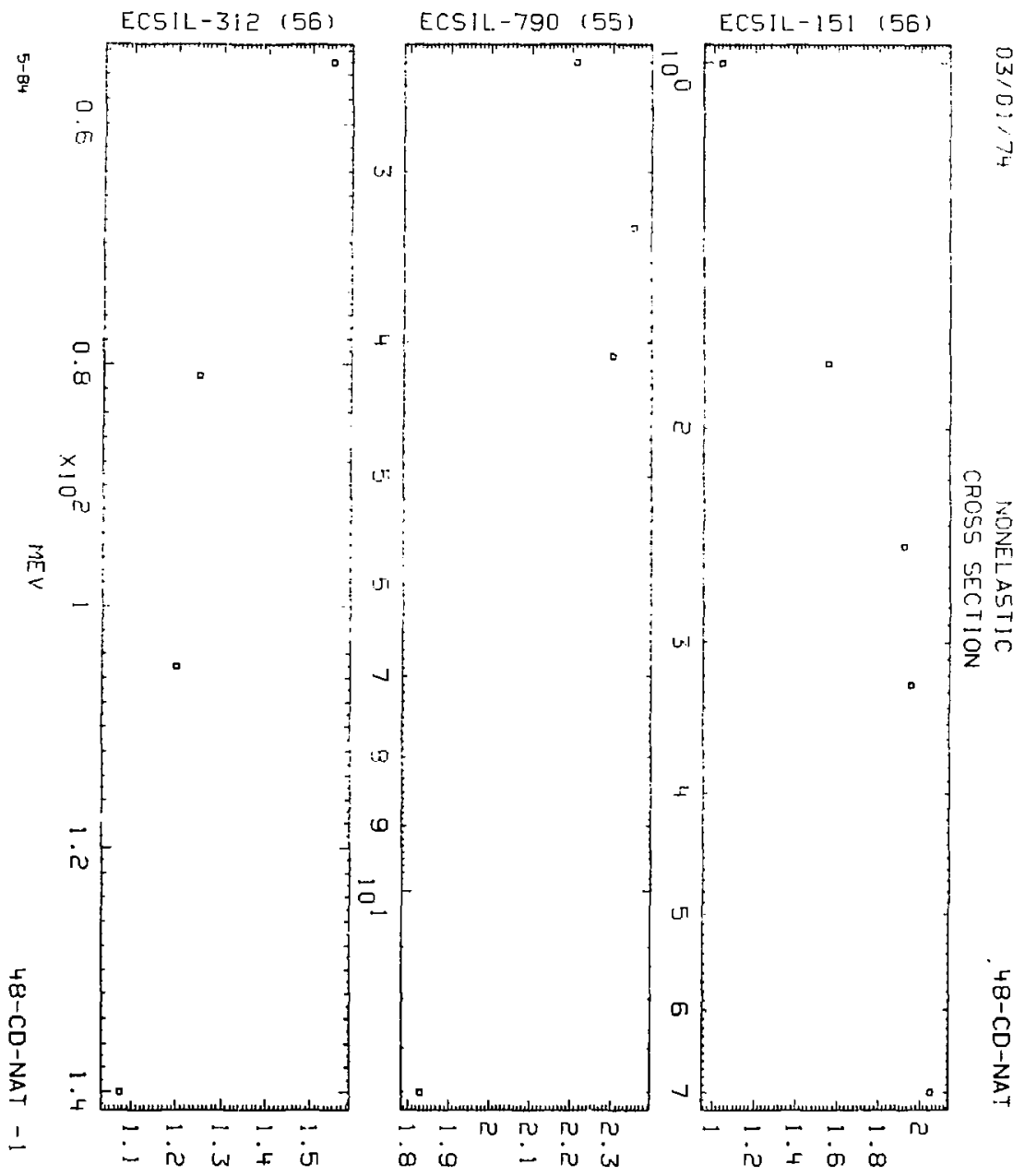

BARNS 

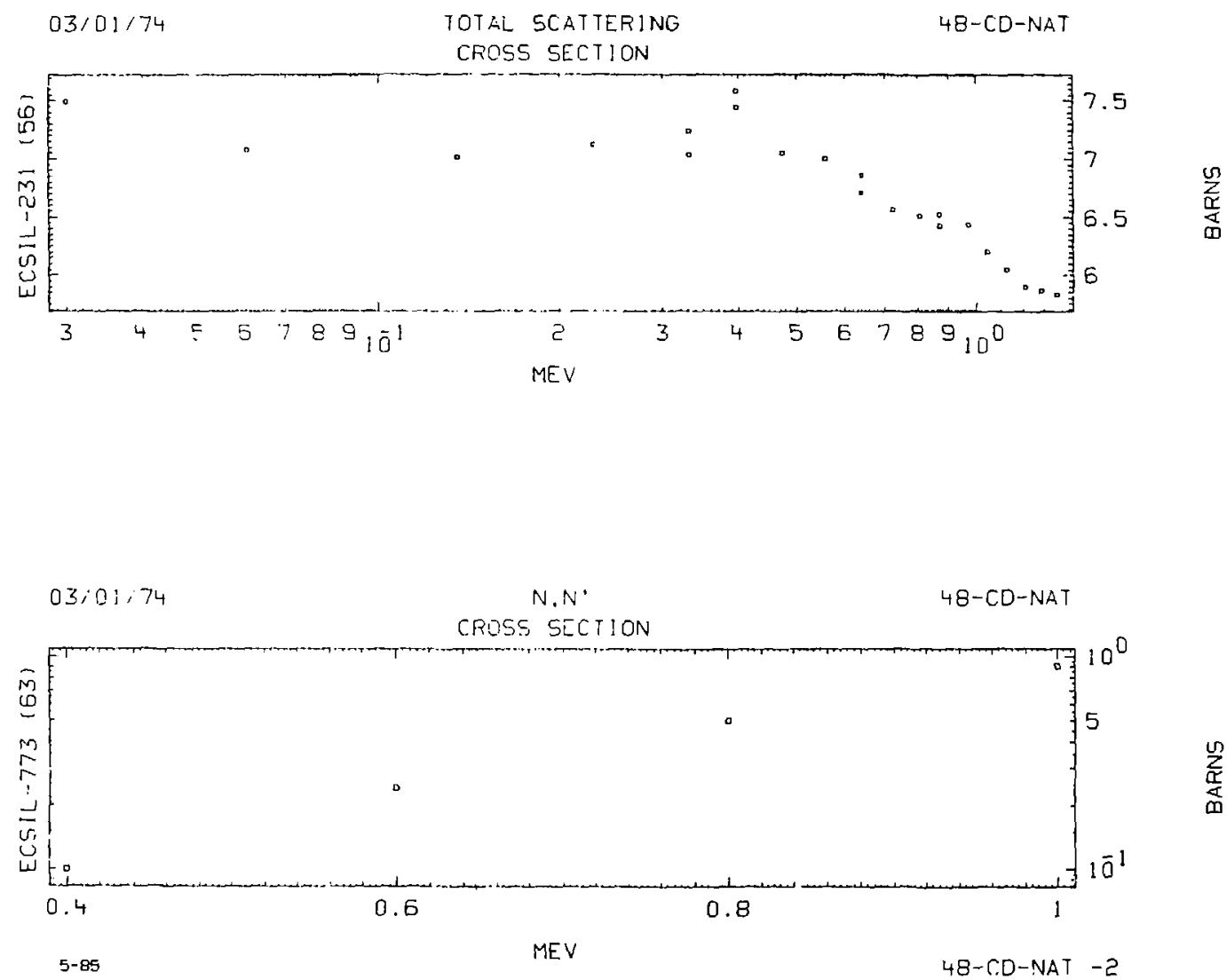

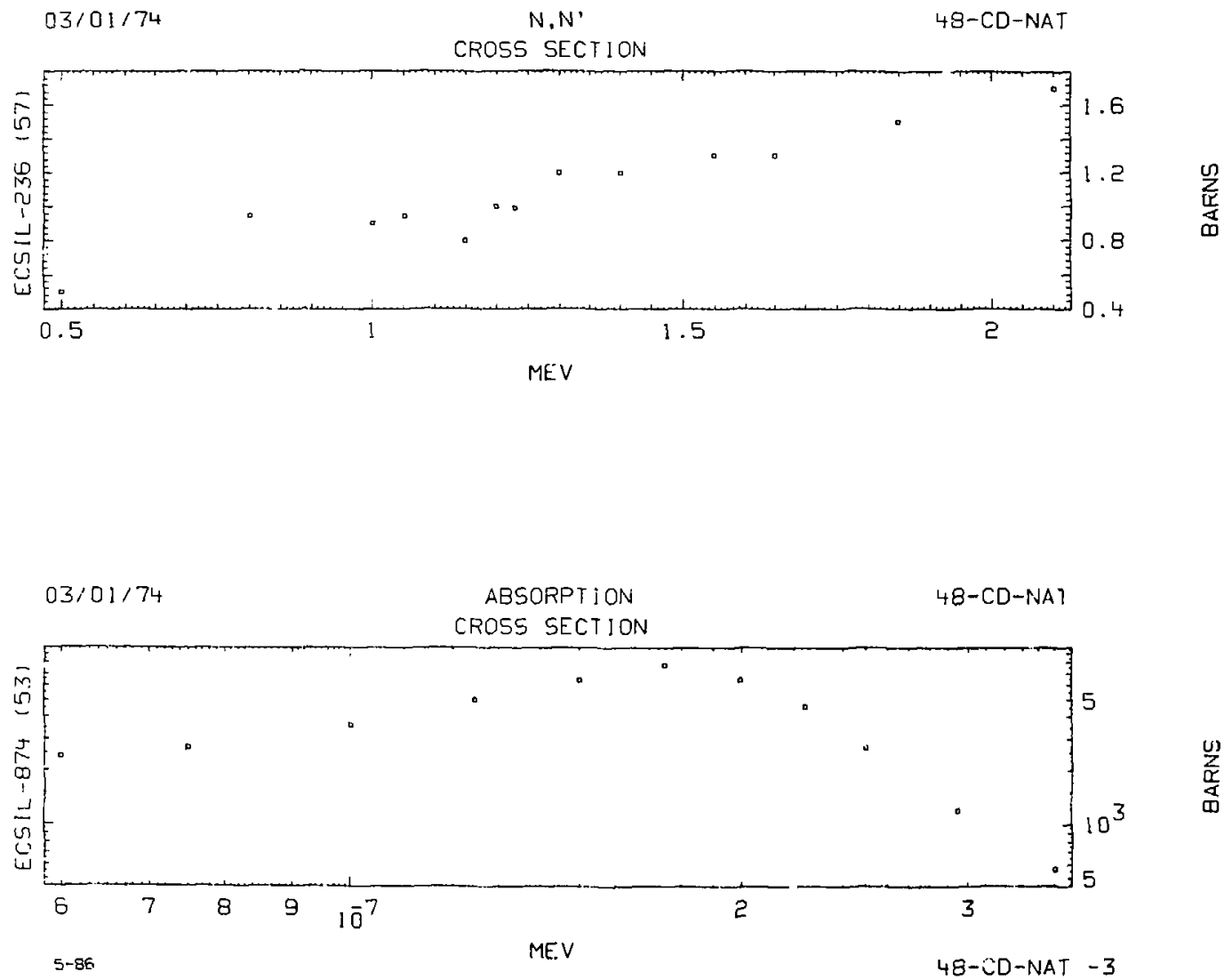

$\frac{03}{\frac{1}{4}}$ 

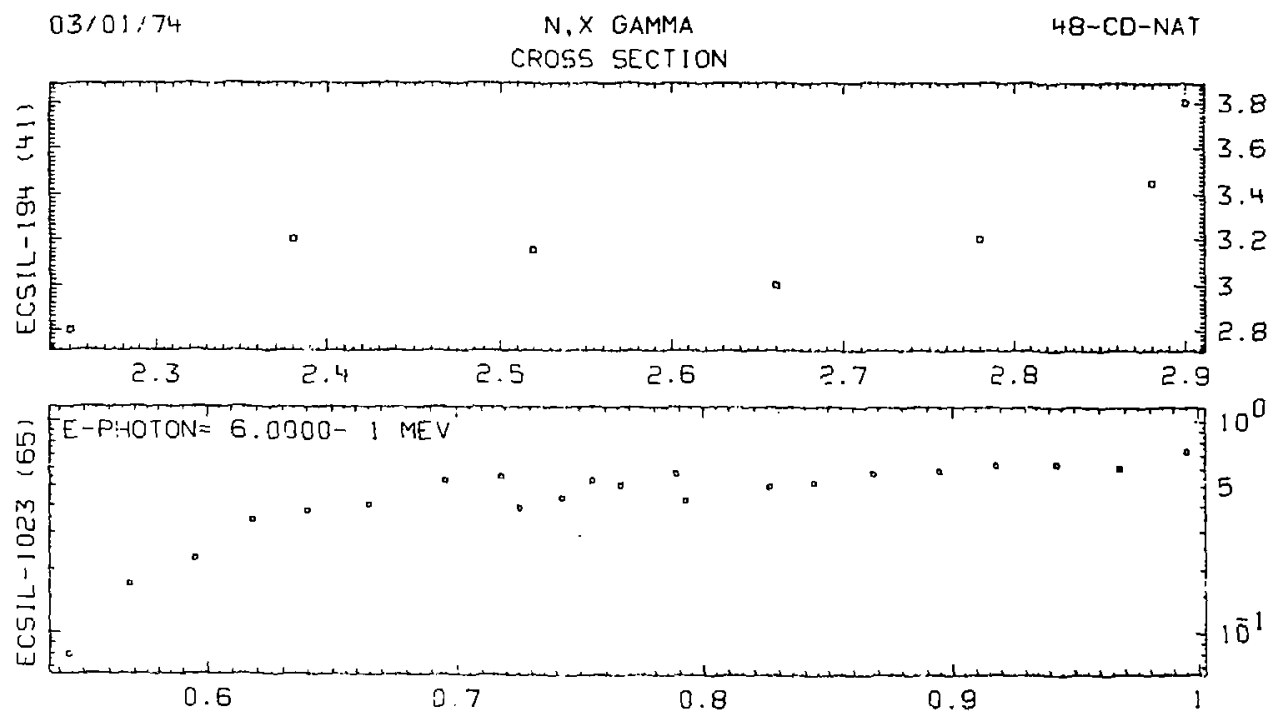

MEV

$03 / 01 \cdot 74$

NONELASTIC

48-CD-NAT

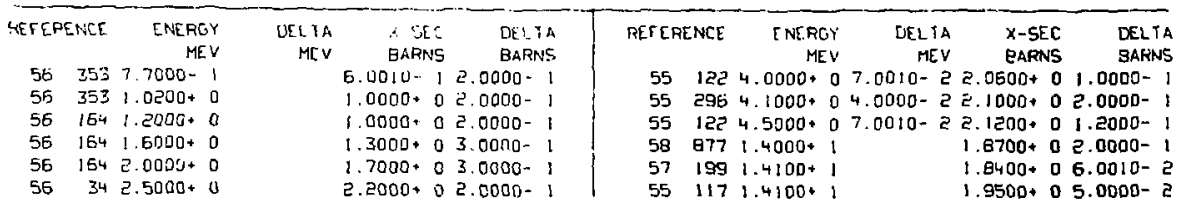




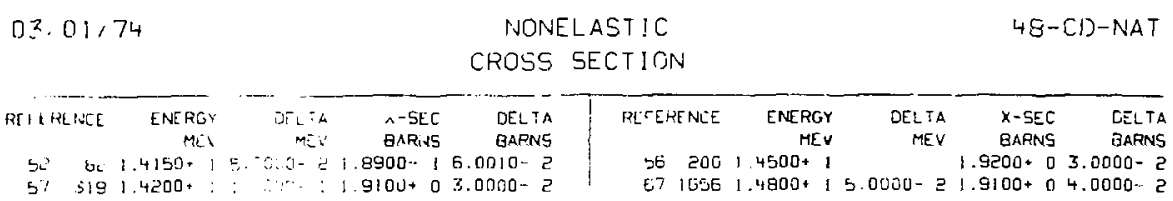

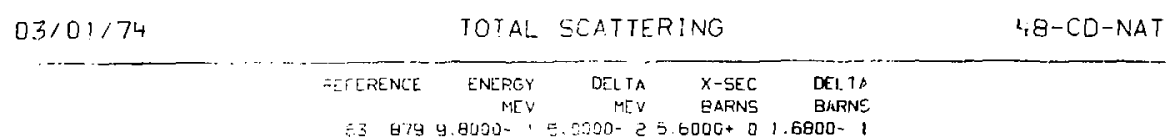

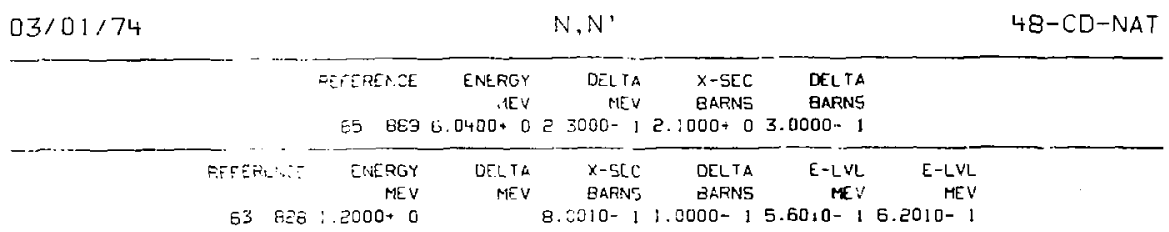

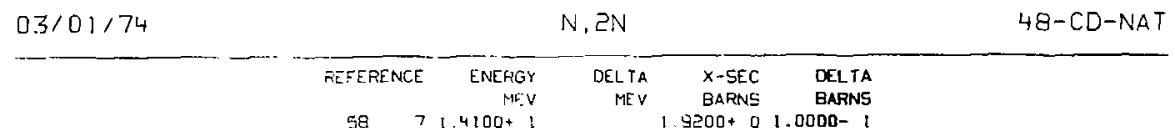

$03 / 01 / 74 \quad$ ABSORPTION 48-CD-NAT

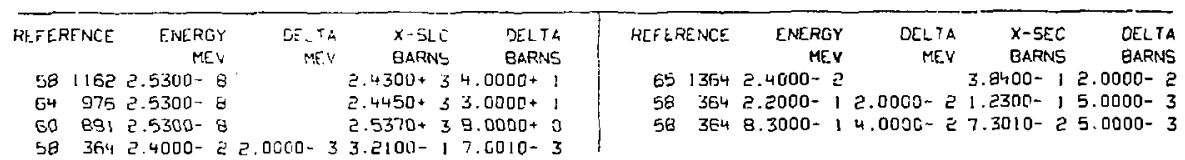


CROSS SECTION

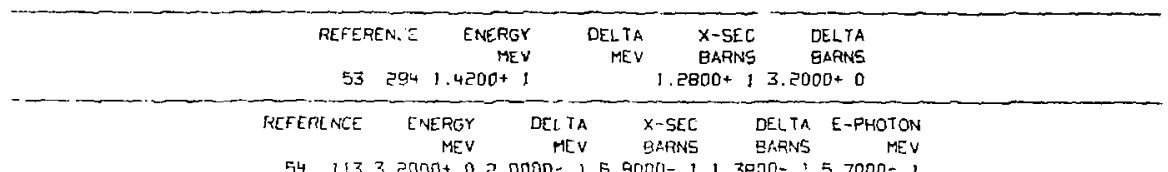

$54 \quad 1133.2000+02.0000-15.9000-11.3000-\div 5.7000-1$

$541133.2000+02.0000 * 11.6000-23.2000-32.8000+0$

03/01/74

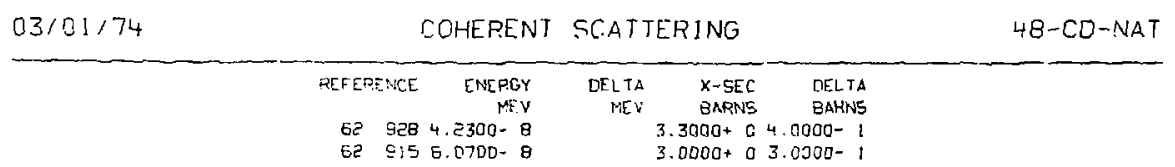
$03 / 01 / 74$
$N, 2 N$
$48-C 0-106$

CROSS SECTION

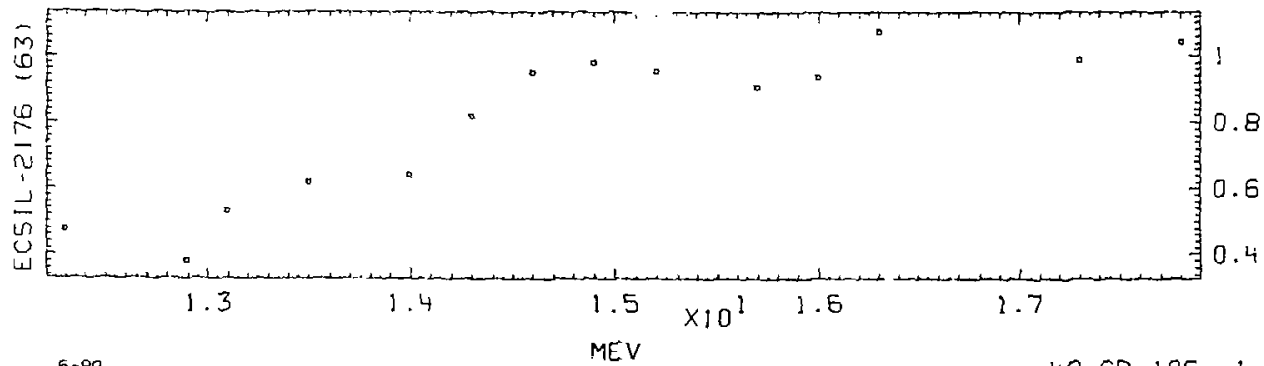




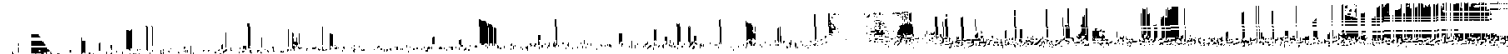

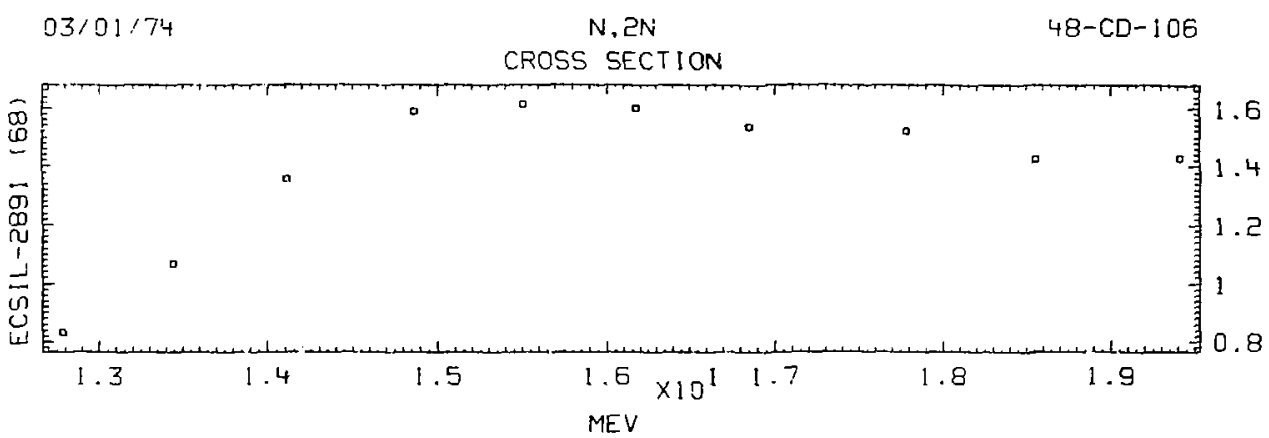

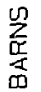

$05 / 01 / 74$

N.P

48-CD-10E

CROSE SECTION

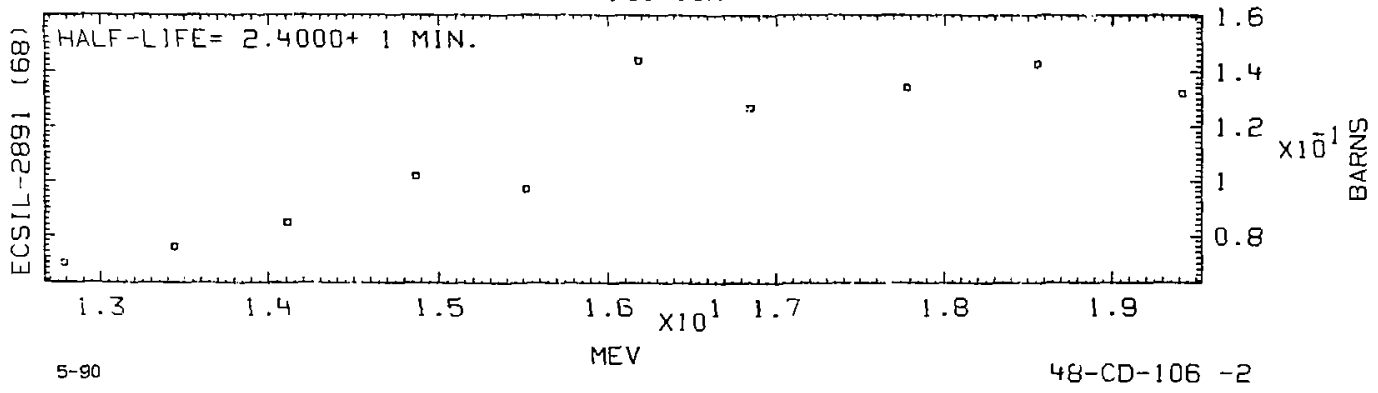




\section{CROSS SECTION}

\begin{tabular}{|c|c|c|c|c|c|c|}
\hline & 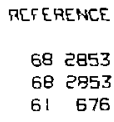 & $\begin{array}{r}\text { ENEREV } \\
\text { OEV } \\
1.4400+1 \\
1.4400+1 \\
1.4400+1\end{array}$ & $\begin{array}{rr}\text { DELTA } \\
\text { MEV } \\
13.0000-1 \\
13.0000-1 \\
13.0000-1\end{array}$ & $\begin{array}{r}X \text {-SEC } \\
\text { BARNS } \\
9.6500-1 \\
9.7500-1 \\
8.2710-1\end{array}$ & $\begin{array}{r}\text { OELTA } \\
\text { BARNS } \\
8.5000-2 \\
8.6000-2 \\
6.6210-2\end{array}$ & \\
\hline $03 / 01 / 74$ & & & $N, N \cdot O$ & & & $48-C D-106$ \\
\hline
\end{tabular}

$6628531.4400+13.0000-12.5500-12.9000-2$

$03 / 01 / 74$

$N, P$

$48-C D-106$

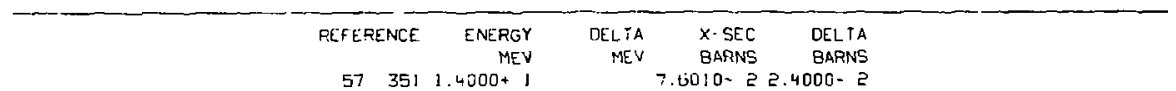

$03 / 01 / 74$

N, ALPHA

$48-C D-106$

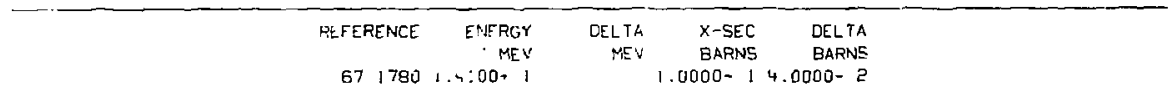

$03 / 01 / 74$

N. टN

$48-60-108$

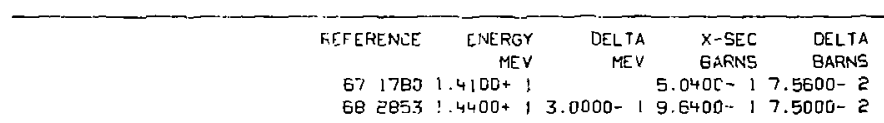




$\begin{array}{rrrr}\text { REFERENCE FNERG } & \text { DELTA } & \text { X-SEC } & \text { DELTA } \\ \text { GEV MARN } & \text { BAFNS }\end{array}$

$6828531.4400 * 13.0000-19.9800-1,1500-1$
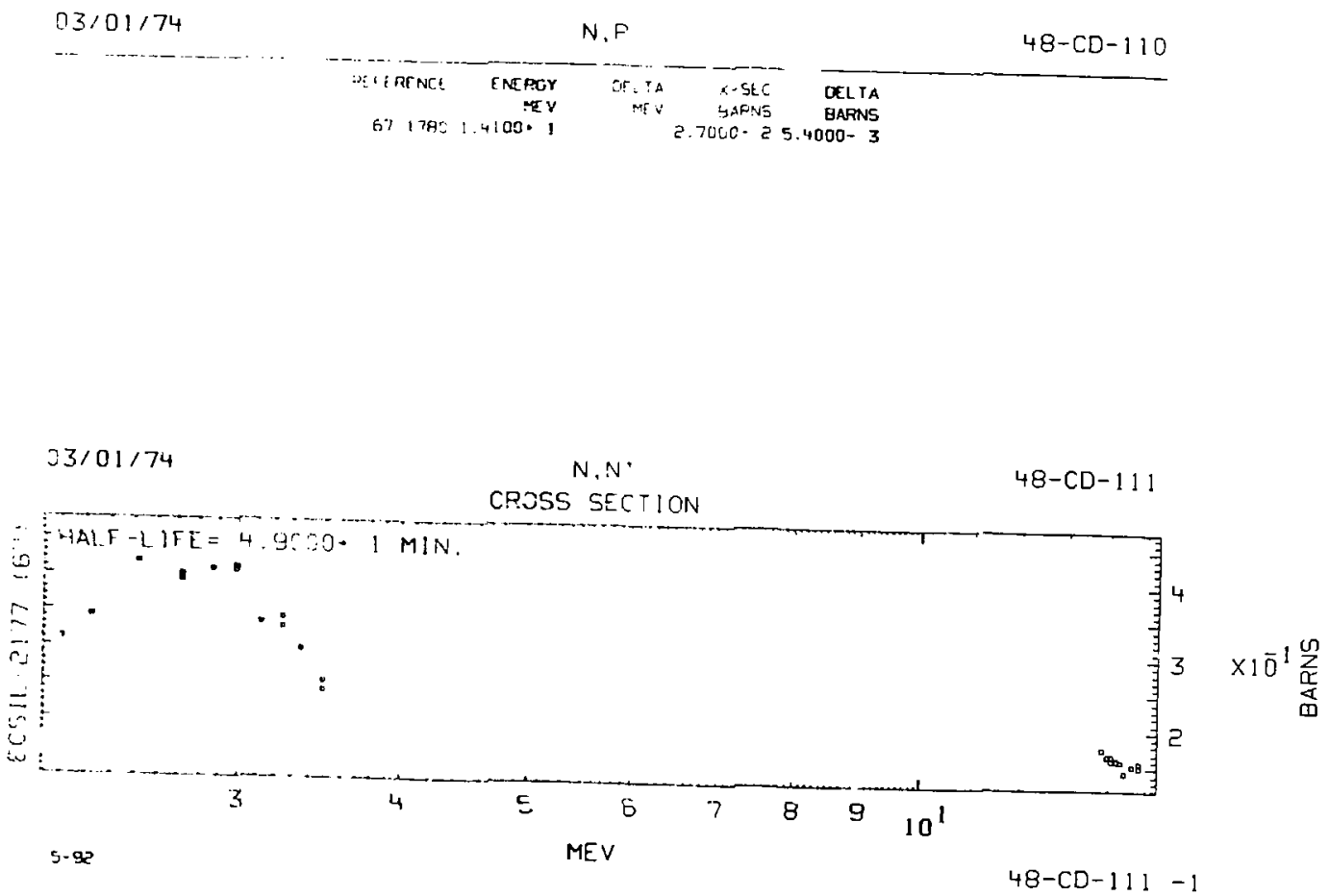

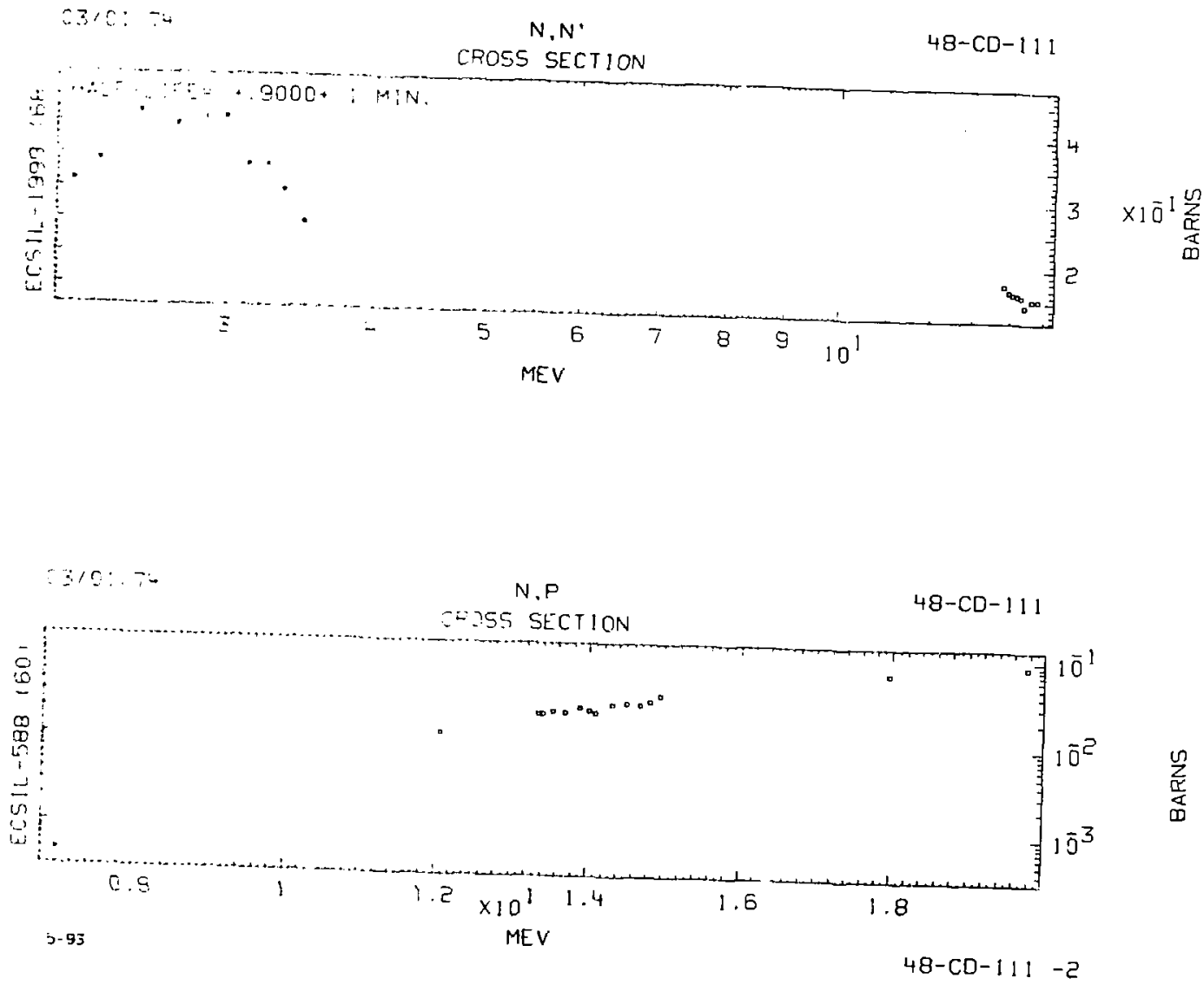
CROSS SECTION

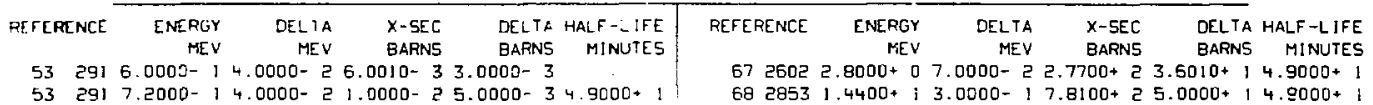

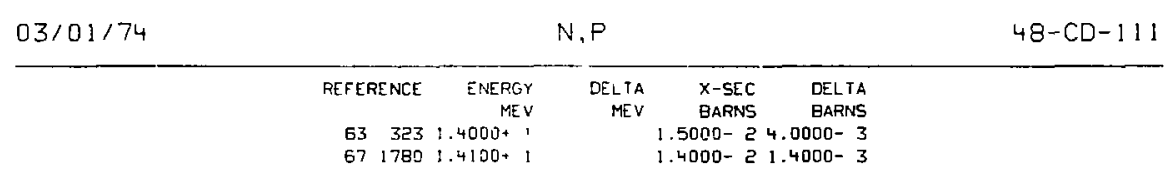

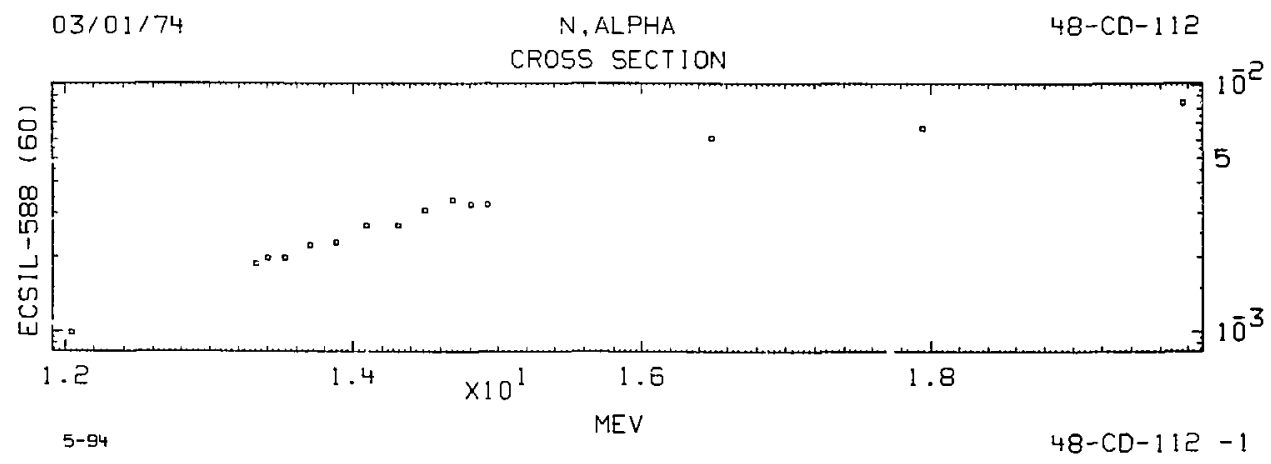


$03 / 01 / 74$

CROSS SECTION

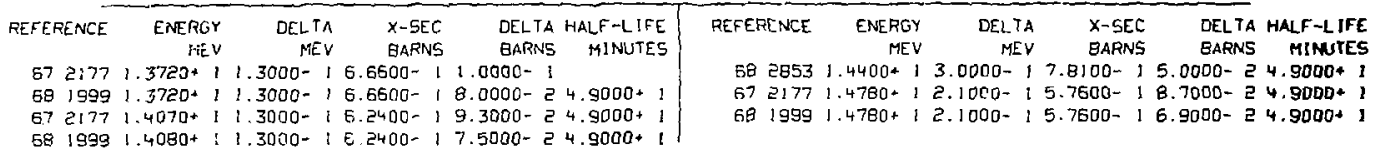

\begin{tabular}{|c|c|c|c|c|c|c|c|c|c|}
\hline \multicolumn{2}{|c|}{$03 / 01 / 74$} & \multicolumn{4}{|c|}{$N, P$} & \multicolumn{4}{|c|}{$48-C D-112$} \\
\hline REFERENC & ENERGY & DELTA & $x-5 E C$ & DEI TA & REFERENCE & ENEROY & DELTA & $x-5 E C$ & DELTA \\
\hline & MEV & ME! & BARNS & BARNS & & MEV & MEV & BARNS & BARN5 \\
\hline $53 \quad 3 z$ & $1.4000 * 1$ & & $1.1000-2$ & $3.0000-3$ & 571780 & $1.4100+1$ & & $1.1000-2$ & $1.1000-3$ \\
\hline 5735 & $1.4000+3$ & & $9.3010-3$ & $32.9000-3$ & 682853 & $1.4400+1$ & $3.0000-1$ & $1.5300-2$ & $1.3000-3$ \\
\hline
\end{tabular}

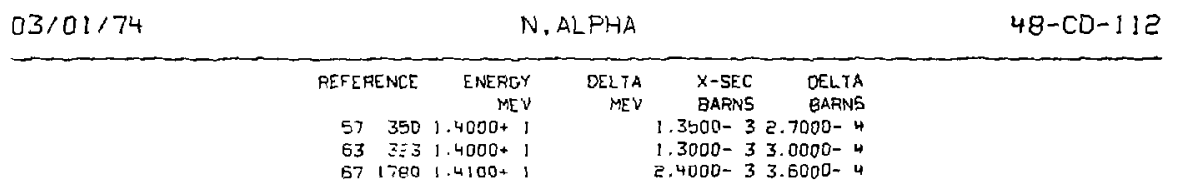

$03 / 01 / 74$

ABSORPTION

$48-C D-113$

$\begin{array}{rrrrr}\text { RETEREIUCE ENERGY } & \text { OELTA } & x-\text { SEC } & \text { OELTA } \\ \text { MEV } & \text { MEV } & \text { BARNS } & \text { GAFNC } \\ \text { SO } 1162 & 2.5300-B & & 1.9800+43.0000+2\end{array}$

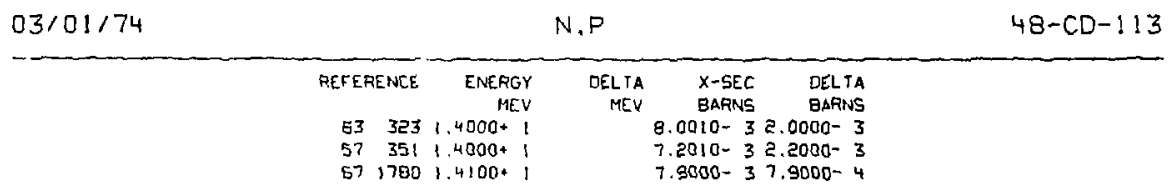


CPOSS SECTION

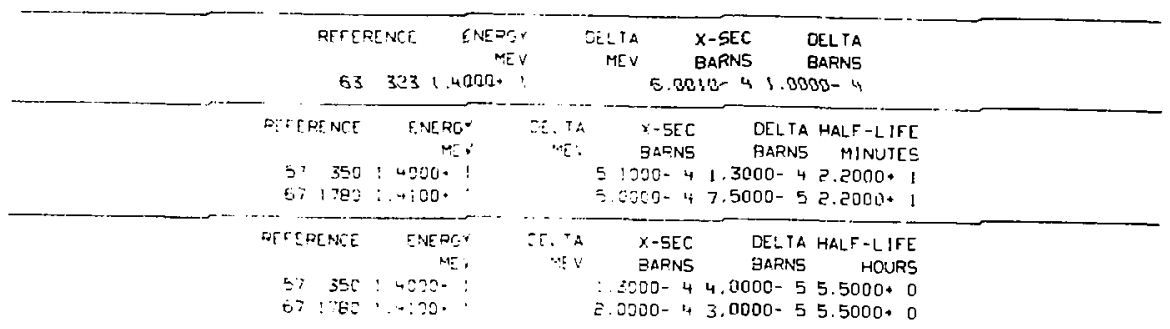

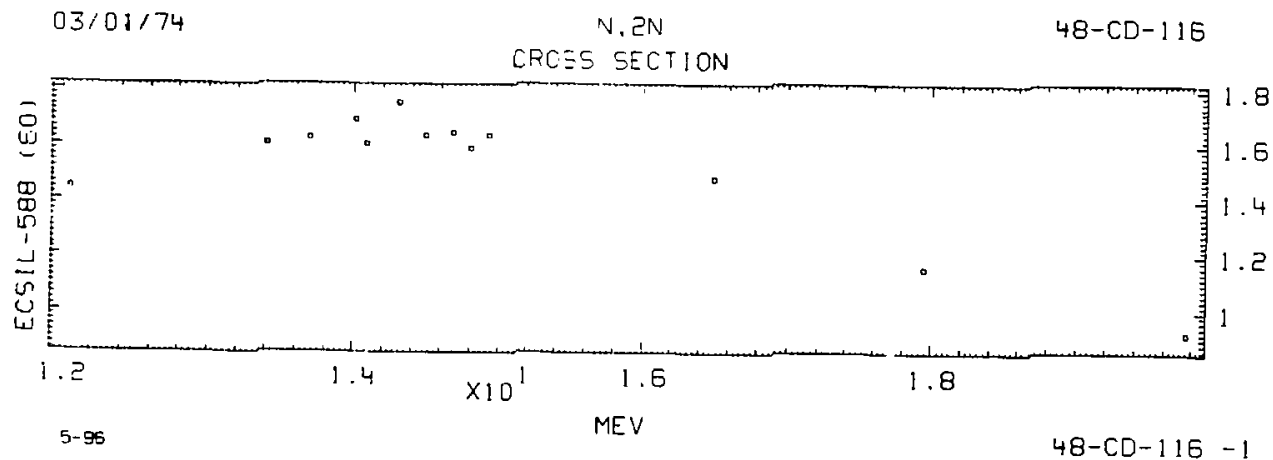



$03 / 01 / 74$
$N, 2 N$
$48-\mathrm{CD}-116$
CROSS SECTION
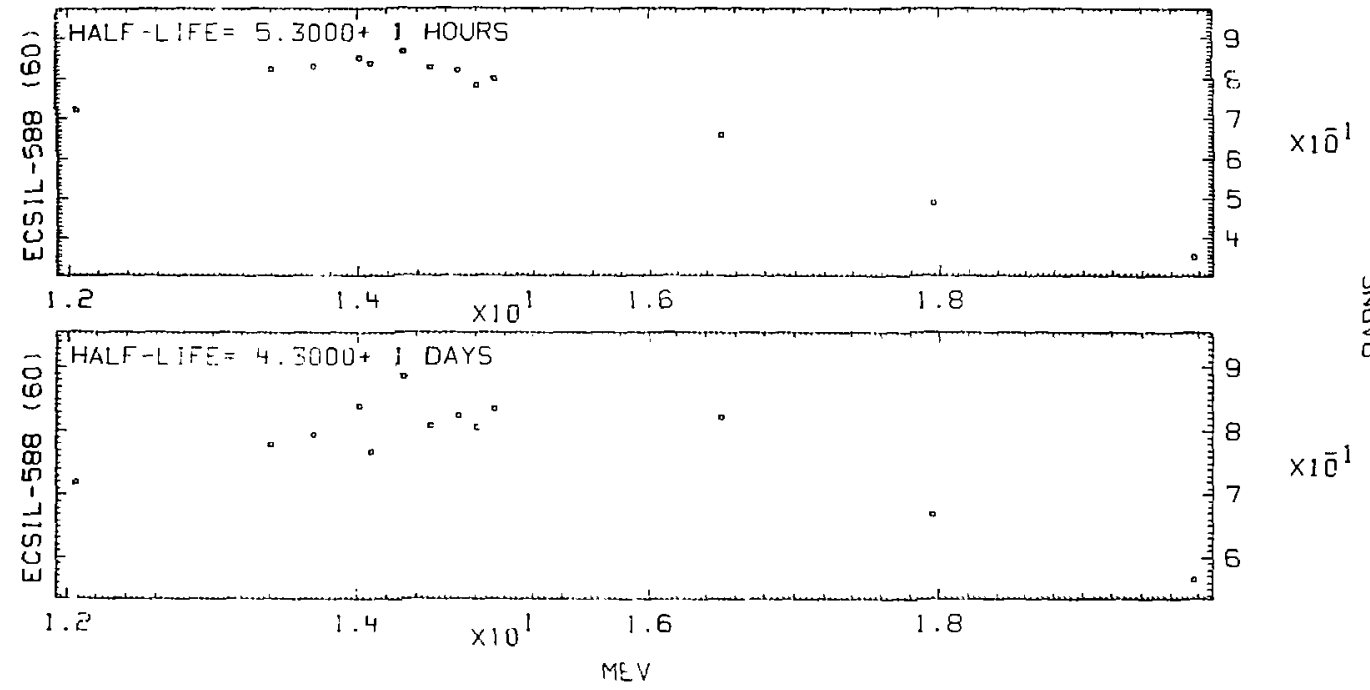

$\frac{n}{d}$

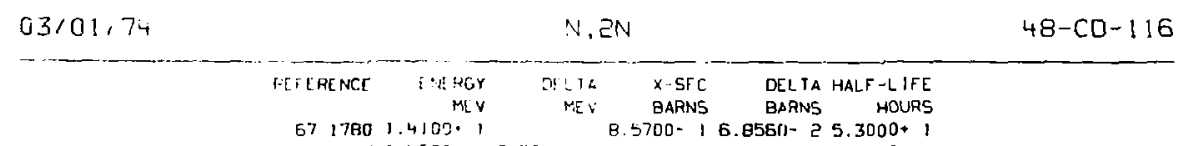

$517031.4800 \cdot 12.5000-15.9010-11.00030$ ? 5.3510 . 
CROSS SECTION

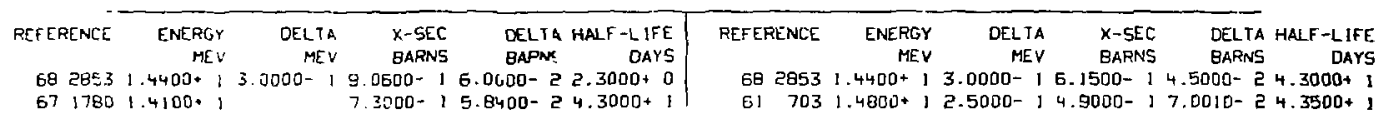

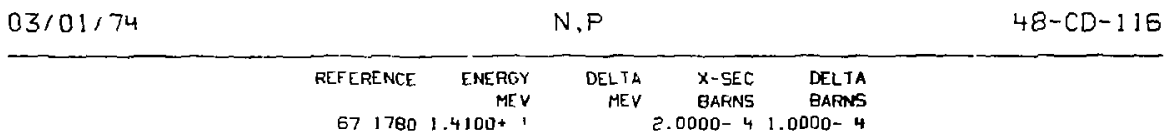

03/01/74

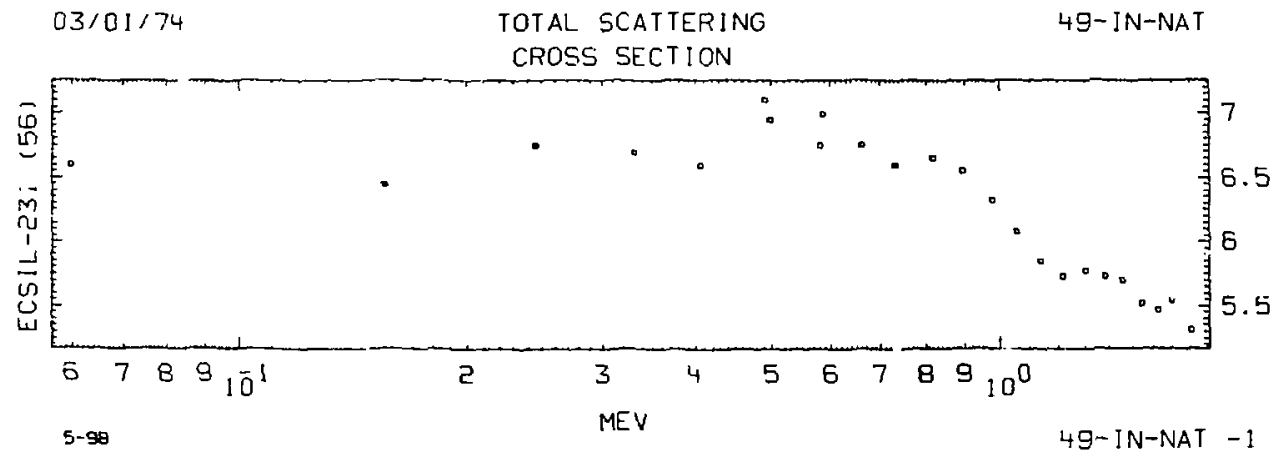


$N, N^{\circ}$

49-IN-NAT

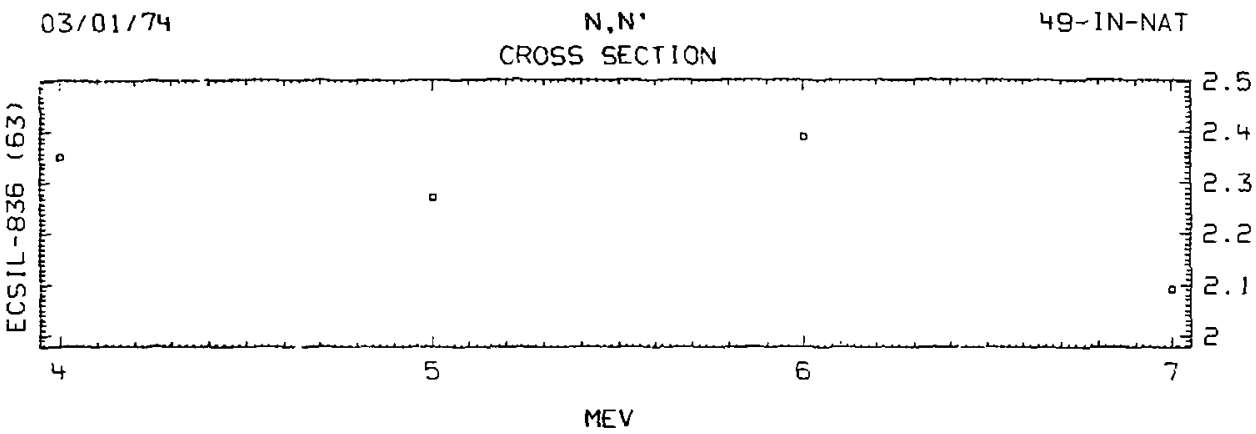

\section{$03 / 01 / 74$}

NONELAST IC

49-IN-NAT

REFERENCE

ENERGY

DELIA

$X-5 E C$

BARNS

DELTA

54 IC3, $0000+05.0000-24.0000-2,5000-1$

$03 / 01 / 74$

N.N

49-IN-NG,T

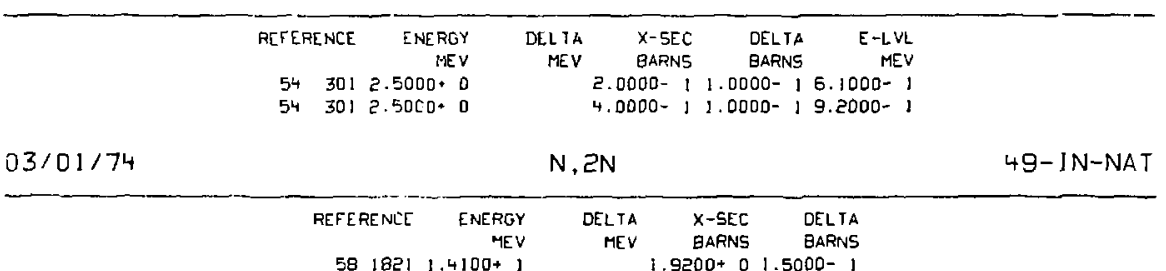




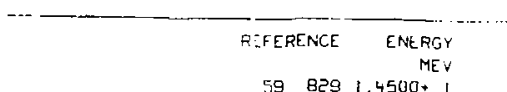

$59829: 4500+1$

CROSS SECTION

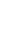

OLL TA

$X-S E C$

DEL TA HALF -L IFE

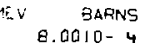

BARNS SECONOS

SECONOS
$4.2000-2$

$03 / 01 / 74$

ABSOPPTION

$49-I N-N A T$

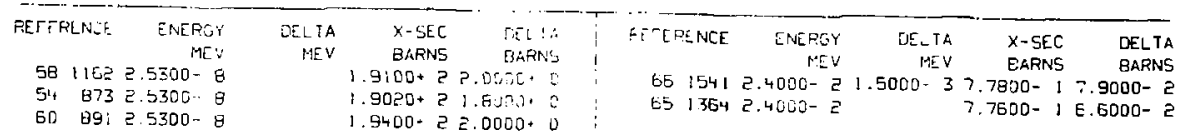

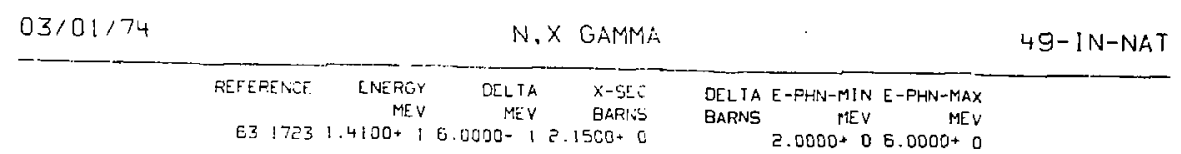

$03 / 01 / 74$

$N, \Gamma$

$49-I N-N A T$

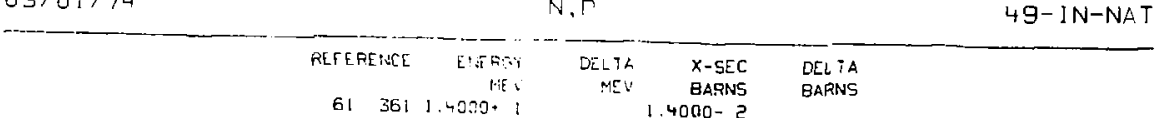

$03 / 01: 74$

N. ALPHA

49-IN-NAT

REFERENCE LNERG:

62 21E0 1.4.000 :

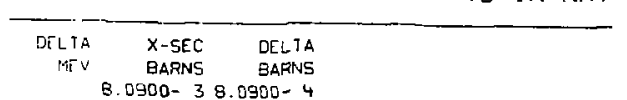

$5-100$

$49-I N-N A T-3$ 


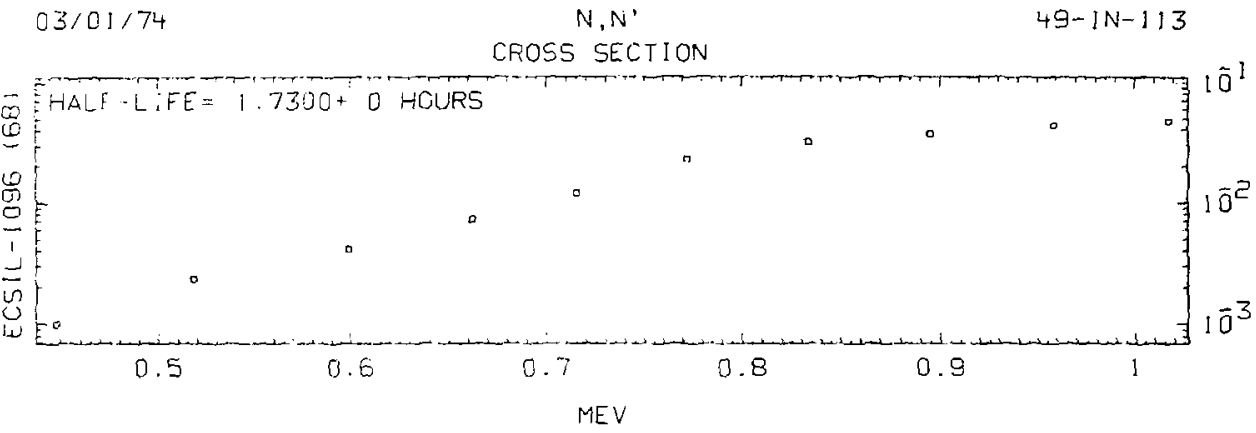

$03 / 0: 174$

$\mathrm{N}, 3 \mathrm{~N}$

$49-1 N-113$ CROSE SECTION

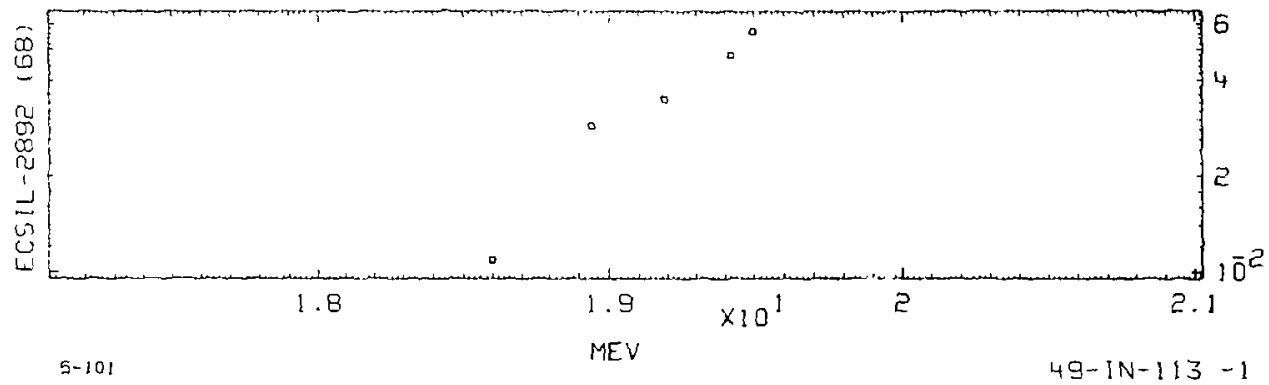

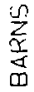




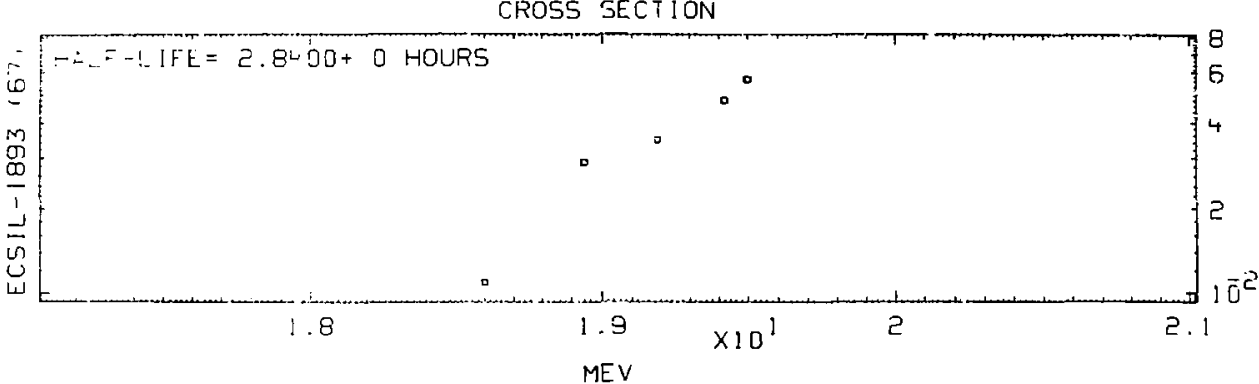

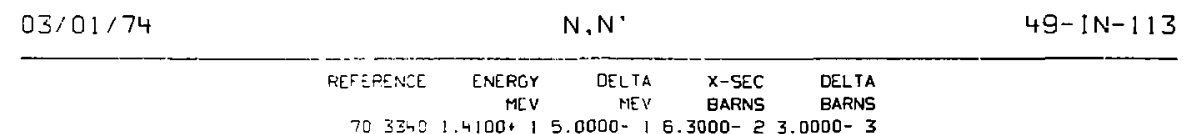

$703 \sin 21.4100+15.0000-16.3000-23.0000-3$

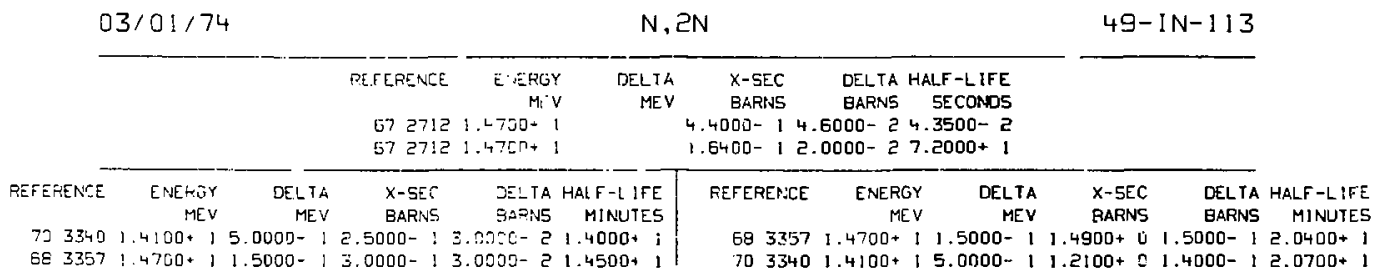



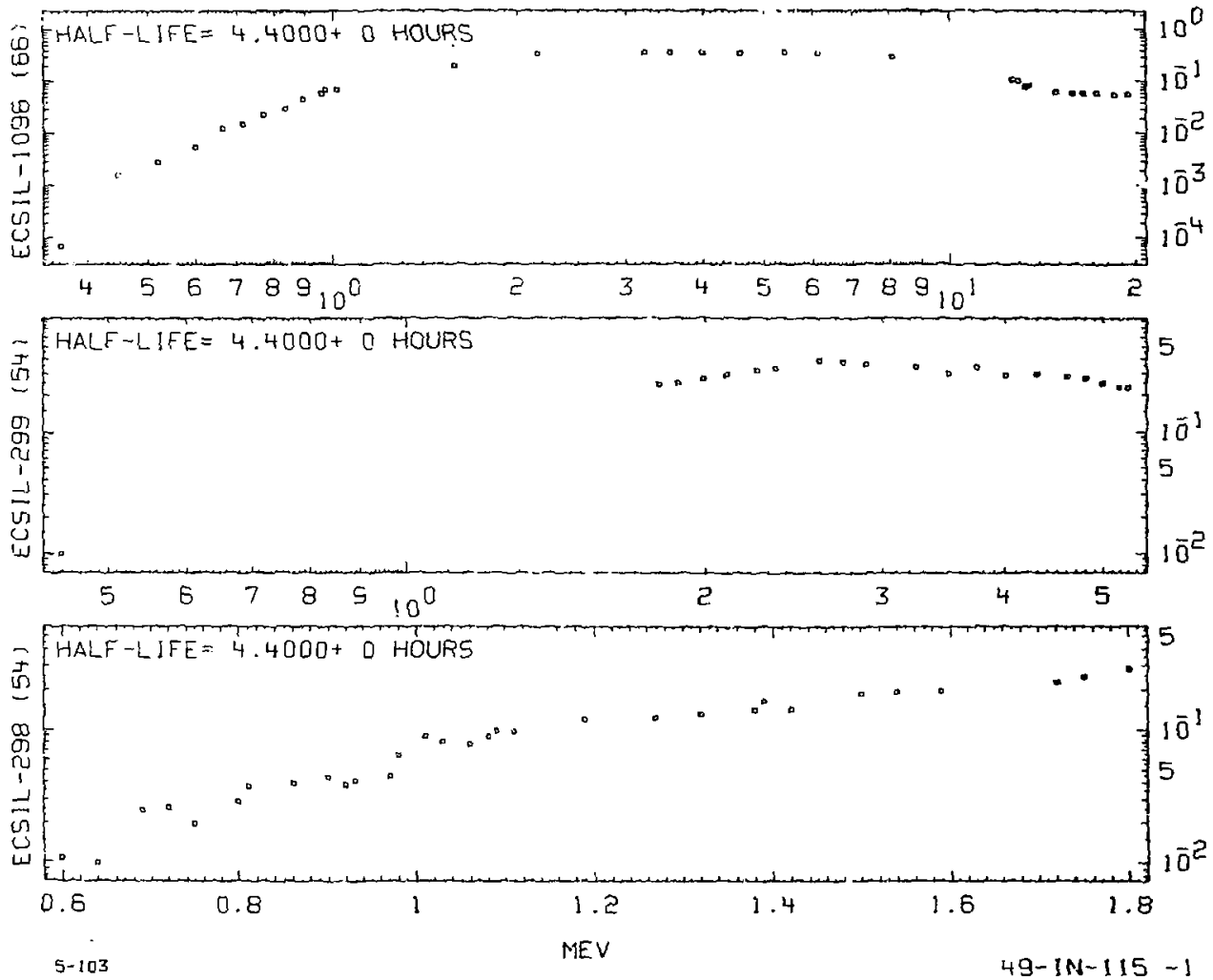
SNY $\forall \theta$

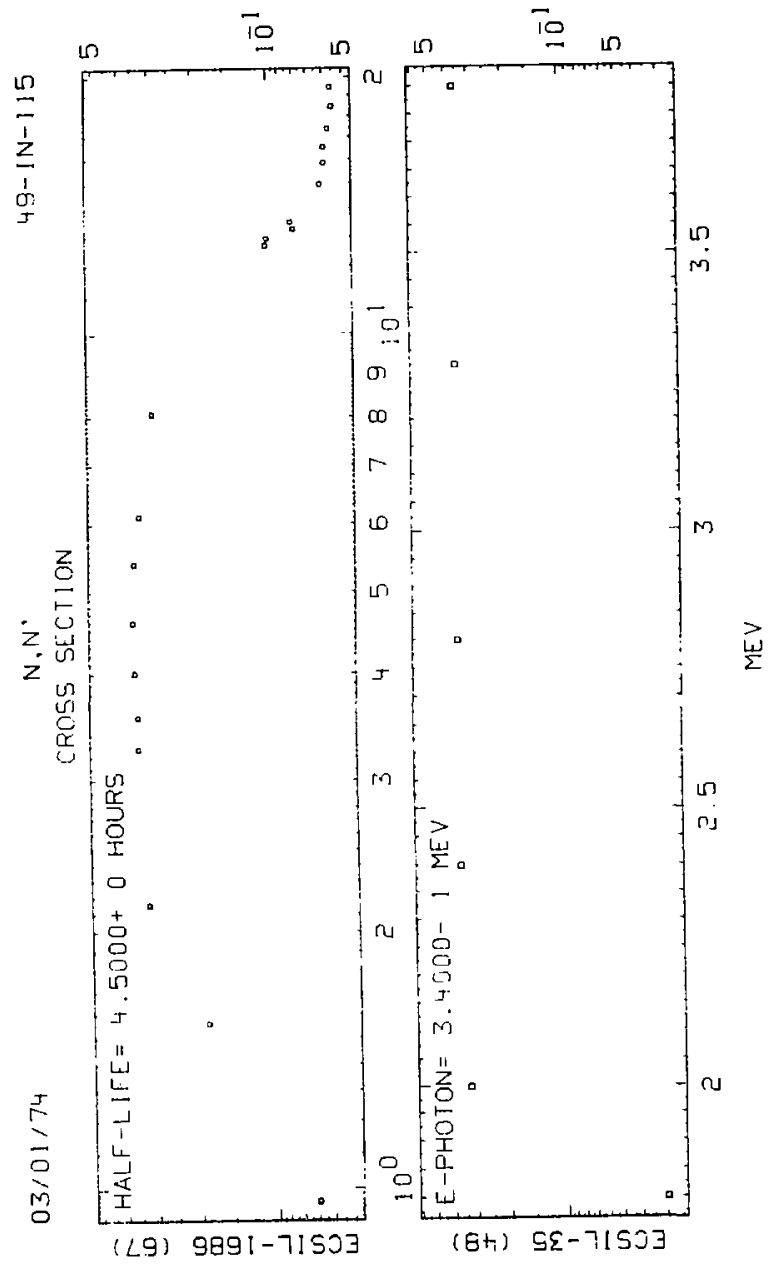

$n$
1
$n$
$\frac{1}{1}$
$\frac{1}{2}$
$\frac{1}{0}$
$\frac{1}{9}$

$\frac{5}{\frac{5}{1}}$ 


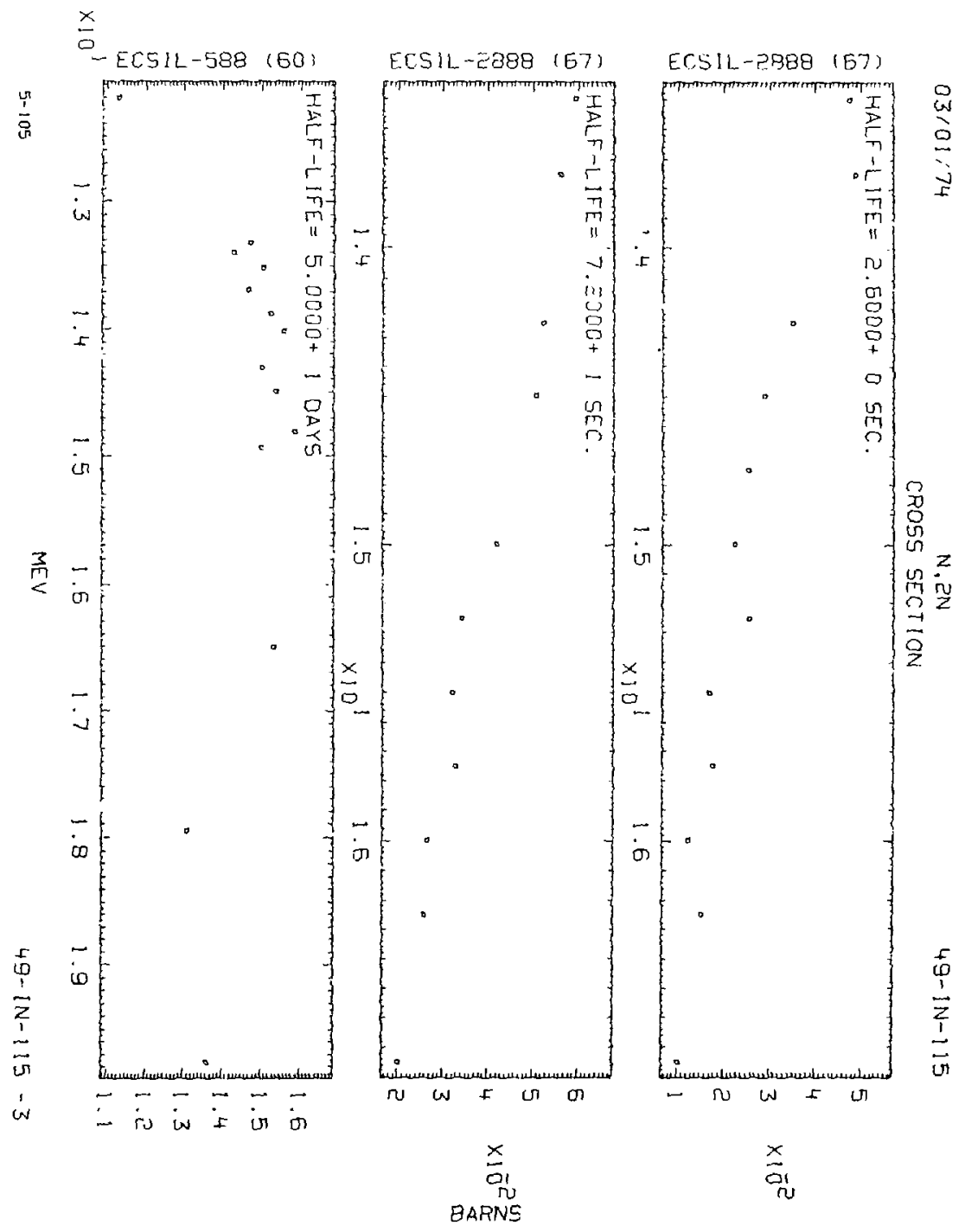




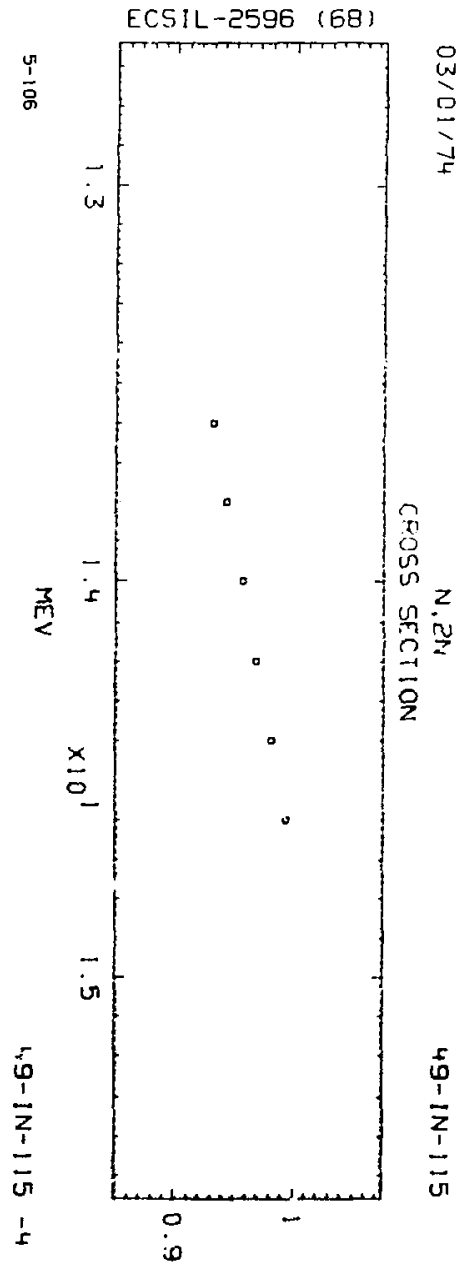

RELATIVE

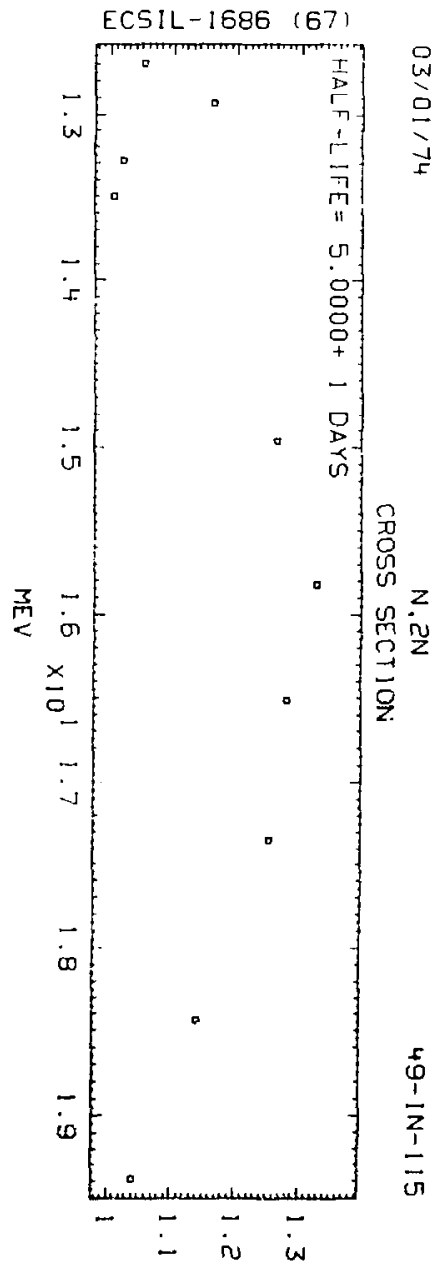

BARNS 


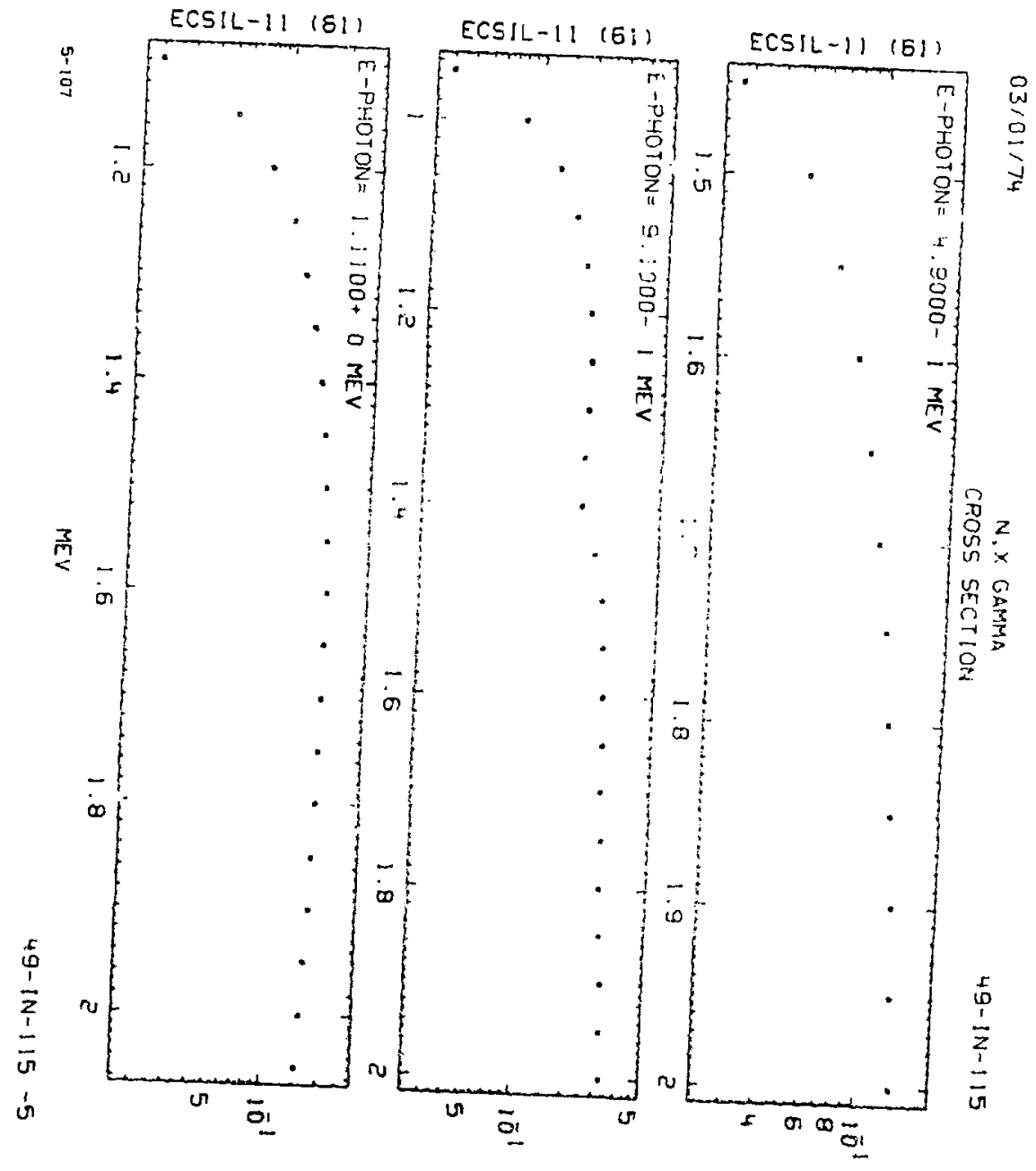

BARNS 


\section{CROSS SECTION}
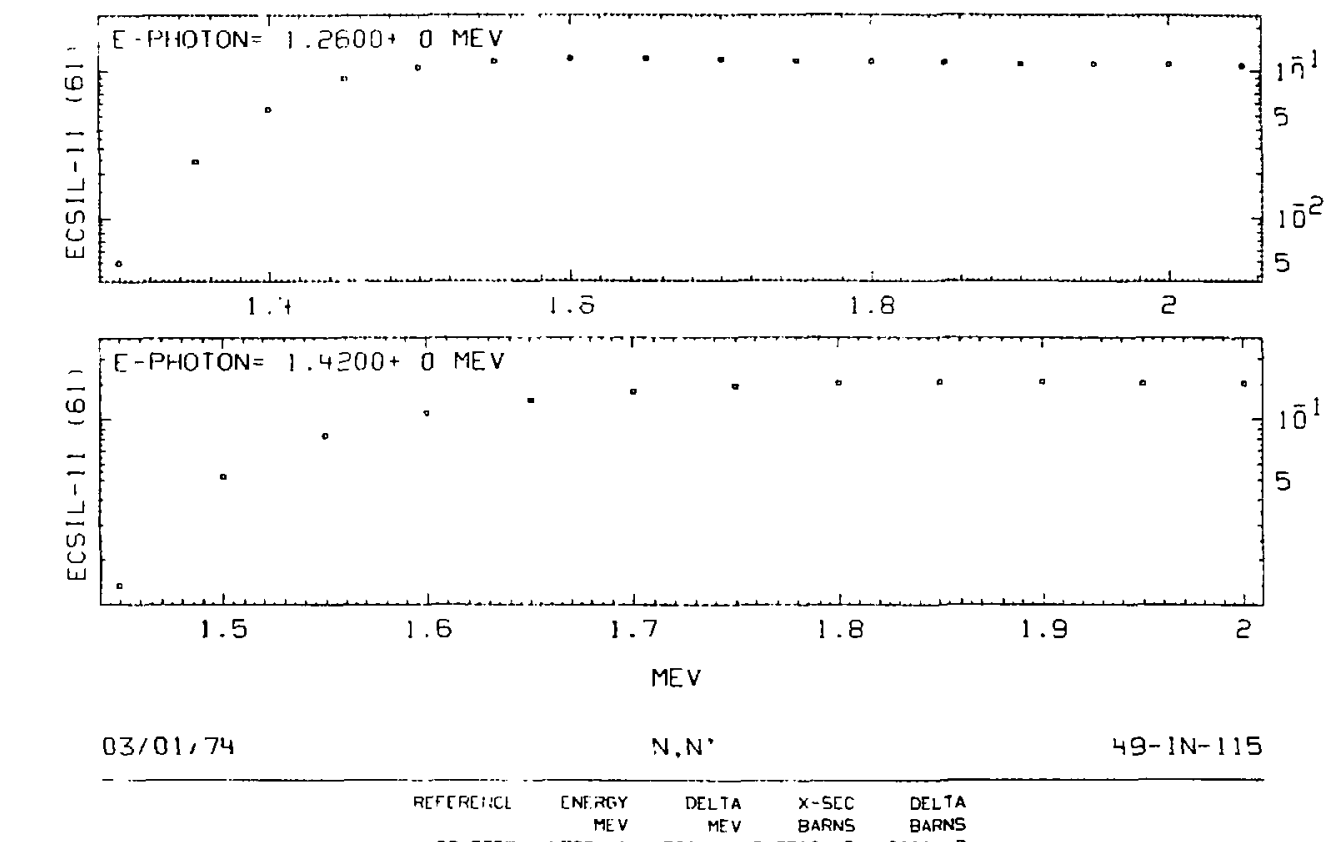

\begin{tabular}{|c|c|c|c|c|c|c|c|}
\hline FFERNCE & ENEFGY & $\begin{array}{r}\text { DEI. TA } \\
\text { MFY }\end{array}$ & $\begin{array}{l}x-5 C C \\
\text { GARN5 }\end{array}$ & DCL TA & HALF - 1 JFE & REГERT NCE & $\begin{array}{r}\text { ENERGY } \\
\text { MEY }\end{array}$ \\
\hline 35,34 & $1.4600+1$ & 2. $0000-1$ & 6. 70ca- & $7.0000-3$ & $4.4000+0$ & 692354 & $1.4790+1$ \\
\hline $5 \%, \quad 177 ?$ & $1.4000+1$ & $2.0000-1$ & $0.1000-2$ & $8.9100-3$ & $4.4000+0$ & 692354 & 1.4800 \\
\hline
\end{tabular}




\section{CROSS SECTION}

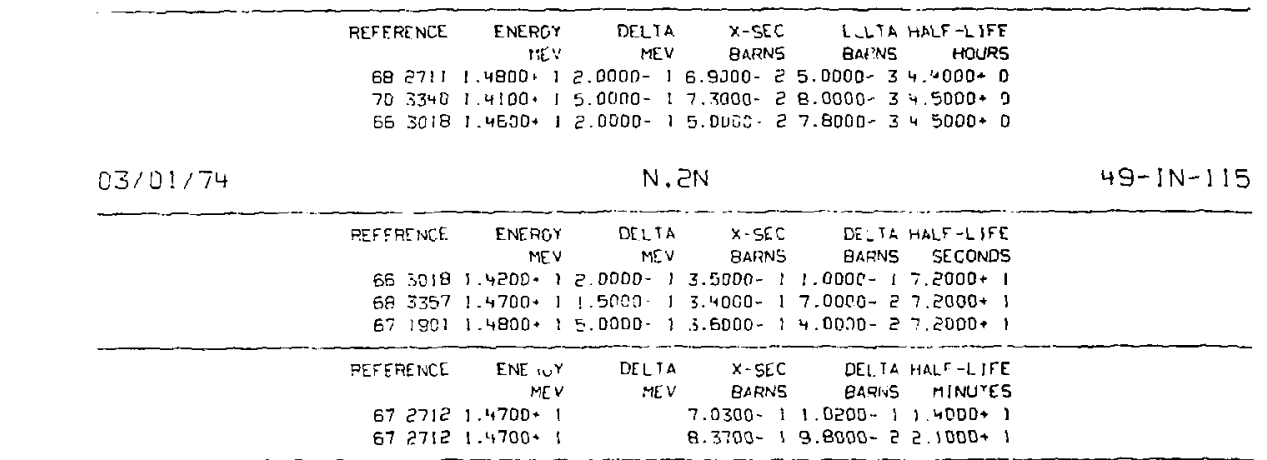

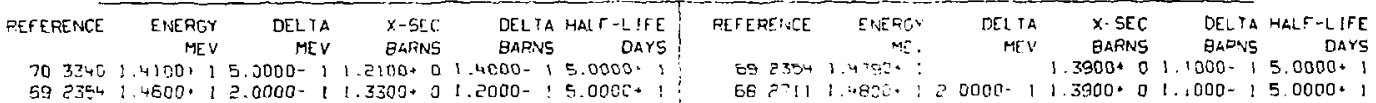

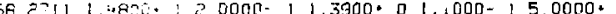

$6833571.4700+11.5000-11.4700+01.2000-15.0000+1$

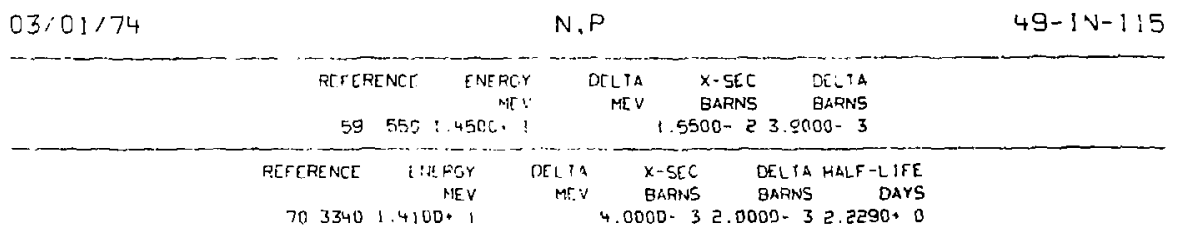




\begin{tabular}{|c|c|c|c|c|c|c|c|c|c|}
\hline RETERENCE & $\begin{array}{r}\text { ENEPGY } \\
\text { MEY }\end{array}$ & $\begin{array}{r}\text { DEL TA } \\
\text { MEV }\end{array}$ & $\begin{array}{l}x-5 E C \\
\text { BARNS }\end{array}$ & $\begin{array}{l}\text { DELTA } \\
\text { BARNS }\end{array}$ & REFERSNLE & $\begin{array}{r}\text { ENERGY } \\
\text { MEV }\end{array}$ & DEL iA & $\begin{array}{l}X \text {-SEC } \\
\text { BARNS }\end{array}$ & $\begin{array}{l}\text { OELTAA } \\
\text { BAFNS }\end{array}$ \\
\hline$: 3 !$ & $\therefore 4 \operatorname{tag}-1$ & & $2.5000-3$ & $34.0000-4$ & 550 & $.4500+$ & $i$ & 2.9000- 3 & $33.0000-4$ \\
\hline$\triangle C$ : & $\therefore+255 \cdot:$ & $5.5010-1$ & $2.5000-3$ & $34.0000-4$ & 663014 & $1.4600 * !$ & $12.0000-1$ & $3.0000-3$ & $31.2000-$ \\
\hline $70 \quad 3340$ & $\therefore 4: 00$. & & $2.5000-3$ & $34.0000-4$ & $65 \quad 1777$ & $1.4600 * 1$ & $12.0000-1$ & $3.0000-3$ & $31.2000-$ \\
\hline
\end{tabular}

\section{$03 / 01 / 74$}

NUNELASTIC

CROSS SECTIGN
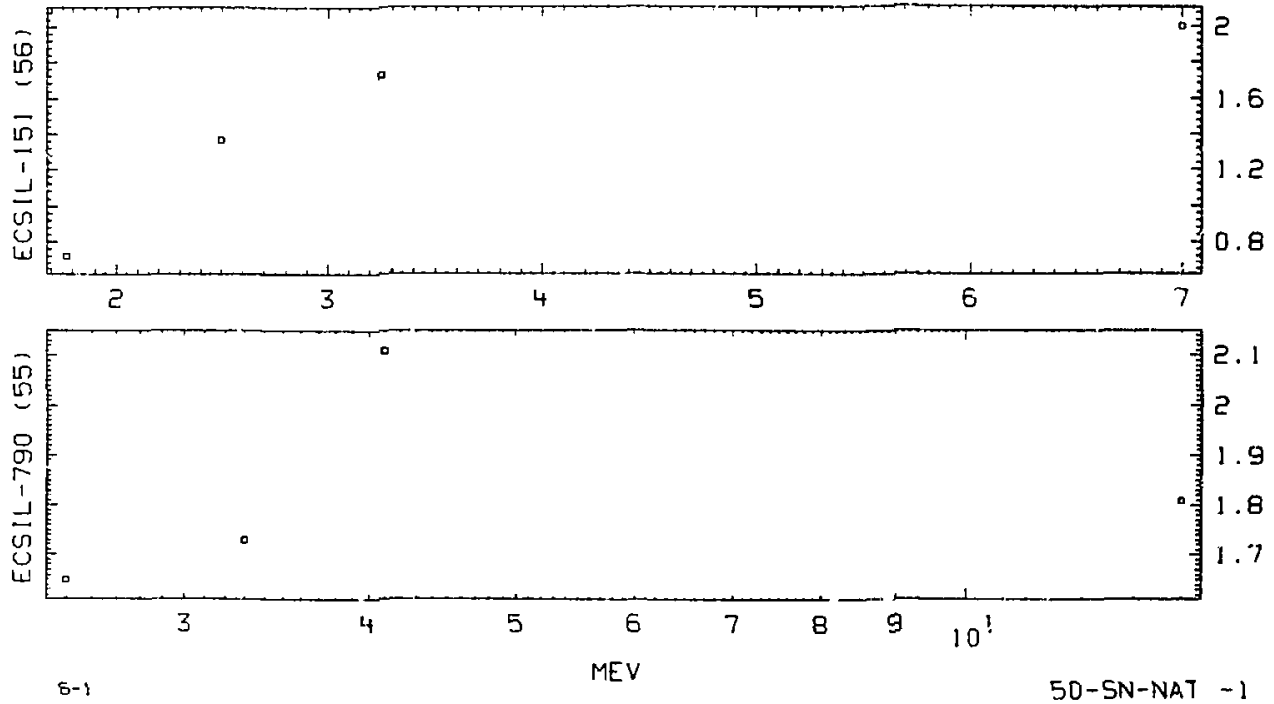
SNYVA

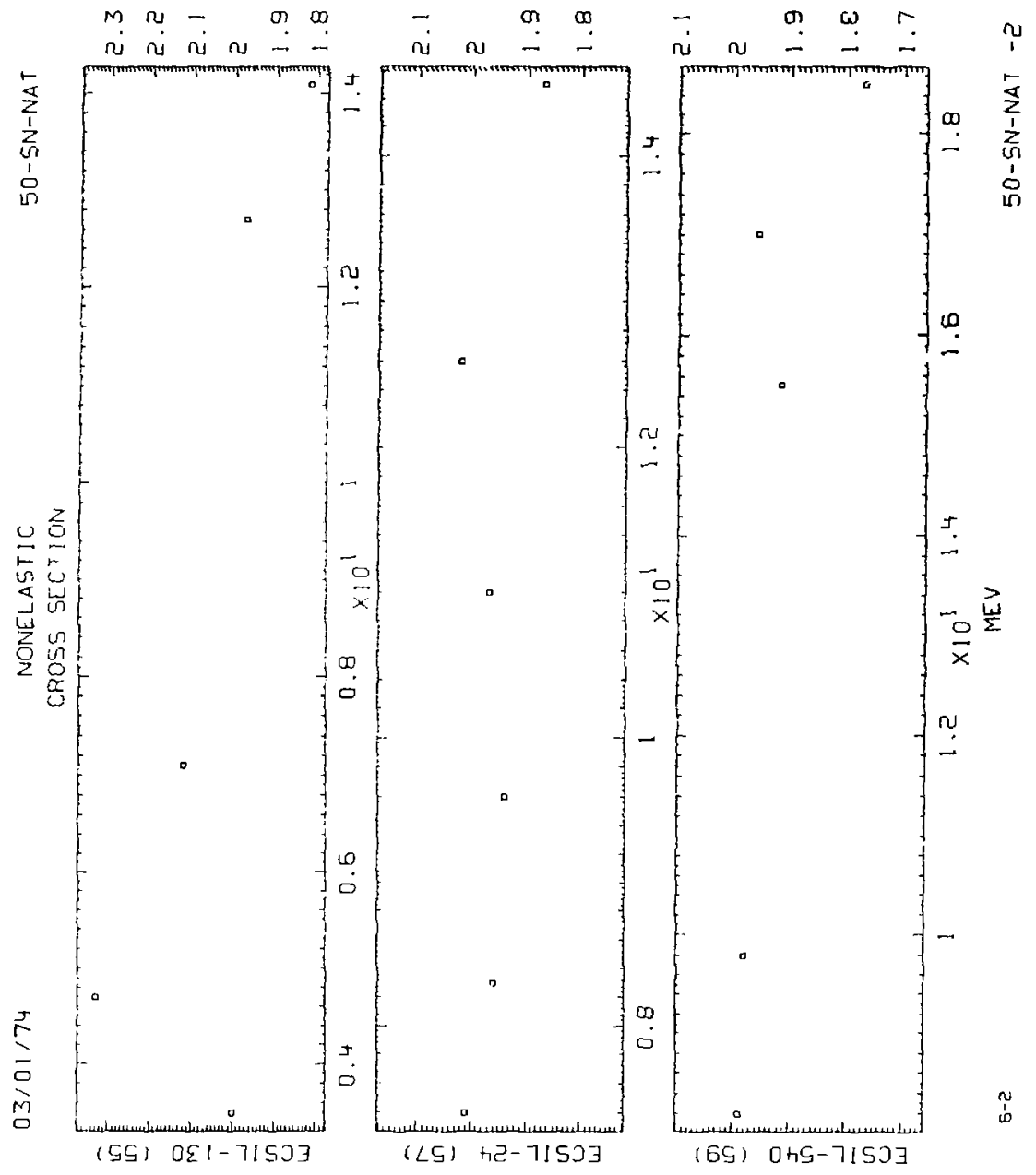



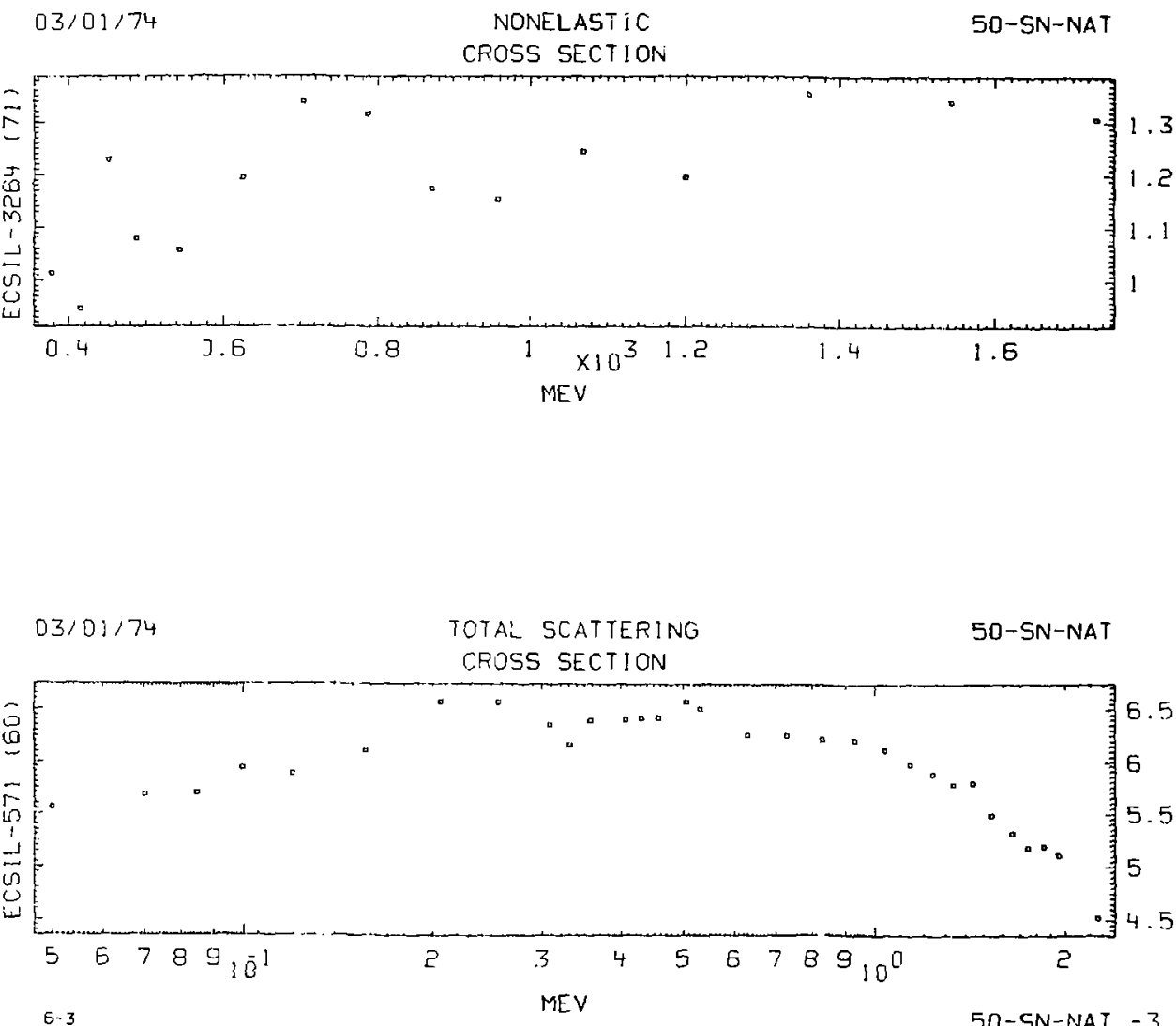

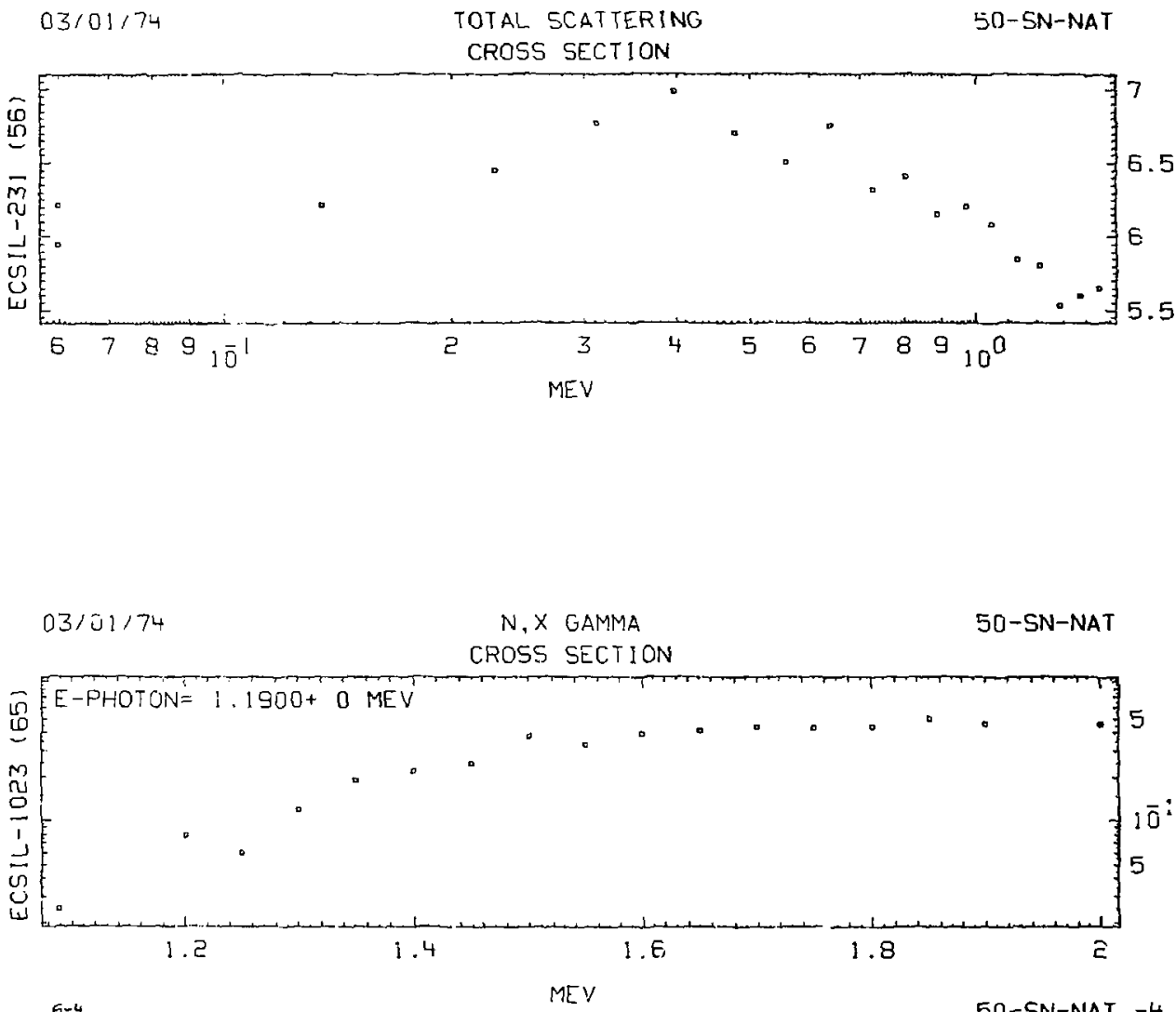

$\frac{n}{\frac{n}{\alpha}}$ 
CROSS SECTION

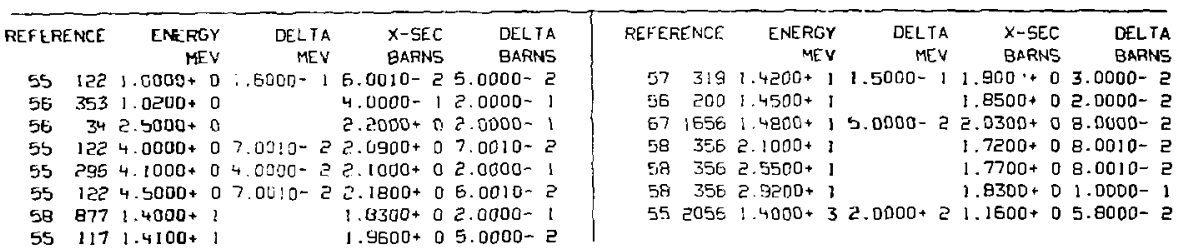

$03 / 01 / 74$

TOTAL SCATTERING

5D-SN-NAT

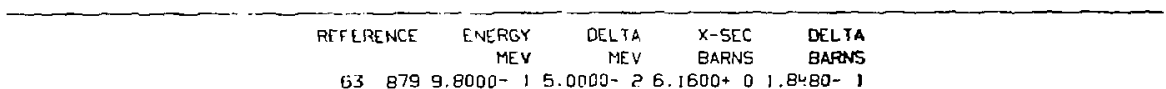

$6387998000-15.0000-26.1600+018080-1$

$03 / 01 / 74$

$N, N^{\circ}$

50-SN-NAT

REFERENCE ENERGY DELTA X-SEC OEI.IA

65889 b. $3400+0$ 2. 3300- I 2.8000+ $050000-1$

$03 / 01 / 74$

$N, 2 N$

50-SN-NAT

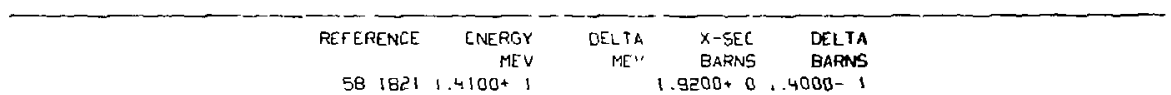

$03 / 01 / 74$

ABSORPT ION

5O-SN-NAT

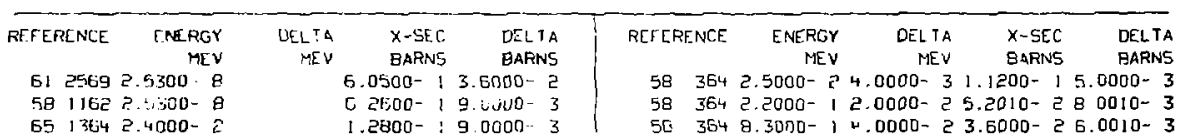




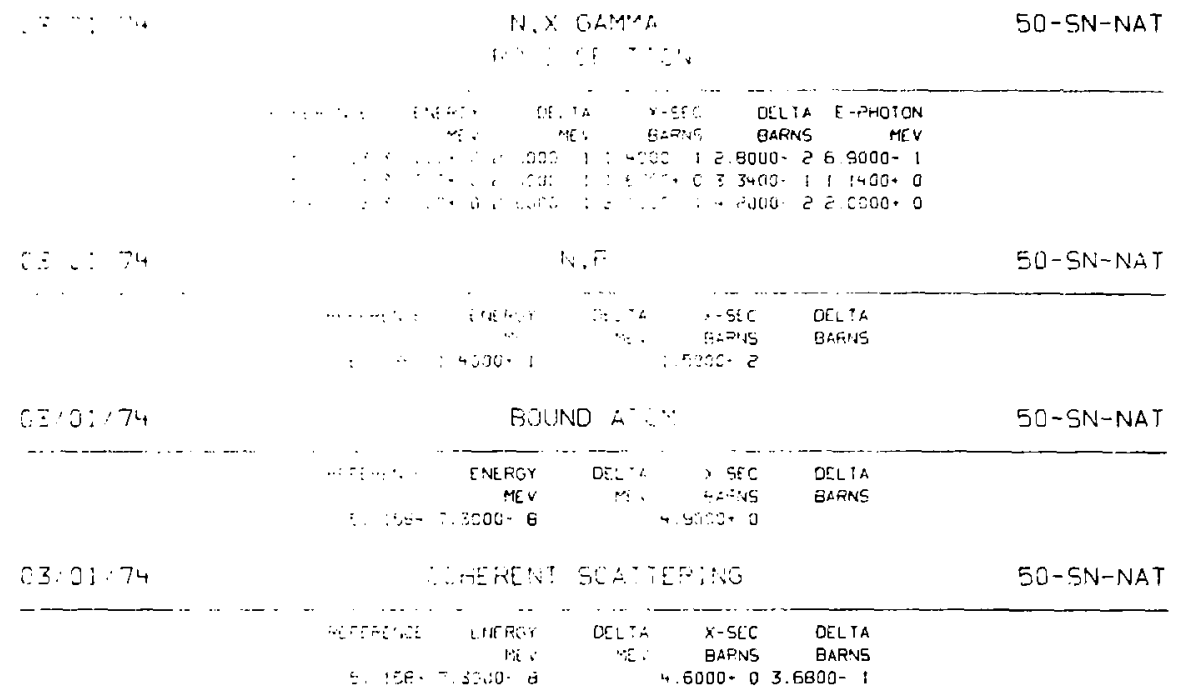




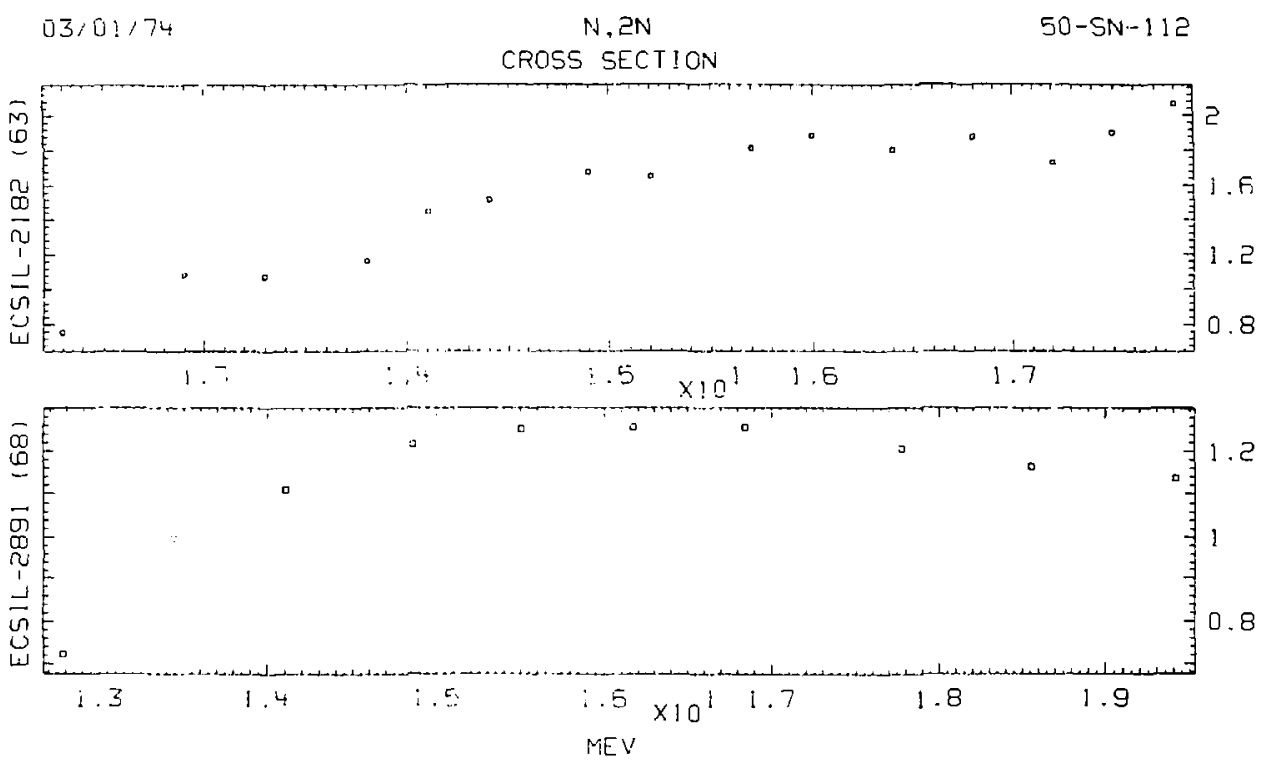


CROSS SECTION

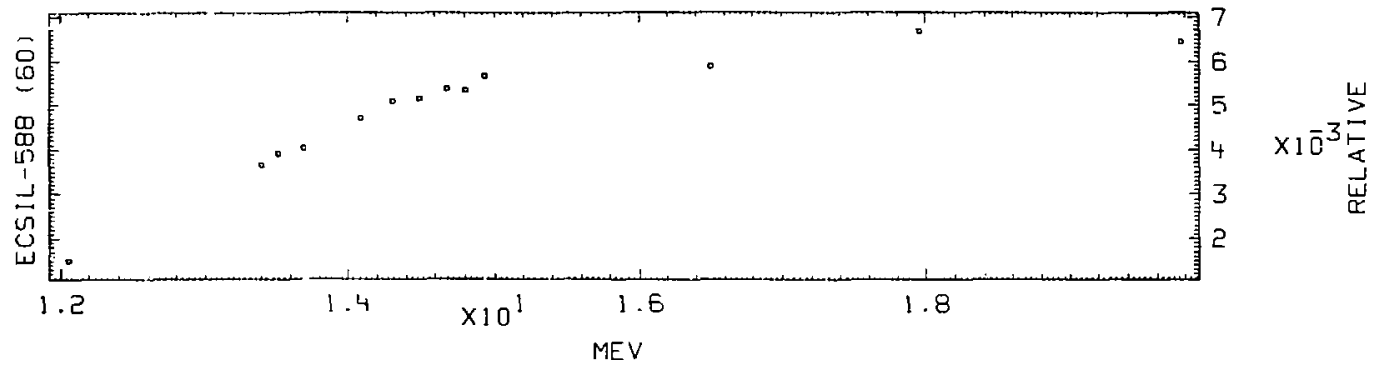

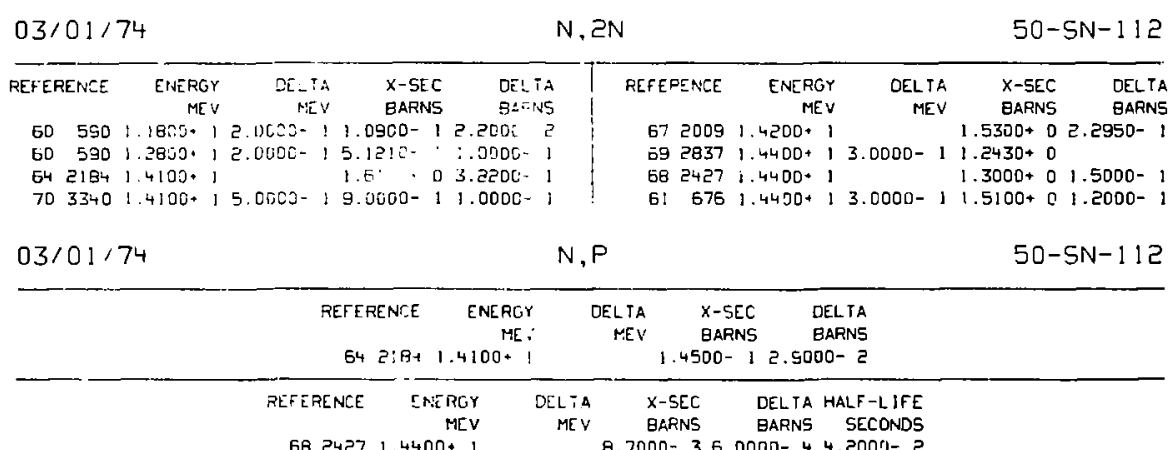


CROSS SECTION

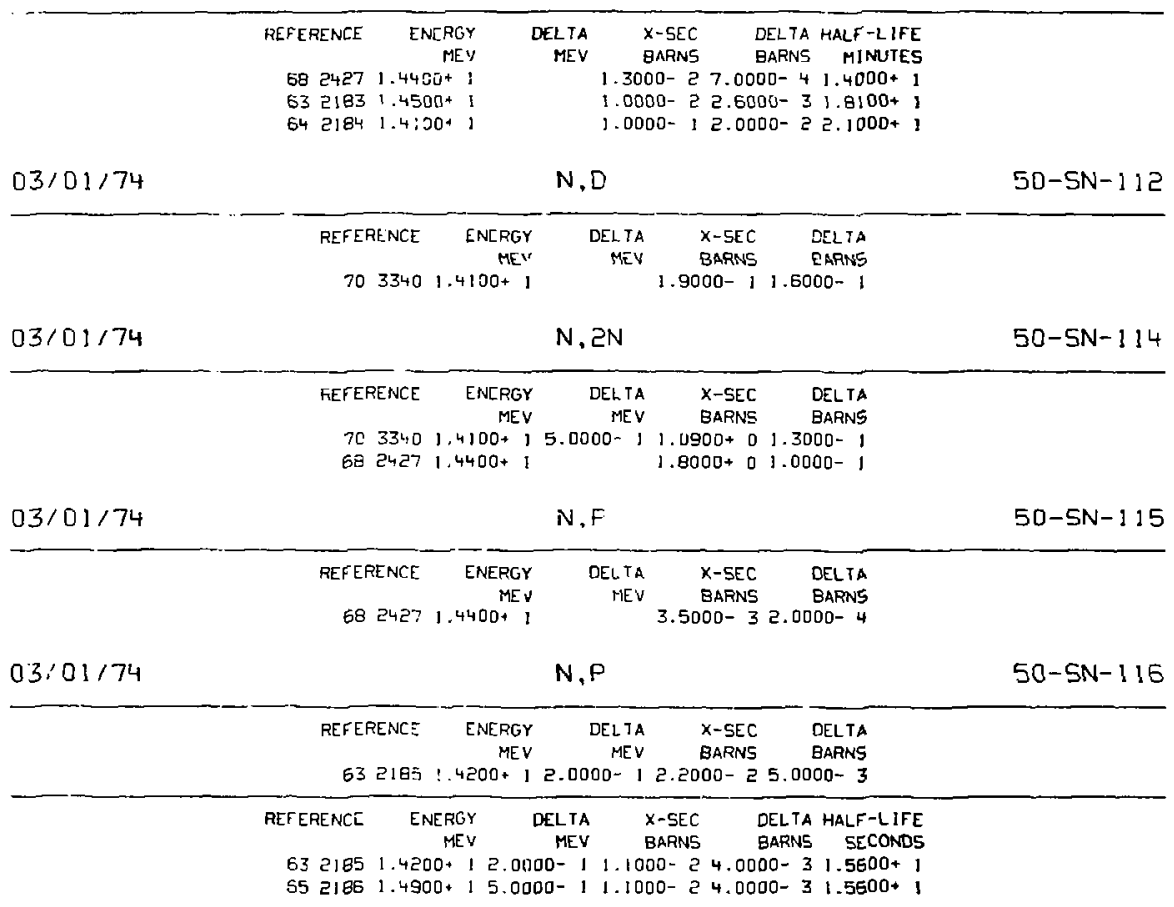




\section{CROSS SECTION}

\begin{tabular}{|c|c|c|c|c|c|c|c|c|c|c|c|c|}
\hline ค1: & schtow & DLLIA & $X-S E C$ & OELI & A HALF-L IFE & RE TEFENCE & [NERGY & & DELTA & $x-$ SEC & DEL IA & A HALF - L JFE \\
\hline & ME & MEV & BARN & BARN & 15 MINUTES & & $\mathrm{MCV}$ & & MEV & iNS & INS & WTES \\
\hline $\overrightarrow{0}$ & $4+2 x^{2}=$ & & 000. & $37.0000-$ & $-5.4000+1$ & $63 ? 105$ & D. : & $1 \ddot{c}$ & $0-1$ & $000-2$ & -3 & 14 \\
\hline 632103 & $-53 \%$, & & 54000 & $3: 5000-$ & $3=-000+1$ & 65 PIAG & $1.4900 \times 1$ & $1 \pm$ & $=500-$ & $1.1000-2$ & $2.0000-3$ & 35.6600 . \\
\hline
\end{tabular}

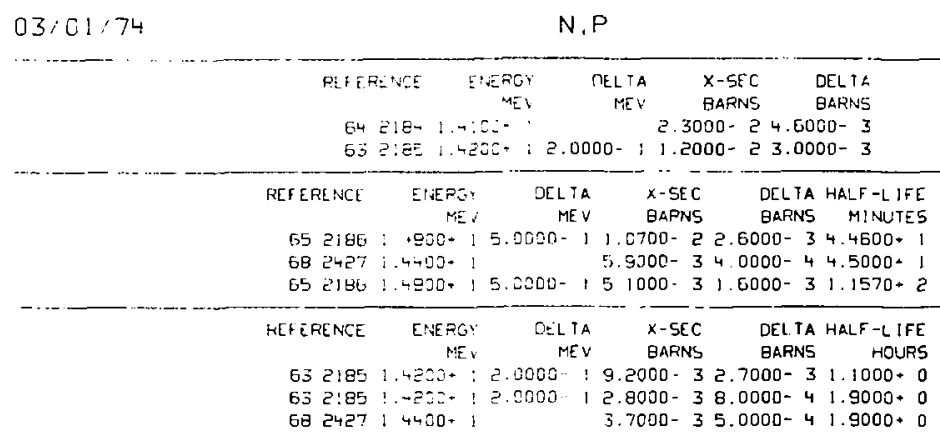

$03 / 01 / 74$

N , ALPHA

$50-S N-118$

CROSS SECTION

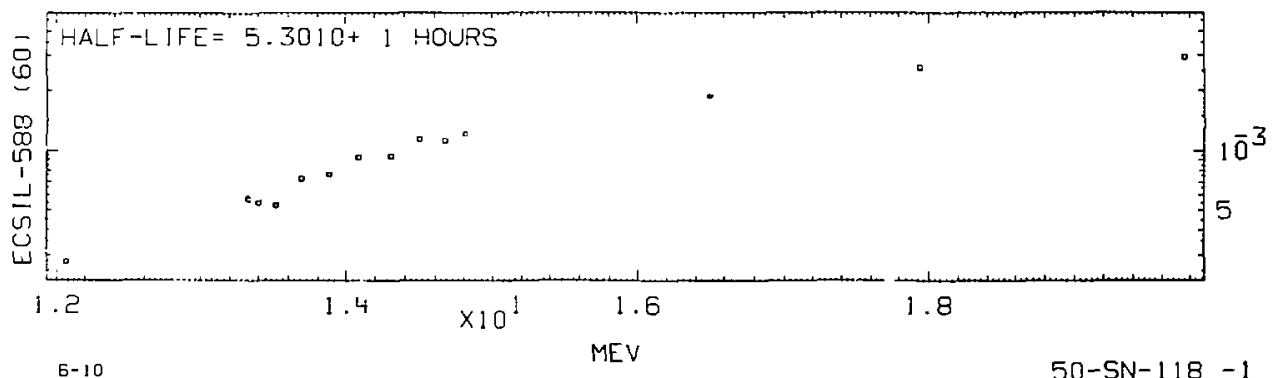


$03 / 01 / 74$

N. $2 N$

$50-5 N-118$

CROSS SECTION

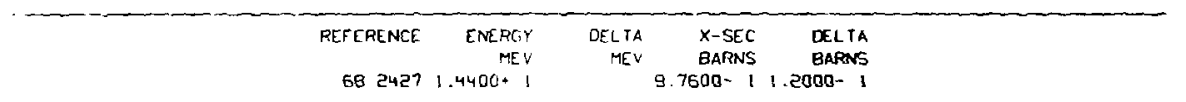

$03 / 01 / 74$

$N, N \cdot P$

$50-5 N-118$

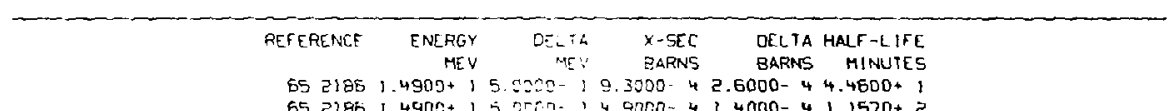

652186,4900

$03101174 \quad$ N.P 50-5N-118

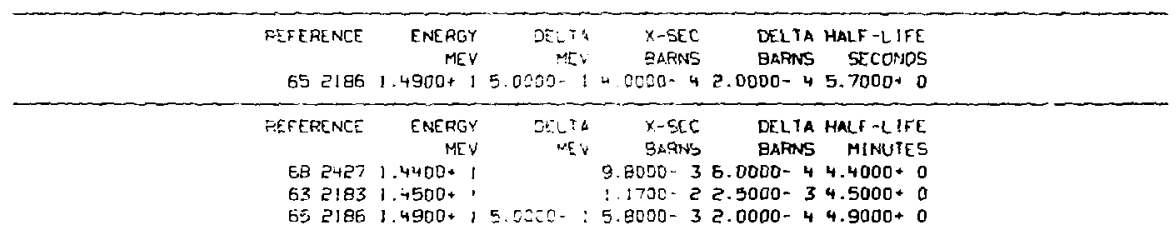

$03 / 01 / 74$

N.P

$50-5 N-119$

\begin{tabular}{|c|c|c|c|c|c|c|c|c|c|c|c|}
\hline REFERENCE & ENFAGY & Cr: : $: 2$ & $x-5 E$ & $D \hat{t}_{-} L 1 / A$ & A HEI F-' IFE & PEFERENCL & ENERGY & DEL IA & $x-\operatorname{SEC}$ & DELTA & HNLF - LIFE \\
\hline & $M[V$ & $M E:$ & GARNS & BARNS & $M N_{L} T[S$ & & MEV & MEV & EARNS & EARNS & MINUTES \\
\hline $6 \theta 2427$ & $1.4400+1$ & & $\vec{r} .5000-3$ & $3.0000 \quad 4$ & 4 & 682427 & $1.4400+1$ & & 2. EROS- 3 & $3.0000-4$ & $1.8000^{*}$ \\
\hline $\begin{array}{l}652185 \\
632183\end{array}$ & $\begin{array}{l}4900.1 \\
4500 \cdot 1\end{array}$ & $5.0300-1$ & $\begin{array}{l}=.3000-3 \\
\text { 1. } 1100-2\end{array}$ & $\begin{array}{l}1.5000-3 \\
2.5000-3\end{array}$ & $\begin{array}{l}32.8000+0 \\
31.7500+1\end{array}$ & EF PIEk & $1,4900 * i$ & 5.0000 & $4.3000 \cdot 3$ & $31.4000-3$ & $2.7 .600+$ \\
\hline
\end{tabular}

O3/01/74




\section{CROSS SECTION}

\begin{tabular}{|c|c|c|c|c|}
\hline REF ERENCE & ENLEGY & DELTA & $X-5 E C$ & DELTA \\
\hline & MEV & MEV & BARN'S & BARNS \\
\hline
\end{tabular}

$03 / 01 / 74$

$N, P$

$50-5 N-120$

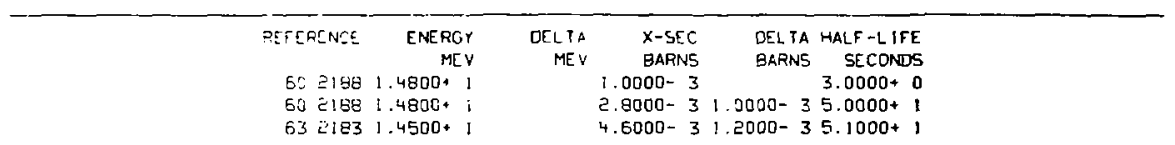

$03 / 01 / 74$

$N, 2 N$

$50-5 N-125$

\begin{tabular}{rrrrr}
\hline REFLPENCE & ENERGY & DELIA & X-SEC & OELTA \\
MEV & MEV & GARNS & BARNS \\
562427 & $1.4400^{+}$ & & $8.7500-1$ & $1.3500-1$
\end{tabular}

$58.2427,4400+$

$N, 2 N$

$50-5 N-124$

$03 / 01 / 74$

DELIA

X-SE?

DELTA HALF-LIFE

REFEREIVCE ENCREY

MEV

MEV BARNS

BARNS MINUTES

b) $21841.4100+1 \quad 9.0000-11.8000=1$

$7033401.4: 60+15.0000-15.4000-16.0000-24.0000+1$

REFERENCL ENERGY DELTA X-SEC DELTA HIALF-LIFE

$5824271.4400+1 \quad 5.4700-12.3000-E 1.2900+2$ 


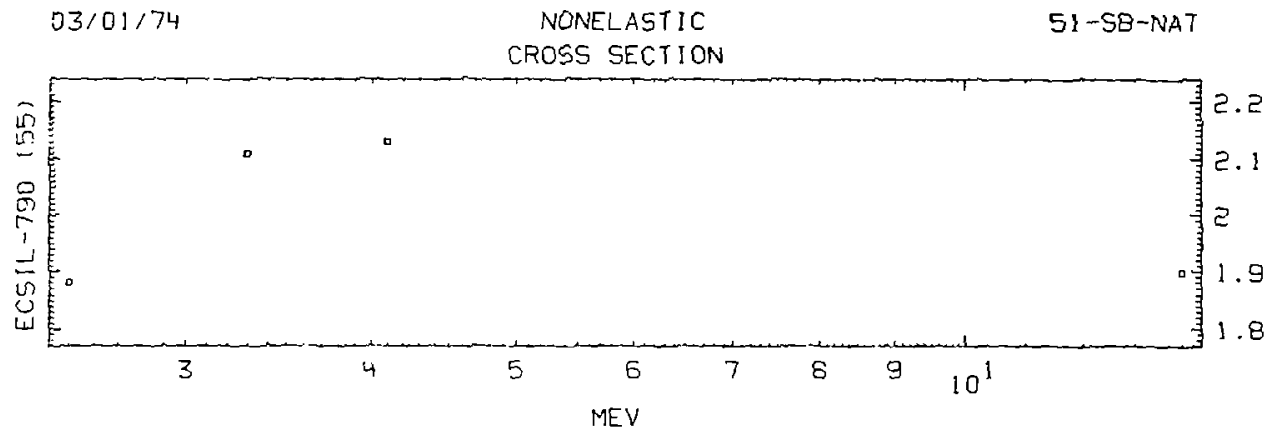

51-SB-NAT

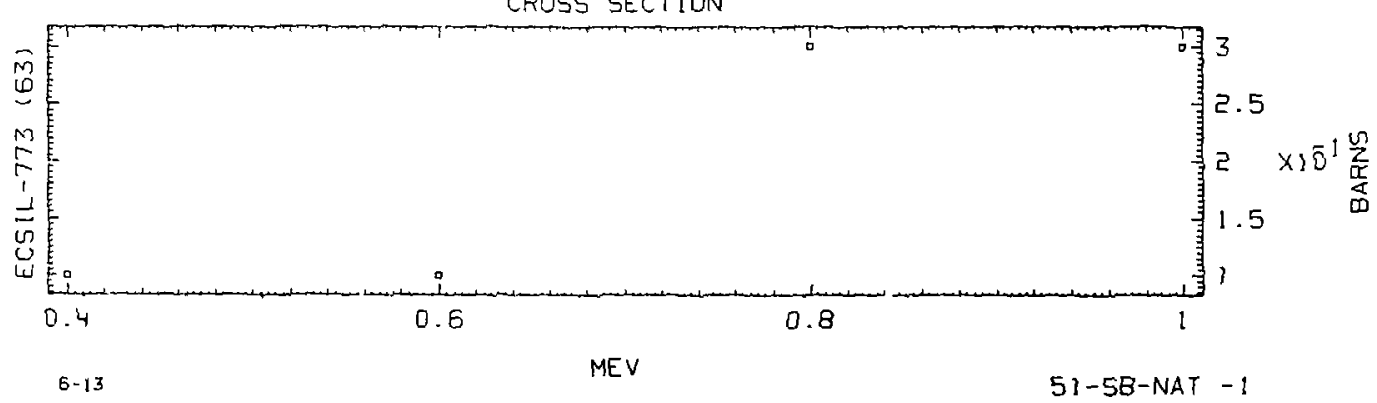



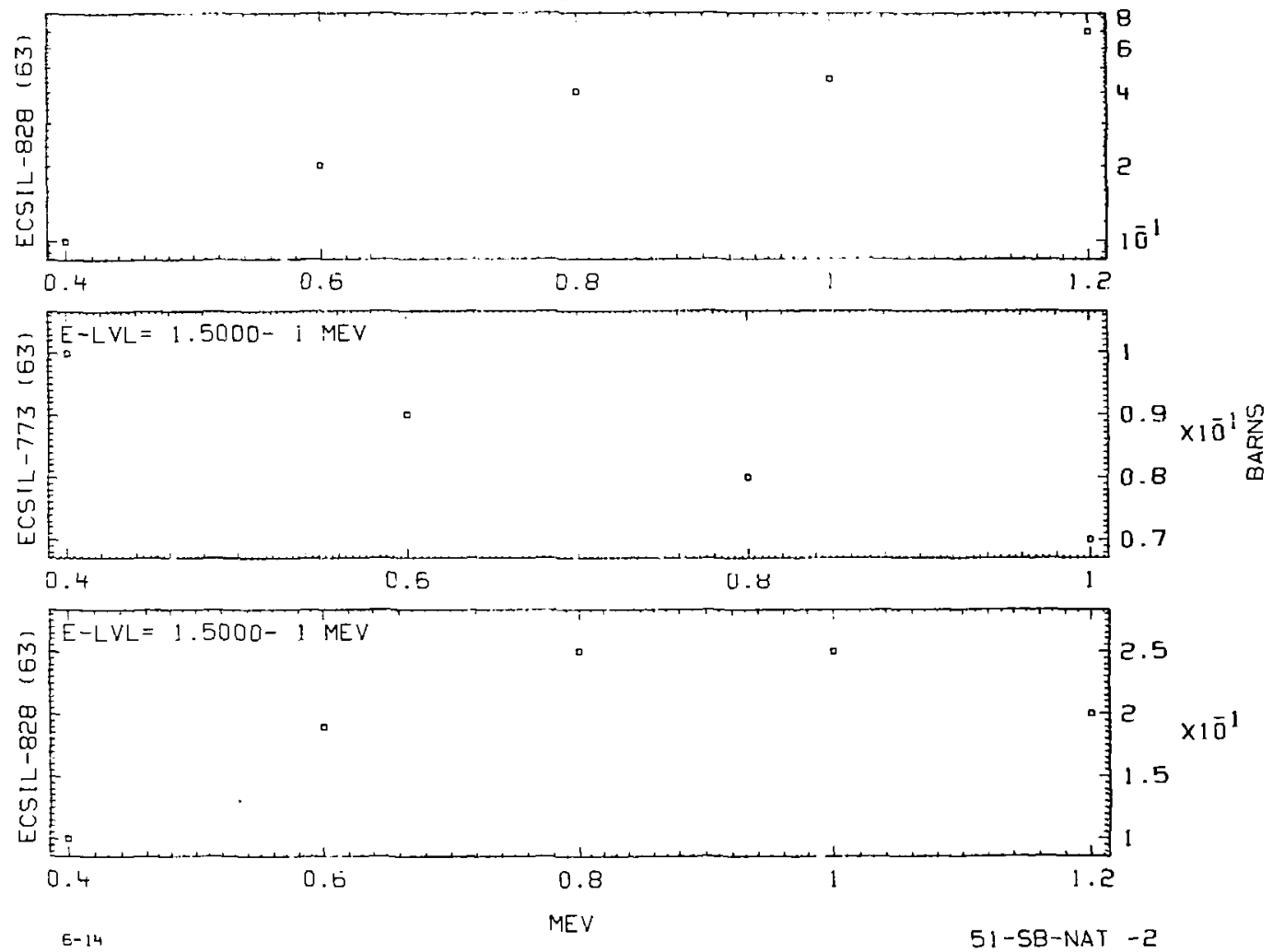

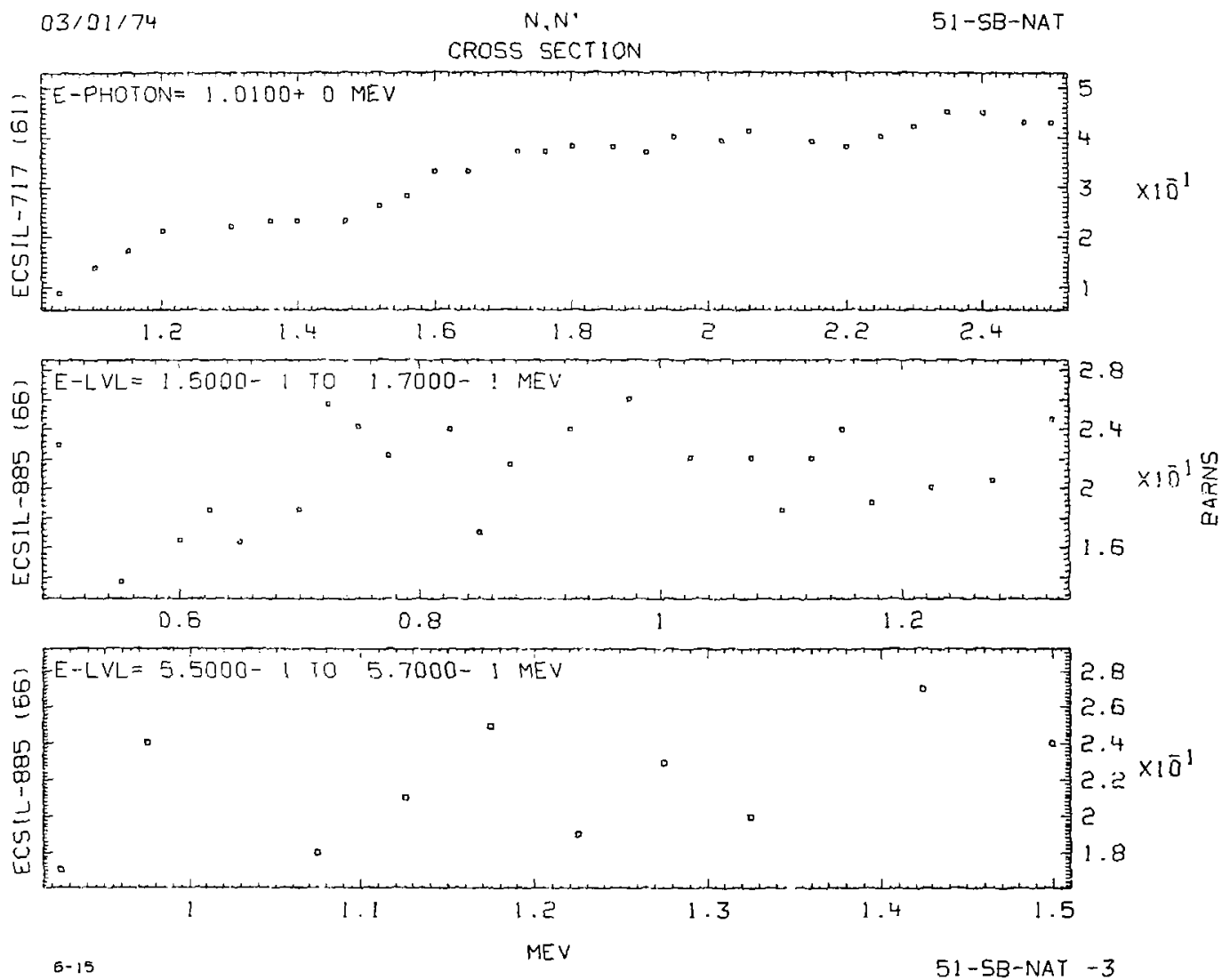


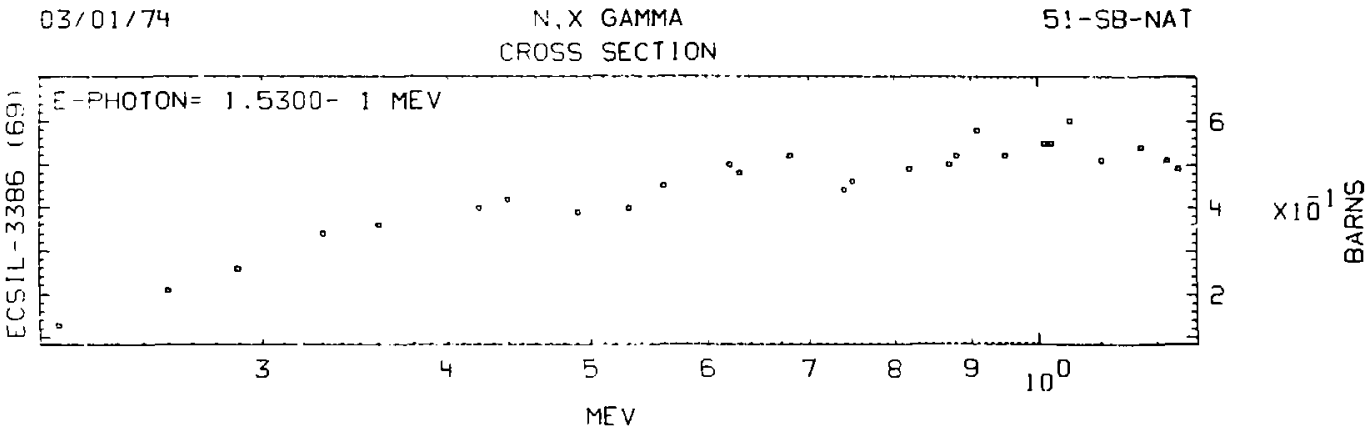

\begin{tabular}{|c|c|c|c|c|c|c|c|c|c|c|c|c|}
\hline \multicolumn{3}{|c|}{$03 / 01 / 74$} & \multicolumn{6}{|c|}{ NONELAST IC } & \multicolumn{4}{|c|}{$51-5 B-N A T$} \\
\hline \multirow{2}{*}{\multicolumn{2}{|c|}{ REFERENCE }} & ENERGY & DE: $:$ & $x-5 E C$ & DELIA & \multicolumn{2}{|c|}{ REF EPENCEE } & ENERG & OEL 1 & & $X$-SEC & DELTA \\
\hline & & MEV & ME & BARNS & BARN5 & & & ME & ME & & BARNS & BAFNS \\
\hline 56 & 353 & $7.7000-1$ & & $4.0000-1$ & $12.0000-1$ & 58 & 877 & $1.4000+$ & 1 & & $1.8500+0$ & $1.3000-1$ \\
\hline 54 & 103 & $1.0000+0$ & D $5.0000-$ & 2 8.001c- 1 & $16.0910-1$ & 57 & 199 & $1.4100+$ & 1 & & $1.8700+0$ & $8.0010-2$ \\
\hline 55 & 353 & $1.020 \overline{+}+0$ & D & $7.0010-1$ & $13.0000-1$ & 57 & 319 & $1.420 \%$ & 11.5000. & 11 & $1.9600+0$ & $3.0000-2$ \\
\hline 56 & 34 & $2.5000+0$ & D & $1.9000+0$ & $02.00 G 0-1$ & 56 & 200 & 1.4590 & $i$ & & $2.0600+0$ & $4.0000-2$ \\
\hline ED & 576 & $4.1000+0$ & $01.0000^{-}$ & $12.3005+0$ & $03.0000-1$ & & & & & & & \\
\hline
\end{tabular}

$03 / 01 / 74 \quad N, N^{\cdot} \quad 51$-SB-NAT

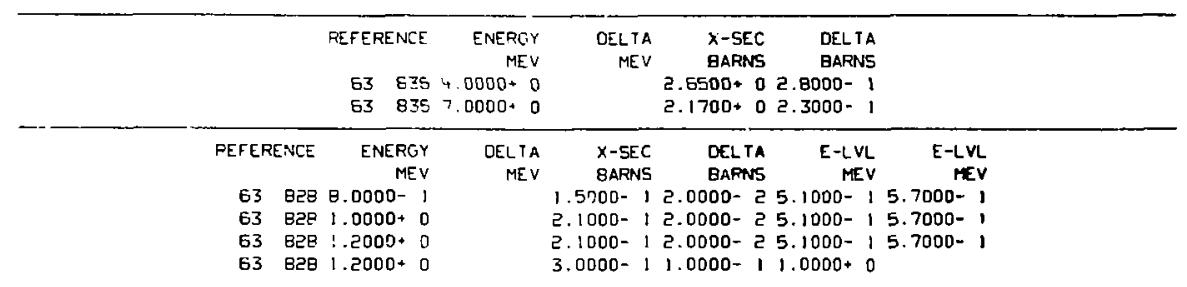




\section{CROSS SECTION}

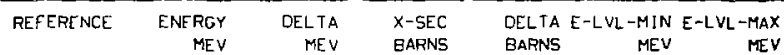

$668855.6000-15.0000-33.0000-15.0000-23.5500-23.8500-2$

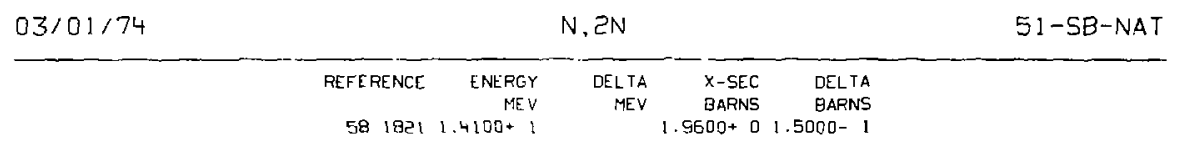

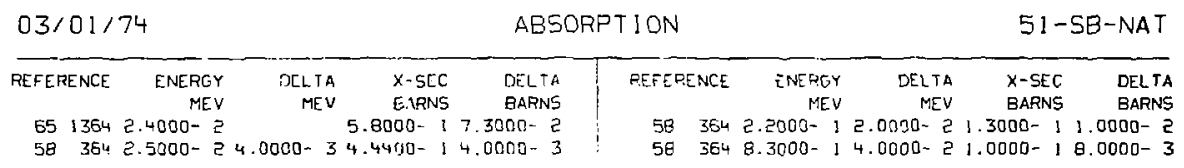

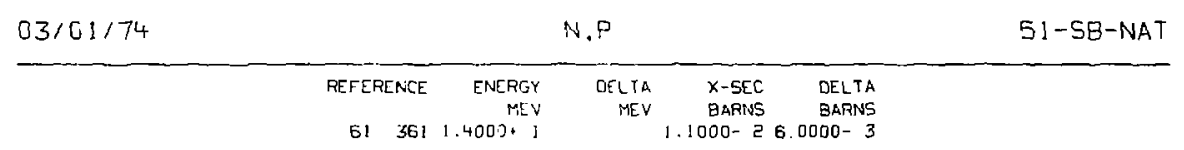

$03 / 01 / 74$ BOUND ATOM

51-SB-NAT

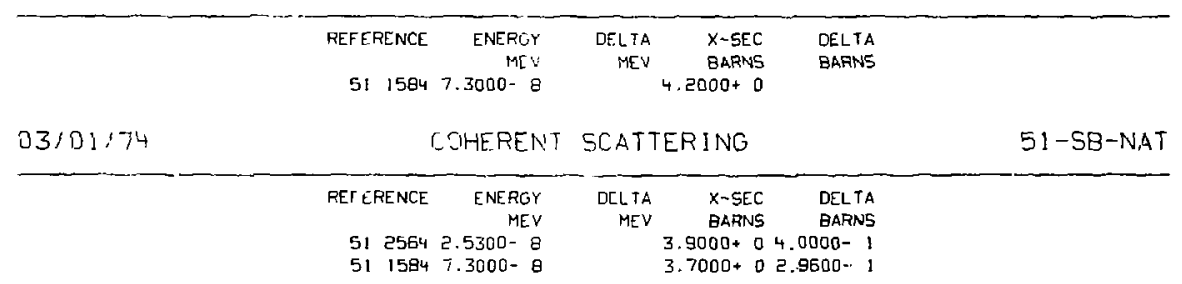



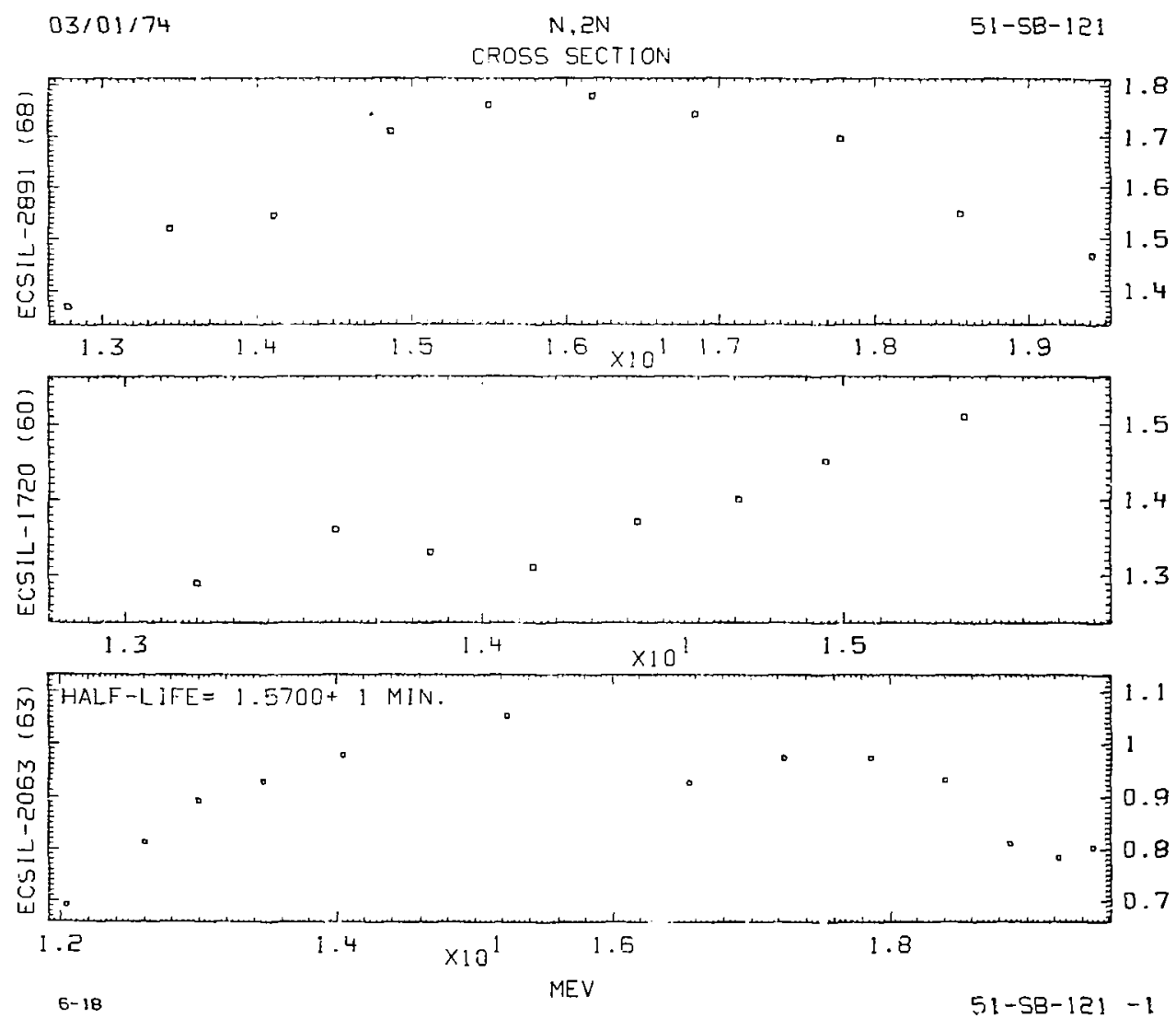

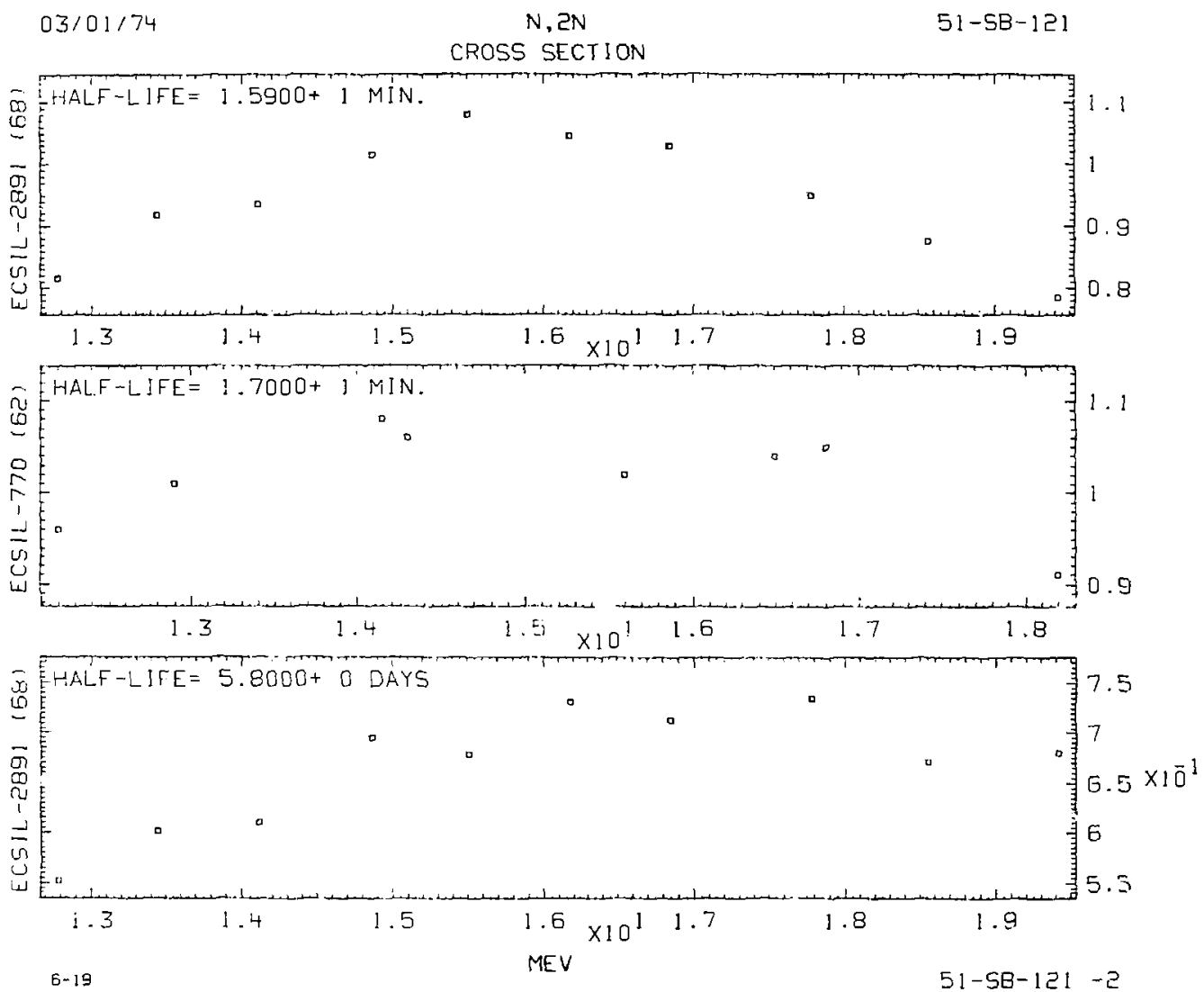
CROSS SECTION

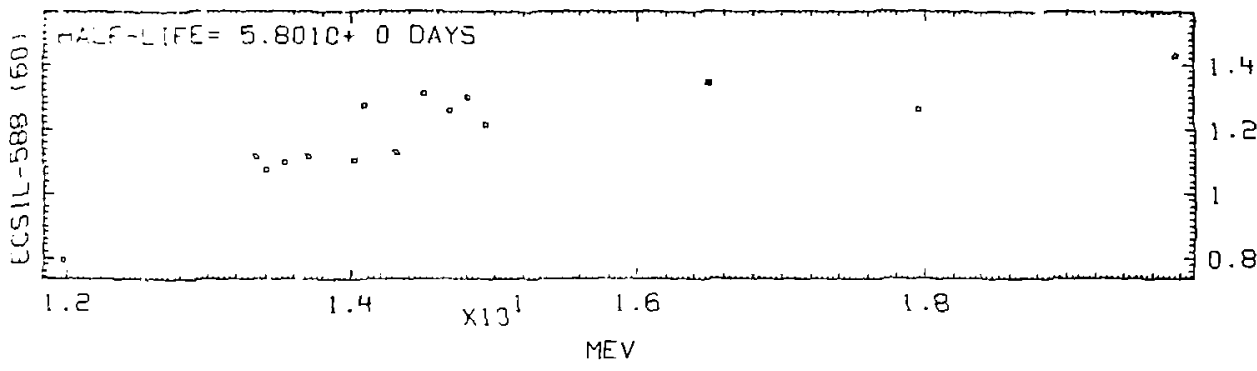

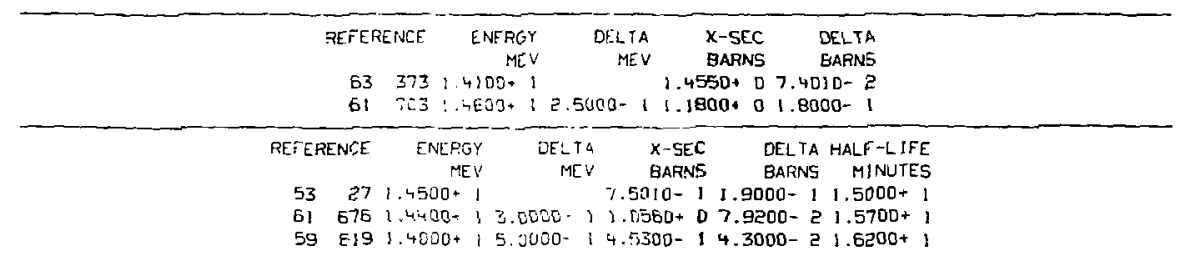



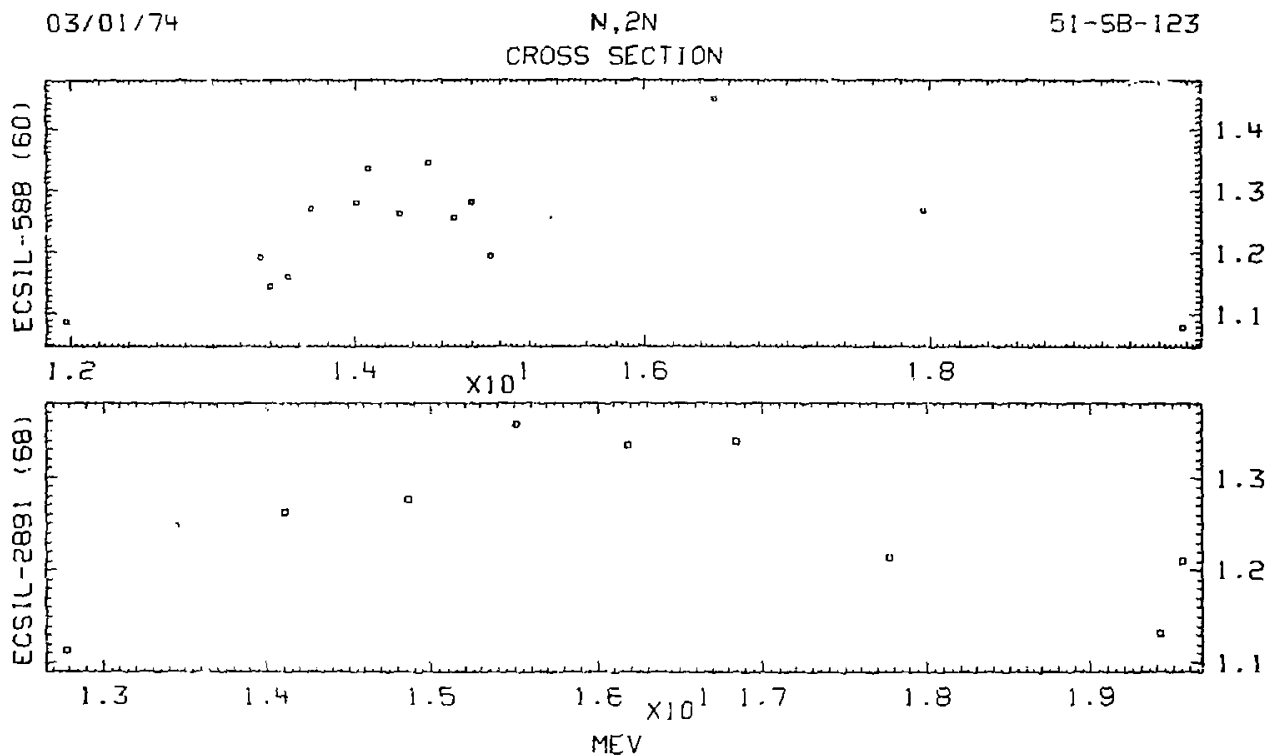

$\underbrace{03101,74}_{\text {REFERENCE }} \underbrace{N, Z N}_{\substack{\text { ENERGY } \\ \text { MEV }}}$

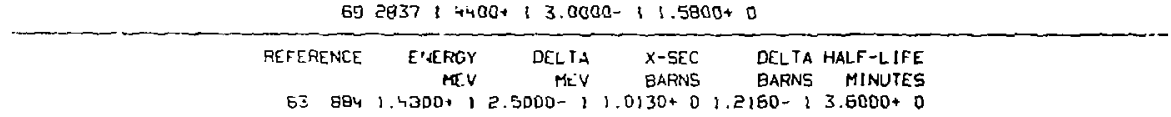

6-21 


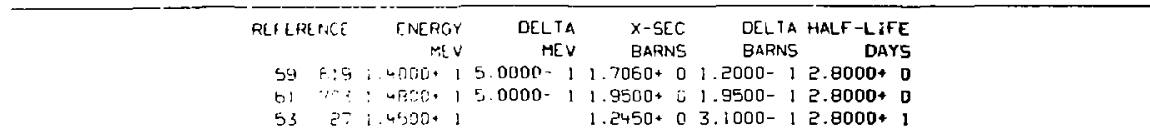

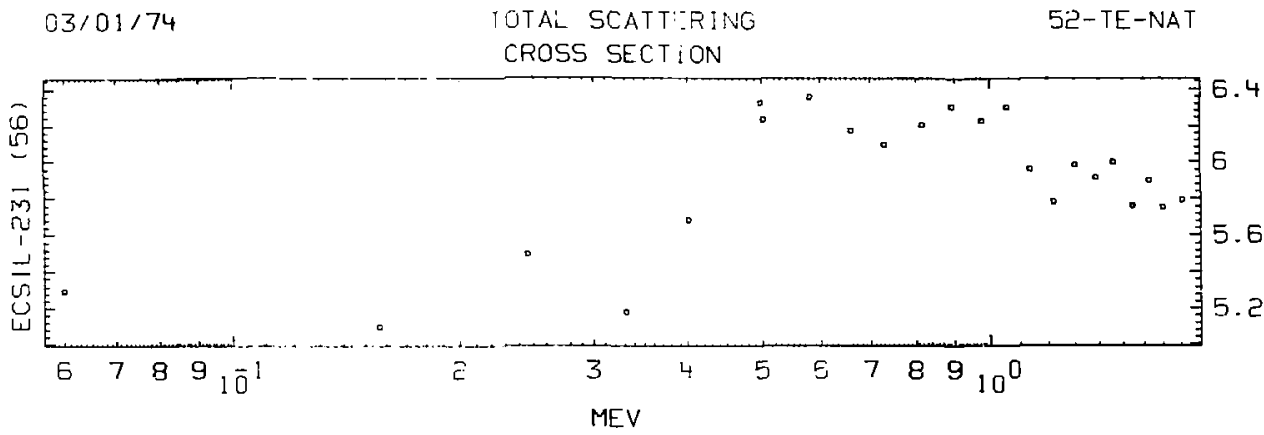




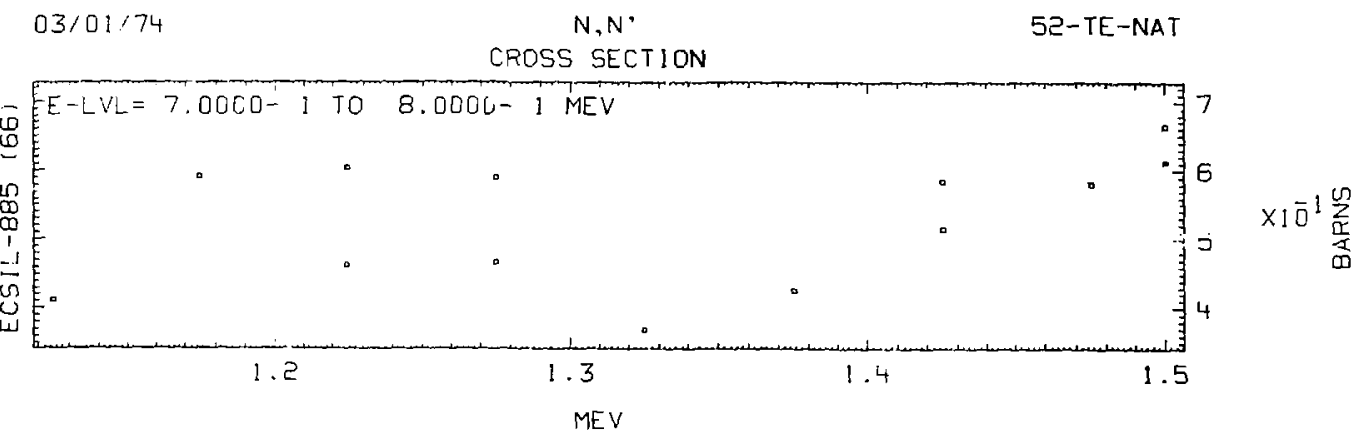

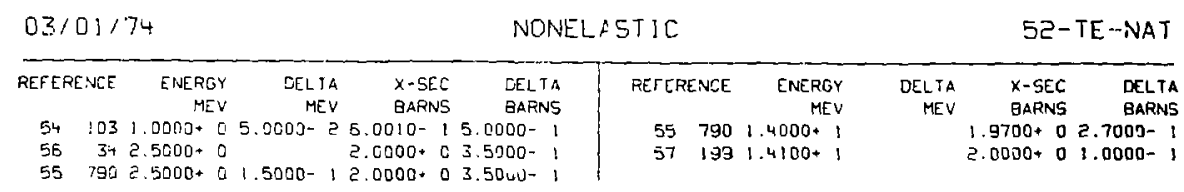

03/01/74 AESORPTION

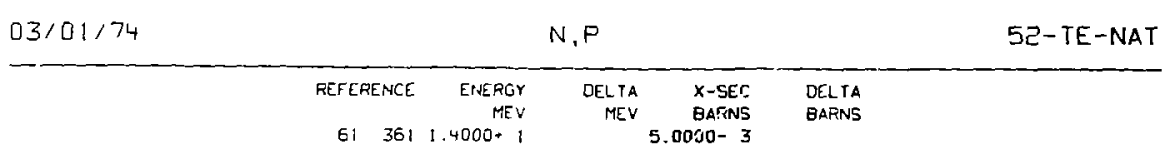


CROSS SECTION

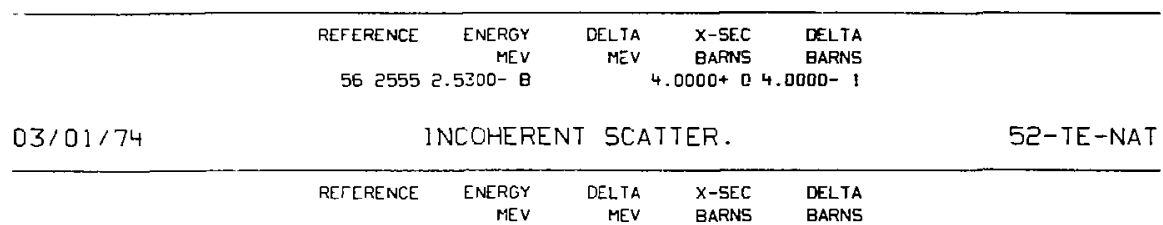

5) 2398 2.5000- 8

6. $0000-1,5000-1$

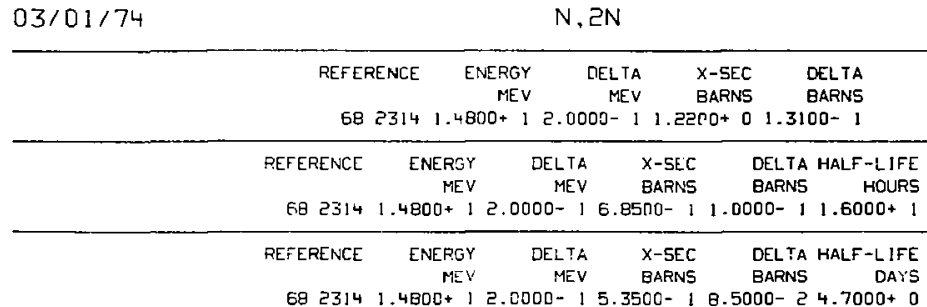

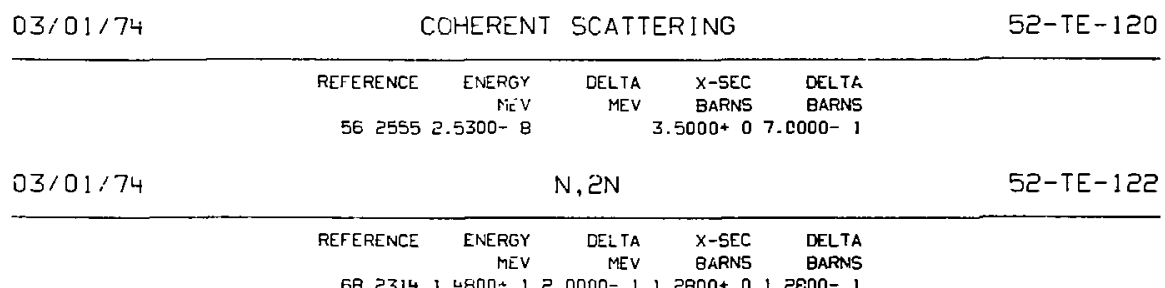

$6823141.4800+12.0000-11.2800+01.2800-1$ 


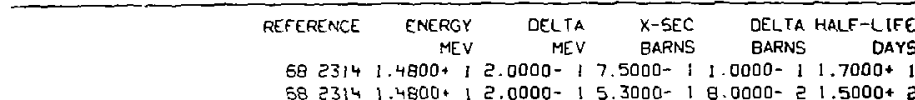

$03 ; 01 / 74$

COHERENT SCATTERING

$52-T E-123$

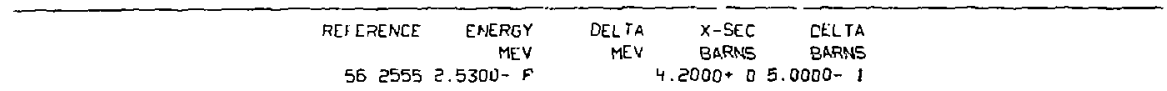

$03 / 01 / 74$

$N, P$

$52-T E-124$

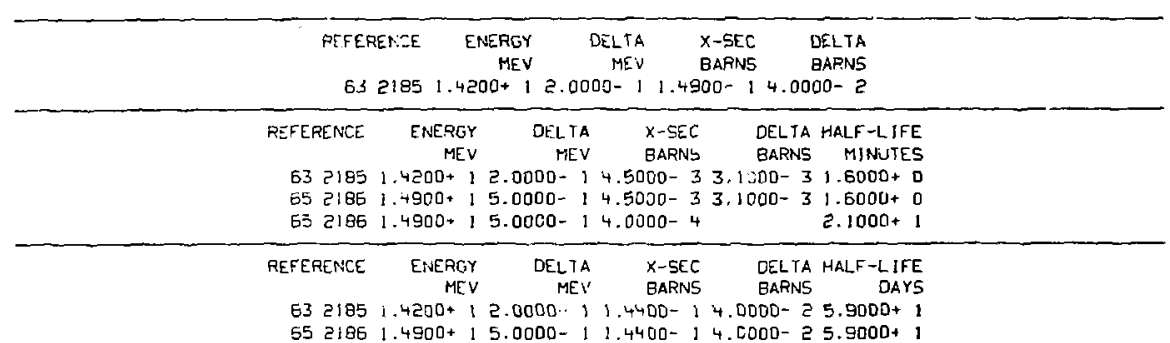

$03 / 01 / 74$

N. ALPHA

$52-T E-124$

REFEREA

EIERGY

DELTA

$x-\operatorname{SEC}$

DELTA HALF-LIFẼ

GE

MEV MEV BARNS

BARNS

HOUR5

$6322031.4800+12.9600-13.6500-32.0000 \cdot 32.7000+1$ 
CROSS SECTION

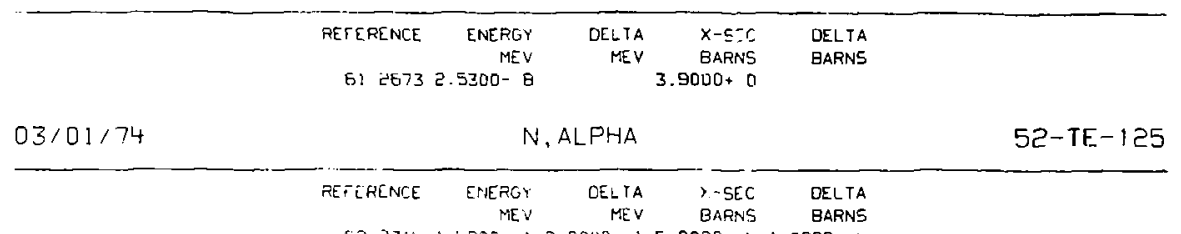

$6 B 2314$ ! $7800+12.0000-15.0000-41.0000-4$

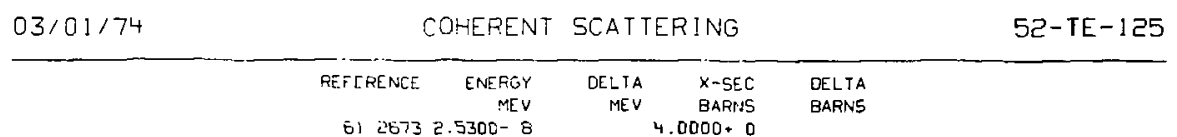

03/01/74

$6823141 .+800+12.0000-11.5000-32.0000-4$

$03 / 01 / 74$

$$
\text { N, ALPHA }
$$

$52-T E-126$

REFFERENCE

\begin{tabular}{|c|c|c|c|}
\hline ENERGY & DELTA & $x-5 E C$ & DELTA HALF-LIFE \\
\hline MEV & MiEV & BARNS & MINUTES \\
\hline
\end{tabular}

$6823141.4800+12.0000-1$ B.0000- $41.0000-44.0000+1$

$632203: .4900+12.9600-15.5000-43.0000-44.0000+1$

-03/01/74

$6923141.4800+12.0000-11.3900+0$ 


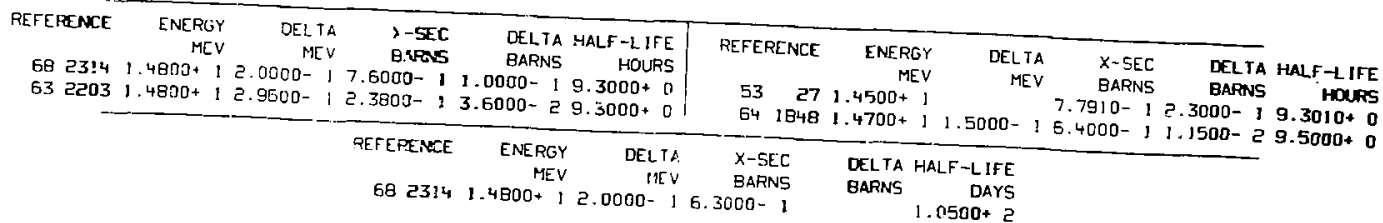

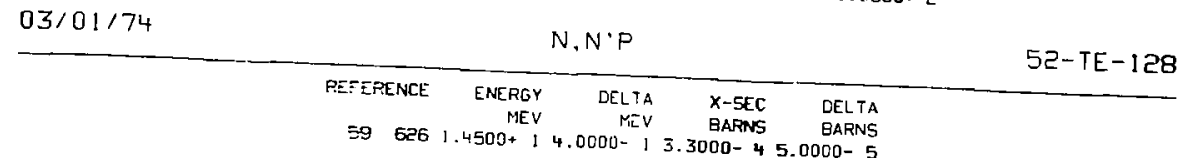

$03 / 01 / 74$

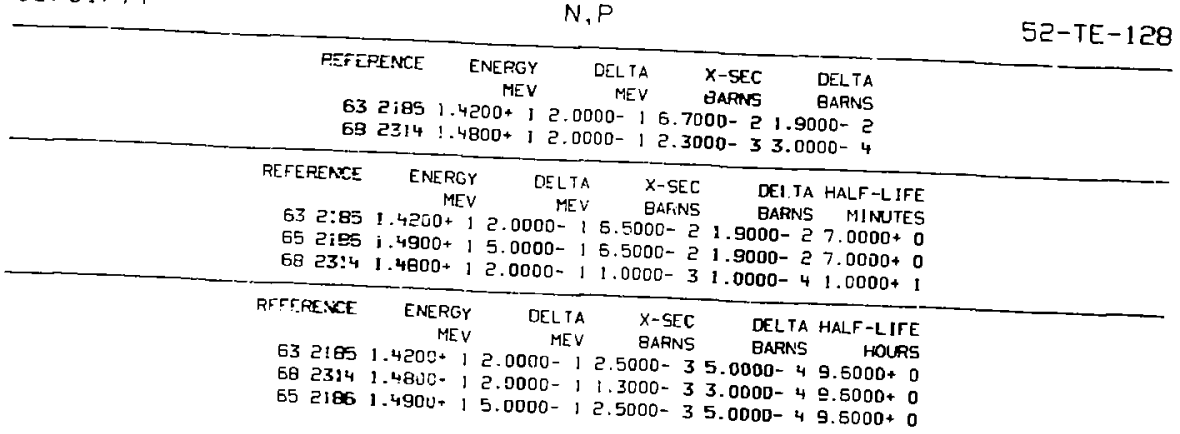

6-27 
CROSS SECTION

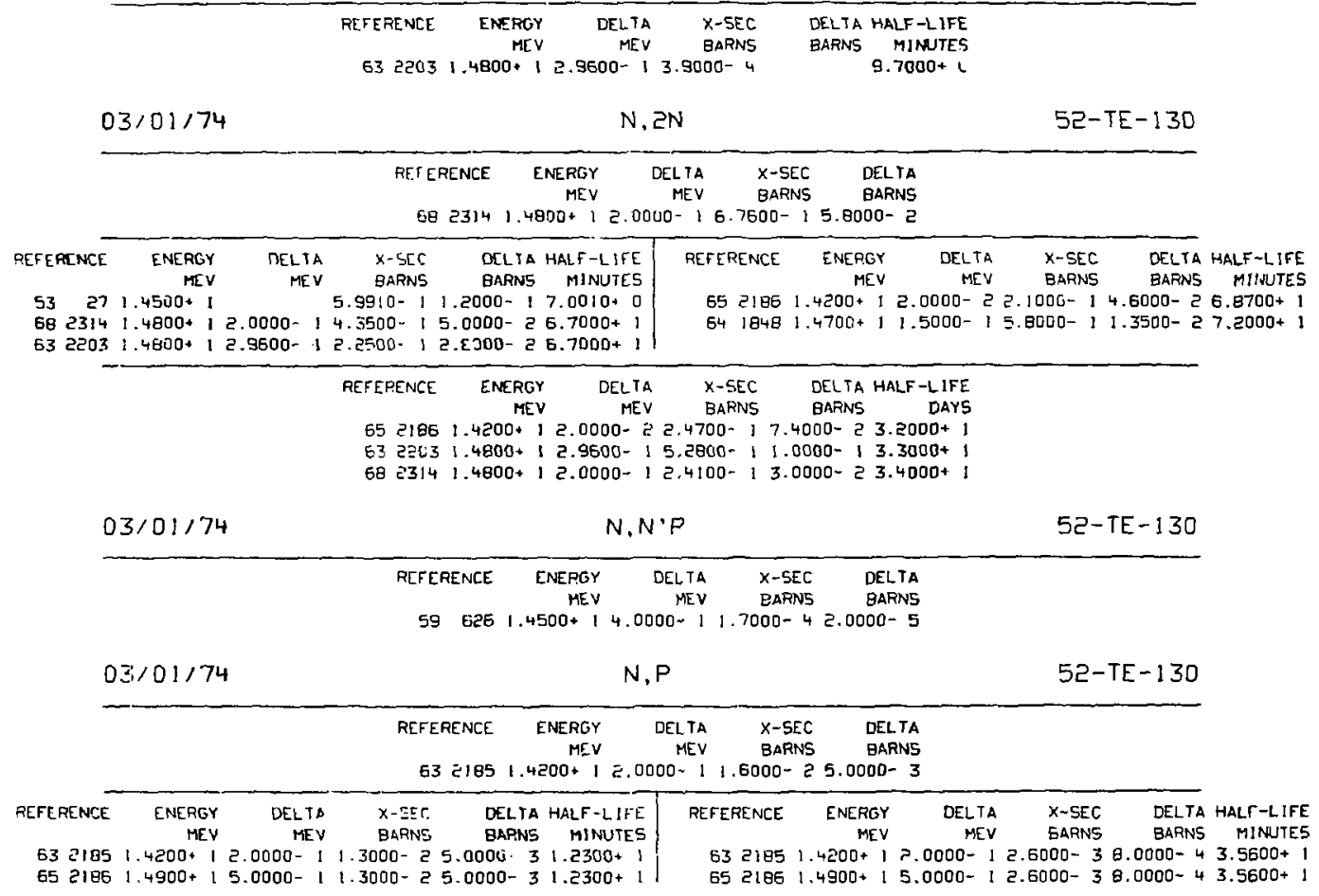


CROSS SECTION

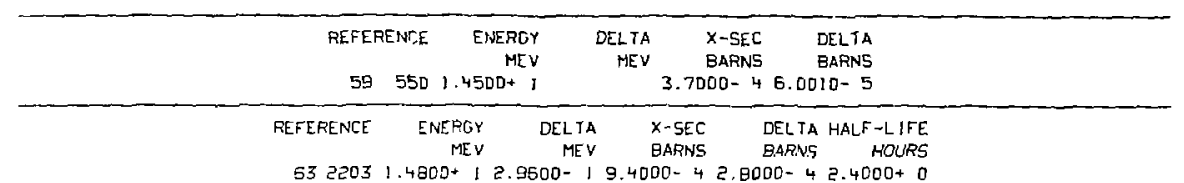

$5322031.4800+12.9600-19.4000-42.8000-42.4000+0$

\begin{tabular}{|c|c|c|c|c|}
\hline AEFERENCE & ENERGY & DEL TA & $x-S E C$ & OELTA \\
\hline & $\begin{array}{r}M E V \\
5300-8\end{array}$ & MEV & $\begin{array}{l}\text { BARMS } \\
000 * 0\end{array}$ & $\begin{array}{l}\text { BARNS } \\
1000-1\end{array}$ \\
\hline
\end{tabular}

$03 / 01 / 74$

\section{CROSS SECTION}

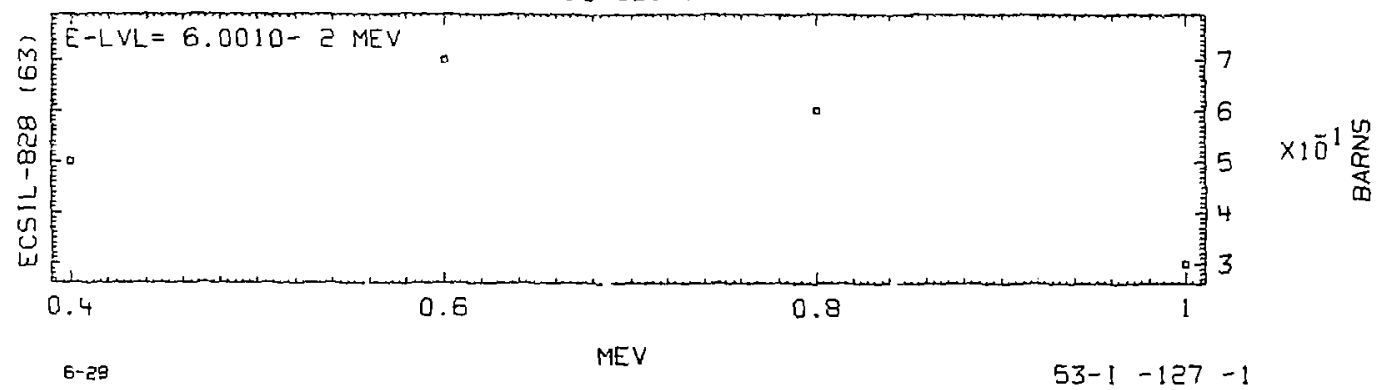



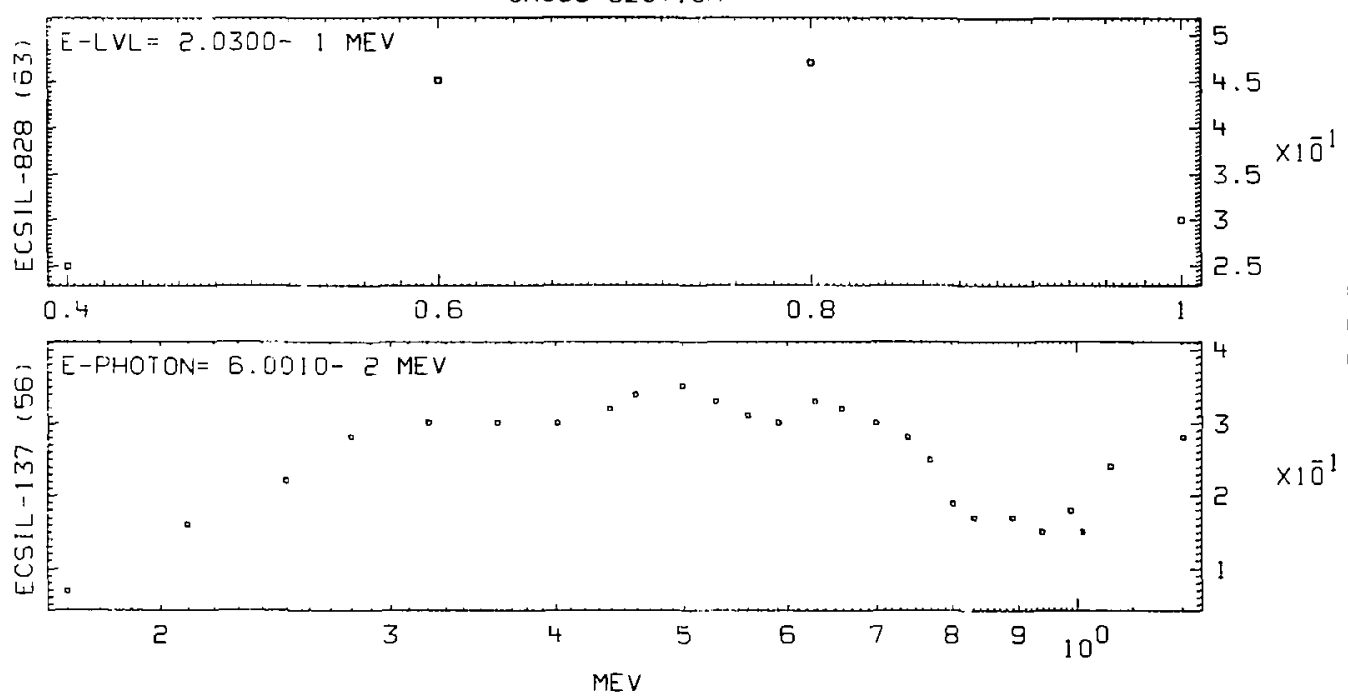

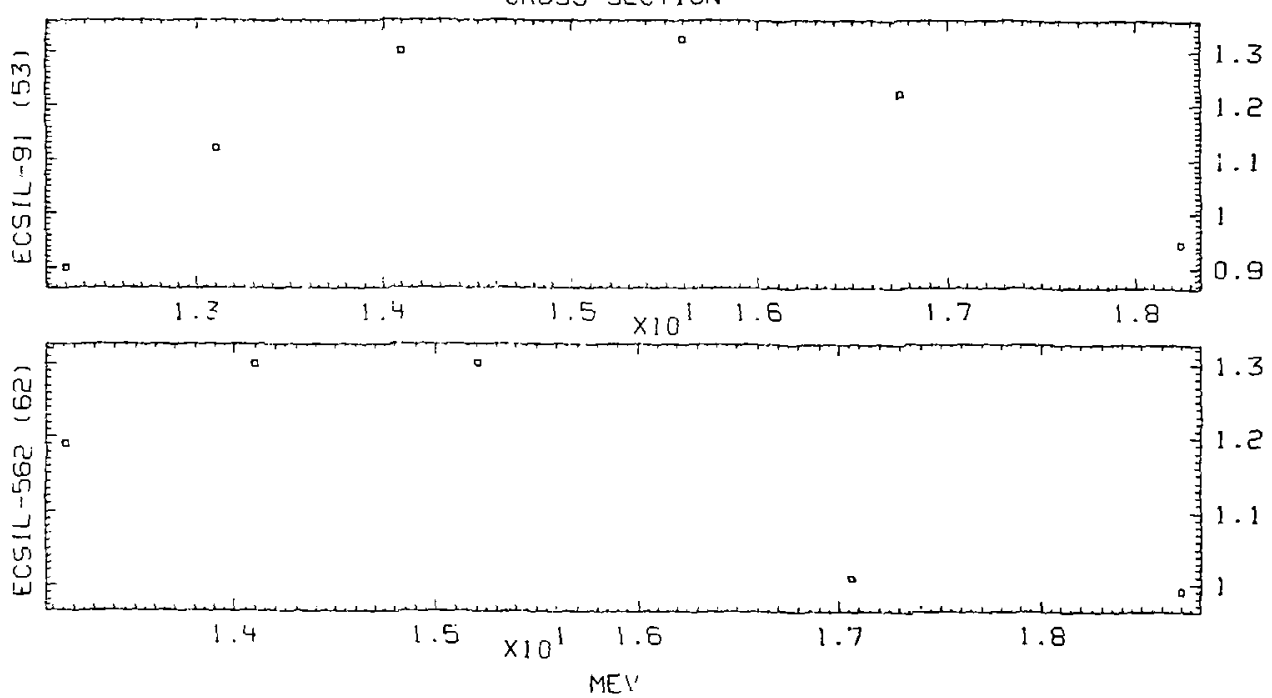

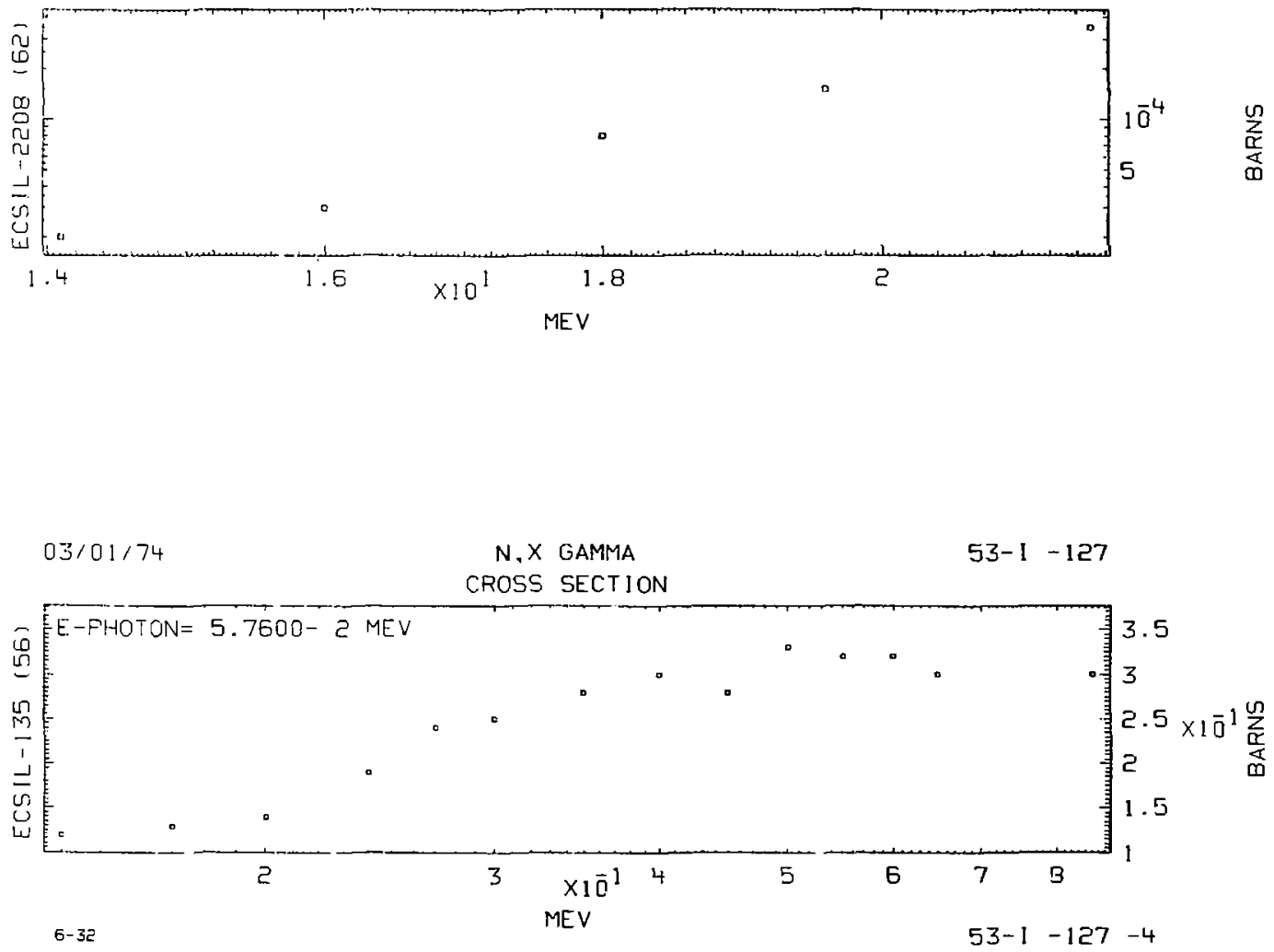


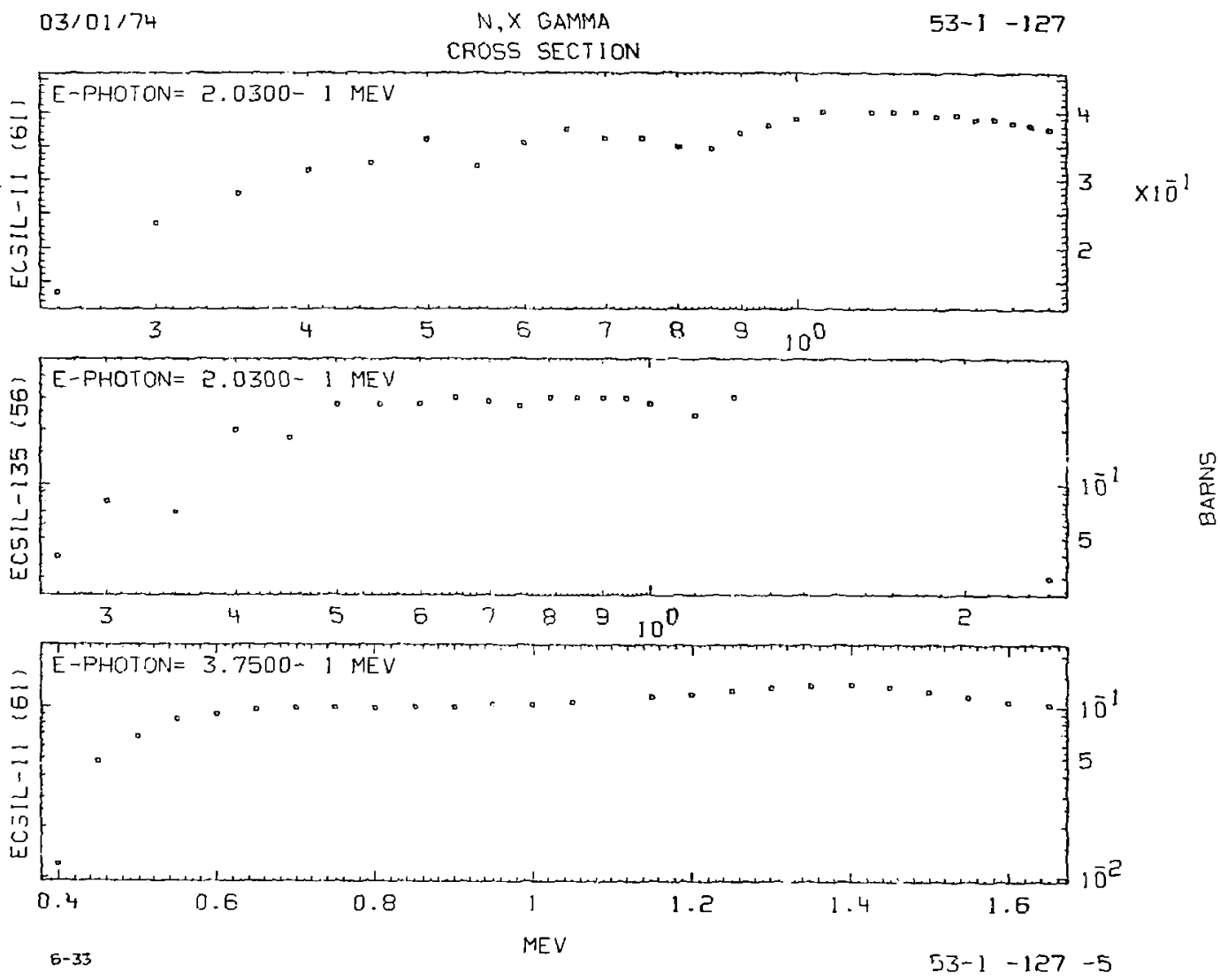




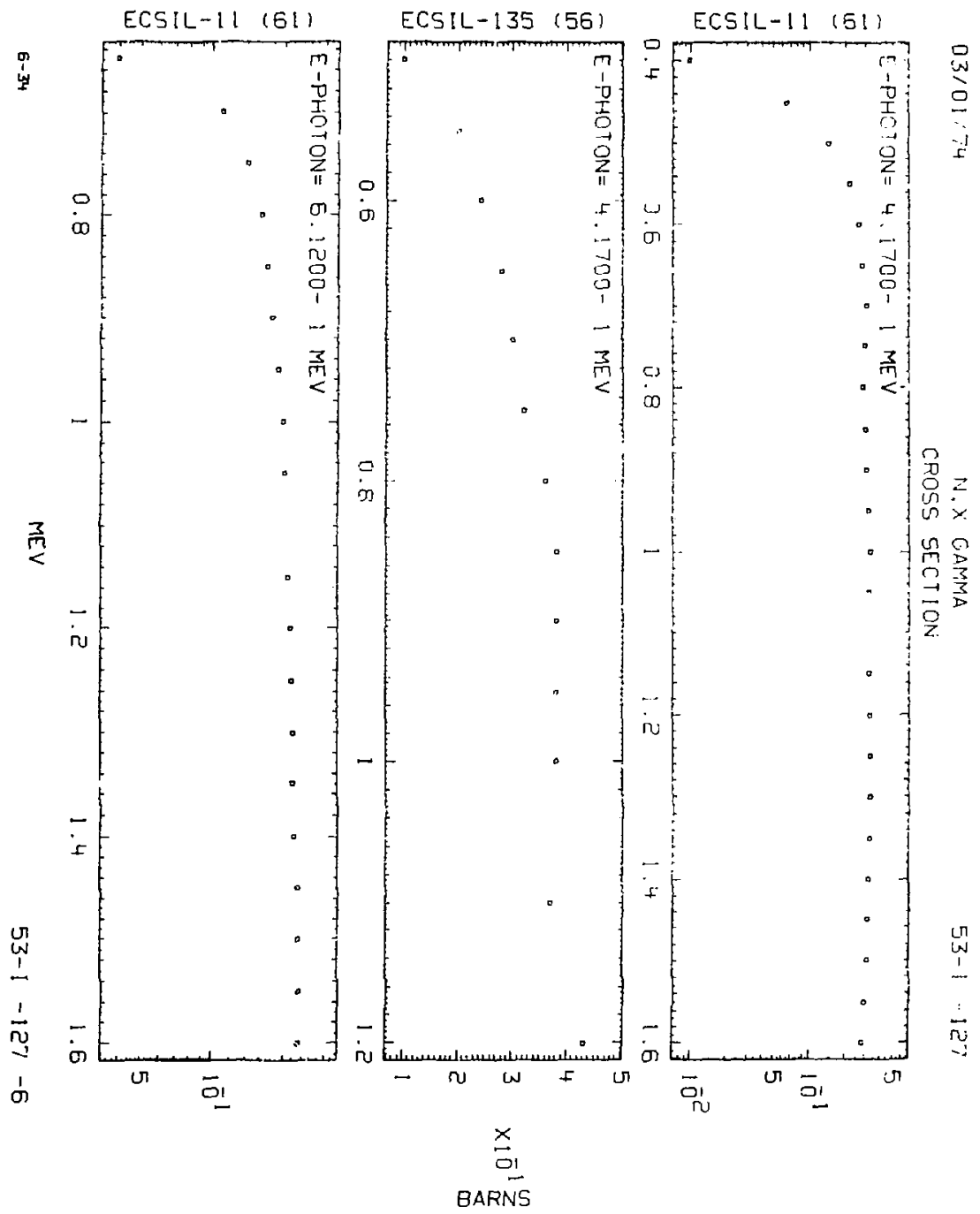



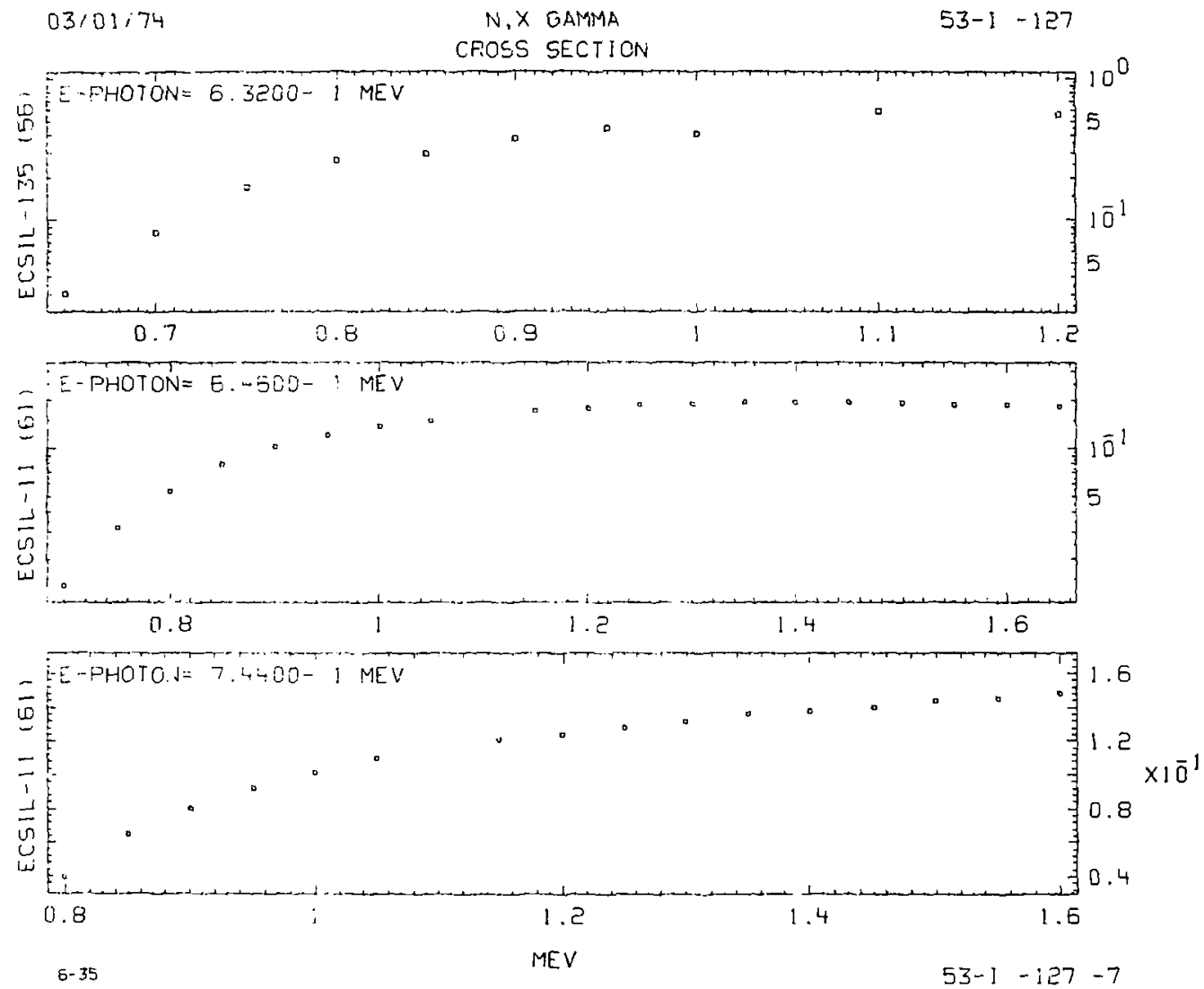


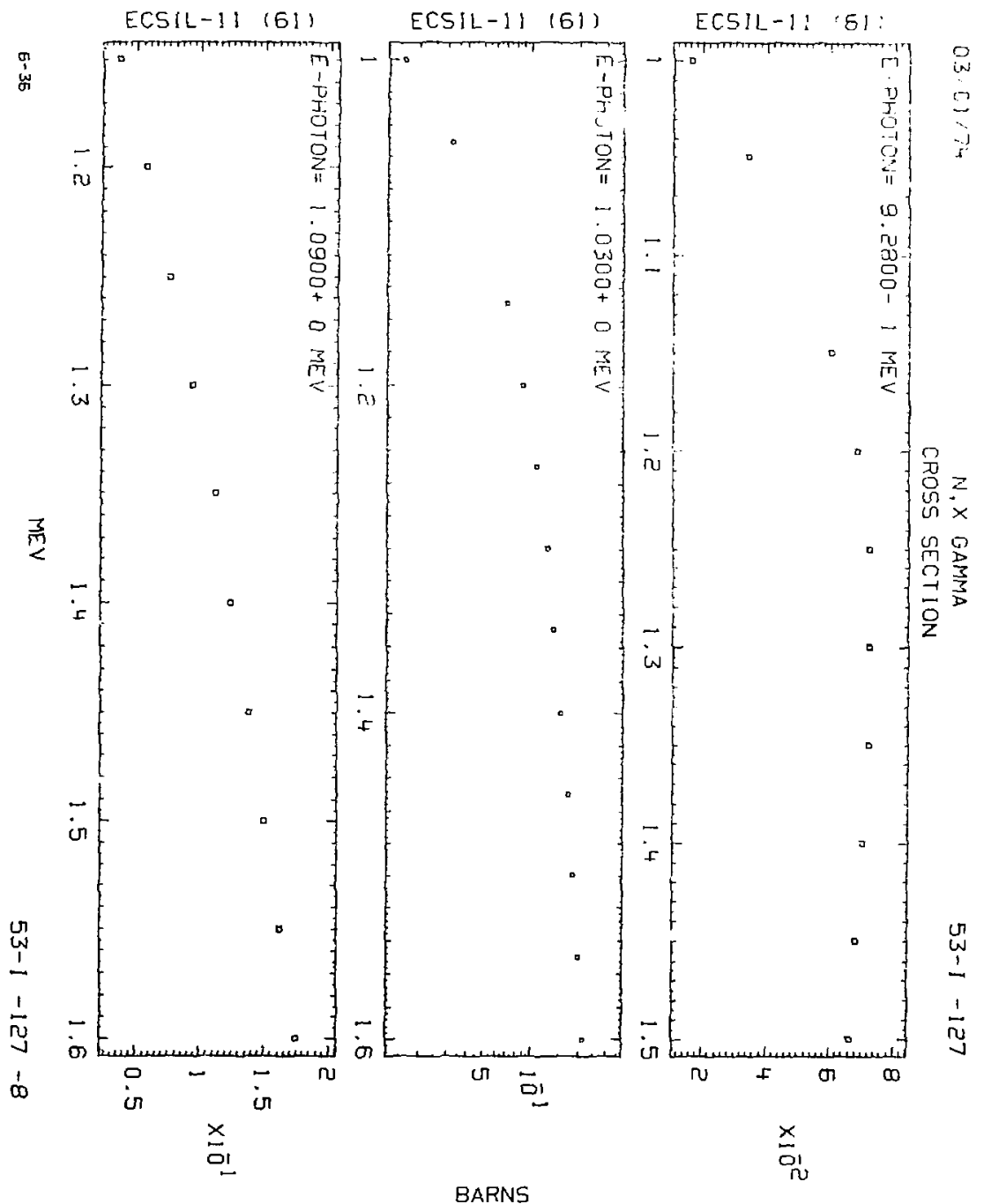




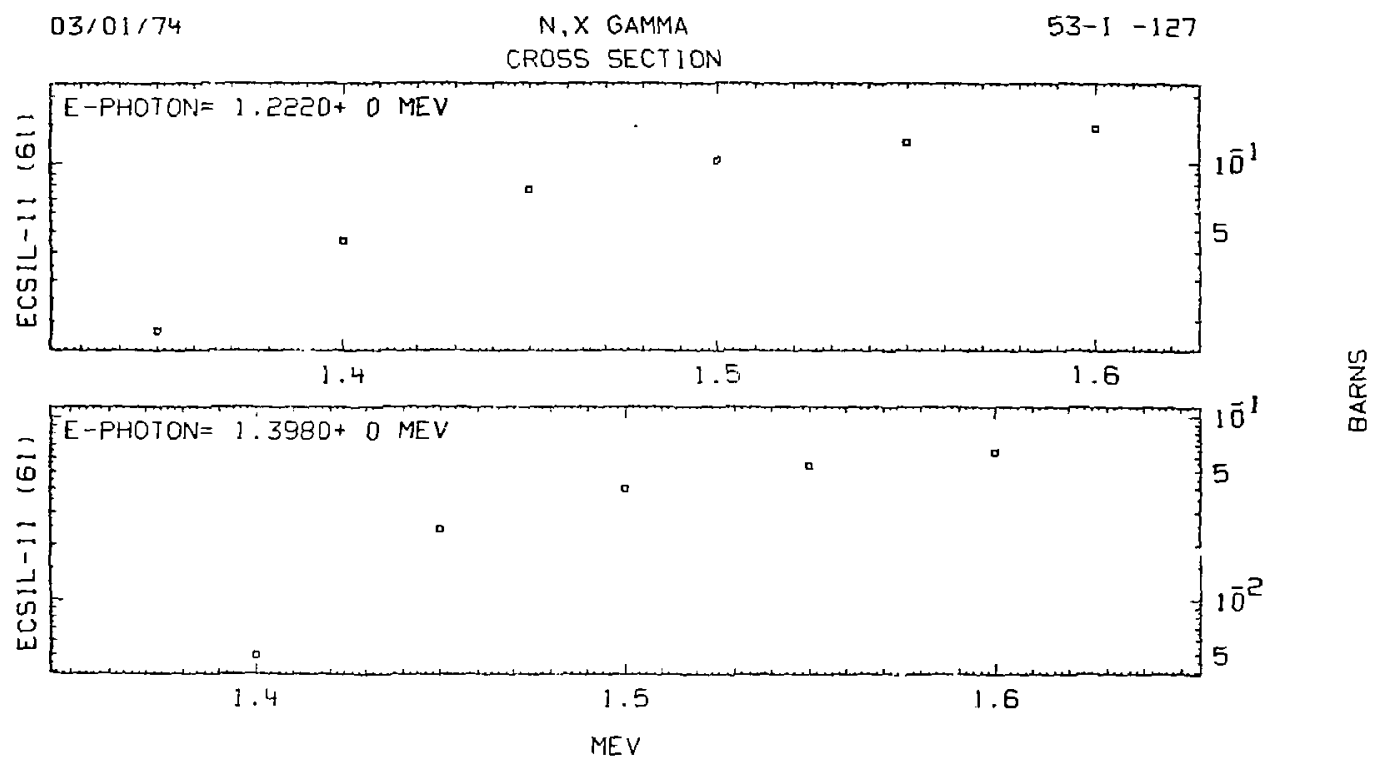

6- 37 


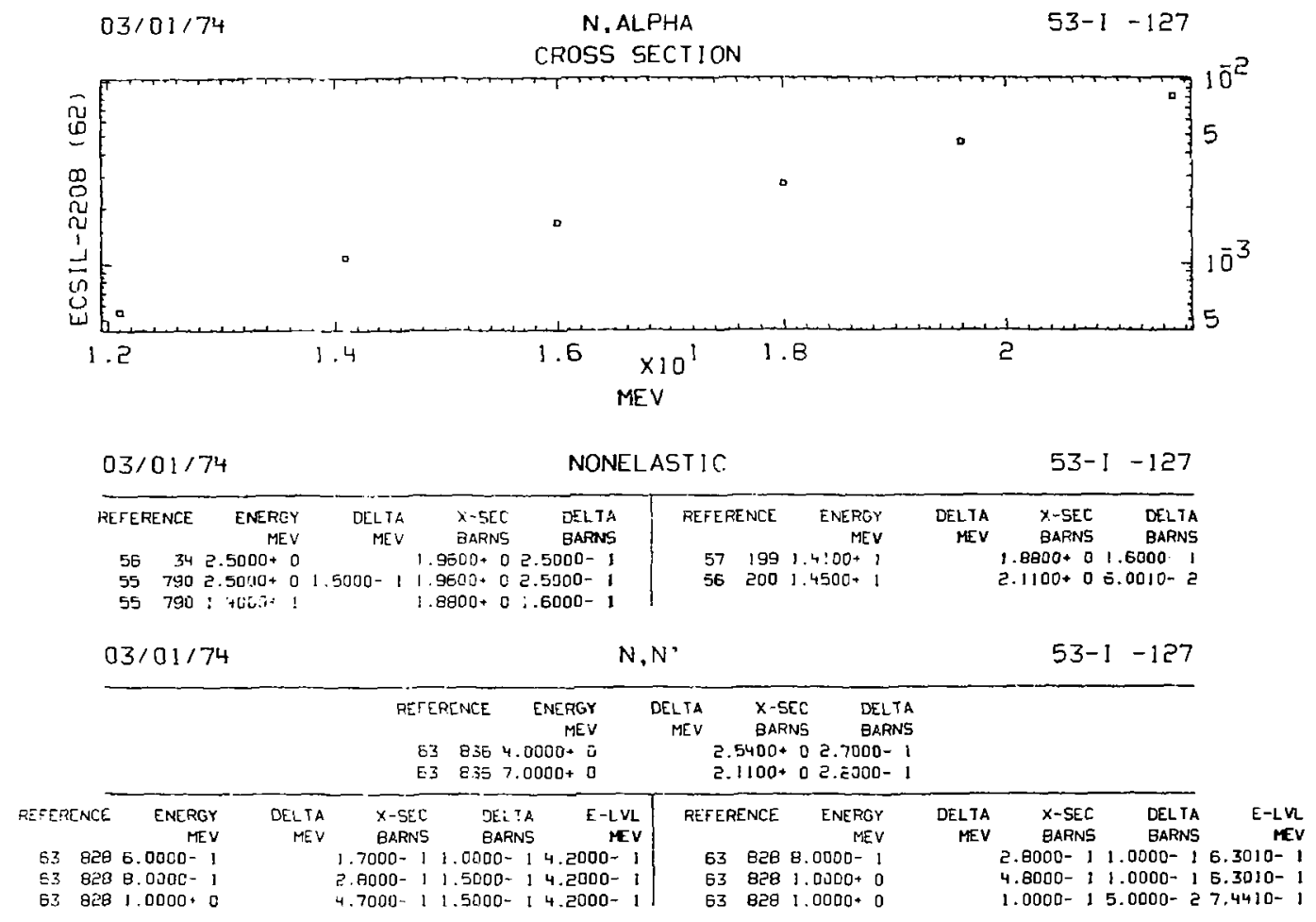




\section{CROSS SECTION}

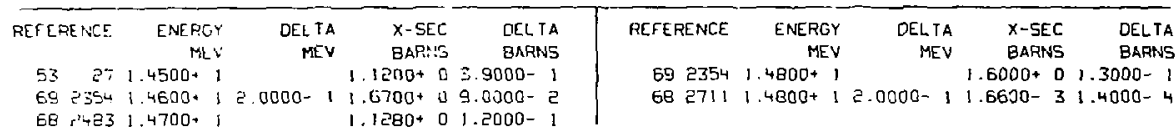

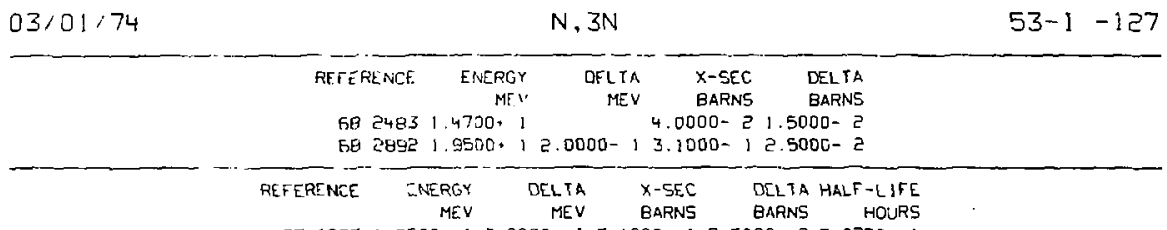

$6716931.9500+12.0000-13.1000-12.5000-26.0250+1$

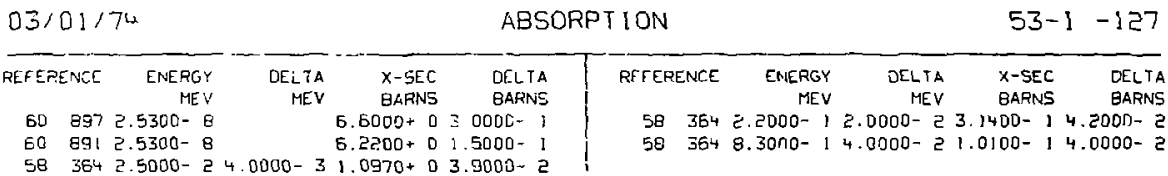

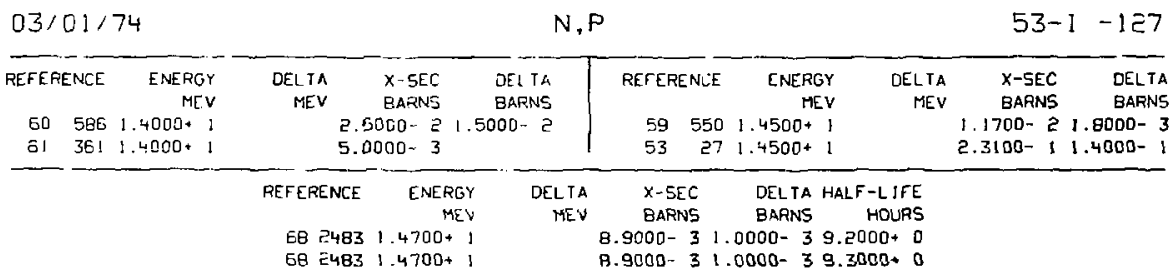


$03 / 01 / 74$

$N, P$

$53-I-127$

CFOSS SECTION

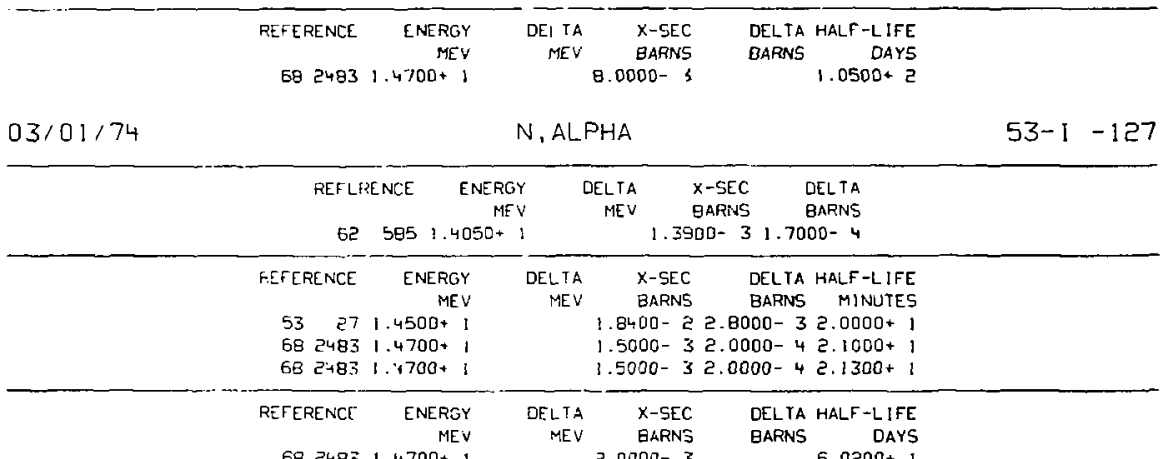

$6824831.4700+1$

$2.0000-3$

$6.0200+1$

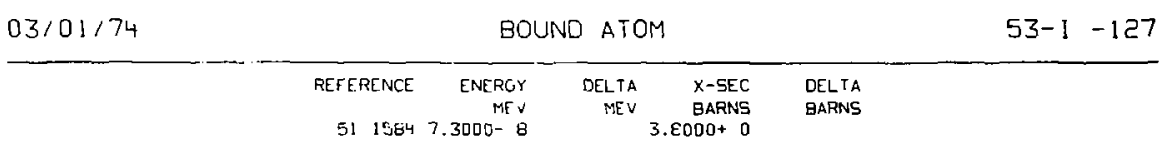

$\begin{array}{lll}51) & \text { 15E4 } 7.3000-8 & 3.8000+0\end{array}$

$03 / 01 / 74$

COHERENT SCATTERING

$53-1-127$

\begin{tabular}{|c|c|c|c|c|}
\hline REFERENCE & ENEPGY & DELTA & $X-S E C$ & DELTA \\
\hline & MEV & MEV & BARNS & BARNS \\
\hline
\end{tabular}


CROSS SECTION

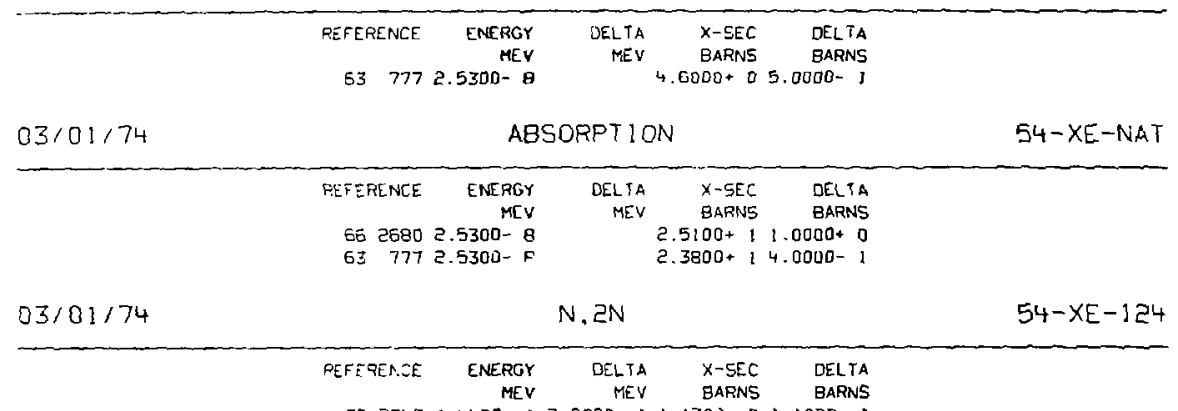

$6828421.4400+13.0000-11.1300+01.1000-1$

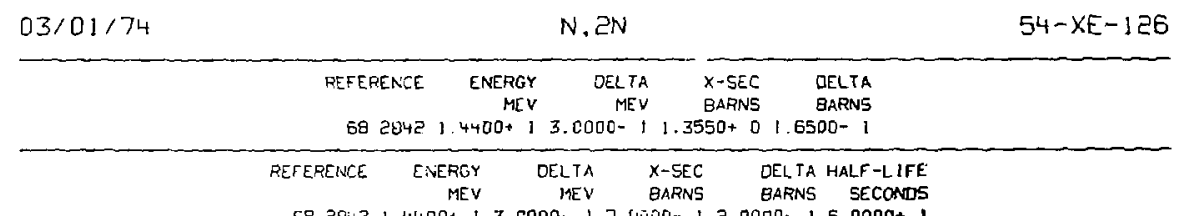

$6828421.4400+13.0000-17.4000-12.0000-16.0000+1$

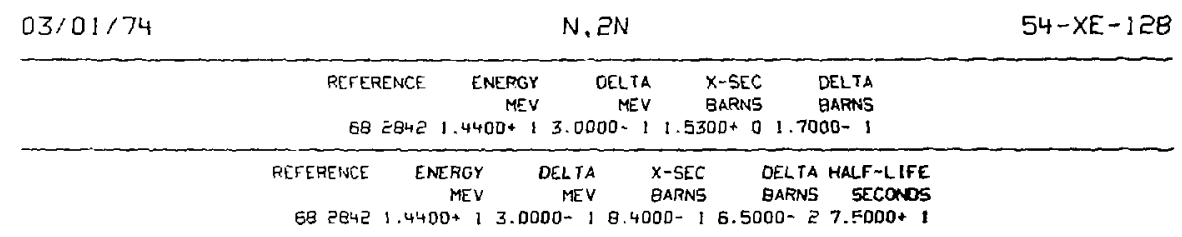




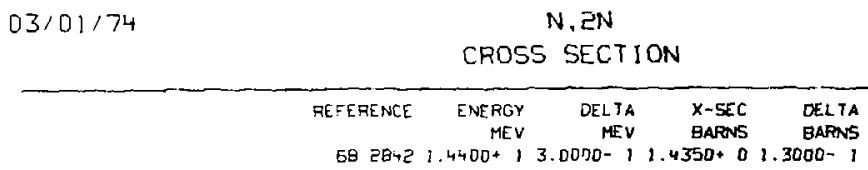

$03 / 01 / 74$

N.P

$54-X E-130$

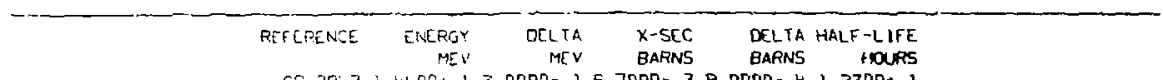

$6920 \div 21.4400+13.0000-16.7000-38.0000-41.2300+1$

-

$6826421.4400+13.0000-15.3000-36.0000-4$

03/01/74

68 28h $1 .+400+13.0000-17.7500-16.5000-2$

DZ/0j/74

68 EE-2 $1.4400+13.0000-12.5000-33.0000-42.2600+0$

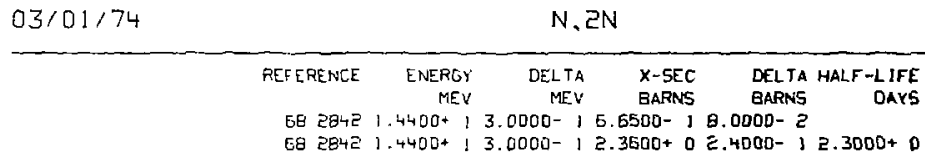


$03 / 01 / 74 \quad N, P \quad 54-X E-134$

CROSS SECTION

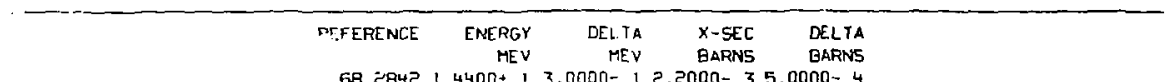

68 त $842,4400+13.0000-12.2000-35.0000-4$

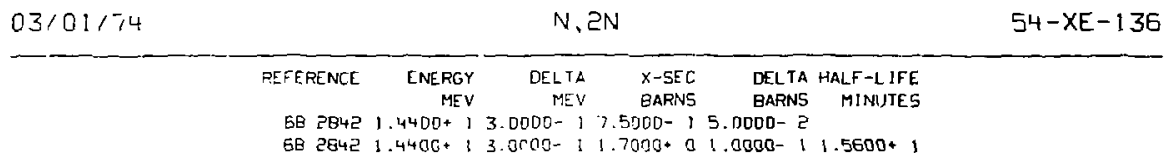

$6828421.4400+13.0000-11.7000 * 01.0000-11.5600 * 1$
$03 / 01 / 74$
$N, 2 N$
$55-\operatorname{cs}-133$

CRDSS SECTION

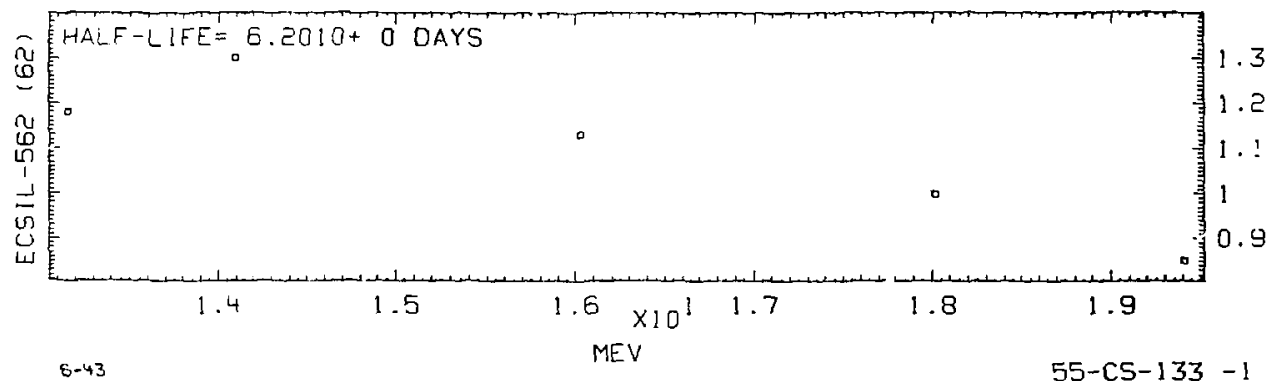




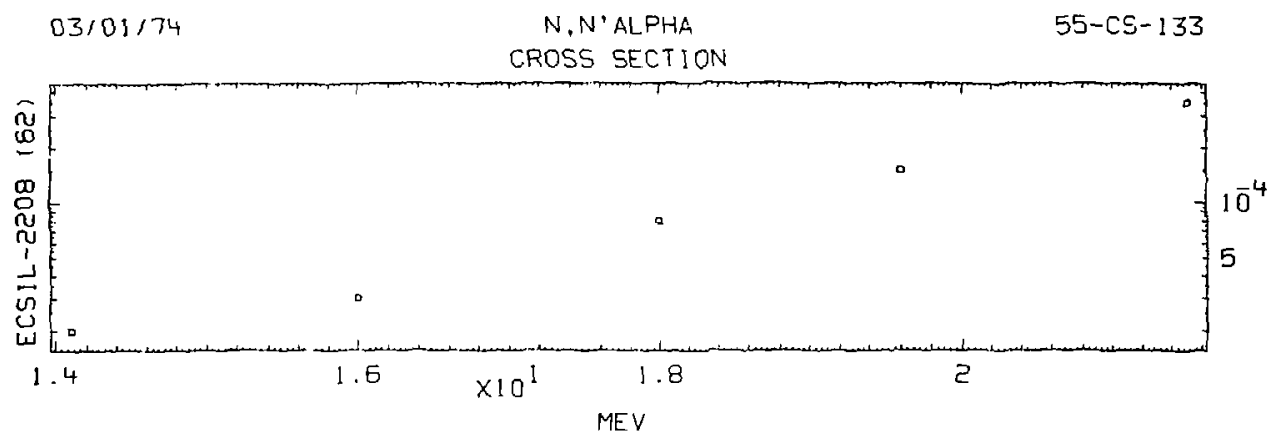

$\underset{\substack{n \\ \alpha \\ 0}}{0}$

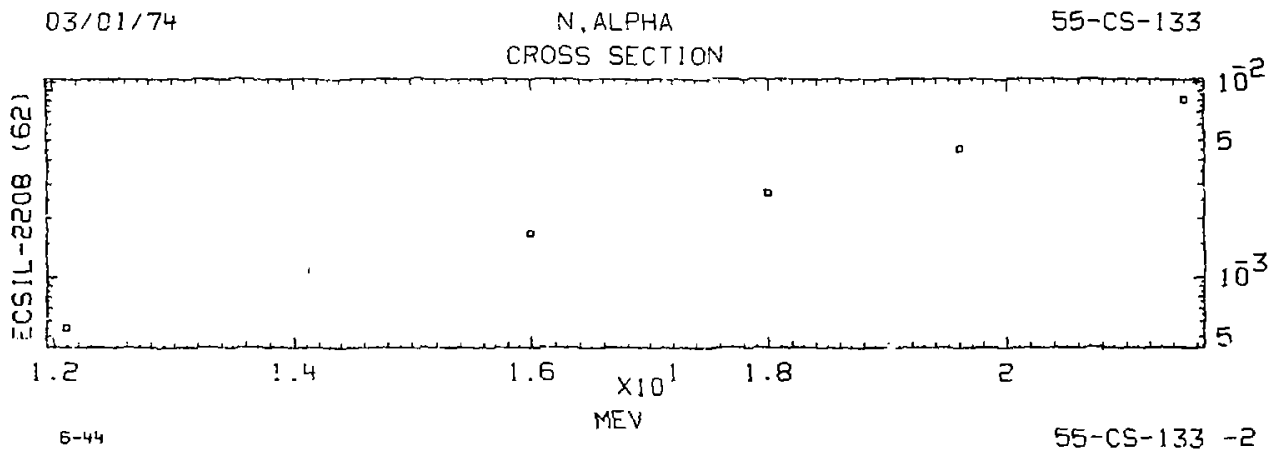

$\underset{0}{\frac{w}{2}}$ 
CROSS SECTION

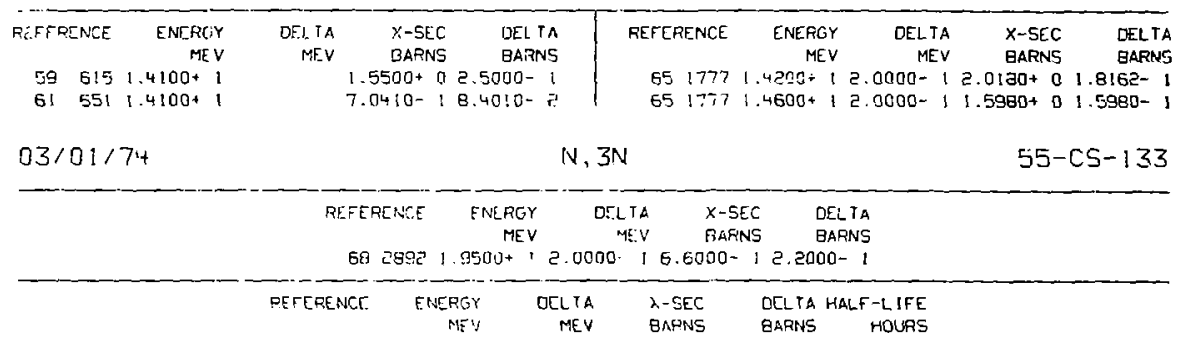

$671893,9500+12.0000-16.5000-12.2000-19.9600+$

03/01/74 ABSORPTION

$58+162$ 2.5300- 9

$55-\operatorname{cs}-133$

$03 / 01 / 74$

$N, H E-3$ $2.8000+1.0000+0$

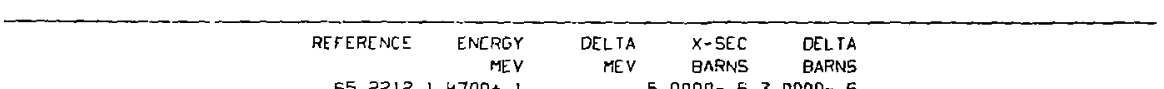

$6522121.4700+1$ $5.0000-53.0000-6$

\begin{tabular}{|c|c|c|c|c|c|c|}
\hline $1 ; 3 / 0: 174$ & & & & $\checkmark, A L P H A$ & & \\
\hline & RETER & ENTE & ENERGY & DELTA & $x-5 E 0$ & DELTA. \\
\hline & & & MEV & MEV & BARNS & BARNS \\
\hline & $5 \theta$ & 401 & $1.4050+1$ & $5.5000-1$ & $1.0000-3$ & $33.0000-4$ \\
\hline & 59 & 550 & $1.4500+1$ & & $1.9000-3$ & $32.0000-4$ \\
\hline & 63 & 756 & $1.48000+1$ & $2.0000-1$ & $1.0000-3$ & $39.0010-4$ \\
\hline
\end{tabular}




\section{$03 / 01 / 74$

$\begin{array}{rrrrr}\text { HLFERENCE } & \text { ENERGY } & \text { DELTA } & \text { X-5EC } & \text { DELTA } \\ & \text { MEV } & \text { MEV } & \text { GARNS } & \text { BARNS } \\ 51: 584 & 7.3000-8 & B & 7.0000+ & 0\end{array}$

$03 / 0: / 74$

COHERENT SCATIERING

$55-$ CS -133

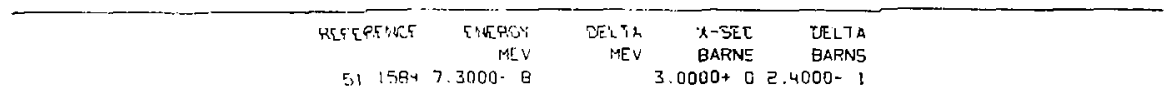

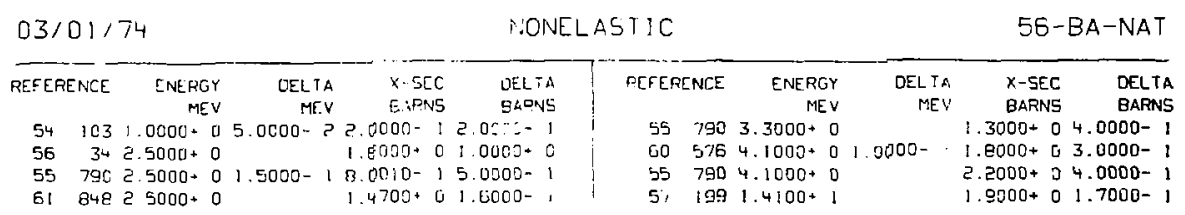

\begin{tabular}{|c|c|c|c|c|c|c|c|c|c|c|c|}
\hline \multicolumn{3}{|c|}{$03 / 01,-4$} & \multicolumn{4}{|c|}{$N, N^{\prime}$} & & \multicolumn{3}{|c|}{$56-B A-N A T$} & \multirow[b]{2}{*}{$E-L V L$} \\
\hline REFERENCE & ENERGY & OFITA & $\times$ SLC & DELTA & $E L V L$ & REFE RENCL & ENERGY & DELTA & $x-5 E C$ & DELTA & \\
\hline 63 อ2e & $\begin{array}{r}\text { MEV } \\
6.0000-1\end{array}$ & MEV & $\begin{array}{r}\text { BAFNNS } \\
\text { E. دO00- । }\end{array}$ & BARNS & $5 \quad$ MEV & bs 828 & $\begin{array}{r}\text { MEV } \\
\text { 8. COOD- } 1\end{array}$ & FEV & $\begin{array}{r}\text { BARNS } \\
2.5000-1\end{array}$ & BARNS & G.6000- 1 \\
\hline $638 c$ & B.0000- 1 & & $3.0000-1$ & $1.5000-1$ & $14.9000-1$ & $63 \quad 828$ & $1.0000+0$ & & $3.0000-1$ & $1.5000-1$ & $6.6000=1$ \\
\hline $63 \mathrm{Eag}$ & $1.0000+0$ & & $2.0000-1$ & $1.0000-1$ & $1+.9000 \% 1$ & Gj B2P & $1.2000+0$ & & $1.5000-1$ & $1.0000-1$ & $1.0400+0$ \\
\hline
\end{tabular}

03/01/74

$606721.4800+18.0010-19.4010$ \% 8.0010- 2 


$\mathrm{J} / 01 / 74$
CROSS SECT JON

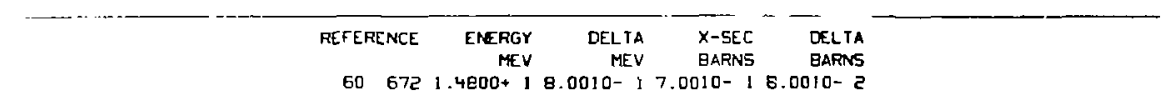

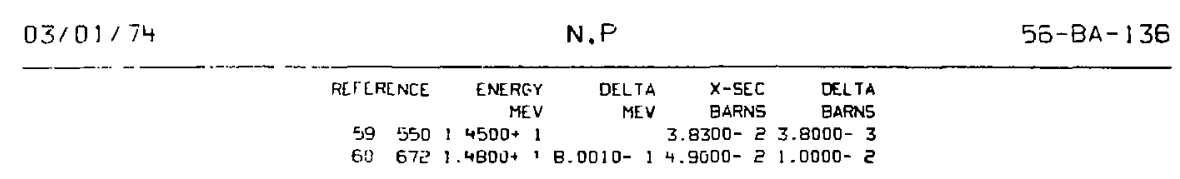

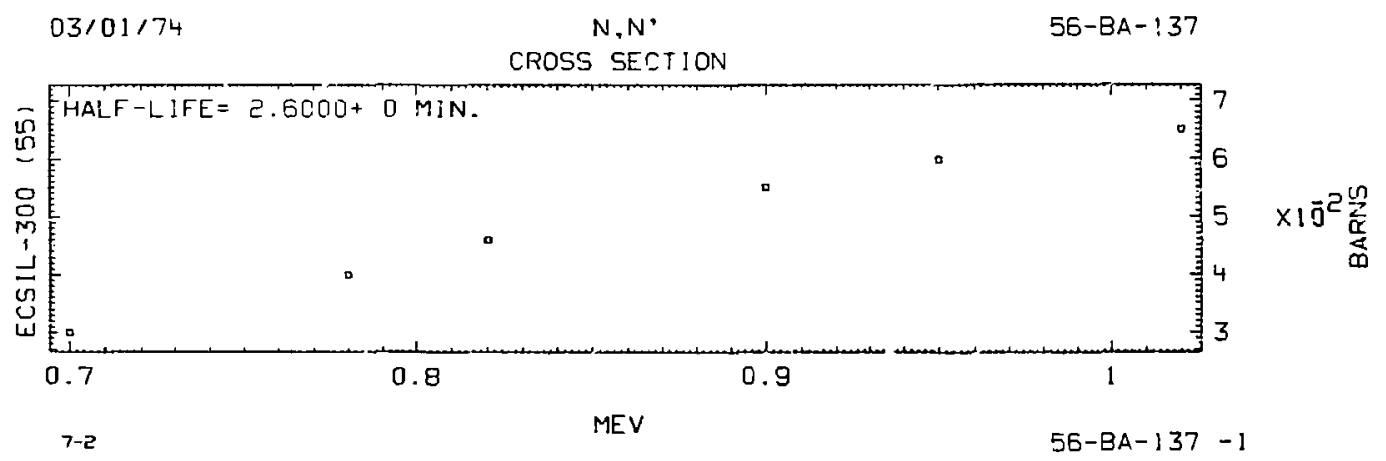




\section{CROSS SECTISRI}

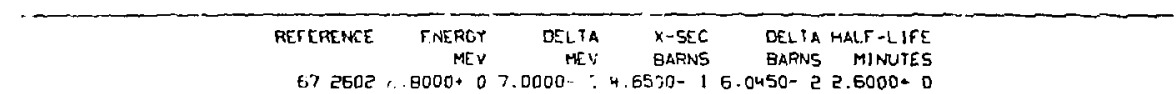

\section{CROSS SECTION}
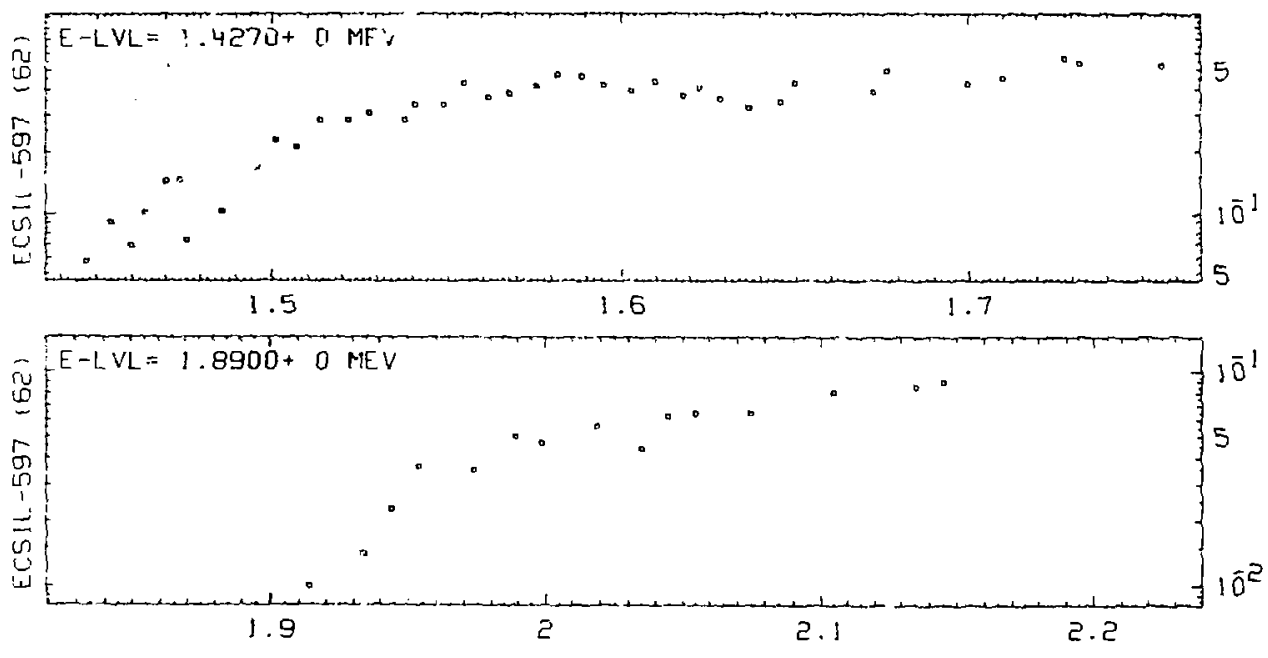

$7-3$ 


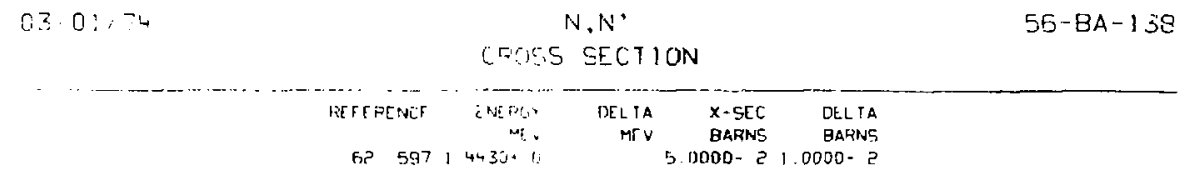

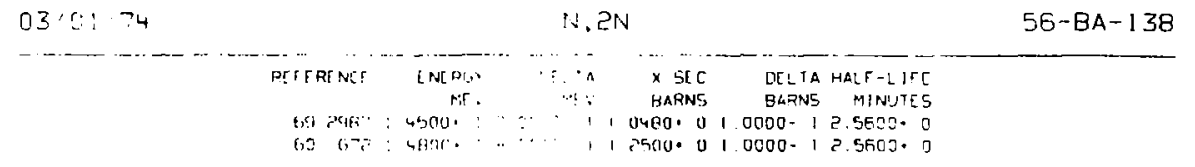

\begin{tabular}{|c|c|c|c|c|c|c|c|c|c|c|}
\hline $03 / 0 i$ & & & & & V.P & & & & $56-$ & $-B A-138$ \\
\hline Derear Nes & $\begin{array}{r}\text { ENERG } \\
\text { MEV }\end{array}$ & $\begin{array}{l}\text { DE IIA } \\
\text { MIV }\end{array}$ & $\begin{array}{l}\therefore \text { SEC } \\
\text { BARNS }\end{array}$ & $\Xi 40$ & & RF $\#$ I SFENCF. & $\begin{array}{r}\text { ENEPG } \\
\text { S: }\end{array}$ & 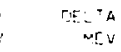 & $\begin{array}{l}x-S E C \\
\text { BARNSS }\end{array}$ & $\begin{array}{l}\text { DELTAA } \\
\text { DARNS }\end{array}$ \\
\hline $63 \quad 223$ & $4000+:$ & & $19300 \cdot 3$ & $=2800$ & $\therefore$ & "? & (. $453 c \cdot 1$ & & $5.50: 0-3$ & $2.2000-3$ \\
\hline 5956 & $-550+1$ & & $\therefore c>00 \quad \overrightarrow{3}$ & s. & . & tig 672 & 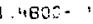 & 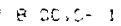 & $2.5000-3$ & $31.0000-3$ \\
\hline
\end{tabular}

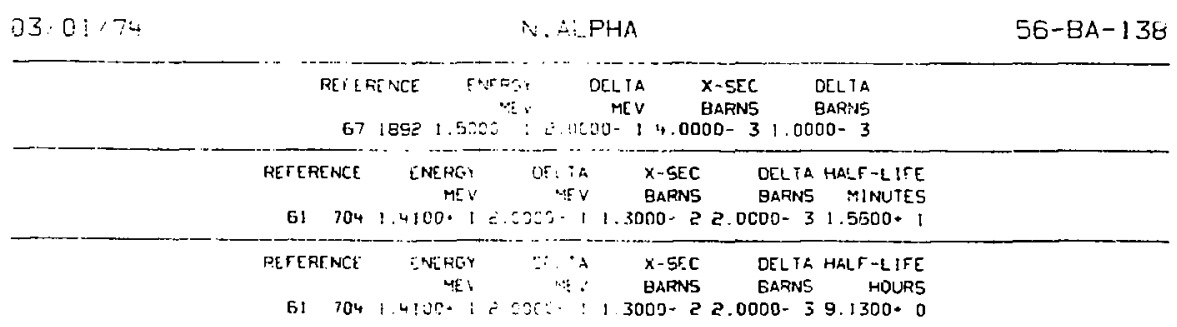




$$
[3 / 01: 74
$$

TOTAL SCATTERING

57-LA-NAT

CROSS SECTION

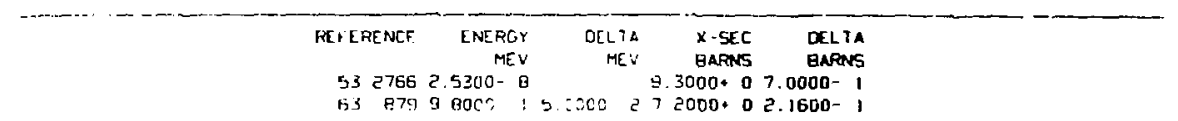

$$
05 / 0: 74
$$

N. i

57-LA-NAT

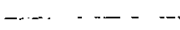

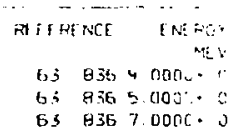

- r.

E: -

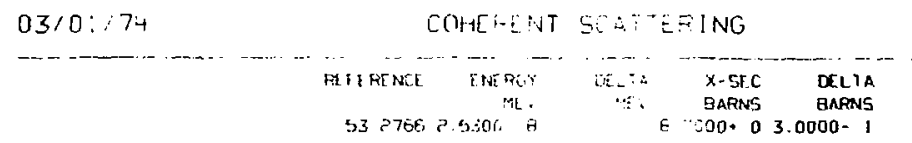

57-LA-NAT

53 2706, a.s.30\% E $=00 * 0$ 3.0000-1

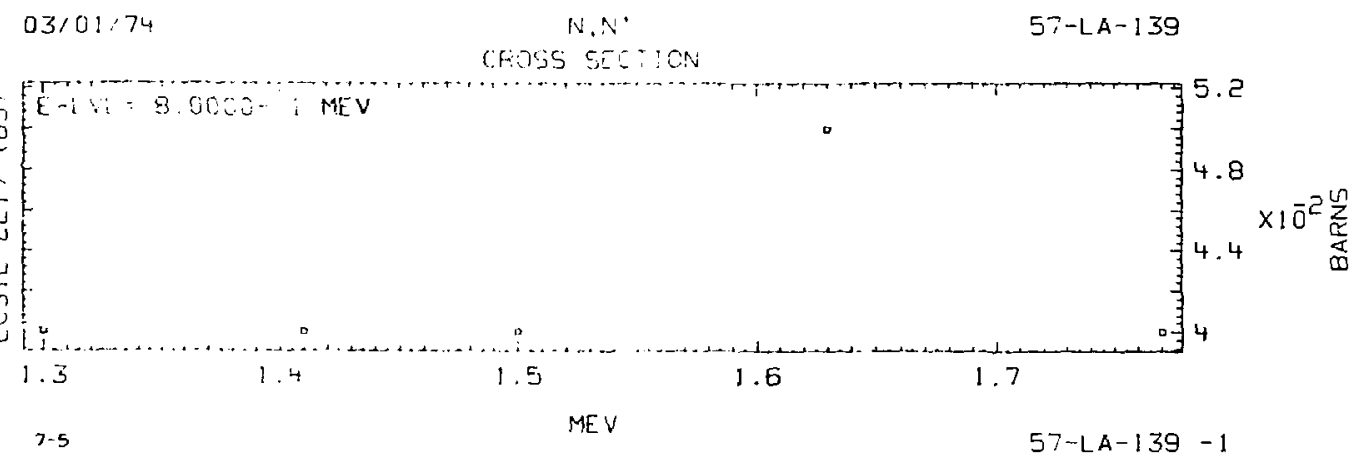




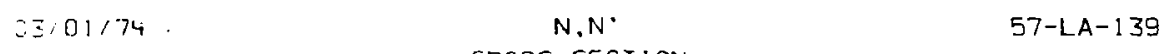

\section{CROSS SECTION}

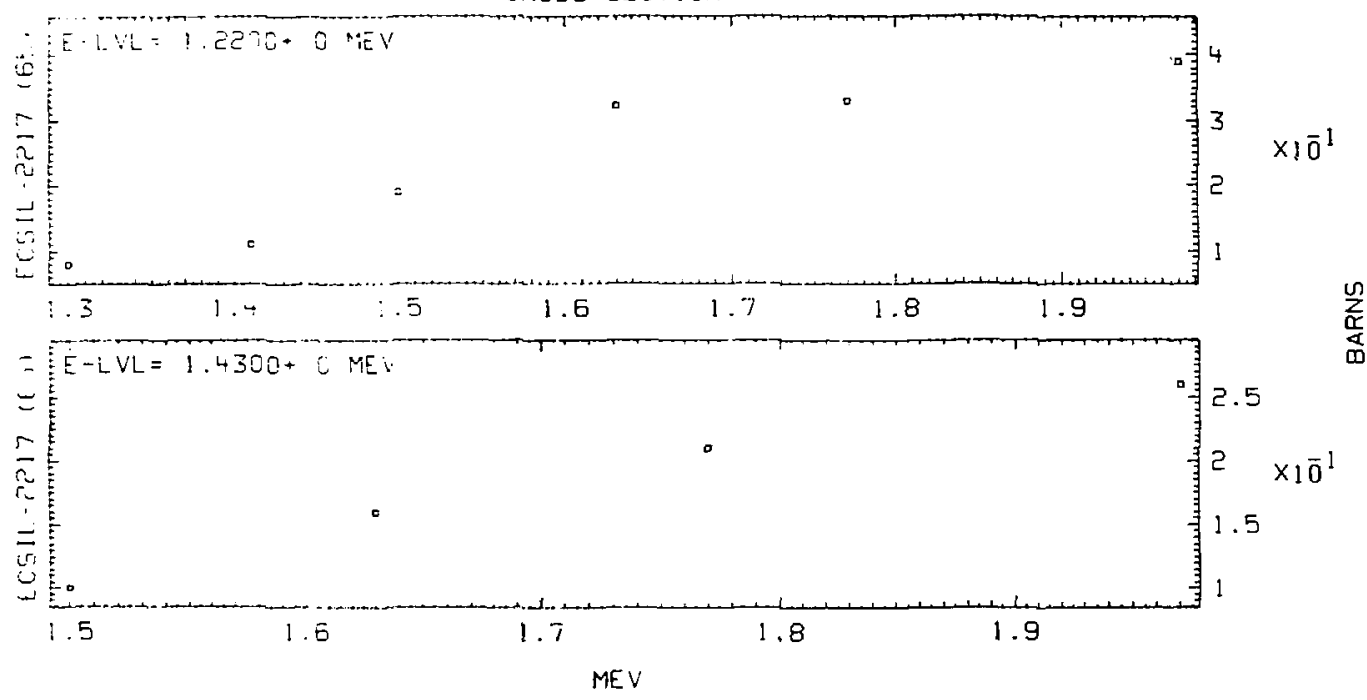

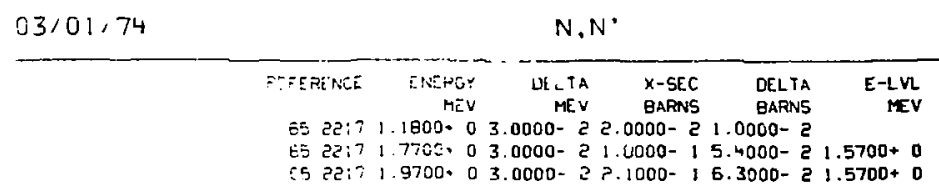


CROSS SECTION

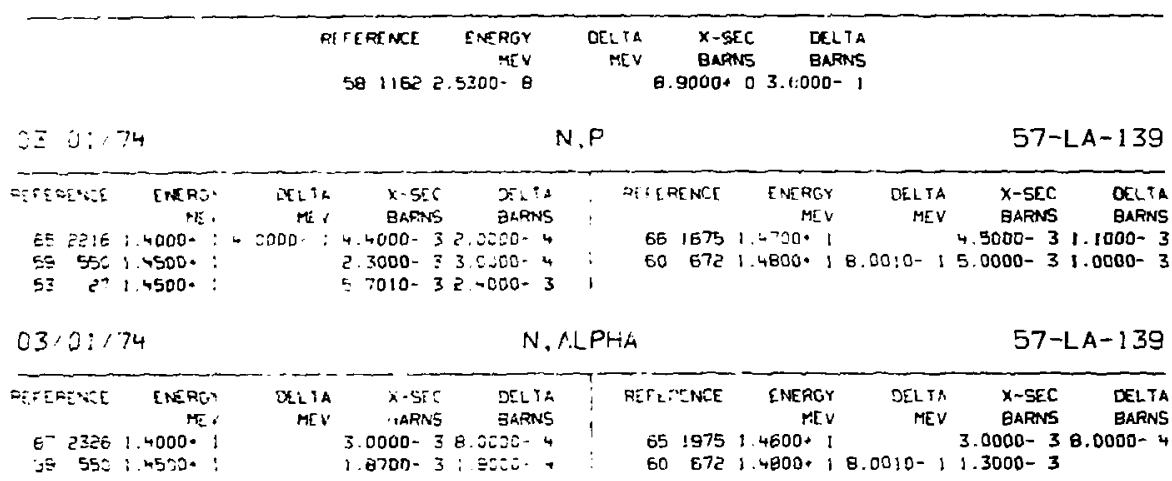

OZ.0:174

$54.031 .0000 .05 .0000-1.0000-11.0000-1$

$67.0551 .4802 \cdot 15.0000-\div 2.4400+06.0000-2$

63:ŨI/74

$638799.6000-15.0600-26.8500+02.0550-1$ 


\section{CFOSS SECTION}

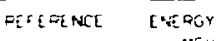

$\begin{array}{rrr}\text { DELTA } & \text { X-SEC } & \text { DELTA } \\ \text { MEV } & \text { BARNS } & \text { BARNS } \\ \text { E.5000*0 } & 5.7000-1\end{array}$

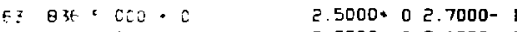

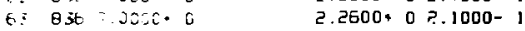

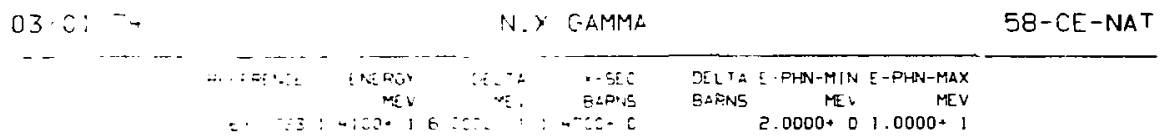

03/0: -4 COHIERENT SCATIERING

53 द.56 z.5300- $\quad$ z.7000+ 0 z.0000- 1

03/01/74

E9 28371.4400 । 3.2000- 1.3530 - 0 


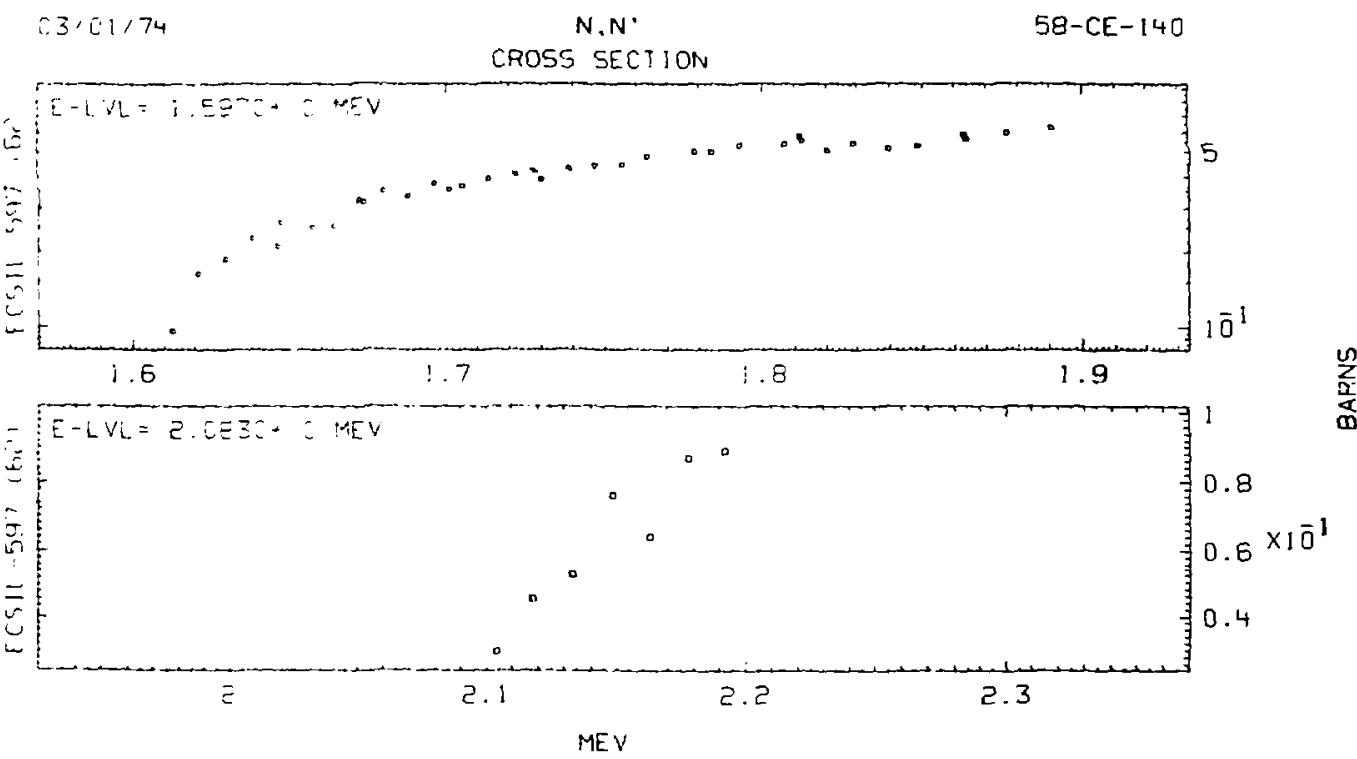



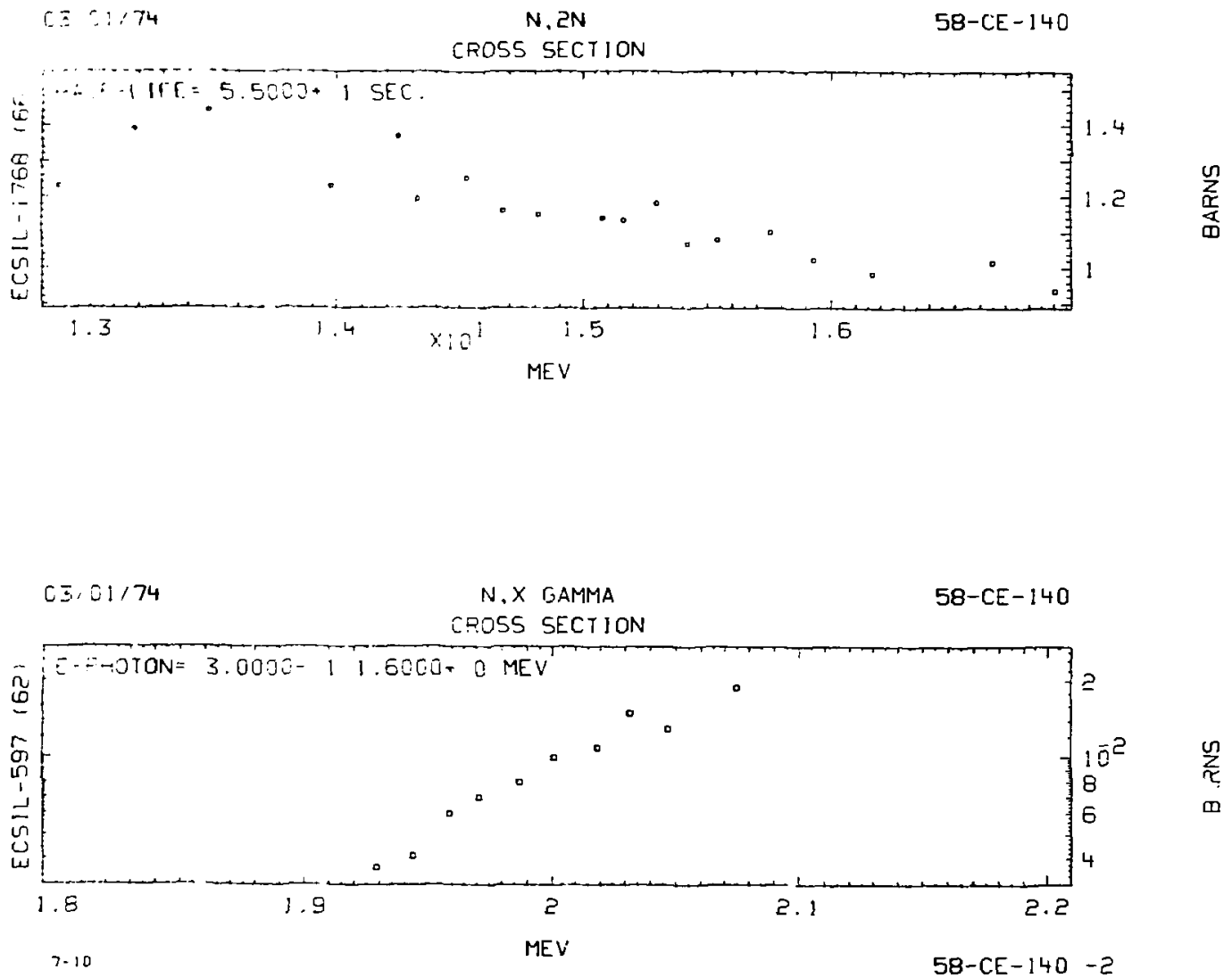


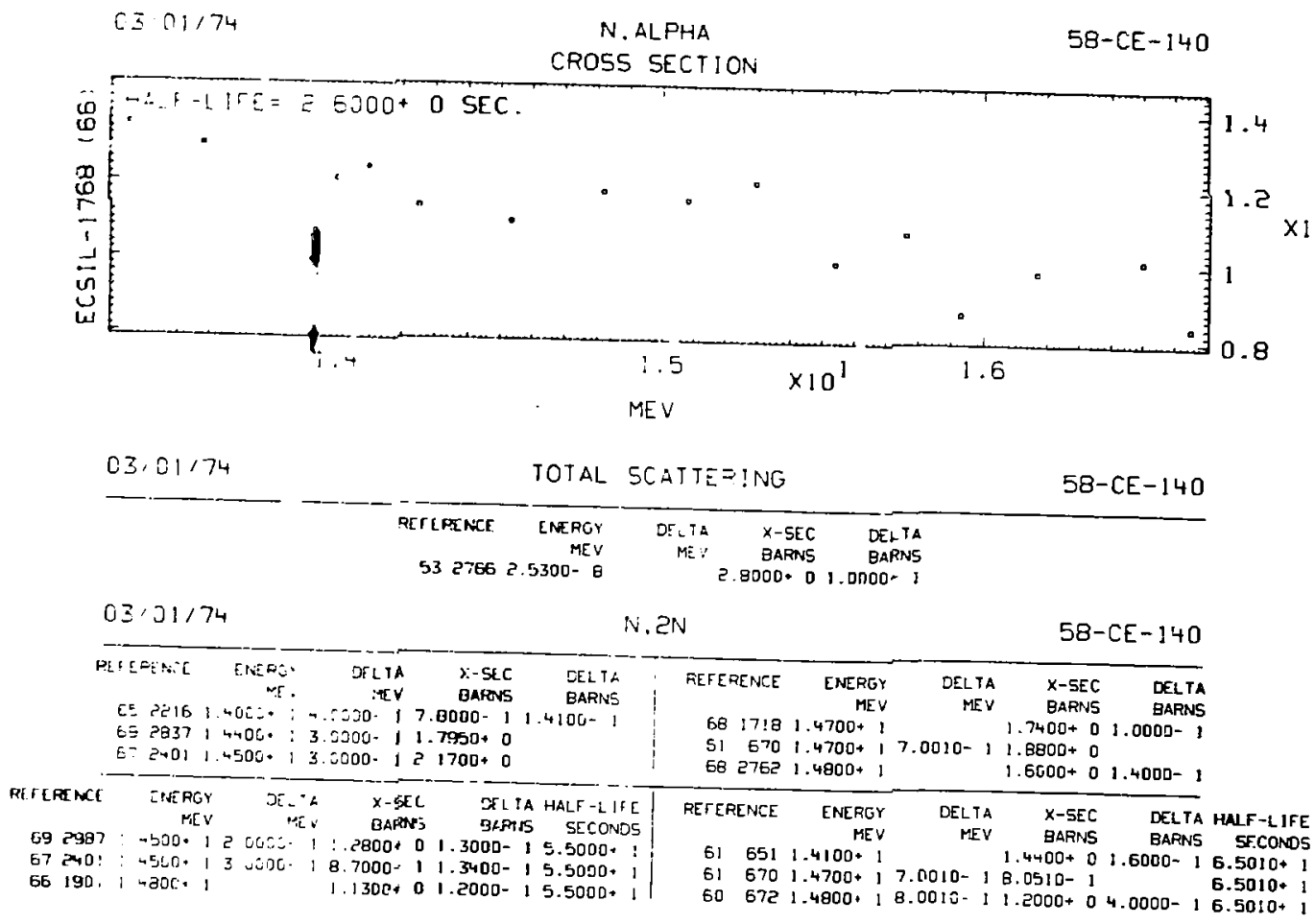


CROSS SECTION

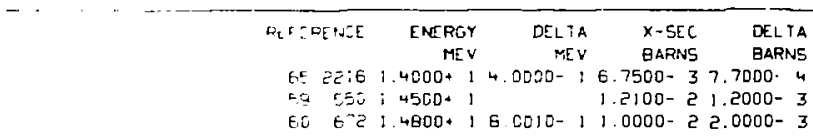

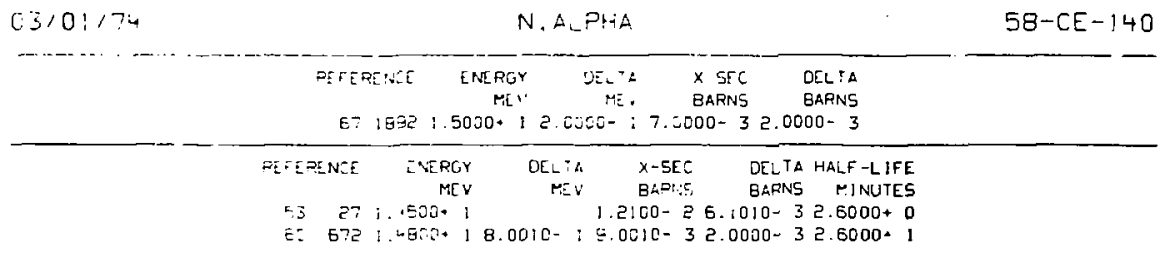

03101/74 COHERENT SCATTERING

53 2ᄀEE Z. $3300-8$ 2. $8000+01.0000-1$

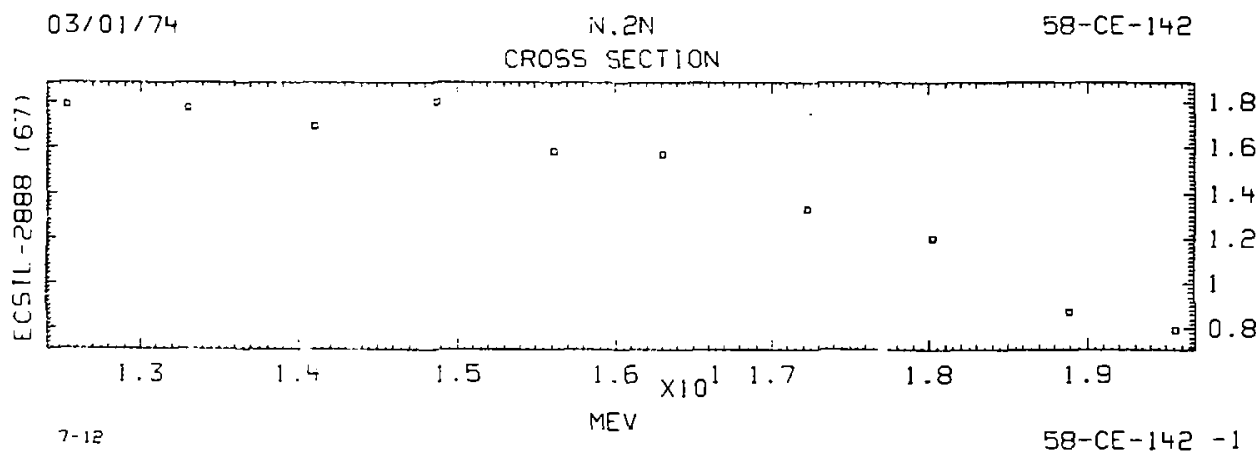




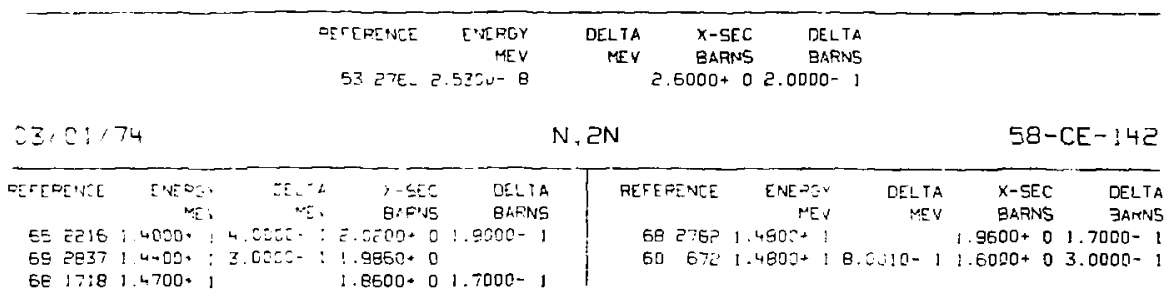

D3/01/74

$595261.4500+14.0000-1$ 1.0000- $32.0000-4$

$03 / 01,74$
PEFERENCE

\begin{tabular}{|c|c|c|c|c|c|c|}
\hline $03 / 01 / 74$ & & & V. ALPHA & & & $5 S-C E-142$ \\
\hline & PEFEREMCE & $\begin{array}{r}\text { ENERGY } \\
\text { MEV }\end{array}$ & $\begin{array}{r}\text { DELTA } \\
\text { MEV }\end{array}$ & $\begin{array}{l}X \text {-SEC } \\
\text { BARNS }\end{array}$ & $\begin{array}{l}\text { DELTA } \\
\text { BARNS }\end{array}$ & \\
\hline & $\begin{array}{rr}55 & 2216 \\
59 & 550 \\
60 & 672\end{array}$ & $\begin{array}{l}1.4000+1 \\
1.4500+1 \\
1.4800+1\end{array}$ & $\begin{array}{l}4.0000-1 \\
8.0010-1\end{array}$ & $\begin{array}{l}5.2000-3 \\
7.0010-3 \\
0.0010-3\end{array}$ & $\begin{array}{l}8.0000-4 \\
1.0000-3 \\
2.0000-3\end{array}$ & \\
\hline
\end{tabular}


CROSS SECTION

\begin{tabular}{|c|c|c|c|c|}
\hline$R E F[R E N C E$ & $\begin{array}{r}\text { ENERGY } \\
\text { MEV }\end{array}$ & $\begin{array}{r}\text { DEL.TA } \\
\text { HEV }\end{array}$ & $\begin{array}{l}\lambda+\text { SEC } \\
\text { BARN }\end{array}$ & $\begin{array}{l}\text { DELIA } \\
\text { BARNS }\end{array}$ \\
\hline
\end{tabular}

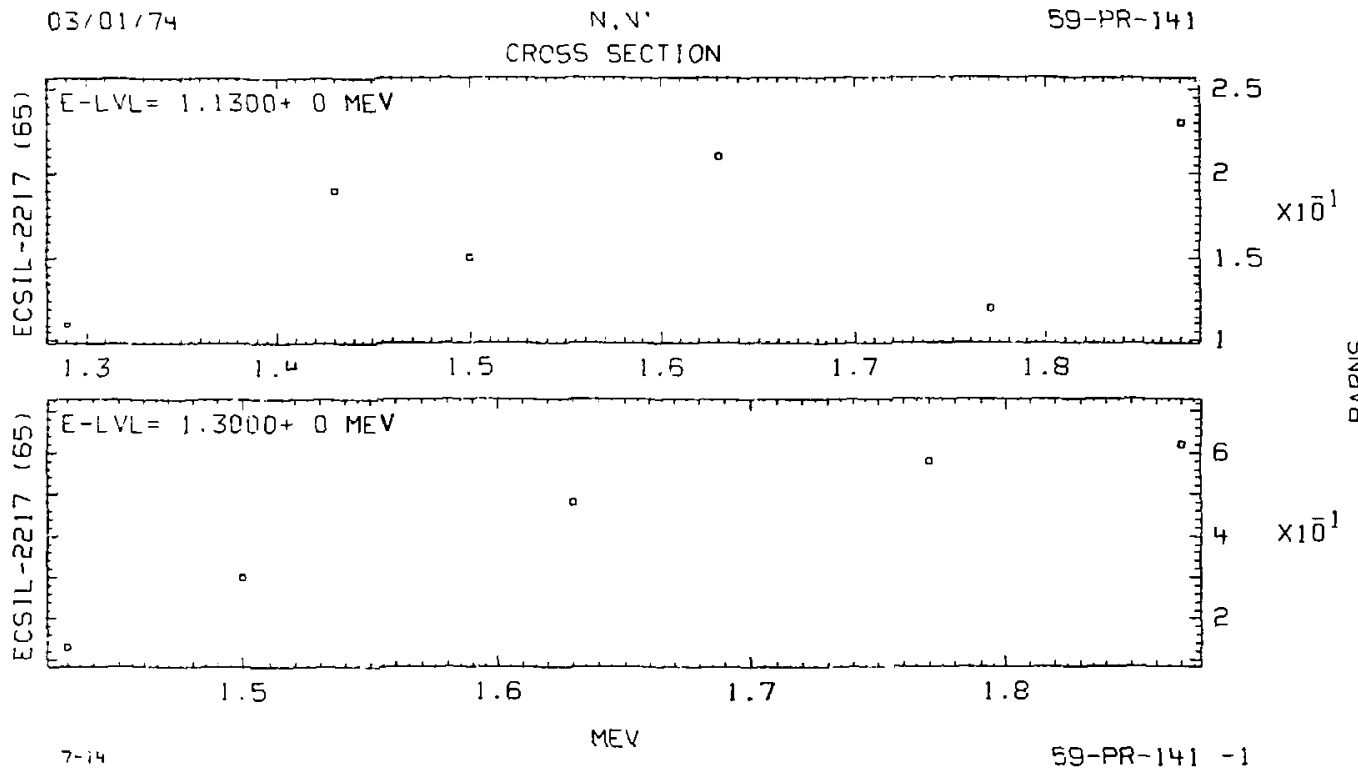



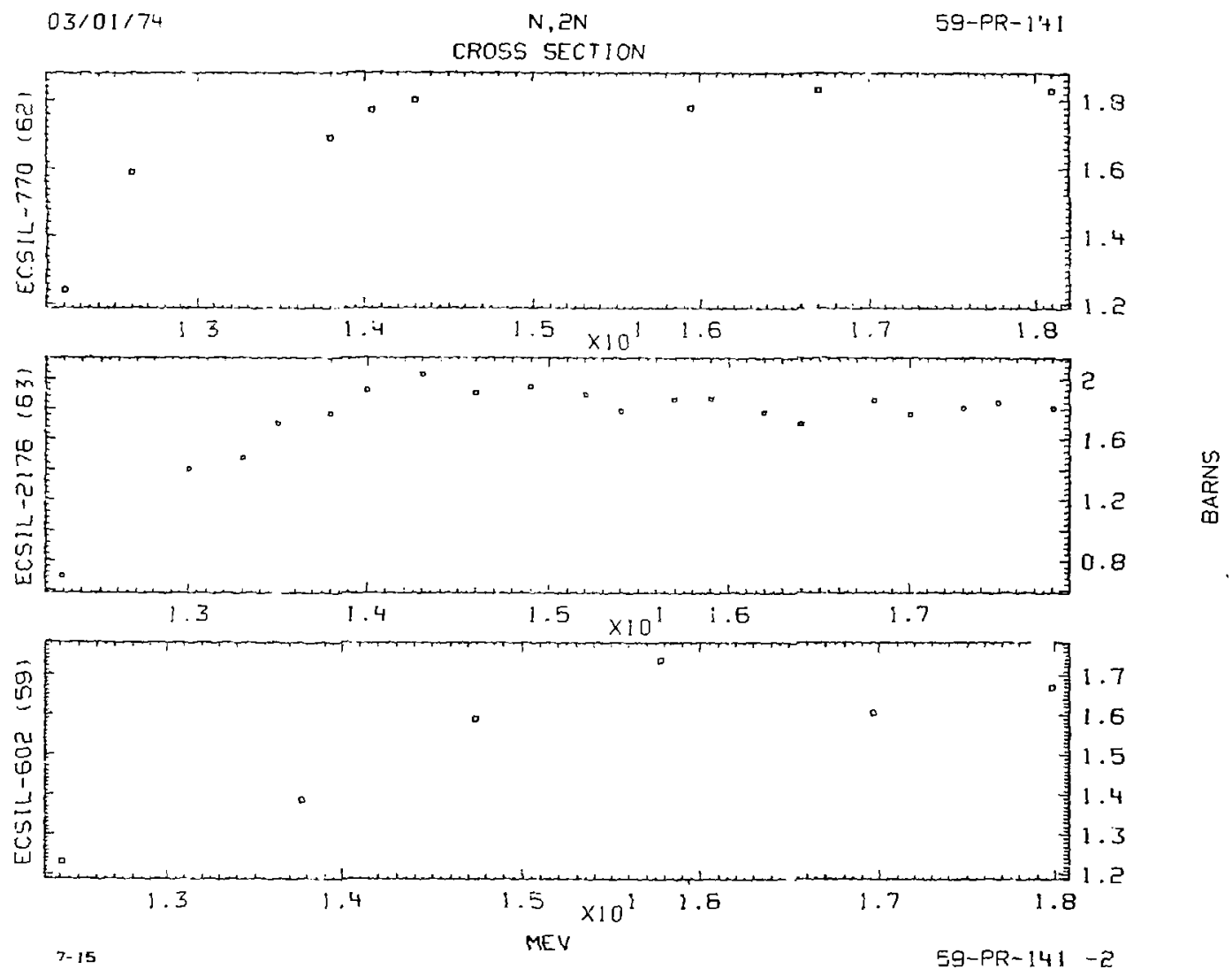

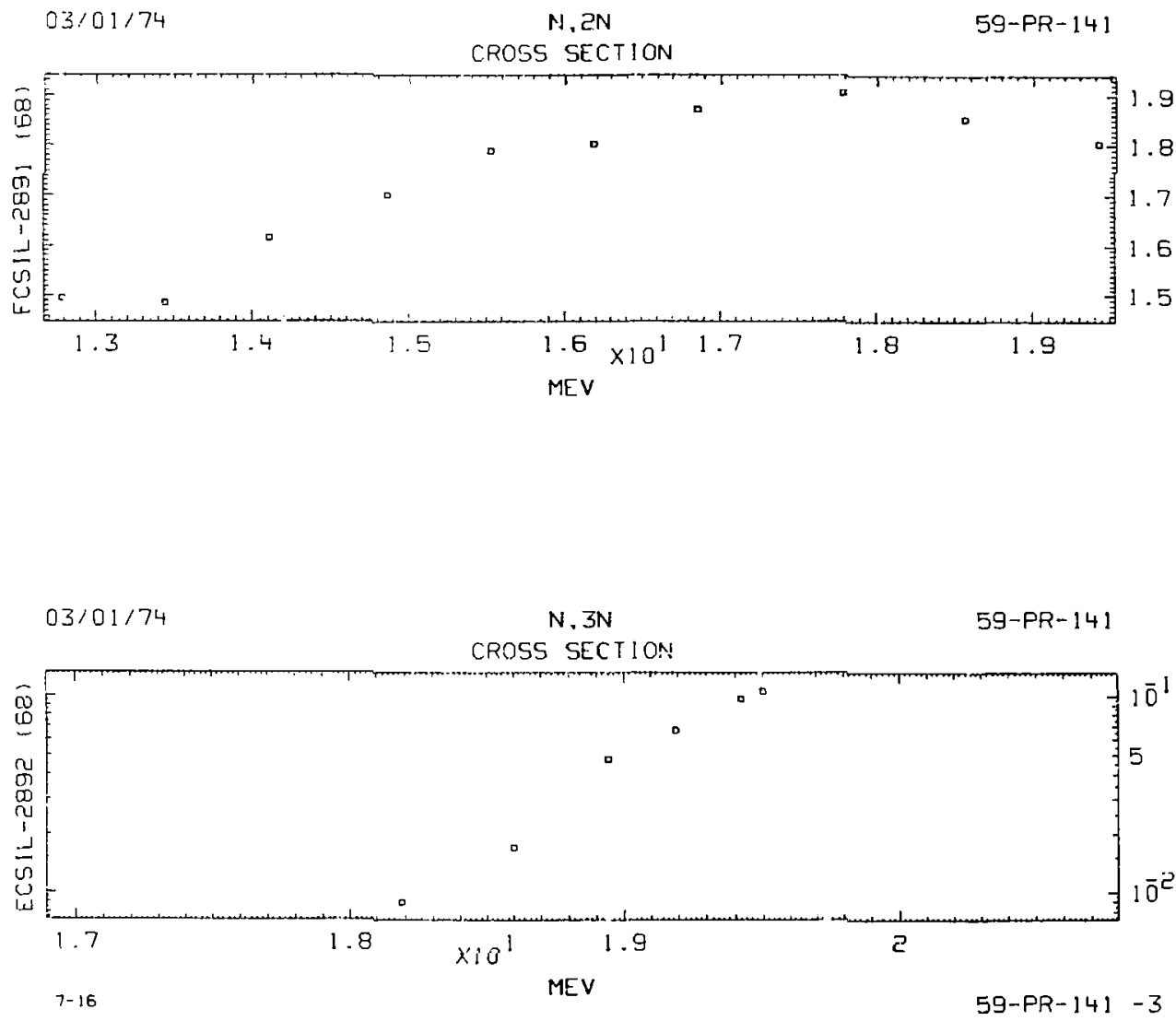


\section{CROSS SECTION}

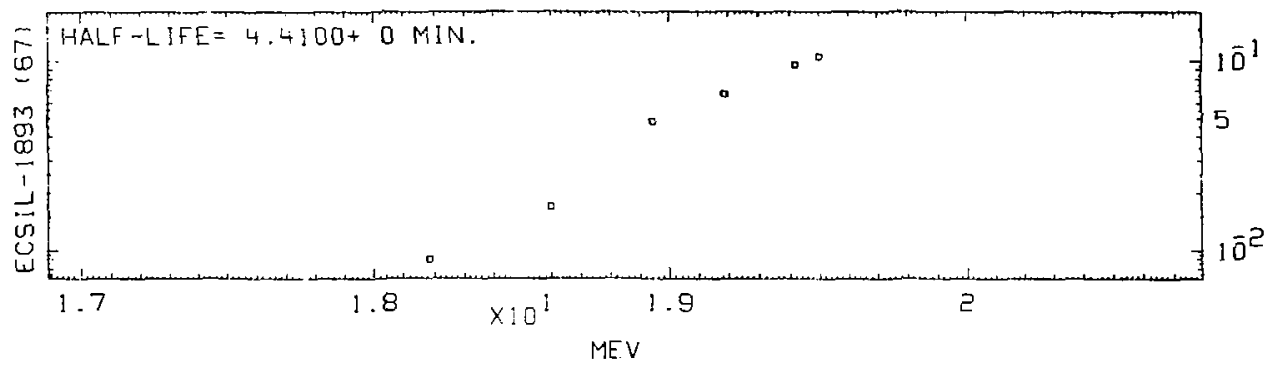

$\begin{array}{rrrrr}\text { REFERENCE } & \text { ENERGY } & \text { OELTA } & \text { x-SEC } & \text { DELTA } \\ & \text { MEV } & \text { MEV } & \text { BARNS } & \text { BARN5 } \\ 532766 & 2.5350-8 & & 4.0000+0 & 1.0000+0\end{array}$

$638799.8005-15.0000 \quad 0.0300+02.0490-1$

$03 / 01 / 74$

N. 己N

$59-P R-141$

\begin{tabular}{|c|c|c|c|c|c|c|c|c|c|c|c|c|c|c|}
\hline \multirow{2}{*}{\multicolumn{2}{|c|}{ REFERENCE }} & ENERGY & OELT & & $X$-SEC & DEL & & PEFEF & RENCE & ENER & & DÉL.?A & $X-5 E C$ & DELTA \\
\hline & & MEV & ME & & BARNS & BAR & & & & & EV & ME & BARNS & GARNS \\
\hline 62 & 100 & $1.4120 \cdot 1$ & $11.0000-$ & 1 & $1.2400+0$ & 7.4010 & 2 & GI & 703 & 1.4800 & 1 & $2.5000-1$ & $1.3780+$ & $02.0700-1$ \\
\hline G1 & G7E & $1.4400+1$ & $13.0000-$ & 1 & $1.8000+0$ & $1.40 \Omega 0$ & $:$ & 60 & Gle & 1.4800. & 1 & $8.0010 \cdot 1$ & $12.1000+0$ & $03.0000-1$ \\
\hline 60 & $6+7$ & $1.4400 * 1$ & 1 & & $1.50 \equiv 0+0$ & & & 60 & 2369 & 1.50004 & 1 & $3,0000-1$ & $12,0500+0$ & $01.8000-$; \\
\hline 67 & 2401 & $\therefore 4500 * 1$ & $13.0000-$ & 1 & $1.0820+0$ & $1.3000-$ & 1 & Go & 547 & $1.7500+$ & 1 & & $1.8850+0$ & 0 \\
\hline 53 & 27 & $1.4500 \cdot 1$ & & & $2.0500+0$ & $07.2010-$ & 1 & & & & & & & \\
\hline
\end{tabular}




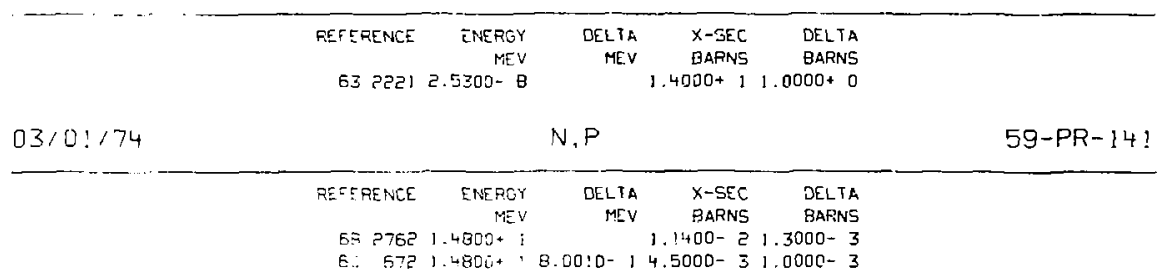

$03 / 01 / 74$

N. ALPHA

$59-P R-141$

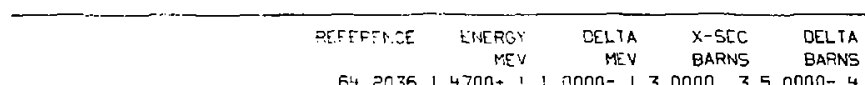

$03 / 01 / 74$ COHERENT SCATTER:NG

59-PR-141

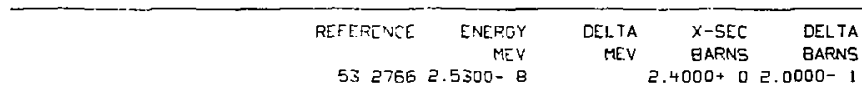

$03 ; 0 j / 74$

NONELASTIC

60-ND-NAT

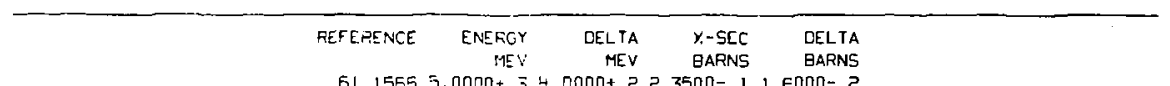

$6115655.0000+34.0000+22.3500-11.6000-2$

$03 / 01: 74$

TOTAL SCATTERING

60-ND-NA !

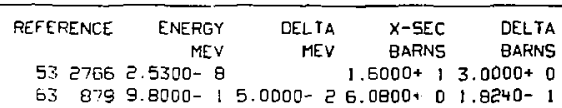




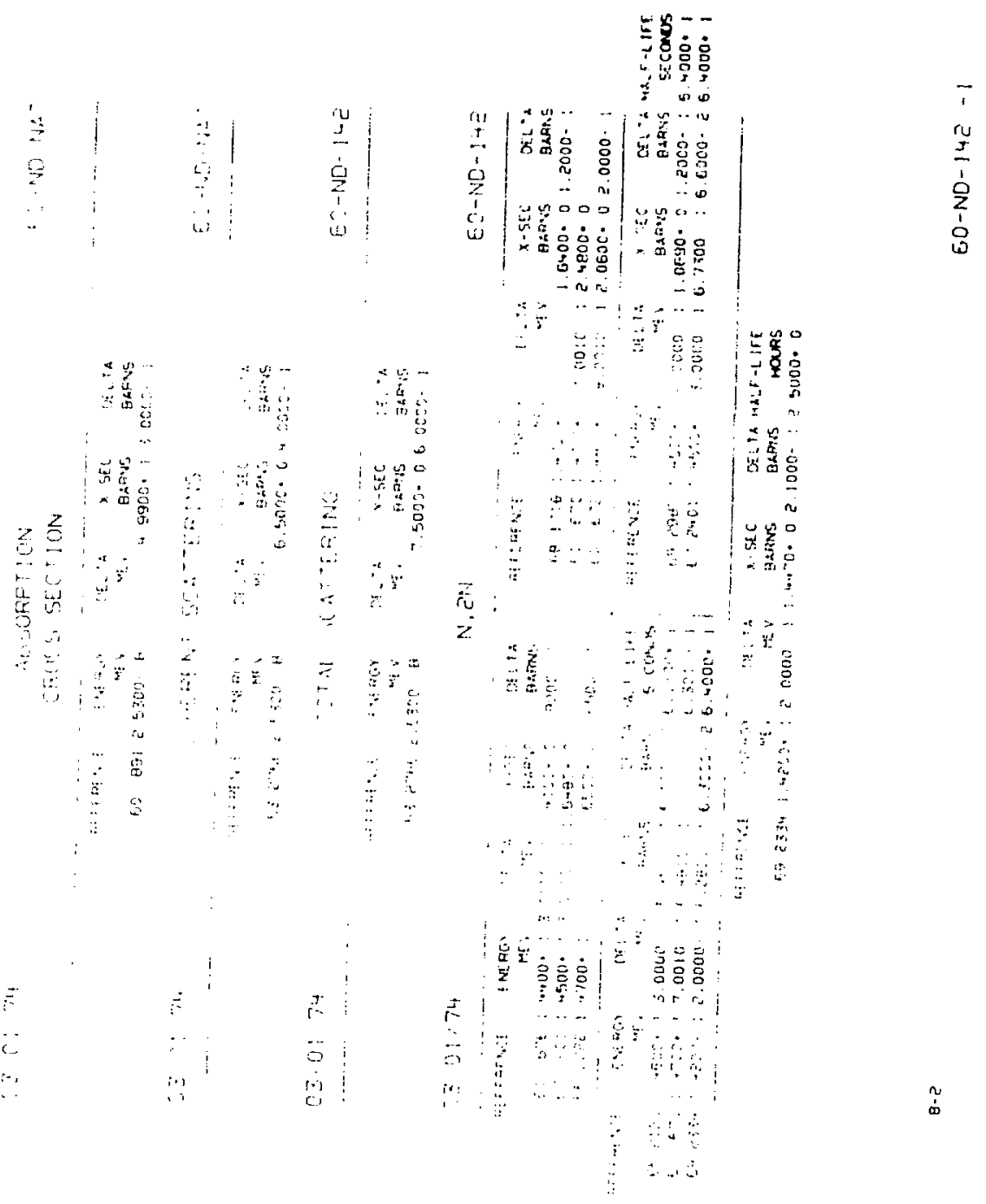




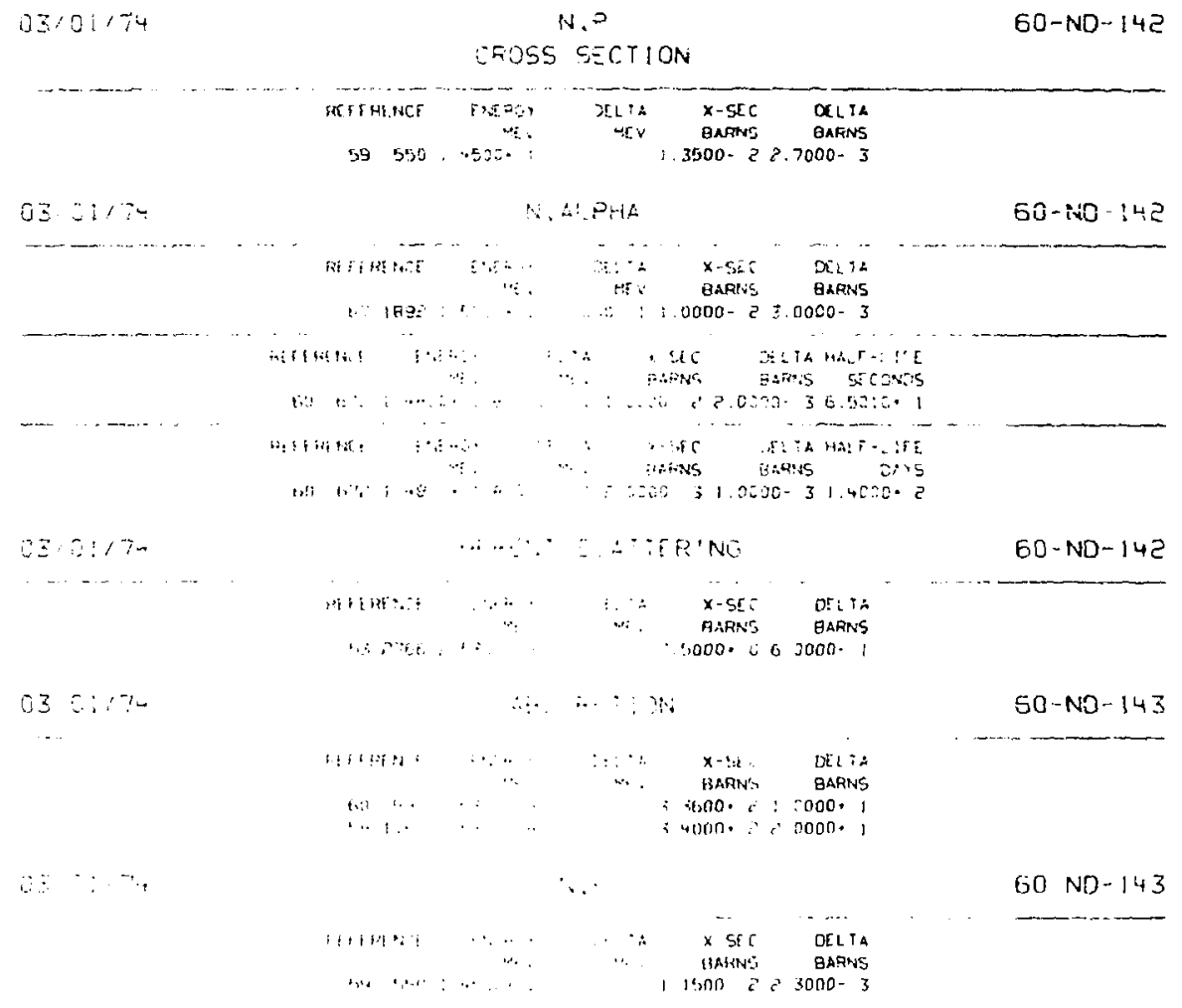




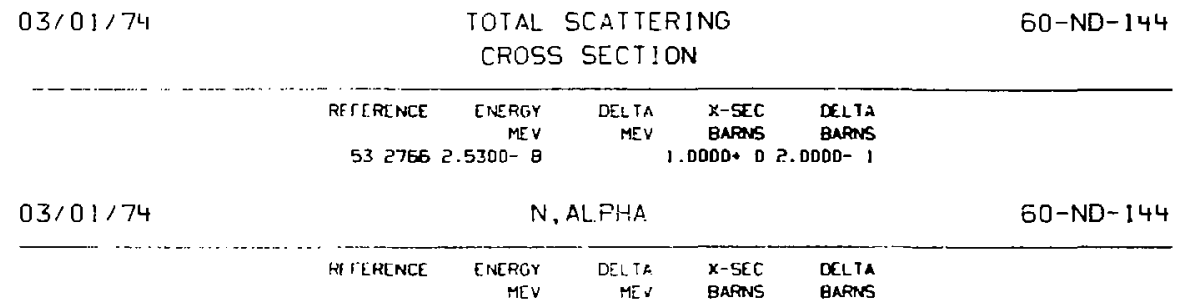

is $23341.4200 * 12.0000-19.0000-31.7000 \cdot 3$

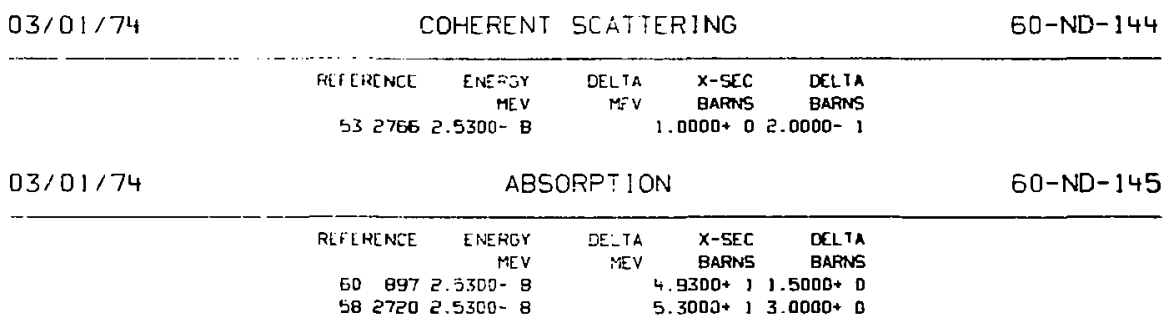

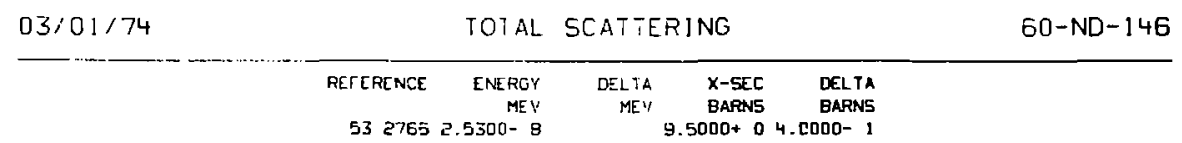

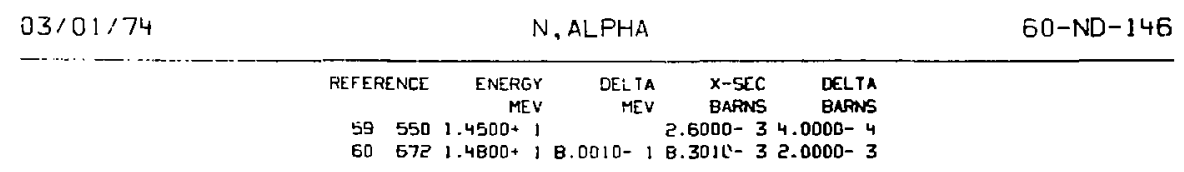

8-4 
$03 / 01 / 74$

CROSS SECTION

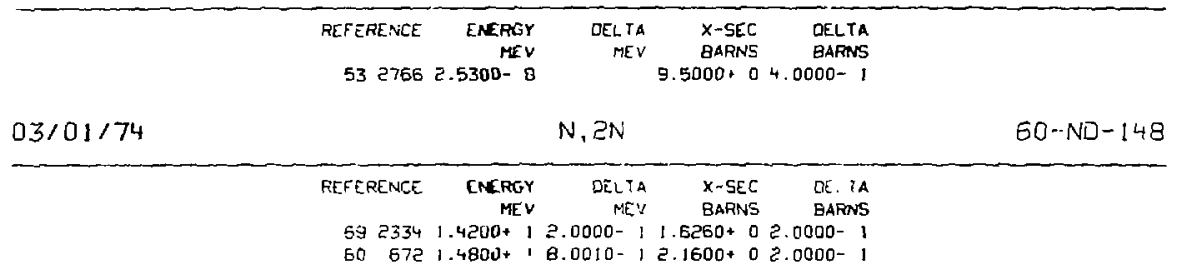

03101774

50 F.? $1.4800+18.00: 0-13.5000-38.0010-4$

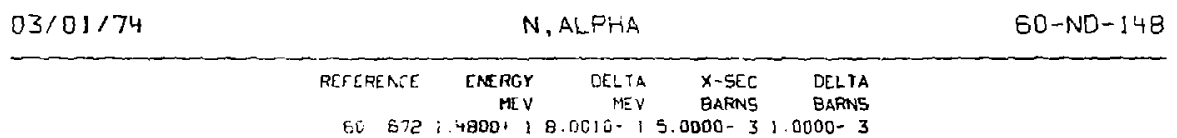

$03,01 / 74$

$N, 2 N$

$60-N D-150$

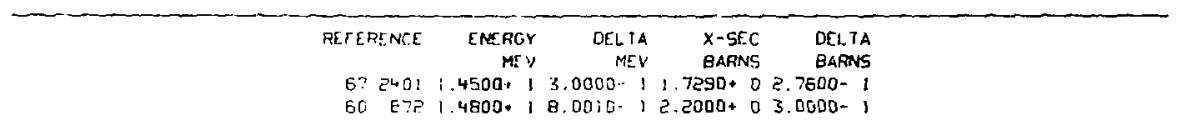

$03 / 01 / 74$

ABSORPTION

61-PM-147

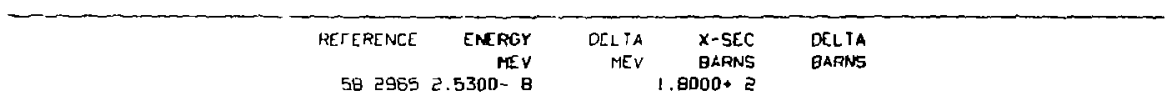



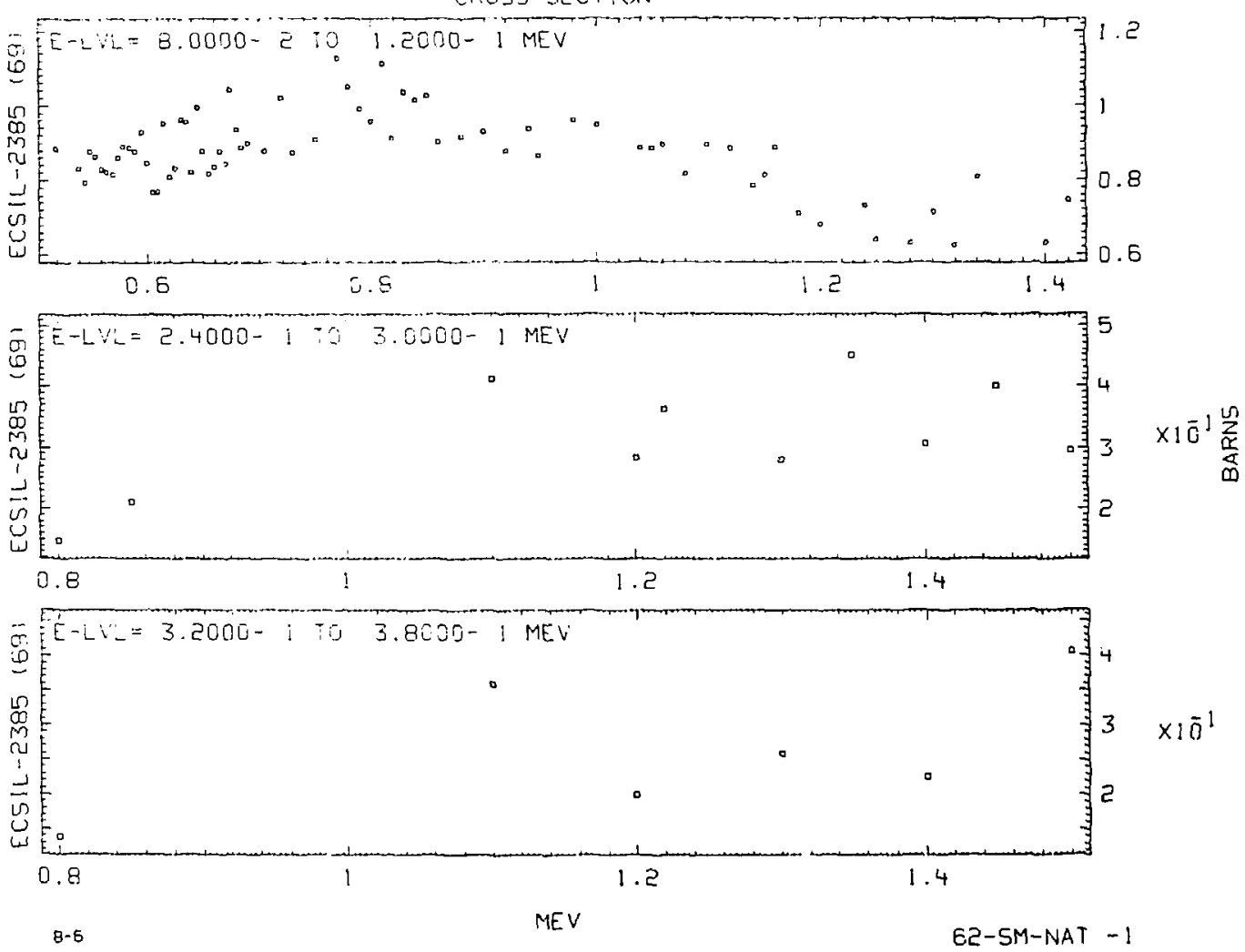

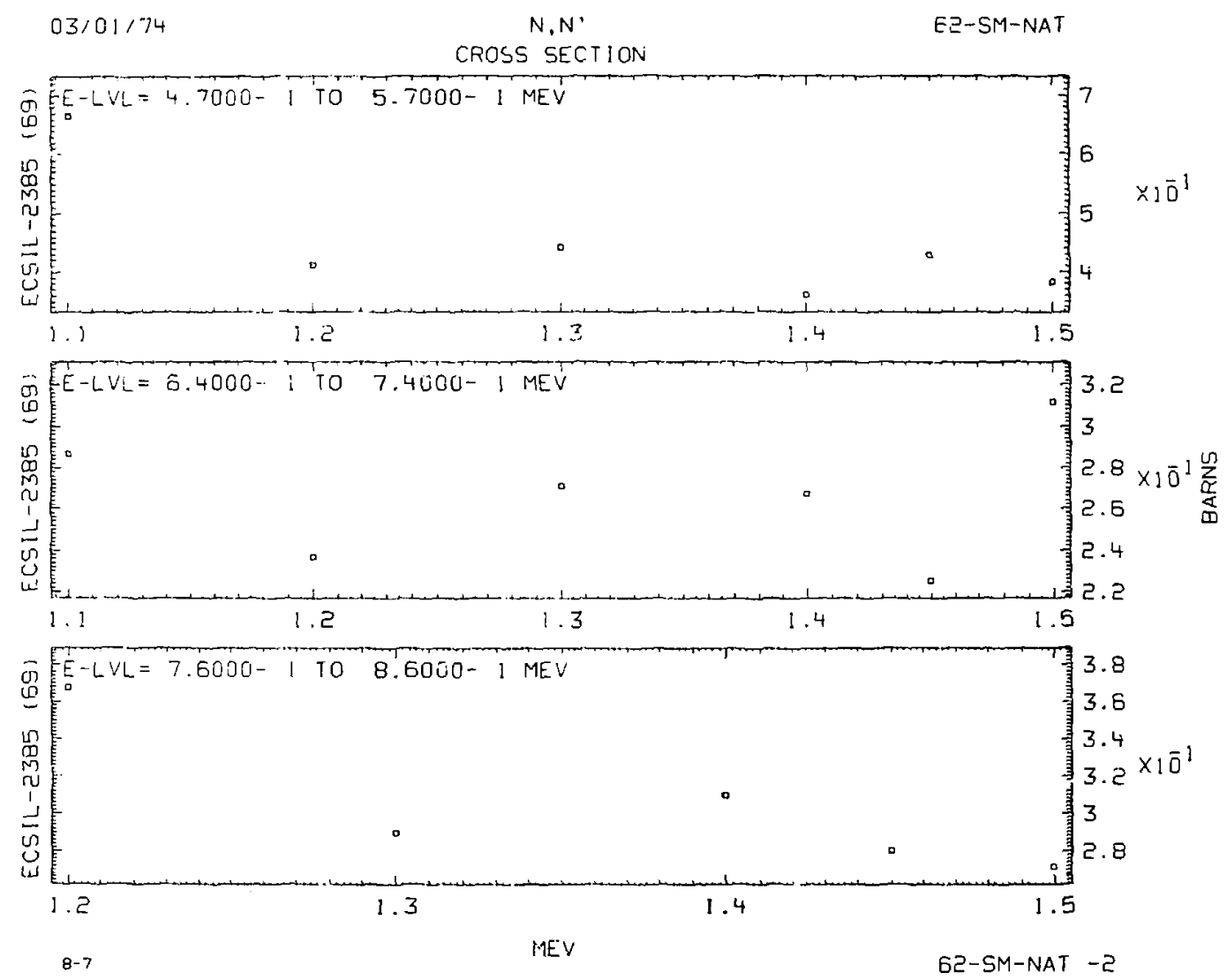


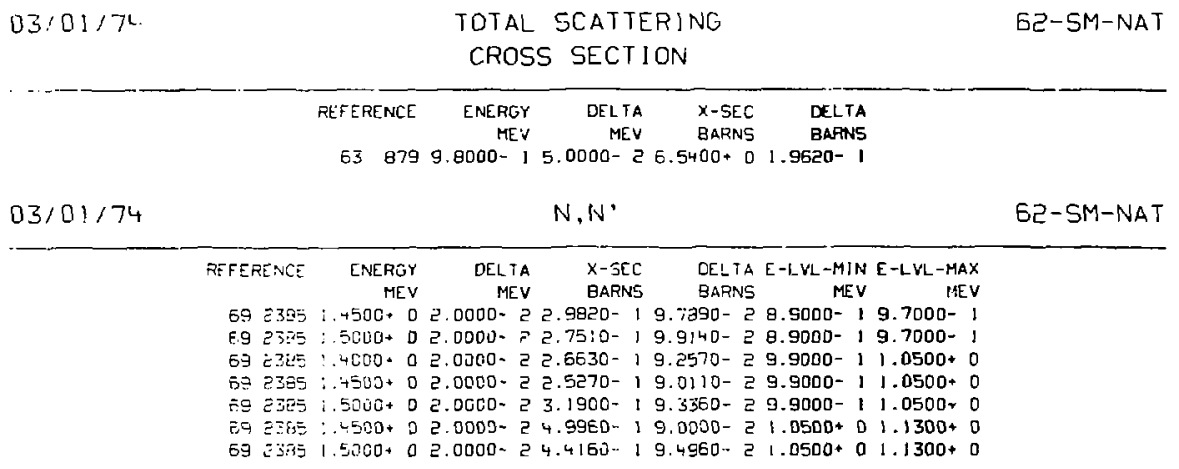

$03 / 01 / 74$ ABSORPT $10 N$

ED-SM-NAT

\begin{tabular}{|c|c|c|c|c|}
\hline PEF ERENCE & $\begin{array}{r}\text { ENERGY } \\
\text { MEV }\end{array}$ & OELTA & $\begin{array}{l}x-\text { SEC } \\
\text { BARNS }\end{array}$ & $\begin{array}{l}\text { OELTA } \\
\text { BARNS }\end{array}$ \\
\hline $\begin{array}{rr}58 & 1162 \\
60 & 891\end{array}$ & $\begin{array}{l}2.5300-8 \\
2.5300-B\end{array}$ & & $\begin{array}{l}5.8100+3 \\
5.8200+3\end{array}$ & $\begin{array}{l}8.0000+1 \\
3.0000+1\end{array}$ \\
\hline
\end{tabular}

$03 / 01 / 74$

$N, 2 N$

$62-5 M-144$

CROSS SECTION

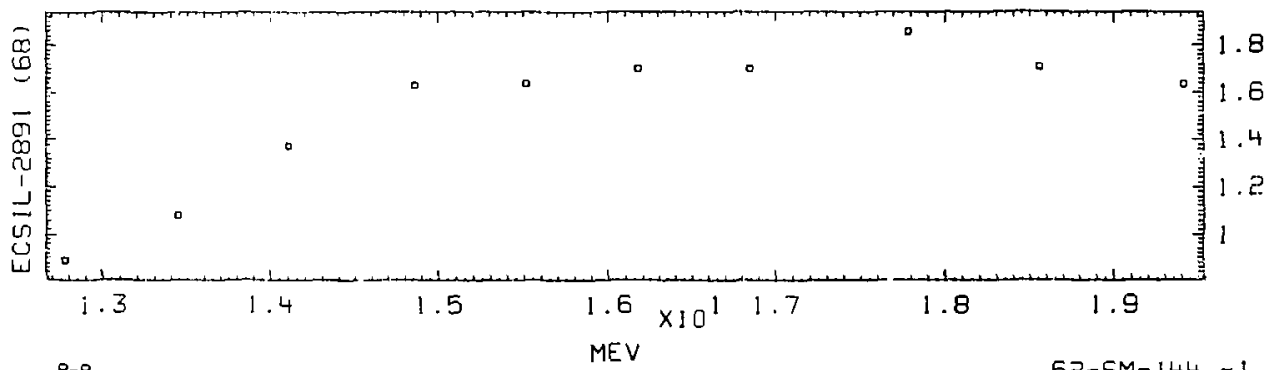




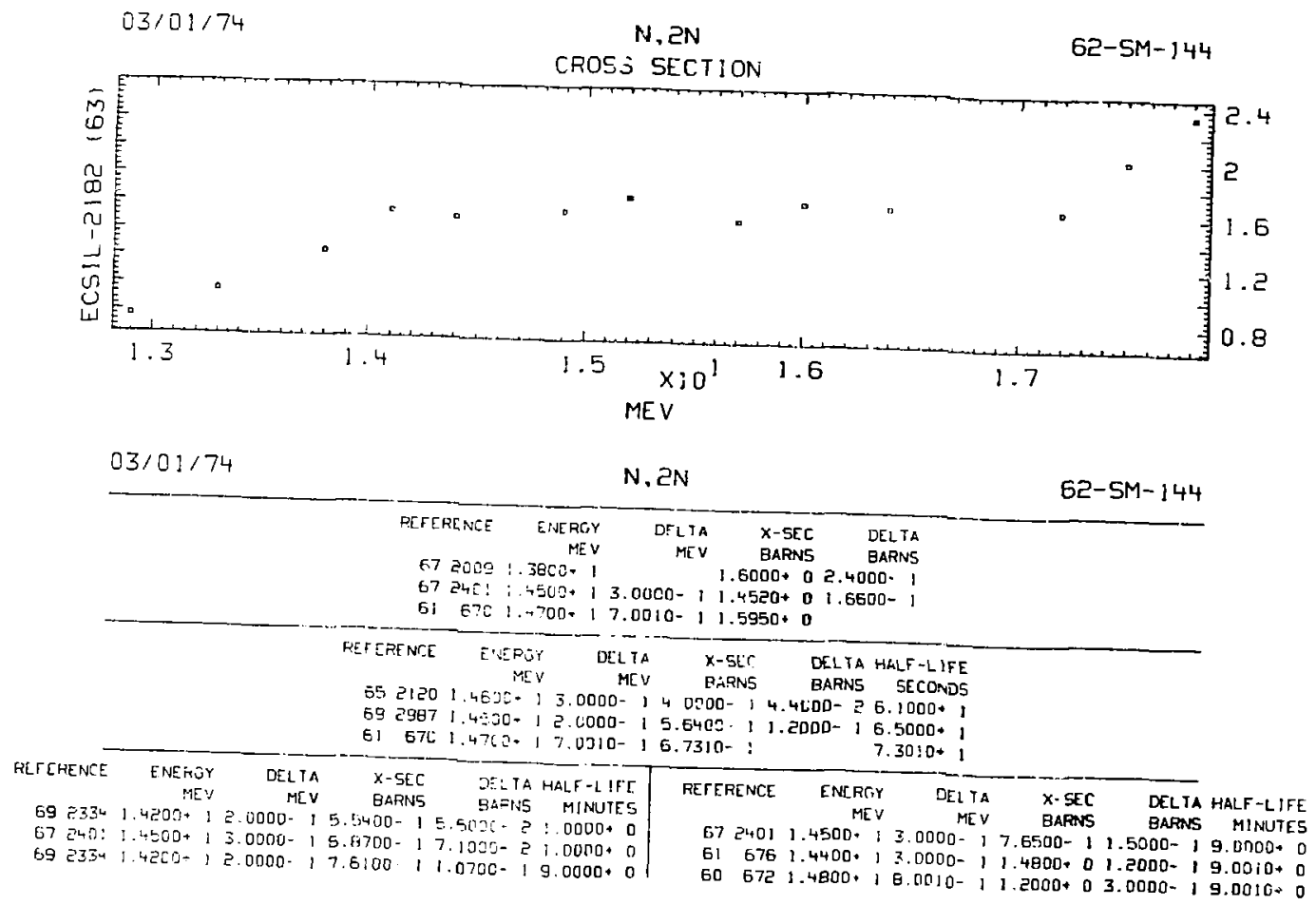




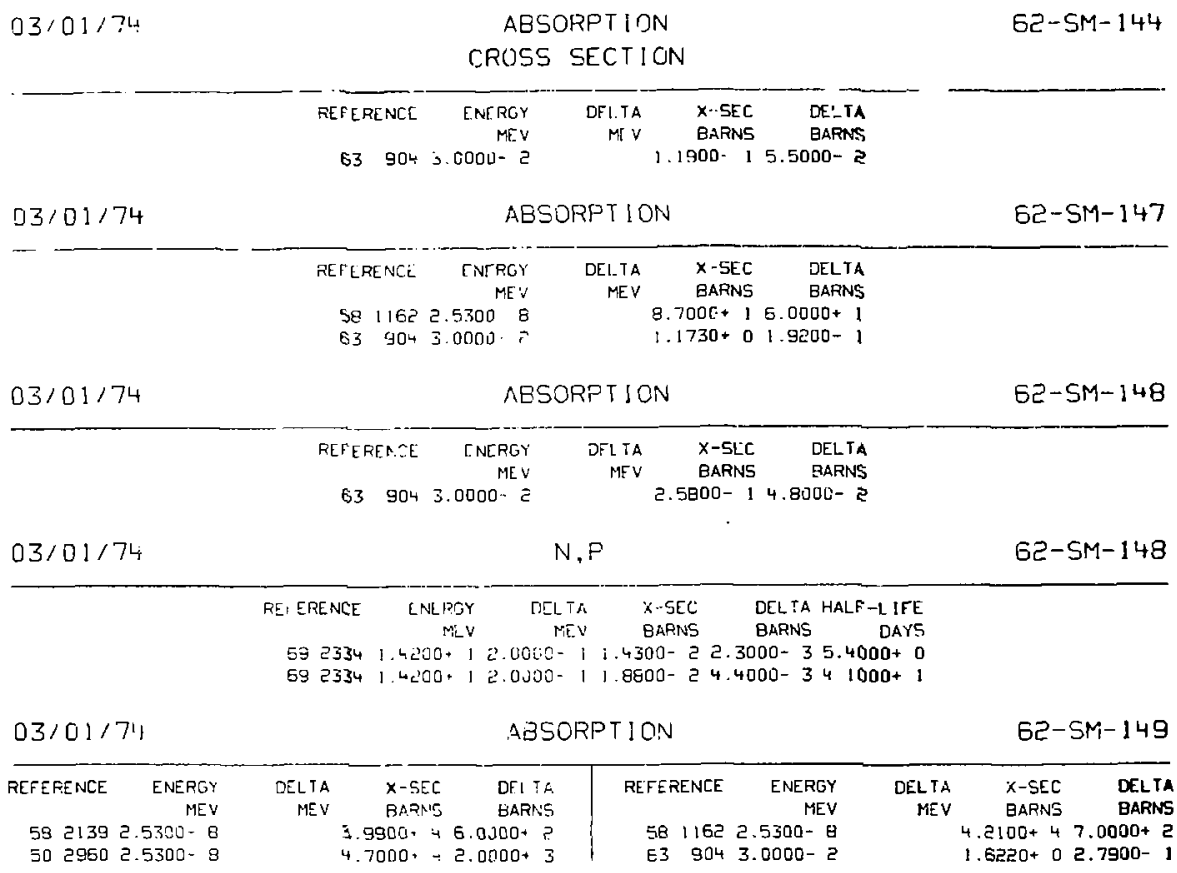


$03 / 01: 74$

CROSS SECTION

$\begin{array}{rrrrr}\text { REFERENCE } & \text { ENERG: } & \text { BELTA } & \text { X-SEC } & \text { DELTA } \\ \text { MEV } & \text { MEV } & \text { BARNS } & \text { BARNS } \\ 63904 & 3.0000-2 & & 3.7000-17.2000-2\end{array}$

03/01/74

\begin{tabular}{|c|c|c|c|c|c|c|}
\hline \multirow[t]{2}{*}{$03 / 01 / 74$} & \multicolumn{5}{|c|}{ ABSORPT ION } & $62-5 M-152$ \\
\hline & PEEFERENCE & $\begin{array}{r}\text { ENERGY } \\
\text { MEY }\end{array}$ & $\begin{array}{r}\text { OELTA } \\
\text { MEV }\end{array}$ & $\begin{array}{l}X \text {-SEC } \\
\text { BARNS }\end{array}$ & $\begin{array}{l}\text { DELTA } \\
\text { BARNS }\end{array}$ & \\
\hline & 62 2.237 & $2.5390-8$ & & $2.0910+2$ & $2.0700+1$ & \\
\hline & $58 \quad 2 ! 39$ & $2.5300-8$ & & $2.0000+5$ & $5.0000+5$ & \\
\hline & 63904 & $3.0000-2$ & & $4.1100-1$ & $7.1000-5$ & \\
\hline
\end{tabular}

\begin{tabular}{|c|c|c|c|c|c|c|}
\hline $03 / 01 / 74$ & & & $P$ & & & $62-5 M-152$ \\
\hline & $\begin{array}{l}\text { PEFEPENCE } \\
50 \quad 672\end{array}$ & $\begin{array}{c}\text { ENES:Y } \\
\text { MEV } \\
\text { G800. }\end{array}$ & $\begin{array}{r}\text { DEL:A } \\
\text { MEV } \\
U: 0-1\end{array}$ & $\begin{array}{l}x-5 E[ \\
\text { BAFINS } \\
000-3\end{array}$ & $\begin{array}{l}\text { DELTA } \\
\text { EARN5 } \\
\text { DOO- } 4\end{array}$ & \\
\hline
\end{tabular}

$03 / 01 / 74$

N, ALPHA

$62-5 M-152$

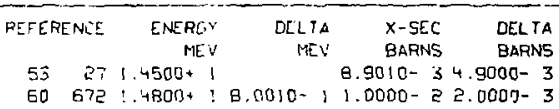




\section{CROSS SECTION}

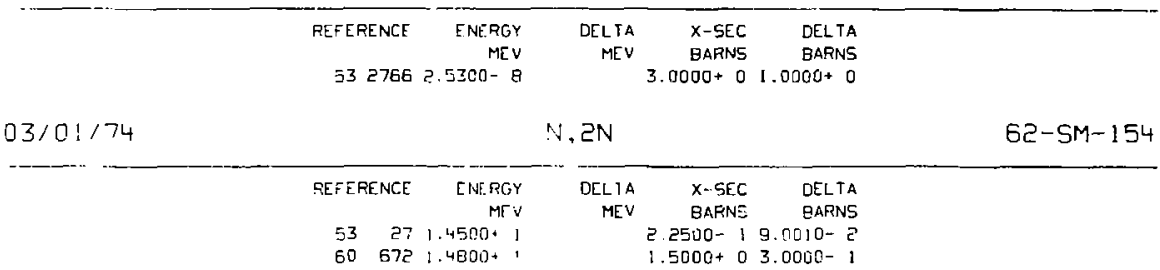

$03 / 01 / 74$

ABSORPT ION

$62-5 M-154$

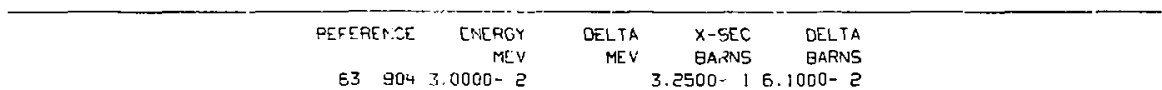

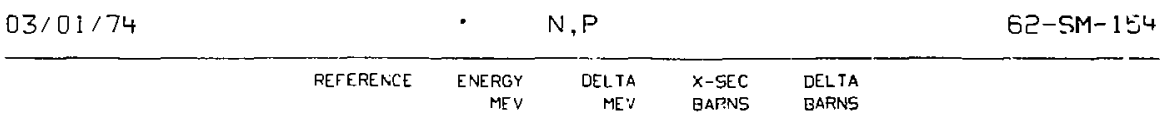

$606721.4600+1$ 8. $0010-13.5000-32.0000-4$

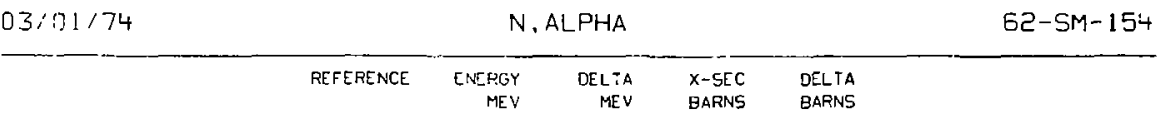

$6067 ? .4800+18.01010-19.0010-33.0000-3$

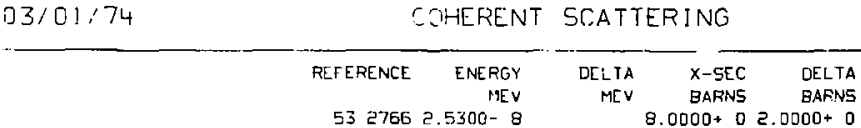




\section{CROSS SECTION}

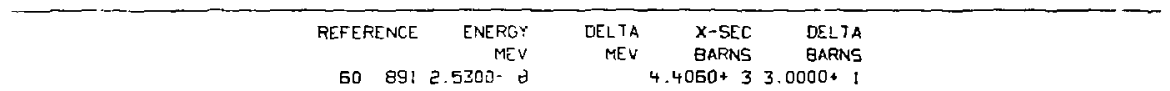

$03 / 01 / 74$ CCHERENT SCATTEKING

63-EU-NAT

$\begin{array}{rrrrr}\text { REFERENCE } & \text { ENFPOY } & \text { DELTA } & \text { X-SEC } & \text { DELTA } \\ \text { MEV } & \text { TIEV } & \text { BARNS } & \text { BARNS } \\ 62 & 9284.2300-8 & & 5.0000+0 & 5.0000-1 \\ 62 & 9284.2300-8 & 6 & 4.5000+0 & 5.0000-1\end{array}$

$03 / 01 / 74$

$N, 2 N$

$63-E U-151$

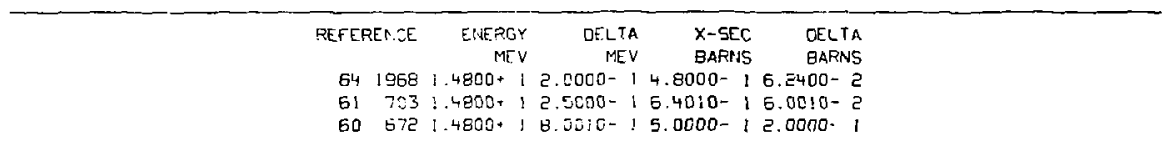

$03 / 01 / 74$ ABSORPT ION

63-EU-151

\begin{tabular}{|c|c|c|c|c|}
\hline REFEPENCE & ENEFG & DELTA & $x-5 E C$ & DEL TA \\
\hline & ME V & MEV & BARISS & $\begin{array}{r}\text { BAFNS } \\
000+1\end{array}$ \\
\hline
\end{tabular}

$03 / 0 ! / 74$

N. Al_PHA

63-EU-151

REFERENCE ENEPGY DELTA X-SEC DELTA HALF-LIFE

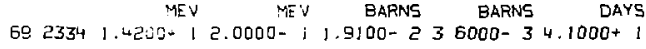




\section{CROSS SECTION}

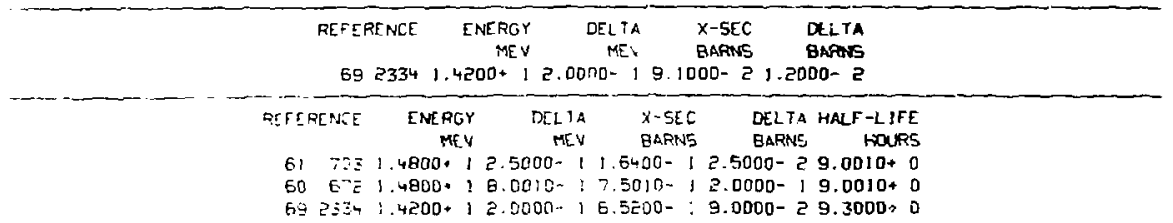

$03 / 01 / 74$ ADSORPTION

$63-E U-153$

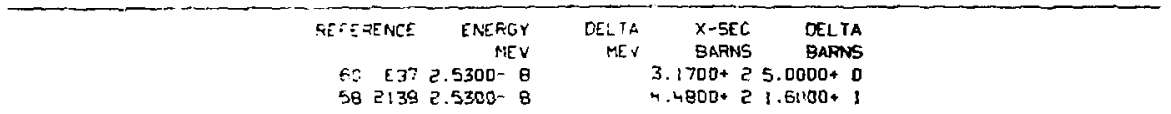

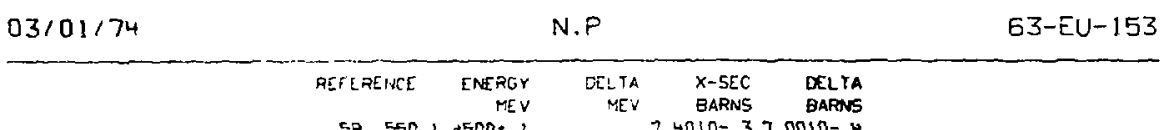

SP $501,+500$. ? $7.4010-37.0010-4$

$03 / 01 / 74$

IV ALI'HA

E3-EU-153

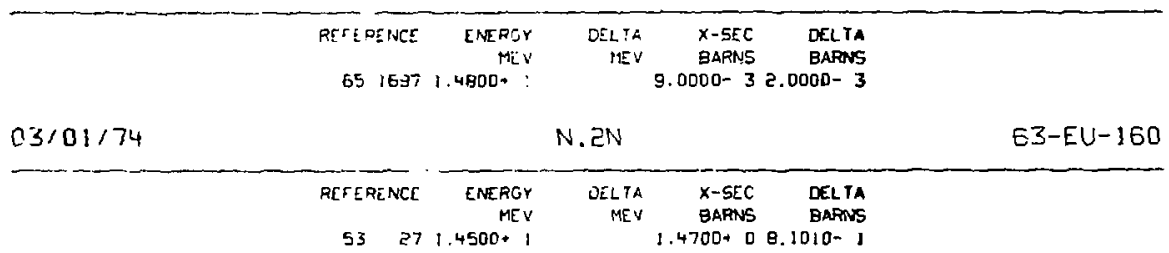

B-14 

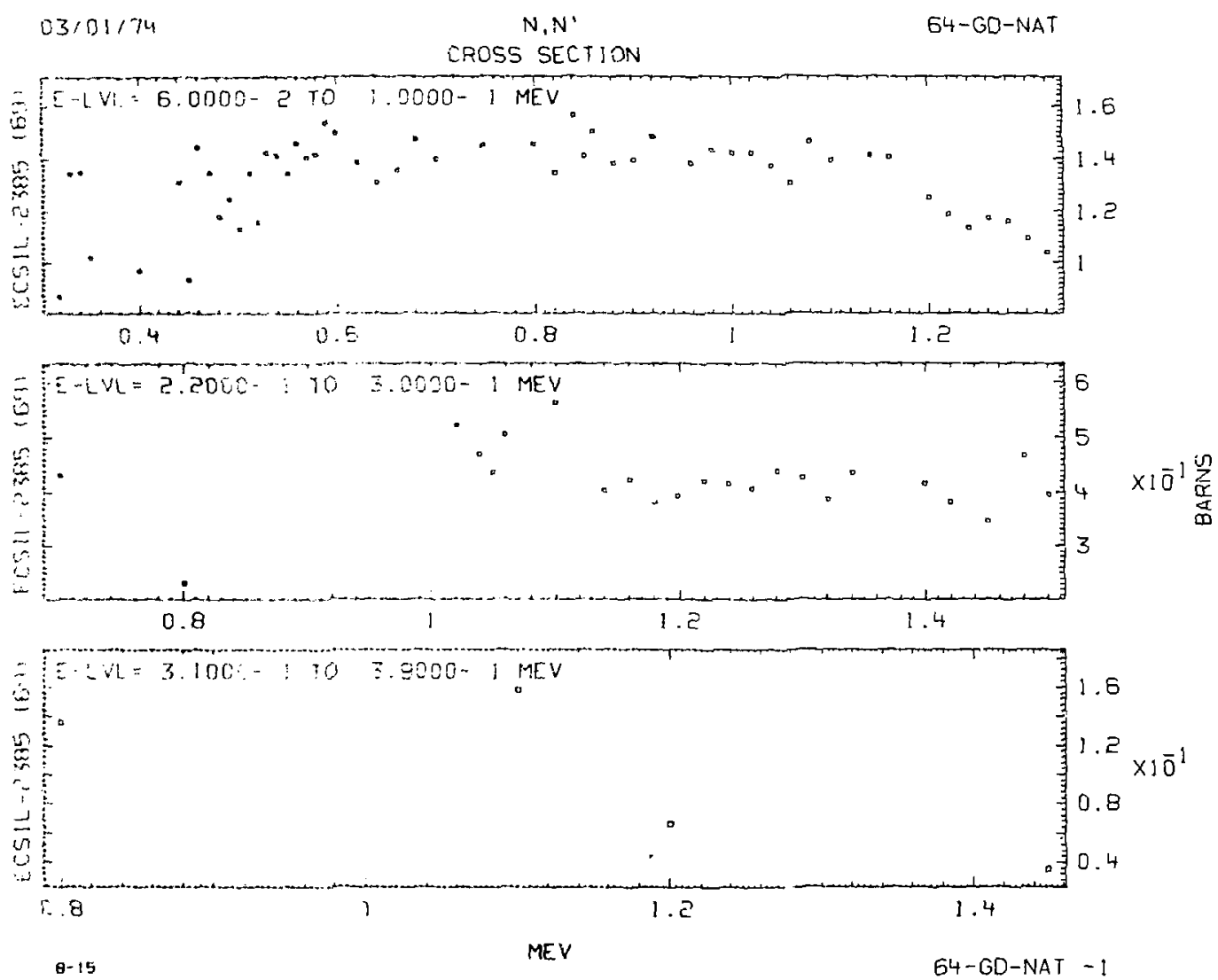
CROSS SECTION

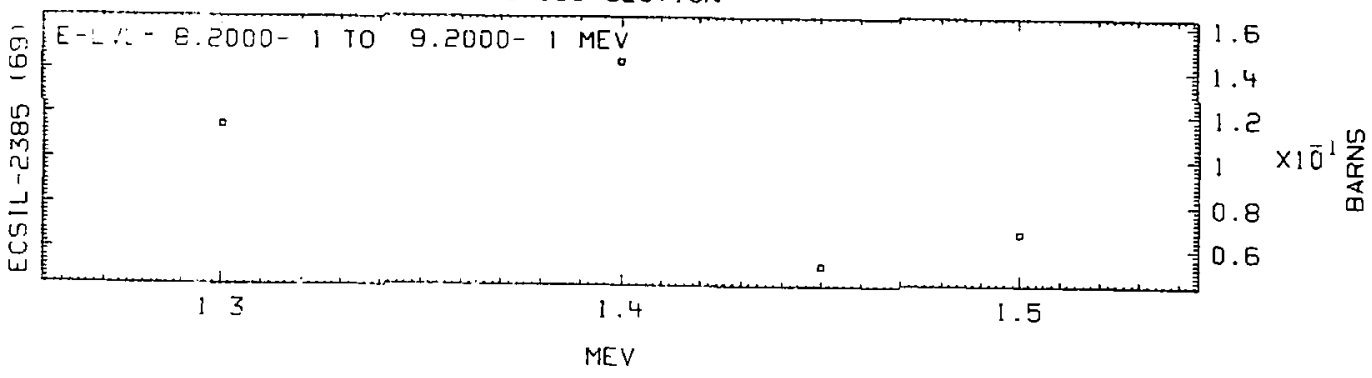

$03 / 0 ! / 74$

TOTAL SCATTERING

64-GD-NAT

\begin{tabular}{|c|c|c|c|c|}
\hline PFF[RENCE & $\begin{array}{r}\text { ENERGY } \\
\text { MEV }\end{array}$ & $\begin{array}{r}\text { DELTA } \\
\text { MEV }\end{array}$ & $\begin{array}{l}\text { X-SEC } \\
\text { BARNS }\end{array}$ & $\begin{array}{l}\text { DELTA } \\
\text { BARNS }\end{array}$ \\
\hline
\end{tabular}

$03 / 01 / 74$

$N, N^{\prime}$

64-GD-NAT

PEFERENCE

ENERGY

MEV DELTA

$X-\operatorname{SEC}$

$x$-SEC

DELTA E-LVL-MIN E-LVL-MAX $8923851.1000+01.0000-21.4830-15.9900-24$ MEV MEV $6923851.2000+0$ i. $1.0000-29.1230-15.9900-24.0000-14.6000-1$

$5923851.3000+01.0000-21.2100-15.6200-24.0000-14.6000-1$

$6923851.4000+32.0000-21.4180-11.5710-14.5000-15.4000-1$

$6923851.4000+0$ z. $0000-2$ B.7040- 2 1.5750- ! +.5000- $15.4060-1$

$6923851.5000+22.0000-21.4300-: 1.5140-14.6000-15.4000-1$ 


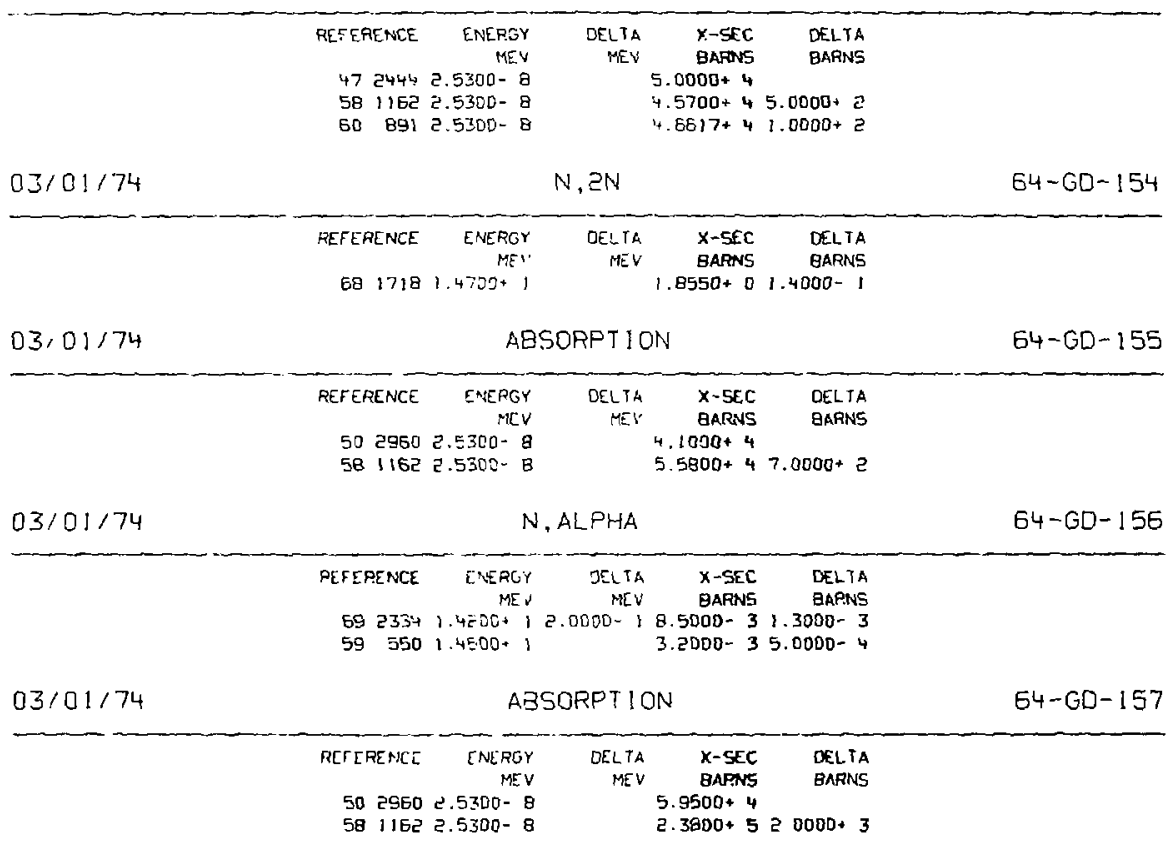




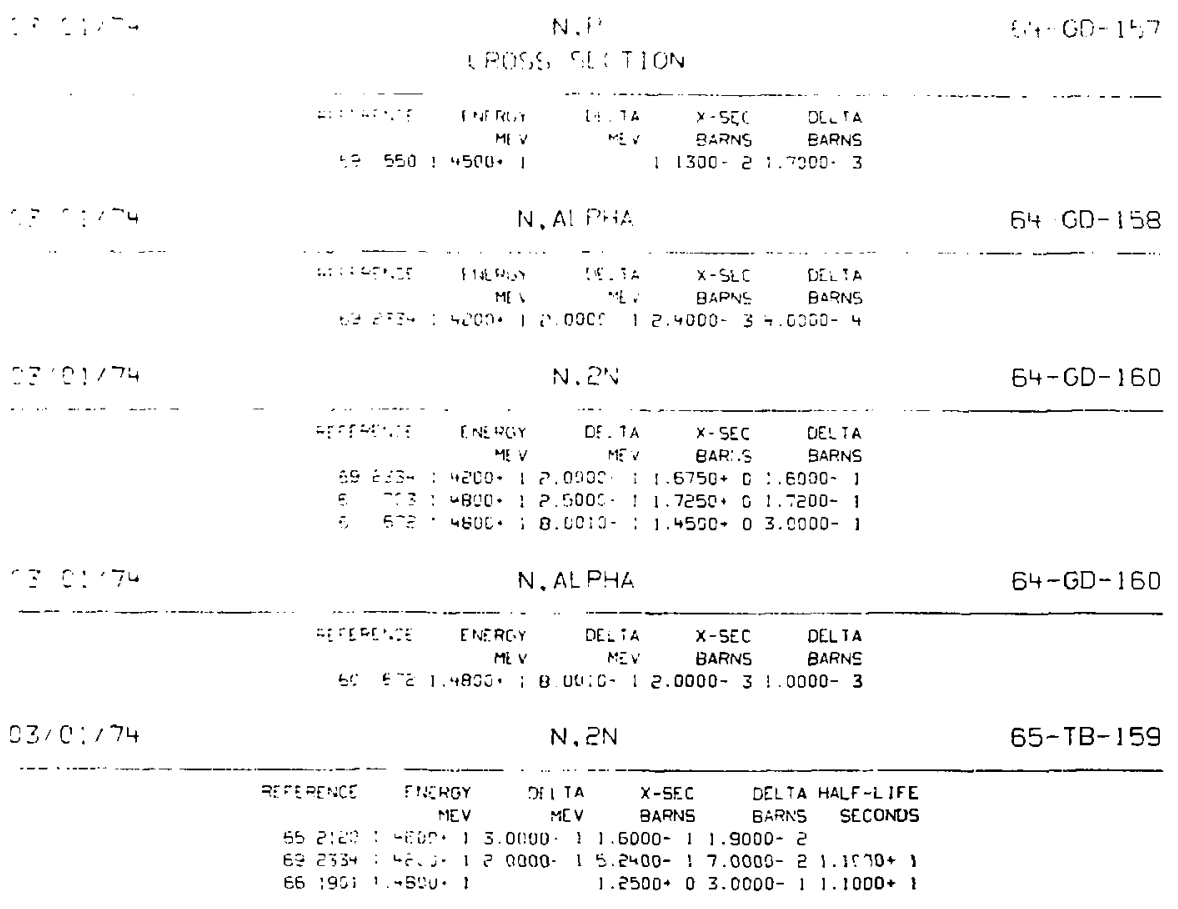




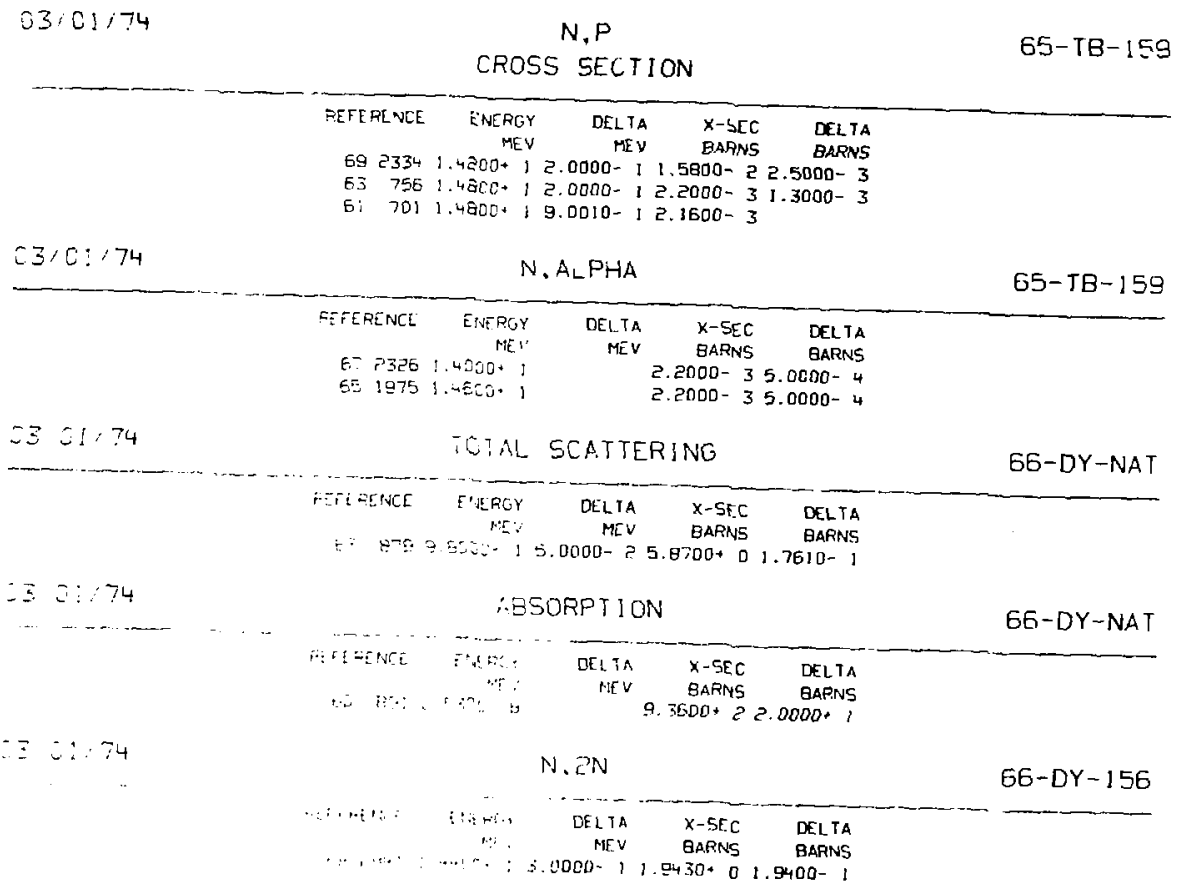




\section{CROSS SECTION}

\begin{tabular}{|c|c|c|c|c|c|c|}
\hline & $\begin{array}{l}\text { REF FPENCE } \\
682841\end{array}$ & $\begin{array}{r}\text { ENEPGY } \\
\text { MEV } \\
4400+1\end{array}$ & $\begin{array}{r}\text { DELTA } \\
\text { MEV } \\
000-1\end{array}$ & $\begin{array}{r}X-S E C \\
\text { BAIZNS } \\
470+0\end{array}$ & $\begin{array}{l}\text { DELTA } \\
\text { BAFNS } \\
500-1\end{array}$ & \\
\hline $03: 01 / 74$ & & &, $2 N$ & & & $66-D Y-160$ \\
\hline & $\begin{array}{l}\text { RETERELCE } \\
\text { 6B } 1718\end{array}$ & $\begin{array}{r}\text { ENERGY } \\
\text { MEV } \\
4700+1\end{array}$ & $\begin{array}{r}\text { OELTA } \\
\text { MCV }\end{array}$ & $\begin{array}{r}x-5 E C \\
\text { BARNS } \\
150+0\end{array}$ & $\begin{array}{l}\text { DELTA } \\
\text { BARNS } \\
000-1\end{array}$ & \\
\hline
\end{tabular}

$03 / 0 ! / 74$

$N, P$

$66-D Y-162$

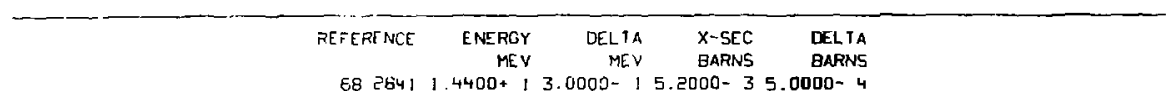

68 2641 1.4400+13.000D- $15.2000-35.0000-4$

$03 / 0 ! / 74$

$$
\text { N, ALPHA }
$$

GG-DY-1GE

PETERENCE ENERGY

$59550 \quad 1.500+1$

$\begin{array}{rrr}\text { DELTA } & X \text { SEC } & \text { DELTA } \\ \text { MEV } & \text { BARNS } & \text { BARNS }\end{array}$

$3.5000-34.0000-4$

$N, P$

66-DY -163

$03 / 0 ! / 74$

$\begin{array}{rrrr}\text { ENEROYY OELTA } & X \text {-SEC } & \text { DELTA } \\ \text { MLV } & \text { MEV } & \text { BARNS } & \text { BAPRS }\end{array}$

PETERTNCE

MLV

$6828+11.4400+13.0000-12.7000-33.0000-4$

$606721.4800+18.0010-13.0000-31.0000-3$

\begin{tabular}{|c|c|c|c|c|c|}
\hline \multirow[t]{2}{*}{$03 / 01: 74$} & \multicolumn{5}{|c|}{$N, A L P H A$} \\
\hline & REFERENCE & $\begin{array}{r}\text { ENERGY } \\
\text { MEV }\end{array}$ & $\begin{array}{l}\text { OELTA } \\
\text { MEV }\end{array}$ & $\begin{array}{l}X-5 E C \\
\text { BARNS }\end{array}$ & $\begin{array}{l}\text { DELTA } \\
\text { BARENS }\end{array}$ \\
\hline & $6828+1$ & $1.4400+1$ & $3.0000=1$ & $9.0000-4$ & $1.0000-4$ \\
\hline & 651697 & $1.4800+1$ & 1 & $4.0000-3$ & $1.0000-3$ \\
\hline & 60 672 & $1.4800 \cdot 1$ & $8.0010-1$ & $4.5000-3$ & $0.0010-4$ \\
\hline
\end{tabular}



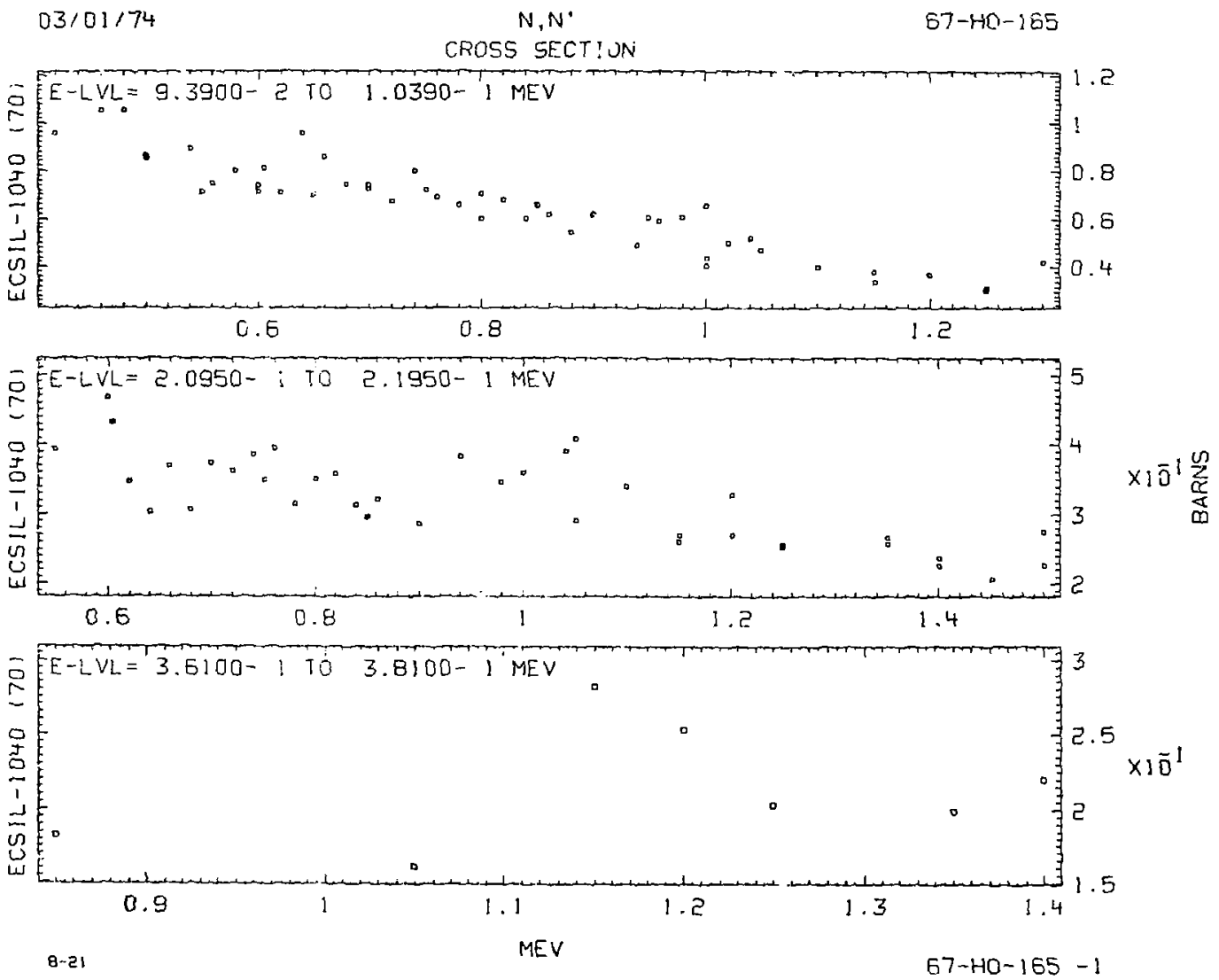

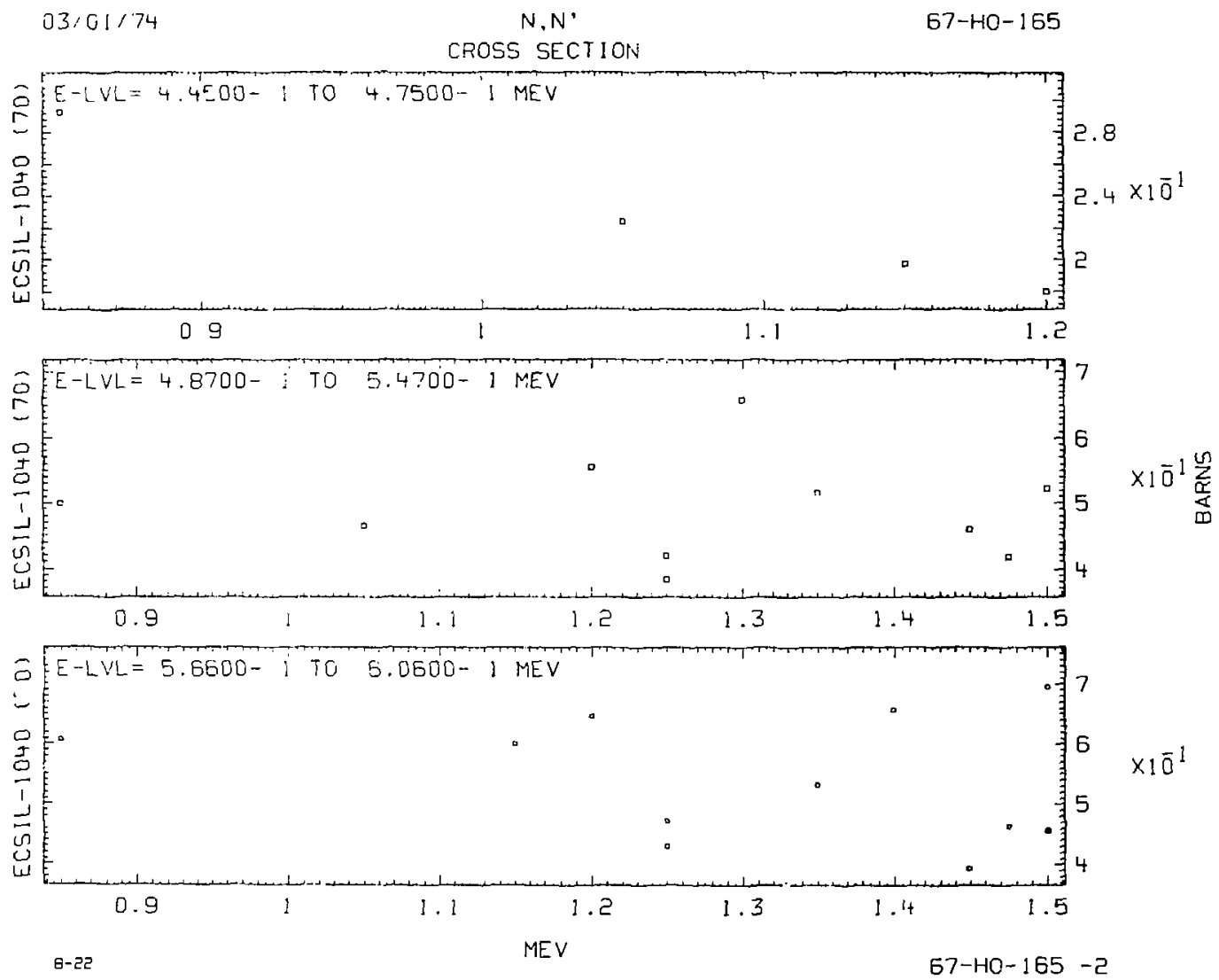


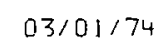

\section{CROSS SECTION}
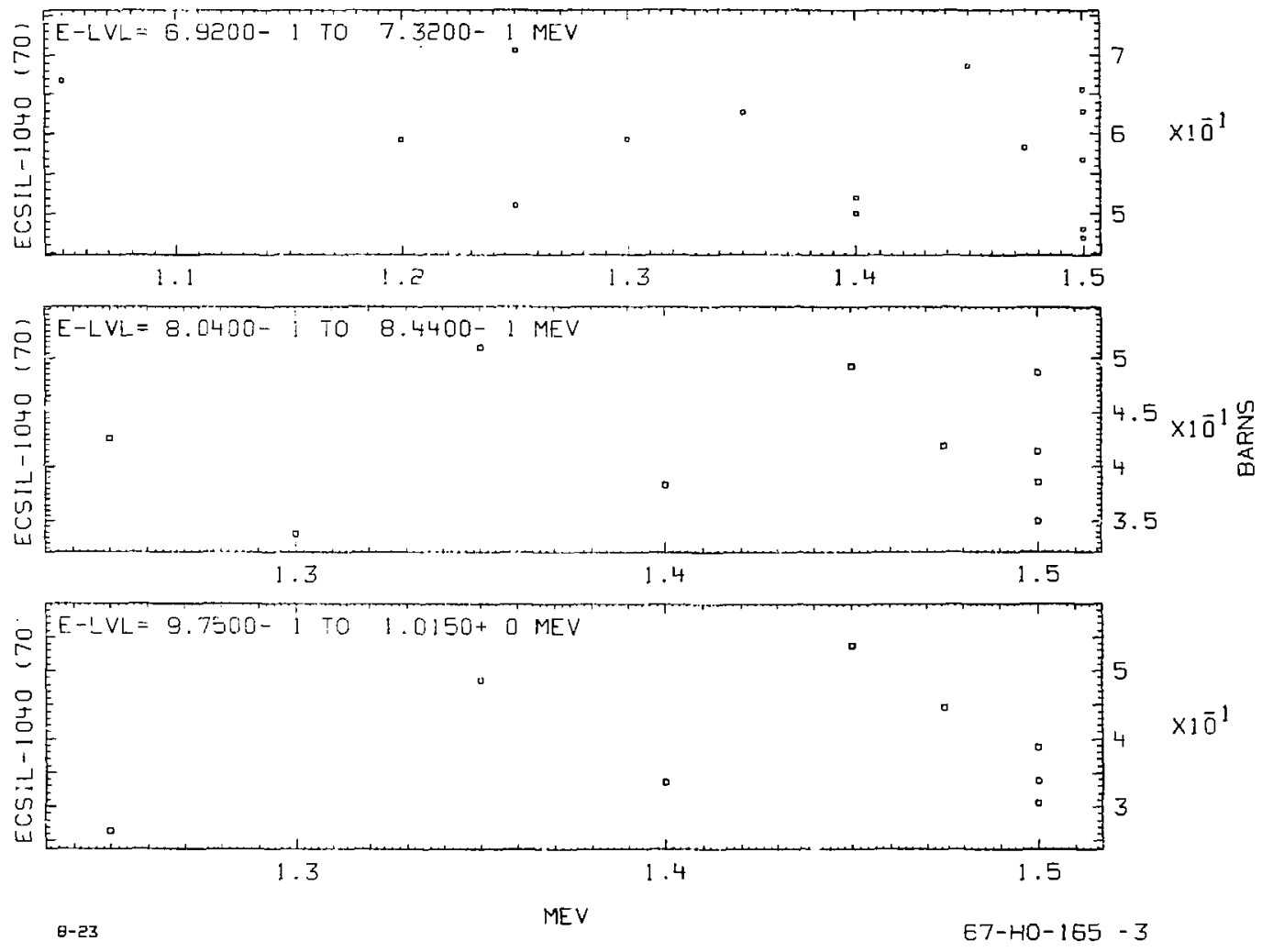
CROSS SECTION
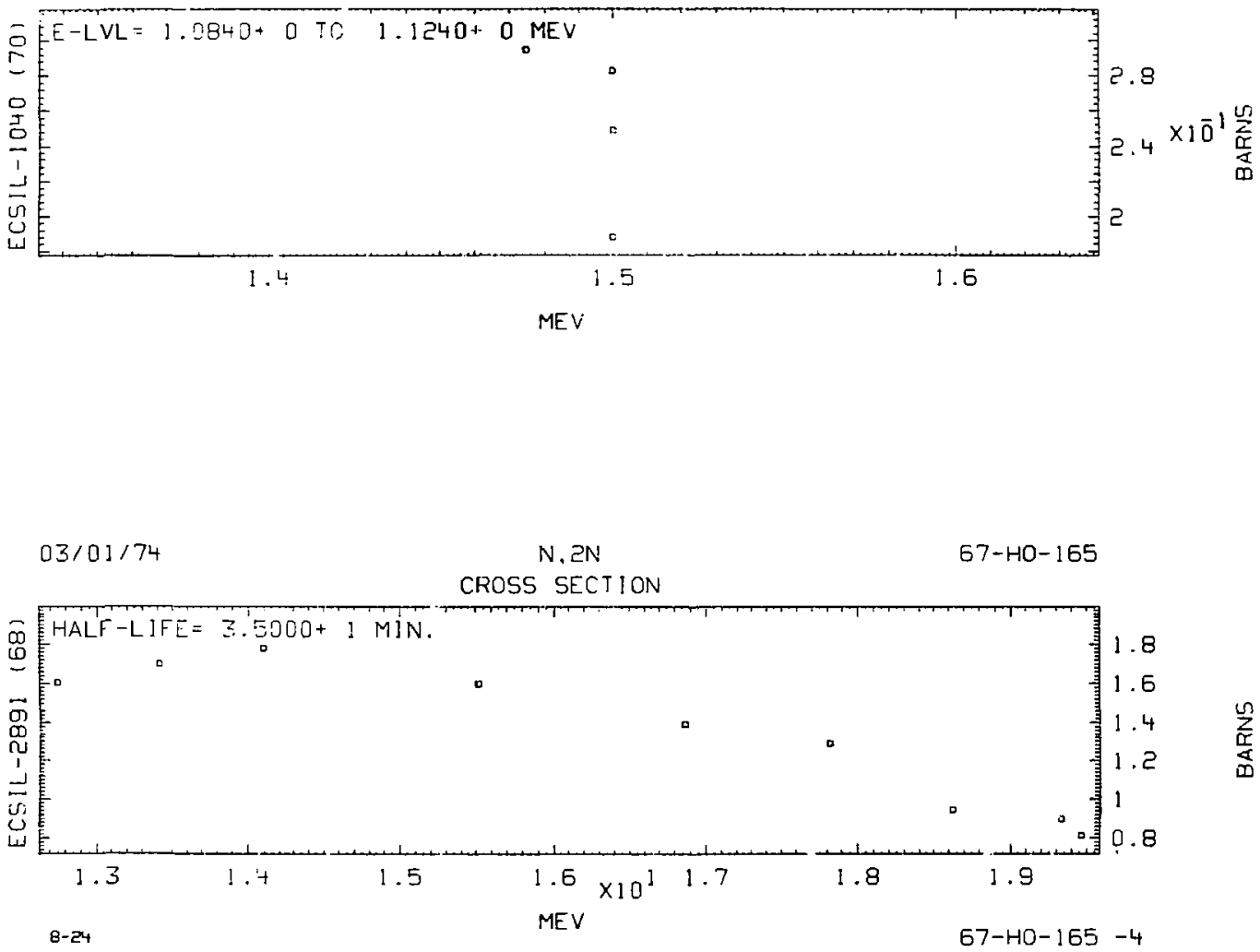


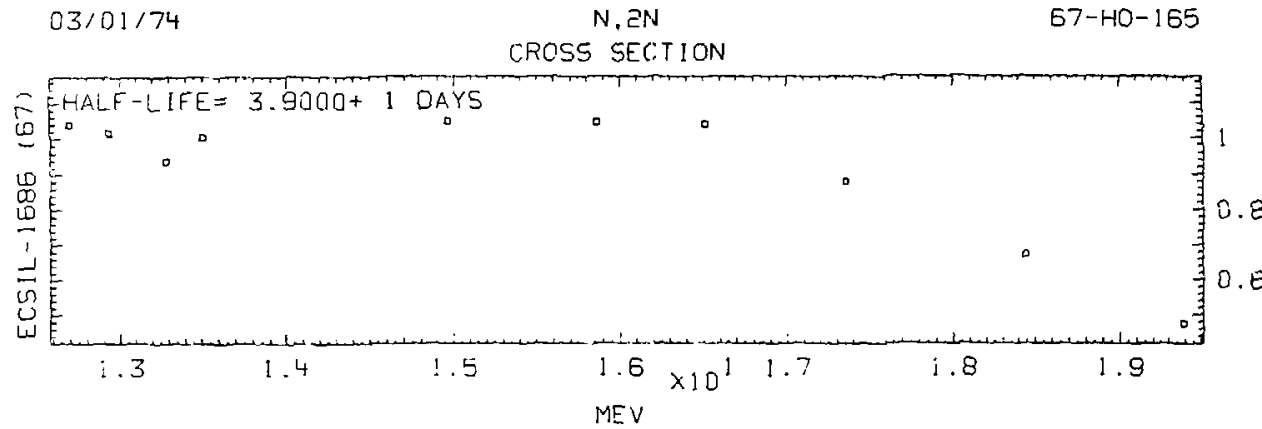

$03 / 01 / 74$

TOTAL SCATTERING

$67--H O-165$

PEFEPLNCE ENLFGY DELTA X.-SEC DELTA

$6529832.5300-8 \quad 9.0000+0$

$635-95.8000-15.0000-24.9100+01.4730-1$

$03 / 01 / 74$

$N, N^{*}$

$67-H O-165$

RE.FERENCE

ENERGY

OELTA X-TSEC

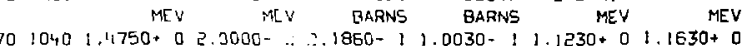

DELTA E-LVL-MIN E L LL - MAX

$03 / 01 / 74$

N. ¿N

$67-\mathrm{HO}-165$

\begin{tabular}{|c|c|c|c|c|}
\hline REFERENO & $\begin{array}{r}\text { ENTRGGY } \\
\text { MEVV }\end{array}$ & $\begin{array}{r}\text { OELTA } \\
\text { MEV }\end{array}$ & $\begin{array}{l}X-S E C \\
\text { BARNS }\end{array}$ & $\begin{array}{l}\text { DELTAA } \\
\text { BARNS }\end{array}$ \\
\hline & $4000+1$ & & $1.0800+0$ & $1.4000=$ \\
\hline 58 & $-4700+1$ & & 2.1100.0 & $3.0000-$ \\
\hline
\end{tabular}

z.5000- 12 
CROSS SECTION

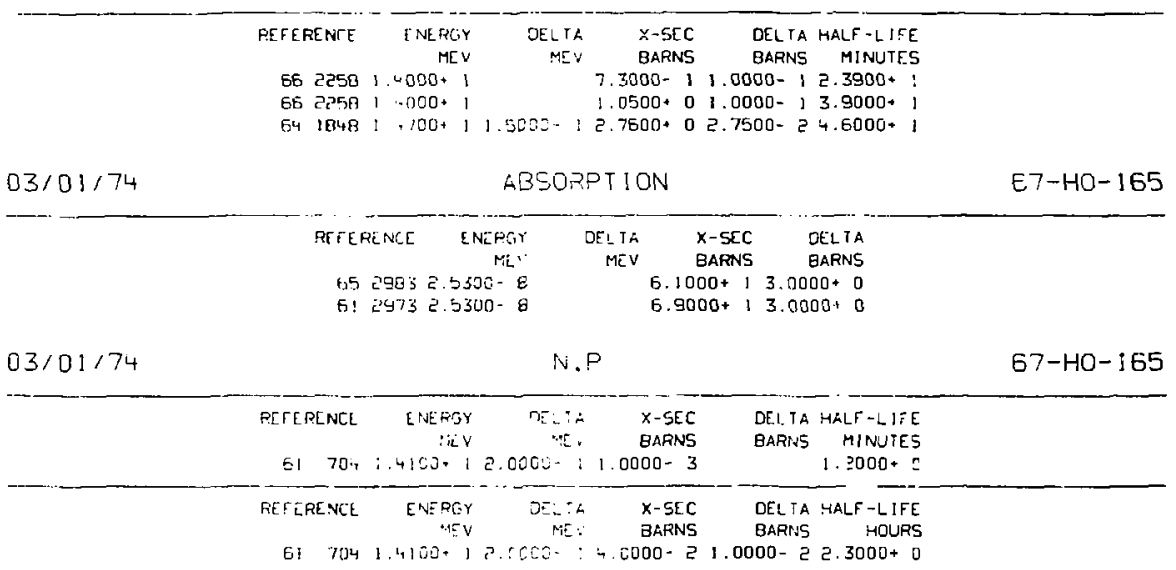

$03 / 01 / 74$

N. ALPHA

$67-140-165$

PEFERENCE

EIERGY TE:TA

$x-5: C$

DEL TA HALF - LIFE

$6923341.4200 .12 .900: \div 2000-34.0000-42.0000+0$

$03 / 01 / 72$

SIEREN: SCATTERING

57-HO-165

REIERENCE ENCRGY

$5829 \%$ 2.5300-
DEL TA

MEV

$X-5 E C$

BARNS

$9.1000+05.0000-1$ 


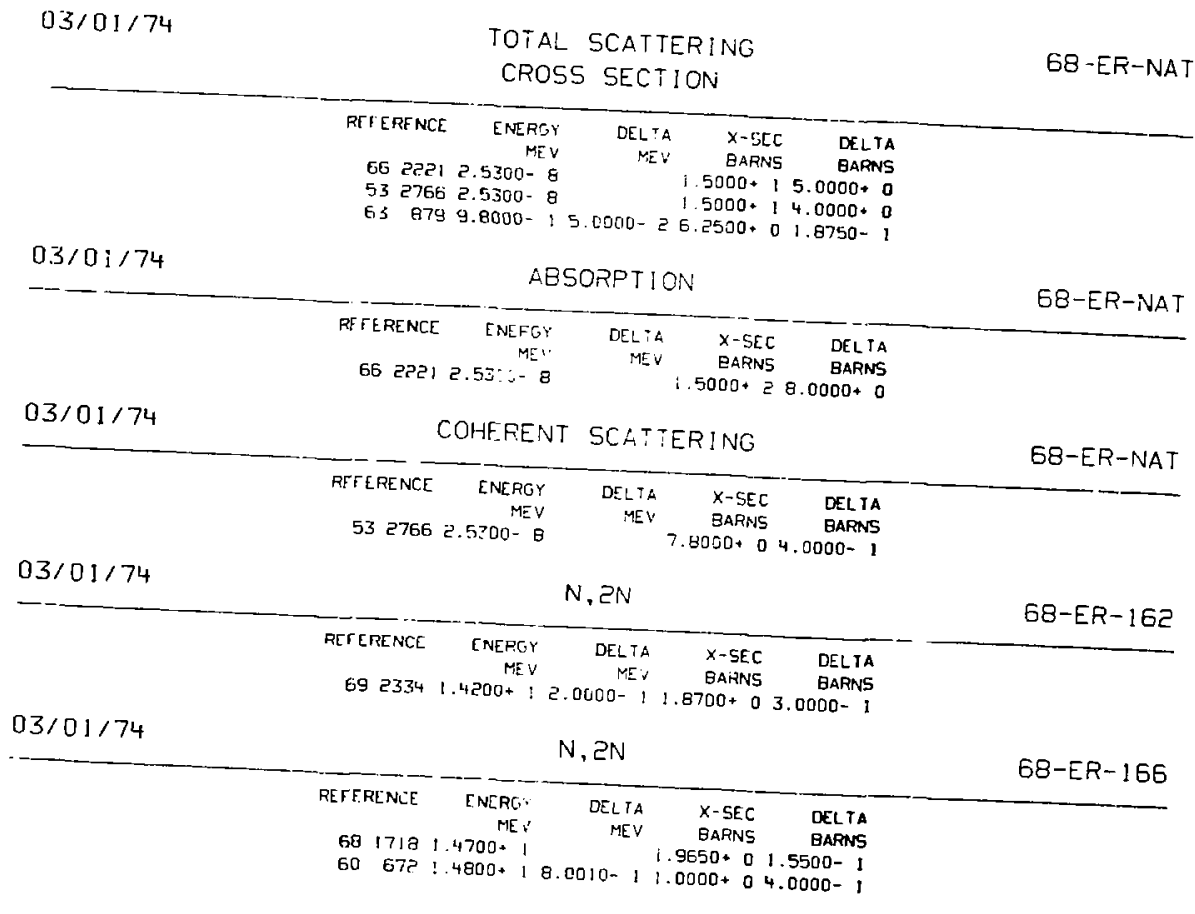

8-27 


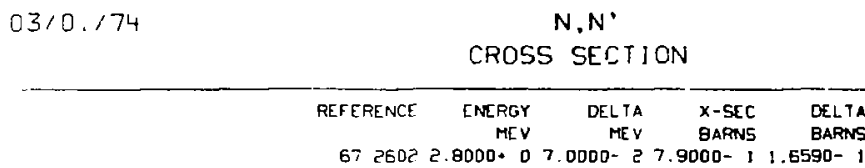

$03 / 01 / 74$

N.P

$68-E R-167$

\begin{tabular}{|c|c|c|}
\hline RENCE & ENEFG & $\begin{array}{r}\text { DELTR } \\
\text { MEY }\end{array}$ \\
\hline
\end{tabular}

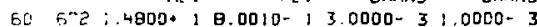

$03 / 01 / 74$

N. $2 N$

68-ER- 168

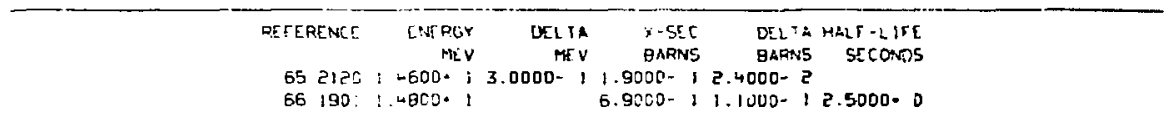

$03 / 01 / 74$

$N, P$

63-ER- 158

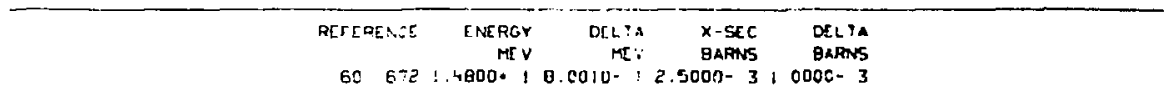

$03: 0: 174$

N. ALPHA

68-ER-168

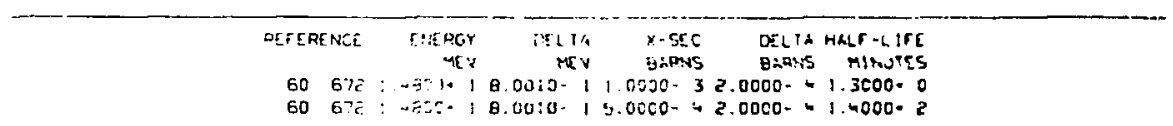

$05 / 01 / 74$

N. ZN

69-ER- 170

\begin{tabular}{|c|c|c|c|c|}
\hline RECRA: & $\begin{array}{r}\text { ENEERGY } \\
\text { MEY }\end{array}$ & OLLiA & $\begin{array}{l}x-\sec \\
\text { BaRns }\end{array}$ & $\begin{array}{l}\text { OLLIA } \\
\text { GNANS }\end{array}$ \\
\hline
\end{tabular}




\section{CROSS SECTION}

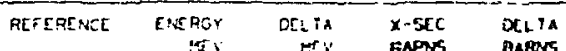

$606721.4000 \cdot 10.00: 0-11.0000-35.0000-4$

D3/01/74

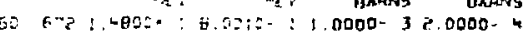

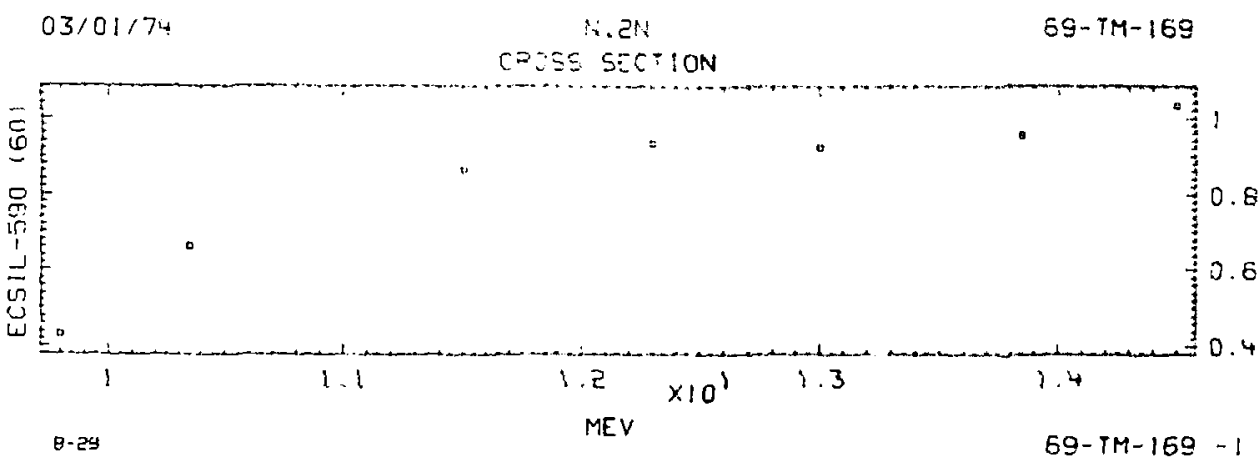


CROS5 SECTION

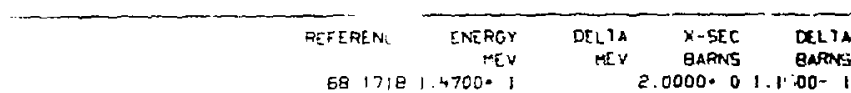

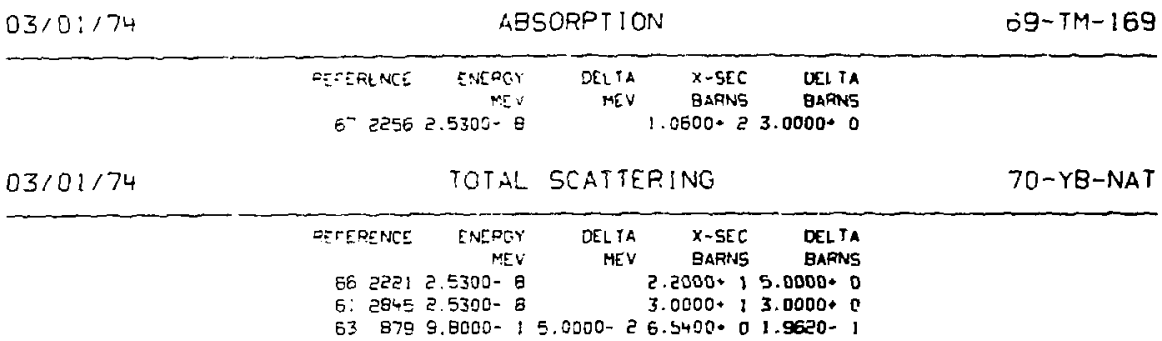

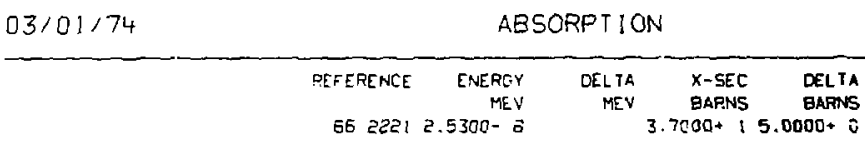

$03 / 01 / 74$

COHERENT SCATTERING

70-YB-NAT

RETERENLE ENERGY DELTA MESEC DELTA

5: $28452.5300-8 \quad$ 2.0000+14.0000-

$0 \overline{3} / 01 / 74$

N.2N

$70-Y B-170$

$\begin{array}{cccccc}\text { REFERENCE } & \text { ENERGY } & \text { DELTA } & x-S E C & \text { OELTA } \\ \text { MEV } & \text { MEV } & \text { BARNS } & \text { BARNS } \\ 66 & 1718 & 1.4700^{\circ} & 1 & 2.0800+0 & 1.1000-1\end{array}$


CROSS SECTION

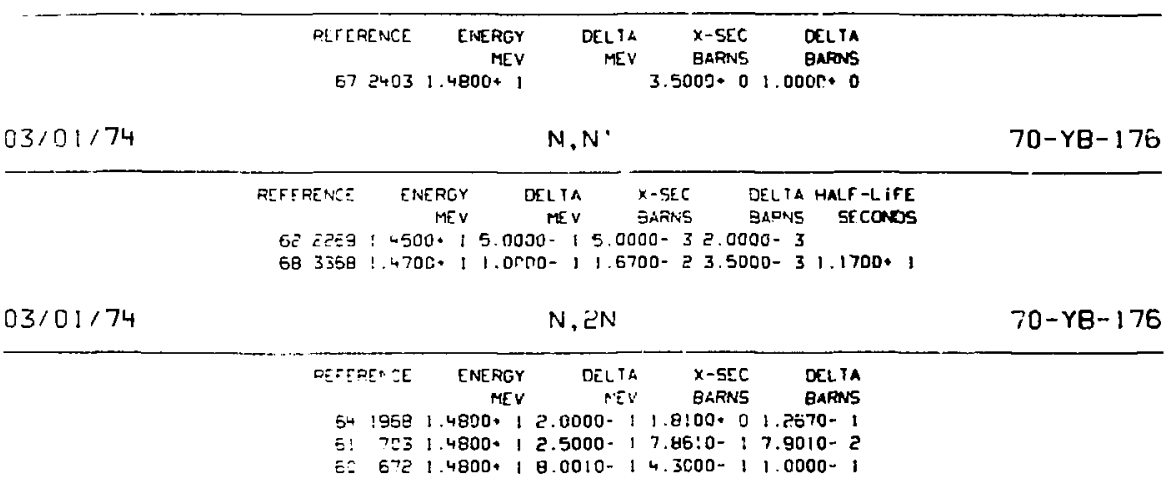

$03 / 01 / 74$ N, ALPHA

$70-Y B-176$

\begin{tabular}{|c|c|c|c|c|c|}
\hline & $\begin{array}{l}\text { PETEPENCE } \\
68 \text { E3!5 }\end{array}$ & $\begin{array}{r}\text { ENERGY } \\
\text { ME } \checkmark \\
1,4 B 00+1\end{array}$ & $\begin{array}{rr}\text { DEL :A } & \text { X-SEC } \\
\text { MEV } & \text { BARNS } \\
& 2.0000-4\end{array}$ & $\begin{array}{r}\text { OELTA } \\
\text { BAFAS } \\
5.0000-5\end{array}$ & \\
\hline $03 / 01 / 74$ & & TOTAL & SCATTERING & & 71-LU-NAT \\
\hline & 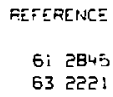 & $\begin{array}{r}\text { ENERGY } \\
\text { MEV } \\
2.5300-8 \\
2.5300-8\end{array}$ & $\begin{array}{rr}\text { DELTA } & \text { X-SEC } \\
\text { ME: } & \text { GARNS } \\
1.3000 * 1 \\
1.0000 * 1\end{array}$ & $\begin{array}{r}\text { DELTA } \\
\text { GAANS } \\
2.0000+0 \\
5.0000 * 0\end{array}$ & \\
\hline
\end{tabular}




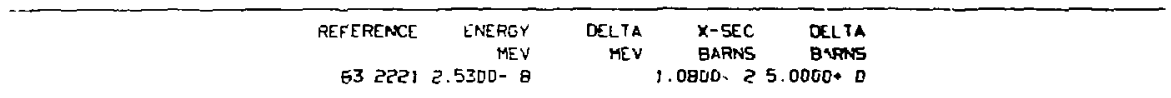

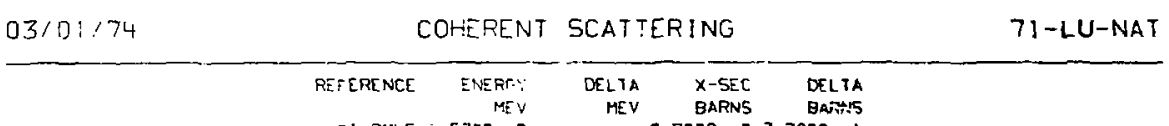

5) 2845 2.5300-

$6.7000+0.7000-1$

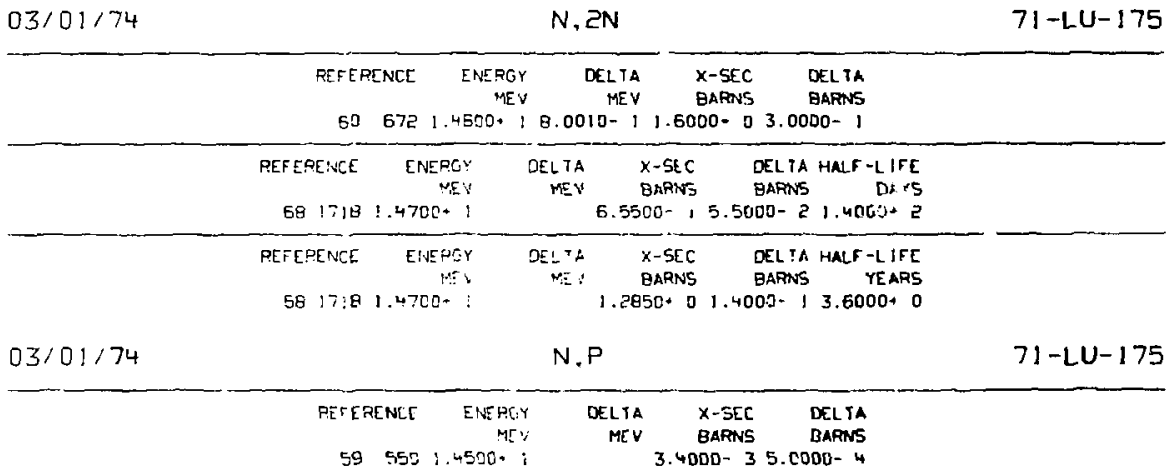



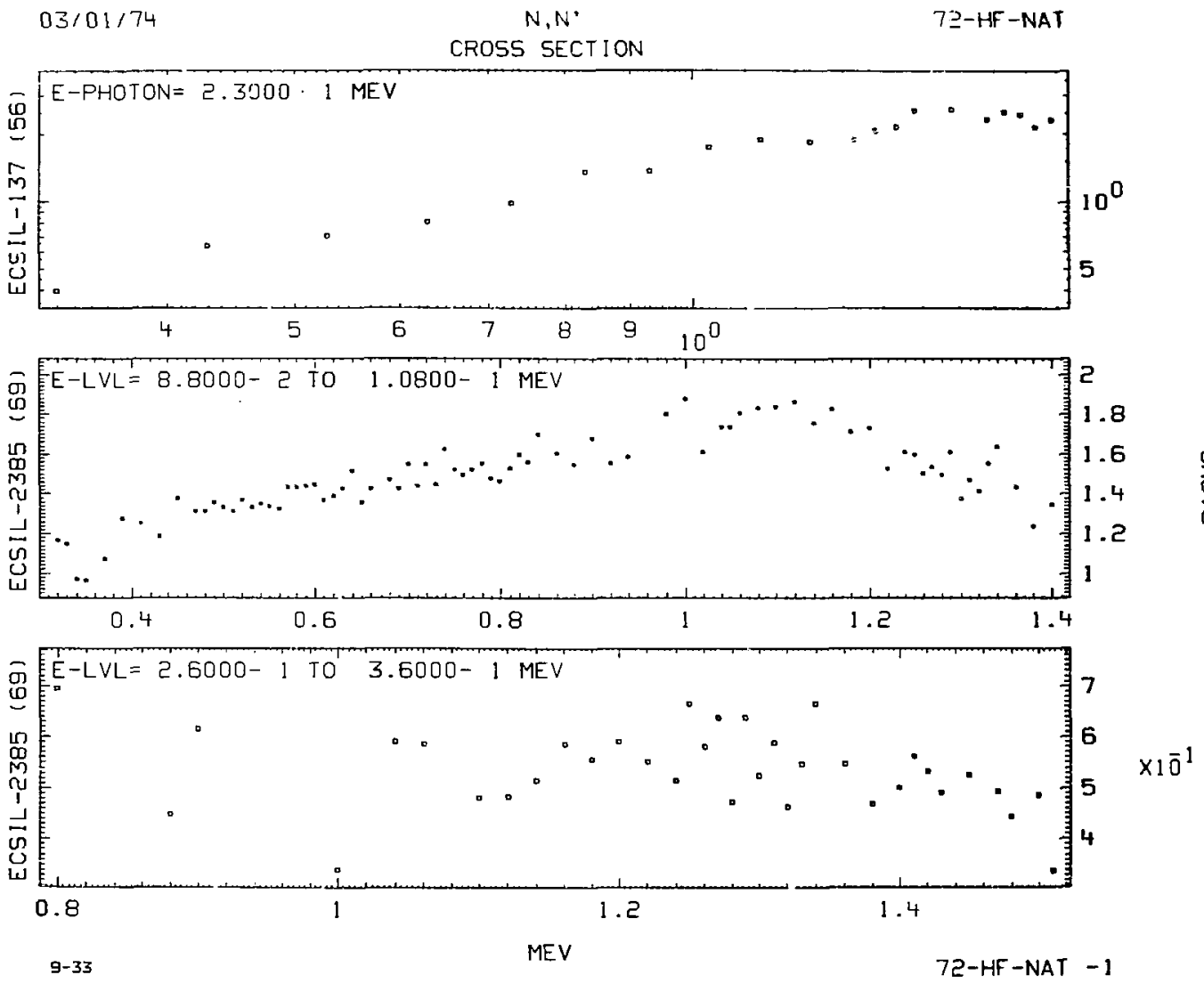


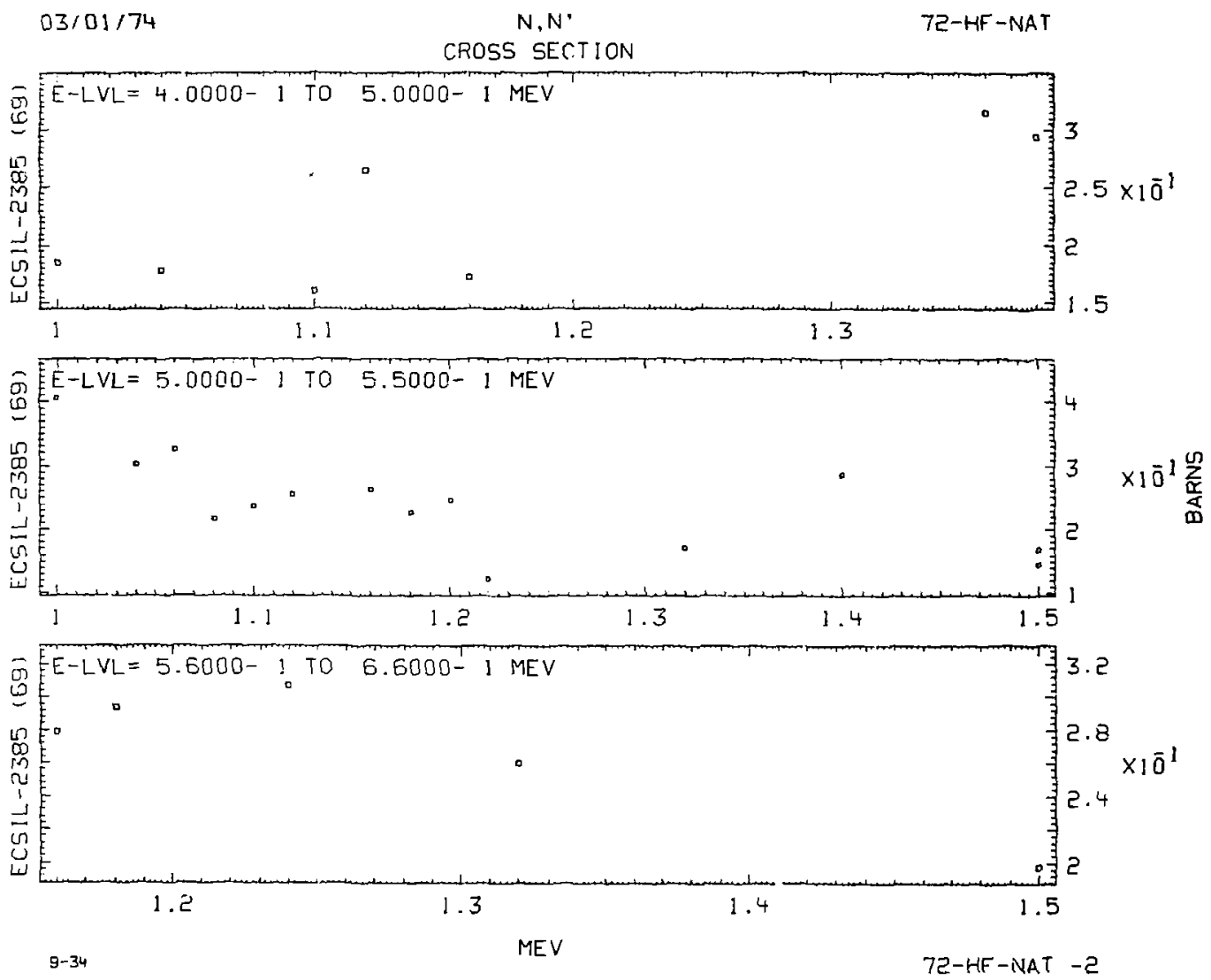


CROSS SECTION

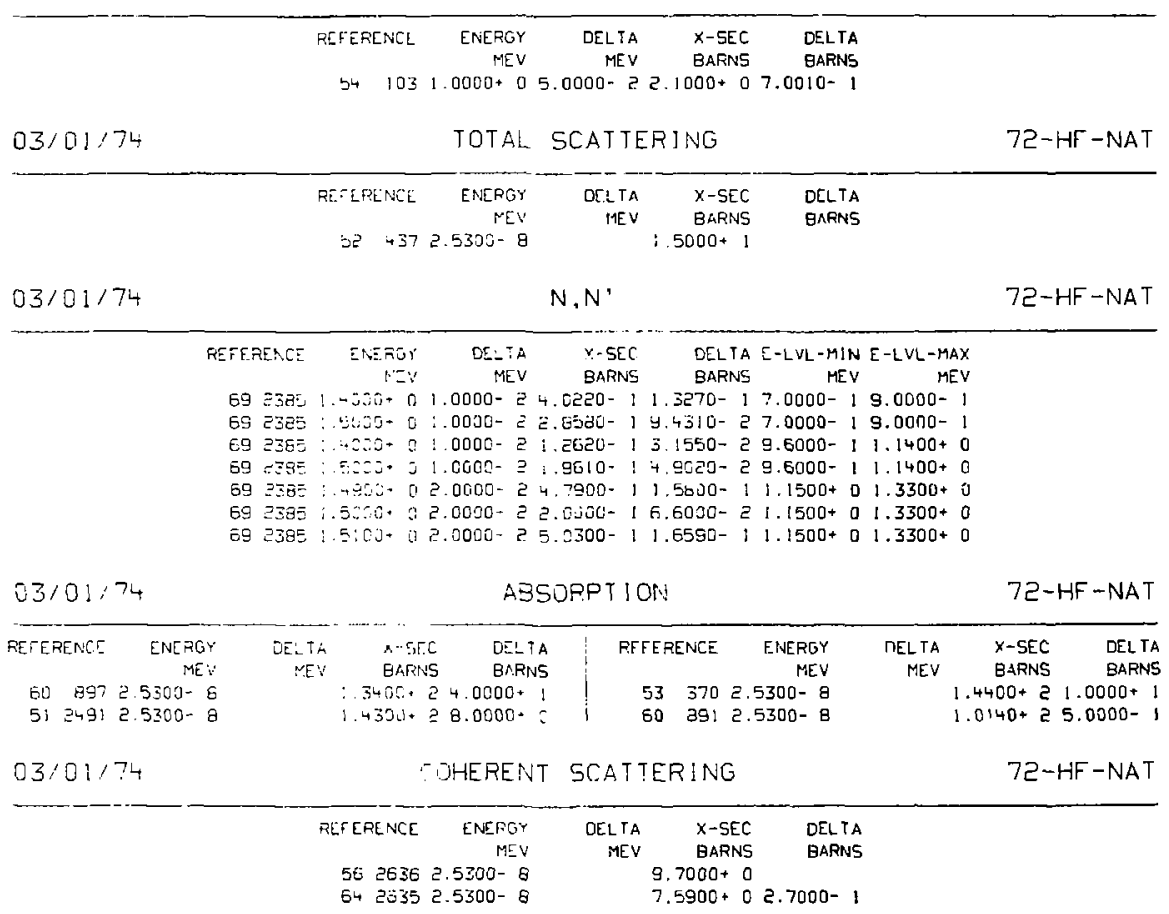


CROSS SECTION

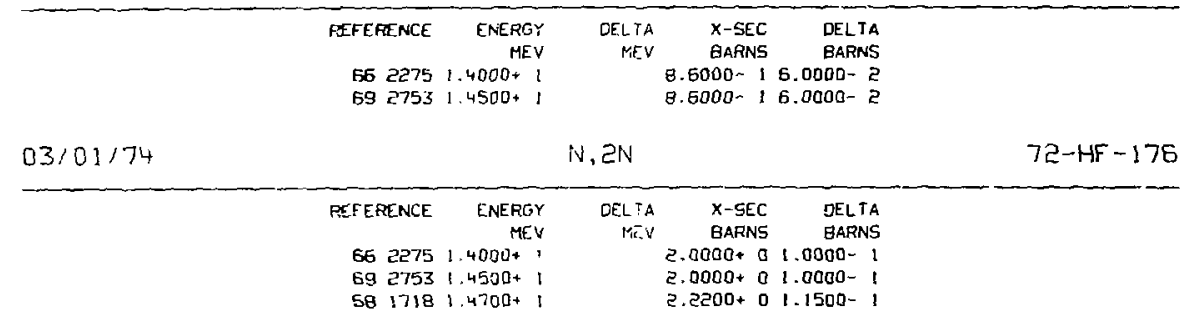

\begin{tabular}{|c|c|c|c|c|c|c|}
\hline \multirow[t]{2}{*}{$03 / 01 / 74$} & \multicolumn{5}{|c|}{$N, A L P H A$} & $72-H F-178$ \\
\hline & FEFERENCE & $\begin{array}{l}\text { ENERGY } \\
\text { MEV }\end{array}$ & $\begin{array}{l}\text { OELTA } \\
\text { ME W }\end{array}$ & $\begin{array}{l}X-S E C \\
\text { GARNS }\end{array}$ & $\begin{array}{l}\text { OELTA } \\
\text { BARNS }\end{array}$ & \\
\hline
\end{tabular}

$03 / 01 / 74$

$N, N$

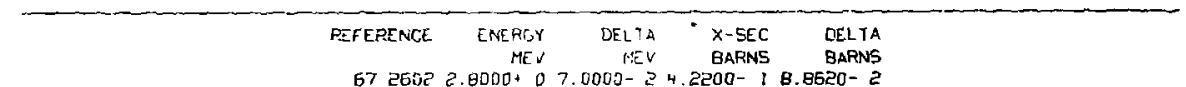

67 2652 $2.6000+07.0000-24.2200-1$ B.8620- 2

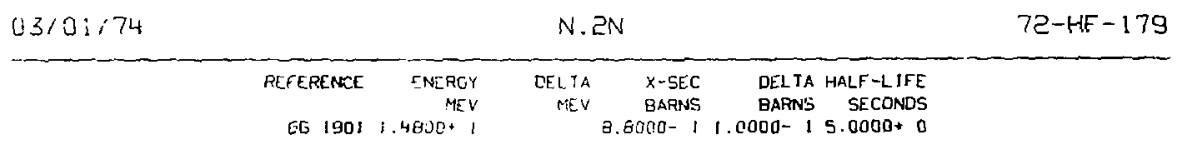


CROSS SECTION

\begin{tabular}{|c|c|c|c|c|c|c|c|}
\hline & $\begin{array}{l}\text { PECERENI } \\
56 \quad 2275 \\
5 E 2753\end{array}$ & $\begin{array}{r}\text { ENEROY } \\
\text { NEV } \\
1.4000+1 \\
1.4500+1\end{array}$ & DELIA & $\begin{array}{l}x-S E C \\
\text { BARNS } \\
400-2 \\
400-2\end{array}$ & $\begin{array}{c}\text { DELIA } \\
\text { ENFANS } \\
\text { DDD- } 4 \\
1000-4\end{array}$ & $\begin{array}{r}\text { HALF -L JFE } \\
\text { HOUPS } \\
5.5000+0\end{array}$ & \\
\hline $03 / 01 / 74$ & & & N.i & & & & $72-H F-180$ \\
\hline
\end{tabular}

$55150 \div 1.4800+1$ $5.7000-i 5.0000-2$ l.

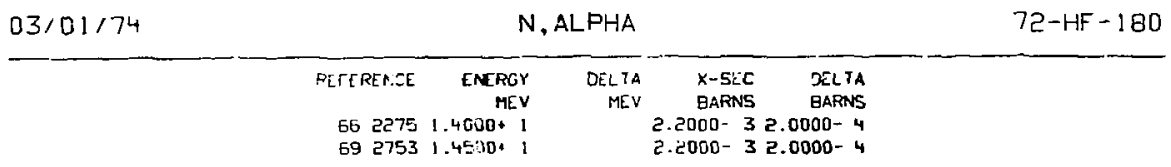

03/01/74 -

$552954.1000+04.0000-22.7000+02.0000-$

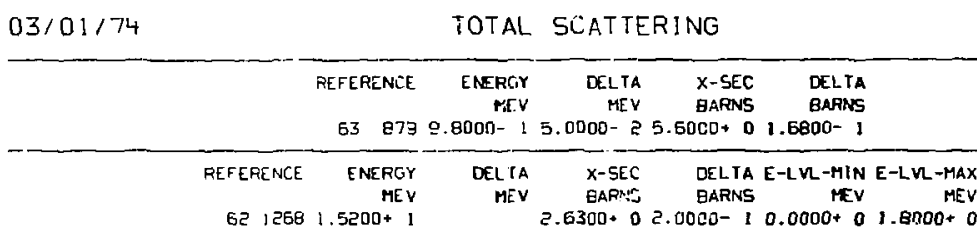


CROSS SECTION

REFEPENCE ENERGY DELTA X-SEC DELTA
MEV MEV BARNS BAFNS

$63 \quad 8367.0000+0 \quad 2.6200+02.9000-1$

$0.3 / 01 / 74$

A.BSORPT ION

73-TA-NAT

$\begin{array}{rrrrr}\text { FEFERENCE } & \text { ENERGY } & \text { DELTA } & \text { X-SEL } & \text { DELTA } \\ \text { MEL } & \text { MEV } & \text { BARNS S BARNS }\end{array}$

$03 / 01 / 74$

BOUND ATOM

73-TA-NAT

REFERENCE ENERIYY DELTA X-SEC DELTA

5) $15847.3000-8 \quad 7.0000+0$

03/01/74 COHERENT SCATTERING

$5115847.3000-8$ $6.1000+04.8000-1$
$03 / 01 / 74$
TOTAL SCATTEFING
$73-T A-181$

CROSS SECTION

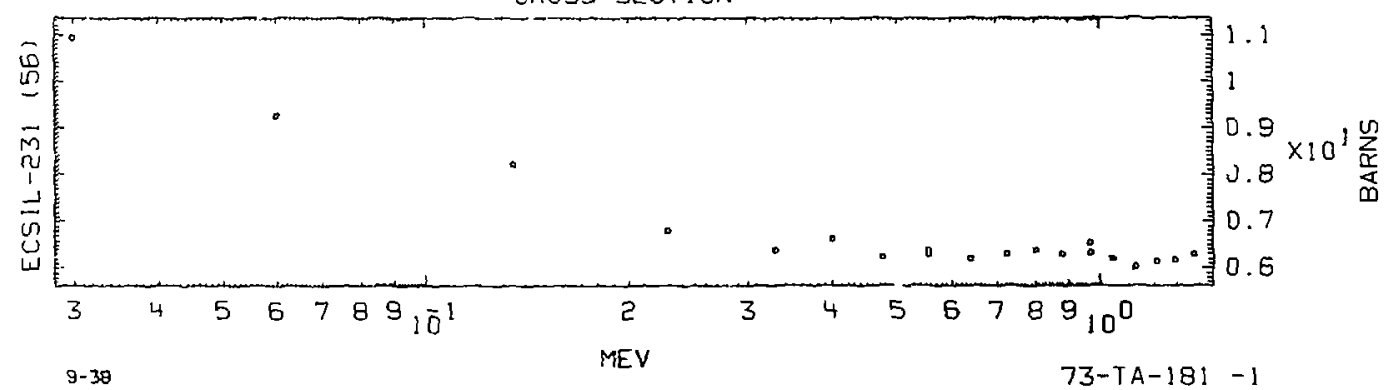



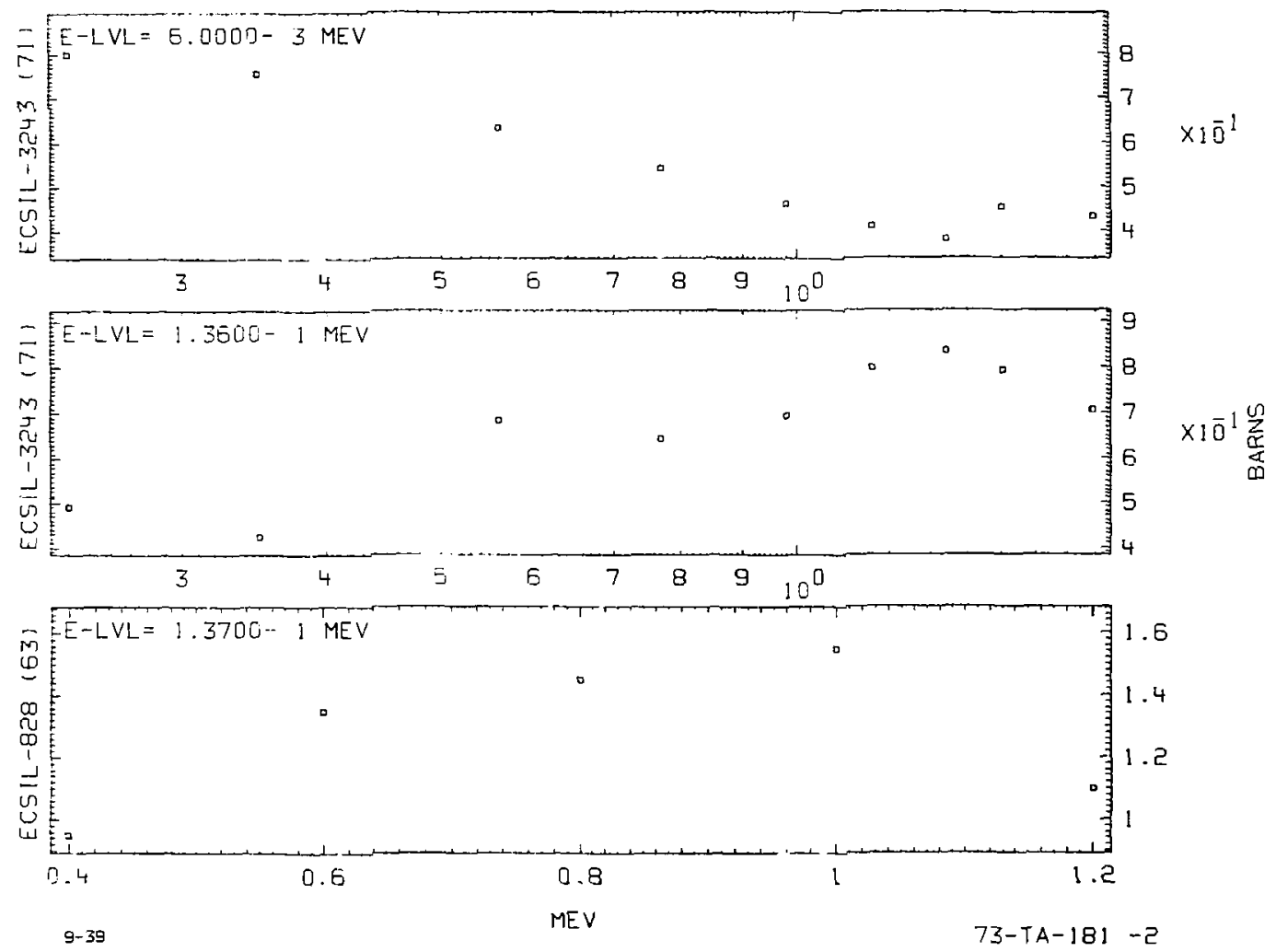


\section{CROSS SECTION}
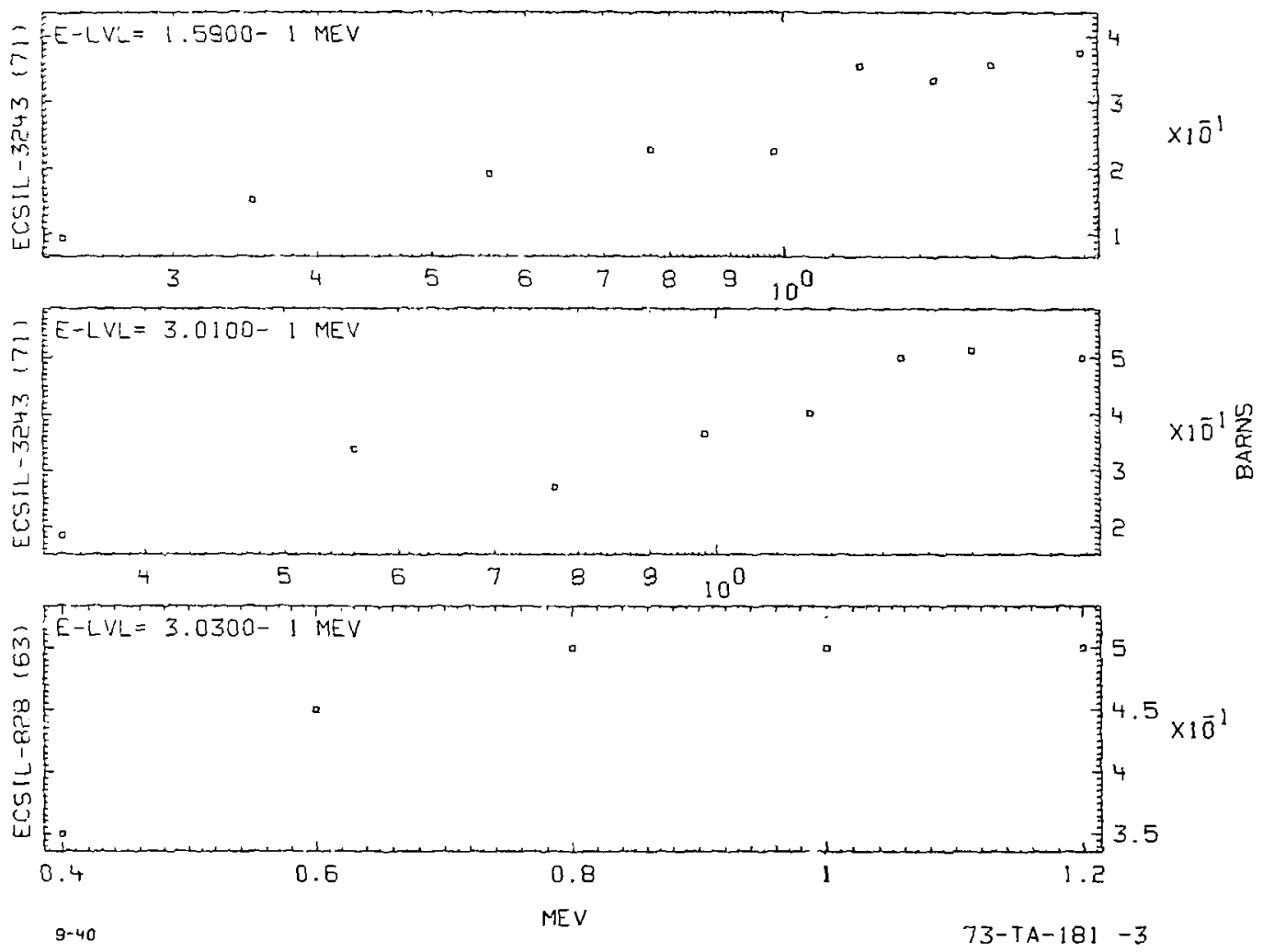

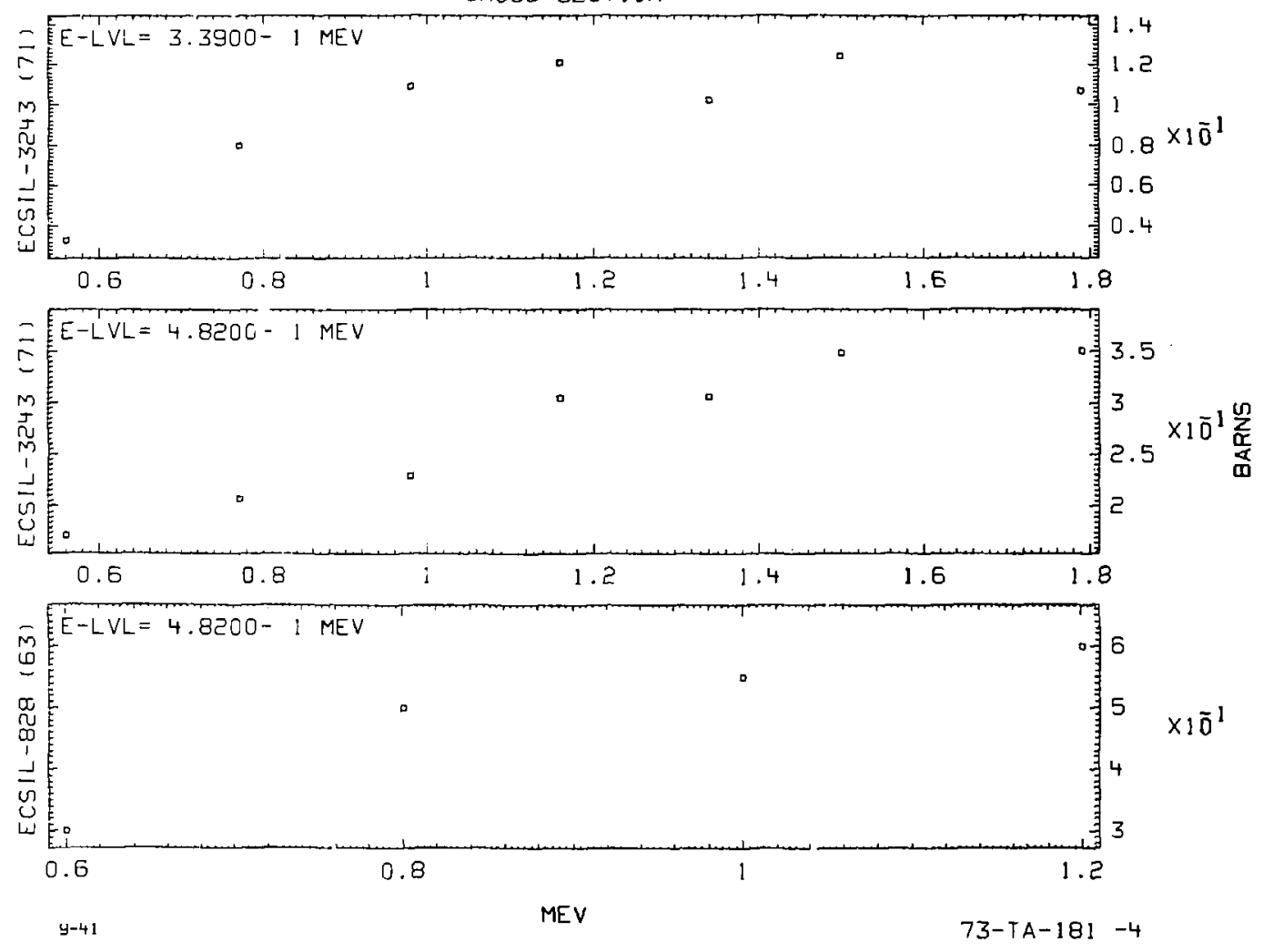

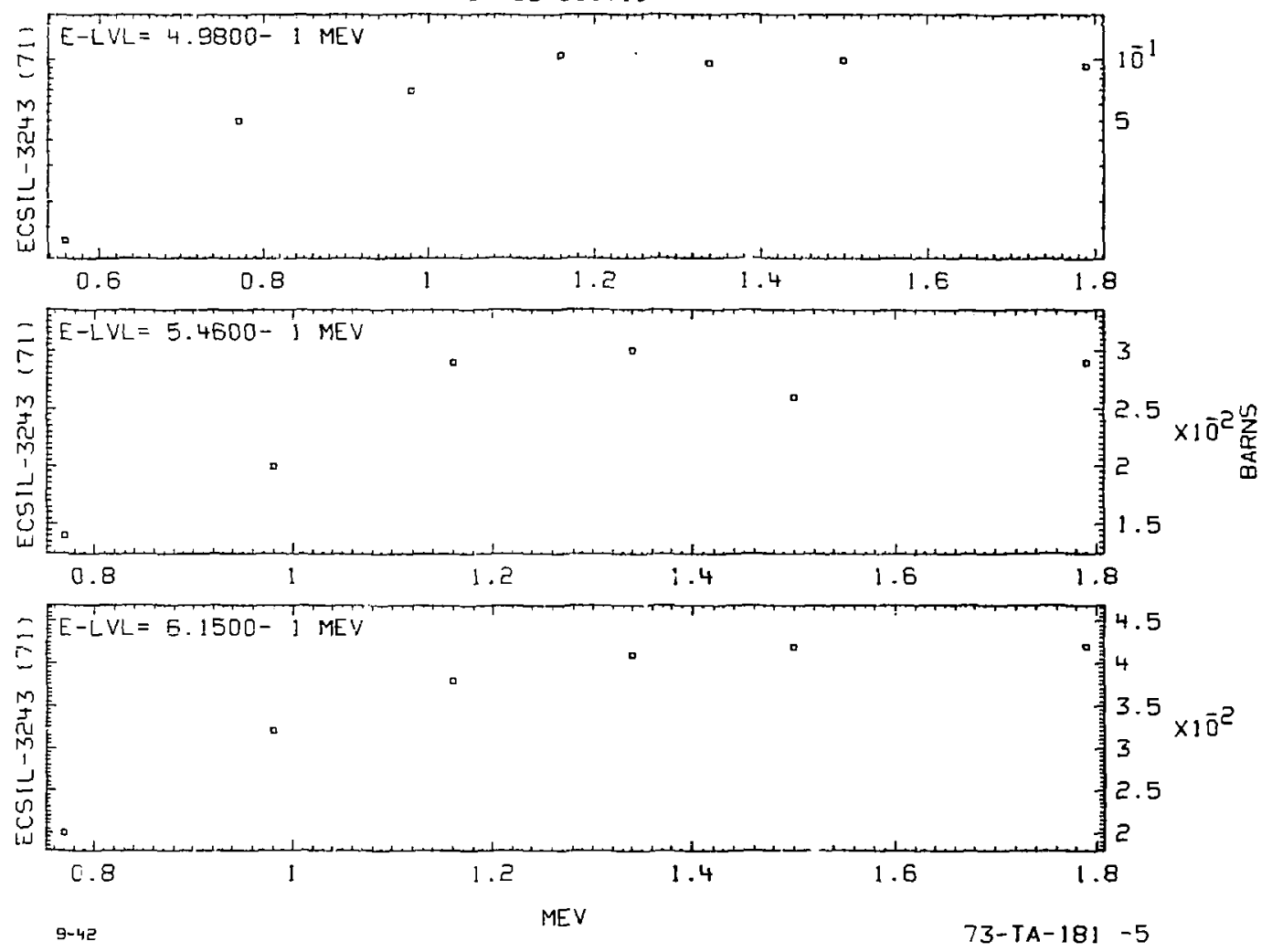

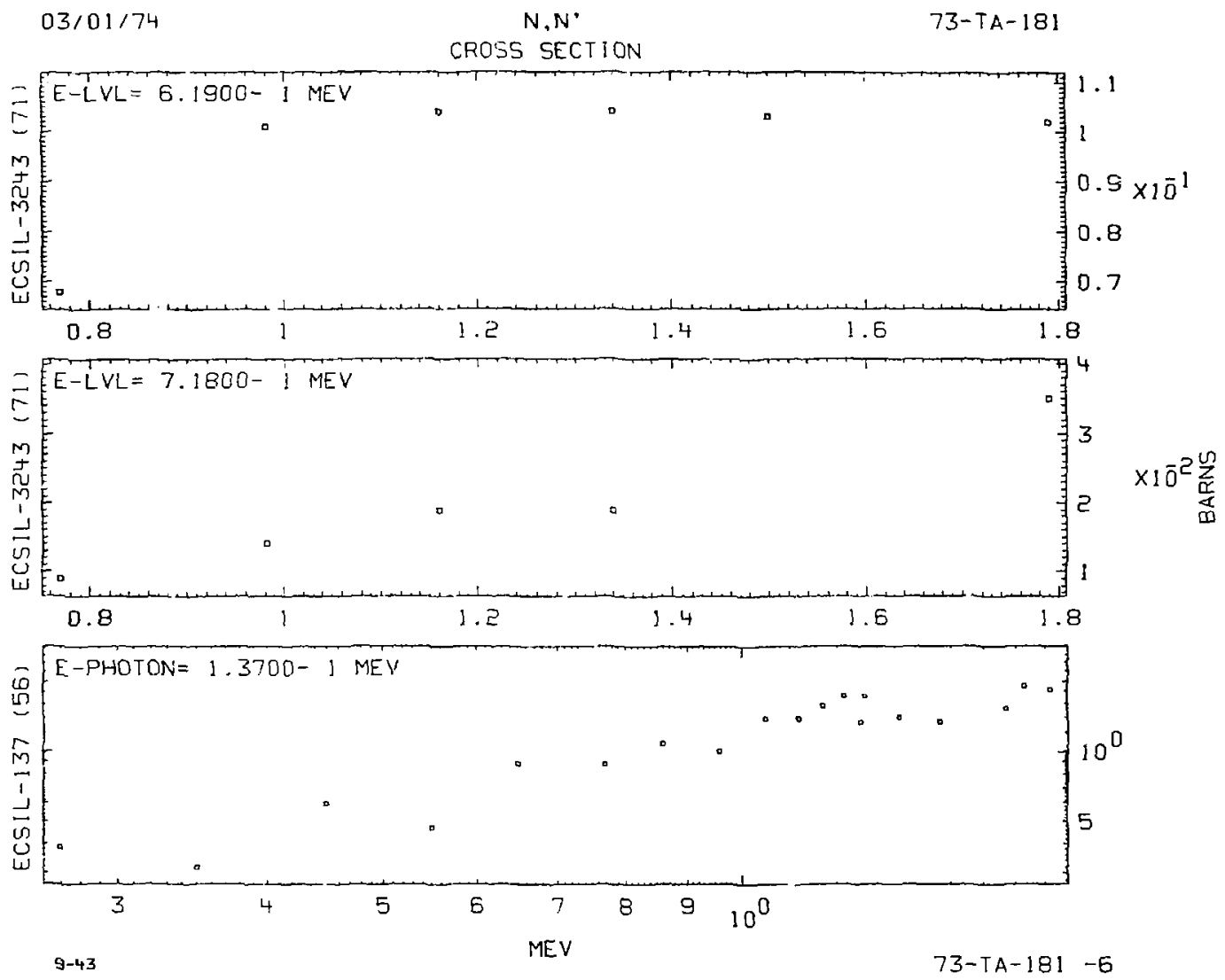


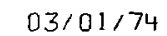

N, N'

$73-T A-181$

\section{CROSS SECTION}
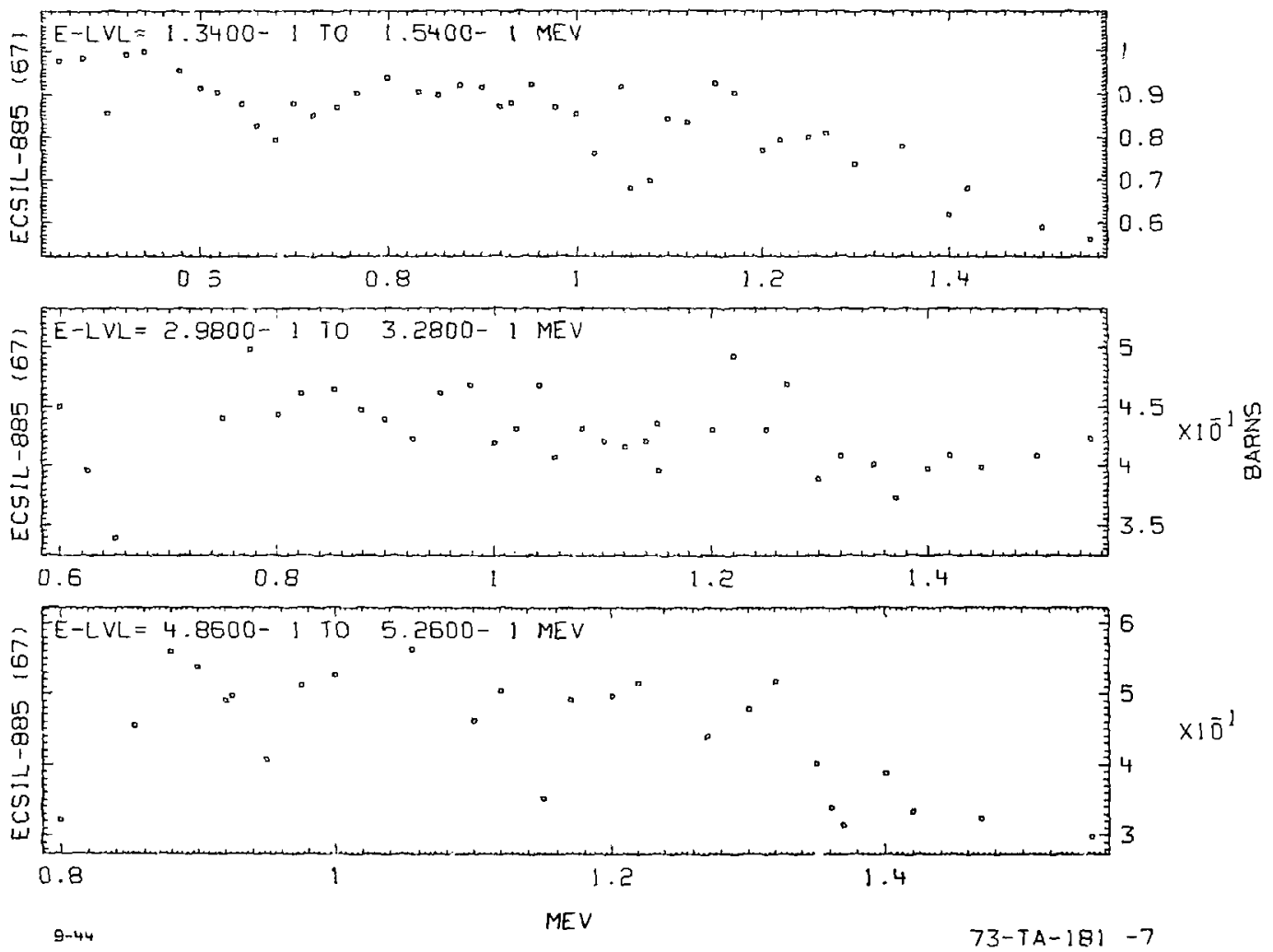

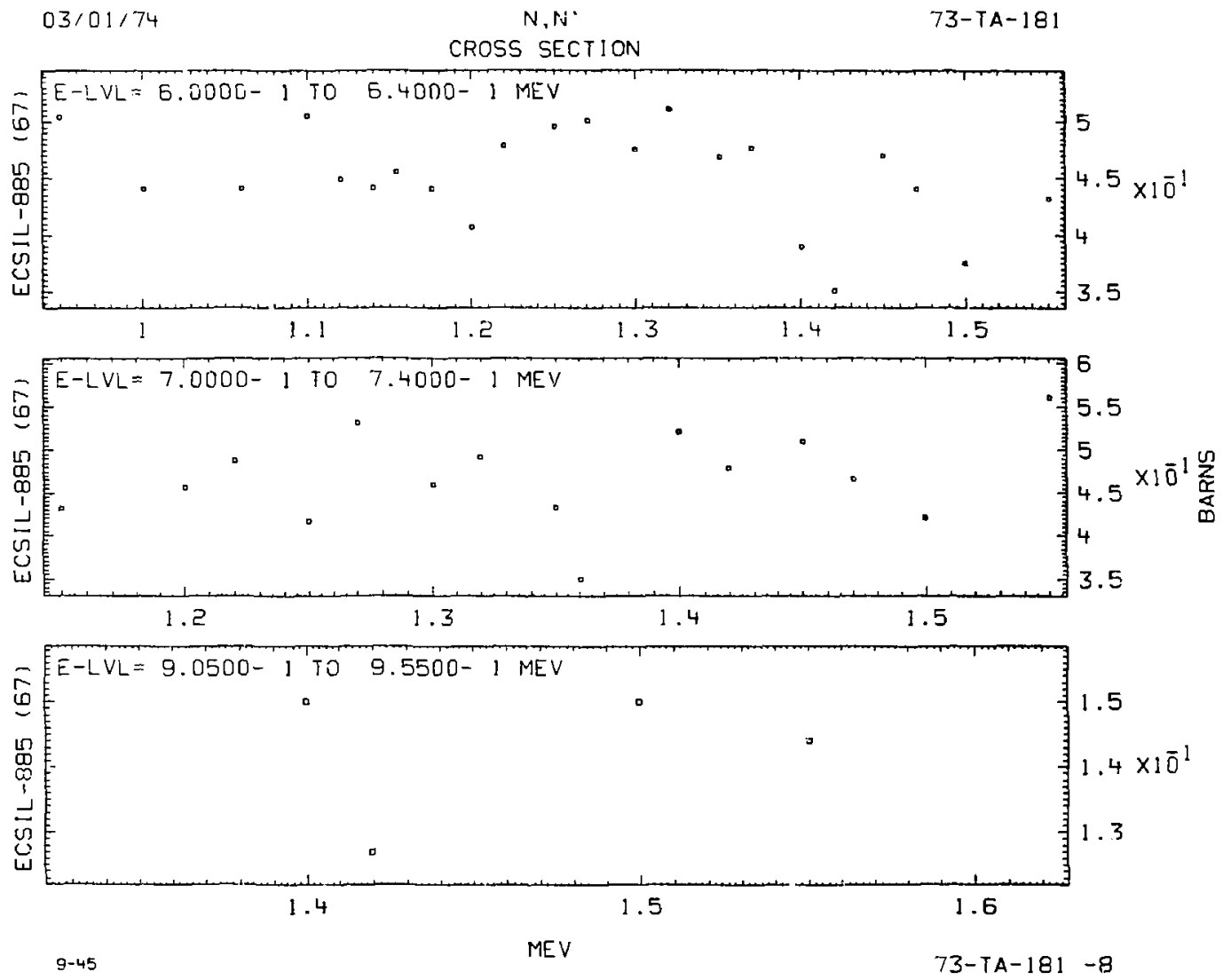


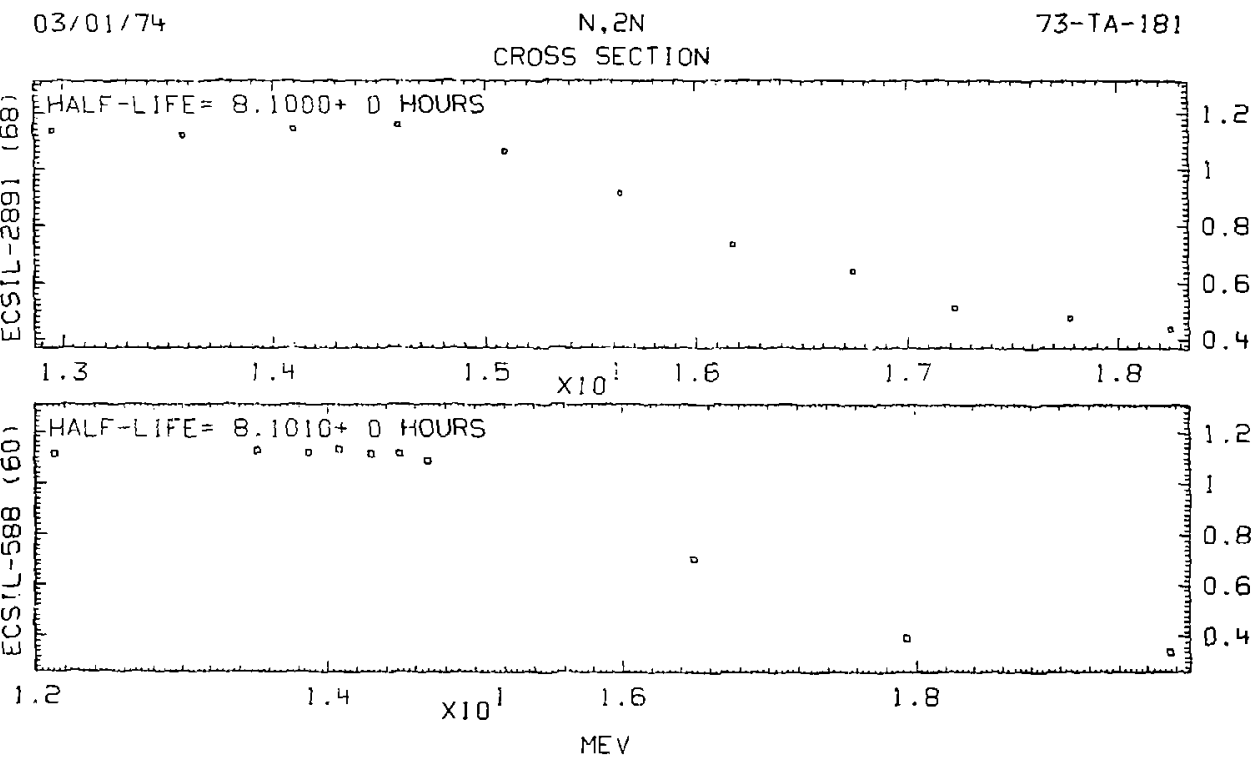




\section{CROSS SECTION}
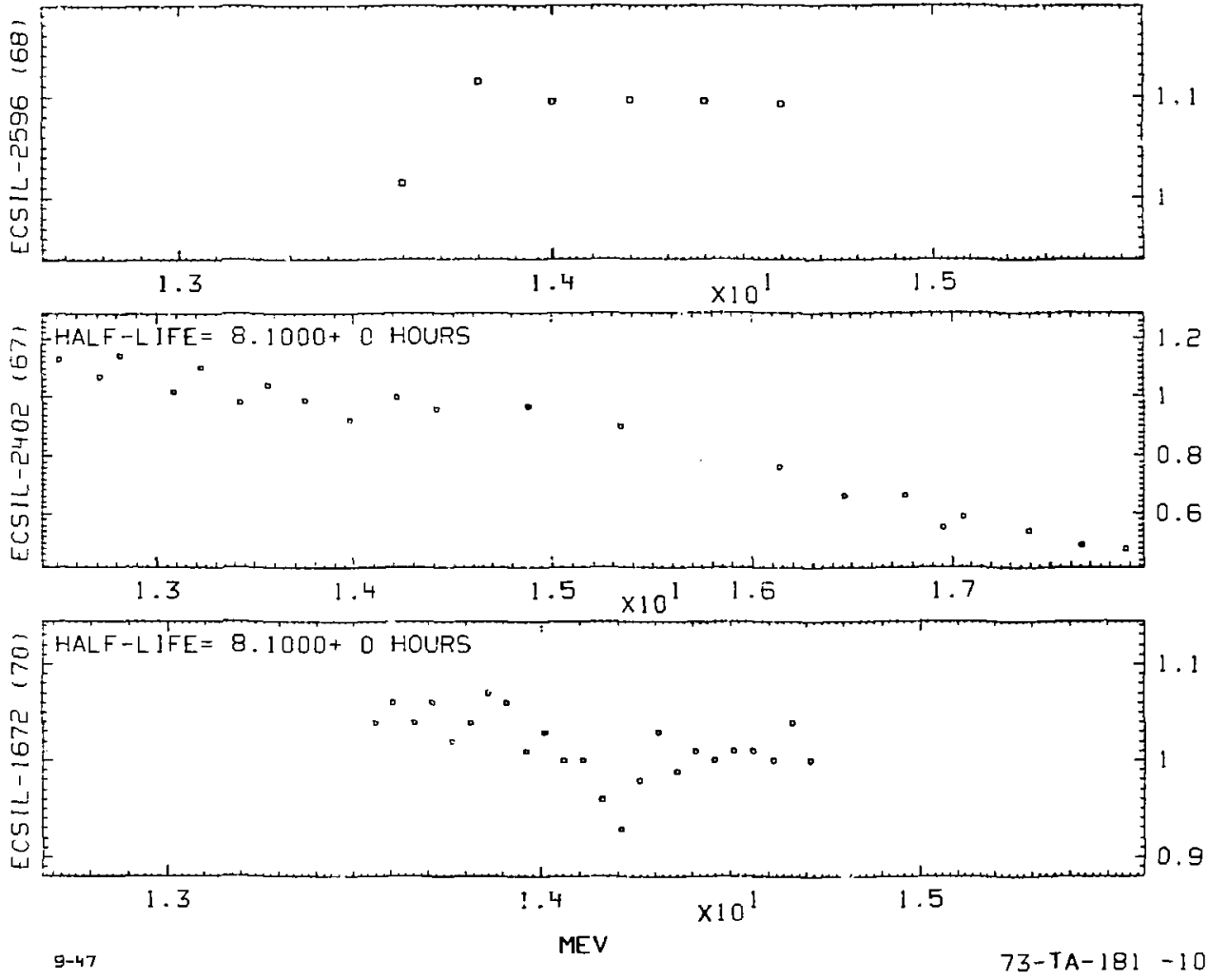

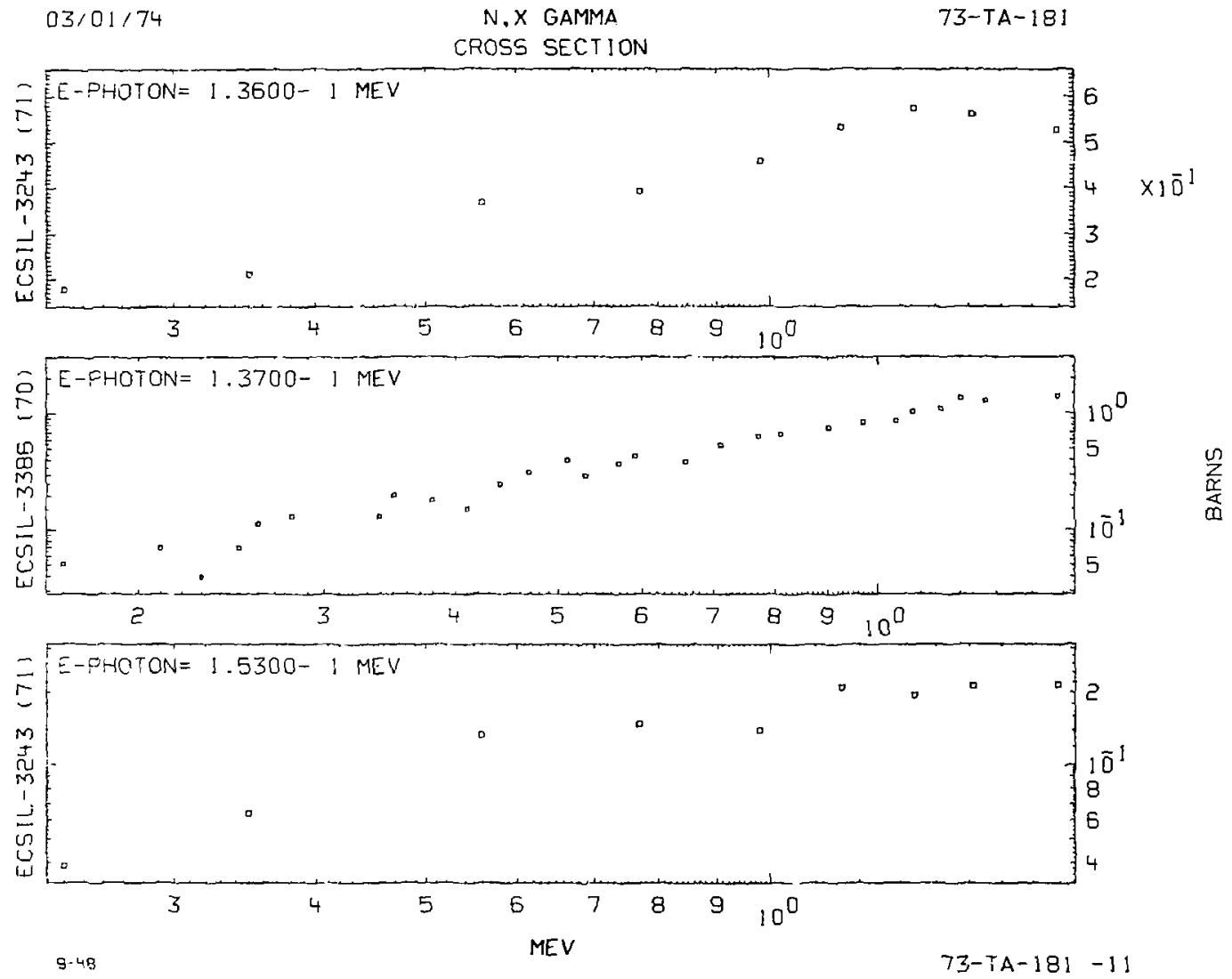

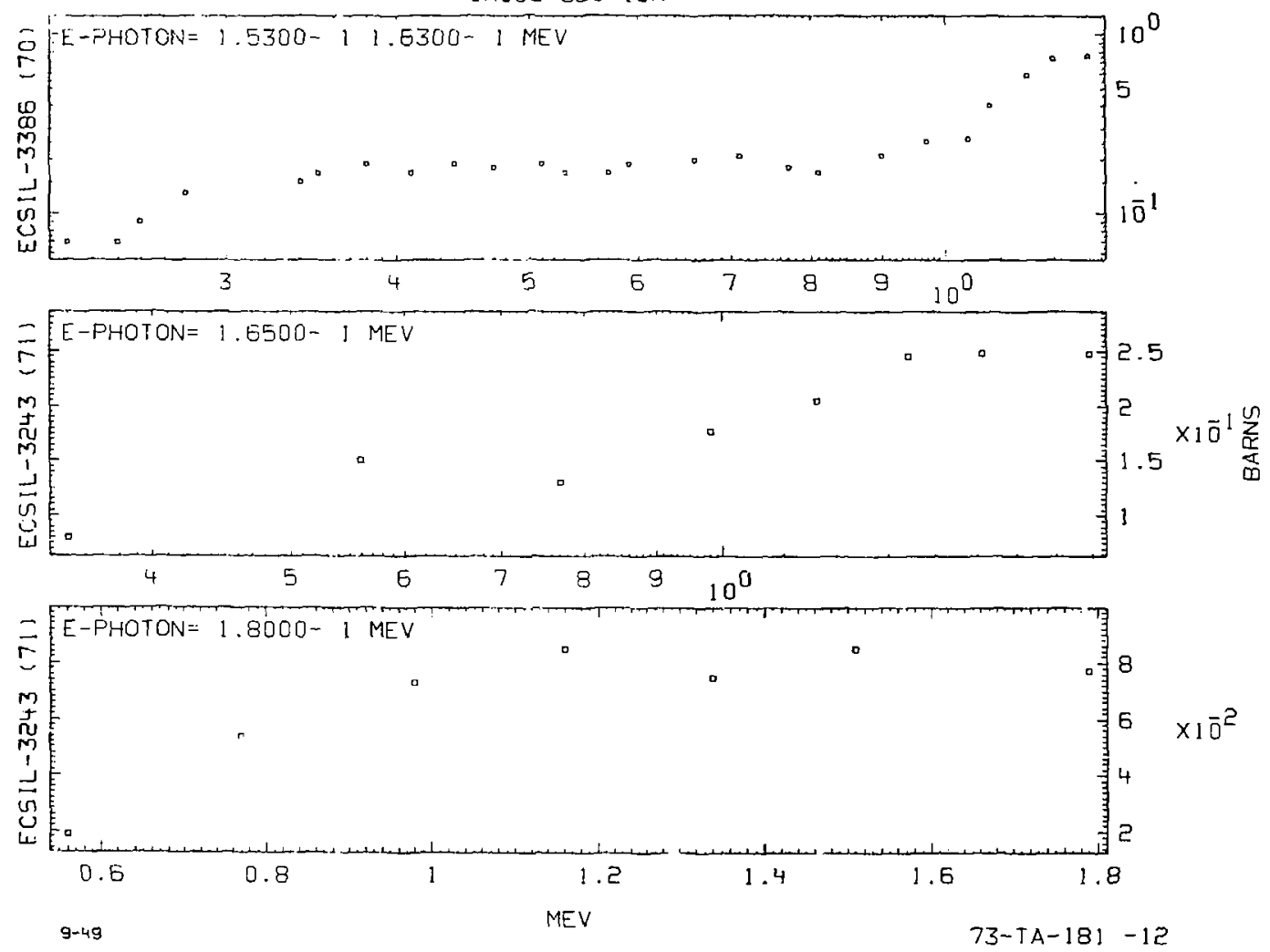

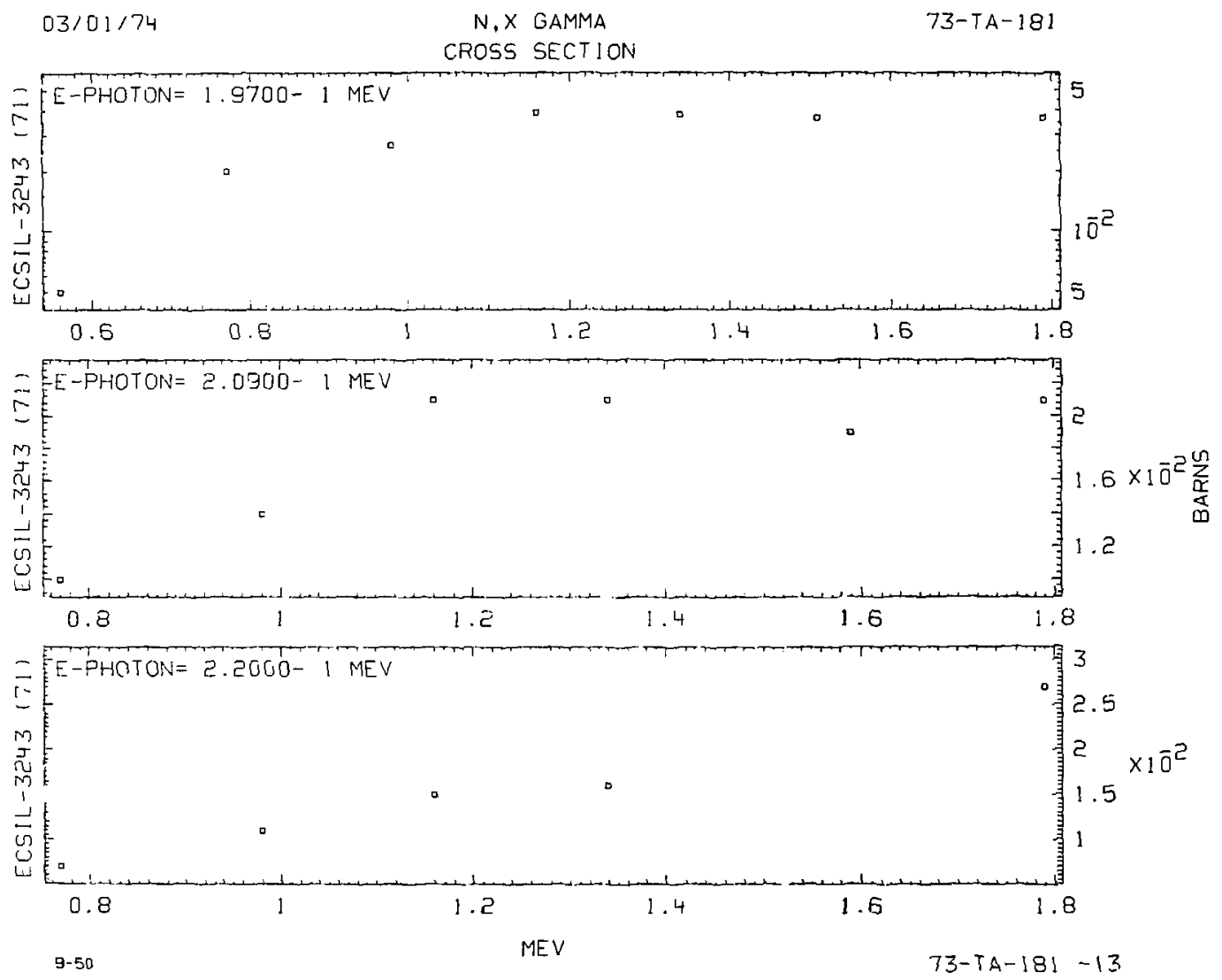


\section{$03 / 01 / 74$}

$N, X$ GAMMA

CROSS SECTION
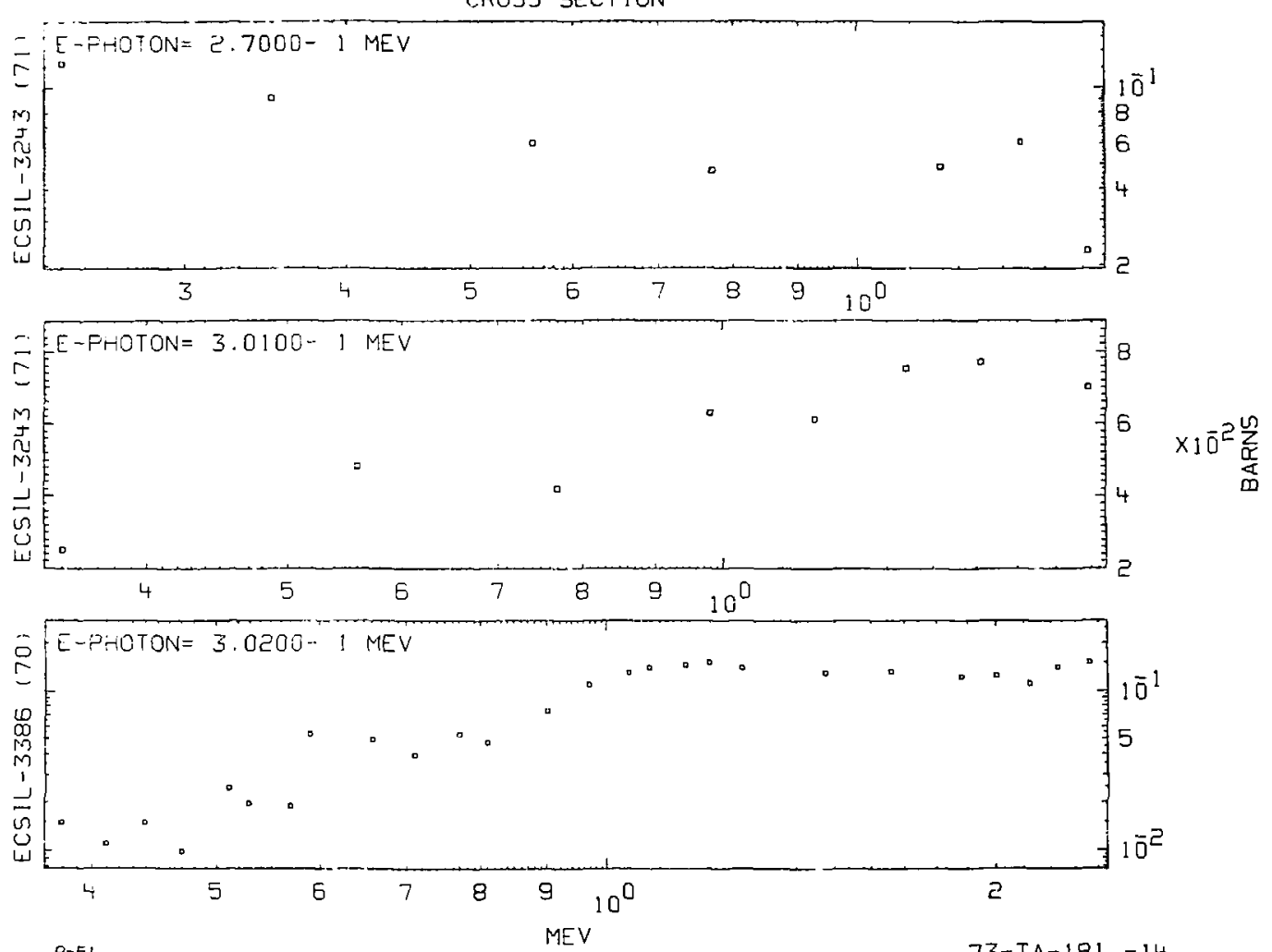

$9-5 !$ MEV
$73-T A-181$ 

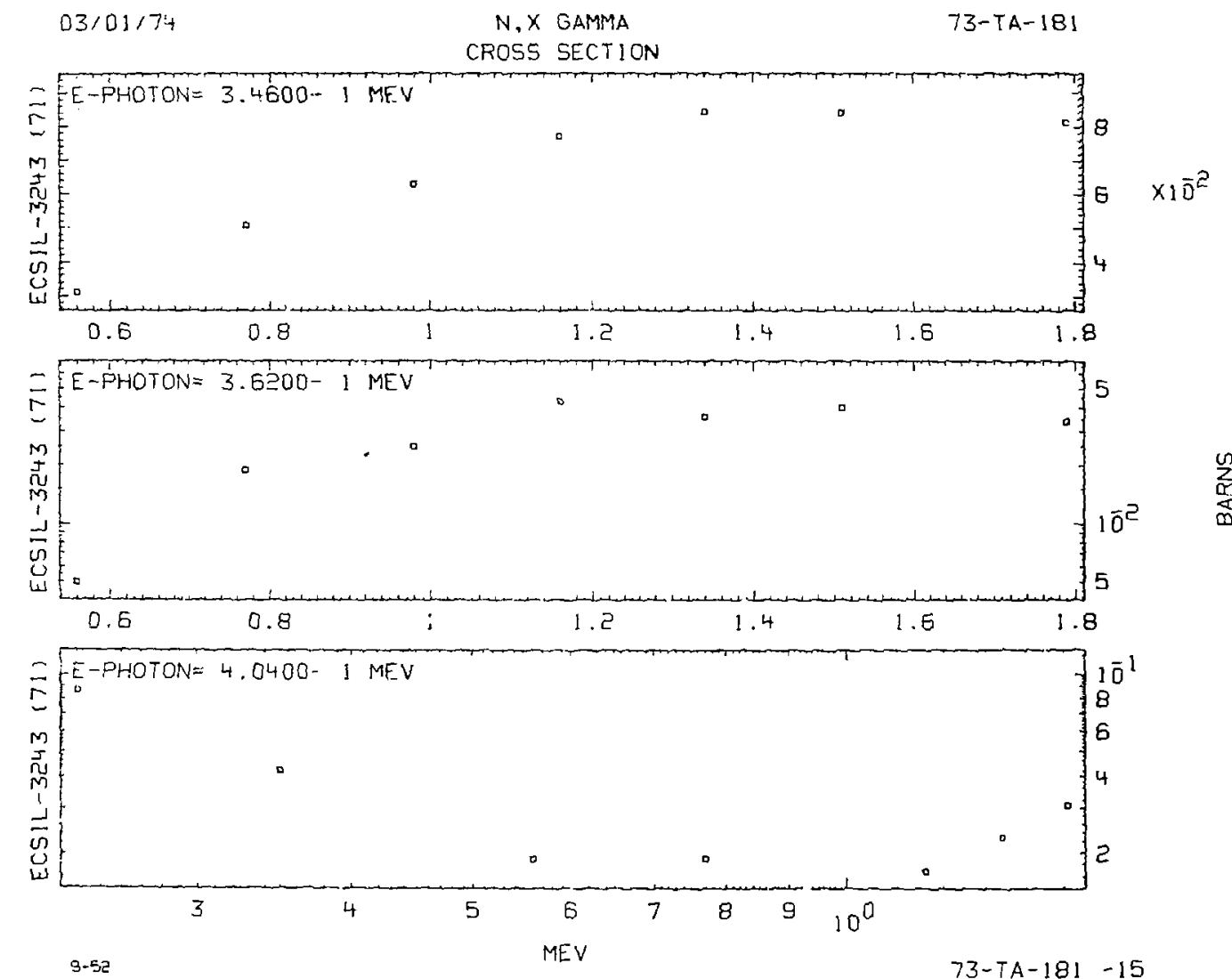


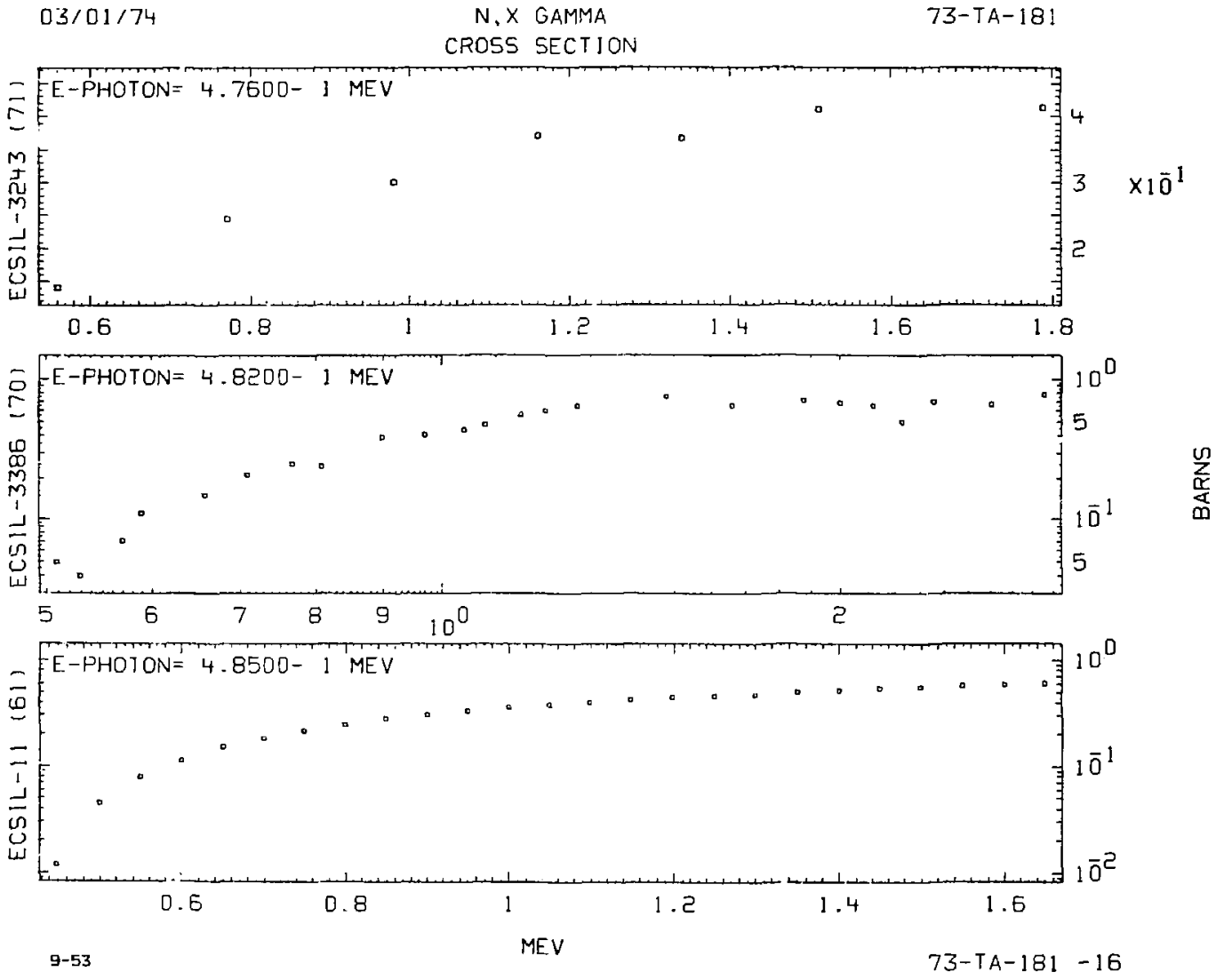




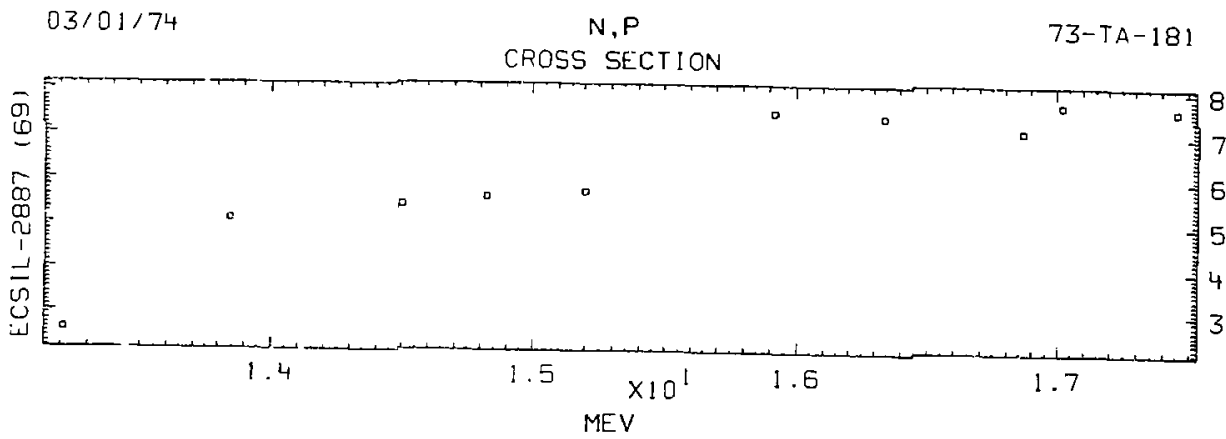

$03 / 01 / 74$

NONELASTIC

73-TA-181

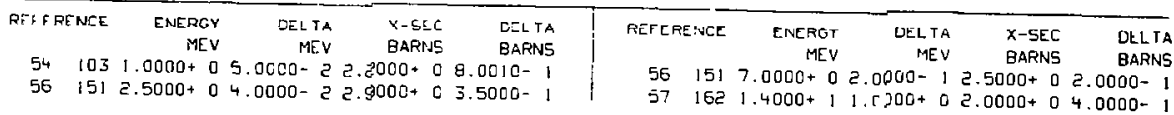

$03 / 01 / 74$

$N, N^{\prime}$

$73-T A-181$

REFENENCE CTERG
$57152 \mathrm{i} .4007+$
ENERGY

61 16557.0700

6) 16529.0100 -

5) $16529.0100-$

DELTA X-SEC DEITA

$\begin{array}{rrrr}\text { ML } V & \text { MELTA } & X-S E C & \text { DEITA } \\ & \text { GARNS } & \text { BARNS }\end{array}$

$1.0000+01.7000-13.0000-2$

$\begin{array}{rrrr}\text { OELTA } & \text { X-SEC } & \text { DELTA } & \text { E-LVL } \\ \text { MEV } & \text { BARNS } & \text { BARNS } & \text { MEV } \\ 1.2300+0 & 1.200 & 1 & 1.3700^{-} \\ 1.1400+0 & 1.0000-1 & 1.3700^{-} & 1 \\ 4.9000-1 & 9.0000-2 & 3.0300^{-} & 1\end{array}$




\section{CROSS SECTION}

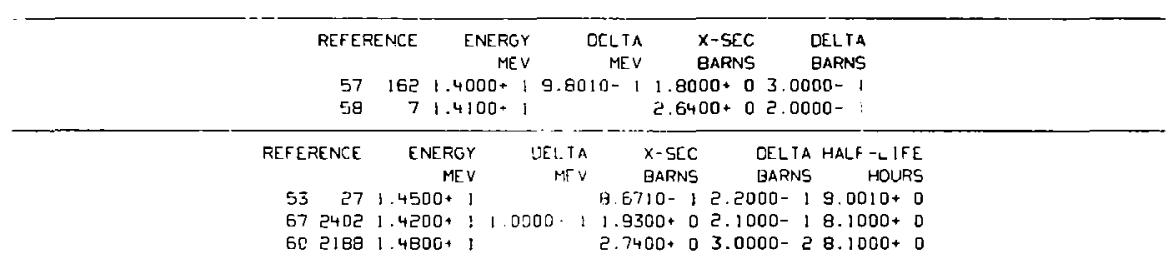

03/01/74 N,X GAMMA 73-TA-181

\begin{tabular}{|c|c|c|c|c|c|c|c|c|c|c|c|c|c|}
\hline \multirow{2}{*}{\multicolumn{2}{|c|}{ REFERENCE }} & ENERGY & DELTA & $x-\operatorname{SEC}$ & DELTA & A [-PHOTON & REFERE & ENCE & ENERGY & DELTA & $X-5 E C$ & DELTA & E-PHOTON \\
\hline & & $\mathrm{MEV}$ & MEV & GAFNS & BARNS & MEV & & & MEV & MEV & BARNS & BARNS & MEV \\
\hline 56 & 140 & $603-0$ & $03.0000-5$ & $4.5200-1$ & $5.4000-2$ & $21.3700 \cdots 1$ & 54 & 113 & $180+0$ & $2.0000-1$ & $1.2600+0$ & $2.5200-1$ & $4.6000-1$ \\
\hline 56 & $: 3$ & $E . \Xi \Xi \Delta J+2$ & {$[3.0000-2$} & $2.4400-1$ & $3.7000-2$ & $21.5400-1$ & 50 & 140 & $2.5600+0$ & $3.0000-2$ & B.5500-- 1 & $1.1000-i$ & $4.8500-1$ \\
\hline 56 & $i+\tau$ & $2.5505+0$ & $03.0000-2$ & 1. $3850-1$ & $4.2000-2$ & $23.5000-1$ & 54 & $1 \mathrm{i3}$ & $3.2000+0$ & $2.0000-1$ & $9.3000-1$ & $1.8600-1$ & $1.4400+0$ \\
\hline
\end{tabular}

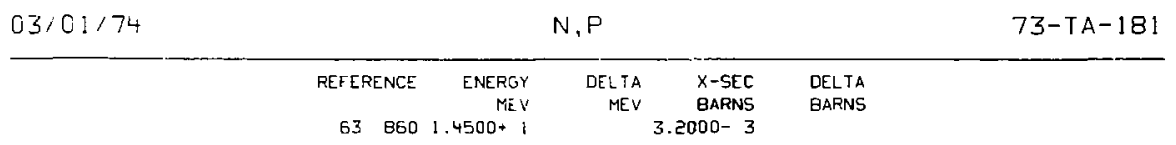

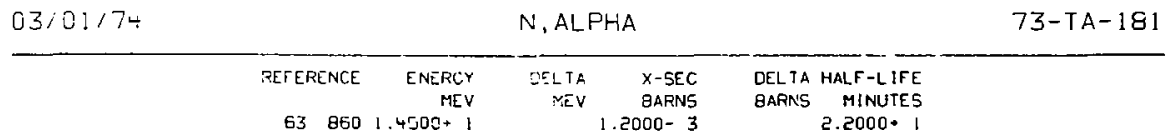



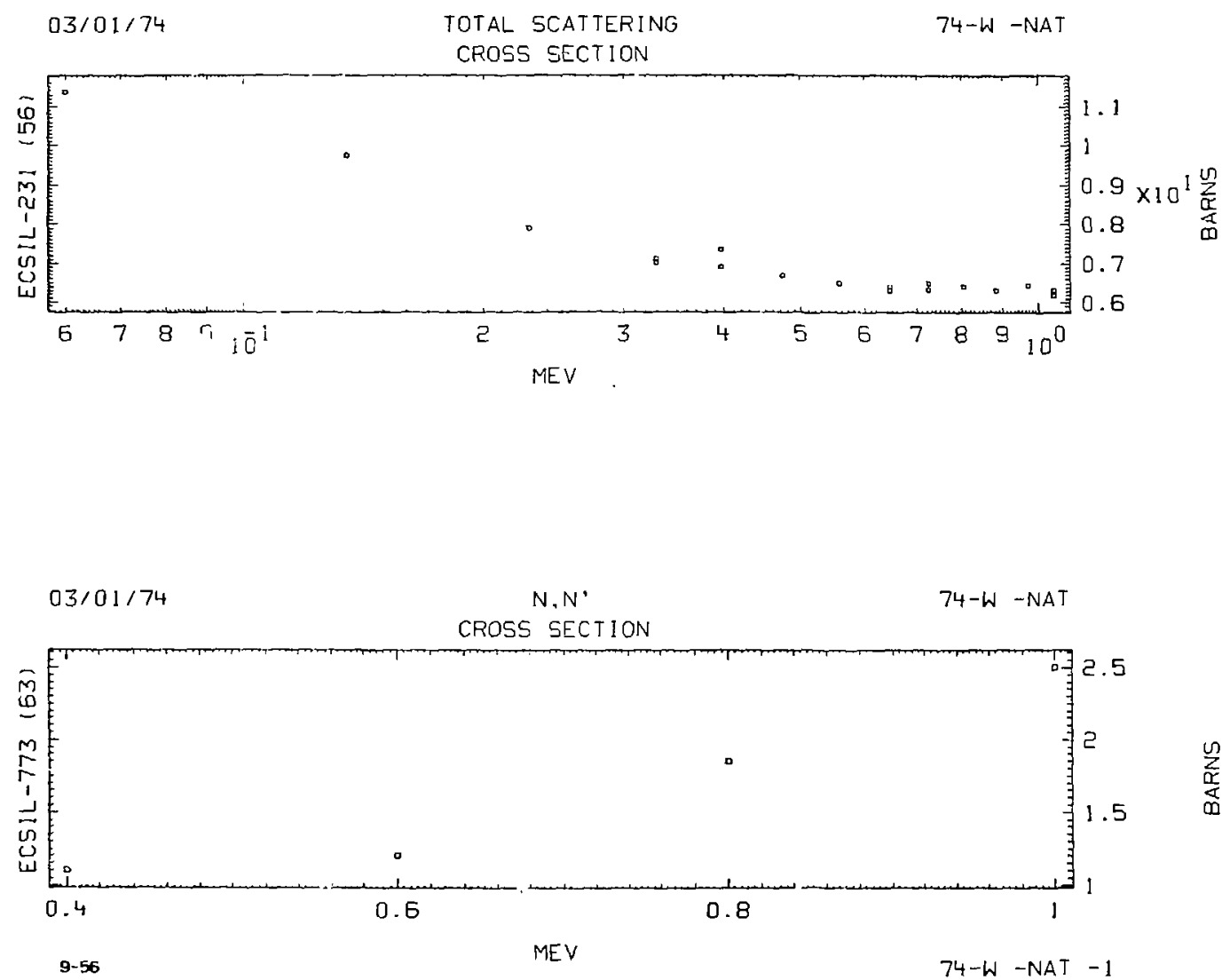
CROSS SECTION

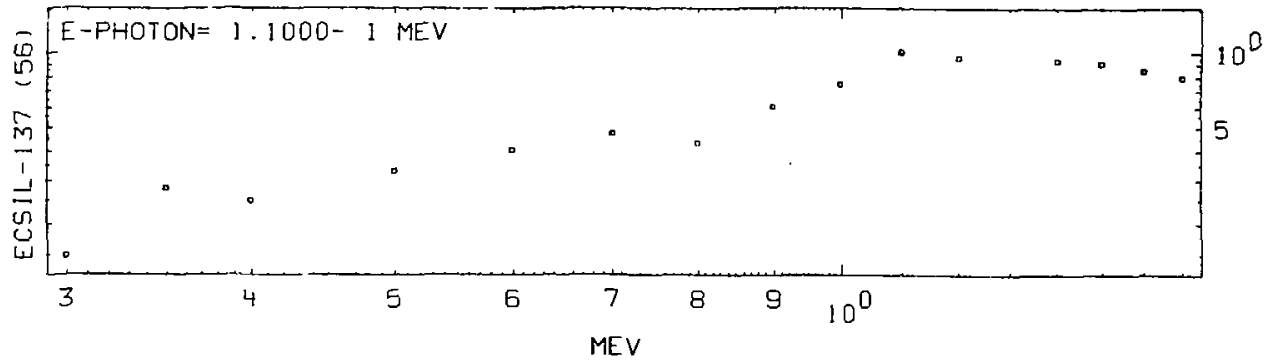

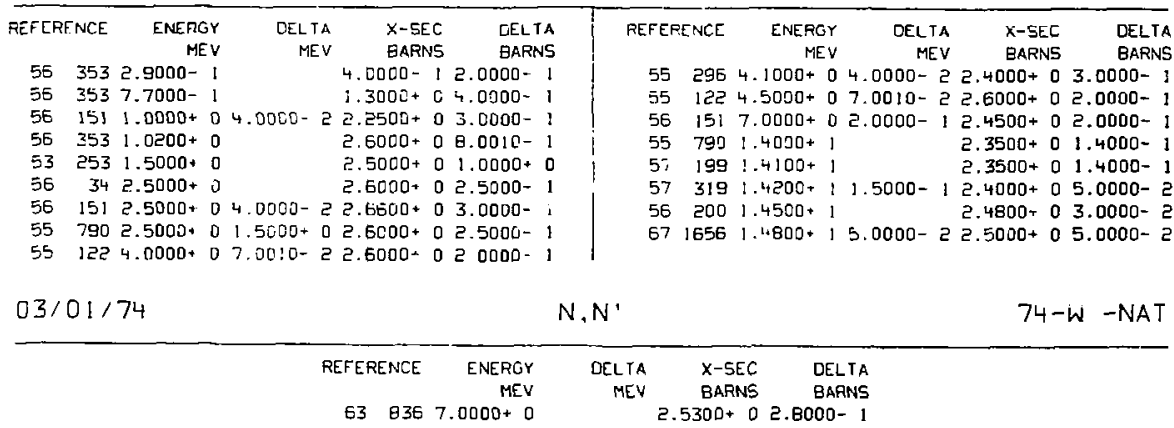


CROSS SECTION

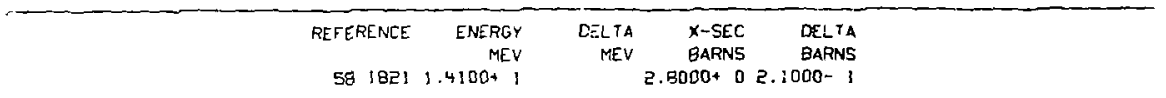

\begin{tabular}{|c|c|c|c|c|c|c|c|c|c|}
\hline $03 / 01 /$ & & & & $\triangle \mathrm{BS}$ & ION & & & $74-1$ & $W$-NAT \\
\hline FERENO & $\begin{array}{r}\text { ENERGY } \\
\text { MEV }\end{array}$ & $\begin{array}{l}\text { OEL IA } \\
\text { MEV }\end{array}$ & $\begin{array}{l}x-5 E C \\
\text { BARN5 }\end{array}$ & $\begin{array}{l}\text { DELTA } \\
\text { BARNS }\end{array}$ & REFERENCE & $\begin{array}{r}\text { ENERGY } \\
\text { MIL: }\end{array}$ & $\begin{array}{r}\text { DELTA } \\
\text { MEV }\end{array}$ & $\begin{array}{l}X-5 E C \\
\text { BARNS }\end{array}$ & $\begin{array}{l}\text { DELTA } \\
\text { BARNS }\end{array}$ \\
\hline $\begin{array}{l}60 \\
65\end{array}$ & $\begin{array}{l}5300-8 \\
\$ 000-z\end{array}$ & & $\begin{array}{l}1000+1 \\
000-1\end{array}$ & $\begin{array}{l}000-1 \\
000-a\end{array}$ & $\begin{array}{ll}58 & \text { ZE } \\
58 & 364\end{array}$ & $\begin{array}{l}2000-1 \\
3000-1\end{array}$ & $\begin{array}{l}0000-5 \\
0000-5\end{array}$ & $\begin{array}{l}3300-1 \\
0000-2\end{array}$ & $\begin{array}{l}3.5000 \sim 2 \\
3.3000 \sim 2\end{array}$ \\
\hline
\end{tabular}

$6513642.4000-2 \quad 3.0000-12.51000-3$

$583642.5000-24.0000-34.2200-12.6000-$

58 364 $8.3000-14.0000-24.0000-33.3000$ -

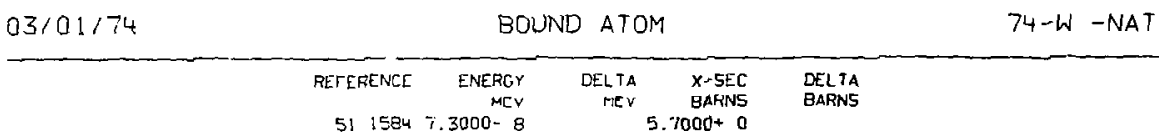

$03 / 01 / 74$

COHERENT SCATTERING

$74-W-N A T$

\begin{tabular}{|c|c|c|c|c|}
\hline RETERENC & $\begin{array}{r}\text { ENERGY } \\
M E V\end{array}$ & $\begin{array}{r}\text { DELTA } \\
\text { MEV }\end{array}$ & $\begin{array}{l}x-S E C \\
\text { BARNS }\end{array}$ & $\begin{array}{l}\text { DELTA } \\
\text { EARNS }\end{array}$ \\
\hline 5 & $050-8$ & & $3000+0$ & $2.6400-1$ \\
\hline
\end{tabular}




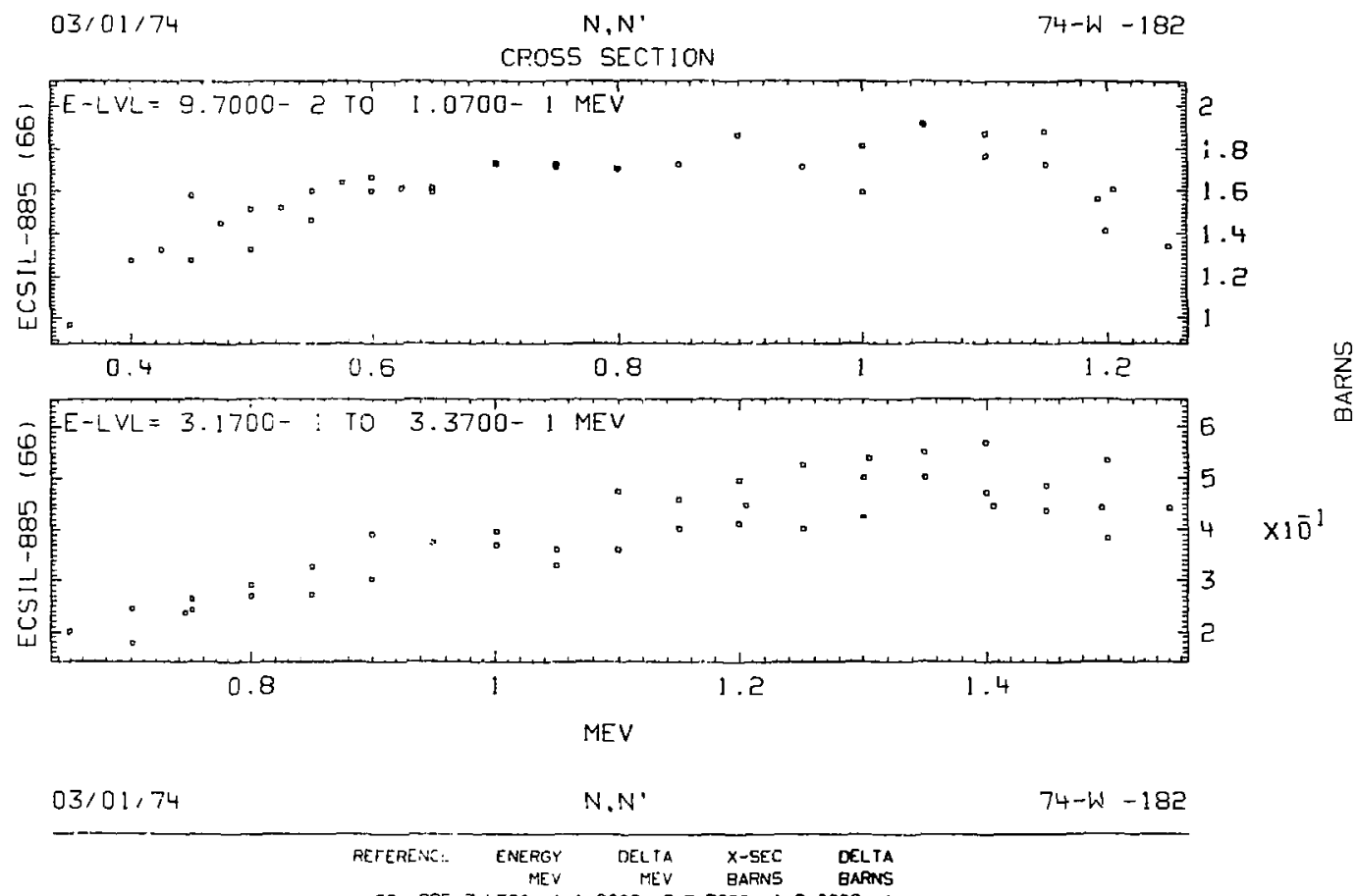

$668853.4500-1,0000-27.7000-12.0000-1$ 


\section{CROSS SECTION}

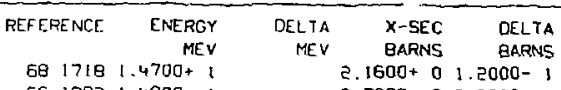

66 IB85 1.4800 .1
$03 / 01 / 74$
$N, N$
$74-W-184$

\section{CROSS SECTION}
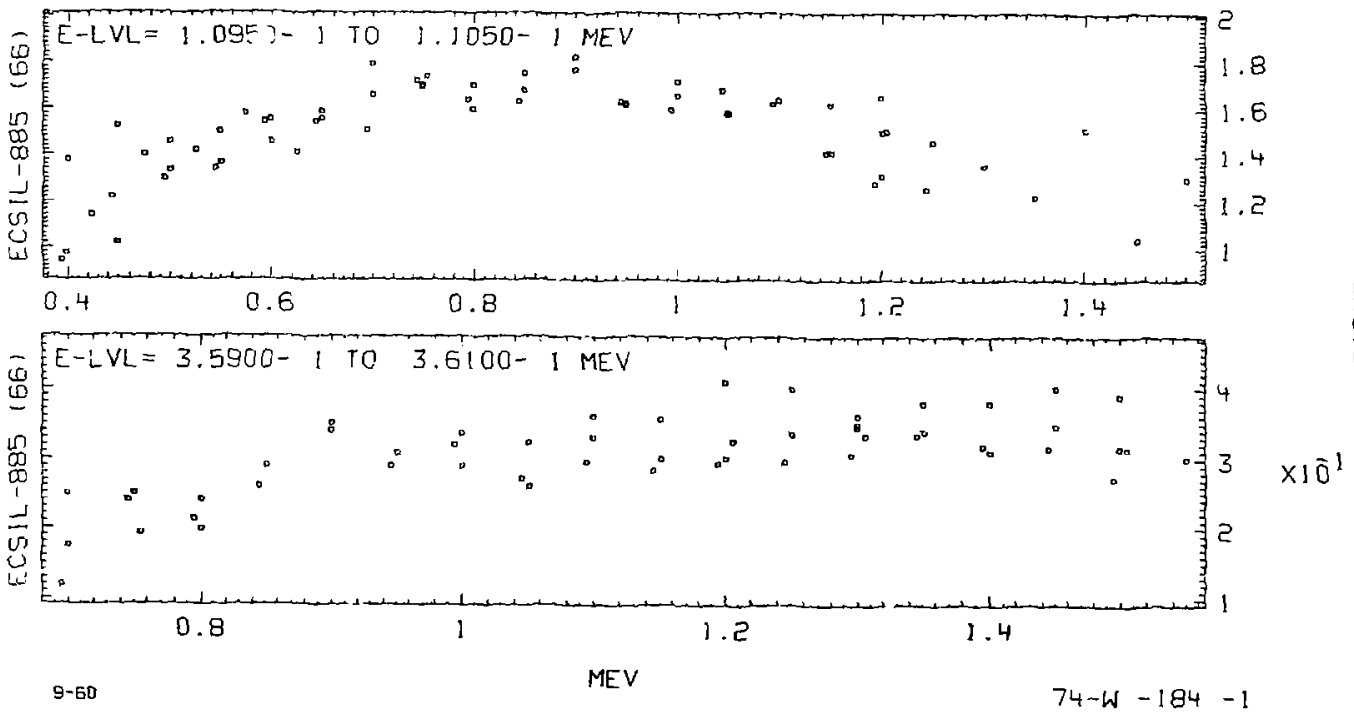

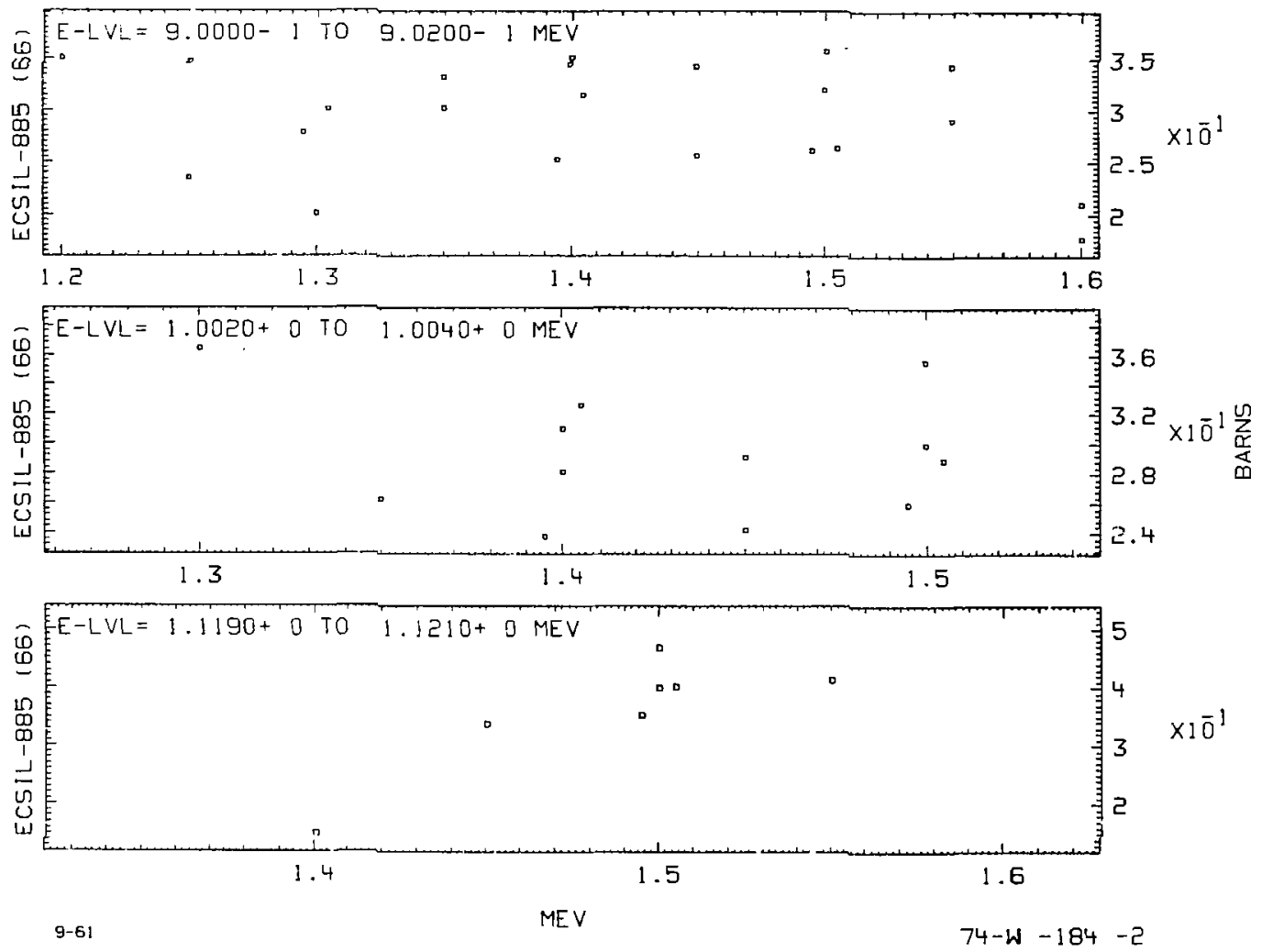


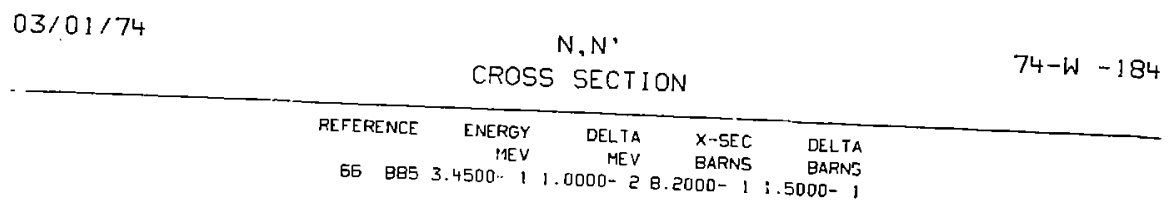

$03 / 01 / 74$

65 $\quad 8853.4500=$

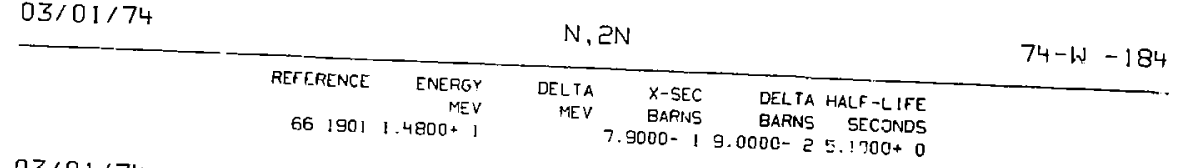

$03 / 01 / 74$

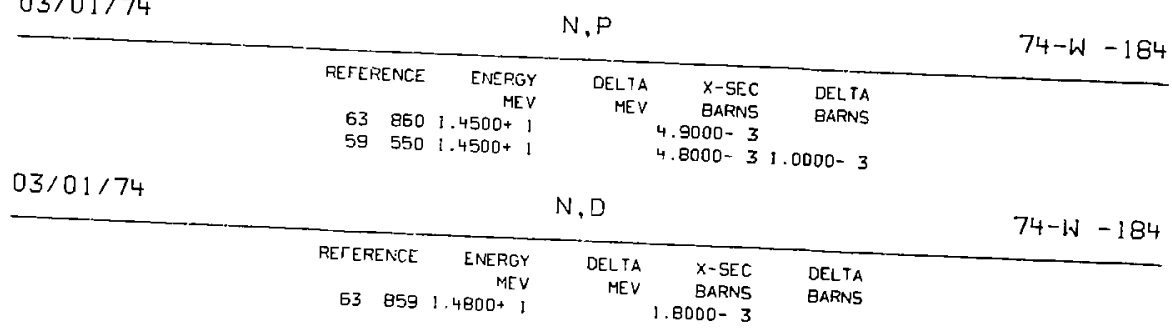




\section{CROSS SECTION}
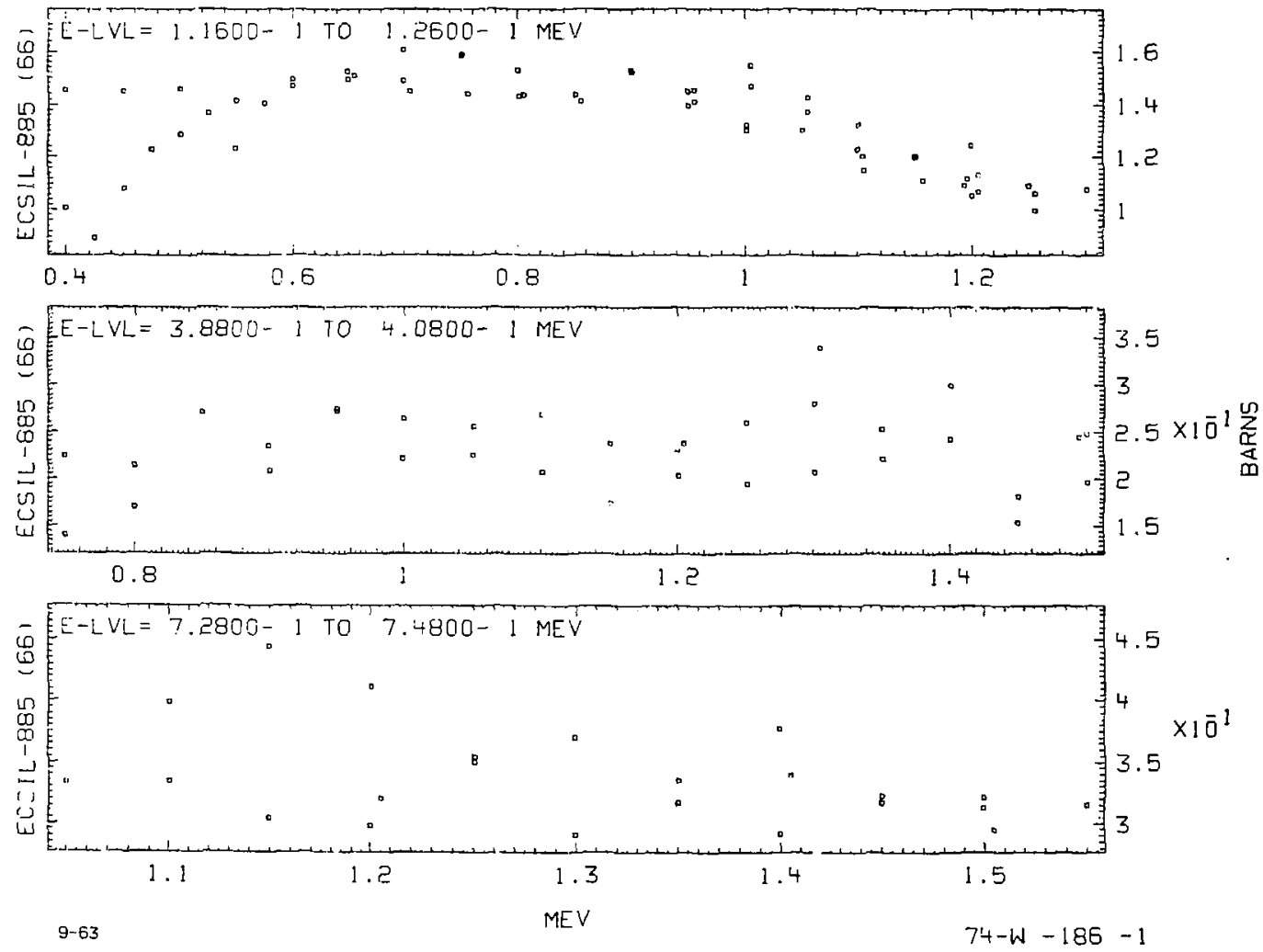


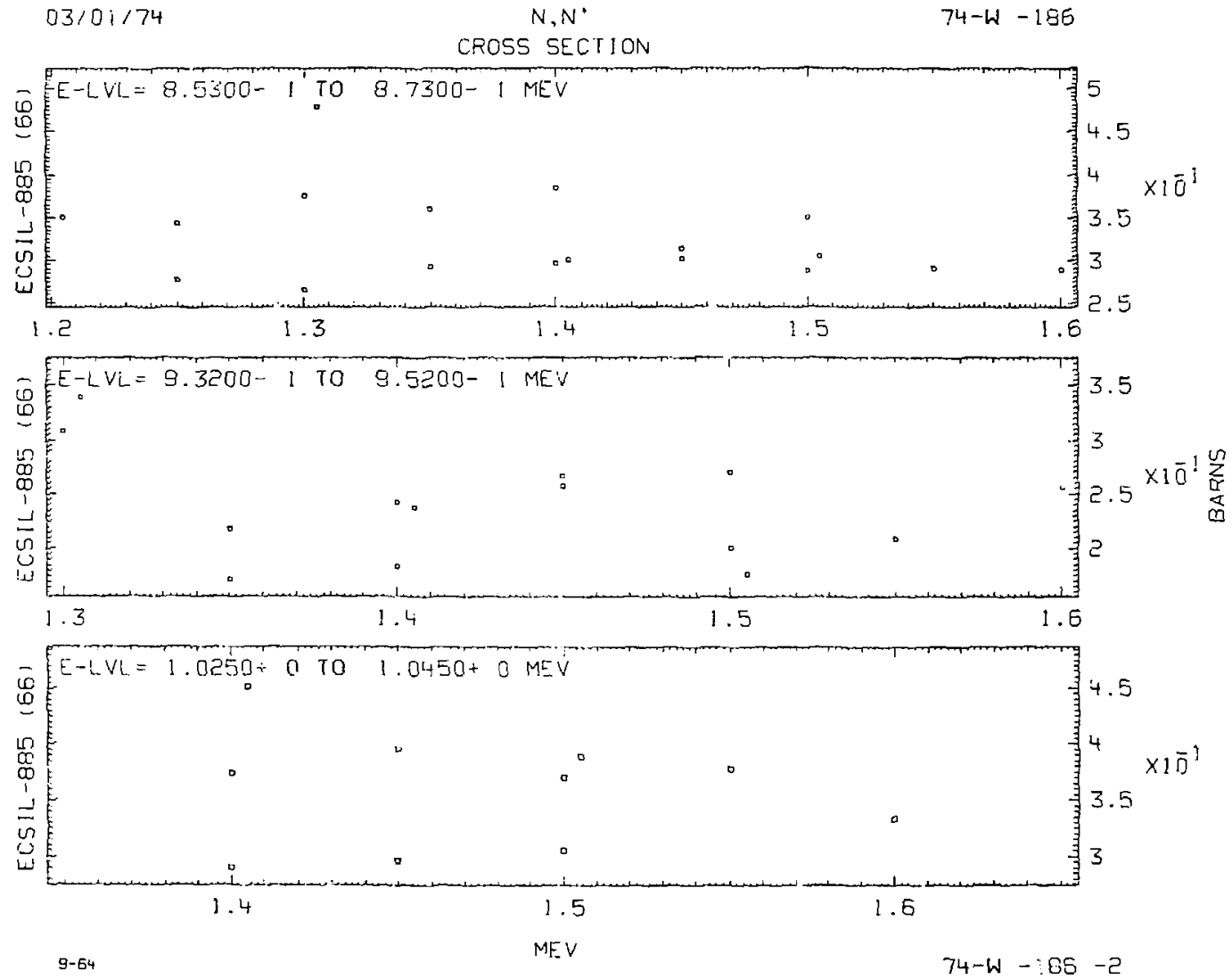



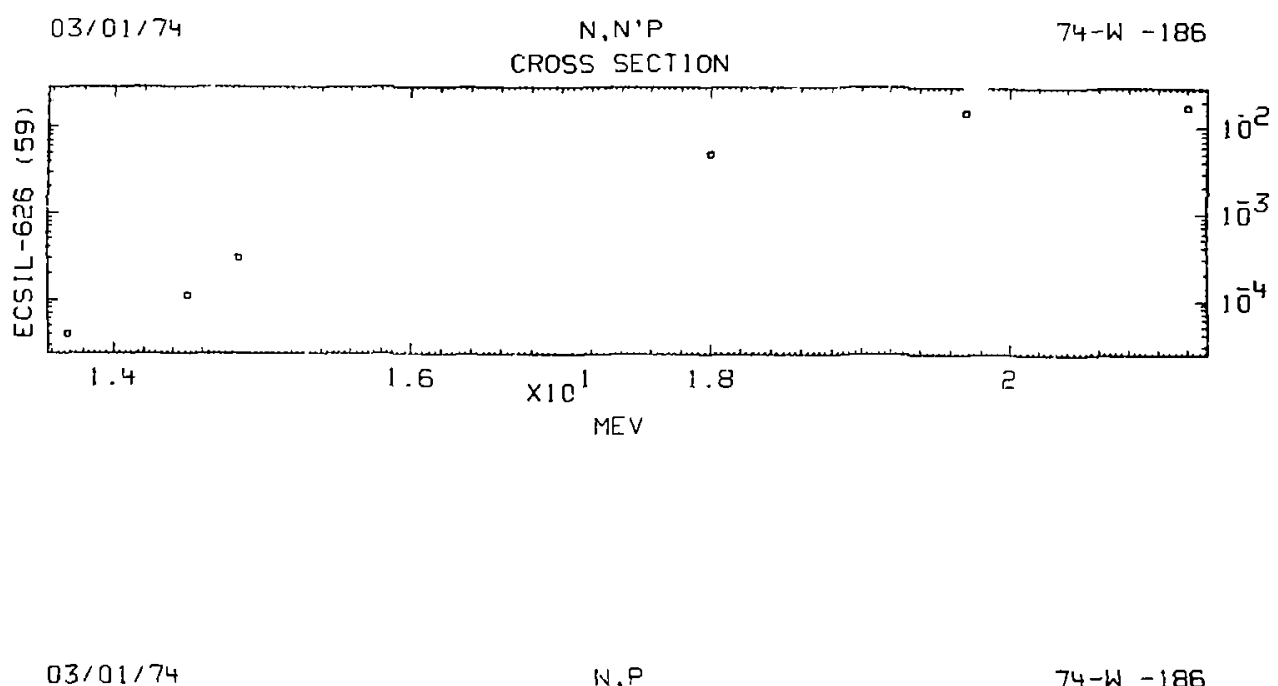

$N, P$

$74-W-186$

CROSS SECTION

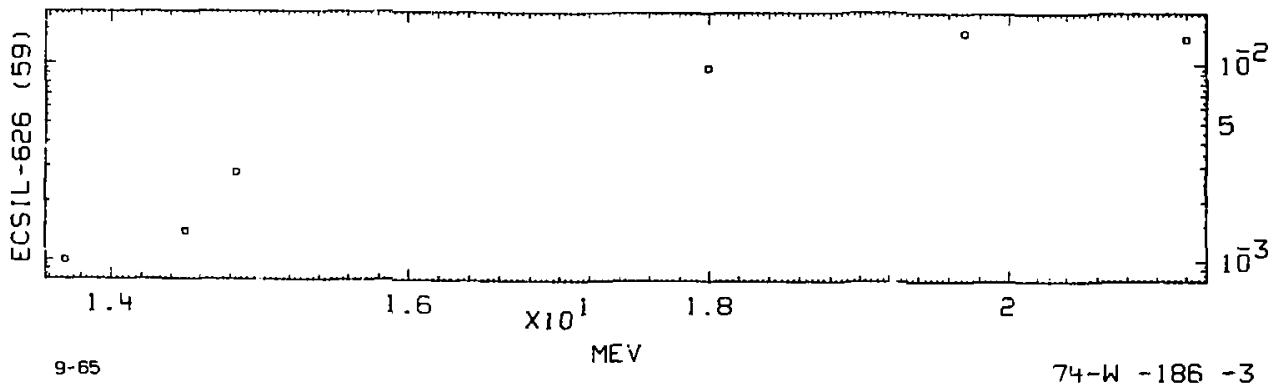

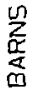




$\underbrace{03 / 01 / 74}_{\text {REFERENCE }}$ CROSS SECTION

$668053.5000-1,2.0000-26.0000-$, 2.0000-

\begin{tabular}{l}
$03 / 01 / 74$ \\
\hline \\
\hline
\end{tabular}




\section{CROSS SECTION}
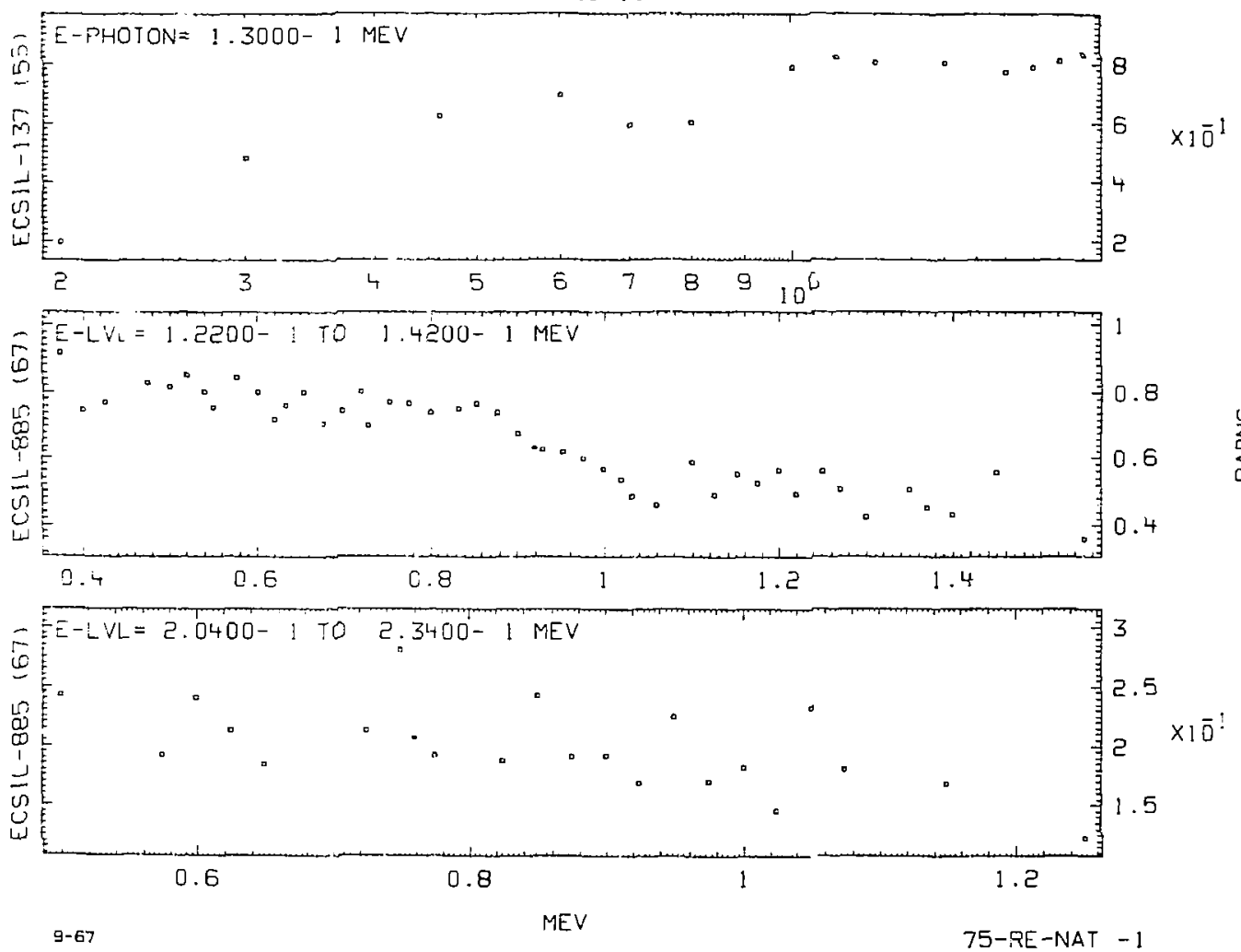

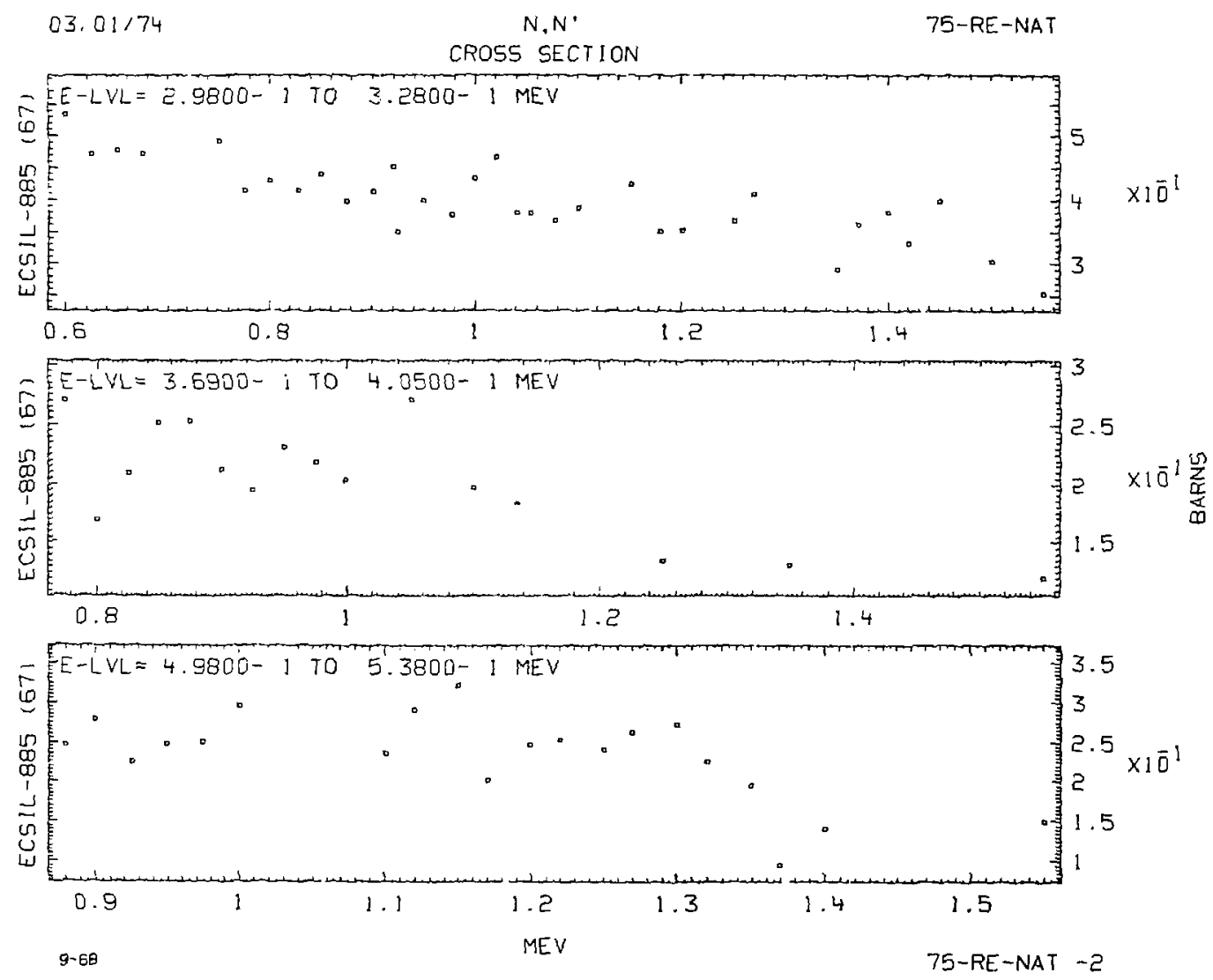

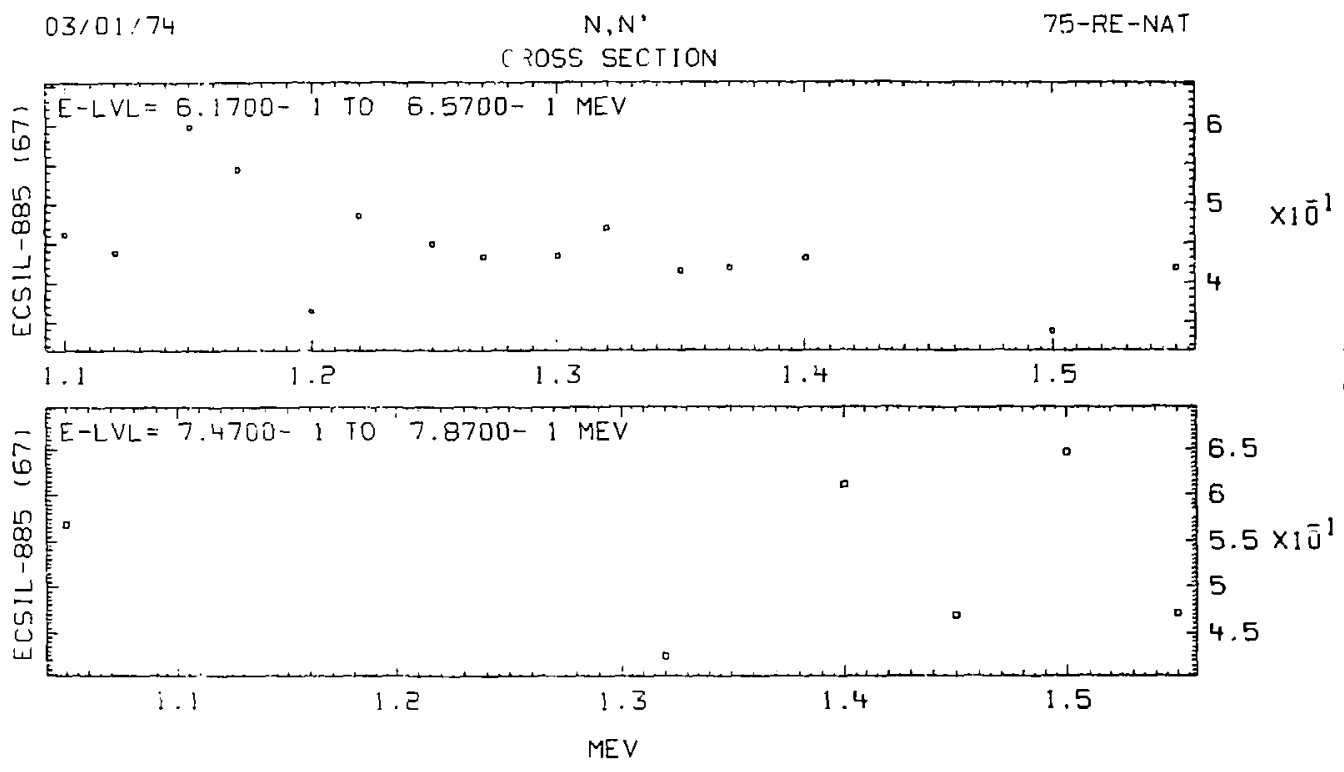

\begin{tabular}{|c|c|c|c|c|c|c|c|}
\hline \multirow[t]{2}{*}{$03 / 01,74$} & \multicolumn{7}{|c|}{$N, N^{*}$} \\
\hline & RETERENCE & $\begin{array}{r}\text { ENEFOY } \\
\text { MEV }\end{array}$ & $\begin{array}{r}D E \perp T A \\
\text { MEV }\end{array}$ & $\begin{array}{l}X \text { X-SEC } \\
\text { BARNS }\end{array}$ & $\begin{array}{l}\text { DELTAA } \\
\text { BARNS }\end{array}$ & E-LVL-MIN & $\begin{array}{l}V E-L V L-\operatorname{MAX} \\
\text { MEV }\end{array}$ \\
\hline & $67 \quad 885$ & $1.3500+0$ & $2.0000-5$ & $3.4900-1$ & $6.4300-?$ & $8.4000-1$ & $18.9000-1$ \\
\hline & 67885 & $1.4500+0$ & $2.0000-3$ & 3. $0400-1$ & $1.2400-1$ & $8.4000-1$ & $18.9000-1$ \\
\hline & $67 \quad 085$ & $1.5500+0$ & $2.0000 \cdot 2$ & $3.7000-1$ & $6.6900-2$ & $8.4000-1$ & $8.9000-1$ \\
\hline & E7 $8 B 5$ & $1.5000+0$ & $2.0000-\bar{E}$ & $3.0300-1$ & $4.6100-2$ & $9 . \leqslant 800-1$ & 19.8800- \\
\hline & $67 \quad 885$ & $1.5 E \cdot 30 \cdot 0$ & $2.0000-2$ & $3.2200-1$ & $1.3600-1$ & $9.3800-1$ & $9.8800-1$ \\
\hline & $67 \quad 885$ & $1.5000+0$ & $2.0000-5$ & 2.2300-1 & $3.4200-2$ & $=1.0350+0$ & b $1.0850+0$ \\
\hline
\end{tabular}


CRUSS SECTION

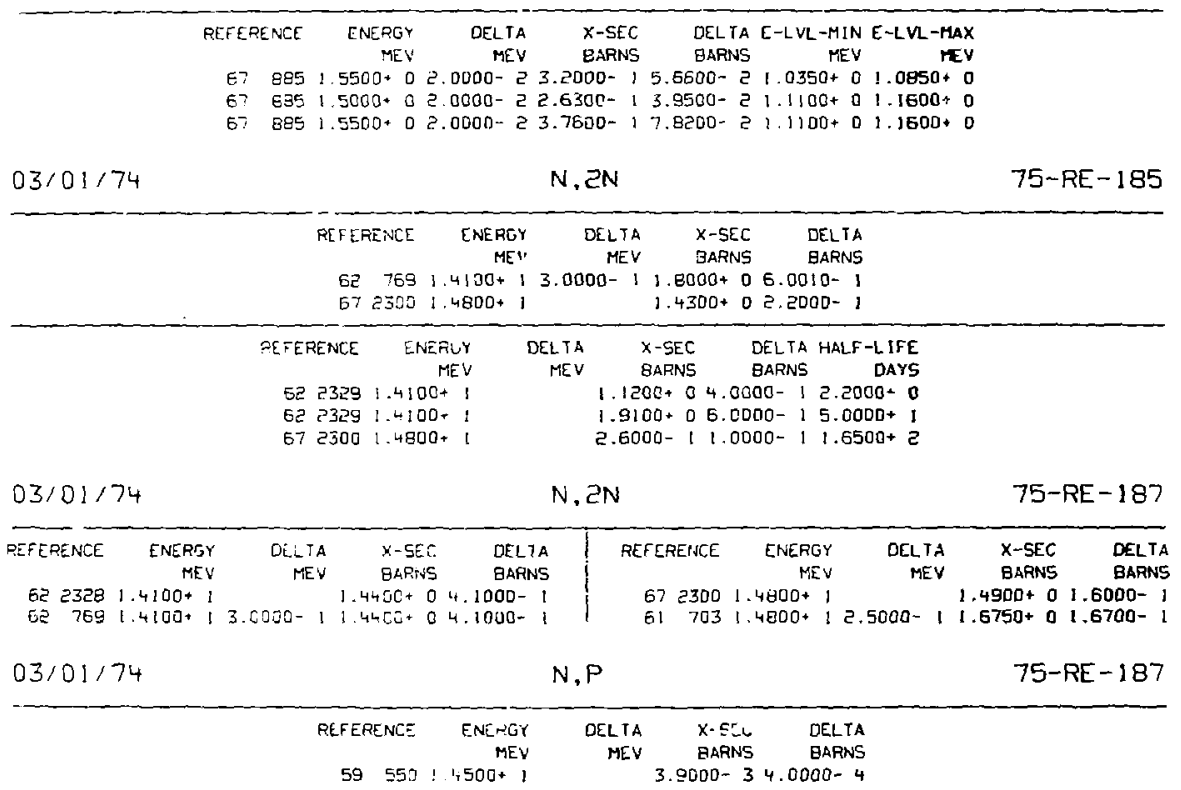


CROSS SECTION

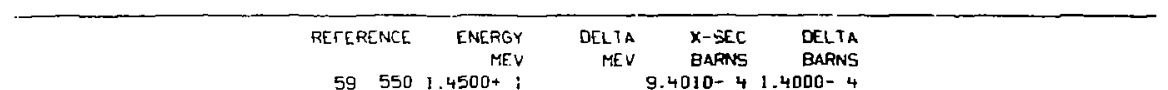

$03 / 01 / 74$

COHEREINT SCATTERING

76-OS-NAT

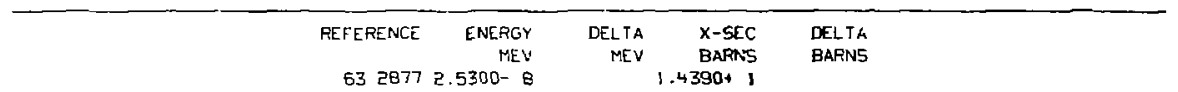

$03 / 01 / 74$

$N, P$

$76-0 S-188$

$\begin{array}{rrrrrr}\text { REFERENCE } & \text { ENERGY } & \text { DELTA } & X-\text { SEC } & \text { DELTA } \\ & & \text { MEV } & \text { MEV } & \text { BAFNS } & \text { EARNS } \\ 65 & 1777 & 1.4600+1 & 2.0000-1 & 0.7000-3 & 1.3050-3 \\ 66 & 1675 & 1.4700+1 & & 7.900-3 & 1.9000-3\end{array}$

$03 / 01,74$ COHERENT SCATTER!NG

$76-05-188$

$\begin{array}{rrrrr}\text { REFERENCE } & \text { ENERGY } & \text { DELTA } & \text { X-SEC } & \text { DELTA } \\ & \text { MEV } & \text { MEV } & \text { BAFNS } & \text { BARNS } \\ 632877 & 2.5300^{-8} & & 7.6500+0 & \end{array}$

$03 ; 0 \mathrm{i} / 74$ COHERENT SCATTERING

$76-0 S-189$

$\begin{array}{rrrrr}\text { REFERENCE } & \text { ENERGY } & \text { DELIA } & \text { X-SEC } & \text { DELTA } \\ & \text { MEV } & \text { MEV } & \text { BARNS } & \text { BARNS } \\ 632877 & 2.5300-8 & & 1.5210+1\end{array}$

$63287725300-8$

$$
N, P
$$

76-0S- 190

$03 / 01: 74$

$\begin{array}{rrrrr}\text { RETERENCE } & \text { ENERGY } & \text { DELTA } & \text { X-SEC } & \text { DELTA } \\ & \text { MEV } & \text { MEV } & \text { BARNS } & \text { BARNS } \\ 65 \quad 3675 & 1.4 \% 00+1 & & 2.0000-35.0000-4\end{array}$


CROSS SECTION

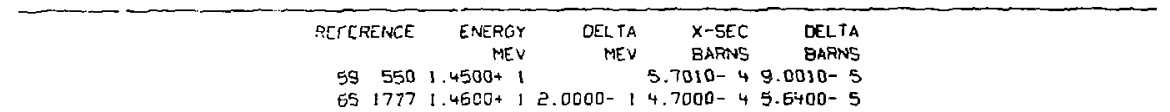

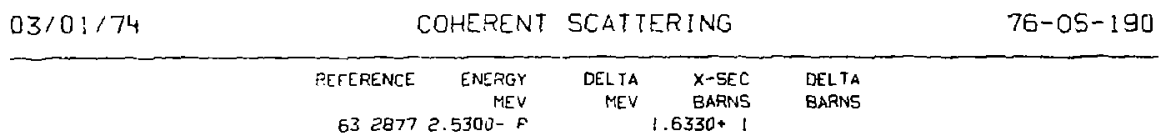

$6328772.5300-f$

$76-05-192$

$03 / 01 / 74$

N. 2N

DELTA

$\begin{array}{rrrrr}\text { REFEREN:EE ENERGY } & \text { DELTA } & \text { X-SEC } & \text { DELTA } \\ & \text { MEV } & \text { MEV } & \text { BARNS } & \text { GARNS }\end{array}$

$703362,1.400 \div, 1.5000-12.1210+02.3500-1$

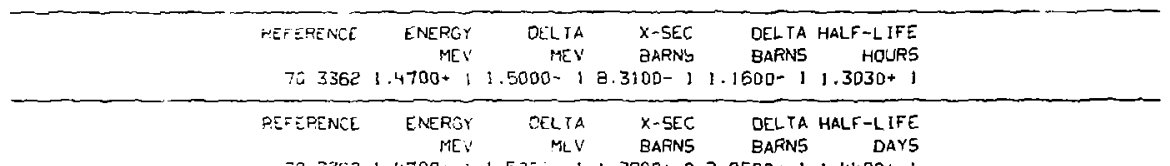

$7333621.4700+11.505-11.2900+02.0500-11.4400+$ i

$03 / 01: 74$

COHERENT SCATTERING

$76-05-192$

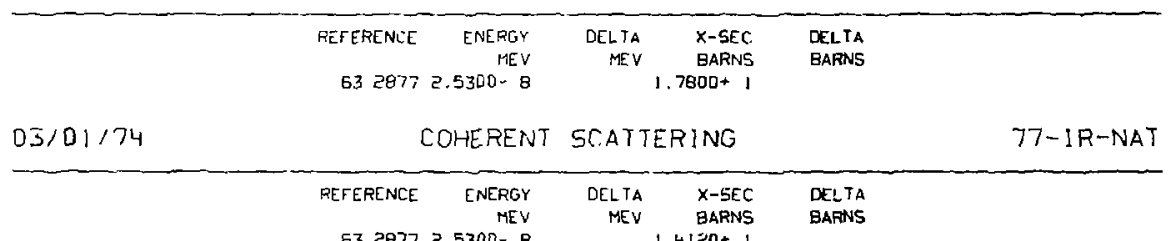

$8328772.5300-8$

$1.4120+1$ 


\section{CROSS SECTION}

REFERENCE ENERGY DELTA XE-SEC DELTA

$6725022.8000+07.0000-25.1000-16.6300=2$

$03 / 01 / 74$

$N$, EN

$77-1 R-191$

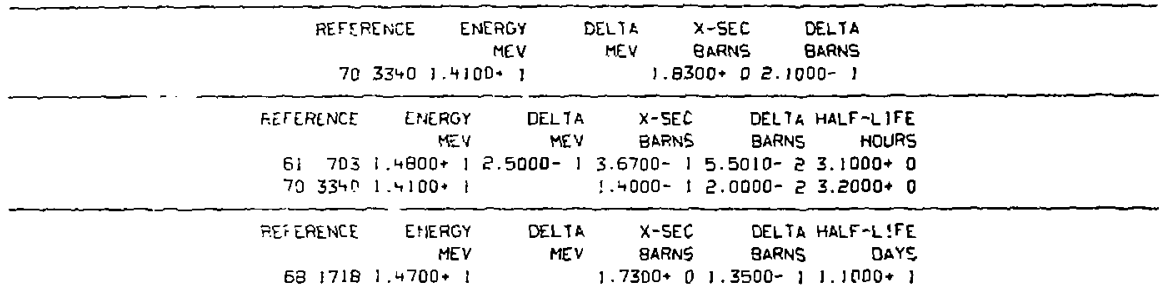

$6817181.4700 \cdot 1$ $1.7300+0,1.3500-; 1.1000+1$

$03 / 01 / 74$

$N, A L P H A$

$77-\mid R-19 !$

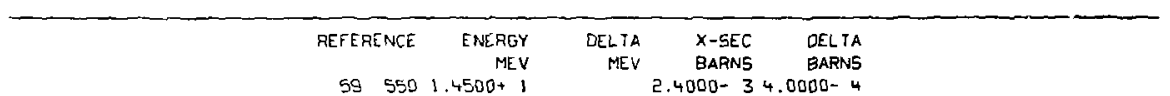

$59550,4500+1$

$77-1 R-193$

$03 / 01 / 74$

$N, 2 N$

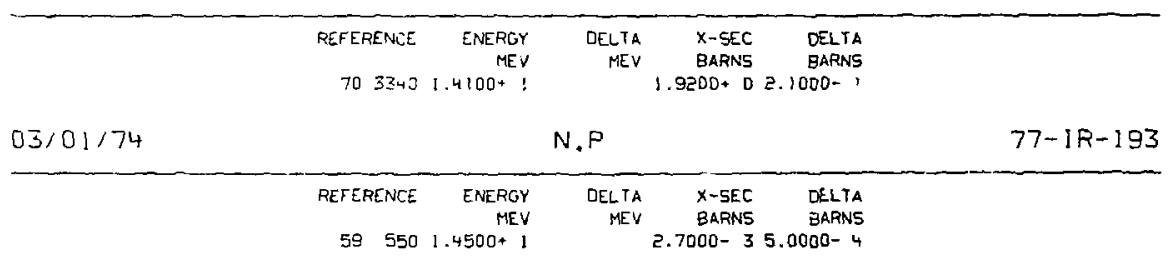



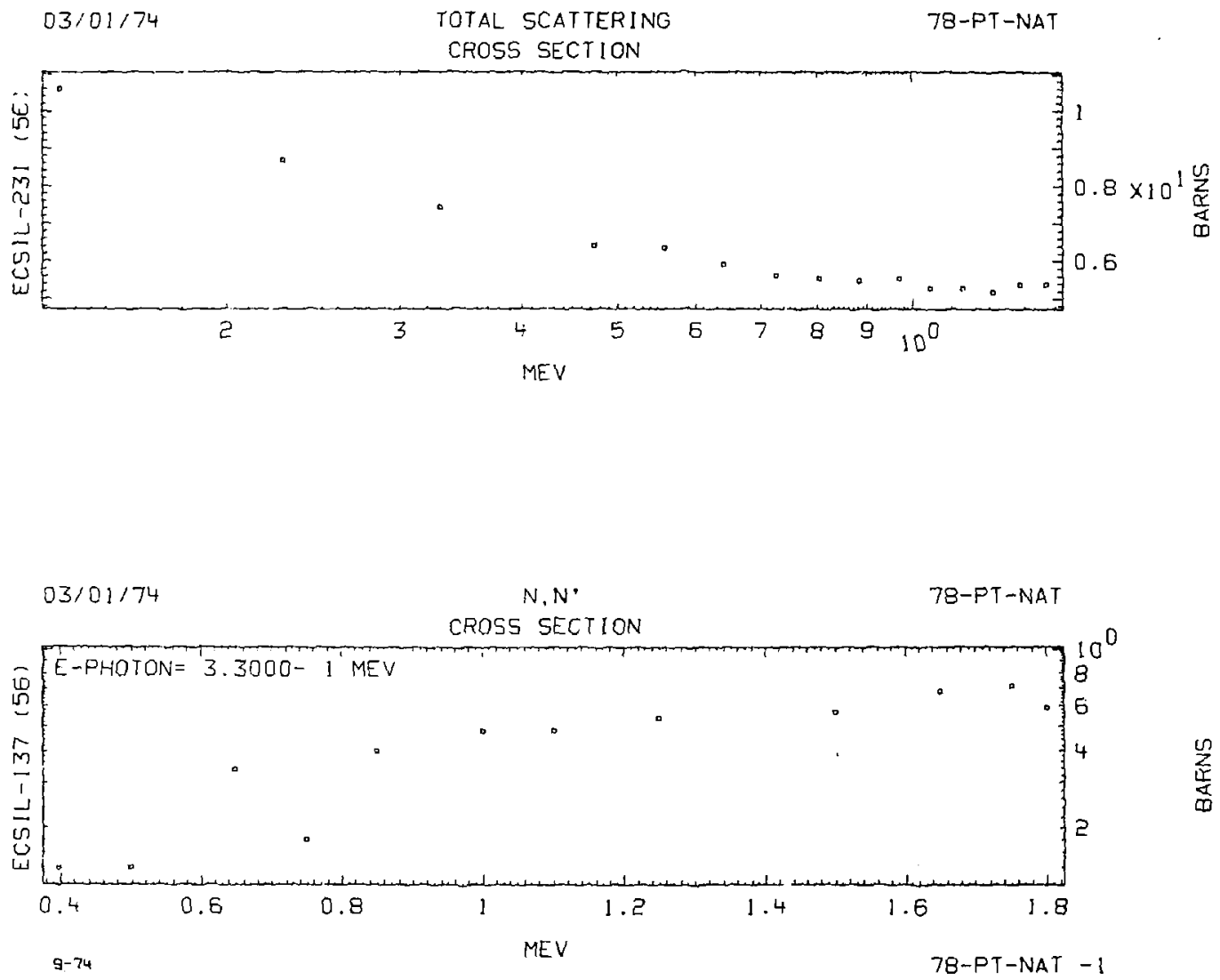

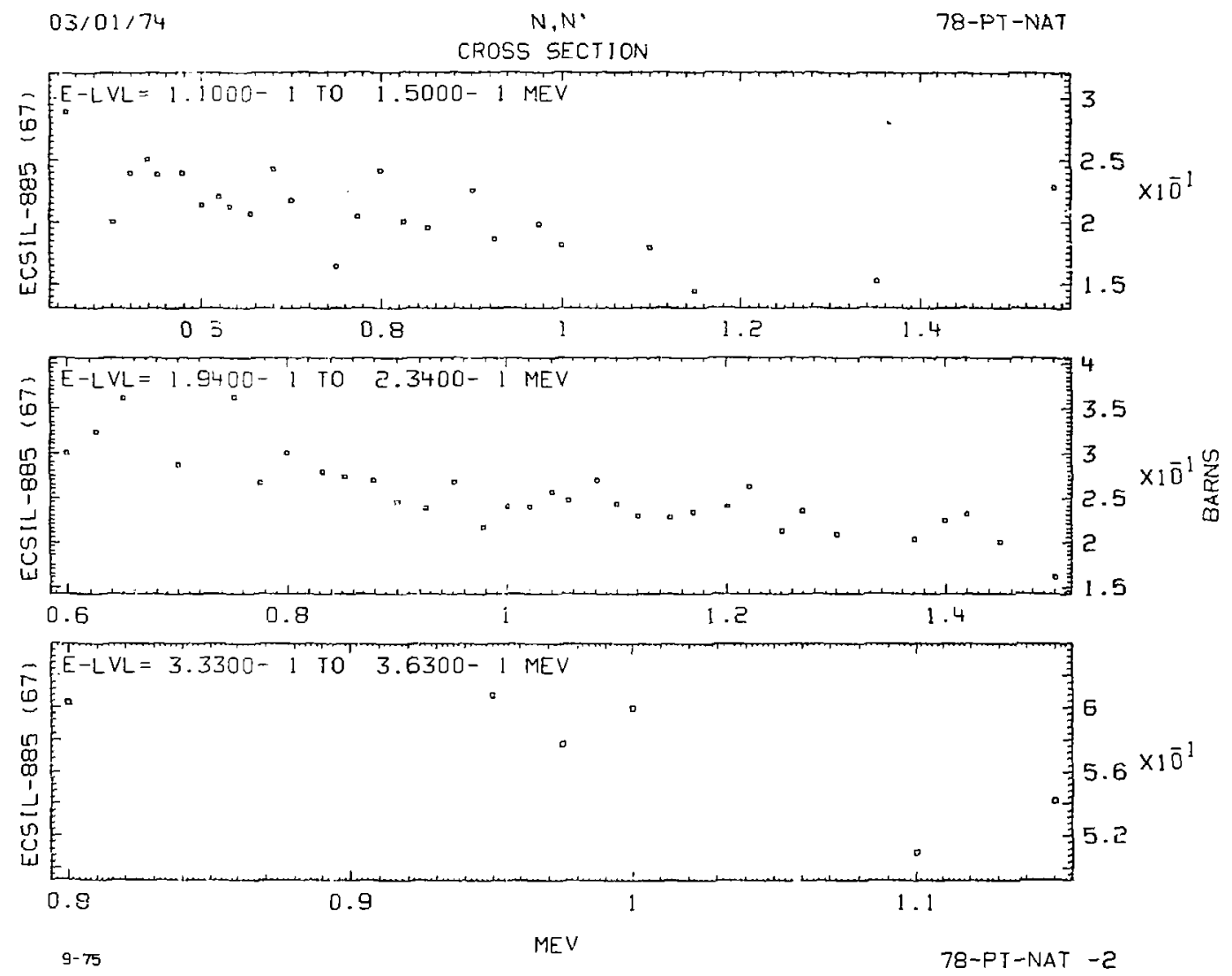


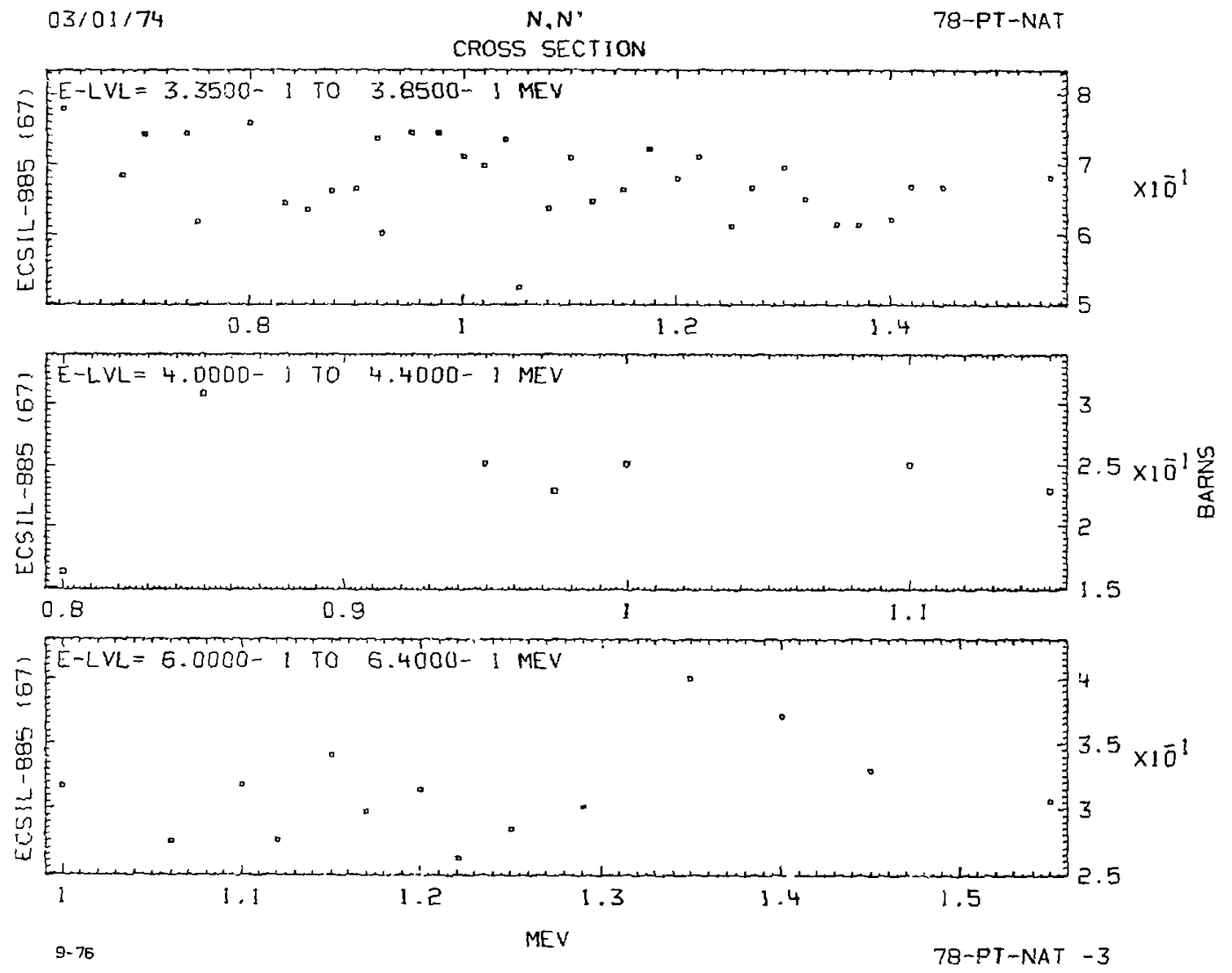




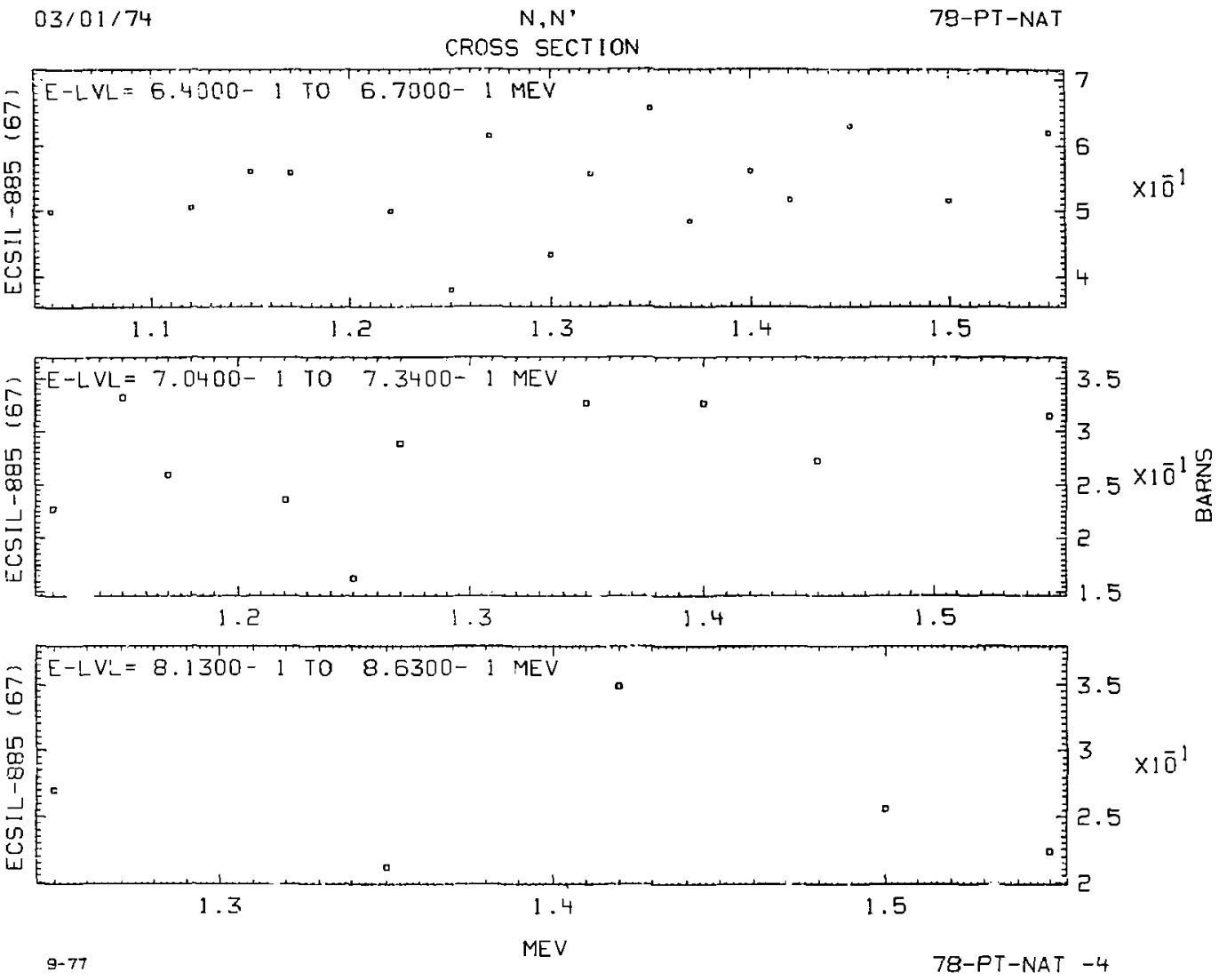




\section{$03 / 0: / 74$}

$N, N^{\prime}$

78-PT-NAT

CROSS SECTION

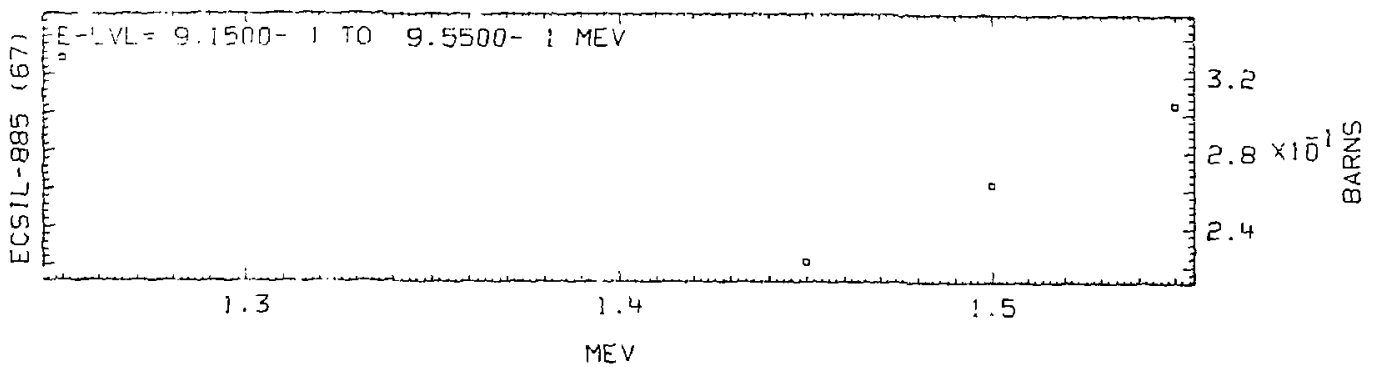

03.01/74

B3/01/74

5) $15847.3000-9$ MEV $1.1200 * 1$

$03 / 0 i / 74$

COHERENT SCATTERING

78-PT-NA?

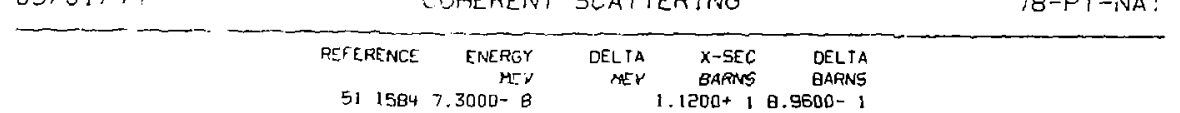




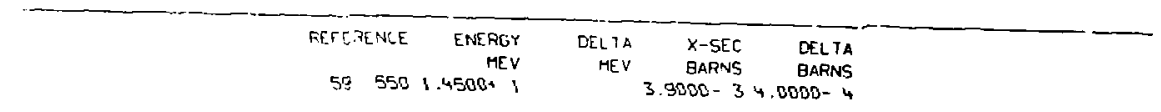

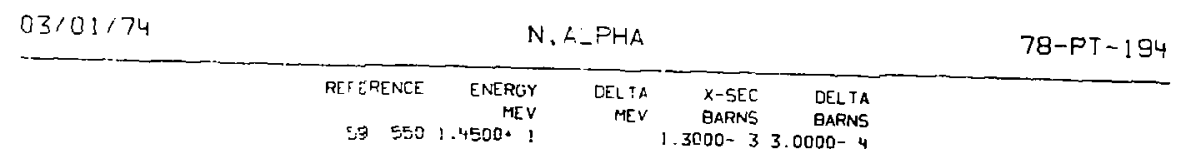

$03 / 01: 74$ $N, P$ 7E-PT - 195

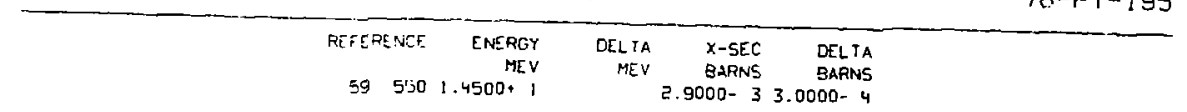

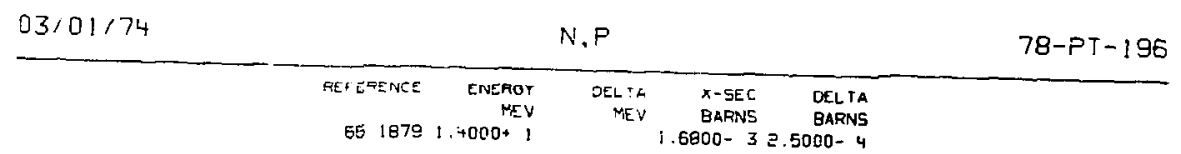

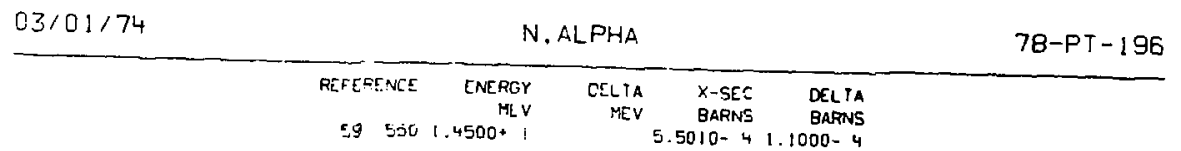

$03 / 01 / 74$
0




\section{CROSS SECTION}

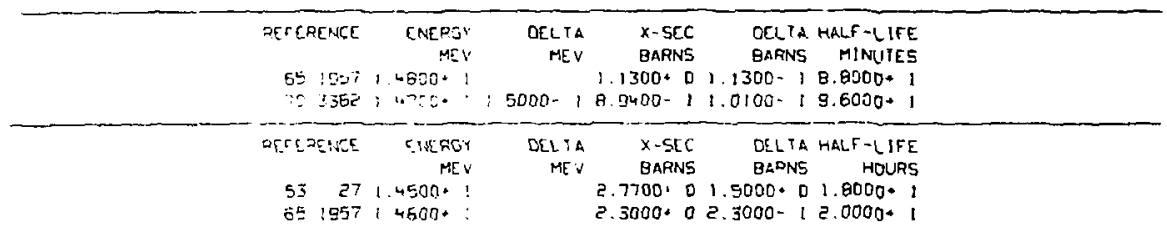

$03: 01 / 74$

NUNELASTIC

79-AU- 197 CROSS SECTION

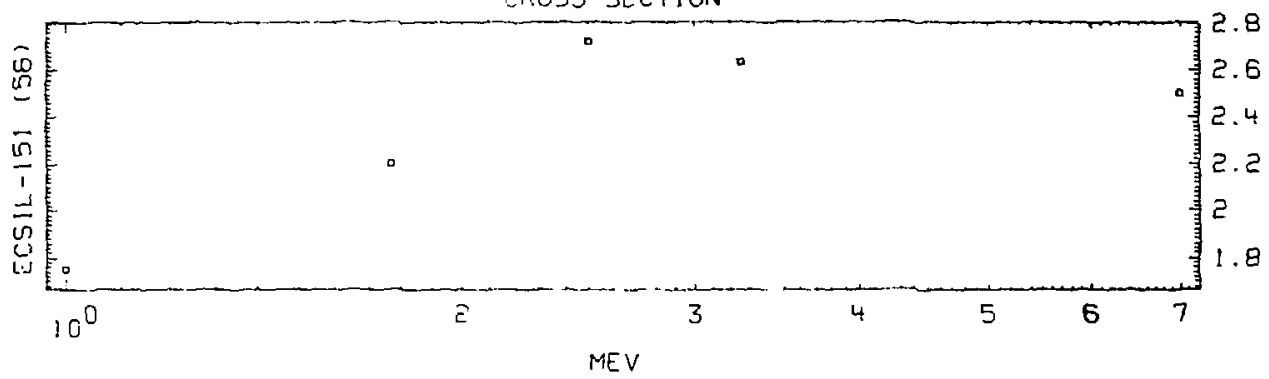



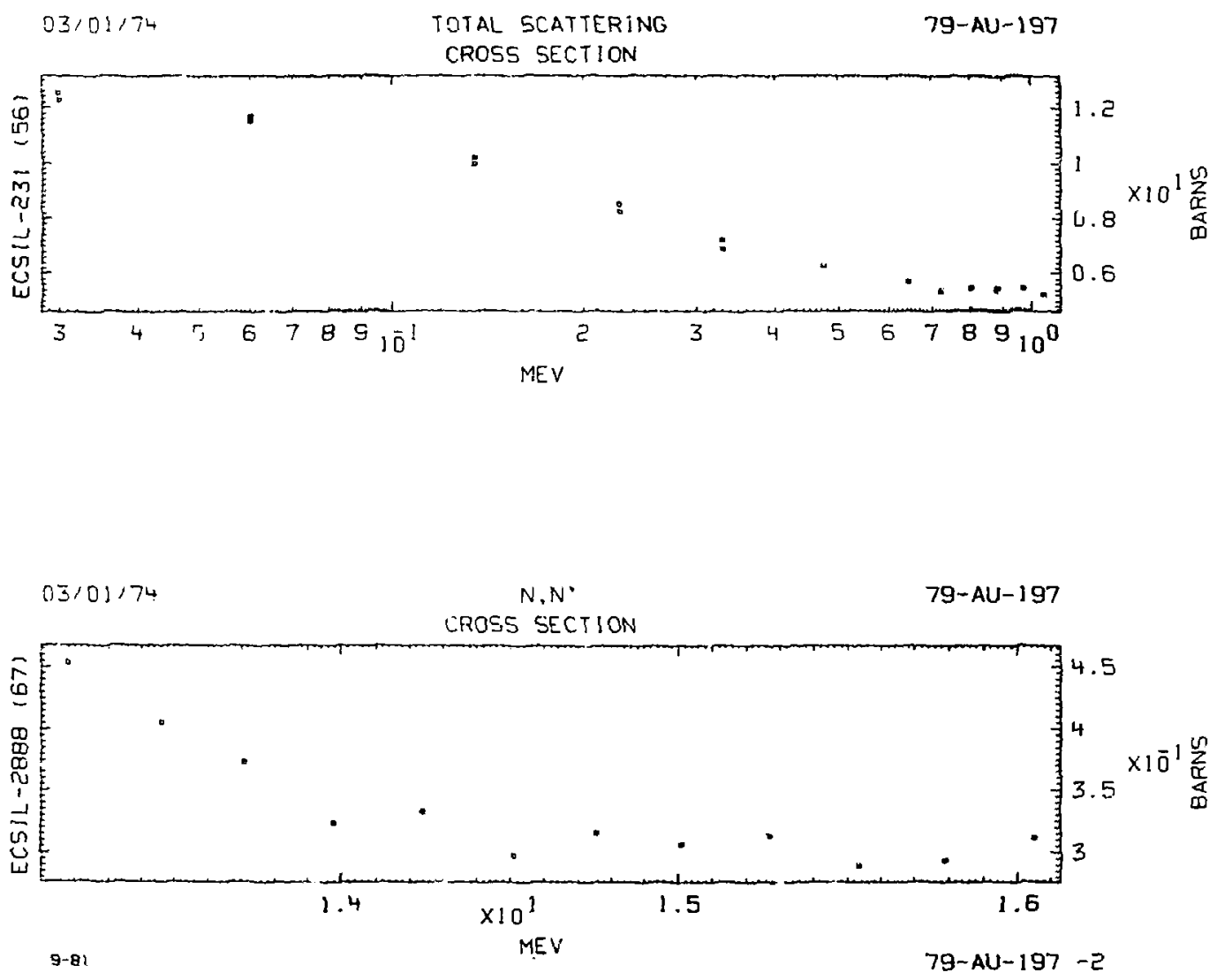


\section{CROSS SECTION}
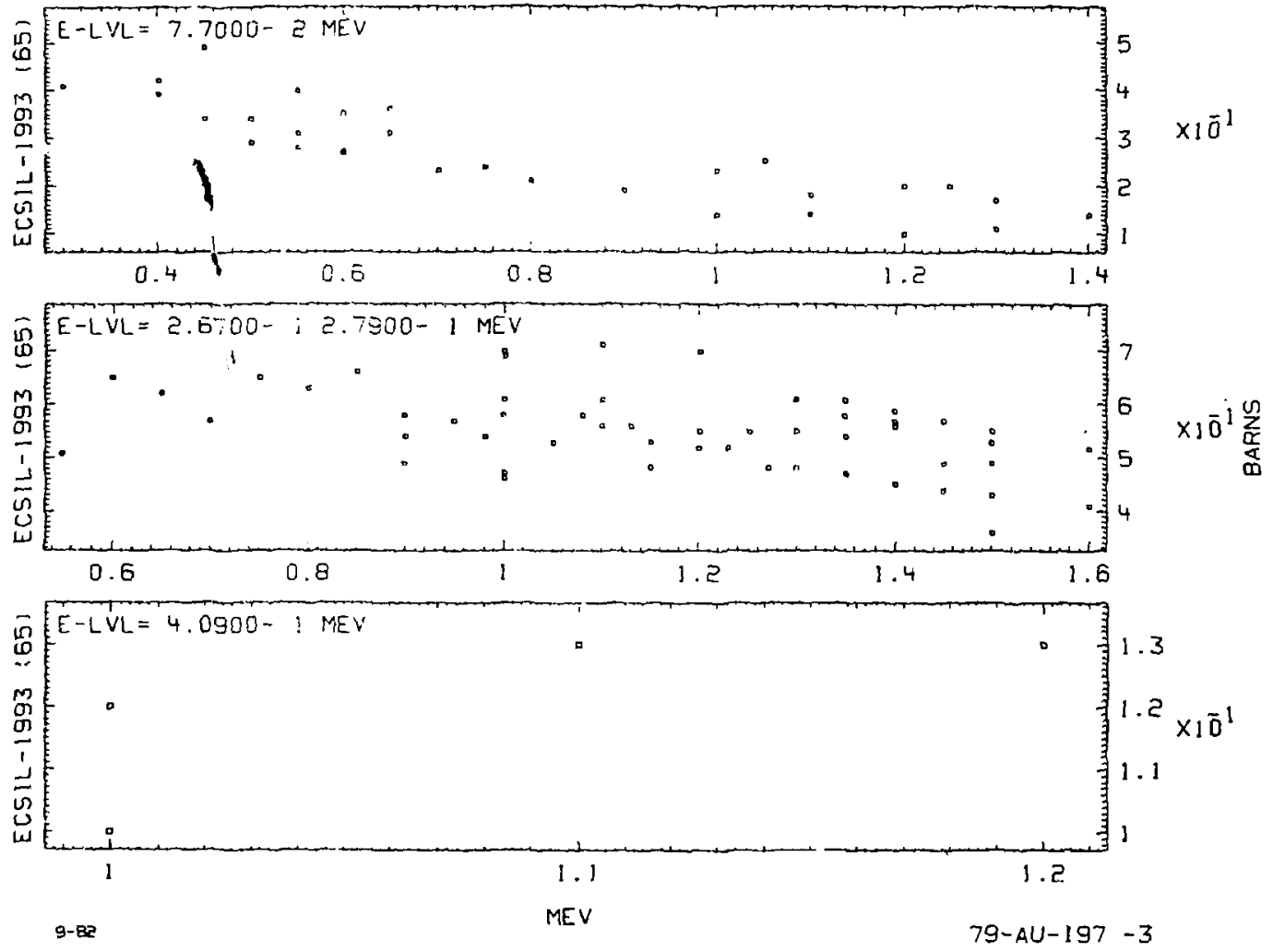

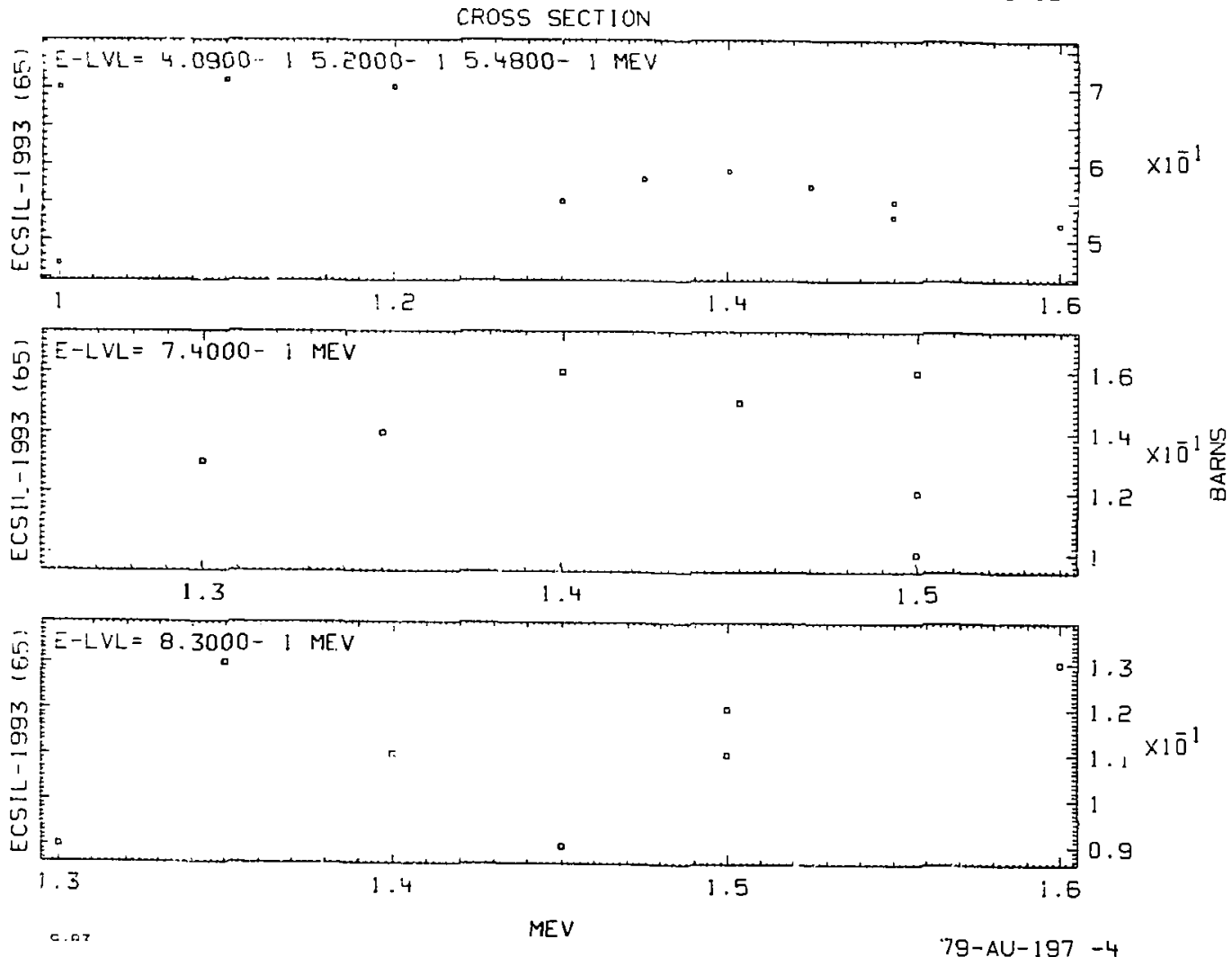
SNYVB

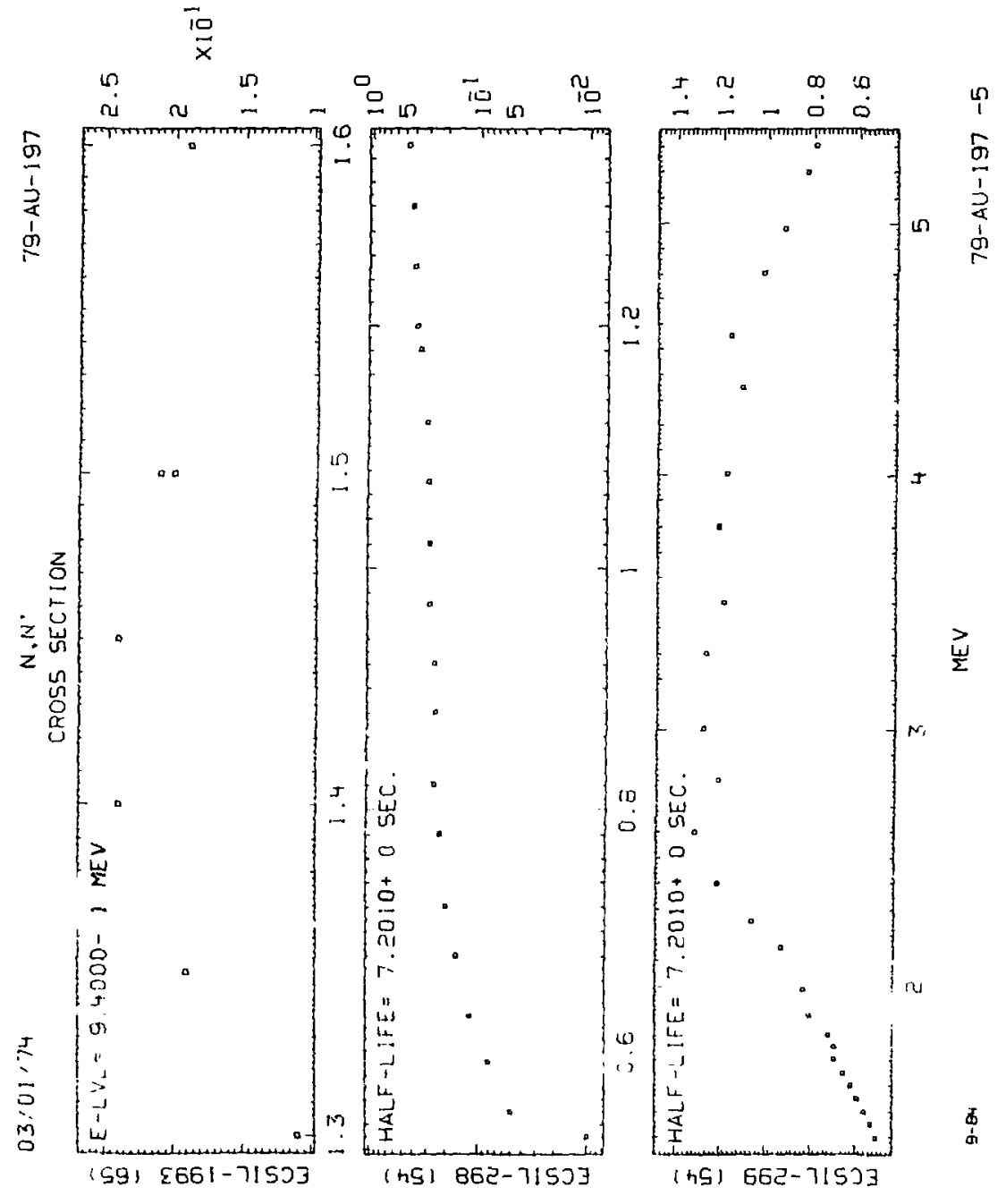



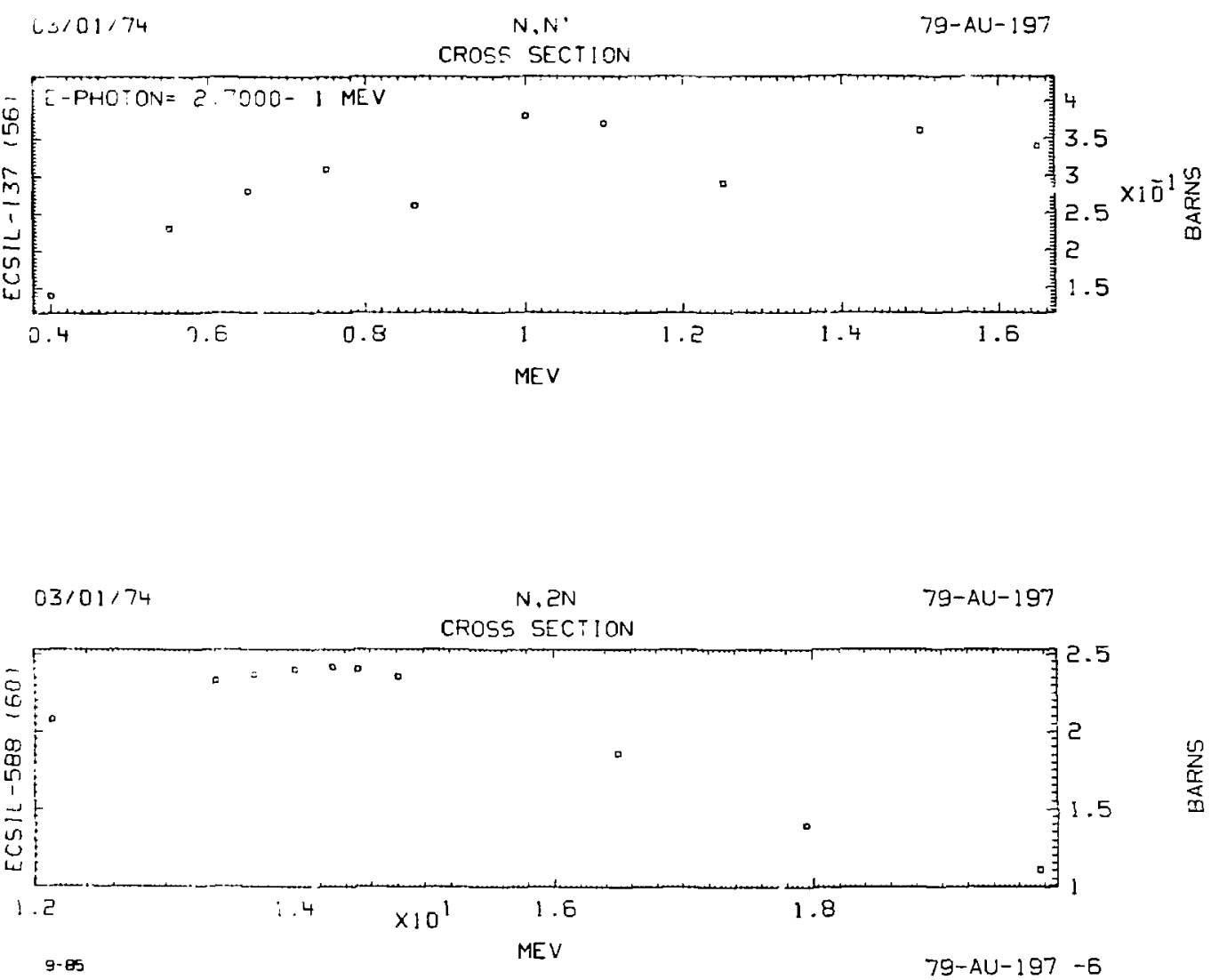

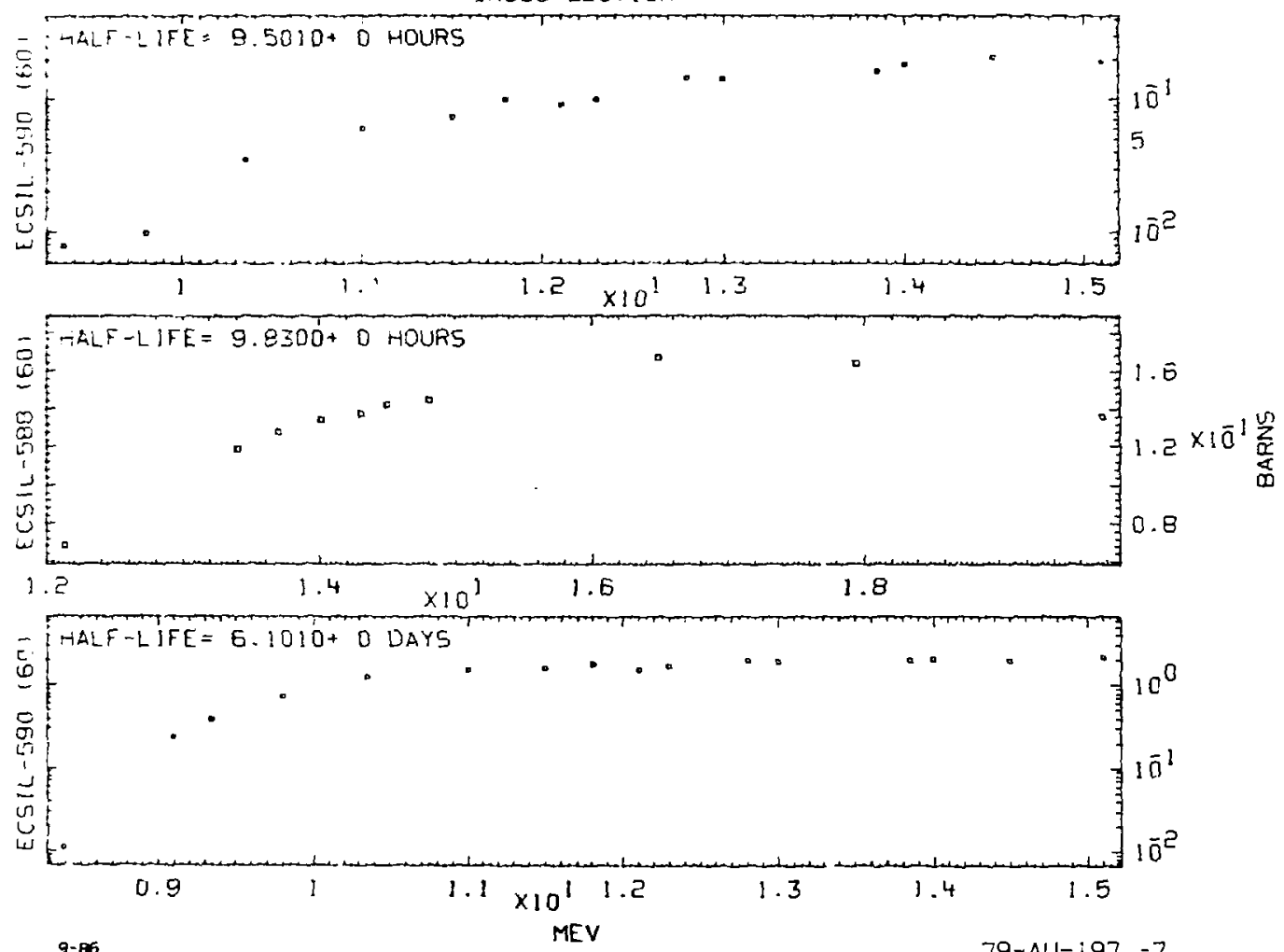


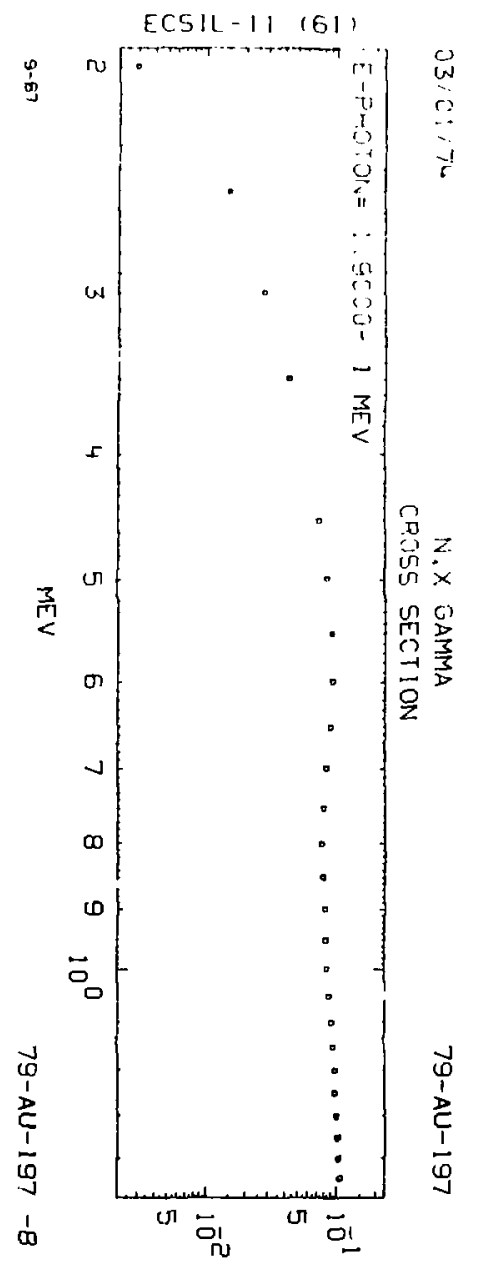

JARNS

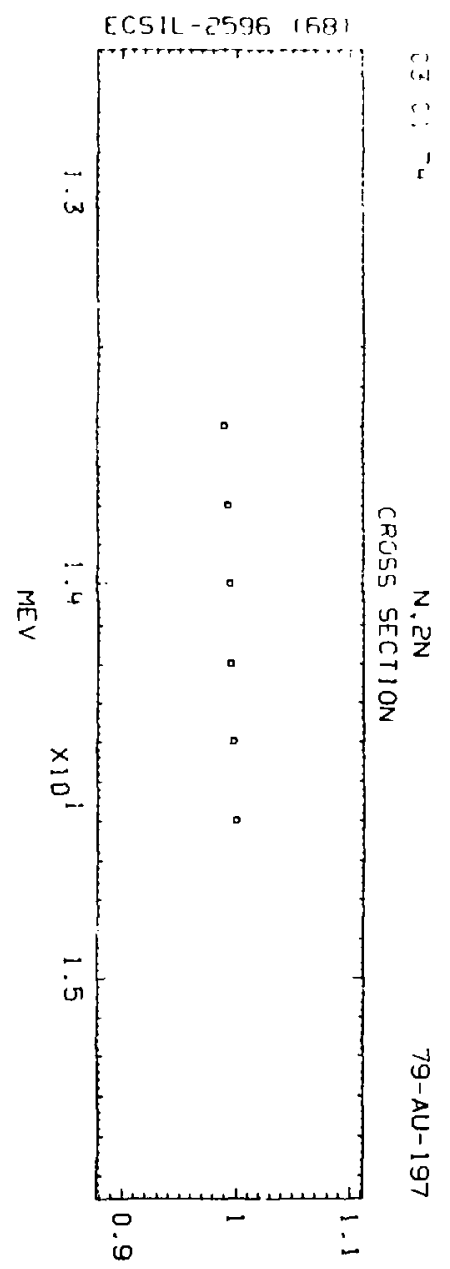

RELAT IVE 

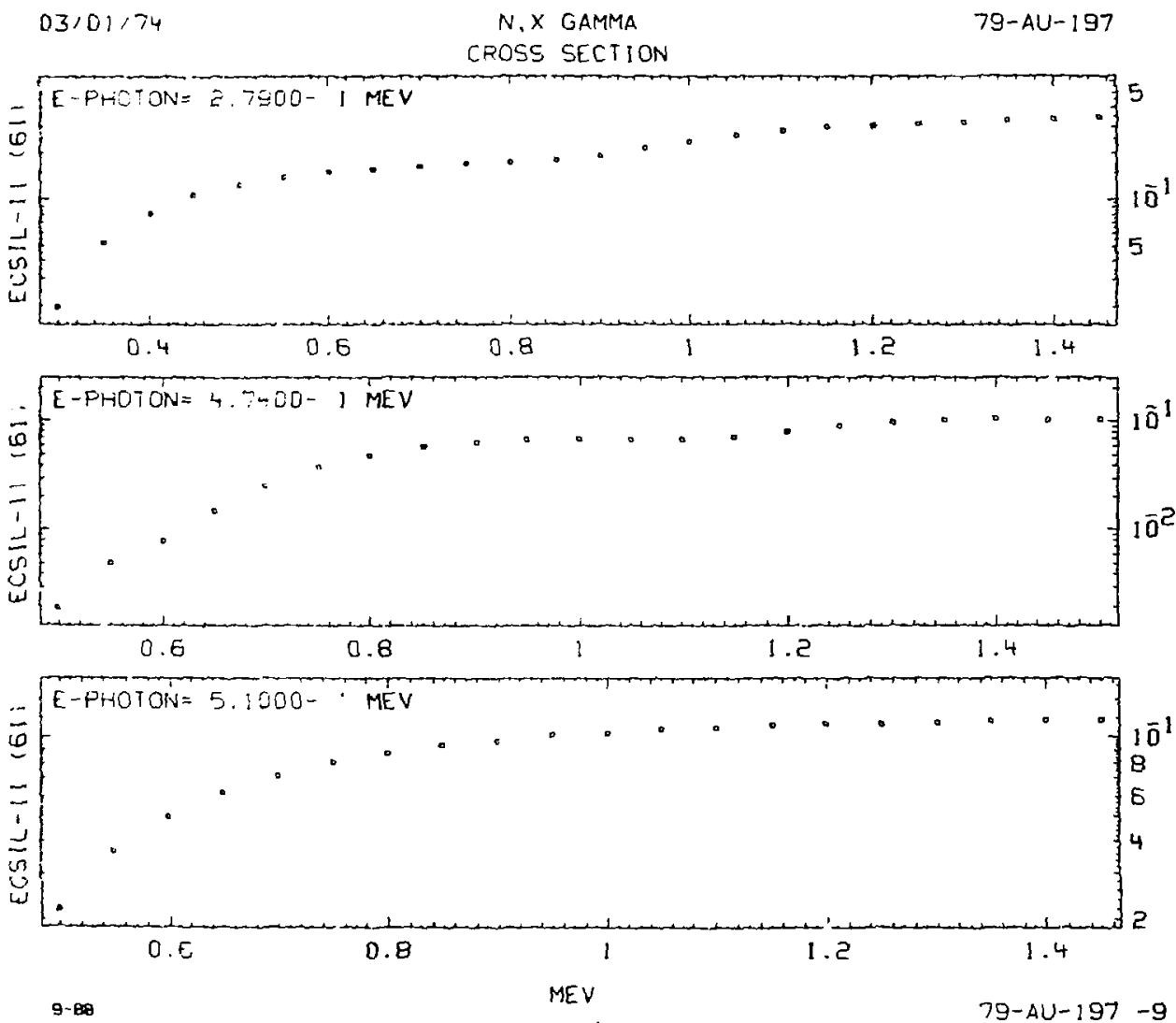

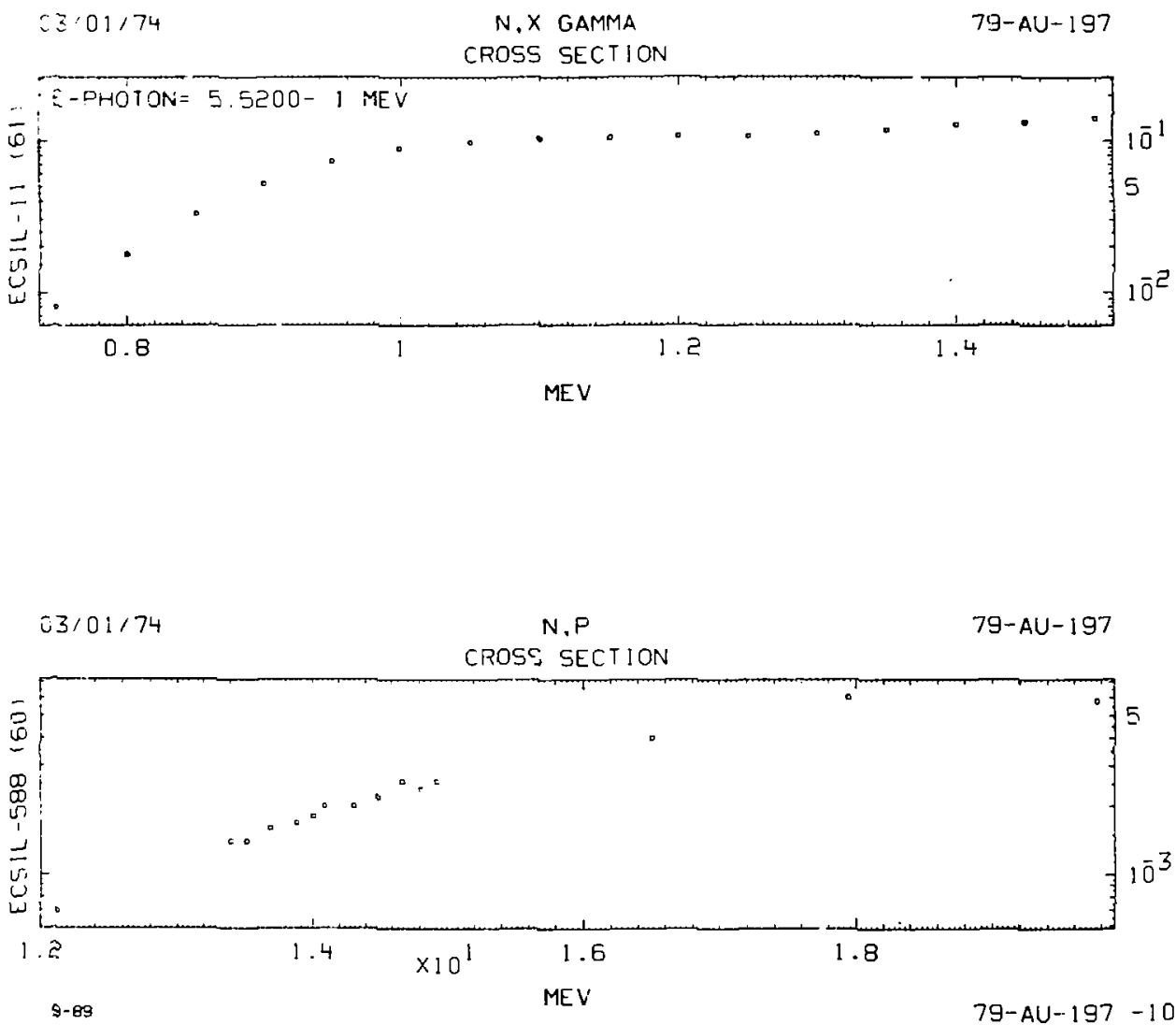

$\frac{0}{2}$

$79-A U-197-10$ 
SNCYG
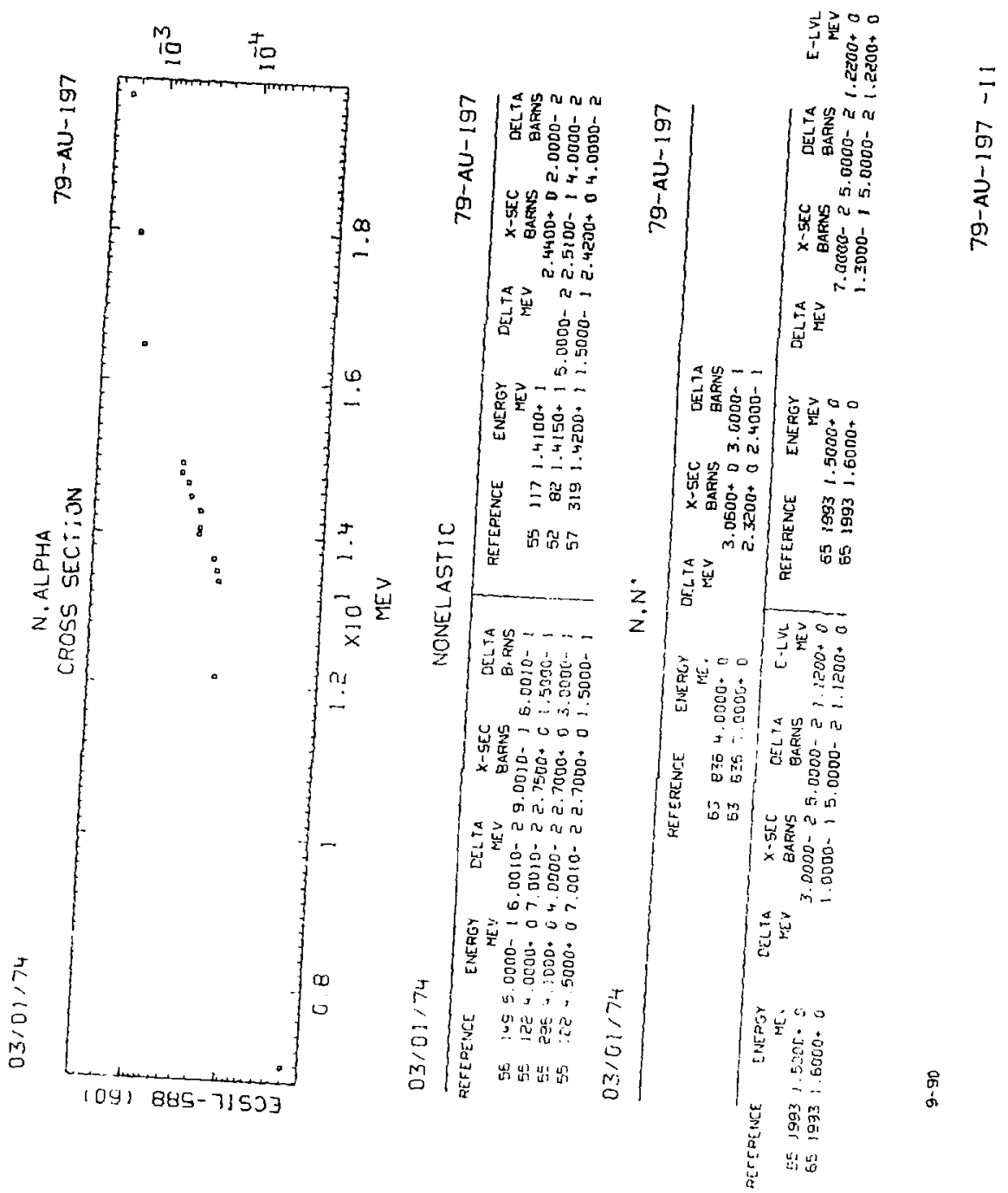


\section{CROSS SECT ION}

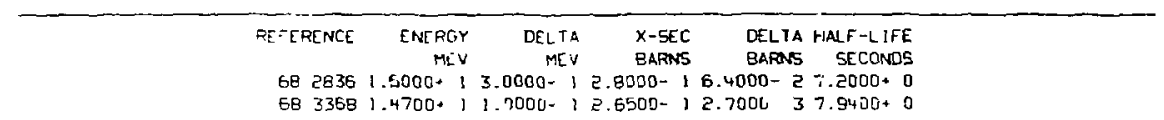

$03 / 01 / 74$

N. $2 N$

$79-A y-197$

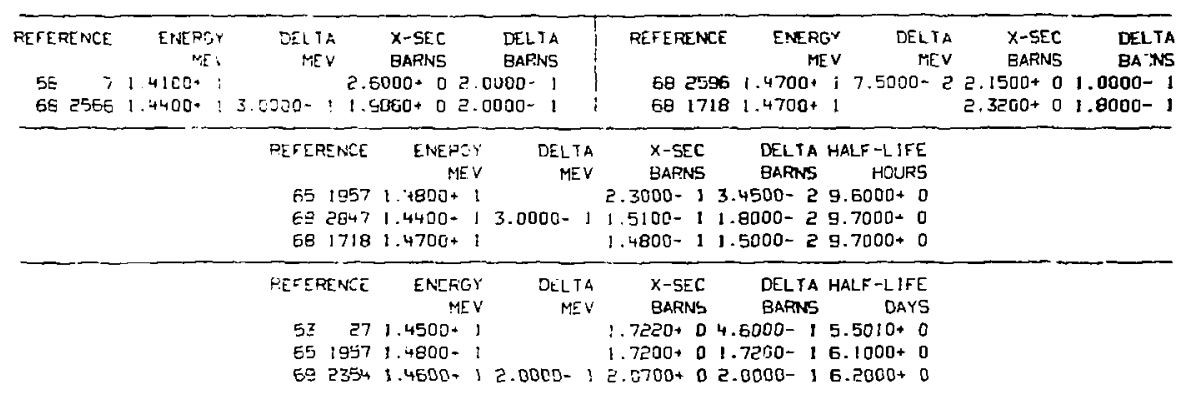

\begin{tabular}{|c|c|c|c|c|c|c|c|c|c|}
\hline \multicolumn{3}{|c|}{$03 / 01 / 14$} & \multicolumn{4}{|c|}{ ABSORP $\because I O N$} & \multicolumn{3}{|c|}{$79-A U-197$} \\
\hline REFEPCNCE & $\begin{array}{r}\text { ENEREY } \\
\text { MEV }\end{array}$ & $\begin{array}{r}\text { TELTA } \\
\text { MEV }\end{array}$ & $\begin{array}{l}x-\text { SEC } \\
\text { BARNS }\end{array}$ & $\begin{array}{l}\text { DELTA } \\
\text { BARNS }\end{array}$ & REFERENEE & $\begin{array}{r}\text { ENERGY } \\
\text { MEV }\end{array}$ & $\begin{array}{r}\text { DELTA } \\
\text { MEV }\end{array}$ & $\begin{array}{l}\text { X-SEC } \\
\text { BARNS }\end{array}$ & $\begin{array}{l}\text { DELTA } \\
\text { BARNS }\end{array}$ \\
\hline $50: 905$ & $2.5000-8$ & & $9.880 u+1$ & I.0000- & 53809 & $2.5300-8$ & & $9.8700 \div 1$ & $6.0000-1$ \\
\hline$E 2265 \%$ & $2.530 \% \mathrm{E}$ & & $9.8900+:$ & $=3.0000-1$ & $60 \quad 891$ & $2.5300-8$ & & $9.8200+1$ & $5.0000-1$ \\
\hline $64 \quad 776$ & 2.5300 & & $9.8600+1$ & $=0000-1$ & $54 \quad 873$ & $2.5300-8$ & & $9.5500+1$ & $7.0000-i$ \\
\hline 54 2E5! & $2.5300-3$ & & Q.840i- : & g.0000-1 & $6 5 \longdiv { 3 6 4 }$ & $2.4000-2$ & & $5.7000-1$ & $3.0000-2$ \\
\hline 591152 & $2.5300 \cdot B$ & & $9.9300+:$ & $\therefore 1.5000+0$ & & & & & \\
\hline
\end{tabular}


CROSS SECTION

\begin{tabular}{|c|c|c|c|c|c|c|c|c|c|c|c|}
\hline \multirow{2}{*}{\multicolumn{2}{|c|}{ FLFERE'VLE }} & CNEPC & DE: ${ }^{-}$ & $x-5 E C$ & dCLTA & \multirow{2}{*}{\multicolumn{2}{|c|}{ REFERENCE }} & \multirow{2}{*}{$\begin{array}{r}\text { ENERGY } \\
\text { MEV }\end{array}$} & \multirow{2}{*}{$\begin{array}{r}\text { DELTA } \\
\text { MEV }\end{array}$} & \multirow{2}{*}{$\begin{array}{l}x-5 E C \\
\text { BAFNS }\end{array}$} & \multirow{2}{*}{$\quad \begin{array}{ll}\text { OELTA } \\
\text { BARNS }\end{array}$} \\
\hline & & $M_{E}=$ & $M_{E}$ & BARVS & BARNS & & & & & & \\
\hline 60 & 590 & $1.1800=$ & $12.0300-1$ & $8.0010-5$ & $1.6000-5$ & 57 & 158 & $1.4100+1$ & & $2.0500^{-}$ & B. $0000=3$ \\
\hline $6:$ & 590 & $1.2300+$ & 1 2.,002- : & $2.1000-4$ & $4.2000-5$ & 50 & 550 & $.4500 *$ & & $2.4200-3$ & $2.4000-$ \\
\hline 6D: & 590 & 1.3850. & $2,1000-$ & $2.6000-4$ & $5.2010-5$ & & & & & & \\
\hline
\end{tabular}

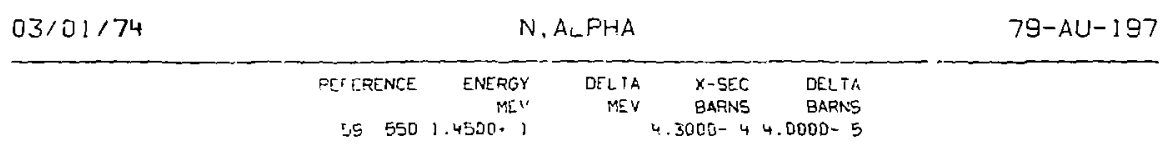

$03 / 01 / 74$

BOUND ATOM

79-AU-197

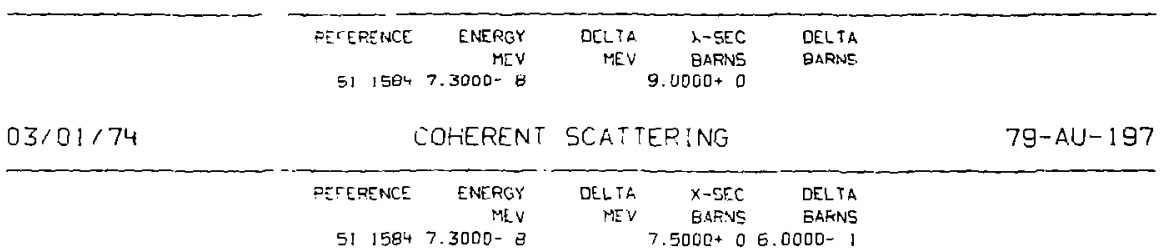



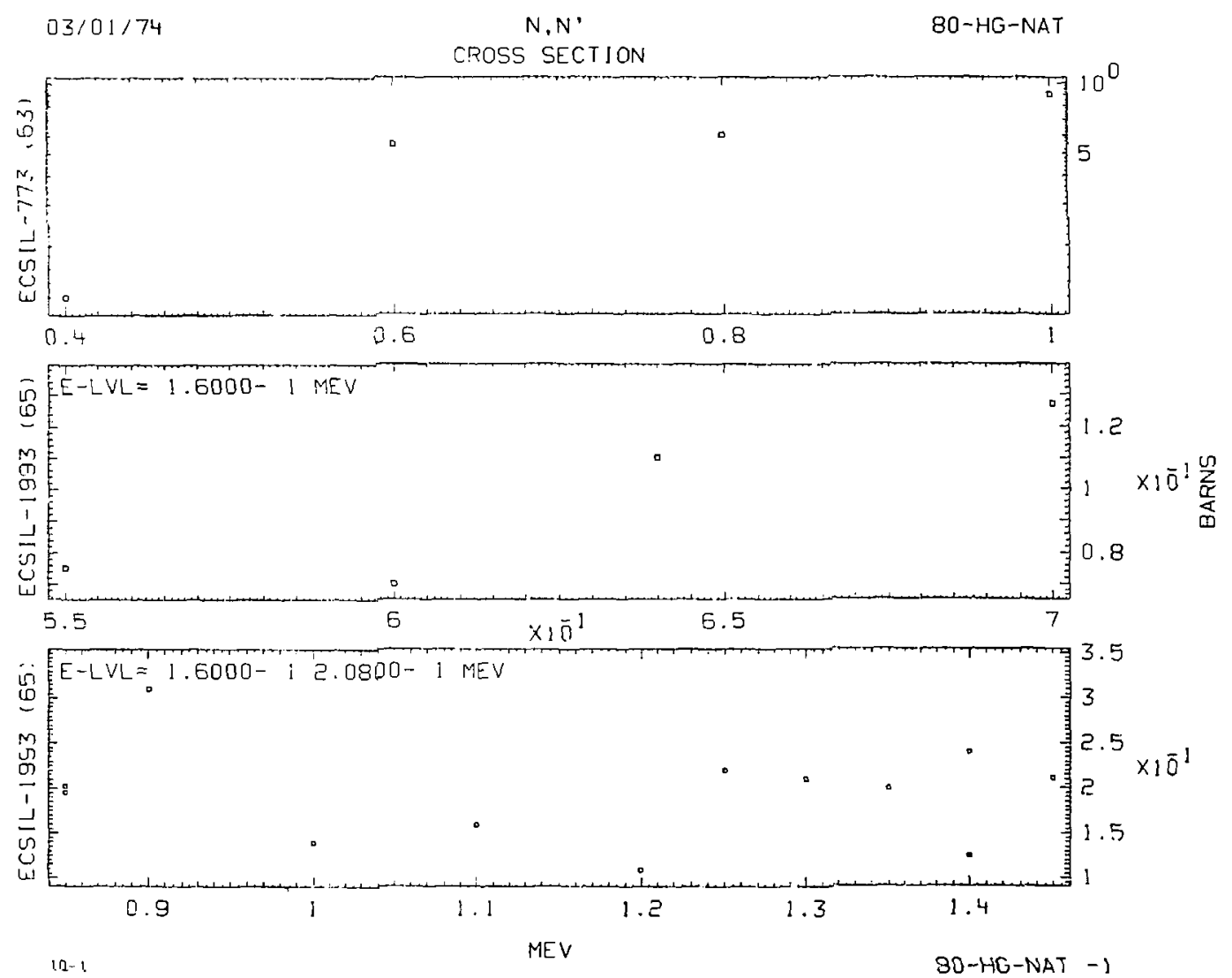

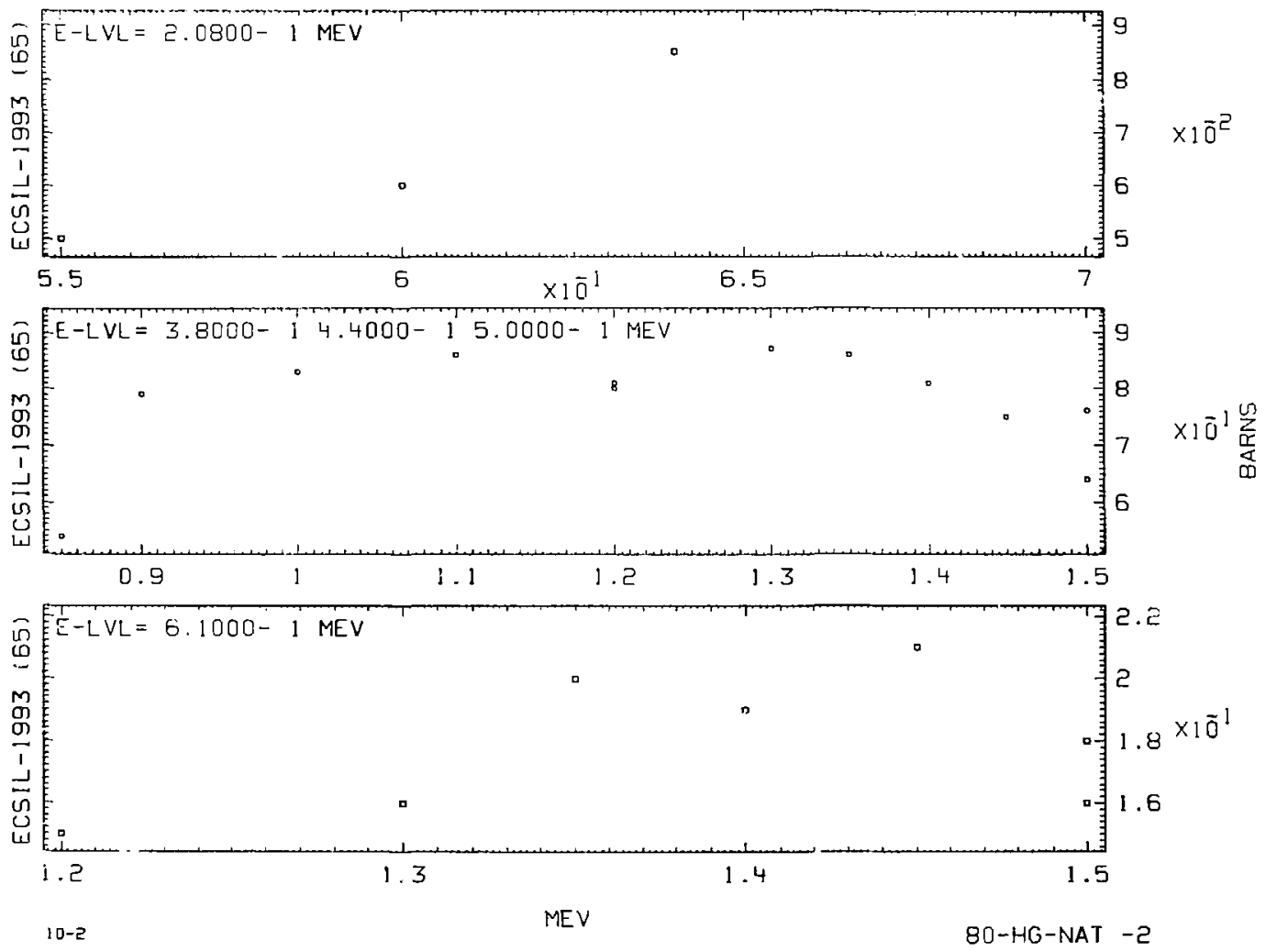


\section{CROSS SECTIION}

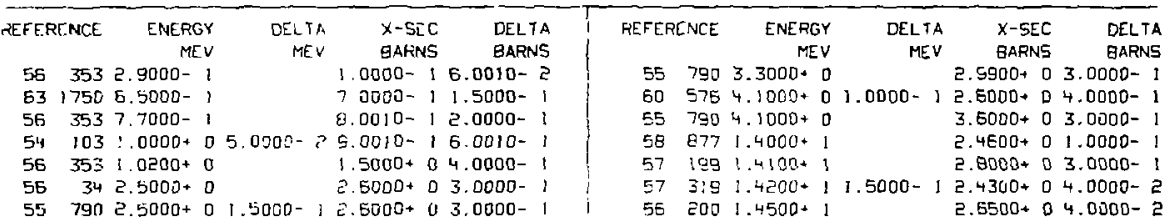

$\begin{array}{lll}03 / 01 / 74 & N, N & \text { 8D-HG-NAT }\end{array}$

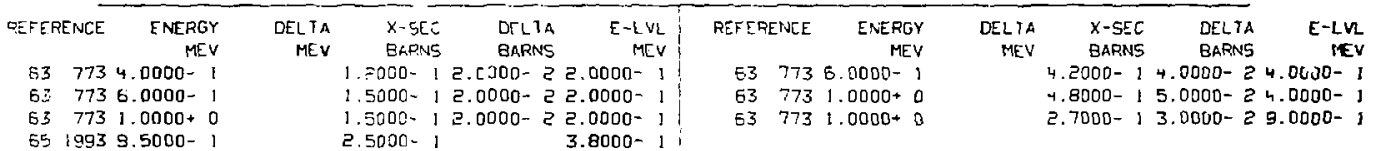

$03 / 01 / 74$

ABSORPTION

BO-HE-NAT

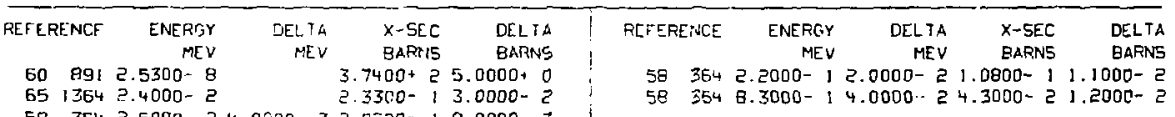

50354 2 $5000-240003-320=00-190000-3$

03/01/74 COHERENT SCATIERING BO-HG-NAT

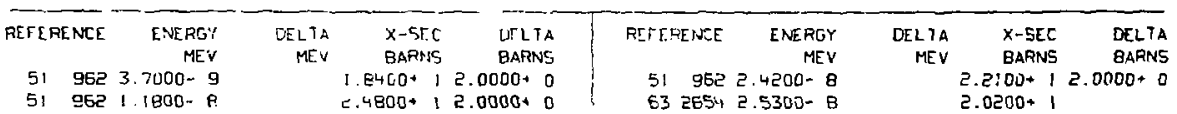




\section{CROSS SECIICN}

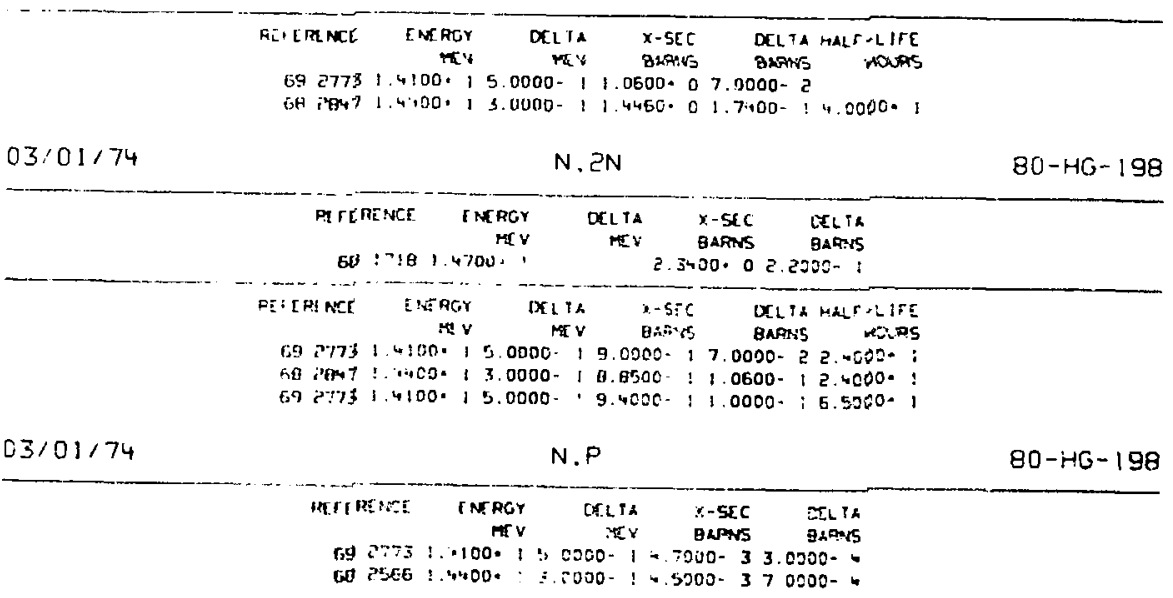




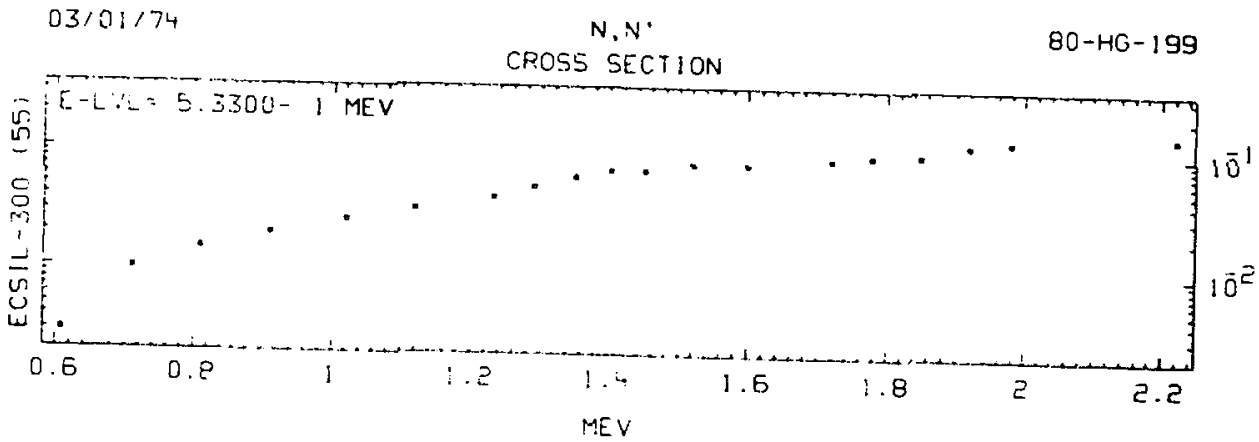

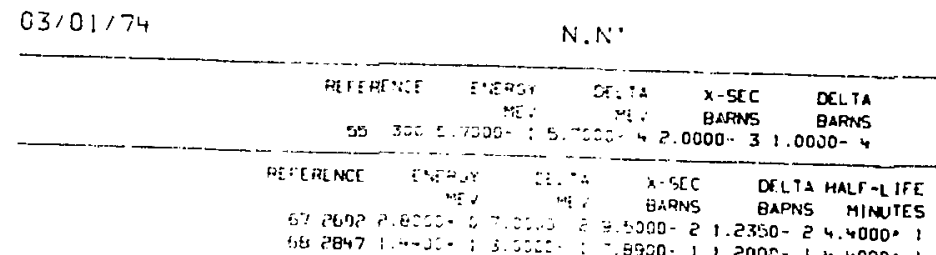

$0310: 74$

N.N?

$80-H G-199$

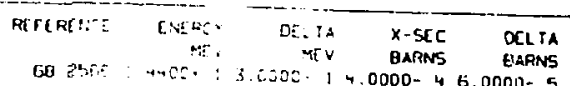


CROSS SECTION

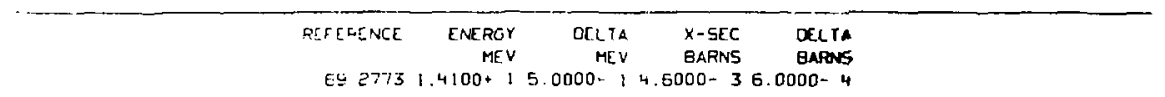

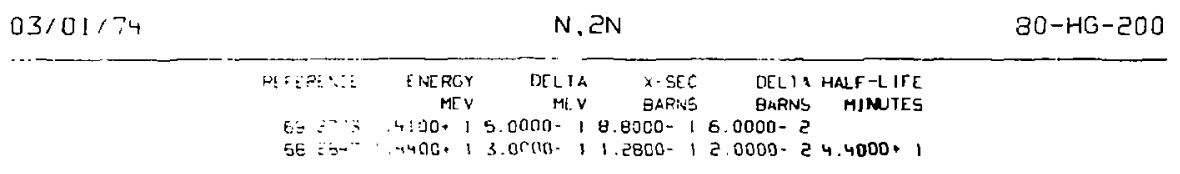

O3/01/74

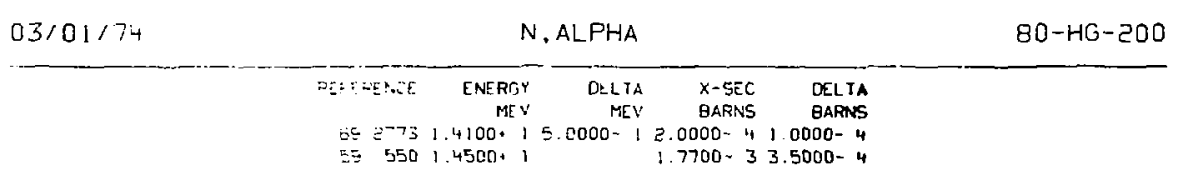

$03 / 01 / 74$

$N, P$

$80-H G-201$

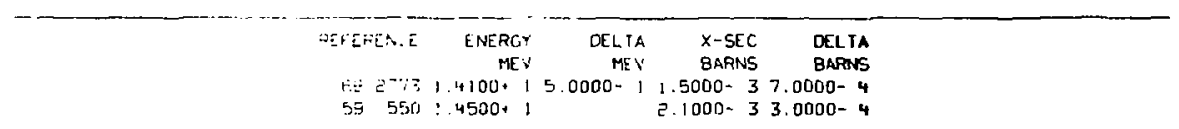


CROSS SECTION

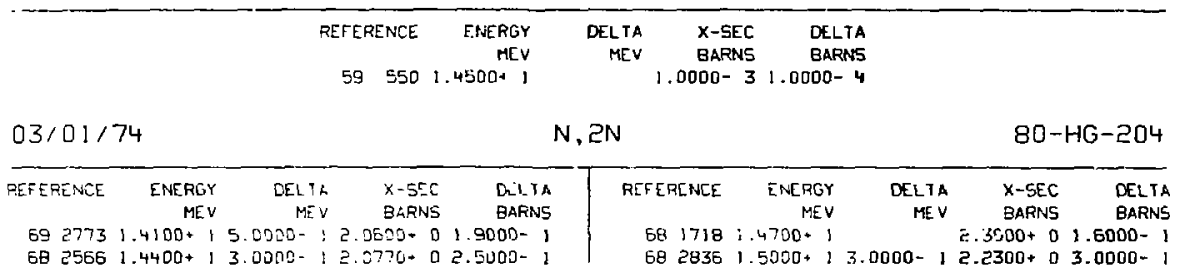

$6825661.4400+13.0000-12.0770$ - $02.5000-$

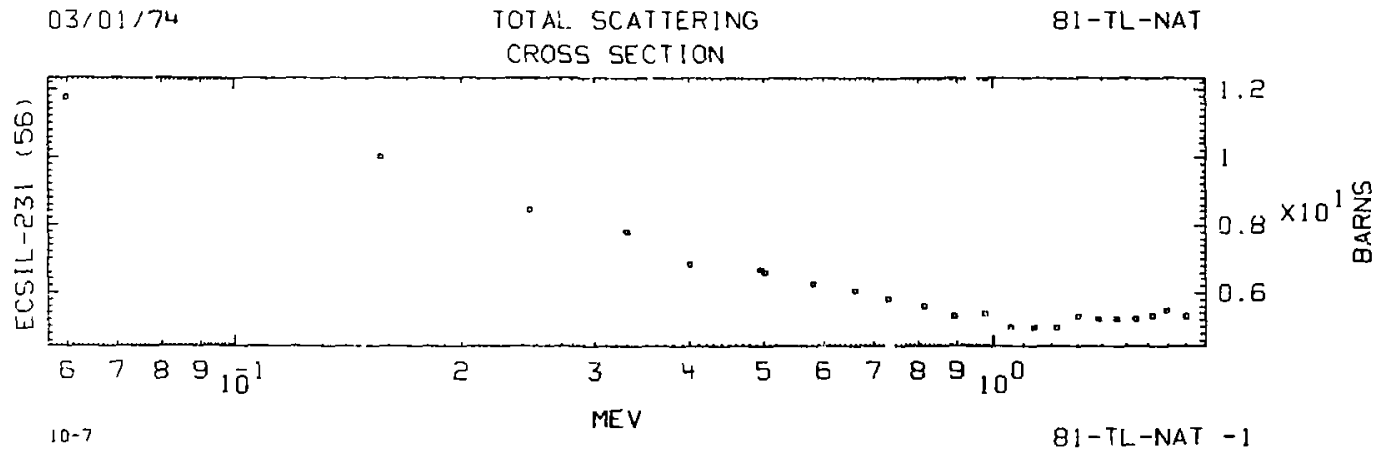



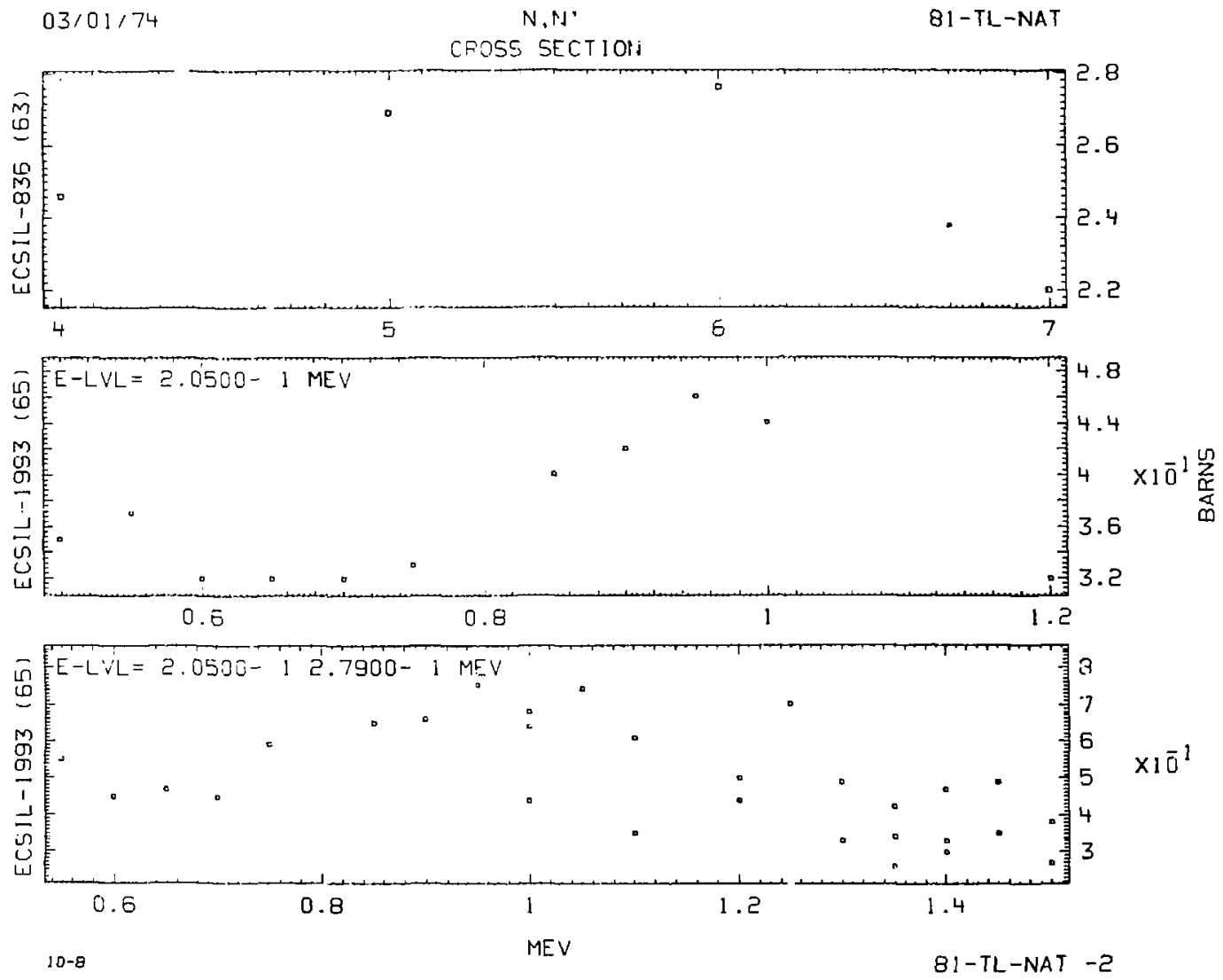

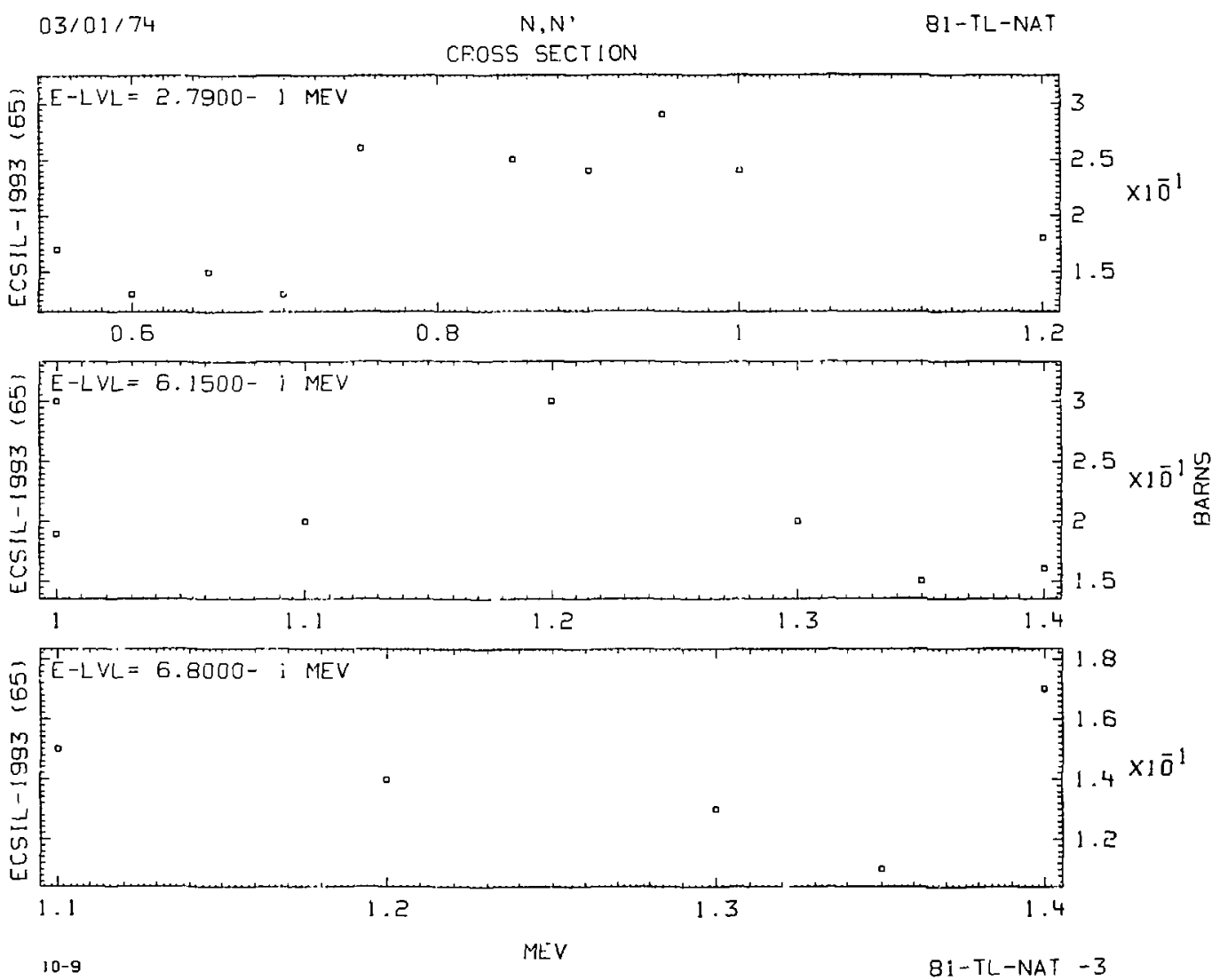


\section{CROSS SECTION}

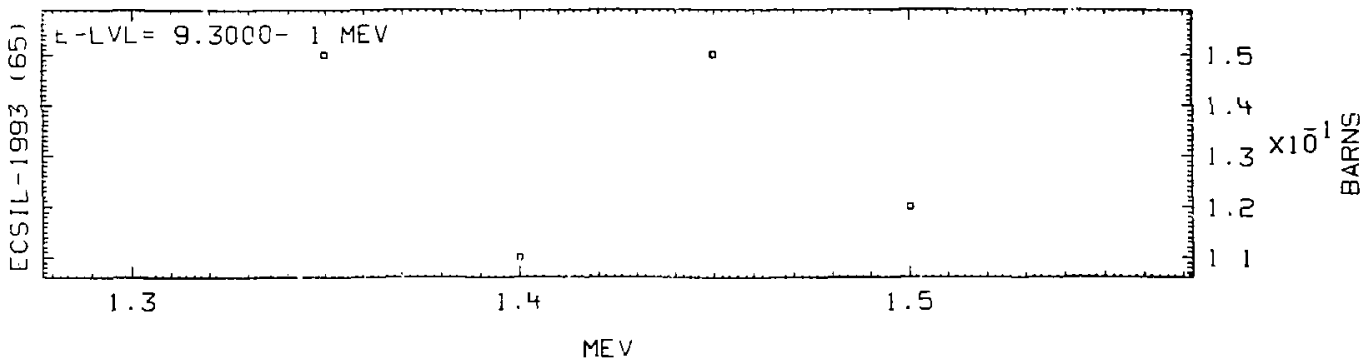

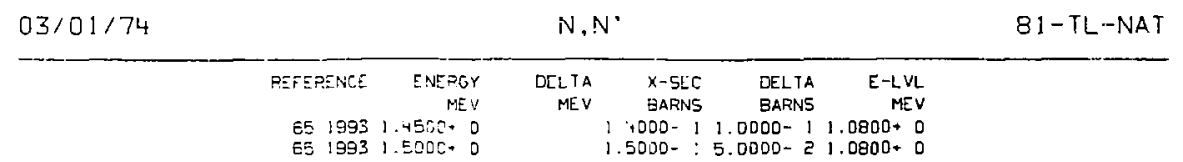

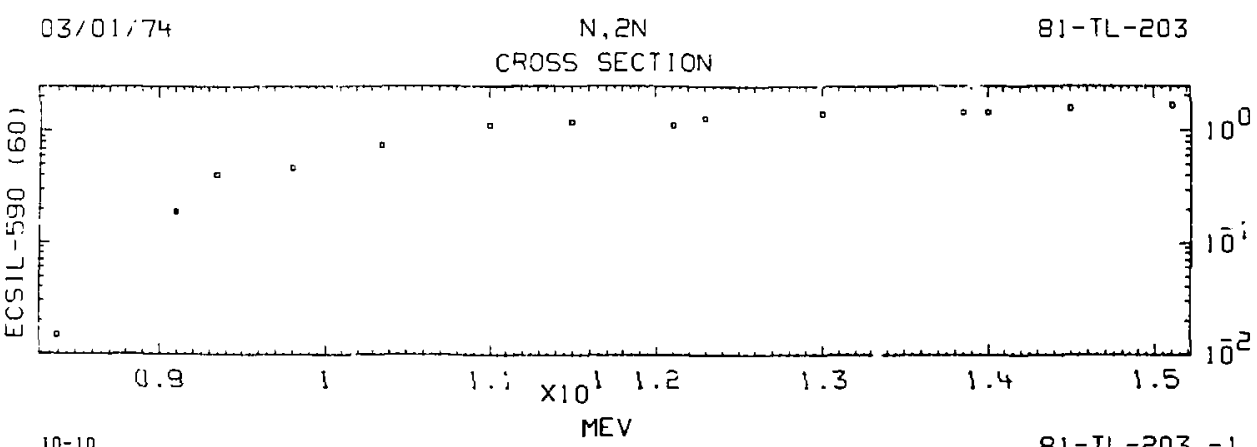



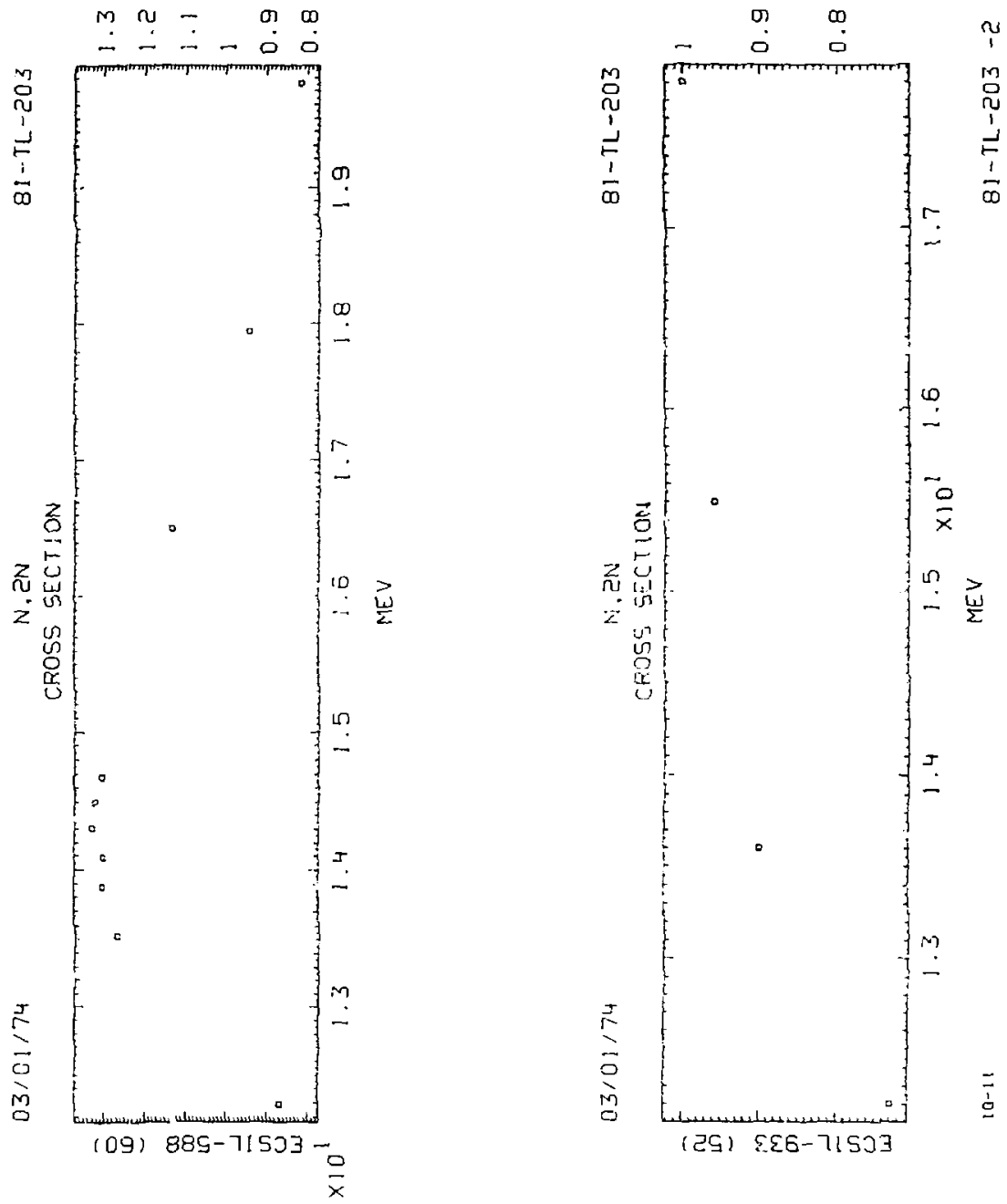


\section{CROSS SECTION}

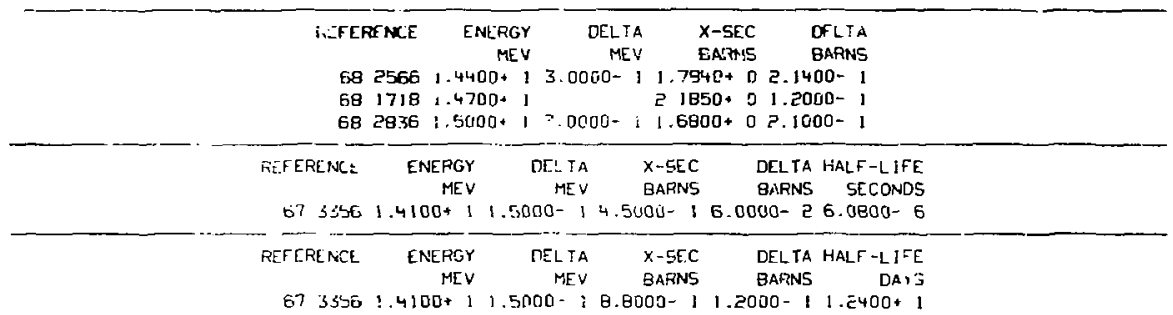

\section{$03 / 01 / 74$} $N, 3 N$

QI-TL-203

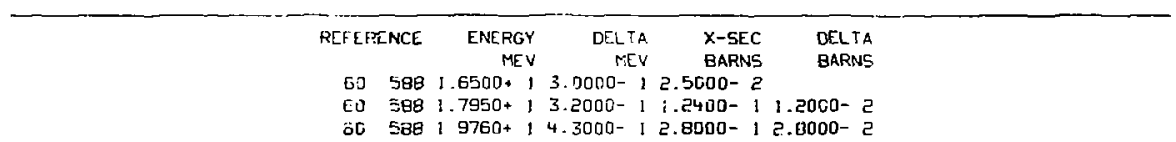

03:01/74
$6825651.4400,13.0000-12.3000-35.0000-4$ $59550: .4500+1 \quad 3.7000-44.0000-5$

$$
N, 2 N
$$

\begin{tabular}{|c|c|c|c|}
\hline REFE ERESEE & $\begin{array}{r}\text { ENERGY } \\
\text { MEV }\end{array}$ & $\begin{array}{r}\text { DEL IA } \\
\text { MEV }\end{array}$ & $\begin{array}{l}X \text {-SEC } \\
\text { BARNS }\end{array}$ \\
\hline
\end{tabular}

$6419581.4800+12.0000-i 1.990 L^{\prime}+01.3930-1$ 
CROSS SECTION

\begin{tabular}{|c|c|c|c|c|}
\hline REFERENCE & $\begin{array}{r}\text { ENERGY } \\
\text { MEV }\end{array}$ & $\begin{array}{r}\text { DELTA } \\
\text { MEV }\end{array}$ & $\begin{array}{l}\text { X-SEC } \\
\text { BARN! }\end{array}$ & $\begin{array}{l}\text { DELTA } \\
\text { BARNS }\end{array}$ \\
\hline$E 8=66$ & $00+1$ & $3.0000-1$ & 6. $2000-5$ & $1.2000-$ \\
\hline 550 & $1.4500+1$ & & $6.8010-3$ & $7.0010-4$ \\
\hline 52 & $1.4500+1$ & & $3.0500-3$ & $1.5000-3$ \\
\hline
\end{tabular}

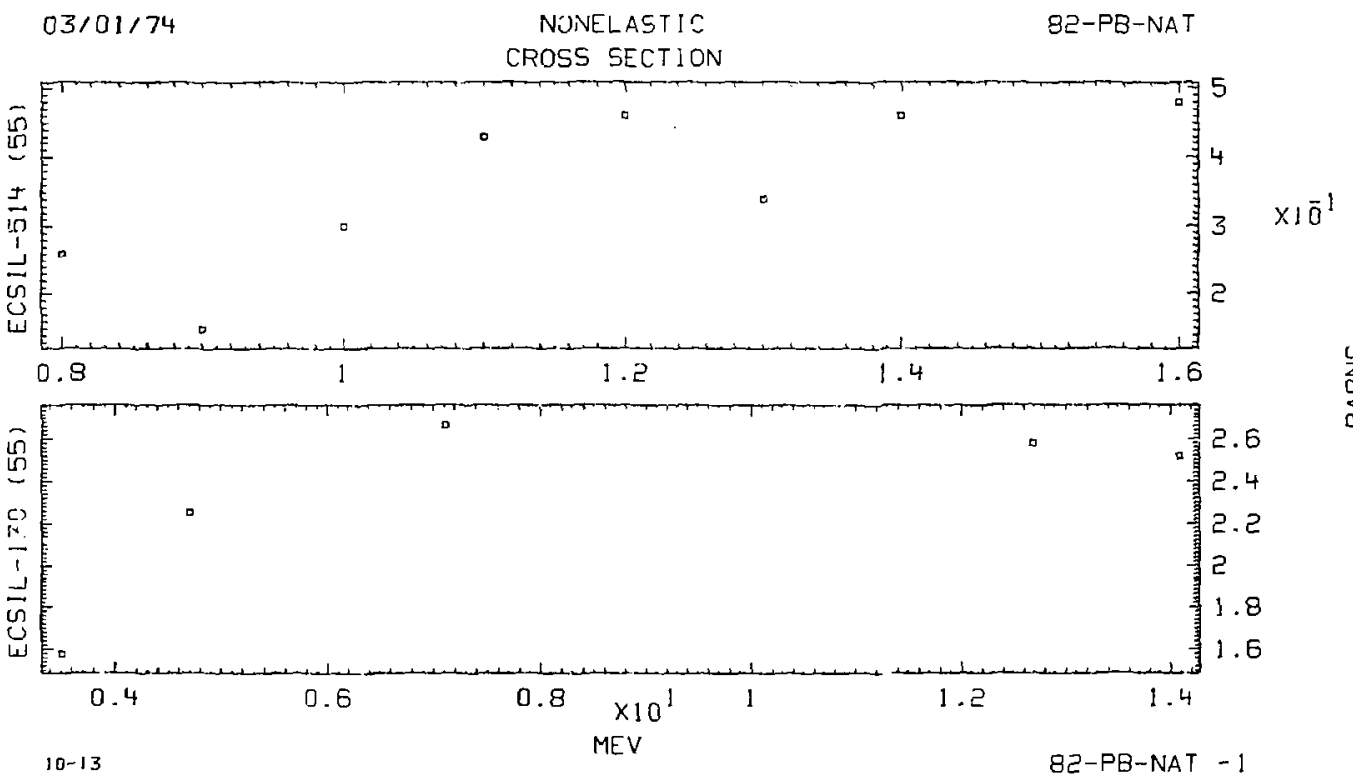




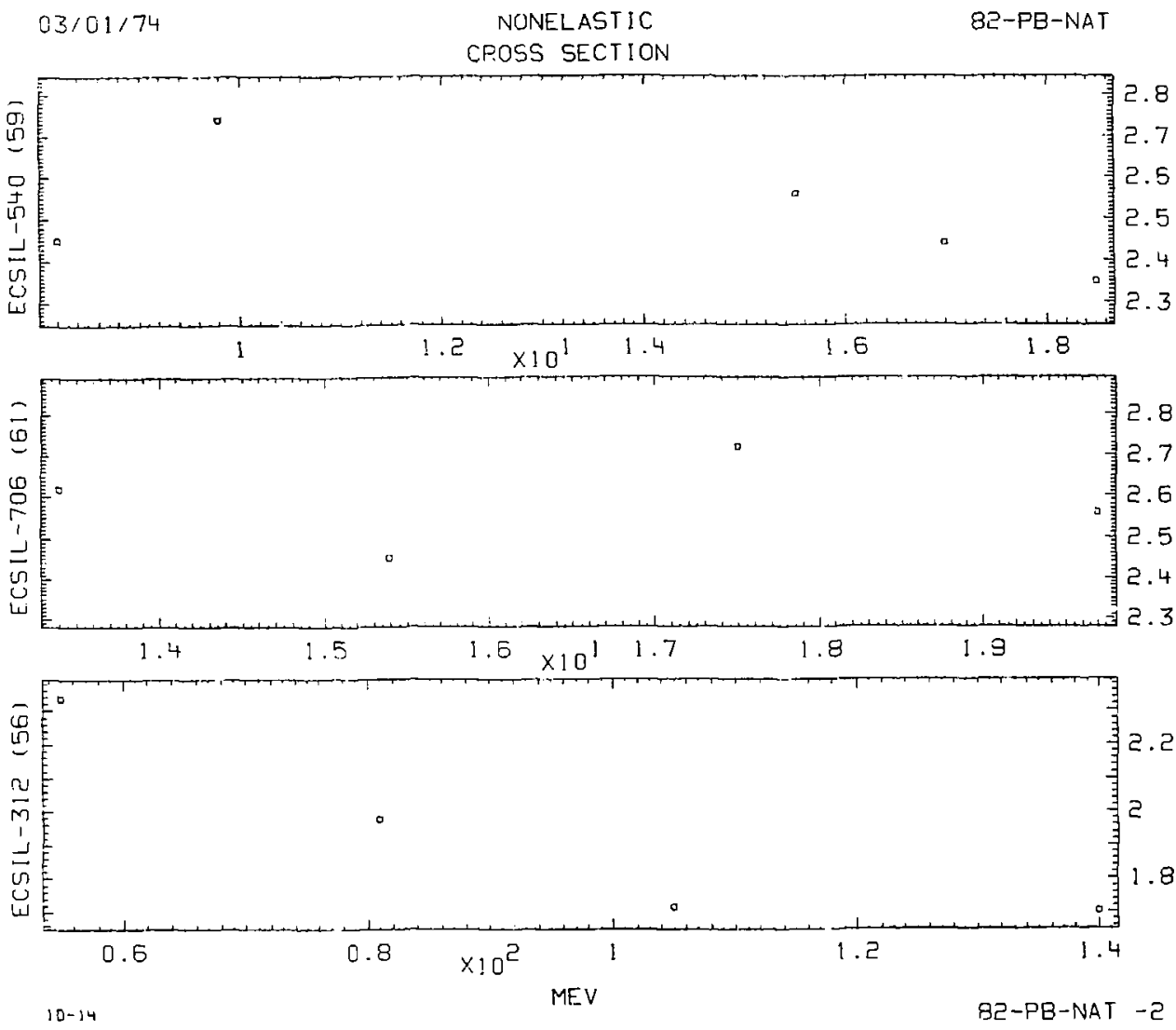



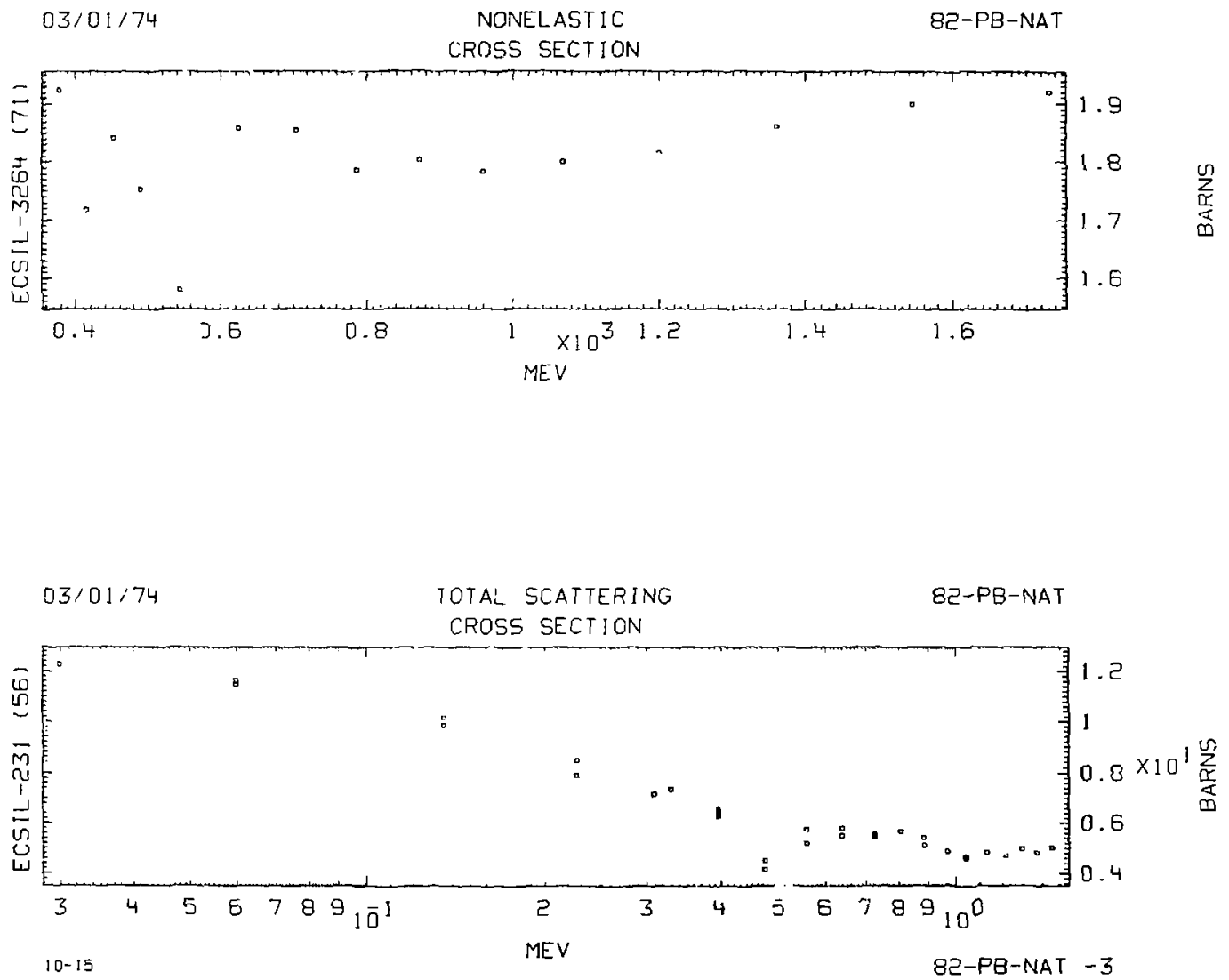

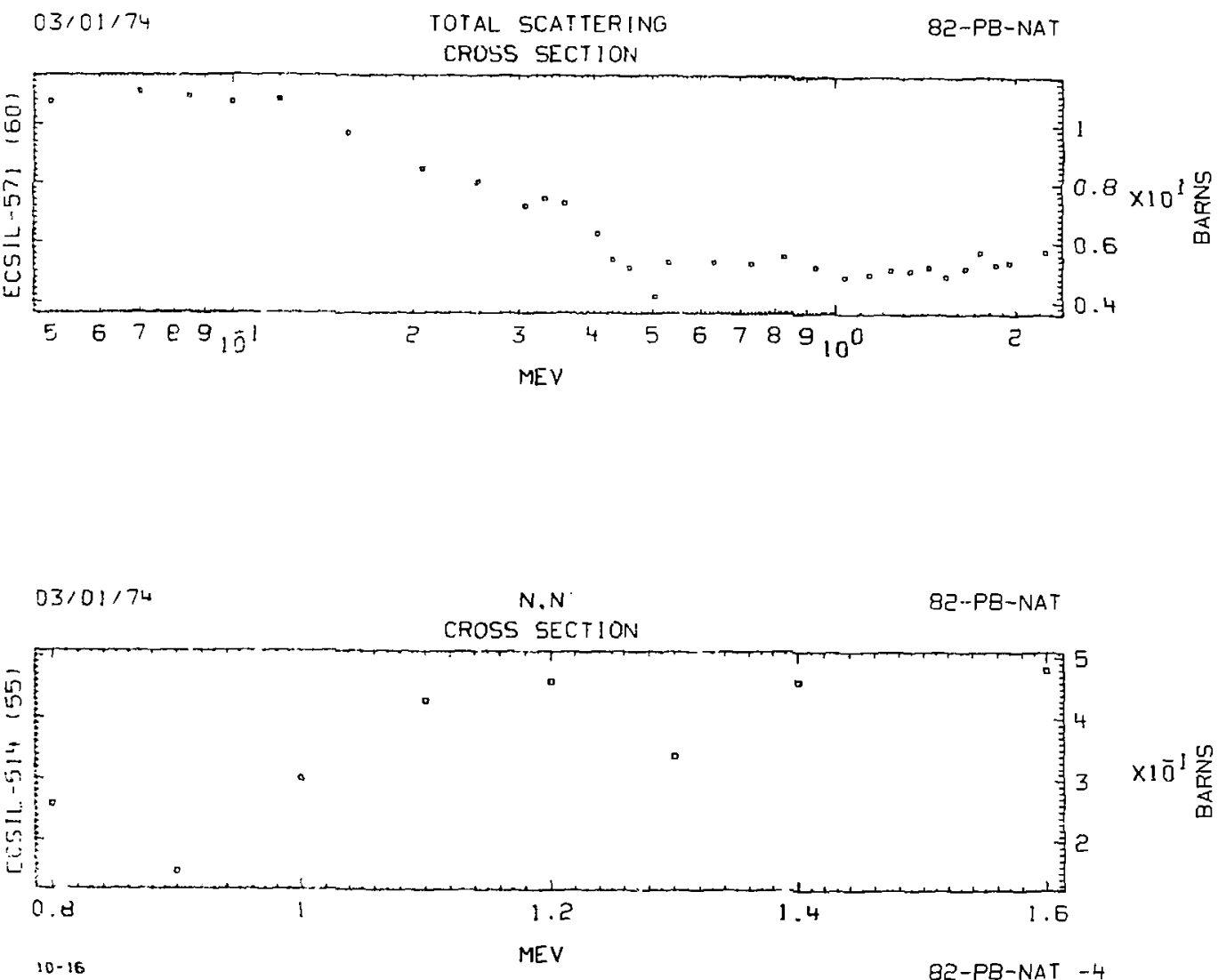
CROSS SECTION
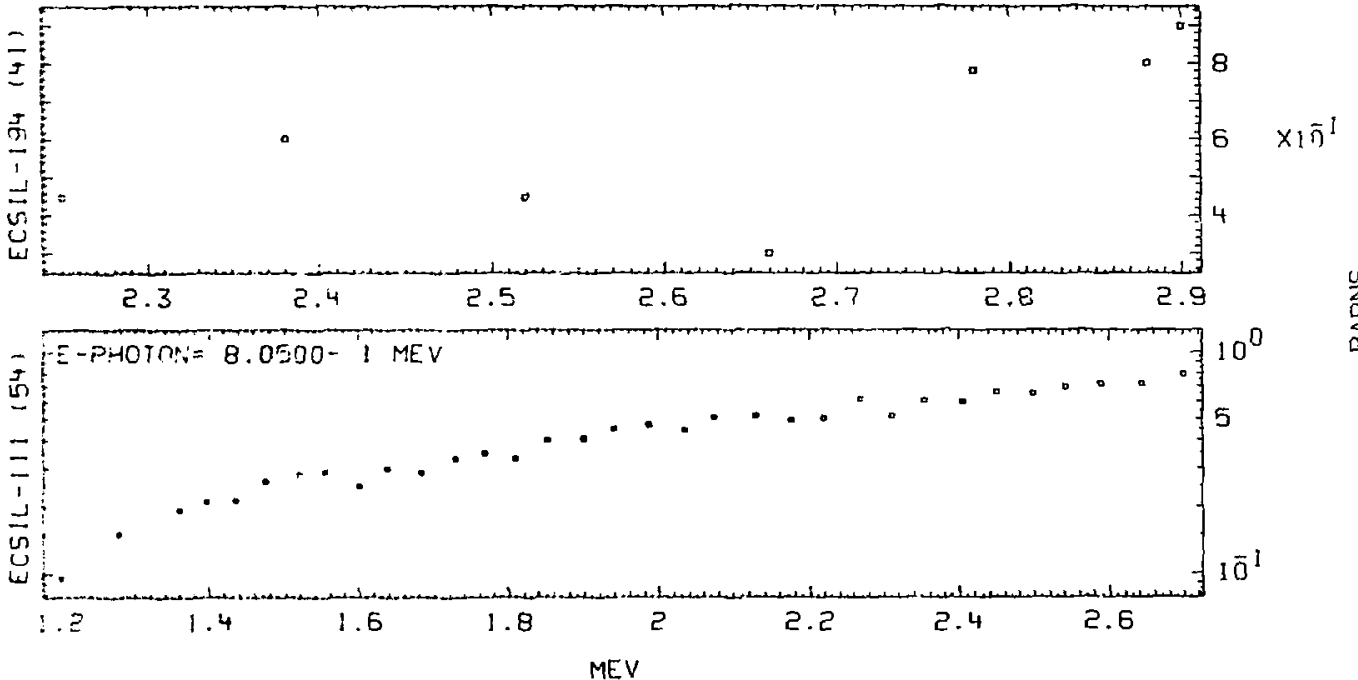

$03 / 01,74$

NONELAST IC

B2-PB-NAT

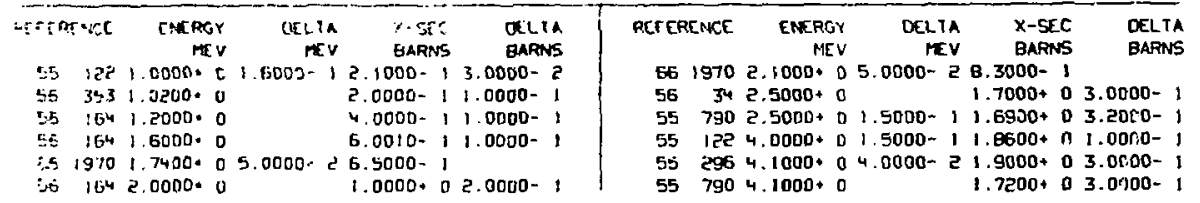

$10-17$

$$
\text { 8Z-PB-VAT - } 5
$$


CROSS SECTIION

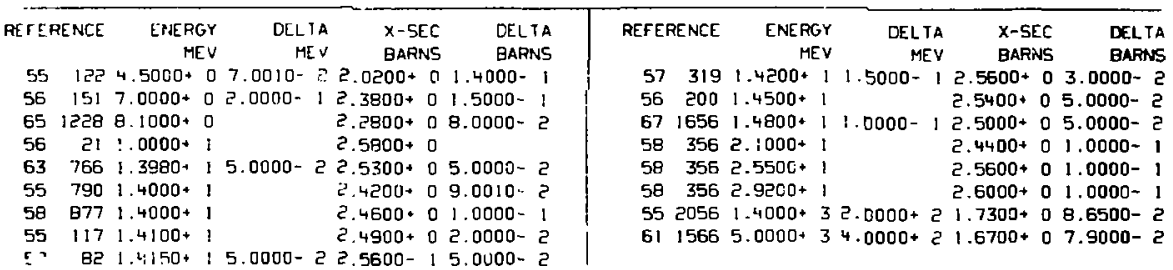

$03 / 01 / 74$

TOTAL SCATTERING

82-PB-NAT

$\begin{array}{rrrr}\text { PEFFFER:C ENEREY } & \text { DELTA } & x-S E C & \text { DELTA } \\ \text { MEV } & \text { MEV } & \text { BARNS } & \text { GARNS }\end{array}$

$638799.8000-15.0000-24.3200+01.2960-1$

56 21 $1.0000+1 \quad 4.6000+0$

$03 / 01 / 74$

NEUTRON NONEL.EMISS.

82-PB-NAT

$\begin{array}{rrrrr}\text { REFERENCE } & \begin{array}{r}\text { ENEROY } \\ \text { MEV }\end{array} & \begin{array}{r}\text { OELTA } \\ \text { MEV }\end{array} & \begin{array}{r}\text { X-SEC } \\ \text { BARNS }\end{array} & \begin{array}{r}\text { DELTA } \\ \text { BARNS }\end{array} \\ 61883 & 1.4000 * 1 & & 1.8006+0 & 3.0000-1\end{array}$

$03 / 01 / 74$

$N$, CN

Z2-PB-NAT

\begin{tabular}{|c|c|c|c|c|}
\hline \multirow[t]{2}{*}{ REFERENLE } & ENERGY & DELTA & $x-5 E C$ & DELTA \\
\hline & MEY & MEV & BARNS & BARN5 \\
\hline E09 & $1.4000+1$ & & $2.3000+0$ & $1.9000-$ \\
\hline 58 & $1.4100+1$ & & $2.7400+0$ & $2.0000-$ \\
\hline 631701 & $1.4500+1$ & & $1.8000+0$ & $2.0000-$ \\
\hline
\end{tabular}




\begin{tabular}{|c|c|c|c|c|c|c|c|c|c|c|}
\hline REF ERENCE & $\begin{array}{r}\text { ENERGY } \\
\text { MEV }\end{array}$ & $\begin{array}{r}\text { DELTA } \\
\text { MEV }\end{array}$ & $\begin{array}{l}X-5 E C \\
\text { BARNS }\end{array}$ & $\begin{array}{l}\text { DELTA } \\
\text { BARNS }\end{array}$ & REFERE & ENCE & $\begin{array}{r}\text { ENERGY } \\
\text { MEV }\end{array}$ & $\begin{array}{r}\text { DELTA } \\
\text { MEV }\end{array}$ & $\begin{array}{l}X-S E C \\
\text { BARNS }\end{array}$ & $\begin{array}{l}\text { DELTA } \\
\text { EARNS }\end{array}$ \\
\hline 6) 2569 & $.5300-8$ & & $1.7200-1$ & $9000-2$ & 58 & 364 & z. $5000-2$ & $4.0000-3$ & $1.3000-2$ & $3.0000=3$ \\
\hline Se 1162 & $.5300-8$ & & 1. $6900-1$ & 0020- 3 & 58 & 354 & $2.2000-1$ & $2.0000-\bar{e}$ & $8.0000-3$ & $4.0000-3$ \\
\hline
\end{tabular}

$03 / 01 / 74$

$N, X$ OAMMA

BC-PE-NAT

$\begin{array}{rrrr}\text { REFERENCE CNERGY DELTA } & X \text { SEC } & \text { DELTA } \\ \text { MEV } & \text { MEV } & \text { BARS } & \text { BARNS }\end{array}$

E3 $17231.4100+16.0000-13.2000 * 0$

$532941.4200+12.0000-14.2000+0$

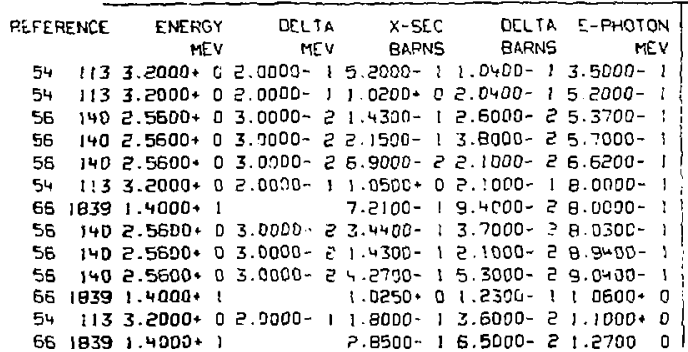

\begin{tabular}{|c|c|c|c|c|c|c|}
\hline \multicolumn{2}{|c|}{ REFERENCE } & $\begin{array}{r}\text { ENCPGY } \\
\text { MEY }\end{array}$ & $\begin{array}{l}\text { DELTA } \\
\text { MEV }\end{array}$ & $\begin{array}{l}X \text {-SEC } \\
\text { BARNS }\end{array}$ & $\begin{array}{l}\text { DELTA } \\
\text { BAPNS }\end{array}$ & 2. E-PHOTON \\
\hline با & 113 & $3.2000+0$ & $02.0090-i$ & $2.5000-1$ & $5.0000-2$ & $1,4000+0$ \\
\hline 56 & 140 & $2.5600+0$ & $00-2$ & $3.2000-2$ & $100-$ & 1.4 \\
\hline 56 & 140 & $2.5600+0$ & $00-2$ & $2.6400-1$ & $100-2$ & $50+0$ \\
\hline 66 & 1839 & $1.4000+1$ & & $4.0800-1$ & 7. & $10 *$ \\
\hline 56 & 140 & $2.5600+0$ & $03.0000-2$ & $4.8000-2$ & $30-2$ & 21.77004 \\
\hline 66 & 1839 & $1.4000+1$ & & $2.9700-1$ & 5.6000 & 2.1 \\
\hline 54 & 113 & $3.2000+0$ & $02.0000-1$ & $1.6000-1$ & $3.2000-$ & $2.2000+$ \\
\hline 66 & 1839 & $1.4000+1$ & 1 & $5.9800-1$ & $7.7000-$ & $2.6000+$ \\
\hline 66 & 1839 & $1.4000 \cdot 1$ & 1 & $1.5000-2$ & $3.7000-$ & $33.6000+$ \\
\hline 53 & 294 & $1.4200+1$ & $12.0000-1$ & $14.8000-2$ & & $4.4000 \%$ \\
\hline 68 & 1839 & $1.4000+1$ & & $1.2000-$ & $6.2000-$ & \\
\hline 53 & $\mathrm{Bm}$ & 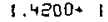 & & 200 & & 500 \\
\hline
\end{tabular}

$03 / 01 / 74$

BOUND ATOM

BD-PB-NAT

\begin{tabular}{|c|c|c|c|c|}
\hline RE $F$ ERENCE & $\begin{array}{r}\text { ENERRY } \\
\text { MEY }\end{array}$ & $\begin{array}{r}\text { DELIA } \\
\text { MEY }\end{array}$ & $\begin{array}{l}X-5 E C \\
\text { BARNS }\end{array}$ & $\begin{array}{l}\text { DEL IA } \\
\text { BAPNS }\end{array}$ \\
\hline $\begin{array}{l}52: 657 \\
5 ! 1584\end{array}$ & $\begin{array}{l}.5300-8 \\
.3000-8\end{array}$ & & $\begin{array}{l}1200+1 \\
1600+1\end{array}$ & $5.0000=1$ \\
\hline
\end{tabular}


CROSS SECTION

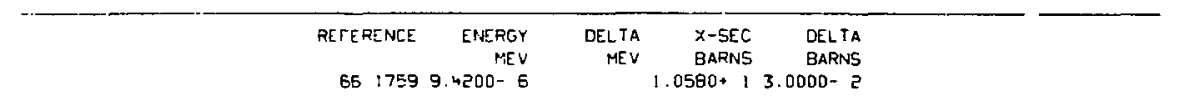

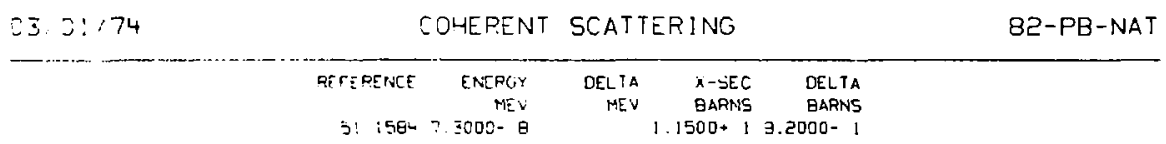

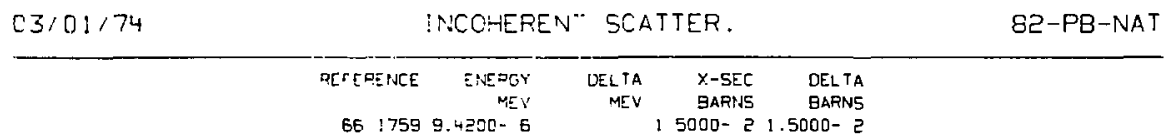

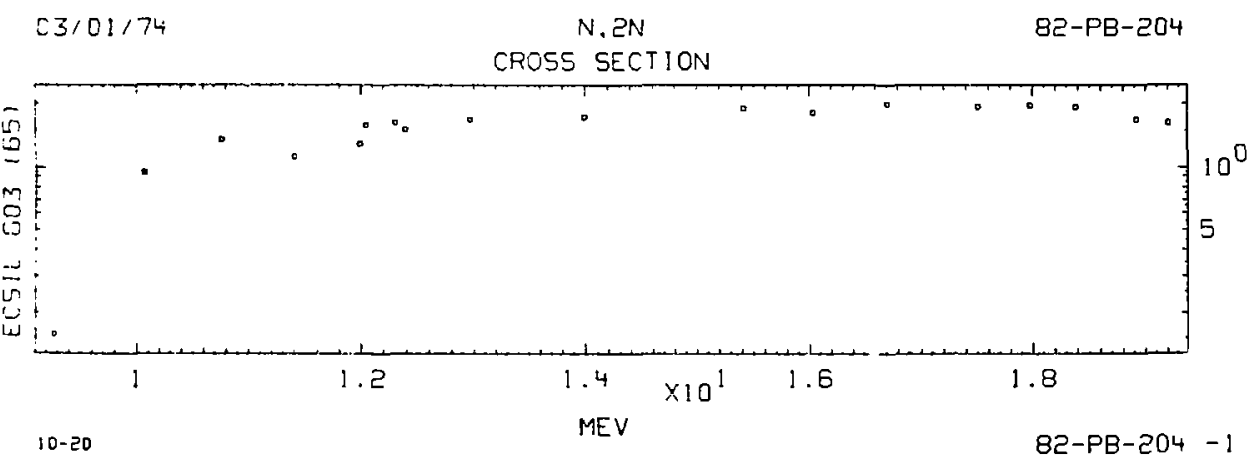



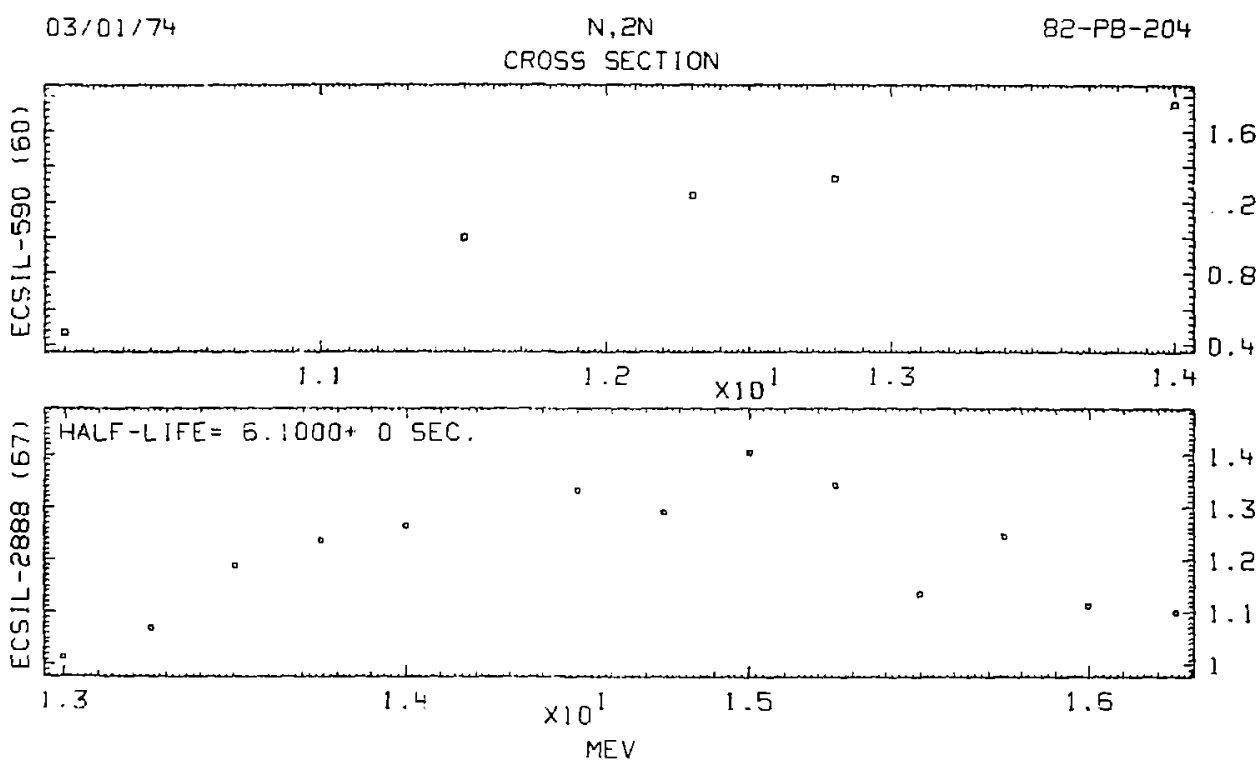

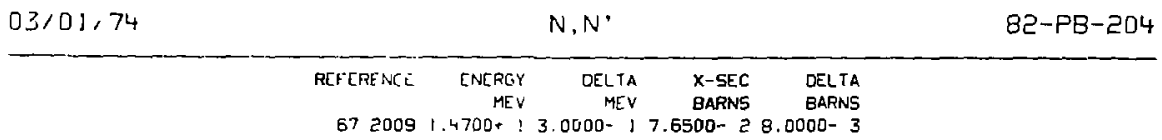

$|0-5|$

$85-P B-504-5$ 
CROSS SECTION

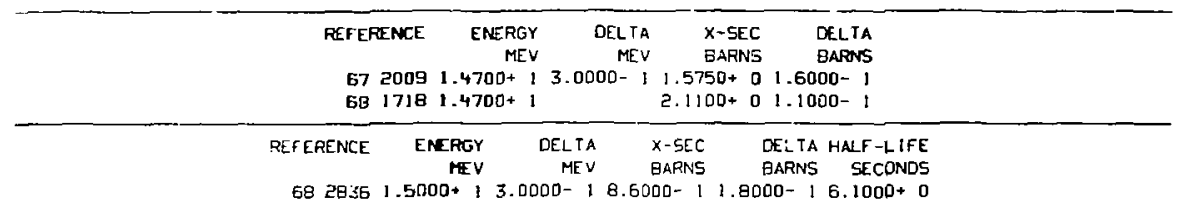
$03 / 01 / 74$
$N, X$ GAMMA
$85-P B-506$ CROSS SECTION
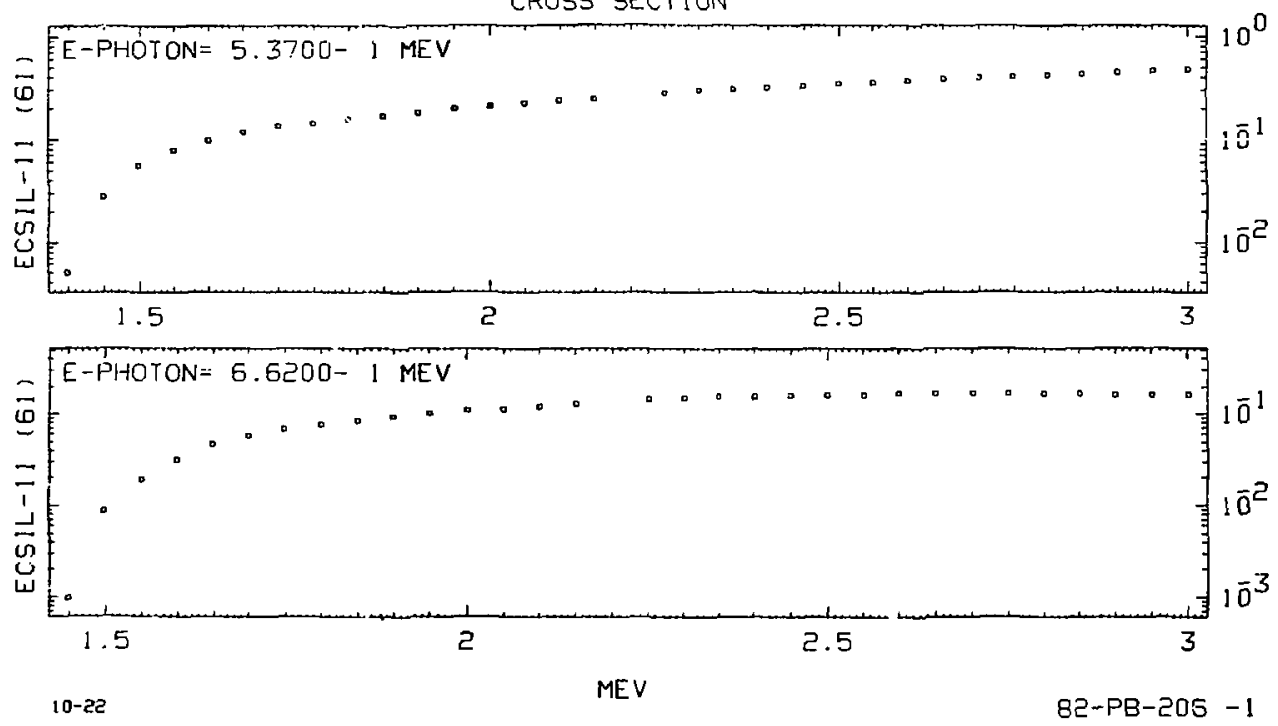


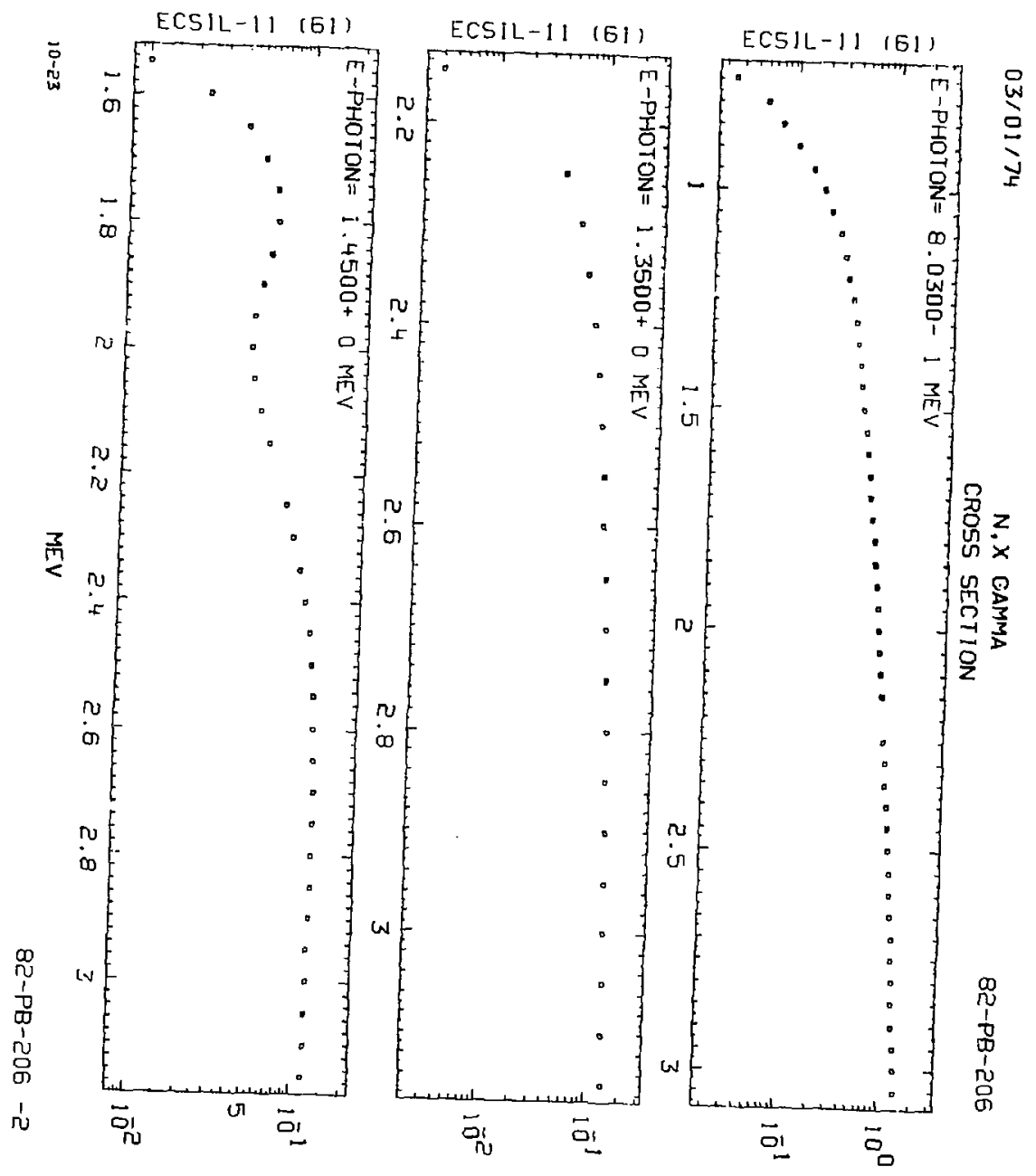

BARNS 

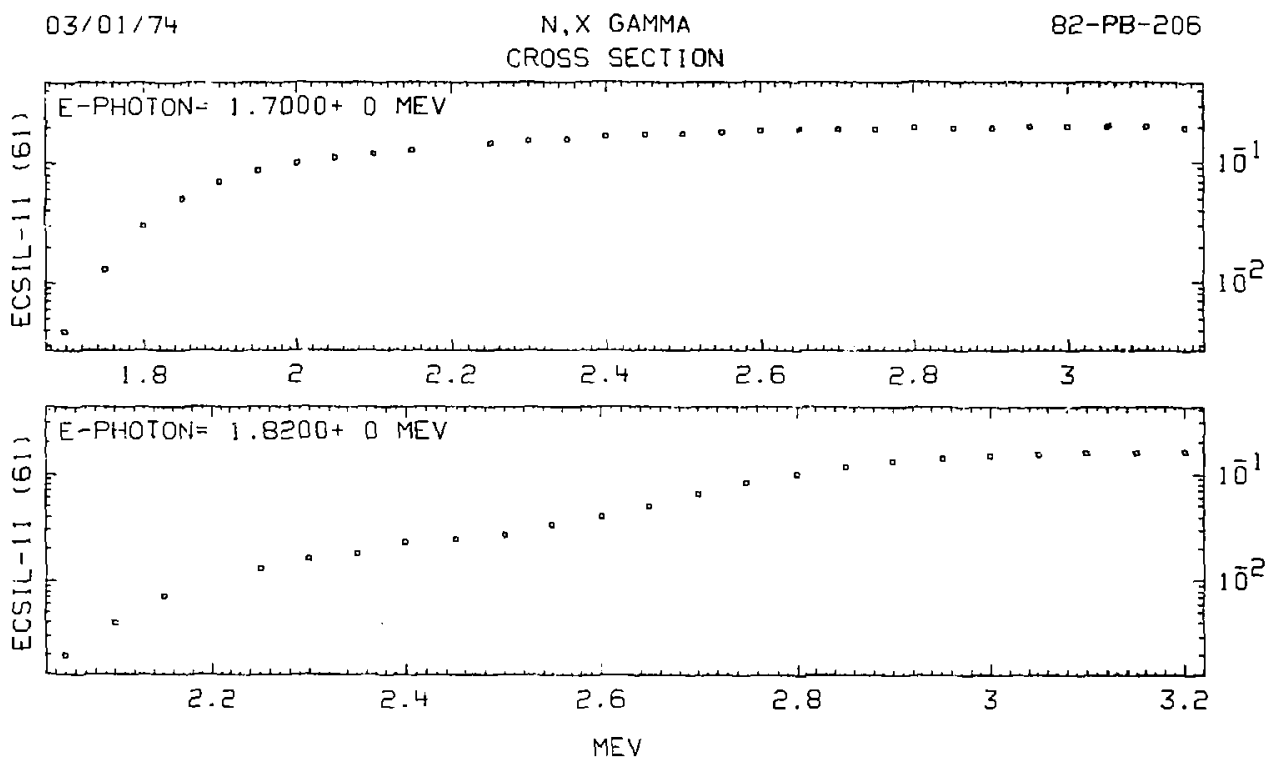

$03 / 01,74$

NONELASTIC

82-PB-206

RETERE,NCE ENERGY DELTA X-SEC DELTA

$541031.0000+0$ 5.0000-2 2.0000- $12.0000-1$ 
$03 / 01 / 74$

$N, N^{\circ}$

82-PB-206

CROSS SECTION

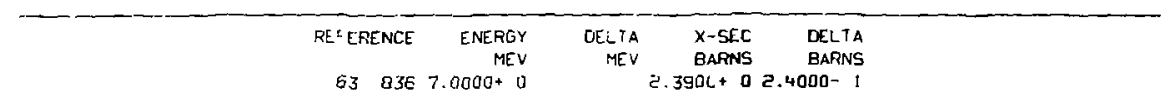

$03 / 0 ! / 74$

$N, X$ GAMMA

$82-P B-206$

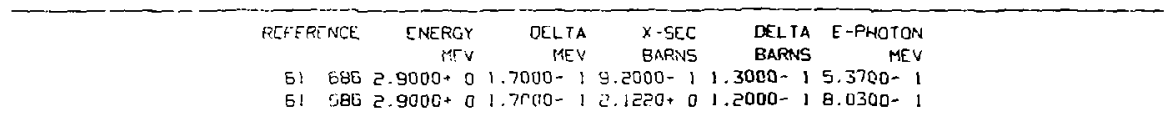

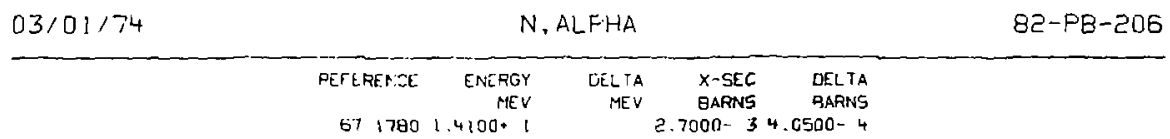

$6717001.4100+1 \quad 2.7000-34.0500-4$

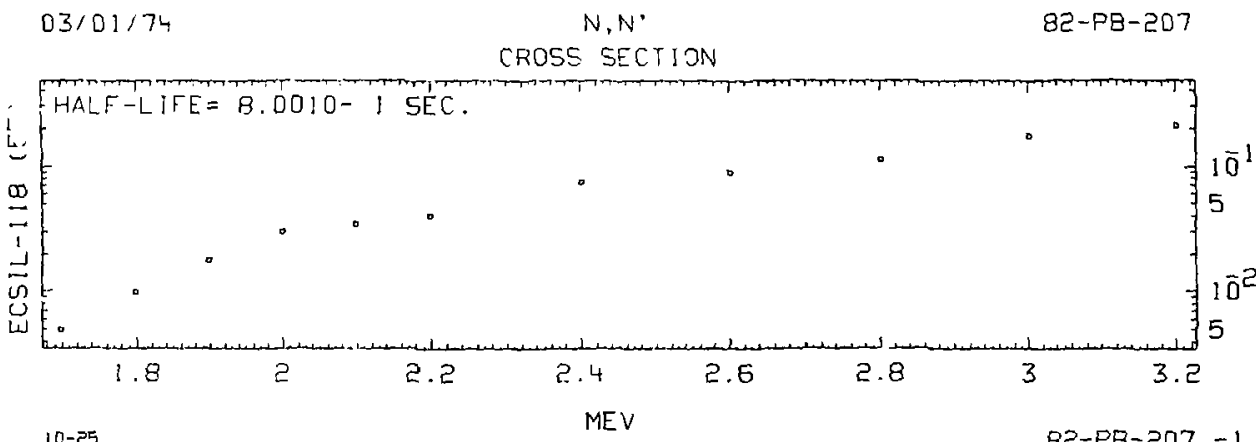

$10-25$ 


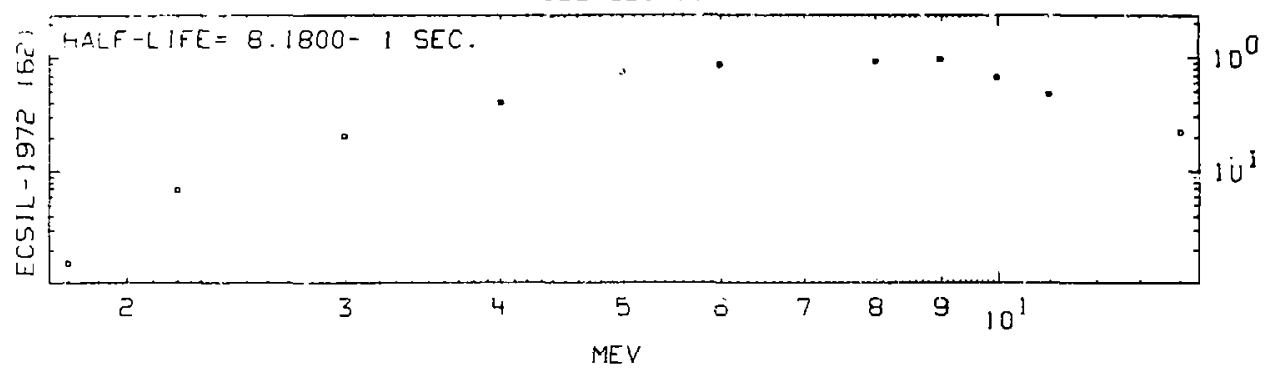

$\frac{1}{x}$

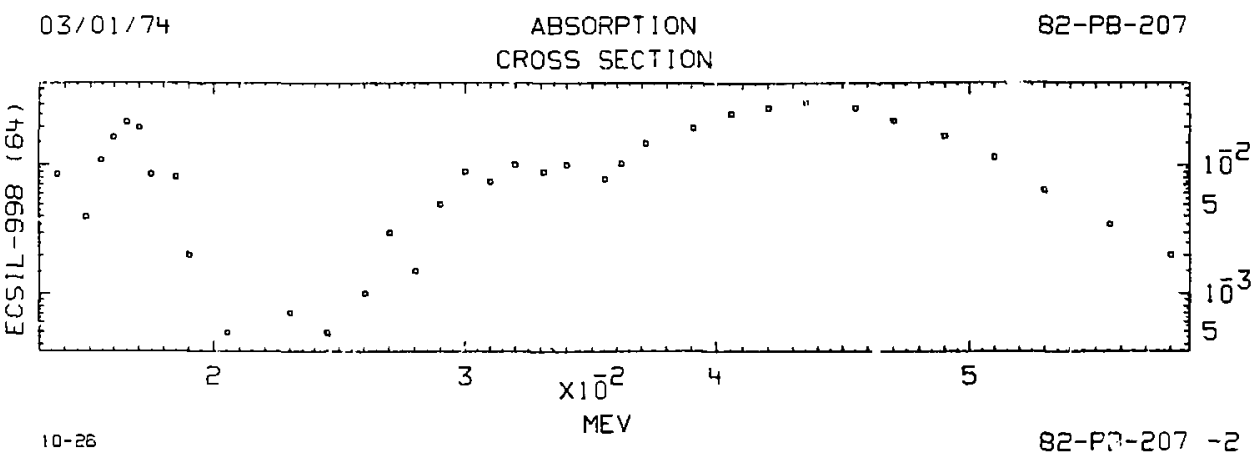




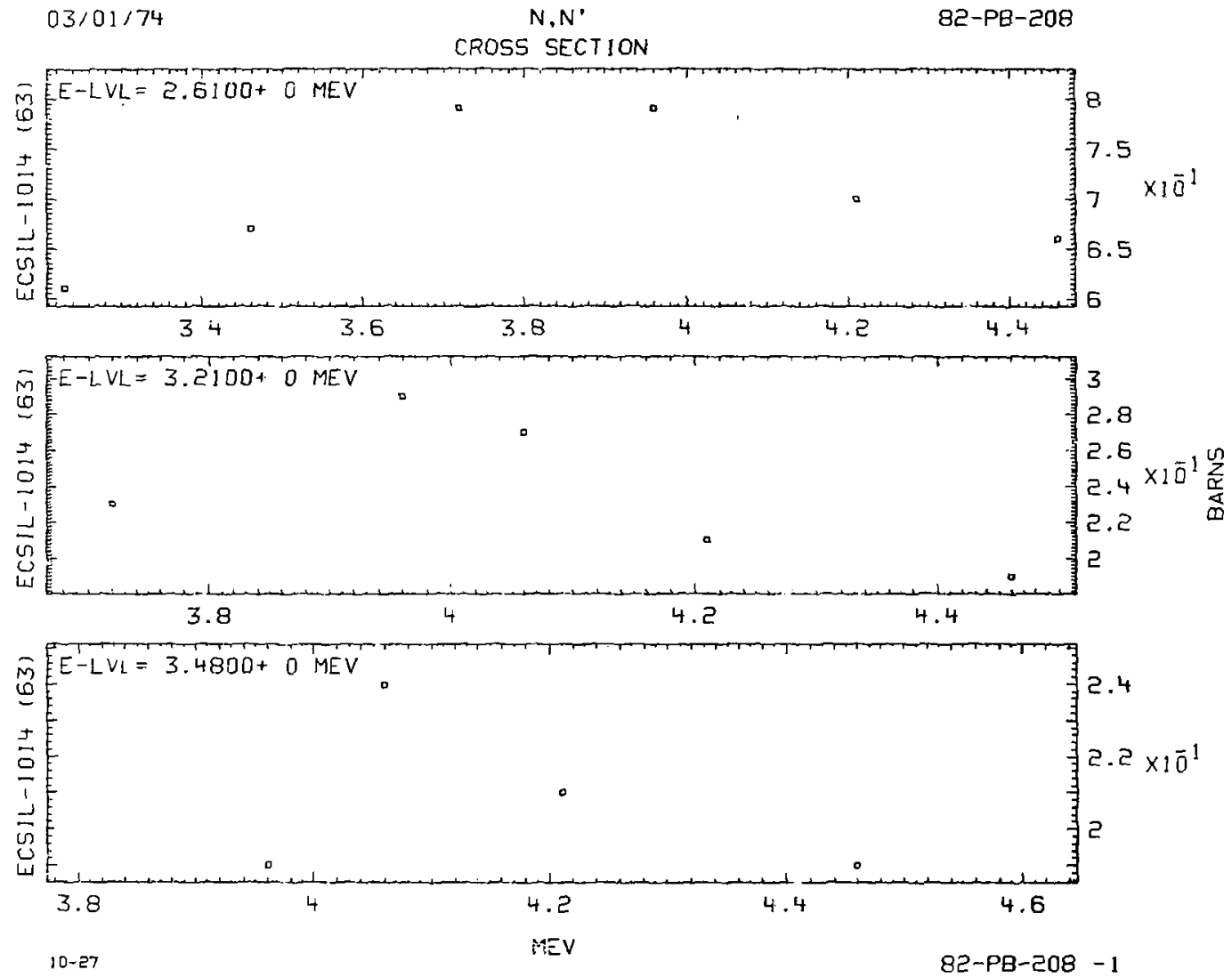




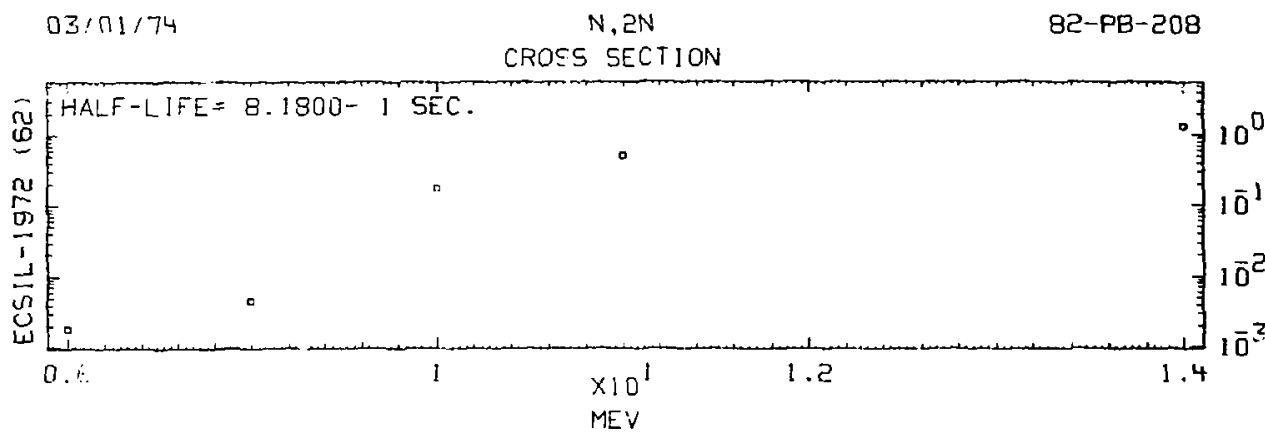

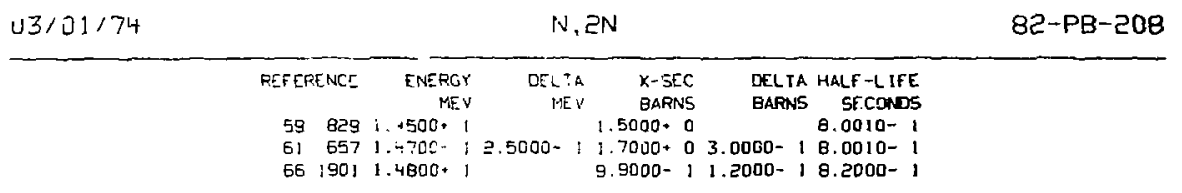

\begin{tabular}{l}
$03101 / 74$ \\
$03101 / 74$ \\
\hline
\end{tabular}


CROSS SECTION

\begin{tabular}{|c|c|c|c|}
\hline REFERENCE & ENEROY & DELTA & $x-5 E C$ \\
\hline
\end{tabular}

$595501.4500+1.6000-3 \geq .0000-4$

$03 / 01 / 74 \quad N . N^{2}$ RADIO LEAD

\begin{tabular}{|c|c|c|c|c|c|}
\hline PEFEPENCE & $\begin{array}{r}\text { ENERGY } \\
\text { MEV }\end{array}$ & $\begin{array}{r}\text { OELTA } \\
\text { MEV }\end{array}$ & $\begin{array}{l}x-5 E C \\
\text { GARNS }\end{array}$ & $\begin{array}{l}\text { DELIA } \\
\text { BARNS }\end{array}$ & $\begin{array}{r}E-L V L \\
\text { MEV }\end{array}$ \\
\hline $\begin{array}{ll}59 & 497 \\
58 & 497\end{array}$ & $\begin{array}{l}000+0 \\
000+0\end{array}$ & $\begin{array}{l}\text { 2000- } 1 \\
\text { 2rno- } 1\end{array}$ & $\begin{array}{l}0000-1 \\
3000-1\end{array}$ & & $300 * 0$ \\
\hline
\end{tabular}

$584972.2000+01.2500-11.3000-1.1 .4300 * 0$

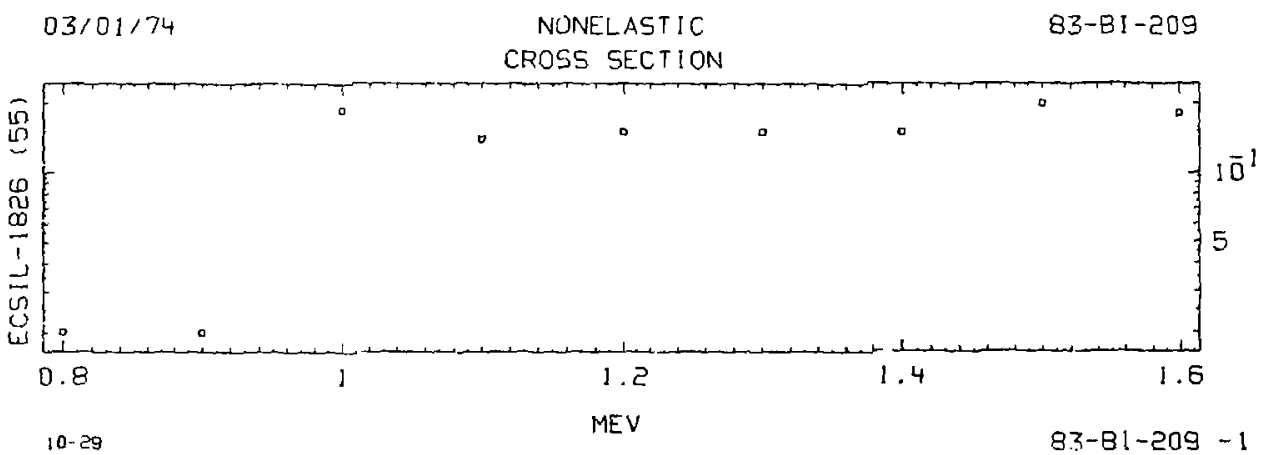




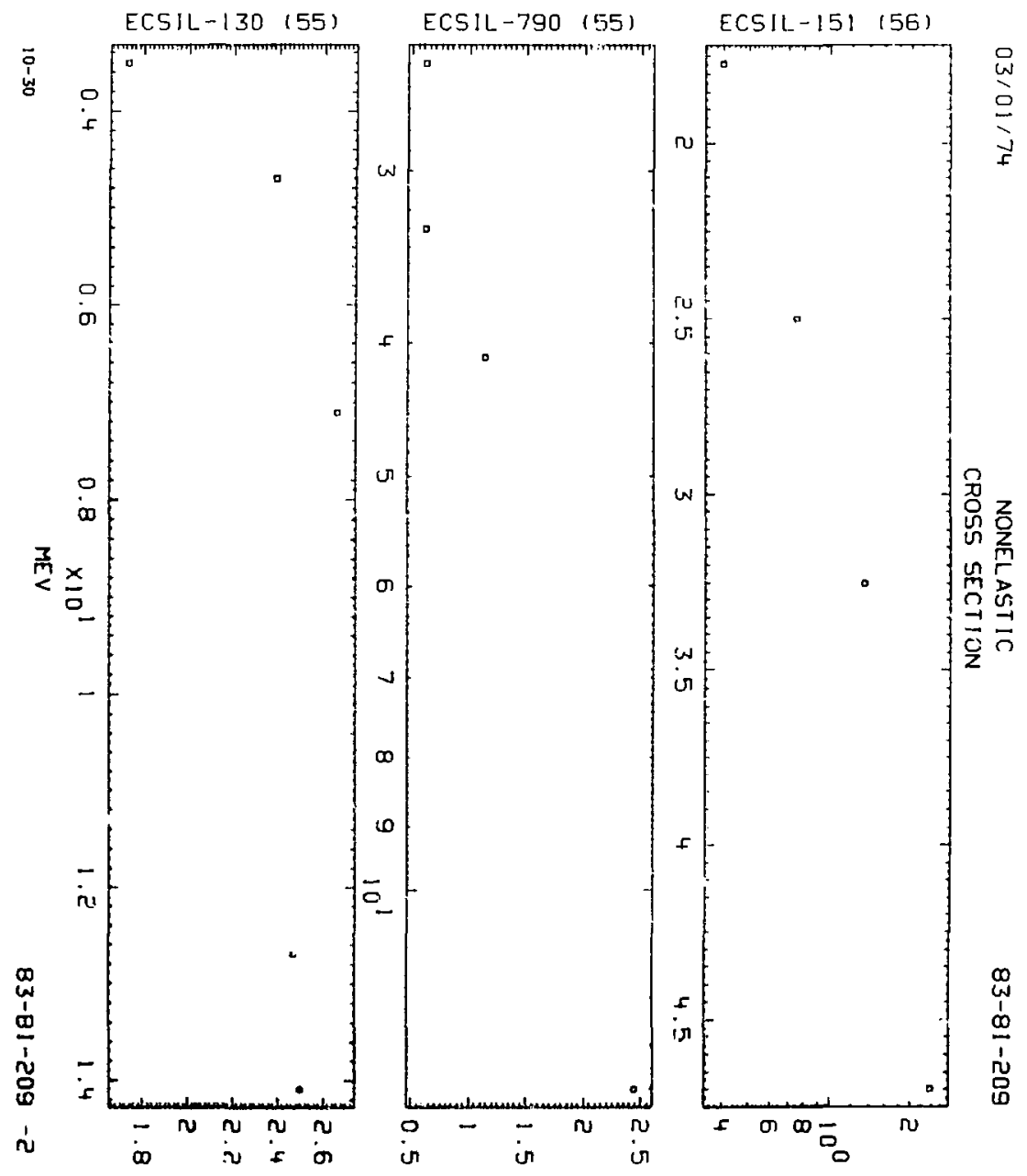

BARNS 
SNeve

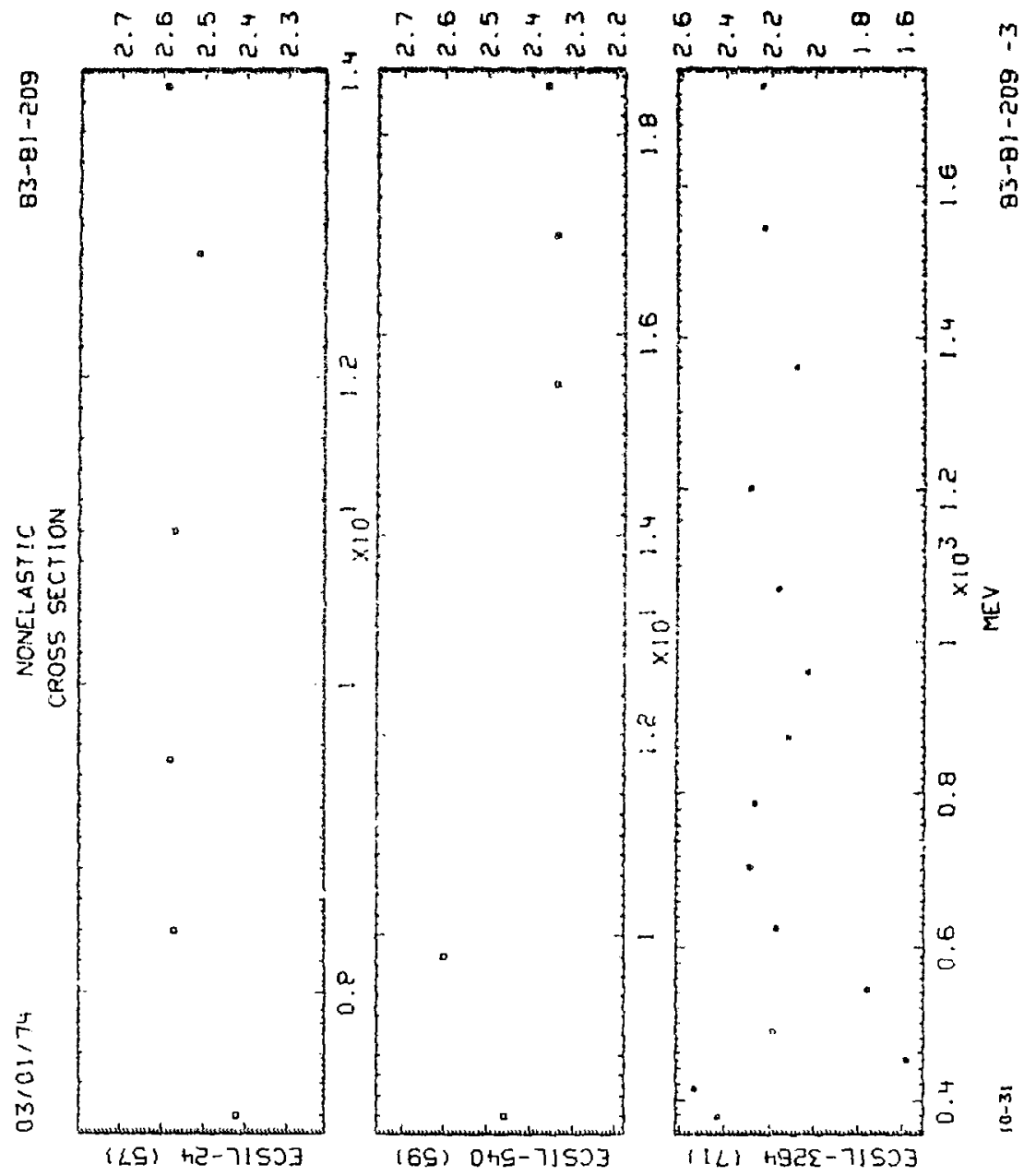



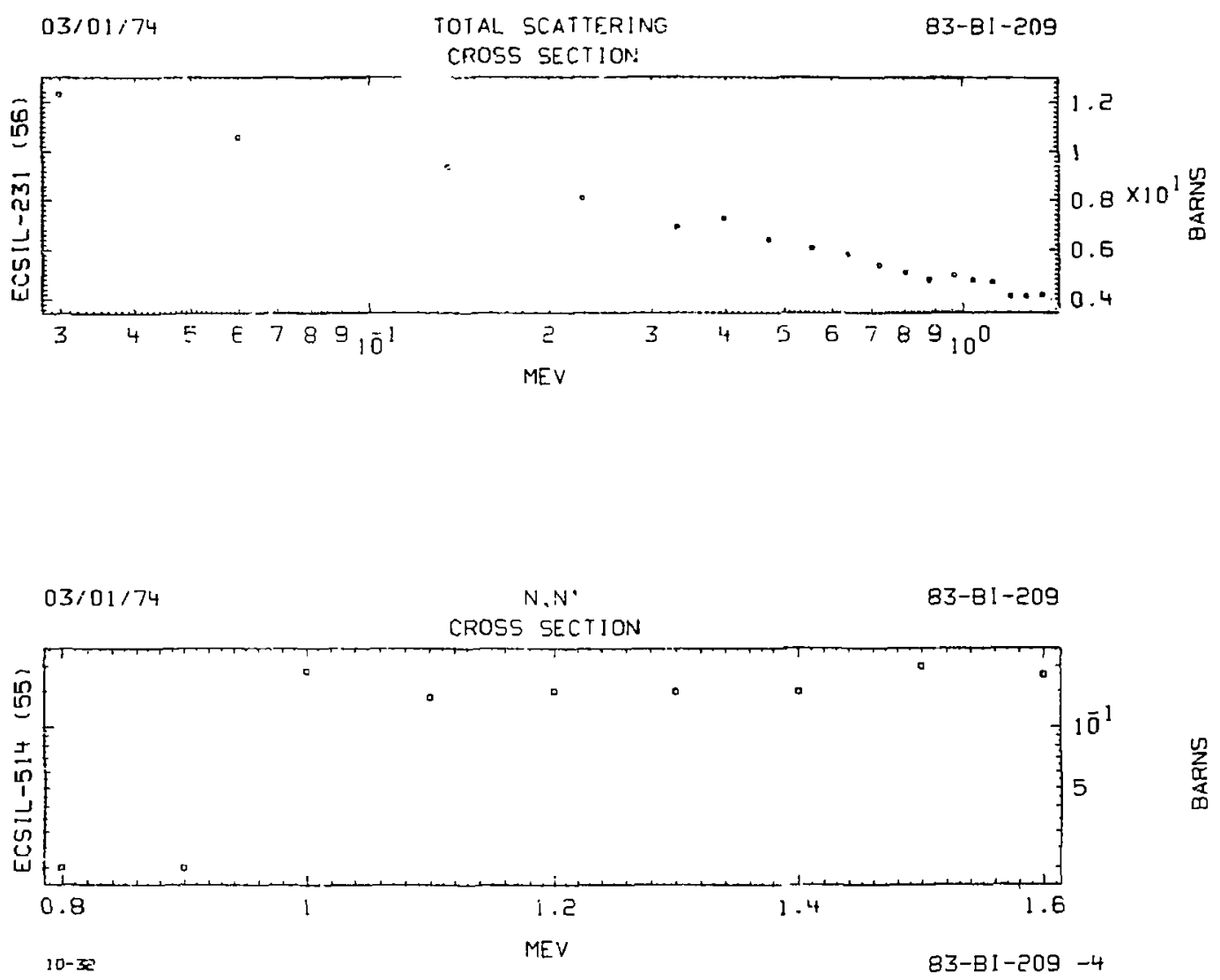

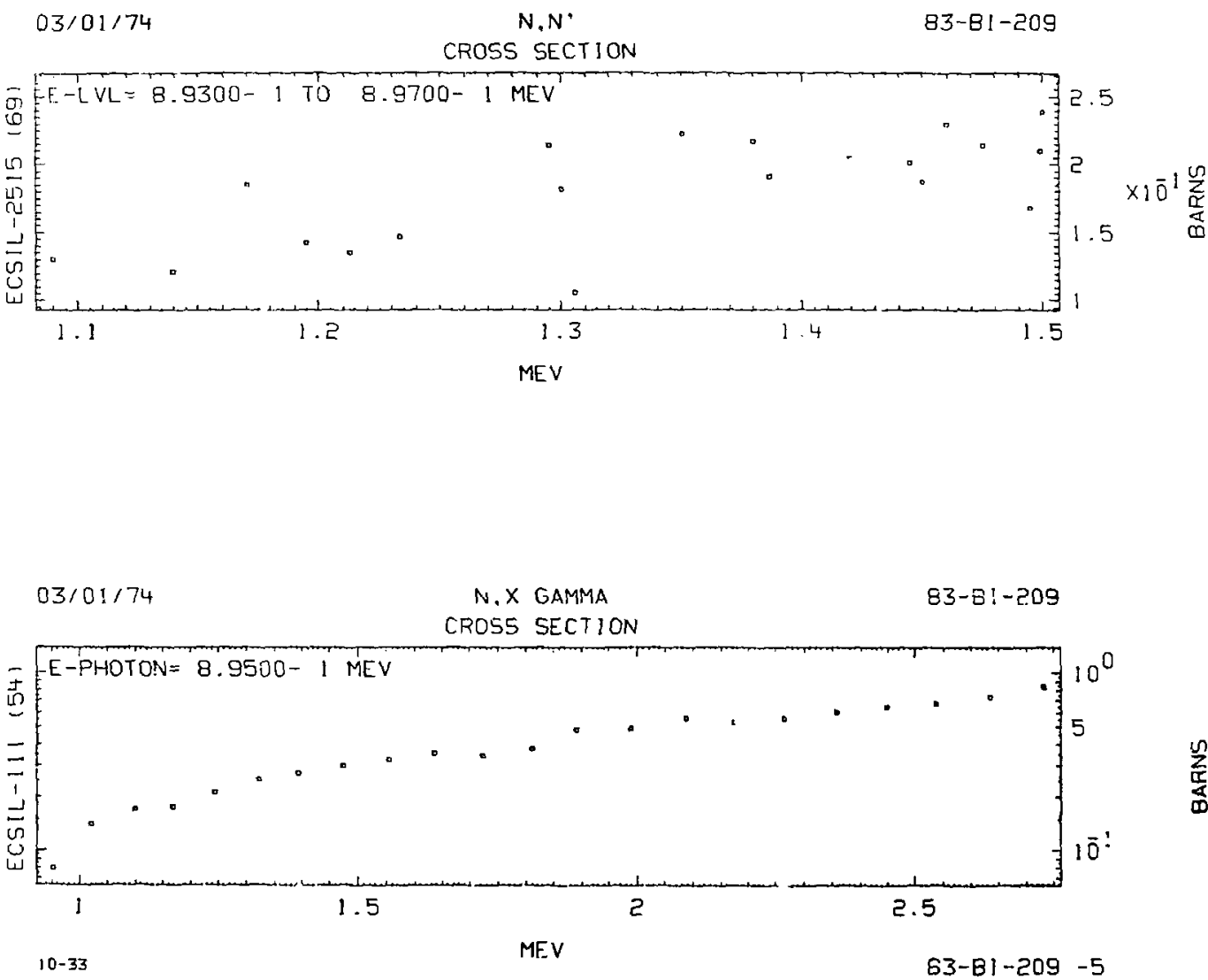


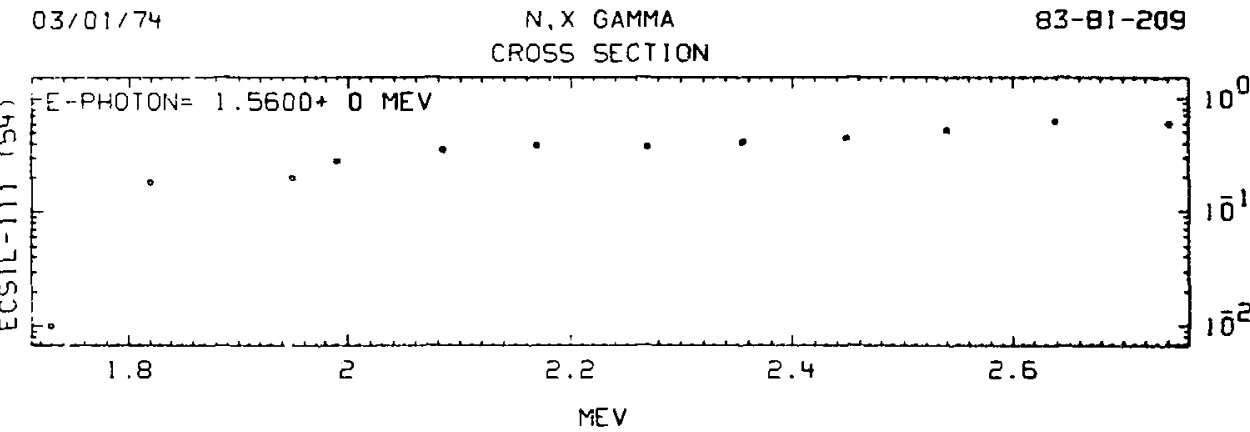

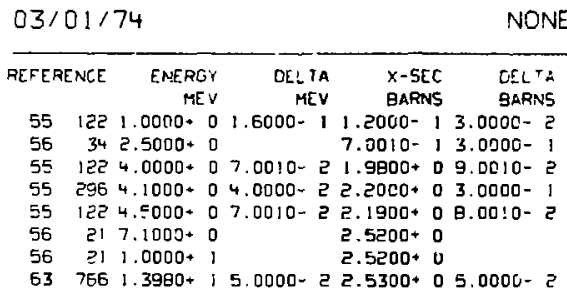

$83-81-209$

$03 / 01.74$

TOTAL SCATTERING

83-81-209

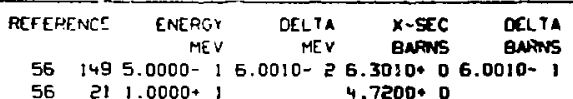




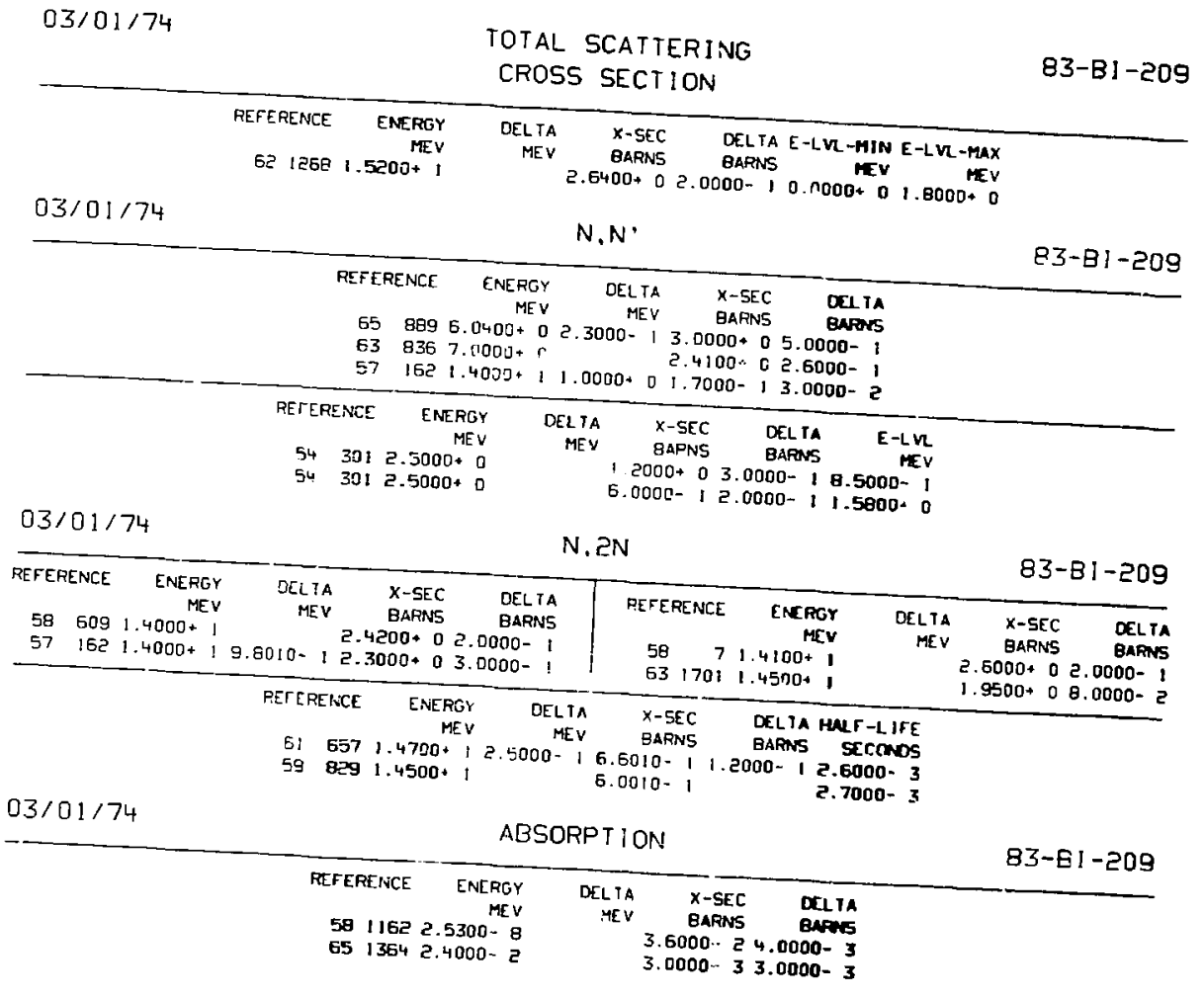

$10-35$ 


\section{CROSS SECTION}

\begin{tabular}{|c|c|c|c|c|}
\hline PEE $\&$ \&E & $\begin{array}{r}\text { ENERGY } \\
\text { MEY }\end{array}$ & $\begin{array}{r}\text { PELTA } \\
\text { MEV }\end{array}$ & $\begin{array}{l}X \text { XEC } \\
\text { BAFINS }\end{array}$ & $\begin{array}{l}\text { DEL 1A } \\
\text { BAPRNS }\end{array}$ \\
\hline
\end{tabular}

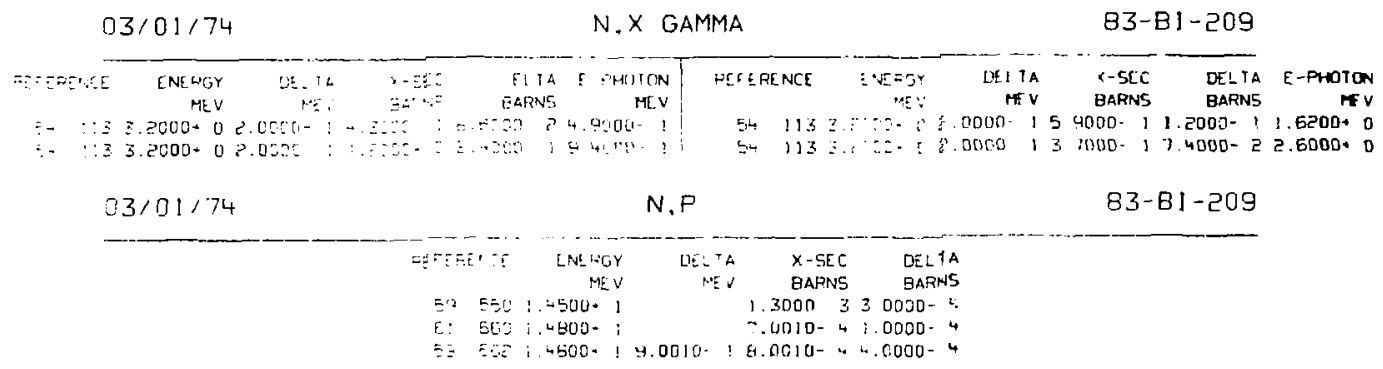

\begin{tabular}{|c|c|c|c|c|c|c|c|c|c|c|}
\hline $33 / 01 /$ & 74 & & & $N$ & $P F A$ & & & & 83- & $-81-209$ \\
\hline AESERENCE & $\begin{array}{c}\text { TNERT, } \\
\text { Mif. }\end{array}$ & $=2$ & $\begin{array}{l}x-75 \\
\text { EAONS }\end{array}$ & $\begin{array}{l}\text { ni: : A } \\
\text { BARIN }\end{array}$ & RET CA & LNE & $\begin{array}{r}\text { ENEPEY } \\
\text { MEV }\end{array}$ & 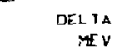 & $\begin{array}{l}x-\text { SEC } \\
\text { EARTS }\end{array}$ & $\begin{array}{l}\text { DELTA } \\
\text { BARNS }\end{array}$ \\
\hline 27 & $1.4500 \cdot i$ & & : Es: 3 & $1.0000 \cdot 3$ & 58 & $66 ?$ & $1.4800 \cdot 1$ & $9.0010^{-1}$ & $1.1000-3$ & $3.0000^{-}$ \\
\hline $59 \quad 550$ & $1.4500 * 1$ & & 든ㅁㅇ․ 4 & B. volc- 5 & $5 !$ & EGD & $1.4000 \cdot 1$ & & $6.0010-4$ & 10000. \\
\hline $5.5 \quad 1975$ & 1.4600. & & $1.0000-3$ & $5.0000-4$ & & & & & & \\
\hline
\end{tabular}

\begin{tabular}{|c|c|c|c|c|c|c|}
\hline $03 / 01,74$ & & & ATO & & & $83-81-209$ \\
\hline & PEFEDEP: & $\begin{array}{r}\text { FNESOYY } \\
\text { PHT }\end{array}$ & $\begin{array}{l}\text { DELIA } \\
\text { MEV }\end{array}$ & $\begin{array}{l}X \text {-SEC } \\
\text { GARNS }\end{array}$ & $\begin{array}{l}\text { OELJA } \\
\text { BARNS }\end{array}$ & \\
\hline & $5 e$ ej & $7.5300 \cdot 8$ & & $9.3700+0$ & $3.0000-2$ & \\
\hline & $5 ! 1584$ & $7.3000-8$ & & $1.0000+1$ & & \\
\hline & 551753 & $9.4100-E$ & & $9.3780+0$ & $7.7000-3$ & \\
\hline
\end{tabular}




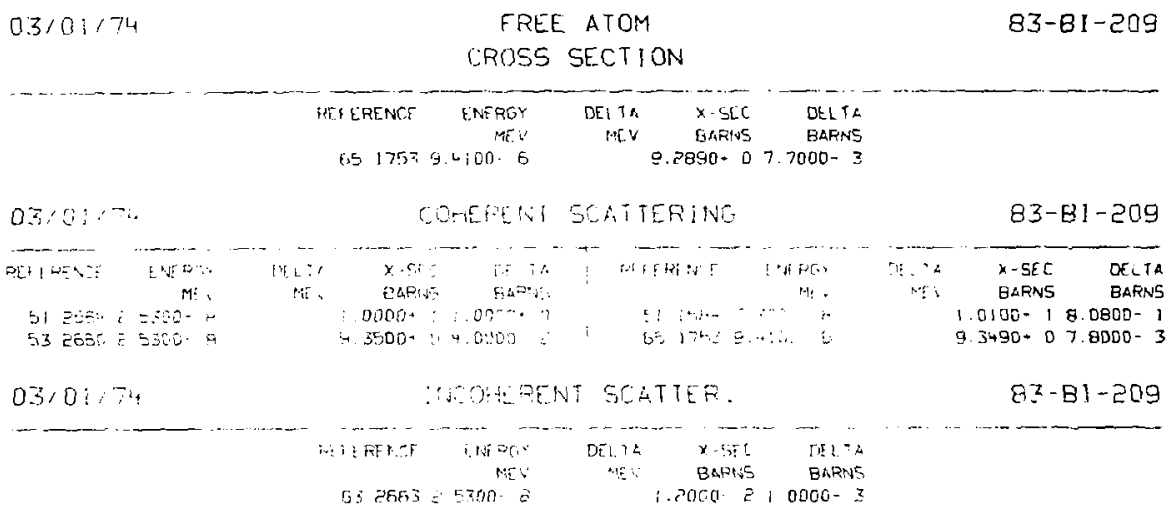

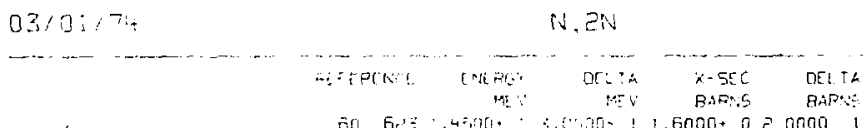

$05: 1: 179$

N. 3N

88-RA-2己6

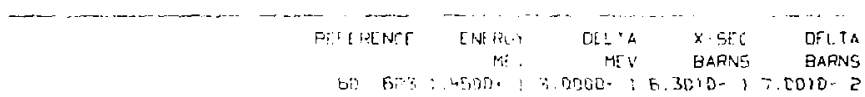

33.01: N. AL PHA

$90-T H-230$

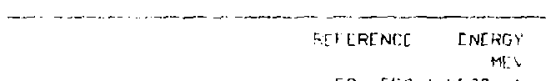

DELTA $\quad$ X-SEC
BELYTA
$4.6000-31.1000 .3$



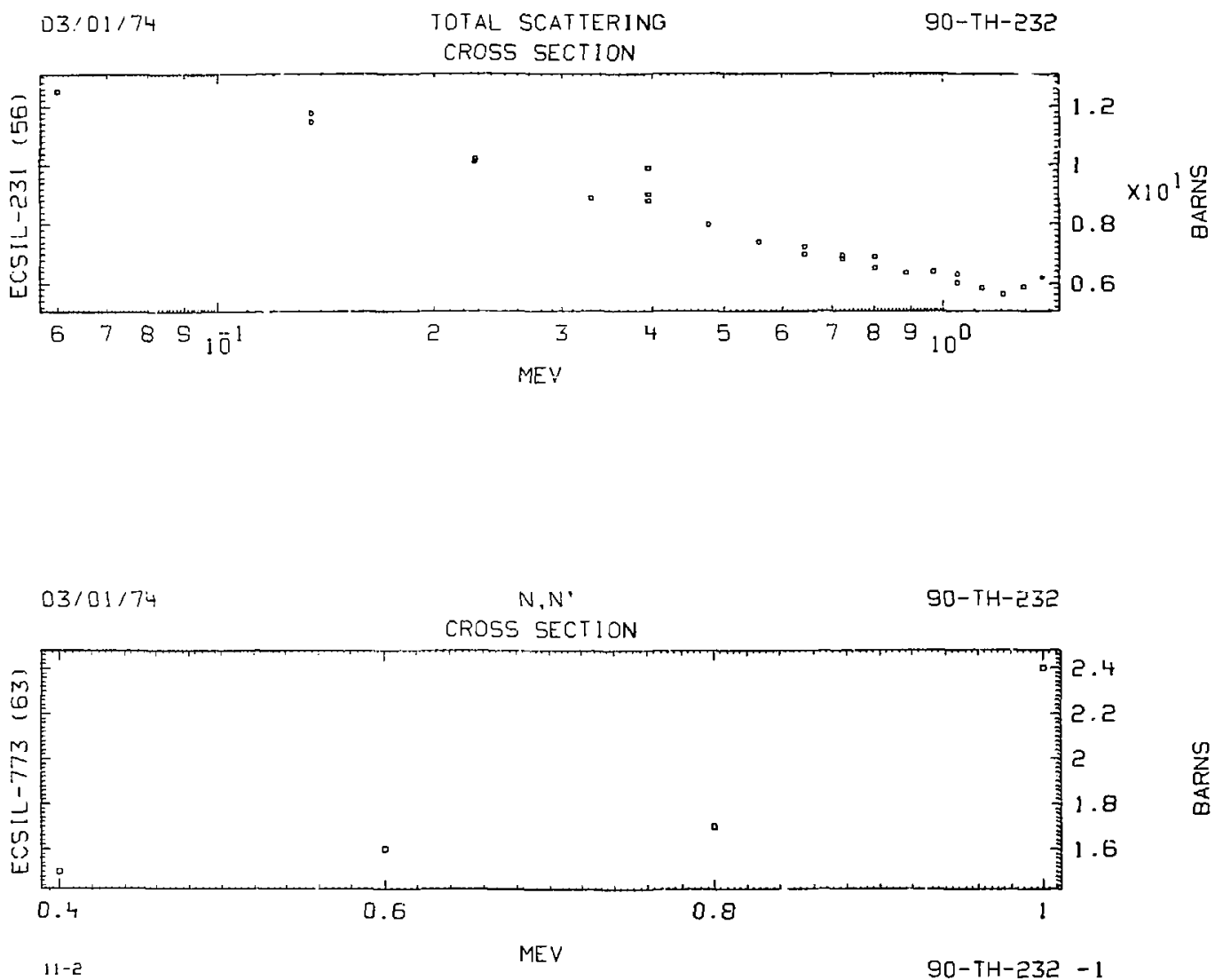
SNYYG

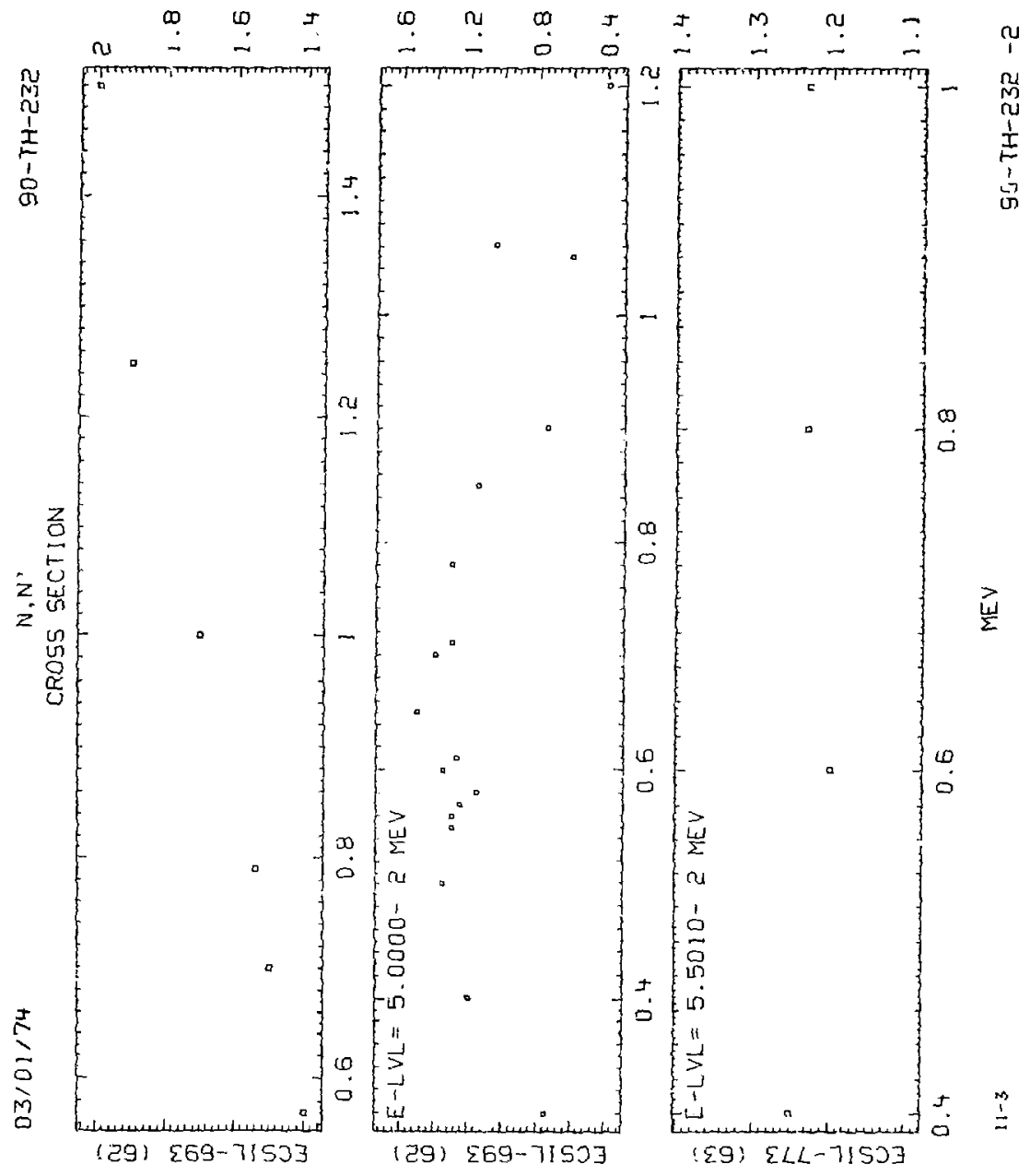




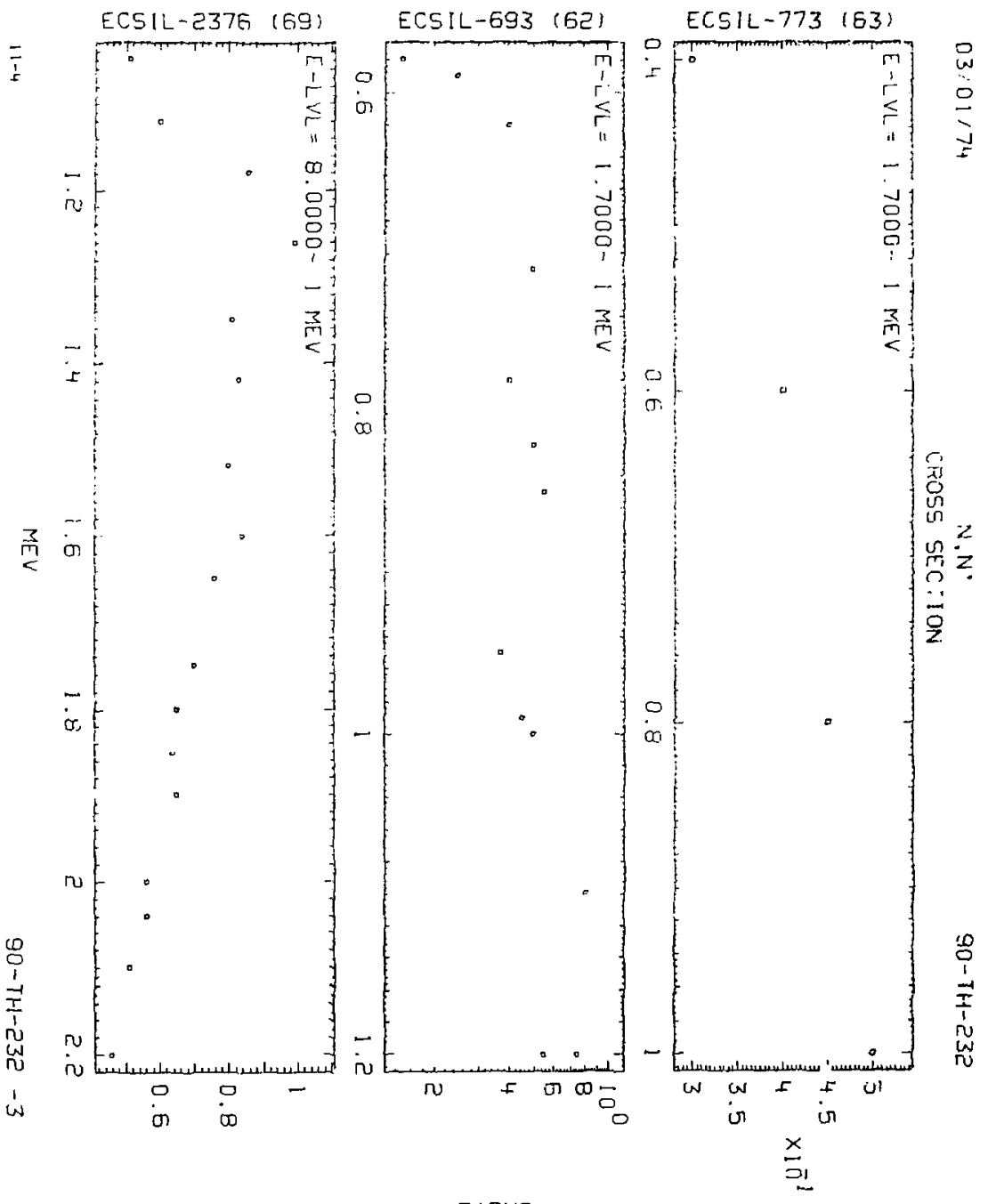

BARNS 
$35101 ; 74$

$N, N$

$90-\mathrm{TH}-232$

CROSS SECTION
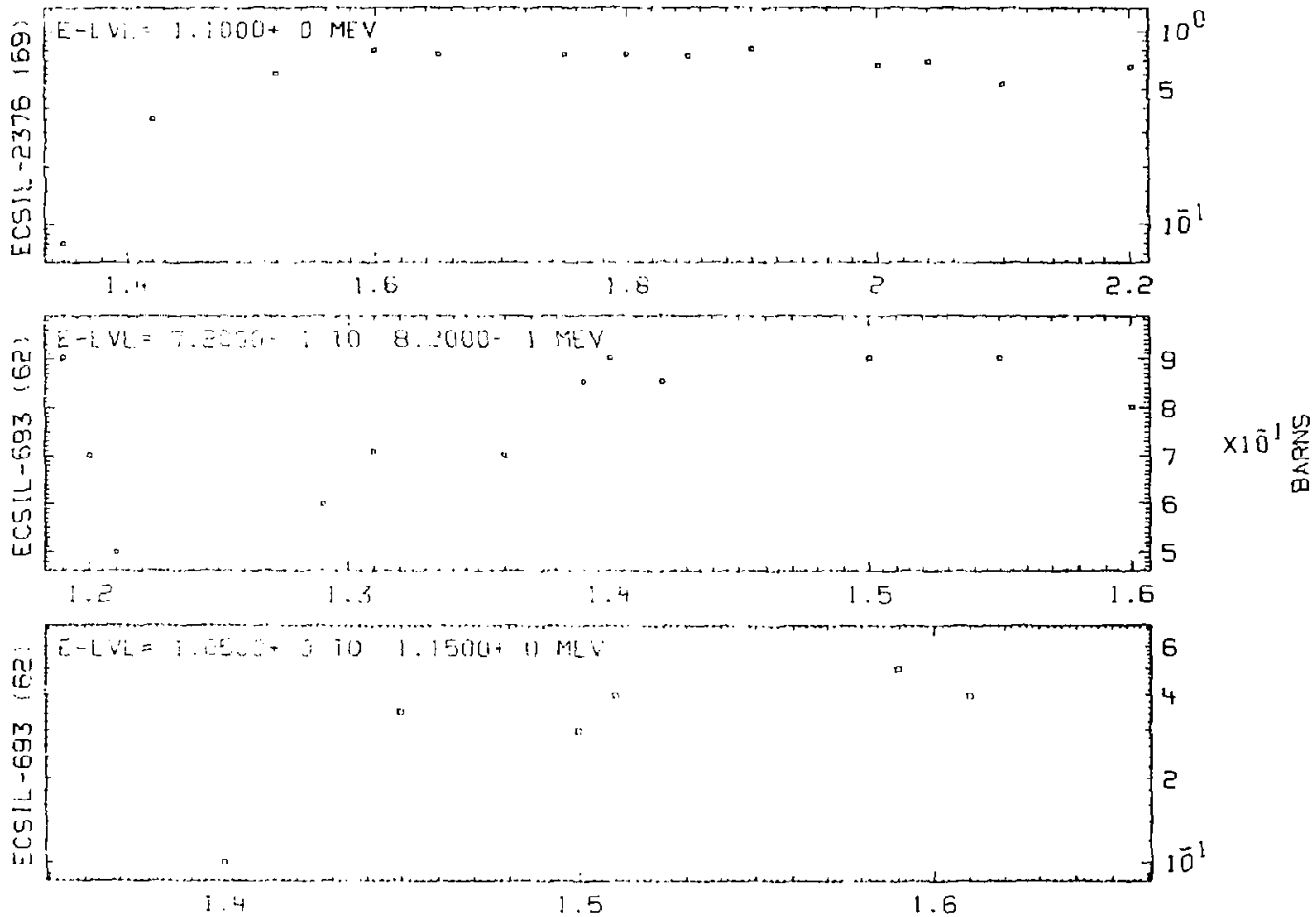

io 1.1500 !) $\mathrm{ML}$ 
CROSS SECTION
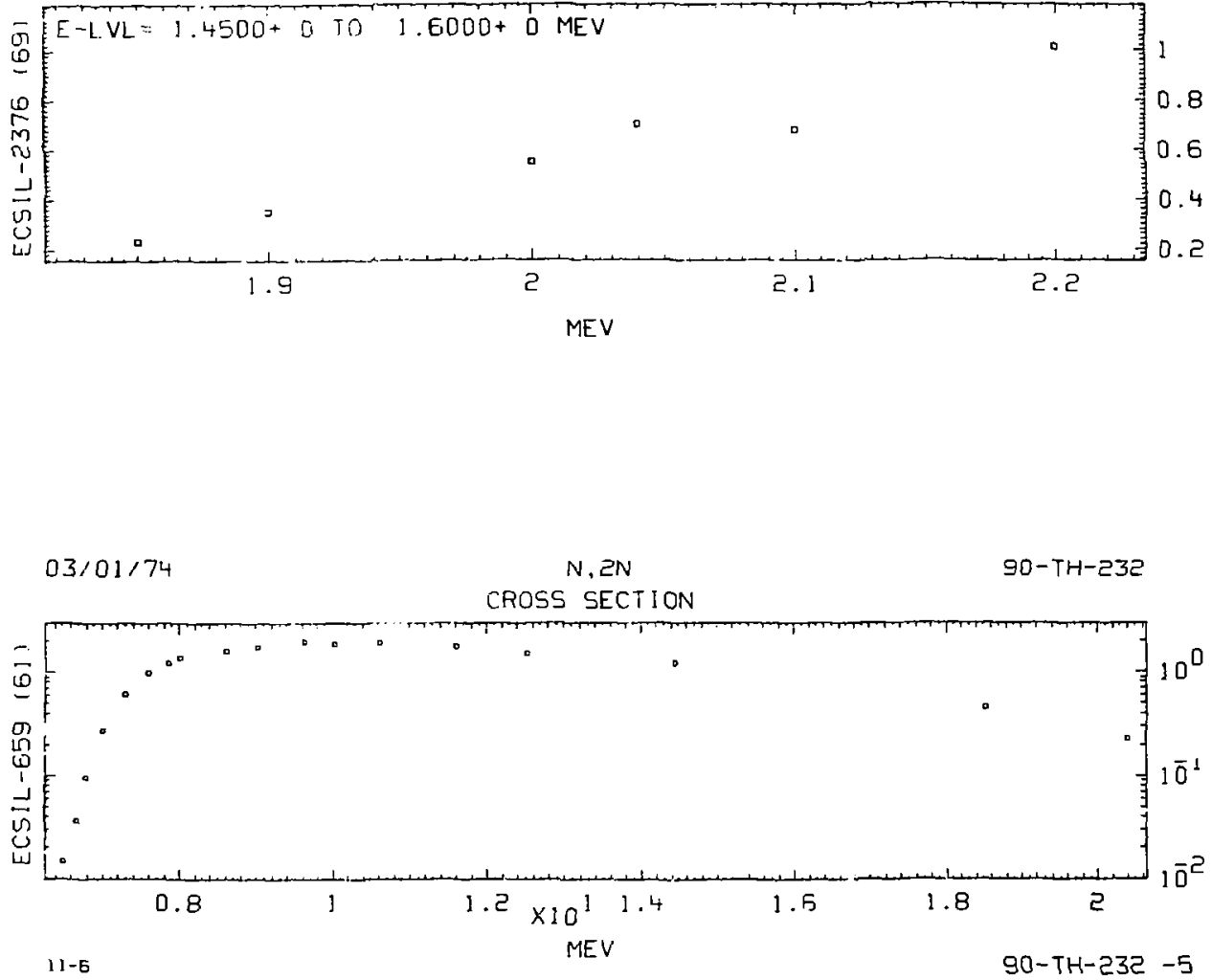


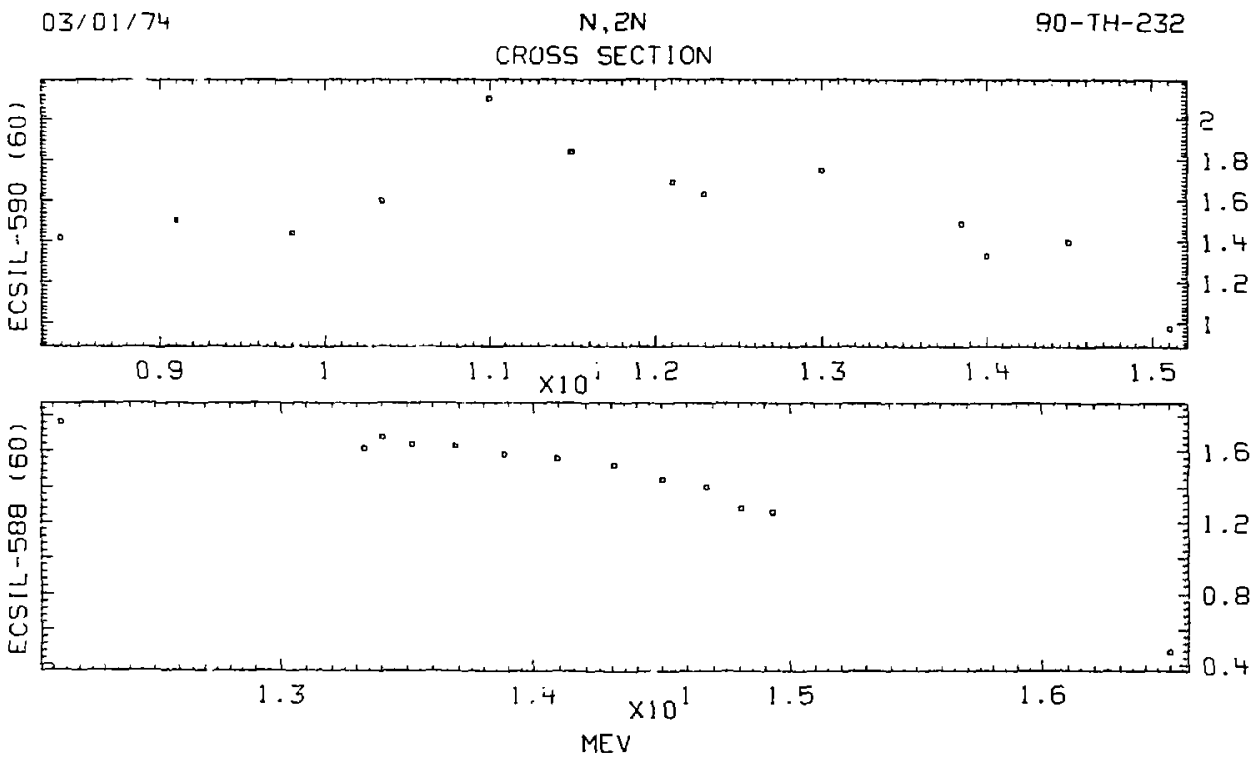


SNYVG

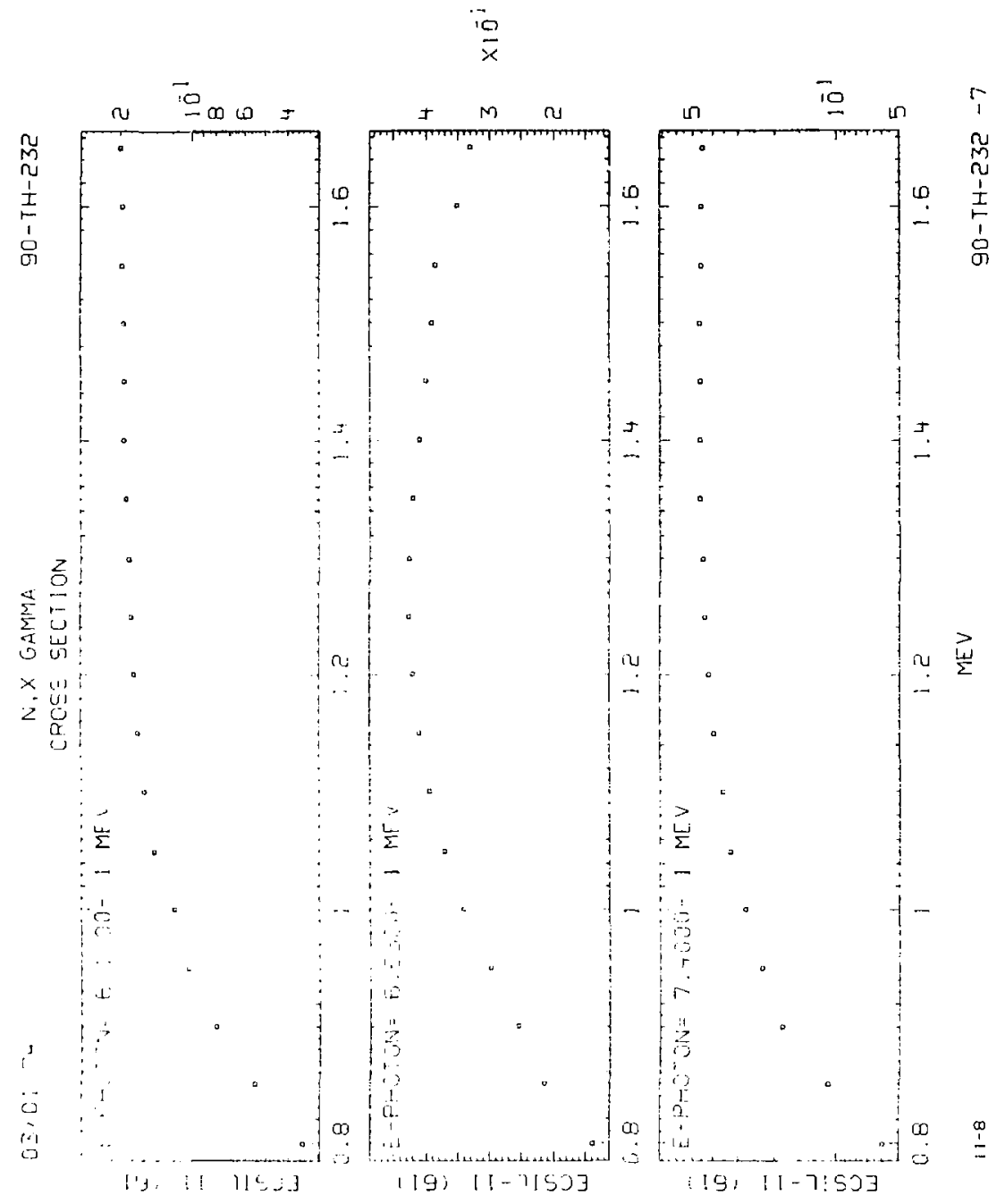


SNavg

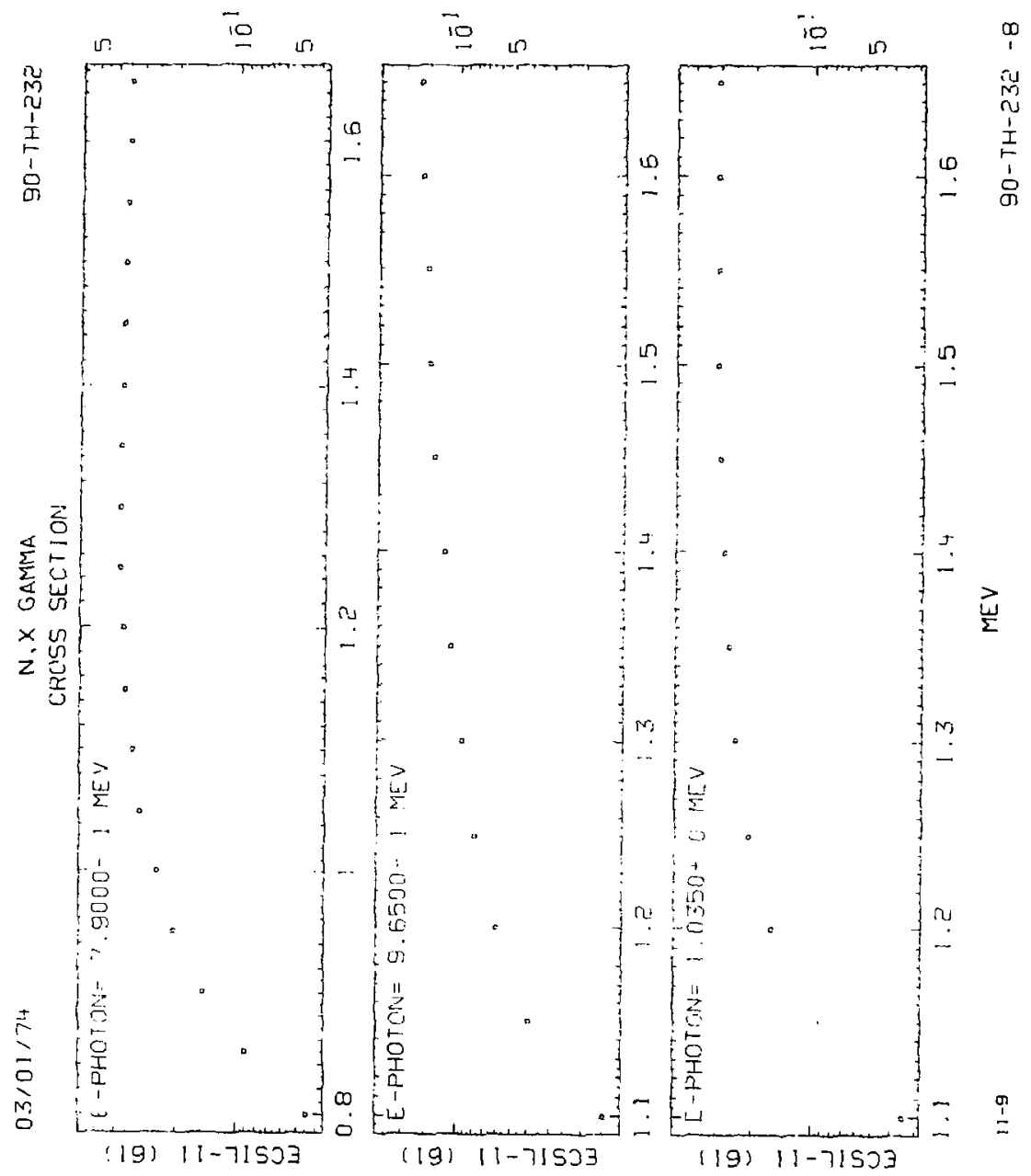




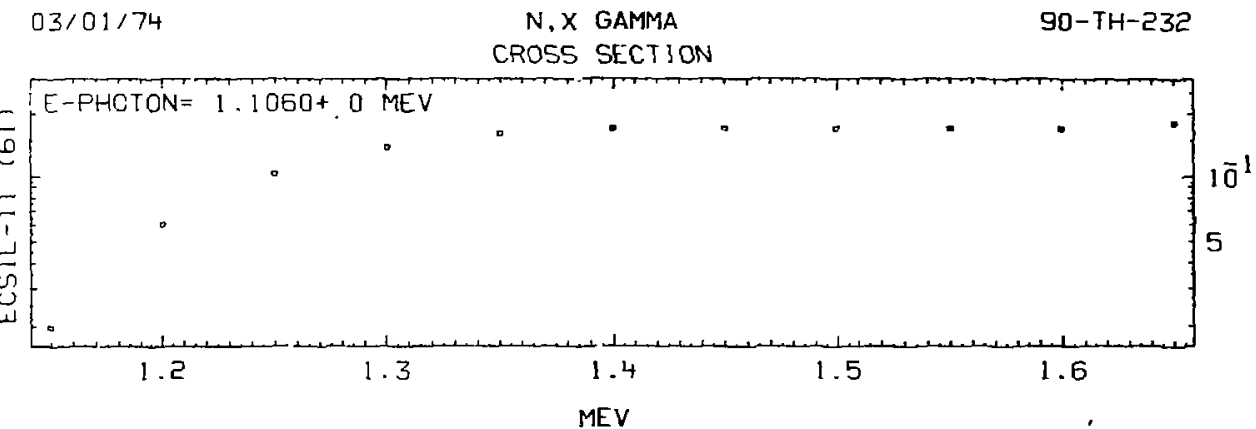

$03 / 01 / 74$

NONELAST $1 \mathrm{C}$

$90-T H-232$

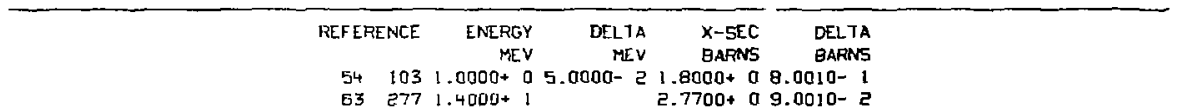

$03 / 01 / 74$

TOTAL SCATTERING

$90-\mathrm{TH}-232$

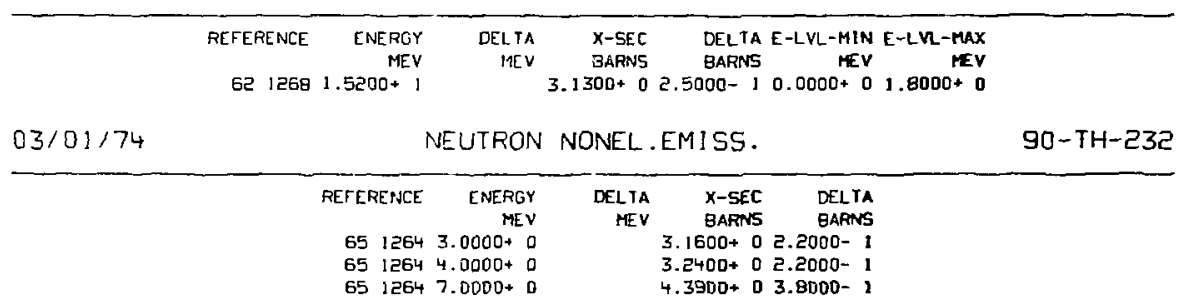


CROSS SECTION

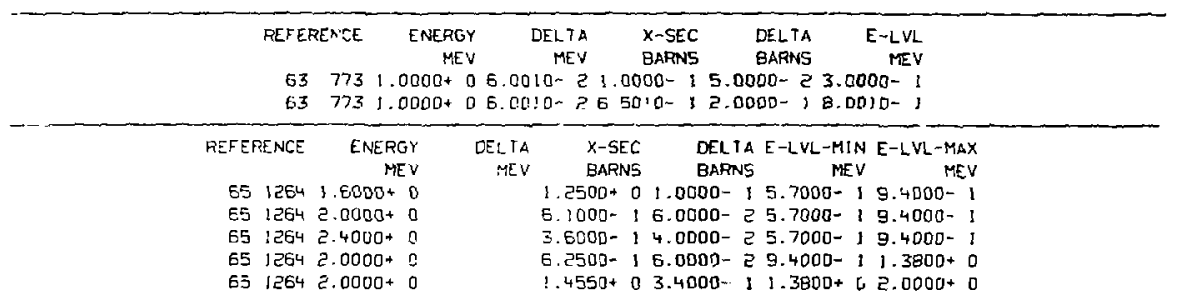

$03 / 01 / 74$

N. 2N

30-TH-232

\begin{tabular}{|c|c|c|c|c|c|c|c|c|c|}
\hline REFERENCE & ENERGY & $\begin{array}{l}\text { DELTA } \\
\text { MEY }\end{array}$ & $X-S E C$ & DELTA & REFERENCE & ENERGYY & DELTA & $x-S E C$ & DEL TA \\
\hline $58 \quad 146 \mathrm{C}$ & $7.0300+0$ & & $2.7700-1$ & 1 e.5000- & $56 \quad 1390$ & $1.5000 * 1$ & & $1.1000+3$ & $1.0000-1$ \\
\hline 6) 745 & $1.4100+1$ & 3. $0000-1$ & $1.2000 \cdot 0$ & $05.0000-2$ & $58 \quad 1482$ & $1.5970+1$ & & $4.8000-1$ & $6.0000-2$ \\
\hline $60 \quad 1520$ & $1.4700+1$ & & $6.5000=1$ & $11.5000-1$ & & & & & \\
\hline
\end{tabular}

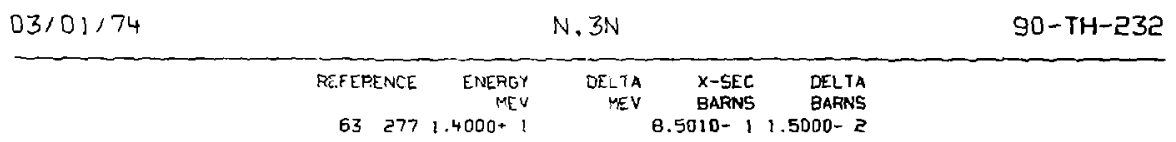

$03 / 01 / 74$

ABSORPTION

90-TH-232

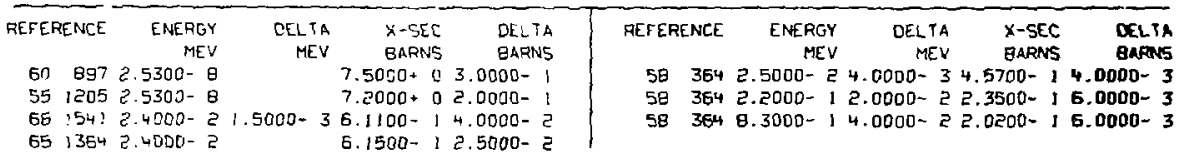


SNม

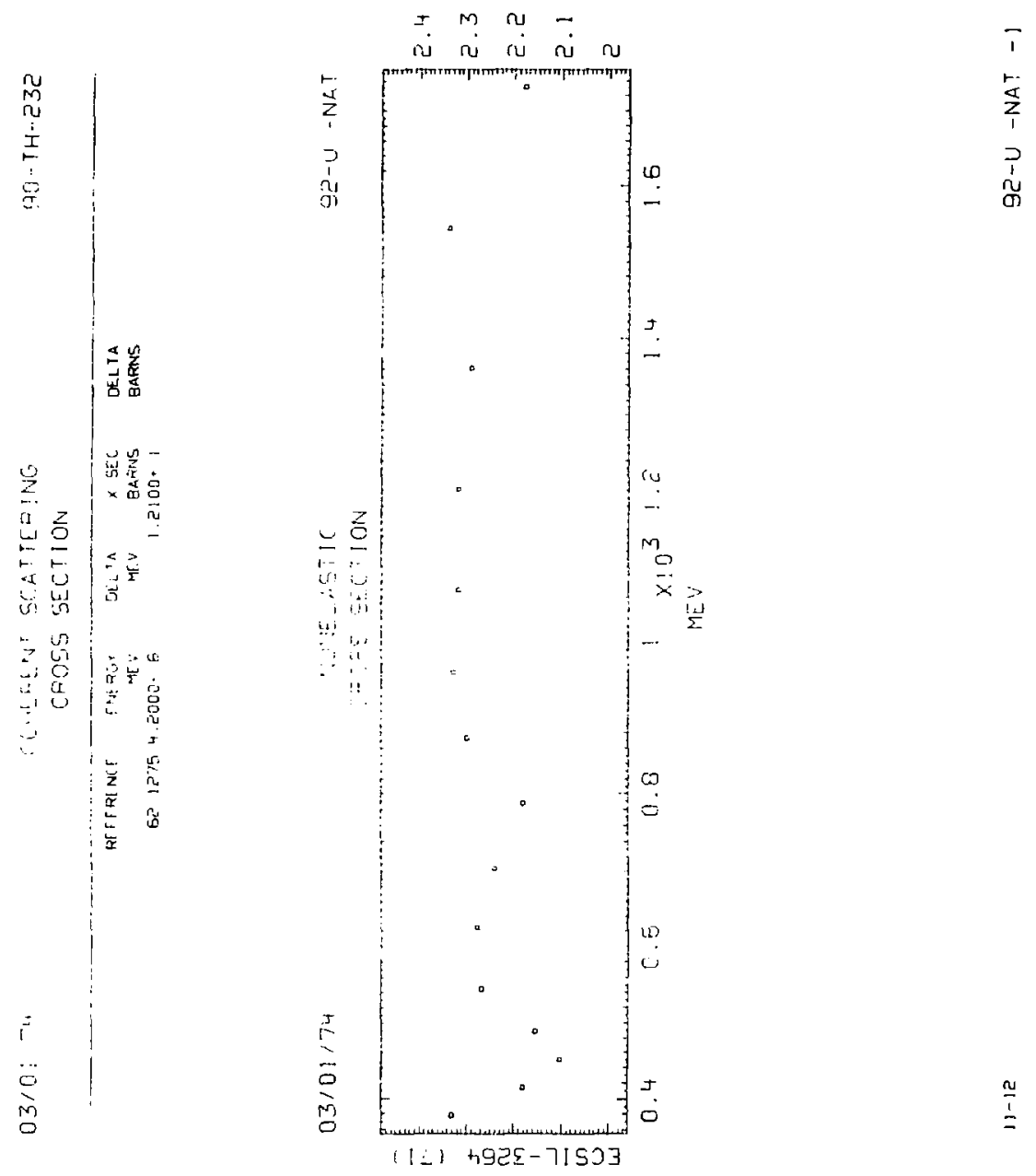




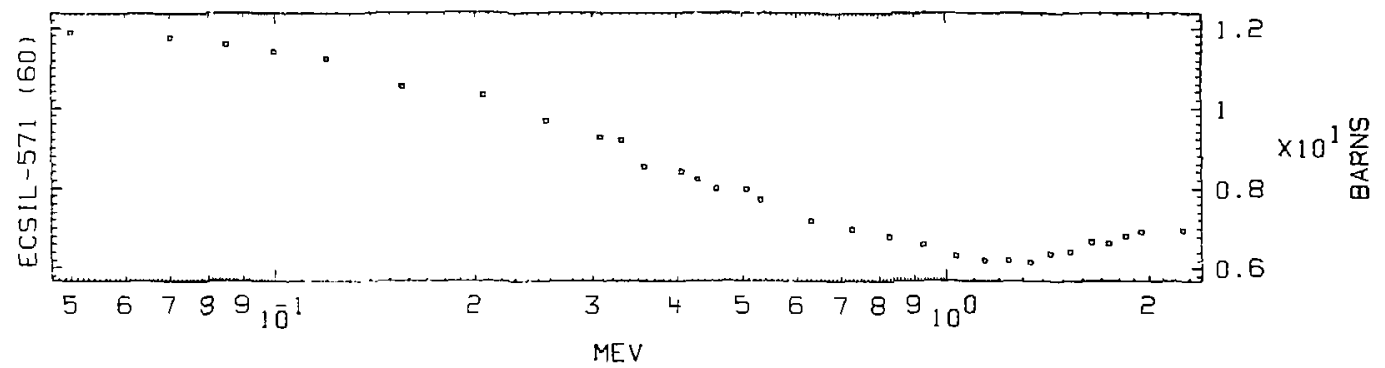

$03 / 01 / 74$

$N, N^{\prime}$

GE-U -NAT CROSS SECTION

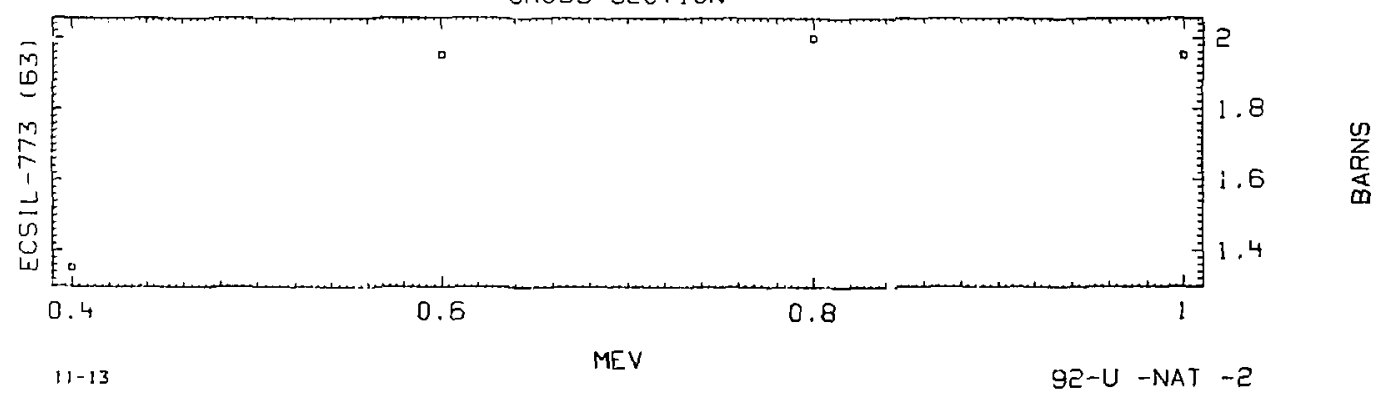



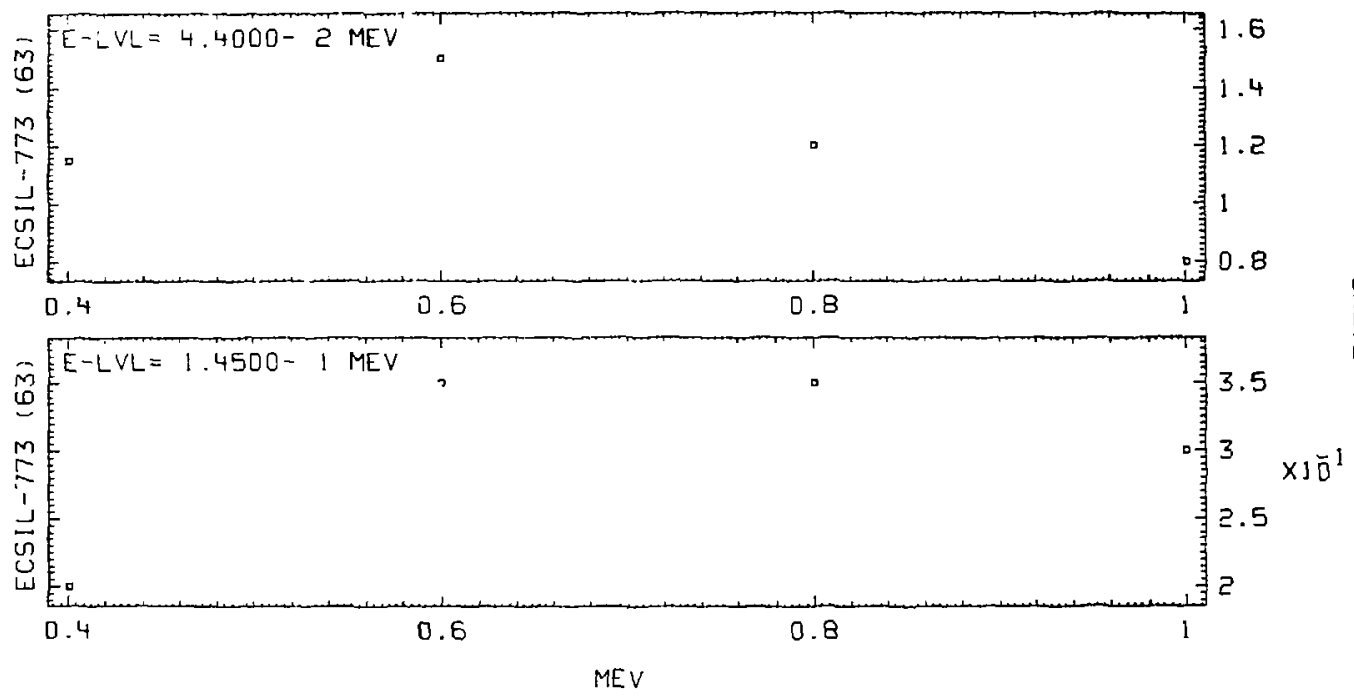

\begin{tabular}{|c|c|c|c|c|c|c|c|c|c|c|}
\hline 31 & $1,-$ & & & & No: & TIC & & & $92-$ & $-U-N A T$ \\
\hline 57 & 4 & $1.5000-1$ & & 6.300 & $0000=1$ & $56 \quad 353$ & $50+0$ & & $1.6000+0$ & $5.0000-$ \\
\hline 57 & 44 & & & & & $56 \quad 151$ & & $00-2$ & & \\
\hline 56 & 353 & 2.90 & & & $1.0000-$ & $55 \quad 1383$ & $7+0$ & & + & \\
\hline 57 & 444 & $5.0000-1$ & I & B. 00 & & $55 \quad 1383$ & $4.5000+0$ & & $10+0$ & \\
\hline 563 & 353 & $7.3000-$ & 1 & $9.00 ! 0-1$ & 13. & $58 \quad 877$ & $1.4000+1$ & & $00+0$ & \\
\hline 56 & $! 5 !$ & $1.0000+$ & $10-2$ & $1.8000+0$ & o $2.5000-:$ & $63 \quad 1271$ & $1.4700+1$ & $.0000-$ & $2.8000+0$ & B.000 \\
\hline
\end{tabular}




\section{CROSS SELTION}

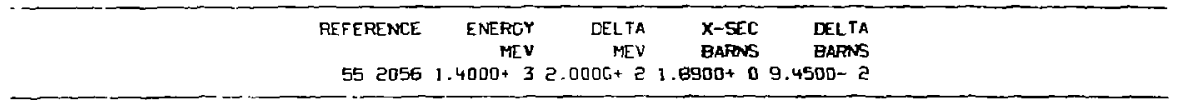

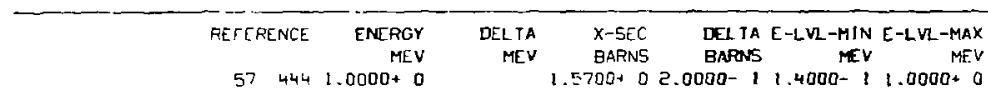

$03 / 01 / 74$

TOTAL SCATTERING

92-U -NAT

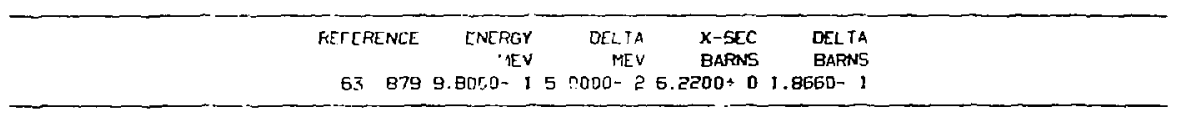

RTFERENCE

TNEFGY

DELTA

$x$-SEC

DELTA

MEV

MEY

$621268, .5200+1$ $3.2100+0.2 .4000-10.0000+01.8000+0$
$03 / 01 / 74$
$N, N^{*}$
92-U -NAT

\begin{tabular}{|c|c|c|c|c|c|c|c|c|c|c|c|c|c|}
\hline \multirow{2}{*}{\multicolumn{2}{|c|}{ REFERENCE }} & ENERGY & DELTA & $x-5[C$ & DELTA & E-L, VL: & \multicolumn{2}{|c|}{ REFERENCE } & ENERGY & DELTA & $x-5 E C$ & DELTA & $E-L V L$ \\
\hline & & MEV & MEV & EARNS & BARNS & MEV & & & MEV & MEV & BARNS & EARNS & MEV \\
\hline 63 & 773 & $0000-!$ & $6.0010-5$ & $1.0000-1$ & $5.0000-2$ & $3.0000-1$ & 63 & 773 & 8.00na- 1 & $16.0110-2$ & $3.0000-1$ & $3.0000-2$ & $7.0010-1$ \\
\hline $\begin{array}{l}63 \\
63\end{array}$ & $\begin{array}{l}773 \\
773\end{array}$ & $\begin{array}{l}0.0000-i \\
1.0000+0\end{array}$ & $\begin{array}{l}6.0010-3 \\
6.0010-3\end{array}$ & $\begin{array}{l}1.5000-1 \\
1.5000-1\end{array}$ & $\begin{array}{l}5.0000-2 \\
2.3000-2\end{array}$ & $\begin{array}{l}3.0000-i \\
3.0000-1\end{array}$ & 63 & 773 & $1.0000+0$ & $06.0010-2$ & $7.0010-1$ & $7.0010-2$ & $7.0010-1$ \\
\hline
\end{tabular}

$637731.0000+06.0010-21.5000-15.0000-23.0000-1$

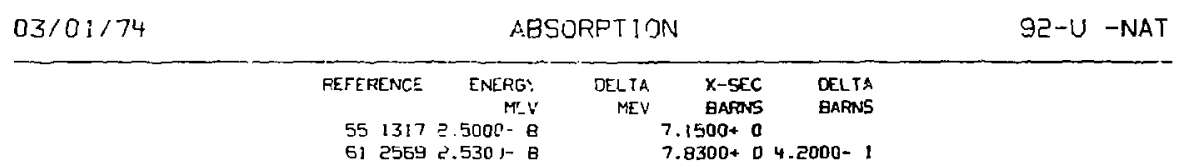

$\begin{array}{ll}5513172.5000-8 & 7.1500+0 \\ 6125692.530 J-B & 7.8300+04.2000-1\end{array}$ 
CROSS SECTION

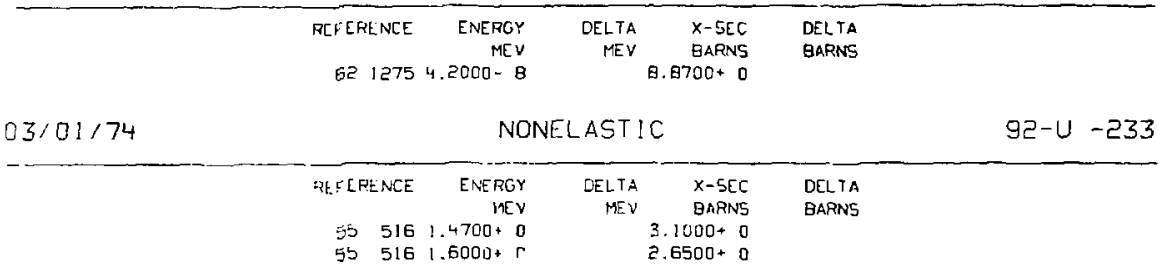

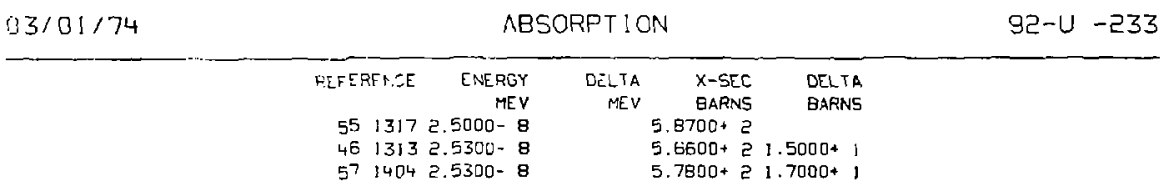

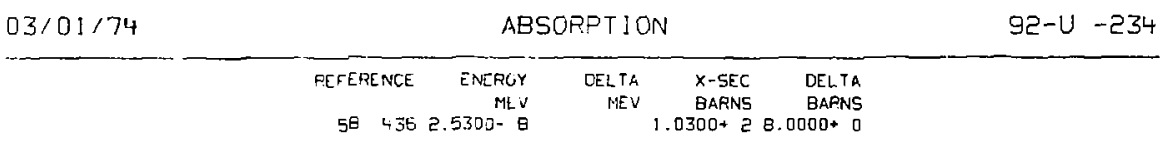



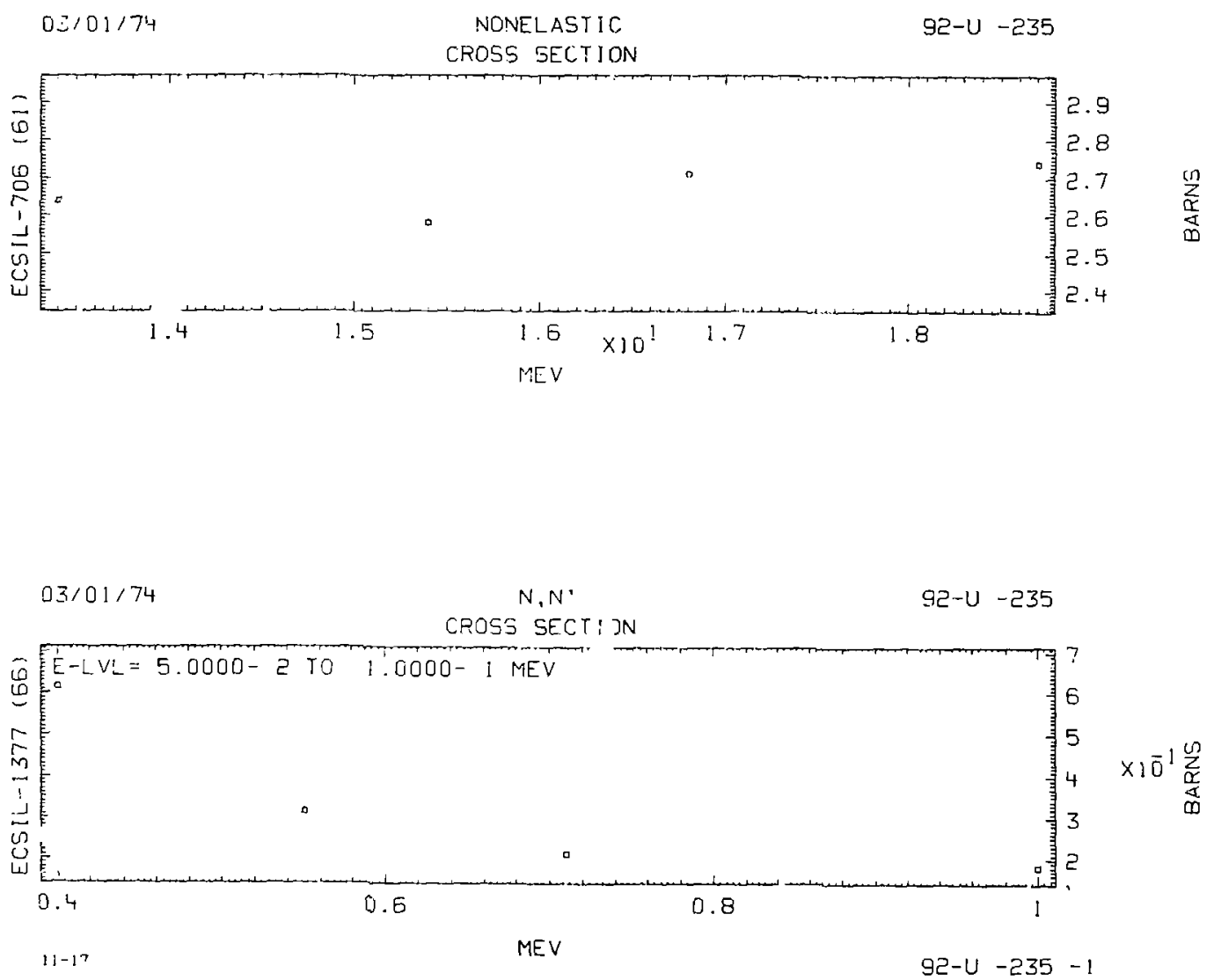


\section{CROSS SECTION}

$92-u-235$
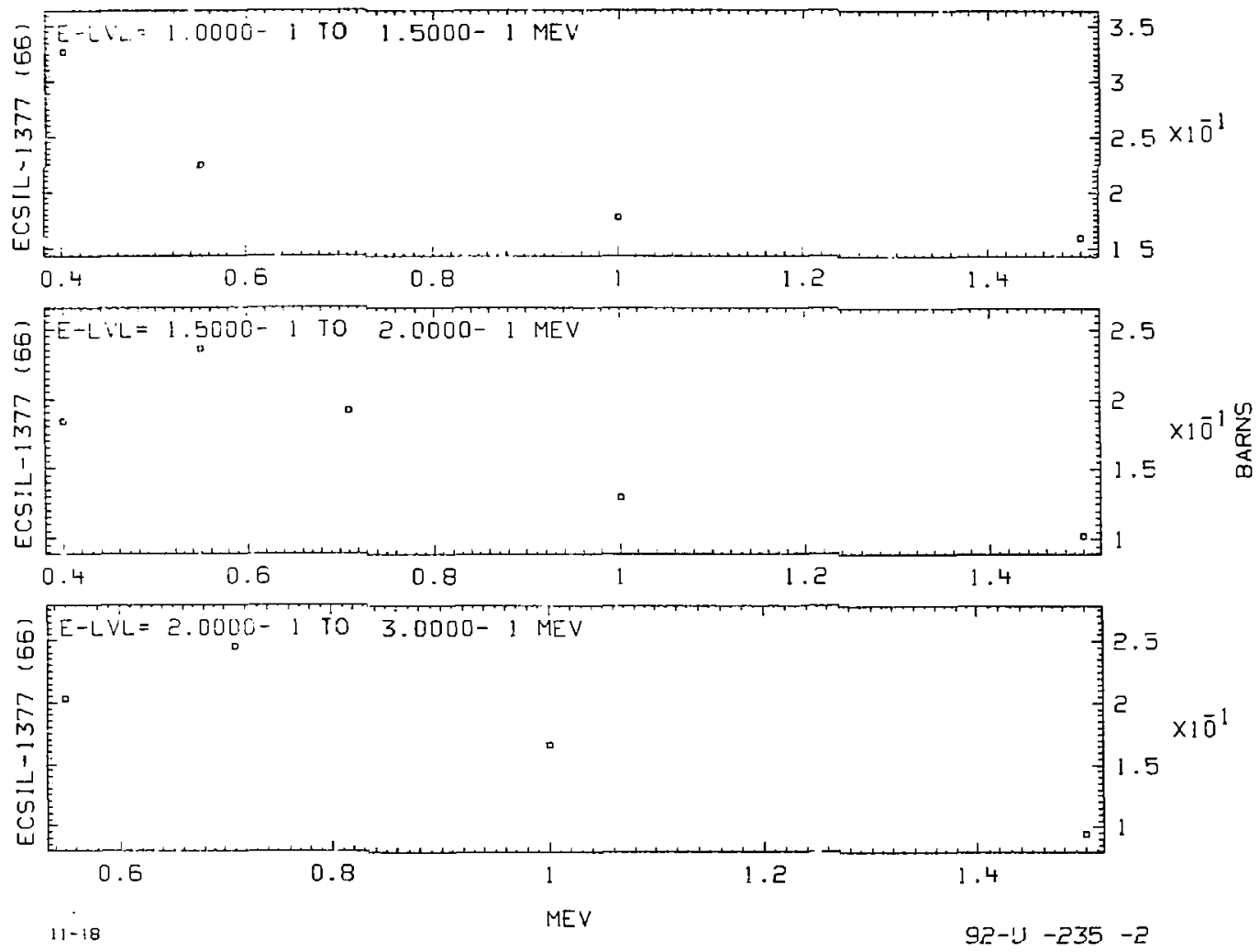

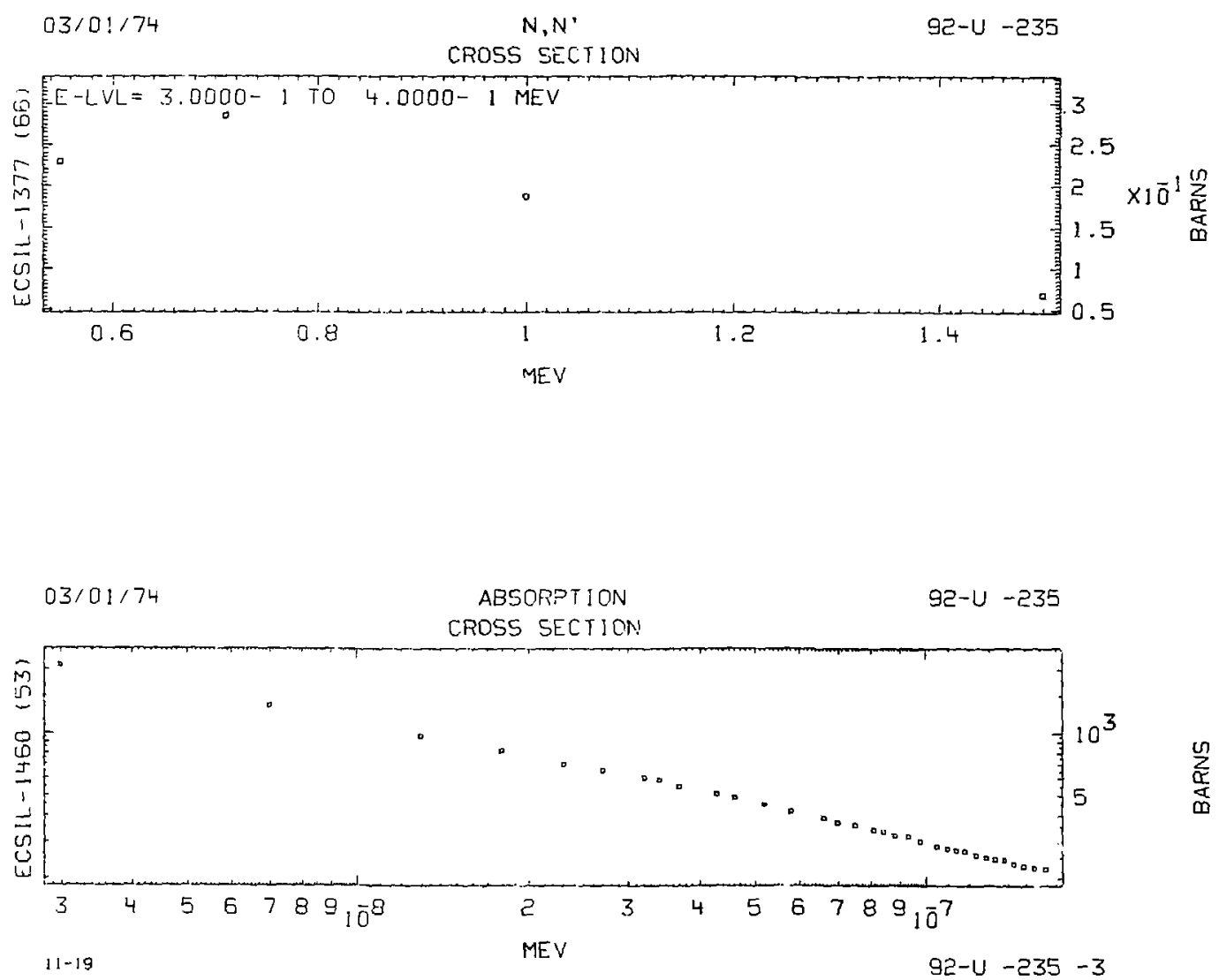


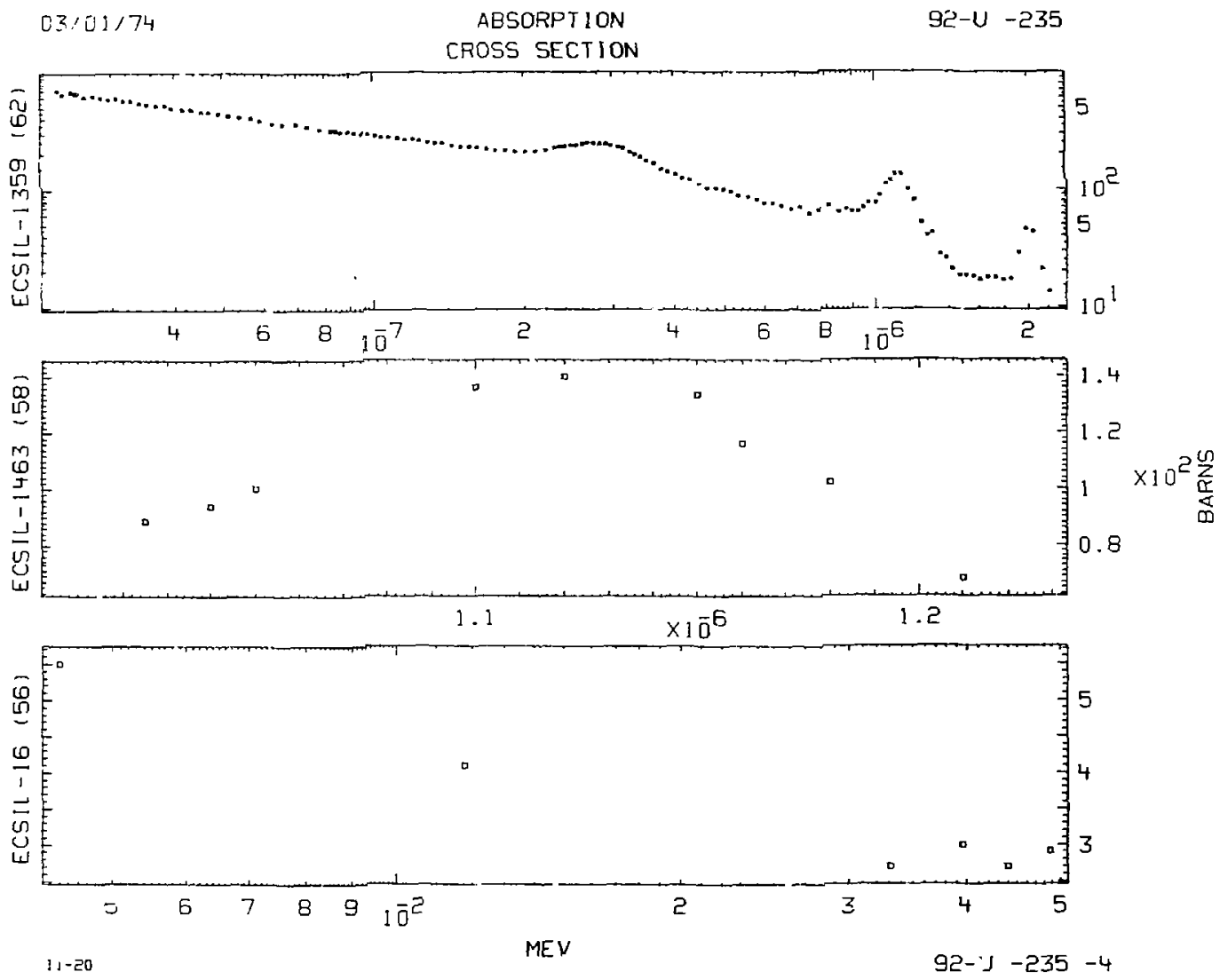




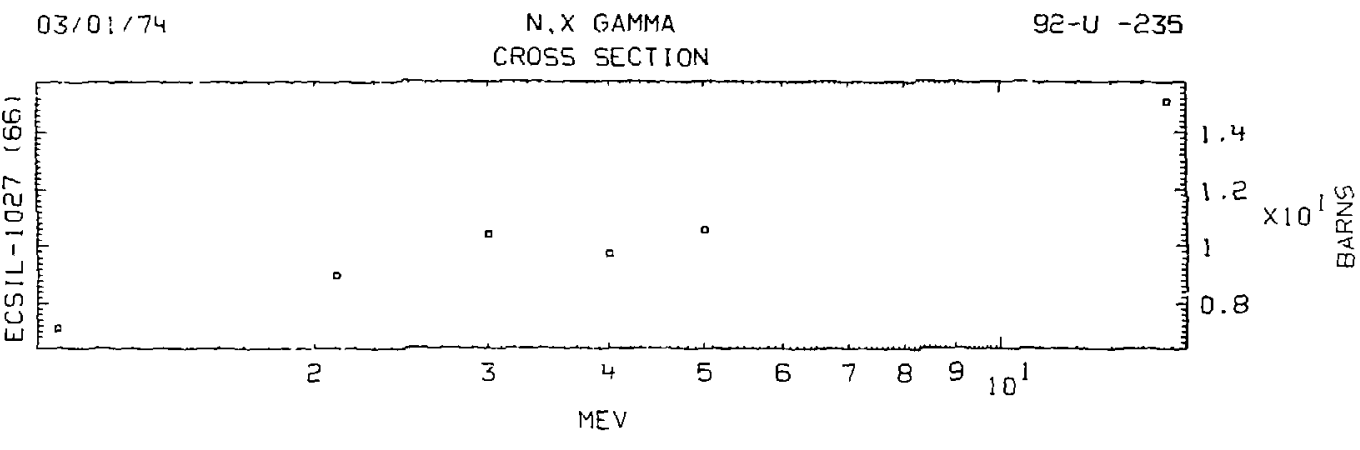

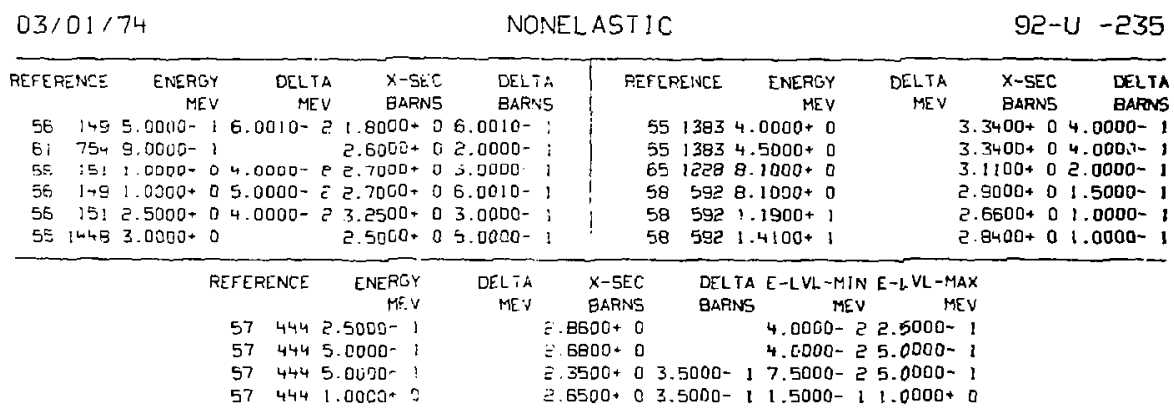


CROSS SECTION

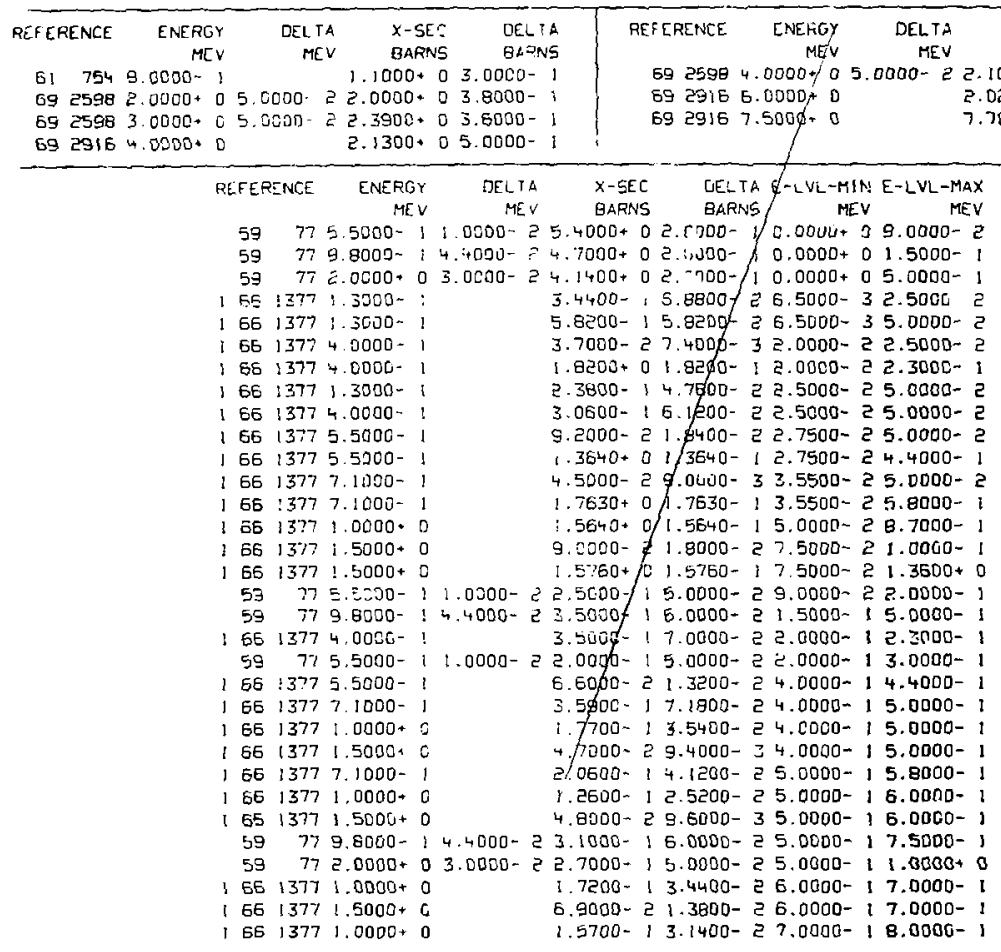


CROSS SECTION

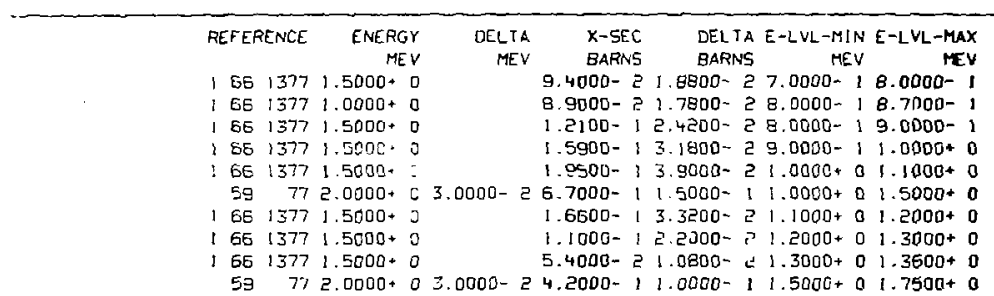

$03 / 01 / 74$

ABSORPTION

$92-u-235$

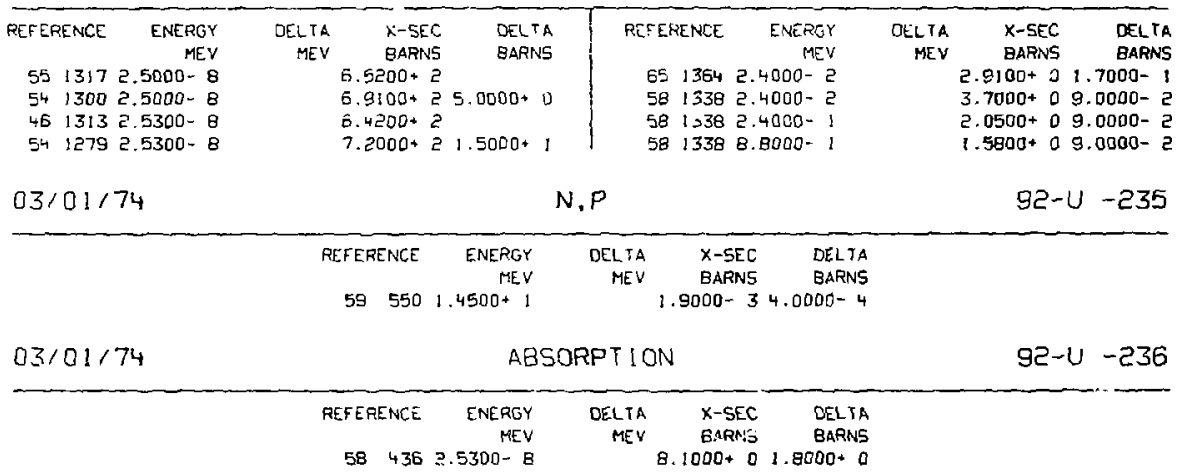




$\begin{array}{rrrrrr}\text { REFERENCE } & \text { ENERGY } & \text { DELIA } & x \text {-SEC } & \text { DELIA } \\ \text { MEV } & \text { MEV } & \text { RARTS } & \text { EARNS } \\ 67 & 195 & 2.5300-8 & & 4.1100+2 & 1.3800+2\end{array}$

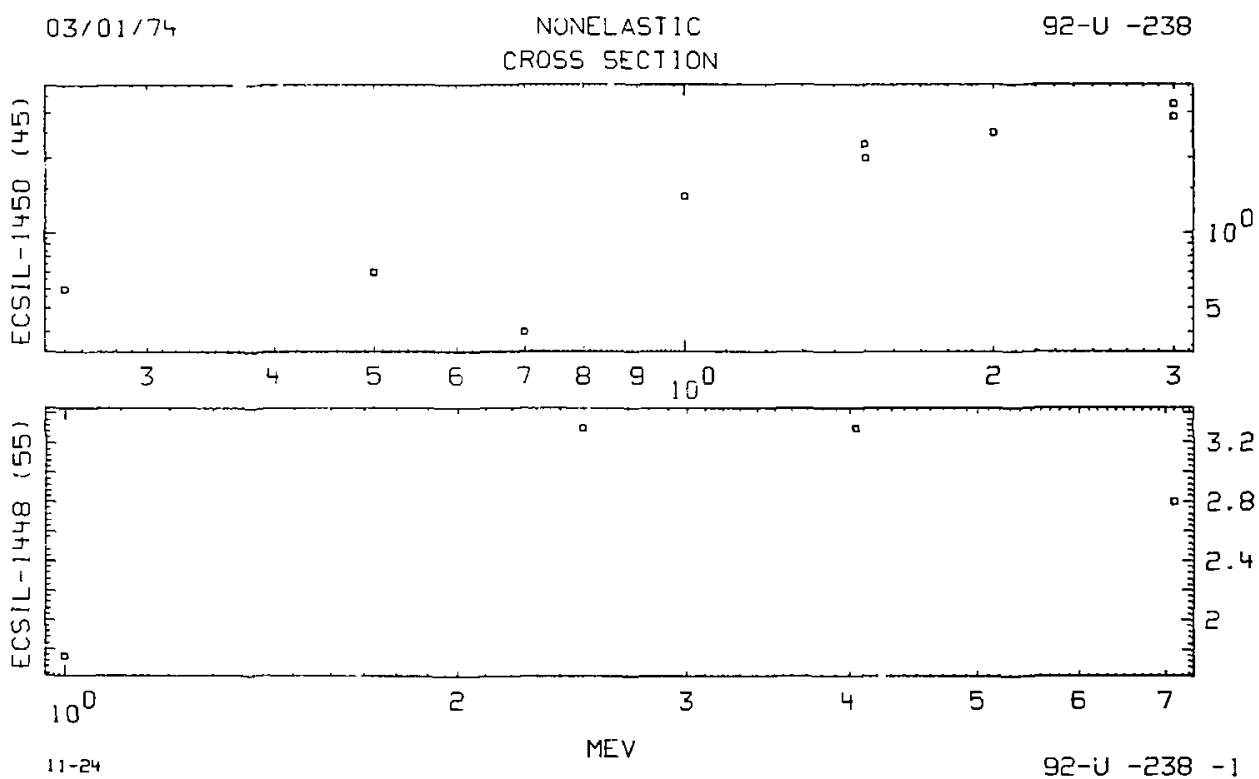


SNYYG

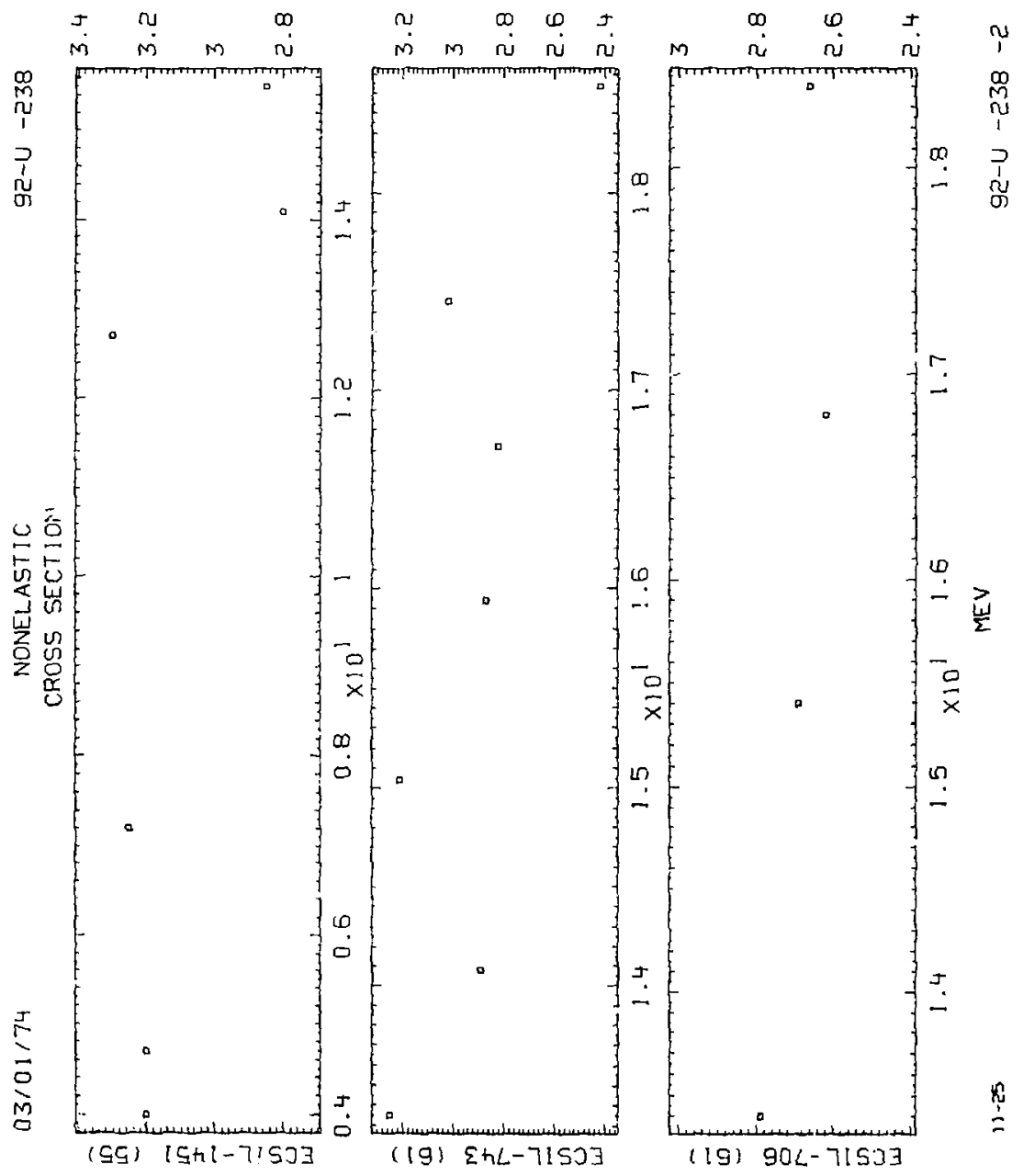



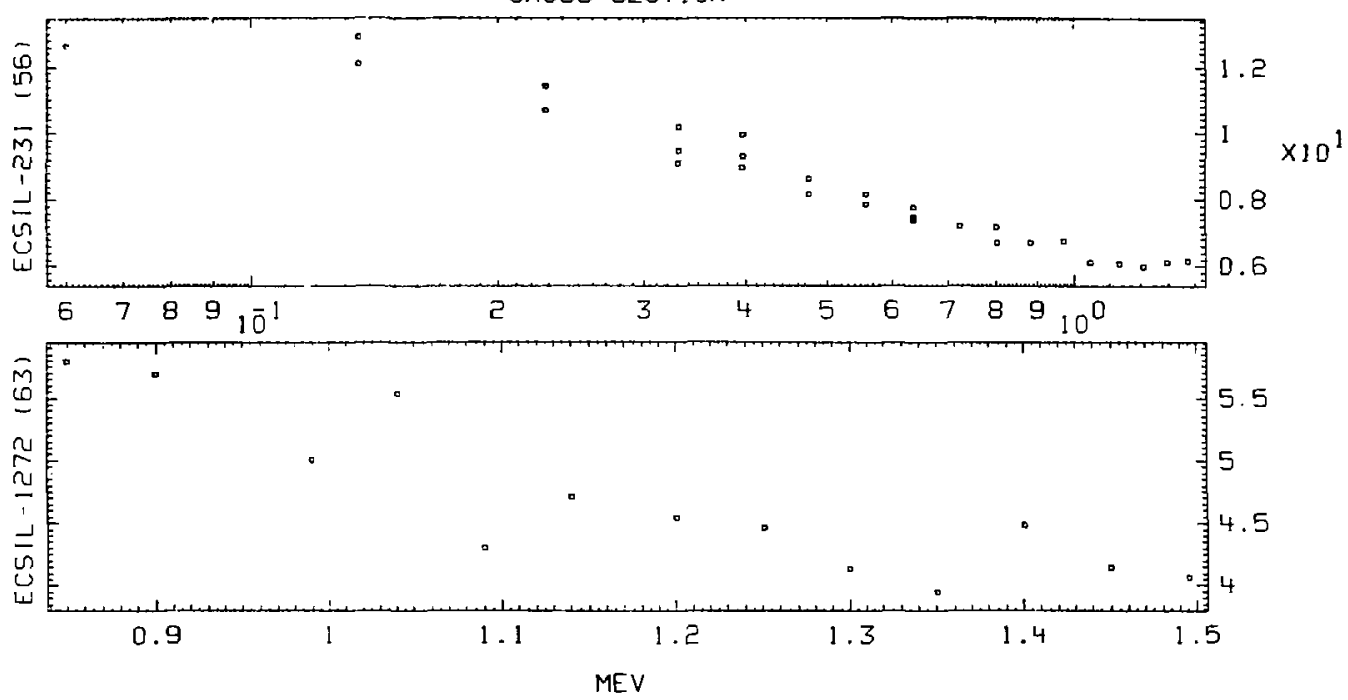

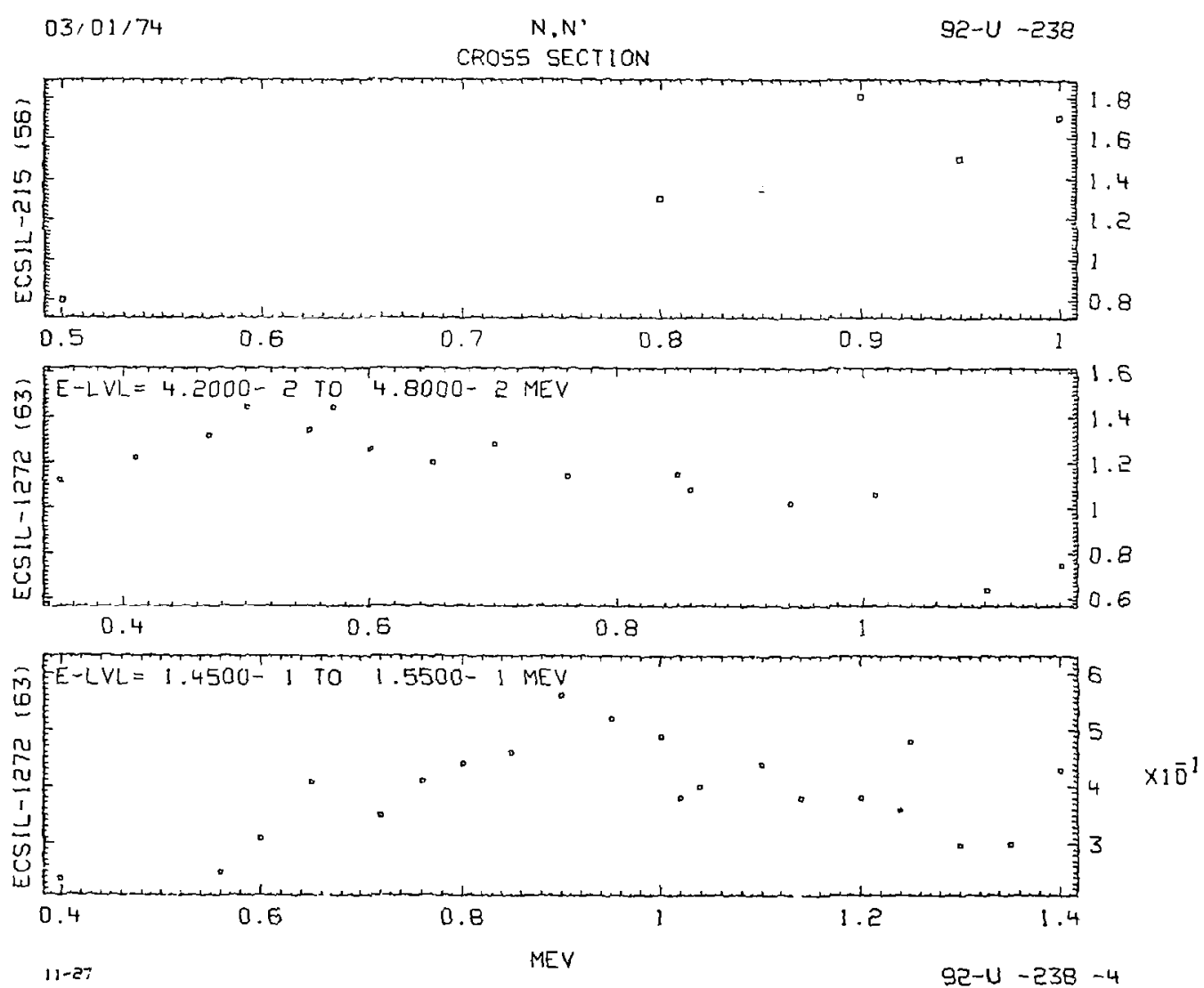

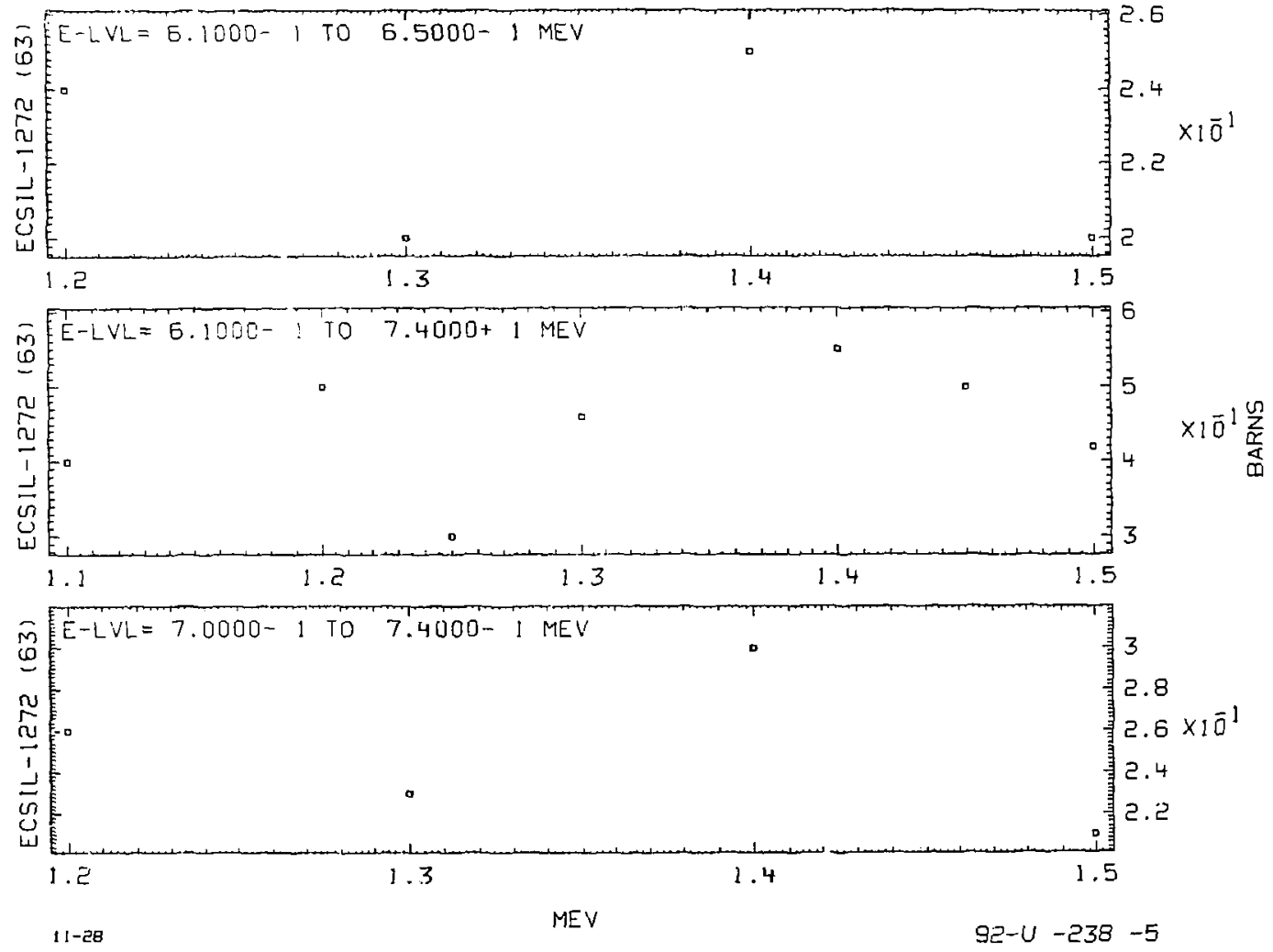

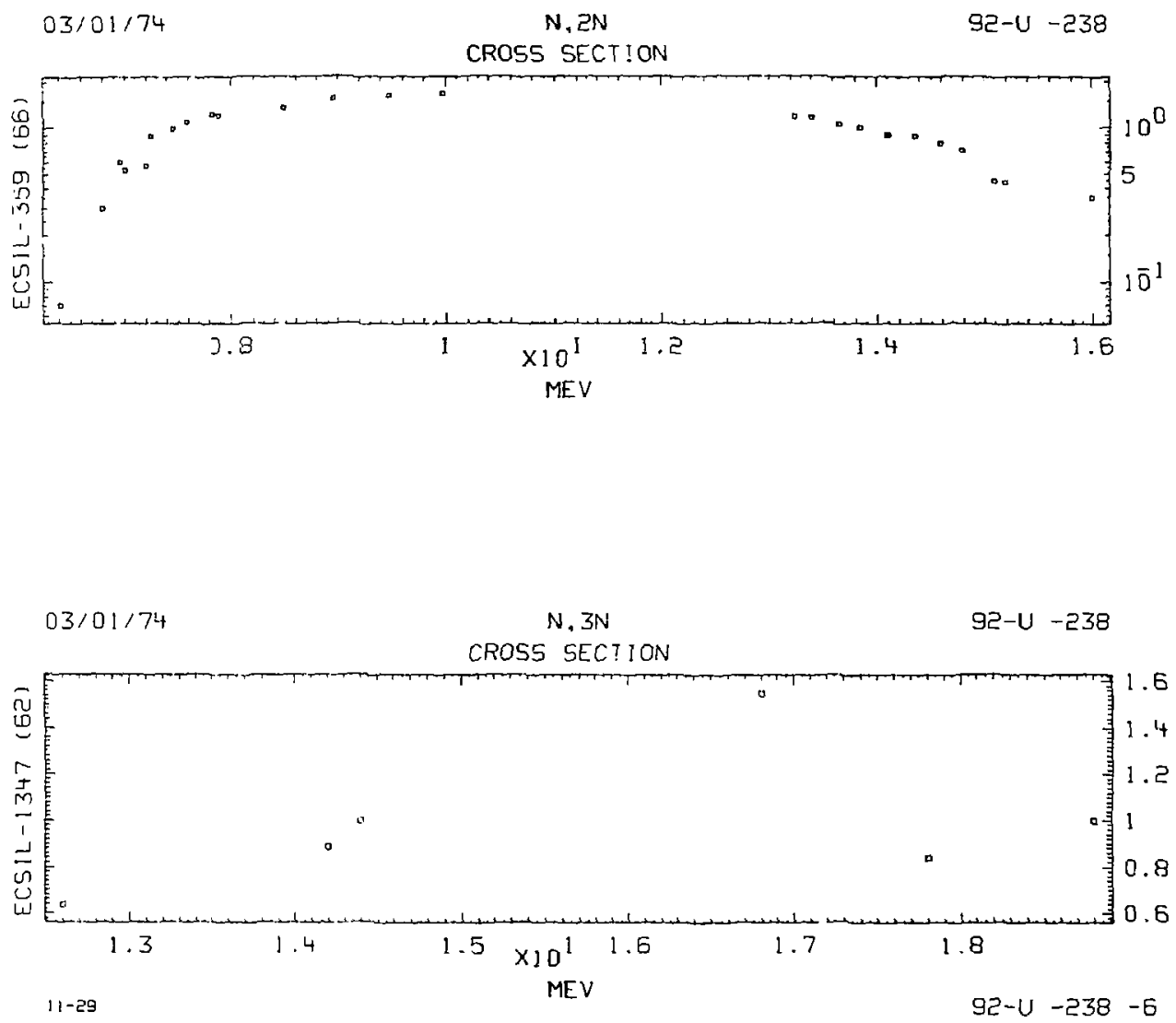


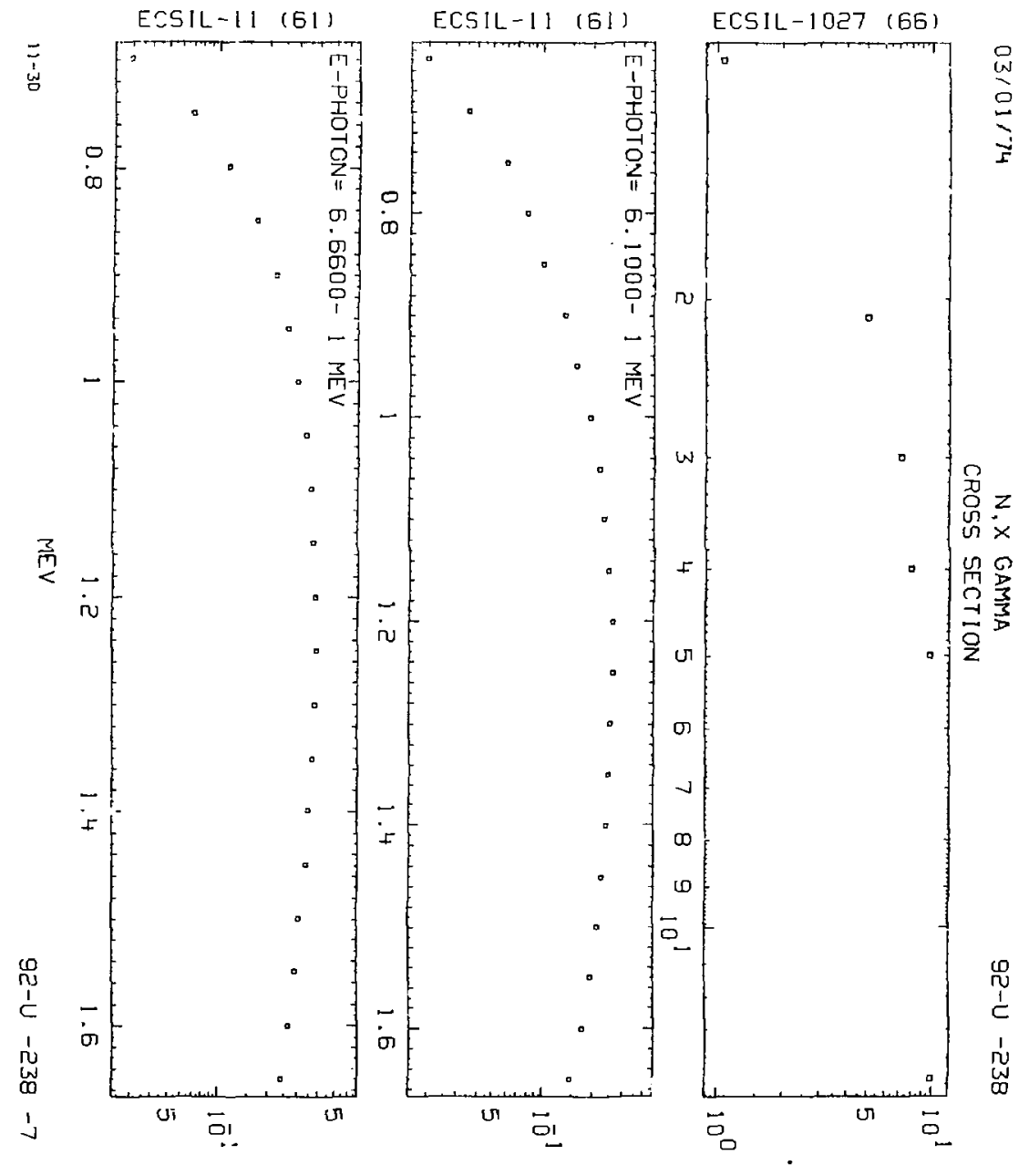

BARNS 

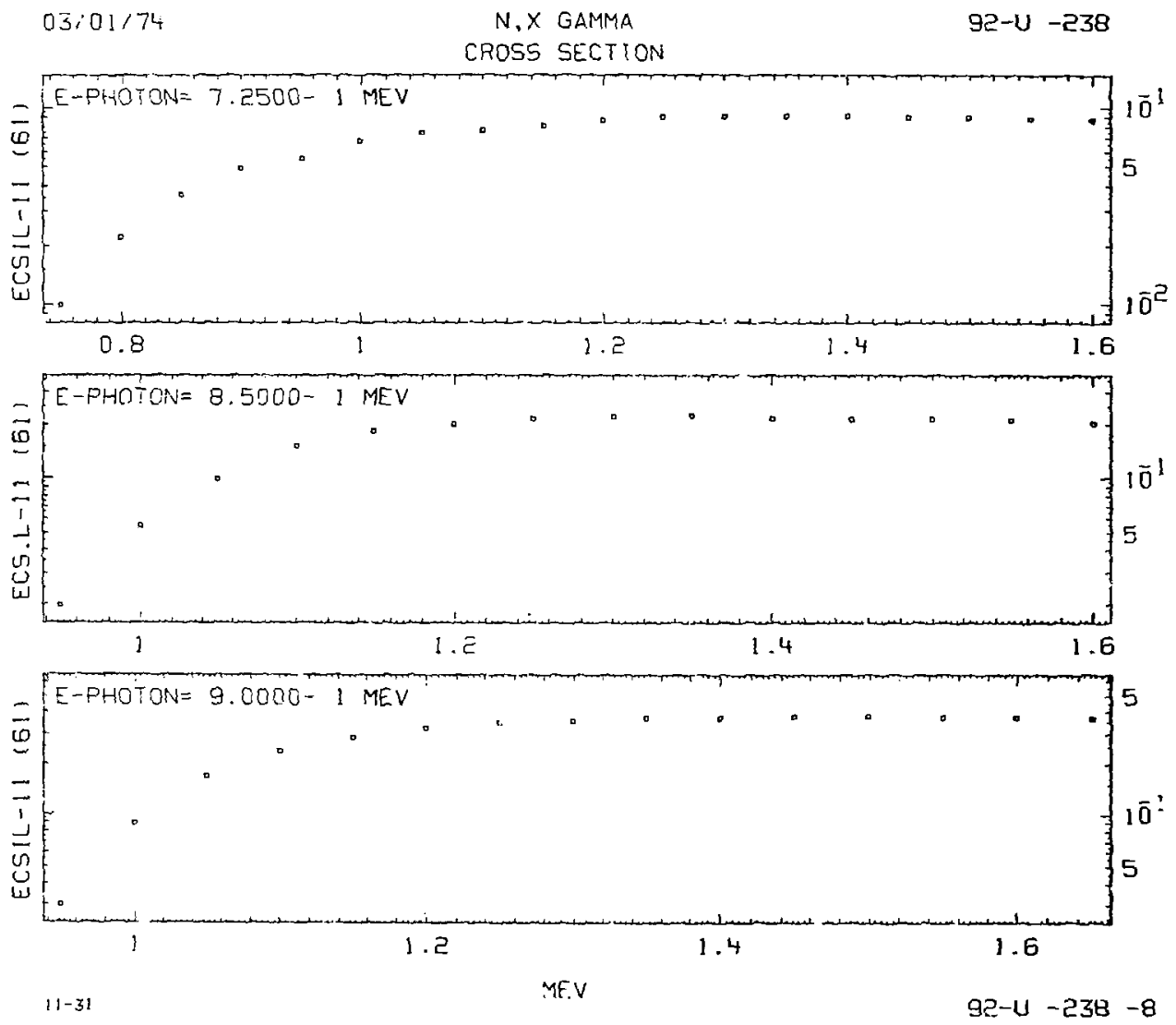


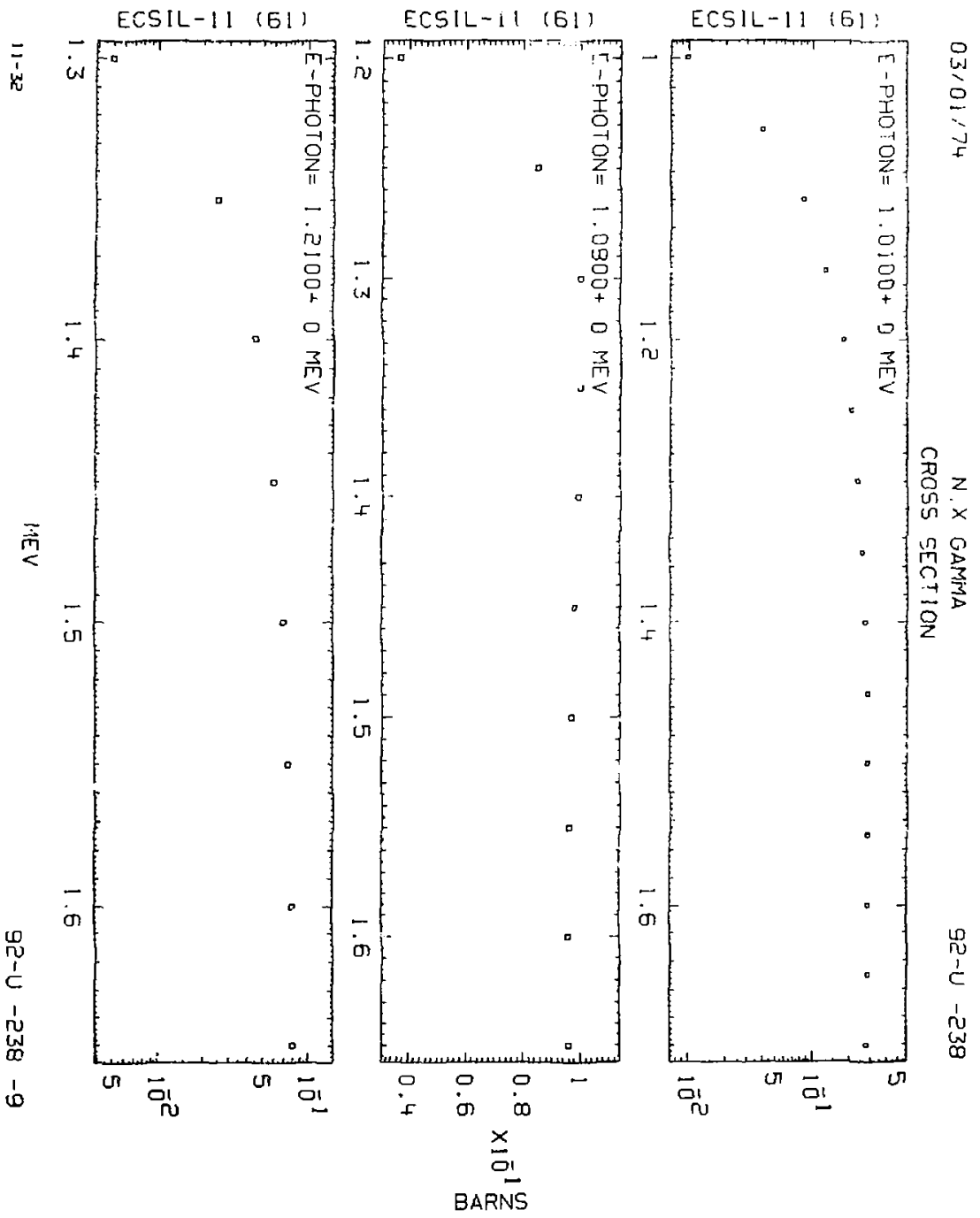


$03 / 01 / 74$

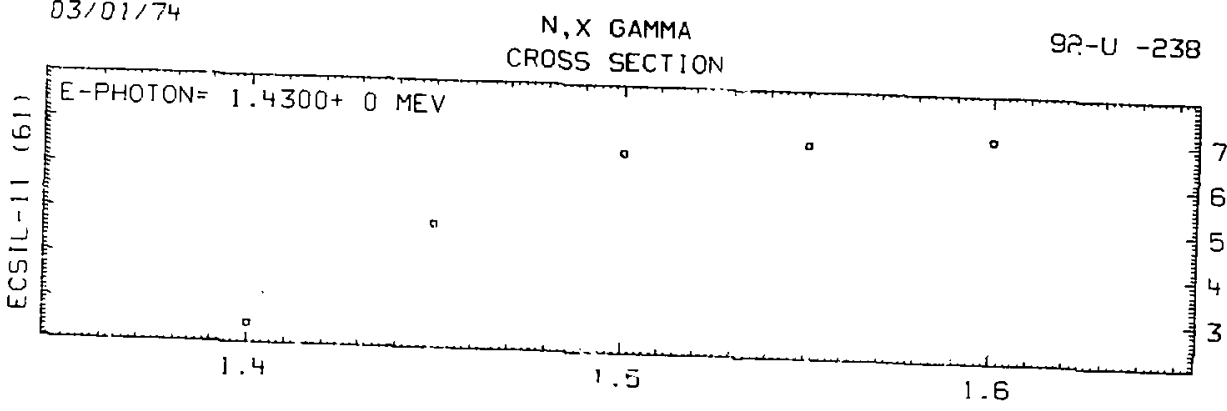

MEV

$03 / 01 / 74$

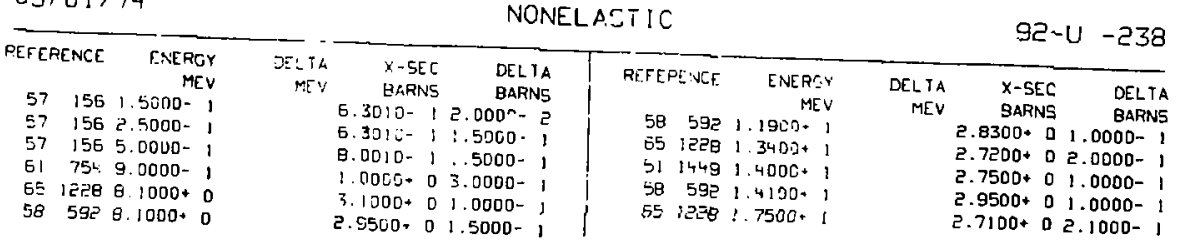

\section{$03 / 01 / 74$}

TOTAL SCATTERING

$92 \cdot \cdot u-238$

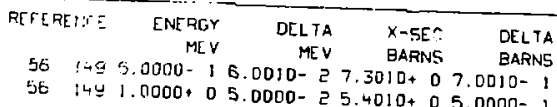

$11-33$ 
CROSS SECTION

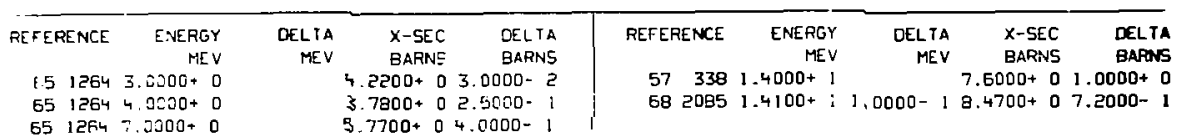

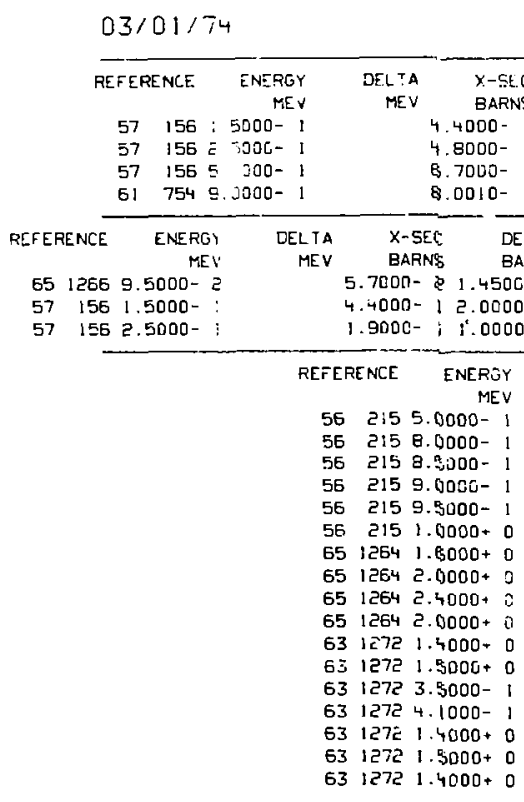

$N, N^{\prime}$

$92-u-238$

OELTA REFEHENCE ENERGY

57338 MEV

$573381.4000+1$

$\begin{array}{rr}\text { DELTA } & X \text {-SEC } \\ \text { MEV BELTA }\end{array}$

$12.0000-$
51 $6521.4100+1$
$.5000-17.0010-2$

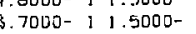

$621347 \quad 1.4200+1$

$1.0000-11.9000-1$

\begin{tabular}{|c|c|c|c|c|c|c|c|c|c|c|c|}
\hline \multirow{2}{*}{ REFERENCE } & ENERG & DELTA & $x-5 E C$ & DELTA & $E-L V L$ & REFERENCE & ENERGY & DELTA & $x-$ SEC & DELTA & E-LVL \\
\hline & MEV' & MEV & BARNS & BARNS & MEV & & MEV & MEV & BARNS & BARN5 & REV \\
\hline 1266 & $.5000-z$ & & $5.7000-$ & $1.4500-1$ & $4.5000-2$ & 156 & $5.0000-1$ & & $1.80[3-1$ & $1.0000-1$ & $5.0000-2$ \\
\hline 156 & $1.5000-:$ & & $4.4000-1$ & $2.0000-1$ & $5.0000-2$ & $57 \quad 156$ & $2.5000-1$ & & $2.9000-1$ & $1.5000=1$ & $1.4000-1$ \\
\hline $57 \quad 156$ & $2.5000-$ & & $1.9000-i$ & $i .0000-1$ & $5.0000-2$ & 156 & $5.6000-1$ & & $4.9000-1$ & $2.5000-1$ & $1.4000-$ \\
\hline
\end{tabular}

DELTA
MEV

$X$-SEC DELTA E-LVL-MIN E-LVL-MAX BARNS BAFNS MEV MEV

8.5000- 1 1.7000- $10.0000+95.0000-1$

7.5000- $11.5000-13.0000-18.0000-1$

$7.5000-11.5000-13.5000-18.5000-1$

6.5000- $11.7000-14.0000-19.0000-1$

8.0000- $11.6000-14.5000-19.5000-1$

6.0000- : :.2000- $15.0000-11.0000+0$

$\equiv .8000-j 4.0000-25.7000-1$ B. $7000-1$

2. $8500-: 3.0000-25.7000-1$ B.7000- 1

2.3000- I 3.0000- 2 5.7000- 1 9.7000- 1

$1.0250+01.0000-18.7000-11.3000+0$

2.6300- $11.0000-19.000 \dot{0}-19.6000-1$

2.1000- $18.0000-29.0000-19.6000-1$

$7.7,00-1.5000-19.0000-11.0000+0$

$7.7800-11.5000-19.0000-11.0000+0$

$2.6100-18.0600-29.7000-11.0300+0$

2.0000- $18.0000-29.7000-11.0300+0$

2. $9900-\mathrm{i} 1.0000-11.0200+01.0800+0$ 
CROSS SECTION

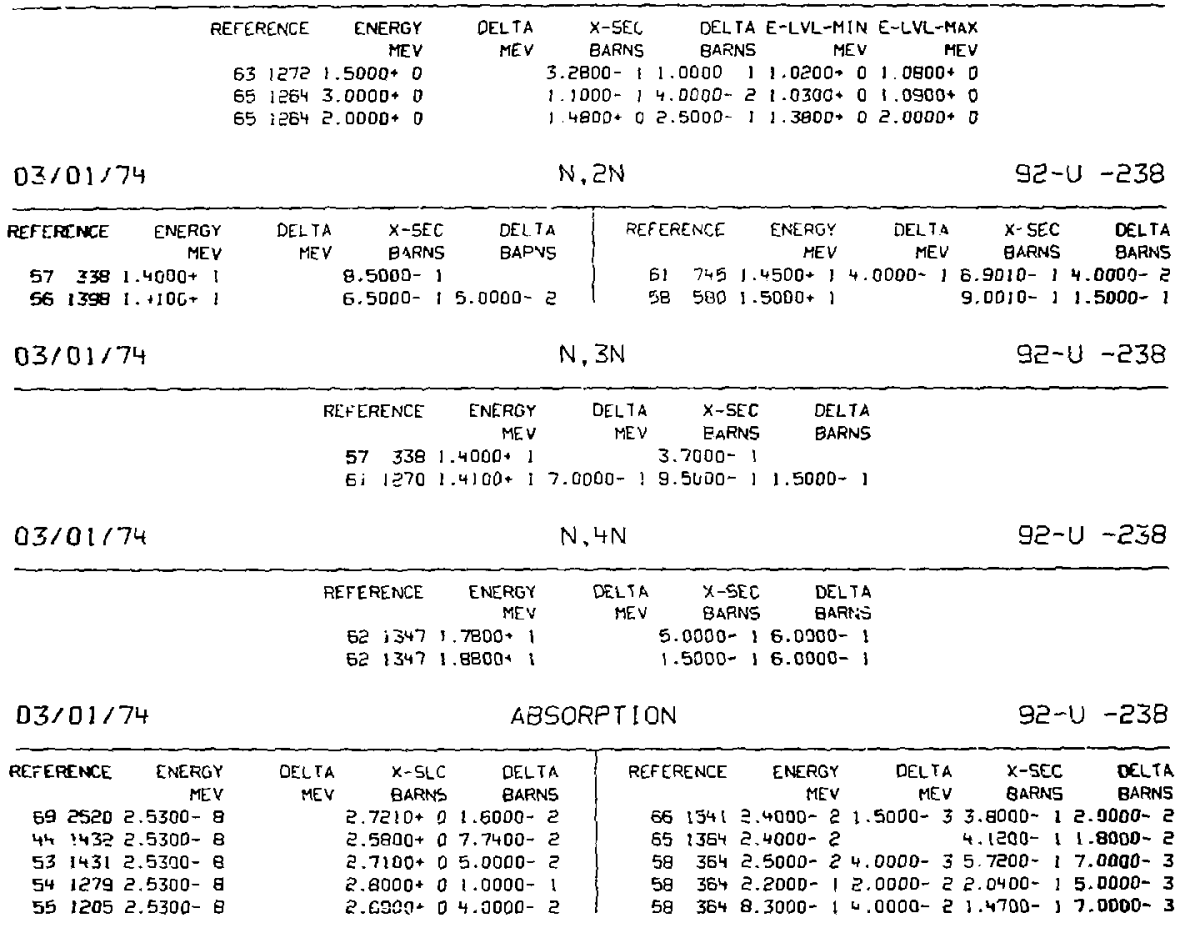




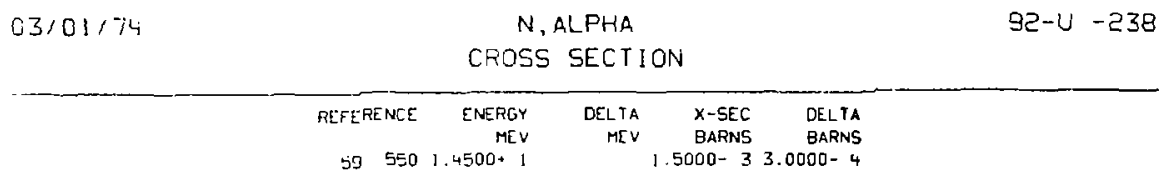

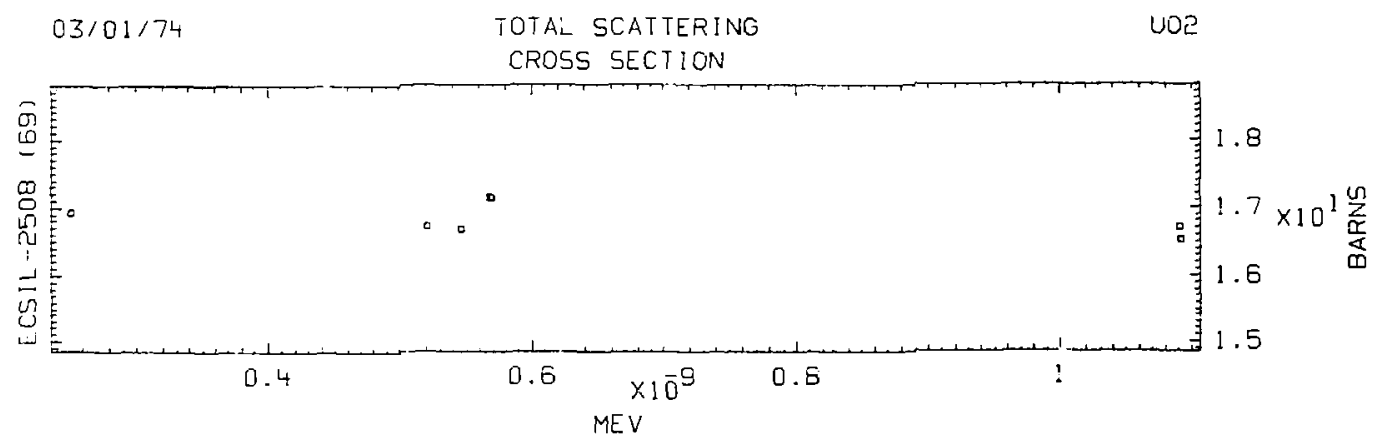




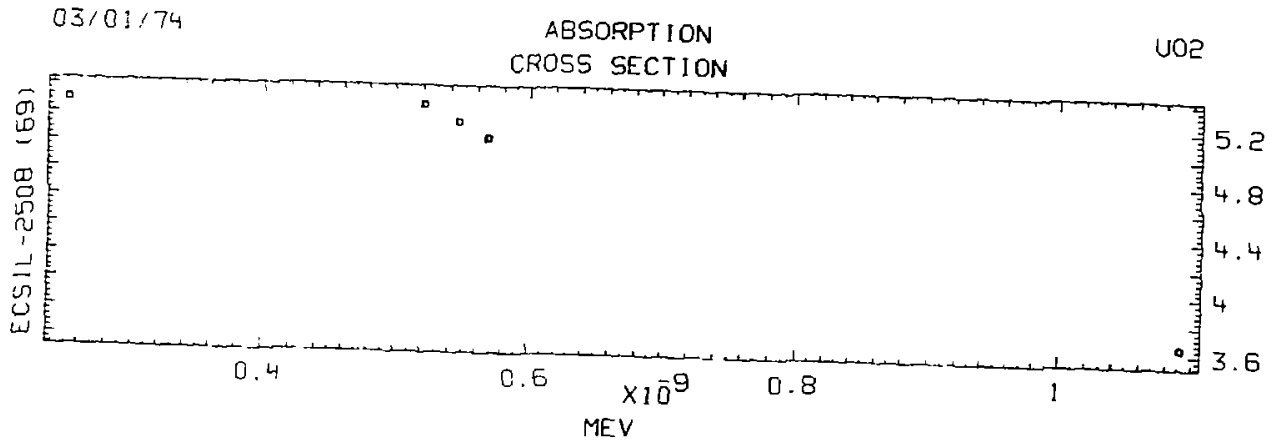

03/01/74

$03 / 01 / 74$ iv, P

93-NP-237

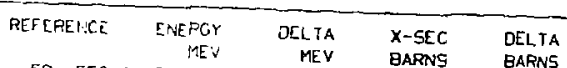

$595501.4500^{*} 1$ MEV BARNS BARNS

$03 / 01: 74$ ABSORPT ION

$94-P U-238$

\begin{tabular}{|c|c|c|}
\hline $\begin{array}{r}\text { ENEREY } \\
\text { MEV } \\
\text { ET } 1387 \quad 2.5300-8\end{array}$ & $\begin{array}{c}\text { DEL TA } \\
\text { MEV }\end{array}$ & $\begin{array}{l}x \text {-SEC } \\
\text { BARNS }\end{array}$ \\
\hline
\end{tabular}




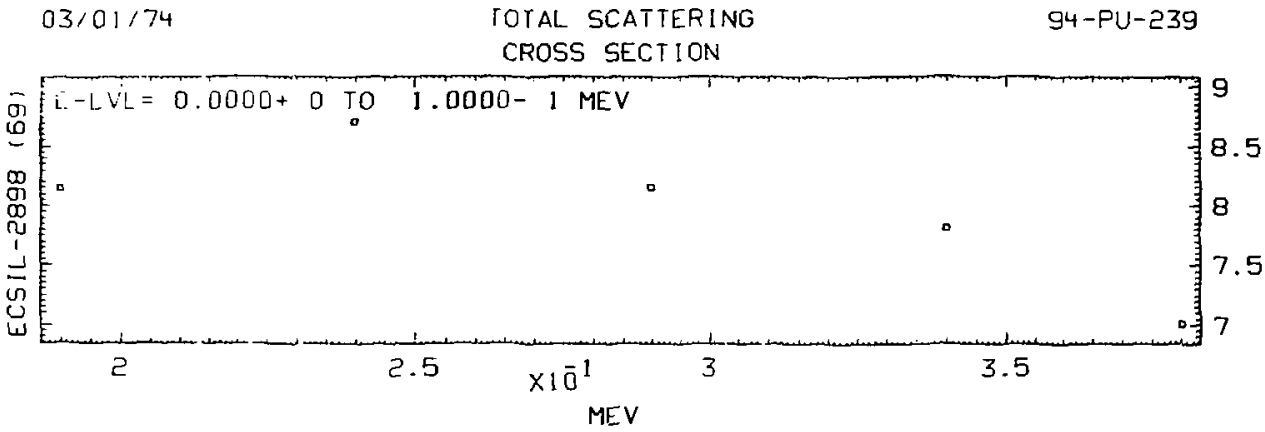

MEV

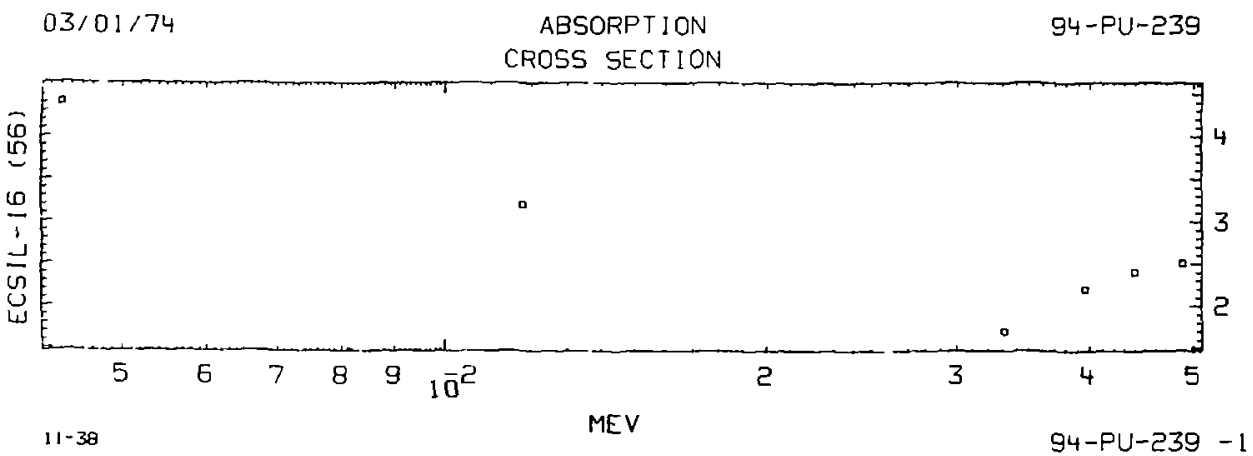




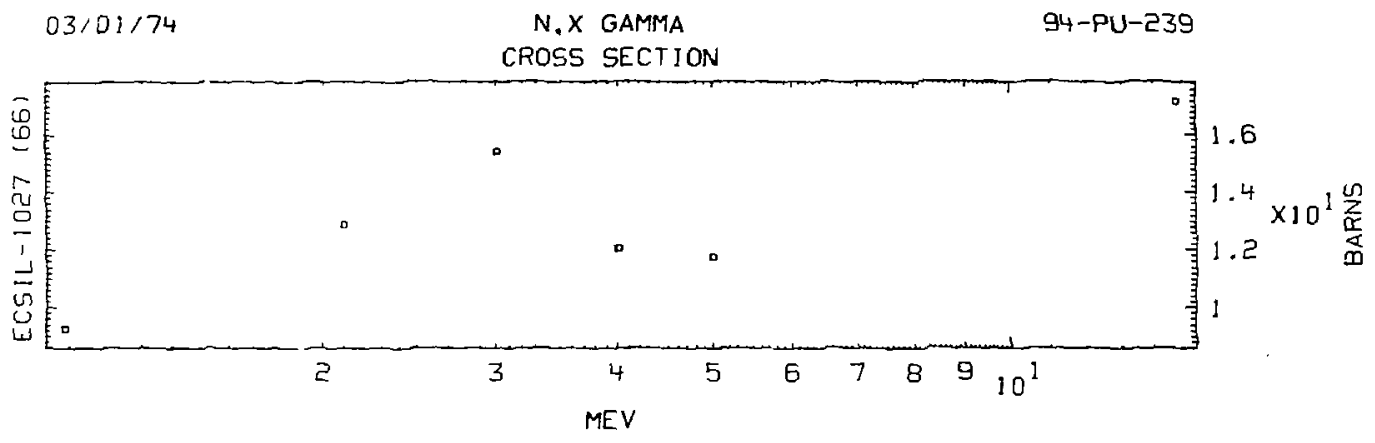

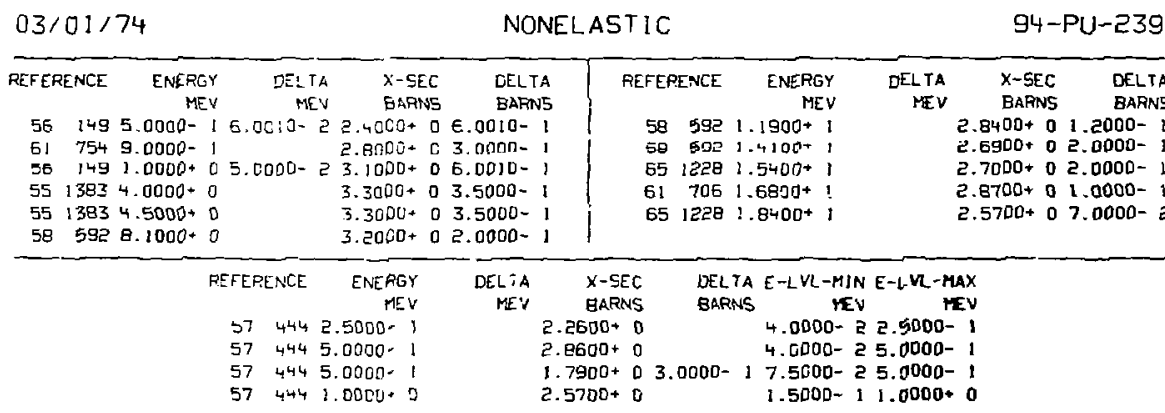




\section{CROSS SECTION}

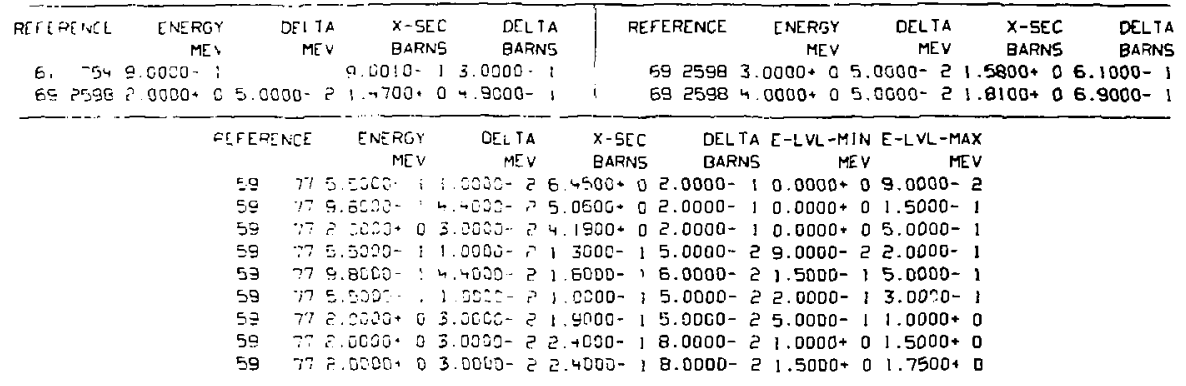

\section{$03 / 01 / 74$ \\ $5613112.5300-8$}

\section{ABSORPTION}

DELTA

BARNS
$1.0000-3$

i. $0.200+3 \% .0000+1$

$1.0210+31.2000+1$

$2.6900+01.7000-1$

$94-P U-239$

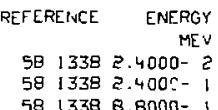

581338 8.8000-

$03: 01: 74$ N.P

$94-P U-239$

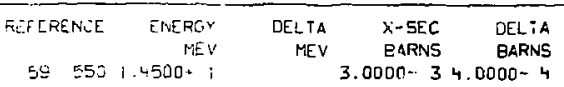

$05 / 01 / 74$

COHERENT SCATTERING

$94-P U-239$

\begin{tabular}{|c|c|c|c|c|c|}
\hline & \multirow[t]{3}{*}{ REF ERENCE } & & & & \\
\hline & & & & & \\
\hline & & $\begin{array}{r}\text { ENERGY } \\
\text { MEV } \\
2000-8\end{array}$ & $\begin{array}{r}\text { DEL TA } \\
\text { MEV }\end{array}$ & $\begin{array}{l}X \text { X-SEC } \\
\text { BARNS }\end{array}$ & $\begin{array}{l}\text { DELTA } \\
\text { BARNS }\end{array}$ \\
\hline
\end{tabular}



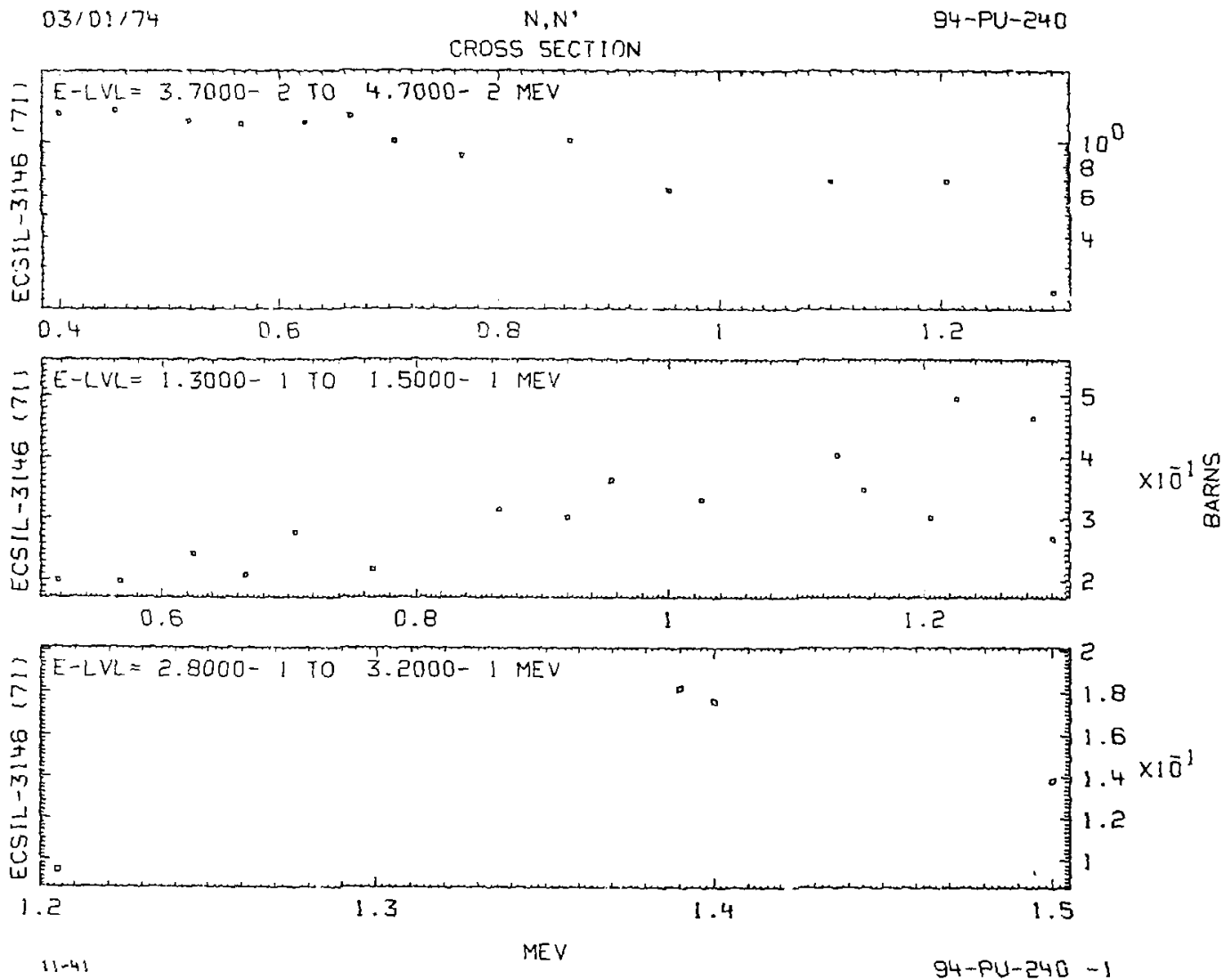

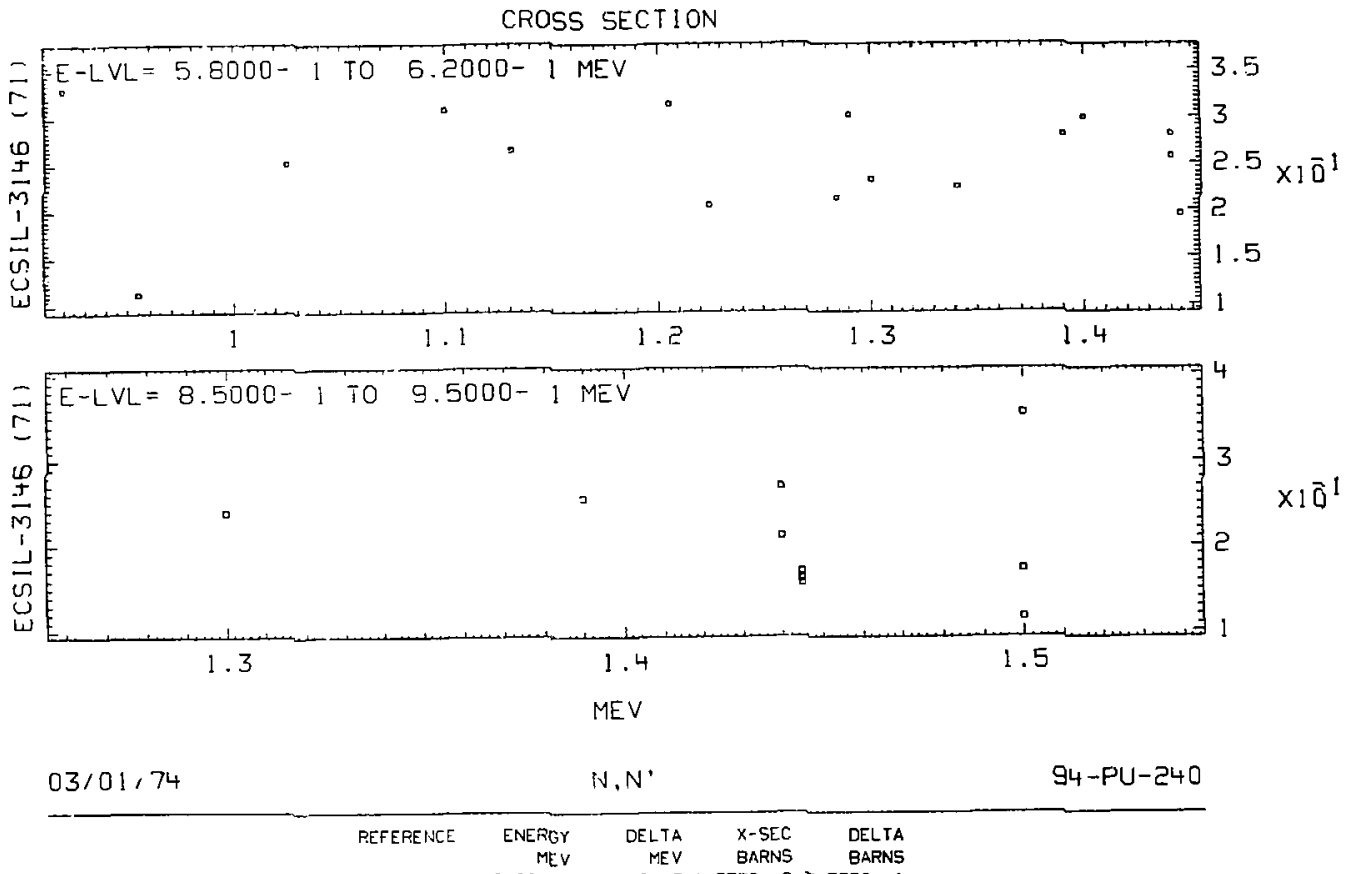

$7131463.5000-12.0000-2.1 .2780+03.7350-1$ 


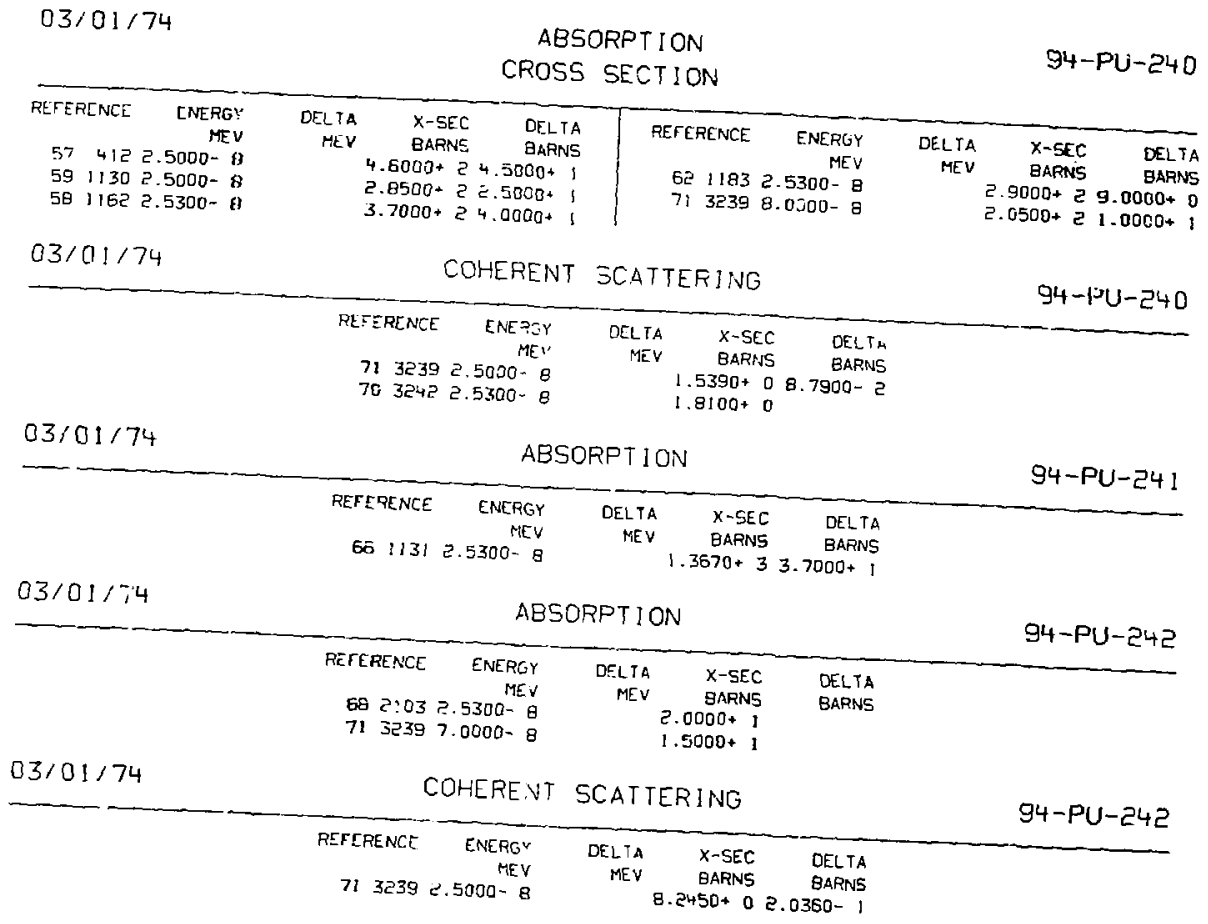




$03 / 01 / 74$
CROSS SECTION

\section{REFERENCE}

ENEPGY

MEV

DELTA

$X-5 E C$ BARNS

DEL TA

$6723191.4100+1$

9.0000- 5

BARN5

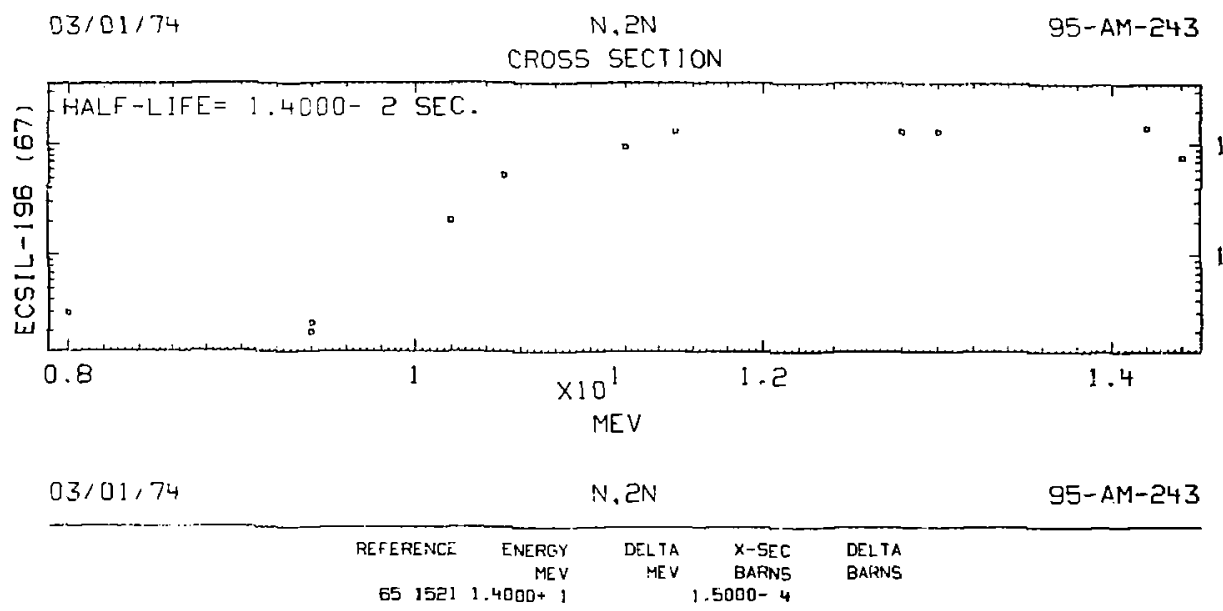




\section{CROSS SECTION}

\begin{tabular}{|c|c|c|c|c|c|c|}
\hline & $\begin{array}{l}\text { REFERENCE } \\
\text { E8 } 2104 \\
682103\end{array}$ & $\begin{array}{r}\text { ENERGY } \\
\text { MEV } \\
2.5300-8 \\
2.5300-8\end{array}$ & $\begin{array}{r}\text { DELTA } \\
\text { MEV }\end{array}$ & $\begin{array}{l}X \sim \text { SEC } \\
\text { BARNS } \\
\text { GDD+1 } \\
000+1\end{array}$ & $\begin{array}{l}\text { DELTA } \\
\text { EARNS }\end{array}$ & \\
\hline $53 / 01 / 74$ & \multicolumn{4}{|c|}{$\triangle B S O R P T I O N$} & & $96-C M-244$ \\
\hline & $\begin{array}{l}\text { RIFERENCE } \\
68 \geqslant 103 \\
68 \geq 104\end{array}$ & $\begin{array}{r}\text { ENERGY } \\
\text { MEV } \\
2.5300-F \\
2.5300-8\end{array}$ & $\begin{array}{l}\text { OT.LTA } \\
\text { MEV }\end{array}$ & $\begin{array}{r}X-S E C \\
\text { BARNS } \\
000+0 \\
500+1\end{array}$ & $\begin{array}{l}\text { DEL', } \\
\text { BARN'; }\end{array}$ & \\
\hline
\end{tabular}

\begin{tabular}{|c|c|c|c|c|c|c|}
\hline \multirow[t]{2}{*}{$03 / 01 / 74$} & \multicolumn{4}{|c|}{ ABSORPT ION } & & $96-C M-246$ \\
\hline & & $\begin{array}{r}\text { ENERGY } \\
\text { MEY }\end{array}$ & $\begin{array}{r}\text { DELTA } \\
\text { MEV }\end{array}$ & $\begin{array}{l}x \text {-SEC } \\
\text { GARINS }\end{array}$ & $\begin{array}{l}\text { DEL IA } \\
\text { BARNS }\end{array}$ & \\
\hline
\end{tabular}

$03 / 01 / 74$

ABSORPTION

$97-8 K-249$

\begin{tabular}{|c|c|c|c|c|c|c|}
\hline & $\begin{array}{r}\text { RE,FERENCE } \\
\text { GB } 2103\end{array}$ & $\begin{array}{r}\text { ENERGY } \\
\text { MEV } \\
5300-8\end{array}$ & $\begin{array}{r}\text { DELTA } \\
\text { MFV }\end{array}$ & $\begin{array}{r}X-S E C \\
\text { BARNS } \\
000+3\end{array}$ & $\begin{array}{l}\text { DEL A } \\
\text { BARNS }\end{array}$ & \\
\hline $03 / 01 / 74$ & \multicolumn{5}{|c|}{ ABSORPT ION } & $98-C F-250$ \\
\hline & $\begin{array}{l}\text { REFERENLE: } \\
682103\end{array}$ & $\begin{array}{r}\text { ENERGY } \\
\text { MEY } \\
5300-\mathrm{B}\end{array}$ & $\begin{array}{r}\text { DELTA } \\
\text { MEV }\end{array}$ & $\begin{array}{r}X-\overline{E E C} \\
\text { BARNS } \\
000+3\end{array}$ & $\begin{array}{l}\text { DFLTA } \\
\text { BAFNS }\end{array}$ & \\
\hline \multirow[t]{2}{*}{$03 / 01 / 74$} & \multicolumn{4}{|c|}{ ABSORPT ION } & & $98-C F-251$ \\
\hline & $\begin{array}{l}\text { REFERENCE } \\
682103\end{array}$ & $\begin{array}{r}\text { ENEHGY } \\
\text { MEV } \\
5300-8\end{array}$ & $\begin{array}{r}\text { DELTA } \\
\text { MEV }\end{array}$ & $\begin{array}{r}X \text {-SEC } \\
\text { BARN5 } \\
000+3\end{array}$ & $\begin{array}{l}\text { OELTA } \\
\text { BARNS }\end{array}$ & \\
\hline
\end{tabular}




\section{CROSS SECTION}

\begin{tabular}{|c|c|c|c|c|}
\hline $\begin{array}{l}\text { REFERENCE } \\
68 \geq 103\end{array}$ & $\begin{array}{r}\text { ENERGY } \\
\text { MEV } \\
5300-8\end{array}$ & $\begin{array}{r}\text { DELIA } \\
\text { MEY }\end{array}$ & $\begin{array}{r}X \text { X-SEC } \\
\text { BARNS } \\
000+0\end{array}$ & $\begin{array}{l}\text { DELTTA } \\
\text { BARNS }\end{array}$ \\
\hline
\end{tabular}

$03 / 01 / 74$ ABSORPT ION

99-ES-253

$\begin{array}{rrr}\text { REFERENCE ENERGY } & \text { DELTA } & \text { X-SEC } \\ \text { MEV } & \text { MEV } & \text { BARNS }\end{array}$

DEL TA

$682.1032 .5300-8$

1. $3000+2$ 